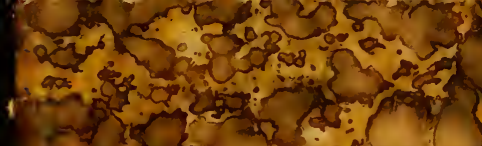

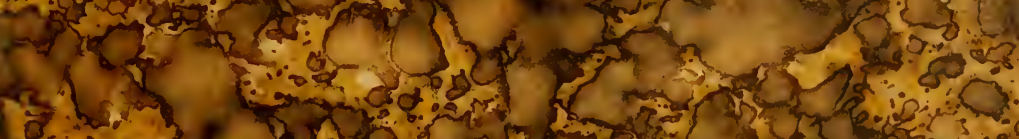

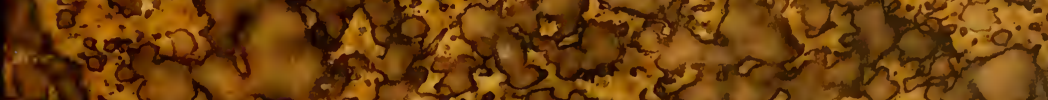

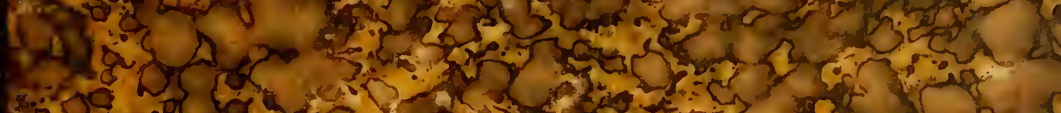

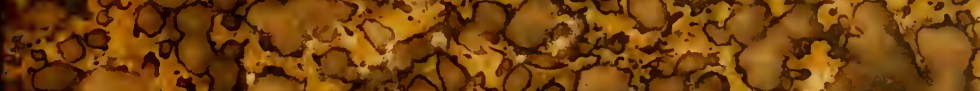
5.

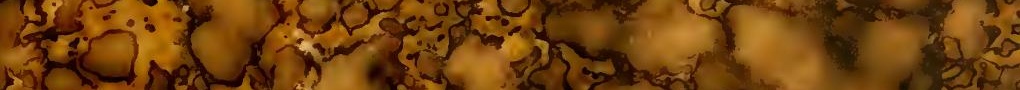

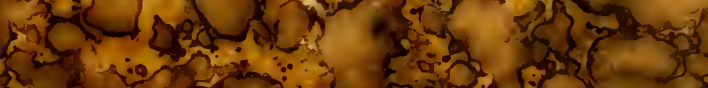

जo

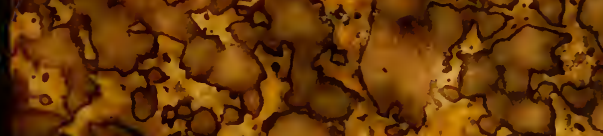

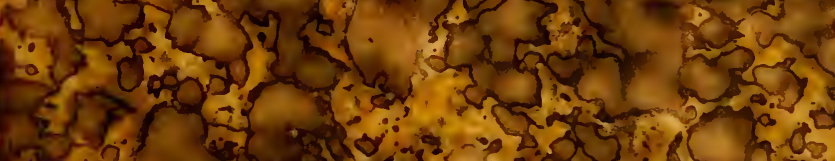

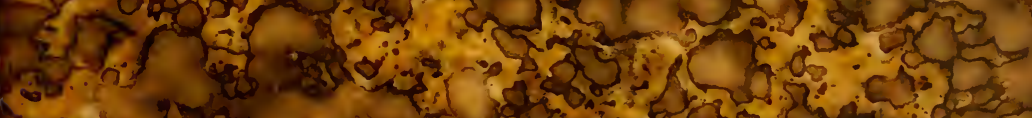

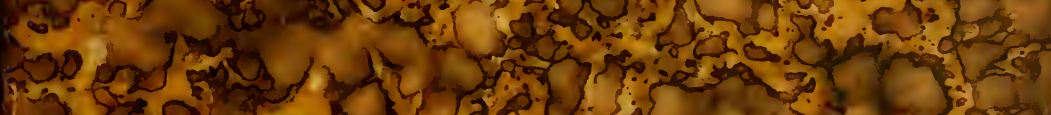
Th

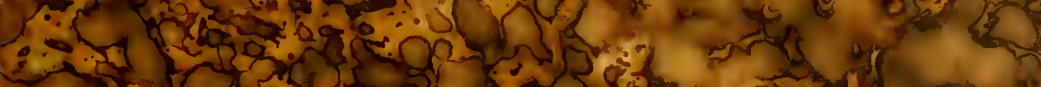

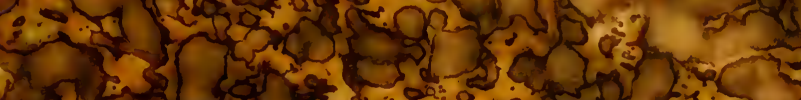
a.

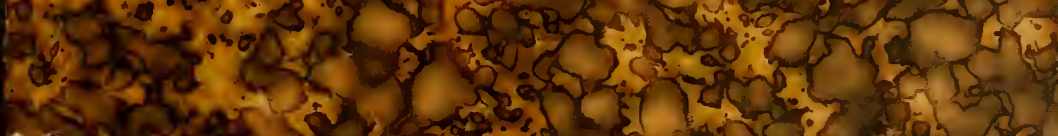

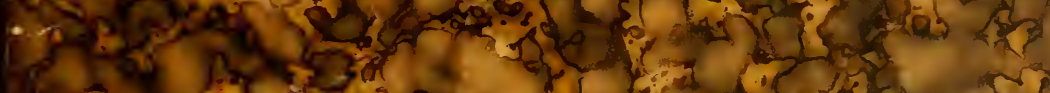

\title{
Aprim 3
}

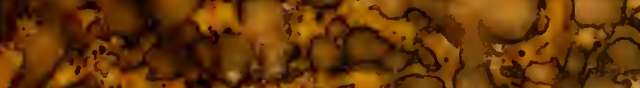

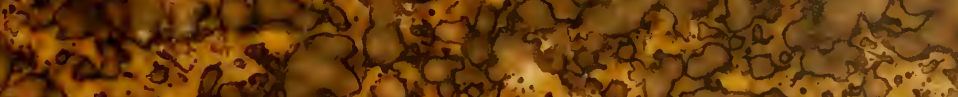

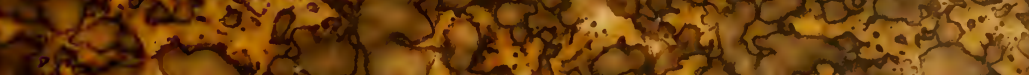

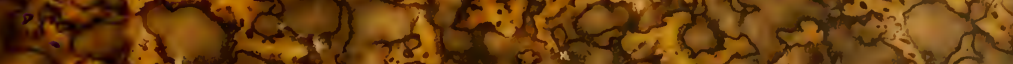

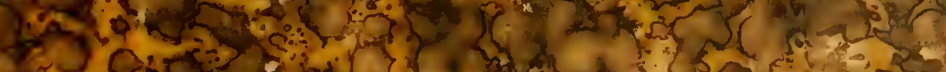

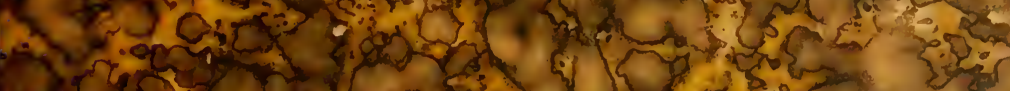

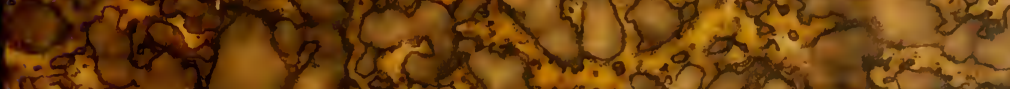

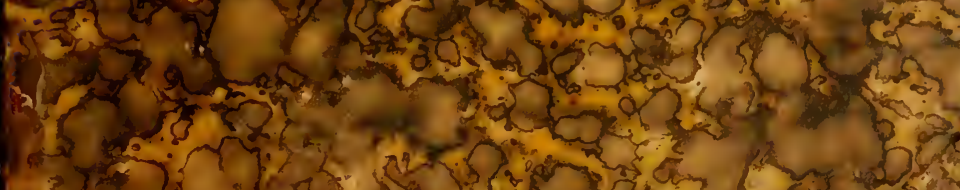

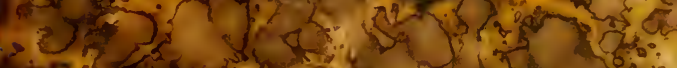




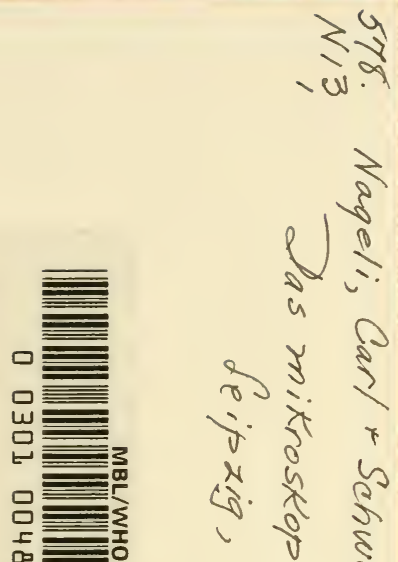

므으을

川

पu

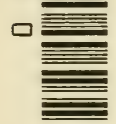

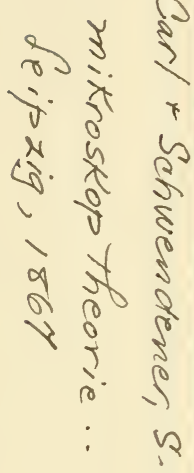




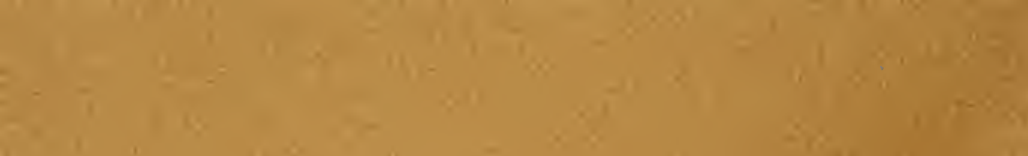

P.

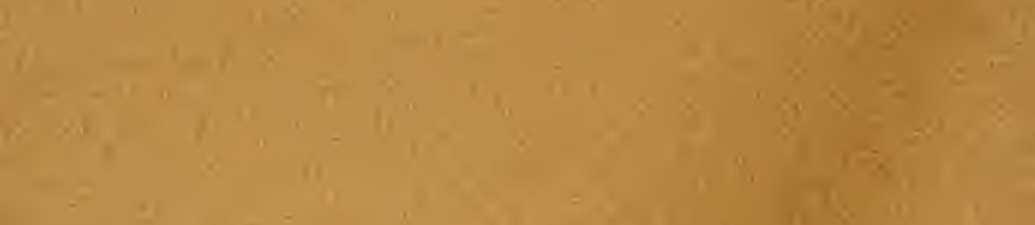

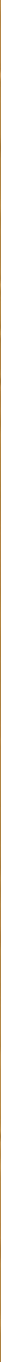




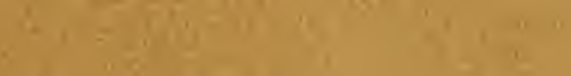

S.

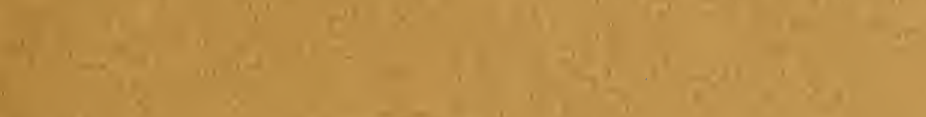

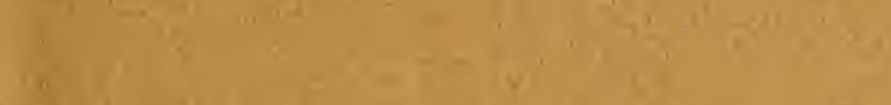

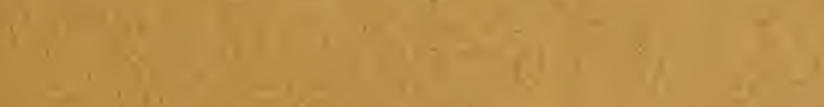

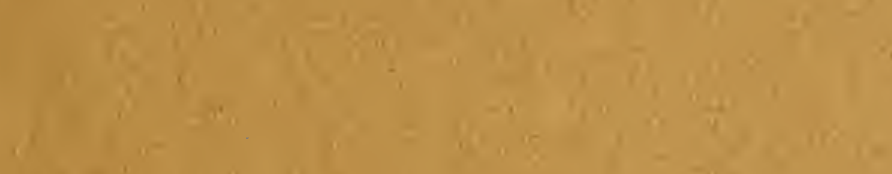

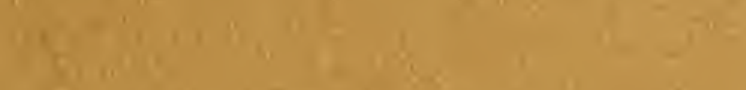

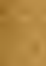

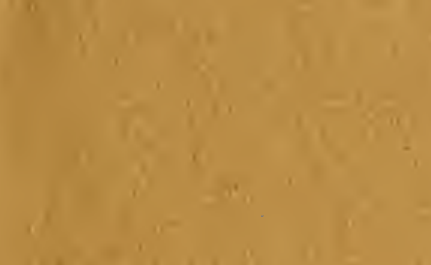


$x=1,82$.

3,

$a^{2}=100$

$=1 \times 1$

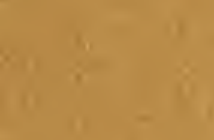<smiles>C1=CC2CCCC2=C1</smiles>

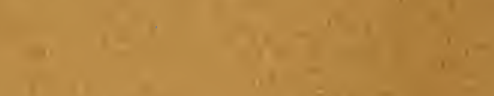

$x^{x}=1$

$6+58,1=$

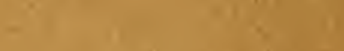

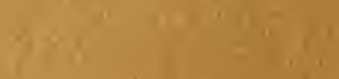
4

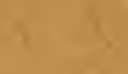

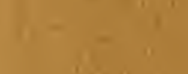

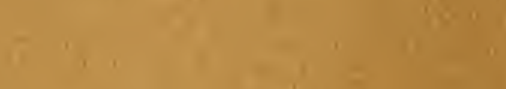

tin

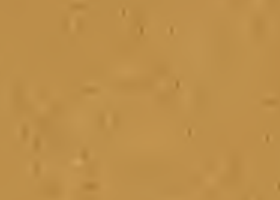

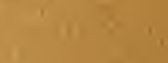

$x^{2}+\frac{1}{2}$

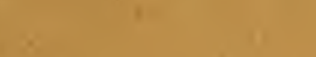

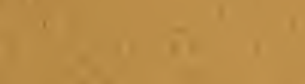

or $x+x=$

$\pm=$

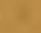

$*$

1) 15

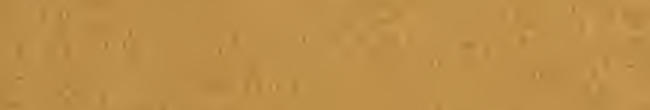

and

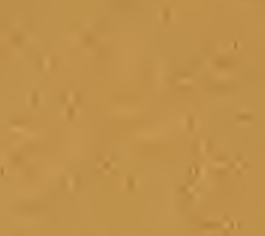

(1)

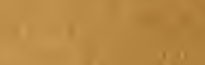

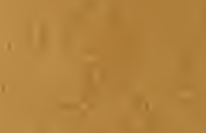

in

14.

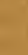

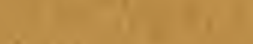

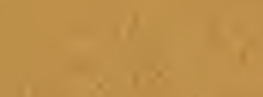

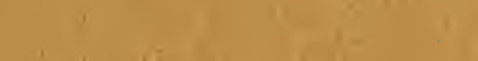

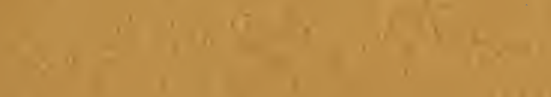

(1)

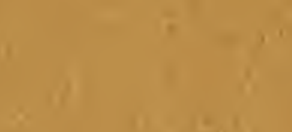

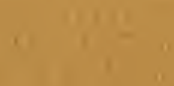

8. -1 $17^{* 11}$

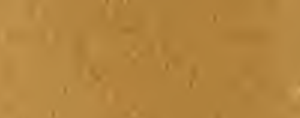
in

n

$+\infty$ 11 $x$ 



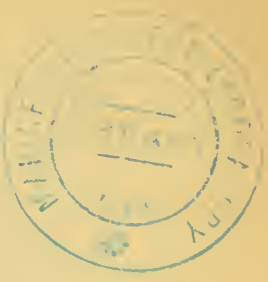




\section{DAS}

\section{I K R O S K O P}

E, L. MAR

VON

\section{CARL NÜGELI,}

PROF. IN MÜNCIEN

UND

\section{S. SCIIIENDENER,}

DOCENTEY DER BOTANIK IY MÜSCHEN.

HIT 276 HOLZSCHSI'TES.

\section{LEIPZIG,}

VERLAG VON WIIHELM ENGELMANN

1567. 
Das Recht der Uebersetzung in die französische und englische Sprache hat sich der Verleger vorbehalten. 


\title{
Inlaltsübersicht.
}

\author{
Erster Theil.
}

\section{Erster Abschuitt: Theorie les Mikroshops.}

I. Einleitung . . . . . . . . . . .

Optische Wirkung des Mikroskops. Gesetze der Lichtbrechung in Linsen und Linsensystemen.

II. Analytische Bestimmung der Cardinalpuncte brechender Systeme, nach Gauss. . . . . . . . . . . . .

Object- und Bildpunct. Hauptebenen und Brennebenen. Combination brechender Systeme.

III. Die Cardinalpuncte des Mikroskops . . . . . . . .

1. Das Objectir.

2. J) as Ocular. Das Campani'sche und das Ramsden'sche Ocular. Das aplanatische, orthoskopische und das bildumkehrende Ocular.

3. Die Mittel zur Theilung der Strahlenbündel. Multoculäre und stereoskopische Mikroskope.

IV. Die chromatische und die sphärische Aberration . .

1. Die chromatische Aberration. Bedingungen der Achromasie.

2. Die sphärische Aberration. Folgen derselben im Objectiv und im Ocular.

V. Yom Einfluss der Deckgläschen . . . . . . . 55

VI. Die Ebemung des Gesichtsfeldes . . . . . . . . . .

Wesen und Ursache der sogenannten Krümmung des Gesichts-

feldes. Beseitigung derselben durch aplanatische und gewöhnliche Oculare.

VII. Das Centriren der Linsensysteme . . . . . . . .

W'irkung einer fehlerhaften Centrirung. Ortsveränderungen des Bildes beim Drehen der Objectivlinsen.

VIII. Die Lichtstärke des Mikroskops . . . . . . . . .

IX. Das optische Termögen des Mikroskops . . . . . . . Kritik der gewöhnlichen Ansicht über die Bedeutung des Oeffnungswinkels und die Begriffe der definirenden und penetrirenden Kraft.

X. Ton der Beleuchtung. . . . . . . . . .

1. Beleuchtung mit durchfallendem Licht. Wirkung des Spiegels und der Beleuchtungslinsen bei begrenzter und unbegrenzter Lichtquelle.

2. Beleuchtung mit auffallendem Licht.

Zweiter Abschnitt: Die mechanische Einrichtung des Miliroshops.

I. Allgemeine Regeln für die Construction der Stative. 1)ie Einstellung. 1)er Objecttisch. Der Beleuchtungsapparat. Die Blendungen. Das Fussgestell. Länge und Stellung der Mikiroskopröhre. 
II. Die Stative der neueren Optiker . . . . . . . . . . Hartnack, Nachet, Plössl, Schiek, Bénèche, Zeiss, Belthle, Baader, Smith und Beck.

\section{Dritter Ibschnitt: Von der Prüfung des Mikroskops.}

I. Prüfung des optischen Vermögens im Allgemeinen . . Absolutes und relatives Unterscheidungsrermögen. Prüfungsmethoden. Organische Probeobjecte. Nobert's Probetäfelchen.

II. Prüfung der sphärischen Aberration . . . . . . . .

III. Prüfung der chromatischen Aberration . . . . . . .

IV. Prüfung der Ebenung des Gesichtsfeldes . . . . .

V. Prüfung der Centrirung ......... 163

VI. Bestimmung des Oeffnungswinkels ....... 165

Theoretische Grundlage. Prüfungsmethoden.

VII. Bestimmung der Vergrösserung und der Brennweite. .

VIII. Bestimmung der Cardinalpuncte . . . . . . . .

Vierter Ibschnitt: Theorie der mikroskopischen Nahrnehmung.

I. Kugelige und cylindrische Objecte . . . . . . . . . Luftblasen in Wasser. Oeltropfen in Wasser. Hohlkugel und Hohlcylinder.

II. Objecte von unregelmässiger Form . . . . . . . .

Membranen mit kleinen Vertiefungen oder Löchern. Membranen mit einer ebenen und einer wellenförmigen Grenzfläche. IIembranen mit parallel-wellenförmigen Grenzflächen. Abwechselnd dichte und wasserreiche Schichten. Erhabenheiten und Vertiefungen im Gegensatz zu dichten und weichen Schichten. Das Sehen durch stereoskopische binoculäre Mikroskope.

III. Interferenzerscheinungen . . . . . . . . . . . Interferenz des directen Lichtes mit reflectirtem. Interferenz des gebrochenen Lichtes mit reflectirtem. Interferenz des gebrochenen und directen Lichtes. Reflexion des Lichtes an kleinen Kügelchen, Körnchen, feinen Fäden etc. und dadurch bedingte Interferenzerscheinungen. Interferenzlinien, welche die Entfernung einer wenig ausgedehnten Lichtquelle über die Objectdistanz hinaus hervorruft.

IV. Die schiefe Beleuchtung . . . . . . . . . .

V. Die Bewegungserscheinungen . . . . . . .

Scheinbare und wirkliche Geschwindigkeit. Scheinbares Schlängeln schraubenförmiger Körper. Rechts- und Linksdrehung.

VI. Die Niveaudifferenzen . . . . . . . . .

Yïnfter lloschnitt: Das einfache Mikroskop und das Billmikroskop.

I. Das einfache Mikroskop : - * * * * . .

Doublets und Triplets. Die mechanische Einrichtung: Loupenträger und Stative der neueren Optiker.

II. Das Bildmikroskop . . . . . . . . . . . . .

Kurze Notiz über die Einrichtung desselben.

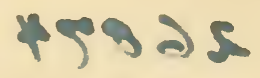




\title{
Inhaltsübersicht.
}

\author{
Zweiter 'Theil.
}

\section{Sechster Abschnitt: Mikroskopische Technik.}

I. Der Gebrauch des Mikroskops . . . . . * Gebrauch der Deckgläser. Die Behandlung des Instruments. Schonung des Sehvermögens. Der Arbeitstisch.

II. Herstellung und Behandlung der Präparate . . . . . . 1)as Zergliedern der Objecte. Anfertigung von Durchschnitten. Entfernung der Luft. Quetschen der Präparate.

III. Auf bewahrung der mikroskopischen Präparate. . . . . Aufzählung der gebräuchlichen Medien : Luft, Canadabalsam, Glycerin etc. Herstellung eines hermetischen Verschlusses. Etikettirung, Einrichtung der Sammlung.

IV. Das Messen mikroskopischer Objecte. . . . . . . . .

1. Das Glasmikrometer. Bestimmung des relativen Werthes der Mikrometertheilungen. Fassung und Einrichtung der Mikrometer. Genauigkeit der Messungen.

2. Das Schraubenmikrometer. Einrichtung desselben. 1) ats Mohl'sche Ocularschraubenmikrometer. Bezeichnung der mikrometrischen Grössen. 'Tabelle zur Reduction der gebräuchlichen Maasseinheiten.

3. Bestimmung von Winkelgrössen. Das Goniometer. Fehlerquellen.

V. Das Zeichnen mikroskopischer Objecte · . A . . . .
Apparate zur genauen Wiedergabe der Unrisse. Ausführung der Zeichnungen. Willkürlichkeiten bei der Darstellung mikroskopischer Objecte.

\section{Siebenter Abschnitt: Die Polarisationserscheinungen.}

I. Einrichtung des Polarisationsmikroskops . . . . . . .

1. Der Yolaris a tor. Das Nicol'sche Prisma. Das Foucault'sche Prisma. Turmaline und Herapathitkrystalle. Stellung des Polarisators zur Lichtquelle.

2. Der Analysator. Die verschiedenen Stellungen desselben.

3. Der Apparat zum Drehen der Objecte.

II. Das Verhalten anisotroper krystallähnlicher Körper, einzeln beobachtet

1. Das Elasticitätsellipsoid.

2. Die Polarisationserscheinungen in ihren Beziehungen zum Elasticitätsellipsoid. Die wirksame Elasticitätsellipse, Form- und Stellungsveränderungen derselben beim Drehen des Objects nach verschiedenen Seiten. Elasticitätsverhältnisse der optisch einaxigen Medien. 
3. Bestimmung der Elasticitätsaxen. Bestimmung der Axen richtungen. Bestimmung der relativen Grösse der Axen. Anwendung der Gypsplättchen etc. Deutung der Interferenzfarben, Tabelle der Additions- und Subtractionsfarben für eine Reihe von Combinationen.

III. Das Verhalten zweier übereinander liegender Krystallähnlicher Körper, deren Schwingungsebenen sich schiefwinklig kreuzen .

Charakter der Interferenzfarbe für verschiedene Werthe des Kreuzun gswinkels. Combination der fest verbundenen, gekreuzten $\mathrm{Kry}$ stallplatten mit einem Gypsplättchen : Additions- und Subtractionsfarben, Farben der orthogonalen Consecutiv- und Alternativstellung. Úmkehrung des Problems: Bestimmung der Elasticitätsellipsen zweier sich kreuzender Platten durch Beobachtung der Polarisationsfarben.

IV. Das Verhalten cylindrischer und kugeliger Objecte mit concentrisch gruppirten anisotropen Elementen

1. Cylindrische Objecte. Wirkung der Querschnitte, der Längsschnitte und der Längsansichten. Zusammenstellung der Combinationen, welche mit Rücksicht auf die Interferenzfarben der zusammengehörigen Quer- und Längsansichten vorkommen können, und Folgerungen daraus. Einzelne besondere Fälle. Bestimmung der optischen Axen.

2. Kugelige und ovale Objecte. Objecte mit gleichwerthigen Durchmessern und solche mit einer Axe.

V. Ueber einige Eigenthümlichkeiten des Baues organisirter Substanzen .

Die doppelbrechende Eigenschaft der Substanz ist durch die $\mathrm{Na}$ tur der Molecüle, nicht durch deren A norden ung bedingt.

VI. Zusammenstellung ven Beispielen . . . . . . . . . .

VII. Ueber die Anwendung des Nörrenberg'schen "Polarisationsmikroskops « .

\section{Achter Abschnitt: Mikrophysik.}

I. Flüssige Körper . . . . . . . . . . . . . . . . .

1. Erkennungund Unterscheidung flüssiger Körper.

2. 1)ie Capillaritätserscheinungen. Maassbestimmung. Capillarattraction in mikroskopisch feinen Röhrchen und in den Molecularinterstitien der Membranen. Zusammenwirken der Capillarität und der Verdunstung in feinen Capillarsystemen.

3. Spannung der Gase und Flüssigkeiten. Spannungsdifferenzen zwischen den Flüssigkeiten und den darin enthaltenen Luftbläschen in Folge der Capillaranziehung. Abnahme der Spannungen in Capillarsystemen von unten nach oben. Ausgleichung der Spannungen durch permeable Membranen. Geringe Grösse der in Geweben vorkommenden Spannungen. Spannung durch Endosmose. Formveränderung der Zellen in Folge der $\mathrm{Zu}$ - oder Abnahme der Spannungen.

4. Ungleiche Concentration der Tösung im Tropfen des Präparats.

5. Bewegungen in einer Flüssigkeit, welche durch ungleiches specifisches Gewicht verursacht werden.

6. Das Saftsteigen. Die Gesammtarbeit der Capillarität und der Endosmose reicht unter den gegebenen Verhältnissen nur 
bis zu einer Höhe von einigen Metern. Sitz der übrigen motorischen Kräfte.

7. Strömungen durch Capillarröhren und Membranen. Formeln von $\mathrm{Po}$ is e uille. Geringe Permeabilität der Gewebe.

5. Die Plasmaströmungen. Verschiedene Ansichten. Der Strömungsvorgang in den Staubfädenhaaren von Tradescantia; die Contractilitätstheorie. Mechanische Gesichtspunkte.

II. Feste Körper .

1. Das Erkennen des Aggregatzustandes.

2. Elasticităt, Weichheit, Dehnbarkeit. Ermittlung der Eigenschaften eines Objects. Verhalten des Primordialschlauches und der Zellmembranen. Verhalten der Gewebe; die Factoren ihrer Elasticität und Biegungsfestigkeit. Gleichgewichtszustand entgegengesetzt gespannter Gewebe, die zu einem Ganzen verbunden sind.

3. Innerer Bau der festen Körper. Organisirte und unorganisirte Körper. Verschiedenheiten in Betreff der Anordnung der Atome. Wesen der Organisation.

4. Cohäsion und Adhäsion.

5. Quellung und Diosmose. Quellung mit und ohne Veränderung der Molecularconstitution. Absorption von Gasen in quellungsfähigen Körpern. Menge und Vertheilung der Imbibitionsflüssigkeit. Quellung absterbender Membranen. Schichtung und Streifung. Diosmose.

III. Licht

1. Bestimmung des Brechungscoefficienten. Nethoden ron $\mathrm{Brewster}$, Moser, Bertin und $\mathrm{Harting}$. Kritik der Harting'schen Formel. Bestimmung des Brechungscoefficienten bei kugeligen und cylindrischen Gebilden.

2. Die Durchleuchtung der Körper.

3. Einfluss des Lichtes a uf Vegetationsprocesse.

IV. Wärme 1. Krystallbildungen bei dem Gefrierén.

2. Das Gefrieren der Gewebe.

3. Verānderung der Zellhäute beim Aufthauen.

1. Einfluss der Temperatur a f die Vegetationspro. cesse.

V. Elektricität .

Ipparate zur Anwendung derselben. Art der Einwirkung galvanischer Ströme auf das Plasma.

\section{Teunter Lbschuitt: Mikrochemie.}

I. Allgemeine Regeln

Steigerung der Concentration anzuwendender Keagentien. Herstellung einer Strömung in der Beobachtungsflüssigkeit. Apparate zu Beobachtungen bei höherer 'T'emperatur.

II. Aufzählung der Reagentien

Aetzkali, wässerige und weingeistige Iodlösung, Iod gelöst in einer Iodverbindung, concentrirte Schwefelsäure, Kupferoxydammoniak, etc. etc.

III. Art des Vorkommens chemischer Verbindungen . . .

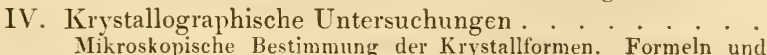
Mikroskopische Bestimmung der Krystallformen. Formeln und
Constructionen, welche vorzugsweise bei mikroskopischen Beobachtungen Anwendung finden. Krystallbestimmungen nach $Z$ en ger und Wertheim. 
V. Specielle Betrachtung der wichtigsten chemischen Verbindungen

1. Kalk und Kieselerde. Vorkommen und Nachweisung derselben. Herstellung der Kieselskelette, Ausziehen der Kieselerde. Beispiele von Verkieselungen.

2. Pflanzensäurenund Gerbst of fe. Nahweisung der Gerbstoffe. Art des Vorkommens derselben (Hartig's „Gerbmehlu). Die Bedeutung der Gerbstoffe nach Wigand. Vorkommen und Vertheilung im Gewebe. Gerbstoffe in absterbenden Zellen.

3. Glycoside.

4. Farbst offe. Farbstoffe, welche eingelagert in Plasma vorkommen Chlorophyll, Phycochrom, Phyeoerythrin, Diatomin, Anthoxanthin). Farbstoffe, welehe in Zellsaft gelöst vorkommen Erythrophyll und Anthocyan). Farbstoffe, welche ursprünglich im Zellsaft gelöst sind und später von den Membranen gespeichert werden (Farbstoff der Kreppwurzel, der Farbhölzer, der Berberiswurzeln, der rothen und violetten Saamenschaalen). Farbstoffe, welche nur eingelagert in die MIembran vorkommen. Farbstoffe, welche von den Zellen ausgeschieden werden und sich zwischen denselben oder an der freien Aussenfläche der Membranen ablagern.

5. Pectinst offe.

6. Kohlenhydrate. Reaction auf'Traubenzucker, Dextrin und Rohrzucker. Vorkommen und Nachweisung des Inulins. Nachweisung der Stärke, Verhalten derselben gegen Iodlösungen und gregen das Speichelferment. Die Cellulosearten, ihr Verhalten gegen Lösungs- und Quellungsmittel und gegen Iodsolution.

7. Proteinverbindungen. Nachweisung derselben im gelösten und ungelösten Zustand.

\section{Zehuter Abschnitt: Morphologie.}

I. Auf bau der organisirten Substanzen . . . . . . . .

1. Stärkekörner und Zellmembranen.

An a to mie: Schichtung und Streifung, Verlauf der Schichten und Streifen, Anordnung der dichten und weichen Partieen im Raume; Formverhältnisse der Membranen.

Wachsthum: Unterscheidung der Intussusception von der Apposition. Vermehrungsweise und Dickenwachsthum der Schichten, Flächenwachsthum der Membranen, ungleiches Wachsthumsvermögen verschiedener Zonen und Schichten.

2. A ufbau der Plasmagebilde. Bläschennatur isolirter Gebilde, speciell der Chlorophyllkörner und Zellkerne. Spermatozoen und Proteinkrystalloide. Entstehung der Einschlüsse, ob durch innere Differenzirung oder durch Auflagerung.

II. Die Gesetze der Zellentheilung . . . . . . . . . . .

1. Zellreihen. Theilungsvermögen der Endzellen und Gliederzellen.

2. Z ellflächen. Theilungsvermögen der Randzellen und der Flächenzellen, peripherisches und intercalares Wachsthum. Scheitelwachsthum, Erkennung der Scheitelzelle und ihrer Theilungsweise; intercalare Theilungen.

3. Zellkörper. Zellkörper, welche aus Zellflüchen entstehen. Kleinere Zellgruppen, welche aus einer einzigen Zelle entstehen. Zellkörper mit peripherischem Wachsthum ohne ausgezeichnete Scheitelzelle. Zellkörper mit einer Scheitelzelle.

III. Allgemeinere Wachsthumsgesetze . . . . . . . . . .

1. Zellenbildung und Zellenausdehnung. Aufgabe des Beobachters. Wachsthum des Stammes von Cladostephus. 
Bildung langgestreckter Żellen in einem kurzzelligen BildungsSeite gewebe. Ausscheidung des Cambiums. Hervorhebung der wichtigsten Momente, welche bei Untersuchungen über das Wachsthum der höhern Pflanzen in Betracht kommen.

2. Weitere Veränderungen im Gewebe. Entstehung ron L tucken und $\mathrm{Gängen,} \mathrm{ob} \mathrm{durch} \mathrm{Auseinanderweichen} \mathrm{der}$ Zellen, durch Desorganisation von Zellen und Zellcomplexen oder durch Zerreissen. Entstehung der Spaltöffnungen. Peridermbildung.

IV. Bildung seitlicher Organe

1. Morphologischer Ort der Entstehung. Verzweigung der Scheitelzelle und der Gliederzellen bei Zellreihen. Anlegung neuer Organe bei Zellflächen und Zellkirpern : die verschiedenen organbildienden Gewebe.

2. Morphologische Unterscheidung der Organe. Trichom, Thallom, Stamm, Blatt und Wurzel. Unterscheidung derselben.

3. Entwicklungsfolge und Stellungsverhältnisse. Die Organe entstehen entweder regellos, oder in Längsreihen, oder in Quirlen, oder in einer fortlaufenden Spirale oder Zickzacklinie. Stellungsverhältnisse der ausgebildeten Organe. Verwachsungen.

4. Systeme gleichwerthiger Organe. Schematische Veranschaulichung der hieher gehörigen Fragen. Unterscheidung des sympodialen Aufbaues vom monopodialen Callithamnion, Solaneen, Weinrebe, Kryptogamen). Aufbaı der Blüthenstände.

V. Entwicklung der Fortpflanzungszellen . . . . . . . .

1. Bildungsweise der. Fortpflanzungszellen. Bildung lurch Netamorphose einer vegetativen Zelle, durch besondere Zelltheilung mit oder ohne Scheidewandbildung, durch Ausstülpung und Abschnürung, durch freie Zellbildung, durch Copulation, durch Befruchtung.

2. T, a ge der keimbildenden Zellen. Sind es Endzellen orler Gliederzellen, Randzellen oder Flächenzellen, Aussenzellen oder Innenzellen? Gruppirung der reproductiven Zellen unter sich.

3. Ursprung und Entwicklungsfolge der keimbildenden $\mathrm{Z}$ ellen. Entstehung eines reproductiven Zellcomplexes aus einer oder aus mehreren ursprünglichen Zellen; Resorption reproductiver Zellen; Zellen mit einheitlichem Ursprung nur theilweise reproductiv. Entwicklungsfolge.

4. Veränderungen benachbarterZellen und Zell complex e. Modification des Inhalts und der Membranen; erhöhte Theilungsfähigkeit benachbarter Zellen.

VI. Gefässbündeluntersuchungen . . . . . . . . . . .

Behandlung der Präparate. Feststellung des Gefässbündelverlaufes. Entwicklung der Gefässbündel. 


\section{Berichtigungen.}

Seite 269 Zeile $\mathrm{b}$ von oben ist zu lesen contrahirt, statt concentrirt.

,, 259 , 5 von unten ist zu lesen beiderlei, statt beiden.

, 313 , 19 von unten ist zu lesen wel chen, statt welcher.

, 350 , 13 von oben ist nach Reagentien das Wort hä u fig einzuschalten.

, 510, , S von unten ist zu lesen Kupferlösungen, statt Zuckerlösungen.

Der einleitende Satz in Capitel über das Saftsteigen (pag. 3\$2) bezieht sich in dieser Fassung auf das nächstfolgende ('apitel (pag. 359), welches im Manuscript ursprünglich vorangestellt war. 


\section{Erster Abschnitt. Theorie des Ilikroskops.}

I.

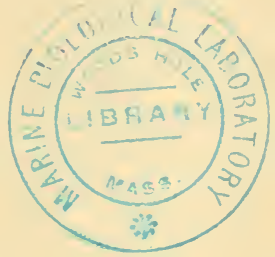

\section{Einleitung.}

Das zusammengesetzte dioptrische Mikroskop besteht in Wesent- 1 lichen aus zwei collectiv brechenden Linsensystemen, woron das eine dem Gegenstand zugekehrte als Objectiv, das andere dem Auge zugewendete als $\mathrm{Ocular}$ bezeichnet wird. Das Objectiv entwirft von dem Gegenstand, der sich etwas ausserhalb seiner Brennweite befindet, ein verkehrtes physisches Bild, welches durch das Ocular wie durch eine Loupe betrachtet wird. Hiernach ist die Stellung des Bildes zum Ocular insofern bestimmt, als der gegenseitige Abstand stets etwas kleiner sein muss, als die Brennweite des letztern.

Die ganze optische Wirkung des Mikroskops lässt sich in umstehender Figur 1 leicht übersehen. Die von dem Gegenstande $a b$ ausgehenden Strahlen rereinigen sich nach dem Durchgang durch die Objectivlinse $A$ zu dem wahren Bilde $b^{\prime} a^{\prime}$, dessen Lage und Grösse einzig und allein von der Brennweite der Linse und der Entfernung des Objectes abhängt. Bezeichnet man diese Grössen beziehungsweise mit $f$ und $p$ und den Abstand des Bildes mit $p^{*}$, so wird die gegenseitige Abhängigkeit bekanntlich durch die Gleichung ausgedrückt

$$
\frac{1}{p}+\frac{1}{p^{*}}=\frac{1}{f}
$$

Das Bild $b^{\prime} a^{\prime}$ verhält sich zur Ocularlinse $B$ wie ein wirkliches Object, und da sein Abstand so geregelt wird, dass es der Linse etwas näher liegt als ihr Hauptbrennpunct, so kommt ein virtuelles Bild $b^{\prime \prime} a^{\prime \prime}$ zu Stande, welches von einem über $B$ befindlichen Auge betrachtet werden kann. Bezeichnen wir mit $p_{1}$ und $p_{1}{ }^{*}$ die Abstände 
der Bilder $b^{\prime} a^{\prime}$ und $b^{\prime \prime} a^{\prime \prime}$ vom Ocular und mit $f_{1}$ die Brennweite des letztern, so besteht die Gleichung

$$
\frac{1}{p_{1}}-\frac{1}{p_{1}^{*}}=\frac{1}{f_{1}}
$$

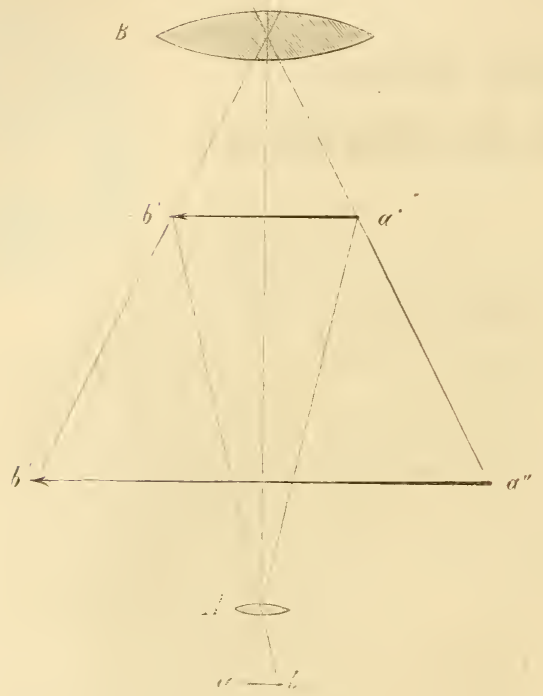

Figur 1.

Sind Ocular und $\mathrm{Ob}$ jectiv in constanter Entfernung von einander und deren Brennweiten $f$ und $f_{1}$ gegeben, so ist $p_{i}^{*}$ durch $p_{1}, p_{1}$ durch $p^{*}, p^{*}$ durch $p$ und folglich auch die erste Grösse $p_{1}^{*}$ durch die letzte $p$ bestimmt. Demzufolge ist es immer möglich, die Entfernung des Gegenstandes vom Objectiv so zu - regeln, dass das schliessliche virtuelle Bild um die Weite des deutlichen Sehens vom Auge absteht.

Die Lineardimensionen des Bildes verhalten sich zu den entsprechenden des Gegenstandes, wie die bezüglichen Entfernungen von der bilderzeugenden Linse. Für das Objectiv wird dieses Verhältniss durch $\frac{p^{*}}{p^{*}}$, für das Ocular durch $\frac{p_{1}^{*}}{p_{1}}$ ausgedrückt; die Combination beider im Mikroskop bedingt somit eine Vergrösserung vo $\frac{p^{*} p_{1}^{*}}{p} p_{1}^{*}$ Mal.

2 Soll das vom Auge wahrgenommene Bild deutlich und hell sein, so müssen die Nachtheile der sphärischen und chromatischen Aberration auf ein Minimum reducirt und die Oeffnungen der Linsen möglichst gross gemacht werden. Diese Bedingungen stehen nun aber insofern mit einander im Widerspruch, als bei einer einfachen Linse die Aberrationen um so stärker hervortreten, je grösser die Oeffnung derselben. Die Deutlichkeit lässt sich also nur auf Kosten der Hellig- 
keit erzielen und umgekehrt. Dieser Uebelstand erreicht bei den älteren Mikroskopen einen solchen Grad, dass ihre Bilder, wenn sie einigermaassen befriedigend sein sollen, schon bei mässiger Vergrösserung äusserst lichtschwach ausfallen.

Erst in neuerer Zeit kam man auf die glückliche Idee, das Objectiv aus zwei bis drei annähernd achromatischen Doppellinsen zusammenzusetzen; man brachte es auch bald dahin, durch geschickte Combination derselben die beiden Aberrationen weit vollständiger zu beseitigen, als diess bei der früheren Einrichtung durch blosse V $\mathrm{Ter}$ kleinerung der Oeffnung irgend erreichbar wäre. Ueberdiess erzielte man dadurch den wichtigen Vortheil, dass -- da die Herumlenkung der Strahlen zum physischen Bilde sich auf mehrere Linsen vertheilt - die Krümmungen derselben bedeutend schwächer sein dürfen und demnach eine grössere Oeffnung zulassen.

Wir werden in der Folge die Principien der Achromasie und des 3 Aplanatismus, soweit dieselben bei der Verfertigung der Mikroskope Anwendung finden oder wenigstens Anhaltspuncte bieten, noch näher erörtern; vorläufig wollen wir ein gewöhnliches, aus drei Doppellinsen bestehendes Objectiv, wie es aus der Hand des Optikers hervorgeht, als gegeben betrachten und den Gang der Lichtstrahlen durch dasselbe - vom Object bis zur Wiedervereinigung im physischen Bilde - verfolgen. Wir legen dabei die »dioptrischen Untersuchungen « von Gauss *) zu Grunde, worin die Gesetze der Lichtbrechung für ein centrirtes System beliebig vieler sphärischer Trennungsflächen, zwischen denen Medien mit verschiedenen Brechungscoefficienten liegen, entwickelt sind. In einem folgenden Kapitel soll diese Entwicklung selbst mit einigen Kürzungen und Abänderungen, welche, wie wir glauben, Nichtmathematikern das Verständniss erleichtern, mitgetheilt werden; hier mag es genügen, wenn wir die wichtigsten Ergebnisse derselben zusammenfassen und gestützt darauf die Unterschiede und Analogieen, welche zwischen einer unendlich dünnen Linse und einem beliebigen Linsensystem bestehen, hervorheben.

Eine unendlich dünne Sammellinse, d. h. eine solche, deren 4 Dicke gegen die Krümmungsradien rernachlässigt werden darf, hat

*, C. F. Gauss, Dioptrische Untersuchungen. Abhandlungen d. Göttinger Gesellschaft I, $15+3$.

*) Centrirt heisst ein System sphärischer Flächen, wenn die Mittelpuncte derselben in einer geraden Linie liegen. 
bekanntlich die Eigenschaft, Strahlen, die nach ihrem optischen Mittelpunct zielen, ungebrochen durchgehen zu lassen und parallel auffallende in einem Puncte, dem Hauptbrennpuncte, zu vereinigen. Ist also $a b$ Fig. 2) die gedachte Linse, $C C^{\prime \prime}$ ihre Axe, d. h. die Linie, in welcher die Krümmungscentra liegen, und $E$ der optische Mittelpunct: sind ferner $F$ und $F^{*}$ zwei um die Brennweite von der

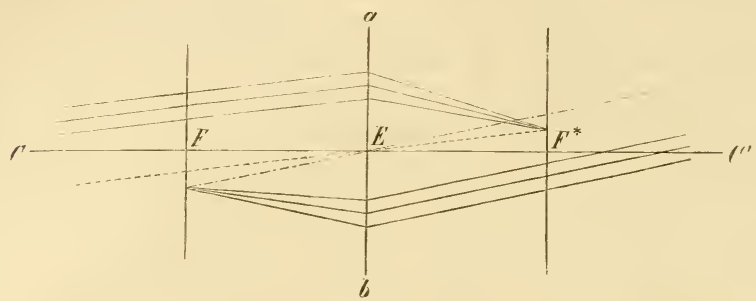

Figur 2.

Linse abstehende Puncte und in denselben senkrecht zur Axe zwei Ebenen errichtet, die wir mit den nämlichen Buchstaben bezeichnen wollen : so werden Strahlen, die ron einem Punct der Ebene $\boldsymbol{F}$ ausgehen, die Linse parallel verlassen, und ungekehrt Strahlen, welche unter sich parallel einfallen, in der Ebene $F^{*}$ sich in einem Punct rereinigen. Jedem einfallenden Strahlenkegel, dessen Spitze in der Ebene $F$ liegt, entspricht ein ausfahrender Strahlenerlinder, und jedem einfallenden Strahlencylinder ein ausfahrender Strahlenkegel, dessen Spitze in die Ebene $F^{*}$ fällt. Sind die unter sich parallelen Strahlen überdiess mit der Axe parallel, so kommt ihr Durchschnittsoder Vereinigungspunct auf der andern Seite der Linse in die Axe, also in $F$ oder $F^{*}$, zu liegen.

Auf dieses Verhalten, verbunden mit der Eigenschaft der sphärischen Flächen, von einem Puncte ausgehende Strahlen so zu brechen, dass sie sich (nöthigenfalls verlängert) wieder in einem Puncte schneiden, gründet sich die bekannte Construction, rermittelst deren für ein gegebenes Object Lage und Grösse des Bildes leicht bestimmt werden kann. Man zieht nämlich von den Endpuncten pt (Fig. 3) des Gegenstandes je zwei Linien $p r$ und $p q$, ron denen die eine die Axe in $F$ schncidet, während die andere parallel mit derselben verläuft; von den Durchschnittspuncten $q$ und $r$ mit der Ebene $E$ sodann zwei andere Linien $r p^{\circ}$ und $q p^{*}$, deren Richtungen gegen jene gleichsam vertauscht sind : $r p p^{*}$ ist parallel mit der Axe, $q p^{*}$ schneidet 
die letztere in $F$. Die beiden Linien $p r$ und $p q$ repräsentiren, wie man leicht sieht, zwei Lichtstrahlen, die sich nach der Brechung in $p^{*}$ vereinigen, und da alle übrigen von $p$ ausgehenden Strahlen in gleicher Weise nach $p^{*}$ gebrochen werden, so entsteht in $p^{*}$ das Bild

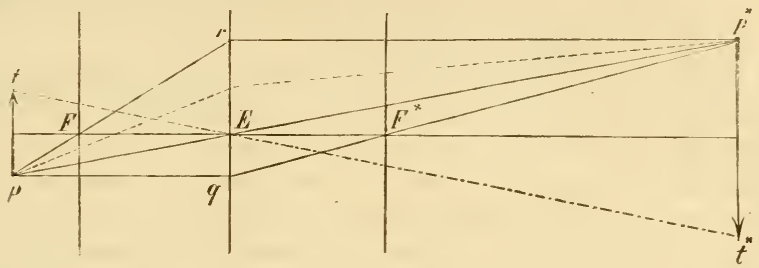

Figur 3.

des Punctes p. Durch eine ähnliche Construction erhält man das Bild des andern Endpunctes $t$, sowie aller übrigen zwischen $p$ und $t$ gelegenen Puncte. Man kann auch, um die Sache noch mehr zu vereinfachen, dic eine der beiden Hülfslinien durch den Richtungsstrahl $p E p^{*}$, welcher ungebrochen durchgeht, ersetzen.

Wollen wir die von Gauss eingeführte Terminologie auch auf 5 diesen einfachen Fall einer unendlich dünnen Linse ausdehnen, so wären die Ebenen $F$ und $F^{*}$ als Brennebenen, und die Ebene $E$ als $\mathrm{Hauptebene} \mathrm{zu} \mathrm{bezeichnen.} \mathrm{Die} \mathrm{Abstände} \mathrm{der} \mathrm{Brennebenen} \mathrm{von}$ der Hauptebene entsprechen der Brennweite, und ihre Durchschnittspuncte mit der Axe den Brennpuncten.

Es darf übrigens nicht ausser Acht gelassen werden, dass die erwähnten Constructionen, sowie überhaupt die in den physikalischen Lehrbüchern gegebenen Formeln, nach denen gewöhnlich die Lage des Bildes berechnet wird, auch für unendlich dünne Linsen nur unter der Voraussetzung genau sind, dass die vom Object ausgehenden Strahlen mit der Axe sehr kleine Winkel bilden und dass der wirksame Theil der brechenden Flächen ein kleiner Theil der ganzen Kugeloberfläche sei. Es ist diess eine Beschränkung, die wir auch bei der nun folgenden Betrachtung der Linsensysteme beibehalten, so dass also die Abweichung wegen der Kugelgestalt unberücksichtigt bleibt.

Wenn die brechenden Flächen, welche die Vereinigung der 6 Strahlen (oder ihrer Verlängerungen) zum Bilde bewerkstelligen, so weit ron einander abstehen, dass eine Vernachlässigung dieser Abstände gegen die übrigen Constanten unstatthaft erscheint, so erlciden die gegebenen Regeln, nach denen die Wege der gebrochenen Strahlen 
bestimmt werden, eine wesentliche Modification. Dieser Fall kann sowohl bei einzelnen Linsen von erheblicher Dicke, als bei Linsensystemen, wie sie im Mikroskop zur Anwendung kommen, eintreten; er ist in der erwähnten Abhandlung von $G$ auss in seiner ganzen Allgemeinheit, d. h. ohne alle Beschränkung der Abstände zwischen den brechenden Flächen, vorausgesetzt.

Ein solches System von brechenden Flächen, deren Krümmungscentra in einer geraden Linie liegen, hat nun zunächst die Eigenschaft mit einer unendlich dümnen Linse gemein, Strahlen, die ron einem Puncte ausgehen, wieder in einen Punct zu vereinigen, oder anders ausgedrückt: homocentrische Lichtbündel so zu brechen, dass sie nach sämmtlichen Brechungen immer noch homocentrisch bleiben. In zweiter Linie lässt sich zeigen, dass unter allen Umständen auf der gemeinsamen Axe zwei Puncte $F$ und $F^{*}$ liegen, welche mit den Brennpuncten einer einfachen Linse vollkommen übereinstimmen, indem die Ebenen, welche in diesen Puncten senkrecht zur Axe errichtet werden, alle Eigenschaften der Brennebenen besitzen. Da jedoch die letzteren hier unter Umständen innerhalb der Grenzflächen des Systems liegen, so können sie nur durch die bereits oben mitgetheilte allgemein gültige Definition charakterisirt werden, nämlich dadurch, dass jedem einfallenden homocentrischen Lichtbündel, dessen Centrum in die (mit Rücksicht auf die Fortpflanzungsrichtung vordere Brennebene fällt, ein ausfahrendes parallelstrahliges Bündel entspricht, und umgekehrt jedem parallelstrahligen einfallenden ein homocentrisches ausfahrendes, dessen Centrum in die hintere Bremebene fällt. Es wäre z. B. ungenau zu sagen, dass parallel auffallende Strahlen nach dem Durchgang durch das System sich in einem Puncte schneiden, da der wirkliche Kreuzungspunct derselben in manchen Fällen innerhalb des Systems liegt und zu den Brennebenen in keinerlei Beziehung steht.

7 Das Unterscheidende eines zusammengesetzten brechenden Systems besteht nun aber darin, dass an die Stelle des optischen Mittelpunctes zwei Puncte $E$ und $E^{*}$ treten, woron der erstere hinsichtlich des einfallenden, der letztere hinsichtlich des ausfahrenden Strahls die Rolle desselben übernimmt. Diese Puncte heissen die Hauptpuncte des Systems und die Ebenen, welche in ihnen senkrecht zur Axe errichtet werden, die Hauptebenen. Ihre Bedeutung wird sofort klar, wenn wir das Bild irgend eines Gegenstandes a 6 Fig. 4 , wie oben bei der Linse, durch Construction zu bestimmen suchen. Ein von $b$ nach dem ersten Hauptpunct $E$ zielender Strahl erfährt auch hier 
keine Ablenkung in dem Sinne, dass die Fortpflanzungsrichtungen vor und nach der Brechung einen Winkel bilden würden; allein der ausfahrende Strahl schneidet, rückwärts verlängert, die Axe im zweiten Hauptpunct $E^{*}$, statt in $E$. Er verhält sich also wie ein ungebrochener Strahl, den man um den Abstand $E E^{*}$ längs der Axe verschoben hätte. Eine ähnliche Verschiebung muss nun auch bei jedem andern Strahl, welches auch seine Richtung sein mag, hinzugedacht und in der Construction berücksichtigt werden. Die ausfahrenden

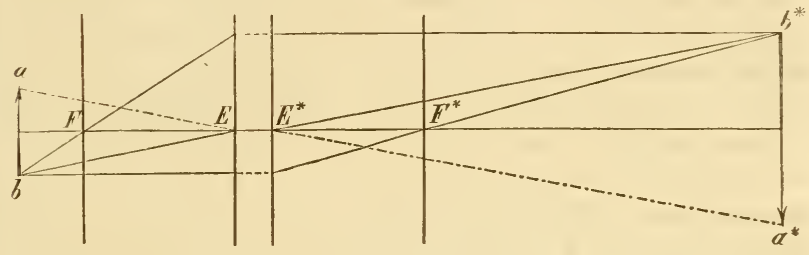

Figur 4.

Strahlen verhalten sich stets so, als ob in der ersten Hauptebene die Brechung und dann eine Verschiebung der gebrochenen Strahlen längs der Axe um den $A$ bstand $E E^{\star}$ stattgefunden hätte, oder was auf dasselbe herauskommt, als ob zuerst die Verschiebung der einfallenden Strahlen und hierauf die Brechung in der zweiten Hauptebene erfolgt wäre. Demzufolge lässt sich die Richtung eines parallel mit der Axe einfallenden Strahls einfach dadurch bestimmen, dass man denselben bis zur zweiten Hauptebene rerlängert und von hier durch den Brennpunct $F^{*}$ ausfahren lässt. Ungekehrt würde ein Strahl, welcher die Axe im ersten Brennpunct $F$ schneidet, von der ersten Hauptebene an parallel mit der Axe zu ziehen sein.

Von einem beliebigen Objectpunct $b$ (Fig. 4), der jedoch nicht in die Axe fallen darf, lassen sich also drei ausgezeichnete Strahlen ziehen, für welche die entsprechenden ausfahrenden ebenso leicht, wie bei der einfachen Linse, zu construiren sind. Zwei derselben genügen, um den Bildpunct $b^{*}$ zu bestimmen; denn die übrigen werden natürlich, wie in der Figur angedeutet, ebenfalls nach diesem Punct hin gebrochen.

Wie man sieht, ist die Gesammtwirkung eines brechenden Sy- 8 stems in jeder Beziehung der Brechung durch eine unendlich dünne Linse analog, aber nicht ganz aequivalent. Eine in $E$ befindliche Linse von gleicher Brennweite entwirft zwar von dem Objecte $a b$ (Fig. 4) ein mit $b^{*} a^{*}$ vollkommen $\ddot{u}^{h}$ ereinstimmendes Bild; das letztere müsste 
aber parallel mit sich selbst um den Abstand der beiden Hauptebenen längs der Axe verschoben werden, um es mit $b^{*} a^{*}$ zur Deckung zu bringen.

Die Brennweiten eines Systems werden durch die Entfernungen der Brennpuncte von den zugeordneten Hauptpuncten gemessen, also durch die Linien $F E$ und $E^{*} F^{*}$. Sie wurden im Vorhergehenden unter sich gleich angenommen, weil diese Gleichheit wirklich besteht, wenn die Endflächen des Systems - wie diess beim Mikroskop gewöhnlich der Fall ist - an dasselbe Medium grenzen. Wo diese Bedingung nicht erfüllt ist, verhalten sich die beiden Brennweiten, wie die Brechungscoefficienten der entsprechenden Medien. Bewegt sich z. B. der einfallende Strahl in Wasser und der ausfahrende in Luft, so verhält sich die vordere Brennweite zur hinteren wie $1 \frac{1}{3}$ zu $1 / 1 \frac{1}{3}$ ist der approximative Brechungscoefficient des Wassers). Ein nach $E$ zielender Strahl erfährt unter dieser Voraussetzung nicht bloss eine Verschiebung nach $E^{*}$, sondern er wird überdiess so gebrochen, als ob er in $E$ aus Wasser in Luft überginge. Der sogenannte Richtungsstrahl, wie der ungebrochen durchgehende Strahl auch hier, entsprechend der Bezeichnung für eine Brechung, gewöhnlich genannt wird, kann also nicht mehr durch $E$ und $E^{*}$, sondern er muss durch Puncte gezogen werden, von denen der erste um die hintere, der zweite un die vordere Brenıweite von dem zugeordneten (näher liegenden) Brennpunct absteht. Man hat diese beiden Puncte, welche sich in diesem Falle in die Rolle des optischen Mittelpunctes einer einfachen Linse theilen, die Knotenpuncte genannt. Für die folgende Betrachtung des Mikroskops erscheint jedoch die Einführung dieser Knotenpuncte entbehrlich, da das Eintauchen der Objectivlinsen in Wasser, sowie die Wirkung der Deckgläschen, ebensogut nachträglich in Rechnung gebracht werden kann.

9 Bezeichnet man den Abstand des Objectes von der ersten Hauptebene mit $p$, denjenigen des Bildes von der zweiten Hauptebene mit $p^{*}$, endlich die Brennweite mit $f$, so besteht die Gleichung:

$$
\frac{1}{p}+\frac{1}{p^{*}}=\frac{1}{f}
$$

welche mit der oben für eine einzige Brechung aufgestellten übereinstimut. Die Grössen $p$ und $p^{*}$ werden conjugirte Vereini$\mathrm{gungsweiten}$ genannt; $p^{+}$ist negativ zu nehmen, wenn Bild und Object auf derselben Seite der Hauptebenen liegen, was immer zutrifft, sobald $p<f$. Das Verhältniss von $p$ zu $p^{*}$ giebt in gleicher Weise, wie bei einfachen Linsen, die lineare Vergrösserungszahl, so 
dass der.oben $\mathrm{Nr}$. 1) gefundene Werth derselben für alle Fälle richtig bleibt.

\section{II.}

\section{Analytische Bestimmung der Cardinalpuncte brechender Systeme.}

Es handelt sich jetzt darum, die Puncte $E$ und $E^{*}, F$ und $F^{* *}, 10$ welche man die optischen Cardinalpuncte genannt hat, für ein gegebenes brechendes System, bei welchem die Krümmungen und Abstände der brechenden Flächen, sowie die Brechungscoefficienten der Medien bekannt sind, zu bestimmen. Diese Aufgabe lässt sich jedoch in unserem speciellen Falle, wo nur Linsen und Combinationen von solchen in Betracht kommen, auf eine viel einfachere zurückführen. Es genügt, die theoretische Betrachtung auf zwei brechende Flächen auszudehnen und die Rechnung nach der gefundenen Formel für die einzelnen das System bildenden Linsen oder Flächenpaare auszuführen. Je zwei Systeme von Cardinalpuncten lassen sich dann in gleicher Weise combiniren, wie zur Bestimmung derselben die Wirkungen zweier Brechungen combinirt wurden. Dasselbe gilt natürlich auch für die resultirenden Systeme; die Combination kann so lange fortgesetzt werden, bis endlich die Gesammtwirkung der brechenden Flächen auf ein System ron Haupt- und Brennpuncten zurückgeführt ist.

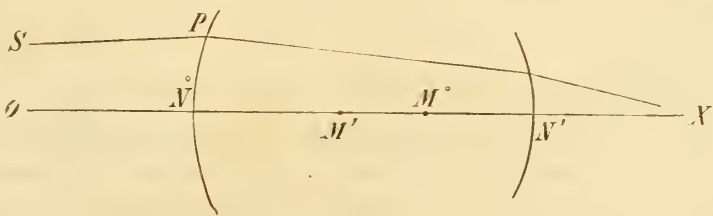

Figur 5.

Es seien nun $N^{0}$ und $N^{\prime \prime}$ Fig. 5) die sogenannten Scheitel einer Linse, d. h. die Puncte, in welchen ihre Grenzflächen von der optischen Axe $O X^{\prime}$ geschnitten werden, ferner $r^{0}$ und $r^{\prime}$ die bezüglichen Krümmungsradien, $I^{0} W^{\prime}$ die zugeordneten Mittelpuncte und $n^{0}, n^{\prime} n^{*}$ die absoluten Brechungscoefficienten der Medien in ihrer Reihenfolge ron links nach rechis: vor, in und hinter der Linse. Ist das erste und letzte Medium Luft, wie bei den meisten optischen Instrumenten, so können $n^{0}$ und $n^{*}=1$ gesetzt werden. Wir lassen jedoch 
diese Grössen, der Uebereinstimmung in der Form der Gleichungen zu lieb, vorläufig unbestimmt figuriren.

Ist nun $S P$ die Linie, in welcher sich der einfallende Strahl fortpflanzt, so lässt sich ihre Lage in der Papierebene durch ein beliebiges rechtwinkliges Coordinatensystem bestimmen, auf welches dann auch alle übrigen in Betracht kommenden Richtungen und Puncte bezogen werden können. Wählen wir die gerade Linie, auf welcher die Krümmungscentra liegen, als Abscissenaxe und bezeichnen wir zur Abkürzung die Abscissen der Puncte $N^{0}, M^{0}, N^{\prime}, M I^{\prime}$ mit diesen nämlichen Buchstaben, so dass also $r^{0}=M^{0}-N^{0}, r^{\prime}=M^{\prime}-N^{\prime}$, (welche Werthe demnach für convexe Brechungsflächen positiv, für concave negativ ausfallen), so nimmt die Gleichung für den einfallenden Strahl folgende Form an:

$$
y=\frac{\beta^{0}}{n^{0}}\left(x-N^{0}\right)+b^{0}
$$

Für Leser, denen die mathematische Ausdrucksweise weniger geläufig ist, sei hiezu bemerkt, dass $y$ die zur optischen Axe rechtwinklige Ordinate, $x$ die zugehörige Abscisse (von einem beliebigen Anfangspunct an gerechnet), $\frac{\beta^{0}}{n^{0}}$ die Tangente des Winkels, welchen der einfailende Strahl mit der Axenrichtung bildet, endlich $b^{0}$ die Ordinate des Punctes ist, in welchem der Strahl eine durch $N^{0}$ senkrecht zur Axe gelegte Ebene trifft.

11 Durch die erste Brechung in $P$ erhält der Strahl eine andere Richtung, die wir durch die Gleichung bestimmen

$$
y=\frac{\beta^{\prime}}{n^{\prime}}\left(x-N^{0}\right)+b^{\prime}
$$

in welcher, wie man leicht einsieht, die Grössen $\frac{\beta^{\prime}}{n^{\prime}}$ und $b^{\prime}$ ron $\frac{\beta^{0}}{n^{0}}$ und $b^{0}$, sowie von der Wölbung der Linsenfläche abhängig sind.

Ist die Oeffnung der Linse, wie wir voraussetzen, im Verhältniss zu den Krümmungsradien sehr klein, so fällt das wirksame Stück der brechenden Fläche nahezu mit einer durch den Scheitel gelegiten Tangentialebene zusammen. Letztere wird daher von dem rückwärts verlängerten gebrochenen Strahl in einem Puncte geschnitten, dessen Abstand $b^{\prime}$ von der Axe bis auf eine sehr kleine Grösse, die wir vernachlässigen dürfen, gleich $b^{0}$ ist. Die Gleichung des gebrochenen Strahls geht daher über in

$$
y=\frac{\beta^{\prime}}{n^{\prime}}\left(x-N^{0}\right)+b^{0}
$$

Es ist nun einleuchtend, dass in gleicher Weise auch die Bezie- 
hung zum zweiten Scheitel $N^{\prime}$ ausgedrückt werden kann. Man hat zu diesem Ende bloss das Absolutglied $b^{0}$ durch ein anderes $b^{*} \mathrm{zu}$ ersetzen, welches den Einfallspunct auf die zweite brechende Fläche, oder streng genommen auf die durch $N^{\prime}$ gelegte Tangentialebene bestimmt. Wir setzen also

$$
y=\frac{\beta^{\prime}}{n^{\prime}}\left(x-N^{*}\right)+b^{*}
$$

Die Gleichsetzung der Ausdrücke rechts in den Gleichungen (2 und (3) giebt

$$
b^{*}=b^{0}+\frac{\beta^{\prime}}{u^{\prime}}\left(\Lambda^{*}-N^{-0}\right)
$$

Um nun noch die unbekannte Grösse $\beta^{\prime}$ durch $\beta^{v} \mathrm{zu}$ bestimmen, errichten wir in $M^{0}$ (Fig. 6) eine Senkrechte, welche den gebrochenen Strahl in $Q^{\prime}$ und die Terlängerung des einfallenden in $Q$ schneidet. Die Winkel, welche dieselbe mit $P Q$ und $P Q^{\prime}$ bildet, seien $\varphi$ und $\varphi^{\prime}$, der Einfallsund Brechungswinkel $\alpha$ und $\alpha^{\prime}$. In den Drei-

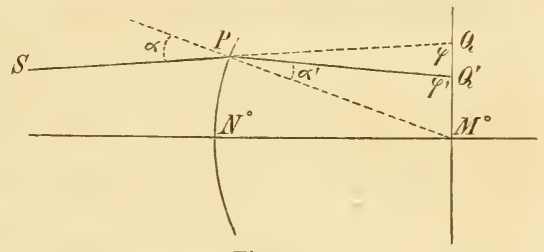

Figur 6. ecken $P Q M^{0}$ und $P Q^{\prime} M^{0}$ bestehen alsdann, da $P M^{0}=r^{0}$, die trigo. nometrischen Beziehungen

Hieraus ergiebt sich

$$
M^{0} Q=r^{0} \frac{\sin \epsilon}{\sin \psi} ; \quad M^{0} Q^{\prime}=r^{0} \frac{\sin \epsilon^{\prime}}{\sin \varphi^{\prime}}
$$

$$
\frac{M^{0} Q^{\prime}}{M I^{0} Q}=\frac{\sin \epsilon^{\prime} \sin \varphi}{\sin \because \sin \varphi^{\prime}}
$$

oder da $\frac{\sin r^{\prime}}{\sin \iota^{\prime}}$ nach dem Brechungsgesetz $=\frac{n^{0}}{n^{\prime}}$

$$
M^{0} Q^{\prime}=\frac{n^{0} \sin q}{n^{\prime} \sin q^{\prime}} M^{0} Q
$$

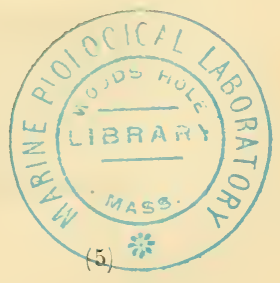

Aus den Gleichungen (1) und (2) für den einfallenden und den gebrochenen Strahl erhält man aber für die Ordinaten der Puncte $Q$ und $Q^{\prime}$, für welche $x-N^{0}=r^{0}$, die Werthe

$$
\begin{aligned}
& y\left(=M^{0} Q\right)=b^{0}+\frac{\beta^{0} r^{0}}{n^{0}} \\
& y\left(=M^{0} Q^{\prime}\right)=b^{0}+\frac{\beta^{\prime} r^{0}}{n^{\prime}}
\end{aligned}
$$

Substituirt man dieselben in die Gleichung $(5)$, so wird

$$
b^{0}+\frac{\beta^{\prime} r^{0}}{n^{\prime}}=\frac{n^{0} \sin \varphi}{n^{\prime} \sin \varphi^{\prime}}\left(b^{0}+\frac{\beta^{0} r^{0}}{n^{0}}\right)
$$


oder

$$
\beta^{\prime}=\frac{n^{0} b^{0}+\beta^{0} r^{0}}{r^{0}} \frac{\sin q^{\prime}}{\sin \varphi^{\prime}}-\frac{n^{\prime} b^{0}}{r^{\circ}} .
$$

In diesem Ausdruck ist das erste Glied rechts streng richtig; allein da $\varphi$ und $\varphi^{\prime}$ nach unserer Voraussetzung vorn rechten Winkel nur um kleine Grössen differiren und also ihre Sinus von der Einheit um Grössen abweichen, die gegen jene selbst wieder sehr klein sind, so wird - da der Quotient noch überdiess mit den kleinen Grössen $b^{0}$ und $\beta^{0}$ zu multipliciren ist - bis auf Grössen von der dritten Ordnung der Kleinheit genau

$$
\beta^{\prime}=\beta^{0}-\frac{n^{\prime}-n^{0}}{r^{0}} b^{0} .
$$

12 Es ist nun ohne Weiteres klar, dass wenn die Gleichung für den Weg des Lichtstrahls nach der zoweiten Brechung an der hintern Linsenfläche in die Form gebracht wird

$$
y=\frac{\beta^{*}}{n^{\prime \prime}}\left(x-N^{*}\right)+b^{*}
$$

die Grösse $\beta^{*}$ genau in derselben Weise durch $\beta^{\prime}$ bestimmt werden kann, wie diese letztere durch $\beta^{0}$. Man hat daher in dem eben gefundenen Ausdruck für $\beta^{\prime}$ bloss die Accente zu ändern. Es ist demnach

$$
\beta^{*}=\beta^{\prime}-\frac{n^{\prime \prime}-n^{\prime}}{r^{\prime}} b^{*}
$$

oder wenn man für $\beta^{\prime}$ und $b^{*}$ deren $W$ erthe aus 6 ) und (4) substituirt

$$
\beta^{*}=\beta^{0}-\frac{n^{\prime}-n^{0}}{r^{0}} b^{0}-\frac{n^{\prime \prime}-n^{\prime}}{r^{\prime}}\left[b^{0}+\left(\beta^{0}-\frac{n^{\prime}-n^{0}}{r^{0}} b^{0}\right)\left(\frac{N^{*}-N^{\mathbf{0}}}{n^{\prime}}\right)\right] \text {. }
$$

Setzen wir zur Abkürzung

$$
\left.\begin{array}{l}
u^{0}=-\frac{n^{\prime}-n^{0}}{r^{\circ}}, \quad u^{\prime}=-\frac{n^{\prime \prime}-n^{\prime}}{r^{\prime}} \\
t^{\prime}=\frac{N^{+}-N^{0}}{n^{\prime}}
\end{array}\right\}
$$

so geht obiger Ausdruck über in

$$
\beta^{*}=\beta^{0}+u^{0} b^{0}+u^{\prime} b^{0}+u^{\prime} t^{\prime} \beta^{\prime \prime}+u^{0} u^{\prime} t^{\prime} b^{0}
$$

oder auch

$$
\beta^{*}=\left(u^{0}+u^{\prime}+u^{0} u^{\prime} t^{\prime} b^{0}+\left(u^{\prime} t^{\prime}+1\right) \beta^{0} .\right.
$$

Ebenso erhält man aus Gleichung (4), wenn man für $\beta^{\prime}$ und $N^{*}-N^{0}$ deren $W$ erthe setzt

$$
b^{*}=u^{0} t^{\prime}+1 b^{0}+t^{\prime} \beta^{0} .
$$

Zur weiteren Vereinfachung dieser Ausdrücke sei

$$
\left.\begin{array}{rl}
u^{0} t^{\prime}+1 & =g \\
t^{\prime} & =h \\
u^{0}+u^{\prime}+u^{0} u^{\prime} t^{\prime} & =k \\
u^{\prime} t^{\prime}+1 & =l
\end{array}\right\}
$$


Man hat also

$$
\left.\begin{array}{l}
\beta^{*}=l b^{0}+l \beta^{0} \\
b^{*}=g b^{0}+h \beta^{0}
\end{array}\right\}
$$

Umgekehrt können natürlich auch die Grössen $\beta^{0}$ und $b^{0}$ durch $\beta^{*}$ und $b^{*}$, wenn diese letzteren gegeben sind, bestimmt werden. Man braucht zu diesem Behufe bloss successive die aus der einen der beiden Gleichungen erhaltenen Werthe von $b^{0}$ und $\beta^{0}$ in die andere zu sub. stituiren und bei der Reduction zu berücksichtigen, dass $g l-h k=1$. Diese letztere Relation lässt sich durch Multiplication der entsprechenden Ausdrücke in $(9)$ leicht beweisen. Man erhält

$$
\left.\begin{array}{l}
\beta^{0}=-k b^{*}+g \beta^{*} \\
b^{0}=l b^{*}-h \beta^{*}
\end{array}\right\}
$$

Es sei nun $P$ ein gegebener Punct auf der (nöthigenfalls verlän-13 gerten geraden Linie, die der einfallende Strahl beschreibt, und $\xi, \eta$ seine Coordinaten. Man hat dann nach Gleichung (1)

$$
\eta=\frac{\beta^{0}}{n^{0}}\left(\xi-N^{0}\right)+b^{0}
$$

oder wenn man für $\beta^{0}$ und $b^{0}$ ihre Werthe aus (11) substituirt

folglich

$$
\eta=\frac{g \beta^{*}-h \cdot b^{*}}{n^{0}}\left(\xi-N^{0}\right)-h \beta^{*}+l b^{*}
$$

$$
b^{*}=\frac{n^{0} \eta+n^{0} h-y \xi-N^{0} \beta^{*}}{n^{0} l-k \xi-N^{0}} .
$$

Setzt man diesen Werth in die Gleichung $\bar{i}$, welche die Richtung des Strahls nach der zweiten und letzten Brechung bestimmt, so wird dieselbe, wemn die mit $\beta^{*}$ multiplicirten Glieder zusammengestellt werden

$$
y=\frac{\beta^{*}}{n^{*}}\left\{x-\left(N^{*}-\frac{n^{0} h-y\left(\xi-N^{* 0}\right)}{\left.n^{0} l-k \xi-N^{0}\right)} \cdot n^{*}\right)\right\}+\frac{n^{0} \eta}{\left.n^{0} l-k \xi-N^{0}\right)}
$$

und schreibt man zur Abkürzung.

so geht dieselbe über in

$$
\left.\begin{array}{r}
N^{*}-\frac{n^{0} h-g\left(\xi-N^{0}\right)}{n^{0} l-k \xi-N^{0}} \cdot n^{*}=\xi \\
\frac{n^{0} \eta}{n^{0} l-k\left(\xi-N^{0}\right)}=r^{*}
\end{array}\right\}
$$

$$
y=r^{*}+\frac{\beta^{*}}{n^{*}}(x-\xi) .
$$

Auf dem letzten Wege des Strahls liegt also nothwendig ein Punct $P^{-}$, dessen Coordinaten $\xi$ und $r^{*}$ sind; denn wenn in obiger Gleichung $x=\xi^{-}$gesetzt wird, so ergiebt $\operatorname{sich} y=\gamma^{*}$. Da nun $\xi^{*}$ und $r^{*}$ einzig und allein durch $\xi$ und $r_{i}$, in Terbindung mit den in $g, l, l, l$ 
eingehenden optischen Constanten, bestimmt werden und von den Grössen $\beta^{0}$ und $b^{0}$ unabhängig sind, so folgt daraus, dass jeder Strahl, der auf seinem ersten $W$ eg durch den Punct $P$ geht, auf seinem letzten Weg durch den Punct $P^{*}$ gehen muss. Mit andern Worten: Einfallenden Strahlen, deren Richtungen sich in Punct $P$ schneiden, entsprechen ausfahrende, die sich (nöthigenfalls verlängert) in $P^{+}$schneiden. Man kann den Punct $P$ auch als Object und $P^{*}$ als sein optisches Bild betrachten; jenes ist aber nur dann reell, wenn $P$ im ersten Medium liegt, also $\xi-N^{0}$ negativ ist, und ebenso kann das Bild nur dann reell werden, wenn $\xi^{*}-N^{*}$ positiv ist oder $P^{*}$ im letzten Medium liegt. In den entgegengesetzten Fällen sind Object oder 'Bild nur virtuell, d. h. die Strahlen gehen nicht wirklich von $P$ aus oder laufen nicht wirklich in $P^{*}$ zusammen, $P$ und $P^{*}$ sind bloss die Durchschnittspuncte ihrer Verlängerungen.

$14 \quad$ Legen wir jetzt durch die Puncte $P$ und $P^{*}$ gegen die Axe senkrechte Ebenen, so ist von selbst klar, dass jedem Punct in der einen Ebene ein coordinirter Bildpunct in der andern entspricht; denn wenn $\xi$ constant bleibt, so erleidet auch $\xi$, das in einem gegebenen System allein ron $\xi$ abhängig ist, keine Teränderungen. Die Entfernungen der zugeordneten Object- und Bildpuncte verhalten sich wie die entsprechenden Ordinaten $r$ und $r^{*}$ oder nach Gleichung (13) wie $1 \mathrm{zu} \frac{n^{0}}{n^{0} l-h\left(\xi-1^{0}\right)}$. Als ein solches System von Puncten kann nun jedes Object ron endlicher Ausdehnung betrachtet werden; es erzeugt daher ein zusammenhängendes Bild, dessen Lineardimensionen durch das eben angegebene Verhältniss - das Object als Einheit betrachtet - bestimmt sind. Bezeichnet man die Grösse $\frac{n^{0}}{n^{0} l-k-N^{0}}$ mit $m$, so ist diess die lineare Vergrösserungszahl. Ihr Vorzeichen entscheidet, ob das Bild aufrecht oder rerkehrt ist; ist sie negativ und mit ihr also auch $\frac{\eta^{*}}{\eta}$, so bedeutet diess, dass Object - und Bildpunct auf entgegengesetzten Seiten der Axe liegen.

15 Die Puncte $P$ und $P^{*}$ können natürlich innerhalb der Grenzen, die durch ihre in (13) dargestellte Abhängigkeit gezogen sind, alle möglichen Lagen annehmen; denn für jedes beliebige §̧ lässt sich das entsprechende $\xi$ berechnen. Von diesen Lagen verdienen namentlich drei eine besondere Beachtung, weil sie geeignet sind, eine einfachere Beziehung zwischen den einfallenden und ausfahrenden Strahlen dar. zubieten.

Wir wollen zunächst die beiden Puncte in eine solche Lage brin- 
gen, dass sie gleich weit von der Axe abstehen. Es ist alsdann $\eta=\eta^{*}$ oder

woraus sich ergiebt

$$
m=\frac{n^{0}}{n^{0} l-k \xi-\lambda^{0}}=1
$$

$$
\begin{aligned}
\xi-\nu^{0} & =-\frac{n^{0}(1-l)}{k} \quad ; \text { folglich } \\
\xi & =N^{0}-\frac{\left.n^{0} 1-l\right)}{k} .
\end{aligned}
$$

Ebenso erhält man für $\xi^{+}$, wenn man diesen Werth in die Gleichung 13j einsetzt

$$
\xi=N^{*}+\frac{n^{*}(1-g)}{l} .
$$

Denken wir uns also auf der optischen Axe zwei Puncte $E$ und $E$, deren Abscissen die wir ebenfalls mit $E$ und $E^{*}$ bezeichnen den eben gefundenen Werthen ron $\xi$ und $\xi$ gleich sind, und stellen wir in denselben zwei Ebenen rechtwinklig zur Axe auf, so wird die erste vom einfallenden Strahl in gleicher Entfernung getroffen, wie die zweite vom ausfahrenden. Die gedachten Puncte sind also nichts anderes, als die Eingangs erwähnten Hauptpuncte des Systems, und die in ihnen errichteten Ebenen sind die Hauptebenen.

Es lässt sich auch leicht beweisen, dass wemn $n^{0}=n^{*}$, ein nach $E$ zielender Strahl ohne Ablenkung ausfährt. Denn macht man in der Gleichung für den einfallenden Strahl, nämlich in

$$
\left.y=\frac{\beta^{0}}{u^{0}} x-N^{0}\right)+b^{0}
$$

$x=E$ und substituirt für $\left(E-N^{0}\right)$ dessen Werth aus 14 , so hat man, da $y$ für $x=E$ Null werden soll

$$
\begin{gathered}
y=b^{0}-\beta^{0}\left(\frac{1-l}{k}\right)=0: \text { folglich } \\
l^{0}=\beta^{0}\left(\frac{1-l}{k}\right) .
\end{gathered}
$$

Führt man diesen Werth in den Ausdruck für $\beta^{*}$ [Gleichung (10] ein, so wird $\beta^{*}={ }^{30}$ und also auch da ja $n^{*}=n^{0} \frac{\beta^{*}}{n^{*}}=\frac{\beta^{0}}{n^{0}}$ d. h. der ausfahrende Strahl bildet mit der Axe denselben Winkel, wie der einfallende: der nach $E$ zielende Strahl ist ein Richtungsstrahl.

Die Consequenzen, die sich für den Fall ergeben, dass $n^{0}$ und $n^{*}$ ungleich sind und demnach $\frac{\beta^{*}}{n^{*}}$ und $\frac{\beta^{0}}{n^{0}}$ sich zu einander verhalten wie $n^{0} \mathrm{zu} n^{*}$, wollen wir hier nicht weiter verfolgen.

Als zweiter Fall sei diejenige Lage der Puncte $P$ und $P^{*}$ er- 16 wähnt, in welcher der Bildpunct in unendliche Ferne fällt, und also 
$\xi^{*}-N^{*}=\infty$ wird. Es ist alsdann, wie man leicht einsieht, auch $\eta^{*}=\infty$ und insofern $\eta>0$ einen endlichen Werth hat, wie wir roraussetzen

$$
m=\frac{n^{0}}{n^{0} l-k\left(\xi-N^{0}\right)}=\infty
$$

$D_{a}$ in diesem Ausdruck der Zähler eine endliche Grösse ist, so muss der Nenner $=0$ sein und daher $k\left(\xi-N^{0}\right)=n^{0} l$, woraus sich ergiebt

$$
\xi=N^{0}+\frac{n^{0} l}{k} \text {. }
$$

Ebenso erhält man für den analogen dritten Fall, in welchem der Objectpunct in unendlicher Ferne liegt, aus Gleichung (13) den entsprechenden Werth von $\xi^{*}$. Berücksichtigt man nämlich, dass die im Zähler und Nenner rorkommenden Grössen $n^{0} h$ und $n^{n} l$ gegen die unendliche Grösse $\left(\xi-N^{0}\right)$ verschwinden, so findet man leicht, dass

$$
\xi^{*}=N^{*}-\frac{\mu^{*} g}{k} \text {. }
$$

Diese Werthe ron $\xi$ und $\xi^{*}$ entsprechen offenbar den Abscissen der beiden Brennpuncte $F$ und $F^{*}$, und die in ihnen senkrecht zur Axe errichteten Ebenen sind die Brennebenen. So oft der eine der beiden Puncte in die entsprechende Brennebene fällt, rückt der andere in unendliche Ferne.

Aus den in den Gleichungen 14 bis 17 gegebenen Abscissen der Haupt- und Brennpuncte lassen sich ihre gegenseitigen Abstände durch einfache Subtraction der entsprechenden Abscissenwerthe bestimmen. Man erhält

$$
\left.\begin{array}{l}
E-F=-\frac{n^{0}}{k} \\
F^{*}-E^{*}=-\frac{n^{*}}{k}
\end{array}\right\}
$$

Die Grössen $-\frac{n^{0}}{k}$ und $-\frac{n^{*}}{k}$, oder die Entfernungen der Hauptebenen von den zugehörigen Brennebenen, hat man die Brennweiten des Systems genannt. Sie haben unter allen Umständen da $n^{\prime \prime}$ und $n^{*}$ ihrer Natur nach positive Zahlen sind - dasselbe, $l$ entgegengesetzte Vorzeichen. Sind sie positiv, liegt also $E$ hinter $F$ und $F^{*}$ hinter $E^{*}$, so heisst das System ein collectives; es wirkt wie eine Sammellinse und kann reelle Bilder liefern. Im entgegengesetzten Falle nennt man das System dispansiv, weil es wie eine Zerstrenungslinse wirkt und ron reellen Objecten nur virtuelle Bil. der liefert

Dic Abstände des Objectes ron der ersten und des Bildes ron der zweiten Hauptebene können, dem Sprachgebrauche bci einfachen 
Brechungen gemäss, als conjugirte Vereinigungsweiten bezeichnet werden. Ihre Werthe lassen sich aus dem Vorhergehenden leicht berechnen. Die Umsetzung der Gleichungen (14) und (15), in denen $\xi=E$ und $\xi^{*}=E^{*}$, ergiebt

$$
\begin{aligned}
& N^{*}=E+\frac{\left.n^{0} 1-l\right)}{k} \\
& N^{*}=E^{*}-\frac{n^{*}(1-g)}{k} .
\end{aligned}
$$

Substituirt man diese Werthe in $(13)$, wo $\xi, \eta$ und $\xi^{*}, \eta^{*}$ die Coordinaten der conjugirten Vereinigungspuncte $P$ und $P^{*}$ darstellen, so werden dieselben

$$
\left.\begin{array}{l}
\xi^{*}=E^{*}-\frac{n^{*} E-\xi}{n^{0}+k E-\xi} \\
\eta^{*}=\frac{n^{0} \eta}{n^{0}+k E-\xi}
\end{array}\right\}
$$

Aus der ersten dieser Relationen erhält man

$$
\frac{n^{0}}{E-\xi}+\frac{n^{*}}{\xi^{-}-E^{-}}=-k
$$

oder wenn man $E-\xi$ mit $p, \xi-E^{*}$ mit $p^{*}$ und die Brennweiten mit $f$ und $f^{*}$ bezeichnet, und endlich noch aus (1S, die Werthe von $-k$ hinzufügt

$$
\frac{n^{0}}{p}+\frac{n^{*}}{p^{*}}=-k=\frac{n^{0}}{f}=\frac{n^{*}}{f^{*}}
$$

Die Analogie mit der Brechung an einer Fläche ist hienach augenfällig.

Die Vergrösserungszahl $m$, welche das Verhältniss der Ordinaten $\imath^{*}: \eta$ ausdrückt, nimmt jetzt, in Folge der Ausdrücke in $(19)$ und $(20$, noch folgende Formen an

$$
\begin{aligned}
m & =\frac{n^{0}}{n^{0}+k p}=\frac{1}{1+\frac{k}{n^{0}} p}=\frac{1}{1-\frac{p}{f}}=-\frac{f}{f-p !} \\
& =\frac{n^{*}+k p^{*}}{n^{*}}=1+\frac{k}{n^{*}} p^{*}=1-\frac{p^{*}}{f^{*}}=\frac{f^{*}-p^{*}}{f^{*}} .
\end{aligned}
$$

Zur Vervollständigung der Analogieen, welche zwischen der opti- 18 schen Wirkung eines Systems und der Brechung an einer Fläche bestehen, sei hier noch die übereinstimmende Bedeutung der Grösse $k$ für den ersten, und der Grösse $u^{0}$ oder $u^{\prime}$ für den letzteren Fall hervorgehoben. Es lässt sich beweisen, dass die in (20) ausgedrückte Relation, nämlich $k=-\frac{n^{0}}{f}=-\frac{n^{*}}{f^{*}}$, in ganz analoger Weise auch für $u^{0}$ und $\iota^{\prime}$ besteht und dass, wenn man mit $\varphi$ und $\varphi^{\prime}$ die Brennweiten der ersten, nit $\varphi^{\prime \prime}$ und $\varphi^{\prime \prime \prime}$ die der zweiten brechenden Fläche bezeichnet, 


$$
\begin{aligned}
& u^{0}=-\frac{n^{0}}{q}=-\frac{n^{\prime}}{q^{\prime}} \\
& u^{\prime}=-\frac{n^{\prime}}{q^{\prime \prime}}=-\frac{n^{\prime \prime}}{q^{\prime \prime \prime}}
\end{aligned}
$$

wird. Setzt man nämlich in der Gleichung für die Richtung des Lichtstrahls nach der ersten Brechung $\left(x-N^{0}\right)=\varphi^{\prime}$, also $x$ gleich der Abscisse des Brennpunctes, und substituirt für $\beta^{\prime}$ seinen Werth $\beta^{0}+u^{0} b^{0}$, so wird

$$
y=\frac{\beta^{0}+u^{0} b^{0}}{n^{\prime}} \varphi^{\prime}+b^{0}
$$

und da dieser Werth für parallel mit der Axe einfallende Strahlen (für welche $\beta^{0}=0$, Null sein muss, so ergiebt sich

$$
\begin{aligned}
& u^{0} b^{0} \frac{q^{\prime}}{x^{\prime}}+b^{0}=0, \text { folglich } \\
& u^{0}=-\frac{x^{\prime}}{q^{\prime}} .
\end{aligned}
$$

Ebenso erhält man aus der Gleichung für den einfallenden Strahl, wenn man für $\beta^{0}$ seinen $W$ erth $\beta-u^{0} b^{0}$ setzt

$$
u^{0}=-\frac{n^{0}}{4} \text {. }
$$

Dass sich in gleicher Weise auch die Beziehungen von $u^{\prime} z u \varphi^{\prime \prime}$ und $\varphi^{\prime \prime \prime}$ ableiten lassen, ist ohne Weiteres klar.

Die Grössen $u^{0}, u^{\prime}, k$ sind also sämmtlich gleich $-\frac{n}{f}$, wenn $f$ die vordere oder hintere Brennweite und $n$ der Brechungscoefficient des Mediums ist, in dem sich der Strahl beziehlich vor oder nach der in Betracht kommenden Brechung bewegt. Die durch letztere verursachte Ablenkung ist also dieselbe, welche eine beiderseits an Luft (für welche $n=1$ ) grenzende unendlich dünne Linse, deren Brennweite $=f$, veranlassen würde.

19 Die eben angeführten Beziehungen geben uns ein Mittel an die Hand, zwei beliebige Systeme von optischen Cardinalpuncten ebenso leicht zu combiniren, wie zwei brechende Flächen: denn rermöge der mitgetheilten Gleichungen ist es verstattet, alle vorkommenden Brechungen auf unendlich dünne Linsen zurückzuführen und die Grössen $u^{0}$ und $u^{\prime}$, welche in den Formeln für $\beta^{\prime}$ und $\beta^{\prime \prime}$ auftreten, den reciproken Brennweiten jener Linsen, negativ genommen, gleich zu setzen.

Sind z. B. $E^{0}$ und $I^{0}$ die Hauptpuncte einer Linse, deren berechnete Brennweite $=f^{0}, E^{\prime} I^{\prime}$ die einer andern mit der Brennweite $f^{\prime}$, so wird rermöge der Eigenschaften der Hauptpuncte ein durch beide hindurch gehender Strahl so gebrochen, als ob in $I^{0}$ und 
$E^{\prime}$ unendlich dünne Linsen mit denselben Brennweiten aufgestellt wären. Der Abstand der Puncte $I^{0}$ und $E^{\prime}$ hat also hier dieselbe Bedeutung, wie bei einer einfachen Linse die Grösse $\frac{N^{*}-N^{0}}{n^{\prime}}=t^{\prime}$. Es folgt diess auch unmittelbar aus den auf die Hauptpuncte bezogenen Gleichungen des Strahls vor und nach der Brechung. Man hat für die Richtung desselben vor der Brechung

nach der ersten Brechung

$$
y=\beta^{0}\left(x-E^{0}\right)+b^{0},
$$

nach der $\mathrm{z} w$ eite $\mathrm{n}$ Brechung

$$
\begin{aligned}
& y=\beta^{\prime}\left(x-I^{0}\right)+b^{n}, \text { oder auf } E^{\prime} \text { bezogen } \\
& y=\beta^{\prime}\left(x-E^{\prime}\right)+b^{*},
\end{aligned}
$$

$$
y=\beta^{*}\left(x-I^{\prime}\right)+b^{*} .
$$

Aus den mittleren Gleichungen ergiebt sich, wenn man die Ausdrücke rechter Hand gleich setzt

$$
b^{*}=b^{0}+E^{\prime}-I^{0} \beta^{\prime},
$$

während wir oben [Gleichung 1 )] gefunden hatten

$$
b^{*}=b^{0}+\frac{N^{*}-N^{0}}{n^{\prime}} \beta^{\prime} \text {. }
$$

Die Analogie ist hienach augenfällig. Da nun aber ausser der Brechung, ron welcher $b$ * allein abhängig ist, auch die Verschiebung der Strahlen von einer Hauptebene zur andern in Rechnung kommt, so entspricht rücksichtlich der Lage des ausfahrenden Strahls zum einfallenden der erste Hauptpunct $E^{0}$ dem vordern, und der letzte $I^{\prime}$ dem hintern Linsenscheitel. Wenn also im Vorhergehenden $E$ und $E^{*}$ in ihrer Lage zu $N^{0}$ und $N^{*}$ durch die Gleichungen bestimmt wurden

$$
E=N^{*}-\frac{1-l}{k}, \quad E^{*}=N^{*}+\frac{1-g}{k},
$$

so werden die Hauptpuncte des resultirenden Systems, die wir mit $\boldsymbol{E}$ und $\boldsymbol{E}^{*}$ bezeichnen wollen, gegeben sein durch

$$
\boldsymbol{E}=E^{0}-\frac{1-l}{k} ; \quad \boldsymbol{E}^{*}=I^{\prime}+\frac{1-g}{k} .
$$

Dasselbe gilt natürlich auch für die Brennpuncte. Man hat

$$
\boldsymbol{F}=E^{0}+\frac{l}{k} \quad ; \quad \boldsymbol{F}^{*}=I^{\prime}-\frac{g}{k} .
$$

Zusammenstellung der Resultate.

Es dürfte wohl Manchem, welcher der vorhergehenden analyti- 20 schen Entwicklung nicht gerne folgt, erwünscht sein, wenn wir die wichtigsten Ergebnisse derselben hier übersichtlich zusammenstellen. 
Die Grössen, welche in den Formeln zur Bestimmung der Hauptund Brennpuncte auftreten und selbstverständlich für ein gegebenes System constant bleiben, sind $g, l, k$. Diese sind ihrerseits wieder abhängig von zwei Reihen anderer Grössen, nämlich $u^{0}, u^{\prime}, u^{\prime \prime} \ldots$ und $t^{\prime}, t^{\prime \prime} \ldots$, wobei $\frac{1}{u^{0}}$ die negativ genommene Brennweite einer unendlich dünnen Linse bezeichnet, welche eine der ersten Brechung aequivalente Ablenkung verursachen würde, und $u^{\prime}, u^{\prime \prime}$ dieselbe Bedeutung für die zweite und dritte Brechung haben, während $t^{\prime}, t^{\prime \prime} \ldots$ die Abstände der eingebildeten aequivalenten Linsen bezeichnen. Es folgt hieraus, dass wenn bei irgend einer Combination bloss zwei Brechungen, sei es an Flächen oder durch eingebildete Linsen, in Betracht kommen, die erste Reihe dieser Grössen auf $u^{0}$ und $u^{\prime}$, die zweite auf $t^{\prime}$ reducirt wird. Auf diesen einfachen Fall haben wir uns in der vorhergehenden mathematischen Betrachtung beschränkt.

Bezeichnet man nun mit $r^{0}$ und $r^{\prime}$ die Krümmungsradien der vorderen und hinteren Linsenfläche und mit $f^{0}$ und $f^{\prime}$ die Brennweiten ron Linsen, deren Wirkung der Brechung an den genannten Flächen gleichkommt, in dem Sinne, dass gleichen Einfallswinkeln gleiche Brechungswinkel entsprechen; bezeichnet man ferner den Brechungscoefficient der Linsensubstanz mit $n$, so wird - wenn das umgebende Medium Luft ist

$$
\begin{aligned}
& u^{0}=-\frac{1}{f^{0}}=-\frac{n-1}{r^{0}} \\
& u^{\prime}=-\frac{1}{f^{\prime}}=-\frac{1-n}{r^{\prime}}=+\frac{n-1}{r^{\prime}} .
\end{aligned}
$$

Hierzu ist zu bemerken, dass die Krümmungsradien $r^{0}$ und $r^{\prime}$ positiv oder negativ zu nehmen sind, je nachdem der einfallende Strahl die convexe oder die concave Seite der zugehörigen Fläche trifft. Ist letztere eben, so wird. $r=\infty$ und folglich das entsprechende $u=0$. Ebenso sind die Brennweiten, wo diese in Rechnung gebracht werden, positiv oder negativ zu nehmen, je nachdem die betreffende Brechung sammelnd oder zerstreuend wirkt, also positiv für collective, negativ für dispansive Linsen und Linsensysteme.

Für die Grösse $t^{\prime}$ erhält man im Fall eį̧er einzelnen Linse, deren Dicke $=d$ gesetzt wird,

$$
t^{\prime}=\frac{d}{n}
$$

und bei der Combination zweier Systeme, wenn die Hauptpuncte des ersten durch ihre Abscissen $E^{0}$ und $I^{0}$, die des zweiten durch $E^{\prime}$ und $I^{\prime}$ bezeichnet werden, 


$$
t^{\prime}=E^{\prime}-I^{0}
$$

d. h. $t^{\prime}$ ist gleich dem Abstand der zugekehrten Hauptpuncte.

Die Operationen, die zur Bestimmung der optischen Cardinal- 21 puncte nothwendig sind, lassen sich jetzt - nachdem $u^{0}, u^{\prime}$ und $t^{\prime}$ als gegeben betrachtet werden dürfen - in tabellarischer Form zusammengestellt leicht übersehen. Man hat

$$
\begin{aligned}
& 1^{\prime \prime} \text { für dieoptischen Constanten } \\
& \qquad \begin{aligned}
g & =u^{0} t^{\prime}+1 \\
l & =u^{\prime} t^{\prime}+1 \\
k & =u^{\prime \prime} u^{\prime} t^{\prime}+u^{\prime \prime}+u^{\prime}=u^{\prime} g+u^{0} \\
h & =t^{\prime}
\end{aligned}
\end{aligned}
$$

\begin{tabular}{|c|c|}
\hline a) zwei brechende Flächen & b) zwei brechende Systeme \\
\hline $\boldsymbol{E}=\boldsymbol{N}^{0}-\frac{1-l}{k}$ & $\boldsymbol{E}=E^{0}-\frac{1-l}{k}$ \\
\hline $\boldsymbol{E}^{*}=N^{*}+\frac{1-g}{k}$ & $\boldsymbol{E}^{*}=I^{*}+\frac{1-g}{k}$ \\
\hline $\boldsymbol{F}=N^{0}+\frac{l}{k}$ & $F^{\prime}=E^{0}+\frac{l}{k}$ \\
\hline $\boldsymbol{F}^{*}=\mathrm{N}^{*}-\frac{g}{k}$ & $\boldsymbol{F}^{*}=I^{*}-\frac{g}{k}$ \\
\hline
\end{tabular}

wobei zur Controle die Gleichung besteht: $g l-h k=1$;

$2^{0}$ für die Cardinalpuncte

Hiebei bedeuten die grossen Buchstaben die Abscissenwerthe der entsprechenden Puncte ron einem beliebigen in der Axe gelegenen Ausgangspunct an gerechnet), und zwar $N^{0} N^{*}$ die des ersten und zweiten Linsenscheitels, $E^{0} I^{*}$ die des ersten und letzten der 4 Hauptpuncte, die bei der Combination von zwei Systemen in Betracht kommen, endlich $\boldsymbol{E} \boldsymbol{E}^{*} \boldsymbol{F} \boldsymbol{F}^{*}$ die der resultirenden Hauptund Brennpuncte.

Ist z. B. in einem gegebenen Fall $\frac{l}{k}=-5^{\mathrm{m} \cdot \mathrm{m} \cdot}$ und $\frac{g}{k}=-4^{\mathrm{m} \cdot \mathrm{m}}$, so liegt der erste Brennpunct $\boldsymbol{F}^{\mathbf{r}} 5^{\mathrm{m} \cdot \mathrm{m}}$. vor dem ersten und der zweite Brennpunct $\boldsymbol{r}^{*} 4^{\mathrm{m} \cdot \mathrm{m}}$. hinter dem zweiten Linsenscheitel. Ebenso sind auch die übrigen Gleichungen zu verstehen. 


\section{III.}

\section{Die Cardinalpuncte des Mikroskops.}

1. Das 0hjectir.

22 Wir wenden uns jetzt zur Bestimmung der Cardinalpuncte eines gegebenen Objectirsystems. Dasselbe bestehe aus drei Doppellinsen und jede der letzteren aus einer planconcaven Flintglaslinse und einer biconvexen, beiderseits gleich gekrümmten Kronglaslinse. Der Brechungscoefficient des Flintglases sei 1,6 und der des Kronglases 1,5. Diess vorausgesetzt ergiebt sich für eine Flintglaslinse, wenn die Dicke $d$ und der Krümmungsradius $r^{\prime}$ vorläufig unbestimmt gelassen werden,

$$
\begin{aligned}
& u^{0}=0, \quad u^{\prime}=\frac{3}{5 r^{\prime}} \quad, \quad t^{\prime}=\frac{5}{8} d, \quad \text { und hieraus } \\
& g=1 \quad, \quad k=u^{\prime}=\frac{3}{5 r^{\prime}}, \quad l=1+\frac{3}{8} \frac{d}{r^{\prime}} ; \text { folglich } \\
& E=N^{0}+\frac{5}{8} d, E^{*}=N^{*}, \quad f^{0}=-\frac{5}{3} r^{\prime} \text {. }
\end{aligned}
$$

Bei einer planconcaven Linse fällt demnach der zweite Hauptpunct mit dem hintern Linsenscheitel zusammen, während der erste um $\frac{d}{n}$ (also hier $=\frac{5}{8} d$ ) von der ebenen Vorderfläche absteht. Die Brennweite $f^{0}$ ist negativ und zwar $=-\frac{1}{u^{\prime}}=\frac{r^{\prime}}{x-1}$.

Ebenso erhält man für eine Kronglaslinse, wenn der Krümmungsradius mit $r$ und die Dicke mit $d$ bezeichnet wird,

$$
\begin{gathered}
u^{0}=u^{\prime}=-\frac{1}{2 r} \quad ; \quad t^{\prime}=\frac{2}{3} d ; \text { hieraus } \\
g=l=1-\frac{d}{3 r} ; \quad k=\frac{1}{6 r^{2}}(d-6 r) ; \text { folglich } \\
E=N^{0}-\frac{2 d r}{d-6 r}=N^{0}+\frac{2 d r}{6 r-d} \\
E^{*}=N^{*}+\frac{2 d r}{d-6 r}=N^{*}-\frac{2 d r}{6 r-d} \\
f^{\prime}=\frac{6 r^{2}}{6 r^{2}-d} .
\end{gathered}
$$

Die Hauptpuncte einer biconvexen (oder auch biconcaven) Linse mit gleichen Krümmungen liegen demnach symmetrisch zu beiden Seiten des optischen Mittelpunctes; die Entfernungen von den beiden Linsenscheiteln sind unter sich gleich. Bei der Kugel, wo $d=2 r$, fallen die Hauptpuncte in das Centrum. Wird $d$ grösser als $2 r$, wie bei 
Cylinderloupen, so kommt der zweite Hauptpunct vor den ersten zu stehen.

Wir geben jetzt den Grössen $r$ und $d$ bestimmte Werthe, um die 23 erhaltenen Formeln auf die drei Doppellinsen unseres Objectivs anzuwenden. Zur grösseren Bequemlichkeit seien $f^{0}$ und $f^{\prime}$ jedesmal die Brennweiten der zusammengehörigen Flint- und Kronglaslinse, $d^{0}$ und $d^{\prime}$ ihre Dicke und $e^{0} i^{0} e^{\prime} i^{\prime}$ ihre Hauptpuncte, ferner $\varphi^{0} \varphi^{\prime}$ und $\varphi^{\prime \prime}$ die Brennweite der ersten, zweiten und dritten Doppellinse und $E^{0} I^{0} E^{\prime} I^{\prime} E^{\prime \prime} I^{\prime \prime}$ deren Hauptpuncte, endlich $N^{0} N^{1} N^{2} \ldots N^{8}$ die auf einander folgenden Linsenscheitel. Bei der Combination der Flint- und Kronglaslinsen wird alsdann $t^{\prime}\left(=e^{\prime}-i^{0}\right)$ gleich dem Abstand des Punctes $e^{\prime}$ von der Berührungsfläche, $u^{0}=-\frac{1}{f^{0}}$ und $u^{\prime}=-\frac{1}{f^{\prime}}$. Da die Rechnung sehr leicht ist, so mag es genügen, nachstehend die Resultate zusammenzustellen.

Erste Doppellinse. Sei $r=1, d^{0}=\frac{1}{2}, d^{\prime}=1$; dann wird: $e^{0}=N^{0}+\frac{5}{16}, \quad i^{0}=N^{\prime}, \quad e^{\prime}=\lambda^{\prime}+\frac{2}{5}, \quad i^{\prime}=N^{2}-\frac{2}{5}, f^{0}=-\frac{5}{3}, f^{\prime}=\frac{6}{5}$. Hieraus ergiebt sich:

$$
\begin{aligned}
& E^{0}=e^{0}+\frac{10}{13}=N^{0}+\left(\frac{5}{16}+\frac{10}{13}\right)=N^{0}+1,08173 \\
& I^{0}=i^{\prime}+\frac{1}{3} \frac{0}{3}=N^{2}+\frac{1}{3} \frac{0}{3} \frac{0}{5}-\frac{2}{5}=N^{2}+0,153846 \\
& \varphi^{0}=\frac{30}{13}=2,3077 .
\end{aligned}
$$

Zweite Doppellinse. Sei $r=4, d^{0}=\frac{2}{3}, d^{\prime}=\frac{4}{3}$; dann wird: $e^{0}=N^{3}+\frac{5}{12}, \quad i^{0}=N^{4}, \quad e^{\prime}=N^{4}+\frac{72}{15 \frac{2}{3}} ; \quad i^{\prime}=N^{5}-\frac{72}{153}, \quad f^{0}=-6 \frac{2}{3}$, $f^{\prime}=4 \frac{1}{18}$. Hieraus erhält man :

$$
\begin{aligned}
E^{\prime} & =e^{0}+1,01803=N^{3}+1,43469 \\
I^{\prime} & =i^{\prime}+0,6193=N^{5}+0,14 S 7 \\
\varphi^{\prime} & =\$, 77347 .
\end{aligned}
$$

Dritte Doppellinse. Sei $r=10, d^{0}=\frac{3}{4}, d^{\prime}=\frac{3}{2} ;$ dann wird: $e^{0}=N^{6}+\frac{1}{3} \frac{5}{2}, \quad i^{0}=N^{7}, \quad e^{\prime}=N^{7}+\frac{10}{1 \frac{0}{9}}, \quad i^{\prime}=N^{8}-\frac{1}{19}, \quad f^{0}=-16 \frac{2}{3}$, $f^{\prime}=10 \frac{10}{39}$. Hieraus

$$
\begin{aligned}
E^{\prime \prime} & =e^{0}+1,23456=N^{6}+1,70331 \\
I^{\prime \prime} & =i^{\prime}+0,7732=N^{8}+0,2469 \\
\varphi^{\prime \prime} & =24,6913 .
\end{aligned}
$$

Da nun die zweite und dritte Doppellinse zur Erzielung schwä- 24 cherer Vergrösserungen auch ohne die erste benutzt werden, so erscheint es zweckmässig, vorerst jene beiden zu combiniren und deren Gesammtwirkung als Objectiv etwas näher zu verfolgen. Wir machen zu diesem Ende die weitere Annahme, die zugekehrten Linsenflächen 
stehen um 0,1487 von einander ab, so dass die Grösse $t^{\prime}$ (der Abstand der zugekehrten Hauptpuncte $I^{\prime}$ und $E^{\prime \prime}$ ) in diesem Fall $=1,70331$ wird, während $u^{0}$ und $u^{\prime}$, wie gewöhnlich, den reciproken Werthen der bezüglichen Brennweiten, nämlich $-\frac{1}{q^{\prime}}$ und $-\frac{1}{q^{\prime \prime}}$, gleich zu setzen sind. Für die Abscissen der resultirenden Haupt- und Brennpuncte, die wir mit $(E)\left(E^{*}\right)$ und $(F)\left(F^{*}\right)$ bezeichnen, erhält man alsdann

$$
\begin{aligned}
& (E)=E^{\prime}+0,47046 \mathrm{~S}=N^{3}+1,90515 \mathrm{~S} \\
& \left.E^{*}\right)=I^{\prime \prime}-1,32419=N^{3}+3,32143 \\
& (F)=(E)-6,52064=N^{3}-4,9154 \mathrm{~S} \\
& \left(F^{*}\right)=\left(E^{*}\right)+6, \text { S2064 }=N^{8}+5,74437 .
\end{aligned}
$$

Die Brennweite $(f)$ des Objectivs ist also $=6,8$ und der Abstand des Brennpunctes $(F)$ von der Vorderfläche desselben $=4,9154$ S. Soll nun das physische Bild im Mikroskop in einer Entfernung von $p^{*}=200^{\mathrm{m} \cdot \mathrm{m} \cdot} \mathrm{zu}$ Stande kommen, wie diess annähernd bei den meisten neueren Instrumenten der Fall ist, so kann der Abstand $p$ des Objectes von der ersten Hauptebene aus der Relation

$$
\frac{1}{p}+\frac{1}{p^{*}}=\frac{1}{f}
$$

leicht bestimmt werden. Man findet $p=7,06116^{\mathrm{m} . \mathrm{m} .}$, folglich $p-f=0,24$. Als Vergrösserungszahl ergiebt sich

$$
m=\frac{f}{f-p}=-2 \mathrm{~s}, 3 .
$$

Das negative Vorzeichen deutet, wie bereits erwähnt, auf die verkehrte Lage des Bildes. - Die Gesammtvergrösserung des Mikroskops hängt natürlich mit von der Wirkung des Oculars ab, welche weiter unten näher besprochen werden soll.

$25 \quad$ Fügen wir jetzt, um das Objectiv zu vervollständigen, noch die erste und stärkste Doppellinse hinzu und wählen wir auch hier den Abstand so, dass die hintere Hauptebene mit der Vorderfläche der zweiten Linse zusammenfällt, so wird für diese Combination

$$
\begin{aligned}
& u^{0}=-\frac{1}{q^{0}}=-0,43333 \ldots, \\
& u^{\prime}=-\frac{1}{f}=-\frac{1}{6,5206}=-0,1466137 \text { und } \\
& t^{\prime}=1,90515 \mathrm{~s},
\end{aligned}
$$

und die Durchführung der Rechnung ergiebt als Abscissenwerthe der Haupt- und Brennpuncte, die wir $E$ und $E^{*}, \boldsymbol{F}$ und $F^{*}$ nennen wollen : 


$$
\begin{aligned}
& E=E^{0}+0,609039=N^{0}+1,6907697 \\
& \left.E^{*}=E^{*}\right)-1, \mathrm{~S} 000 \mathrm{~S}=N^{0}+3,175196 \\
& F=E-2,15042=N^{0}-0,45965 \\
& F^{*}=E^{*}+2,15042=N^{8}-0,69656 .
\end{aligned}
$$

Hienach beträgt also die Brennweite bloss 2,18 und der Abstand des Brennpunctes von der Vorderfläche 0,49 Längeneinheiten. Die Objectdistanz sinkt bei einer Tubuslänge von c. 200 auf 0,5 herunter.

Zur Versinnlichung dieser Zahlenverhältnisse ist in Fig. 7 das vorausgesetzte $\mathrm{Ob}$. jectirsystem mit seinen Haupt- und Brennebenen bei 5maliger Vergrösserung (der Millimeter als Einheit gedacht) dargestellt. Durch punctirte Linien wurden ausserdem die Cardinalebenen $(\boldsymbol{F})(\boldsymbol{E})\left(\boldsymbol{E}^{*}\right)\left(\boldsymbol{F}^{*}\right)$ der beiden hintern

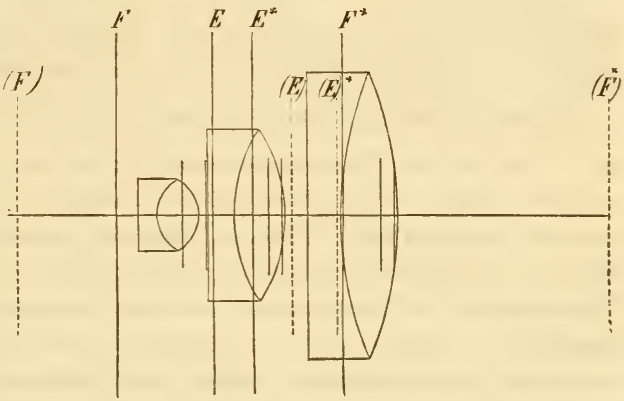
Linsen und durch kürzere ausgezogene die Hauptebenen der einzelnen Doppellinsen angedeutet.

Die Objectdistanz ist, wie man leicht einsieht, eine vom 26 Focalabstand abhängige Grösse; sie nimmt - ceteris paribus - mit dem letzteren $a b$ und $z u$, und wird demselben bei den stärksten $\mathrm{Ob}$. jectiven nahezu gleich. Mit der Brennweite des Objectivs und der davon abhängigen Vergrösserungszahl steht sie dagegen nicht in unmittelbarem Zusammenhang, und es ist bekannt, dass Instrumente aus verschiedenen Werkstätten rücksichtlich der Objectdistanz bei übrigens gleicher Stärke oft beträchtlich differiren. Die Frage, welche Umstände auf diese Grösse von Einfluss seien, ist daher nicht ohne praktisches Interesse. Sie lässt sich nach dem Vorhergehenden leicht beantworten, wenn man aus den Formeln für die Cardinalpuncte des Systems den Focalabstand $\left(N^{0}-F\right)$ bestimmt und für die Grössen $l$ und $\dot{k}$ ihre Werthe einsetzt. Ist $f$ (wie bisher) die Brennweite des ganzen Objectivs, $\varphi^{0}$ die der ersten Doppellinse und $(\boldsymbol{f})$ die der beiden übrigen zum System verbundenen Linsen, so hat man 


$$
f=-\frac{1}{k}=-\frac{1}{u^{0} u^{\prime} t^{\prime}+u^{0}+u^{\prime}}=\frac{\varphi_{0} f}{\varphi_{0}+(f)-t^{\prime}},
$$

und ebenso erhält man für den ersten Hauptpunct

$$
E=E^{0}+\frac{l-1}{k}=E^{0}+\frac{u^{\prime} t^{\prime}}{u^{0} u^{\prime} t^{\prime}+u^{0}+u^{\prime}}=E^{0}+\frac{t^{\prime} q^{0}}{q^{0}+(f)-t^{\prime}}
$$

Die Subtraction dieses letztern Werthes rom ersten für die Brenn. weite ergiebt als Focalabstand

$$
N^{0}-F=\frac{\psi^{0}\left[f-t^{\prime}\right]}{q^{0}+(f)-t^{\prime}}-E^{0}=\frac{\eta^{0}}{1+\frac{\psi^{0}}{\left(f-t^{\prime}\right.}}-E^{0} .
$$

Werden die Linsen und folglich auch ihre Hauptpuncte und Brennweiten als gegeben betrachtet, so erreicht offenbar $N^{0}-F$ einen um so grössern Werth, je kleiner $t^{\prime}$, denn der Nenner $1+\frac{\eta^{0}}{f)-t^{\prime}}$ nimmt mit $t^{\prime} \mathrm{ab}$ und zu. Der Focalabstand ist also am grössten, wenn $t^{\prime}$ möglichst klein, d. h. wenn die erste Linse der zweiten so viel als thunlich genähert wird. Diese Annäherung, die natürlich in der Berührung der beiden Linsen ihre Grenze findet, bedingt zugleich eine Verkleinerung der Brennweite, weil der für letztere gefundene Ausdruck mit $t^{\prime}$ steigt und fällt. Das Zusammenschieben der Linsen gewährt also einen doppelten Vortheil : eine stärkere Vergrösserung und trotzdem einen grösseren Focalabstand. Und zwar gilt diess nicht bloss für die erste und zweite Linse, sondern auch für die zweite und dritte; denn da die eben entwickelten Formeln für zwei beliebige Systeme von Cardinalpuncten Geltung haben, so müsste die Combination der dritten Linse mit den beiden vordern rücksichtlich der hier auftretenden Grösse $t^{\prime} \mathrm{zu}$ denselben Folgerungen führen. Es geht diess auch aus der Formel für die Brennweite, auf $(f)$ angewendet, hervor. Dieselbe wird um so kleiner, je geringer die Entfernung der betreffenden Hauptpuncte hier $I^{\prime}$ und $E^{\prime \prime}$. Der kleinste Werth von $(f)$ entspricht aber, wie ein Blick auf den Werth von $N^{0}-F$ zeigt, der grössten Objectdistanz (wobei freilich die erlaubte Voraussetzung gemacht ist, dass $\left.(f)>t^{\prime}\right)$.

Es ist einleuchtend, dass die besprochene Annäherung der zugekehrten Hauptpuncte auf jede Combination von brechenden Vorrichtungen, und daher auch auf die einzelnen Kron- und Flintglaslinsen, sich ausdehnen lässt. Da nun bei letztern der Abstand der Hauptpuncte von der Berührungsfläche mit der Dicke zu- und abnimmt, so folgt daraus, dass behufs Vergrösserung des Focalabstandes die Flintund Kronglaslinsen möglichst dünn gemacht werden müssen, wodurch dann zugleich eine stärkere Vergrösserung erzielt wird. 
Der Focalabstand und mit ihm die Objectdistanz wird also unter übrigens gleichen Umständen um so grösser, je geringer die Abstände der brechenden Flächen.

Damit ist indessen nicht gesagt, dass die Summe der Abstände maassgebend sei; es rersteht sich vielmehr ron selbst, dass die stärkeren Linsen auch in dieser Beziehung vorzugsweise ins Gewicht fallen.

Die Brechungscoefficienten des Flint- und Kronglases wurden 27 im Vorhergehenden zu 1,6 und 1,5 angenommen. Dass eine Aenderung dieser Zahlen nicht ohne Einfluss auf die Lage der optischen Cardinalpuncte sein kann, ist ron vorn herein einleuchtend, und es hält auch nicht schwer, sich im Allgemeinen die Wirkung der Zuoder Abnahme klar zu machen. Eine Tergrösserung der Brechungscoefficienten verstärkt natürlich, wenn das Verhältniss zwischen Kronund Flintglas dasselbe bleibt, und noch mehr, wenn bloss das Kronglas veränderlich gedacht wird, die optische Wirkung der einzelnen Linsen und setzt dem entsprechend bei gleichem Effect schwächere Krümmungen roraus. Sie wirkt also gleichsam, wie eine Annäherung der brechenden Flächen, indem sie das Verhältniss der Linsendicke zu den Krümmungsradien oder zur optischen Wirkung verkleinert. Bei gleicher Stärke des Objectivs wird also der Focalabstand ceteris paribus um so beträchtlicher, je grösser der Brechungscoefficient der Linsensubstanz; bei gleichen Krümmungen nimmt die Vergrösserungszahl mit dem Brechungscoefficienten zu, während die Objectdistanz je nach Umständen zu-oder abnimmt.

Betreffend die Naassbestimmung dieser Einflüsse, sind in nachstehender Uebersicht, um wenigstens einige Anhaltspuncte zu bieten, die wichtigsten Elemente unseres Objectirsystems für die in den beiden ersten Columnen angegebenen Fälle zusammengestellt. Die Form der Linsen und der Brechungscoefficient des Flintglases $(1,6)$ wurden dabei als constant betrachtet, die Entfernungen $e_{1}$ und $e_{2}$ der Doppellinsen dagegen $\left(e_{1}\right.$ zwischen der vorderen und mittleren, $e_{2}$ zwischen dieser und der letzten, so wie ferner die Brechungscoefficienten $n_{1} n_{2}$ und $n_{3}$ der Kronglaslinsen als variabel. Wir werden in der Folge von den hier erwähnten Combinationen diejenige auswählen, welche zur Beseitigung der Aberrationen am geeignetsten erscheint. 


\begin{tabular}{|c|c|c|c|c|c|c|}
\hline \multicolumn{2}{|c|}{ Gegeben. } & \multirow{2}{*}{$\begin{array}{l}\text { Brenn- } \\
\text { weite. }\end{array}$} & \multirow{2}{*}{$\begin{array}{l}\text { Focal- } \\
\text { abstand. }\end{array}$} & \multirow{2}{*}{$\begin{array}{l}\text { Object- } \\
\text { distanz. }\end{array}$} & \multirow{2}{*}{$E^{-}-E$} & \multirow{2}{*}{$\begin{array}{l}\text { Vergrösse- } \\
\text { rung. }\end{array}$} \\
\hline & $e_{1}$ & & & & & \\
\hline$e_{2}=0,14 \delta 7$ & 0,1538 & 2,1504 & $0,4 S 96$ & $0,5 \check{1} 1379$ & $1,4 \delta 442$ & 90,725 \\
\hline $\begin{array}{c}n_{1}=n_{2}=n_{3} \\
=1,50\end{array}$ & 1,0000 & 2,4682 & $0,390 \mathrm{~s}$ & 0,4220 . & 0,80137 & 80,0297 \\
\hline$e_{2}=0,50$ & 0,1535 & 2,2469 & 0,4719 & 0,50026 & 0,99712 & 88,0096 \\
\hline $\begin{array}{l}n_{1}=1,50 \\
n_{2}=n_{3}=1,52\end{array}$ & 1,0000 & $2,552 \mathrm{~s}$ & 0,3692 & 0,4022 & 0,21753 & 77,3452 \\
\hline$e_{2}=0,50$ & 0,1538 & 2,1469 & (1), 4271 & 0,453 & 0,94787 & 92,1555 \\
\hline $\begin{array}{c}n_{1}=n_{2}=n_{3} \\
=1,52\end{array}$ & 1,0000 & 2,4522 & 0,3346 & $0,36 \mathrm{~s}$ & 0,1179 & S0, 5594 \\
\hline
\end{tabular}

2. Das 0enlar.

28 Die Oculare haben zunächst den Zweck, die divergenten Strahlenbündel, welche das reelle Objectivbild erzeugen, so zu lenken, dass die Pupille des beobachtenden Auges sie sämmtlich aufzufangen vermag. Sie haben überdiess der selbstverständlichen Anforderung zu genügen, von dem ihnen als Object gebotenen Luftbilde unter den gegebenen Verhältnissen ein möglichst vollkommenes virtuelles Bild zu entwerfen. Es ist nun ohne Weiteres klar, dass eine einzelne Linse diese letztere Bedingung. nur für das Centrum des Gesichtsfeldes in befriedigender Weise erfült, für die peripherischen Puncte dagegen, weil die von hier ausgehenden Strahlenbündel den Rand der Linse durchsetzen, eine störende Farbenabweichung hervorruft. Aus diesem Grunde werden die Oculare der neueren Mikroskope in der Regel aus zwei Linsen zusammengesetzt, welche in gemeinsamer Fassung so angebracht sind, dass ihre Aberrationen sich gegenseitig nahezu aufheben. Die Combination dieser Linsen lässt in optischer Hinsicht einige Modificationen zu, von denen wir folgende hervorheben.

\section{a. Das Campanische 0cular.}

Das sogenannte Campanische $\mathrm{Ocular}$ besteht bekanntlich aus zwei einfachen Planconvexlinsen, woron die untere als Collectiv-, die obere als $\mathrm{Ocularglas}$ bezeichnet wird. Jenes fängt die vom Objectiv kommenden convergirenden Strahlen auf, ehe sie sich zum Bilde vereinigt haben; es bewirkt das Zustandekommen des 
letzteren innerhalb der Brennweite der Ocularlinse, so dass es durch diese wie durch eine Loupe betrachtet werden kann.

Für die mathematische Betrachtung des Oculars ist es rollkommen gleichgültig, in welcher Weise dasselbe mit dem Objectir combinirt wird. Man kann z. B. zunächst das Collectir in Rechnung bringen und hierauf die Ocularlinse mit dem resultirenden System verbinden, oder umgekehrt zuerst die Wirkung des ganzen Oculars bestimmen und dann erst die Combination mit dem Objectiv rornehmen. Wir wählen das Letztere.

Seien die Brennweiten der Collectiv - und Ocularlinse bezieh. lich 40 und $30^{\mathrm{m} \cdot \mathrm{m}}$, ihre Dicke 3 und $2^{\mathrm{m} \cdot \mathrm{m}}$. Bezeichnet man nun mit $E^{0} I^{0}$ und $E^{\prime} I^{\prime}$ die beiden Paare von Hauptpuncten und mit $N^{0} N^{1} N^{2} N^{3}$ die Scheitel der brechenden Flächen in ihrer Reihenfolge von unten nach oben, so erhält man, wenn der Brechungscoefficient der Linsen zu 1,5 und der gegenseitige Abstand derselben zu $43^{\mathrm{m} \cdot \mathrm{m} \cdot}$ angenommen wird,

$$
\begin{aligned}
E^{0} & =N^{0} \quad, \quad I^{0}=N^{0}+1 ; \\
E^{\prime} & =N^{2} \quad, \quad I^{\prime}=N^{2}+\frac{2}{3}, \text { folglich } \\
t^{\prime} & =E^{\prime}-I^{0}=45
\end{aligned}
$$

und hieraus für die resultirenden Haupt- und Bremnpuncte $E E^{*} F F^{*}$

$$
\begin{array}{ll}
E=E^{0}+72=N^{3}+24 ; & E^{*}=I^{\prime}-54=N^{3}-55 \frac{1}{3} \\
F=N^{3}-24 ; & F^{*}=N^{3}+7 \frac{1}{3} \\
E-F=F^{*}-E^{*}=45 . &
\end{array}
$$

Mit Rücksicht auf dieses System von Cardinalpuncten, welche 30 das Ocular als Ganzes ı epräsentiren, ist natürlich nicht das wirklich zu Stande kommende physische Bild, sondern dasjenige, welches das Objectiv für sich allein ohne Mitwirkung der Collectivlinse entwerfen würde, als Object zu betrachten und zwar als ein virtuelles, weil es hinter die erste brechende Fläche des Systems fällt. Seine Lage ist durch das schliessliche virtuelle Bild der Ocularlinse bestimmt, welches für jeden Beobachter um die Weite des deutlichen Sehens vom Auge åbsteht; sie muss also, da die Sehweite keine bestimmte Grösse ist, für jedes Auge eine andere sein. Nohmen wir, um eine bestimmte Vorstellung zu haben, an, das virtuelle Bild falle in eine Ebene, deren Entfernung von der letzten Fläche des Oculars $200^{\mathrm{m} \cdot \mathrm{m} \cdot}$ beträgt, wonach also die Vereinigungsweite $p^{*}=144^{2} \mathrm{~m} \cdot \mathrm{w} \cdot \mathrm{zu}$ setzen ist, so erhält man als conjugirten Werth $p=36,041^{\mathrm{m} \cdot \mathrm{m}}$.

Das reelle Bild des Objectivs müsste hienach in einem Abstand ron 12,041 $\mathrm{m} . \mathrm{m}$. von der letzten Fläche des Oculars zu Stande kommen, um ron dem beobachtenden Auge in der angenommenen Ent- 
fernung von $200^{\text {m.m. }}$ gesehen zu werden. Die Ocularvergrösserung $m^{\prime}$, die unter diesen Umständen hervorgebracht wird, ist gegeben durch

$$
m^{\prime}=\frac{f}{f-p}=4,01 \text {. }
$$

Hat nun das Mikroskoprohr eine solche Länge, dass die oben zu $200^{\mathrm{m} \cdot \mathrm{m}}$. angenommene hintere Vereinigungsweite des Objectivs der eben bezeichneten Lage des Objectivbildes zum Ocular entspricht, so ist, wie leicht einzusehen, die Gesammtvergrösserung des Mikroskops das $m^{\prime}$ fache der oben gefundenen Objectivvergrösserung. Für jede andere Länge des Mikroskoprohrs dagegen muss vorerst die dem Ocular entsprechende hintere Vereinigungsweite $p^{*}$ des Objectivs berechnet und hienach die Vergrösserungszahl reducirt werden. Ist z. B. die letzte Fläche des Oculars $200^{\mathrm{m} \cdot \mathrm{m}}$. von der ersten des Objectivs entfernt und der zweite Hauptpunct des letzteren in einem Abstand von 2,4011 von der Vorderfläche, so erhält man für $p^{*}$ den Werth $200-12,041+2,4011)=155,55 \mathrm{~S}$ und hieraus eine Objectivrergrösserung $m=1-\frac{p^{*}}{f}=\$ 1,5 \$ 4$, welche letztere Ziffer, mit 1,01 multiplicirt, die Gesammtrergrösserung des Mikroskops giebt.

31 Die Gesammtvergrösserung eines Mikroskops ist keine bestimmte Zahl, die sich ein für alle Mal feststellen liesse. Sie hängt von der Sehweite des beobachtenden Auges ab und kann daher, weil das letztere innerhalb gewisser Grenzen accommodationsfähig ist, nicht einmal für denselben Beobachter als eine constante Grösse betrachtet werden. Namentlich erleidet die Ocularvergrösserung sehr bedeutende Schwankungen. Die Ziffer 4,01, welche einer Sehweite von $200^{\mathrm{m}, \mathrm{m}}$. entspricht, sinkt z. B. für ein kurzsichtiges Auge von $100^{\mathrm{m} . \mathrm{m}}$. Sehweite auf 1,93 herunter. Aber auch die Objectivvergrösserung bleibt nicht ganz constant, da mit der Sehweite auch die Lage des reellen Bildes und dadurch das Verhältniss der vorderen zur hinteren Vereinigungsweite sich ändert. Der Kurzsichtige bringt das Objectivbild der Ocularlinse näher, um dadurch auch das schliessliche virtuelle Bild näher zu rücken; er vergrössert also die hintere Vereinigungsweite des Objectivs und verkleinert in Folge dessen die vordere. Die Objectivvergrösserung wird demnach verstärkt, während die Ocularvergrösserung geschwächt wird. Da jedoch das Letztere in weit höherem Grade stattfindet, so ist das schliessliche virtuelle Bild un so kleiner, die Gesammtvergrösserung folglich um so geringer, je kürzer die Sehweite. Zur Vergleichung sind nachstehend die Vergrösserungszahlen für verschiedene Sehweiten zusammengestellt. Die Tubuslänge von 
der ersten bis zur letzten brechenden Fläche wurde dabei zu $200^{\mathrm{m}, \mathrm{m}}$. und die Objectivvergrösserung für den Fall, dass $p^{+}=200^{\mathrm{m} . \mathrm{m}}$, zu 88,0096 angenommen (siehe die Tabelle auf pag. 2S).

\begin{tabular}{c|c|c|c|c}
\hline Sehweite. & $p^{*}$ & $\begin{array}{c}\text { Objectiv- } \\
\text { vergrösserung. }\end{array}$ & $\begin{array}{c}\text { Ocular- } \\
\text { vergrösserung. }\end{array}$ & $\begin{array}{c}\text { Gesammt- } \\
\text { vergrösserung. }\end{array}$ \\
\hline 200 & 155,558 & $\$ 1,581$ & 4,01 & 327,152 \\
150 & 194,551 & 85,586 & 2,97 & 254,19 \\
100 & $19 S, 462$ & 86,921 & 1,93 & 167,75
\end{tabular}

Aus dieser Zusammenstellung geht zunächst herror, dass die Ocularvergrösserung zur Sehweite in annähernd proportionalem Verhältniss steht, während die Objectivverg̈rösserung geringe Schwankungen im umgekehrten Sinne zeigt. Daraus folgt natürlich, dass auch die Gesammtvergrösserung mit der Sehweite steigt und fällt; allein die mathematische Beziehung ist damit noch keineswegs gegeben, und ein Blick auf die letzte Columne genügt, um sich zu überzeugen, dass das Verhältniss der Vergrösserungsziffern um mehrere Einheiten von dem der Sehweiten abweicht. Es wäre nun eine Sache der Rechnung, zu untersuchen, ob und in welchem Grade diese Abweichungen noch fortbestehen, wenn statt der letzten Fläche des Oculars ein nahe liegender Punct der Axe, welcher ungefähr der Lage des Auges während der Beobachtung entspricht, als Ausgangspunct bei Bestimmung der Sehweiten gewählt würde. Auf diese Weise könnte durch arithmetische Beispiele gezeigt werden, in wie weit die von verschiedenen Beobachtern gefundenen Vergrösserungsziffern differiren können, wenn die Reduction auf die nämliche conventionelle Sehweite durch eine einfache Proportion geschieht.

Wir halten es indess für zweckmässiger, die Frage einer mehr 32 mathematischen Betrachtung zu unterziehen, indem wir die Wirkung des Objectivs und des Oculars auf ein einziges System von Cardinalpuncten zurückführen. Da die Combination genau in derselben Weise geschieht, wie bisher, so mag es genügen, wenn wir hier bloss die Ergebnisse der Rechnung zusammenstellen. Wir bezeichnen die neuen Hauptpuncte mit $\boldsymbol{E}^{0}$ und $\boldsymbol{E}^{*}$, die Brennpuncte mit $\boldsymbol{F}^{0}$ and $\boldsymbol{F}^{*}$ und die erste und letzte brechende Fläche des Mikroskops, deren Abstand $200^{\mathrm{m} . \mathrm{m}}$. betragen soll, beziehlich mit $N^{\mathrm{*}}$ und $N^{*}$. Dann ist

$$
\begin{array}{cc}
\boldsymbol{E}^{0}=N^{0}-1,1283 & \boldsymbol{E}^{*}=N^{*}+6,727 \\
\boldsymbol{F}^{0}=N^{0}-0,5174 & \boldsymbol{F}^{*}=N^{*}+6,116 \\
\text { Brennweite }=0,611 .
\end{array}
$$


Das resultirende System stellt sich also, wie zu erwarten war, als ein dispansives heraus, $d . h$. es liefert ron reellen Objecten nur virtuelle Bilder. Die Brennpuncte stehen nämlich (im Gegensatz zu allen früheren Combinationen) weniger weit von einander ab als die zugehörigen Hauptpuncte.

Wie bei einem solchen System die letzten Wege der Strahlen zu construiren sind, ist in Figur $S$ reranschaulicht; $a b$ ist das Object,

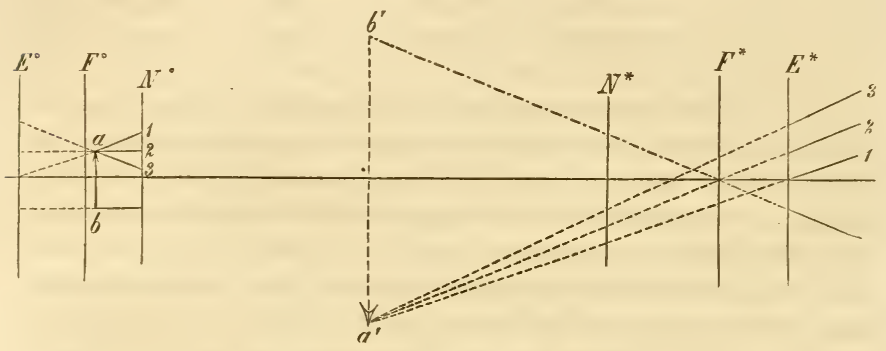

lïgur $\$$.

$a^{\prime} b^{\prime}$ das virtuelle Bild. Die beiderseits mit 1, 2, 3 bezeichneten $\mathrm{Li}$ nien entsprechen sich; sie schneiden die Hauptebenen $E^{0}$ und $E^{*}$ in gleichen Abständen von der optischen Axe und sind in ihrer Richtung durch die bekannten Brechungsgesetze bestimmt.

Ist nun $p^{*}$ der Abstand des Bildes von der zweiten Hauptebene und $f$ die Brennweite, so ist die Vergrösserungsziffer durch die allgemeingültige Formel $m=1-\frac{p^{*}}{f}$ gegeben, wobei das negative Vorzeichen auf die Umkehrung des Bildes deutet. Betrachtet man $m$ als positiv, so wird dieser Ausdruck

$$
m=\frac{p^{*}}{f}-1=\frac{p^{*}-f}{f},
$$

aus welcher letzteren Formel sich ohne Weiteres folgende Beziehung ableiten lässt :

Befindet sich das beobachtende Auge im zweiten Brennpunct des Mikroskops, so dass die Sehweite durch $p-f$ ausgedrückt wird, so ist die Vergrösserungsziffer dieser Sehweite genau proportional. Mit andern Worten: die virtuellen Bilder, welche das Mikroskop bei verschiedenen Einstellungen (für kurzsichtige und weitsichtige Augen. entwirft, werden vom zweiten Brennpunct aus unter dem nämlichen Winkel gesehen und müssen sich demnach rollkommen decken.

33 Die Gesammtwirkung des Mikroskops ist im Torhergehenden 
vollständig festgestellt. Es bleibt uns jetzt noch übrig, den wirklichen Gang der Lichtstrahlen im Oculareinsatz und nach dem Austritt aus der Ocularlinse zu verfolgen. Da das Objectivbild, welches für das Ocular das virtuelle Object darstellt, bei einer Sehweite von $200^{\mathrm{m} . \mathrm{m}}$. in einer Entfernung von 12,041 $\mathrm{m} . \mathrm{m}$. von der ebenen Fläche der Ocularlinse gedacht werden muss, so lässt sich die Lage des rom Collectiv entworfenen physischen Bildes leicht berechnen. Ist die Brennweite desselben, wie oben angenommen, $40^{\mathrm{m} . \mathrm{m} .}$, so erhält man aus dem gegebenen Abstand des virtuellen Objectes $(=49-12,041=35,959)$ eine conjugirte Vereinigungsweite von $15,936^{\mathrm{m}, \mathrm{m}}$. Diess ist die Entfernung, vom zweiten Hauptpunct des Collectivs an gerechnet, in welcher das wahre Bild wirklich zu Stande kommt und in welcher daher auch das sogenannte Diaphragma und das Ocularmikrometer angebracht sein müssen, um vom Beobachter mit gleicher Schärfe, wie das Bild, gesehen zu werden.

Die Lichtkegel, welche das Objectiv verlassen, stehen mit ihrer Basis auf der zweiten Hauptebene desselben; ihre Neigung gegen die Axe ist durch die Richtungsstrahlen bestimmt, welche von den entsprechenden Puncten des Objectes ausgehen und als Axen der Lichtkegel betrachtet werden können. Da nun diese Axen sämmtlich von einem Puncte, nämlich vom zweiten Hauptpunct des Objectivs, ausgehen, so müssen sie sich nach der Brechung im Ocular auch in einem Puncte schneiden, und \%war ist dieser letztere Punct das Bild des ersteren. Seine Lage ist für die Collectivlinse allein durch die bekannte Relation bestimmt : $\frac{1}{p}+\frac{1}{p^{*}}=\frac{1}{f}$, wobei $p$ laut früheren Annahmen über die Tubuslänge und die Lage der in Betracht kommenden Hauptpuncte $=200-(4 \mathrm{~S}+2,4011)=149,5989$ und $f=40^{\mathrm{m} \cdot \mathrm{m} \cdot}$. beträgt. Man erhält $p^{*}=54,595^{\mathrm{m} \cdot \mathrm{m} \cdot}$. und indem man den hierdurch bestimmten Punct als virtuelles Object der Ocularlinse betrachtet, ergiebt die Rechnung als Abscissenwerth des schliesslichen reellen Bildpunctes $N^{*}+5,93 \mathrm{~S}$, wobei $N^{*}$ die letzte brechende Fläche des Oculars.

Die Axen der Lichtbündel, welche den verschiedenen Puncten des Objectes entsprechen, schneiden sich also sämmtlich in einem Puncte, welcher c. $6^{\text {m.m. }}$ über der Ocularlinse liegt. Man kann diesen Punct den Augenpunct nennen. Eine in ihm senkrecht zur Axe errichtete Ebene wird von jedem einzelnen Lichtkegel in Allgemeinen in einer Ellipse, von allen zusammen dagegen in einem Kreise geschnitten, dessen Durchmesser bei gegebenen optischen Constanten vom Oeffnungswinkel des Mikroskops abhängt. Ist der 
letztere z. B. $60^{\circ}$, so wird der erstere etwas grösser als $1 / 2^{\mathrm{m} . \mathrm{m} .}$; beide nehmen gleichzeitig zu und ab. Da nun die Pupille des beobachtenden Auges einen beträchtlich grösseren Durchmesser besitzt, so leuchtet ein, dass dieselbe nicht nothwendig in den Augenpunct, sondern bloss in dessen Nähe gebracht werden muss, um sämmtliche Strahlen der austretenden Lichtkegel auf die Netzhaut gelangen zu lassen.

34 Der Augenpunct eines Mikroskops ist gewissermaassen zum Voraus gegeben; er muss stets eine solche Lage haben, dass wenn der Beobachter sein Auge in die gewohnte Entfernung von der Ocularlinse bringt, alle ausfahrenden Strahlen zum schliesslichen virtuellen Bilde beitragen, so dass das ganze Gesichtsfeld gleichmässig beleuchtet erscheint. Die Brennweite der Collectivlinse muss also jedenfalls so gewählt werden, dass der Bildpunct, welcher dem zweiten Hauptpunct des Objectivs entspricht, wenigstens $10-20^{m \cdot n}$. über die Ocularlinse zu liegen kommt; denn da die letztere die Convergenz der Strahlen noch verstärkt, so ist der Abstand des genannten Bildpunctes stets etwas grösser als der des Augenpunctes.

35 An der Stelle, wo das Objectivbild unter Mitwirkung der Collectivlinse wirklich zu Stande kommt, wird bekanntlich ein Diaphragma mit kreisförmiger centraler Oeffnung angebracht. Dasselbe bildet gleichsam den Rahmen des Objectivbildes und bestimmt also mit der Ocularlinse die Grösse des Gesichtsfeldes. Der Durchmesser des letzteren ist gleich dem Durchmesser der Diaphragma-Oeffnung, multiplicirt mit der Vergrösserungszahl der Ocularlinse, welche je nach Lage und Sehweite des Auges einen andern Werth annimmt.

\section{b. Das Ramsden'sche 0cular.}

36 Fast alle neueren Mikroskope sind mit dem besprochenen Campani'schen Oculare, da es allgemein als das passendste für ein aplanatisches Mikroskop gilt, ausgestattet. Unter besondcren Umständen jedoch werden auch andere Einrichtungen des Oculars, worunter diejenige von $\mathrm{R}$ amsden die bekannteste ist, mit Vortheil angewandt.

Das Ramsden'sche Ocular besteht. aus zwei planconvexen Linsen, deren gewölbte Flächen einander zugekehrt sind. Die Entfernung derselben ist so klein, dass sie zusammen wie ein Doublet wirken, dessen vergrössernde Kraft einer einzigen stärker gekrümmten Linse gleichkommt. Dem entsprechend muss das Object so eingestellt werden, dass das Objectivbild in geringer Entfernung vor dem untersten Glase, also zwischen diesem und dem Objectiv, zu Stande kommt.

Der Gang der Lichtstrahlen durch ein solches Doublet lässt sich 
bei gegebenen Abständen und Krümmungen der brechenden Flächen genau in derselben Weise ermitteln, wie beim Campani'schen Ocular. Werden z. B. die nämlichen zwei Linsen, die wir im Vorhergehenden als Collectiv- und Ocularglas vorausgesetzt haben, nach Ramsden'schem Princip combinirt, und beträgt der Abstand der zugekehrten Hauptpuncte $20^{\mathrm{m} . \mathrm{m} .}$, so erhält man für die Brenıweite des Systems $24^{\mathrm{m}, \mathrm{m}}$. und für die beiden Hauptpuncte $E=\lambda^{{ }^{0}}+1 \mathrm{~s}$ und $E^{*}=\lambda^{00}+11$, wobei $N^{0}$ die erste brechende Fläche des Oculars bezeichnet. Der zweite Hauptpunct liegt also $7^{\text {m.n. }}$ vor dem ersten. - Es versteht sich übrigens auch hier von selbst, dass der Optiker darauf zu sehen hat, den Augenpunct durch richtige $W$ ahl der Brennweiten in eine für die Beobachtung bequeme Lage zu bringen.

Die Vereinigung zweier Linsen zur Loupe, wie wir sie in der Einrichtung von Ramsden verwirklicht sehen, gewährt den Vortheil, dass das Objectivbild nicht erst verkleinert, vielmehr durch jede der beiden Linsen vergrössert wird. Das schliessliche virtuelle Bild (von der Blendung als Rahmen unschlossen; erscheint daher, wenn man Linsen mit denselben Krümmungen und Oeffnungen voraussetzt, wie oben beim Campani'schen Ocular, beträchtlich grösser als bei diesem letzteren, d. h. mit andern Worten: das Ocular von Ramsden giebt unter übrigens gleichen Umständen ein grösseres Gesichtsfeld. Es gestattet überdem eine beinahe vollkommene Ebenung des Gesichtsfeldes*) und eignet sich daher besonders zu Messungen mit dem Ocularmikrometer, indem die Vergrösserung von der Mitte bis zum Rande sehr annähernd dieselbe bleibt.

Diesen Vorzügen steht nun allerdings ein kleiner Nachtheil gegenüber. Der Umstand, dass das Objectivbild der Oberfläche der unteren Linse sehr nahe liegt, hat nämlich die unangenehıne Folge, dass die geringsten Fehler der Politur, kleine Risse, Stäubchen etc. auch im Gesichtsfelde auftreten und dadurch die Klarheit des Bildes beeinträchtigen. Wir haben indess nicht gefunden, dass dieser Uebelstand bei einem auch nur mit der gewöhnlichsten Sorgfalt gereinigten Ocular wirklich störend sei. Jedenfalls ist derselbe nicht hoch anzuschlagen. Alles wohl erwogen, wüssten wir in der That nicht, warum das Ramsden'sche Ocular nicht in jedem beliebigen Falle ein Campani'sches ersetzen könnte.

*) Die Ebenung des Gesichtsfeldes werden wir weiterhin eingehend erörtern. Vorläufig sei nur bemerkt, dass die Angaben Harting's über diesen Punct zum Theil unrichtig sind, und dass er in Folge dessen dem Ramsden'schen Ocular Mängel zuschreibt, die es in Wirklichkeit nicht hat. 


\section{c. Das aplanatische und das orthoskopische 0cular.}

In den Preisverzeichnissen einiger Optiker figuriren ausser dem gewöhnlichen Campani'schen auch aplanatische und orthoskopische Oculare, welche durch eine vollkommenere Ebenung des Gesichtsfeldes sich auszeichnen sollen. Von diesen Ocularen ist uns nur das aplanatische von Plössl näher bekannt. Dasselbe unterscheidet sich vom gewöhnlichen Ramsden'schen Ocular eigentlich bloss durch die aplanatischen Linsen. Es stellt nämlich eine aus zwei Doppellinsen zusammengesetzte Loupe dar, deren ebene Endflächen c. $23^{\text {m.m. }}$ von einander abstehen und deren Vergrösserung ungefähr $4 \frac{1}{2}$ : beträgt. Das Bild, welches dieses Ocular gewährt, ist in der That in seiner ganzen Ausdehnung scharf, gleichmässig vergrössert (nicht verzerrt) und nur sehr schwach gekrümmt.

Wahrscheinlich sind die aplanatischen Oculare ron Schiek u. A. im Wesentlichen ähnlich construirt. Die orthoskopischen von Kellner dagegen stimmen mit der Campani'schen Einrichtung überein, indem sie aus einem einfachen planconvexen Collectiv und einem achromatischen oder vielmehr übercorrigirten Ocular bestehen, welches die vorausgegangenen Aberrationen aufheben soll. Nach Harting gewährt dieses Ocular ein grosses geradflächiges Gesichtsfeld, womit wahrscheinlich gesagt werden soll, dass die Bildfläche eben und die Vergrösserung eine gleichmässige sei.

Die beiden Benennungen "aplanatisch " und "orthoskopisch * scheinen übrigens, soweit wir die Sache kennen, so ziemlich dasselbe $\mathrm{zu}$ bedeuten. Um die Verzerrung des Bildes zu beseitigen, müssen die einfallenden Strahlenbündel so gelenkt werden, dass ihre Richtungslinien die optische Axe in demselben Puncte schneiden (s. hierüber das Kapitel von der Ebenung des Gesichtsfeldes). Das Ocular muss also aplanatisch sein. Da nun an orthoskopischen Ocularen gerade das Freisein von Verzerrungen besonders gerühmt wird, so scheint ihr Hauptvorzug ebenfalls darin zu liegen, dass sie aplanatisch sind. Und wenn sie auch ausserdem die Krümmung der Bildfläche in vollkommnerem Grade aufheben, als die aplanatischen Oculare von Plössl u. A., was wir dahingestellt sein lassen, so ist doch der Ausdruck » orthoskopisch " nicht sehr bezeichnend, da er von andern Optikern auch für bildumkehrend, resp. aufrichtend, also in einem ganz anderen Sinne gebraucht wird. 


\section{d. Das bildumkehrende 0cular.}

Da die umgekehrte Lage, welche das zusammengesetzte Mikro- 38 skop den Bildern giebt, wenn auch nicht die Untersuchung, so doch das Präpariren der Objecte auf dem Objecttisch erschwert, so kamen die neueren Optiker auf den Gedanken, auf katoptrischem oder dioptrischem Wege eine Wiederumkehrung des Bildes zu bewerkstelligen. Das einfache Mikroskop, welches sonst gewöhnlich zu Zergliederungen benutzt wird, sollte auf diese Weise verdrängt und durch ein besseres Instrument ersetzt werden, welches insbesondere den wichtigen Vortheil eines grösseren Focalabstandes gewährt. Die Ausführung dieses Planes wurde in folgender Weise versucht.

Man fügte zu dem gewöhnlichen Ocular noch zwei Linsen hinzu, welche in gemeinsamer Fassung, die convexe Seite nach oben gewendet, in die Mikroskopröhre eingesetzt wurden. Das ganze Ocular erhielt dadurch dieselbe Einrichtung, wie beim terrestrischen Fernrohr, und musste also auch wie dieses eine Wiederumkehrung des Objectivbildes bewirken. Instrumente mit solchen Ocularen und zum Theil mit ausziehbaren Röhren wurden sowohl von Plössl als von Oberhäuser und ebenso von den meisten englischen Optikern hergestellt, haben jedoch unseres Wissens nie eine ausgedehntere Verbreitung gefunden.

Eine andere Methode, welche Oberhäuser zuerst anwandte, be- 39 steht darin, ein vollständiges zusammengesetztes Mikroskop mit schwacher V'ergrösserung als Ocular zu benutzen und dasselbe dem Objectiv so weit zu nähern, dass das von letzterem entworfene reelle Bild in geringer Entfernung von demselben zu Stande kommt. Es leuchtet ein, dass auf diese Weise ein Objectivabstand gewonnen wird, welcher bis zu ziemlich starken Vergrösserungen den freiesten Gebrauch der Präparirinstrumente gestattet. Dagegen lässt sich erwarten, dass die Schärfe der Bilder im Vergleich mit denen eines gewöhnlichen Mikroskops Manches zu wünschen übrig lässt. Solche Dissectionsmikroskope werden von Hartnack, dem Nachfolger Oberhäusers, gegenwärtig noch geliefert.

Endlich lässt sich die Umkehrung des Bildes auch durch reflecti- $\mathbf{4 0}$ rende Prismen erzielen, welche entweder über dem Ocular oder in der Mikroskopröhre angebracht werden. Die Wirkung eines solchen Prismas mit zwei rechtwinklig zusammenstossenden Flächen ist in Fig. 9 veranschaulicht. Dasselbe bedingt, wie man sieht, eine Umkehrung mit Rücksicht auf rechts und links, bringt dagegen in der 
Richtung senkrecht zur Papierfläche keine Veränderung hiervor. Um die Umkehrung zu vervollständigen, muss daher ein zweites recht-

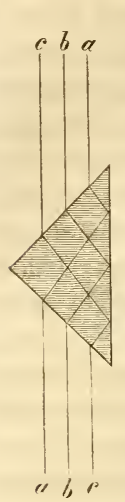
winklig zum ersten stehendes Prisina hinzugefügt werden. Es ist übrigens ohne Weiteres klar, dass eine solche Verbindung auch durch ein einzelnes Prisma ersetzt werden kann, wenn dasselbe so geschnitten ist, dass in seinem Innern eine zweimalige Totalreflexion von aequivalenter Wirkung stattfinden muss. Beide Mittel wurden von Chevalier, Nachet, Amici u. A. in verschiedener Weise in Anwendung gebracht. Am zweckdienlichsten dürfte immerhin eine Vorrichtung sein, wie sie in neuester Zeit von $\mathrm{N}$ a chet geliefert wird: ein in ein Kästchen eingeschlossenes Prisma, welches nach Belieben aufgesetzt oder weggenommen werden kann, je nachdem man das Mikroskop zu Zergliederungen oder zu Beobachtungen gebrauchen will. Dieses bildumkehrende Prisma

Figur 9. Prisme redresseur) von Nachet ist in Fig. 10 abgebildet. Die untere Fläche desselben steht senkrecht zur Mikroskopaxe und bildet mit der oberen, durch welche die Strahlen heraustreten, einen Winkel von $5 \mathrm{~s}^{0}$. Dadurch wird übrigens nichts Anderes

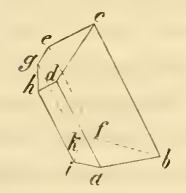

Figur 10. bezweckt, als dass die optische Axe sich um etwa $30^{0}$ gegen den Horizont neigt, so dass die Haltung des Kopfes eine bequemere wird. Die Flächen $a b c d$ und $b c e f$, welche in der Kante $c b$ zusammenstossen, sind die reflectirenden; sie bilden unter sich einen Winkel von $81^{1 / 2}{ }^{0}$, so dass die Reflexionsebenen der von unten einfallenden Strahlen, wie die Rechnung ergiebt, sich rechtwinklig schneiden.

Die übrigen Flächen des Prismas sind ohne Einfluss auf die optische Wirkung desselben.

Wollte man auf die Bequemlichkeit verzichten, den Apparat nach

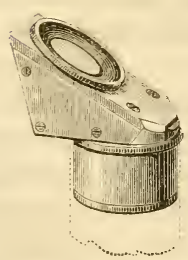

Figur 11. Belieben wegnehmen zu können, so wäre es vortheilhafter, die untere Fläche des Prismas convex zu schleifen und dadurch die Ocularlinse zu ersetzen, - eine Einrichtung, wie sie Nachet seinen älteren bildumkehrenden Mikroskopen mit zwei rechtwinkligen Prismen gegeben hat vgl. $\mathrm{Har}$ ting, Mikr. p. 763). Die Umkehrung des Bildes würde in diesem Fall ohne Lichtverlust erzielt.

Das verbesserte bildumkehrende Prisma 
(prisme redresseur perfectionné, Fig. 11), welches Nachet in seinem neuesten Katalog noch anführt, ist zur Vergrösserung des Gesichtsfeldes mit einem besonderen Ocular combinirt.

\section{Die Mittel zur Theilung der Strahlenbündel.}

Englische und französische Optiker verfertigen seit einiger Zeit 41 sogenannte multoculäre Mikroskope, durch welche gleichzeitig mehrere Personen ein und dasselbe Object beobachten können. Obschon nun freilich die Bedeutung solcher Instrumente für die Wissenschaft vorläufig noch zweifelhaft ist, so dürfen wir doch die Principien, auf denen die Construction derselben beruht, nicht ganz mit Stillschweigen übergehen.

Wenn wir von den älteren Versuchen dieser Art absehen, so geschieht die Vervielfältigung des Bildes im Grunde durchgehends in derselben Weise, nämlich durch Spaltung der Strahlenbündel - unmittelbar nach dem Durchgang durch das Objectiv - in zwei oder mehr gleiche Theile, von denen jeder durch ein besonderes Rohr dem entsprechenden Ocular zugelenkt wird. Diese Spaltung wird nun aber bald auf dioptrischem, bald auf katoptrischem Wege bewirkt; auf dioptrischem durch ein achromatisches Prisma, wie es in Fig. 12 dargestellt ist, auf katoptrischem durch Prismencombinationen, welche die Strahlenbündel durch Totalreflexion nach rerschiedenen Richtungen ablenken Fig. 13 und 14). Die optische Wirkung dieser

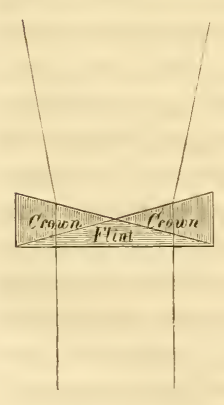

Figur 12.

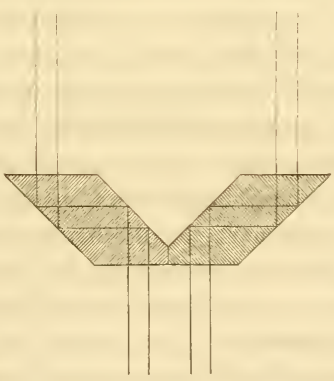

Figur 13.

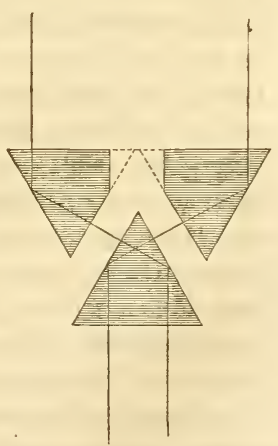

Figur 14.

Prismen ist für den Fall einer Zweitheilung der Strahlenbündel ohne Weiteres aus der Construction ersichtlich; auch leuchtet ein, dass 
wenn in Fig. 14 die seitlichen Prismen (oder ganz allgemein die Flächen, welche die zweite Reflexion bewirken) um $90^{\circ}$ gedreht werden, eine vollständige Wiederumkehrung des Objectivbildes stattfinden muss. Der Optiker hat es also in seiner Gewalt, dem schliesslichen virtuellen Bild eine aufrechte oder verkehrte Lage zu geben.

Soll eine Theilung der Lichtkegel in drei oder vier Bündel erzielt werden, so müssen die brechenden oder reflectirenden Flächen, welche dieselbe bewirken, nach eben so vielen Richtungen gegen die Medianlinie geneigt sein. Die einspringenden Kanten in Fig. 12 und 13 erscheinen alsdann als körperliche Winkel mit drei oder vier Beg! enzungsflächen; das mittlere Prisma in Fig. 14 wird zur 3-4seitigen Pyramide. Dasselbe Ziel würde man übrigens auch erreichen, wenn man die Spaltung an einem oder an beiden Theilbündeln in gleicher Weise wiederholte.

Die Vervielfältigung des Objectivbildes ist natürlich mit einer entsprechenden Schwächung der Lichtintensität verbunden; dazu kommen die Verluste, welche die Einschaltung brechender Substanzen schon an und für sich verursacht. Aus diesem Grunde sind bei multoculären Mikroskopen nur schwächere Linsensysteme anwendbar, und auch diese lassen, competenten Urtheilen zufolge, gar Manches zu wünschen übrig.

42 Die binoculären Mikroskope können auch so construirt werden, dass sie nach Art der Opernperspective zur Beobachtung mit beiden Augen dienen und dann eine stereoskopische Wirkung hervorbringen. Zu diesem Ende werden die zwei Röhren am besten so gestellt, dass sie der Convergenz der Augenaxen entsprechen, weil sonst die beiden Bilder sich nicht leicht zu einem vereinigen lassen. Man kann auch, un bei parallelen Röhren eine aequivalente Wirkung zu erzielen, über jedem Ocular ein achromatisches Prisma anbringen, welches im Maximum eine Ablenkung von c. $7^{0}$ hervorruft und durch symmetrische Drehung der Ablenkungsebenen den Convergenzwinkel der opti. schen Axen so lange verkleinern, bis die beiden Felder sich vollkommen decken. Diese lctztere Einrichtung hat z. B. das binoculäre stereoskopische Mikroskop von $\mathrm{Nachet}$ in Paris, die erstere dasjenige von $\mathrm{Crouch}$ in London.

Dass das stereoskopische Mikroskop gleich anderen stereoskopischen Vorrichtungen den Anschein der Körperlichkeit hervorbringen muss, lässt sich voraussehen; ob aber damit für die Wissenschaft irgend Etwas gewonnen, ob z. B. die Unterscheidung der Form- und Dichtigkeitsverschiedenheiten erleichtert sei, das möchten wir vor der 
Hand sehr bezweifeln. Auf das rein Physikalische der Erscheinung werden wir weiter unten, im Abschnitt über die mikroskopische Wahrnehmung, näher eingehen.

\section{IV.}

\section{Die chromatische und die sphärische Aberration.}

1. Die chromatische Aberration.

Die verschiedenfarbigen Strahlen, aus welchen das weisse Licht $\mathbf{4 3}$ zusammengesetzt ist, werden bekanntlich beim Durchgang durch ein brechendes Medium ungleich gebrochen. Jeder einzelnen Farbe entspricht daher in einem gegebenen System ron Linsen eine andere Lage der Cardinalpuncte und folglich auch des schliesslichen Bildes. Die Störungen, die aus diesem Umstande hervorgehen, bezeichnet man als chromatische Aberration. Ihre Beseitigung wird, wie wir hier als bekannt voraussetzen, durch die Eigenschaft der brechenden Substanzen möglich, bei geringer Verschiedenheit im Brechungsvermögen doch in sehr ungleichem Grade zerstreuend auf die verschiedenen Farben zu wirken. Bei Kronglas mit dem mittleren Brechungscoefficienten 1,5342 und bei Flintglas mit dem mittleren Brechungscoefficienten 1,6490 erhält man z. B. als Brechungsindex für die extremen Strahlen

$\begin{array}{lcc} & \text { Kronglas } & \text { Flintglas } \\ \text { Aeusserstes Roth } & 1,525 \mathrm{~S} & 1,6277 \\ \text { Violett } & 1,5166 & 1,6711\end{array}$

Als Differenz zwischen diesen extremen Brechungswerthen ergiebt sich bein Kronglas 0,0205 und beim Flintglas 0,0434. Die beiden hier erwähnten Glassorten weichen also mit Rücksicht auf ihr Zerstreuungsvermögen um mehr als das Doppelte von einander ab.

Wenn man nun erwägt, dass Concar- und Convexlinsen entgegengesetzt wirken, so leuchtet ein, dass die Farbendispersion, welche eine Sammellinse von Kronglas hervorruft, durch Hinzufügen einer concaven Flintglaslinse vollständig beseitigt werden kann, ohne dadurch die Ablenkung der Lichtstrahlen gleichzeitig aufzuheben. Denn wäre die ablenkende Kraft in beiden Linsen gleich, aber entgegengesetzt, die Brennweiten also gleich, so würde die Flintglaslinse vermöge ihres doppelt so starken Zerstreuungsvermögens die Farbendispersion der Kronglaslinse nicht nur vernichten, sondern noch eine 
entgegengesetzte von ungefähr gleicher Stärke hervorrufen. Es lässt sich also ein bestimmtes Verhältniss der Brennweiten denken, wobei das Linsenpaar für die extremen Strahlen achromatisch ist und doch die Eigenschaften einer Sammellinse besitzt.

Bezeichnet man die Brennweiten der Flintglaslinse für rothe und violette Strahlen mit $F_{r}{ }_{r}$ und $F^{\prime}{ }_{v}$ und die entsprechenden Brennweiten der Kronglaslinse mit $F^{\prime \prime}{ }_{r}$ und $F^{\prime \prime}{ }_{v}$, so ist die Bedingung des Achromatismus

$$
\frac{1}{F_{r}^{\prime}{ }_{r}}+\frac{1}{F_{r}^{\prime \prime}{ }_{r}}=\frac{1}{F_{v}^{\prime}}+\frac{1}{F^{\prime \prime}{ }_{v}} .
$$

Ist nun die Flintglaslinse planconcav und die Kronglaslinse biconvex und überdiess der Krümmungsradius der drei sphärischen Flächen derselbe, nämlich $=R$, wie wir diess für unser Objectiv vorausgesetzt haben, so wird obige Gleichung, wenn man für die Brennweiten ihre Werthe substituirt,

$$
-\left(n^{\prime}{ }_{r}-1\right) \frac{1}{R}+\left(n^{\prime \prime}{ }_{r}-1\right) \frac{2}{R}=-\left(n^{\prime}{ }_{v}-1\right) \frac{1}{R}+\left(n^{\prime \prime}{ }_{v}-1\right) \frac{2}{R},
$$

wobei $n_{r}^{\prime} n_{v}^{\prime} n^{\prime \prime}{ }_{r} \quad n^{\prime \prime}{ }_{v}$ die den gleich bezeichneten Brennweiten entsprechenden Brechungscoefficienten sind. Durch Multiplication sämmtlicher Glieder mit $R$ ergiebt sich

$$
2\left(n^{\prime \prime}{ }_{v}-n^{\prime \prime}{ }_{r}\right)=n_{v}^{\prime}-n_{r}^{\prime},
$$

d. h. das Zerstreuungsvermögen des Flintglases muss doppelt so gross sein, als das des Kronglases, wenn eine nach obiger Annahme construirte Doppellinse achromatisch sein soll. Sobald

$$
2\left(n^{\prime \prime}{ }_{v}-n^{\prime \prime}{ }_{r}\right)>n_{v}^{\prime}-n^{\prime}{ }_{r} \text {, }
$$

wird der Einfluss der Kronglaslinse, im umgekehrten Fall derjenige der Flintglaslinse vorwiegend.

44 Eine vollständige Vereinigung der Strahlen von verschiedener Brechbarkeit lässt sich übrigens bei einer Doppellinse nur für zwei bestimmte Farben des Spectrums, wie z. B. für Roth und Violett, erzielen. Da nämlich das Verhältniss der Dispersion im Kron- und Flintglas für verschiedene Farbenpaare ein anderes ist, so können, auch wenn das rothe und violette Bild sich rollkommen decken, die von den zwischenliegenden Strahlen erzeugten Bilder nicht mit jenen zusammenfallen. Die verschiedenfarbigen Bilder erscheinen daher nie genau gleich gross; die einen ragen mehr oder weniger über die andern hervor und bedingen dadurch den farbigen Saum, den man im weissen Lichte stets beobachtet. Im vollsten Sinne des Wortes ist also eine Doppellinse nie achromatisch.

Ganz dasselbe gilt natürlich auch für Linsensystenıe; es kann 
sich immer nur darum handeln, durch geschickte Combination der Flint- und Kronglaslinsen dem Achromatismus möglichst nahe zu kommen. Dabei kommt ausser dem richtigen Verhältniss der Brennweite namentlich auch die Wahl der Glassorten in Betracht, indem vorzugsweise solche geeignet sind, bei welchen die Partialdispersionen, d. h. die Zerstreuungsverhältnisse der gleichnamigen Farbenpaare (Frauenhofer'schen Linien) im Flint- und Kronglas möglichst wenig von einander abweichen.

Es versteht sich übrigens von selbst, dass bei Mikroskopen, deren Ocular aus einfachen Linsen besteht und folglich nicht achromatisch ist, die Flintglaslinsen des Objectivs einer um so grössern zerstreuenden Kraft bedürfen, da sie nicht bloss den damit verbundenen Kronglaslinsen, sondern auch dem Ocular das Gleichgewicht halten sollen. Das Objectiv muss also, wie man sich gewöhnlich ausdrückt, überverbessert sein. Nur ist dabei zu bemerken, dass wenn die von einem Objectpunct einfallenden Lichtkegel so gebrochen werden, dass die verschiedenfarbigen Objectivbilder sich seitlich gegen einander verschieben (was häufig vorkommt), eine Compensation zwischen Objectiv und Ocular unmöglich wird. Wir werden diesen Punct weiterhin (s. die Prüfung des Mikroskops) im Zusammenhang mit andern, welche das Verständniss desselben erleichtern, eingehend erörtern. Hier sei nur noch bemerkt, dass der blaue Rand des Gesichtsfeldes oder eines grösseren Objectes noch keineswegs den Beweis dafür liefert, dass das Objectiv wirklich überverbessert sei, und noch weniger, dass es im Verhältniss zu den unterverbesserten Ocularlinsen ein chromatisches Uebergewicht besitze.

\section{Jie sphärische Aberration.}

Die sphärische Aberration oder die Abweichung wegen der 45 Kugelgestalt beruht bekanntlich darauf, dass die Brennweite der Randstrahlen stets kleiner ist, als die der Centralstrahlen und zwar um so mehr, je grösser der Abstand von der Axe. Wenn man die Linsenoberfläche in concentrische Zonen theilt, so entspricht also jeder Zone eine andere Brennweite und folglich auch eine andere Lage des Bildes. Die Terbindung von Flint. und Kronglas dient nun auch dazu, die hieraus erwachsenden Störungen zu beseitigen. Es lässt sich nämlich bei einer achromatischen Doppellinse ein solches Verhältniss der Brechungen herstellen, dass die Randstrahlen, welche von der concaven Flintglaslinse um eine gewisse Grösse stärker von der Axe abgelenkt werden, als die Centralstrahlen, durch die Kronglas- 
linse un die nämliche Grösse stärker in entgegengesetzter Richtung gebrochen werden, so dass ihr Vereinigungspunct mit dem der Centralstrahlen zusammenfällt. Eine Doppellinse, bei welcher diese Vereinigung erzielt ist, heisst a $\mathrm{pl}$ a natis $\mathrm{ch}^{*}$.

Jedes achromatische Linsenpaar kann auch aplanatisch gemacht werden. Denn da der Achromatismus, wie aus der oben mitgetheilten Bedingungsgleichung hervorgeht, von den Brennweiten und Zerstreuungsverhältnissen, der Aplanatismus dagegen von den Krümınungen abhängt, so können die bezüglichen Bedingungen nicht in Widerspruch gerathen. Selbst wenn die Vorderfläche der Flintglaslinse gegeben ist, lassen sich die Krümmungsradien der übrigen Flächen so bestimmen, dass jede Aberration verschwindet. Ist $z$. B. eine Doppellinse mit ebener Vorderfläche und gleichen Krümmungen, wie wir sie für unser Objectiv vorausgesetzt haben, achromatisch, aber nicht aplanatisch, vielmehr der Einfluss des Flintglases auf die Randstrahlen zu schwach, so braucht man bloss die Berührungsfläche der beiden Linsen etwas stärker zu wölben und dafür die hintere Fläche der Kronglaslinse ebenfalls entsprechend zu ändern, so dass das Verhältniss der Brennweiten unverändert bleibt. Im entgegengesetzten Fall müsste dagegen der Krümmungsradius der Berührungsfläche vergrössert und hierauf die Hinterfläche der Kronglaslinse aus der Bedingungsgleichung für den Achromatismus bestimmt werden. Für den praktischen Optiker ist es natürlich am vortheilhaftesten, wenn die Glassorten so beschaffen sind, dass sie eine nahezu gleichseitige Krümmung der Kronglaslinse erlauben, indem durch solche Verbindungen mit den stärksten herstellbaren Krümmungen die kleinsten Brennweiten erzielt werden.

46 Im vollsten Sinne des Wortes ist indessen der Aplanatismus ebensowenig als der Achromatismus errcichbar. Die Flintglaslinsen üben nämlich auf die Randstrahlen einen um so grösseren Einfluss aus, je weiter von der Axe entfernt sie einfallen. Wenn daher auch der Vereinigungspunct der äussersten Randstrahlen mit dem der Centralstrahlen zusammenfällt, so zeigen die näher der Axe durchgehenden Strahlen doch immer noch Spuren der Abcration.

* Manche Autoren gehen diesem Ausdruck eine etwas weitere Bedeutung. Sie nennen ein Linsensystem nur dann a plan a t is $\mathrm{ch}$, wenn nicht nur die sphärische, sondern auch die chromatische Aberration möglichst beseitigt ist. Wir folgen in diesem Puncte Radicke (Handbuch der Optik) und anderen mathematischen Schriftstellern. 
Ueberdiess zeigt sowohl die Rechnung, als die Erfahrung, dass eine Doppellinse, welche für parallel auffallende Strahlen aplanatisch ist, diese Eigenschaft nicht mehr besitzt, sobald die Strahlen unter sich convergiren oder divergiren; dass überhaupt der Aplanatismus nur für bestimmte Entfernungen der (reellen oder virtuellen) Objectpuncte zu erzielen ist. Ist z. B. die Doppellinse $A B$ (Fig. 15) für den etwas ausserhalb der Brennweite liegenden Punct $a$ aplanatisch, so wird, wenn ein Object von hier aus der Linse näher rückt, sogleich eine Ueberverbesserung bemerkbar, welche allmählich zu- und dann wieder abnimmt, bis sie endlich im Puncte $b$ wieder verschwindet. Bei noch grösserer Annäherung, desgleichen beim Fernerrücken über $a$ hinaus tritt die entgegengesetzte Aberration, also Unterverbesserung ein.

Die beiden Puncte $a$ und $b$, von welchen aus die Lichtstrahlen ohne Aberration durchgehen, werden die aplanatischen Brennpuncte der Doppellinse genannt. Ihre Bestimmung ist durch die Rechnung nur auf dem mühsamen Wege der Annäherung möglich und fällt um so unsicherer aus, je grösser die Oeffnung im Verhältniss zu den Krümmungsradien. Bei der Herstellung von Objectiven mit grösseren Oeffnungswinkeln (z. B. $60^{\circ}-$ $80^{0}$ ) ist daher der praktische Optiker vorzugs-

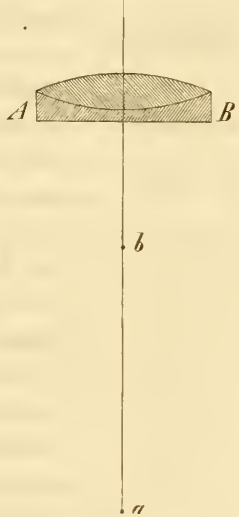

Figur 15. weise auf seine eigenen Erfahrungen angewiesen; er muss durch wiederholtes Versuchen sowohl die geeignetsten Glassorten, als das richtige Verhältniss der Krümmungsradien und der Linsenabstände herauszufinden und auf diesem rein empirischen Wege die beiden Aberrationen möglichst zu beseitigen suchen. Nur versteht sich von selbst, dass eine vorgängige theoretische Prüfung verschiedener Combinationen immerhin geeignet ist, manche beachtenswerthe Winke zu geben.

Bei der Vereinigung von Doppellinsen zu Objectiven ist also $\mathbf{4 7}$ darauf zu achten, dass das reelle oder virtuelle Object für jedes Linsenpaar in einen aplanatischen Brennpunct fällt. Sind z. B. $A, B, C$ (Fig. 16) drei Objectivlinsen, $P$ ein in der Axe gelegener Punct des Objectes, $P_{1}$ und $P_{2}$ die von der ersten und zweiten Linse entworfenen virtuellen Bilder, also $P_{2}$ das Bild von $P_{1}$ und virtuclles Object für die dritte Linse, so müssen, wenn das Objectiv aplanatisch sein 
soll, die Puncte $P, P_{1}$ und $P_{2}$ mit den entsprechenden aplanatischen Brennpuncten zusammenfallen, oder, wenn diess nicht genau zutrifft, die kleinen Abweichungen der einen Linse durch die entgegengesetzten einer andern vernichtet werden. Grössere Abweichungen sind unzulässig, weil eine gegenseitige Aufhebung derselben nur für ganz bestimmte Randstrahlen, nicht aber für die der Axe näher oder entfernter liegenden möglich wäre. Sobald also die besonderen Aberrationen der einzelnen Doppellinsen eine gewisse Grenze überschreiten, wird dadurch die Schärfe des Bildes wesentlich beeinträchtigt.

Aus der Bedeutung der aplanatischen Brennpuncte ergiebt sich von selbst, dass wenn die Linsenpaare annähernd richtig construirt sind, kleine Aenderungen ihrer Abstände die Deutlichkeit des Objectivbildes erhöhen können. Ist z. B. ein aus den Linsen $A B$ (Fig. 16) bestehendes System in der gezeichneten Lage aplanatisch, fällt also das virtuelle Bild der ersten Linse nahezu mit dem aplanatischen Brennpunct der zweiten zusammen, so muss, wenn der Objectpunct $P$ seine Lage beibehält, jede Distanzveränderung eine Unterverbesserung oder Ueberverbesserung zur Folge haben. Umgekehrt muss es daher auch möglich sein, einem gegebenen unvollkommen verbesserten Linsenpaare durch Veränderung des Figur 16. Linsenabstandes einen höheren Grad von Aplanatismus zu geben.

Der eben erwähnte Fall, in welchem der Objectpunct seine Lage zur ersten Linse beibehält, stimmt übrigens nicht ganz mit der Wirklichkeit überein. Durch stärkere Annäherung der Linsen wird nämlich, wie oben nachgewiesen wurde, die Brennweite des Objectivs kleiner und die Objectdistanz grösser, folglich auch die besondere Aberration der ersten Linse geändert. War die letztere vorher aplanatisch, so erscheint sie nach dem Zusammenschieben der Linsen, weil jetzt der Objectpunct etwas weiter absteht und zwischen die beiden aplanatischen Brennpuncte fällt, überverbessert, während die zweite Linse, deren virtuelles Object ebenfalls in grössere Ferne rückt und nun (im Fall sie die letzte des Objectivs ist) ausserhalb der aplanatischen Brennpuncte zu liegen kommt, eine Unterverbesserung zeigt. Diese entgegengesetzten Aberrationen können sich nun allerdings wechsel- 
seitig aufheben, jedoch in genügender Weise nur dann, wenn sie unter sich gleich sind und eine gewisse Grenze nicht überschreiten.

Ist in einem Objectiv jedes Linsenpaar für sich aplanatisch, so kann das letzte Paar auch allein oder in Verbindung mit dem vorletzten gebraucht werden, da der Objectpunct alsdann genau an die Stelle des von der vorhergehenden Linse entworfenen virtuellen Bildes tritt, folglich der Aplanatismus keine Störung erleidet. Dagegen können die vorderen Paare nach Wegnahme des letzten, wie leicht einzusehen, nur ein undeutliches Bild gewähren.

Aus dem Angeführten erklärt sich denn auch die Thatsache, dass gleich bezeichnete Objective aus der nämlichen Werkstatt immer nur annähernd übereinstimmen. Bei der absoluten Unmöglichkeit, dieselben Krümmungen wieder herzustellen, ist nämlich der Optiker bei jeder Linsencombination immer wieder auf's Probiren angewiesen, und hat er endlich die Aberrationen möglichst beseitigt, so ist es ein reiner Zufall, wenn das hergestellte Objectiv mit einem früheren genau dieselbe vergrössernde Kraft besitzt. Erfahrene Optiker verstehen es jedoch, diese unvermeidlichen Abweichungen in ziemlich engen Grenzen zu halten.

Es bleibt uns jetzt noch übrig, die oben zur Bestimmung der $\mathbf{4 9}$ Cardinalpuncte angenommene Linsencombination mit Rücksicht auf die beiden Aberrationen zu prüfen. Diese Prüfung kann natürlich nur eine rein theoretische scin; sie hat auch weniger den $Z_{w e c k}$, die verschiedenen Voraussetzungen, auf welche die erwähnte Bestimmung sich stützt, gegen einander abzuwägen, als vielmehr für jede ähnliche Linsencombination ein Beispiel einer annähernden Berechnung zu geben.

Zur Beurtheilung der chromatischen Aberration fehlen indess die Anhaltspuncte, da die Zerstreuungsverhältnisse der Flint- und Kronglaslinsen für die angenommenen Brechungscoefficienten nicht bekannt sind. Wir beschränken uns daher auf die sphärische Aberration und führen auch hier noch die weitere Vereinfachung ein, dass die zu verfolgenden Randstrahlen von einem Puncte der optischen Axe ausgehen.

Es sei $A B$ Fig. 17) die erste Objectivlinse, $a$ ein in der Axe gelegener Punct des Objectes, dessen Entfernung von der Linse $=\delta$, a $p$ ein Randstrahl, welcher mit der Axe und daher auch mit dem Einfallsloth der ersten brechenden Fläche den Winkel $\varphi$ bildet, $a_{1} p$ die Richtung desselben nach der ersten Brechung: dann ist der Winkel $\varphi_{1}$, welchen der gebrochene Strahl mit der Axe bildet, durch das 
Brechungsverhältniss des Flintglases bestimmt. Folglich kann auch der Abstand des Punctes $a$ von der brechenden Fläche oder die dem

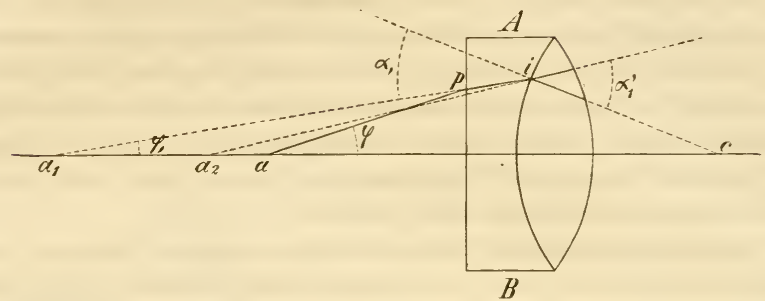

Figur 17.

Objectabstand $\delta$ entsprechende Tereinigungsweite, die wir mit $f_{1}$ bezeichnen wollen, als gegeben betrachtet werden. Man hat nämlich

$$
f_{1}=\delta \frac{\tan g \varphi^{\prime}}{\tan \eta_{1}} .
$$

Der gebrochene Strahl ist num mit Rücksicht auf die zweite brechende Fläche, die Berührungsfläche der beiden Linsen, als einfallender zu betrachten; der Winkel $\alpha_{1}$, den er mit der vom Krümmungsmittelpunct durch den Einfallspunct gezogenen Geraden bildet, ist der Einfallswinkel. Seine Grösse ist durch die trigonometrische Beziehung gegeben

$$
a_{1} c: c i=\sin c_{1}: \sin \varphi_{1},
$$

oder wenn man den Krümmungsradius mit $r$ und die Dicke der Flintglaslinse mit $d$ bezeichnet,

$$
\begin{gathered}
\left(f_{1}+d+r\right): r=\sin \alpha_{1}: \sin \varphi_{1} ; \text { folglich } \\
\sin \alpha_{1}=\frac{f_{1}+d+r}{r} \sin \varphi_{1} .
\end{gathered}
$$

Der zugehörige Brechungswinkel, welcher $\alpha_{1}^{\prime}$ heissen mag, ergiebt sich aus den bekannten Brechungsverhältnissen des Flint- und Kronglases. Somit ist auch die Richtung des Strahls nach der zweiten Brechung und damit der Winkel $\Upsilon_{2}$, den er mit der Axe bildet, als bekannt zu betrachten. Im Dreieck $a_{1} i a_{2}$ ist nämlich die Summe der Winkel $\alpha_{1}$ und $i$ gleich dem Aussenwinkel $\varphi_{2}$, oder da $L i=\alpha_{1}^{\prime}-\alpha_{1}$

$$
\varphi_{2}=\varphi_{1}+\alpha_{1}^{\prime}-\alpha_{1} \text {. }
$$

Hieraus ergiebt sich für den Abstand $f_{2}$ des Punctes $a_{2}$ von der zweiten brechenden Fläche

$$
\begin{gathered}
f_{2}=a_{2} c-r, \quad \text { oder da } a_{2} c: c i=\sin \alpha_{1}^{\prime}: \sin \varphi_{2} \\
f_{2}=r \frac{\sin \alpha_{1}^{\prime}}{\sin \varphi_{2}}-r .
\end{gathered}
$$


In gleicher Weise kann für die letzte brechende Fläche der Doppellinse der Einfallswinkel $\alpha_{2}$ und hicraus der Brechungswinkel $\alpha_{2}{ }^{\prime}$ und

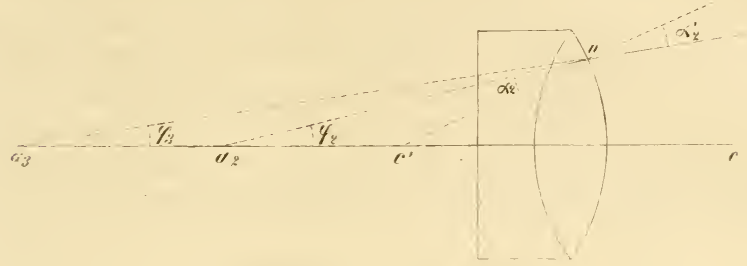

Figur \.

der Winkel des gebrochenen Strahls mit der Axe $\left(f_{3}\right.$ berechnet werden. Das Drcieck $a_{2} c_{1} n$ Fig. Is ergiebt

$$
\sin \alpha_{2}=\frac{a_{2} c^{\prime}}{c^{\prime} n} \sin \varphi_{2}=\frac{f_{2}+d-r}{r} \sin \varphi_{2}
$$

nnd ebcnso ist im Dreieck $a_{3} a_{2} n$ die Summe der beiden spitzen Winkel $=\varphi_{2}$, folglich

$$
\varphi_{3}=\varphi_{2}-\alpha_{2}{ }^{\prime}-\alpha_{2} \text {. }
$$

Endlich crhält man aus dem Dreieck $a_{3} c^{\prime} n$ dic Länge $a_{3} c^{\prime}$ und hieraus durch Addition von $r$ die Entfernung des Punctes ${ }_{3}$ von der letzten brechenden Fläche, also $f_{3}$. Es ist

$$
f_{3}=r \cdot \frac{\sin \epsilon_{2}^{\prime}}{\sin \eta_{3}}+r \text {. }
$$

Damit ist der Gang des Randstrahls durch die erste Doppellinse bestimmt. Dic aufgestellten Formeln gelten natürlich auch für die folgenden Doppellinsen, für welche die Rechnung genau in derselben Weise zu wiederholen ist. Der Punct $a_{3}$ ist für die Vorderfläche der zweiten Linse als Objectpunct zu betrachten; sein Abstand ist gleich $f_{3}+e_{1}$, wenn die letztere Grösse die Entfernung der beiden Linsen bedeutet. Der Winkel $\mathscr{\varphi}_{3}$ ist für die ebene Vorderfläche zugleich Einfallswinkel.

Bei der letzten Brechung erhält der Winkel $\varphi$ einen negativen Werth, d. h. der Lichtstrahl wendet sich wieder der Axe zu und zeigt also die entgegengesetzte Neigung zu derselben. Demzufolge gcht auch im Ausdruck für das entsprechende $f_{3}$, wie sich aus der Construction ron selbst ergiebt, das Zeichen + in - über, und man hat

$$
f_{3}^{\prime}=r \cdot \frac{\sin \epsilon_{2}^{\prime}}{\sin q_{3}}-r .
$$

Nur wo der Einfluss der Flintglaslinsen ein überwiegender ist, kann der Fall eintreten, dass die Randstrahlen nach ihrem Durchgange 
durch das Objectiv sich immer weiter von der Axe entfernen. Es müsste alsdann entweder der Krümmungsradius der Flintglaslinsen grösser oder deren Brechungscoefficient kleiner gewählt werden.

50) Nehmen wir jetzt an, die äussersten Randstrahlen bilden mit der Axe einen Winkel von $30^{\prime \prime}$ (was bei einem Oeffnungswinkel von $60^{\circ}$ der Fall ist, und bezeichnen wir die Vereinigungsweite derselben - von der Hinterfläche der Linse an gerechnet - mit $f_{3}$ und die entsprechende Grösse für Centralstrihlen mit $\left(f_{3}\right)$, so ergiebt die Rechnung für die erste Doppellinse unseres Objectivs folgende Beziehungen :

Erste Objectivlinse.

\begin{tabular}{|c|c|c|c|}
\hline $\begin{array}{c}\text { Objectdistanz. } \\
\delta\end{array}$ & \multicolumn{2}{|c|}{$\begin{array}{c}\text { Vereinigungsweiten. } \\
f_{3}\end{array}$} & Differenz. \\
\hline 0,4 & 1,00417 & $3,732 \mathrm{~S}$ & 0,27137 \\
0,4724 & 4,63716 & 4,59605 & 0,04111 \\
0,50026 & 4,9034 & 4,57655 & 0,02655 \\
0,5075 & 4,96517 & 4,9504 & 0,01477 \\
0,51634 & 5,0475 & 5,0431 & 0,00410 \\
\hline
\end{tabular}

Aus dieser Zusammenstellung geht num zunächst.hervor, dass die erste Doppellinse für eine Objectdistanz ron $0,51634^{\mathrm{m} \cdot \mathrm{m} .}$ annähernd aplanatisch, für kleinere Distanzen dagegen merklich unterverbessert ist, da die rückwärts verlängerten Randstrahlen die Axe in grösserer Entfernung schneiden, als die Centralstrahlen. Dabei ist jedoch vorausgesetzt, dass die vom Objectpunct ausgehenden Strahlen die Vorderfläche der Linse ohne Ablenkung erreichen, was bei der gewöhnlichen Beobachtungsweise bekanntlich nicht der Fall ist. Der Lichtstrahl gelangt durch die Flüssigkeit, in welcher das Object sich befindet, zum Deckgläschen und geht von diesem in Luft über, so dass er also erst nach zweimaliger Brechung das Objectiv trifft. Die Divergenz der Randstrahlen wird dadurch verstärkt; sie scheinen schliesslich von einem Puncte auszugehen, welcher über dem wirklichen Objectpunct liegt und um so weiter von demselben absteht, je dicker das Deckgläschen und je grösser der Winkel, den die Strahlen mit der Axe bilden. Wir werden diese Erscheinung weiterhin noch genauer verfolgen; hier genügt zu bemerken, dass in Folge davon die Objectdistanz für Randstrahlen etwas kleiner zu setzen ist, wenn die liechnung für die gewöhnlich vorkommenden Fälle Geltung haben soll. 
Wählen wir als Objectdistanz 0,5 m.m. (genauer 0,50026$)$, wie sie oben (Nr. 25) für eine bestimmte Linsencombination berechnet wurde, so würde eine Verkleinerung derselben von c. 0,005 ${ }^{\mathrm{m}, \mathrm{m}}$. für die Randstrahlen gerade hinreichen, um cine vollständige Gleichheit der Tercinigungsweiten $f_{3}$ und $f_{3}$ herzustellen. Nun ist freilich diese kleine Reduction der Objectsweite dem Einfluss gewöhnlicher Deckgläschen nicht aequivalent; allein da kine andere Combination dem Aplanatismus des Objectivs so nahe kommt, so mag es für unsern Zweck genügen, dic hier gewählte auch den weitern Berechnungen zu Grunde zu legen und demnach für die zweite und dritte Doppellinse diejenigen Abstände und Brechungscoefficienten (s. die Tabelle zu Nr. 27) vorauszusetzen, welche der Objectdistanz 0,5 entsprechen. Die Vereinigungsweiten der Rand- und Centralstrahlen werden alsdann durch folgende Ziffern ausgedrückt.

\begin{tabular}{|c|c|c|c|c|c|}
\hline \multicolumn{3}{|c|}{ Zweite 1)oppellinse. } & \multicolumn{3}{c|}{ Dritte Joppellinse. } \\
\hline$\delta$ & $f_{3}$ & $f_{3}$ & $\delta$ & $f_{3}$ & $\left(f_{3}\right)$ \\
\hline 5,03069 & 23,502 & 23,403 & 24,302 & 177,203 & 177,20 \\
\hline
\end{tabular}

Wie man sieht, ist die sphärische Abcrration hicr sozusagen vollständig beseitigt. Doch gilt diess natürlich bloss für Randstrahlen ron $30^{\circ}$, und es ist damit noch kcineswegs bewiesen, dass diese Linsencombination auch für die übrigen Randstrahlen und also für den ganzen wirksamen Strahlenkegel eine möglichst aplanatische sei. Es wäre im Gegentheil leicht möglich, dass der grössere inmere Theil des Strahlenkegels bei etwas veränderten Linsenabständen ein günstigeres Bild lieferte. Die Durchführung der Rechnnng für alle innern Strahlen von $5 \mathrm{zu} 5$, oder von $10 \mathrm{zu} 10^{0}$ würde hierüber Aufschluss geben.

So umständlich alle diese Rechnungen auch sind, wenn sie für 51 verschiedene Fälle immer wieder von vorn angefangen werden sollen, bis sich endlich ein Minimum der Abweichung ergiebt, so würde sich doch die Mühe reichlich lohnen, wenn damit ein für allemal die Aufgabe gelöst wäre, Objective von grösstmöglicher Vollkommenheit in einer beliebigen Zahl von Exemplaren herzustellen. Allein es ist eine technische Unmöglichkeit, den Anforderungen der Mathematik beim Schleifen der Linsen Genüge zu leisten, und zwar sind die unvermeidlichen Abweichungen in den Krümmungen so gross, dass die Rechnung einen praktischen Werth eigentlich nur zum Behuf einer 
allgemeinern Orientirung beibehält, und alles Weitere der Geschicklichkeit und Erfahrung des Optikers anheimzustellen ist.

Der praktische Optiker muss schon bei der Herstellung der Doppellinsen diejenigen Paare aus seinem Linsenvorrathe heraussuchen, deren Gesammtwirkung seinen Musterlinsen möglichst nahe kommt, wobei er bald einen schwachen Grad von Unter- oder Uteberverbesserung, bald vollständigen Aplanatismus in Auge haben kann. In gleicher Weise lässt sich auch für die Verbindung der Doppellinsen zum Objectiv nur durch wiederholtes Probiren der erforderliche Grad der Verbesserung erzielen. Dabei werden gewöhnlich die zweite und dritte Linse, mit denen der Anfang gemacht wird, entweder unbeweglich verbunden, oder sie bilden wenigstens ein unzerlegbares System, das nur in seincr Gesammtwirkung ein befriedigendes Bild erzeugt. Das. selbe gilt bei manchen neucren Objectiven für alle drei Linsen, so dass jeder Vergrösserung, deren das Mikroskop bei gleichem Tubus und Ocular fähig ist, ein anderes Objectivsystem entspricht*). Die erste Linse ist bei den stärksten Objectiven häufig so gefasst, dass sie der folgenden mehr oder weniger genähert werden kamn, je nachdem es der Einfluss der Deckgläschen oder überhaupt die bercits stattgefundene Ablenkung der einfallenden Strahlen erheischt.

Die Verbesserung der Aberrationen geschieht also in der-Praxis, wie in der Theorie, auf dem Wege der Annäherung. Jene beginnt die Prüfung mit den letzten Brechungen im System und schreitet rückwärts zu der ersten; diese verfolgt den Lichtstrahl von der Vorderfläche des Objectivs bis zu dessen Endfläche.

52 Besondere Erwähnung verdienen die Folgen der sphärischen Aberration im Ocular. Da nämlich die Lichtkegel, welche nach den Puncten des Objectivbildes zielen, sehr verschmälert sind, und nur einen äusserst kleinen Theil der Collectirlinse treffen, so sind es nicht, wie beim Objectiv, einzelne Strahlen, welche die stärkere Brechung des Linsenrandes erfahren, sondern die ganzen bilderzeugenden Strahlenbündel, welche diesen Rand durchsetzen. Die Kugelab-

*) Nach diesem Princip sind $\mathrm{z}$. B. die stärkeren (Objectirsysteme von Hart nack, Bénèche, Kellner, Plössl etc. construirt. Die beiclen hinteren Linsen geben für sich allein ein sehr undeutliches Bild, das sowohl sphärisch als chromatisch stark übercorrigirt ist. Der blaue Lichtnebel, welcher die Contouren umzieht, ist sogar meistens so augenfällig und ausgebreitet, dass man a priori daran zweifeln möchte, ob eine so bedeutende Abweichung durch Hinzufügen der vordersten Linse in befriedigender Weise compensirt werden könne. J)essenungeachtet lässt sich nicht in Abrede stellen, dass die praktische Optik mit solchen Linsencombinationen bis jetzt die günstigsten Erfolge erzielt nat. 
weichung kann sich also nicht durch Verwischung der einzelnen Bild. puncte liundgeben, weil die Aberrationen innerhalb eines Strahlenbündcls so gut wie Null sind; sie wirkt dagegen auf die Richtung der Bündelaxen nach der Brechung und in Folge dessen auf dis gegenseitige Lage der Bildpuncte. Zur Versinnlichung dieser Wirkung sei in Fig. $19 E^{*}$ der zweite Hauptpunct des Objectivs, in welchem die Axen der bilderzeugenden Lichtkegel sich schneiden,

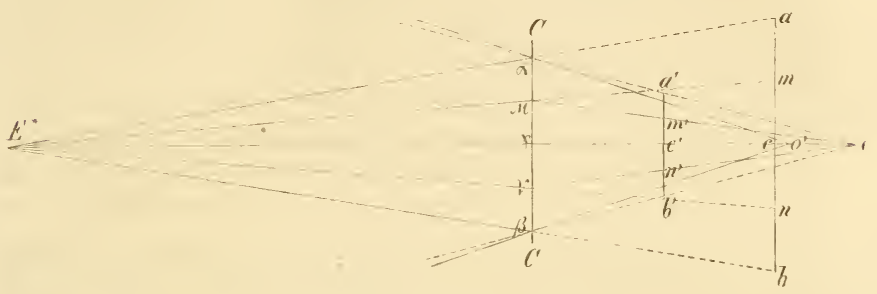

Figur 19 .

$C C$ das unendlich dünn gedachte Collectiv, $a b$ das nicht zu Stande kommende) Objectivbild und $a^{\prime} b^{\prime}$ das reelle Bild des Collectivs. Wäre nun die Collectivlinse aplanatisch, so müssten die nach $a$ und $b$ zielenden Lichtkegel in der Figur sind sie durch einfache Linien dargestellt) die optische Axe in demselben Puncte schneiden, in welchem auch die mehr centralen Lichtkegel, wie 'z. B. $E^{*} m$ und $E^{*} n$, sich kreuzen. Beliebige Puncte $m, n \ldots$ in der Ebene $a b$ müssten als. dann eine entsprechende Lage im reellen Bilde $a^{\prime} b^{\prime}$ erhalten, denn es bestehen die Proportionen

$$
\begin{aligned}
a m: m c & =\alpha \mu: \mu \gamma=a^{\prime} m^{\prime}: m^{\prime} c^{\prime} \text { und ebenso } \\
b n: n c & =\beta^{\prime}: v^{\prime} \gamma^{\prime}=b^{\prime} n^{\prime}: n^{\prime} b^{\prime} .
\end{aligned}
$$

Das Objectivbild würde also eine durchweg gleichmässige Vorkleinerung erfahren.

Durch die stärkere Brechung der peripherischen Bündel wird nun aber diese Gleichmässigkeit gestört. Während die nach $m$ und $n$ zielenden Bündel nach $o$ gebrochen werden, kreuzen sich die nach $a$ und $b$ gehenden schon in $o^{\prime}$. Die Puncte $a^{\prime}$ und $m^{\prime}$ auf der einen, $b^{\prime}$ und $m^{\prime}$ auf der anderen Seite werden in Folge dessen, wie sich unmittelbar aus der Figuı ergiebt, einander näher gerückt, als diess bei gleichmässiger Verkleinerung der Fall wäre. Dasselbe Raisonnement findet natürlich auch auf beliebige andere Puncte, welche in radialer Richtung neben einander liegen, Anwendung. So gelangen wir also zu dem allgemeinen Schluss, dass die Flächenelemente des Objectiv- 
bildes in Folge der sphärischen Aberration des Collcetivs um so stärker verkleincrt werden, je grösser ihr Abstand von der optischen Axe. Dem entsprechend würde z. B. ein quadratisches Maschennetz Fig. 20, als Objectivbild gedacht, im reellen Bilde des Collectivs wie in Fig. 21 erscheinen.

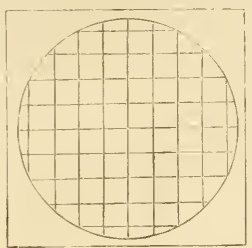

Figur 20.

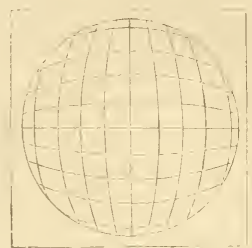

Figur 21.

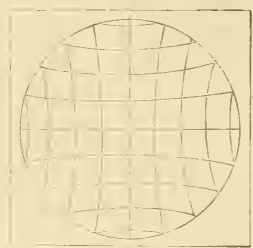

Figur 22.

Gerade umgekehrt ist die Wirkung, wenn eine Linse unter übrigens gleichen Voraussetzungen so gestellt ist, dass sie statt reeller virtuelle Bilder liefert. Es leuchtet diess sogleich ein, wenn man in Fig. 19 die nach $o$ und $o^{\prime}$ gezogenen Linien rïckwärts verlängert; die peripherischen Bildpuncte rücken alsdann in Folge der Kugelabweichung über die Stelle hinaus, die sie bei Anwendung einer aplanatischen Linse einnehmen würden. Die Randpartieen des Bildes erscheinen also stärker vergrössert als die centralen; das quadratische Maschennetz erhält das Aussehen von Fig. 22. Bekanntlich ist diess die Verzerrung, die man bei jeder nicht achromatischen Loupe in höherem oder geringerem Grade beobachtet und die man irrthümlich als Krü mmung des Gesichtsfeldes zu bezeichnen pflegt. Da nun die Ocularlinse selbstrerständlich eine ähnliche Verzerrung hervorruft, folglich der Collectivlinse entgegengesetzt wirkt, so lässt sich immer ein Verhältniss denken, bei welchem das schliessliche virtuelle Bild des Mikroskops eine nahezu gleichmässige Tergrösserung zeigt oder, wie man sich gewöhnlich ausdrückt, ziemlich geradflächig erscheint. Auf der Herstellung eines solchen Verhältnisses beruht die sogenannte Ebenung des Gesichtsfeldes, auf welche wir weiterhin in eincm besonderen Kapited zurückkommen werden.

5:3 Die sphärische Aberration des Collectiv- und Ocularglases bedingt also unter den im Mikroskop gegebenen Verhältnissen stets eine Verzcrrung des reellen Bildes in dem Sinne, dass die Randparticen schwächer vergrössert erscheinen als die Mitte, und cine Verzerrung des schliesslichen virtuellen Bildes in entgegengesetztem Sinne. Ob hiebei die Bildpuncte in einer cbenen oder gekrümmten Fläche liegen, 
ist völlig gleichgültig; die (wirkliche) Krümmung der Bildfläche ist eine Erscheinung ganz anderer Art, welehe von den Mikrographen mit Unrecht als die Ursache der Verzerrung bezeichnet wird. Wir werden geeigneten Orts näher auf diesen Punct eingehen; hier kann es sich nur um die Frage handeln, ob und in welcher Weise die sphärische Aberration auf die Bildfläche selbst influire, oder mit andern Worten, welche Veränderungen am Bilde einer aplanatisch gedachten Linse eintreten, wenn die letztere durch eine nicht aplanatische von gleicher Brennweite für Centralstrahlen) ersetzt wird. Die Frage ist leicht $\mathrm{zu}$ beantworten. Eine nicht aplanatische Linse wirkt auf die peripherischen Lichtbündel, weil sie nur einen kleinen Theil der Linse treffen, genau so, wie eine aplanatische ron etwas kürzerer Brennweite; sie rückt also ceteris paribus reclle Bildpuncte etwas näher und entfernt virtuelle. Die sphärische Aberration des Collectivs wirkt somit gleichsam anziehend auf die Randpartieen des reellen Bildes, während diejenige des Oculars auf das schliessliche virtuelle Bild einen abstossenden Einfluss übt. Anziehung und Abstossung nehmen natürlich von aussen nach innen ab und werden im Centrum Null. Die Krünmung der Bildfäche betreffend, ergiebt sich also, dass dieselbe in Folge der Kugelabweichung stärker oder schwächer ausfällt, je nachdem die convexe Seite im aplanatischen Systeme nach oben oder nach unten gekehrt ist.

\section{V.}

\section{Vom Einfluss der Deckgläschen.}

Ein Blick auf die nebenstehende Fig. 23 lehrt, dass zwei Strah- 54 len, die von einem J'uncte $a$ ansgehen, nach dem Durchgang durch ein von parallelen Flächen $m u$ und $p q$ ) begrenztes Medium ron einem Puncte $\iota^{\prime}$ zu kommen scheinen, welcher mehr oder weniger vom Objectpuncte $a$ absteht. Sind beide Strahlen gleich gegen die brechenden Flächen geneigt, so fallen die Puncte $a$ und $a^{\prime}$ in eine mit dem Einfallsloth parallele Gerade; sind sie dagegen ungleich geneigt, so bildet ihre Verbindungslinie einen schiefen Winkel mit der Richtung des Perpendikels.

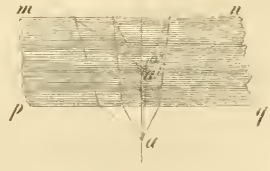

Figur 23. 
Ein Lichtbündel, dessen Strahlen vom Objectpuncte $a$ aus divergiren, wird demzufolge nach dem Austritt aus dem Deckgläschen nicht mehr homocentrisch sein, sondern aus unendlich vielen in einander geschachtelten Kegeln bestehen, deren Spitzen senkrecht oder schief über einander liegen, je nachdem der einfallende Lichtkegel mit Rücksicht auf das Deckgläschen ein senkrechter oder schiefer war. Der reelle Objectpunct stellt sich also virtuell als eine Linie dar, deren Länge, wie leicht einzusehen, mit der Dicke des Deckgläschens und dem Oeffnungswinkel des Objectivs zu- und abnimmt.

Ist $a b$ Fig. 24 ein einfallender Strahl, welcher das Deckgläschen in der Richtung $b c$ durchsetzt und hierauf in

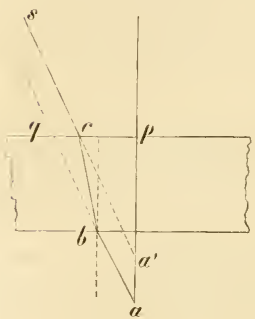

Figur 24. das ursprüngliche Medium übergeht, so ist cs parallel mit $a b$. Die Lage des Punctes $a^{\prime}$, in welchem der rückwärts verlängerte ausfahrende Strahl die Senkrechte ap schneidet, lässt sich alsdann trigonometrisch bestimmen. Bezeichnet man nämlich den Einfallswinkel mit $\alpha$, den Brechungswinkel mit $\alpha^{\prime}$ und die Dicke des Deckgläschens mit $D$, so ist zunächst $b c=\frac{I}{\cos e^{\prime}}$. Das Dreieck $q c b$ ergiebt sodann $\quad q c=b c \cdot \frac{\sin \left(\varkappa-c^{\prime}\right)}{\cos \varkappa}$.

Endlich erhält man aus dem Dreieck $a q p$, da $a^{\prime} c$ mit $a q$ parallel ist: $a a^{\prime}: q c=a p: p q=\cos \alpha: \sin \alpha$, folglich

$$
u a^{\prime}=q c \cdot \frac{\cos \iota}{\sin \omega} .
$$

Substituirt man nun für $q c$ und $b c$ deren Werthe, so hat man

$$
a a^{\prime}=D \frac{\sin \left(a-a^{\prime}\right)}{\sin \left(c \cos a^{\prime}\right.}
$$

und nach leicht zu übersehender Reduction

$$
u u^{\prime}=D\left(1-\frac{\operatorname{tang} \iota^{\prime}}{\operatorname{tang} \iota^{\prime}}\right) .
$$

Wird $\alpha$ zu $40^{0}$ und der Brechungscoefficient des Deckgläschens zu 1,5 angenommen, so erhält man, wenn das umgebende Medium Wasser ist,

$$
u a^{\prime}=0,165106 . D
$$

und wenn als ungebendes Medium Luft vorausgesetzt wird,

$$
\left.a a^{\prime}=0,565037.7\right) \text {. }
$$

Im gewöhnlichsten Fall, wenn nämlich unterseits Wasser, oberscits Luft sich befindet, erhält der letztere Ausdruck noch einen kleinen Zuwachs, welcher mit der Entfernung des Objectpunctes von der 
untern Fläche des Deckgläschens grösser und kleiner und für die Entfernung $=0$ ebenfalls Null wird.

Es ist nun nach den oben (s. Nr. 50) mitgetheilten Angaben über 55 den Gang der Randstrahlen einleuchtend, dass eine Verkleinerung der Objectlistanz, welche selbst bei Deckgläschen von nur $1 / 3, \mathrm{~m}, \mathrm{~m}$. Dicke für Strahlen von $40^{\prime \prime}$ Neigung noch circa $1 / 9 \mathrm{~m} . \mathrm{m}$. beträgt, einen merklichen Einfluss auf die Lage des entsprechenden Objectivbildes und somit auch auf die Verbesserung der Aberrationen üben muss. Ein Mikroskop, welches von unbederkten Objecten ein scharfes Bild entwirft, wird bei Anwendung eines Deckgläschens un so trübere Bilder liefern, je grösser die dadurch bewirkte Veränderung der Objectdistanz. Ebenso wird ein Instrument, dessen Objectiv zum Eintauchen in Wasser bestimmt ist, sich bei der Beobachtung in Luft als weniger aplanatisch erweisen, wenn nicht eine entsprechende Correction durch Teränderung der Linsenabstände den Fehler gut macht. Dabei versteht sich von sclbst, dass Objectirsysteme mit Oeffnungswinkeln von 120 bis $160^{\circ}$, wie sie von Amici, Nachet, Ross und andern Mikroskoprerfertigern geliefert werden, gegen solche Einflüsse weit empfindlicher sind als diejenigen, deren Oeffnungswinkel nur $60-80^{\circ}$ beträgt. Darum sind denn auch die stärksten Objective neuester Construction mit Vorrichtungen bedacht, welche den $\mathrm{Ab}$ stand der ersten Linse von den beiden übrigen zu verändern gestatten, so weit die Compensation der vorausgegangenen Brechung diess erheischt. Als Regel gilt dabei, dass der Linsenabstand um so kleiner gemacht wird, je grösser die scheinbare Annäherung des Objectes durch das Deckplättchen. Correctionsvor richtungen dieser Art besitzen z. B. die Objectirsysteme $\mathrm{Nr} .3-\mathrm{S}$ ron $\mathrm{Nachet}$ objectifs à corrections), Nr. 9 und 10 von Hartnack, ferner die stärkeren Linseneinsätze von $\mathrm{Plössl}$ und die englischen Objective von Ross, Smith, Powell u. a. Der Mechanismus derselben ist aus

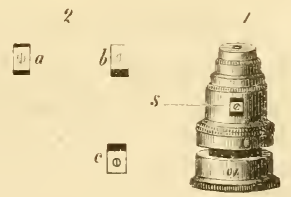

Figur 25.

Fig. $25 \mathrm{zu}$ ersehen, in welcher der Metallschieber $s$ die verschiedenen Linsenstellungen anzeigt. Seine mittlere Lage $a$ und die beiden extremen $b$ und $c$ sind nebenan noch besonders dargestellt.

Ueber den Einfluss der Deckplättchen auf Objective von mittlerer Stärke hat sich Mohl in seiner Mikrographie ausführlich verbreitet, und wir verweisen rücksichtlich der älteren Systeme von Plössl und Amici auf seine Angaben. Was die neueren Instrumente betrifft, 
die wir zu untersuchen Gelegenheit hatten, so haben wir nicht gefunden, dass Verschiedenheiten der Dicke, wie sie bei käuflichen Deckgläschen gewöhnlich vorkommen, wenn z. B. 3-6 auf einen Millimeter gehen, auf das mikroskopische Bild in irgend erheblichem Grade influiren. Es rührt diess ohne $/{ }^{\prime}$ weifel daher, dass die neveren $\mathrm{Op}_{\mathrm{p}} \mathrm{ti}$ ker ihre mittelstarken Objective für gewöhnliche Deckgläschen von c. $1 /{ }^{m}$.m. Dicke construiren, während die Amici'schen Systeme ausdrücklich für Deckplättchen von verschiedener und zum 'Theil sehr beträchtlicher Dicke (bis zu $1,5^{\mathrm{m} \cdot \mathrm{m} \cdot}$ ) bestimmt sind. Ebenso giebt auch Plössl zu seinen neueren Mikroskopen ziemlich dicke Deckgläschen, bei deren Anwendung allerdings die vordere Linse eingeschoben werden muss.

\section{VI.}

\section{Die Ebenung des Gesichtsfeldes.}

5f Betrachtet man durch eine Linse oder ein Linsensystem cine gerade Linie, so erscheint sie im Bilde im Allgemeinen nur dann gerade,

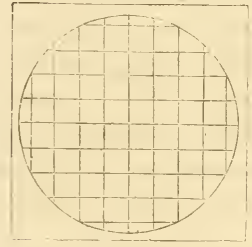

Figur 2i.

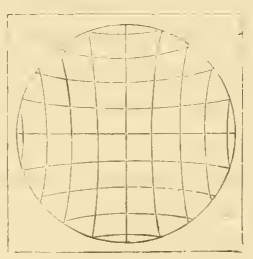

Figur 27. wenn sie durch das Cen trum des Gesichtsfeldes geht, in jeder andern Lage dagegen als eine Curve, deren convexe Seite nach innen gekehrt und deren Krümmung un so stärker ist, je grösser der Abstand vom Centrum. Ein aus quadratischen Maschen bestehendes Netz Fig. 26j wird dem entsprechend so wahrgenommen, wie es in Fig. 27

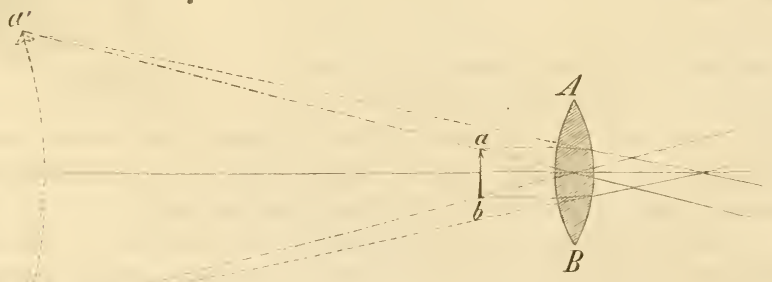

Figur 2ל. 
dargestellt ist, und ebenso erscheint anch jedes andere Object im virtuellen liilde mehr oder weniger verzerrt.

Man pflegt diese Verzerrungen dadurch zu erklären, dass die Puncte des virtuellen Bildes $a^{\prime} b^{\prime}$ Fig. 25), welches die Linse $A B$ von der zur optischen Axe senkrecht gedachten Ebene $a l$ entwirft, in cincr gekrümmten Fläche liegen, deren convexe Seite dem Objecte zugekehrt ist, und dass die peripherischen Theile dicser Fläche in Folge ihrer grösseren Entfernung eine etwas stärkere Vergrösserung zeigen. In gleicher $W$ cise soll auch dic entgegengesetzte Verzerrung der reellen Bilder Fig. 29), bei welcher die Vergrösserung von innen nach aussen abnimmt, durch eine entsprechende

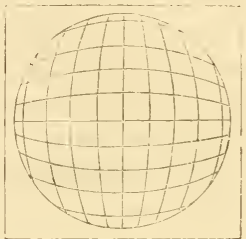

Figur 29. Krümmung der Bildfäche (Fig. 30) hervorgerufen worden (vgl. Harting, das Mikroskop p. 134 u. $27 \mathrm{~s}$.

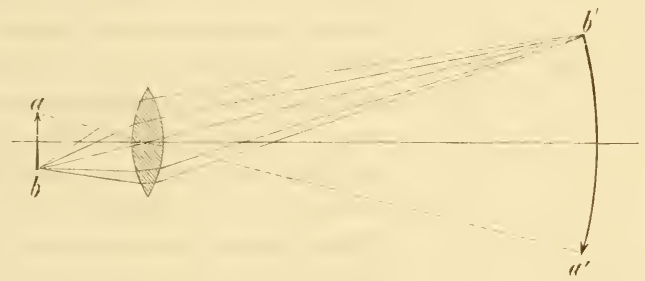

Figur 311

Dass diese Darstellungsweise eine durchaus irrige ist, geht schon aus dem oben Nr. 52 und 53j Angeführten klar genug hervor. Es wurde dort gezeigt, dass solche Verzerrungen nicht in der Krümmung der Bildfläche, sondern in der stärkeren Brechung der peripherischen Lichtbündel, also in der sphärischen Aberration der bilderzeugenden Linsen ihre Erklärung finden; gleichzeitig aber auch angedeutet, dass unabhängig davon eine wirkliche Krümmung des Bildes vorkommen könne und dass dieselbe durch die Kugelabweichung der Linsen vermehrt oder vermindert werde, je nachdem ihre convexe Seite nach oben oder nach unten gekehrt sei. Dessenungeachtet mag es nicht ganz üherflüssig sein, wenn wir hier noch einmal auf diesen Gegenstand zulrückkommen, um an einem möglichst einfachen Fall nicht allcin die Ursachen der Verzerrung durch die Ocularlinse, sondern gleichzeitig auch diejenigen der Krümmung des virtuellen Bildes klar darzulegen. 
Es sei $a b$ (Fig. 31) das Collectivbild, dessen verschmälerte Stıahlenkegel die in der Figur durch einfache Linien dargestellt sind

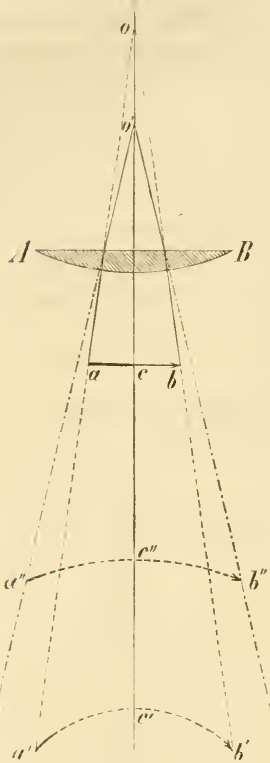

Figur 31 . nach dem Puncte $o$ convergiren; ferner $A B$ die Ocularlinse, und der Krümmungsmittelpunct der convexen Fläche in o. Endlich sei das beobachtende Auge auf unendliche Entfernung eingestellt. Alsdann erfahren die nach o convergirenden Lichtbündel, weil sie in der Richtung des Radius einfallen, an der nach unten gekehrten Fläche keine Ablenkung, indem sich die Brechung darauf beschränkt, den Convergenzpunct in der Richtung der Bündelaxe in unendliche Ferne zu rücken. Das hiebei zu Stande kommende virtuelle Bild $a^{\prime} b^{\prime}$ (das man sich in unendlicher Ferne* zu denken lat stimmit natürlich rollkommen mit dem Objecte überein, d. h. es findet zwischen den einzclnen Objectpuncten und ihren Bildern perspectivische Deckung statt. Quadratische Maschen müssten also auch im Bilde quadratisch erscheinen. Dessenungeachtet ist dieses virtuelle Bild ziemlich gewölbt, weil die Randpuncte des eben gedachten Objectes weiter von der brechenden Fläche abstehen, als das Centrum.

Durch die zweite Brechung an der oberen Fläche der Ocularlinse wird selbstverständlich der Parallelismus nicht gestört: das Bild bleibt in unendlicher Ferne. Allein die Strahlenbündel werden von ihrer Richtung abgelenkt, und zwar um so stärker, je grösser der Winkel, den sie mit der Axe des Mikroskops bilden. Die Vergrösserung, welche das virtuelle Bild dadurch erfährt, wird annähernd durch den Brechungscoefficienten ausgedrückt; sie ist jedoch keine durchweg

* Unsere Figur ist für die gewählten endlichen Entfernungen genau. Das virtuelle Bild wird in diesem Fall durch die zweite Brechung un den $\left(\frac{n-1}{n}\right)$ ten Theil seines früheren Abstandes näher gerückt, wobei $u$ den Brechungscoefficienten bezeichnet. Im Uebrigen ist der Strahlenverlauf genau derselbe. 
gleichmässige. Denkt man sich nämlich das Object $a b$ in eine beliebige Zahl gleicher Theile getheilt, so treffen die von den 'Theilungspuncten ausgehenden Strahlenbündel auch das Ocular, und rückwärts verlängert die Projectionsebene des virtuellen Bildes $a^{\prime} b^{\prime}$, in gleichen Abständen. Eine gleichmässige Vergrösserung würde also offenbar voraussetzen, dass die abgelenkten Lichtbündcl die Axe des Mikroskops in dem nämlichen Puncte schneiden. Diese Voraussetzung trifft num aber nicht zu, indem der Kreuzungspunct der peripherischen Strahlen der Ocularlinse stets näher zu liegen kommt, als der der mittleren. Dadurch wird aber das schliessliche virtuelle Bild nothwendig mehr oder weniger verzerrt. Denn ist $c^{\prime \prime}$ Fig. 32 das Bild des in der Axe liegenden Objectpunctes $c, p p^{\prime \prime}$ dasjenige eines beliebigen 'Theilungspunctes $p$, so müsste cin doppelt so weit abstehender Punct $q$ bei gleichmässiger Vergrösserung auch in Bilde in doppelter Entfernung, also in $q^{\prime \prime}$, entworfen werden. In Wirklichkeit dreht sich nun aber das bilderzeugende Licht. bündel etwas stärker um seinen Einfallspunct $r$ in der oberen Fläche der Ocularlinse, da es die Axe in etwas geringerer Entfernung schneidet. Der Punct $q^{\prime \prime}$ fällt also, wie die punctirte Linie diess andeutet, um eine gewisse Grösse weiter nach aussen; folglich wird in virtuellen Bilde, das wir beobachten, $c q^{\prime \prime}>2 \times c^{\prime \prime} p^{\prime \prime}$ und $p^{\prime \prime} q^{\prime \prime}>c^{\prime \prime} p^{\prime \prime}$. Das heisst aber nichts anderes, als dass die Vergrösserung mit der Entfernung von der Axe zunimmt. Diese Zunahme beschränkt sich jedoch, wie leicht cinzusehen, auf die radiale Richtung; die tangentiale wird bloss insofern betroffen, als mit der Verschiebung der Bildpuncte in radialer Richtung natürlicher Weise auch eine

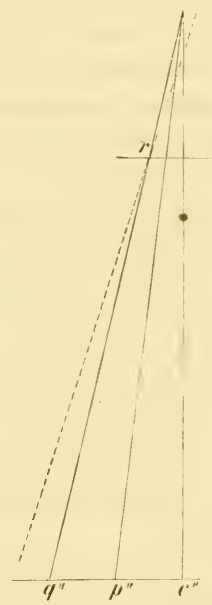

Figur 32. proportionale Veränderung ihrer Abstände verbunden ist. Gerade Linien im Object, welche (nöthigenfalls verlängert) sich im Mittelpunct des Gesichtsfeldes schneiden, müssen daher auch im Bilde als gerade Linien sich darstellen; in jeder andern Richtung dagegen bedingt die ungleichmässige Vergrösserung eine um so stärkere Krümmung derselben, je weiter sie vom Mittelpunct abstehen.

Wir dürfen es hienach als festgestellt betrachten, dass Krüm- 58 mung und Terzerrung zwei durchaus verschiedene Erscheinungen sind, die sich in keiner Weise wechselseitig bedingen. Die Verzer- 
rung hängt, wir wiederholen es, von der sphärischen Aberration der brechenden Flächen, die Krümmung dagegen von den ungleichen Abständen der zugehörigen Objectpuncte ab (wobei das Bild der vorhergehenden Fläche für die nächstfolgende als Object zu betrachten ist). Ist dic sphärische Aberration auch ausgeglichen, so folgt daraus noch nicht, dass das mikroskopische Bild damit geebnet sei, und umgekehrt kann ein vollkommen ebenes Bild noch mehr oder weniger verzerrt erscheinen. Beide Uebelstände müssen gehoben sein, wenn die Ebenung des Gesichtsfeldes im herkömmlichen Simne des Wortes cine vollständige sein soll.

- Die Verzerrung sowohl, als dic Krümmung, lässt sich auf zwei verschiedene Arten beseitigcn, einmal dadurch, dass das Ocular durch Hinzufügen planconcaver Flintglaslinsen aplanatisch und orthoskopisch gemacht wird, sodann zweitens durch geschickte Wahl und Combination einfacher Planconvexlinsen als Cellectiv und Ocular, indem die entgegengesetzten Abwcichumgen so regulirt werden, dass sic sich aufheben.

Nachdem die Principien, auf denen der Aplanatismus beruht, bercits in einem früheren Kapitel auseinandergesetzt worden, haben wir nicht nöthig, hier noch eimmal auf den Gegenstand zurückzukommen. Man sieht leicht ein, dass die Construction aplanatischer Oculare eine viel einfachere Aufgabe ist, als diejenige der Objectire, weil es möglich ist, die Krümmungen der Linsen den Anforderungen der Rechnung gemäss herzustellen. Es bleibt uns also nur die Frage zu erörtern übrig, wie in einem gewöhnlichen Ocular die Abcrrationen verbessert werden können, und wie im Allgemeinen die Krüumungen der brechenden Flächen auf die Krümmung des Bildes influiren.

59 Was zunächst den ersteren Punct betrifft, so giebt folgende Betrachtung die nöthigen Anhaltspuncte. Es sei $b q$ Fig. 33) der Weg cines peripherischen Strahlenbündels nach der Brechung in einem aplanatisch gedachten Collectiv $C$ oder, wenn man lieber will, diejenige Richtung, welche das gebrochene Bündel einschlagen müsste, um ein völlig correctes, d. h. mit dem dargebotenen Object übcreinstimmendes reelles Bild zu liefern; ferner $b_{p}$ ) der Weg des nämlichen Bündels nach dem Durchgang durch eine einfache Collectivlinse von gleicher Brennweite oder, was damit gleichbedeutend ist, durch dasselbe Collectiv, nicht aplanatisch gedacht. Es ist num ohne Weiteres klar, dass die Abweichung dieses letzteren Strahlenbündels nur dann vollständig ausgeglichen wird, wonn es nach dem Durehgang durch 
das Ocular von einem Puncte zu kommen scheint, weleher der Richtung des Bündels $b q$ nach einer aberrationslosen Brechung in der

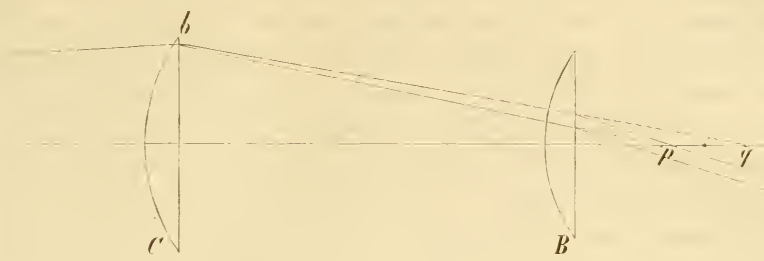

Figur 33.

aplanatisch gedachten Ocularlinse entspricht. Ist das Auge auf unendliche Ferne eingestellt, so müssen folglich die beiden Strahlenbündel nach dem Austritt ans dem Ocular parallel rerlaufen, was voraussetzt, dass der Parallelismus schon dureh die Brechung an der unteren Linsenfläche hergestellt sei. An diesen einfachen Fall wollen wir unsere weiteren Betrachtungen anknüpfen.

Wir denken uns nun die Ocularlinse so gestellt, dass ihr Krümmungscentrum in die Mitte zwischen die Puncte $p$ und $q$ fällt. Alsdann werden beide Bündel so gut wie ohne Aberration und gleich stark gegen einander gebrochen, weil sie unter gleichen und sehr kleinen Winkeln (c. $1-1,5^{0}$ ) einfallen. Zur Herstellung des Parallelismus ist jetzt offenbar bloss nöthig, dass der Punct $b$, von welchem die Bündel ausgehen, in den Brennpunct der brechenden Fläche falle. Da nun der entsprechende Punct des Collectivbildes genau dieselbe Lage haben muss, um im virtuellen Bilde in unendlicher Ferne gesehen zu werden, so folgt daraus, dass der Aplanatismus unter den angenommenen Voraussetzungen nur hergestellt werden kann, wenn die Ocularlinse um ihre Brennweite vom Collectiv absteht und dem entsprechend das reelle Bild im Niveau des letzteren zu Stande kommt. Eine Vergrösserung dieses Abstandes bei gleicher Lage des Krümmungsmittelpunctes (man denke sich ein schwächeres Collectiv oder ein stärkeres Ocular) muss nothwendig die Convergenz, eine Verkleinerung die Divergenz der austretenden Strahlenbündel bedingen. In ersteren Falle würde das aberrirende Bündel dem eingebildeten aberrationslosen zugebrochen, seine Verlängerung nach rückwärts entspräche einem der Axe zu nahe liegenden Punct: das virtuelle Bild müsste nach aussen zu schwächer vergrössert erscheinen. Im zweiten Fall ist die Wirkung entgegengesetzt; das Bündel trifft, rück- 
wärts verlängert, einen von der Mitte zu weit abstehenden Punct: das Bild zeigt die entgegengesetzte Verzerrung.

Anders gestalten sich die Verhältnisse, wenn der Krümmungsmittclpunct der Ocularlinse dieser letzteren näher liegt, als die Puncte $p$ und $q$. Der Einfallswinkel des aberrirenden Lichtbündels wird nämlich in diesem Falle merklich grösser, als im vorhergehenden, und in Folge dessen die Aberration auch in der Ocularlinse spürbar; das Bündel wird stärker gegen die Axe gebrochen als das cingebildete aberrationslose. Würde jetzt der Ausgangspunct $b$ der bciden Bündel um die Brennweite von der sphärischen Fläche abstehen, so müssten dieselben nach dem Durchgang durch das Ocular divergiren, während sic im vorhergehenden Fall parallel waren. $T_{m}$ den Parallelismus herzustellen, muss folglich der Abstand etwas grösser gewählt werden als die Brennweite, und zwar um so mehr, je grösser der Einfallswinkel des aberrirenden Bündels. Das reelle Bild kommt also nicht im Niveau des Collectivs, sondern über demselben zu Stande, - bekanntlich die gewöhnliche Einrichtung des Campani'schen Oculars.

Durch ein ähnliches Raisonnement lässt sich darthun, dass die Verschiebung des Krümmungsmittelpunctes nach rechts (was übrigens eine schwache Ocularlinse voraussetzt/ für den Aplanatismus die Bedingung ergiebt, dass der Abstand der beiden Linsen kleiner sein muss, als die Brennweite der oberen. Das Ocular erhält in diesem Fall eine Einrichtung, welche im Princip mit der Ramsden'schen übereinstimmt, indem das reelle Bild vor die untere Linse fällt.

(i) Es ist also nach dem Vorhergehenden möglich, einfache Linsen in verschiedener Weise zu einem unter den gegebenen Verhältnissen aplanatischen Systeme zu verbinden. Nur versteht sich von selbst, dass die strenge Erfüllung der Brdingungen im Allgemeinen nur für ganz bestimmte Bündel ausführbar ist, wie ja auch die Beseitigung der sphärischen und chromatischen Aberration im Objectiv sich theoretisch auf bestimmte Neigungen und Farben beschränkt. Ein Ocular, welches für violettes Licht aplanatisch ist, kann es für rothes in der Regel nicht mehr sein, weil sowohl die Lage des Krümmungscentrums als der gegenseitige Abstand der Linsen sich nach der Brechbarkeit der Strahlen richtet. Der Punct $p$ in unserer Figur rückt nämlich, wie man leicht einsieht, um so weiter nach links, je grösser die Brechbarkeit der Strahlen, während $q$, wie wir annehmen dürfen, seine Lage nicht verändert; überdiess ist die Brennwcite der Ocularlinse für jede Farbe eine andere. Die Störungen, welche hieraus für 
die Brechung an der untern Fläche der Ocularlinse erwachsen, hängen natürlich mit vom Zerstreuungsvermögen des Glases ab; sie werden aber namentlich auch durch die jedesmalige Lage des Punctes $p$ bedingt, in welchem die Verlängerungen der verschiedenfarbigen Bündel die Axe schneiden. Liegt $p$ für alle Farben links vom Krümmungsmittelpunct, dann wird ein für violette oder mittlere Strahlen aplanatisches Ocular die Randpuncte des rothen Bildes noch etwas zu weit nach ausser rücken, weil der Divergenzpunct $b$ für diese Farbe sich noch innerhalb der Brennweite befindet. Das Gesichtsfeld müsste also roth umsäumt erscheinen. Diese Farbenabweichung findet nun aber in der Brechung an der oberen Linsenfläche ein Gegengewicht, weil hier die violetten Strahlen stärker gegen die Axe abgelenkt werden, als die rothen. Man begreift auch, dass dieses Gegengewicht so lange vorwiegen muss, als sämmtliche Strahlen durch die Gesammtwirkung der Linse der Axe zugebrochen werden. Der rothe Saum des Gesichtsfeldes geht hienach im schliesslichen Bilde in einen blauen über.

Dasselbe Endresultat erhält man auch, wenn der Punct $p$ sich für sämmtliche Farben rechts rom Krümmungscentrum befindet; allein da in diesem Fall die sphärische Aberration des unter grösserem Winkel einfallenden rothen Bündels mit dem Abstand der beiden Linsen wächst, so giebt es eine Grenze, wo sie der Farbenabweichung das Gleichgewicht hält. Darüber hinaus geht der blaue Rand des Gesichtsfeldes in einen rothen über. Da nun diese Grenzlage bei gegebenen Krümmungen einzig und allein vom Zerstreuungsvermögen der Gläser abhängt, so lässt sich unter allen Umständen eine Glassorte denken, welche die Herstellung des Aplanatismus für rothes und violettes Licht gleichzeitig gestattet. Und wenn z. B. das Kronglas diese Eigenschaft für eine bestimmte Linsencombination annähernd besitzt, so muss es möglich sein, durch kleine Aenderungen der Abstände und Krümmungen die noch vorkommenden Abweichungen auf ein Minimun zu reduciren. Wir gelangen also zu dem Schluss, dass die Ausgleichung der Farbenzerstreuung mit der Beseitigung der sphärischen Aberration vereinbar sei.

Was nun noch die $\mathrm{Kr}$ ümmung der Bildfläche betrifft, so $\mathbf{6 2}$ ist die gewöhnliche Darstellung, nach welcher das Collectirbild seine convexe Seite nach unten kehrt, eine irrthümliche. Gerade das Gegentheil findet statt. Man überzeugt sich hievon, indem man eine ebene, mit feinen Stäubchen bedeckte Glasplatte oder eine Mikrometertheilung auf die Blendung der Ocularröhre legt und die Ränder derselben im mikroskopischen Bilde mit denjenigen des Collectivbildes rergleicht. 
Man findet alsdann, dass der Rand des Collectivbildes eine etwas tiefere Einstellung der Ocularlinse erfordert, als die gleich gelegenen Puncte der Glasplatte. Das Collectivbild muss also nach oben gewölbt sein. Es kann auch aus theoretischen Gründen sich unmöglich anders verhalten. Denn denken wir uns in $A B$ Fig. 34 eine brechende Fläche, welche alle mit der Axe $a c$ parallelen Strahlen zwischen $p q$ und $r s$ in Brennpuncte $F$ zur Vereinigung bringt, so werden natürlich

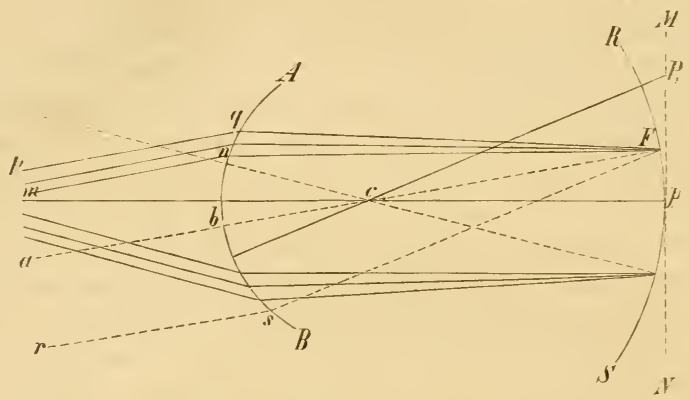

Figur 34 .

auch die Strahlen des peripherischen Bündels $p q m n$ nach diesem Puncte gebrochen. Ganz dasselbe gilt auch für jeden anderen Strahlencylinder und die mit ihm parallel verlaufenden Bündel. Und zwar ist der Abstand der verschiedenen Brennpuncte von der brechenden Fläche, auf der durch das Krümınungscentrum gehenden Cylinderaxe gemessen, und folglich auch der Abstand vom Krümmungscentrum selbst eine unveränderliche Grösse. Die Brennpuncte gehören demnach einer Kugelfäche an, deren Centrum mit dem der brechenden Fläche zusammenfällt.

Lassen wir jetzt die cylindrischen Strahlenbündel in schwach convergirende übergehen, so zwar, dass die Convergenzpuncte der verschieden geneigten Bündel gleich weit rom Krümmungscentrum der brechenden Fläche abstehen, so rücken ihre reellen Bildpuncte der brechenden Fläche etwas näher; sie bilden aber nach wie ror eine gekrümmte Fläche mit demselben Krümmungsmittelpunct. Auf das Collectiv übertragen heisst das: wenn das als virtuelles Object dargebotene Objectivbild eine nach oben convexe Krümmung zeigt, deren Centrum mit dem des Collectivs zusammenfällt, so erhält auch das durch die Brechung an der sphärischen Fläche erzeugte Bild eine daınit parallele Krümmung. 
Es lässt sich nun ferner zeigen, dass eine Krümınung in gleichem 63 Sinne noch stattfindet, wenn das Objectirbild eben gedacht wird. Nehmen wir der Einfachheit wegen an, dasselbe falle in die Tangentialebene $M N$ Fig. 34) der erwähnten Brennfläche, und bezeichnen wir den Abstand des Objectpunctes $P$ von der brechenden Fläche mit $p$ und den des entsprechenden Bildpunctes mit $p^{*}$, ferner den $\mathrm{Ab}$ stand des Objectpunctes $P_{1}$ und seines Bildpunctes mit $p_{1}$ und $p_{1}$ ", endlich die Brennweite mit $f$ und den Krümmungsradius des Collectivs mit $r$. Damn ist nach Früherem $\frac{1}{p^{*}}=\frac{1}{f}+\frac{1}{p}$, folglich im gegebenen Falle $p^{*}=\frac{p f}{p+f}=\frac{1}{2} f=\frac{1}{2} p$, und wenn der Brechungscoefficient zu 1,5 angenommen wird, $p^{*}=\frac{3}{2} r$. Die Grösse $p_{1}$ ist durch die Proportion $\left(p_{1}-r\right):(p-r)=1: \cos \varphi$ bestimmt, wenn nämlich $\varphi$ den Winkel $P_{1} c P$ bezeichnet und der Radius der Brennfläche als Einheit gewählt wird. Man erhält hieraus

$$
\begin{aligned}
& p_{1}=r+\frac{p-r}{\cos \psi}=r+\frac{2 r}{\cos \psi} ; \text { folglich } \\
& p_{1}^{*}=\frac{p_{1} f}{p_{1}+f}=\frac{\left(r+\frac{2 r}{\cos q}\right) \cdot 3 r}{r+\frac{2 r}{\cos \psi}+3 r}=\frac{3 r}{2} \cdot \frac{2+\cos q}{1+2 \cos \psi} .
\end{aligned}
$$

Die Abstände $\eta^{*}$ und $\eta_{1}^{*}$ sind also beziehlich $\frac{3 r}{2}$ und $\frac{3 r}{2} \cdot \frac{2+\cos \varphi}{1+2 \cos \varphi}$, folglich die Entfernungen der Bildpuncte vom Krümmungscentrum, die wir $l^{*}$ und $l_{1}^{*}$ nennen wollen, $\frac{1}{2} r$ und $\frac{3}{2} r \cdot \frac{2+\cos q}{1+2 \cos q} \cdot r$. Durch eine leicht zu übersehende Reduction erhält tnan

$$
\begin{aligned}
l_{1}{ }^{*} & =\frac{1}{2} r \cdot \frac{4-\cos \psi}{1+2 \cos \psi} \text { und hieraus } \\
l^{*}: d_{1}^{*} & =1: \frac{4-\cos \psi}{1+2 \cos \psi} .
\end{aligned}
$$

Befänden sich dic beiden Bildpuncte in einer zur Mikroskopaxe senkrechten Ebene, so wäre das Verhältniss ihrer Entfernungen vom Puncte $c$ offenbar gegeben durch $1: \frac{1}{\cos \%}$; es fragt sich nun, ob das zweite Glied im ersten oder im zweiten Ausdruck grösser sei. Setzt $\operatorname{man} \beta=1-\cos \varphi$, so ergiebt sich

$$
\frac{1-\cos \varphi}{1+2 \cos \varphi}: \frac{1}{\cos \varphi}=\frac{3+\beta}{3-2 \beta}: \frac{3}{3-3 \beta} .
$$

In dieser letzteren Form stellen die beiden Werthe zwei Brüche vor, bei welchen der Zähler grösser ist, als der Nenner. Dabei sind Zähler und Nenner des ersteren Bruches um $\beta$ grösser als im zweiten, folglich 
$\frac{3+\beta !}{3-2 \beta}<\frac{3}{3-3 \beta}$. Die Bildfäche ist also auch in diesem Falle gekrümmt und ihre convexe Seite nach oben gerichtet. Diese Krümmung ist freilich unter den gegebenen Verhältnissen so gut wie Null; denn die Grösse $p_{1}{ }^{*}$ fällt z. B., wenn $\varphi=4^{0}$ und $r=20^{\mathrm{m}, \mathrm{m}}$. gesetzt wird, nur um circa 0,02 Mikromillimeter kleiner aus, als in dem eben gedachten Bilde. Dieselbe wird nun aber in Wirklichkeit noch durch den Umstand verstärkt, dass die brechende Fläche nicht, wie wir vorausgesetzt haben, aplanatisch, sondern mit der bekannten Abweichung wegen der Kugelgestalt behaftet ist. Sie wirkt also, wie bereits hervorgehoben wurde, auf die peripherischen Strahlenbündel, wie eine aplanatische Fläche von kürzerer Brennweite und rückt in Folge dessen die entsprechenden Bildpuncte etwas näher. Dadurch muss die Krümmung, auch wenn die Länge der sphärischen Aberration nur zu 0,1 der Brennweite angenommen wird, eine augenfällige werden.

64 Die Wirkung der Ocularlinse wurde bereits oben für einen bestimmten Fall erörtert. Es ergab sich, dass das von ihr entworfene Bild einer ebenen Fläche gekrümmt sein müsse, weil die peripherischen Puncte derselben weiter von den brechenden Flächenelementen abstehen, als die centralen. Eine solche Krümmung muss offenbar immer eintreten, wenn die sphärische Aberration, wie es bei einfachen Linsen der Fall ist, in gleichem Sinne wirkt. Das schliessliche virtuelle Bild eines gewöhnlichen Oculars kann also unmöglich eben sein, es sei denn, dass das Objectivbild selbst gekrümmt sei und seine convexe Seite nach unten kehre. Die günstigste Stellung der Ocularlinse wird immerhin diejenige sein, bei welcher die vom Collectiv kommenden Strahlenbündel unter möglichst kleinen Winkeln auf die sphärische Fläche einfallen.

Bei der Ramsden'schen Einrichtung des Oculars sind die Verhältnisse, welche auf die Krümmung influiren, verwickelter. Da hier die untere Linse ihre ebene Fläche dem reellen Objectivbilde zukehrt, so müsste das von ihr entworfene virtuelle Bild nach unten gewölbt sein, würde nicht die sphärische Aberration., welche nach Früherem in entgegengesetztem Sinne wirkt, das Uebergewicht erreichen. Das Letztere ist nun aber in der Regel der Fall, so dass die Gesanmtwirkung des Oculars so ziemlich dieselbe bleibt, wie bei der Campani'schen Einrichtung.

In praktischer Hinsicht hat übrigens eine schwache Krümmung des Gesichtsfeldes wenig zu bedeuten. Es's sind uns auch keine Oculare bekannt geworden, die aplanatischen von Plössl nicht ausgenom- 
men, bei welchen dieselbe vollständig gehoben wäre. Das Hauptaugenmerk der Optiker ist mit Recht darauf gerichtet, vor Allem die Verzerrung der Bilder für die verschiedenen Farben möglichst zu beseitigen und die noch übrig bleibenden Abweichungen so zu reguliren, dass die rothen und violetten Bildpuncte sich wenigstens im mittleren Theil des Gesichtsfeldes vollkommen decken. Ist diess für eine bestimmte Tubuslänge erreicht, so muss das Ocular jedes beliebige Objectivbild bei gleicher Tubuslänge möglichst scharf wiedergeben.

\section{VII.}

\section{Das Centriren der Linsensysteme.}

W'ir haben unseren bisherigen Betrachtungen über den Strahlen- 65 verlauf im Mikroskop durchgehends die Annahme zu Grunde gelegt, dass die brechenden Flächen ein genau centrirtes System bilden, d. h. dass ihre Krümmungsmittelpuncte sämmtlich in einer geraden Linie liegen. Der praktische Optiker wird auch stets bemüht sein, diese Annahme zu verwirklichen, allein das Höchste, was er erreicht, ist doch immerhin nur eine Annäherung, die namentlich bei den stärkeren Objectiven weit hinter dem Zustand der Vollkommenheit zurückbleibt. Es drängt sich daher die Frage auf, ob und in welcher Weise eine fehlerhafte Centrirung die Reinheit des Bildes beeinträchtige, und welche Abweichungen etwa vorzugsweise ins Gewicht fallen.

Nach der gewöhnlichen Ansicht ist die genaue Centrirung Bedingung des Aplanatismus. Schon eine geringe Abweichung, meint Harting*), müsse nothwendiger Weise sehr nachtheilige Folgen haben, und auch $\mathrm{Mohl}^{* *}$ ) spricht sich dahin aus, dass eine Verzerrung des Bildes nach einer Seite hin damit verbunden sei. Diese Ansicht erscheint auf den ersten Blick auch sehr plausibel, ja sogair selbstverständlich; nichtsdestoweniger steht sie sowohl mit der Theorie als mit der Beobachtung, wie im Folgenden gezeigt werden soll, im Widerspruch.

Wir denken uns ein aus 3 Doppellinsen bestehendes, vollkom- 66 men centrirtes Objectivsystem, welches für alle Puncte eines Gesichtsfeldes von gegebenem Durchmesser möglichst aplanatisch ist, und

- H arting, das Mikroskop p. 275.

**, Mohl, Mikrographie p. 176. 
legen uns nun die Frage vor, welchen Einfluss eine kleine seitliche Terschiebung der Linsen auf die Gesammtwirkung des Systems aus-

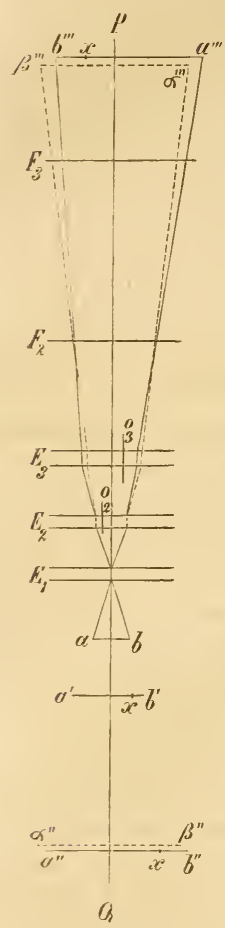

Figur 35. übe. Es seien $E_{1} E_{2}$ und $E_{3}$ (Fig. 35 ) die Hauptebenenpaare der 3 Doppellinsen, $F_{2}$ und $F_{3}$ die entsprechenden Brennebenen der beiden hinteren Linsen, $O_{1} O_{2}$ und $o_{3}$ die optischen Axen, woron die erste, wie wir voraussetzen, mit der Axe $P Q$ des Mikroskops zusammenfällt, während die beiden andern nach rechts und nach links, parallel mit sich selbst, verschoben sind; endlich sei $a b$ das Object, dessen einzelne Puncte bei genauer Centrirung gleich vollkommene Bilder liefern. Construirt man nun mit Hülfe der Richtungsstrahlen den Verlauf der Lichtbündel, welche von den Randpuncten $a$ und $b$ zum Objectir gelangen, und vergleicht denselben mit dem Strahlenverlauf, wie or im genau centrirten System stattfinden müsste, so lassen sich die Nachtheile, welche die Verschiebung mit sich bringt, leicht überblicken. In unserer Figur beziehen sich die ausgezogenon Linien auf das nicht centrirte, die unterbrochenen dagegen auf das centrirte System. Die virtuellen oder reellen Bilder, welche die einzelnen Doppellinsen entwerfen, wurden bei ersterem mit $a^{\prime} b^{\prime}, a^{\prime \prime} b^{\prime \prime}$ und $a^{\prime \prime \prime} b^{\prime \prime \prime}$, bei letzterem mit gleich accentuirten griechischen Buchstaben bezeichnet. Die Lage dieser Bilder zur Axe ist natürlich schon durch die Richtung der nöthigenfalls rückwärts verlängerten Strahlen bestimmt; ihre Abstände richten sich nach den Brennweiten und sind selbstverständlich in beiden Fällen dieselben, sie wurden jedoch der grösseren Deutlichkeit wegen etwas verschieden angenommen. Es ist nun an und für sich klar, dass das virtuelle Bild $a^{\prime} b^{\prime}$ der ersten Linse durch die Verschiebung keine Veränderung erleidet. Nur insofern es Object ist für die zweite Linse, kommt sein rechter Rand $b^{\prime}$ in eine etwas ungünstigere Stellung, da er nunmehr um die T $\mathrm{cr}$ schiebungsgrösse weiter von der optischen Axe $o_{2}$ absteht. Von diesem Randthcil entwirft demnach die Linse, wie sich mit Wahrscheinlichkeit annehmen lässt, ein weniger vollkommenes Bild. Der ganze übrige, weitaus grössere Theil dagegen erfüllt nach wie vor die Be- 
dingung, dass keines seiner Flächenelemente ausserhalb des Gesichts. feldes fällt, für welches die zweite Linse möglichst aplanatisch ist. Macht man also $b^{\prime} x$ der Verschiebungsgrösse gleich, so wird im Bilde $a^{\prime \prime} b^{\prime \prime}$ ein entsprechendes Stück $b^{\prime \prime} x$ unbefriedigend ausfallen, während $a^{\prime \prime} x$ seine ursprüngliche Schärfe behält. Nun fällt aber das ganze Bild, wie die Figur zeigt, etwas weiter nach rechts als vor der Vorschiebung, und zwar um eine Grösse, welche zu $b^{\prime \prime} x$ sich verhält, wie $a^{\prime \prime} b^{\prime \prime}$ zu $a^{\prime \prime} b^{\prime \prime}-a^{\prime} b^{\prime}$. Man hat, um sich hievon zu überzeugen, nur nöthig, durch $b^{\prime}$ und den oberen Hauptpunct der zweiten Linse in seinen zwei verschiedenen Lagen Linien zu ziehen, dieselben nach unten bis $\beta^{\prime \prime}$ und $b^{\prime \prime}$ zu verlängern und die in $b^{\prime}$ zusammenstossenden Dreiecke mit einander zu vergleichen.

Das virtuelle Bild $a^{\prime \prime} b^{\prime \prime}$ nimmt also zur Axe $o_{3}$ im Allgemeinen eine veränderte Stellung ein. Nur wenn es zufällig gerade so weit, als diese Axe selbst, nach rechts rückt, bleibt natürlich die relative Lage dieselbe. Das reelle Objectivbild $a^{\prime \prime \prime} b^{\prime \prime \prime}$ erreicht in diesem speciellen Falle die grösstmögliche Schärfe; da jedoch das Stück $b^{\prime \prime} x$ des Objectes bereits undeutlich ist, so wird es im Bilde auch undeutlich wiedergegeben. Ist dagegen die Terschiebung des virtuellen Bildes grösser oder kleiner, als die der Axe, so kommt im ersten Fall auf der linken, im zweiten auf der rechten Seite ein entsprechender Randtheil des reellen Bildes unter weniger günstigen Bedingungen zu Stande und wird in Folge dessen weniger scharf. Das Stück $l^{\prime \prime \prime} x$ wird also möglicher Weise vom Rande her zum zweiten Male verundeutlicht.

So verwischt sich also mit jeder Verschiebung ein entsprechendes Randstück des Objectivbildes, so dass in Wirklichkeit, wenn die fehlerhafte Centrirung der Flint- und Kronglaslinsen ebenfalls in Rechnung gebracht wird, die ganze Peripherie des Gesichtsfeldes mehr oder weniger darunter leiden muss und folglich nur ein mittleres Stück, das jedoch eine beliebige excentrische Lage haben kann, sich in seiner ursprünglichen Reinheit erhält.

Um über die Grenzlinien, bis zu welchen die in unserer Figur dar- 67 gestellten Verschiebungen das mikroskopische Bild beeinträchtigen, einige Anhaltspuncte zu gewinnen, wollen wir annehmen, die erste Linse vergrössere $3 \mathrm{mal}$, die zweite und dritte beziehlich 4 und $6 \mathrm{mal}$ - ein Verhältniss, welches mit einem wirklich beobachteten annähernd übereinstimmt. Die Verschiebung der Axe $o_{2}$ betrage 0,25, die der Axe $o_{3} 0,50^{\mathrm{m} \cdot \mathrm{m} .}$ Alsdann ist $b^{\prime} x=0,25, b^{\prime \prime} x=1, b^{\prime \prime \prime} x=6^{\mathrm{m} \cdot \mathrm{m} .}$; ferner $\beta^{\prime \prime} b^{\prime \prime}$ (in der Richtung senkrecht zur Axe) $=(4-1) \times 0,25$ $=0,75^{\mathrm{m}, \mathrm{nn}}$. und folglich ein Stück von $6 \times(0,75-0,50)=1,5^{\mathrm{m} \cdot \cdots}$. 
Breite in Objectivbilde, von $b^{\prime \prime \prime}$ an gemessen, zum zweiten Mal verundeutlicht. Dieses Stück fällt jedoch, wenn die Blendung im Ocular unbeweglich gedacht wird, auf den Rand derselben; denn da $a^{\prime \prime} b^{\prime \prime}$ um $0,25^{\mathrm{m} . \mathrm{m}}$. weiter nach rechts geschoben erscheint als $o_{3}$, so kommt das Objectivbild mit Rücksicht auf $o_{3} 6 \times 0,25=1,5^{\mathrm{m} . \mathrm{m}}$, also mit Rücksicht auf $P Q$ oder auf $\alpha^{\prime \prime \prime} \beta^{\prime \prime \prime}$, dem Gesichtsfelde des Oculars im centrirten System, um 1,5-0,5=1 m.m. weiter nach links zu liegen. (In der Figur ist das Verhältniss umgekehrt.) Beträgt der Durchmesser dieses Gesichtsfeldes, d. h. der Blendungsöffnung im Ocular, $18^{\mathrm{m} . \mathrm{m}}$, so bleiben also von dem undeutlichen Stück $b^{\prime \prime \prime} x$ noch $5^{\text {m.m. }}$ sichtbar, während auf der andern Seite, zwischen $a^{\prime \prime \prime}$ und $\alpha^{\prime \prime \prime} 1^{\text {m.m. }}$ der Oeffnung leer ausgeht und nur ausgefüllt werden kann, wenn das Object $a b$ bei $a$ einen kleinen Zuwachs von $\frac{1}{7}^{\mathrm{m}} \mathrm{m}$. erhält. Dieser Zuwachs wird im Bilde $a^{\prime} b^{\prime}$ etwas weniger scharf, erleidet aber durch die folgenden Brechungen keine weitere Einbusse.

Die fehlerhafte Centrirung des Objectirsystems kann nun ferner auch darin bestehen, dass die optischen Axen

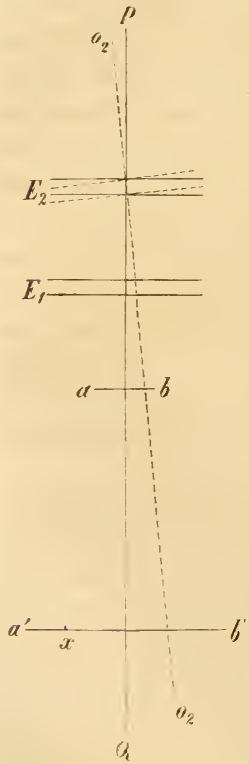

Figur 36 . mit der Axe des Mikroskops kleine Winkel bilden, - und das ist ein zweiter Punct, den wir zu erörtern haben. Seien wieder $E_{1}$ und $E_{2}$ Fig. 36) die Hauptebenen der ersten und zweiten Doppellinse eines vollkommen centrirten Systems, $P Q$ die gemeinsame optische Axe, $a b$ das Object und $a^{\prime} b^{\prime}$ das virtuelle Bild der ersten Linse, also Object für die zweite. Wird jetzt diese letztere um einen ihrer Hauptpuncte gedreht, ohne dass dieser seinen Ort im Raume verändert, während die optische Axe $\mathrm{O}_{2} \mathrm{O}_{2}$ aus der Richtung $P Q$ heraustritt, so kommt dadurch das Stück $a^{\prime} x$ des virtuellen Bildes, ähnlich wie im vorhergehenden Falle, in eine ungünstigere Stellung. Insoweit ist also die Wirkung die nämliche, wie bei der seitlichen Verschiebung der optischen Axe, nur dass die durch die Winkelabweichung verursachte Störung mit dem Abstande des Objectes zunimmt. Nun kommt aber noch hinzu, dass in Folge der Neigung der Linse auch das von ihr entworfene Bild geneigt erscheint, wodurch das schliessliche Objectiv- 
bild, auch wenn die Neigung durch entgegengesetzte Abweichungen wieder compensirt würde, jedenfalls nur verlieren, nicht gewinnen kann. Im Allgemeinen wirkt also die fragliche Abweichung der optischen Axen noch nachtheiliger als die blosse seitliche Verschiebung derselben; doch ist dabei zu berücksichtigen, dass beispielsweise ein Winkel von circa $2^{0}$ dazu gehört, um bei einem Objectabstand von $7-S^{\mathrm{m} \cdot \mathrm{m}}$, wie er etwa für die zweite Linse angenommen werden kann, der oben vorausgesetzten Verschiebung von 0,25 m.m. aequivalent $\mathrm{zu}$ sein. Der Praktiker mag hiernach entscheiden, welche Art von Abweichungen leichter zu corrigiren sei.

Wenn beiderlei Abweichungen in einem Linsensysten vorkommen, so ist die resultirende Wirkung genau dieselbe, wie wenn zuerst eine Verschiebung der Axen parallel mit sich selbst und damn eine Neigung derselben oder auch umgekehrt, stattgefunden hätte. Die arithmetische Bestimmung der Störungen geschieht also einfach durch Addition der beiden Effecte, die im Vorhergehenden gesondert erörtert wurden.

Es ist also nach dem Angeführten allerdings richtig, dass eine fehlerhafte Centrirung auf das mikroskopische Bild einen schädlichen Einfluss übt. Dieser Einfluss beschränkt sich jedoch, wenn wir von der schwachen Neigung der Bilder gegen die Axe absehen, zunächst nur auf die Ränder des Gesichtsfeldes und erreicht erst bei stärkeren Abweichungen (die doch wohl zu vermeiden sein dürften) das Centrum desselben. Daher die bekannte Erscheinung, dass schwierigere Objecte im peripherischen Theil des Gesichtsfeldes fast durchgehends weniger deutlich gesehen werden, als in der Nähe des Mittelpunctes.

Zum Schlusse mag hier noch eine Betrachtung Platz finden, auf 69 welche wir später, wenn ron der Prüfung der Centrirung die Rede ist, Bezug nehmen werden. Es soll gezeigt werden, welche Ortsveränderungen das Bild eines beliebigen Objectpunctes bei mangelhafter Centrirung erfährt, wenn das bilderzeugende Objectirsystem um die Axe des Mikroskops (PQ Fig. 36) gedreht wird. Wir gehen zu diesem Ende von den oben gewonnenen Ergebnissen aus, wonach eine Verschiebung der Linsen im Allgemeinen auch eine Verschiebung des Objectivbildes zur Folge hat. In dem angeführten Beispiel, wo die optischen Axen um 0,25 und $0,50^{\mathrm{m} . \mathrm{m} .}$ nach rechts und links gerückt waren, betrug diese Verschiebung $1^{\mathrm{m} . \mathrm{m}}$. nach links. Denken wir uns nun das Objectiv auf der linken Seite mit einem Zeichen versehen, so ist einleuchtend, dass während der Drehung um die Axe $P Q$ die Verschiebung immer in der Richtung stattfinden muss, welche 
durch dieses Zeichen bestimmt ist. Der Mittelpunct des kreisförmigen Objectivbildes nimmt also zum Centrum $o$ (Fig. 37) des von der Ocu-

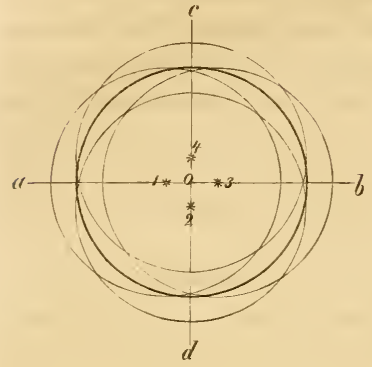

Figur 37 . larblendung begrenzten Gesichtsfeldes, in welchem man sich ein Fadenkreuz $a b c d$ ausgespannt denken mag, nach einander die Stellungen ein, welche mit 1, 2, 3, 4 bezeichnet sind. Derselbe beschreibt also einen Kreis, welcher den Punct o zum Centrum und die Verschiebungsgrösse zum Radius hat. Ebenso beschreibt aber auch jeder andere Punct im Bilde, da ja seine Lage zum Mittelpuncte dieselbe bleibèn muss, einen Kreis ron gleichem Diameter, dessen Centrum mit dem entsprechenden Bildpunct des centrirten Systems zusammenfällt.

Aehnliche Erscheinungen beobachtet man natürlich auch, wemn statt des ganzen Objectivs bloss einzelne ungenau centrirte Linsen um ihre Axe gedreht werden. Die Verschiebungen können sogar noch weit beträchtlicher ausfallen, weil Abweichungen, die sonst ein Gegengewicht bildeten, sich in Folge der Drehung zu anderen addiren. Es besteht überhaupt zwischen den Abweichungen der einzelnen Axen und der resultirenden Verschiebung des Objectivbildes keine so leicht zu übersehende Bezichung, wie man gewöhnlich annimmt. Wenn z. B. Harting angiebt, dass jede Abnormität sich genau so vielınal vergrössere, als das Object selbst, dass folglich eine J)ifferenz von $10 \mathrm{Mik}$. in einem $500 \mathrm{mal}$ vergrösserten Bilde $5^{\mathrm{m} . \mathrm{m}}$. ausmache, so ist das eine ganz irrthümliche Darstellung, die schon in dem angeführten Beispiel eine hinlängliche Widerlegung findet. Es ist im Gegentheil immer denkbar, dass sich die Mängel der Centrirung gegenseitig aufheben, so dass das resultirende Bild, obschon es an Schärfe verliert, doch keine Verschiebung erleidet.

\section{VIII.}

\section{Die Lichtstärke des Mikroskops.}

70 Die Lichtstärke eines Mikroskops ist zu definiren als diejenige Lichtmenge, welche dasselbe auf die Flächeneinheit der Netzhaut 
bringt, wenn als Object eine mit gewisser Intensität gleichmässig leuchtende Fläche dient. Als arithmetischer Ausdruck derselben mag das Verhältniss gelten, in welchem diese Lichtmenge zu derjenigen steht, welche dieselbe leuchtende Fläche bei unmittelbarem Sehen auf die Flächeneinheit der Netzhaut bringt. Diess ist bekanntlich eine volı der Entfernung rom Auge unabhängige Grösse, da das Netzhautbildchen eines beliebigen Gegenstandes durch Veränderung der Objectdistanz in demselben Verhältniss grösser oder kleiner wird, in welchem die Oeffinung der ron den einzelnen Puncten ausgehenden Lichtkegel zu- oder abnimmt. Die in den grösseren Strahlenbündeln enthaltene grössere Lichtmenge vertheilt sich also stets auf eine in demselben Verhältniss grössere Fläche der Netzhaut.

Es liesse sich nun denken, dass dieselbe Beziehung auch für das bewaffnete Auge fortbestehe, dass also die Vergrösserungszahl des Mikroskops mit dem Oeffnungswinkel der einfallenden Strablenkegel in demselben Terhältniss steige und falle. Die Lichtstärke des Mikroskops wäre alsdann der Einheit gleich, d. h. wir würden damit die Gegenstände ebenso hell sehen, wie mit blossem Auge. Ein solcher Fall dürfte in Wirklichkeit auch bei den schwächsten Vergrösserungen nur selten vorkommen; für die stärkeren ist er jedenfalls eine Unmöglichkeit*). Der Durchmesser des mikroskopischen Bildes (und daher auch des Netzhautbildes) nimmt nämlich bei steigender Vergrösserung in einem viel rascheren Verhältniss zu, als die Oeffnungswinkel der einfallenden Strahlenkegel, welche von den Objectpuncten zum Objectiv und ron da zum Auge gelangen. Beim Sehen mit blossem Auge beträgt dieser Winkel, wenn wir den Durchmesser der Pupille zu 2 bis $2 \frac{1}{2} 2^{\mathrm{m} \cdot \mathrm{m}}$. und die Sehweite $z u 250^{\mathrm{m} \cdot \mathrm{m}}$. festsetzen, 2S-34 Minuten, also annähernd 1/2 Grad; beim mikroskopischen Sehen dagegen je nach der Stärke und Eigenthümlichkeit des Objectirs bis zu su" und darüber. Ton jedem Punct der Einstellungsebene

Nach Fick (Med. Physik pag. 4^9) lässt sich in aller Allgemeinheit und Strenge beweisen, dass man keine Combination von Linsen erdenken kann, durch welche gesehen ein Object heller erschiene, als mit freiem Auge gesehen. Wir wissen nicht, ob und in welcher Weise dieser Beweis wirklich geführt worden ist, müssen aber jedenfalls seine Allgemeinheit bezweifeln. Ein Objectiv von Ross mit $12.7 \mathrm{~m} \cdot \mathrm{m}$. Brennweite und $60^{\circ}$ Oeffnungswinkel giebt z. B. bei gewöhnlicher Tubuslänge eine Objectivvergrösserung von c. 13 Mal. Denken wir uns hiezu ein Ocular, welches die Vergrösserung auf 60 steigert, so wird die Lichtstärke ausgedrückt durch $v=4 \cdot\left(\frac{60}{60}\right)^{2}=4$. Was Object erscheint also jedenfalls heller, als bei der Beobachtung mit blossem Auge. 
gelangt in diesem Fall eine Lichtmenge zum Auge, welche im Verhältniss von $S 0^{2}:\left(\frac{1}{2}\right)^{2}=160^{2}: 1$ grösser ist als diejenige, welche das blosse Auge empfängt. Diese Lichtmenge vertheilt sich nun aber auf eine $m^{2}$ mal grössere Fläche der Netzhaut, wenn $m$ die lineare Vergrösserungszahl ist. Die resultirende Helligkeit des Gesichtsfeldes, die wir mit $v$ bezeichnen wollen, wird also ausgedrückt durch $v=\frac{160^{2}}{\mathrm{~m}^{2}}$ oder ganz allgemein, wenn der Oeffnungswinkel des Objectes $=w$, derjenige des blossen Auges $=1 / 2$ gesetzt wird $v=4\left(\frac{w}{m}\right)^{2}$. Die Lichtstärke ist hienach $=1$, wenn $m=2 w$; sie ist kleiner als 1 , wenn $m>2 w$, was offenbar der gewöhnliche Fall ist. Dabei ist selbstverständlich vorausgesetzt, dass der einfallende Strahlenkegel gross genug sei, um die ganze Oeffnung des Objectivs auszufüllen. Diese Bedingung wird jedoch bei der mikroskopischen Beobachtung bekanntlich nur selten erfüllt, da die Blendung die Neigung der einfallenden

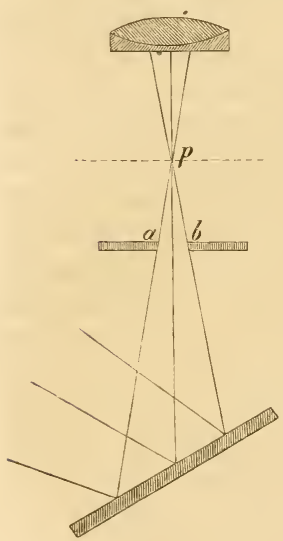

Figur $3 \varsigma$.

Strahlen beschränkt. An die Stelle von $w$ tritt alsdann der Winkel ap $b$ (Fig. 3s), unter welchem die Blendung $a b$ vom Puncte $p$ der Einstellungsebene aus gesehen wird. Ist dieser Winkel $=\delta$, so geht obiger Ausdruck über in $v=\left(\frac{2 \delta}{m}\right)^{2}$. Bei der nämlichen Beleuchtung verhalten sich demnach die Helligkeiten des Gesichtsfeldes umgekehrt wie die Quadrate der linearen Vergrösserungszahlen. Wählen wir z. B. die Blendung so, dass $\delta=30^{\circ}$, so werden die Vergrösserungszahlen 240,300, 360, 420 etc., wie sie bei stärkeren Objectiven vorkommen, beziehungsweise die Helligkeiten $\frac{1}{16}, \frac{1}{25}, \frac{1}{36}, \frac{1}{49}$ etc. ergeben. Steigern wir dagegen $\delta$ (nöthigenfalls vermittelst eines Beleuchtungsapparates) auf das Doppelte und Dreifache des angenommenen Werthes, so erreicht die Lichtstärke - immer vorausgesetzt, dass $w$ wenigstens ebenso gross sei beziehlich das Vier- und Neunfache obiger Brüche; diese erhalten daher bei gleichem Nenner die Zähler 4 und 9 .

Natürlich ist bei dieser Berechnungsweise der Lichtstärke stillschweigend vorausgesetzt, dass die vom Objecte ausgehenden Lichtkegel ohne Verlust ins Auge gelangen. Diese Voraussetzung ist inso- 
fern richtig, als die aus der Ocularlinse hervortretenden Lichtbündel so verengt sind, dass sie die Pupille jedenfalls nie ganz ausfüllen und somit ungeschwächt die Netzhaut erreichen; sie lässt aber die durch Reflexion und Absorption verursachten Verluste unberücksichtigt. Wie viel die letzteren in einem gegebenen Falle betragen, lässt sich nicht leicht genau bestimmen; soviel aber ist sicher, dass sie nur einen kleinen Bruchtheil der berechneten Lichtstärke ausmachen und folglich der Richtigkeit des mathematischen Ausdrucks nicht wesentlich Eintrag thun.

\section{IX.}

\section{Das optische Vermögen des Mikroskops.}

Die Leistungsfähigkeit der Mikroskope.steht bekanntlich mit der 71 Vergrösserungszahl keineswegs in einem proportionalen Verhältniss. Während die einen bestimmte Einzelnheiten und Formverhältnisse eines gegebenen Objectes beispielsweise schon bei 100 maliger Vergrösserung erkennen lassen, bedarf es bei andern einer 150-200 maligen Vergrösserung, um dieselben zum Vorschein zu bringen. Dem entsprechend heben die stärksten Objective bei jenen noch Détails hervor, welche bei diesen, gleiche Brennweiten vorausgesetzt, nicht mehr wahrnehmbar sind. Auf diese Differenzen gründet sich nun der Begriff, den man gewöhnlich als opt isches Vermögen bezeichnet; er umfasst alle die Eigenschaften, welche die Schärfe und Klarheit des mikroskopischen Bildes bedingen. U'nd zwar pflegen die Mikroskopiker zwei verschiedene Momente oder Richtungen desselben zu unterscheiden, die sich bei der Prüfung der Instrumente in abweichender Weise kundgeben, nämlich die sogenannte definirende und die penetrirende Kraft, die wir nun näher zu erörtern haben.

Man versteht unter definirender Kraft eines Mikroskops das Vermögen, Formen und Umrisse der Körper im Bilde scharf und bestimmt wieder zu geben, und unter penetrirender Kraft die Fähigkeit, feine Structurverhältnisse, wie die Schichten der Zellmembran, die Zeichnungen der Diatomaceenpanzer u. dgl., zur Wahrnehmung zu bringen. Diese Unterscheidung wurde zuerst von W. Herschel für die Teleskope aufgestellt und später von Goring auf die Mikroskope übertragen. Herschel machte nämlich darauf aufmerksam, dass Teleskope mit grösserer Oeffnung, auch wenn sie sonst fehlerhaft construirt seien, sich besonders dazu eignen, lichtschwache Nebelflecken 
und Sterngruppen sichtbar zu machen, die mit kleineren Instrumenten von der besten Art nicht zu unterscheiden sind; diese letzteren werden dagegen leuchtende Puncte, die nur wenig von einander abstehen, wie z. B. die Doppelsterne, noch getrennt zeigen, während sie bei ersteren in ein en Lichtpunct zusammenfliessen.

Die penetrirende Kraft oder das Durchdringungsvermögen steht also hienach mit der Grösse der Oeffnung, die definirende Kraft oder das Begrenzungsvermögen mit der genaueren Construction, d. h. mit dem Grad der Verbesserung der beiden Aberrationen im Zusammenhang. Es ist auch an und für sich klar, dass jedes optische Instrument, wie auch jedes unbewaffnete Auge, um so schärfer begrenzte Bilder liefert, je näher die Vereinigungspuncte der verschiedenfarbigen und verschieden geneigten Strahlen auf der Netzhaut zusammenfallen; dass dagegen kleine Verschiedenheiten der Leuchtkraft lichtschwacher Objectpuncte um so augenfälliger werden, je grösser die Lichtmenge, welche von solchen Puncten zur Netzhaut gelangt. Darum eben sehen Thiere mit weit geöffneter Pupille bei Nacht besser als der Mensch und treten Gegenstände in dunkeln Räumen auch für das menschliche Auge in dem Maasse deutlicher hervor, als die Pupille sich allmählich erweitert.

Die Unterscheidung der definirenden und penetrirenden Kraft, wie sie Herschel für die Teleskope aufstellte, ist also ganz allgemein für jeden optischen Apparat, das unbewaffnete Auge nicht ausgenommen, vollkommen begründet. Nur vergesse man nicht, dass die penetrirende Kraft eigentlich mit der Oeffnung der vom Objecte ausgehenden und zum Auge gelangenden Lichtkegel, nicht mit derjenigen des brechenden Apparats zu- und abnimmt. Es versteht sich von selbst, dass wenn die einfallenden Lichtbündel die Oeffnung des Objectivs nur theilweise ausfüllen, die absolute Grösse des unausgefüllten Theils völlig gleichgültig ist.

i2 Untersuchen wir nun, ob und in welchem Sinne der Begriff der penetrirenden Kraft, wie er im Vorhergehenden festgestellt wurde, sich auf das Mikroskop übertragen lasse, und ob die Eigenschaften, die man mit obigem Ausdrucke zu bezeichnen pflegt, wirklich dem nümlichen Begriff entsprechen. Bei Teleskopen füllen natürlich die Lichtkegel, welche von den meist sclbstleuchtenden) Objectpuncten ausgehen, die Oeffnung des Objectivs vollständig aus. Eine Erweiterung dieser letzteren wirkt also wie für das unbewaffnete Auge die Erweiterung der Pupille. Das eine wie das andere hat aber nur dann einen Wcrth, wenn das von den Objecten ausgehende Licht sehr 
schwach ist, wird dagegen in allen Fällen, wo die Leuchtkraft derselben eher zu gross als zu klein ist, sogar einen störenden Einfluss äben, da Apparate mit grösserer Oeffnung gewöhnlich auch mit stärkeren Aberrationen behaftet sind. Da nun bei der mikroskopischen Beobachtung eine beliebige Steigerung der Beleuchtung möglich ist - man könnte ja nöthigenfalls directes Sonnenlicht dazu verwenden - so kann die grössere Oeffnung des Objectivs ron diesem Gesichtspuncte aus ganz und gar nicht in Betracht kommen. Bekanntlich sind denn auch die Blendungen der Beleuchtungsapparate so klein, dass die nach den Puncten der Einstellungsebene convergirenden Strahlen meist nur Kegel von c. 20-30 Grad Oeffnung bilden. Diese nämlichen Strahlen gruppiren sich aber, nachdem sie im Object eine Ablenkung erfahren, abermals in Lichtkegel, welche ron den einzelnen Objectpuncten zu kommen scheinen und im Mikroskop deren Bild entwerfen. Die Oeffnung dieser Lichtkegel ist im Maximum, je nach der Stärke der Ablenkung, etwas grösser oder kleiner als die der einfallenden; die Differenzen sind aber so klein, dass sie für unsere Betrachtung vernachlässigt werden dürfen. Die zum Objectiv gelangenden Lichtkegel füllen also die Oeffnung desselben, wenn wir diese beispielsweise zu $60-S 0^{0}$ annehmen, jedenfalls nur theilweise aus; sie sind unter den gegebenen Verhältnissen ron der Grösse dieser Oeffnung durchaus unabhängig. Dadurch verliert aber die von Goring u. A. gezogene Parallele zwischen Teleskop und Mikroskop ihre Berechtigung. Was man bei dem letzteren penetrirende liraft genannt hat, nämlich die Fähigkeit, feine Structurverhältnisse, Strichelchen, Pünctchen etc. zur Wahrnehmung zu bringen, ist auch in der That, wie schon Harting mit Recht hervorgehoben, etwas ganz anderes, als das raumdurchdringende Vermögen der Teleskope. Man würde, wenn man durchaus an der Parallele festhalten wollte, das Unterscheidungsvermögen der Mikroskope richtiger mit der Eigenschaft der Fermröhre vergleichen, Doppelsterne in getrennte Puncte aufzulösen.

Es kann sich jetzt nur noch um die Frage handeln, in welcher 73 Weise, da doch die einfallenden Lichtkegel rom Oeffnungswinkel des Objectivs unabhängig sind, dennoch die Grösse dieses Winkels auf das mikroskopische Bild Einfluss übe. Man könnte zunächst auf die Vermuthung kommen, die Wirkung der grösseren Oeffnung beruhe vielleicht auf einer günstigeren Vertheilung ron Licht und Schatten, da es eine bekannte Thatsache ist, dass Oeltropfen, Stärkekörner ı. dergl. bei schwächerer Vergrösserung einen starken Randschatten 
werfen, während derselbe bei Anwendung stärkerer Objective mit grösserem Oeffnungswinkel verschwindet. Es liesse sich nun denken, dass durch grössere Ausbreitung der Lichtpartieen gewissermaassen ein Gleichgewicht zwischen Hell und Dunkel hergestellt würde, in dem Sinne, dass z. B. bei gestreiften Objecten Schatten- und Lichtlinien nahezu gleiche Breite erhielten und in Folge dessen auch leichter zu unterscheiden wären. Allein eine solche Erklärung ist aus zwei Gründen nicht stichhaltig. Einmal giebt es Probeobjecte genug, wo die Lichtpartieen im Bilde ein solches Uebergewicht haben, dass eine Verkleinerung derselben nur vortheilhaft wirken müsste, und doch ist ihre Auflösung nur durch Objective mit grossem Oeffnungswinkel möglich. Sodann hängt, wie später ausführlicher gezeigt werden soll, die Vertheilung ron Licht und Schatten nicht allein vom Objectiv, sondern auch von der Grösse der Blendung ab. Der Ablenkungswinkel der Strahlen, welche den Grenzpuncten des Kern- und Halbschattens entsprechen, wird stets durch Formeln bestimmt, in welchen die beiden Oeffinungswinkel $w$ und $\delta$ nur als Summe oder als Differenz auftretęn, und wenn nun auch die Grenzpuncte selbst dadurch noch nicht mathematisch gegeben sind, so ist doch ihre Lage nahezu dieselbe, wie wenn die Brechung durch eine aequivalente, unendlich dünne Linse im Niveau des Objectes stattfände. Jedenfalls ist es für unsere Betrachtung erlaubt, an die Stelle der brechenden Flächenelemente einer Membran, z. B. einer Diatomaceenschale, eine solche

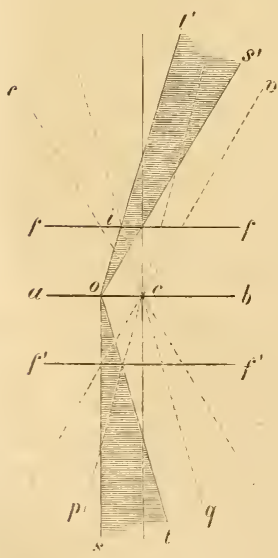

Figur 39. Linse zu substituiren, ohne dadurch die Richtigkeit der Schlüsse irgendwie zu beeinträchtigen. Alsdann ist es aber für die Theorie vollkommen gleichgültig, ob man mit einem Objectiv von $60^{\circ}$ eine Blendung von $30^{\circ}$, oder umgekehrt ein Objectiv von $30^{\circ}$ mit einer Blendung von $60^{\circ}$ Oeffnung combinire. Das Bild müsste in beiden Fällen bis auf unmerkliche Differenzen dasselbe sein.

Wir wollen diese Folgerung noch durch eine Figur veranschaulichen. Sei $a b$ (Fig. 39) die aequivalente Linse, $c$ ihr Mittelpunct und $f f, f^{\prime} f^{\prime}$ ihre beiderseitigen Hauptbrennebenen, welche folglich die durch $c$ gehende Senkrechte in den Hauptbrennpuncten schneiden, ferner $r c v=60^{\circ} \mathrm{der}$ 
Oeffnungswinkel des Objectivs und $p \bullet q=30^{\circ}$ der Oeffnungswinkel der Blendung. Dann lässt sich der Gang der Strahlen nach den in der Einleitung mitgetheilten Principien leicht bestimmen. Der durch den Brennpunct parallel mit $v c$ gezogene Strahl verläuft nach der Brechung parallel mit der Axe; der von unten parallel mit $q c$ einfallende Strahl wird so gebrochen, dass er die obere Brennebene mit der Verlängerung von $q c$ in demselben Puncte schneidet. Dadurch sind die Randstrahlen der zur Beleuchtung des Punctes $o$ beitragenden Lichtkegel, des einfallenden und ausfahrenden, bestimmt. Alle Strahlen, welche nach rechts oder links stärker abweichen, als die gezeichneten, treffen entweder auf den Rand der Blendung oder auf denjenigen des Objectes. Ebenso leicht lassen sich die wirksamen Lichtkegel für beliebige andere Puncte construiren. Der Grenzpunct des Kernschattens ist z. B. durch eine Linie bestimmt, welche parallel mit $v c$ durch $i$ gezogen wird.

Denkt man sich nun die Figur um $150^{\circ}$ gedreht, so dass das, was jetzt oben ist, unten zu stehen kommt, so giebt dieselbe Construction, wie leicht einzusehen, den Strahlenverlauf für den Fall, dass die Blendung 60 und das Objectiv nur $30^{\circ}$ Oeffnung besitzt. Die Grenzlinien zwischen Licht und Schatten bleiben dabei selbstverständlich nach wie vor dieselben, und wenn die rom Objecte ausgehenden Lichtkegel nach der Brechung im Objectiv homocentrisch bleiben, was wir natürlich für beide Fälle annehmen, so ist kein Grund vorhanden, welcher irgend eine merkliche Aenderung, sei es der Schärfe oder der Lichtstärke etc., im Bilde erklären könnte. Es ist demnach vollkommen richtig, dass die Grösse des Oeffnungswinkels bei Objectiven, theoretisch betrachtet, nicht mehr und nicht weniger $\mathrm{zu}$ bedeuten hat, als die Grösse der Blendungsöffnung. Die Vorzüge, welche jener voraus hat, - so schliessen wir weiter - können folglich nur praktischer Natur sein.

$U_{m}$ das Nähere hierüber festzustellen, verweisen wir noch ein- it mal auf die in Fig. 39 gegebene Construction des Strahlenganges. Ist $t^{\prime}$ o $s^{\prime}$ der vom Object ausgehende Lichtkegel, so treffen seine Randstrahlen, und also auch alle übrigen, den peripherischen Theil des Objectivs; das Centrum des letzteren geht leer aus. Kehrt man dagegen die Figur um und betrachtet $s o t$ als den vom Objecte kommenden Lichtkegel, so sind hier alle Neigungen von $0^{0}$ bis $15^{0}$ vertreten; derselbe füllt also die halbe Oeffnung des Objectivs aus. Da nun das Experiment zeigt, dass alle stärkeren Objective mit grossem Oeffnungswinkel, soweit wenigstens unsere Beobachtungen reichen, für 
Centralstrahlen bis zu $15^{\circ}$ Neigung und darüber weit weniger aplanatisch sind, als für Randstrahlen von c. $45^{\circ}$ bis $60^{\circ}$, so erklärt sich hieraus die Differenz in der Schärfe des mikroskopischen Bildes. Die Bedeutung des Oeffnungswinkels liegt also nur darin, dass der Optiker, wie es scheint, die Aberrationen leichter für schief auffallende Lichtkegel, als für gerade, zu beseitigen im Stande ist oder wenigstens, da er Beides zugleich nicht erreicht, das erstere vorzieht. Aber es unterliegt keinem Zweifel, dass der Erste, welcher den nämlichen Verbesserungsgrad für die mittleren Strahlen, wäre es auch nur bis zu 12 oder $15^{0}$ Neigung erreicht, Objective liefern wird, die bei richtiger Beleuchtung ganz dasselbe leisten, wie solche mit $\mathrm{S}_{0}-120^{\circ}$ Oeffnung.

7.) Halten wir jetzt nach diesen Erörterungen die beiden Begriffe, welche man als penetrirende und definirende Kraft zu unterscheiden beliebt hat, noch einmal gegeneinander, so fliessen sie, streng genommen, in einen zusammen. Das Mikroskop entwickelt, abgesehen von der Lichtstärke und der V'ergrösserungsziffer, keine andere Kraft und kann keine andere entwickeln, als diejenige, welche mit der Verbesserung der beiden Aberrationen gleichen Schritt hält. Wo diese Verbesserung sich gleichmässig auf alle Strahlen bezieht, so dass z. B. ein einfallender Lichtkegel von $10^{\circ}$ Oeffnung eine gleich günstige Brechung erfährt, er mag die Mitte oder den Rand der Objectivlinse treffen, da kann von einem Unterschied zwischen penetrirender und definirender Kraft auch in der Praxis nicht die Rede sein. Das Instrument ist nach beiden Richtungen gleich vollkommen oder unvollkommen. Ist dagegen die Mitte des Objectivs in höherem Grade aberrationsfrei, so hängt es rein von der Natur des Objectes und ron der Beleuchtung ab, ob diese Eigenschaft dem mikroskopischen Bilde zu Gute komme oder nicht. Gerade Beleuchtung und eine kleinere Blendung vorausgesetzt, wird z. B. ein schwarzer Fleck von Tusche auf dem Objectträger, in welchen man mit der Nadel feine Puncte oder Linien gezeichnet hat, ein möglichst scharfes Bild liefern, weil sämmtliche dazu beitragende Lichtkegel durch die Mitte des Objectirs gehen. Dagegen vermag ein solches Objectiv die schwierigeren Probcobjecte nicht befriedigend zu lösen, weil gerade die Strahlenkegel, welche im Bilde den Grenzzonen zwischen Licht und Schatten entsprechen, in Folge der Ablenkung im Object durch den peripherischen Theil des Objectivs gehen und daher ein so verwischtes Bild liefern, dass die Lichtpartieen übereinander greifen. Nur dic Begrenzung des ganzen Objects wird ziemlich bestimmt ausfallen, weil die dic Ründer strcifenden Lichtkegel, wie in vorigen Falle, die Mitte 
des Objectivs treffen. Sowie man aber diese begrenzenden Lichtbündel durch Anwendung einer ringförmigen Blendungsöffnung nach dem Rande zu lenkt, erfährt dadurch auch die »definirende Kraft " eine entsprechende Abnahme.

Auf diese Weise lassen sich alle Erscheinungen, welche nach 76 der bisherigen Annahme mit der definirenden oder penetrirenden Kraft im Zusammenhange stehen, in höchst einfacher und befriedigender Weise erklären. Es sind stets die Randstrahlen, welche " penetriren " und die Centralstrahlen, welche »definiren ", aber beide thun eigent. lich dasselbe. Um hierüber keinen Zweifel aufkommen zu lassen, wollen wir zu dem bereits erwähnten noch einige Beispiele hinzufügen. Die Probeobjecte, welche ron Goring und v. Mohl zur Prüfung der definirenden Kraft benutzt wurden, haben fast alle die Eigenschaft mit einander gemein, dass gewisse Stellen entweder wirklich undurchsichtig sind oder in Folge eingelagerter Luft oder eigenthümlicher Formverhältnisse genan wie undurchsichtige wirken. Die Lichtstrahlen, welche rom Spiegel nach den Objectpuncten convergiren, gelangen entweder ohne merkliche Ablenkung zum Objectiv, oder der Weg dahin wird ihnen gänzlich abgeschnitten. Diess gilt zunächst für alle Objecte, wo es sich nur um den äusseren Umriss, d. h. um die Abgrenzung vom Gesichtsfeld handelt. Zwar ist die dunkle Linie, welche diesen Umriss bildet, an und für sich von der Natur des Objectivs unabhängig, weil sie ja nicht durch bestimmte Lichtbündel, sondern durch einen Lichtausfall zu Stande kommt; sie kann aber offenbar nur da scharf und bestimmt hervortreten, wo die angrenzenden Puncte des Gesichtsfeldes scharfe Bilder liefern. Da num das Gesichtsfeld durch Lichtkegel erhellt wird, welche bei gerader Beleuchtung die Mitte des Objectivs treffen, so ist einleuchtend, dass die Schärfe der Umrisse wesentlich von der Brechung der mittleren Strahlen abhängt. Dasselbe Raisonnement findet natürlich auch auf die dunkeln Stellen im Innern der Objecte Anwendung, wofern nur die hellen Puncte der nächsten Umgebung sich annähernd wic die Puncte des Gesichtsfeldes verhalten. Es gilt z. B. für die kleinen, eiförmigen Schüppchen von Lycaena Argus, wo die dunkcln Puncte scharf und deutlich getrennt gegen den helleren Grund abstechen sollen, ferner für die thierischen Haare mit abwechselnd hellen und dunkeln Stellen (wenigstens für die Mitte der zugekehrten Seite), für dicht gedrängte, durchgehende Poren in zarten Membranen $\mathrm{u}$. s. w. Man darf ganz allgemein behaupten, dass die fraglichen Testobjecte zur Prüfung der "definirenden Kraft " um so geeigneter 
sind, je weniger die Lichtkegel, welche nach dem Durchgang durch das Object rom Rande der dunkeln Stellen, Linien oder Puncte zu kommen scheinen, gegen die Axe des Mikroskops geneigt sind, je weniger also der peripherische Theil des Objectivs bei der Brechung derselben betheiligt ist.

it Man begreift nun auch, warum bei Objectiven mit grösserem Oeffnungswinkel bald die Abhaltung der Centralstrahlen, bald die der Randstrahlen die Schärfe des Bildes erhöht, indem dadurch derjenige Theil der brechenden Fläche ausser Wirksamkeit kommt, welcher am wenigsten aberrationsfrei ist. Nur dürfte es in der Regel vortheilhafter sein, die betreffenden Blendungen am Objectiv selbst (sei es unter der Vorderfläche, was jedenfalls am besten wäre, oder hinter der letzten Fläche oder zwischen den Linsen), statt am Beleuchtungsapparat anzubringen.

Eine solche verbessernde Einrichtung am Objectiv wurde schon von Harting (Mikr. p. 254) vorgeschlagen; derselbe ist sich jedoch über den zu erreichenden Zweck nicht ganz klar, da er ganz allgemein gewöhnliche Blendungen mit grösseren und kleineren Oeffnungen empfiehlt, welche nur die Mitte des Objectivs frei lassen. Es versteht sich ron selbst, dass dadurch unter Umständen gerade der bessere Theil der brechenden Fläche abgeschnitten würde.

Aus dem Angeführten geht auch hervor, dass die gewöhnlichen Probeobjecte, die Nobert'schen Probetäfelchen mit inbegriffen, nur im Allgemeinen über das optische Vermögen des peripherischen Theils der Objective Aufschluss geben, ohne dass damit für Strahlen verschiedener Neigung der Grad der Verbesserung relativ bestimmt werden könnte. Viel besser müssten sich hiezu helle Liniensysteme auf dunkelm Grunde, z. B. auf einem mit einer schwarzen Substanz überzogenen Objectträger eignen, wobei aber das Glas selbst nicht geritzt sein dürfte. Die nach der Einstellungsebene zielenden Lichtkegel wären alsdann den von hier ausfahrenden hinsichtlich der Neigung und Oeffnung vollkommen gleich, und man hätte es in seiner Gewalt, durch Anwendung geeigneter Blendungen nach Belieben senkrechte Strahlenbündel oder mehr oder weniger geöffnete Strahlentrichter mit ringförmigem Querschnitt zum Objectiv gelangen zu lassen. Die $\mathrm{Zu}$ - und Abnahme des optischen Vermögens in den verschiedenen concentrischen Zonen des Objectivs könnte nach dieser Methode leicht und sicher festgestellt werden. Die Frage ist nur, ob sich solche Liniensysteme, sei es nun auf Glas oder auf Collodium mittelst der Photographie oder auf irgend einem anderen Wege herstellen lassen. 
Für die schwächeren Objective, deren Durchmesser es erlaubt, beliebige Zonen durch passende Blendungen zuzudecken oder offen zu lassen, lässt sich übrigens eben so gut das von einer Luftblase entworfene Bild eines Drahtgeflechtes benutzen, welche Methode in einem folgenden Kapitel ausführlich besprochen werden soll.

\section{$\mathrm{X}$. \\ Von der Beleuchtung.}

Es ist nicht unsere Absicht, hier alle die verschiedenen Beleuch- is tungsapparate für durchfallendes und auffallendes Licht, wie sie von diesem oder jenem Optiker hergestellt werden, ausführlich zu besprechen. Wer hierüber Belehrung wünscht, findet dieselbe im ausgedehntesten Maasse in den bekannten mikrographischen Werken von Mohl, Harting u. A. Was uns zunächst wichtiger erscheint, ist die Klärung der meist sehr unklaren Begriffe, die man sich gewöhnlich über den Einfluss der Beleuchtungsapparate macht, indem man ihnen Eigenschaften und Vorzüge zuschreibt, die sie unmöglich haben können ${ }^{*}$. Wir stellen uns daher vorzugsweise die Aufgabe,

*) Es dürfte nicht ganz überflüssig sein, einige Ansichten, welche über den Einfluss der Beleuchtung auf die Wahrnehmung mikroskopischer Détails ausgesprochen wurden, zusammenzustellen. Sie beweisen am besten, wie unklar die Vorstellungen waren, die sowohl Optiker als Mikroskopiker sich über diesen Punct gemacht haben. Schleiden sagt pag. 103 seiner "Grundz. d. wiss. Bot." wörtlich: "Man macht ihn (den Beleuchtungsspiegel) plan oder concav, und zwar letzteres so, dass der von ihm ausgehende Lichtkegel genau die Oeffnung des Tisches ausfüllt ....... Wo möglich ist die Beleuchtung mit dem Planspiegel vorzuziehen; zwar ist hier die Lichtmenge nicht so gross, aber der Parallelismus der Strahlen ist entschieden für die Sicherheit der Beobachtung vortheilhafter. Es scheint nämlich, als ob durch die Convergenz der Strahlen beim Hohlspiegel in dem Bilde Verschiebungen veranlasst werden können. Ich bin oft auf diese Erscheinungen aufmerksam geworden, gestehe aber, dass ich nichts darüber zu sagen weiss, da die Optiker uns hier ganz im Stiche lassen." Frühere Autoren, wie Wollaston, Brewster, Dujardin hielten dagegen convergirendes Licht für das günstigste und die beiden letzteren glaubten sogar, das Object müsse sich genau im Brennpuncte der convergirenden Strahlen befinden. Nach Pritch ard endlich sollen schwierige Probeobjecte nur bei divergirendem Lichte gut gesehen werden. Harting, welcher diese Anschauungen erwähnt, erklärt dieselben aus dem verschiedenartigen Einfluss der Objecte auf den Gang der Lichtstrahlen und stellt seinerseits die eklektische Ansicht auf, die Beleuchtung müsse balả durch paralleles, bald durch convergirendes oder divergirendes Licht geschehen, je 
die für das Verständniss und die Anwendung der verschiedenen Beleuchtungsarten erforderliche theoretische Grundlage festzustellen.

\section{Belenchtnng mit dnrchfallendem Licht.}

Der wichtigste und allein unentbehrliche Bestandtheil jedes Beleuchtungsapparates für durchfallendes Licht ist der Spiegel. Um seine Wirkung theoretisch festzustellen, denken wir uns denselben in die Strahlung einer unbegrenzten oder wenigstens sehr ausgedehnten und auf allen Puncten gleichmässig leuchtenden Lichtquelle eingetaucht. Jedes Element der spiegelnden Fläche wird alsdann nach eben so vielen Richtungen Licht aussenden, als es Licht empfängt. Wenn wir daher von der äusserst geringen Differenz der Verluste absehen, welche die unter ungleichen Winkeln reflectirten Strahlen erleiden, so wirkt der Spiegel mit Rücksicht auf die Einstellungsebene des Mikroskops genau so, wie eine selbstleuchtende Fläche und jedes Flächenelement desselben wie ein selbstleuchtender Punct. Dabei ist es vollkommen gleichgültig, ob derselbe eben, hohl oder erhaben sei, da ja die Leuchtkraft des cinzelnen Flächenelements von sciner Neigung gegen die Axe des Instruments unabhängig und folglich die Helligkeit der ganzen Spiegelfläche dieselbe ist, ob diese Neigung sich von Element zu Element ändere oder constant bleibe. Ein beliebiges Flächenelement der Einstellungsebene $p$ (Fig. 10) wird daher, wenn $a b$ die Blendung darstellt, von Strahlen beleuchtet, welche von den Puncten der Spiegelfläche zwischen $m$ und $n$ ausgehen. Von dem ganzen nach oben divergirenden Lichtkegel, welchen jeder einzelne dieser Puncte aussendet in der Figur wurde derselbe für den Punct $o$ angedeutet) wirkt aber nur ein unendlich schmaler Theil mit, dessen

nachdem die besonderen Umstände und die Art des Objects diess verlangen. Weiterhin, bei Besprechung der Mittel, durch welche angeblich die gewünschte Strahlenrichtung hergestellt werden soll, wird unter Anderem bemerkt, dass die Form des ebenen Spiegels gleichgültig sei, der Hohlspiegel dagegen müsse natürlich rund sein. Goring war in Betreff dieses letzteren Punctes anderer Ansicht. Er legte einen grossen Werth darauf, dass der Beleuchtungsspiegel elliptisch und nicht kreisförmig sei, damit er von oben gesehen sich kreisförmig darstelle. Zugleich gab er demselben eine wahrhaft colossale Grösse (beinahe 5 " Länge bei $f^{\prime \prime}$ Breite), um dadurch die Lichtstärke des Bildes zu steigern.

Wir denken, der unbefangene Leser wird aus der folgenden Darstellung die Ueberzeugung gewinnen, dass die cinfallenden Strahlen, welche zur Beleuchtung der Flächenelemente des Gesichtsfeldes beitragen, immer convergiren und dass irgend eine bestimmte Form beim Hohlspiegel ebensowenig als beim Planspiegel geboten ist. 
Basis $p$ ist. Die Intensität der Beleuchtung wird demnach, insofern die Spiegelfläche hinreichend ausgedelnnt ist, durch die Blendung $a b$ bedingt, weil hieron die Oeffnung des einfallenden Lichtkegels $m p n$ abhängt. Es ist aber vollkommen gleichgültig, ob die spiegelnde Fläche dem Gesichtsfeld näher oder ferner stehe; denn wenn auch die Lichtstärke eines Flächenelementes im quadratischen Verhältniss der Entfernung sich ändert, so wird im nämlichen Verhältniss auch die Zahl derselben grösser oder kleiner. Die Gesammtlichtmenge bleibt also nach wie vor dieselbe.

Es folgt auch aus dem Vorhergehenden, dass ein Hohlspiegel die Einstellungsebene gleich gut erhellt, mag sein Brennpunct in diese Ebene selbst oder ausserhalb dersel-

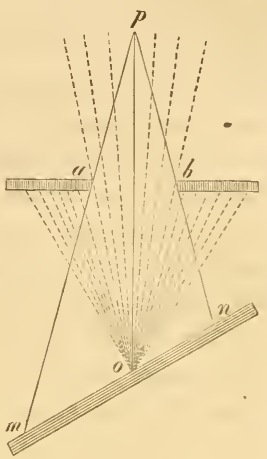

Figur 40. ben zu liegen kommen, jedoch immer unter der Voraussetzung, dass seine Oberfläche eine gewisse, durch die Blendung bestimmte Grenze der Kleinheit nicht überschreite. Da nämlich die Krümmung des Spiegels, wie oben gezeigt wurde, ohne allen Einfluss ist, so hat auch die Lage des Brennpunctes keinerlei optische Bedeutung.

Sehen wir jetzt zu, bis zu welchem Grade die Bedingung einer 80 unbegrenzten (d. h. über die durch die Blendung bestimmten Grenzen hinausgehenden) und gleichmässig leuchtenden Lichtquelle in der Praxis erfüllt wird. Ist das Mikroskop in der Nähe eines Fensters aufgestellt und der Spiegel gegen den hellen Himmel gekehrt, so hat man, um obiger Bedingung zum mindesten sehr annähernd Genüge zu leisten, bloss dafür Sorge zu tragen, dass die Strahlenbündel, welche die Beleuchtung des Gesichtsfeldes vermitteln, wenn man sie rückwärts zur Spiegelfläche und ron da nach der Lichtquelle verfolgt, diese letztere ohne Schwächung erreichen. Sind z. B. $p m$ und $p n$ (Fig. 41) zwei Grenzstrahlen, welche den Rand der Blendung $a b$ streifen, so werden dieselben von der ebenen Spiegelfläche $A B$ nach $s$ und $t$, von der concaven $C D$ nach $s^{\prime}$ und $t^{\prime}$ reflectirt, während der centrale Strahl po in beiden Fällen nach $r$ geht. Treffen nun die Strahlen $s$ und $t$ in der Wand $f f$ die nämliche Fensterscheibe, oder liegt ganz allgemein zwischen den Richtungen derselben kein Hinderniss, so werden auch alle zwischenliegenden Strahlen, welche zur Beleuchtung des Gesichtsfeldes beitragen, sich ohne Verlust nach 
der Lichtquelle, dem hellen Himmel, fortbewegen und folglich auch in umgekehrter Richtung ohne Verlust das Gesichtsfeld erreichen.

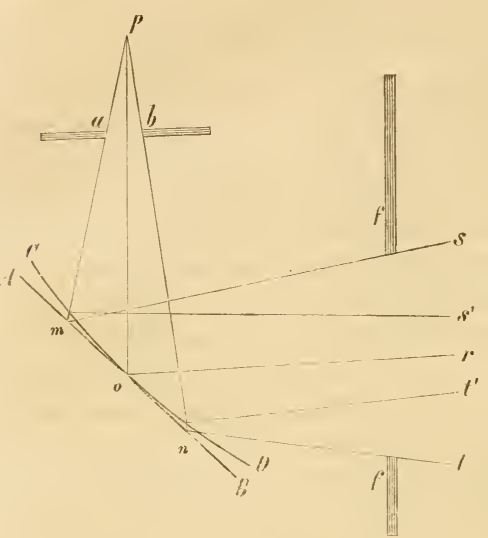

Figur 11. $\mathrm{Ob}$ sie auf diesem Wege, je nach der Krümmung des Spiegels, divergiren, convergiren oder parallel verlaufen, ist natürlich vollkommen gleichgültig, wofern nur ein hinreichend grosses Stück des Himmelsgewölbes gleichmässige Beleuchtung zeigt. Finden sich dagegen auf dem Wege zwischen dem Gesichtsfelde und der Lichtquelle irgend welche Hindernisse, welche unter den angenommenen Verhältnissen einen Lichtausfall herbeiführen, so erhalten Form und Stellung der Spiegelfläche ihre Bedeutung. Es wirkt alsdann diejenige Combination am günstigsten, welche das fragliche Hinderniss zu umgehen oder wenigstens den dadurch verursachten Verlust am vollständigsten zu vermeiden gestattet. Ist z. B. eine bestimmte Stelle am Himmel intensiver beleuchtet, als die benachbarten, so giebt ein Concavspiegel, welcher die von dort kommenden Lichtstrahlen in $p$ vereinigt, ein Maximum der Helligkeit. Ebenso wird für jede andere Lichtquelle von relativ geringer Ausdehnung, wie z. B. eine Lampenflamme, ein weisses Stück Mauer u. dgl., der Hohlspiegel mit Rücksicht auf Stärke der Beleuchtung den Vorzug verdienen, und zwar müsste derselbe stets so gestellt sein, dass Lichtquelle und Gesichtsfeld annähernd in conjugirten Vereinigungsweiten davon abständen.

Die Grösse des Spiegels kommt selbstverständlich erst dann in Betracht, wenn der Rand ganz oder zum Theil innerhalb der Grenze liegt, bis zu welcher seine Oberfläche bei gegebener Oeffnung der Blendung optisch wirksam sein könnte. Denken wir uns die Blendung ganz weg, so bildet die Spiegelfläche die Basis des einfallenden Lichtskegels, und die Oeffnung desselben wird dann um so grösser, je kleiner der Abstand vom Gesichtsfeld.

Alles das beruht, wie man sieht, auf den einfachsten Gesetzen 
der Optik. Es ist daher um so unbegreiflicher, wenn selbst in den neueren mikrographischen Werken von parallelem oder gar divergirendem Licht die Rede ist, welches je nach Umständen zur Beleuchtung des Gesichtsfeldes (d. h. doch wohl seiner Flächenelemente) verwendet werden soll. Das Licht, welches einen bestimmten Punct des Gesichtsfeldes erhellt, ist ja immer convergirend, d. h. die vom Spiegel ausgehenden Strahlen kreuzen sich in dem betreffenden Punct und divergiren von da aus gegen das Objectiv. Es scheint uns überflüssig, die gegentheilige Annahme hier ausführlicher zu widerlegen.

Was zweitens die verschiedenen Linsen und Linsensysteme be- $\mathbf{1}$ trifft, welche man irgendwo auf dem Wege des einfallenden Lichtes einzuschalten pflegt, so lässt sich leicht beweisen, dass sie ebenso wie die Form und Stellung des Spiegels nur in bestimmten praktischen Fällen Einfluss üben, dagegen in allen Fällen, wo Spiegel und Lichtquelle als unbegrenzt betrachtet werden dürfen, wirkungslos bleiben. Ist wieder $p$ (Fig. 12) ein Flächenelement des Gesichtsfeldes und $a b$ die Blendung, welche die Oeffnung des einfallenden Lichtkegels bestimmt, so verhält sich ganz allgemein die erste brechende oder reflectirende Fläche unterhalb der Blendung wie eine unbegrenzte Lichtquelle. Denn jeder Punct derselben empfängt aus allen in Betracht kommenden Richtungen Lichtstrahlen und sendet also auch solche nach allen

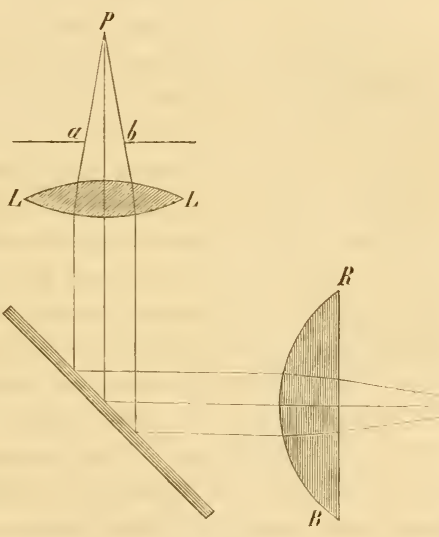

Figur 42 .

Richtungen aus. Dabei ist es vollkommen gleichgültig, ob die empfangenen Strahlenbündel auf geradem Wege oder erst nach verschiedenen Brechungen oder Reflexionen zu der fraglichen Fläche gelangen (abgesehen natürlich von den Verlusten, welche die Ablenkung bedingt), da die Richtungsverschiedenheit der einfallenden Strahlen wegen der Unbegrenztheit der eigentlichen Lichtquelle nicht in Betracht kommt. Wir können überhaupt jede beliebige Ebene unterhalb der Blendung, die Blendung selbst mit inbegriffen, als leuchtende Fläche betrachten, mag in derselben eine Ablenkung durch Brechung 
oder Reflexion stattfinden oder nicht. Tersetzen wir also einstweilen unsere leuchtende Fläche in das Niveau der Blendung, so wirkt jeder Punct der letzteren wie ein selbstleuchtender Punct, und die Beleuchtungsapparate $L L$ und $R R$ können offenbar keine andere Wirkung haben, als dass die Strahlen, welche zur Beleuchtung des Punctes $p$ beitragen, auf ihrem Wege zwischen der Blendung und der ursprünglichen Lichtquelle mehrere Ablenkungen erfahren, wie diess in der Figur durch den Verlauf der Linien veranschaulicht ist.

Anders gestalten sich die Verhältnisse, wenn die Oeffnung des einfallenden Lichtkegels durch den Spiegel bestimmt wird. Das Einschalten einer Sammellinse bewirkt in diesem Falle, wie man aus Fig. 13 ersieht, eine stärkere Convergenz der Strahlen und daher

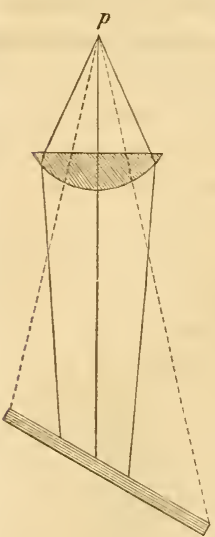

Figur 43. unter Umständen einen grösseren Oeffnungswinkel. Es ist nämlich immer möglich, die Stellung der Linse so zu wählen, dass der wirksame Lichtkegel, dessen Spitze in $p$ liegt, die ganze Linsenoberfläche zur Basis hat. Die Linse leistet alsdann genau dasselbe, wie eine im gleichen Niveau befindliche Blendungsöffnung, welche ihr Licht ron einer relativ unbegrenzten Spiegelfläche erhält. Sie giebt wie diese eine um so grössere Lichtstärke, je geringer ihr Abstand von der Einstellungsebene. Die Steigerung erreicht jedoch in beiden Fällen ihre Grenze, sobald die rückwärts construirten Randstrahlen die Peripherie des Spiegels treffen.

Diese Betrachtung findet natürlich auch auf den Fall Anwendung, dass die ursprüngliche Lichtquelle begrenzt, die spiegelnde Fläche dagegen unbegrenzt ist. Man braucht nur das erstere Wort für das letztere zu substituiren, um den vorstehenden Sätzen auch für diese Voraussetzung buchstäbliche Geltung zu geben. Sie lassen sich mutatis mutandis auch auf den gewöhnlich rorkommenden Fall ausdehnen, dass sowohl Lichtquelle als Spiegelfläche begrenzt oder doch ungleichmässig beleuchtet sind. Die grösstmögliche Lichtstärke, die sich durch Beleuchtungsapparate erzielen lässt, kann unter keinen Umständen diejenige übertreffen, welche ein hinreichend grosser Spiegel bei relativ unbegrenzter Lichtquelle für sich allein bieten würde.

82 Es folgt auch aus dem Vorhergehenden, dass wenn der Beleuchtungsapparat mit einer Blendung versehen ist, welche die Ungleichheit 
der Bedingungen für die verschiedenfarbigen Strahlen aufhebt, in dem Sinne, dass alle ohne Ausnahme, rückwärts construirt, zur Lichtquelle gelangen würden, irgend ein Unterschied zwischen achromatischen oder nicht achromatischen Linsensystemen unmöglich bestehen kann. Nur wenn die Lichtquelle eine so geringe Ausdehnung hätte, dass z. B. die blauen Randstrahlen dieselbe noch treffen, während die rothen bereits daneben fallen, oder umgekehrt; wenn es überhaupt nicht möglich wäre, die Beleuchtung so zu reguliren, dass die verschiedenfarbigen Strahlen von annähernd gleich hellen Puncten der Lichtquelle, z. B. des hellen Himmels, kommen und also rückwärts construirt auch solche treffen, dann würde allerdings ein achromatisches System den Vorzug verdienen. Da jedoch solche Beschränkungen in der Praxis, namentlich wenn das Instrument mit einem Hohlspiegel versehen ist, nur selten vorkommen und jedenfalls in den meisten Fällen vermieden werden können, dürfte die Herstellung achromatischer Beleuchtungsapparate so ziemlich überflüssig sein.

Die verschiedenen Beleuchtungsapparate sind also nach dem Angeführten nur nach zweierlei Richtungen wirksam: sie geben dem Lichtkegel, welcher ein bestimmtes Flächenelement des Gesichtsfeldes erhellt, eine im ganzen Querschnitt gleiche Intensität und vergrössern zweitens dessen Oeffnungswinkel. Was man sonst über ihren Einfluss angegeben findet, wie z. B. dass sie die Interferenzlinien am Rande der Objecte zum Verschwinden bringen und schwierige Details um so besser auflösen, je vollständiger die Aberrationen beseitigt seien u. dgl., ist pure Einbildung. Bei gleicher Blendung und gleicher Brennweite wird eine beliebige Sammellinse stets dieselben Dienste thun, wie das complicirteste Linsensystem, wofern nur die Durchmesser der brechenden Flächen und des Spiegels für alle Farben der Grösse der Blendung entsprechen. Unter dieser Voraussetzung muss auch der Oeffnungswinkel des einfallenden Lichtkegels um so grösser werden, je kleiner der Abstand der Blendung von der Einstellungsebene. Dabei ist es völlig gleichgültig, ob der Brennpunct des Beleuchtungsapparates in die Einstellungsebene falle oder nicht. Seine Lage gewinnt nur dadurch eine praktische Bedeutung, dass bei zu grosser Annäherung an das Objectiv die rückwärts construirten Randstrahlen die Spiegelfläche nicht mehr treffen, und folglich allerdings das Maximum der Lichtstärke nahezu erreicht ist, wenn das vom Beleuchtungsapparat entworfene Bild entfernter Gegenstände im Gesichtsfelde erscheint.

Soll der Beleuchtungsapparat allen Anforderungen genügen, so 83 
muss er ausser der Blendung über der letzten brechenden Fläche, wodurch seine Oeffnung bestimmt wird, auch mit Vorrichtungen ausgestattet sein, welche einen beliebigen Theil des Lichtkegels verfinstern. Manche Objecte treten nämlich am deutlichsten hervor, wenn die Centralstrahlen rom Gesichtsfelde abgehalten werden; andere wieder deutlicher, wenn nur einseitig geneigte Strahlen zur Beleuchtung beitragen. Um also die Beleuchtung nach Bedürfniss zu regeln, ist es nothwendig, ausser der gewöhnlichen Blendung auch solche anzubringen, welche die Mitte der Oeffnung oder einen grösseren oder kleineren Abschnitt derselben verdecken. Man könnte diess am einfachsten bewerkstelligen, indem man auf dem Ring der gewöhnlichen Blendung (oder auf der Blendungsscheibe) noch einen drehbaren Kreissector oder ein Rad anbrächte und daran grössere und kleinere Scheibchen befestigte, die dann nach Belieben über die Blendungsöfnung vorgeschoben werden könnten. Auch kleinere Schieber, wie sie gewöhnlich an Fernröhren zum Schutze der Oculare angebracht sind, oder Stopfenblendungen wie beim Wenham'schen Paraboloid, können unter Umständen zweckdienlich sein. Es ist übrigens ziemlich einerlei, in welcher Weise man die gewünschte Beleuchtung erzielt ; nur ist es aus den oben angeführten Gründen rathsam, die fraglichen Vorrichtungen über dem Beleuchtungsapparat, nicht unter demselben, wie es öfter geschieht, anzubringen.

84 Die sogenannte schiefe Beleuchtung, welche man in neuerer Zeit häufig anwendet, um schwierige Einzelheiten zu erkennen,

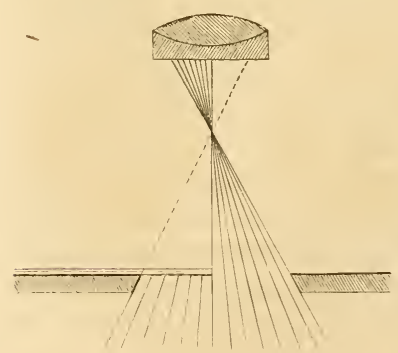

Figur 44 . setzt einen einfallenden Lichtkegel voraus, dessen Axe gegen diejenige des Mikroskops mehr oder weniger geneigt ist. Ein solcher Lichtkegel wird natürlich schon dadurch hergestellt, dass man ohne weitere Hülfsmittel den Spiegel oder die Blendung etwas seitlich rückt; er kommt auch dadurch zu Stande, dass man, ohne den Spiegel oder die Blendung aus ihrer Lage zu bringen, einen 'Theil der Blendungsöffnung vom Rande her zudeckt, so dass z. B. bloss die Hälfte des ursprünglichen Lichtkegels wirksam bleibt (Fig. 44). Es leuchtet ein, dass wenn der Oeffnungswinkel der Blendung demjenigen des Objectivs gleich wäre und eine Ablenkung im Gesichtsfelde nicht stattfände, 
nach dieser letzteren Methode jede überhaupt mögliche schiefe Beleuchtung hergestellt werden könnte. Da jedoch die erstere Bedingung gewöhnlich nicht erfüllt wird (die Blendung besitzt fast immer eine relativ kleinere Oeffnung) und die letztere nicht erfüllt werden kann, so mag es in manchen Fällen einigen Vortheil gewähren, wenn der Beleuchtungsapparat selbst um eine horizontale Axe drehbar und somit geeignet ist, Lichtstrahlen von beliebiger Neigung zu liefern. Sehr hoch möchten wir indess den Werth solcher Vorrichtungen gerade nicht anschlagen. Eine seitlich rerschiebbare Blendung, wie sie die meisten neueren Mikroskope besitzen, wird - mit einer entsprechenden Spiegelstellung combinirt - in den meisten Fällen ganz dieselben Dienste thun.

\section{Belenchtnng mit anffallendem Licht.}

Die Beleuchtung undurchsichtiger Gegenstände von oben gewährt 85 den Vortheil, dass dadurch die mikroskopische Wahrnehmung dem Sehen mit blossem Auge ähnlicher wird, indem das schliessliche Bild auf der Netzhaut in beiden Fällen von Strahlen herrührt, die an der Oberfläche der Körper reflectirt werden. Eine vollkommene Uebereinstimmung besteht aber desswegen noch lange nicht, da Schatten und Licht für das bewaffnete Auge wegen der grösseren Oeffnung der wirksamen, rom Objecte ausgehenden Lichtkegel sich ceteris paribus stets anders vertheilen, als für das unbewaffnete. Mit diesem Unterschied in der Grösse der Oeffnungswinkel hängt denn auch die Schwierigkeit zusammen, für jeden Lichtkegel, der vom Objectpunct zum Objectiv gelangen soll, den entsprechenden einfallenden zu liefern, d. h. die Beleuchtung so $\mathrm{zu}$ regeln, dass wenn man die Lichtbündel rückwärts construirt, jeder Strahl die gegebene Lichtquelle trifft. Ist z. B. $A B$ (Fig. 45) die Oberfläche eines Körpers mit halbkugelförmigen Erhabenheiten und gh der optisch wirksame Theil

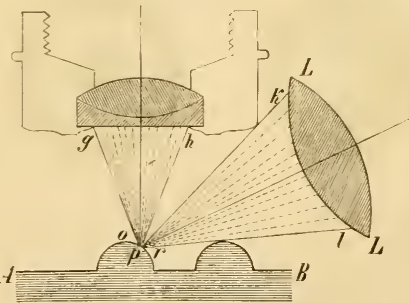

Figur 45. des Objectirs, so wird der nach $p$ zielende Lichtkegel $g h p$, wie die Construction ergiebt, so reflectirt, dass seine Randstrahlen die Richtungen $p k$ und $p l$ einschlagen. Sie streifen also unter den in der Figur gegebenen Dimensionsverhältnissen einerseits die Oberfläche des Kör- 
pers und andererseits den Rand des Objectivs und erreichen auf diesem Wege durch das Fenster des Beobachtungszimmers die unbegrenzte Lichtquelle, den hellen Himmel. Allfällige Hindernisse, welche der Fortpflanzung des Lichtes entgegenstehen, können durch Einschalten einer Sammellinse ( $L L$, in obiger Figur) oder eines Hohlspiegels, der hier ganz dieselben Dienste thut, wie bei durchfallendem Licht, umgangen werden. Alle zwischenliegenden Strahlen gelangen natürlich ebenfalls zur Lichtquelle und folglich auch in umgekehrter Richtung von dieser zum Objectiv. Der Punct $p$ wird also durch einen vollen Lichtkegel beleuchtet, dessen Oeffnung derjenigen des Objectivs gleichkommt.

Denken wir uns jetzt ähnliche Lichtkegel nach den Puncten rechts und links von $p$ construirt, so ist ohne Weiteres klar, dass dieselben nur theilweise zur Lichtquelle gelangen, da ein anderer Theil entweder nach dem Objectiv oder nach Puncten der Körperoberfläche reflectirt wird. Die gedlachten Lichtkegel kommen also in Wirklichkeit nur theilweise zu Stande. Die Verluste werden um so grösser, je mehr wir uns einerseits dem Scheitel $o$ und andererseits dem Rand der Halbkugel nähern. In $o$ muss unter allen Umständen vollkommene Dunkelheit eintreten, weil der einfallende Lichtkegel mit dem reflectirten zusammenfällt; ebenso ist für den rechts von $p$ gelegenen Punct $r$ unter den angenommenen Verhältnissen eine Beleuchtung unmöglich, da alle in $r$ reflectirten Strahlen neben den wirksamen Theil des Objectivs fallen. Die Halbkugel erscheint also nur in der
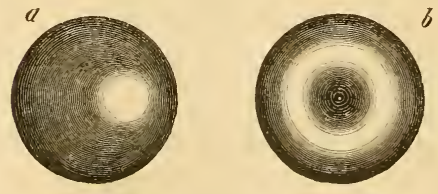

Figur 46. Umgebung von $p$ hell (Fig. $46 \mathrm{a})$, und selbst wenn die Lichtquelle für alle gleichweit von $o$ abstehende Puncte dieselbe Intensität besässe - was in der Praxis nicht der Fall ist, da das Licht seitlich einfällt - würde diese helle Stelle sich nur als schmale kreisförmige Zone darstellen (Fig. $46 \mathrm{~b}$ ).

Wir werden weiter unten, wo es sich um die Theorie der mikroskopischen Wahrnehmung handelt, die Vertheilung von Licht und Schatten für einige Körperformen genauer zu bestimmen suchen ; hier sollte bloss gezeigt werden, dass eine solche Beleuchtung im Allgemeinen nicht günstig sein kann, um sich über die Formverhältnisse eines gegebenen Objects zu orientiren, da schon bei mässiger Oeffnung des Objectivs ein grosser Theil der Oberfläche in den Kern-oder 
Halbschatten fällt. Sie findet auch in der Regel nur Anwendung, wenn die Vergrösserung nicht viel über 100-120 Mal steigt, so dass die Oeffnung des einfallenden Lichtkegels (kpl in Fig. 45) bedeutend grösser ist, als diejenige des Objectivs. Das Einschalten einer Sammellinse gewährt alsdann, wie beim durchfallenden Licht, den praktischen Vortheil, dass die Herstellung eines solchen Lichtkegels noch möglich ist, wemn das Mikroskop auch zicmlich weit vom Fenster aufgestellt wird, insofern nur die Brennweite der Linse im Verhältniss zum Durchmesser derselben nicht zu gross ist. Dass übrigens ein aequivalenter Hohlspiegel oder ein Selligue'sches Prisma (rechtwinkliges Prisma, dessen beide unter dem rechten Winkel zusammenstossende Flächen convex geschliffen sind) ganz dasselbe leistet, was eine Beleuchtungslinse, ist an und für sich klar. Doch dürfte die letztere in den meisten Fällen aus rein praktischen Rücksichten den Vorzug verdicnen.

Der angedeutete Uebelstand, dass bei dieser Beleuchtung der 86; grössere Theil der Körperoberfläche in den Schatten fällt, lässt sich übrigens bis auf einen gewissen Grad beseitigen. 1)a nämlich die Vertheilung ron Licht und Schatten im mikroskopischen Bilde einzig und allein von der Lage und Oeffnung des einfallenden Lichtkegels abhängt (das Objectivsystem wird als gegeben betrachtet), so ist es möglich, durch geschickte Verwendung spiegelnder Flächen dem erhellten Theile des Bildes eine grössere Ausdehnung zu geben. Ist 7. B. das Fenster des Arbeitszimmers oder die Beleuchtungslinse die (secundäre) Lichtquelle, so wirkt ein gewöhnlicher Spiegel, welcher auf der entgegengesetzten Seite der Mikroskopröhre in geeigneter Stellung dem Lichte zugewendet wird, wie eine Verdoppelung dieser Lichtquelle. Ein kugelförmiger Körper, welcher bei einseitiger Beleuchtung eine einzige excentrische Lichtstelle zeigt, erhält auf diese Weise deren zwei; ebenso kommt zu der Lichtlinie, welche ein parallel mit dem Fenster verlaufender Metalldraht entwirft, in Folge der Spiegelung eine zweite symmetrische hinzu. Stände das Mikroskop in einem geschlossenen Halbkreis von Spiegeln und nahe am Fenster, so müsste der Lichteffect annähernd derselbe sein, wie wenn es unter freiem Himmel oder in einem Glashaus mit unbeschränktem Seitenund Oberlicht aufgestellt wäre. Eine ähnliche Wirkung, wenn auch nicht eine vollkommen aequivalente, müsste auch ein kleiner cylindrischer oder im Querschnitt parabolischer Hohlspiegel hervorbringen, welcher am untern Ende des Objectivs so befestigt wäre, dass das von ihm entworfene Bild des Fensters im Focus des Mikroskops zu Stande 
käme. Man könnte, um seine Wirkung noch etwas zu steigern, demselben auch in der Richtung der Axe eine entsprechende Krümmung

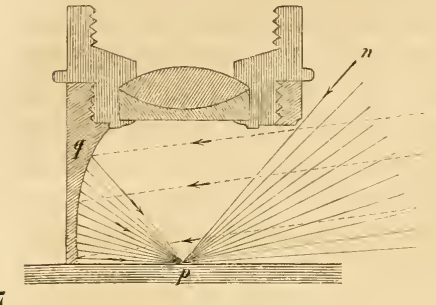

Figur 47 . geben, wie diess in Fig. 47 veranschaulicht ist. Der Objectpunct $p$ würde auf diese Weise so beleuchtet, als wäre derselbe in die Strahlung des ganzen Himmelsgewölbes, mit Ausnahme der durch den Winkel $q p n$ bestimmten Scheitelregion eingetaucht.

Ein solcher Beleuchtungsapparat ist unseres Wissens nie hergestellt worden. Das Wenham's che Paraboloid*) und einige andere Apparate, welche besonders in England Verbreitung gefunden haben, sind nur insofern mit ihm verwandt, als das Licht, welches zur Beleuchtung beiträgt, ebenfalls seitlich oder von allen Seiten, aber nur innerhalb gewisser, ziemlich eng gezogener Grenzen der Neigung einfällt. Dagegen besitzen wir in dem Lieberkühn'schen Spiegel gewissermassen sein Gegenstück, indem derselbe gerade die dem Winkel $q p n$ entsprechende Strahlung herstellt und also denjenigen Theil des Himmelsgewölbes repräsentirt, der in unserem Falle ausgeschlossen war. Diese Wirkung wird durch ein in der Mitte durchbrochenes Concavspiegelchen erzielt, welches mittelst seiner Fassung so an das Objectiv angeschraubt wird, dass der wirksame Theil der Objectivlinse die Oeffnung des Spiegels ausfüllt und so die reflectirende Fläche wieder vervollständigt $\left.{ }^{* *}\right)$. Als Lichtquelle dient der gewöhnliche Be-

*) Das Wenham'sche Paraboloid ist ein nach unten gekehrter und am Scheitel durchbrochener parabolischer Spiegel, welcher nach Art einer Cylinderblendung in den Objecttisch eingeschoben wird. Soll derselbe auffallendes Licht liefern (er wurde zunächst für durchfallendes construirt), so bringt man das zu beleuchtende Object in ein starkbrechendes Medium (Terpentinöl, Canadabalsam u. dgl.) und bedeckt es mit einem Deckglas. Alsdann erfahren die rom Spiegel kommenden Randstrahlen, welche unter einem Winkel ron c. $42^{\circ}$ und darüber einfallen, an der Oberfläche des Deckglases eine totale Reflexion und bilden nun einen nach oben geöffneten Strahlentrichter, dessen Spitze bei richtiger Einstellung des Apparates die Oberfläche des Objectes trifft.

**) Die Spiegelung der Objectivlinse ist so beträchtlich, dass das von ihr entworfene Schattenbild eines Quecksilbertropfens in diesem letzteren selbst wieder ein verkleinertes Bildchen herrorruft, das mikroskopisch noch deutlich wahrnehmbar ist. 
leuchtungsspiegel, welcher durch eine weite Oeffnung im Objecttisch das Licht nach oben wirft, wobei natürlich die Strahlen, welche von unten auf das Object selbst fallen, abgehalten werden. Dic Krümmung des Concavspiegelchens muss dem entsprechend eine solche sein, dass die von den Objectpuncten rückwärts construirten Strahlenbündel auf den Beleuchtungsspiegel fallen, was nur möglich ist, wenn die Brennpuncte des Spiegelchens und des Objectivs cinander nahe liegen oder zusammenfallen; das letztere ist übrigens keineswegs nothwendig.

Soll der Gegenstand sich auf einem dunkeln oder beliebig gefärbten Grunde abzeichnen, so wird er auf eine entsprechende undurchsichtige Unterlage gelegt, welche so gross ist, dass sie das ganze Gesichtsfeld ausfüllt. Das Festhalten des Objectes mit oder ohne Unterlage geschicht durch einen geeigneten Halter oder einfach durch Auflegen auf eine Glasplatte.

Die Wirkung des Lieberkühn'schen Spiegels steht zur Belenchtung durch seitlich einfallendes Licht in demselben Gegensatz, wie in öffentlichen Gebäuden (Kunstgalerien ctc.) das reine Oberlicht zum gewöhnlichen Seitenlicht. Während das letztere an jedem Gegenstande und an jeder Erhabenheit eine Licht- und eine Schattenseite hervorhebt, drängt das erstere den Schatten auf die dem Auge abgewendete Seite zurück, so dass der sichtbare Theil der Körper ziemlich gleichmässig beleuchtet erscheint. 


\section{Zweiter Abschnitt. \\ Die mechanische Kinrichtung des Mikroskops.}

88 Wenn wir der mechanischen Einrichtung des Mikroskops einen besonderen Abschnitt widmen, so geschieht diess vorzugsweise, um auch dem Leser, welchem andere mikrographische Werke nicht zu Gebote stehen, gerecht zu werden. Wir beschränken uns dabei auf eine kurze Darlegung der Grundsätze, welche in den verschiedenen Werkstätten in diesem Betreff befolgt werden, und eine darauf folgende Beschreibung der Mikroskopgestelle, wie sie gegenwärtig von den namhafteren Optikern geliefert werden.

\section{I.}

\section{Allgemeine Regeln für die Construction der Stative.}

Die Einstellung. Das Stativ des zusammengesetzten Mikroskops hat zunächst den Zweck, das Objectiv in die richtige Entfernung vom Object zu bringen und darin unverrückt festzuhalten. 'Zu diesem Behufe muss dasselbe mit Torrichtungen ausgestattet sein, welche sowohl die grösseren Distanzyeränderungen, wie sie z. B. beim Wechsel der Objective nothwendig sind, als auch die feinere Einstellung auf ein gegebenes Niveau erlauben. Der Mechanismus dieser Vorrichtungen lässt drei Modificationen zu, ron denen jede in sehr verschiedener Weise Anwendung findet. Die Einstellung geschieht nämlich a) durch Bewegung der Mikroskopröhre gegen den feststehenden Objecttisch, auf welchem der zu untersuchende Gegenstand liegt, oder b) durch Bewegung des Objecttisches gegen die unbewegliche Mikroskopröhre, oder auch c) durch eine Combination beider Bewe- 
gungen, wobei gewöhnlich die Mikroskopröhre für die gröbere und der Objecttisch für die feinere Einstellung gewählt wird. Jede dieser Modificationen bietet natürlich ihre Vor- und Nachtheile, und es ist zum Theil eine Sache der individuellen Beurtheilung, wie man dieselben gegen einander abwiegt. Mohl spricht sich entschieden gegen jede Bewegung des Objecttisches aus, weil das so störende Schlottern desselben bei längerem Gebrauch sonst nicht zu vermeiden sei, und weil das nach seinem Dafürhalten unentbehrliche Schraubenmikrometer nur an einem durchaus feststehenden Tische hinreichend sicher befestigt werden könne. Der erste Grund ist jedenfalls beachtenswerth; der letztere will uns bei der geringen Verbreitung der Srhraubenmikrometer weniger einleuchten. Auf der andern Seite ist mit der Unbeweglichkeit der Mikroskopröhre der Vortheil verbunden, dass der Kopf beim Gebrauch verschiedener Objective immer in gleicher Höhe gehalten werden kann, während seine Lage im entgegengesetzten Fall von der Vergrösserung abhängt. Indess sind die Niveaudifferenzen, welche die Einstellung mit sich bringt, nur mit Rücksicht auf die allerschwächsten Objective als Uebelstand zu betrachten, und auch hier kann derselbe durch entsprechende Verkürzung des Rohres beseitigt werden. Der triftigere Grund spricht also immerhin zu Gunsten der vollständigen Unbeweglichkeit des Objecttisches in der Richtung der Mikroskopaxe.

Die gröbere Einstellung wird entweder durch einen Trieb, der wieder in sehr verschiedener Weise angebracht sein kann, orler durch Verschieben der Mikroskopröhre in einer etwas federnden Hülse mittelst der Hand bewerkstelligt. Die erstere Art der Bewegung findet sich z. B. bei den Stativen von Plössl und Amici und bei den englischen Instrumenten, die letztere bei der grossen Mehrzahl der deutschen und französischen Mikroskope. Die Hülse hat vor dem Trieb die grössere Einfachheit und die sanftere Bewegung voraus; allein bei längerem Gebrauche nützen sich die Berührungsflächen allmählich ab und bedecken sich gleichzeitig in Folge der Oxydation mit Schmutz. Die Röhre schiebt sich alsdann zu leicht oder zu schwer, je nachdem sie blank geputzt oder angelaufen ist. Indess kann dem Uebelstand, dass dieselbe sich durch ihr eigenes Gewicht senkt, durch schwaches Zusammendrücken der Hülse leicht abgeholfen werden.

$\mathrm{Der} \mathrm{Objecttisch}$ soll hinreichend gross mindestens $2 \frac{1}{2}-3 \mathrm{Zoll} 90$ im Durchmesser, eben und, wie schon erwähnt, möglichst fest sein. Vorstehende Schraubenköpfe, festsitzende Federklammern u. dgl. erweisen sich immer als unpraktisch, weil sie das Auflegen grösserer 
Glasplatten und das Verschieben derselben in der Einstellungsebene hindern. Dagegen ist die Form des Tisches, ob rund oder viereckig, ziemlich gleichgültig; auch möchten wir gerade kein grosses Gewicht darauf legen, ob seine Oberfläche schwarz angestrichen sei oder nicht, da der Glanz des Metalls sich ohnehin bald verliert und das falsche Licht, welches namentlich bei Anwendung schwacher Vergrösserungen nicht selten in störender Weise ins Mikroskop geworfen wird, doch vorzugsweise vom Oljjecttrïger herrührt. Wo die Sicherheit der Beobachtung schon durch geringe Mengen reflectirten Lichtes beeinträchtigt wird, muss dasselbc trotz des schwarzen Anstriches durch Vorhalten der Hand oder durch eine passende Vorrichtung ausgeschlossen werden.

Die Oeffnung des Objecttisches muss selbstrerständlich wenigstens so gross sein, als das Gesichtsfeld des schwächsten Objectirs. Da jedoch für manche Untersuchungen eine viel kleinere Oeffnung, für andere eine sehr grosse von wenigstens 1 Zoll Durchmesser wünschenswerth ist, so dürfte es am zweckmässigsten sein, dem Objecttisch selbst eine grosse Oeffnung zu geben und dieselbe durch in der Nitte durchbohrte Scheiben, die von oben in eine entsprechende Vertiefung des Tisches eingelassen werden, auf den gewünschten Umfang zu reduciren. Solche Vertiefungen sind anch für andere Zwecke, z. B. zum Auflegen der Gypsplättchen bei Untersuchungen im polarisirten Lichte, sehr bequem.

Ein Schlitten an der Unterfläche des Tisches gewährt den Vortheil, dass mit demselben der ganze Blendungsapparat nach Belieben seitlich gerückt oder auch ganz entfernt werden kann, was namentlich bei manchen physikalischen Untersuchungen sehr praktisch ist.

Grössere Stative werden zweckmässig so eingerichtet, dass der Tisch mit dem ganzen oberen Theil des Mikroskops um dessen optische Axe drehbar ist, indem es dadurch möglich wird, das schief einfallende Licht unter jedem beliebigen Winkel auf das Object wirken zu lassen. Diese Einrichtung, welche wir O berhä user verdanken, findet sich gegenwärtig fast bei allen grösseren Mikroskopen. Bei kleineren Gestellen kann dieselbe auch durch eine auf dem Objecttisch befestigtc drehbare Scheibe ersetzt werden, welche jedoch für die stärkeren Vergrösserungen mit einer besonderen Vorrichtung zur Centrirung ausgestattet sein muss. Da nämlich die geringste Excentricität der Drchungsaxe Ortsveränderungen des Objectes während der Drehung zur Folge hat, die sich leicht bis zum Verschwinden aus dem Gesichtsfelde steigern, und andererseits die optischen Axen der 
verschiedenen Objective nie genau in der nämlichen Verticale liegen, so ist es absolut unmöglich, die Scheibe ein für allemal richtig zu placiren; sie muss daher innerhalb gewisser Grenzen rechtwinklig versehoben werden können. Diese Verschiebbarkeit ist auch noch in anderer Beziehung von Nutzen; sie erleichtert bei mikrometrischen und Winkelmessungen die genaue Einstellung eines 'Theilstriches oder des Fadenkreuzes auf einen bestimmten Punct und leistet dadurch namentlich bei krystallographischen Untersuchungen wesentliche Dienste. $\mathrm{Zu}$ empfehlen ist indess, diese Scheibe so anzubringen, dass sie nach Belieben aufgesetzt oder weggenommen werden kann.

Der Beleuchtungsapparat. Nach dem, was oben über die $\mathbf{9 1}$ Beleuchtung gesagt wurde, kann dieselbe nach zwei Richtungen verschieden sein, nämlich a) mit Rücksicht auf dic Oeffnung der einfallenden Lichtkegel und b) mit Rücksicht auf die Neigung derselben. Ein vollständiger Beleuchtungsapparat muss folglich in diesen beiden Puncten jede wünschbare Modification gestatten.

In den meisten Fällen genügt dieser Anforderung schon ein Planoder Hohlspiegel von gewöhnlicher Grösse, wenn derselbe dem Object hinreichend genähert und überdiess seitlich verstellt werden kann. Ist das so erzielte Licht noch zu schwach, so kann die Convergenz der Strahlen durch Beleuchtungslinsen gesteigert werden. Die Begrenzung der einfallenden Lichtkegel geschieht in beiden Fällen durch Blendungen, welche unter dem Objecttisch befestigt oder in denselben eingesenkt sind.

Grössere Instrumente sind gewöhnlich mit Plan- und Hohlspiegel in gemeinsamer Fassung ausgerüstet und lassen jede beliebige Bewegung derselben im Raume oder wenigstens in der Verticalebene zu; kleinere besitzen gewöhnlich nur einen Hohlspiegel, welcher um seinen eigenen Mittelpunct drehbar und zuweilen in der Richtung der Axe verschiebbar ist, - eine Vereinfachung, welche insofern zulässig erscheint, als die schiefe Beleuchtung doch nur in bestimmten Fällen Wichtigkeit erlangt und dann durch besondere Vorrichtungen erzielt werden kann. Dagegen ist eine noch weiter gehende Beschränkung der Spiegelbewegung, wie wir sie z. B. bei den kleinen Oberhäuser'schen Instrumenten finden, unter Umständen mindestens unbequem zu nennen.

Im Betreff der Apparate zur Beleuchtung opaker Gegenstände verweisen wir auf das oben Mitgetheilte.

Die Blendungen. Es ist an und für sich klar, dass eine kleine 92 Blendungsöffnung, welche beispielsweise um einen Millineter von 
der Einstellungsebene absteht, die einfallenden Lichtkegel in gleicher Weise begrenzt, wie eine Oeffnung von doppeltem Durchmesser bei doppeltem Abstand. Theoretisch ist es also rollkommen gleichgültig, in welcher Weise und in welchem Niveau zwischen Spiegel und Object die Blendungen angebracht werden, wenn nur die Grösse der Ocffnung zu ihrem Abstand vom Object in dem gewünschten Verhältnisse steht. Die Praxis stellt jedoch die weitere Anforderung, dass der Blendungsapparat leicht und bequem zu handhaben sei, dass er ohne das Object zu verschieben die verschiedensten Nüancirungen der Beleuchtung gestatte und überdiess alles fremde Licht, welches vom Arbeitstisch oder Stativ reflectirt wird, vollständig ausschliesse. Um diess zu erreichen, brachte man früher drehbare Scheiben mit grösseren und kleineren Oeffnungen unter dem Objecttisch an, welche zuweilen auch in senkrechter Richtung verschiebbar waren. Die Oeffnungen sind so geordnet, dass sie beim Drehen nach einander in die Axe des Mikroskops fallen und also nach Belieben benutzt werden können. Wir finden, dass eine solehe Vorrichtung, richtig construirt, dem beabsichtigten Zweck in befriedigender Weise entspricht; nur darf dieselbe nieht zu weit vom Objeetträger abstehen.

Neben diesen Drehscheiben kamen in neuerer Zeit die durch Oberhäuser eingeführten $\mathrm{C}_{\mathrm{y}}$ linderblendungen mehr und mehr in Gebrauch. Es sind diess cylindrische Röhren mit gleichgeformter oder kegelförmiger Höhlung, welche nach oben in die grössere oder kleinere Blendungsöffnung übergeht; sie werden gewöhnlich einem ähnlich gestalteten grösseren Cylinder, der sich in einer Hülse auf und nieder schieben lässt, aufgesetzt. Die Cylinderblendungen vereinigen alle Vorzüge der Drehscheiben und bieten überdiess die Annehmlichkeit, dass die Blendungsöffnung dicht unter die Objectplatte zu liegen kommt, wodurch das zeitraubende Suchen kleiner Gegenstände wesentlich erleichtert wird.

Die Vorrichtungen zum Abhalten der Centralstrahlen übergehen wir hier, da dieselben bereits früher Erwähnung gefunden. Auch auf die Beschreibung der complicirteren Blendungsapparate, wie sie manche englische Instrumente besitzen, glauben wir füglich verzichten zu dürfen.

93 Das Fussgestell. Dasselbe hat vor Allem die Bestimmung, dem ganzen Instrument die nöthige Stabilität zu geben; es darf also nicht zu klein und nicht zu leicht sein. Seine Form kommt nur insofern in Betracht, als bei gleicher Zweckmässigkeit verschiedener Gestelle das bequemere und compendiösere den Vorzug verdient. Als 
Mustermodell darf wohl in dieser Hinsicht das Hufeisenstativ von Oberhäuser bezcichnet werden, welches mit grosser Solidität auch den Vortheil verbindet, dass der Beleuchtungsspiegel bis auf das Niveau des Arbeitstisches gesenkt werden kann, wodurch der nöthige Raum für andere Vorrichtungen gewonnen wird, die man allenfalls unter dem Objecttische anbringen will. Weniger bequem, weil nur für centrische Beleuchtung eingerichtet, jedoch bei kleineren Instrumenten vollkommen ausreichend, ist das sogenannte Trommelstativ Oberhäusers, welches auf einer mit Blei ausgegossenen Scheibe ruht, die mit dem Objecttisch durch eine cylindrische, vorn offene Röhre von gleichem Durchmesser verbunden ist. Andere Optiker verbinden ähnliche Scheiben durch eine oder zwei Säulen mit dem Objecttisch und dem ganzen oberen Theil des Stativs; noch andere geben dem Fuss die Form eines Dreizacks, dessen Arme bald feststehen, bald zum Zusammenlegen eingerichtet sind u. s. w. Kleine Instrumente, namentlich die sogenannten Reise- und Taschenmikroskope, werden zweckmässig so construirt, dass das Stativ auf den Deckel des Kästchens, welches zur Aufnahme desselben dient, aufgeschraubt werden kann. Für den täglichen Gebrauch möchten wir indess eine solche Einrichtung nicht empfehlen.

Länge und Stellung der Mikroskopröhre. Die meisten 94 neueren Optiker auf dem Continent geben der Mikroskopröhre von der Vorderfläche des Objectivs bis zur Endfläche des Oculars eine Länge von c. $200-220^{\mathrm{m} \cdot \mathrm{m}}$, so dass die Gesammthöhe des Instruments

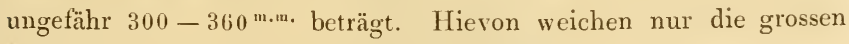
Mikroskope von Plössl und seiner Nachahmer (Pistor, Schiek) wesentlich $a b$, indem dieselben durch die ansehnliche Tubuslänge von c. $300^{\mathrm{m} . \mathrm{m} .}$ eine Höhe von c. $450^{\mathrm{m} m}$. erhalten, so dass man bei gewöhnlicher Tischhöhe nur stehend damit arbeiten kann. Auch die englischen Instrumente, die wir übrigens nicht näher kennen, scheinen sich im Allgemeinen durch eine beträchtlichere Grösse auszuzeichnen, - nach unserem Dafürhalten gerade kein Vorzug.

Bei den grossen Stativen ist zuweilen die Einrichtung getroffen, dass das Mikroskoprohr mit dem Objecttisch um eine horizontale Axe gedreht und also beliebig geneigt werden kann. Damit soll zunächst eine bequemere Haltung des Kopfes, sodann eine horizontale Stellung der Mikroskopröhre für gewisse Untersuchungen ermöglicht werden. Uns scheinen jedoch diese Vortheile durch die Unbequemlichkeit, welche die Neigung des Objecttisches mit sich bringt, mehr als aufgewogen zu werden. Wo eine horizontale Stellung der Mikro- 
skopröhre geboten ist, was doch im Ganzen selten vorkommt, lässt sich dieselbe ganz einfach herstellen, indem man das Instrument umlegt. Die Hufeisenstative eignen sich sogar vortrefflich hiezu, da die beiden Enden des Hufeisens mit dem Objecttisch einen schweren Drrifues bilden.

95 Sollen wir die wichtigsten Eigenschaften eines guten Stativs zusammenstellen, so verdient die solide und compendiöse Messingarbeit, ein fester, hinreichend grosser Tisch, ein um seinen Mittelpunct frei beweglicher Beleuchtungsspiegel mit einer ebenen und einer concaven Spiegelfläche und eine zweckmässige Blendungsvorrichtung zuerst hervorgehoben zu werden. Die Verschiebbarkeit des Spiegels nach seitwärts und in senkrechter Richtung die übrigens bei den meisten Instrumenten leicht einzurichten ist), namentlich aber die Drehbarkeit des Tisches um die Mikroskopaxe möchten wir erst in zweite Linie stellen; es sind diess Eigenschaften, die man nöthigenfalls auf einfache Weise ersetzen kann, erstere durch Anwendung einer zur Hälfte bedeckten, ziemlich starken Linse oder eines Condensors statt der Blendung, letztere durch die viel wohlfeilere drehbare Scheibe auf dem Objecttisch. Wo indess die Form des Stativs die Herstellung einer möglichst freien Bewegung des Spiegels gestattet, ist dieselbe um so eher zu empfehlen, als das Mikroskop dadurch fast gar nicht vertheuert wird. Alle übrigen Eigenschaften und Vorrichtungen endlich, welche im Vorhergehenden erwähnt wurden, sind untergeordneter Natur und können bei den meisten Untersuchungen entbehrt werden.

\section{II.}

\section{Die Stative der neueren Optiker.}

Wir gehen nun an die Beschreibung der bekannteren Stativformen, welche gegenwärtig von den namhafteren Mikroskopverfertigern geliefert werden.

E. Hartnack (Nachfolger von G. Oberhäuser) in Paris. Das grosse $\mathrm{Hufeisenstativ} \mathrm{von} \mathrm{Oberhäuser} \mathrm{(Fig.} \mathrm{18),} \mathrm{welches}$ Hartnack ohne wesentliche Abänderungen beibehalten und mancher andere Optiker mehr oder weniger modificirt angenommen hat, wurde bereits oben als wahres Musterstativ bezeichnet. Es verdient diese Benennung, weil es, wie kein anderes, den Vorzug grösster Zweckmässigkeit mit einfacher Construction verbindet. Die grobe Einstellung 
geschieht durch Verschicbung des Rohres in einer Hülse, die feinere durch eine Mikrometerschraube, welche diese Hülse hebt und senkt. Der 'Tisch ist drehbar und an seiner Unterfläche mit einem Schlitten

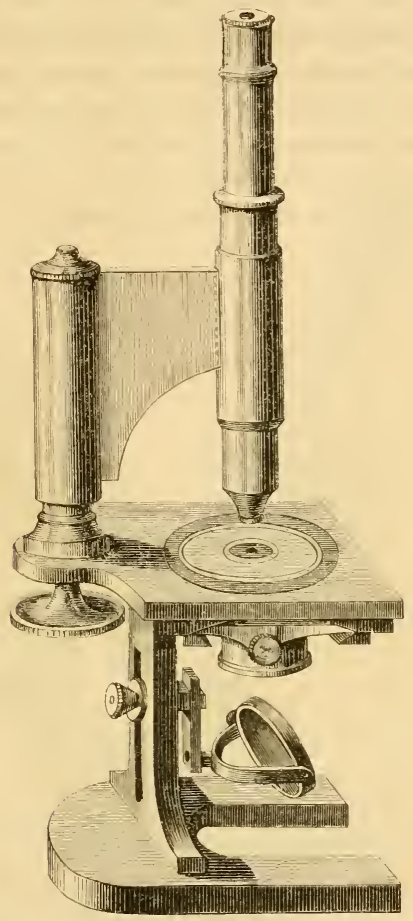

Figur 4s.

versehen, in welchen die Blendungen von unten eingeschoben werden; der Spiegel seitwärts und in senkrechter Richtung beweglich, auf der einen Seite mit ebener, auf der anderen mit concaver Spiegelfläche.

Das kleinere $\mathrm{H}$ ufeisenstativ hat dieselbe Einrichtung, wie das vorhergehende, nur fehlt der drehbare Objecttisch. Da es für die meisten Untersuchungen vollkommen genügt, und mit einer vortreff- 
lichen Ausstattung um den mässigen Preis von 375 Franken geliefert wird, so ist es mit Recht sehr beliebt.

Die nach dem älteren Modell construirten Trommelstative möchten wir für grössere Instrumente nicht empfehlen ; für kleinere, wie sie Hartnack zu $140 \mathrm{Fr}$. berechnet, sind sic dagegen sehr zweckıässig und jedenfalls den ganz kleinen Röhrenstativen, welche zum Aufschrauben auf den Mikroskopkasten eingerichtet sind, vorzuzichen. Letztere sind wegen ihres allzu schmalen Objecttisches und der mangelhaften Beleuchtungsvorrichtungen für manche Untersuchungen sehr unbequem. Die grosse Verbreitung, die sie trotzdem gefunden haben, erklärt sich durch ihre Wohlfeilheit und ihre Compendiosität.

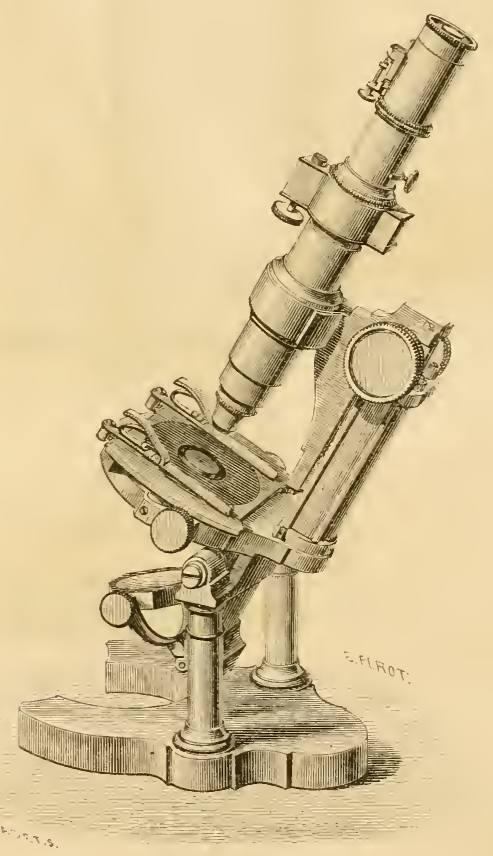

Figur 49.

97 Nachet und Sohn in Paris. Die grössten und besten Mikroskope dieser Firma haben ein Gestell, wie es in Fig. 49 dargestellt 
ist * . Der ganze optische Apparat hängt an einer horizontalen Axe zwischen zwei Säulen und kann also aus der senkrechten Stellung in eine beliebig geneigte gebracht werden. Die grobe Einstellung geschicht durch einen in ein vierkantiges Gehäuse eingeschlossenen Trieb, die feinere mittelst der Mikrometerschraube, welche in der Mitte der Mikroskopröhre angebracht ist und welche die Verschiebung einer inneren Röhre bewirkt, an deren unterem Ende die Objective angeschraubt sind. Der Tisch ist drehbar und überdiess mit einer Vor-

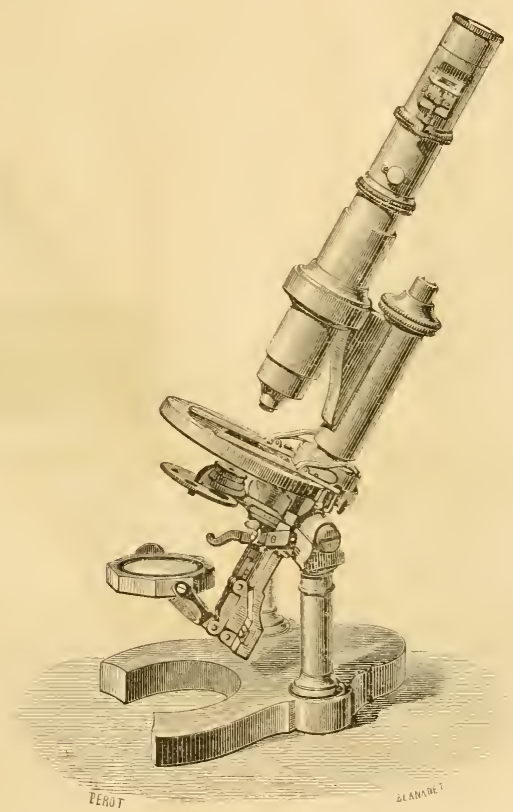

Figur 50 .

richtung zur seitlichen Verschiebung der Objecte mittelst Schrauben ausgestattet. Zwei Federklammern dienen zur Befestigung der Objectträger, ein Hebelapparat zur Auf- und Abbewegung der Blendungen

*) Nach et hatte die Gefälligkeit, uns die Holzschnitte aus seinem neuesten Katalog zur Benutzung mitzutheilen. 
und Condensatoren. Das Ocularmikrometer ist zum Einschieben eingerichtet und mit einer Schraube zur scharfen Einstellung für das Auge versehen. Ausgerüstet mit S Objectiven (die 5 letzten mit Correction für Deckgläser von verschicdener Dicke), 3 Ocularen, Ob. jectiv- und Ocularmikrometer, Goniometer, Polarisationsapparat nebst Gypsblättchen, Zeichnenprisma, Condensator und anderem Zubehör kommt dieses Instrument auf $1300 \mathrm{Fr}$. zu stehen.

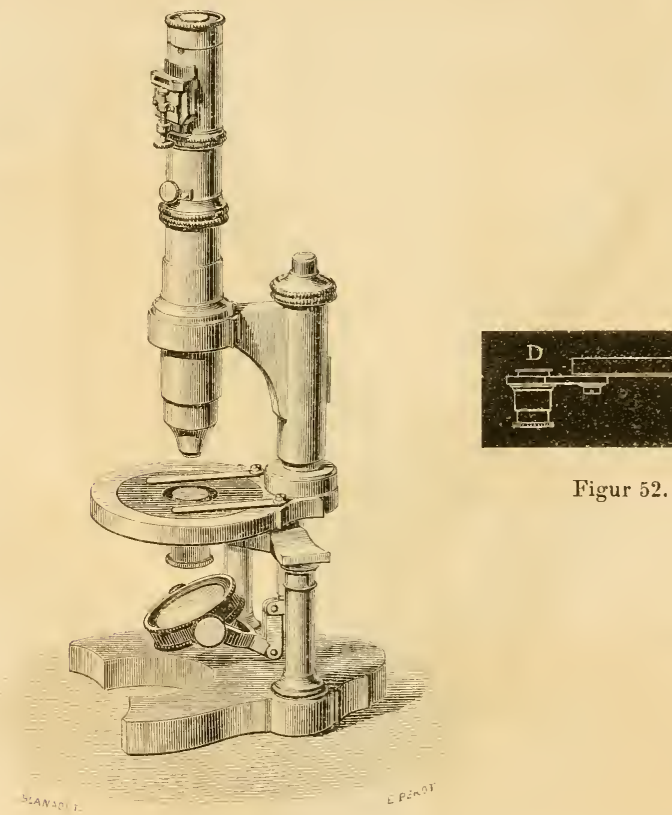

Figur 51.

Ein etwas älteres Modell (Microscope grand modèle [Fig. 50]), das grösste des früheren Katalogs vom Jahr 1556, ist ähnlich construirt, jedoch ohne verschiebbare innere Röhre. Die Einstellung geschieht wie bei den grösseren Hartnack'schen Instrumenten. Dieselbe Construction zeigt in Wesentlichen auch das grosse verticale Mikroskop (M. grand modèle droit [Fig. 51]) ; nur ist hier die Vorrichtung zum Einsetzen und Verschieben der Blendungen und des 
Condensators eine andere. Diese werden nämlich von unten in eine Hülse $D$ (Fig. 52) eingeschoben, welche am Objectisch $A$ mittclst einer um einen peripherischen Punct drehbaren Platte befestigt ist.

Sehr zu empfehlen sind die im Katalog als Nr. 4-7 aufgeführten mittelgrossen und kleinen Stative mit und ohne Horizontalstellung M. moyen modèle inelinant et droit [Fig. 53 u. 54]; M. petit modèle inclinant et droit [Fig. 55 u. 56$]$ ). Erstere sind mit 5 Objectiven und 3 Ocularen nebst Ocularmikrometer zu 420 und 350 , letztere je nach

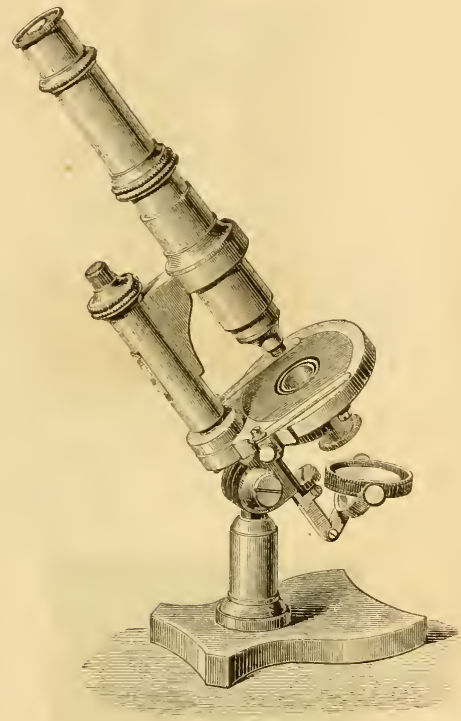

Figur 53.

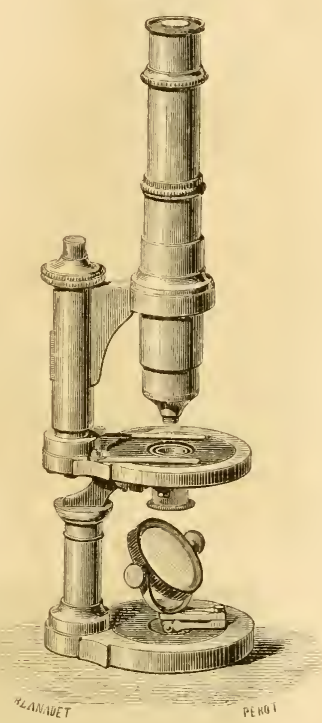

Figur 54 .

der Ausstattung mit 2 oder 3 Objectiven zu 125-175, resp. $150-$ $200 \mathrm{Fr}$. angesetzt. Die verstellbaren Spicgel der beiden kleinen Mikroskope sind in Fig. 57 u. $5 \mathrm{~s}$ zur Veranschanlichung des Mechanismus noch besonders dargestellt.

Ebenso preiswürdig ist auch das Stativ, welches nach Belieben als zusammengesetztes oder als einfaches Mikroskop gebraucht werden kann (Fig. 59). Dasselbe besitzt einen langen Tisch und trägt auf der einen Seite den zur Aufnahme der Doublets bestimmten Arm, auf 
der andern eine Säule, welche sammt dem daran befestigten Tubus entfernt werden kann, wenn das Mikroskop als Simplex gebraucht werden soll.

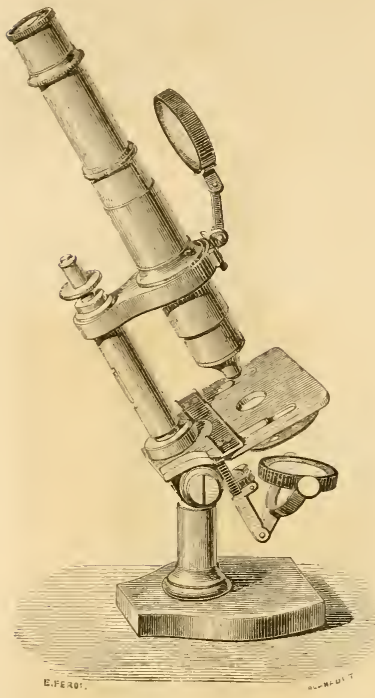

Figur 55.

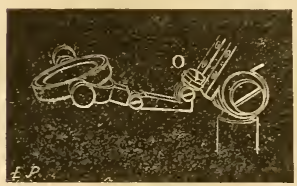

Figur 57.

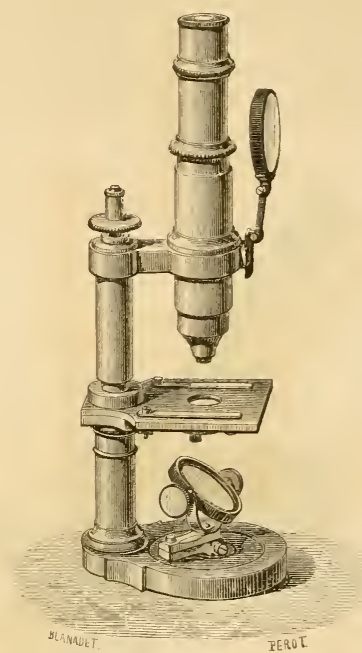

Figur 56 .

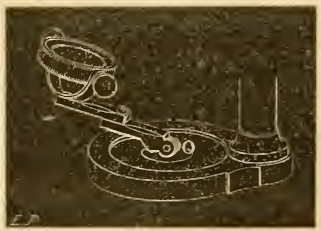

Figur 54.

Ausserdem liefert Nachet auch stereoskopische binoculäre Mikroskope (Fig. 60), welche für beide Augen berechnet sind, sowie ferner binoculäre und trioculäre, an denen zwei oder drei Personen zu gleicher Zeit beobachten können (Fig. 61). Alle diese Instrumente sind indess zunächst nur für schwächere Vergrösserungen bestimmt. Sie werden daher gewöhnlich nur mit den Objectiven Nr. 0, 1 und 3 ausgerüstet, doch sollen die neuesten Verbesserungen, 
Die Stative der neueren Optiker.

wie Nachet versichert, auch die Anwendung der Objective 5 und 6 gestatten.

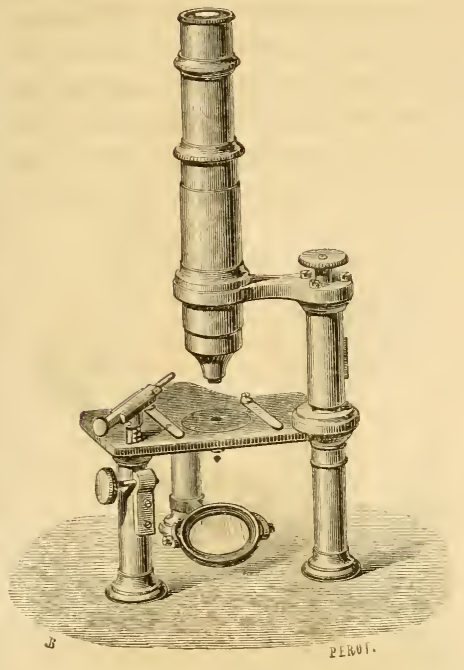

Figur 59.

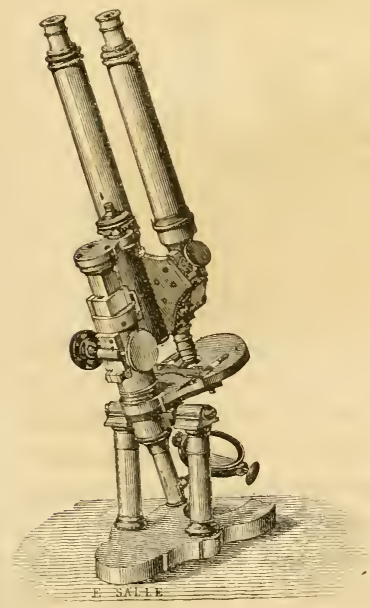

Figur 60 .

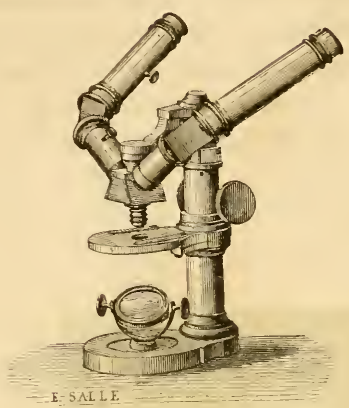

Figur 61 .

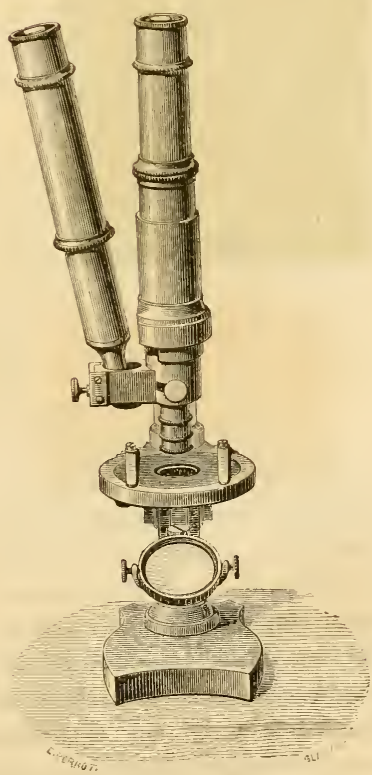

Figur 62 . 
Der binoculäre Appparat (appareil binoculaire [Fig. 62]), welchen Nachet um $150 \mathrm{Fr}$. liefert, gestattet die Unwandlung eines gewöhnlichen Mikroskops in ein stereoskopisches. Die Mikroskopröhre wird durch eine andere $A$ (Fig. 63) ersetzt, mit welcher die Röhre $B$, die unten in das Kästchen mit den Prismen eingefügt ist, fest verbunden werden kann. Eine ähnliche Torrichtung dient zur TImwandlung cines gewöhnlichen Mikroskops in ein binoculäres für zwei Beobachter (Fig. (64); sie wird mit 2 Ocularen zu So Fr. geliefert.
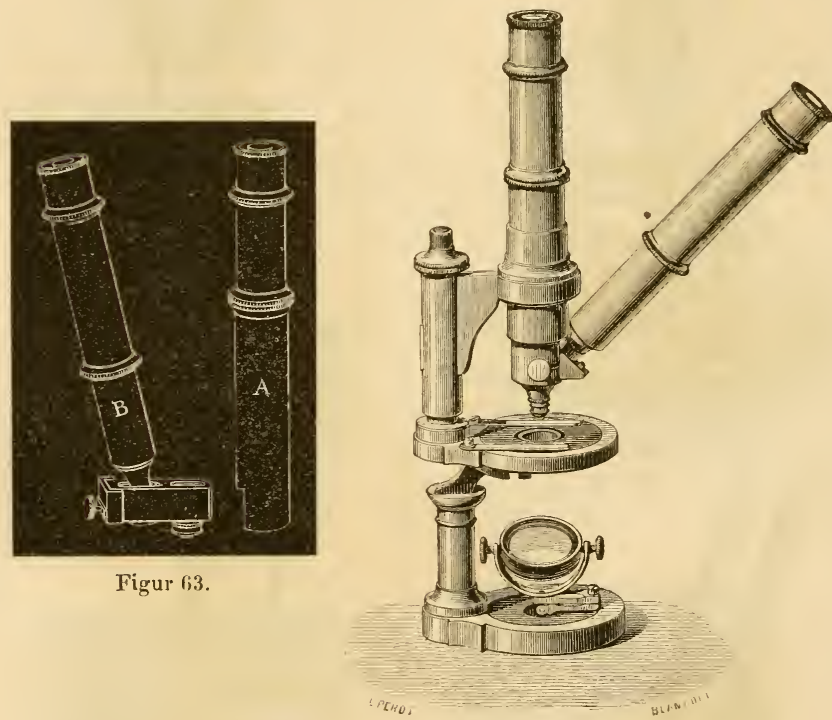

Figur 64 .

Von eigenthümlicher Construction ist das für chemische Untersuchungen eingerichtete umgekchrte Mikroskop (Fig. 65), bei welchem der Beleuchtungsspiegel über und das Objectivsystem unter dem Objecttisch angebracht ist, un dadurch der Beschädigung der Linsen durch Dämpfe, Säuren etc. vorzubeugen. Der Mikroskopkörper ruht auf dem scheibenförmigen Fuss und kann mittelst eines Schlittens unter dem Objecttisch hervorgezogen werden. Die Herumlenkung der Strahlenbündel geschieht durch zweimalige innere Reflexion in einem entsprechend geschnittenen Prisma. - Neuer- 
dings hat $\mathrm{Nachet}$ anch ein besonderes Präparirmikroskop für Laboratorien M. de disscetion pour laboratoire [Fig. 66]) construirt, welches mit einem bildumkehrenden Oculare versehen ist und c. S-70 mal vergrëssert. Der in der Figur dargestellte Objecttisch mit Holzfuss ist zur Beobachtung bei durchfallendem Lichte bestimmt und kann nach Belieben entfernt und durch Glasgefässe, Korkplatten etc. ersetzt werden.

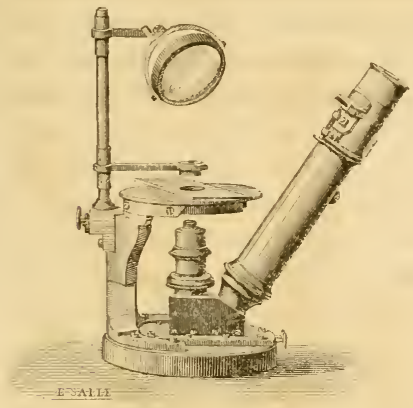

Figur 6.5 .

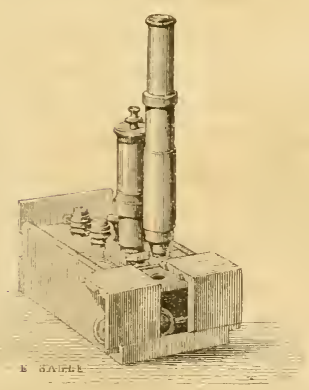

Figur 6i:

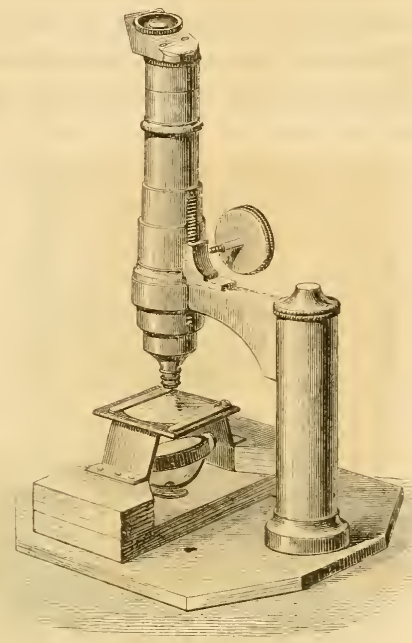

Figur 66.

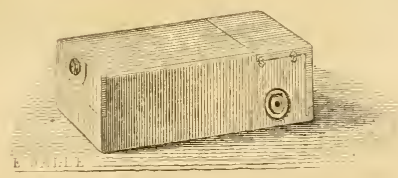

Figur 6s.

Sehr sinnreich ist femer das Taschenmikroskop Nachet's (Fig. 67) eingerichtet, welches mit Zubchör zu $200 \mathrm{Fr}$. angesetzt ist. Dasselbe kann in ein Kästchen von $90^{\mathrm{m} \cdot \mathrm{m}}$. Länge und $50^{\mathrm{m} . \mathrm{m}}$. Breite Fig. 65) cingepackt werden und besitzt ein Rohr von nur $14 \mathrm{~m} . \mathrm{m}$. Durchmesser und (wenn die inncre Röhre ausgezogen ist) 10 Centimeter Länge, ist aber dessenumgeachtet für die meisten Untersuchun- 
gen vollkommen ausreichend, da es mit den nämlichen Objectiven ausgestattet wird, wie die grösseren Instrumente, und überdiess einen hinlänglich grossen Objecttisch besitzt.

Im neuesten Katalog von 1863 figurirt auch zum ersten Mal ein photographisches Mikroskop (Fig. 69). Dasselbe ist zur Beleuchtung undurchsichtiger Körper mit einem grossen Lieberkühn'schen Spiegel $M$ ausgestattet, welcher das von oben einfallende Licht nach dem. auf zwei Glasstangen ruhenden Objectträger $O$ reflectirt. Beim Photographiren mit durchfallendem Licht wird über dem $\mathrm{Ob}$ ject ein Condensor angebracht in der Figur nicht dargestellt), welcher das Licht von einem zweckdienlich aufgestellten Spiegel erhält.

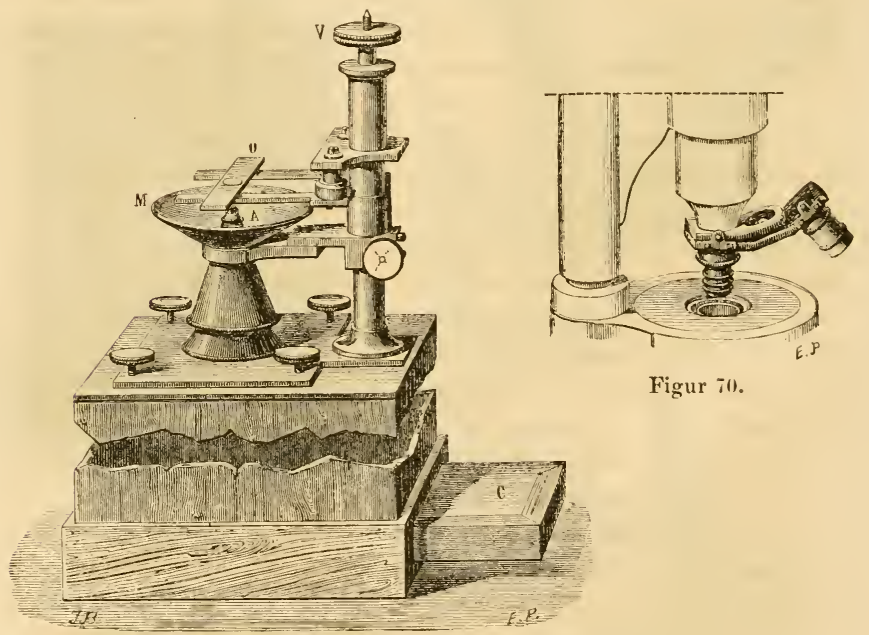

Figur 69.

Die scharfe Einstellung des Objectivbildes auf die empfindliche Platte $C$, auf welche das Auge durch ein kleines Perspectiv herunterblickt, geschieht durch die Schraube $V$. Mit einer Reihe von Objectiven ausgestattet, wird dieses Instrument zu $300 \mathrm{Fr}$. berechnet.

Endlich verdient noch der Revolver-Objectivträger (Revolver porte-objectif [Fig. 70]) hier erwähnt zu werden. Derselbe gestattet Objective von verschiedener Stärke während der Beobachtung rasch zu wechseln, indem man sie um eine schief stehende Axe dreht. 
Simon Plössl in Wien. Das grosse zusammengesetzte 98 Mikroskop ruht auf einem kreisrunden messingenen Postament. und kann auf demselben mittelst eines horizontalen Armes um seine Axe gedreht werden. Mit diesem Arm steht nänlieh die dreikantige Stange in Verbindung, welche den unbewegliehen Objecttisch und das durch Triebwerk verschiebbare Rohr trägt. Die feinere Einstellung, wie sie bei den starken Vergrösserungen nothwendig wird, geschieht durch eine Mikrometerschraube. Der eoncave auf der Rückseite geschwärzte Beleuchtungsspicgel ist mit einem beweglichen Doppelarme versehen und nach allen Richtungen der Ebene verstellbar. Zur Beleuchtung mit auffallendem Licht dient ein sphärisehes Prisma nach Selligue, zur Verstärkung des Lichtes (rorzugsweise des Lampenlichtes) eine. Beleuchtungslinse mit besonderem Fusse. Der obere Theil der ungewöhnlich langen Mikroskopröhre kanu abgeschraubt und nach Einschaltung eines Prisma rechtwinklig angesetzt werden, wodurch zunächst das Horizontal-Einsehen während der Beobachtung, zugleich aber anch bei Anwendung des Sömmerring'sehen Spiegelchens das Projiciren des Bildes auf die Ebene des Arbeitstisches möglich gemacht wird. Die Ocularmikroneter mit Theilungen der Wiener Duodecimallinie in 30 und 60 Theile oder des Millimeters in 25 und 50 Theile sind zum Einschieben in das Ocular Nr. 2 eingerichtet und können mittelst einer an der Fassung der Ocularlinse angebrachten Schraube scharf eingestellt werden. Das ganze Instrument ist c. $150 \mathrm{~m} \cdot \mathrm{m}$. höher als die meisten anderen Mikroskope, so dass man an einem Tisch von gewöhnlicher Höhe nur stehend damit arbeiten kann. - Mit vollständiger optischer Ausstattung drei Oculare, neun achromatischen Linsen und einem noch stärkeren Linseneinsatz) nebst Glasprisına, Sömmerring'schem Spiegel und den genamnten Beleuchtungsapparaten kommt ein solches Instrument auf 292 fl. österr. Währung zu stehen. Schraubenmikrometer, Polarisationsvorrichtungen $u$. dgl. sind nicht inbegriffen.

Die älteren Stative mit einem zum Zusammenlegen eingerichteten Dreifuss sind in den neuesten Preisverzeichnissen nicht mehr aufgeführt.

Das kleine zusammengesetzte Mikroskop ist ähnlich construirt, nur fehlt der horizontale Arm zur Rotation um die Mikroskopaxe und die Mikrometerschraube zur feineren Einstellung. Die dreikantige Stange, welche Tisch und Rohr trägt, ist hier unbeweglich mit dem runden messingenen Postamente verbunden und die Einstellungsvorrichtung auf ein 'Triebwerk beschränkt. Die Dimen- 
sionen sind durchgehends beträchtlich kleiner als beim grossen Mikioskop, so dass die Gesammthöhe des Stativs nur etwa $30^{\mathrm{m} . \mathrm{m} .}$ mehr beträgt als bei clen Mikroskopen von Hartnack, Bénèche etc. - Mit zwei Ocularen und sechs achromatischen Linsen (die drei stärkeren mit Correction zum Gebrauche mit und ohne l)eckgläser), einer kleineren Beleuchtungslinse und den oben erwähnten Ocularmikrometern ist dieses Instrument zu 95fl. ö. WV. angesetzt. Das Glasprisma zum Horizontileinsehen nebst Sömmerring'schem Spiegel steigert den Preis auf c. $120 \mathrm{fl}$.

Plössl verfertigt überdiess grössere und kleinere Reisemikroskope, bei welchen der Objecttisch durch Triebwerk gegen die Liusen bewegt wird, ferner ein zusammengesetztes Arbeitsmikroskop, welches anfrechte Bilder liefert. Die grösseren Reisemikroskope sind zum Aufschrauben auf den Mikroskopkasten eingerichtet; die kleineren und das Arbeitsmikroskop besitzen einen messingenen Fuss und werden in ein mit Leder gefüttertes Futteral von Maroquin eingepackt.

F. W. Schiek in Berlin liefert Mikroskope ron sehr verschiedener Grösse, sowohl nach Plössl'schen als nach Oberhäuser'schen Modellen. Nach Schacht ist die Messingarbeit überall vortrefflich und sind die kleinen und mittleren Mikroskope preiswürdig und sehr zu empfehlen.

100) L. Bénèche in Berlin. Die grösseren Instrumente haben das Oberhäuser'sche Hufeisenstativ (mit oder ohne drehbaren Tisch) und werden auf Verlangen auch zum Umlegen eingerichtet; die kleineren, welche zu 30 Thlr. angesetzt sind, stehen auf einem runden Fuss und besitzen einen Objecttisch mit Mikrometerbewegung nach Nobert. Der 'Tisch hängt nämlich mit zwei Stiften, wie eine Klappe in ihren Angeln beweglich, an der Stange des Stativs und wird zum Behuf der feinen Einstellung durch eine Schraube etwas gehoben oder gesenkt. Nach Schacht haben die Instrumente dieser Art in nenester Zeit wesentliche Verbesserungen erfahren, so dass auch bei längerem Gebrauch ein Schlottern des Tisches nicht mehr zu befürchten ist.

Ausserdem fertigt Bénèche auch ganz kleine Mikroskope nach dem Modell von Lerebours in Paris, wo die eine Seitenwand und der Boden des Kastens mit zum Stativ gehören.

(10) C. Zeiss in Jena führt ein grosses Hufeisenstativ nach Oberhäuser, dlann kleinere Hufeisenstative und solche mit rundem, ringförmigem oder schciben förmigen Fuss nach eigener Construction. Der Blendungsapparat besteht bei den kleineren Instrumenten aus einer drehbaren gewölbten Scheibe, deren Oeffnungen unmittelbar unter 
den Objectträger zu liegen kommen. Die Mikrometerbewegung ist durchweg an der 'Tubussäule angebracht; der spiegel wenigstens seitlich, bei den Stativen I, III und IIIb auch nach vorn verstellbar.

F. Belthle (Nachfolger von C. Kellner) in Wetzlar. Wir 102 kennen die neueren Mikroskope dicses Instituts nur aus dem Preisverzeichniss. Hienach wird die grobe Einstellung bei den grossen und mittleren Stativen durch Zahn und Trieb, bei den kleinen und kleinsten durch 'Tubusverschiebung bewirkt. Die feine Einstellung geschieht ohne Ausnahme durch Hebung und Senkung des Rohrs mittelst Mikrometerschraube. Sämmtliche Instrumente sind für schicfe Beleuchtung eingerichtet, die grösseren übcrdicss un die optische Axe drehbar.

M Baader in M ünchen. Der Körper des Mikroskops ruht 10.3 auf einem viereckigen, schwarz lackirten Fuss ron Gusseisen. Die grobe Einstellung geschieht bei den kleineren Instrumenten wie gewöhnlich durch '́lubusverschicbung, bei den grösseren mittelst Kahn und Trieb. Die feine Einstellung vollzicht eine Nikrometerschraube, welche den Tubus hebt und senkt. Der Tisch ist unbeweglich, der spiegel seitlich verstellbar. - Die kleineren Instrumente sind äusserst preiswürdig ( 15 fl.) und aller Empfohlung werth.

Smith, Beck \& Beck in London. Als Beispiel eines compliciten englischen Stativs mag hier noch das grosse Mikroskop der genannten Firma Erwähnung finden. Dasselbe ist in Fig. 71 dargestellt. Der Körper des Mikroskops hängt an einer horizontalen Axe zwischen zwei Säulen mol kamn also beliebig gencigt oder horizontal gestellt werden. Die grobe Einstellung

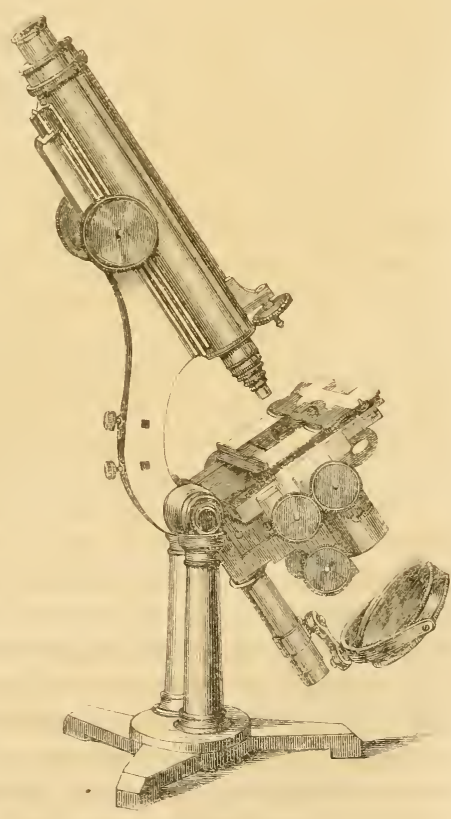

Figur 71. 
$11 \mathrm{~S}$ Mechan. Finricht. des Mikroskops, - Die Stative d. neueren Optiker.

der Mikroskopröhre wird durch ein Triebwerk, dessen geränderte Knöpfe in der Mitte des 'Tubus angebracht sind, in der Art bewirkt, dass die am 'Tubus befestigte Stange sich in einer entsprechenden Rinne des gebogenen Armes bewegt. Zur feineren Einstellung dient die etwas tiefer stehende Mikrometerschraube, durch welche ein ausziehbares Stück des Rohrs sich auf und nieder schieben lässt. Der Objecttisch ist mit Schrauben und Schlitten reichlich bedacht und kann mittelst derselben nach allen Richtungen bewegt werden; derselbe gestattet überdiess die Einfügung eines achromatischen Condensors. 


\section{Dritter $\Lambda$ bschnitt. \\ Von der Prifing des Mikroskops.}

I.

Prufung des optischen Vermögens im Allgemeinen.

Nachdem wir in einem frühern Kapitel gezeigt haben, dass alle 10.; Eigenschaften, welche das optische Vermögen eines Mikroskops und folglich auch die Schärfe und Klarheit seiner Bilder bedingen, sich eigentlich für jede Vergrösserung nur auf das Freisein von beiden Arten der Aberration reduciren, könnten wir füglich auch die Prüfung des Instrumentes auf diesen einen Punct und auf die Bestimmung der Vergrösserungsziffer beschränken. Zur Beurtheilung eines Mikroskops ist sogar hierüber eine genaue Orientirung nicht einmal nothwendig, da es sich einfach darum handelt, ob dasselbe die Vergleichung mit andern bekannten Instrumenten aushalte, ob es überhaupt den Anforderungen entspreche, die man gegenwärtig an die Mikroskopverfertiger zu stcllen berechtigt ist. Mit dieser vorzugsweise praktischen Frage wollen wir uns zu allernächst bcschäftigen und erst nach Erledigung derselben den einzelnen Factoren nachgehen, welche bei einer specielleren Prüfung in Betracht kommen.

\section{Absolntes Unterscheidnngsvermögen.}

Wie kann also, fragen wir zuerst, die Güte eines Mikroskops 106 taxirt werden, wenn man es vermeiden will, alle Eigenthümlichkeiten und Fehler der Construction zu prüfen, von denen sie abhängt? Gewöhnlich geschieht diess, wie bekannt, durch die sogenannten Probeobjecte, von denen man weiss, dass gewisse Détails bei eincr bestimmten Vergrösserung durch die besscren Instrumente noch gelöst werden, während die weniger guten sie entweder gar nicht oder nur undeutlich 
zur Walırnehmung bringen. Aber cben diese Probcobjecte sind es, welche zu den unklaren Begriffen der penetrirenden und definirenden Kraft geführt haben, weil das mikroskopische Bild, wie oben gezcigt wurde, nur von einem bestimimten Theil der brechenden Flächen des Objectivs, bald vom centralen, bald vom peripherischen, aber nicht von der Gesammtwirkung beider abhängig ist. Die Resultate der Prüfung, die man mit solchen Probeobjecten erhält, können daher unmöglich vergleichbar sein, da gerade die Lichtbündel, welche vorzugswcise die Schärfe dor Zeichnung bedingen (nämlich die, welche in Bilde die peripherischen Puncte der Lichtparticen entwerfen und folglich die Schärfe der Schatten bestimmen), bei dem einen Objectiv den vollkommensten, bei dem andern den unvollkommensten 'Theil der brechenden Flächen treffen. Diese Ungleichlheit der Beclingungen kann nur vermieden werden, wenn das Probeobject so beschaffen ist, dass die von ihm ausgehenden Lichtbündel die ganze Oeffnung des Objectirs ausfüllen und also nur in der Intensität, aber nicht in der Neigung differiren. Um dieser Anforderung zu genügen, könnte man es versuchen, Systeme von abwechselnd hellen und dunkeln (d. h. durchsichtigen und undurehsichtigen) Linien nach Art der Nobcrt'schen Probetäfelchen herzustellen. Es wäre damit, wie bereits bemerkt, der Vortheil verbunden, dass man nach der vorläufigen Prüfung, wobci der einfallende Lichtkegel dieselbe Oeffnung haben müsste, wic das Objectiv, durch einfaches Zurückzichen der Blendung und durch Anwendung ringförmiger Blendungsöffnungen nach Belieben liandstrahlen oder Centralstrahlen innerhalb bestimmter Grenzen der Neigung wirken lassen könnte. Man erreicht übrigens, abgeschen von diesem Vortheil für die speciellere Prüfung, dassclbe Zicl, wenn man als Probcobject nach der von Harting mitgetheilten Methode das von einer Luftblase entworfene Bild eines Drahtnetzes wählt und die Entfernung dieses letzteren so regulirt, dass das Bild eben noch deutlich wahrnehmbar ist. Die Grösse der Maschen an dicser äussersten Grenze der Sichtbarkeit steht alsdanm im umgekchrten Verhältniss zum optischen Vermögen und kann folglich als arithmctischer Ausdruck desselben betrachtet werden.

117 Wir wollen diese Prüfungsmethode, weil sie wirklich als die beste cmpfohlen zu werden verdient, etwas ausführlicher besprechen. sie vercinigt alle Vorzüge in sich, die wir nach den bisherigen Erörterungen als wesentlich zu betrachten haben. Kunächst verdient hervorgchoben $z u$ werden, dass sie für die verschiedensten Vergrösserungen gewissermassen ein und dasselbe Probeobject zu benutzen ge- 
stattet, indem die stets mit gleicher Schärfe entworfenen virtuellen Bilder ciner kugelförmigen Luftblase sogar über dio Grenzen der Unterscheidbarkcit hinaus verkleincrt werden können, ohne dass desswegen das V'erhältniss zwischen Licht und Schatten eine Aenderung erleidet. Dazu kommt, dass dic Strahlenkegel, welche von den Puncten des virtuellen Bildchens zu kommen scheinen, den vorhin gestellten Anforderungen vollkommen entsprechen, indem sie die Oeffinung des Objectivs unter allen Linständen ganz ausfüllen. I lie vom Drahtnetz ausgehenden Lichtbündel, die wegen der Kleinheit der Luftblase als parallelstrahlig zu betrachten sind, erfahren nänlich, wic diess in Fig. 72 veranschaulicht ist, cine solche Brechung, dass sie, den Raum eines wcit geöffneten Kegcls ausfüllend, nach dem Objectiv divergiren. Die Figur ist für die Brechung in 1 asser nach berechneten Winkeln genau construirt.)

Auch die rein praktische Seite dieses Verfahrens bietet manche Bequemlichkeit. Die Herstellung von Luftblisen der verschiedensten Grössc ist überaus leicht. Bei der Auflösung von arabischem Gummi in Wasser cntstehen sie meist von selbst, weil die zwischen den Pulvertheilchen enthaltene Luft nicht ganz absorbirt wird. Ebenso einfach erhält man dieselben, wenn man einen 'Tropfen Glycerin oder Oel, den man auf den Objectträger gebracht hat, mit einem flachen Gegenstande, z. 13. mit ciner Messerklinge, wiederholt schlägt, bis cr zu schäumen beginnt, und dann mit einem Deckglïschen bedeckt, wobei jedoch die Vorsicht zu beachten, zur Verhütung der Abplattung irgend einen geeigneten Gegenstand (Baumwollenfasern, Papierschnitzel It. dgl.) zu unterlegen. Auch Kohlensäurebläschen, welche man leicht erhält, wenn man etwas K reidepulver und hierauf' ein 'Tröpfchen verdünnter Salzsäure in dic Elüssigkeit bringt, leisten natürlich denselben Dienst. Bei der grossen Auswahl von Luftblasen der verschiedensten Grösse ist es möglich, mit demselben Drahtnetz, anch wenn die Objectelistanz nur wenig verändert wird, Bilder zu erzielen, welche nach Belieben für die 
stärkeren oder schwächeren Vergrösserungen die Grenze der Unterscheidbarkeit erreichen.

Un die Grösse der Maschen an der äussersten Grenze der Unterscheidbarkeit noch sicher bestimmen zu können, verfährt man am besten auf folgende Weise. Ein quadratförmiges Stück des Drahtgeflechtes, welches circa $5 \times 5$ bis $10 \times 10$ Maschen enthält, wird dureh schwarze Papierstreifen eingerahmt (Fig. 73) und alsdann zwischen Spiegel und Luftblase in ein solches Niveau gebracht, dass das Bildchen eben noch sichtbar ist. Misst man nun die Länge einer ganzen Quadratseite, so brancht man bloss durch die bekannte Zahl der Interstitien, die auf eine solche Seite kommen, zu dividiren, um den Abstand der Drähte oder, was dasselbe ist, den Durchmesser der Maschen zu erhalten. Hat z. B. das ganze Quadrat, wie es in obiger Figur dargestellt ist, noch einen Durchmesser

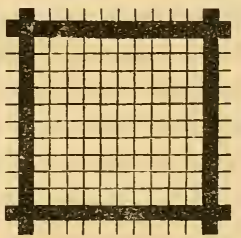

Figur 73. von 7,5 Mik., so ist der Abstand der Drähte (wenn man beiderseits eine halbe Drahtdicke vernachlässigt) genau 10 Mal kleiner, also $=0,75$ Mik. ${ }^{*}$ ).

Zum Auflegen des Drahtnetzes eignet sich am besten ein Halter, welcher aus einem horizontalen, mit einem Ring versehenen Arm besteht, der an einem verticalen verschiebbar ist. Man kann sich jedoch auch mit einer Cylinderblendung behelfen, indem man das Object mittelst Wachs am untern Rande derselben befestigt und durch Zurückziehen des ganzen Apparates die Entfernung regulirt. Es kann überhaupt Niemanden schwer fallen, diese Prüfungsmethode mit den gerade zu Gebote stehenden Mitteln auszuführen. Man gebrauche nur immer die Vorsicht, Luftblasen zu wählen, welche nette und scharfe Bilder liefern.

108 Wir geben nun nachstehend eine kleine Zusammenstellung der Resultate, welche die mit verschiedenen Instrumenten angestellten Messungen ergeben haben. Die Grenze der Sichtbarkeit wurde durchweg da angenommen, wo die Maschen des Netzes auch von einem mit

*) Harting giebt bei solchen Messungen die Dicke der 1)rähte und die Grösse der Interstitien gesondert an. Wir halten diese Unterscheidung fur die in Frage stehende l'rüfung nicht gerade für nothwendig, da wir bei Anwendung verschiedener Drahtgeflechte, bei denen das Verhältniss der 1)rahtdicke zum Maschenraum zwischen 1:5 und 1:2 schwankte, immer nahezu dieselben Resultate erhielten. 
dem Object nicht vertrauten Beobachter eben noch deutlich erkannt werden können. Da hiebei die Intensität der Beleuchtung begreiflicher Weise nicht ganz gleichgültig ist, so wurden die meisten Bestimmungen bei hellem und bewölktem Himmel öfter wiederholt und die mittleren Grenzwerthe als maassgebend betrachtet. Als Durchmesser der Maschen ist nach der oben mitgetheilten Berechnungsw cise der Abstand der Drahtaxen bezeichnet; derselbe ist natürlich gleich der Summe der Durchmesser eines Drahtes und eines Interstitiums.

Die auf Amici bezüglichen Ziffern wurden dem Werke Har tings das Mikroskop p. 301 und 722) entnommen und dabei die Objective eines älteren Instruments vom Jahr 1835 mit B, die eines neueren vom Jahr $1 \$ 49$ mit A bezeichnet. Die unter A angeführten Plössl'schen Objective gehören zu einem älteren grossen Mikroskop; nur $0^{*}$ ist neueren Datums und mit einer Correctionsvorrichtung versehen. Die Objective B bilden die optische Ausstattung des "kleinen zusammengesetzten "Mikroskops, welches im neuesten Preisverzcichniss zu $95 \mathrm{fl}$. angesetzt ist, und wurden auch an diesem geprüft. $\mathrm{O}$ ist der starke Linseneinsatz mit Correctionsvorrichtung zum Gebrauche mit und ohne Deckplättchen. Die Mikroskope von Bénèche und $\mathrm{H}$ artnack wurden in den letzten Jahren bezogen und können daher als ganz neu bezeichnet werden. Das zweite Objectiv Nr. 9 des Letzteren ist das Immersionssystem init Correctionsapparat. Auch das Baader'sche Instrument war ganz neu. Das dazu gehörige Objectiv Nr. 3 wurde nachträglich am Stativ von Bénèche und mit dessen Ocular Nr. 2 geprüft.

\begin{tabular}{|c|c|c|c|c|c|c|}
\hline & 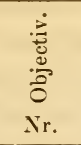 & 离 & 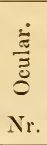 & 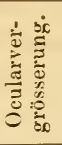 & 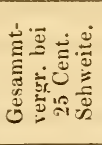 & 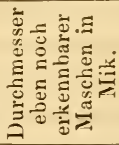 \\
\hline O berhäuser. & $\begin{array}{l}1 \\
2 \\
1\end{array}$ & $\begin{array}{l}52 \\
30 \\
15,6\end{array}$ & $\begin{array}{l}3 \\
3 \\
3\end{array}$ & $\begin{array}{l}4 \\
" 1 \\
"\end{array}$ & $\begin{array}{l}15 \\
33 \\
45\end{array}$ & $\begin{array}{l}9,24 \\
5,04 \\
3,3\end{array}$ \\
\hline H artnack. & $\begin{array}{c}4 \\
7 \\
9 \\
9 \mathrm{Imm} .\end{array}$ & $\begin{array}{l}11,3 \\
3,3 \\
2,02 \\
1,47\end{array}$ & $\begin{array}{l}3 \\
3 \\
3 \\
3\end{array}$ & $\begin{array}{l}4,7 \\
" \\
\prime \\
\prime \prime\end{array}$ & $\begin{array}{l}100 \\
340 \\
555 \\
655\end{array}$ & $\begin{array}{c}1,6 \\
0,7-0,62 \\
0,5 \\
0,45\end{array}$ \\
\hline Amici. & $\begin{array}{r}2 \\
6 \\
11 \\
1 \\
2 \\
3 \\
4\end{array}$ & $\begin{array}{r}7,45 \\
4,00 \\
2,67 \\
25 \\
4,46 \\
6,59 \\
3,57\end{array}$ & $\begin{array}{l}1 \\
1 \\
1 \\
1 \\
1 \\
1 \\
1\end{array}$ & $\begin{array}{l}7 \\
" \\
" 1 \\
7 \\
" 1 \\
" \\
\text { " }\end{array}$ & $\begin{array}{r}217 \\
423 \\
650 \\
50 \\
154 \\
206 \\
374\end{array}$ & $\begin{array}{l}0,63 \\
0,56 \\
0,43 \\
2,50 \\
0,9 \\
0,756 \\
0,671\end{array}$ \\
\hline
\end{tabular}




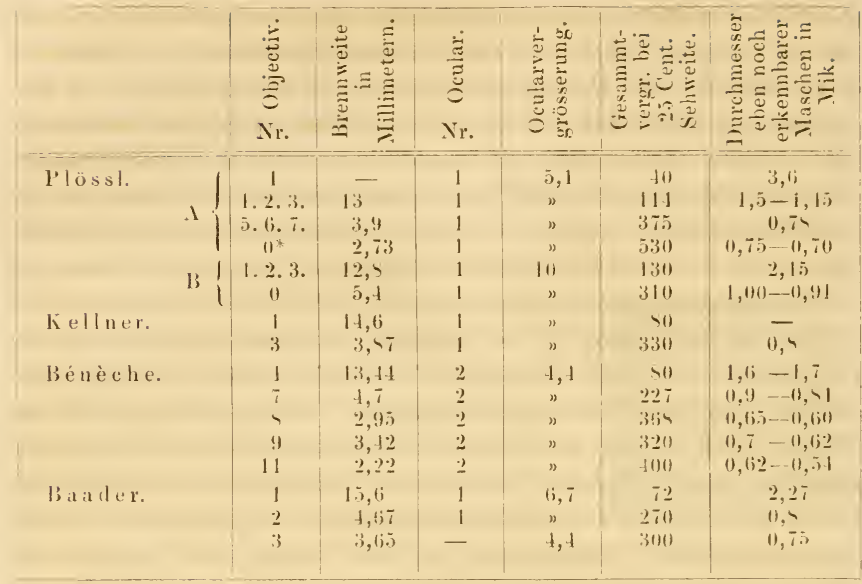

Aus dieser Zusammenstellung geht zunächst hervor, dass das optische Vermögen des Mikioskops weder mit der Stärke der Objective, noch mit der Gesammtvergrösserung gleichen Schritt hält. Von wel: chem bestimmten Fall man auch ausgehen mag, es bedarf stets einer mehr als doppelt so starken Vergrösserung, um den Durchmesser der eben noch unterscheidbaren Maschen auf die Hälfte zu reduciren, und umgekehrt einer weniger als halb so starken, um doppelt so grosse Maschen noch erkennen zu lassen. Man darf sonach ron den schwächern Systemen mit Recht verlangen, dass sie relativ die grösste optische Kraft entwickeln, und hinwiederum bei den stärkeren und stärksten die Anforderungen nicht zu hoch schrauben. Wenn bei letzteren das Steigen der Vergrösserungsziffor bis zur Grenze des Erreichbaren übes haupt noch einen entschiedenen Gewinn bringt, so hat der Optiker geleistet, was man gegenwärtig von. ihm erwarten darf. Ucbrigens richtet sich, wie man sicht, das Unterscheidungsvermögen der Mikroskope mehr nach der Brennweite der Objective als nach der Vergrösserungsziffer. Die geringe Stcigerung der Deutlichkeit, welche man bei Anwendung stärkerer Oculare beobachtet, steht in keincom Verhältniss zu dex dadurch bewirkten Grössenzunahme des Bildes. Nur die Amici'schen Mikroskope leisten ausnahmsweise mit starken ()cularen und atufallend schwachen Objectiven chen so viel, als die neueren Instrumente mit vorwiegender Objectivvergrösserung.

Wenn wir zweitens aus den mitgetheilten Zahlenreihen dicjeni- 
gen hervorheben, welche sich auf die stärksten Systeme bezichen. womit kleinere Instrumente gewöhnlich ausgestattet sind, wie z. B. dis System 7 von Oberhäuser und Hartnack, System 9 von Bénèche ete., so schwanken die Brennweiten derselben fast durchgehends zwischen 3 und 4 Millimeter und die Vergrösserungszahlen zwischen 300 und $350-375$. Man darf von solchen Combinationen verlangen, dass sie die Maschen des Drahtgeflechtes bei einem Durchmesser ron $0,7-0,5$ Mik. noch deuțlich erkennen lassen. Die rorzüglichsten derselben erlanben sogar eine Verkleinerung dieses Durchmessers auf $0,55-0,6$ Mik. Der starke Linseneinsatz zu dem Plössl'schen klcinen Mlikroskop ist unter den angeführten der einzige, welcher bei etwas grösserer Brennweite und allerdings nur 30maliger Objectivvergrösserung betriichtlich hinter den gestellten Anforderungen zurückbleibt. Er ist nach unserem Dafürhalten für cin Mikroskop, das bei den meisten Untersuchungen ausreichend sein soll, etwas zu schwach. - Das Objectiv Nr. S von Bénèche erwies sich auffallender W $\mathrm{C}$ cise etwas stärker als das System Nr. 9, was sich auch bei der Prüfung mit organischen l'robeobjecten mehr oder weniger deutlich aussprach: doch stehen sich die beiden Nummern immerhin so nahe, dlass sie füglich als eine einzige betrachtet werden könnten. Ein zweites Objectiv $\mathrm{Nr}$. 9, welches wir zu vergleichen Gelegenheit hatten, hielt so zicmlich die Jitte zwischen denselben; seine Brennweite betrug 3,15 "m."m, die Gesammtvergrösserung mit Ocular Nr. 2 c. $310^{*}$ ). Das optische Vermögen war aber dessenungeachtet etwas geringer als bei dem in der Tabelle aufgeführten Nr. 9.

Dic absolut stärksten bis jetzt hergestellten systeme, die wir zu untersuchen Gelegenheit fanden, worunter nanentlich das Immersionssystem $\mathrm{Nr}$. 9) von $\mathrm{Hartnack}$, lassen noch Maschen von 0,4(1), 15 Mik. Diameter mit den gewöhnlichen zur Beobachtung benutzten Ocularen unterscheiden und ergeben bei der günstigsten Verstärkung der Ocularvergrösscrung noch eine Steigerung des optischen Vermögens bis auf c. 0,3 Mik. Maschendurchmesser. Ob die besten englischen Objective mehr leisten, ist uns nicht bekannt**).

* In der dem Mikroskop beigegebenen Tabelle ist die Vergrösserung ron Nr. 9 ebenfalls zu 310 angegeben, die von $\mathrm{Nr}$. ' dagegen nur zu 240. Hienach scheint eine Verwechslung stattgefunden zu haben.

* ) Die Hartnack'schen Objective Nr.9 und lo gehören gegenwärtig unstreitig zu den besten, die man kennt. So weit wir nach eigenen Beobachtungen und zuverlässigen Mittheilungen darüber urtheilen können, werden sie auf dem 
Wir bemerken drittens, dass die Messungen, welche man in der angegebenen Weise ausführt, bei Objectiven mit grossem Oeffnungswinkel nothwendig etwas höhere Ziffern für die kleinsten noch unterscheidbaren Abstände ergeben müssen, als ähnliche Beobachtungen an Diatomeenpanzern bei günstiger schiefer Beleuchtung. Denn in letzterem Falle rührt das Bild bloss ron Randstrahlen her, welche die kleinsten Aberrationen zeigen, während bei der ersteren Beobachtungsart günstige und ungünstige Strahlen zum Bilde beitragen, womit dann natürlich der Nachtheil verbunden ist, dass die Grenzlinien zwischen Schatten und Licht nicht so scharf und die Schatten selbst nicht so dunkel sind, folglich das ganze Bild sich etwas früher verwischt. Es ist z. B. noch möglich, mit den Objectiven Nr. 9 von Bénèche und Nr. 7 von $\mathrm{Hartnack}$ die Querstreifen von Pleurosigma angulatum ganz deutlich zur Wahrnehmung zu bringen, obschon dieselben jedenfalls etwas weniger als 0,5 Mik. von einander abstehen. Dieser Abstand verhält sich aber zu den oben gefundenen Mittelwerthen nahezu wie 10:13. Jene Mittelwerthe erfahren indess annähernd dieselbe Steigerung (wenigstens bis zu c. $0,5-0,51$ Maschendurehmesser), wenn die Centralstrahlen durch geeignete Blendungen, die man am bequemsten über der hintersten Linse anbringt, abgehalten werden, - ein Beweis, dass die eben gegebene Erklärung vollkommen begründet ist.

\section{Relatives Unterscheirlıngsvermögen.}

110 Obschon in Vorhergehenden der gegenwärtige Standpunct der praktischen Optik gewissermassen arithmetisch bestimmt ist, insofern nach den mitgetheilten Zahlen der Grad der Vollkommenheit, den die besseren Instrumente besitzen, jederzeit bemessen werden kann, so gewährt es doch ein besonderes Interesse, das bereits Erreichte mit dem zu vergleichen, was nach der Theorie erreicht werden müsste, wenn das Mikroskop in jeder Beziehung mathematisch vollkommen wäre. Es ist geometrisch klar, dass mit einem solchen Instrument das

Continent von keinen anderen übertroffen, in 1)eutschland ron keinen erreicht. 1) Objective von $H$ a s ert, welche nach der Ankündigung mehr leisten sollen, a's die besten englischen unà französischen, und wovon wir zwei (das stärkere hatte eine Brennweite von $1,41^{m . m .}$ ) zu untersuchen Gelegenheit hatten, halten die Vergleichung mit Nr.9 von Hartnack nicht aus. Sie stehen ihm zwar in der Auflösung gewöhulicher Probeobjecte sehr nahe, bleiben dagegen in anderen Fällen, wenn es sich z. B. um die feine Streifung aufgequollener Membranen u. dgl. handelt, ganz entschieden zurück. 
Bild eines Drahtgeflechtes bei $m$ maliger Vergrösserung gerade so deutlich gesehen werden müsste, als würde dasselbe in $m$ fachem Maassstab mit blossem Auge betrachtet. Nur die Lichtstärke des Bildes ist, weil abhängig vom Oeffnungswinkel des Objectivs, nicht nothwendiger Weise dieselbe, und insofern dieser Umstand auf die Unterscheidbarkeit der Maschen Einfluss übt, ist es allerdings denkbar, dass auch ganz vollkommene Instrumente mit der Vergrösserungszahl nicht gleichen Schritt halten; sie können relativ weniger, unter Umständen auch mehr leisten als das unbewaffinete Auge. Wir wollen indess der Einfachheit wegen vorläufig annehmen, die Lichtstärke des Mikroskops sei entweder $=1$, oder die Wahl der Lichtquelle werde stets so getroffen, dass die resultirenden Bilder gleiche Helligkeit besitzen. Ist alsdann $D$ der Durchmesser der Maschen an der Grenze der Sichtbarkeit bei unmittelbarem Sehen, $d$ der Durchmesser derselben bei cincr bestimmten Vergrösserung $m$, so ist (abgesehen von allfälligen Einflüssen physiologischer Natur) $d=\frac{D}{m}$ oder was auf dasselbe herauskommt $-\frac{D}{m d}=1$, wenn das Instrument vollkommen, dagegen $\frac{D}{m d}<1$, wenn es unvollkommen ist. Im letzteren Falle steht natürlich der grössere oder kleinere Werth des Bruches in Beziehung zum optischen Vermögen; er giebt aber nicht die absolute Grösse desselben an, sondern nur sein Verhältniss zur Leistungsfähigkeit eines vollkommenen Instruments. Wir können daher auch sagen, $\frac{D}{m d}$ sei der mathematische Ausdruck für das relative Unterscheidungsvermögen.

Die Grösse $D$ lässt sich leicht bestimmen, indem man in Erman-111 gelung hinreichend grosser Luftblasen ein geeignetes Objectiv, z. B. Nr. 7 von Oberhäuser, so auf den Objectträger bringt, dass seine Vorderfläche nach oben gekehrt ist, und hierauf das von demselben entworfene. Bild des Drahtnetzes durch die leere Mikroskopröhre, oder nöthigenfalls nach Wegnahme derselben, mit blossem Auge beobachtet. Man hält dabei das letztere in derjenigen Entfernung vom Object, für welche es sich am leichtesten accommodirt, und bestimmt schliesslich, wemn das Bildchen eben noch deutlich erkennbar ist, auf mikrometrischem Wege die Grösse desselben.

Man erhält jedoch auf diese Weise, und wie uns scheint ganz allgemein bei ähnlichen Beobachtungen mit blossem Auge, nicht so übereinstimmende Resultate, wie beim Sehen durchs Mikroskop. Inn- 
sere öfter wiederholten Messungen ergaben z. B. bei einer Sehwcite von 20 ( $^{\mathrm{m}}{ }^{\mathrm{m}}$. für $D \mathrm{~W}$ Werthe, die zwischen 100 und $12 \mathrm{~S}$ Mik. schwanken, welche Grössen, wenn man sich das Bildehen in der conventio-

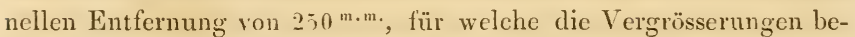
rechnet sind, projicist denkt, bezichlich auf 125 und 160 Mik. steigen. 112 Unter diesen VerhäInissen dürfte die graphische Darstellung sich wohl am-besten dazu eignen, die Resultate der Rechnung dem Auge in übersichtlicher Weise vorzuführen, weil dic Construction dieselbe bleibt, mag man diese oder jene Vergrösserung als Ausgangspunct wählen. Wir haben daher auf eine tabellarische Zusammenstellung verzichtet und dafür in Fig. 74 die Vergrösserungszahlen nach

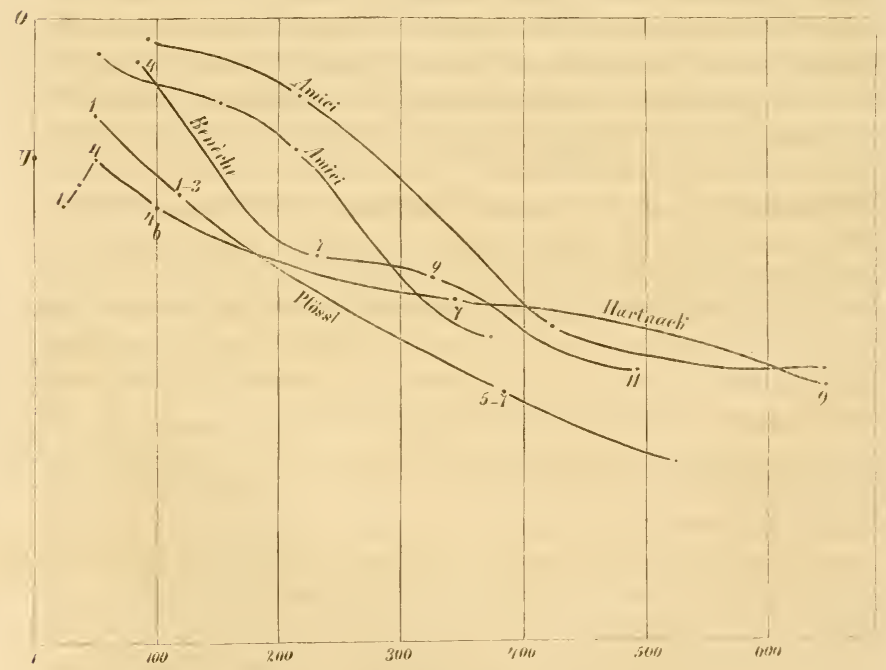

Figur if.

cinem ganz beliebigen. Maassstab als Abscissen und die entsprechenden Werthe von $\frac{D}{m l}$ nach einem beliebigen anderen Maassstab als Ordinaten aufgetragen. Die Verbindung der den zusammengehörigen Objectivsystemen entsprechenden Endpuncte der Ordinaten durch Linien gestattet alstann sowohl die Vergleichung der Systeme unter sich, als auch der Leistungen der betreffenden Optiker. Die absolute Grösse von I) kommt erst in Betracht, wenn es sich un liestimmung 
der dem blossen Auge (Vergr. 1) entsprechenden Ordinate handelt, und man kann sich dieselbe für jeden beliebigen Werth von $D$ leicht hinzudenken. In der Figur entspricht der Punct $U^{\top}$ dem oberen Grenzwerth ron 160 und der Punct $O$ dem untern Grenzwerth von 125 Mik. Maschendurchmesser.

Was an rorstehender Figur zunächst in die Augen springt, ist 113 die auffallende Thatsache, dass die am weitesten hinaufsteigenden Curven sogar die dem unbewaffneten Auge entsprechende Nireaulinie, wenn wir den mittleren Werth als maassgebend betrachten, überschreiten. Es gilt diess nicht bloss für die Curve der Amici'schen Objectirsysteme, deren Vergleichbarkeit mit den übrigen man am Ende noch in Zweifel ziehen könnte, weil sie nach Messungen eines andern Beobachters construirt ist, welcher sogar ausdrücklich hervorhebt, dass diese nämlichen Objectivsysteme hinsichtlich ihres optischen Vermögens dem blossen Auge nachstehen Harting l.c. pag. 306) - es gilt, nur in etwas weniger auffallendem Grade, auch für das Objectiv 4 von Bénèche. Wir bemerken übrigens, dass die auf die Oberhäuser'schen Mikroskope bezüglichen Messungen Harting's mit den unsrigen übereinstimmen und dass bei dem anerkannten Ruf der Amici'schen Objective kein Grund vorhanden ist, den dargestellten Verlauf der betreffenden Curven für unwahrscheinlich zu hảlten. Die Differenzen in den Schlussfolgerungen scheinen einzig und allein auf den allerdings nicht übereinstimmenden Beobachtungen mit blossem Auge zu beruhen $*$.

Es ist somit immerhin als sicher zu betrachten, dass es Mikro-11t skope giebt, die bei Anwendung schwächerer Vergrösserungen, trotz ihrer Unvollkommenheit, mehr leisten, als ein ganz vollkommenes, ideales Instrument der Theorie zufolge leisten müsste. Offenbar kann

-) Wie wenig überhaupt solche Beobachtungen übereinstimmen, zeigt die von $\mathrm{H}$ arting 'pag. 71 , mitgetheilte Tabelle, in welcher die Gesichtswinkel der Maschen an den Grenzen der Unterscheidbarkeit für + rerschiedene Beobachter zusammengestellt sind. Wir halten indess die dabei zu Grunde gelegte Beobachtungsmethode, nach welcher das Drahtnetz direct beobachtet und die Objectdistanz bis zu 3 Meter vergrössert wird, nicht für zweckdienlich, da man nicht wohl annehmen kann, dass das Auge sich für verschiedene Entfernungen immer gleich gut accommodire. Jedenfalls sind die Messungen an dioptrischen Bildern, wenn sie bei möglichst günstigem Abstand des Auges angestellt werden, behufs einer Vergleichung mit mikroskopischen Beobachtungen vorzuziehen. Das Netzhautbildchen entsteht alsdann im einen wie im anderen Fall unter annähernd gleichen Bedingungen, und die Reduction auf die conventionelle Entfernung von 25 Centim. ist Sache der Rechnung. 
diese paradoxe Erscheinung ihre Erklärung nur in Eigenthümlichkeiten finden, welche die mikroskopische Wahrnehmung, mögen nun die brechenden Linsensysteme mehr oder weniger unrollkommen sein, rom Sehen mit blossem Auge unterscheiden. Als solche Eigenthümlichkeiten lassen sich anführen: 1) die vom Oeffnungswinkel abhängige Verschiedenheit der Lichtstärke, woron bereits oben die Rede war ; 2. der Umstand, dass die aus dem Mikroskop ins Auge tretenden Lichtbündel meist weniger als $1^{\mathrm{m} . \mathrm{m}}$. Durchmesser haben und folglich die Pupille nur theilweise ausfüllen; 3 die chromatische Abweichung dieser Lichtbündel, welche bekanntlich nie ganz aufgehoben werden kann; 4 die sphärische Abweichung derselben.

Von diesen 4 Puncten - und wir wüssten keine weiteren hinzuzufügen - fällt der erste, wie die experimentelle Prüfung sogleich herausstellt, ausser Betracht; denn die Erscheinung bleibt dieselbe, auch wenn die Lichtstärke des mikroskopischen Bildes durch geeignete Wahl der Beleuchtung so geregelt wird, dass das unbewaffnete Auge sich in dieser Hinsicht sogar im entschiedenen Vortheil befindet. Ebenso wenig kann die unter 4 erwähnte sphärische Abweichung den Ausschlag geben, weil das Auge für Lichtbündel, welche annähernd in der Richtung seiner Axe auffallen, eine merkliche Aberration der Randstrahlen nicht hervorruft*) und folglich an eine Compensation einer solchen Abweichung durch die entgegengesetzte der einfallenden Strahlen nicht wohl gedacht werden kann. Dagegen muss der zweite Punct, nämlich die Verschmälerung der Lichtkegel bei übrigens gleicher Lichtstärke, einen günstigen Einfluss üben, weil dadurch die Schärfe der Netzhautbilder auch bei einem optisch vollkommenen Instrumente, ähnlich wie bei der directen Beobachtung, noch gesteigert wird. Sieht man z. B. durch eine kleine Oeffnung

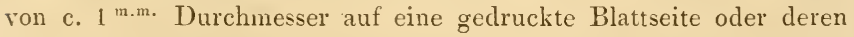
Bild, so erscheint die Schrift entschieden deutlicher, die Lettern schwärzer und schärfer contourirt. Ebenso ist es denkbar, dass die chromatische Abweichung des Auges, welche bekanntlich einen sehr merklichen Grad erreicht und dadurch vorzugsweise die Erscheinungen der veigentlichen ächten " Irradiation herrorruft***), durch ein schwach überverbessertes Mikroskop beseitigt wird, so dass auch von dieser Seite eine Verstärkung des W'ahrnehmungsvermögens mög-

* Vgl. hierüber Fick, Medizin. Physik S. 310 und die Abhandlung ron Volkmann über das »Sehen in R. Wagner's Handwörterbuch der Physiologie.

*+) Vgl. hierüber Fick 1. c. pag. 321. 
lich ist. Jedenfalls findet diese Erklärung auf das Objectiv 4 von Bénèche Anwendung, welches, obgleich deutlich überverbessert, im ganzen mittleren Theil des Gesichtsfeldes die entgegengesetzte chromatische Abweichung des Auges nicht einmal zu compensiren vermag. Wir werden weiterhin auf die Prüfung solcher Erscheinungen näher eintreten; hier wollten wir bloss die einfache Thatsache erwähmen, um die Richtigkeit der gegebenen Erklärung wenigstens für einen bestimmten Fall ausser Zweifel zu setzen.

Die graphische Darstellung zeigt zweitens; dass das relative opti-115 sche Vermögen der Mikroskope gegen die stärkeren und stärksten Vergrösserungen zu beträchtlich abnimmt, indem die entsprechenden Curven sich nach der rechten Seite zu ziemlich rasch der Abscissenaxe nähern und zuletzt sogar in den günstigsten Fällen ungefähr auf halbe Höhe heruntersinken. Wir dürfen hieraus den Schluss ziehen, dass die praktische Optik noch lange nicht an der Grenze des Erreichbaren angekommen ist, und ohne uns durch die öfter ausgesprochene Ansicht, es sei wenig Hoffnung vorhanden, das Mikroskop auf eine höhere Stufe der Vollkommenheit zu bringen, beirren zu lassen, noch wesentliche Verbesserungen für die Zukunft in Aussicht stellen.

Für die mittleren Vergrösserungen zwischen $300-400$ Mal sind die Leistungen der angeführten Optiker, wie man sieht, nahezu dieselben, während bei den schwächeren Objectiven nicht unerhebliche Differenzen hervortreten. Diese letzteren dürften jedoch in den meisten Fällen nicht sowohl im Können, als vielmehr im Wollen ibre Erklärung finden, weil der Grad der Vollkommenheit bei schwächeren Systemen, die man meistens nur der grösseren Lebersicht wegen benutzt, weniger ins Gewicht fällt, und folglich das Autbieten aller Kräfte nicht so lohnend erscheint. Zu gering darf man indessen die Torzüge eines guten Objectirs auch bei den schwächsten Vergrösserungen nicht anschlagen; man wird sie im Gegentheil bei allen $\mathrm{Cn}$ tersuchungen, wo Schärfe der Bilder und grosse Uebersicht vereinigt sein sollen, wie z. B. bei Gefässbündeluntersuchungen, immer in hohem Grade schätzen lernen.

Die Prüfung der Mikroskope vermittelst dioptrischer Bilder, die 116; man allınählich bis zur Grenze der Unterscheidbarkeit verkleinert, gestattet natürlich mancherlei Modificationen. Man kann statt eines Drahtnetzes beliebige andere Gegenstände, kugelförmige, fadenförmige, quadratische etc. zur Beobachtung wählen und dabei nicht bloss die Unterscheidbarkeit, sondern auch die Erkennbarkeit der Form, z. B. der Ecken eines Quadrats oder Sechsecks, als Maassstab 
zur Vergleichung benutzen. Auch zwei oder mehrere punctförmige Oeffnungen in einem dunkeln Schirm liefern ein ganz brauchbares Probeobject, indem die Entfernung von der Luftblase so gewählt werden kann, dass die einzelnen Puncte im Bilde eben noch getrennt gesehen werden. Selbstrerständlich sind jedoch die auf diese oder jene Art erhaltenen Resultate nur unter sich, nicht aber mit den auf einem anderen Wege gefundenen Ziffern vergleichbar. Für die Erkennbarkeit der Form eines einzelnen Quadrats wird man z. B. bei einer bestimmten Tergrösserung ganz andere Grenzwerthe erhalten, als für die Unterscheidbarkeit der quadratischen Maschen eines Drahtgeflechts, und dieselben Differenzen zwischen den absoluten Grössen treten auch bei der Beobachtung mit blossem Auge herror. Dagegen ist es nicht wohl denkbar, dass die relativen Grössenverhältnisse, wie sie im Verlauf der Curren sich darstellen, wesentlich anders ausfallen, und jedenfalls unrichtig, dass die Resultate der Prüfung bei Anwendung von Drahtgeflechten der "penetrirenden Kraft ", und bei kugelund fadenförmigen Objecten der definirenden Kraft " proportional sind*). Denn in allen Fällen, wo das von einer Luftblase entworfene Bild als Probeobject dient, füllen die zum Objectiv gelangenden Lichtkegel die Oeffnung desselben vollständig aus und werden daher von den Unvollkommenheiten der brechenden Flächen in gleicher W'eise beeinflusst.

Wir haben mehrere dieser Modificationen in Anwendung gebracht, jedoch immer gefunden, dass keine einzige derselben die nämliche Sicherheit der Beurtheilung gestattet, wie die zuerst erwähnte. Namentlich ist die Grenze der Erkennbarkeit bei kugelförmigen und fadenförmigen Objecten keineswegs leicht festzustellen und wird daher von verschiedenen Beobachtern auch in ziemlich abweichender Weise bestimmt. Dazu kommt, dass man zuletzt nicht mehr das scharfe Bild des Gegenstandes, sondern das ron Zerstreuungskreisen gebildete rerwischte Bild desselben beobachtet, welches wegen seiner grösseren Ausdehnung etwas länger wahrnehmbar bleibt. Es geht diess schon aus der Thatsache, dass die berechnete Grösse der Netzhautbildchen bei fadenförmigen Objecten oft entschieden kleiner ausfällt, als der Durchmesser der empfindenden Elemente ${ }^{*-}$, un-

-) Diese Ansicht sucht $\mathrm{H}$ arting l. c. pag. 30 - plausibel zu machen, indem er sie als eine sich selbst aufdrängende Folgerung der ron ihm mitgetheilten Beobachtungsreihen hinstellt.

-. Nach den neuesten Untersuchungen der Netzhaut besteht die Stäb- 
zweifelhaft hervor; denn es lässt sich nicht annehmen, dass diese letzterên qualitativ verschiedene Reize als solche zum Bewusstsein bringen. In letzter Instanz hängt demnach die Sichtbarkeit einer dunkeln Linie auf hellem Grunde vorzugsweise davon ab, ob das beobachtende Auge einen schwachen Lichtausfall, welcher sich nur über einen Theil der einzelnen Netzhautelemente erstreckt, noch wahrzunehmen rermag. Die rermeintliche Prüfung des Mikroskops läuft also wesentlich auf eine Prüfung des Auges hinaus.

Unter diesen Verhältnissen verzichten wir auf die Zusammenstellung unserer Messungen und rerweisen Diejenigen, welche sich aus diesem oder jenem Grunde für solche Beobachtungen interessiren, auf das ausführliche Werk von Harting.

\section{Organische Probeobjecte.}

Unter den organischen Körpern, deren feinere Structurverhält-117 nisse ein gutes Mikroskop erst bei einer gewissen Vergrösserung zur Wahrnehmung bringt, bieten namentlich die kleinen Schüppchen, welche auf der Haut vieler Insecten, insbesondere auf SchmetterlingsHügeln rorkommen, sowie ferner die Kieselschalen der Diatomeen die rerschiedensten Abstufungen. Erstere wurden demn auch lange Zeit fast ausschliesslich als Probeobjecte benutzt und einige derselben finden auch jetzt noch vielfach Anwendung; die letzteren, zuerst in England in Torschlag gebracht und zur Prüfung starker Objective besonders geeignet, kamen in neuester Zeit so allgemein in Gebrauch, dass sie jetzt wohl die gewöhnlichste Zugabe der Optiker bilden. Obschon wir nun freilich aus den oben angeführten Gründen die mit diesen Probeobjecten erhaltenen Resultate der Prüfung nicht für streng maassgebend betrachten, so lässt sich doch nicht in Abrede stellen, dass sie uns ein leicht anwendbares Mittel an die Hand geben, die Leistungsfähigkeit eines Mikroskops approximativ zu beurtheilen. Die

chenschicht, welche als das eigentlich lichtpercipirende Organ betrachtet wird, im gelben Flecke der am besten sehenden Stelle bloss aus sogenannten Zapfen, deren Durchmesser c. 5 Mik. beträgt. Diese Grösse entspricht, wenn der Abstand des Kinotenpunctes von der Netzhaut zu $15^{\mathrm{m} \cdot \mathrm{m}}$. angenommen wird, einem Sehwinkel ron ungefähr $65^{\prime \prime}$ und bei einer Objectdistanz von 25 Cent. einem Durchmesser von 53 Mik. Nun sind aber nach Harting (Nikr. pag. 29y) fadenförmige Objecte bei 50maliger Vergrösserung noch mikroskopisch wahrnehmbar, wenn ihre wirkliche Dicke $=0,19+$ Mik. und folglich der Durchmesser des mikroskopischen Bildes $=50 \times 0,194=9,7$ Mik. beträgt. Das entsprechende Netzhautbildchen würde also nicht einmal den sten Theil eines Netzhautelementes einnehmen. 
Kenntniss der gebräuchlichsten Probeobjecte ist daher immerhin ron praktischem Werth, und es ist jedem Mikroskopiker anzuempfehlên, sich die Schärfe und Klarheit der Bilder zu merken, welche dieselben in einem guten Instrumente bei einer bestimmten Vergrösserung hervorrufen. Wir wollen daher eine gedrängte Aufzählung der Schmetterlingsschuppen und Diatomeenpanzer, welche in neuester Zeit als besonders geeignet zu Testobjecten vorzugsweise benutzt werden, hier folgen lassen und, wo es nöthig erscheint, eine kurze Beschreibung derselben hinzufügen.

118 Was zunächst die Schmetterlingsschuppen betrifft, so zeigen dieselben gewöhnlich deutliche Längsstreifen, welche unter sich parallel oder etwas dirergirend ron der Basis des Schüppchens nach seinem oberen Rande verlaufen, und weniger deutliche $Q$ uerstreifen, welche rechtwinklig zu jenen stehen und bei etwas tieferer Einstellung zum Vorschein kommen. Diese Streifensysteme sollen bei den nachstehend bezeichneten Vergrösserungen deutlich herrortreten.

1. Lepisma saccharinum. Längsstreifen der grösseren Schüppchen schon bei 40 maliger, der kleineren bei $100-150$ maliger Vergr. deutlich. Die grösseren Schüppchen sind keilförmig, die kleineren mehr rundlich, mit blasseren, dichter gestellten Streifen.

2. Hipparchia Janira. a Schuppen ron den Flügeln des Weibchens. Längsstreifen nach Schacht schon bei sofacher, Querstreifen bei schiefer Beleuchtung mit den Objectiren $5-\bar{i}$ ron Hartnack, 7 von Bénèche, C ron Zeiss, also bei c. 200-300maliger Vergrösserung sichtbar. Durch stärkere Objective sollen die Querstreifen auch bei geradem Licht deutlich als scharfe Linien nicht körnig oder unterbrochen gesehen werden. Die langen und hellen schuppen sind, wie immer, schwieriger als die dunkler gefärbten. b) Schuppen ron der Oberseite der Flügel des Männchens. Längsstreifen nach Mohl nur mit den stärksten Amici'schen Objectiren und schiefer Beleuchtung sichtbar; ron Querstreifen, die ohne Zweifel auch rorhanden sind, keine Spur.

3. Podura plumbea. Schuppen mit längsverlaufenden kurzen Streifen, die schon bei schwächerer Vergrösserung deutlich hervortreten, übrigens in Bezug auf Grösse sehr ron einander differiren. Querlinien nach Harting fehlend, nach Schacht* dagegen, welcher eine Abbildung der Schuppen giebt, schon mit den gewöhnlichen Objectiren bei schiefer Spiegelstellung sichtbar.

- H. schacht. I)as Mikioskop (1562 pag. 32 . 
4. Lycaenu Argus. Schuppen ron der Oberfläche der Vorderflügel: a) Solche, die bei auffallendem Lichte blau, bei durchfallendem hellgelb erscheinen. Längsstreifen schon bei schwächerer Tergr. (60-So Mal), Querlinien erst bei 300-400 maliger Vergr. sichtbar. Wegen der grossen Gleichförmigkeit der Schuppen besonderer Beachtung werth. b) Solche, welche bei auffallendem Lichte hellbraun, im durchgehenden grau und dunkel erscheinen. Längsstreifen wie bei den vorigen; Querstreifen, obgleich enger gezogen, etwas weniger schwierig, jedoch nicht unter einer 300 maligen Tergrösserung wahrnehmbar. c) Schüppchen von ovaler Form, welche im auf- und durchfallenden Lichte eine gelbliche Färbung zeigen. Mit Reihen von dunkeln Puncten, die c. $2 \frac{1}{2}-3$ Mik. ron einander abstehen und daher schon mit mässigen $\mathrm{V}$ ergrösserungen scharf begrenzt gesehen werden sollen.

Weit mannigfaltiger, als bei den Schmetterlingsschuppen, ist die 119 Zeichnung der Diatomeenpanzer. Als Prüfungsobjecte werden indess meistens solche benutzt, welche zwei oder drei Liniensysteme erkennen lassen, die sich im ersten Fall unter einem rechten, im letzteren unter schiefen Winkeln schneiden. Ob diese Liniensysteme von herrorragenden Leisten, oder von kleinen Erhabenheiten oder Vertiefungen, welche reihenförmig gestellt sind, oder endlich von Dichtigkeitsverschiedenheiten herrühren, ist in den meisten Fällen unentschieden, indem die rerschiedenen Ansichten, welche man hie und da, und zuweilen mit grosser Zuversicht, darüber ausgesprochen findet, der näheren Begründung entbehren. Wir lassen daher diese Frage unerörtert und beschränken uns einfach auf die Charakteristik des mikroskopischen Bildes, das bei der Prüfung ja ohnehin einzig und allein in Betracht kommt.

5. Pleurosigmu angulatum. (Fig. 75.) Zwei gleich starke und gegen die Mittellinie gleich geneigte Streifensysteme schneiden sich unter Winkeln von c. $53^{0}$ (nicht wie gewöhnlich angegeben wird, unter $60^{\circ}$; ein drittes, etwas weniger deutliches System steht rechtwinklig auf der Mittellinie und bildet mit den beiden schiefen Systemen Winkel

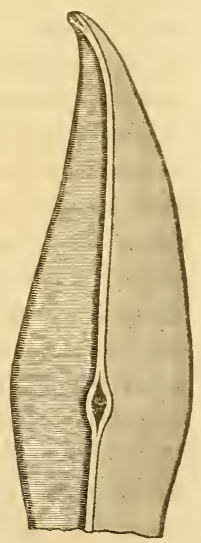

Figur 75 . von ungefähr $63^{1 / 2}{ }^{\circ}$. Jedes dieser Liniensysteme soll bei schiefer Beleuchtung, wenn das Licht im rechten Winkel gegen dasselbe einfällt, schon durch mittelstarke Objective, wie Nr. 7 ron Hartnack, 
Nr. 9 von Bénèche, also bei c. 300-350 maliger Vergrösserung '), für sich allein deutlich gesehen werden, so dass beim Drehen des Objectes alle drei Systeme nach einander zum Vorschein kommen. Die stärkeren Objective, welche eine Vergrösserung von 500-600 Mal geben, lassen die drei Liniensysteme schon in geraden Licht gleichzeitig hervortreten und lösen dieselben bei schiefer Beleuchtung in helle Puncte auf, welche sich nach den drei genannten Richtungen in Reihen ordnen. Mit den besten Objectiven endlich und der günstigsten Ocularvergrösserung ist es möglich, diese hellen Puncte als nicht ganz regelmässige Sechsecke zu erkennen, deren zwei längste Seiten mit der Mittellinie parallel laufen Fig. 76). Wir machen auf diese

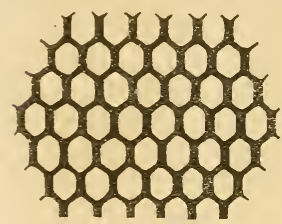

Figur 76 .

Lage der Sechsecke besonders aufmerksam, weil dieselbe von $\mathrm{Schacht} \mathrm{t}^{*}$ und Anderen in wesentlich abweichender Weise beschrieben und abgebildet wird, dazu mit einer Regelmässigkeit, welche überhaupt in der Natur nicht rorkommt. Unsere Darstellung, die übrigens mit bereits bekannten übereinstimmt, stützt sich auf Beobachtungen mit einer vortrefflichen Immersionslinse von Hartnack, combinirt mit den stärksten Ocularen von Bénèche, und darf in allen wesentlichen Puncten - also abgesehen von der genauen Form der Sechsecke, der Schärfe der Ecken u. dgl. - als vollkommen richtig und naturgetreu betrachtet werden. Die dunkeln Linien, welche bei schwächerer Vergrösserung vollkommen geradlinig erscheinen, sind also in Wirklichkeit Zickzacklinien, und zwar bestehen die beiden schiefen Systeme, wie obige Figur zeigt, aus abwechselnd längs und schief verlaufenden Elementen, während die Querlinien nur von diesen letzteren gebildet werden. Da nun die längsverlaufenden Elemente durchweg stärker sind, als die schiefen, so erklärt sich hieraus die grössere Deutlichkeit der schiefen Streifensysteme. Dagegen widerstreitet dieses Verhalten der von Schacht vertheidigten Ansicht, dass die Streifensysteme, weil sie gewöhnlich bei verschiedener Einstellung am deutlichsten gesehen werden, verschiedenen Schichten entsprechen. Die scheinbare Niveauverschiedenheit beruht auch in der That nur auf einem optischen Effect, wel-

*) Diese Vergrösserungsziffern setzen eine Ocularvergrösserung ron c. $4 \frac{1}{2}-$ 5 Mal voraus, z. B. Ocular Nr. 2 von Bénèche und Nr. 3 von Hartnack.

${ }^{++}$S chach t, 1)as Mikr. p. 25 u. T'af. I Fig. 9 u. 10. 
cher in der ungleichen Stellung der schief gestellten Streifenelemente gegen das einfallende Licht seine Erklärung findet*). Daher rührt es, dass ein und dasselbe System bei einer gewissen Stellung der Mittelrippe entschieden höher, nach einer Drehung von ungefähr $90^{\circ}$ dagegen ebenso entschieden tiefer zu liegen scheint.

Dieses ausgezeichnete Probeobject kann, wie auch alle folgenden, durch Bourgogne in Paris bezogen werden. Die Exemplare liegen gewöhnlich in Balsam und zwar in so grosser Zahl, dass man nicht erst lange zu suchen braucht, um ein zur Beobachtung taugliches zu finden. Die grösseren zeigen, wie sich erwarten lässt, eine etwas deutlichere Zeichnung als die kleineren. Man darf indess vollkommen zufrieden sein, wenn das Mikroskop die Prüfung mit den grössten und schönsten Exemplaren in der angedeuteten Weise besteht.

6. Pleurosigma uttenuatum. Mit stärkeren Längsstreifen, welche parallel der Mittelrippe verlaufen, und rechtwinklig darauf stehenden zarten Querlinien. Längsstreifen im geraden Licht schon bei 150-200 maliger Tergrösserung deutlich, so z. B. mit Objectiv Nr. 7 und Ocular Nr. 1 ron Bénèche; Querstreifen bei c. 300 maliger Vergrösserung im geraden Licht angedeutet und stellenweis deutlich, bei schiefer Beleuchtung durchgehends sehr scharf, so z. B. mit Objectiv Nr. 9 von Bénèche und Mr. $i$ ron Hartnack. Mit stärkeren Objectiven lösen sich die hellen Linien, wie immer bei ähnlichen Zeichnungen, sehr deutlich in kleine Quadrate oder eigentlich Rechtecke auf, deren Ecken mehr oder weniger abgestumpft sind, so dass die dunkeln Scheidelinien hier knotig verdickt erscheinen.

i. Pleurosigma balticum. Mit Längsstreifen und etwas zarteren Querstreifen; erstere schon bei 200 maliger Vergrösserung im schiefen Lichte sichtbar, letztere unter 300 maliger Vergrösserung kaum deutlich. Nr. 7 von Bénèche zeigt die Längslinien nur mit den stärkeren Ocularen entschieden und deutet die Querlinien am Rande an; mit Nr. 9 dagegen und Nr. 7 ron Hartnack lassen sich beide Systeme in aller Schärfe erkennen.

8. Grammatophora marina. Randpartieen mit Querstreifen und zwei weniger deutlichen schiefen Streifensystemen, ähnlich wie bei Pleurosigma angulatum. Alle drei Streifensysteme lassen sich durch das Objectiv Nr. 9 ron Bénèche erkennen, und zwar die Querstreifen

-) Da nämlich die stärkeren, längs gestellten Elemente den beiden schiefen Streifensystemen angehören und daher in jeder beliebigen Lage gegen das einfallende Licht für beide in gleicher Weise wirken, so kann die Verschiedenheit des Effectes nur von den schief gestellten Elementen herrühren. 
schon mit den gewöhnlich benutzten Ocularen Nr. 1 und 2, die schiefen dagegen ganz deutlich erst mit den stärkeren Ocularen. Ziemlich dasselbe gilt auch für das Objectir Nr. 7 ron Hartnack. Man darf demmach jedenfalls rerlangen, dass ein Mikroskop mit $340-400$ maliger Vergrösserung die drei Streifensysteme zur Wahrnehmung bringe.

9. Surivella Gemma. (Fig. 77. Zwischen den starken, in

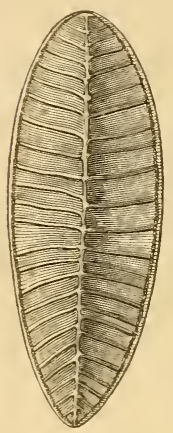

Figur 7 ;.

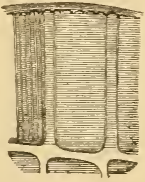

Figur 75. unregelmässigen Entfernungen auftretenden Querleisten zu beiden Seiten der Mittelrippe und parallel mit denselben verlaufen zartere Querstreifen, welche selbst wieder von äusserst feinen Längslinien Fig. is rechtwinklig geschnitten werden. Diese letzteren werden nur durch die allerstärksten Objective, wie Nr. 9 und 10 ron Hartnack, deutlich gesehen; die erstern erfordern dagegen bloss eine etwa $400-500$ malige Tergrösserung.

10. Nitzschia sigmoidea Sigmatella Nitzschii. Der lange und schmale Panzer zeigt zarte, dicht gestellte Querlinien, welche nach Schacht selbst durch die Wasserlinse ron Hartnack Nr. 10, erst bei schiefem Lichte gelöst werden, übrigens bei derselben Beleuchtung auch mit den stärksten Objectiren ron Bénèche und Zeiss sichtbar sind. Diese Angaben Schacht's beziehen sich auf trocken aufbewahrte Exemplare, welche bekanntlich weniger schwierig sind, als die in Balsam liegenden.

11. Grammatophora subtilissima. (Fig. 79, 1.) Randpartie $a$ mit äusserst zarten und dichtge. stellten Querstreifen Fig. 79, 2, welche (wenn das Präparat in Canadabalsam liegt

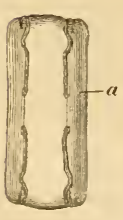

\section{2}

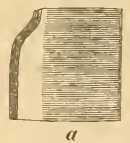

Figur 79. nur durch die allerstärksten Objective aufgelöst werden. Mit dem Immersionssystem Nr. 9 ron Hartnack rermochten wir kaum eine Andeutung dieser Streifung zu sehen.

12. Navicula "ffinis. Mit Längsund Querstreifen, erstere deutlicher und 
nicht sehr schwierig, letztere äusserst scharf und fein. Wurde auf der letzten Londoner Industrieausstellung in Canadabalsam liegend als Testobject benutzt.

Ausser den rorstehend aufgeführten Probeobjecten wurden in 120 neuester Zeit noch manche andere, die ebenso geeignet sein mögen, in Vorschlag gebracht und finden gewiss auch hie und da Anwendung, so z. B. verschiedene Arten von Navicula, Coscinodiscus, Frustulia saxonica, Hyalodiscus subtilis u. a. mehr, worunter manche eine so feine Streifung zeigen sollen, dass $4-5$ Linien auf einen Mikromillimeter kommen. Wir halten indess unsere Aufzählung: für vollkommen genügend und sind nicht geneigt, der Entdeckung neuer Probeobjecte bei dem gegenwärtigen Standpunct der praktischen Optik eine besondere Wichtigkeit beizulegen. Wir möchten sogar jedem Mikroskopiker den Rath geben, eine Auswahl ron höchstens 3 oder + zu treffen und sich dafür um so genauer zu merken, wie sich dieselben unter verschiedenen Mikroskopen darstellen. Diess wird ihm bei der Prüfung eines unbekannten Instrumentes stets besser zu Statten kommen, als die einfache Thatsache, ob dasselbe ein bestimmtes Prüfungsobject löst oder nicht.

Wir wollen auch nicht unerwähnt lassen, dass in Ermangelung eigentlicher Probeobjecte zarte Durchschnitte durch Tannenholz oder andere dickwandige Gewebe zur Prüfung benutzt werden können. Hier muss das Netzwerk, welches die Scheidelinien der sich berührenden Zellen oder die peripherischen Schichten an einander stossender Membranen unter sich bilden, sowie ferner der Cmriss der Hohlräume, bei 200-400 naliger Vergrösserung zart und scharf gezeichnet erscheinen. Dicke, verschwommene Umrisse oder Farbensäume, welche dem Object nicht angehören, deuten immer auf eine mangelhafte Terbesserung der sphärischen oder chromatischen Aberration. Auch Querschnitte durch geschichtete Bastzellen mit Porencanälen, Pollenkörner, Stärkekörner, Parenchymzellen mit Siebporen u. s. w. können über die Güte eines Mikroskops im Allgemeinen Aufschluss geben; ja es giebt überhaupt wenig Objecte in der organischen Natur, welche - wenn man sie genau kennt - nicht die erforderlichen Anhaltspuncte zur Beurtheilung des mikroskopischen Bildes böten. Nur ist es natürlich mit solchen Mitteln nicht möglich, das optische Vermögen des Mikroskops in Zahlen auszudrücken. 


\section{Nobert's Probetäfelchen.}

121 Mit der Anwendung organischer Probeobjecte ist stets der Nachtheil verbunden, dass die Resultate, welche der Beobachter erhält, mit denen eines andern Beobachters nie vollkommen vergleichbar sind, weil die gleichnamigen Objecte in Grösse und Dentlichkeit zu sehr ron einander differiren. Um diesem Cebelstand abzuhelfen, kam Nobert auf den glücklichen Gedanken, ein künstliches Prüfungsobject in Form einer mikrometrischen Theilung auf Glas herzustellen. Er verfertigte schon $1 \$ 16$ Probetäfelchen mit 10 Liniengruppen, wobei die Abstände der einzelnen Linien in der ersten Gruppe am grössten, in jeder folgenden etwas kleiner und in der letzten am kleinsten waren. In der Folge vermehrte er die Zahl der Gruppen auf 12, 15,20 und neuerdings sogar auf 30 , reränderte aber zugleich die Abstände in den vorhergehenden Nummern, so dass die mit älteren Probetäfelchen erhaltenen Resultate mit den an neueren angestellten Beobachtungen nicht vergleichbar sind. Die Abstände der Linien auf den neueren Probetäfelchen und zugleich die Zahl derselben auf $1^{\mathrm{m} . \mathrm{m}}$. sind in der folgenden Tabelle nach Warren de la Rue is. Harting, las Mikr. p. S\$3) zusammengestellt.

\begin{tabular}{|c|c|c|c|c|c|}
\hline Gruppe. & $\begin{array}{c}\text { Abstand } \\
\text { in } \\
\text { Iik. }\end{array}$ & $\begin{array}{c}\text { Linien } \\
\text { auf } \\
1 \mathrm{~m} \cdot \mathrm{m} .\end{array}$ & Gruppe. & $\begin{array}{c}\text { Abstand } \\
\text { in } \\
\text { Iik. }\end{array}$ & $\begin{array}{c}\text { Linien } \\
\text { in } \\
1 \mathrm{~m} \cdot \mathrm{m} .\end{array}$ \\
\hline \hline 1 & 2,256 & +43 & 10 & 0,620 & 1612 \\
2 & 1,945 & 514 & 11 & $0,59 \mathrm{~L}$ & 1692 \\
3 & 1,647 & 607 & 12 & 0,565 & 1772 \\
1 & 1,399 & 715 & 13 & 0,533 & 1575 \\
5 & 1,240 & 506 & 14 & $0,50 \mathrm{~S}$ & 1969 \\
6 & 1,052 & 924 & 15 & 0,451 & 2216 \\
7 & 0,902 & $110 \mathrm{~S}$ & 20 & 0,377 & 2653 \\
$\mathrm{~S}$ & 0,759 & 1267 & 25 & 0,323 & $309 \mathrm{~S}$ \\
9 & $0,+576$ & $147 \mathrm{~S}$ & 30 & $0,2 \mathrm{~S} 2$ & 35.14 \\
& & & & & \\
\hline
\end{tabular}

Wie man aus dieser Tabelle ersieht, stehen die Nobert'schen Probeblättchen an Feinheit der Theilung nur wenig hinter den schwierigsten organischen Objecten zurück. Sie stimmen auch in sofern mit denselben überein, als Licht und Schatten im Bilde hier ebenfalls durch Brechung der Strahlen in einer farblosen Substanz, nicht durch dumkle und helle Stellen im Object bedingt wird. Wir lassen es übrigens, da wir dieselben aus eigener Beobachtung nicht näher kennen, 
dahingestellt, ob sie wirklich einen zurerlässigeren Maassstab zur Prüfung bieten, als die Kieselpanzer der Diatomeen oder die von Amici und Mohl empfohlenen Schmetterlingsschuppen. Dass indess eine vollständige Uebereinstimmung der gleichnamigen Liniensysteme, insbesondere mit Rücksicht auf die Stärke der Striche, mit keiner Maschine erreicht werden kann, lässt sich schon a priori mit Gewissheit behaupten.

Wir bemerken noch, dass Nobert die Probetäfelchen mit 10 Gruppen zu 5 Thaler, solche mit 15 Gruppen zu 10 Thaler, endlich solche mit 30 Gruppen zu 30 Thaler berechnet.

\section{II.}

\section{Prüfung der sphärischen Aberration.}

Wir stellen uns jetzt, nachdem wir die Methoden erörtert, welche 122 das optische Termögen des Mikroskops im Allgemeinen zu prüfen gestatten, die veitere Aufgabe, die verschiedenen Momente oder Factoren zu untersuchen, welche jenes Vermögen bedingen. Unter diesen Factoren nimmt erfahrungsgemäss die sphärische Aberration die erste Stelle ein: sie festzustellen und die jedesmalige Wirkung der angewendeten Linsencombination genau zu ermitteln, ist daher namentlich für den Optiker, wenn er nicht im Finstern herumtappen will, eines der wichtigsten Probleme.

Es handelt sich dabei in der Praxis zunächst um die Frage, wie das Torhandensein der sphärischen Aberration sich im mikroskopischen Bilde kundgebe, und in zweiter Linie um die Entscheidung, ob dieselbe auf eine Unterverbesserung oder Ueberverbesserung des $\mathrm{Ob}$ jectirs hindeute. Damit ist freilich die Aufgabe, wie man leicht einsieht, noch keineswegs in ihrem ganzen Umfange gelöst; denn es liesse sich ja denken und kommt auch in der That häufig genug ror, dass das Objectir für die mittleren Strahlen, beispielsweise bis zu einer Neigung von $10-15^{\circ}$, unterverbessert, für die Randstrahlen dagegen überverbessert wäre. Da jedoch der Praktiker nur auf den rorwiegenden Effect sieht, so betrachtet er ein Linsensystem als möglichst aplanatisch, wenn entweder der grössere centrale Theil, oder der grössere peripherische Theil des einfallenden Strahlenkegels keine merklichen Aberrationen zeigt. Er sieht also im einen Falle, um die herkömmliche Ausdrucksweise der Mikrographen zu gebrauchen, mehr auf die definirende, im andern mehr auf die penetrirende Kraft. 
123 Die Wirkung der sphärischen Aberration im Allgemeinen läss - sich leicht durch die Construction reranschaulichen. Ist al Fig. Sol

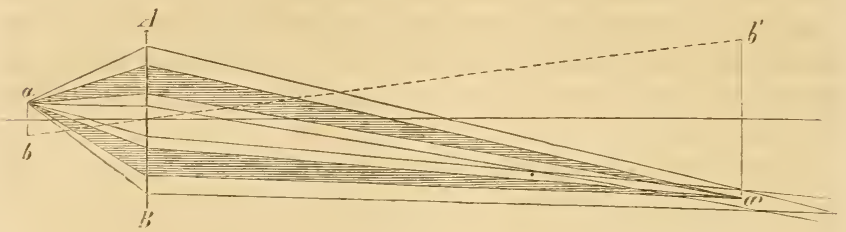

Figur su.

ein selbstleuchtendes Object, dessen Strahlenkegel die Oeffnung des Objectivs $A B$ ganz ausfüllen, und nehmen wir an, die ron $a$ und $b$ ausgehenden Lichtstrahlen vereinigen sich nach der Brechung zum grösseren Theil in der Figur ist diess für die Strahlen mittlerer Neigung angenommen $j$ in den Puncten $a^{\prime}$ und $b^{\prime}$, während die übrigen nach etwas näher oder entfernter liegenden, übrigens mehr oder weniger von einander abstehenden Puncten convergiren, wie es in der Figur für ein mittleres und ein peripherisches Strahlenpaar angedeutet ist. Alsdann kommt in $a^{\prime}$ das reelle Bild des Punctes $a$ zu Stande, ebenso in $b^{\prime}$ das Bild von $b$ und folglich in den zwischenliegenden Puncten die Bilder der entsprechenden des Objects. Eine durch die Puncte $a^{\prime}$ und $b^{\prime}$ gelegte bildauffangende Ebene würde aber, wie die Construction zeigt, ausserhalb dieser Puncte noch ron Strahlen getroffen, deren Kreuzungspuncte nach unserer Annahme ror oder hinter diese Ebene fallen. Und zwar rühren diese Strahlen nicht bloss von den äussersten Randpuncten des Objects $a$ und $b$ her, sondern auch von den benachbarten bis zu einer gewissen Entfernung rom Rande, von wo an auch die aberrirenden Strahlen die Projectionsfläche des Bildes treffen. Das beobachtende Auge muss also, wenn es das rom Objectiv entworfene Bild durch das Ocular in welchem die Ebene der Blendung den bildauffangenden Schirm darstellt beobachtet, ausserhalb der Ränder $a^{\prime}$ und $b^{\prime}$ der leuchtenden Bildfläche noch einen Lichtschimmer wahrnehmen, welcher von den mit Aberration behafteten Strahlen herrührt.

Die Prüfung der Aberrationsverbesserung kann also einfach dadurch geschehen, dass man eine kleine leuchtende Fläche oder ein reelles oder virtuelles Bild, das sich wie eine solche Fläche verhält, als Object unter das Mikroskop bringt und dafür Sorge trägt, dass von der Umgebung kein Licht ins Auge gelangt. Je schwächer als- 
dann der Lichtschimmer, welcher das mikroskopische Bild umgiebt, um so vollständiger ist die Aberrationsverbesserung.

Die Herstellung eines geeigneten Objectes betreffend, kennen 124 wir kein besseres Mittel als clas, welches im Princip schon Mohl und später auch Harting in Anwendung gebracht hat. Man bedeckt eine Glasplatte durch wiederholtes Auftragen mit dem Pinsel mit einer hinreichend dicken, vollkommen undurchsichtigen Schicht von chinesischer Tusche, in welche man hierauf mit einer feinen Nadel oder einem Messer feine Puncte oder Linien, welche das Licht durchlassen, einschneidet. Man kann auch einfach die Platte längere Zeit liegen lassen; es bilden sich dann in Folge der Zusammenziehung der Tuscheschicht eine Unzahl von kleinen, scharf berandeten Oeffnungen in derselben, welche noch besser als die künstlichen zur Prüfung geeignet sind.

Bei dem Gebrauche muss natürlich die Bedingung erfüllt werden, welcher überhaupt jedes Probeobject genügen soll, dass nämlich die Strahlenkegel, welche ron den leuchtenden Puncten ausgehen, die ganze Oeffinung des Objectirs ausfüllen was Mohl und Harting, wie es scheint, nicht berücksichtigt haben. Zu diesem Ende muss bei schwächeren Objectiven die Blendung entfernt oder hinreichend gross gewählt und der Spiegel genähert, bei stärkeren aber eine Beleuchtungslinse oder ein geeignetes Objectirsystem eingeschaltet werden, um die Convergenz der einfallenden Strahlen in entsprechendem Grade zu verstärken. Hat das zu prüfende Objectirsystem beispielsweise eine Oeffnung von $60^{\circ}$, so muss dem auf die Glasplatte einfallenden Beleuchtungskegel eine mindestens eben so grosse Oeffinung gegeben werden.

Die übrigen Objecte, welche von den Mikrographen empfohlen worden sind, wie z. B. die ron einer Luftblase oder einem Quecksilbertropfen (auf dunkler Unterlage) entworfenen Bildchen der Fensterrahmen, sind unseres Erachtens nicht so geeignet, um den Grad der Aberrationsverbesserung darnach zu bemessen, als die erwähnten wirklichen Oeffnungen in einem sonst schwarzen Gesichtsfelde. Letztere gewähren nämlich den wesentlichen Vortheil, dass ein Zurückziehen der Blendung oder des Beleuchtungsapparates die Randzone des Objectivs ausser Wirkung bringt und folglich den Beobachter in den Stand setzt, die Prüfung sticcessive auf einen immer kleineren centralen Theil der brechenden Flächen zu beschränken. Man macht öfter die Wahrnehmung, dass der starke Lichtschimmer, welcher das mikroskopische Bild umsäumt, sogleich verschwindet, sobald die 
äussersten Randstrahlen abgeschnitten werden, während er in anderen Fällen nur unmerklich abnimmt und daher rorzugsweise ron den mittleren Strahlen herrührt. Solche Verschiedenheiten festzustellen, ist natürlich mit eine Aufgabe der Prüfung: sie kann aber mittelst Quecksilbertropfen und Luftblasen nur dadurch gelöst werden, dass man die entsprechenden Blendungen am Objectiv anbringt. Dazu kommt, dass weder die Fensterrahmen noch die Limgebungen des Fensters hinreichend dunkel sind, um in einem katoptrischen oder dioptrischen Bilde einen schwarzen Hintergrund zu bilden, woraus dann folgt, dass das Vorhandensein eines schwachen Lichtnebels sich weniger leicht erkennen lässt. Mit Rücksicht hierauf würden wir eine grosse kugelförmige Luftblase, welche das Bild einer kleinen, dazu noch zurückgezogenen Blendungsöffnung entwirft, einem Quecksilbertropfen noch vorziehen, wei] wenigstens die L'mgebung des Bildchens bis zum inneren hellen Ring rollkommen schwarz erscheint. Der Lichtschimmer, den ein solches Bildchen hervorruft, fällt aber immer etwas schwächer aus, als bei einer wirklichen Oeffnung, weil die Randstrahlen durch theilweise Reflexion an der Oberfläche der Luftblase beträchtlich geschwächt werden.

125 Die Beantwortung der weiteren Frage, ob ein mit Aberration behaftetes Objectiv unter- oder überverbessert sei, stützt sich auf die Erscheinungen, welche eine höhere oder tiefere Einstellung des Oculareinsatzes oder, was im Wresentlichen auf dasselbe herauskommt, die Vergrösserung oder Verkleinerung der Objectdistanz herrorruft. Denken wir uns vorerst den einfachen Fall, dass die rorkommenden Abweichungen sämmtlich in demselben Sinne stattfinden, so zwar, dass die Brechung im Objectiv rom Centrum nach der Peripherie, wenn sie überhaupt eine Veränderung erleidet, continuirlich zu- oder abnimmt, so lassen sich die Wirkungen einer veränderten Einstellung leicht überblicken. Ist wieder $A B$ Fig. $\$ 1)$ das Objectir, $p$ der Tereinigungspunct oder der kleine Tereinigungsraum aller mittleren

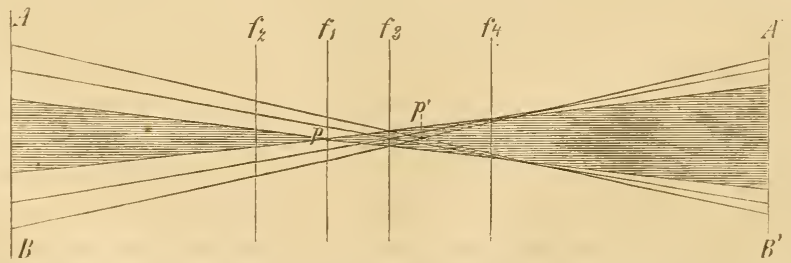

Figur $\rightarrow 1$ 
Strahlen bis zu einer gewissen Neigung und $p p^{\prime}$ die grösste Längenabweichung der Randstrahlen, für welche also das Objectiv überverbessert ist; so wird das 'reelle Bild auf einem auffangenden Schirm sich offenbar dann am schärfsten darstellen, wenn derselbe mit einer durch den Punct $p$ gelegten Ebene $f_{1} f_{1}$ zusammenfällt ; es erscheint aber umsäumt von einem Lichtnebel, der von den in der Umgebung auffallenden Randstrahlen herrührt. Wird jetzt der Schirm weiter nach links in die Lage $f_{2}$ gebracht, so schneidet er sowohl den bilderzeugenden centralen Kegel, als die aberrirenden peripherischen Strahlen in einer grösseren Fläche; das Bild muss sich folglich verwischen, während der Lichtnebel an Umfang und Breite zunimmt. Findet dagegen die Verschiebung in der entgegengesetzten Richtung statt, so wird der Querschnitt durch die gesammte Strahlenmasse zunächst kleiner und erreicht in $f_{3}$, wo die peripherischen Strahlen sich mit den bilderzeugenden kreuzen und folglich der Lichtnebel verschwindet, sein Minimum. Der Schirm wird also in $f_{3}$ durch einen kleinen, scharf begrenzten Lichtkreis erhellt. Weiter nach rechts hin nimmt der letztere an Umfang wieder zu; er behält aber die nämlichen scharfen Umrisse, weil die peripherischen Strahlen sich innerhalb derselben projiciren. In der Nähe von $f_{4}$ erscheint sogar die Randzone des Lichtkreises entschieden heller, weil die aberrirenden Strahlen sich hier der Oberfläche des centralen Kegels nähern; sie sticht also noch entschiedener als vorher gegen die dunkle T'mgebung ab.

Gerade umgekehrt sind die Erscheinungen, wenn die sphärische Aberration für die peripherischen Strahlen unterverbessert ist. Um die nämliche Construction auch auf diesen Fall anzuwenden, denken wir uns in obiger Figur das Objectiv in $A^{\prime} B^{\prime}$, statt in $A B$. Der Strahlenverlauf entspricht alsdann der entgegengesetzten Abweichung, und dieselbe Bewegung des Schirmes, die in Bezug auf $A B$ eine Annäherung war, ist ein Fernerrücken in Bezug auf' $A^{\prime} B^{\prime}$. Selbstrerständlich bleiben aber die Projectionen der gesammten Strahlenmasse in den verschiedenen Lagen dieselben.

Ist also das Mikroskop möglichst genau auf die leuchtende Fläche eingestellt, so hat das Hineinschieben des Oculars bei einem überverbesserten Instrument ein stärkeres Hervortreten des Lichtnebels, bei einem unterverbesserten dagegen die Bildung einer scharf begrenzten, am Rande etwas helleren Lichtscheibe zur Folge, während das Herausziehen des Oculars natürlich jedesmal die entgegengesetzte Erscheinung hervorruft. Den nämlichen Effect erzielt man auch, wenigstens innerhalb der in Betracht kommenden Grenzen, wenn für 
die Verschiebungen des Oculars, die ohne besondere Vorrichtungen mit mancherlei Unbequemlichkeiten rerbunclen sind, entsprechende Verschiebungen des Objects substituirt werden. Statt das Ocular mit Rücksicht auf das Objectiv näher oder entfernter zu rücken, nähert oder entfernt man das Object, senkt oder hebt man die Mikroskopröhre. Wo demnach eine tiefere Einstellung einen stärkeren Lichtnebel, eine höhere einen scharf begrenzten Lichtkreis hervorruft, besteht Ueberverbesserung; wo die Erscheinungen in umgekehrter Folge hervortreten, Unterverbesserung.

$\mathrm{Zu}$ diesen Wirkungen der sphärischen Aberration, die für sich allein schon sehr deutlich in die Augen fallen, gesellen sich noch diejenigen der chromatischen, welche in der Regel die Gegensätze noch steigern. Der Lichtnebel erscheint in Folge dessen bläulich und die Lichtscheibe erhält einen grünlich-gelben, aussen meist deutlich rothen Saum, der bis zu einer gewissen Grenze um so entschiedener hervortritt, je grösser sein Durchmesser. Die Unterscheidung der unter- und überverbesserten Aberration wird dadurch noch wesentlich erleichtert.

126 In mikrographischen Werken wird als ferncres Criterium der beiden entgegengesetzten Aberrationen noch hinzugefügt, dass die Details der Zeichnung im Bildchen, wie z. B. die Fensterrahmen bei Benutzung von Quecksilbertropfen, in welchen das Fenster sich spiegelt, oder die Formen der Ränder kleiner Oeffnungen in einem sonst schwarzen Gesichtsfelde, bei der Annäherung des Objectes auf einmal, beim Fernerrücken dagegen langsan rerschwinde, wenn das Objectiv unterverbessert sei, und umgekehrt bei einem überverbesserten Instrument. So allgemein ausgesprochen ist diese Angabe offenbar unrichtig, und es stellt sich diess auch bei der experimentellen Prüfung heraus*; . In unserem speciellen Fall, wie er in Fig. $\$ 1$ dargestellt ist, müsste sogar das gerade Gegentheil stattfinden. Denn es ist eimleuchtend, dass eine Verschicbung des bildauffangenden Schirms in der Richtung von $f_{1}$ nach $f_{4}$ die Schärfe des Bildes weniger beeinträchtigt, als die entgegengesetzte, weil alle Vereinigungspuncte der peripherischen Strahlen und folglich auch die denselben entsprechenden Bilder rechts von $f_{1}$, zwischen $p$ und $p^{\prime}$, liegen. Eine Verschiebung in die-

* Wir haben noch neuerdings ein Objectirsystem kennen gelernt, welches bei richtiger Einstellung das Luftblasenbildchen unseres Drahtgeflechtes sehr scharf wiedergab. Das Bild verschwand beim Heben und Senken des Tubus ziemlich rasch, kam jedoch bei stärkerer Hebung abermals, nur etwas verschwommen, zum Vorschein. 
ser Richtung entspricht aber bei einem unterrerbesserten Mikroskop einer Annäherung, bei einem überverbesserten einem Fernerrücken des Objects. Ist dagegen das Objectiv so construirt, dass die Randstrahlen des Lichtkegels bis zu einem gewissen Minimum der Neigung die bilderzeugenden sind, während die Centralstrahlen nach der einen oder andern Seite hin aberriren Fig. \$2 , dann allerdings trifft die

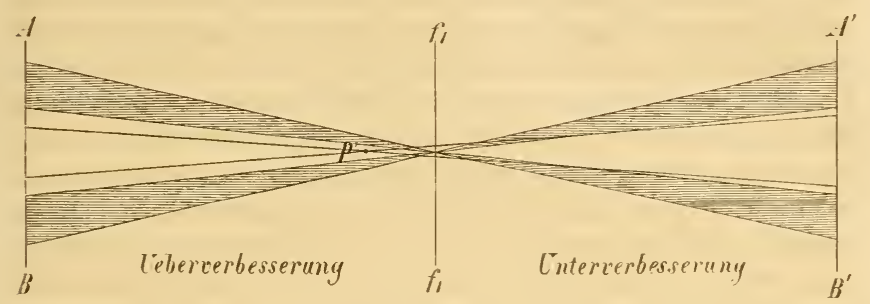

Figur $=2$.

ron den Mikrographen aufgestellte Regel zu. Es ist diess aber nur eine der mancherlei Combinationen, die sich denken lassen, und wenn sie auch möglicher Weise am häufigsten rorkommt was wir übrigens bezweifeln, so ist es doch nicht gestattet, sie bei der Prüfung ohne Weiteres vorauszusetzen. Wir können daher das langsamere oder raschere Verschwinden des Bildchens beim Heben oder Senken des Focus nicht als Criterium der Teber- oder Unterverbesserung gelten lassen, es sei denn, dass seine Anwendbarkeit vorher auf irgend eine Weise erwiesen worden.

Bei dem in Fig. S2 dargestellten Strahlenverlauf bedingt die 127 Einstellung des bildauffangenden schirmes oder des Oculareinsatzes auf die Ebene $f_{1} f_{1}$, in welcher das Objectirbild zu Stande kommt, nothwendig einen schwachen, von den Centralstrahlen herrührenden Lichtschimmer, der indess bei einer kleinen Verschiebung nach rechts oder links sogleich rerschwindet. Dabei ist es rollkommen gleichgültig, ob das Objectiv in $A B$ oder in $A^{\prime} B^{\prime}$ gedacht werde; der Lichtkreis, der sich bei veränderter Einstellung auf dem Schirme ausbreitet, erscheint im einen wie im andern Falle rollkommen scharf begrenzt. Die sphärische Aberration giebt sich also bei einem solchen Strahlenverlauf nur in der Ebene des Bildes kund und zwar durch einen Lichtnebel, der beim Zurückziehen der Blendung, wodurch die Oeffnung des gesammten wirksamen Strahlenkegels verkleinert wird, keine merkliche Veränderung zeigt. 
Kommen dagegen zu den bilderzeugenden peripherischen Strahlen noch weitere hinzu, welche wie die mittleren mit Aberration behaftet sind, so werden die Erscheinungen complicirter. Die Randstrahlen deuten alsdann durch die Wirkung, die sie bei höherer und tieferer Einstellung hervorbringen, auf Ueber-oder Unterverbesserung, gleichviel, ob die Centralstrahlen in der nämlichen oder in der entgegengesetzten Richtung aberriren. Es ist in diesem Falle nöthig, die Blendung so lange zu verkleinern oder zurückzuziehen, bis der bläuliche Lichtschimmer sich bei mittlerer Einstellung nicht weiter verändert und bei tieferer oder höherer Einstellung total verschwunden ist. Die zurückgebliebenen Spuren der Aberration können alsdann nur noch von den Centralstrahlen herrühren, und das oben erwähnte Criterium der Unter- und Ueberverbesserung, nämlich das raschere oder larigsamere Verschwinden des Bildchens beim Heben oder Senken der Mikroskopröhre, findet - wie aus der Construction ohne Weiteres herrorgeht - seine Anwendung. Man wird indess in den meisten Fällen, wenn die Aberration der Centralstrahlen nicht einen sehr erheblichen Grad erreicht, ziemlich unsichere Resultate erhalten, weil auch die bilderzeugenden Strahlen sich nicht, wie wir vorausgesetzt haben, genau in demselben Puncte schneiden, sondern zum Theil mit der entgegengesetzten Längenabweichung behaftet sind. Die Umrisse des Bildchens verschwinden alsdann weder bei höherer noch bei tieferer Einstellung plötzlich, und es ist schwer zu sagen, welche von beiden langsamer wirkt. Diess ist auch der Grund, warum wir auf die Erörterungen weiterer Combinationen, welche mit Rücksicht auf die Aberrationen der verschieden geneigten Strahlen rorkommen können, rerzichten. Die Erscheinungen, welche man für diese oder jene Annahme theoretisch festgestellt hat, treten bei der experimentellen Prüfung zu sehr getrübt und unentschieden hervor, als dass sie zur Beurtheilung des Objectirs noch sichere Anhaltspuncte lieferten.

128 Das wirklich praktische Prüfungsverfahren beschränkt sich also, wenn wir das Vorhergehende kurz zusammenfassen, auf folgende Puncte.

1. Man giebt dem rom Spiegel kommenden Lichtkegel eine wenigstens ebenso grosse Oeffnung, als sie das zu untersuchende Objectiv besitzt. Bei stärkeren Objectiven geschieht diess durch Anwendung eines passenden Beleuchtungsapparates oder in Ermangelung desselben durch Einschalten einer 3-- ${ }^{m, m}$. im Durchmesser haltenden Objectirlinse unter dem Objectträger. 
2) Man stellt hierauf das Mikroskop auf diejenige Ebene ein, in welcher die Details des Bildes, wie z. B. die Ränder kleiner Oeffnungen in einer geschwärzten Platte, am deutlichsten gesehen werden. Ist alsdann ein bläulicher Lichtnebel in der Umgebung des Bildchens bemerkbar, so ist die sphärische Aberration nicht gehörig corrigirt.

$3 \mathrm{Um}$ zu entscheiden, welche Strahlen des auffallenden Lichtkegels mit Aberration behaftet sind, ziehe man den Beleuchtungsapparat oder die Blendung allmählich zurück. Wenn alsdann der Lichtschimmer rasch abnimmt oder gänzlich verschwindet, so beschränkt sich die Aberration auf die Randstrahlen; behält er dagegen längere Zeit dieselbe Intensität, so liegt die Ursache der Erscheinung in den mittleren Strahlen. Im letzteren Fall, welcher übrigens seltener vorkommt, muss der Lichtschimmer verschwinden, wenn der centrale Theil des Objectivs durch eine geeignete Blendung ausser Wirkung gesetzt wird.

4) Man prüft die Erscheinungen, welche eine höhere oder tiefere Einstellung herrorruft, wobei in zweifelhaften Fällen die Verschiebung des Oculars den Vorzug verdient. Die U'eberverbesserung des Objectirs init Rücksicht auf die Randstrahlen ist hiebei daran zu erkennen, dass der bläuliche Lichtnebel bei tieferer Einstellung sich weiter ausbreitet, bei höherer dagegen sogleich verschwindet, so dass das mikroskopische Bild sich als scharf begrenzter, meist grünlichgelb eingefasster Lichtkreis darstellt. Die Unterverbesserung ist durch die nämlichen Gegensätze in umgekehrter Aufeinanderfolge charakterisirt.

5 Die Aberration der Centralstrahlen lässt sich nur dann genauer ermitteln, wenn der dadurch hervorgebrachte Lichteffect ziemlich augenfällig ist - ein Fall, der nach unseren Erfahrungen fast gar nicht vorkommt.

6) Wenn die unter 4, erwähnten Erscheinungen unentschieden ausfallen, indem z. B. der Lichtschimmer sowohl bei höherer als bei tieferer Einstellung noch einige Zeit wahrnehmbar bleibt, so ist das ein Zeichen, dass im peripherischen Theil des Lichtkegels beiderlei Aberrationen vorkommen, vielleicht in Folge einer ungleichförmigen Krümmung der brechenden Flächen.

Wir haben uns bemüht, für die Kugelabweichung der verschie-129 den geneigten Strahlen noch irgend eine andere, wo möglich genauere Prüfungsmethode ausfindig zu machen, jedoch ohne den gewünschten Erfolg. Indess mag folgendes Verfahren, welches wenigstens grössere Fehler sehr deutlich veranschaulicht, hier noch Erwähnung finden. 
Man bedecke die hintere Endfläche des Objectirsystems mit einem kreisförmigen Blättchen ron Papier oder Stanniol, in welchem 4-6 kleine Löchelchen so angeordnet sind, dass die am weitesten von einander abstehenden die äussersten Randstrahlen, die übrigen die mehr centralen Strahlen des wirksamen Lichtkegels durchlassen. Bringt man alsdann eine feine Lichtlinie, wie sie z. B. ein mit Luft gefülltes und ron $W$ asser umgebenes Glasröhrchen liefert, als Object unter das Mikroshop, so erscheint dieselbe in jedem ordentlichen Mikroskop bei mittlerer Einstellung einfach, jedoch meistens etwas verwischt, bei höherer oder tieferer dagegen, der Zahl der Löcher entsprechend, 4-6fach. Diẹse Erscheinung kann an und für sich Niemanden auffallen: sie erklärt sich ganz einfach dadurch, dass der gemeinsame Kreuzungspunct der Strahlenbündel bei veränderter Einstellung ausserhalb der bildauffangenden Ebene (im Oculareinsatz liegt, so dass sich auf derselben die noch nicht rereinigten, oder nach der Vereinigung wieder divergirenden Bündcl einzeln projiciren und folglich durch die Ocularlinse auch einzeln, als getrennte Bilder, gesehen werden. Der gegenseitige Abstand dieser Bilder nimmt natürlich mit der Entfernung des gemeinsamen Kreuzungspunctes ron der Projectionsebene zu und ab.

Nun kommen aber noch folgende besondere T'mstände hinzu. Wenn man etwas genauer die Art und Weise beobachtet, wie die bei mittlerer Einstellung zusammenfallenden Bilder während der Hebung oder Senkung des Focus oder des Oculars auseinander treten, so macht man die Wahrnehmung, dass sich je nach der Eigenthümlichkeit des Objectirs bald die den peripherischen Bündeln entsprechenden extremen Linien, bald die mittleren zuerst ron einander trennen, so dass im letzteren Fall zunächst eine Theilung in zwei Hälften und erst später eine weitere Spaltung dieser letzteren stattfindet. Die Deutung dieser Erscheinungen ergiebt sich ron selbst, wenn man den Strahlenrerlauf nach der Brechung in einem mit Aberration behafteten Objectiv durch die Construction veranschaulicht und dabei die bildauffangende Ebene in verschiedene Lagen bringt.

Sei $A B$ Fig. $\$ 3$ ein überverbessertes, $A^{\prime} B^{\prime}$ ein unterverbessertes Objectir und $P Q$ und $P^{\prime} Q^{\prime}$ die Blendungen mit den 4 Löchelchen abcd, durch welche eben so viele Strahlenbündel in die Mikroskopröhre eintreten; dann muss eine bildauffangende Ebene in der Lage $f_{1}$ eine einfache Lichtlinie, in den Lagen $f_{2}$ und $f_{3}$ beziehlich 3 und 2 Lichtlinien, endlich in $f_{4}$ und $f_{5}+$ Lichtlinien zur Wahrnehmung bringen. Ganz dasselbe gilt natürlich auch ron der entsprechenden 
höheren oder tieferen Einstellung des Mikroskops. Die Annäherung des Objects hat bei einem überverbesserten Objectiv zunächst eine

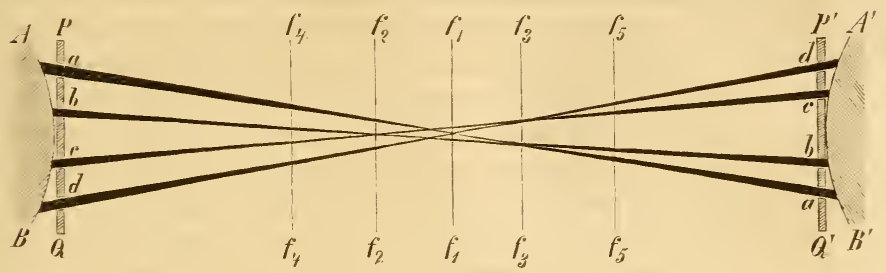

Figur $\$ 3$.

Dreitheilung, bei einem unterverbesserten dagegen eine $\mathrm{Z}$ weitheilung zur Folge. Das Fernerrücken des Objects ruft natürlich jedesmal die entgegengesetzte Wirkung herror.

\section{III.}

\section{Prüfung der chromatischen Aberration.}

Das einfachste und zuverlässigste Mittel, die chromatische Aber-130 ration eines Linsensystems zu prüfen, besteht darin, die eine Hälfte der vorderen (oder nöthigenfalls hinteren) Endfläche mit einem $\mathrm{Pa}$ pier- oder Stanniolblättchen zu bedecken, so dass nur die andere Hälfte optisch wirksam bleibt. Bringt man alsdann eine Lichtlinie oder eine kleine leuchtende Fläche z. B. eine kleine Oeffnung in einer geschwärzten Platte) als Object unter das Mikroskop, so erscheint dasselbe in einem vollkommen achromatischen Instrument farblos, in einem über- oder unterverbesserten dagegen auf der einen Seite blau, auf der andern roth-orange oder gelb berandet. Welche Anordnung diese Farben je nach der Art der Abweichung zeigen, lässt sich ohne Weiteres aus Fig. $\mathrm{S} 1$ entnehmen. Es sei $A B$ das zu untersuchende Objectiv, dessen rechte Hälfte durch die Blendung $P$ bedeckt ist. Da nun die offengelassene linke Hälfte wie ein Prisma wirkt, so müssen, wenn die chromatische Aberration unterverbessert ist, die rerschiedenfarbigen reellen Bilder des Objects $a b$ sich offenbar so rerschieben, dass das violette $\left(a_{v}^{\prime}, b_{v}^{\prime}\right)$ auf der rechten, das rothe $\left(a_{r}^{\prime} b^{\prime}{ }_{r}\right)$ auf der linken Seite am weitesten vorsteht. Das mikroskopische Bild erhält also auf der rechten Seite einen violetten oder blauen, 
auf der linken einen rothen oder orangefarbigen Saum. Ist dagegen die chromatische Aberration überverbessert, so erscheint die linke Seite violett und die rechte roth oder orange.

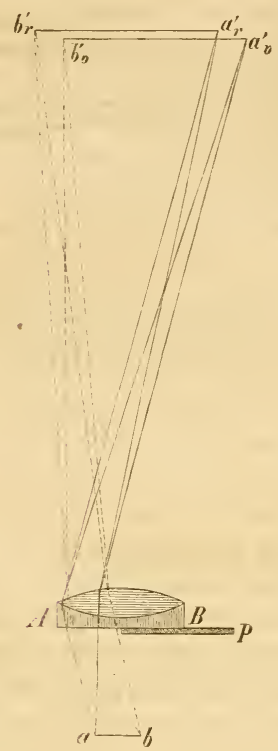

Figur $\$ 4$.

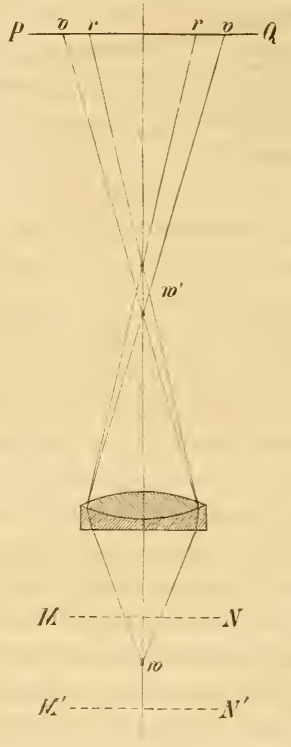

Figur $\varsigma^{5}$.

131 In dem Vorhergehenden findet auch die von $\mathrm{Nohl}$ und $\mathrm{Har}$ ting empfohlene Methode ihre Begründung. Sei $w$ Fig. S5) die als Object dienende selbstleuchtende Fläche, z. B. der virtuelle Brennraum einer Luftblase oder eines Quecksilbertropfens. Die mittlere Einstellung giebt alsdann ein scharfes, meist ganz farbloses Bild, weil die einfallenden Lichtkegel die ganze Oeffnung des Objectivs ausfüllen und die entgregengesetzten Aberrationsfarben der rechten und linken Hälfte sich zu Weiss ergänzen. Hebt man dagegen den Focus des Mikroskops in die Ebene $M N$, so werden dadurch die Bedingungen der Strahlenbrechung wesentlich geändert. Das eigentliche Bild kommt jetzt weiter unten in der Mikroskopröhre bei $\mu^{\prime}$ zu Stande; das Ocular erhält also bloss die davon ausgehenden divergirenden Strahlen, die sich auf der bildauffangenden Ebene $P Q$ als Lichtkreis 
projiciren. Jede Hälfte des Oculars wirkt also gesondert: ein beliebiger Sector des Lichtkreises wird ron cinem entsprechenden, aber opponirten Sector des Objectivs entworfen und zeigt daher auch die Spuren der dem letzteren eigenthümlichen Aberration. Ist das Objectiv unterverbessert, werden also die violetten Strahlen $(v)$ stärker gebrochen als die rothen $(r)$, so erhält der Lichtkreis, wie man ohne Weiteres aus der Construction ersieht, einen blauen, im Fall einer Ueberverbesserung dagegen einen rothen Saum.

Ebenso lässt sich durch eine ganz ähnliche Betrachtung darthun, dass wenn das Mikroskop auf die tiefer gelegene Ebene $\boldsymbol{I}^{\prime} \mathrm{N}^{\prime}$ eingestellt wird, die entgegengesetzten Farben zum Vorschein kommen müssen. Ein rother Saum deutet alsdann auf Unterverbesserung, ein blauer auf Ueberverbesserung.

Dieses Prüfungsverfahren ist unstreitig sehr einfach und theoretisch betrachtet vollkommen begründet. Man wird jedoch in den meisten Fällen die Ueberzeugung gewinnen, dass die zuerst erwähnte Methode bei kleinen Aberrationen entscheidendere Ergebnisse liefert. Will man das etwas umständliche Bedecken der Linsen vermeiden, so braucht man bloss eine kleine Oeffnung auf dunkelm Grunde als Object zu wählen, dieselbe in die Mitte des Gesichtsfeldes zu placiren und hierauf den Spiegel so weit seitlich zu schieben, dass er von der Axe des Mikroskops nicht mehr geschnitten wird. Es ist einleuchtend, dass alsdam der einfallende Lichtkegel nur die dem Spiegel opponirte Hälfte der Objectivorderfläche trifft.

Prüft man nun verschiedene Mikroskope in der angegebenen 132 Weise, so wird man in der Mehrzahl der Fälle die Charaktere einer entschiedenen Unterverbesserung oder Teberverbesserung wahrnehmen. Die Objective, welche für die rothen und violetten Strahlen achromatisch sind und daher bloss die Farben des secundären Spectrums hervorrufen, sind nach unseren Erfahrungen ziemlich selten. Bei manchen Mikroskopen erscheinen die Farbensäume am Rande des Gesichtsfeldes viel intensiver als in dessen Mitte; ja es kann sogar vorkommen, dass die an einer Stelle des Gesichtsfeldes beobachtete Aberration an einer andern mehr centralen oder opponirten Stelle in die entgegengesetzte umschlägt. Diess ist z. B. bei den Objectiven Nr. 7 und 9 ron Bénèche in einem sehr merklichen Grade der Fall. Andere sind für die Randpartieen des Gesichtsfeldes achromatisch, für die Mitte dagegen unterverbessert.

Wir haben im Vorhergehenden stillschweigend vorausgesetzt, 133 dass die Farbensäume, welche von der chromatischen Aberration des 
Objectivs herrühren, von dem beobachtenden Auge unverändert gesehen werden. Diese Voraussetzung war für eine rorläufige Betrachtung zulässig, da es sich vor Allem um qualitative, nicht um quantitative Verschiedenheiten in den Erscheinungen handelte. Dieselbe ist jedoch, wie leicht einzusehen, in keinem Fall streng genommen richtig, weil sowohl die Brechungen im Ocular, als diejenigen im Auge des Beobachters selbst wieder mit Farbenzerstreuung verbunden sind. Beide Puncte, die Wirkung des Oculars und diejenige des Auges, verdienen daher eine eingehende Erörterung.

Was zunächst das Ocular betrifft, so ist es ein vielverbreiteter Irrthum, der in mikrographischen Werken und physikalischen Lehrbüchern stereotyp geworden, dass das Zusammenwirken der Collectivund Ocularlinse die fehlende Achromasie des Objectirs bis zu einem gewissen Grade ersetze. Die Sache wird gewöhnlich so dargestellt und begründet, dass man das rothe und violette Objectivbild, sowie die entsprechenden Bilder des Collectivs und des Oculars, in gewohnter Weise mit Hülfe der Richtungsstrahlen (d.h. der Strahlen, welche durch den optischen Mittelpunct der Linsen gehen construirt, wobei sich dann allerdings die Möglichkeit herausstellt, der Ocularlinse stets eine solche Lage zu geben, dass die schliesslichen virtuellen Bilder, nahezu unter dem nämlichen Winkel gesehen werden und sich folglich decken müssen.' Diese Theorie des Campani'schen Oculars, wie sie z. B. in Müller-Pouillet's Lehrbuch der Physik, in Fick's medizinischer Physik, in Harting's "Mikroskop " etc. entwickelt ist, entbehrt jedoch, wie im Folgenden gezeigt werden soll, jeder thatsächlichen Grundlage. Die Schlüsse sind zwar vollkommen richtig, aber die Toraussetzungen sind falsch.

Es wurde bereits früher darauf hingewiesen, dass das rom Collectiv entworfene reelle Bild unter ganz besonderen Verhältnissen zu Stande kommt, in Folge deren die Construction desselben durch einfaches Ziehen der Richtungsstrahlen unstatthaft wird. Genau dasselbe gilt aber auch für das virtuelle Bild des Oculars. Jeder Punct dieser Bilder wird ron einem anderen Flächenelement der Linse entworfen als der benachbarte; je weiter der Bildpunct vom Centrum des Gesichtsfeldes absteht, um so weiter ist auch das betreffende Stück der brechenden Fläche rom Centrum der Linse entfernt. Dazu kommt, dass die einfallenden Lichtkegel, da wo sie die Linse treffen, so verschmälert sind, dass sie kaum einen Durchmesser von $1^{\mathrm{m} . \mathrm{m}}$. besitzen, folglich beinahe wie einfache Strahlen gebrochen werden.

134 Nach dieser Feststellung der thatsächlichen Verhältnisse, welche 
die herkömmliche Darstellungsweise ignorirt, wollen wir es versuchen, die Wirkung des Campani'schen Oculars durch eine Construc. tion zu veranschaulichen, in welcher alle wesentlichen Factoren berücksichtigt sind. Es sei $A$ Fig. $\delta 6$, das Objectir, $B$ das Collectiv und $C$ das Ocular. Als Object mag das ganze Gesichtsfeld, oder eine kleine Oeffuning in einer geschwärzten Platte, oder irgend ein anderer Gegenstand angenommen werden, insofern er nur der Bedingung genügt, dass die von ihm ausgehen. den Strahlenkegel die ganze Oeffnung des Objectiv's oder doch wenigstens den centralen Theil derselben ausfüllen. Diess rorausgesetzt, werden die verschiedenfarbigen Strahlen offenbar so gebrochen, dass die einem bestimmten

Objectpuncte entspre. chenden ausfahrenden Lichtkegel die Axe mit einander gemein haben. Die Richtungslinien, in welchen die Spitzen rerschiedenfarbiger Kegel liegen,

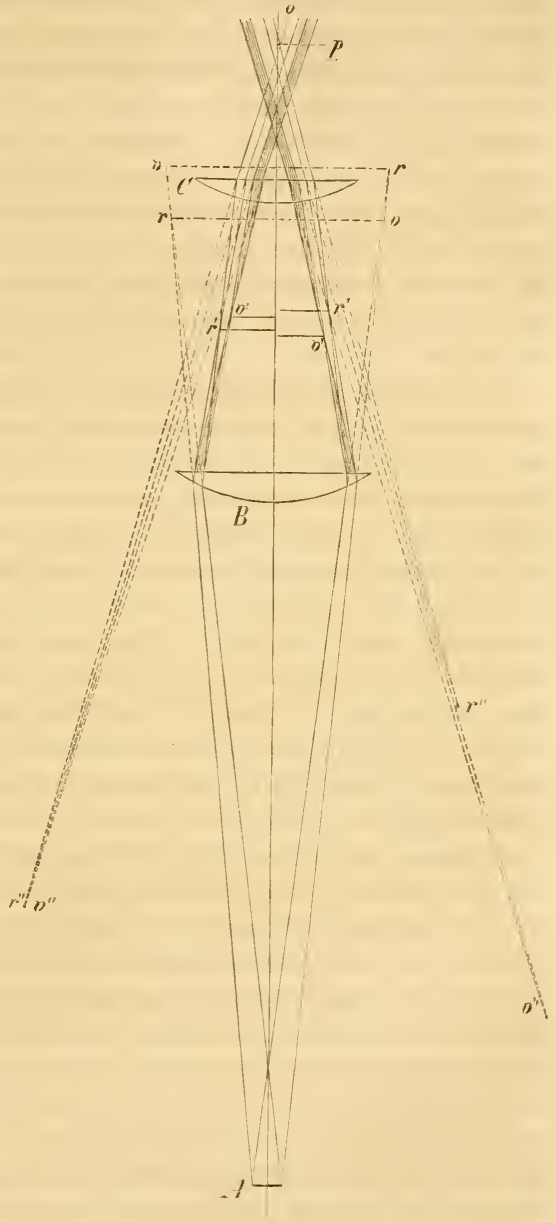

Figur $>6$. sind also gegeben; nur das Niveau dieser Spitzen ist unbestimmt, 
weil abhängig von der Farbenabweichung des Objectivs. In unserer Figur entsprechen die beiden symmetrischen Lichtkegel, rechts und links von der Mittellinie, zwei opponirten Randpuncten des Objects. Da die Brechungen, welche sie erfahren, natürlich ebenfalls symmetrisch sind, so hätte es genügt, die Construction auf der einen Seite auszuführen und die Bildpuncte der andern in gleichen Abständen hinzuzufügen. Statt dessen wurden zur bequemeren Vergleichung zwei entgegengesetzte Fälle neben einander gestellt: linker Hand der Strahlengang bei chromatischer Ueberverbesserung des Objectivs, rechter Hand derselbe bei eben so starker Unterverbesserung. Die Scheitel der violetten Strahlenkegel sind beiderseits mit $v$, die der rothen mit $r$ bezeichnet; ebenso die entsprechenden Puncte des reellen Bildes mit $v^{\prime}$ und $r^{\prime}$.

Es ist nun ohne Weiteres klar, dass die rothen und violetten Lichtbündel im Collectiv beiderseits die nämliche Ablenkung erfahren, weil sie dasselbe auch unter dem nämlichen Winkel treffen. Die Kreuzungspuncte $o$ und $p$ der gleichnamigen Bündel liegen also nothwendig in der Axe. Betreffend die Lage der reellen Bildpuncte $v^{\prime}$ und $r^{\prime}$ ist wenigstens so viel sicher, dass auf der linken Seite $r^{\prime}$, auf der rechten $c^{\prime}$ dem Collectiv näher zu liegen kommt, als der gleichnamige Bildpunct der andern Seite. Der Abstand in der Richtung der Axe ist jedoch nothwendig kleiner, als derjenige der beiden $r$ oder der beiden $v$. Ebenso ist klar, dass bei gleichem Abstand der virtuellen Objecte $v$ und $r$ das violette Bild $v^{\prime}$ in etwas geringerer Entfernung vom Collectiv zu Stande kommt, als das rothe $r^{\prime}$. Die beiderseitigen reellen Bilder müssen demnach ungefähr die Anordnung zeigen, wie sie in der Figur dargestellt ist.

Die Brechung im Ocularglas hängt natürlich, wie bereits oben (Nr. 61 und die vorhergehenden) gezeigt wurde, von der Lage des letzteren ab. Liegt der Krümmungsmittelpunct der brechenden Kugelfläche zwischen den Kreuzungspuncten $o$ und $p$, so findet die erste Brechung der beiden Lichtbündel in entgegengesetztem Sinne statt, und es lässt sich, je nach Bedürfniss, ein Verhältniss herstellen, welches die Divergenz derselben in einem beliebigen Grade mildert oder auch einen vollständigen Parallelismus herstellt. Zur Erreichung dieses Zieles ist übrigens die Brechung in entgegengesetztem Sinne keineswegs unerlässliche Bedingung. Der Umstand, dass die rothen Strahlen die Ocularlinse in grösserer Entfernung rom Centrum treffen, als die blauen, und daher wegen der Kugelabweichung auch stärker gebrochen werden, genügt vollkommen, um solche Differenzen 
der Neigung aufzuheben, ja sogar in die entgegengesetzten überzuführen. Erwägt man, dass die hierauf beruhenden Unterschiede in der Ablenkung um so bedeutender sind, je weiter das Ocular rom Collectiv absteht, so wird es sehr erklärlich, dass eine allmähliche Vergrösscrung dieses Abstandes die ausfahrenden Bündel endlich zur Convergenz bringt. In diesem Falle treffen sie aber, rückwärts verlängert, die Ebene der virtuellen Bilder so, dass das Roth im Gesichtsfeld aussen, das Violett innen zu stehen kommt. Das Object erhält alsclann einen rothen oder orangefarbigen Saum. Umgekehrt bewirkt eine zu grosse Annäherung des Oculars an das Collectiv einen blauen Saum, weil die Divergenz der ausfahrenden Strahlen dadurch wieder gesteigert wird, so dass nunmehr die violetten Bündel das Gesichtsfeld weiter aussen treffen.

Aus dem eben Gesagten geht hervor, dass sich für jedes Auge eine bestimmte Stellung der Ocularlinse ausfindig machen lässt, bei welcher die austretenden verschiedenfarbigen Lichtbündel, rückwärts verlängert, genau in der Entfernung sich kreuzen, für welche dasselbe eingestellt ist. Sie vereinigen sich alsdann in einem Puncte der Netzhaut zu weissem Licht, und das resultirende Bild ist frei von Farbensäumen.

Bis hieher haben die gezogenen Schlüsse, wie leicht einzusehen, 135 allgemeine Gültigkeit, da die Ueber- oder Unterverbesserung des Objectivs dabei gar nicht in Betracht kommt. Zur vollständigen Achromasie ist nun aber weiter erforderlich, dass die rirtuellen Bilder von $r^{\prime}$ und $v^{\prime}$, die wir schliesslich beobachten, in der nämlichen Entfernung zu Stande kommen, in welcher die entsprechenden Lichtkegel sich kreuzen. Mit andern Worten: die Axen der verschiedenfarbigen Lichtkegel müssen rückwärts nach denselben Puncten convergiren, von welchen auch die einzelner Strahlen eines Kiegels zu kommen scheinen. Offenbar kann diese Bedingung nicht gleichzeitig für die rechte und linke Seite der Figur erfüllt werden, weil die Entfernungen der gleichfarbigen reellen Bilder rom Ocularglas nicht die nämlichen sind. Wegen der Farbenabweichung * des letzteren ist es

*) Zur genaueren Orientirung mögen folgende Ziffern dienen. Eine planconvexe Kronglaslinse, deren Krümmungsradius $=15^{\mathrm{m} \cdot \mathrm{m} \cdot}$, giebt für die Brennweite der violetten Strahlen $27,77^{\mathrm{m}} \cdot \mathrm{m} \cdot$, für die der rothen $2 \mathrm{~S}, 54^{\mathrm{m} \cdot \mathrm{m}}$, also eine chromatische Längenabweichung von $1 \mathrm{m.m}$. In gleicher Weise entsprechen sich auch die Brennweiten von 46,3 und $45 \mathrm{~m}$.m . bei einem Krümmungsradius von $25^{\mathrm{m} . \mathrm{m}}$. Wird die letztere Linse als Collectiv, die erstere als Ocular benutzt, und wird der 
sogar unerlässlich, dass $v^{\prime}$ etwas näher zu liegen komme als $r^{\prime}$, wenn die virtuellen Bilder $v^{\prime \prime}$ und $r^{\prime \prime}$ coincidiren sollen. Die umgekehrte Anordnung, wie sie die Unterverbesserung des Objectivs mit sich bringt, ist somit unvereinbar mit den Bedingungen der Achromasie, - und insofern ist die herkömmliche Darstellungsweise vollkommen begründet. Es folgt aber daraus noch keineswegs, dass ein unterverbessertes Objectirbild durch das Ocular einen rothen oder orangefarbigen Saum erhalte. Denn da die Bildpuncte $v^{\prime \prime}$ und $r^{\prime \prime}$ die Spitzen der ausfahrenden Lichtkegel sind und folglich beim Näher- und Fernerrücken der Ocularlinse sich etwas gegen einander verschieben während die Abstände constant bleiben', so ist es immer möglich, denselben eine solche Lage zu geben, dass sie für das beobachtende Auge sich decken. In diesem Falle erscheint aber das resultirende Bild entweder rollkommen farblos oder doch nur von den Farben des secundären Spectrums umsäumt.

Die Beseitigung der blauen oder rothen Farbensäume bildet demnach noch kein Criterium der eigentlichen, wahren Achromasie; sie ist bei unterverbesserten und achromatischen Objectiven eben so gut möglich, als bei überverbesserten, - und insofern ist die gewöhnliche Darstellungsweise unrichtig*).

Vollkommen unhaltbar aber wird diese Darstellung, wenn das reelle Bild von einem excentrischen Theil des Objectivsystems, z. B. von der einen Hälfte desselben, entworfen wird - ein Fall, der bei mikroskopischen Untersuchungen weitaus am häufigsten rorkommt. Der Mangel an Achromasie muss sich alsdann, wie oben gezeigt wurde, dadurch kundgeben, dass die verschiedenen Farben seitlich gegen einander verschoben sind, so dass auf der einen Seite das Roth, auf der andern das Violett vorsteht. Es ist klar, dass unter solchen Verhältnissen eine Correction des Objectivbildes durch das Ocular absolut ummöglich wird. Die farbigen Säume können wohl etwas mo-

Abstand des virtuellen Objects rom Collectiv zu 5 ( $^{\text {m.m. }}$. angenommen, so konmt das violette Collectivbild in einem Abstand von $24 \mathrm{~m} \cdot \mathrm{m} \cdot \mathrm{zu}$ stande, und das rothe rückt noch um ${ }^{1}{ }_{2}{ }^{m} \cdot m \cdot$ höher hinauf. Da nun die Farbenabweichung des Oculars gerade die entgegengresetzte Anordnung verlangt, so muss das Objectiv so stark üherrerbessert sein, dass die rothen Strahlen nach einem etwa $6^{\mathrm{m} \cdot \mathrm{m}}$. tiefer liegenden Puncte convergiren.

* 1as Fehlen der Farbensäume beweist eigentlich nach Früherem nur, dass Collectiv und Ocular ein für rothes und blaues Licht gleich aplanatisches System bilden. Wie Convergenzpuncte der verschiedenfarbigen Strahlenbündel kommen dabei nicht in Betracht. 
dificirt, aber niemals auf beiden Seiten zugleich zum Verschwinden gebracht werden.

Die chromatische Aberration des Objectirs kann also, wir wie-136 derholen es, durch die entgegengesetzte des Oculars nur in ganz bestimmten Fällen, in der Regel aber nicht beseitigt werden. Dasselbe gilt natürlich auch, und zwar ohne alle Einschränkung, von der sphärischen Aberration. Denn da die einfallenden Lichtkegel im Ocular weniger als einen Quadratmillimeter der brechenden Flächen treffen, so ist bei den rerhältnissmässig schwachen Krümmungen derselben nicht wohl anzunehmen, ja es ist geradezu unmöglich, dass eine irgend erhebliche Aberration noch stattfinden oder eine schon vorhandene compensirt werden könne.

So gelangen wir denn schliesslich zu dem Ergebniss, dass die Merkmale der chromatischen und sphärischen Ueber- oder Unterverbesserung, welche das mitgetheilte Prüfungsrerfahren wobei nur die Hälfte des Objectivs optisch wirksam ist zur Wahrnehmung bringt, in allen Fällen, wo sie entschieden hervortreten, einzig und allein auf das Objectiv zu beziehen sind.

Der zweite Punct, den wir zu berücksichtigen haben, nämlich 137 die chromatische Aberration des Auges, ist im Princip als erledigt zu betrachten. Es ist rollkommen sicher, dass das Auge mit einer sehr merklichen Farbenabweichung behaftet ist, ron der man sich leicht überzengen kann, wenn man die Pupille zur Hälfte bedeckt und den Blick nach irgend einem hellen Gegenstande, z. B. nach einer Fensterscheibe richtet. Der eine Rand erscheint alsdam. ganz wie im mikroskopischen Bilde, deutlich blau, der andere orange oder gelb. Es kann also nur noch die Frage in Betracht kommen, ob diese Farbenabweichung diejenige des Mikroskops in einem erheblichen Grade zu steigern oder zu compensiren vermöge. Um hierüber Aufschluss zu erhalten, hat man nur nöthig, die aus dem Ocular hervortretenden Lichtbündel durch einen möglichst excentrischen Theil der Pupillenöffnung auf die Netzhaut gelangen zu lassen. Zu diesem Ende hält man das Ange ungefähr in der Höhe, in welcher diese Lichtbündel die optische Axe schneiden (in den sogenannten Augenpunct) und bewegt dasselbe soweit nach rechts und nach links, bis das mikroskopische Bild eben noch sichtbar ist. Man wird dabei immer beobachten, dass die rothen und blauen Ränder desselben je nach der Lage des Auges intensiver oder schwächer erscheinen, dass sie oft vollständig verschwinden oder sogar in die entgegengesetzten übergehen. Diese Erscheinungen lassen sich in jedem gegebenen Falle am leich- 
testen erklären, wenn man die Wirkung des blossen Auges auf weisses Licht als Ausgangspunct wählt. Ist $E E$ Fig. $\delta 7$ und S\$) die Hauptebene des Auges, $R$ die Retina und $P$ die Pupille, welche durch die.

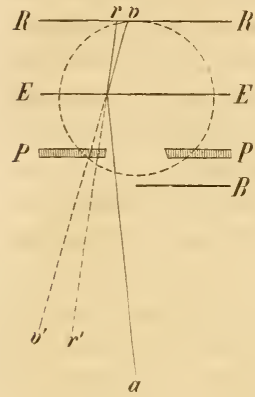

Figur $\$$;

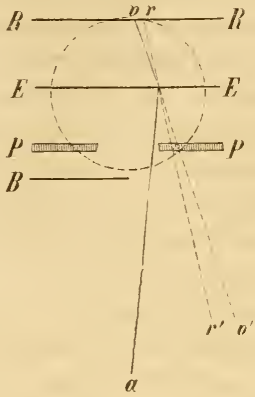

Figur is.

Blendung $\boldsymbol{B}$ in der angedeuteten $W$ eise zur Hälfte bedeckt ist, so muss ein farb. loses Object $u$ unter den in Fig. 87 dargestellten Verhältnissen links blau und rechts roth berandet erscheinen, weil das violette Bild $v$ eines beliebigen Objectpunctes auf der Netzhaut mehr rechts zu

liegen kommt und daher vom Bewusstsein einem mehr links liegenden Gegenstand $v^{\prime}$ zugeschrieben wird. Deckt man dagegen, wie in Fig. 55, die linke Hälfte der Pupillenöffnung zu, so ist die Anordnung der Farbensäume, wie ein Blick auf die Construction zeigt, die entgegengesetzte.

Wo demnach in einem dioptrischen Bilde die nämlichen Farbensäume in gleicher Anordnung vorhanden sind, wie sie auch die Brechung im Auge hervorruft, da muss sie das letztere noch verstärkt zur Wahrnehmung bringen, während die entgegengesetzte Anordnung natürlicher Weise eine Verschmälerung und unter Umständen ein Verschwinden derselben zur Folge hat. Daraus folgt aber, dass die Aberration des Auges in allen Fallen, wo es sich um seitliche Verschiebungen der verschiedenfarbigen Bildpuncte handelt, eben so gut einem unterverbesserten, als einem überverbesserten Objectivbilde zu Gute kommen kann, da ja die Anordnung der Farben nur davon abhängt, ob die eine oder die andere Hälfte des Objectivs oder das Auges wirksam sei. Beruht dagegen die chromatische Aberration gleichzeitig oder ausschliesslich auf Niveaudifferenzen der verschiedenfarbigen Bilder, wie z. B. bei der Prüfung des optischen Termögens mit dem Drahtnetz, so ist es einleuchtend, dass das Auge nur die entgegengesetzten Abweichungen zu mildern oder zu compensiren vermag. Dieser Umstand mag in der praktischen Optik einige Beachtung rerdienen; entscheidend ist er aber nicht, weil bei organischen 
Objecten gerade die seitlichen Verschiebungen die häufigsten sind und diese letzteren, weil sie in den verschiedensten Richtungen stattfinden, sich nicht beseitigen lassen.

Die günstigste Combination für das Netzhautbildchen bleibt also 138 immerhin ein aberrationsfreies mikroskopisches, Bild als Object und das gewohnte Sehen durch den centralen Theil der Pupillenöffnung. Und als bestes Objectiv stellt sich nach all' diesen Erörterungen dasjenige heraus, welches sowohl mit Rücksicht auf sphärische als auf chromatische Aberration möglichst corrigirt ist.

Ob die Herstellung achromatischer oder schwach überverbesserter Oculare die damit verbundene Mühe und grösseren Kosten lohnen würde, wollen wir dahin gestellt sein lassen. Es versteht sich jedoch ron selbst, dass das mikroskopische Bild durch eine günstige Combination von Collectiv- und Oculardoppellinsen nur gewinnen könnte.

\section{IV.}

\section{Prüfung der "Ebenung des Gesichtsfeldes"。}

Da der herkömmliche Ausdruck "Krümmung des Gesichtsfeldes", 139 wie wir oben gezeigt haben, zwei von einander unabhängige Begriffe umfasst, nämlich 1) die Verzerrung des Bildes und 2) die Wölbung der Bildfäche, so sind bei der Prüfung des Mikroskops diese beiden Momente gesondert in Betracht zu ziehen. Was zunächst die Verzerrung des Bildes betrifft, so lässt sich der Grad derselben am besten mit Hülfe eines quadratischen Maschennetzes, z. B. eines in viereckige Felder getheilten Glasmikrometers bestimmen, welches als Object unter das Mikroskop gebracht wird. Dasselbe erscheint näılich, je nachdem die Vergrösserung von innen nach aussen zu- oder abnimmt, wie in Fig. 22 oder wie in Fig. 21 (pag. 54), und nur wenn gar keine Verzerrung stattfindet, stimmen die Maschen des Bildes mit denen des Objectes überein. Aus der Krümmung der Linien in Fig. 21 und 22 ergiebt sich übrigens, dass schon eine einzige gerade Linie, wenn dieselbe dem Rande des Gesichtsfeldes genähert wird, ein rollkommen ausreichendes Probeobject bildet.

Will man das Verhalten der Bilder prüfen, welche das Objectiv für sich allein und unter Mitwirkung der Collectivlinse entwirft, so geschieht diess am einfachsten in folgender Weise. Man legt auf die Blendung im Oculareinsatz (nach Wegnahme der Ocularlinse) ein 
Deckgläschen mit geradem Rande, und zwar so, dass der letztere in der kreisförmigen Blendung als Sehne erscheint ' $m n$ in Fig. \$9). Mit

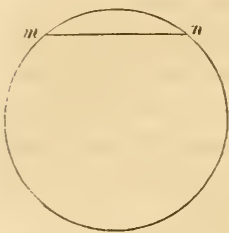

Figur $\$ 9$. dieser Sehne sucht man das reelle Bild einer anderen Geraden, die als Object dient, zur Deckung zu bringen, was genau in derselben Weise bewerkstelligt wird, wie z. B. bei der mikrometrischen Messung das Einstellen eines bestimmten Theilstriches auf den Rand eines Objectes. Findet eine vollkommene Deckung statt, d. h. fallen die beiden Geraden - gleichviel, ob sie im virtuellen Bilde gerade oder gekrünmt erscheinen - in ihrer ganzen Länge zusammen, so ist das reelle Bild "geradflächig ", in jedem andern Falle dagegen verzerrt. Eine Verzerrung wie in Figur 21, wobei die Randpartieen schwächer vergrössert erscheinen, als die im Centrum liegenden, wird dadurch bemerkbar, dass, wenn die beiden Linien sich in der Mitte berühren, die Enden der im Oculareinsatz angebrachten Geraden $m n$ mehr nach

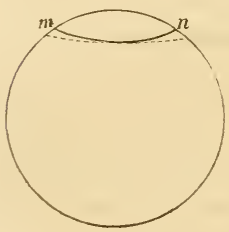

Figur 911.

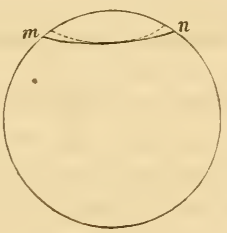

Figur 91. aussen $\mathrm{zu}$ liegen kommen Fig. 90), während die umgekehrte Verzerrung durch die Abweichung dieser Enden nach innen zu angezeigt wird Fig. 91. Aus der Krümmung der Geraden $m n$ selbst ergiebt sich diejenige des virtuellen Bildes, welches die Ocularlinse unter den gegebenen Verhältnissen ron einer ebenen Fläche entwirft.

Die in der angegebenen Weise untersuchten Instrumente Oberhäuser, Hartnack, Bénèche, Merz, Kellner) zeigten übrigens wider Erwarten keine irgend nennenswerthe Verzerrung des Objectivbildes, man mochte dasselbe mit oder ohne Collectiv untersuchen. Nur war in letzterem Falle das schliessliche virtuelle Bild viel stärker verzerrt, weil die Ocularlinse in ihrem ganzen Durchmesser, also mit weit grösserer Oeffnung, optisch wirksam und überdiess die Richtung der einfallenden Strahlen eine ungünstigere war. Dasselbe Resultat ergab auch eine andere Prüfungsweise, wobei die mit oder ohne Collectiv zu Stande gebrachten Objectivbilder am obern Ende der Mikroskopröhre (nach Wegnahme des Oculars) auf mattem Glas aufgefangen wurden. 
Um num noch die Wölbung der Bildfläche zu prüfen, bedient man sich einer genau ebenen Fläche mit feiner Zeichnung, wie man sie z. B. erhält, wenn man eine Glasplatte mit der Fingerspitze reibt, als Object und untersucht alsdann, ob alle Puncte des Gesichtsfeldes gleichzeitig deutlich gesehen werden können. Ist diess nicht der Fall und findet man, wie gewöhnlich, dass die peripherischen Puncte eine tiefere Einstellung erfordern, als die centralen, so ist die Bildfläche, wie leicht einzusehen, nach oben convex. Die Wölbung ist natürlich um so stärker, je grösser die Niveaudifferenz.

Das Auflegen eines Deckgläschens mit ähnlicher Zeichnung auf die Blendung im Oculareinsatz giebt auch hier ein Mittel an die Hand, die Wölbung des Objectivbildes nach denselben Principien zu ermitteln, wie in Vorhergehenden die Verzerrung.

\section{V}

\section{Prïfung der Centrirung.}

Wir haben oben gezeigt, dass die ungenaue Centrirung eines 140 Linsensystems sich im Allgemeinen auf zweierlei Weise kundgebe: 1) durch eine Verundeutlichung der Bilder, welche zunächst nur den Rand des Gesichtsfeldes trifft und erst bei grösseren Abweichungen sich bis gegen die Mitte erstreckt, in allen Fällen jedoch von ausven nach innen abnimmt; 2) durch die Ortsreränderungen, welche ein beliebiger Bildpunct erfährt, wenn das Objectiv oder einzelne Linsen desselben um die Axe des Mikroskops gedreht werden. Der erste Punct wird am einfachsten dadurch geprüft, dass man das optische Vermögen des Mikroskops für verschiedene Stellen des Gesichtsfeldes bestimmt und die erhaltenen Ergebnisse unter sich vergleicht. Man hat dabei namentlich darauf $z u$ achten, ob vielleicht der linke Rand entschieden schwächere Bilder liefere, als der rechte, ob überhaupt eine störende Ungleichheit in der Vertheilung der optischen Kraft und in deren Abnahme rom Centrum gegen die Peripherie stattfinde. Wo solche Differenzen nicht vorkommen, wo höchstens ein geringer, durch die Aberrationen des Oculars bedingter und daher gleichmässiger Ausfall gegen den Rand zu sich nachweisen lässt, da darf man rersichert sein, dass die Fehler der Centrirung möglichst vermieden, d. h. auf Zonen reducirt sind, die ausserhalb des Gesichtsfeldes liegen oder doch nur wenig über den Rahmen desselben hereinragen. 
141 Was den zweiten Punct betrifft, so ist ror Allem daran zu erinnern, dass die fraglichen Ortsveränderungen den Abweichungen der of tischen Axen keineswegs proportional sind; dass sie möglicherweise abnehmen (ja sogar Null werden, während die letzteren zunehmen, und umgekehrt. Ferner ist zu berücksichtigen, dass bei dem gewöhnlichen Prüfungsverfahren, wobei die Drehung der Linsen durch Zurückschrauben derselben bewerkstelligt wird, die Drehungsaxe nicht nothwendig mit der Axe des Mikroskops zusammenfällt. Unter diesen Verhältnissen müssen bei der Prüfung der Ortsverände. rungen, welche die Linsenumdrehung verursacht, folgende Fälle unterschieden werden.

1) Ist die Centrirung des Objectivsystems vollkommen und fällt seine optische Axe mit der Drehungsaxe zusammen, so zeigt das Bild während der Drehung keinerlei Ortsveränderung.

2 Ist die Centrirung des Objectirsystems rollkommen; fällt aber seine optische Axe nicht mit der Drehungsaxe zusammen, so beschreibt das Bild einen grösseren oder kleineren Kreis. Denn ist z. B. $D D$ Fig. 92) die Drehungsaxe, $O O$ die optische Axe, $E$ der untere und $E^{\prime}$ der obere Hauptpunct des Objectivs, so kommt das Bild des Objectes $a$ in $a^{\prime}$, nach einer Drehung ron $150^{\circ}$ dagegen, wic man ohne Weiteres aus der Figur ersieht, in $a^{\prime \prime}$ zu Stande. Dasselbe beschreibt also einen Kreis, dessen Durchmesser bei gegebener Tubuslänge ron dem Winkel abhängt, unter welchem die Verschiebung des ersten Hauptpunctes vom Object aus gesehen wird. Die Construction bleibt im Wesentlichen dieselbe, die beiden Axen mögen parallel sein oder nicht. Der Kreis $a^{\prime} a^{\prime \prime}$ wird in beiden Fällen unmerklich klein, wenn der erste Hauptpunct in die Drehungsaxe fällt. Sein Durchmesser ist alsdann der Verschiebung des zweiten Hauptpunctes gleich.

Figur 92.

3) Ist die Centrirung des Objectirsystems ungenau, so sind zwar noch bestimmte Fälle denkbar, in welchen keine Ortsveränderung erfolgt ; im Allgemeinen aber muss eine solche stattfinden, welche Lage man auch der Drehungsaxe geben mag. Dagegen können einzelne Linsen oder Linsencombinationen, deren optische Axe mit der Drehungsaxe zusammenfällt, für sich allein ohne irgend welche Folgen gedreht werden. Die nicht centrir- 
ten Linsen verursachen, einzeln gedreht, eine um so grössere Verschiebung, je weiter ihre Hauptpuncte von der Drehungsaxe abstehen.

Für die Praxis geht aus diesen Folgerungen klar hervor, dass die während der Umdrehung der Linsen durch Losschrauben stattfindenden Ortsveränderungen des Bildes eben so sehr von der genauen Construction der Fassungen und Schraubengewinde, als ron den Abweichungen der optischen Axen vor dem Losschrauben abhängig sind. Nur wenn die Linsen einen rerhältnissmässig grossen Durchmesser haben, wie z. B. das Collectiv und das Ocular, bilden die Fehler der Centrirung den maassbestimmenden Factor und können daher in der angegebenen Weise bestimınt werden. Beim Ocular sind jedoch wirklich störende Fehler ziemlich leicht zu vermeiden, so dass eine Prüfung hier weniger nothwendig erscheint.

\section{II.}

\section{Bestimmung des Oeffnungswinkels.}

Obschon der Oeffnungswinkel an und für sich, wie oben gezeigt 142 wurde, nicht die Bedeutung hat, die man ihm gewöhnlich zuschreibt, so bleibt er doch immer ein Factor, den man kennen muss, wäre es auch nur, um die Beleuchtung darnach einzurichten. Die Bestimmung desselben kann in sehr verschiedener Weise geschehen; doch laufen im Grunde alle Methoden, welche die Mikrographen in Vorschlag gebracht haben, auf das Nämliche hinaus. Sie können auch unmöglich eine andere Basis haben, als die leicht zu übersehenden Erscheinungen, die mit dem bekannten Strahlengang im Mikroskop in Beziehung stehen. Daher genügt denn auch eine einzige schematische Darstellung, die verschiedensten Prüfungsmethoden zu begründen und zu veranschaulichen.

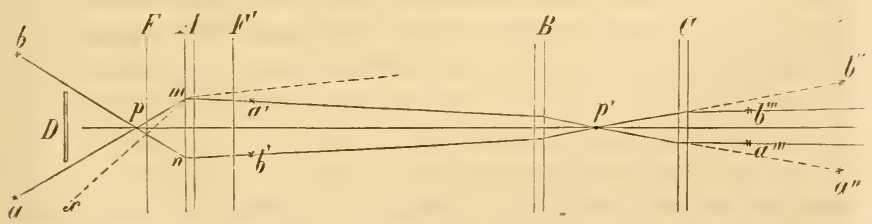

Figur 93.

Es seien $A, B$ und $C$ Fig. 93 die drei Hauptebenenpaare des Objectirs, des Collectirs und des Oculars, $F$ und $F^{\prime}$ die zu $A$ gehöri- 
gen Brennebenen und $p$ das Centrum des Gesichtsfeldes. Ist alsdann $m p n$ der Oeffnungswinkel des Objectirs, so ist natürlich ein Beleuchtungskegel ron gleicher Oeffnung nöthig, um denselben auszufüllen; aber es ist ebenso klar, dass auch ein beliebiger kleiner Theil desselben für sich allein das Flächenelement $p$ nach Maassgabe seiner Intensität erhellt. Wenn also eine Lichtquelle von geringer Ausdehnung, sei es nun eine vom Spiegel beleuchtete Blendung, oder der Beleuchtungsspiegel selbst, oder eine in einiger Entfermung aufgestellte Lampenflamme etc., in der Richtung ron $a$ nach $b$ oder umgekehrt von $b$ nach $a$ bewegt wird, so erscheint das Object $p$ so lange erhellt, als die gedachte Lichtquelle sich ganz oder doch zum Theil innerhalb des vom Winkel $a p b=m p n$ begrenzten Raumes befindet. Sowie sie diesen Raum rerlässt, gelangen die nach $p$ zielenden Lichtstrahlen entweder nicht mehr zum Objectiv, oder sie werden durch letzteres so gebrochen, dass sie das Ocular nicht erreichen; das Gesichtsfeld muss sich folglich verdunkeln. (In der Figur ist dieser Fall durch die punctirte Linie $x m$ angedeutet.) Dasselbe Resultat müsste auch eintreten, wenn eine in den vollen Beleuchtungskegel eingetauchte kreisförmige Blendung $D$ dem Object $p$ so lange genähert würde, bis ihre Ränder die Oberfläche des Kegels berühren.

Zwischen dem Collectiv und dem Ocular kommt das reelle Bild $p^{\prime}$ zu Stande. Ton hier aus divergiren die Strahlen wieder und werden von der Ocularlinse so gebrochen, dass sie von einem Puncte der optischen Axe zu kommen scheinen, welcher um die Weite des deutlichen Sehens vom Auge absteht. Ist das letztere auf unendliche Entfernung eingestellt, so rerlaufen sie unter sich und mit der Axe parallel. Wird daher ungekehrt ein parallelstrahliges Bündel in der Richtung der Axe auf das Ocular geleitet, so kreuzen sich die Strahlen zunächst in $p^{\prime}$ und dann in $p$ und divergiren ron hier aus nach allen Richtungen zwischen $p a$ und $p b$. Ein links von $p$ senkrecht zur Axe aufgestellter Schirm wird alsdann in einer Breite beleuchtet, welche bei gegebenem Abstand rom Oeffnungswinkel des Objectirs abhängt. Giebt man demselben die Form eines um $p$ beschriebenen Kreisbogens und theilt ihn in Grade ein, so kann der Oeffnungswinkel direct abgelesen werden.

Wird die in einiger Entfernung angebrachte Lichtquelle $a$ als Object betrachtet, so kommt das Objectirbild derselben etwas hinter $F^{\prime}$ in $a^{\prime}$ zu Stande. Ton diesem Bilde würde das Collectiv ein zweites in $a^{\prime \prime}$ entwerfen; allein die Ocularlinse fängt die Strahlen schon vor ihrer Tereinigung auf, so dass das wirkliche Bild nun in $a^{\prime \prime \prime}$ ent- 
steht. Bewegt sich jetzt die Lichtquelle von $a$ nach $b$, so rückt auch das Bildchen von $a^{\prime \prime \prime}$ nach $b^{\prime \prime \prime}$; es rerschwindet aber sogleich, sowie die Grenzlinie $b p$ oder die gegenüberliegende ap überschritten wird. Die Terkleinerung des Bildchens lässt sich für bekannte Abstände und Brennweiten leicht berechnen. Ist z. B. der Abstand der Lichtquelle rom Objectiv $=1^{\mathrm{m}}$, die Brennweite des letzteren, des Collectirs und des Oculars beziehungsweise 5, 50 und $25^{\mathrm{m} . \mathrm{m}}$. und die Länge des Oculareinsatzes $50^{\mathrm{m} \cdot \mathrm{m} .}$, so erhält man bei einer gewöhnlichen Tubuslänge ron c. $200^{\mathrm{m} \cdot \mathrm{m}}$, eine Verkleinerung ron c. S00 Mal.

Auf Grund dieser theoretischen Ableitungen liesse sich nun 143 eine ziemliche Zahl von Prüfungsmethoden und Modificationen derselben anführen, welche in mehr oder weniger einfacher Weise zum Ziele führen. Es mag indess genügen, wenn wir hier nur die einfachsten und zweckdienlichsten noch besonders besprechen.

1) Die Methode von Lister. Das Mikroskop wird horizontal gestellt und eine in einiger Entfernung rom Objectiv (im dunkeln oder halbdunkeln Zimmer aufgestellte Kerzenflamme als Lichtquelle benutzt. Dieselbe wird hierauf so weit nach rechts und nach links ron der Verlängerung der optischen Axe entfernt, bis nur noch das halbe Gesichtsfeld erleuchtet erscheint. Der Winkel, unter welchem alsdann die extremen Standpuncte der Lichtquelle $(a$ und $b$ Fig. 93 rom Brennpunct des Objectivs oder, was bei grösseren Abständen auf dasselbe herauskommt, rom vorderen Ende der Mikroskopröhre aus gesehen werden, ist der gesuchte Oeffnungswinkel. Man hat also nur nöthig, das Mikroskop auf eine passende Unterlage zu bringen, das Lineal anzusetzen, nach den beiden extremen Standpuncten Linien zu ziehen und den erhaltenen Winkel mit dem Transporteur zu messen.

Noch einfacher ist das Verfahren, wenn man die Lichtquelle unbeweglich stehen lässt und dafür die Mikroskopröhre um eine senkrechte, durch den Brennpunct gehende Axe dreht, so dass das Ocularende einen horizontalen Bogen beschreibt. Es liegt auf der Hand, dass das Resultat genau dasselbe sein muss, wie im rorhergehenden Falle. Man braucht also nur die Drehung nach beiden Seiten hin so lange fortzusetzen, bis das Gesichtsfeld sich zur Hälfte verdunkelt, und in diesen extremen Lagen Linien parallel mit der Axe des Mikroskops zu ziehen, die man nachher bis zu ihrem Kreuzungspunct rerlängert. Der Winkel, den dieselben bilden, ist dem Oeffnungswinkel gleich und kann mit dem Transporteur direct gemessen werden. Es versteht sich übrigens von selbst, dass das Resultat annähernd 
dasselbe bleibt, wenn die Drehung nicht gerade um den Brennpunct, sondern einfach um das vordere Ende des Mikroskops geschieht.

Wer zu solchen Messungen eine besondere mechanische Torrichtung wünscht, der mag sich eine solche nach der Angabe Goring's construiren lassen. Der Goring'sche Apparat besteht im Wesentlichen aus einer messingenen Platte, auf welcher das Mikroskop mittelst zweier Stützen befestigt und welche selbst wieder auf einer andern mit Gradeintheilung versehenen Platte drehbar ist, und zwar um eine Spindel, in deren Verlängerung sich eine feine Nadel befindet, auf welche das Mikroskop eingestellt wird. Eine genauere Beschreibung mit Abbildung giebt Mohl in seiner Mikrographie S. 193.

2) Die Methode von Wenham. Das Mikroskop wird, wie im vorhergehenden Falle, horizontal gestellt und nach einer entfernten Lichtquelle, z. B. nach der Flamme einer Lampe, gerichtet. Statt aber in gewohnter Weise das Gesichtsfeld zu beobachten, sieht das mit einer Loupe bewaffnete Auge nach dem Flammenbildchen über dem Ocular ( $a^{\prime \prime \prime}$ und $b^{\prime \prime \prime}$ Fig. 93). Die Mikroskopröhre wird dann wieder in einer horizontalen Ebene nach rechts und nach links gedreht, bis ein bestimmter Punct des Bildchens, z. B. die Mitte desselben, eben verschwindet. Der Bogen, welchen das Mikroskop während dieser Bewegung durchläuft, darf auch hier als dem Oeffnungswinkel des Objectivs entsprechend betrachtet werden*).

Dieses Verfahren hat unstreitig den grossen Torzug, dass sich dadurch nicht bloss die Oeffnung des Objectivs, soweit sie überhaupt Licht durchlässt, bestimmen lässt, sondern auch der wirklich nutzbare

-) Die Bemerkung Harting's Mikr. p. 263), dass diese Methode nicht ganz gleiche Resultate liefern könne, wie jene von lister, weil durch das Hinzufügen einer Loupe der Hauptbrennpunct verschoben werde, ist jedenfalls unrichtig motivirt. Es ist im Gegentheil völlig gleichgültig, ob man die Flammenbildchen $a^{\prime \prime \prime}$ und $b^{\prime \prime \prime}$ mit blossem Auge, mit einer Loupe oder mit einem zweiten Mikroskop betrachte. Ihr Verschwinden ist von dem hinzukommenden Linsensystem in keiner Weise abhängig. Eine kleine Differenz besteht aber desswegen doch, nur ist die Ursache eine ganz andere. Bei der Lister'schen Methode werden nämlich die Strahlenbündel in den Grenzlagen des Mikroskops so gebrochen, dass sie in $p^{\prime}$ die Axe schneiden, weil nur unter dieser Bedingung die Mitte des Gesichtsfeldes eben noch erleuchtet erscheint. Bei der Wenham'schen Methode dagegen genügt es, dass die Strahlenbündel nach der Brechung im Objectiv das Collectiv erreichen, eine Bedingung, die selbst dann noch erfullt wird, wenn sie auf ihrem Wege dahin sich etwas von der Axe entfernen. Der Oeffnungswinkel erhält dadurch denselben Werth, ja sogar noch einen etwas grösseren, wie wenn der einfallende Lichtkegel rom Brennpunct des Objectirs ausginge. 
Theil derselben, d. h. der Theil, welcher scharfe, aberrationsfreie Bilder liefert. Man beobachtet nämlich oft, dass die Flammenbildchen vor ihrem Verschwinden undeutlich, nebelartig und verzerrt erscheinen, während sie sonst sehr scharf begrenzt und in ihrer wahren Gestalt sich darstellen. Offeubar können diese undeutlichen und verbogenen Bilder nur von Randstrahlen herrühren, für welche das Objectiv nicht mehr gehörig corrigirt ist, und welche daher besser abgeschnitten würden. Der wirklich nutzbare Oeffnungswinkel ist demnach durch die Grenzen bestimmt, innerhalb welcher die Flamme scharf und rein erscheint.

3) Die Robinson'sche Methode. Ein Bündel paralleler Strahlen wird in der Richtung der Axe auf das Ocular geleitet und nach erfolgter Kreuzung der Strahlen im Brennpuncte des Mikroskops mit einem Schirme aufgefangen. Aus dem Durchmesser $d$ des Lichtkreises, welcher hier zu Stande kommt, und der Entfernung $l$ des Schirmes rom Brennpunct des Mikroskops resp. dem vorderen Ende desselben, wenn der Abstand verhältnissmässig gross ist) erhält man alsdann den Oeffnungswinkel $u$ nach der Formel

$$
\operatorname{tang} \frac{u}{2}=\frac{d}{2 l} \text {. }
$$

Die Bestimmung desselben kann übrigens mit hinreichender Genauigkeit auch durch Construction geschehen.

Welche von den genannten Methoden man übrigens auch an-144 wenden mag, die Bestimmung ist doch immer nur annähernd genau, und zwar erreicht der mögliche Fehler bei stärkeren Vergrösserungen wenigstens 2 Grad. Es rührt diess daher, dass Licht und Schatten im Gesichtsfelde oder auf dem erhellten Schirm wegen der mancherlei Verluste, welche die Randstrahlen erleiden, nicht scharf begrenzt erscheinen, vielmehr allmählich in einander übergehen, so dass also die Grenzpuncte, auf welche es ankommt, immer etwas willkürlich gewählt werden müssen. Dieser Uebelstand hat indessen so gut wie keine praktische Bedeutung, da es rollkommen gleichgültig ist, ob der Oeffnungswinkel eines Mikroskops beispielsweise 70 oder nur 65 Grad betrage. Es ist geradezu lächerlich, wie Harting mit Recht bemerkt, wenn man bei stärkeren Objectiven, wie es Manche gethan haben, die Grösse des Oeffnungswinkels bis auf Bruchtheile eines Grades angiebt. Und ebenso lächerlich und unpraktisch ist es, Objective mit Oeffnungswinkeln bis zu $160^{\circ}$ und darüber herzustellen, wenn hieron wenigstens $40-50^{\circ}$ auf einen total unbrauchbaren 
peripherischen Theil des Systems fallen, wie diess bei manchen englischen Systemen wirklich rorkommt.

Schliesslich wollen wir noch bemerken, dass bei solchen Objectiven, welche zum Zwecke der Immersion in Wasser, oder um der verschiedenen Dicke der Deckgläschen Rechnung zu tragen, mit Correctionsapparaten versehen sind, der Oeffnungswinkel sich nothwendiger Weise verändert, wenn der Abstand der untersten Linse ron der nächstfolgenden grösser oder kleiner gemacht wird, weil in Folge dessen auch die Brennweite des ganzen Systems eine Veränderung erleidet. Dagegen ist der Einfluss, welchen die Ocularvergrösserung auf den Oeffnungswinkel ausübt, keineswegs so erheblich, wie man nach der Darstellung Harting's glauben möchte. Die Vergrösserung an und für sich kommt eigentlich gar nicht in Betracht, sondern einzig und allein der Umstand, dass bei kürzeren Ocularen der Abstand des Collectivs rom Objectiv etwas grösser ist, was in der Regel auch eine geringe Vergrösserung der hinteren Vereinigungsweite des letzteren und somit eine Verkleinerung des Objectabstandes nöthig macht. Man begreift, dass in Folge dessen der Oeffnungswinkel etwas zunimmt; allein es ist ebenso klar, dass die Brechungen, welche nach dem Zustandekommen des reellen Bildes noch stattfinden, eine weitere Zu- oder Abnahme nicht bedingen, da der Strahlengang im Objectir. hievon ganz unabhängig ist. Bei gegebener Lage des Objectivbildes ist es demnach völlig gleichgültig, ob die Ocularlinse joder jo Mal rergrössere.

\section{VII.}

\section{Bestimmung der Vergrösserung und der Brennweite.}

145 Man ist gewohnt, die Stärke eines Mikroskops nach der Gesammtvergrösserung, diejenige der Objective dagegen nach ihren Brennweiten zu beurtheilen. So wenig nun auch die erstere einen sicheren Anhaltspunct bietet, da sie durch Factoren von sehr ungleichem Werthe bestimmt wird, so ist doch die Kenntniss derselben schon aus praktischen Rücksichten unerlässlich. Andererseits steht die Brennweite annähernd in umgekehrtem Verhältniss zur Objectivvergrösserung; sie ist gewissermaassen als ein ron der Tubuslänge unabhängiger Ausdruck derselben zu betrachten und bildet daher bei der Tergleichung verschiedener Objective den hiezu erforderlichen Maassstab. Die Bestimmung der Brennweite sowohl, als der Gesammt- 
vergrösserung, gehört daher mit zur vollständigen Prüfung eines Mikroskops.

\section{Iie Tergrösserung.}

Es wurde früher gezeigt, dass die Vergrösserungsziffer $m$ zum 146 Abstande des virtuellen Bildes rom zweiten Brennpunct oder, was nahezu auf das Nämliche herauskommt, rom Augenpunct des Mikroskops in proportionalem Verhältniss steht, so dass also einen doppelten Abstand eine doppelte Vergrösserung entspricht. Sollen daher die Vergrösserungsziffern unter sich rergleichbar sein, so müssen sie sich folgerichtig auf gleiche Abstände beziehen. Wie gross übrigens diese letzteren gewählt werden, ist für die Vergleichung vollkommen gleichgültig; es hätte jedoch keinen Sinn, die Wahl so zu treffen, dass damit die Grenzen der wirklich vorkommenden Fälle überschritten würden. In neuerer Zeit ist man so ziemlich allgemein übereingekommen, die Vergrösserungen für eine Entfernung ron 25 Centimeter zu berechnen.

Die sogenannte "Krümmung des Gesichtsfeldes « bringt es mit sich, dass die Vergrösserung der Randpartieen gewöhnlich etwas stärker ist, als die der centralen. Aus diesem Grunde ist eine genaue Bestimmung der Vergrösserungsziffer nur für einen verhältnissmässig kleinen Theil des Gesichtsfeldes möglich; sie wird auch aus bekannten praktischen Rücksichten in der Regel nur für die Mitte, mit Weglassung einer ziemlich breiten peripherischen Zone, ausgeführt.

Was nun die Methoden betrifft, deren man sich zur Bestimmung 147 der Tergrösserungsziffer bedient, so laufen sie alle darauf hinaus, das Bild eines Objectes von bekannter Grösse auf die conventionelle Entfernung von 25 Centimeter zu projiciren und den direct gemessenen Durchmesser desselben mit dem des bildliefernden Objects zu vergleichen. Die Projection geschieht mit Hülfe eines Sömmerring'schen Spiegelchens oder eines reflectirenden Prisma's, wobei die spiegelnde Fläche, wenn das Verfahren ganz genau sein soll, eine solche Lage haben muss, dass der zweite Brennpunct des Mikroskops mit dem Kreuzungspunct der Strahlen im beobachtenden Auge zusammenfällt. Ist $N^{*}$ (Fig. 94) die letzte brechende Fläche die ebene Fläche der Ocularlinse), $F^{*}$ der zweite Brennpunct und $s$ eine unter $45^{\circ}$ geneigte reflectirende Fläche, so wird dadurch der Strahlenverlauf so verändert, als ob die optische Axe $(o x)$ des Systems horizontal und der Brennpunct nach $(F)^{*}$ verlegt wäre. In diesem letzteren Punct muss sich also das Auge befinden, wenn die Resultate der Messungen genau 
und unter sich vergleichbar sein sollen. Seine Lage entspricht sehr annähernd der Stelle, an welcher die austretenden Strahlenbündel auf

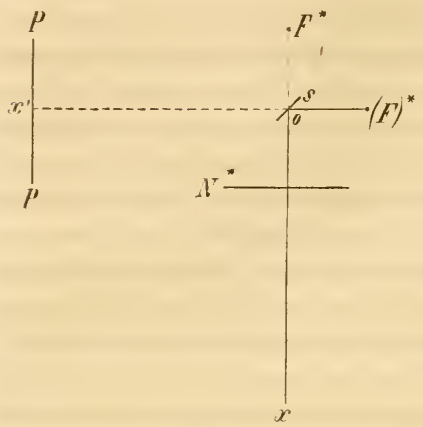

Figur 94 . einem senkrecht zur Axe gestellten Schirme (von mattem oder angehauchtem Glas) den kleinsten Lichtkreis bilden. Es versteht sich überdiess ron selbst, dass die Ebene, auf welche das Bild projicirt wird (PP Fig. 94), mit der durch die Reflexion bestimmten Richtung der optischen Axe $\left.o x^{\prime}\right)$ einen rechten Winkel bilden muss.

Bei der Wahl des Objects ist darauf zu achten, dass die Ränder desselben oder überhaupt die Puncte, deren Entfernung gemessen werden soll, auch im Bilde deutlich gesehen werden. Wo eine mikrometrische Theilung auf Glas dieser Bedingung Genüge leistet, mag dieselbe mit Vortheil angewendet werden; wo dagegen die Striche verwischt erscheinen, was bei stärkeren Vergrösserungen gewöhnlich der Fall ist, leisten beliebige andere Objecte mit scharfen Rändern, wie z. B. Luftblasen, Quecksilberkügelchen, Krystalle etc., deren Durchmesser mikrometrisch bestimmt wird, bessere Dienste. Die Genauigkeit der Bestimmung hängt übrigens in beiden Fällen ron der Genauigkeit der mikrometrischen Theilung ab.

Die Messung des rirtuellen Bildes auf der Projectionsebene geschieht am besten mittelst eines Zirkels, dessen Oeffnung nachher auf einer hinreichend feinen Scala ermittelt wird. Man kann auch die Begrenzungslinien mit der feinen Spitze eines Bleistifts wiederholt auf die Projectionsebene zeichnen und den mittleren Werth der aufgezeichneten Maasse als Durchmesser des virtuellen Bildes in Rechnung bringen. Beträgt dieser Durchmesser beispielsweise 26,5 m.m., derjenige des Objectes $100 \mathrm{Mik} .=0,1^{\mathrm{m} . \mathrm{m}}$, , so ist die Vergrösserungszahl $m=265$.

148 Wo es auf eine genaue Bestimmung der Vergrösserungsziffer ankommt, muss natürlich allen Bedingungen, welche die Theorie vorschreibt, möglichst Genüge geleistet werden. Es ist in diesem Falle sogar wünschenswerth, die Grösse des Objects auf eine zuverlässigere Weise bestimmen zu können, als diess mit Hülfe der nicht immer 
genauen mikrometrischen Theilungen möglich ist. Zur Erreichung dieses Zweckes macht Harting den Vorschlag, einen dünnen Metalldraht einige hundert Male um einen dickeren Draht $\mathrm{zu}$ winden, dergestalt, dass jede Windung genau an der vorhergehenden anliegt, woron man sich mittelst des Mikroskops überzeugen muss. Man misst dann genau, welche Strecke die sämmtlichen Windungen auf dem dickeren Draht einnehmen und zählt endlich die Anzahl der Windungen, am besten durch Abwickeln auf der Drehbank. Die Gesammtlänge der Windungen, dividirt durch die Anzahl derselben, giebt alsdann die Dicke des Drahtes mit einer Genauigkeit, die bei mikrometrischen Messungen nicht erreichbar ist. Ein solcher Draht kann entweder unmittelbar als Object oder auch zur Bestimmung der wirklichen Länge der mikrometrischen Theilungen benutzt werden.

In den meisten praktischen Fällen ist indess eine so grosse Vorsicht ganz und gar überflüssig. Es ist vollkommen gleichgültig, ob die Vergrösserungsziffer um einige Einheiten höher oder niedriger ausfalle, ob sie z. B. zu 360 oder zu 355 angenommen werde, da die Objecte, um deren Messung und Darstellung es sich handelt, hinsichtlich ihrer Grösse durchweg um mehr als soviel differiren. Man braucht sich also um den zweiten Brennpunct des Mikroskops, die Lage des Auges, die Genauigkeit der Mikrometertheilung etc. keineswegs ängstlich zu bekümmern; es genügt, die Sehweite von der Mitte des Oculars an zu messen und die gewöhnliche Sorgfalt auf die Bestimmung der Grössenverhältnisse zu verwenden, um ein hinlänglich genaues Resultat zu erzielen.

Die Vergrösserungen, welche man durch Combination verschie-149 dener Objective mit dem nämlichen Ocular erhält, verhalten sich natürlich wie die linearen Dimensionen der reellen Objectivbilder. Deckt z. B. das Bild eines Objectivs 10 Theilstriche eines im Ocular befindlichen Mikrometers und das eines andern Objectivs 15 Theilstriche, so verhalten sich die Vergrösserungsziffern wie $10 \mathrm{zu} 15$. Wird umgekehrt eine Mikrometertheilung als Object benutzt, so ist die Zahl der Theilstriche, welche innerhalb eines gegebenen Rahmens (z. B. des durch ein enge Blendung rerkleinerten Gesichtsfeldes) gesehen werden, um so kleiner, je stärker die Vergrösserung, und zwar ist das Verhältniss abermals ein proportionales. Diese Beziehungen geben uns ein Mittel an die Hand, die Vergrösserungswerthe für verschiedene Objectivsysteme in Verbindung mit dem nämlichen Ocular durch Rechnung zu bestimmen, wenn dieser Werth für ein einziges derselben bekannt ist. Ist z. B. die Zahl der Theilstriche eines Object- 
mikrometers, welche im Durchmesser des verkleinerten Gesichtsfeldes bei vier verschiedenen Objectiven gesehen werden, beziehungsweise $60,45,20,12$, und die mit dem ersten erzielte Gesammtvergrösserung $m=50$, so beträgt dieselbe für die übrigen drei Objective $\frac{60}{45}, \frac{60}{2} \frac{0}{9}$ und $\frac{60}{12}$ mal 50 , also $66 \frac{2}{3}, 150$ und 250 .

150 Es ist in manchen Fällen vortheilhaft, nicht bloss die Vergrösserungszahl, sondern auch den wahren Durchmesser des ganzen Gesichtsfeldes zu kennen. Die Bestimmung desselben geschieht einfach dadurch, dass man den scheinbaren Durchmesser in der Entfernung der Sehweite auf der Projectionsebene misst und den gefundenen Werth durch die Vergrösserung dividirt. Die Messung kann übrigens auch direct mit $\mathrm{Hülfe}$ einer Mikrometertheilung, welche die ganze Blendungsöffnung im Ocular ausfüllt oder doch seitlich verschiebbar ist, vollzogen werden.

Ebenso kann es zuweilen zweekdienlich sein, die Objectivvergrösserungen für sich allein zu ermitteln. Auch diess geschieht am einfachsten mittelst eines Ocularmikrometers, indem man dasselbe nach Wegnahme des Collectivs so weit hineinschiebt, bis das gegebene Objectivbild scharf gesehen wird. Da nämlich die Theilstriche des Mikrometers um eine bekannte Grösse, und zwar gewöhnlich um $0,1^{\text {m.m. }}$ von einander abstehen, so kann damit auch der Durchmesser des reellen Bildes gemessen werden. Das Verhältniss des letzteren zum Durchmesser des Objects giebt aber offenbar die Objectivergrösserung.

\section{Die Brennweite.}

Bei der Bestimmung der Brennweite kommt ror Allem die Frage in Betracht, in welcher Weise die bekannten mathematischen Formeln, wie sie in der Einleitung mitgetheilt wurden, zu verwerthen seien, um zu einem möglichst genauen Resultat zu gelangen. Da die Hauptpuncte des Objectivsystems unbekannt sind, so kann natürlich von einer directen Messung der Brennweite oder der conjungirten Vereinigungsweiten keine Rede sein. Die Formel $\frac{1}{p}+\frac{1}{p^{+}}=\frac{1}{f}$, in welcher $p$ und $p^{*}$ die conjungirten Tereinigungsweiten und $f$ die Brennweite bezeichnet, findet daher nicht unmittelbar Anwendung. Was als gegeben betrachtet werden kann, ist nur das Grössenverhältniss zwischen Bild und Object, sowie ferner die eine der beiden Vereinigungsweiten, insofern dieselbe so gross gewählt wird, dass eine nur annähernd genaue Messung rollkommen genügt. Aus diesen 
Daten lässt sich indess die Brennweite sehr leicht berechnen. Es seien $D$ und $d$, wobei $D>d$, die Durchmesser des Bildes und des Objectes oder ungekehrt, und $p^{*}$ die grössere der beiden Vereinigungsweiten; dann erhält man aus der Proportion $D: d=p^{*}: p$ und der oben citirten Gleichung $\frac{1}{p}+\frac{1}{p^{+}}=\frac{1}{f}$ die Beziehung $\frac{1}{f}=\frac{1}{p^{*}} \cdot \frac{D+d}{d}$ und hieraus die einfache Formel

$$
f=p^{*} \cdot \frac{d}{D+d}
$$

oder, wenn $d$ gegen $D$ verschwindend klein ist

$$
f=p^{*} \frac{l}{1} \text {. }
$$

Die Bestimmung von $p^{*}, d$ und $D$ kann nun in folgender $W$ eise geschehen.

1) Ein passendes Object ron bekannter Grösse, wie z. B. eine Mikrometertheilung oder eine Luftblase, deren Diameter durch Messung zu bestimmen ist, wird in die Mitte des Gesichtsfeldes gebracht und hierauf das zu Stande kommende Objectivbild auf einem Schirme ron mattem Glas, welcher nach Wegnahme des Oculars auf die Mikroskopröhre gelegt wird, aufgefangen. Hat man die richtige Einstellung gefunden, bei welcher das Bild scharf abgegrenzt erscheint, so kann seine Grösse mittelst eines Zirkels mit hinreichender Genauigkeit gemessen werden. Noch genauer fällt die Messung aus, wenn man das Objectivbild durch ein mit einem Mikrometer rersehenes Ocular, von dem das Collectiv losgeschraubt wurde ), beobachtet. Da nämlich die Theilstriche der Ocularmikrometer, wie bereits bemerkt,

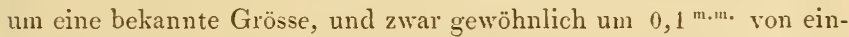
ander abstehen, so kann der Durchmesser des reellen Bildes auf diesem Wege sehr leicht bis zu einem kleinen Bruchtheil eines Millimeters genau bestimmt werden. Endlich misst man den Abstand $p^{*}$ der Projectionsebene rom Objectiv eigentlich rom zweiten Hauptpunct desselben mit Hülfe eines Zirkels oder Maassstabs, wobei ein kleiner Fehler von 2-3 ${ }^{\text {m.m. }}$ nicht in Betracht kommt.

Ist z. B. $d=100$ Mik. $=0,1^{\mathrm{m} \cdot \mathrm{m} \cdot}, D=7, \mathrm{~S}^{\mathrm{m} \cdot \mathrm{m} \cdot} \cdot$ und $p^{*}=210$, so wird $\frac{d}{I}=\frac{1}{79}$ und folglich $f=\frac{210}{79}=2,65 \mathrm{~S}$. Wird $p^{*} \mathrm{zu} 20 \bar{i}$ angenommen, so fällt dieser Werth auf 2,620 herunter, differirt also bloss um 0,03 S oder ungefähr $\frac{1}{2 \frac{1}{6}}$ eines Millimeters.

* Wir setzen auch hier ein gewöhnliches Campani'sches Ocular voraus. Bei einem Ramsden'schen Ocular braucht [natürlich die untere Linse nicht losgeschraubt zu werden. 
2) Das zu prüfende Objectiv wird dergestalt auf den Objectträger gelegt, dass die ebene Vorderfläche nach oben gekehrt ist, und hierauf in einer Entfernung von 0,2-1 Meter und darüber ein geeignetes Object, z. B. eine über der Kerzenflamme geschwärzte Glasplatte, auf dem Arbeitstische oder am Fenster befestigt. Man dreht nun den Beleuchtungsspiegel, der zu diesem Zweck eben sein muss, so, dass das Spiegelbild des Objectes in die optische Axe des zu prüfenden Objectivs fällt und folglich über der Brennebene des letzteren ein kleines dioptrisches Bildchen erzeugt, dessen Diameter durch directe Messung bei geeigneter Vergrösserung bestimmt wird. Die Grössen $D$ und $d$ sind jetzt bekannt; der Abstand $p^{*}$ wird mit dem Maassstab gemessen, wobei die Entfernungen vom Object bis zum Spiegel und von da bis zum Objectiv zu addiren sind. Nöthigenfalls kann dem Mikroskop eine horizontale Stellung gegeben und der Tubus direct nach dem Object gerichtet werden.

152 Hat man die Brennweite eines Objectivs genau bestimmt, so kann die eines anderen auf einfacherem Wege durch Vergleichung ermittelt werden. Aus der Formel für die Tergrösserung $m=1-\frac{p^{*}}{f}$ erhält man nämlich $f=-\frac{p^{*}}{m-1}$ oder, wenn $m$ als positiv betrachtet wird $f=\frac{p^{*}}{m+1}$, d. h. die Brennweiten rerhalten sich umgekehrt wie die un 1 vermehrten Objectivvergrösserungen. Da die letzteren sich ihrerseits wie die Lineardimensionen rerhalten, welche die Bilder eines gegebenen Objectes auf dem Ocularmikrometer ausfüllen, so braucht man also bloss die Theilstriche von einem Rand bis zum andern abzuzählen, un das Verhältniss der bekannten Brennweite zu einer oder mehreren unbekannten $z u$ bestimmen und hieraus diese letzteren $\mathrm{zu}$ berechnen.

In gleicher Weise, wie die Brennweite der Objectirsysteme, kann natürlich auch diejenige einzelner Linsen bestimmt werden. Wo indess die Krümmungen sehr schwach sind und die Brennweiten beispielsweise mehrere Centimeter betragen, da ist es für die meisten praktischen Zwecke genügend, den Abstand des Somnenbildchens von der Linse zu messen oder überhaupt eines der einfachen Verfahren anzuwenden, welche in den physikalischen Lehrbüchern mitgetheilt werden. 


\section{VIII.}

\section{Bestimmung der Cardinalpuncte.}

Man kann sich endlich noch die Aufgabe stellen, ein gegebenes 153 Objectiv auch mit Rücksicht auf die Lage der Cardinalpuncte der einzelnen Doppellinsen sowohl, als des ganzen Systems kennon zu lernen, d. h. die Abstände der Haupt- und Brennebenen unter sich und von den brechenden Flächen auf empirischem Wege in analoger Weise zu ermitteln, wie wir diess oben unter bestimmten Voraussetzungen durch die Rechnung gethan haben. Um diese Aufgabe mit annähcrnder Genauigkeit zu lösen, kann man folgendes Verfahren einschlagen.

1) Man bestimmt die Brennweiten der einzelnen Doppellinsen, dann der beiden hinteren zum System verbundenen Linsen, endlich diejenige des ganzen Objectivs. Zur Erzielung grösserer Genauigkeit ist bei stärkeren Linsen eine wiederholte Messung nach dieser oder jener Methode rathsam.

2) Man bestimmt die Abstände des ersten und zweiten Brennpunctes von der Vorder- und Hinterfläche der Doppellinse oder des Systems. Zu diesen Behufe legt man dieselben dergestalt auf den Objectträger, dass die betreffende Fläche nach oben gekehrt ist, und dreht nun den Planspiegel des Mikroskops so, dass im Brennpunct der Linsencombination das Bild eines entfernten Gegenstandes (z. B. eines Baumes oder einer Wolke etc.) sichtbar wird. Ist das Mikroskop möglichst scharf eingestellt, so ritzt man am oberen oder unteren Rande der Hülse, in welcher die Mikroskopröhre verschiebbar ist, eine feine Linie in die letztere ein und senkt hierauf den Focus des Instruments, bis die nach oben gekehrte Fläche des zu untersuchenden Systems (die man zu diesem Zwecke mit dem Finger betupft oder irgendwie verunreinigt) im Gesichtsfelde erscheint. Diese Stellung der Mikroskopröhre wird in gleicher Weise durch Einritzen einer feinen Linie bezeichnet. Der Abstand der beiden Linien, welcher offenbar der gesuchten Grösse gleich ist, kann nun entweder mit dem Zirkel oder, wenn er sehr klein ist, mit Hülfe eines zweiten Mikroskops bei schwacher Vergrösserung mikrometrisch bestimmt werden.

3) Man misst die Dicke der Doppellinsen oder des Systeıns, d. h. den Abstand der ersten und letzten brechenden Fläche. Da die Vorderflächen der Doppellinsen mit dem Rande der Fassungen meist ziemlich genau in derselben Ebene liegen, so geschieht die Messung 
am einfachsten in der eben beschriebenen Weise, indem man die Linse mit ihrer Vorderfläche auf den Objectträger legt und das Mikroskop nach einander auf diesen und auf die hintere gewölbte Fläche der Linse cinstellt. Wo die Fassung um eine nicht zu vernachlässigende Grösse vorsteht, wird dieselbe nachträglich besonders bestimmt und abgezogen.

Aus den Daten, welche diese Messungen liefern, lässt sich die Lage der Haupt- und Brennebenen durch einfache Addition und Subtraction berechnen. Bezeichnen, wir mit $N_{0} N_{1} N_{2} N_{3} N_{4} N_{5}$ die auf einander folgenden Grenzflächen der drei Doppellinsen, mit $\tau_{0}$ ${ }^{\prime}{ }_{1}$ und $\varphi_{2}$ ihre Brennweiten und mit $e^{0} i^{0}, e^{\prime} i^{\prime}, e^{\prime \prime} i^{\prime \prime}$ ihre Hauptebenenpaare, ferner mit $(f)$ die Brennweite der beiden hinteren zum System verbundenen Linsen und mit $(\boldsymbol{E})(\boldsymbol{E})^{*}(\boldsymbol{F})(\boldsymbol{F})^{*}$ die Hauptund Brennebenen dieses Systems, desgleichen mit $f$ die Brennweite des ganzen Objectivs und mit $E E^{*} F F^{*}$ dessen Haupt- und Brennebenen, endlich mit $d_{1}$ und $d_{2}$ bei jeder beliebigen Combination den Abstand des entsprechenden Brennpunctes von der Vorder- und Hinterfläche; dann sind die Abscissen der verschiedenen Hauptebenen, von vorn nach hinten gerechnet, durch die Gleichungen gegeben :

$$
\begin{aligned}
e^{0} & =N_{0}+\varphi_{0}-d_{1} ; & i^{\prime \prime} & =N_{1}+d_{2}-\varphi_{0} \\
e^{\prime} & =N_{2}+\varphi_{1}-d_{1} ; & i^{\prime} & =N_{3}+d_{2}-\varphi_{1} \\
e^{\prime \prime} & =N_{4}+\varphi_{2}-d_{1} ; & i^{\prime \prime} & =N_{5}+d_{2}-\varphi_{2} \\
(E) & =N_{2}+(f)-d_{1} ; & E)^{*} & =N_{5}+d_{2}-(f) \\
E & =N_{0}+f-d_{1} ; & E^{*} & =N_{5}+d_{2}-f
\end{aligned}
$$

und ebenso erhält man

$$
\begin{aligned}
& E^{*}-E=N_{5}-N_{0}+d_{2}+d_{1}-2 f \\
& N_{0}-F=f-\left(E-N_{0}\right)
\end{aligned}
$$

Zur Controle dienen die Eingangs festgestellten Beziehungen zwischen den Cardinalpuncten zweier zu combinirender Systeme und denjenigen des resultirenden Systems. Man erhält durch leicht zu übersehende Substitutionen und Umsetzungen

$$
\begin{aligned}
(f) & =\frac{\varphi_{1} \tau_{2}}{\psi_{1}+\tau_{2}-(t)}, \quad \text { wobei } \\
(t) & =e^{\prime \prime}-i^{\prime}=\varphi_{1}+\tau_{2}-\frac{\psi_{1} f_{2}}{(f)}
\end{aligned}
$$

und ebenso für das ganze Objectivsystem

$$
\begin{aligned}
& f=\frac{\varphi_{0}(f)}{\varphi_{0}+(f)-t}, \text { wobei } \\
& t=(E)-i^{0}=\varphi_{0}+(f)-\frac{\varphi_{0}(f)}{f} .
\end{aligned}
$$


Die Grössen $N_{0}-F$ und $E^{*}-E$ sind durch die Gleichungen bestimmt :

$$
\begin{aligned}
e^{0}-F & =f\left[1-\frac{t}{(f)}\right] \\
E^{*}-E & =\left[(E)^{*}-e^{0}\right]-f t\left[\frac{1}{\psi_{0}}+\frac{1}{\left.(f)^{\prime}\right)}\right]
\end{aligned}
$$

welche, wenn man die entsprechenden Werthe substituirt, ganz allgemein für zwei beliebige Systeme von Cardinalpuncten Geltung haben.

Als Beispiel einer in der beschriebenen Weise ausgeführten Be-15t stimmung der Cardinalpuncte theilen wir nachstehend die numerischen Data mit, die wir für ein Objectiv $\mathrm{Nr}$. 9 von Bénèche erhiel. ten. Die Brennweiten, Focalabstände und Flächenabstände betrugen in Millimetern:

1) Brennweiten.

$$
\begin{aligned}
\Upsilon_{0} & =2,6 \quad, \quad \Upsilon_{1}=12 \quad, \quad \Upsilon_{2}=11,4 \\
(f) & =6,21 \\
f & =3,15
\end{aligned}
$$

2) Focalabstände.

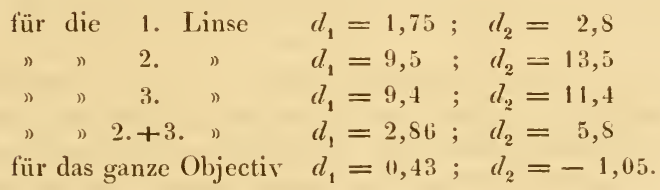

3) Flächenabstände.

$$
\begin{array}{ll}
N_{1}-N_{0}=1,37 ; & N_{3}-N_{2}=2 ; \quad N_{5}-N_{4}=2 ; \\
N_{5}-N_{2}=5,15 ; & N_{5}-N_{0}=7, \quad \text { und somit } \\
N_{2}-N_{1}=0,45 ; & N_{4}-N_{3}=1,15 .
\end{array}
$$

Aus diesen Grössen ergiebt sich zunächst für die Hauptebenen

$$
\begin{array}{ccc}
e^{0}=N_{0}+0,55 \quad ; \quad & i^{0}=N_{1}+0,1 \\
e^{\prime}=N_{2}+2,5 \quad ; \quad & i^{\prime}=N_{3}+1,5 \\
e^{\prime \prime}=N_{4}+1,9 \quad ; \quad i^{\prime \prime}=N_{5}+0 \\
(E)=N_{2}+3,38 \quad ; \quad(E)^{*}=N_{5}-0,44 \\
E=N_{0}+2,72 ; \quad E^{*}=N_{0}+2, \mathrm{~S} \\
i^{\prime \prime}-e^{\prime}=2,65 \\
(E)^{*}-e^{0}=5,71 .
\end{array}
$$

Die weiteren Ableitungen sind in folgender Tabelle (Columne "Beob- 
achtet (1) enthalten und zur Vergleichung mit den nach obigen Formeln berechneten Werthen zusammengestellt ${ }^{*}$.

\begin{tabular}{|c|c|c|}
\hline & Beobachtet. & Berechnet. \\
\hline \hline$e^{\prime \prime}-i^{\prime}$ & 1,55 & 1,5 \\
$(E)-i^{0}$ & 3,76 & 3,66 \\
$N_{2}-(E)$ & 1,33 & 1,05 \\
$E^{*}-E$ & 2,56 & 2,92 \\
$N_{0}-F$ & 0,08 & 0,57 \\
& 0,43 & 0,45 \\
\hline
\end{tabular}

Die auffallendste Eigenthümlichkeit des untersuchten Objectivs, die wir hier noch besonders hervorheben, besteht jedenfalls darin, dass die vordere Linse stärker ist, als das ganze System. Die Bedingungsgleichung für diesen Fall ergiebt sich unmittelbar aus der Formel für die Gesammtbrennweite, indem man

$$
\varphi_{0}\left[\frac{(f)}{\%_{0}+(f)-t}\right]>r_{0}
$$

setzt und hierauf beiderseits durch $\varphi_{0}$ dividirt. Man erhält

$$
t>\varphi_{0} \text {. }
$$

Unter den mittelstarken Systemen, die wir genauer kennen, ist übrigens $\mathrm{Nr}$. 9 von Bénèche das einzige, welches die genannte Eigenthümlichkeit besitzt; die entsprechenden Nummern von Oberhä user und Plössl theilen sie nicht. Dagegen scheint dieselbe bei schwächeren Objectiven, namentlich wenn diese aus zwei weit von einander abstehenden Doppellinsen zusammengesetzt sind, ziemlich

*) Die Differenzen zwischen den beobachteten und berechneten Werthen in dieser Tabelle dürften zum Theil darin ihre Frklärung finden, dass die Bestimmung von $d_{i}$ für die einzelnen Linsen wegen der Undeutlichkeit des Bildes in der entsprechenden Lage nicht mit hinreichender Genauigkeit möglich ist. Jazu kommt aber noch, dass die Annahme einer in beiden Lagen gleichen Brennweite streng genommen nur für Centralstrahlen gereehtfertigt erscheint, für Randstrahlen dagegen unstatthaft wird, weil die Grösse der sphärischen I,ängenabweichung und damit auch der Abstand des Brennraumes beim Umkehren der Linsen eine kleine Veränderung erfährt. Eine solche Veränderung macht sich sogar bei stärkeren Linsen schon bemerkbar, sobald die conjugirten Vereinigungsweiten in einem wesentlich anderen Verhältniss stehen. Desswegen stimmen z. B. auch die nach verschiedenen Methoden gefundenen Werthe für die Brennweiten nie genau überein. 
häufig vorzukommen; wir beobachteten sie z. B. an Nr. 4 von Béniche und $\mathrm{Nr}, 4$ von Hartnack. Auch beim Immersionssystem Nr. 9 von Hartnack ist die vorderste Linse etwas stärker, als das ganze Objectiv, und es dürfte diess auch bei den stärksten Systemen anderer Optiker, besonders wenn die erste Linse eine einfache Kronglaslinse ist, gerade kein seltener Fall seịn.

Zum Schlusse mögen noch einige Beobachtungen über die Lage der Haupt- und Brennebenen in verschiedenen anderen Objectivsystemen Platz finden. Die letzte brechende Fläche ist mit $N^{*}$ bezeichnet, alle übrigen Grössen wie oben.

\begin{tabular}{|c|r|c|c|c|c|c|}
\hline & Nr. & $f$ & $N_{0}-F^{\prime}$ & $N+-F^{*}$ & $N+N_{0}$ & $E^{*-E}$ \\
\hline \hline Hartnack & 7 & 3,3 & 0,5 & $+0,15$ & 7,1 & $+0,55$ \\
" " & 9 & 1,57 & 0,35 & $+1,15$ & 5,1 & $+0,27$ \\
Bénèche & + & 12,5 & 3,7 & $+3,00$ & 16,5 & $-7,5$ \\
" " & 7 & 1,7 & 1,5 & $-2,00$ & 7,25 & $+1,35$ \\
" " & 11 & 2,22 & 0,25 & $+3,2$ & 5,2 & $-2,19$ \\
Kellner & 3 & 3,57 & $0,5 \mathrm{~S}$ & 0 & $\delta, 2$ & $+1,04$ \\
\hline
\end{tabular}




\section{Vierter Abschnitt. \\ 'Theoric der mikroskopischen Wahrnehmung.}

15.) Dic mikroskopische Wahrnehmung weicht in mancher Beziehung von der gewöhnlichen mit blossem Auge ab. Es crfordert daher eine ]ängere Uebung, um in der Beurtheilung der erhaltenen Lichteindrücke jene Sicherheit zu erlangen, welche allein die Zuverlässigkeit der Beobachtung verbürgt. Durchs Mikroskop zu sehen und nach dem Gesehenen die Form und Beschaffenheit eines Objectes zu bestimmen, ist eine Kunst, die gelernt sein will, so gut wie jede andere.

Als Eigenthümlichkeit des mikroskopischen Sehens kommt zunächst in Betracht, dass das Bild, das wir beobachten, eigentlich nicht dem Gegenstande selbst, sondern nur einer bestimmten Durchschnittsebene desselben entspricht, auf welche gerade eingestellt wird. Was höher oder tiefer liegt, ist für das Auge nur undeutlich oder gar nicht sichtbar. Das Mikroskop giebt uns also nur über die Dimensionsverhältnisse der versehiedenen Durchschnittsebenen directen Aufschluss, nicht aber über deren Entfernung in der Richtung der Mikroskopaxe. Die letztere lässt sich zwar in manchen Fällen approximativ schätzen, es ist z. B. möglich, ohne Weiteres zu entscheiden, ob ein gegebenes Object kugelförmig, flach gedrückt oder seitlich zusammengedrückt sei; allein eine genauere Bestimmung der Formverhältnisse kann nur durch Drehen des Körpers um seine Axe, also durch Combination verschiedener Ansichten erzielt werden.

Nicht so beim gewöhnlichen Sehen. Hier genügt oft ein flüchtiger Blick, uns über die Form und Gruppirung nahe liegender Körper zu unterrichten, weil die Grenzen, zwischen welchen das Auge zu gleicher Zcit deutlich sieht, ziemlich weit auseinander liegen. Wir sche" also die Körper in ihrer stereometrischen Form und in ihren räuแnlichen Verhältnissen zu benachbarten. Ob wir dabei mit zwei 
Augen oder nur mit Einem sehen, wie beim Mikroskopiren, macht keinen wesentlichen Unterschied.

In zweiter Linie ist die Beleuchtung bei der mikroskopischen 156; Wahrnehmung eine ganz andere, als im gewöhnlichen Leben. Durchs Mikroskop sehen wir die Gegenstände in der Regel bei durchfallendem, mit blossem Auge dagegen vermittelst auffallendem oder reflectirtem Licht. Ein beliebiger Punct des mikroskopischen Bildes erscheint daher um so heller, je grösser die Zahl der Lichtstrahlen, welche vor ihrem Eintritt ins Objectiv, rückwärts ver]ängert, nach dem entsprechenden Punct des Objectes zielen. Bilden diese Strahlen einen vollen Lichtkegel, der mit seiner Basis den optisch wirksamen Theil der Objectiv-Vorderfläche ausfüllt, so erhält der betreffende Punct das Maximum der Helligkeit. Ist dagegen die Kegelbasis nur halb so gross, so erscheint auch der betreffende Punct im Bilde nur halb erleuchtet u. s. f. Das Mikroskop entwirft also gewissermassen ein Schattenbild, in welchem die undurchsichtigen Stellen des Objectes dunkel, die durchsichtigen sich mehr oder weniger hell darstellen, nur dass die Unebenheiten und Dichtigkeitsdifferenzen des Objectes in Folge der Brechung, die sie veranlassen, wesentlich mit zur Lichtvertheilung im Bilde beitragen.

Ganz dasselbe gilt natürlich auch für das Sehen mit blossem Auge, wenn durchscheinende Körper unter denselben Verhältnissen betrachtet werden. Dessenungeachtet ist das Bild, das wir in diesem Falle erhalten, ein wesentlich anderes, als bei der Bcobachtung durchs Mikroskop, und es müssen die entgegengesetzten Angaben, die sich hie und da in mikrographischen Werken ; finden, als unrichtig bezeichnet werden. Sie beruhen nämlich auf der stillschweigend gemachten Voraussetzung, dass die ungleich grössere Oeffnung der einfallenden Lichtkegel, welche durch das Mikroskop dem Auge zugelenkt werden, auf den resultirenden Lichteffect keinen Einfluss übe. Nun lässt sich aber durch dic mathematische Betrachtung dieser Frage, wie sie im Folgenden für einige Fälle durchgeführt ist, leicht nachweisen, dass die Vertheilung von Licht und Schatten im mikroskopischen Bilde vom Oeffnungswinkel des Instruments abhängig und daher nicht einmal für verschiedene Vergrösserungen, geschweige denn für das unbewaffnete Auge, die nämliche ist.

Es lässt sich also nicht in Abrede stellen, dass man die Dinge durchs Mikroskop wirklich anders sieht, als mit blossem Auge. Der

*) Harting, Das Mikroskop pag. 339. 
mikroskopische Beobachter hat es sonach mit Bildern zu thun, die ihm anfänglich neu und ungewohnt sind; er muss sie erst richtig deuten lernen, wie die Keichen und $W$ örter einer fremden Sprache. Obschon nun freilich hiezu vor Allem eine praktische Schule nothwendig ist, die sich durch keine Theorie ersetzen lässt, so möchte doch eine theoretische Begründung des mikroskopischen Sehens selbst für den geübten Beobachter nicht ganz überflüssig sein, da sie in manchen Fällen willkommene Anhaltspuncte zu weitern Raisonnements bietet. Aus diesem Grunde haben wir nachstehend eine Reihe von Fällen einer eingehenden Erörterung unterzogen und dieselbe so oft als thunlich auf mathematische Entwicklungen gestützt. In erster Linie sind die Brechungs- und Reflexionserscheinungen, welche das mikroskopische Bild gegebener Objecte bestimmen, ins Auge gefasst. Hieran reihen sich die auf Interferenz beruhenden Lichteffecte, w clche gewöhnlich als Beugungserscheinungen gedeutet werden; endlich ist auch der schiefen Beleuchtung und den Bewegungserscheinungen eine kurze Betrachtung gewidmet.

\section{I.}

\section{Kugelige und cylindrische 0 bjecte.}

1. Luftblasen in Wasser.

157 Es sei $A B$ (Fig. 95) der senkrechte Durchschnitt einer in Wasser frei schwimmenden, also kugelförmigen Luftblase, und $M N$ die Einstellungsebene des Mikroskops. Alsdann wird ein beliebiger Punct $P$ dieser Ebene im mikroskopischen Bild durch diejenigen Strahlen erhellt, welche nach ihrem Durchgang durch die Luftblase von diesem Puncte zu kommen scheinen und durch die Brechung im Mikroskop den Auge zugeführt werden. Die Neigung dieser Strahlen zur Senkrechten kann selbstverständlich nicht grösser werden als der halbe Oeffnungswinkel des Objectivs. Wird dieser letztere z. B. zu $60^{\circ}$ angenommen, so erreicht sie ihr Maximum mit $30^{\circ}$. Ebenso wird die Neigung der von unten kommenden Strahlen, wenn nämlich Spiegel und Lichtquelle eine hinlängliche Ausdehnung haben, durch die Grösse der Blendung bestimmt. Der Winkel, unter welchem die letztere vom Centrum der Luftblase aus gesehen wird, ist der nämliche, den dic peripherischen Strahlen des einfallenden Lichtkegels bilden. Beträgt dieser Winkcl $=30^{\circ}$, so ist hiemit auch die Grösse des Ab- 
lenkungswinkels, welchen die ausfahrenden Strahlen uit den zugehörigen einfallenden bilden, für Randstrahlen wie $T S$, welche vor und nach der Brechung an der Oberfläche des Lichtkegels liegen, bestimmt.

Zieht man nämlich durch den Kreuzungspunct $O$ des einfallenden und ausfahrenden Strahls das Perpendikel $X Q$, so hat man, wenn die angenommenen Oeffnungswinkel von $60^{\circ}$ unl $30^{\circ}$ ganz allgemein (1) und $\delta$ 'genannt werden

$$
\angle S O T=1 S 0^{\circ}-\angle T O R
$$

oder da $\angle T O R=\angle Q O R-\angle Q O T=\frac{(1)-\delta}{2}$

$$
\begin{aligned}
& \angle S O T=150^{\circ}-\frac{(1)-\delta}{2}, \text { also im gegebenen Falle } \\
& \angle S O T=150^{\circ}-15^{\circ}=165^{\circ} .
\end{aligned}
$$

Da nun ein durch $O$ gezogener Radius diesen Ablenkungswinkel halbirt und die Richtung des Strahls in der Luftblase rechtwinklig kreuzt, so ergiebt sich, wenn man mit $\alpha$ den Einfallswinkel, mit $e^{\prime}$ den Brechungswinkel und mit $\varrho$ den halben Ablenkungswinkel bezcichnet, die woitere Beziehung

$$
a^{\prime}-\varepsilon=90^{0}-\varrho=7 \frac{1}{2^{0}} .
$$

Nimmt man den mittleren Brechungscoefficienten des Wassers zu 1,3356 an, so wird dieser Gleichung Ge-

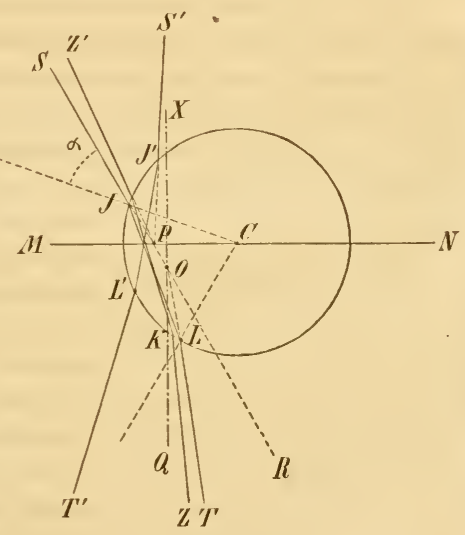

Figur 95. nüge geleistet, wenn $\alpha=20^{\circ} 45^{\prime}$, indem alsdann $\alpha^{\prime}=2 S^{0} 15^{\prime}$.

Die Lage des Punctes $P$ ist hierdurch bestimmt; das Dreicek $C I J$ giebt die Relation

$$
\begin{aligned}
C P: r & =\sin \alpha: \sin \left[150^{\circ}-\left(90^{\circ}-\frac{\omega}{2}\right)\right] ; \text { folglich } \\
C P & =r \cdot \frac{\sin \omega}{\sin \left(90^{\circ}+\frac{\omega}{2}\right)}=\frac{\sin 20^{\circ} 45^{\circ}}{\sin 60^{\circ}} \cdot r=0,64 \mathrm{~S} 3 \mathrm{~S} \cdot r .
\end{aligned}
$$

Denken wir uns nun einen nahe liegenden zweiten Strahl $Z K$, welcher weniger gegen die Verticale geneigt ist und nach der Brechung ebenfalls vom Puncte $P$ zu kommen scheint, so ist einleuchtend, dass 
derselbe sich mit dem ersten Strahl irgendwo kreuzen muss und daher etwas näher dem Centrum die Objectivlinse trifft. Denn verfolgt man die beiden Strahlen in umgekehrter Richtung von oben nach unten, so rückt ihr Convergenzpunct $P$ in Folge der Brechung an der unendlich klein gedachten Fläche bei $J$ bloss etwas nach links und kommt dabei in ein anderes Niveau zu liegen; eine Kreuzung findet aber unter allen Umständen innerhalb der Luftblase statt. Dasselbe gilt natürlich auch von jedem folgenden Strahl mit Rücksicht auf den vorhergehenden. Je weiter wir also im ausfahrenden Lichtkegel von der Linken zur Rechten fortschreiten, um so mehr rückt der entsprechende einfallende Strahl von der Rechten zur Linken; seine Neigung gegen die Senkrechte wird allmählich kleiner und geht dann in die entgegengesetzte über, deren Maximum ebenfalls 15" beträgt.

Es ist von selbst klar, dass dieses Maximum der Abweichung eintreten muss, ehe die ausfahrenden Strahlen auf der rechten Seite den Grenzwerth von $30^{0}$ erreicht haben, da ja die zweimalige Brechung immer eine Ablenkung nach links verursacht. Die Rechnung zeigt, dass im gegebenen Falle der Randstrahl $T^{\prime \prime} L^{\prime}$ nach dem Durchgang durch die Luftblase noch um etwas mehr als $15^{\circ}$ nach links geneigt ist.

158 Diese Erörterungen führen zunächst zu dem Schluss, dass alle in der Ebene des Papiers liegende Strahlen des einfallenden Lichtkegels*) zur Erleuchtung des Punctes $P$ beitragen. Aber auch von den Strahlen, die nicht in diese Ebene fallen, geht keiner verloren. Denn da sie nach der Brechung sämmtlich vom Puncte $P$ zu kommen scheinen und überdiess mit dem nach dem Austrittspuncte gezogenen Radius in derselben Ebene liegen, sonach die Papierebene in der Linie $M N$ schneiden, so wird man alle möglichen Lagen derselben erschöpfen, wenn man alle Strahlen zwischen $S J$ und $S^{\prime} J^{\prime}$ (Fig. 95) unter Beibehaltung des Convergenzpunctes aus der Papierebene heraushebt und sie nach oben und unten so weit divergiren lässt, dass die entsprechenden einfallenden Strahlen den Rand der Blendung streifen. Dass die Neigung der herausgehobenen Strahlen zur Papierebene im gegebenen Falle höchstens $15^{\prime \prime}$ betragen kann und für die beiden Randstrahlen $=0$ wird, ist ohne Weiteres klar. Es hält auch nicht schwer, sich davon zu überzeugen, dass unter diesen Umstän-

*) Jer Ausdruck lichtkegel ist für die einfallenden Strahlen nicht streng mathematiseh zu verstehen, da dieselben keinen gemeinsamen Convergenzpunet haben. 
den sämmtliche ausfahrende Strahlen den wirksamen Theil der Objectivlinse treffen.

Der Punct $P$ erscheint demnach, da der ganze einfallende Lichtkegel zu seinem Bilde beiträgt, ebenso hell, als irgend ein anderer Punct des Gesichtsfeldes. Dasselbe gilt natürlich auch von allen Puncten, welche dem Centrum näher liegen; nur ist für diese die Brechung eine geringere, so dass die ausfahrenden Lichtkegel einen mehr centralen Theil der Objectivvorderfläehe treffen. Der Mittelpunct selbst wird von Strahlen erhellt, welche ungebrochen durchgehen.

Dagegen macht sich für die Puncte, welche weiter vom Centrum abstehen, wie z. B. $p$ (Fig. 96), ein Ausfall des Lichtes bemerkbar. Für diese wird nämlich der Austrittswinkel (= Einfallswinkel) $\alpha$, wic ein Blick auf die Figur zeigt, grösser und folglich $\varrho \quad\left(=90^{\circ}-\left[\alpha^{\prime}-\alpha\right]\right)$ kleiner. Ein mit $T L$ (Fig. 95 und 96) paralleler Randstrahl wird daher so gebrochen, dass er mehr als $30^{0}$ von der Senkrechten abweicht, also für das Auge verloren geht. Dieser Verlust tritt natürlich schon für den zunächst gelegenen Punct ein; er erstreckt sich allmählich, wenn wir der Peripherie immer näher rücken, auch auf die mehr links gelegenen Strahlen des Lichtkegels, bis endlich nur noch der mit $T^{\prime} L^{\prime}$ parallele Randstrahl $l l$ das Auge erreicht. Alle ausserhalb der

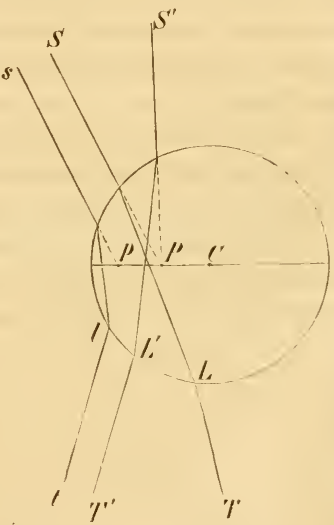

Figur 96. Papierebene verlaufenden Strahlen sind für diese Grenzlage unwirksan.

Die Bestimınung dieses Grenzpunctes geschieht genau in derselben Weise, wie diejenige des Punctes $P$. Ist $\varrho$ der halbe Ablenkungswinkel, so besteht die Gleichung

$$
\begin{aligned}
& \varrho=90^{\prime \prime}-\frac{(1)+\delta}{4}, \text { also im gegebenen Fall } \\
& \varrho=90^{0}-\frac{60^{\circ}+30^{\circ}}{4}=67 \frac{1}{2^{0}} .
\end{aligned}
$$

Aus der oben abgeleiteten Relation $\alpha^{\prime}-\omega^{\prime}=90^{\circ}-\varrho$ ergiebt sich ferner $\alpha^{\prime}-\alpha=221 / 2^{0}$. Diese letztere Differenz tritt für den angenommenen 
Brechung:coelficienten cin, wenn $\alpha=13^{\prime \prime}$; alsdann wird $\alpha^{\prime}=65^{\prime \prime} 37^{\prime}$. Die fragliche Entfernung des Grenzpunctes -- es sei $p$ in Fig. 96 ist demnach durch die Formel gegeben

$$
C p=\frac{\sin 13^{\circ}}{\sin 60^{\circ}} \cdot r=0,7575 \cdot r .
$$

159 Die Luftblase müsste also unter eincm Mikroskop mit den angenommenen Oeffnungswinkeln einen schwarzen Rand zcigen, dessen Breite $=(1-0,7575 ; r=0,2125 . r$. Der mittlere Theil bis $P$ w ürde so hell als das Gcsichtsfeld erscheinen und die Kone zwischen $P$ und $P$ den Uebergang vermitteln. Eine Aenderung der Oeffnungswinkel durch Anwendung verschiedener Objective und Blendungen könnte nur die numerischen Verhältnisse, nicht aber die Lichtvertheilung im Allgemeinen modificiren. Bei grösscren Werthen für (1) und $\delta$ müsste der schwarze Rand schwächer, bei kleineren breiter ausfallen. Schiefe Beleuchtung hätte eine excentrische Lage des hellen Kreises zur Folge.

In Wirklichkeit zeigt nun aber das mikroskopische Bild der Luftblase ein wesentlich anderes Aussehen. Der helle innere Theil erscheint zwar allerdings von einer dunkleren Zone umschlossen, welche allmählich in vollkommenes Schwarz übergeht; dieselbe erstreckt sich aber nicht bis zum Rand, sondern wird nach aussen durch einen hellen Ring abgegrenzt, auf welchen sodann bis zur Peripherie

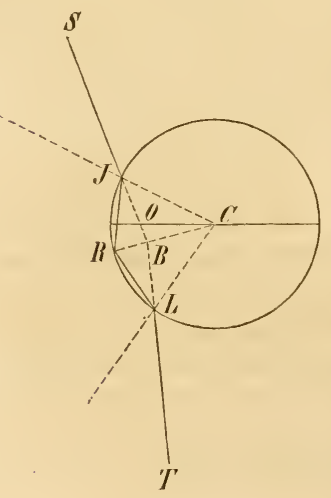

Figur $9 \overline{7}$. ein ziemlich gleichmässiger Halbschatten folgt. Bei genauerer Beobachtung erkennt man etwas ausserhalb des erwähnten hellen Ringes noch einen zweiten weniger deutlichen; ja der ganze Halbschatten erweist sich als von abwechselnd helleren und dunkleren concentrischen Kreisen gebildet.

Diese Erscheinungen lassen sich durch die Brechung allein nicht erklären; sie rühren von Strahlen her, welche ausserdem eine ein- oder zweimalige innere Reflexion erfahren haben. Es sei $T L$ (Fig. 97) ein solcher Strahl, welcher in $R$ reflectirt und in $J$ zum zweiten Mal gebrochen wird; dann ist, wie sich ohne Weiteres aus der Figur ergiebt, $J B C^{\prime}$ der halbe Ablenkungswinkel, für den wir wieder das Zeichen $\varrho$ einführen 
wollen. Da $\varrho$ ein Aussenwinkel zum Dreieck $J B R$, so hat man $0=\angle B J R+\angle B R J$, oder wenn $*$ wieder den Einfalls- und $\iota^{\prime}$ den Brechungswinkel bezeichnet

$$
\varrho=\left(\iota^{\prime}-\alpha\right)+\alpha^{\prime}=2 \alpha^{\prime}-\alpha .
$$

Es wäre leicht, nach dieser Gleichung die Grenzen zu bestim-160 men, zwischen denen die Luftblase in Folge der innern Spiegelung beleuchtet erscheint. Damit wäre indess die Frage noch keineswegs erledigt. Es erscheint zweckmässiger, von einem bestimmten Falle auszugehen, wclcher direct zur Lösung unseres Problems führt, von dem Falle nämlich, wo der ein- und austretende Strahl in derselben geraden Linie liegen und folglich der Winkel $\varrho$ ein rechter wird. Dieselbe Grösse erreicht alsdann auch die Differenz $2 c^{\prime}-\alpha$, woraus sich für " ein Werth von $43 \frac{1}{2}$ ergiebt. Denken wir uns nun statt des einfallenden Strahls ein paralleles Strahlenbündel st (Fig. 9S), so geht natürlich nur derjenige Strahl, dessen " genau den bezeichneten Werth hat, in der ursprünglichen Richtung weiter. Alle übrigen Strahlen des Bündels werden mehr oder weniger abgelenkt, und zwar - wie die Rechnung zeigt - nach links von der Verticalen,

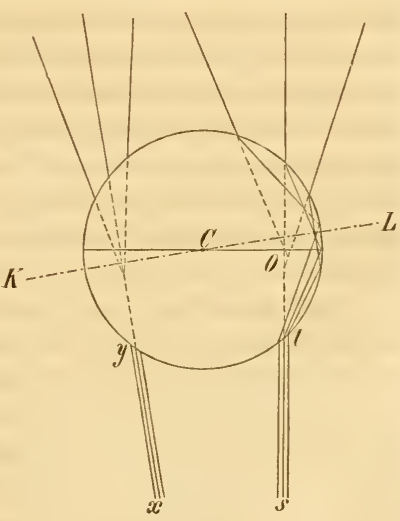

Figur 94 . wenn $\alpha<431 / 2^{0}$ und nach rechts, wenn $\alpha>131 / 2^{0}$. Als Beispiele sind nachstehend einige berechnete Werthe zusammengestellt. Die erste Columne enthält die Einfallswinkel $\alpha$, die zweite die entsprechende Ablenkung $\varphi$ von der Verticalen nach rechts oder links; in der dritten wurden die Entfernungen der Puncte hinzugefügt, in welchen die austretenden Strahlen die Einstellungsebene schneiden.

\begin{tabular}{|c|c|c|}
\hline $\begin{array}{l}\text { Finfallswinkel } \\
\qquad\end{array}$ & $\begin{array}{l}\text { Abweichung ron ler } \\
\text { Senkrechten } \% \text {. }\end{array}$ & $\begin{array}{l}\text { Abstand d. Durchschnitts- } \\
\text { puncte vom Centrum. }\end{array}$ \\
\hline $\begin{array}{l}37^{0} \\
39^{\circ} \\
40^{\circ} \\
42^{0} \\
43^{1 / 2^{0}} \\
45^{0} \\
47^{0}\end{array}$ & $\begin{array}{l}40^{\circ} \quad \text { links } \\
29^{\circ} 12^{\prime}, " \\
23^{\circ} 24^{\prime} " ~ \\
10^{\circ} 40^{\prime} " ~ " \\
00^{\circ} \\
13^{\circ} 12^{\prime} \text { rechts } \\
36^{\circ} 32^{\prime} \text { " }\end{array}$ & $\begin{array}{l}0,7856 \cdot r \\
0,7209 \cdot r \\
0,7004 \cdot r \\
0,6509 \cdot r \\
0,(i 4-3 \cdot r \\
0,7263 \cdot r \\
0,9314 \cdot r\end{array}$ \\
\hline
\end{tabular}


Parallele Strahlen, deren Einfallswinkel zwischen 40 und circa $44^{0}$ variiren, erhalten demnach durch die innere Spiegelung, verbunden mit der Brechung an der Oberfläche, eine solche Richtung, dass sie sämmtlich von Puncten zu kommen scheinen, deren Abstand rom Centrum $0,68-0,70 . r$ beträgt und also höchstens um 1/\% des Radius differirt. Mit andern Worten: dem einfallenden parallelstrahligen Lichtbündel entspricht ein ausfahrender Lichtkegel, dessen virtueller Convergenzpunct $O$ etwas unterhalb die Einstellungsebene, jedoch nahezu in die Linie fällt, welche den ohne Ablenkung austretenden Strahl darstellt. Hier concentrirt sich also für unser Auge der ganze Lichteffect, welchen das einfallende Bündel auf diesem Wege hervorzubringen vermag. Dazu kommt, dass jedes andere Strahlenbündel $x y$ (Fig. 95), welches bei gleichen Einfallswinkeln um einige Grade nach rechts oder links abweicht (wurde, um Verwirrung zu vermeiden, auf der opponirten Seite gezeichnet) sich mit Rücksicht auf die rechtwinklig dazu errichtete Diametralebene $K L$ ebenso vcrhält, so dass also die Helligkeit des Punctes $O$ noch durch unendlich viele andere verstärkt wird, welche etwas höher oder tiefer liegen und mit jenem eine ununterbrochene Lichtlinie bilden.

Auf diese Weise wird es erklärlich, dass ein kleiner Raum in einem Abstand von $\mathrm{C}^{\prime} \mathrm{O}=0,69 . \mathrm{r}$ vom Centrum, mitten im Randschatten so entschieden beleuchtet und von oben gesehen als heller Ring erscheint. Man begreift anch, dass die Breite dieses Ringes, wenigstens inncrhalb der gewöhnlichen Grenzen, mit den Oeffnungswinkeln des Objectivs und der Blendung zu- und abnimmt und dass eine höhere oder tiefere Einstellung die Verwischung seiner Umrisse zur Folge haben muss.

Wenclen wir jetzt dasselbe Raisonnement auf Strahlen an, welche eine zweimalige innere Reflexion erfahren haben, so erklärt sich auch das Vorhandenscin eines weniger deutlichen äusseren Ringes. Ist $S T$ (Fig. 99) ein solcher Strahl, welcher in $R$ und $Q$ reflectirt und in $P$ zum zweiten Mal gebrochen Figur 99. wird, so sind die Dreiecke CPQ, CQR 
und $C R T$ congruent und ihre den Sehnen $P Q, Q R$ und $R T$ anliegenden Winkel $=a^{\prime}$. Folglich messen die drei Centriwinkel $P C Q$, $Q C R$ und RCT zusammengenommen $=3\left(150^{\circ}-2 \alpha^{\prime}\right)$. Andererseits giebt das Dreieck $P C D$ die Beziehung

$$
\begin{aligned}
\angle P D C & =\varrho=F C P-C P T=F C P-a \\
\text { oder da } F(Y) & =\frac{360^{\circ}-P\left({ }^{\prime} T\right.}{2} \\
\varrho & =\frac{\left.360^{\circ}-3(14)^{\circ}-2 u^{\prime}\right)}{2}-\bullet=3 \iota^{\prime}-\iota-90^{\circ}
\end{aligned}
$$

Für den Fall, dass der einfallende Strahl ohne Ablenkung austritt, also $\varrho=90^{\circ}$, besteht hiernach die Bedingung $3 \alpha^{\prime}-\alpha=150^{\circ}$. Dieser Bedingung wird Genüge geleistet, wenn $\alpha=46^{0} 2 \mathrm{~S}^{\prime}$, worans sich der Abstand des Punctes $D$ vom Centrum auf $0,725 . r$ berechnet. Die nachstehende Uebersicht, in welcher dieselben Grössen zusammengestellt wurden, wic in der oben mitgetheilten, zeigt nun, dass parallele Strahlen, deren Einfallswinkel etwas grösser oder kleiner als $46^{0} 2 S^{\prime}$, wie im vorhergehenden Falle einen virtuellen Brennraum bilden, dessen kleinster Durchmesser etwas oberhalb der Einstellungs-

\begin{tabular}{|c|c|c|}
\hline $\begin{array}{c}\text { Einfallswinkel } \\
\varkappa\end{array}$ & $\begin{array}{c}\text { Abweichung } \\
\text { von der Senkrechten } \\
q\end{array}$ & $\begin{array}{l}\text { Abstand der Durch- } \\
\text { schnittspuncte in der } \\
\text { Einstellungsebene } \\
\text { vom C'entrum. }\end{array}$ \\
\hline $\begin{array}{l}43^{1} /^{0} \\
44^{0} \\
45^{0} \\
46^{0} \\
46^{0} 25^{\prime} \\
47^{0} \\
45^{0}\end{array}$ & $\begin{array}{l}46^{0} \quad \text { links } \\
39^{1} / 2^{0} \quad " \\
25^{0} 12^{\prime}{ }^{\prime \prime} \\
\left.5^{0} 36^{\prime} "\right) \\
0^{0} \\
11^{0} 4 \delta^{\prime} \text { rechts } \\
42^{0}\end{array}$ & $\begin{array}{l}0,995 \cdot r \\
0,900 \cdot r \\
0,751 \cdot r \\
0,727 \cdot r \\
0,725 \cdot r \\
0,747 \cdot r \\
1,000 \cdot r\end{array}$ \\
\hline
\end{tabular}
ebene und der Richtungslinie des ohne Ablenkung austretenden Strahls sehr nahe liegt.

Der äussere helle Ring kommt demnach in einer Entfernung von $0,725 . r$ vom Centrum zu Stande. Er steht un 0,0366.r oder annähernd um den 27 sten Theil des Halbmessers vom inneren ab und erscheint in einem etwas höhcren Niveau am schärfsten contourirt. Seine geringere Lichtstärke erklärt sich theils durch den stärkeren Verlust in Folge der zweimaligen Spiegelung, theils durch die enger gezogenen Grenzen der Einfallswinkel (c. $\left.451 / 2^{0}-47^{0}\right)$.

Aus dem Angeführten lässt sich zugleich die Folgerung ziehen, 1(i2 dass weitere helle Ringe durch Strahlenbündel gebildet werden, 
welche eine $3-4$ oder mehrmalige innere Reflexion erfahren haben. Es mag genügen, für diese Fälle die Bedingungen zusammenzustellen, unter welchen die ausfahrenden Strahlen keine Ablenkung zeigen und hienach die Puncte zu bestimmen, in welchen sie, rückwärts verlängert, die Einstellungsebene schneiden. Die Abstände dieser Puncte dürfen hier ohne Weiteres mit denen der entsprechenden Ringe identificirt werden.

\begin{tabular}{|c|c|c|c|c|}
\hline $\begin{array}{c}\text { Zahl } \\
\text { der innern } \\
\text { Reflexionen. }\end{array}$ & $\begin{array}{l}\text { Bedingungs- } \\
\text { gleichung für den } \\
\text { ohne Ablenkung } \\
\text { austretenden Strahl. }\end{array}$ & $\begin{array}{l}\text { Einfalls- } \\
\text { winkel } \\
\qquad\end{array}$ & $\begin{array}{c}\text { Brechungs- } \\
\text { winkel } \\
\alpha^{\prime}\end{array}$ & $\begin{array}{l}\text { Abstand der } \\
\text { Ringe rom } \\
\text { Centrum. }\end{array}$ \\
\hline 3 & $4 \alpha^{\prime}-\alpha=270^{\circ}$ & $47^{0} 23^{\prime}$ & $79^{0}-23^{\prime}$ & $0,7359.2$ \\
\hline 4 & $5 \alpha^{\prime}-\alpha=360^{\circ}$ & $47^{0}+7^{\prime}$ & $S 1^{\circ} 33^{\prime}$ & $0,7406.2$ \\
\hline 5 & $6 \alpha^{\prime}-u=450^{0}$ & $15^{0}$ & $53^{0}$ & $0,7+31 . \gamma$ \\
\hline 6 & $7 \alpha^{\prime}-\alpha=540^{\circ}$ & $45^{0} 7^{\prime}$ & $\delta 4^{0} 3^{\prime}$ & $0,7447 . r$ \\
\hline
\end{tabular}

Es versteht sich von selbst, dass diese Reihe ihren Abschluss findet, sobald der Einfallswinkel seinen Grenzwerth, welcher für Wasser und Luft $45^{0} 29^{\prime}$ beträgt, erreicht hat. Der diesem Grenzstrahl entsprechende Ring, der übrigens nicht mehr wahrnehmbar sein kann, würde um $0,7.457 . r$, also annähernd $3 / 4$ des Halbmessers vom Centrum abstehen. Daraus folgt indessen noch nicht, dass der übrig bleibende peripherische Theil des Randes nicht ebenfalls durch die innere Spiegelung beleuchtet werde. Vielmehr geht aus den mitgetheilten Tabellen hervor, dass die hier in Betracht kommenden Lichtstrahlen, sofern sie nicht zur Bildung der Ringe beitragen, sämmtlich so abgelenkt werden, dass sie von Puncten zu kommen scheinen, welche ausserhalb des entsprechenden Ringes liegen. Als Gesamıntwirkung muss sich daher eine schwache Erhellung des Randes ergeben, während der Kernschatten innerhalb der Ringe wegen gänzlichen Lichtmangels vollkommen schwarz erscheint.

Da die Abstände der Ringe von Grössen abhängen, welche ihrerseits durch den Brechungsindex des ungebenden Mediums bestimmt werden, so lässt sich erwarten, dass Flüssigkeiten von grösserer Dichtigkeit, wie Oel, Glycerin u. dgl, , die mitgetheilten Zahlenverhältnisse modificiren. In Oel mit dem Brechungscoefficienten 1,5 erhält man z. B. für den innersten hellen Ring einen Abstand von 0,5957.v vom Centrum, was mit der Beobachtung vollkommen übereinstimnt. Aus demselben Grunde liegen die Ringe im blauen Licht stets etwas 
näher dem Centrum, als im rothen, woraus sich denn erklärt, dass sie bei Anwendung ron weissem Licht auf der Innenseite blau und auf der Aussenseite roth umsäumt erscheinen.

Auffallend deutlich treten die hellen Ringe, und damit auch die 164 Farbensäume, an den zugekehrten Seiten benachbarter Luftblasen hervor. Das schwache Halblicht, welches dem Randschatten einen grauen Ton verleiht, steigert sich hier zu einem intensiven Lichtstreifen, der nach innen zu scharf gezeichnete, den Ringen entsprechende Linien erkennen lässt, nach aussen dagegen als homogener Schimmer erscheint. Wie eine solche Verstärkung des Lichteffectes durch die Wirkung einer Luftblase auf eine andere hervorgebrarlit wird, lässt sich an einfachsten darthun, indem man die Strahlen dcs ausfahrenden Lichtkegels rückwärts verfolgt und an den Reflexionsstellen durch Brechung ins Wasser übergelien lässt, worauf sie durch die benachbarte Luftblase theilweise nach unten gegen die Blendung

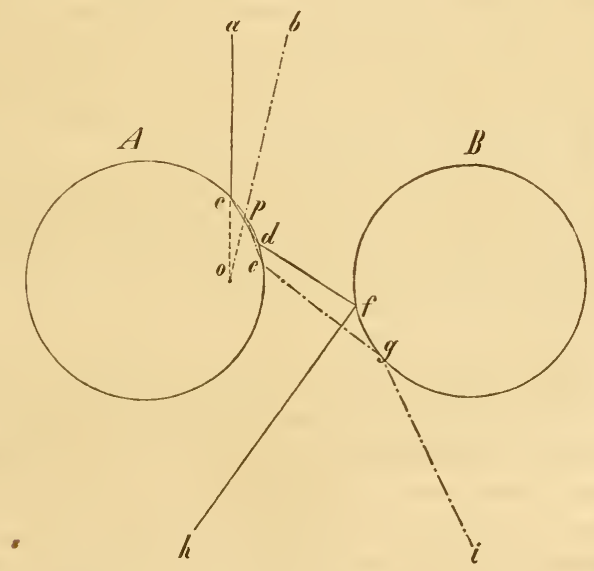

Figur 100.

reflectirt werden. So gelangen z. B. die Strahlen $a c$ und $b p$ (Fig. 100), welche nach dem Puncte $o$ im zweiten Ringe der Luftblase $A$ convergiren und nach zweimaliger Brechung sich in den Richtungen $d f$ und $e g$ fortbewegen, durch Reflexion an der Luftblase $B$ nach $h$ und $i$. Sind $a c$ und $b p$ die Randstrahlen eines von oben einfallenden Lichtkegels, so sind $f h$ und $g i$ auch die Randstrahlen des entsprechenden ausfahrenden. Ungekehrt müssen daher auch, wenn die Bewegung 
des Lichtes von unten nach oben stattfindet, die Strahlen des weit geöffneten Kegels $h f g i$ sich zu dem spitzen Bündel $a c p b$ sammeln und somit die Beleuchtung des Punctes $o$ vermitteln. Nähern sich hf und ig der Verticalen, was mit der Verkleinerung der Blendung gleichbedeutend ist, so rücken auch $a c$ und $b p$ sich gegenseitig näher. Das zum Objectiv gelangende Lichtbündel wird dadurch geschwächt, bleibt aber nach wie vor etwas nach rechts geneigt. Diese Neigung schlägt aber in die cntgegengesetzte um, wenn die Luftblasen sich beträchtlich weiter von einander entfernen. Die Richtungslinien $d f$ und $e g$ nähern sich alsdann mehr der Horizontalen; $a c$ und $b p$ rücken in Folge dessen weiter nach links, fast so, als ob dic Luftblase $A$ sich in derselben Richtung um ihre Axe drehte. Das ansfahrende Lichtbündel wechselt also je nach der Entfernung der beiden Luftblasen seine Neigung zur Axe des Mikroskops.

In ähnlicher Weise lässt sich auch die Verstärkung der übrigen Ringe, wie überhaupt die intensivere Beleuchtung des Randes veranschaulichen. Man hat nur nöthig, den entsprechenden Lichtkcgel zu construiren und einzelne Strahlen desselben, ähnlich wie in Fig. 100 , rückwärts zu verfolgen, um sich über die verschiedenen hieher gchörigen Erscheinungen Rechenschaft zu geben.

Betrachtet man die Luftblase ohne Rücksicht auf die Einstellungsebene als brechenden Apparat, so wirkt sie im Wesentlichen wic eine biconcave Linse. Ihre Brennweite $f$, welche natürlich negativ ausfällt, wird durch die Fornel bestimmt

$$
f=-\frac{r}{2(n-1)}
$$

wobei $r$ der Radius und $n$ der Brechungscoefficient des umgebenden Mediums. Da die beiden Hauptpuncte, wie in jeder Kugel, mit dem Centrum zusammenfallen, so ist obiger Ausdruck auch gleich dem Abstand des Brennpunctes vom Mittelpuncte. In Oel mit dem Brechungsindex 1,5 wird $f=-r$, in Wasser annähernd $-3 / 8 r$, welche Werthe indess durch die Aberration der Randstrahlen mehr oder minder (in Wasser um circa $0,2, r$ ) reducirt werden ${ }^{*}$ ).

*) Durch ein achromatisches Iinsensystem wird ein einfallender Lichtkegel stets so gebrochen, als ob derselbe von Strahlen von ungefähr mittlerer Neigung gebildet würde, $d$, h. der lichtkegel verhält sich wie ein Kegelmantel von geringercr (Oeffunng. Hieraus erklärt sich, dass das Auflegen eines l)eckplättchens auf ein beliebiges Object eine scheinbare Annäherung desselben um eine bestimmte Grösse bedingt, obschon der mathematische Ausıluck für diese Annäherungr rom Neigungswinkel der Lichtstrahlen ahhängig ist und daher keinen 
Senkt man also den Focus des Mikroskops auf das Niveau des Brennpunctes herunter, so kommt dort das Bild entfernterer Gegenstände, die gerade im Spiegel sich reflectiren oder in den einfallenden Lichtkegel eingetaucht werden, zum Vorschein. Seine Umrisse erscheinen um so schärfer gezeichnet, je mehr man durch die Wahl der Blendung oder der Beleuchtung schief gegen die Axe einfallende Strahlen ausschliesst und je weniger die Randstrahlen des zum Objectiv gelangenden Lichtkegels von der Senkreehten abweichen. Ein senkrecht von unten einfallendes, parallelstrahliges Lichtbïndel liefert bei Anwendung einer müssigen Vergrösserung ein so scharfes Bild, dass es bei etwas höherer oder tieferer Einstellung sich sogkich verwischt.

Die ungleiche Brechbarkeit der verschiedentarbigen Strullen bringt es mit sich, dass der ausfahrende Lichtkegel in der Mitte nur rothe, an der Peripherie nur violette Strahlen enthält. Man küunte versucht sein, hieraus die 'Thatsache zu erklären, dass der helle, farblose Kreis, welcher das Bild der Blendung darstellt, bei etwas höherer Einstellung nicht nur beträchtlich grösser wird, sondern auch cin röthliches Centrum und einen bläulichen Saum zeigt. Diese Farbenerscheinungen, wie sie in gleicher Weise auch bei reellen Bildern vorkommen, haben jedoch ihre wahre Trsache nicht in Object selbst, sondern in der chromatischen Aberration des Mikroskops, welche durch höhere Einstellung übcrverbessert, durch tiefere unterverbessert wird. Man überzeugt sich hievon durch das einfache Experiment, welches man gewölnnlich bci der Prüfung des Aberrationszustandes anwendet, indem man nämlich das Bildchen eines Fensters, das sich in einem Quecksilbertropfen abspiegelt, als Object benutzt. Hebung und Senkung des Focus führen alsdann dieselben Farbenerscheinun-

bestimmten Werth ergiebt. Ein Deckplättchen von 227 Mik. Dicke bewirkt z. B. für die Objective 7 und 9 von Bénèche eine Hebung des Objectpunctes ron (1) Mik., woraus sich die maassgebende Neigung, wenn der Brechungscoefficient des Glases zu 1,5 angenommen wird, auf c. 15" berechnet. Diese nämliche Neigung bedingt auch die Lage des Brennpunctes einer Luftblase. Sie verursacht überdiess (wenn das Objectiv nicht in Wasser getaucht wird) noch eine weitere Verkürzung der Brennweite, welche daher rührt, dass ein im Wasser befindliches Object um so stärker gehoben erscheint, je tiefer es liegt. Der Brennpunct erfährt demnach eine stärkere Hebung, als das Centrun der Luftblase, und wird dadurch dem letzteren scheinbar näher gerückt. Wir werden diese Erscheinung, die bei directer Messung von Niveaudifferenzen nicht vernachlässigt werden darf, weiterhin ausführlich besprechen. 
gen herbei, welche auch die durch Brechung entworfenen Bildchen der Luftblasen zeigen.

2. 0eltropfen in Wasser.

160

Wir betrachten den Oeltropfen in Wasser ganz allgemein als Repräsentant eines beliebigen Körpers mit kreisförmigem Verticalschnitt, der in ein Medium mit kleinerem Brechungscoefficienten eingetaucht ist. Um die Lichtvertheilung in einer gegebenen Durchschnittsebene, anf welche das Mikroskop eingestellt ist, zu bestimmen, wenden wir auch hier das Princip der Reciprocität des Strahlenganges an, indem wir Tichtbündel rückwärts vom Objectiv nach beliebigen Puncten

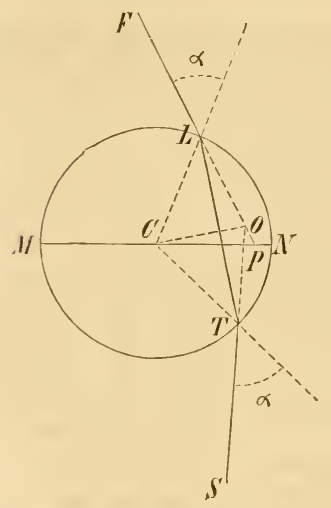

Figur 101. der Einstellungsebene construiren, und hierauf deren Wege nach der Blendung hin rerfolgen. Seien wiederum $\omega$ und $\delta$ die Oeffnungswinkel des Objectivs und der Blendung, $\boldsymbol{M} \boldsymbol{N}$ (Fig. 101) die Einstellungsebene, $F L$ ein nach dem Punct $P$ zielender Strahl, welcher nach zweimaliger Brechung in der Richtung $T S$ sich fortbewegt, endlich $\alpha$ und $\alpha^{\prime}$ der Einfalls - und Brechungswinkel; dann ist der halbe Ablenkungswinkel

$$
\varrho=\frac{1}{2} L O T=L O C
$$

und man erhält aus dem rechtwinkligen Dreieck, dessen Hypotenuse $I, O$, die Relation

$$
\varrho=90^{\circ}-\left(\alpha-\alpha^{\prime}\right) .
$$

Für diejenigen Puncte in der Einstellungsebene, deren Helligkeit der des Gesichtsfeldes gleichkommt, gelten nun aber dieselben Bezichungen und Deductionen, welche bereits oben (Nr. 157) entwickelt wurden. Die dort beigefügten Constructionen finden auch hier Anwendung, wenn man sich die Strahlenkegel, so wie sie dargestellt. sind, von der linken Hälfte des Kreises auf die rechte hinübergeschoben denkt, so dass die Brechungsstellen wieder auf die Peripherie fallen. Man hat also

$$
\varrho>90^{0}-\frac{\omega-\delta}{4}
$$

und hieraus durch Combination mit obiger Gleichung

$$
a-\alpha^{\prime}=\frac{\omega-\delta}{4} \text {. }
$$


Ebenso ergiebt sich für die Grenzpuncte, welehe nur noch von den äussersten Randstrahlen erhellt werden

$$
\begin{aligned}
& \varrho=90^{\circ}-\frac{(\omega+\delta}{4} \text { und sonach } \\
& \alpha-\alpha^{\prime}=\frac{\omega+\delta}{1} .
\end{aligned}
$$

Mit Hülfe dieser Gleichungen könnten nun leicht die Grenzen 16 б bestimmt werden, bis zu welchen in irgend einem gegebenen Falle Kern- und Halbsehatten reichen. Bei der grossen Verschiedenheit der Zahlenverhältnisse, die in der Praxis vorkommen können, gewährt jedoch die Erörterung eines bestimmten Beispiels kein besonderes Interesse; es mag genügen, auf cinige allgemeinere Folgerungen hier noeh aufimerksam zu machen.

Es sei sh Fig. 102 cin Randstrahl des ausfahrenden Lichtkegels, welcher rückwärts verlängert) die durch $C$ gelegte Einstellungsebene im Punete $P$ der Kugeloberfläche schncidet. Alsdann ist sein Einfallswinkel $\alpha$, wie ein Blick auf die Figur zeigt, gleich dem Winkel $R P^{\prime} C=90^{0}-\frac{(1)}{2}$. Ist nun für diese Grösse des Einfallswinkels $\alpha-a^{\prime}<\frac{\omega+\delta}{1}$ oder sogar kleiner als $\frac{(1)-\delta}{4}$, so fällt im ersteren Fall der Kernschatten, in zweiten auch der Halbschatten weg. Die Kugel erscheint also unter Umständen von einem Rand bis zum andern gleichmässig beleuchtet. Dieser Fall tritt ein, wenn der Brechungscoefficient der-

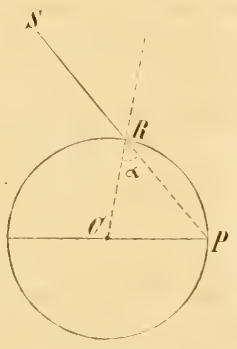

Figur 102. selben $=1,5,(1)=60^{0}$ und $\delta<22^{0}$ ist ; diess vorausgesetzt wird nämlich $\alpha-\alpha^{\prime}=91 / 2^{0}$ und $\frac{(\omega-\delta}{4}>9 \frac{1}{2}{ }^{0}$. Oeltropfen, kugelige Stärkekörner, cylindrische Haare $u$. dgl., deren Brechungsvermögen von dem eben angenommenen nicht sehr abweicht, zeigen daher bei stärkeren Vergrösserungen keinen Randschatten, während die schwächern Objective ihn um so deutlicher hervortreten lassen, je kleiner ihr Oeffnungswinkel. Am breitesten müsste er natürlich bei der Beobachtung mit blossem Auge erscheinen, da alsdann $\omega$ als verschwindend klein zu betrachten wäre.

Wenu bei gleichbleibendem $\omega$ der Winkel $\delta$ variirt, so ändert sich die Lichtvertheilung in folgender Weise. Ist $\delta=0$, die einfallenden Strahlen also parallel, so werden die Bedingungsgleichungen für 
den Kern- und Halbschatten identisch, d. h. die Grenzen beider fallen zusammen oder was dasselbe ist, der Halbschatten fällt weg. Nimut $\delta$ alluählich zu, so wird der Kernschatten schmäler, der Halbschatten breiter. Die innere Grenze des letztern erreicht endlich, wenn $\delta=\omega$, das Centrum; die Kugel erseheint damn nirgends so hell beleuchtet, als das Gesichtsfeld. Wird $\delta>(1)$, so rückt die Grenzlinie des Halbschattens wieder nach aussen, ebenso die des Kernschattens. Bcide erreichen früher oder später, je nach der Grösse von $(\omega)$ die Kugeloberfläche.

Werden nun auch diese theoretischen Folgerungen durch die ITngleichheit des Verlustes, welchen die verschieden geneigten Strahlen in Folge der Reflexion an den Linsenoberflächen erleiden, sowie ferner durch dic Aberrationen des Objectes und des Mikroskops etwas modificirt, so lehrt doch das Experiment, dass die berechneten Grenzen zwischen Licht und Schatten für jerle beliebige Combination von w und $\delta$ nahezu mit den beobachteten übercinstimmen. Sieht man z. B. durch die Mikroskopröhre nach Wegnahme des Objectiv- und Oculareinsatzes) bei gewöhnlicher Beleuchtıng auf eine Glaskugel oder einen cylindrischen Glasstab herunter, welche in den einfallenden Lichtkegel cingetaucht sind, so erscheint die belcuchtete Mitte beinahe nur als Punct oder als Linie und der breite Randschatten tief schwarz. Hält man aber dieselben Objecte gegen den freien Himmel, wobei also $\delta$ sehr gross wird, so erscheinen sic von einem Rande bis zum andern hell.

168 Die Brennweite $f$ einer Kugel oder eines Cylinders für parallel einfallende Lichtstrahlen wird durch die Formel bestimmt

$$
f=\frac{n^{\prime} r}{2\left(n^{\prime}-n^{0}\right)}
$$

wobei $n^{\prime}$ und $n^{\prime \prime}$ bezichlich dic Brechungsexponenten der Kugelsubstanz und des umgebenden Mediums und $r$ den Radius der Kugel bezeichnet. Ist z. B. $n^{\prime}=1,5$ und $n^{0}=1$, so ergiebt sich als Abstand des Brennpunctes vom Centrum $3 / 2 r$. - Stellt man also das Mikroskop auf das entsprechende Niveau cin, so erscheint dort das reelle Bild entfernterer Gegenstände, von welchen gerade Licht durch die Blendung zum Object gelangt. Dasselbe zcichnet sich sowohl bei Oeltropfen und kugeligen Stärkekörnern, als auch bei cylindrischen Haaren, Bastzellen u. dgl. mit auffallender Schärfe, wenn man nur die Blendıng ziemlich weit nach unten zurückzieht oder auf irgend eine andere Weise den Parallelismus der einfallenden Strahlen herstellt. Unter günstigen Unständen ist es sogar möglich, aus der be- 
kannten Entfernung und Grösse des Gegenstandes und der genau gemessenen Grösse des Bildchens den Brechungscoefficienten der Substanz bis auf die zweite Decimale genau zu bestimmen. Die dabei anzuwendende Formel lässt sich leicht aus der cben abgeleiteten für die Brennweite*) und der bekannten Relation der conjungirten Vereinigungsweiten $\left(\frac{1}{p}+\frac{1}{p^{\prime}}=\frac{1}{f}\right)$, welche jenen Grössen proportional sind, entwickeln. Ist $\boldsymbol{M}$ der Durchmesser des fraglichen Gegenstandes, z. B. der Blendung, $p$ scine Entfernung vom Object, $m$ der Durchmesser des Bildchens, endlich $\iota^{0}$ und $\iota^{\prime}$ die Brechungscoefficienten, so findet man

$$
n^{\prime}=\frac{-2 m^{0}}{2 p-\left(1+\frac{M}{m}\right) r} \text {, oder annähernd } n^{\prime}=\frac{2 m^{0}}{2 p-\frac{M}{m} r}
$$

wobei in der letzteren Formel vorausgesetzt ist, dass 1 im Verhaltniss zu $r$ sehr gross sei.

Wollte man diese Formeln auf Kugeln mit negativen Brennweiten anwenden, so wäre dis zweite Glicd des Nenners positiv zu nchmen. Man hätte also

$$
n^{\prime}=\frac{2 m^{0}}{2 p-\frac{M}{m} r} \text { und hicraus } n^{0}=\left(1+\frac{M r_{r}}{2 m^{\prime}}\right) n^{\prime} .
$$

\section{Hohlkugel und Hohleylinder.}

Die folgende Betrachtung findet ihre Anwendung auf röhren-169 förmige Zellen, Oeltropfen und Zellkerne mit Vacuolen, Stärkekörner mit rundlichen Höhlungen u. dgl. Der Kürze wegen und um eine bestimmte Vorstellung zu haben ist jedoch durchgehends nur vom Hohlcylinder die Rede. Die Lichtbündel, welche bci einem solchen Object auf das mikroskopische Bild Einfluss äben, nehmen - wie sich erwarten lässt - einen vierfach verschiedenen Verlauf. Es sind nämlich 1) Randstrahlen, welche die Wandung der cylindrischen Röhren durchsetzen, ohne das Lumen zu erreichen; 2) Randstrahlen, welche die Innenfläche des Cylinders sehr schiefwinklig treffen und dort reflectirt werden ; 3) Strahlen, welche in das Lumen eindringen, an der Wandung reflectirt werden und dann nach zweimaliger Brechung

*) Die Formel für die Brennweite bedarf übrigens wegen der Kugelabweichung der Randstrahlen einer kleinen Correction, die zum Theil von der Eigenthünlichkeit des ()bjectivs abhängt. Hierüber gilt, was oben über die Brennweite der Luftblase bemerkt wurde (s. Anmerkung zu Nr. 165). 
zum Objectiv gelangen; 1) Strahlen, welche das Lumen geradlinig durchsetzen und folglich eine viermalige Brechung erleiden.

Die Randstrahlen, welche bloss zwei Mal gebrochen werden, verhalten sich natürlich genau, wie im soliden Cylinder. Es hängt hier aber nicht bloss von den Oeffnungswinkeln $\omega$ und $\delta$, sondern auch von

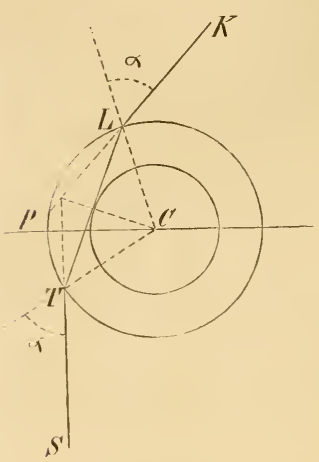

Figur 103. der Dicke der Wandung $a b$, ob und wieviel sie zur Beleuchtung der letzteren beitragen. Ist $r$ der kleine und $l$ der grosse Radius des Hohlcylinders, die Dicke der Wand also $R-r$, ferner STLK Fig. 103) ein Grenzstrahl, welcher nach der ersten Brechung die Innenwand tangirt, $\alpha-a^{\prime}$ sein Einfallsund Brechungswinkel und $n$ der Brechungsindex, so hat man $\sin \alpha^{\prime}=r$, $\sin \alpha=\frac{n \sin c^{\prime}}{k}$, folglich $\sin \alpha=\frac{n r}{k}$. Für die Randstrahlen in Allgemeinen gilt dennach die Bedingung $\sin \alpha>\frac{n r}{R}$.

Da sic überdiess, wenn sie bei mittlerer Einstellung zur Erhellung der Wand mitwirken sollen, der allgemeinen Gleichung genügen müssen $\alpha-a^{\prime}<\frac{(1+\delta}{4}$, so gehen sie für das mikroskopische Bild verloren, sobald $\frac{m}{R}$ eine gewisse Grösse erreicht. Sie kommen also bei gegebenen Brechungsverhältnissen nur bei dickeren Wandungen in Betracht.

Ist z. B. $n=\frac{1,619}{1,335}$ Brechungsverhältniss zwischen Flintglas und Wasser) und $\frac{r}{R}=0,8$, so findet man $\alpha>S 1^{0}, \alpha^{\prime} \geq 53^{0} \mathrm{~S}^{\prime}, \alpha-\alpha^{\prime}$ also beinahe $25^{0} \mathrm{im}$ Minimum. Die Summe der Oeffnungswinkel $\omega+\delta^{\prime}$ nüsste also nahezu $1 \times 2 S=112^{0}$ betragen, wenn auch nur die innersten Strahlen zur Beleuchtung der Cylinderwandung beitragen sollen. Die letztere müsste also, würde ihr nicht ein anderer Strahlengang Licht verleihen, selbst bei ziemlich starker Vergrösserung gewöhnliche Beleuchtung vorausgesetzt) vollkommen schwarz erscheinen.

Die unter 2) angeführten Randstrahlen, welche an der innern Grenzfläche der Wanclung wieder nach der äussern zurückgeworfen werden und hier die «weite Brechung erfahren, bilden etwas oberhalb 
der Mitte einen virtuellen Focus, welcher - ähnlich, wie in der Luftblase - nahezu mit dem Puncte zusammenfällt, in welchem die Richtungslinie des ungebrochen durchgehenden Strahls die durch das Centrum gelegte Einstellungsebene schneidet. Um diesen Punct zu bestimmen, sei $S T$ (Fig. 104) ein senkrecht von unten einfallender Strahl, welcher in $H$ reflectirt und in $M$ zum zweiten Mal gebrochen wird; ferner $\alpha$ und $a^{\prime}$ der Einfalls- und Brechungswinkel, $r$ der kleine und $R$ der grosse Radius, endlich $\varrho=L M K I I$ und $\eta=L M H K$. Dann giebt das Dreieck WHK $\varrho=150^{\circ}-\left[\left(u-u^{\prime}\right)+r_{i}\right]$; folglich $\sin \varrho=\sin \left(\alpha-\alpha^{\prime}+\eta\right)=\sin \left(\alpha-\alpha^{\prime}\right) \cos \eta$ $+\cos \left(\alpha-\alpha^{\prime}\right) \sin \eta$.

In Dreieck $C H I I$ verhält sich aber CII: $C I I=\sin \eta: \sin \alpha^{\prime}$ und hicrnach ist

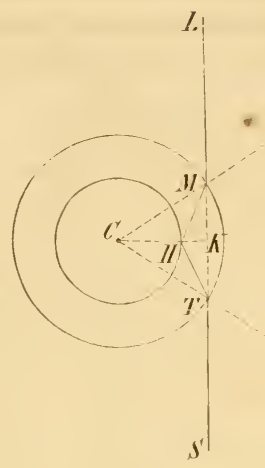

Figur 104 .

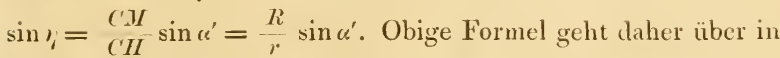

$$
\begin{aligned}
\sin \varrho & =\sin \left(\alpha-\alpha^{\prime} \sqrt{1-\left(\frac{k}{r} \sin \alpha^{\prime}\right)^{2}}\right. \\
& +\cos \left(\alpha-\alpha^{\prime}\right) \frac{R}{r} \sin \alpha^{\prime} .
\end{aligned}
$$

Mit Hülfe dieser Gleichung lässt sich die Richtung des ausfahrenden Strahls für jeden beliebigen Einfallswinkel bestimnen. Im Falle $\varrho=90^{\circ}$ wird $\eta$ der complementäre Winkel $z u \propto-a^{\prime}$. Man hat alsdann

$$
\begin{aligned}
\cos \left(\alpha-\alpha^{\prime}\right) & =\sin \eta=\frac{R}{r} \sin \alpha^{\prime}, \text { und hieraus } \\
\frac{r}{R} & =\frac{\sin \alpha^{\prime}}{\cos \left(\alpha-c^{\prime}\right)} .
\end{aligned}
$$

Aus dem letzteren Ausdruck geht hervor, dass bei jedem beliebigen Einfallswinkel sich ein Verhältniss der Radien denken lässt, welches dem austretenden Strahl die Richtung des einfallenden giebt. Da nun die Richtungslinie des ohne Ablenkung austretenden Strahls, und mit ihr der virtuelle Focus, um so weiter nach innen rückt, je kleiner $\alpha$, so ist es nicht ohne praktisches Interesse, die Lage dieses Brenuraumes, welcher in mikroskopischen Bilde als helle Linie erscheint, mit dem Grössenverhältniss zwischen $R$ und $r$ zu vergleichen und sich im Allgemeinen über die hier bestehenden Beziehungen zu orientiren. Es wurden daher nachstehend einige Werthe von $r: R$ 
mit den entsprechenden Abständen des virtuellen Focus vom Centrum (in der Tabelle mit $F$ bezeichnet) zusammengestellt und die zugchörigen Einfalls- und Brechungswinkel beigesetzt. Der Brechungscoefficient wurde dabei zı $\frac{1,5}{1,3356}$ angenommen und $R$ als Einheit gewählt. Die Grössen $F$ und $r$ sind also in Bruchtheilen des grösseren Halbmessevs ausgedrückt.

\begin{tabular}{|c|c|c|c|}
\hline \& & $\alpha^{\prime}$ & $r$ & $F$ \\
\hline $20^{\circ}$ & $17^{0}+1^{\prime}$ & 0,301 & 0,3120 \\
\hline $25^{0}$ & $22^{\prime \prime} \quad 6^{\prime}$ & $0,37 \mathrm{kS}$ & 0,4226 \\
\hline $30^{\circ}$ & $26^{\prime \prime} 26^{\prime}$ & 0,1160 & 0,500 \\
\hline $35^{\prime \prime}$ & $30^{0} \quad 13^{\prime}$ & 0,5121 & 0,5735 \\
\hline $10^{\circ}$ & $34^{\prime \prime} 55^{\prime}$ & 0,5746 & 0,6427 \\
\hline $45^{\circ}$ & $39^{\circ} \quad 1^{\prime}$ & 0,6331 & 0,7070 \\
\hline $50^{\circ}$ & $13^{0} \ldots$ & $0,6 S 72$ & 0,7660 \\
\hline $55^{\circ}$ & $16^{\circ} 50^{\prime}$ & $0,736 \mathrm{~s}$ & 0,5191 \\
\hline $60^{\circ}$ & $50^{0} \quad 27^{\prime}$ & 0,7501 & 0,8660 \\
\hline $65^{\prime \prime}$ & $53^{0} 15^{\prime}$ & 0,522 & 0,9063 \\
\hline $70^{\circ}$ & $56^{\prime \prime} 15^{\prime}$ & (), 5594 & 0,9397 \\
\hline $75^{\circ}$ & $59^{\prime \prime} 19^{\prime}$ & 0,5933 & 0,9659 \\
\hline $50^{\circ}$ & $61^{0} 16^{\prime}$ & 0,9259 & 0,9548 \\
\hline
\end{tabular}

Der virtuclle Brennraum steht also durchweg etwas weiter vom Centrum ab, als die innere Grenzfläche der Cylinderwandung. Da nnn, wie die Rechnung zeigt, alle Strahlen, deren Einfallswinkel bei gleichen Radien etwas grösser oder kleiner sind als die oben bezeichneten, stets von Puncten zu kommen scheinen, welche der Peripherie näher liegen, so folgt daraus, dass der innerste Theil der Wandung in einer Breite ron $F-r$ in den Kernschatten fällt, während der peripherische (ähnlich wie bei der Luftblase der Rand ausserhalb der Ringe) eine schwache Beleuchtung erhält, die jedoch unter den oben entwickelten Bedingungen durch die sub 1. erwähnten Randstrahlen verstärkt wird. Die resultirende Helligkeit erreicht in vielen Fällen, wenn das ungebende Medium Wasser ist und (1) und $\delta$ ziemlich gross gewählt werden, diejenige des Gesichtsfeldes, so datss die helle Linie gegen den Rand zu ohne bestimmte Abgrenzung und somit nur noch als schwache Steigerung des Lichteffectes erscheint.

Die Voraussetzung, die in der Praxis gewöhnlich stillschweigend gemacht wird, dass nämlich das Lumen einer cylindrischen Kelle soweit reiche als der Randschatten, ist also nach dem Angeführten eine 
wesentlich unrichtige. Der Irrthum ist um so grösser, je stärker das Brechungsvermögen der Substanz; er wird nur dann verschwindend klein, wenn das Object in eincm Medium von annähernd gleicher Dichtigkeit liegt. Dasselbe gilt natürlich auch von den Hohlräumen in Stärkekörnern, Zellkernen, Oeltropfen u. dgl.; sie erscheinen sämmtlich etwas grösser, als sie wirklich sind.

Da bei dünneren Wandungen die Reflexion eine vollständigere und in vielen Fällen eine totale ist, so erreicht die helle Linie hier auch eine grössere Intensität. Am schönsten tritt sie in Glasröhren hervor, welche von Wasser umgeben und mit Luft gefüllt sind.

Die ungleiche Brechbarkeit der verschicdenfarbigen Strahlen verursacht auch hier, wie bei der Luftblase, schmale Farbensäume an den Rändern der hellen Linie, und zwar erscheint, wie sich aus den Brechungsverhältnissen von selbst ergiebt, der äussere Saum blau und der innere roth.

Zum Schlusse mag hier noch cine kleine Tabelle Platz finden, welche den Einfluss des Brechungscoefficienten $n$ auf den Abstand der hellen Linie für verschiedene $W$ erthe von $r$ veranschaulicht. Die Zahlen wurden theilwcise durch Interpolation bestimmt, sind jcdoch bis zur dritten Decimale genau. Als Einheit wurde, wic oben, der grössere Halbmesser $R$ ? angenommen.

\begin{tabular}{|c|c|c|c|}
\hline $\begin{array}{c}\text { Halbmesser } \\
\text { des } \\
\text { Hohlraums }\end{array}$ & \multicolumn{2}{|c|}{ Abstand der liellen Linie rom Mittelpunct. } \\
\cline { 2 - 4 }$r$ & $u=\frac{1,5}{1,3356}$ & $u=\frac{1,1}{1,3356}$ & $u=\frac{1,35}{1,3356}$ \\
\hline \hline 0,5 & 0,5595 & 0,5236 & 0,5054 \\
0,6 & 0,6707 & 0,6254 & 0,6064 \\
0,7 & 0,7795 & 0,7329 & 0,7075 \\
0,5 & 0,3512 & 0,5366 & 0,5055 \\
0,9 & 0,9695 & 0,9375 & 0,9095 \\
\hline
\end{tabular}

Wir haben drittens die Strahlen $z u$ verfolgen, welche in den 172 Hohlraum eindringen und an der Wandung reflectirt werden, so dass sie erst nach vicrmaliger Brechung und einmaliger Reflexion zum Objectiv gelangen. Dieser Strahlengang bedingt, wie der entsprechende in der Luftblase, die Bildung einer zweiten hellen Linie, welche wie immer dem Puncte entspricht, in welchem der ohne Ablenkung austretende Strahl (rückwärts verlängert) die Einstellungs. ebene schneidet. Um diesen Punct zu bestimmen, betrachten wir den 
senkrecht von unten einfallenden Strahl ST (Fig. 105), dessen Einfalls- und Brechungswinkel, wie bisher, $\alpha$ und $\alpha^{\prime}$ heissen mögen. Die Winkel, welche mit Rücksicht auf die

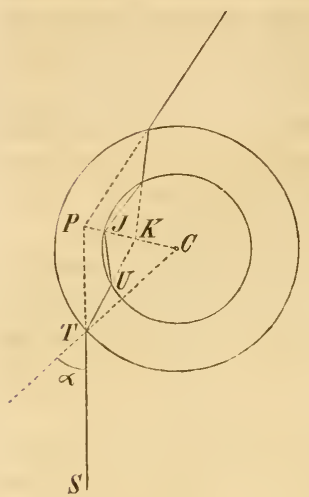

Figur 105. innere Grenzfläche der Wandung als Einfalls- und Brechungswinkel erscheinen, seien $a^{\prime \prime}$ und $\iota^{\prime \prime \prime}$ und der halbe $\mathrm{Ab}$ lenkungswinkel $C P T=\varrho . A$ lsdann ist $\varrho=L\left(K T-\left(\alpha-\alpha^{\prime}\right)\right.$, oder da $C K^{\prime} T$ als Aussenwinkel zum Dreieck $U \boldsymbol{K} J$

$$
\begin{aligned}
& \left.=u^{\prime \prime \prime}-\alpha^{\prime \prime}\right)+u^{\prime \prime \prime}=2 u^{\prime \prime \prime}-u^{\prime \prime} \\
g & =2 u^{\prime \prime \prime}+a^{\prime}-\left(u^{\prime \prime}+\alpha\right)
\end{aligned}
$$

wobei $\sin \alpha^{\prime \prime}=\frac{R}{r} \sin \alpha^{\prime}=\frac{R}{m} \sin u^{\prime}$ und $\sin \alpha^{\prime \prime \prime}=n \sin \alpha^{\prime \prime}=\frac{R}{r} \sin \alpha$, wenn $n$ der relative Brechungscoefficient der Cylindersubstanz. Für den ohne Ablenkung austretenden Strahl ergiebt sich also die Bedingung $2 \alpha^{\prime \prime \prime}+\alpha^{\prime}-\left(\alpha^{\prime \prime}+\alpha\right)=90^{\circ}$. Ist das umgebende Medium, sowie das eingeschlossene, Wasser und der Brechungscoefficient des Hohlcylinders $n=\frac{1,5}{1,3356}$, so erhält man für die nachstehend angenommenen Verhältnisse zwischen $r$ und $R$ die beigesetzten $W$ erthe von $\alpha$ und hieraus die Abstände $F$ der hellen Linie rom Centrum.

\begin{tabular}{|l|c|c|c|c|c|}
\hline$\frac{r}{R}$ & $\alpha$ & $\alpha^{\prime}$ & $\alpha^{\prime \prime}$ & $\alpha^{\prime \prime \prime}$ & $F$ \\
\hline $0, S$ & $51^{0} 4 S^{\prime}$ & $41^{0} 21^{\prime}$ & $61^{0}$ & $79^{0} 13^{\prime}$ & 0,7859 \\
0,8904 & $61^{0} 30^{\prime}$ & $51^{\prime \prime} 30^{\prime}$ & $61^{0} 30^{\prime}$ & $80^{0} 45^{\prime}$ & 0,5788 \\
\hline
\end{tabular}

Bei der zweiten Reihe wurde $\frac{r}{R}=\frac{1}{n}$ gesetzt, wodurch

$$
\sin \alpha^{\prime \prime}=\sin \alpha, \text { folglich } \alpha^{\prime \prime}=\alpha
$$

wird. - Die Vergleichung der letzten Columne mit der ersten ergiebt, dass die Werthe von $F$ etwas kleiner sind als diejenigen von $r$, oder mit anderen Worten, dass die innere helle Linie in den Hohlraum fällt. Es ist übrigens ohne Weiteres klar, dass der Abstand derselben von der Wandung mit dem Brechungscoefficienten zu- und abnimmt; denn da $a^{\prime \prime \prime}$ von $n$ unabhängig ist, so wird, wenn man die Bedingungsgleichung in die Form bringt 


$$
2 \alpha^{\prime \prime \prime}-\left[\alpha+\left(\alpha^{\prime \prime}-\alpha^{\prime}\right)\right]=90^{\circ}
$$

der in [] stehende Ausdruck kleiner, wenn $n$ zunimmt, weil alsdann $a^{\prime \prime}$ und $\alpha^{\prime}$ und damit auch ihre Differenz kleiner wird. Es muss daher ein grösseres $\iota$ gewählt werden, um in diesem Fall der Gleichung Genüge zu leisten ; die helle Linie rückt weiter nach innen. Ebenso erklärt sich das Hinausrücken der Linie, wenn $n$ abnimmt. Diese Verschiebungen sind jedoch, wie die Rechnung zeigt, so klein, dass sie in den meisten vorkommenden Fällen geradezu vernachlässigt werden können. Beispielsweise sind nachstehend einige Werthe von $n$ und $F$ zusammengestellt. Das dabei vorausgesetzte Verhältniss der Radien ist $r=0,8 R$.

\begin{tabular}{|l|c|c|c|}
\hline Werthe von $n$ & 1,1231 & 1,2345 & 1,6490 \\
\hline $\begin{array}{c}\text { Zugehörige Werthe } \\
\text { von } F\end{array}$ & $0,75.59$ & 0,7799 & 0,7694 \\
\hline
\end{tabular}

Bleibt der Brechungscoefficient constant, während das Verhält-173 niss der Radien sich ändert, so steigt die Differenz zwischen $r$ und $\boldsymbol{F}$, bis $r$ ungefähr $1 / 2 R$, und fällt nachher wieder, wenn $r<1 / 2 R$. Aber auch hier sind die Veränderungen so gering, dass sie in den meisten Fällen vernachlässigt werden dürfen. Sie erreichen z. B. von $r=0, S$ bis $r=0,5$ kaum die Höhe von $0,007 . R$. Zur Vergleiclunng mag auch hier eine kleine Ulebersicht folgen, in welcher die Grösse $r-F$ (der Abstand der hellen Tinie von der Wandung) für verschiedene Werthe von $r$ gegeben ist. Als Brechungsverhältniss wurde $n=1,649$ vorausgesetzt.

\begin{tabular}{|c|c|c|c|c|c|}
\hline Werthe von $r$ & $0, \mathrm{~S}$ & 0,6 & 0,5 & 0,4 & 0,2 \\
\hline $\left.\begin{array}{l}\text { Zugehörige } W \text { erthe } \\
\text { von } r-F\end{array}\right\}$ & 0,0306 & 0,0365 & 0,0372 & 0,0345 & 0,0211 \\
\hline
\end{tabular}

Ist der Hohleylinder mit Luft gefüllt und von Wasser umgeben, 17t so nimmt die inncre helle Linic nahezu die nämliche Stelle ein, wie in einer freien Luftblase; sie wird durch den Einfluss der Cylinderwandung nur um eine äusserst geringe Grösse dem Centrum näher gerückt. Es sei z. B. der absolute Brechungscoefficient der Cylinderwandung $=1,4$, der des Wassers $=1,3356$, dann ergeben sich für die Abstände $F$ der Linie vom Centrum die nachstchend in erster Reihe aufgeführten Werthe, zn welchen als zweite Reihe die etwas 
höheren hinzugefügt wurden, wie sie bei gleichem $r$ sich in dem frei gedachten Luftcylinder herausstellen müssten. Alle Zahlenverhältnisse sind, wie bisher, in Bruchtheilen von $R$ ausgedrückt.

\begin{tabular}{|c|c|c|c|}
\hline & \multicolumn{3}{|c|}{ Abstand der hellen Linie rom C'entrum. } \\
\hline & $r-0, s$ & $r=0, \bar{i}$ & $r=0,5$ \\
\hline $\begin{array}{l}\text { In Hohleylinder } \\
\text { InI frei gedachten }\end{array}$ & $0, \div 455$ & 0,4792 & (1),341i \\
\hline Luftcylinder . & 0,5501 & 0,45755 & 0,3412 \\
\hline Differenz · · · & 0,0022 & 0,0026 & 0,0027 \\
\hline
\end{tabular}

Steigt der Brechungsindex der Cylindersubstanz auf 1,5, so rückt die helle Linie noch etwas weiter nach innen. Ihr Abstand reducirt sich alsdann, wenn $r=0,5 R$, auf $0,5458 R$; die als Differenz bezeichnete Grösse steigt dabei auf 0,0054 . - Der Einfluss der Cylinderwandung auf die fraglichen Abstände bleibt also, wie aus den angeführten Beispielen hervorgeht, wohl in allen vorkommenden Fällen auf die dritte Decimale beschränkt; demnach beträgt dic dadurch verursachte Verschiebung der Linie, so lange $R$ klciner als 100 Mik., weniger als I Mik. und kann füglich rernachlässigt werden. In diesem Falle lässt sich aus der Lage unserer Linie in der eingeschlossenen Luft der Radius $r$ des Lumens und daher auch die Dicke der Wandung $(R-r)$ berechwen. Man hat nämlich nach Früherem für dic freie Luftblase $F=0,65536 . r$, folglich für den Hohlcylinder, wenn man als mittlere Verschiebung c. 0,00536.r in Rechnung bringt, $F=0,683 . r$, woraus $r=\frac{F}{10,6 \uparrow 3}=1,464 F$. Die Grösse $F$ wird an genauesten durch directe Messung von $2 F$, d. h. des Abstandes der beiderscitigen hellen Linien, bestimmt.

175 Die innere helle Linie liegt, ganz wie bei der Luftblase der innere Ring, dem Centrum näher, als jeder andere Punct, welcher auf dem nämlichen Wege beleuchtet wird. Innerhalb derselben kommt also (natürlich nur mit Rücksicht auf diesen Strahlengang, rollkonmen dunkler Kernschatten, weiter nach aussen dagegen ein schwach crhellter Halbschatten zu Stande, der gegen die äussere helle Linie zu allmählich dunkler wird. Unter günstigen Verhältnissen treten im inneren Theil des Halbschattens noch weitere helle Linien hervor, deren Entstehung sich durch mehrmalige innere Reflexion erklärt.

176 Endlich sind noch dic Strahlen in Betracht zu ziehen, wclche ohne innere Reflexion das Lumen durchsetzen und also bloss eine 
viermalige Brechung erfahren. Es ist von vorn herein klar, dass dieselben den mittleren Theil des Hohlcylinders erhellen, aber gegen die Ränder zu für unser Auge verloren gehen. Die Puncte, wo der Halbschatten beginnt und wo er in den Kernschatten übergeht, verändern natürlich je nach der Grösse der Oeffnungswinkel ( $)$ und $\delta$, der Dicke der Wandung und dem Brechungsvermögen der verschiedenen Medien ihre Lage. Zur Bestimmung der letzteren durch eine allgemein gültige Formel fühırt folgende Betrachtung. Würde der von unten einfallende Strahl $S T$ (Fig. 106), wie im vorhergehenden Falle, an der Innenwand reflectirt, so wäre der Ablenkungswinkel des nach $\mathbb{R}^{\prime}$ ausfahrenden Strahls durch die Gleichung gegeben

$20=4 \alpha^{\prime \prime \prime}+2 \alpha^{\prime}-2\left(\alpha^{\prime \prime}+\alpha\right)$.

Durch den Umstand, dass die Reflexion unterbleibt, erleidct nun aber der Strahlengang dieselbe Modification, wie wenn in obiger Figur die Linie $C N^{\prime}$ mit dem unbeweglich damit verbundenen reflectirten Strahl um den Punct $C$ wie ein Uhrzeiger nach links gedreht würde, bis $C N^{\prime}$ mit $C N$

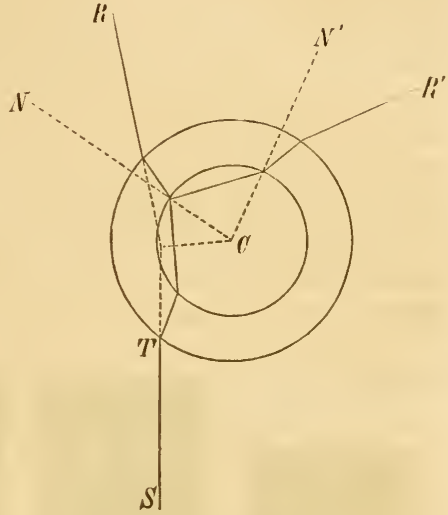

Figur 106. zusammenfiele. Führen wir diese Bewegung in Gedanken aus, so wird der Ablenkungswinkel 20 um den Winkel $N^{\prime \prime}\left(N=1 S 0^{\prime \prime}-2 a^{\prime \prime \prime}\right.$ grösser. Durch Addition dieses Werthes zu dem oben angeführten erhält man sonach den Ablenkungswinkel 2o für den viermal gebro. chenen Strahi und hieraus

$$
\varrho=90^{\circ}+\alpha^{\prime \prime \prime}+\alpha^{\prime}-\left(\alpha^{\prime \prime}+\alpha\right) \text {. }
$$

Die Richtung des ausfahrenden Strahls ist hiedurch für jede beliebige Neigung des einfallenden bestimmt. Sind daher die Oeffunngswinkel des Objectivs (w) und der Blendung ( $)$ ) gegeben, so lassen sich die Grenzen des Kern- und Halbschattens in der Einstellungsebene berechnen. Man findet für dic Abstände dieser Grenzlinien vom Centrum, wenn $R=1, n=\frac{1,500}{1,3356 i}, \omega=1 ; 0^{\circ}$ und $\delta=12^{\circ}$ gesetzt wird, die in nachstehender Uebersicht gegebenen Werthe. 


\begin{tabular}{|c|c|c|}
\hline$r$ & $\begin{array}{c}\text { Grenzlinien } \\
\text { des } \\
\text { Halbschattens. }\end{array}$ & $\begin{array}{c}\text { Grenzlinien } \\
\text { des } \\
\text { Kernschattens. }\end{array}$ \\
\hline $0, \mathrm{~S}$ & 0,562 & 0,947 \\
0,5 & 0,557 & 0,57 \\
\hline
\end{tabular}

In der Wirklichkeit liegen jedoch die Grenzlinien des Schattens, wenn die eben gemachten Voraussetzungen annähernd zutreffen, stets etwas weiter nach innen. Es rührt diess offenbar daher, dass die Intensität der Grenzstrahlen, für welche z. B. $\alpha^{\prime \prime \prime} s 0^{n}$ und darüber crreichen kann, durch die wiederholte Reflexion an den brechenden Flächen bedeutend geschwächt und daher für das beobachtende Auge früher als nach der Theorie Null wird. Auf diese Weise wird es er-* klärlich, dass die innere helle Linie auch bei ziemlich starker Vergrösserung noch in den Randschatten des Hohlraums fällt.

Um die Wirkung der vier verschiedenen Strahlensysteme zu veranschaulichen, wurde in Fig. 107 die Vertheilung von Licht und Schatten für jeden einzelnen Strahlengang bildlich dargestellt, und

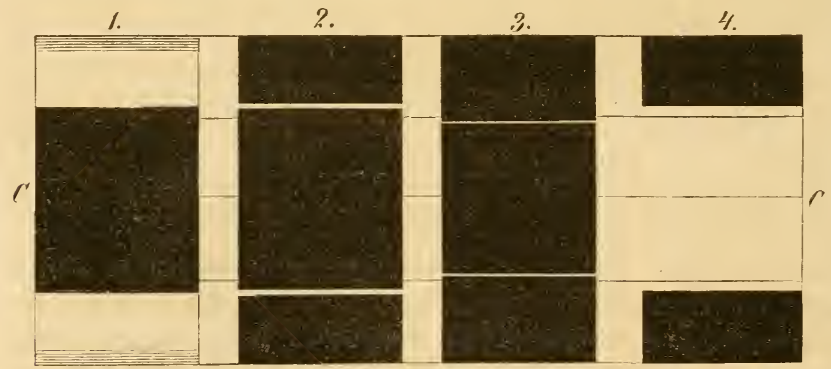

Figur $10 \%$.

zwar für den Fall, dass $R=2 r$. Da Kern- und Halbschatten beinahe zusammenfallen, so wurden der Einfachheit wegen nur die Grenzlinien des Kermschattens gezogen und zur Orientirung die äusseren und inneren Tmrisse der Cylinderwandung und die Cylinderaxe $\mathrm{CC}$ als durchgehende Linien hinzugefügt.

177 Betrachten wir den Hohlcylinder, ohne Rücksicht auf die Einstellungsebene, einfach als brechenden Apparat, so wirkt or auf die Randstrahlen, welche nicht in das Lumen eindringen, wic eine Kugel von gleicher Dichtigkeit, auf die mittleren Strahlen dagegen, welche 
den Hohlraum durchsetzen, wie eine Zerstreuungslinse. Er entwirft daher von Gegenständen, die sich im Spiegel reflectiren, gleichzeitig reelle und virtuelle Bilder, welche beide für das Auge wahrnehmbar werden, sobald man den Tubus auf das entsprechende Niveau einstellt. Die Lage des reellen Brennpunctes ist natürlich annähernd dieselbe, wie bei der Kugel; diejenige des virtuellen lässt sich aus den früher entwickelten Formeln für die optischen Constanten brechender Medien bestimmen. Bezeichnet man die negative Brennweite, von der Axe des Cylinders an gerechnet, mit $F$, den absoluten Brechungsindex mit $n$ und die Radien wie bisher mit $R$ und $r$, so ergeben sich unter den nachstehend angeführten Voraussetzungen die beigesetzten Werthe.

\begin{tabular}{|c|c|c|}
\hline Medium. & $\begin{array}{l}\text { Wrerthe von } F \\
\text { wenn } n=1,5 \text {. }\end{array}$ & $\begin{array}{l}\text { Werthe von } F \\
\text { wenn } n=1,6 \text {. }\end{array}$ \\
\hline$r=0,5\left\{\begin{array}{l}\text { In Wasser } \\
\text { In Luft } \\
\text { Mit Luft ge- } \\
\text { füllt, ungeben } \\
\text { von Wasser }\end{array}\right.$ & $\begin{array}{c}3,314 R=6,629 . r \\
1,5 R=3 . r\end{array}$ & $\begin{array}{l}2,189 R=1,378 . r \\
1,333 R=2,666 . r\end{array}$ \\
\hline$r=0,1\left\{\begin{array}{l}\text { In Wasser } \\
\text { In Luft }\end{array}\right.$ & $\begin{aligned} 0,363 R & =3,63 . r \\
0,166 \ldots R & =1,66 . r\end{aligned}$ & $\begin{array}{l}0,23 \varsigma R=2,35 . r \\
0,14 S R=1,4 \delta . r\end{array}$ \\
\hline
\end{tabular}

Diese Uebersicht gestattet freilich nur eine sehr oberflächliche Orientirung über die Lage des Brempunctes in Hohlcylindern. Sie hat auch nur den Zweck, durch Beispiele zu zeigen, welchen Einfluss im Allgemeinen das Verhältniss der Radien und das umgebende Medium auf die Brennweite üben. Man begreift übrigens leicht, dass wenn $r$ gegen $R$ sehr klein wird, die Krümmung der Cylinderoberfläche nicht mehr berücksichtigt zu werden braucht; der eptische Effect ist dann annähernd derselbe, welchen ein Hohlraum von gleichem Halbmesser in einer homogenen Substanz von der Dichtigkeit der Cylindermembran und mit ebenen Grenzflächen nach oben und unten hervorbringen würde. Ebenso ist einleuchtend, dass wenn das Verhältniss $r: R$ sich der Einheit nähert, die Brennweite immer grösser und zuletzt unendlich wird. Dabei bleibt das virtuelle Bild natürlich nur bis zu einer gewissen Grenze, jedoch bei absolut kleinen Werthen von $r$ und $R$ noch an ziemlich dünnwandigen Röhren mikroskopisch wahrnehmbar. 
Werden die Brennweiten für die oben zusammengestellten Fälle auf experimentellem Wege bestimmt, indem man die Verschiebung der Mikroskopröhre mit Hülfe eines zweiten, wagrecht gestellten Mikroskops misst, so erhält man auch hier durchgehends kleinere Werthe, als die berechneten, weil die beobachtete Brennweite, wie bereits oben $(\mathrm{Nr} .165)$ hervorgehoben wurde, sich stets nur auf Randstrahlen bezieht; welche je nach der Stärke und Eigenthümlichkeit des Objectivs mehr oder weniger (z. B. c. $15-20^{\circ}$, gegen die Axe geneigt sind.

Da das Bild eines Hohlcylinders, wie jedes reelle oder virtuelle Bild, als Lichtquelle betrachtet werden kann, so wird die Einstellung auf die Ebene desselben in jedem achromatischen Instrumente ein farbloses mikroskopisches Bild liefern, eine höhere oder tiefere Einstellung dagegen die bekannten rothen und blauen Farbensäume hervorrufen. Demzufolge erscheinen kleine Hohlräume, welche ein Medium von geringerem Brechungsvermögen einschliessen, wie die Lumina der Bastfasern, die Kerne der Stärkekörner etc., wenn wir ein chromatisch unterverbessertes Mikroskop roraussetzen, bei tieferer Einstellung farblos und hell, bei höherer röthlich und zuletzt dunkel. Die wahre mittlere Einstellung auf das Centrum des Hohlraumes liegt unter allen Umständen zwischen diesen beiden Extremen und liefert daher, wenn die Dimensionen klein genug sind, ein röthliches Bild.

\section{II.}

\section{Objecte von unregelmässiger Form.}

1. Membranen mit kleinen Vertiefungen oder Löcherm.

178 Es ist ohne Weiteres klar, dass kleine schüsselförmige oder rinnenförmige Vertiefungen, wie sie in Fig. $10 \mathrm{~s}$ dargestcllt sind, wie Concavlinsen wirken und folglich bei

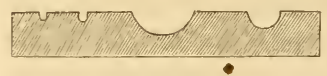

Figur 108. entsprechender Senkung des Tubus das virtuelle Bild der Blendung zeigen. Und zwar müsste dasselbe, insofern nicht seine Kleinheit ein Hinderniss bildet, sowohl dem unbewaffneten als bewaffneten Auge deutlich erscheinen. Sobald aber die Form der Vertiefung sich wesentlich ändert, z. B. prismatisch oder cylindrisch wird, so dass sie nach unten 
eine ebene Grenzfläche erhält, so verschwindet das Bild für das blosse Auge, während es im Mikroskop wegen des ungleich grösseren Oeffnungswinkels immer noch wahrnehmbar bleibt. Man überzeugt sich hievon, wenn man eine Salzlösung (Kochsalz, Bittersalz u. a.) auf dem Objectträger ausbreitet und an der Luft eintrocknen lässt. Es bilden sich dann stellenweise zuweilen namentlich sehr schön nach Zusatz von wasserhaltigem Alkohol) grössere homogene Lamellen oder ausgedehnte Krusten mit einer Unzahl von kleinen porenartigen Löchern oder Vertiefungen von der verschiedensten Form, an andern Stellen mit Spalten, Rinnen u. s. w. Bei den meisten derselben kommt das Bild der Blendung, der Fensterrahmen etc., wenn man den Focus etwas unter die mittlere Einstellungsebene senkt, mit ziemlicher Schärfe zum Vorschein, oft ebenso deutlich als bei einer etwas abgeplatteten Luftblase.

Wie diese Bilder zu Stande kommen, ist aus Fig. 109 ersichtlich. 179 Der Rand der Oeffnung oder Vertiefung bewirkt einerseits eine Ablenkung der ron einem entfernten Puncte ausgehenden und folglich annähernd parallel einfallenden Strahlen nach $n$, andererseits eine Herumlenkung derselben durch Totalreflexion nach $m$. Die beiden Bündel scheinen also nach dem Durchgang durch das Object ron dem kleinen Raume o zu kommen, in welchem sic sich rückwärts verlängert kreuzen; sie entwerfen in $o$ das virtuelle Bild der entfernten Lichtquelle. Rückt die letztere weiter nach rechts, so macht auch ihr Bild eine Bewe. gung in glcichem Sinne, wie diess überhaupt bei virtuellen Bildern der Fall ist.

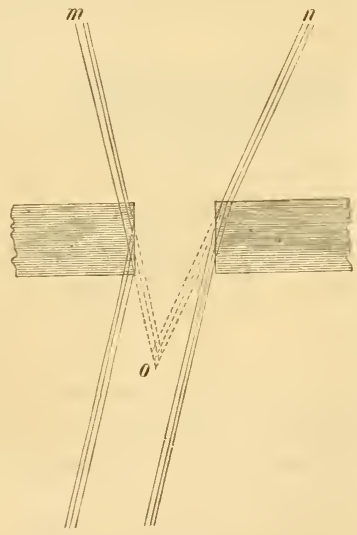

Figur 109.

Das Zustandekommen des Bildes hängt übrigens keineswegs von der Regelmässigkeit der brechenden Flächen ab, wie sie in unserer Figur vorausgesetzt wurde. Es ist ziemlich gleichgültig, ob die gebrochenen Strahlen genau parallel verlaufen, oder ob sie etwas divergiren oder convergiren, da hierdurch bloss der Raum, in welchem ihre Verlängerungen sich kreuzen, etwas grösser oder kleiner wird. Er bleibt aber immerhin so klein, dass er gegen die grösseren Ab. 
weichungen, welche das Deckplättchen rerursacht, nicht in Anschlag kommt und dem beobachtenden Auge als Punct erscheint.

Selbst weǹn die einfallenden Strahlenbündel nur durch den einen Rand der Oeffnung zum Auge gelangen, sich also rückwärts verlängert nicht kreuzen, entsteht aus demselben Grunde, wie bei Licht. strahlen, die durch eine kleine Oeffnung gehen, ein undeutliches Bild. Es nimmt aber in diesem Falle keine bestimmte Stelle ein, sondern erscheint nur um so grösser, je tiefer man einstellt. Bei günstiger Einstellung müssen zu diesem Bilde sogar Strahlen beitragen, welche die Oeffnung ohne Brechung durchsetzen.

180 Auf welchem Wege nun auch das Bild zu Stande komme, ob es mehr oder weniger verwischt oder scharf gezeichnet erscheine, immer wird die Einstellung auf ein höheres oder tieferes Niveau dieselben Erscheinungen hervorrufen, die wir schon beim virtuellen Bild der Luftblase kennen gelernt haben. Bei Hebung des Tubus wird die Mitte roth und der Rand bläulich erscheinen, während eine Senkung unter den virtuellen Brennraum die umgekehrte Anordnung der Farben bedingt - jedoch selbstverständlich Beides nur unter der Voraussetzung, dass das Objectiv unterverbessert sei. Da diess bei den meisten Mikroskopen der Fall ist, so sehen kleine Poren, Spalten, rinnenförmige Vertiefungen $u$. dgl., wenn man ungefähr auf ihre Mitte einstellt, immer röthlich aus und zwar je nach der Eigenthümlichkeit des Instruments mehr oder weniger. Auch die bläuliche Einfassung ist trotz ihrer geringen Breite in manchen Fällen beinerkbar.

2. Membranen mit einer ebenen und einer wellenförmigen Grenzfliiche.

181 Die erhabenen Stellen solcher Membranen (Fig. 110) wirken offenbar wie Sammellinsen, die Vertiefungen wie Zerstreuungslinsen. Demnach muss die Licht- und Farbenvertheilung im Allgemeinen folgende sein. Bei höchster

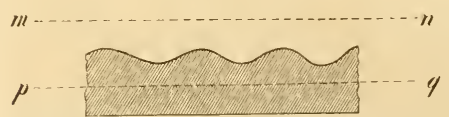

Figur 110. Einstellung $(m n)$ auf die reellen Bilder der Vorsprünge erscheinen diese hell und die Vertiefungen je wach der Krïmmung dunkel oder röthlich. Senkt man den 'Tubus, so erhalten die Vorsprünge einen bläulichen Ton, und die Vertiefungen bleiben so lange roth, bis man die Ebene $(p q)$ ihrer virtuellen Bilder erreicht hat. Bei noch tieferer Einstellung werden diese letzteren bläulich; die röthlichen Farben- 
säume, die sie umschliessen, nehmen dann - zu je zweien verschmolzen -- die Stelle der Erhabenheiten ein, so dass diese nun gerade so aussehen, wie bei höherer Einstellung die Vertiefungen. Welche Farbentöne bei einer gegebenen Einstellung alterniren, hängt natürlich mit von der Krümmung der Oberfläche ab.

Springen die Erhabenheiten sehr stark und in der Art vor, dass sie mit etwas verschmälerter Basis aufsitzen, so kommt zu der eben erwähnten Erscheinung noch die durch Reflexion hervorgerufene hinzu, wie man sie bei kleinen Körperchen, Quccksilbertröpfchen etc. beobachtet, und wovon weiter unten ausführlicher die Rede sein wird. So z. B. bei manchen Spiral- und Ringgefässen, bei dendritischen Krystallanflügen die wie Verdickungen des Objectträgers wirken), Diatomaceenpanzern etc. Bei allen diesen Objecten kommt es häufig vor, dass einzelne Fasern, auch wenn sie ganz isolirt sind, bei tieferer Einstellung röthlich erscheinen.

Die optische Wirkung der Erhabenheiten und Vertiefungen bleibt für das Mikroskop auch dann noch annähernd dieselbe, wenn die Wellenform der Grenzfläche in einen scharfwinkligen Zickzack Fig. 111) übergeht; denn vorspringende Kanten geben immer reelle, einspringende virtuelle Bilder. Hieher gehörige Formen kommen in-

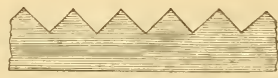

Figur 111. dess in pflanzlichen Organismen nur selten vor; dagegen beobachtet man sie öfter bei Krystallanflügen, z. B. an jenen Ketten von (unvollständigen) Kochsalzkrystallen, welche ungefähr das Bild eines Festungsplanes gewähren.

3. Membranen mit parallel-wellenförmigen Grenzflächen.

Eine wellig gefaltete Membran, wie sie in Fig. 112. im Durch-182 schnitt dargestellt ist, lässt sich in rinnenförmige Stücke von Hohlcylindern zerlegen, welche abwechselnd ihre convexe und concave Seite nach oben kehren. In der Figur ist diese Zerlegung durch gerade Linien, welche die

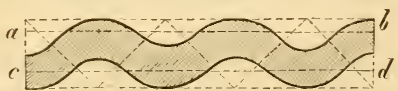

Figur 112. Krümmungscentren verbinden, sowie durch verschiedene Schraffirung der Membranstücke veranschaulicht. Da nun der Hohlcylinder sich optisch wie eine Concavlinse verhält, so wirken auch solche Rinnen stets zerstreuend auf das einfallende Licht. Und zwar fallen die beiden Hauptpuncte mit dem Krümmungscentrum zusammen, wcnn 
das umgebende Medium Luft ist, rücken dagegen auseinander und nähern sich zugleich den brechenden Flächen, wenn das umgebende Medium Wasser oder eine andere Flüssigkcit ist. Hierüber und über die Grösse der Brennweiten giebt folgende Zusammenstellung einige berechnete Beispiele. Mit $e$ und $e^{\prime}$ sind die Abstände der Hauptpuncte vom Krümmungscentrum, mit $\gamma$ die Brennweite, mit $r$ der Halbmesser der stärkern Krümınung und endlich mit $n$ der absolute Brechungscoefficient bezeichnet. Als Maasseinheit ist der Radius der schwächeren Krümmung $(R)$ und als ungcbendes Medium IVasser mit dem Index $4 / 3$ angenommen.

\begin{tabular}{cc|c|c|c|c}
\hline$r$ & $n$ & $e$ & $e^{\prime}$ & $\varphi$ \\
\hline \hline \multirow{2}{*}{$1 / 2$} & 1,5 & $1 / 4$ & $1 / 8$ & 6,75 \\
& $1 / 10$ & 1,6 & $1 / 4$ & $1 / 8$ & 4,5 \\
& 1,5 & $1 / 4$ & $1 / 40$ & 0,75 \\
& 1,6 & $1 / 4$ & $1 / 40$ & 0,50 \\
\hline
\end{tabular}

Die Hauptebenen der rinnenförmigen Membranstücke, von welchen die virtuellen Bilder gleich weit abstehen, liegen also nicht in demselben Niveau. Sie fallen z. B. unter den in Fig. 112 dargestellten Verhältnissen für die nach oben concaven Rinnen mit der Linie $a b$, für die damit alternirenden mit $c d$ zusammen. Die virtuellen Bilder selbst liegen somit abwechselnd höher und tiefer, und da sie wie mikroskopisch kleine Lichtquellen wirken, so erklären sich hieraus die verschiedenen Farben, welche man bei höherer und tieferer Einstellung beobachtet. Wir wollen hier nur den einen Fall hervorheben, in welchem das Instrument auf eine Ebene eingestellt ist, die höher als die unteren und tiefer als die oberen virtuellen Bilder liegt. Letztere erscheinen alsdann bläulich, erstere röthlich.

4. Abwechselnd dichte und wasserreiche schichten.

Wasserreiche Schichten, welche mit dichteren alterniren, wirken auf einer Durchschnittsansicht wie verdünnte Stellen oder Spalten in einer homogenen Substanz. Die Wirkungen sind sogar, wie leicht einzusehen, vollkommen aequivalent, wenn das Brechungsverhältniss zwischen dichteren und weicheren Schichten dasselbe ist, wie zwischen der homogenen Substanz und der die Sןalte ausfüllenden Flüssigkeit. Das mikroskopische Bild, das wir beobachten, zeigt daher, 
ganz wie bei faserförmigen Verdickungen, abwechselnd bläuliche und röthliche Linien, welche den nicht genau in die Einstellungsebene fallenden virtuellen und reellen Bildern der Schichten entsprechen. Der Wechsel der Helligkeit, welcher durch Veränderung der Objectdistanz an bestimmten Bildpuncten hervorgerufen wird, sowie die Stärke der Schatten bieten dem geübteren Auge wichtige Anhaltspuncte, die vorkommenden Dichtigkeitsverschiedenheiten annähernd zu schätzen. $\mathrm{Ob}$ abcr in einem gegebenen Falle wirkliche Spalten oder bloss wasserreichere Schichten vorhanden seien, das hienach ohne Weiteres zu unterscheiden, ist eine theoretische Unmöglichkeit.

\section{Erhabenheiten und Vertiefungen im Gegensatze zu dichten und weichen Schichten.}

Da die Erhabenheiten, wie bereits hervorgehoben, optisch genau 184 so wirken, wie entsprechende Verdichtungen der Substanz, so ist die Entscheidung der Frage, ob eine fcine Zeichnung, wie sie bei Diatomeen, an gestreiften Zellmembranen etc. vorkommt, auf Dichtigkeits- oder auf Formenverhältnissen beruhe, durch die blosse Betrachtung der Gegenstände in Wasser nicht möglich. Es giebt indessen ein Mittel, welches in den meisten Fällen sicher zum Ziele führt. Bringt man nämlich das betreffende Object in ein Medium, welches das Licht stärker bricht, als die dichtesten Stellen des Objects, z. B. in Schwefelkohlenstoff, so bleibt die Zeichnung im Wesentlichen unverändert, wenn sie durch Dichtigkeitsverschiedenheiten bedingt wird; sie ändert dagegen ihren Charakter, wenn die Ursache in den Unebenheiten der Oberfläche liegt, und zwar dergestalt, dass das Verhältniss von Licht und Schatten sich umkehrt, wie auf der negativen photographischen Platte. Die Poren einer Membran sehen alsdann tus wie warzenförmige Erhabenheiten, faserförmige Verdickungen wie Spalten, und ungekehrt; man könnte das ganze Bild ebenfalls als negatives bezeichnen.

Die Erklärung dieser Erscheinungen liegt nahe. Ist das Object ron ebenen Flächen begrenzt, so ist es auch der umgebende Schwefelkohlenstoff. Der letztere wirkt daher wie Glasplatten von entsprehender Dicke; er hebt die Objectpuncte, ohne ihre Bilder zu ändern. Finden sich dagegen Vertiefungen oder Erhabenheiten auf der zuoder abgekehrten Seite des Objects, so bildet sich an der BerührungsHäche des umgebenden Mediums das entgegengesetzte Relief, und da das letztere dichter ist, so bedingt es die Lichtrertheilung im mikro- 
skopischen Bilde. Das Object selbst verhält sich optisch wie ein Hohlraum von gleicher Form in einer brechenden Substanz.

Bei Anwendung dieses Verfahrens muss natürlich ein Austrocknen des Objects aufs Sorgfältigste vermieden werden. Weiche und dichte Schichten müssen ron Wasser durchdrungen séin, weil sonst die letzteren in Folge des stärkeren Verlustes der wasserreichen Partieen nach aussen vorspringen und dadurch die optische Wirkung stören. Im vollkommen trockenen Zustande ist selbstverständlich keine Schichtung vorhanden.

6. Das Sehen durch stereoskopische hinoculäre Mikroskope.

185 Die merkwürdige 'Täuschung, welche stereoskopische Vorrichtungen jeder Art hervorrufen, ist zum guten Theil eine rein psychische Erscheinung, die wir hier nicht weiter zu verfolgen haben. Wir stellen uns bloss die physikalische Frage, wic die zwei Bilder, welche das binoculäre Mikroskop den beiden Augen darbietet, sich ron einander unterscheiden; ob sie in Hinsicht der Licht- und Schattenvertheilung in einem ähnlichen Verhältniss zu einander stehen, wic etwa die photographischen Aufnahmen der käuflichen Stereoskope. Ist das letztere wirklich der Fall, so reiht sich die in Frage stehende Wahrnehmung andern bekannten Erscheinungen an, und wir können die weitern Betrachtungen darüber der Physiologie überlassen.

Wenn wir uns die dioptrische oder katoptrische Spaltung der Strahlenbündel noch einmal vergegenwärtigen vgl. Fig. 11-13, so leuchtet sogleich ein, dass dem einen Auge ein Bild geboten wird, welches von der rechten, dem andern ein solches, welches von der linken Hälfte des Objectivs entworfen ist. Und zwar liegen die bilderzeugenden Objectivhälften bei der dioptrischen Spaltung stets auf der nämlichen Seite der Medianebene, wie das beobachtende Auge, bei der katoptrischen unter Umständen, wenn z. B. gleichseitige Prismen nach Nachet in Anwendung kommen, auf der entgegengesetzten. Je nachdem das eine oder das andere der Fall ist, muss natürlich auch der Eindruck, den die Verschmelzung der beiden Bilder im Bewusstsein hervorruft, ein verschiedener sein.

In welcher Weise nun aber die von, der rechten und linken $\mathrm{Ob}$. jectivhälfte entworfenen Bilder differiren, lässt sich im Allgemeinen sowohl durch Rechnung, als auf experimentellem Wege mit dem gewöhnlichen Mikroskop entscheiden, indem man nach einander dic cine und andere Hälfte des Objectirs zudcckt. Es sei z. B. ein kugelförmiges Stärkekorn oder ein Oeltropfen als Object gegeben, dann 
wird der Randschatten, welcher im gewöhnlichen Bilde bei gerader Beleuchtıng überall gleich breit erscheint, durch Ausschliessung der einen Objectishälfte auf der entspreehenden Seite vorwiegend, so zwar, dass die Lichtstelle im Bilde mit dem wirksamen Theil der Linsen auf der nämlichen Seite der Medianebene liegt. Dieselbe Erscheinung muss ganz allgemein bei jedcm Gegenstande eintreten, welcher gleich den erwähnten wie eine Sammellinse wirkt. Ist dagegen das Object cine Luftblase oder ein Hohlraum, überhaupt ein Gegenstand, der sich wie eine Zerstreuungslinse verhält, so bewegt sich die Lichtstelle unter gleichen Voraussetzungen zwar ebenfalls seitwärts, aber in entgegengesctzter Richtung. Die zwei Bilder, welche das binoculäre Mikroskop entwirft, zeigen also in beiden Fällen eine Licht- und Sehattenvertheilung, wie sie in $A$ und $B$ (Fig. 113) dargestellt ist. Welches von beiden dem rechten, welches dem linken Ange dargeboten wird, hängt bei gegebenem Object von der optischen Einrichtung ab, welche die Spaltung der Strahlenbündel bewirkt. Die Gruppirung von $A$ und $B$ mit Rücksicht auf Rechts und Links bedingt aber offenbar den

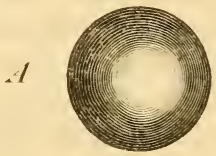
stereoskopischen Effect ${ }^{*}$ ).

Gehen wir nun in Ermangelung eigener Beobachtungen von den 186 übereinstimmenden Angaben Harting's und $\mathrm{N}$ a ehet's aus, wonach die ron Letzterem construirten binoculären Mikroskope die Erhöhungen und Vertiefungen als solche darstcllen, so liegt der Sehluss nahe, dass andere Mikroskope dieser Art, durch welche die Bilder in permutirter Anordnung gesehen werden $B A$ statt $A B$, den entgegengesetzten Eindruck hervorrufen, folglich die Erhabenheiten als Vertiefungen zeigen und umgekehrt. Diese pseudoskopische Erseheinung wurde auch in der That, wie uns Harting berichtet, sowohl von Riddell bei seinem katoptrischen, als von $W$ enham bei seinem dioptrischen binoculären Mikroskop » manchmal "beobachtet**). Die Einschränkung, welche in dem Worte » manchmal « liegt, kann nicht auffallen, da die Unterscheidung der Erhabenheiten von Vertiefungen

*) Jabei ist nich: zu vergessen, dass eine balbe Umkehrung durch einmalige Reflexion denselben Effect herrorbringt, wie das Wechseln der Bilder.

** Harting, Das Mikr. p. 195 und 775. 
sich keineswegs nur auf die Vertheilung von Licht und Schatten stützt, sondern auch durch die ungleiche Farbenzcrstreunng wesentlich erleichtert wird. Kleine Höhlungen und Spalten erscheinen z. B. rötlılich und werden diese Farbe auch bei der stereoskopischen Wahrnehmung beibehalten. Uebrigens kann Näheres hierüber nur durch Bcobachtung festgestellt werden.

Wie Harting zu der Ansicht gelangte, dass die Tiefe des Gesichtsfeldes bei der stercoskopischen Wahrnehmung ganz besonders in Betracht komme, vermögen wir nicht einzusehen. Unseres Erachtens kommt sie ganz und gar nicht in Betracht. Wie bei den käuflichen Stereoskopen zwei flächonhafte Ansichten zu einem stereoskopischen Bilde vereinigt werden, so müssen auch die Bilder des binoculären Mikroskops den Eindruck der Körperlichkeit hervorrufen, selbst wenn die Tiefe des Gesichtsfeldes Null wäre.

Endlich wollen wir noch auf einen Punct aufmerksam machen, der bisher, wie es scheint, ganz übersehen wurde. Erhabenheiten und Vertiefungen lassen sich bei durchfallendem Lichte stets durch Dichtigkeitsdifferenzen ersetzen, welche genau dieselbe optische Wirkung hervorbringen. Denken wir uns also eine Membran von durchweg gleichmässiger Dicke, abcr mit dichtcren und weicheren Stellen, so müssen die ersteren im stereoskopischen Bilde convex, die letzteren concav erscheinen und folglich eine Täuschung hervorrufen, welche den combinirenden Verstand irre leitet. Aus diesem Grunde halten wir es unter allen Umständen für gerathener, wissenschaftliche Untersuchungen mit dem gewöhnlichen monoculäron Mikroskope anzustellen.

\section{III.}

\section{Interferenzerscheinungen.}

187 Die Interferenzlinien, welche man am Rande dunkler Körper, Luftblasen etc. beobachtet, wurden bisher bekanntlich für Beugungserscheinungen erklärt. Man bedachte nicht, dass wemn auch die Bedingungen der Beugung gegeben wären, was in den meisten Fällen nicht der Fall ist, die resultirenden Interferenzen sich der mikroskopischen Wahrnehmung doch stets entziehen müssten. Denn da die einfallenden Strahlen nicht parallel verlaufen, sondern einen mehr oder minder geöffneten Lichtkegel bilden, so werden die dunkeln Linien, welche bestimmten Neigungen entsprechen, stets wieder durch 
Strahlen anderer Neigung erhellt, so dass für das beobachtende Auge eine gleichmässige Beleuchtung resultirt. Man wird auch in allen Fällen, wo Interferenzlinien wahrnehmbar sind, sich vergeblich bemühen, die Annahme einer Beugung durch eine auf Messungen basirte Construction zu reranschaulichen, sondern im Gegentheil immer die Ueberzeugung gewinnen, dass Factoren, welche auf Beugungsphänomene modificirend einwirken, hier entweder keinen oder einen ganz andern Einfluss üben; dass die beobachteten Abstände der dunkeln Linien mit den durch Construction oder Berechnung gefundenen nicht stimmen u. s. w. Dagegen unterliegt es keiner Schwierigkeit, die verschiedenen hieher gehörigen Erscheinungen auf Interferenzen anderer Art zurückzuführen.

\section{Interferenz des directen Lichtes mit reflectirtem.}

Stellt man eine ebene spiegelnde Fläche $A C$ (Fig. 114, z. B. ein 188 Deckgläschen oder die Randfläche eines Metallstückes, unter das Mikroskop und lässt durch eine kleine etwas seitlich gelegene Spalte $O$ Licht auf dieselbe fallen, so treten an Rande der Spiegelfläche und parallel mit derselben abwechselnd helle und dunkle Linien auf, welche bei hinreichend starker Vergrösserung Spectralfarben zeigen. Dieselben entstehen durch Interferenz des directen Lichtes mit dem reflectirten. Die Spalte $O$ und ihr Spiegelbild $O^{\prime}$ sind nämlich als zwei Lichtquellen zu betrachten, deren Wellensysteme nach bekannten Gesetzen sich stellenweise verstärken und an andern Stellen aufheben. Ein beliebiger Punct $P$ der Einstellungsebene, die hier den auffangenden Schirm vertritt, wird hell erscheinen, wenn die von

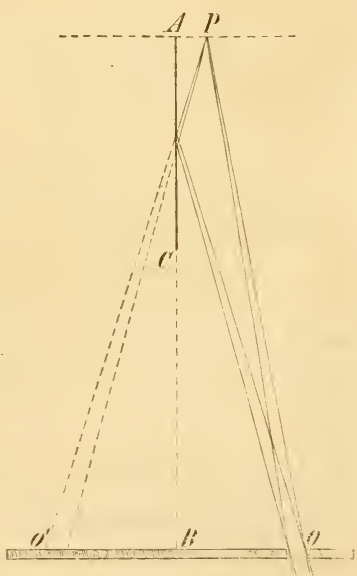

Figur 114. den beiden Lichtquellen kommenden Strahlen in diesem Puncte die nämliche Phase besitzen, dunkel dagegen, wenn die Schwingungszustände der Strahlen entgegengesetzt sind. Da nun der reflectirte Strahl durch die Reflexion selbst um eine halbe Wellenlänge verzögert wird, so ist die erstere Bedingung mit einem Gangunterschied 
von $1,3,5,7 \ldots$, die letztere mit einem Gangunterschied von 2, 4, $6 \ldots$ halben Wellenlängen gleichbedeutend. Der Abstand der ersten dunkeln Linie von der Spiegelfläche entspricht also einer Lage des Punetes $P$, in welcher dessen Entfernung von der Spalte $O$ um eine Wellenlänge kleiner ist, als ron dem Spiegelbild $O^{\prime}$.

Bezeichnet man den $A b s t a n d ~ A B$ der Einstellungsebene von der Spalte mit $a$, den Abstand $B O$ der letzteren von der Ebene des Spiegels mit $d$, und den Winkel $B . A O$ mit $\varphi$; zieht man ferner von den Puncten $O$ und $O^{\prime}$ concentri-

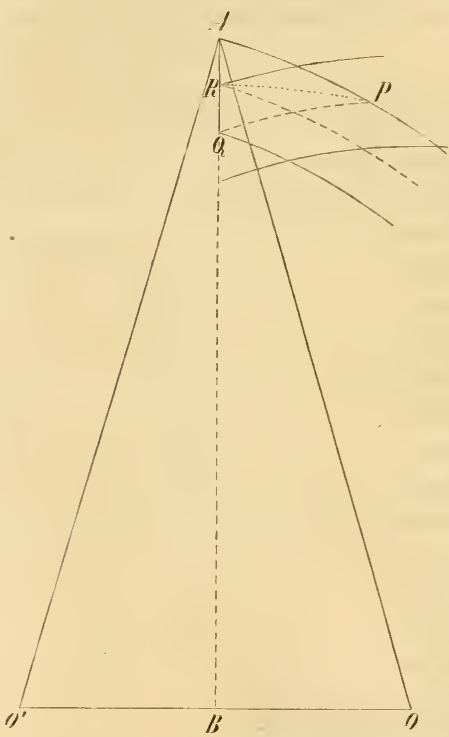

Firgur 115 . sche Kreise (Fig. 115), welche den Lichtwellen entsprechen, und zwar so, dass die punctirten Bogen die Wellenthäler und die ausgezogenen die Wellenberge darstellen wobei die durch die Reflexion verursachte Verzögerung um eine halbe Wellenlänge $z u$ berücksichtigen ist), so ergeben sich folgende Beziehungen. Das Dreieck $A Q P$,. dessen Scheitel $P$ der ersten dunkeln Linie entspricht und das wegen der Kleinheit der Bogen $A P$ und $Q P$ als geradlinig betrachtet werden darf, ist dem Dreieck $A O^{\prime} O$ ähnlich. 'Zieht man also ein Perpendikel $P R$, welches den Abstand des Punctes $P$ von der Spiegelfläche angiebt, so ist auch das Dreieck $R Q P$ ähnlich dem

Dreieck $A B O$ und man hat $P R: R Q=a: d$, folglich $P R=R Q \cdot \frac{a}{d}$ oder da $P R=\frac{\lambda}{2} \cdot \frac{1}{\cos \psi}$, wenn $\lambda$ eine Wellenlänge bezeichnet,

$$
P R=\frac{a^{\circ}}{d} \cdot \frac{\lambda}{2 \cos \psi} .
$$

Dieser Ausdruck gestattet in allen Fällen, wo es sich um mikrometrische Messungen handelt, noch die Vereinfachung, dass $\cos q=1$ ge- 
setzt werden kann, ohne dass der dadurch begangene Fehler messbar wäre. Man hat alsdann

$$
P R=\frac{a}{2 d} \lambda .
$$

Die folgenden Kreuzungspuncte, welche der zweiten, dritten, vierten ... dunkeln Linie entsprechen, stehen ebensoweit von dem unmiltelbar vorhergehenden $a b$, wie der erste von der Spiegelfläche. Sie liegen sämmtlich auf einem von $B$ aus durch $P$ gezogenen Kreisbogen, der jedoch bei der Kleinheit der in Betracht kommenden Abstände als gerade Linie zu betrachten ist und folglich durchg'ehends in die Einstellungsebene fällt. Die Interferenzlinien erscheinen demnach, wenn man sie in homogenem lichte bcobachtet, sämmtlich gleichweit von einander entfernt und zwar um die Grösse $\frac{a}{2 d} \lambda$. Sie rücken also um so näher, je grösser ฯ d. h. je weiter die Spalte von der Spiegelebene entfernt wird, und zeigen, wenn $d=\frac{1}{2} a$, nur noch cinen gegenseitigen Abstand ron eincr Wellenlänge.

Mit diesen theoretischen Ableitungen stimmen die Messungen 189 vollkommen überein. In einem gegebenen Fall war z. B. $d=2,75^{\mathrm{m} \cdot \mathrm{m}}$, $\iota=30^{\mathrm{m} . \mathrm{m}}$, der Abstand der Linien in weissen Licht 3,1 Mik.; die Rechnung ergab für die Wellenlänge $\lambda=0,567$ Mik., welcher Werth zicmlich genau den mittleren Strahlen entspricht.

Die prismatischen Farben der Interferenzlinien sind natürlich in Wirklichkeit immer so geordnet, dass das Violett der Spiegelfläche zugekehrt, das Roth davon abgekehrt ist. Sie erscheinen aber unter dem Mikroskop nur dann so, wenn dassclbe achromatisch oder überverbessert ist, während ein unterverbessertes Instrument die Ordnung der Farben umkehrț oder doch wenigstens deren Intensität schwächt. Dabei wird man gewöhnlich beobachten, dass der Einfluss der chromatischen Abweichung nicht für alle Linien denselben Grad erreicht, indem die einen oft noch die ursprüngliche, die andern bereits die umgekehrte Farbenfolge zeigen. Es rührt diess daher, dass die Neigung der Lichtbündelpaare, welche das mikroskopische Bild entwerfen, für jede folgende Interferenzlinie etwas verändert wird.

Ist die spiegelnde Fläche sphärisch gekrümmt, so erhält der 190 Winkel $\uparrow$, welchen die reflectirten Strahlen mit der Spiegelebene, oder was hier dasselbe ist, mit der entsprechenden Tangentialebene bilden, für jede folgende Interferenzlinie einen grössern Werth. In Fig. 116 ist z. B. $A A$ die Spiegelebene, welche dem Punct $a, B B$ diejenige, welche dem Punct $b$ entspricht; $q$ und $\varphi^{\prime}$ sind die zuge- 
hörigen Neigungswinkel der einfallendeu Strahlen. Dem entsprechend werden die Abstände der dunkeln Linien um so kleiner, je

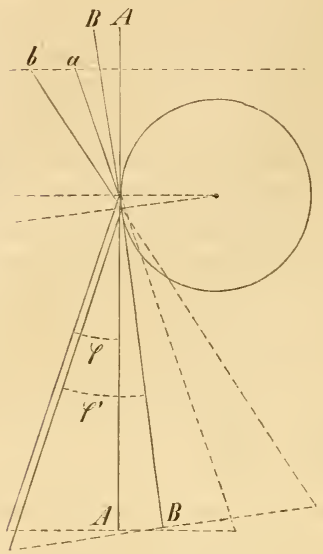

Figur 116. grösser ihre Entfernung ron der spiegelnden Fläche. Man beobachtet diess z. B. an Luftblasen, Quecksilbertropfen und anderen reflectirenden Körpern, und zwar besonders deutlich, wenn man statt der gewöhnlichen kreisförmigen Blendungsöffnung eine spaltenförmige in geeigneter Entfernung vom Object langsam hin und her bewegt, um dadurch die günstigste Lage im Verhältniss zu den reflectirenden Flächen zu finden.

Auf die eben angegebene Weise lassen sich auch die Linien, welche man hie und da auf Durchschnitten durch Gewebe (z. B. Kork) den Wandungen entlang verlaufen sieht, sehr schön zur Erscheinung bringen. Die Zu- und Abnahme ihrer Abstände je nach der Neigung der einfallenden Lichtstrahlen beweist, dass sie zu den im Vorhergehenden besprochenen Interferenzerscheinungen gehören.

2. Interferenz des gebrochenen Lichtes mit reflectirtem.

191 Ist pqrs Fig. 117) der Durchschnitt eines brechenden Körpcrs, z. B. eines Krystalls, so werden die von unten parallel einfallenden

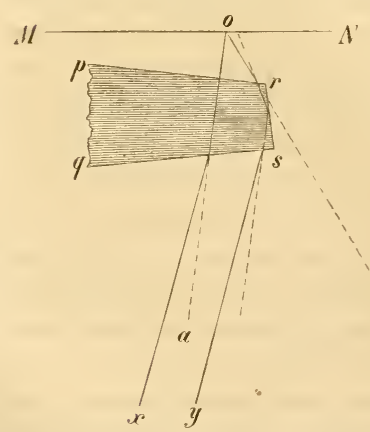

Figur 11:.
Lichtstrahlen $x$ und $y$ an den Flächen $q s$ und $p r$ gebrochen und der letztere überdiess ron der schief stehendeu Randfläche reflectirt. Ein in der Einstellungsebene $M N$ liegender Punct $o$ wird daher gleichsam von zwei Lichtquellen $a$ und $b$ beleuchtet, deren Lage

b durch die Gesetze der Brechung und der Reflexion bestimmt ist. Die Möglichkeit der Interferenz ist dadurch gegeben, und es wäre ein Lcichtes, für irgend einen 
gegebenen Fall die Abstände der Interferenzlinien zu berechnen. Für die Praxis hätte jedoch die Ausführung einer solchen Rechnung keinen besondern Werth, da die erforderlichen Data sich nur selten durch directe Beobachtung bestimmen lassen, hier also willkürlich festgestellt werden müssten. Soviel ist indess ohne Weiteres klar, dass die Interferenzlinien, von oben gesehen, sich auf die Fläche $p r$ projiciren und dass ihre gegenseitigen Abstände um so kleiner werden, je grösser die Entfernung der Lichtquelle Blendung) ron der Ebene der reflectirenden Fläche.

\section{Interferenz des gebrochenen und directen Lichtes.}

Die Herumlenkung einfallender Strahlen nach eincm direct be-192 leuchteten Puncte $p$ der Einstellungsebene Fig. 11.5) kann ebensogut durch Brechung als durch Reflexion remittelt werden, und da der gebrochene Strahl stets einen grössern Weg zurücklegt als der directe, so muss auch in diesem Fall Interferenz stattfinden. Die Entscheidung, ob gebrochene oder reflectirte Strahlen mit directen interferiren, ist indess nicht immer leicht, da die Ncigung der reflectirenden oder brechenden Fläche, das Brechungsrerhältuiss etc. überhaupt die nöthigen Anhaltspuncte zur Bestimmung des Strahlenganges sich in manchen Fällen nicht ermitteln lassen.

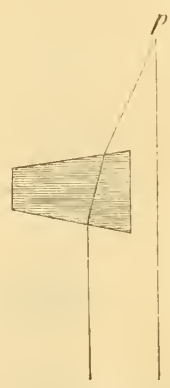

Figur 11 s.

\section{Interferenz gebrochener oder reflectirter Strahlen unter sich.}

Die Interferenzlinien, welche man an Krystallen innerhalb der 193 Contouren parallel mit den zugekehrten Kanten verlaufen sieht, rühren von Strahlen her, welche durch Brechung oder Reflexion nach denselben Puncten der Einstellungsebene gelenkt werden und sich hier je nach ihrem Gangunterschied schwächen oder verstärken. Denselben Ursprung haben die Interferenzlinien, welche bei Hohlcylindern an der Stelle der äusseren und inneren hellen Linie auftreten, sobald die den Rand oder das Lumen erhellenden Strahlen noch über dieselben hinaus zur Belenchtung beitragen. 
๖. Reflexion des Lichtes an kleinen lï̈gelchen, fiörnchen, feinen Fäden ete. und daduch bedingte Jnterferenzerscheinungen.

Ist $a b$ (Fig. 119) ein kleines Quecksilberkügelchen, beispielsweise von 20 Mik. Durchmesser, so erscheint dasselbe bei mittlerer Einstellung, wenn wir die Spiegelung des Objectivs unberücksichtigt lassen, als schwarzer Kreis, umsäumt von einem deutlichen hellen

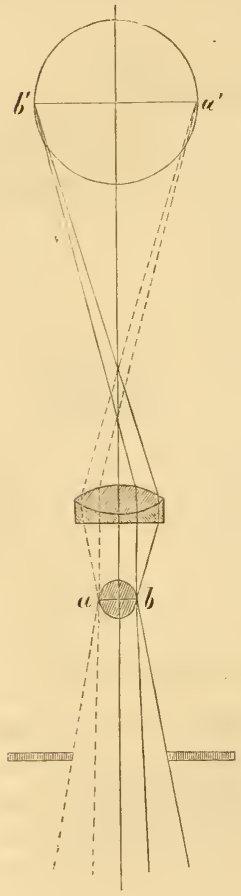

Figur 119. Ring, der angeblichen "Diffractionslinie". Die letztere rührt von Lichtstrahlen her, die an den Rändern der spiegelnden Kugel zurückgeworfen werden und daher gleichsam von diesen Rändern, die man als leuchtende Puncte betrachten kann, ausgehen. Genauer gesprochen ist die helle Linie nichts anderes, als das virtuelle Bild der Blendung, wie es ron der durch die Puncte $a$ und $b$ gehenden Kugelzone entworfen wird. Ein den einfallenden Lichtkegel schneidender Gegenstand (Fensterrahmen, Bleistift etc.) stellt sich in diesem Spiegelbilde als dunkle Linie dar, welehe an zwei opponirten Stellen des Kreisumfanges kürzere oder längere Bogen bildet.

Es leuchtet nun ron selbst ein, dass wenn das Mikroskop auf den spiegelnden Rand des Quecksilberkügelchens eingestellt ist, dieser lctztere auch im Objectivbilde als helle Einfassung erscheint, da ja alle Strahlen, welche zum Bilde beitragen, von Puncten der Einstellungsebene ausgehen. Anders gestalten sich dagegen die Verhältnisse, wenn der Focus des Mikroskops in einem tieferen oder höheren Niveau liegt. Es treten alsdann in Betreff des leuchtenden Kugelrandes dieselben Erscheinungen herror, welche die Annäherung oder Entfernung einer wenig ausgedehnten Lichtquelle immer hervorruft. Nur kommt in unserem Falle die besondere Einschränkung hinzu, dass die von der Lichtquelle ausgehenden Strahlenbündel, wie ein Blick auf die Figur zeigt, stets nur durch den entsprechenden Randtheil des Objectirs gehen, so dass z. B. für cinen rechts gelegenen Punct $b$ des Kugel- 
randes die linke Hälfte des Objectirs ausser Wirkung bleibt. Unter diesen Verhältnissen wirkt eine Hebung des leuchtenden Punctes $b$ wie eine Verschiebung desselben nach links, d. h. die Neigung des zum Objectiv gelangenden Lichtkegels oder seiner Axe wird durch die Hebung stärker, die des gebrochenen dagegen schwăcher (Fig. 120). Der Bildpunct $b^{\prime}$ rückt daher nach rechts, und aus denselben Gründen bewegt sich $a^{\prime}$ um eben so viel nach links. Das Bild des leuchtenden Randes wird daher immer kleiner; der helle Ring zieht sich immer mehr zusammen, bis er endlich, wenn die Hebung lange genug fortgesetzt wird, nur noch als leuchtender Punct erscheint, welcher die Mitte des dunkeln Schattenbildes der Kugel einnimmt. Dabei ist natürlich vorausgesetzt, dass die Bildpuncte $a^{\prime}$ und $b^{\prime}$ trotz dieser Verschiebung ihre ursprünglichen Abstände von der Ocularlinse nicht wesentlich ändern, da im entgegengesetzten Falle ein deutliches Bild selbstverstăndlich nicht wahrgenommen würde. Bei den meisten Objectiven rerwischt sich denn auch das Bild so rasch, dass das letzte Stadium, der helle Punct in der Mitte, nur bei

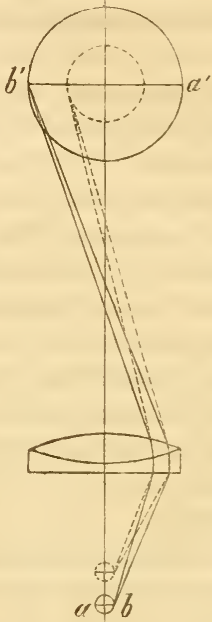

Figur 120. äusserst kleinen Kügelchen, die also auch nur eine ãusserst geringe Verschiebung erfordern, noch deutlich.wahrgenommen wird. So z. B. bei den stärkeren Systemen von Oberhäuser und Hartnack, beim System 7 von Bénèche und Wasserlein etc., wăhrend das System 9 der letztgenannten Optiker bei Kügelchen von 25 Mik. Diameter nicht nur den centralen Punct, sondern bei noch tieferer Einstellung (wobei die Bildpuncte ihre relative Lage wechseln, indem $b^{\prime}$ rechts und $c^{\prime}$ links zu liegen kommt) abermals einen hellen Kreis zeigt.

Hat der zum Objectir gelangende Lichtkegel eine beträchtliche195 Oeffnung, so kommt nicht bloss die Neigung seiner Axe, sondern auch die seiner einzelnen Strahlen in Betracht. Die schwächer geneigten bedingen eine geringere, die äussersten Randstrahlen eine stärkere Verschiebung der Bildpuncte $a^{\prime}$ und $b^{\prime}$. Der ausfahrende Lichtkegel sondert sich also in viele, wovon jeder sein eigenes Bildchen liefert. Einzelne dieser Bildpuncte kōnnen auch in der Lăngs- 
richtung so verschoben werden, dass sie für unser Auge verschwinden. Jedenfalls werden sich bei der Hebung des Objectes die einen früher, die andern später verwischen; die übrig bleibenden bilden aber immer eine ununterbrochene radiale Reihe und demnach im Gesammtbilde einen Ring. Der letztere erscheint aber nicht, wie man vielleicht erwarten möchte, gleichmässig beleuchtet, sondern aus abwechselnd hellen und dunkeln Linien zusammengesetzt, welche unverkennbar auf Interferenzerscheinungen deuten. Man begreift auch, dass Interferenzen stattfinden nü̈ssen, wenn man erwägt, dass die Strahlen, welche sich in einem Bildpuncte kreuzen, nahezu parallel verlaufen und dabei ungleiche Wege zurücklegen, und zwar einen um so längeren Weg, je mehr sie gegen die Axe geneigt sind. Beträgt nun der Gangunterschied der Randstrahlen eines ausfahrenden Lichtbündels eine gerade Zahl von halben Wellenlängen, so wird der entsprechende Bildpunct dunkel, bei einer ungeraden Zahl von halben Wellenlängen dagegen hell erscheinen. Die Abstände dieser Interferenzlinien lassen sich jedoch nicht so leicht, wie bei einfachen Brechungen, mathematisch feststellen, da der Strahlengang im Objectiv, wenn es auf Wellenlängen ankommt, sich jeder Berechuung entzieht.

196 Stellt man das Mikroskop auf die Ebene ein, in welcher das vom Kugelrand entworfene virtuelle Spiegelbild als ein centraler kleiner Kreis erscheint, so verhält sich dasselbe - abgesehen von der geringeren Schärfe und Lichtstärke - vollständig wie das virtuelle Bild einer Luftblase. Fensterrahmen, die sich im Spiegel reflectiren, erscheinen alsdann als gerade Linien; eine kleine Hebung des Tubus bewirkt eine rothe Färbung des Centrums und einen bläulichen Rand, eine Senkung ein bläuliches Centrum mit rothem Rand. Diese Farbenerscheinungen verdienen Beachtung, weil sie auch bei den kleinsten Kügelchen von 2-3 Mik. Durchmesser vorkommen und gerade hier die Unterscheidung derselben von kleinen Hohlräumen nicht wenig erschweren. Beide erscheinen nämlich bei einer gewissen Einstellung, die bei so kleinen Dimensionen nur wenig von der mittleren differirt, röthlich, bei etwas tieferer Einstellung hell und bei höherer dunkel. Nur wo die Kügelchen ein deutliches reelles Bild entwerfen, das also jedenfalls über dem rothen virtuellen liegt, ist ein theoretisch begründetes Unterscheidungsmerkmal gegeben und daher eine Verwechslung nicht wohl möglich. Allein in den meisten Fällen, die auch für den geübteren Mikroskopiker zweifelhaft sind, lässt uns dieses Criterium so ziemlich im Stich; jeder einzelne Fall erfordert 
alsdann eine besondere Betrachtung und kann daher nur von einem Beobachter desselben gedeutet werden.

Es ist in manchen Fällen zu empfehlen, optische Erscheinungen der angedeuteten Art unter verschiedenen bekannten Instrumenten zu beobachten, da das verschiedene Aussehen des miliroskopischen Bildes, wenn auch nicht immer direct belehrt, doch wenigstens vor voreiligen Schlüssen bewahrt.

6. Interferenzlinien, welche die Entfernung einer wenig ausgedehnten Lichtquelle ïber die Objectlistanz hinatus hervorruft.

Im Vorhergehenden wurde gezeigt, dass die Annäherung eines 197 leuchtenden Punctes gegen die Focalebene des Mikroskops eine Verschiebung seines Objectivbildes und unter Umständen die Bildung ron Interferenzlinien zur Folge habe, sobald die einfallenden Lichtbündel nur die eine Hälfte der Linsen treffen. Die entgegengesetzte Bewegung der Lichtquelle oder, was dasselbe ist, die Hebung des Mikroskoprohres, bringt natürlich eine analoge Wirkung hervor; der Bildpunct im mikroskopischen Bilde wird ebenfalls verschoben, aber in entgegengesetzter Richtung. Der Lichtsaum, welchen der spiegelnde Rand eines Quecksilbertropfens hervorruft, rückt also in diesem Falle nach aussen. Er kann sich dabei, je nach der Eigenthümlichkeit des Objectivs, in deutliche Interferenzringe auflösen oder aber sehr rasch rerwischen. Eine Verwischung wird immer eintreten, wenn die entgegengesetzte Verschiebung Ringe, Ringbildung dagegen, wenn sie Verwischung bedingt.

Es leuchtet übrigens ein, dass das angeführte Beispiel zur Beobachtung dieser Erscheinung nicht gerade günstig ist, da der grösser werdende Lichtsaum auf das erhellte Gesichtsfeld fällt. Viel geeigneter sind feine Linien oder Puncte in einer (mit Tusche oder über der Kerzenflamme) geschwärzten Glasplatte oder die Spiegelbildchen kleiner Quecksilberkügelchen auf dunkelm Grunde. Die Interferenzlinien treten alsdann, wenn sie überhaupt zu Stande kommen, auffallend scharf und die peripherischen sogar mit deutlichen prismatischen Farben hervor. Wenn man die eine Hälfte des Objectirs bedeckt oder den Spiegel seitlich verstellt, so kamn man sich leicht überzeugen, dass die Verschiebung in der angedeuteten Weise stattfindet, wie denn überhaupt nach dieser Methode sowohl Hebung als Senkung der Mikroskopröhre sich in ihren Wirkungen bequem studiren lassen.

Wie die angeführten Lichtquellen verhalten sich natürlich auch alle reellen oder virtuellen Bilder, deren Umgebung nur schwach 
oder gar nicht beleuchtet erscheint, so z. B. die hellen Linien in der Luftblase und im Hohlcylinder, die Brenulinien cylindrischer Fäden und Röhren etc.

\section{IT.}

\section{Die schiefe Beleuchtung.}

Es wurde früher hervorgehoben, dass ein schief einfallender Lichtkegel rücksichtlich der Aberrationen des Objectivs günstiger wirken könne, als ein gerader, unter der Voraussetzung nämlich, dass gerade diejenigen Neigungen darin vertreten seien, für welche das Instrument am vollkommensten aplanatisch ist. Hier sehen wir von dieser Bedeutung der schiefen Beleuchtung ganz ab, wir setzen ein vollkommen aplanatisches Mikroskop voraus, bei welchem die schiefe Lage des einfallenden Lichtkegels nur die Lichtintensităt, nicht aber die Schărfe des Bildes beeinflusst. Es bleibt aber noch die Frage zu erörtern, wie die schiefe Beleuchtung im Gegensatz zu der geraden auf die Lichtvertheilung im mikroskopischen Bilde wirke, wenn als Object eine zart geschichtete Substanz oder eine Membran mit schwachen Erhabenheiten oder Vertiefungen gegeben ist. Da diese beiden Fälle sich hinsichtlich der Gesammtwirkung auf den einen zurückführen lassen, dass entsprechende Flächenstücke des Gesichtsfeldes sich abwechselnd wie Sammellinsen und Zerstreuungslinsen rerhalten,

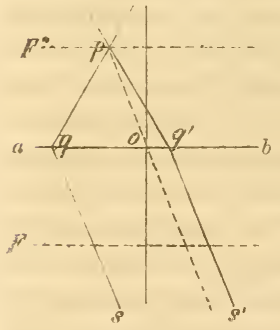

Figur 121. so ist es zunächst unsere Aufgabe, auch das resultirende Bild von diesem allgemeineren Gesichtspuncte aus zu untersuchen.

Sei $a b$ Fig. 121) ein Flächenelement, welches reelle Bilder liefert, und nehmen wir an, der Beleuchtungsspiegel sei so gestellt, dass alle einfallenden Strahlen nach der nämlichen Seite von der Senkrechten abweichen. Das Minimum dieser Abweichung sei $\delta$, das Maximum $\delta^{\prime \prime}$; der Oeffnungswinkel des Objectivs mag wie bisher (1) heissen. Unter diesen Toraussetzungen sind die Grenzlinien des Kern- und Halbschattens durch die entsprechenden Werthe des Ablenkungswinkels $\varrho$ bestimmt. Die Abhăngigkeit derselben von der Neigung der einfallenden Lichtstrahlen tritt 
jedoch in klarerer Weise herror, wenn man ihre Abstände vom Centrum der brechenden Flächenelemente direct durch die Brennweite $(f)$ der letzteren ausdrückt. Seien also $F$ und $F^{*}$ die beiden Brennebenen, $s q$ und $s^{\prime} q^{\prime}$ einfallende Strahlen mit der Neigung $\delta^{\prime}$, welche so gebrochen werden, dass sie gerade noch das Objectiv erreichen; dann geben die Dreiecke $o p q$ und $o p q^{\prime}$ die trigonometrischen Beziehungen $o p: o q=\cos \frac{\omega}{2}: \sin \left(\frac{\omega}{2}+\delta^{\prime}\right)$, folglich

$$
\begin{aligned}
& o q=\frac{\sin \left(\frac{m}{2}+\delta^{\prime}\right)}{\cos \frac{\omega}{2} \cdot o p}, \text { oder da op }=\frac{f}{\cos \delta^{\prime}} \\
& o q=f \frac{\sin \left(\frac{\omega}{2}+\delta^{\prime}\right)}{\cos \frac{\omega}{2} \cos \delta^{\prime}}=f\left(\operatorname{tang} \frac{\omega}{2}+\operatorname{tang} \delta^{\prime}\right)
\end{aligned}
$$

und ebenso erhält man

$$
o q^{\prime}=f\left(\operatorname{tang} \frac{\omega}{2}-\operatorname{tang} \delta^{\prime}\right) .
$$

Die Grenzlinie des Kernschattens rückt also einerseits gegen den optischen Mittelpunct vor und fällt mit diesem zusammen, sobald $\delta^{\prime}=\frac{\omega}{2}$; andererseits entfernt sie sich von demselben und erreicht bei starken Vergrösserungen, wenn z. B. $\omega=\delta v^{0}$ und $\delta^{\prime}$ etwas grösser als $45^{\circ}$, leicht einen Abstand ron $2 f$. Dasselbe Raisonnement gilt natürlich auch für den Halbschatten; die Formeln bleiben dieselben, nur dass $\delta^{\prime}$ an die Stelle von $\delta^{\prime}$ kommt. Damit ist aber bewiesen, dass die schiefe Beleuchtung bei Flächenelementen, deren Breite weniger als $2 f$ beträgt, auf der einen Seite den Schatten ganz aufhebt, während sie ihn auf der andern verstärkt. Wo demnach viele solcher kleinen Sammellinsen sich unmittelbar aneinander anschliessen, da zeigt das mikroskopische Bild ebenso viele helle Stellen, welche mit dunkeln alterniren, wie diess auch bei gerader Beleuchtung der Fall ist. Während aber die letztere möglicher Weise nur den Halbschatten zur Erscheinung bringt, erzeugt das schiefe Licht den viel augenfälligeren Kernschatten und steigert dadurch •die Gegensätze zwischen Hell und Dunkel.

Wechseln dagegen unter denselben Voraussetzungen die kleinen Sammellinsen mit Zerstreuungslinsen oder mit Flächenelementen ab, die keine Ablenkung verursachen, so bleiben diese letzteren hell, während die Zerstreuungslinsen Licht und Schatten in umgekehrter Anordnung zeigen. Die belcuchteten Theile benachbarter Flächen- 
elemente schliessen sich also aneinander an; je zwei Elemente bilden zusammen eine helle und eine dunkle Stelle. Die Zahl der Licht- und Schattenpuncte im mikroskopischen Bilde wird folglich auf die Hälfte reducirt, und es ist nicht zu verwundern, wenn in Folge dessen bei schwierigen Objecten Streifen zum Torschein kommen, welche bei gerader Beleuchtung nicht wahrnehmbar sind.

Diese Folgerung hat auch dann noch Geltung, wenn die Brechung ziemlich unregelmässig stattfindet, indem z. B. die Brennweiten der Randstrahlen viel kleiner ausfallen, als die der centralen; nur ist selbstrerständlich in diesem Fall die Grösse $f$ einzig und allein auf die Grenzstrahlen zu beziehen.

199 Wir kennen nun freilich keine Objecte, bei denen der eben bewiesene Satz sich auf experimentellem Wege bestätigen liesse. Er ist aber nichtsdestoweniger unzweifelhaft richtig, und ein Glasplättchen mit wellenförmiger Oberfläche müsste die Erscheinungen genau so zeigen, wie die Theorie es verlangt, d. h. die Zahl der dunkeln Streifen könnte bei hinreichend schiefer Spiegelstcllung nur halb so gross sein, als bei gerader.

Wenn wir bei den gewöhnlichen Probeobjecten, bei gestreiften Membranen $u$. dgl, eine solche Wirkung der schiefen Beleuchtung nicht wahrnehmen, so liegt die Ursache darin, dass dieselben nur in gleichartige Linsen, die sich unmittelbar berühren, zerlegt werden können, oder dass die Brennweite der brechenden Flächenelemente im Verhältniss zur Breite zu klein ist. Zuweilen mag es auch daher rühren, dass zu den Brechungen noch Reflexionserscheinungen hinzukommen, welche ihre besonderen Schatten hervorrufen. In anderen Fällen, wenn nämlich das Object sehr dick ist, so dass seine tiefer liegenden Theile gleichsam mit zum Beleuchtungsapparat gehören, hängt natürlich auch hievon Licht- und Schattenvertheilung im Bilde ab. Eine eingehende und dabei allgemein gültige Betrachtung solcher Verhältnisse ist indess nicht wohl möglich; jeder einzelne Fall muss besonders construirt oder berechnet werden.

Wir wollen als Beispiel nur die Wirkung erörtern, welche der senkrechte Rand einer Membran oder eines Deckgläschens bei schiefer Beleuchtung hervorbringt. Ist $q r$ (Fig. 122) die senkrechte Randfläche und $B$ die seitlich verschobene Blendung, welche die Neigung des einfallenden Lichtkegels bestimmt, dann ist ohne Weiteres aus der Figur ersichtlich, dass wenn das Mikroskop auf die Oberfläche des Deckgläschens eingestellt wird, der Punct $p$ eben noch voll belenchtet erscheint. Weiter nach rechts werden die rückwärts con- 
struirten Strahlen zunächst theilweise, dann sämmtlich von der senkrechten Randfläche nach links reflectirt oder doch so gebrochen, dass sie die Blendungsöffnung nicht erreichen. Der Rand des Deckgläschens fällt also in den Schatten. In ähnlicher Weise lässt sich zeigen, dass wenn man bei gleicher Beleuchtung den linken Rand $m n$ (Fig. 122) eines Deckgläschens beobachtet, der letztere selbst hell, dagegen das angrenzende Stück $m t$ der Ein. stellungsebene dunkel erscheint.

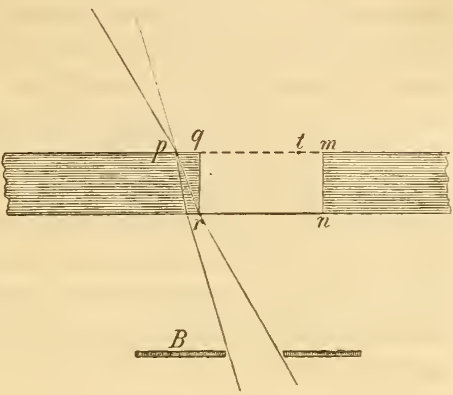

Figur 122 .

Denken wir uns also ein Object mit vorstehenden Leisten (Fig. 123 A), so muss nach dem eben Angeführten die Einstellung auf die Oberfläche der Erhabenheiten ein Bild liefern, wie es in Fig. $123 B$ dargestellt ist. Die Leisten sowohl als die Tertiefungen zwischen denselben fallen je mit ihrer rechten Kante in den Schatten, und zwar fällt derselbe um so breiter aus, je schiefer

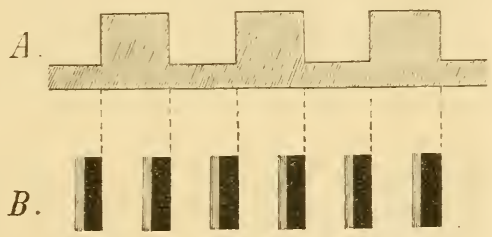

Figur 123. die Beleuchtung. Den nämlichen Effect müssten natürlich auch abwechselnd dichtere und weichere Schichten mit senkrechten Grenzflächen hervorrufen, wenn das Mikroskop auf die Oberfläche derselben eingestellt wird.

Die Bedeutung der schiefen Beleuchtung liegt also vorzugsweise 200 darin, dass sie die Gegensätze zwischen Licht und Schatten steigert und die Schattenlinien überdiess breiter und daher deutlicher zur Erscheinung bringt. In besonderen Fällen kommt noch hinzu, dass die Zahl derselben bei hinreichend schiefer Beleuchtung nur halb so gross sein kann, als bei gerader, wodurch natürlich die Wahrnehmbarkeit in noch höherem Grade gesteigert wird.

Der Neigungswinkel des einfallenden Lichtkegels, oder genauer 
seiner Axe, muss natürlich für jeden gegebenen Fall durch Tatonnement besonders bestimmt werden. Sein Werth richtet sich nicht bloss nach der Natur des Objẹctes und der Oeffnung $\omega$ des Objectivs, sondern auch nach der Differenz zwischen den extremen Werthen von $\delta$. Da nämlich die Unterscheidbarkeit abwechselnd positiver und negativer Gesichtseindrücke am grössten ist, wenn weder die einen noch die anderen ein entschiedenes Uebergewicht haben, so ist stets diejenige Combination die günstigste, durch welche die Schatten- und Lichtlinien nahezu gleiche Breite und erstere überdiess ihre grösste Tiefe erhalten. Wo beides zugleich nicht erreichbar ist, lässt sich freilich eine grössere Breite der Schatten nur auf Kosten ihrer Dunkelheit, und eine grössere Dunkelheit nur auf Kosten ihrer Breite herstellen. Das Auge hat dann zu entscheiden, welche Mittelstufe für die Beobachtung die zweckdienlichste ist.

$201 W$ as die schiefe Beleuchtung durch Randstrahlen eines geraden, ziemlich weit geöffneten Lichtkegels betrifft, wie sie durch Anwendung einer ringförmigen Blendungsöffnung erzielt wird, so waren wir nie im Falle, die Vorzüge dieser Beleuchtungsart bei dieser oder jener Untersuchung praktisch kennen zu lernen. Soweit aber die unit Probeobjecten angestellten Experimente ein Urtheil erlauben, möchten wir dieselben gerade nicht allzu hoch anschlagen. Theoretisch betrachtet kann eine solche Beleuchtung nur die Wirkung haben, dass die Lichtstärke des mikroskopischen Bildes in demselben Verhältnisse abnimmt, in welchem der Querschnitt des wirksamen Lichtkegels durch Abhaltung der Centralstrahlen sich verkleinert. Die Grenzlinien des Kern- und Halbschattens aber behalten unter allen Umständen ihre Lage bei, da sie in jedem gegebenen Falle nur von der Neigung der extremen Randstrahlen, d. h. von den Maximalwerthen von $\delta$ und $\omega$ abhängen. Eine gemilderte Lichtintensität lässt sich aber eben so leicht auch dadurch herstellen, dass man den Spiegel einer weniger intensiven (jedoch hinreichend ausgedehnten) Lichtquelle zuwendet oder statt desselben ein Stück weisses Papier als reflectirende Fläche benutzt, oder indem man die einfallenden Strahlen durch einen halbdurchsichtigen Gegenstand (Seidenpapier, mattgeschliffenes Glas u. dgl.) gehen lässt.

Eine wesentlich günstige Wirkung der fraglichen Beleuchtungsart würde nur dann erklärlich sein, wenn das Objectiv bloss für Randstrahlen innerhalb gewisser Grenzen der Neigung, nicht aber für Centralstrahlen, aplanatisch wäre. In diesem Falle müsste jedoch 
eine ringförmige Blendung nicht bloss für gewisse Objecte, sondern für alle ohne Ausnahme vortheilhaft sein.

\section{V. \\ Die Bewegungserscheinungen.}

Die Beobachtung der Bewegungserscheinungen unter dem Mi-202 kroskop hat schon zu manchen irrigen Vorstellungen über die Natur dieser Bewegungen geführt. Wenn man z. B. Schwärmsporen den Raum des ganzen Gesichtsfeldes in einer Secunde zurücklegen sieht, so möchte man glauben, dieselben schiessen pfeilgeschwind durch das Wasser, während sie in Wirklichkeit viclleicht nur den dritten Theil eines Millimeters zurücklegen, was auf die Stunde etwas mehr als einen Meter ausmacht. Man darf also nie vergessen, dass die Bewegungsgeschwindigkeit mikroskopischer Objecte immer nur cine scheinbare ist und dass die richtige Beurtheilung derselben nur dadurch möglich wird, dass man das wirkliche Verhältniss zwischen Raum und Zeit als Maassstab nimmt. Will man behufs gewisser Vergleichungen auch die Grösse der sich bewegenden Körper in Rechnung bringen, so mag man das immerhin thun; die Ermittlung der wirklichen Geschwindigkeit bleibt jedoch bei jeder fortschreitenden Bewegung die Hauptsache.

Wenn ein schraubenförmig gewundenes Object ron geringer 203 Dicke sich in der Einstellungsebene um seine Axe dreht und zugleich vorwärts bewegt, so gewährt dasselbe den täuschenden Schein einer Schlangenbewegung. Es rührt diess daher, dass dic den aufeinanderfolgenden Zeitmomenten entsprechenden Horizontalprojectionen eines solchen Objects genau diesclben sind, wie wenn die Bewegung eine wirkliche Schlangenbewegung wäre. Als Beispiel einer hieher gehörigen Erscheinung führen wir das angebliche Schlängeln von Spirillum und Vibrio an.

Aehnliche Täuschungen rufen zuweilen auch Schwärmsporen und Spermatozoen hervor; sie scheinen Schlangenlinien zu beschreiben, während sie in Wirklichkeit sich in einer Spirale bewegen. Man glaubte überhaupt früher eine Menge verschiedener Bewegungserscheinungen unterscheiden zu müssen, während neuere Beobachter die meisten derselben als ein mit Drehung verbundenes Vorwärtsrücken erkannt haben, wobei die Drehung bald um eine centrale, 
bald um eine excentrische Axe erfolgt*,. Dahin gehören beispielsweise auch die vermeintlichen Schwingungen der Oscillarien, deren Nireauveränderungen während der Schwingung man früher übersehen hatte.

Zur Charakteristik einer Spiralbewegung gehört natürlich auch die Angabe, ob sie rechts- oder linkswendig sei. Diess zu unterscheiden ist bei kugeligen oder cylindrischen Körpern, die sich um eine centrale Axe bewegen, keineswegs leicht und in manchen Fällen, wenn das Object sehr klein und der Inhalt homogen ist, geradezu unmöglich. Die kleinen Abweichungen ron der Cylinder- oder $\mathrm{Ku}$ gelform, wie sie bei jeder Zelle vorkommen, reichen alsdann gerade aus, um wenigstens erkennen zu lassen, dass irgend eine Drehung stattfindet. Die Unterscheidung der Drehungsichtung ist nur dann möglich, wenn feste Puncte, deren Lage zur Axe der Spirale bekannt ist, in ihrer Bewegung um dieselbe mindestens ein Stück weit rerfolgt werden können. Dasselbe gilt mutatis mutandis auch ron spiralig gewundenen Fäden, Spiralgefässen etc.; man muss die zu- und abgekehrte Seite der Windungen sicher ron einander unterscheiden können.

Ist der Verlauf der Windungen sehr unregelmässig, wie z. 13. in Fig. 124, so erfordert es einige Uebung und Torsicht, um bei kleinen Objecten eine Spirallinie als solche zu erkenmen. Das mikroskopische Bild kann alsdann leicht zu der Annahme führen, man habe es mit einem cylindrischen Körper zu thun, der aus ineinander geschachtelten Glocken oder Trichtern zusammengesetzt sei. So wurden z. B. die spiraligen Terdickungsfasern, wie sie aus den Epidermiszellen mancher Samenhäute hervorquellen, gedeutet, obschon man hie und da neben den unregelmässigen auch ganz regelmässige Spiralen beobachtet.

Tebrigens darf man nicht rergessen, dass im mikroskopischen Bilde eine Spirallinie stets in gleicher Weise gewunden erscheint, wie mit blossem Auge gesehen, während in Spiegelbilde (da die Umkehrung nur eine balbe ist eine rechtsläufige Schraube sich bekanntlich linksläufig darstellt, und umgekehrt. Wird daher das mikroskopische Bild durch einen Spiegel betrachtet, wie z. B. beim Zeichnen mittelst

* Vgl. hierüber X̃ägeli. Beiträge II. pag. «ৎff. 
des Sömmerring'schen Spiegelchens, ocler werden überhaupt die bilderzeugenden Strahlenbündel irgendwo durch einmalige Reflexion abgelenkt, so findet eine ähnliche Umkehrung der Rechtswendung in Linkswendung statt, welche indess durch eine zweite Reflexion, wie sie z. B. bei der Oberhäuser'schen Camera lucida und bei manchen multoculären Mikroskopen rorkommt, wieder aufgehoben wird. Das Alles ist, wie man sieht, sehr einleuchtend und für den praktischen Beobachter so zu sagen selbstverständlich: dessenungeachtet haben schon manche Mikroskopiker den Beweis geliefert, dass sie über dergleichen Dinge noch ganz im Unklaren sind.

II.

\section{Die Niveaudifferenzen.}

Da man durch das Mikroskop nur solche Gegenstände, welche 205 genau in der Einstellungsebene liegen, scharf sieht, so ist es möglich, die Entfernung zweier Objectpuncte in der Richtung der Mikroskopaxe dadurch zu ermitteln, dass man mit Hülfe eines zweiten horizontal gestellten Mikroskops oder auch vermittelst einer hiefür besonders construirten Mikrometerschraube die Niveaudifferenz der entsprechenden Einstellungsebenen misst. Bei diesem Verfahren ist jedoch, insofern die gegebenen Objecte in ein flüssiges oder festes Medium, z. B. in Wasser, eingetaucht sind, eine Fehlerquelle zu berücksichtigen, welche in sehr erheblichem Grade auf die Resultate der Messung influirt. Bestimmt man nämlich die Tubusverschiebung, welche nothwendig ist, um abwechselnd den einen und andern der beiden gegebenen Objectpuncte in die Einstellungsebene zu bringen, so fällt die Verschiebungsgrösse immer beträchtlich kleiner aus, als die wirkliche Niveaudifferenz. Als Brennweite einer kugelförmigen Luftblase in Wasser erhält man z. B. 0,9S-1,04 (der Radius als Einheit gedacht, während sie in Wirklichkeit für die maassbestimmenden mittleren Strahlen circa 1,3 beträgt.

Dieser Fehler rührt daher, dass der Tebergang der Lichtbündel aus Wasser in Luft das Deckplättchen kommt hier nicht in Anschlag für das bewaffnete Auge im Allgemeinen dieselbe Wirkung herrorbringt, wie für das unbewaffnete. Ein in Wasser befindlicher Gegenstand wird nämlich scheinbar gehoben und zwar absolut genommen um so mehr, je tiefer er liegt. Das virtuelle Bild einer Luftblase wird 
also stärker gehoben, als das Centrum derselben, die Brenuweite folglich verkürzt, und aus denselben Grunde wird ganz allgemein der senkrechte Abstand zweier Puncte verkleinert. Das Maass dieser Verkleinerung hängt natürlich vom Einfallswinkel der wirksamen Lichtstrahlen ab und wird für kleine Werthe desselben, so lange die Bogen sich wie die Sinus verhalten, ganz allgemein durch $1-\frac{1}{n}$ ausgedrückt, wenn $n$ den Brechungscoefficienten bezeichnet. Da nun die einfallenden Lichtkegel im Objectiv so gebrochen werden, als ob sie aus Strahlen von bestimuter mittlerer Neigung beständen und diese Neigung bei den stärkeren der untersuchten Systeme nicht über $12-18^{0}$ steigt, so ist obiger Ausdruck in den meisten vorkommenden Fällen annähernd richtig und folglich die trigonometrische Bestimmung*) des Fehlers überflüssig. In Wasser mit dem Brechungscoeffi- cienten $4 / 3$ wird demnach jede Niveaudifferenz $\mathrm{nm}$ den 4 ten Theil ihrer wirklichen Grösse verkleinert, d. h. auf $3 / 4$ reducirt. Die genaue Berechnung giebt bei einem Einfallswinkel von $18^{0}$ statt $3 / 4$ den etwas kleineren Werth 0,7395.)

Es giebt übrigens ein einfaches Mittel, die genannte Fehlerquelle $\mathrm{zu}$ beseitigen; man hat nur nöthig, die Luftschicht zwischen Objectiv und Deckglas durch Wasser zu ersetzen. Die Messungen stimmen alsdann genau mit den wahren Werthen überein.

*) Ist $D$ die wirkliche und $d$ die scheinbare Niveaudifferenz, $a$ der Einfallswinkel und $\iota^{\prime}$ der grössere, Brechungswinkel, so erhält man

$$
\begin{aligned}
d & =\frac{\cos a^{\prime} \sin \omega}{\sin a^{\prime} \cos \theta} \cdot D \text { und } \\
D-d & =\frac{\sin c^{\prime}-c^{\prime}}{\cos c^{\sin \epsilon^{\prime}}} \cdot D .
\end{aligned}
$$




\section{Fünfter Abschnitt.}

\section{Das einfache Mikroskop und das Bildmikroskop.}

Das zusammengesetzte dioptrische Mikroskop nimmt heut zu 206 Tage unter allen optischen Hülfsmitteln, welche zur Beobachtung kleiner Gegenstănde benutzt werde̊n können, unstreitig den ersten Rang ein. Es ist das eigentliche Beobachtungsinstrument des Naturforschers, die Hauptwaffe des Mikroskopikers geworden. Der Wirkungskreis, welcher seinem früheren Nebenbuhler, dem einfachen Mikroskope, noch geblieben ist, wird von Jahr zu Jahr kleiner, und das Bildmikroskop je nach der Beleuchtungsart Sonnen-, Gas- oder photoelektrisches Mikroskop genannt hatte für die Wissenschaft von jeher so gut wie keine Bedeutung. Der Leser wird es unter diesen Umständen gerechtfertigt finden, wenn wir den genannten Apparaten nur eine rerhăltnissmässig kurze, nachträgliche Erörterung widmen.

\section{I.}

\section{Das einfache Mikroskop.}

A. Allgemeine Grundsätze.

Als einfaches Mikroskop ist im Grunde jede Linse oder Linsen-207 combination $z u$ betrachten, welche in der Weise Auwendung findet, dass das Auge das von derselben entworfene virtuelle Bild direct beobachtet. In der Praxis pflegt man indess nur die stärker vergrössernden Linsen oder Linsensysteme, welche zum bequemeren Gebrauch an einem Stativ befestigt sind, mit dem gedachten Ausdruck eines einfachen Mikroskops zu bezeichnen, wăhrend die schwảcheren Linsen, 
welche in freier Hand gehalten werden können, Loupen genannt werden. Es versteht sich übrigens von selbst, dass diese Unterscheidung eine ziemlich willkürliche sein muss, da man auch die Loupe nicht selten mit einem Gestelle vẹrsieht, mittelst dessen sie in die gewünschte Lage zum Object gebracht werden kann, und umgekehrt auch die stärkeren Systeme des einfachen Mikroskops zuweilen als Loupe in die Hand nimmt oder an einem gewöhnlichen Halter befestigt. Die übliche Benennung richtet sich also mehr nach der Form, welche man dem ganzen Apparat giebt, als nach seiner optischen Beschaffenheit.

208 Für die Theorie ist es natürlich vollkommen gleichgültig, ob die Vergrösserung stärker oder schwächer sei; das Zustandekommen eines scharfen Bildes ist in allen Fällen an die Bedingung geknüpft, dass die beiden Aberrationen für den gegebenen Objectabstand, der natürlich immer etwas kleiner ist, als die Brennweite, möglichst beseitigt seien. Die Herstellung einer guten Loupe oder eines einfachen Mikroskops ist daher genau mit denselben Schwierigkeiten verbunden, wie diejenige eines gewöhnlichen Objectivsystems von ungefähr gleicher Brennweite. Der Umstand, dass im ersteren Fall virtuelle Bilder, statt reellen, in Betracht kommen, macht die Sache weder leichter noch schwerer, obschon er natürlich berücksichtigt werden muss. Alles, was früher über die Verbindung von Flintglas- und Kronglaslinsen zu aplanatischen Systemen gesagt wurde, findet demzufolge auch hier ummittelbare Anwendung, und auch die Prüfung des optischen Vermögens und der rergrössernden Kraft kann in derselben Weise geschehen, wie beim zusammengesetzten Mikroskop. Es bleibt uns daher nur übrig, diejenigen Puncte noch besonders herrorzuheben, welche zum Verständniss des Strahlenganges unter den gegebenen Verhältnissen, die sich in mancher Beziehung von den früher betrachteten unterscheiden, wesentlich sind.

\section{Oeffnung der wirksamen Lichtkegel.}

209 Die Oeffnung der von den Objectpuncten einfallenden Strahlenkegel hängt bei einem gegebenen System von der Pupillenöffnung des beobachtenden Auges und von der Oeffnung der Blendungen ab. Ist $a b$ Fig. 125) das Object, $F$ die vordere und $F^{*}$ die hintere Brennebene, $E E^{*}$ das Hauptebenenpaar und $P$ die Pupille, dann ist der Durchmesser der letzteren für alle endlichen Entfernungen des virtuellen Bildes $a^{\prime} b^{\prime}$ offenbar immer etwas grösser, als der Durchmesser der Flächen, in welchen die optisch wirksamen Lichtkegel die Haupt- 
ebenen schneiden. Bei einer Mehrzahl von brechenden Flächen trifft demnach jeder einfallende Lichtkegel die erste derselben $\left\langle\boldsymbol{N}^{\mathbf{v}}\right\rangle$ in einem ganz kleinen Kreis, jede folgende in einem etwas.grösseren,

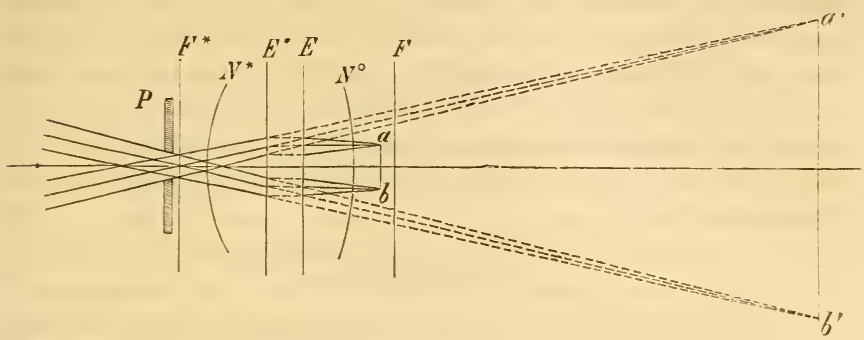

Figur 125 .

bis endlich sein Durchmesser demjenigen der Pupille annähernd gleichkommt. Die Lage dieses Kreises entspricht dem" betreffenden Objectpunct; sein Abstand ron der Axe nimmt mit dem Abstand des letzteren $a b$ und $z u$.

Ist das Auge auf unendliche Entfernung eingestellt und folglich der Durchschnitt der einfallenden Lichtkegel mit den Hauptebenen der Pupillenöffnung gleich, dann ist der Oeffnungswinkel w für die Mitte des Gesichtsfeldes, wie leicht einzusehen, durch die Formel bestimmt

$$
\operatorname{tang} \frac{(1)}{2}=r \cdot \frac{d}{2 f}
$$

worin $d$ den Pupillendurchmesser und $f$ die Brennweite bedeutet. Kleinere Oeffnungswinkel stehen also annähernd im umgekehrten Verhältniss zur Brennweite. Wird $d \mathrm{zu} 3^{\mathrm{m} \cdot \mathrm{m} \cdot}$ angenommen, so ergiebt die Rechnung beispielsweise folgende zusammengehörige Werthe:

\begin{tabular}{|c|c|c|c|c|c|c|c|}
\hline $\begin{array}{l}\text { Brennweite in } \\
\text { Millimetern }\end{array}$ & 2 & 3 & 4 & 5 & 6 & 10 & 12 \\
\hline Oeffnungswinkel & $73^{0} 44^{\prime}$ & $53^{0} \mathrm{~S}^{\prime}$ & $41^{0} 4^{\prime}$ & $33^{0} 2 t^{\prime}$ & $25^{0} 4^{\prime}$ & $17^{0} 4^{\prime}$ & $14^{0} 14^{\prime}$ \\
\hline
\end{tabular}

Mit diesen Werthen stimmen natürlich annähernd auch die überein, die man unter übrigens gleichen Voraussetzungen für eine endliche Sehweite von $100-250^{\mathrm{m}, \mathrm{m}}$. erhalten würde.

Befindet sich über der letzten Fläche des Systems eine Blendung, deren Oeffnung kleiner ist als die Pupille, so ist selbstverständlich 
die Grösse dieser Oeffnung maassbestimmend für die einfallenden Lichtkegel. Dasselbe gilt in gewissem Sinne auch für beliebige andere Blendungen, welche irgendwo zwischen die brechenden Flächen eingeschaltet werden; nur werden dadurch, wie man ohne Weiteres aus der Construction ersieht, zunächst die peripherischen Bündel ganz oder theilweise abgeschnitten, während die mittleren noch ungeschwãcht durchgehen. Solche Blendungen bedingen demnach die Grösse des Gesichtsfeldes und verschmälern vorzugsweise die Lichtkegel, welche ron den peripherischen Puncten desselben auf die Netzhaut gelangen.

\section{Lichtstärke.}

210 Wenn die optisch wirksamen Lichtkegel die Pupillenöffnung ganz ausfüllen, was für die mittleren Objectpuncte ein gewöhnlicher Fall ist, so besitzen sie nach der letzten Brechung, wodurch ihr Convergenzpunct in die Entfernung der Sehweite gerückt wird, selbstverständlich denselben Oeffnungswinkel, wie diejenigen Lichtbündel, welche das Auge bei unmittelbarem Sehen empfängt. Die Lichtstärke des virtuellen Bildes ist in diesem Falle (abgesehen von den durch Reflexion oder Absorption verursachten Verlusten) nahezu der Einheit gleich, d. h. die Gegenstände werden durch das einfache Mikroskop ungefähr so hell gesehen, wie mit dem unbewaffneten Auge. Genauer wird die resultirende Helligkeit, wie beim zusammengesetzten Mikroskop, durch dic Formel ausgedrückt:

$$
v=\left(\frac{\omega}{\rho m}\right)^{2}
$$

worin $v$ die Helligkeit, $\omega$ der Oeffnungswinkel des Systems, $\varrho$ der Oeffnungswinkel des unbewaffneten Auges für eine bestimmte Sehweite und $m$ die lineare Vergrösserungszahl für die nämliche Sehweite bezeichnet. Betrăgt $\varrho=1^{\circ}$, was z. B. bei einer Sehweite von $172^{\mathrm{m} . \mathrm{m}}$. und einer Pupillenöffnung von $3^{\text {m.m. }}$. der Fall ist, so vereinfacht sich obiger Ausdruck, wenn der Grad als Einheit genommen wird, in $\left(\frac{\omega}{m}\right)^{2}$. Da nun die Vergrösserungszahlen; wenn man die Sehweite vom hinteren Brennpunct an rechnet, sich wie die Tangenten der halben Oeffnungswinkel verhalten indem beide im umgekehrten Verhältniss zu den Brennweiten stehen, so folgt daraus, dass die Lichtstärke uın so kleiner ausfällt, je stärker die Vergrösserung. Einige Beispiele, in welchen die entsprechenden Wcrthe ron (1) und $m$ zusammengestellt sind, mögen diese Abnahme veranschaulichen. 


\begin{tabular}{|c|c|c|c|c|c|c|c|}
\hline Bremnweite & 12 & 10 & 6 & 5 & 4 & 3 & 2 \\
$m$ & 14,2 & 17,1 & 25,1 & 33,4 & 41,1 & 53,1 & 73,7 \\
$m$ & 14,3 & 17,6 & 25,6 & 34,4 & 43,0 & 57,3 & 56 \\
\hline
\end{tabular}

\section{Krümmung des Gesichtsfoldes.}

Die sogenamnte "Krümmung " des Gesichtsfeldes ist keineswegs 211 durch dieWölbung der Bildfäche, sondern durch die Ablenkung der ins Auge gelangenden Lichtbündel, resp. ihrer Axen, zu erklären. Hierüber gilt im Allgemeinen, was früher über die Ebcnung d's Gesichtsfeldes und die Wirkung der Ocularlinse gesagt wurcle. Die specielle Anwendung jener Betrachtungen auf die Cylinderloupe, dis Doublet etc. ist un so leichter, als der Terlauf der einfallenden und ausfahrenden Strahlenbündel fast genau derselbe ist, wie beim Ramsden'schen Ocular. Der Convergenzpunct der ausfahrenden Büıdel ist durch die Lage des beobachtenden Auges bestimmt; derselbe rerhält sich aber zum Kreuzungspunct der rückwärts rerlängerten einfallenden, wie ein Object zu seinem Bild, und kann daher immer so gewählt werden, dass der letztere, wie beim Ocular, um c. $200^{\mathrm{m} . \mathrm{m}}$. von den brechenden Flächen absteht. Die Uebereinstimmung ist alsdann cine rollkommene.

Um die Verzerrung des Bildes zu beseitigen, handelt es sich al=o 212 in allen Fällcn darum, die brechenden Flächen so zu combiniren, diss sie ein für die gegebenen Vereinigungswciten, d. h. für die Abstände der genannten Kreuzungspuncte, möglichst aplanatisches System bilden. Die Wölbung der Bildfläche ist hieron unablängig; sie rührt daron her, dass die Objectpuncte nicht gleich weit von den brechenden Flächenelementen abstehen.

\section{Die Vergrösserungszahl.}

Die Vergrösserungszahl ist durch die bekannte Formel gegeben: $m=\frac{f-p^{*}}{f}$ oder, da $p^{*}$ hier negativ ist, $m=\frac{f+p^{*}}{f}$. Da nun $p^{*}$ ron der hinteren Hauptcbene an gerechnet werden muss, so ist einleuch. tend, dass die Vergrösserung bei gegebener Sehweite um so geringer ausfällt, je weiter das Ange von dieser Hauptebene oder überhaupt rom Linsensystem absteht. Daher ist cs im Allgemeinen Regel, das Auge so nah als möglich an die letzte brechende Fläche zu halten. 


\section{Die Grösse des Gesichtsfeldes.}

213 Die Grösse des Gesichtsfeldes hängt bei einen gegebenen Linsensystem ron der Oeffnung der Linsen und der Lage des beobachtenden Auges ab. Je grösser der Abstand des letzteren, um so kleiner ist das Gesichtsfeld. Ist wieder $N^{0}$ (Fig. 126) die erste und $N^{\prime}$ die letzte brechende Fläche des Systems, dessen Haupt- und Brennebenen in gewohnter Weise bezeichnet sind, und ist die Oeffnung desselben

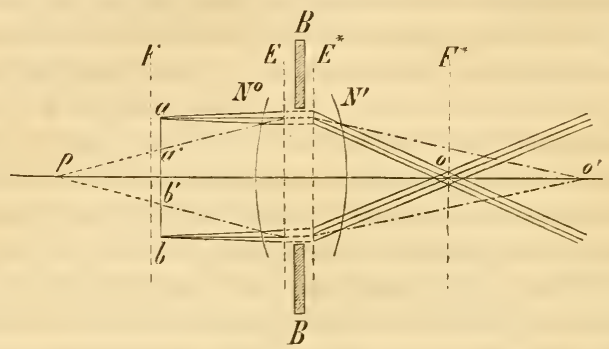

Figur 126.

durch die Blendungen oder Fassungen $B B$ bestimmt, so übersieht ein in $o$ befindliches Auge das Object $a b$ in seiner ganzen Ausdehnung, weil alle parallel mit der Axe einfallenden Lichtbündel nach o gebrochen werden. Befindet sich dagegen das Auge in $o^{\prime}$, so können nur Lichtbündel dahin gelangen, welche unter sich divergiren, so zwar, dass ihr Convergenzpunct $p$ sich zu $o^{\prime}$ verhält, wie ein Object zu seinem Bild. Das Gesichtsfeld wird daher nothwendig kleiner, als die Oeffnung des Systems; die äussersten Puncte, welche noch wahrnehmbar bleiben, sind $a^{\prime}$ und $b^{\prime}$. Eine noch grössere Entfernung des Auges müsste natürlich auch eine stärkere Divergenz der einfallenden Lichtbündel und daher eine weitere Verkleinerung des Gesichtsfeldes zur Folge haben, während umgekehrt eine grössere Annäherung eine Vergrösserung des Gesichtsfeldes bedingen würde. Dass das letztere überdiess von der Oeffnung der Linsen abhängt und durch kleinere Blendungen reducirt wird, ist an und für sich klar.

\section{B. Die optische Einrichtung.}

214 Wir gehen jetzt zur Aufzählung der bekannteren Formen über, welche man in neuerer Zeit der Loupe und dem einfachen Mikroskop gegeben hat. Die Bemühungen des verflossenen Jahrhunderts mit zu besprechen liegt ausserhalb unserer Aufgabe; wir verweisen in diesem 
Betreff, wie überhaupt in Bezug auf die Geschichte des Mikroskops, auf das ausführliche Werk von Harting.

Brewster kam zuerst auf den glücklichen Gedanken, durch Einschleifen einer ziemlich tiefen Rinne in eine Glaskugel (Fig. 127) eine Loupe herzustellen, welche beinahe vollkommen aberrationsfreie Bilder liefert. Coddington erleichterte deren Herstellung, indem er der Rinne eine schärfere Form (Fig. 12S) gab und die beiden Hälften der Kugel getrennt aus geeigneten Stücken planconvexer Linsen anfertigte, welche nachher mit ihren ebenen Flächen zusammengekittet wurden. Auf die Form der Rinne kommt es übrigens nicht an,

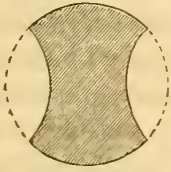

Figur 127.

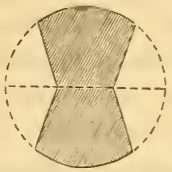

Figur 12s.

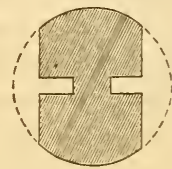

Figur 129.

und es ist einleuchtend, dass die in Fig. 129 dargestellte Construction

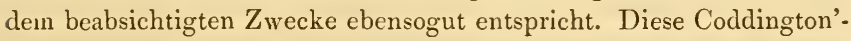
schen Loupen (auch Coneopside oder Vogelaugenlinsen genannt), wie sie Lerebours in Paris in den Handel brachte, fanden allgemein eine beifällige Aufnahme; sie geben nach Mohl eine mehr als 20 fache Vergrösserung und sind aller Empfehlung werth. Dieselben leiden indess an zwei Unvollkommenheiten, welche bei manchen Untersuchungen sehr nachtheilig sind; das Gesichtsfeld ist nämlich sehr beschränkt und der Abstand des Focus von der unteren Fläche nur ungefähr 1/4 des Kugeldurchmessers. Wo es sich daher um den Ueberblick eines grösseren Gegenstandes handelt, was in der Praxis der häufigste Fall ist, sind die neueren aplanatischen Linsencombinationen vorzuziehen. - Coddington'sche Loupen, aus einem einzigen Glascylinder gefertigt, sind im neuesten Preisverzeichniss von $\mathrm{Na}$. chet zu 5 Fr. angesetzt.

Mit den eben genannten sind auch die $\mathrm{C} y$ linderloupen rerwandt, welche namentlich in Deutschland seit längerer Zeit Terbreitung fanden. Dieselben bestehen aus einem cylindrischen Stück Glas, dessen beide Endflächen convex geschliffen, jedoch zur Verminderung der Aberration ungleich gekrümmt sind (Fig. 130\%. Gewöhnlich wird die schwächere Krümmung dem Object zugewendet. Die Cylinderloupen liefern etwas weniger voll-

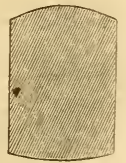

Fig ur 130. 
kommene Bilder, als die Coddington'schen, und sind wie diese mit dem Nachtheil einer kurzen Focaldistanz behaftet; dessenungeachtet müssen sie immer noch zu den besten und wohlfeilsten Loupen gezählt werden. Kehrt man die stärkere Krümmung dem Objecte zu, so gewinnt man dadurch einen grösseren Objectabstand; allein die Aberrationen sind in dieser Stellung merklich grösser und folglich die Bilder weniger scharf.

215 In neuester Zeit, etwa seit 1530 , kamen die aus zwei oder drei Planconvexlinsen bestehenden Systeme, die sogenannten Doublets und Triplets, mehr in Aufschwung. Zwar hatten sich schon frühere Optiker, namentlich Euler und John Herschel, vielfach mit solchen Linsencombinationen beschäftigt; allein bei der Unmöglichkeit, den Ergebnissen der Rechnung beim Schleifen der Linsen Genüge zu leisten, waren die theoretisch wohl begründeten Ansichten ron geringer praktischer Bedeutung. Wollaston war der erste, welcher die Schärfe des Bildes mehr durch den relativen Abstand der Linsen, den er durch den Versuch bestimmte, als durch die genaue Form derselben, zu steigern verstand. Seine Doublets bestehen aus zwei mit der ebenen Fläche nach unten gewendeten Planconvexlinsen, deren Brennweiten sich ungefähr wie $3 \mathrm{zu} 1$ verhalten und welche so übereinander geschraubt sind, dass der Abstand der ebenen Flä:hen c. 1,5 der kürzeren Brennweite (Fig.

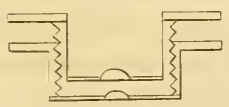

Figur 131.

131 ; beträgt. Der Beifall und die Aufmerksamkeit, welche diese Doublets erregten, führten bald zu weiteren Verbesserungen.

Pritchard fand, dass die günstigste Entfernung der beiden Linsen der Differenz ihrer Brennweiten gleich sei, dass aber diese letzteren innerhalb gewisser Grenzen z. B. zwischen dem Verhältniss $1: 3$ und $1: 6$ variiren können. Er verfertigte Doublets, deren Leistungen nach Mohl in Hinsicht auf Klarheit und Schärfe des Bildes bis zu einer Tergrösserung ron c. 200 Mal überraschend sind, und woron die schwächeren sich ganz besonders dazu eignen, um unter ihnen zu präpariren. Die stärksten, welche etwas über $300 \mathrm{Mal}$ vergrössern, lassen die 6te Gruppe der Nobert'schen Probetäfelchen noch deutlich erkennen.

Chevalier stellte zwei planconvexe Linsen

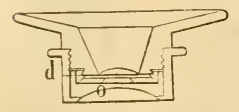

Figur 132. ron gleicher Brennweite, aber ungleicher Grösse Fig. 132) sehr nahe und zwar so übereinander, dass die grösscre dem Object zugekehrt war. Zwischen beiden befand sich ein Diaphragma $d$ 
mit der Oeffnung $o$. Chevalier erzielte dadurch eine grössere Lichtstärke und zugleich einen grösscren Abstand des Objects von der ersten brechenden Fläche. Um diesen Abstand bei schwächeren Vergrösserungen, wie sie zum Präpariren auf dem Objecttisch benutzt werden, noch mehr zu steigern, brachte er über dem Doublet eine achromatische Concarlinse, an, welche nicht bloss dem beabsichtigten Zweck entspricht, sondern auch die Vergrösserung etwas verstärkt, - eine Einrichtung, welche späterhin auch $\mathrm{Brücke}$ ) für seine achromatische Stativloupe (Fig. 133) benutzte.

Die Doublets von Chevalier halten den Pritchard'schen, nach den Beobachtungen Harting's zu schliessen, so ziemlich die $W$ age. Bei einer 45 maligen Vergrösserung waren auf dem Nobert'schen Probetäfelchen die Striche der ersten Gruppe, bei einer 317 maligen die der 6ten Gruppe erkennbar.

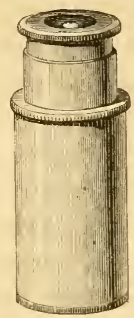

Figur 133.

Die beiden genannten Optiker verfertigten überdiess auch Triplets, deren Construction im Wesentlichen auf dem nämlichen Princip beruht. Dieselben bestehen aus drei planconvexen Linsen von rerschiedener Brennweite und geben, wenn auf die Herstellung die nöthige Sorgfalt verwendet wird, noch etwas schärfere Bilder, als die Doublets.

Es lässt sich nicht läugnen, dass die Wollaston'sche Idee, das 216 Hauptaugenmerk auf die relativen Abstände der Linsen zu richten, für die praktische Optik eine höchst glückliche war und in einem Zeitraum ron wenigen Jahren zu wesentlichen Verbesserungen führte. Das Doublet erreichte einen Grad der Tollkommenheit, welcher auch gegenwärtig noch in manchen praktischen Fällen rollkommen genügt. Allein die besten Combinationen dieser Art leiden doch immer in sehr erheblichem Grade an mangelhafter Verbesserung der sphärischen und insbesondere der chromatischen Aberration ${ }^{*}$ ), was natür-

*) Sitzungsberichte der k. k. Akad. zu Wien 1551. Bd. VI. p. 554. - Wir finden diese Brücke'sche Loupe nur in den Preisverzeichnissen von $\mathrm{Nachet}$, $\mathrm{Schiek}$ und Belthle besonders angefüht. Obige Figur ist dem Katalog von Nachet entnommen.

-.) Die chromatische Aberration durch eine Verbindung von 2 oder mehreren planconvexen Linsen $\mathrm{zu}$ beseitigen, ist principiell unmöglich; durch richtige Wahl der relativen Abstände wird höchstens der Parallelismus der rothen und violetten Strahlenbündel, resp. ihrer Axen, hergestellt, wie diess bereits bei Besprechung der Oculare erörtert wurde. Eine Kreuzung der optisch wirksamen 
lich um so fühlbarer wird, je stärker die Vergrösserung. Sie stehen daher den neueren achromatischen Systemen hinsichtlich des optischen Vermögens entschieden nach. Ihre praktische Verwendbarkeit beschränkt sich gegenwärtig fast nur noch auf die Loupe und das Präparirmikroskop, wo sie bis zu einer Vergrösserung von circa $60-$ $100 \mathrm{Mal}$ in der That auch ganz brauchbar sind; allein es fragt sich, ob sie nicht auch auf diesem Felde den aplanatischen Systemen mit der Zeit weichen müssen, da diese letzteren bereits bis zu den schwächsten Vergrösserungen von circa 5-10 Mal vielfach in Gebrauch sind.

217 Zur Vergleichung der Leistungen neuerer Doublets und Loupen theilen wir nachstehend einige Beobachtungen mit, welche in derselben Weise, wie bei der Prüfung des zusammengesetzten Mikroskops, angestellt wurden. Die Brennweiten und Objectabstände (für die Cylinderloupen die den beiden Stellungen entsprechenden) sind in Millimetern angegeben.

\begin{tabular}{|c|c|c|c|c|c|c|c|}
\hline & $\begin{array}{l}\text { Bezeich- } \\
\text { nung. }\end{array}$ & 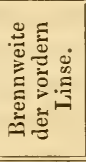 & 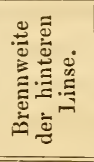 & 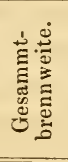 & 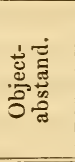 & 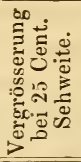 & 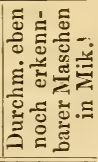 \\
\hline $\begin{array}{c}\text { Z e is s } \\
" \\
" \\
\text { Bé n"e che } \\
" \\
n\end{array}$ & $\begin{array}{c}30 \\
60 \\
120 \\
\text { Triplet } \\
\text { Loupe } \\
\text { Nr. 1 } \\
\text { Nr. 2 } \\
\text { Nr. 3 } \\
\text { Cylinder- } \\
\text { loupe. } \\
\text { Cylinder- } \\
\text { loupe. } \\
\text { Loupe. }\end{array}$ & $\begin{array}{c}12,2 \\
5,2 \\
2,53 \\
0,92 \\
40 \\
23,25 \\
5,09 \\
5,22 \\
- \\
- \\
-\end{array}$ & $\begin{array}{c}17 \\
5,5 \\
4,25 \\
2,3 ; 3,7 \\
35 \\
23,25 \\
23,25 \\
11,75\end{array}$ & $\begin{array}{c}7,3 \\
3,78 \\
1,72 \\
0,73 \\
21 \\
12,5 \\
6,65 \\
3,93 \\
15,5 \\
14 \\
44\end{array}$ & $\left.\begin{array}{c}5,3 \\
2 \\
- \\
\overline{11} \\
8,5 \\
3,5 \\
2,5 \\
8,5 \\
10 \\
6 \\
5 \\
39\end{array}\right\}$ & $\begin{array}{r}33 \\
64 \\
140 \\
330 \\
12 \\
19 \\
36 \\
62 \\
13,5 \\
15 \\
4,5\end{array}$ & $\begin{array}{c}3,55 \\
2,3 \\
1,3 \\
0,7 \\
17 \\
6,7 \\
3,5 \\
2,3 \\
16 \\
12 \\
32\end{array}$ \\
\hline
\end{tabular}

Wie man aus dieser Zusammenstellung ersieht, leisten die Doublets von $Z$ eiss und Bénèche ungefähr so viel, als ein zusammen-

Strahlenbündel zwischen den brechenden Flächen findet nicht statt. In dieser Beziehung ist die Darstellung $\mathrm{H}$ a r'ting's (Mikr. p. 113 u. Fig. VIII der beigegebenen 'Tafel) durchaus unrichtig, weil der von ihm angenommene Strahlenverlauf für das beobachtende Auge nicht existirt. Wie sollten auch die austretenden Lichtbündel, wenn sie so stark divergiren, wie in der citirten Figur, durch eine Pupille ron 2-3m.m. Durchmesser auf die Netzhaut gelangen? 
gesctztes Mikroskop mit gleich starker Gesammtvergrösserung. Das Triplet von $\mathrm{Z}$ eiss hält sogar den Objectiven Nr. 7 ron Hartnack und Nr. 9 von Bénèche das Gleichgewicht; es zeigt auch die Querstreifen von Pleurosigma attenuatum bei geradem Licht mit wenigstens gleicher Deutlichkeit. Doch gilt das alles nur für den Fall, dass das Object genau in die Mitte des Gesichtsfeldes gebracht wird; in jeder anderen Lage ist das Bild unbrauchbar. Dazu kommt, dass das Sehen durch eine kleine Blendung von nur 0,7 m.m. Durchmesser, wie sic Zeiss bei seinen Triplets sowohl als bei den stärksten Doublets über den Linsen anbringt, sehr bald ermüdet. Die Preise betreffend, so sind zwar die Doublets beträchtlich billiger, als achromatische Objective; sie werden von Zeiss zu 2-3 Thlr., Triplets von 200300 facher Vergrösserung zu 6-S Thlr. geliefert, während ein Objectivsystem immerhin doppelt so viel kostet. Allein ein vollständig ausgestattetes einfaches Mikroskop kommt dessenungeachtet auf 26 Thlr. (bei Plössl auf 59 fl. österr. W.) zu stehen, welche Summe gerade ausreicht, um sich ein kleines zusammengesetztes Mikroskop von $\mathrm{B}$ a a der zu kaufen.

\section{Die mechanische Einrichtung.}

Ueber die Fassungen der Linsen und Linsensysteme, sowie fer-21S ner die Torrichtungen, welche zu ihrer Befestigung dienen, können wir uns kurz fassen, da in diesem Punct jedes namhafte optische Institut allen Anforderungen, die man billiger Weise stellen kann, genügt. Es rersteht sich von selbst, dass der Beobachter unter den mancherlei Formen und Einrichtungen, welche käuflich zu haben sind, sich diejenige auszuwählen hat, welche dem Gebrauche, den er daron zu machen beabsichtigt, am besten entspricht. Wer ganz spe-

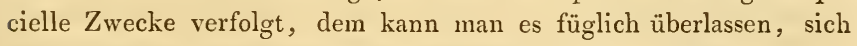
einen geeigneten Apparat selbst auszudenken und herzustellen.

Die Loupenträger, welche in mikrographischen Werken beschrieben sind, stimmen alle darin überein, dass sie mit einem beweglichen, oft mit Gelenken versehenen Arm ausgestattet sind, welcher auf einem Kästchen oder an einer senkrechten Stange dergestalt befestigt ist, dass sein freies Ende, welches die Loupe trägt, durch Drehen oder Verschieben in jede beliebige Lage gebracht werden kann. Eines der zweckmässigsten Gestelle dieser Art, das in den meisten Fällen ein complicirteres Stativ ersetzt, scheint uns das von Mohl (Mikr. p. 35̃) empfohlene zu sein. Es ist ein Kästchen von etwa 1520 Centimeter Länge auf $\delta$ Centimeter Breite und Höhe, welches auf 
der dem Fenster zugewendeten Seite offen ist und einen Planspiegel enthält, der mittelst eines auf der rechten Scite hervorragenden Kno-

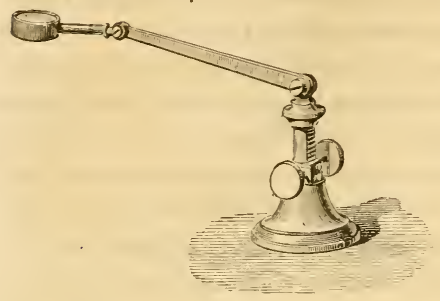

Figur 134 . pfes um eine horizontale Axe gedreht werden kann. Auf der oberen Seite ist eine durch eine Glasplatte $\mathrm{zu}$ verschliessende Oeffnung angebracht; ein mit zwei Charniergelenken versehener, am Kästchen angeschraubter Arm trägt die Loupe. - Ein einfacher Loupenträger neuester Construction, wie ihn Nachet zu 15 Fr.

und ohne Trieb zu S Fr. liefert, ist in Fig. 134 dargestellt.

Das Stativ des cinfachen Mikroskops lässt natürlich ebenfalls mannigfache Modificationen zu. Die Haupterfordernisse, welche der Optiker in Auge zu behalten hat, sind etwa folgende: 1j ein feststehender, nicht zu kleiner Objecttisch, auf welchem eine Klemmfeder oder eine andere geeignete Vorrichtung zum Festhalten der Objectträger anzubringen ist; 2) ein Fussgestell, welches den Händen während der Zergliederung auf dem Objecttisch einen bequemen Stützpunct bietet; 3 ) eine passende Vorrichtung zur scharfen Einstellung, wobei die Linse gegen das Object und nicht umgekehrt dieses gegen jene beweglich sein soll; 4 ein zweckmässiger Beleuchtungsapparat, welcher nöthigenfalls Lichtkegel zu liefern rermag, die die Oeffnung des Linsensystems oder die Pupille des beobachtenden Auges ganz ausfüllen.

219 Die Einzelnheiten der Einrichtung können wir um so eher mit Stillschweigen übergehen, als das Urtheil hierüber in den meisten Puncten doch nur ron Liebhaberei und Gewohnheit abhängt, also ein rein individuelles ist. Wir beschränken uns darauf, einige der bckannteren Stative in Kürze zu beschreiben und durch Abbildungen zu veranschatilichen; der Leser mag Lob oder Tarlel nach eigenem Ermessen selbst hinzufügen .

Karl Zeiss in Jena gicbt scinen einfachen Mikroskopen, die schon seit Jahren rühmlich-t bekannt sind, einen ziemlich schweren Holzfuss, der beiderscits eine herrorragende Backe zum Auflegen der Hände besitzt (Fig. 135). Ueber dem Beleuchtungsspiegel ist eine Convexlinse angebracht, welche seitlich verschoben werden kann. Der Tisch ist feststchend und dic Einstellung doppelter Art. - 
A'sserdem verfertigt Zeiss auch etwas complicirtere Stative, die auch für schiefe Beleuchtung eingerichtet sind.

Bénèche in Berlin führt ein ähnliches Stativ, bei welchem die gröbere Einstellung durch Auf- und Niederbewegung des Linsenarmes, die feinere durch Mikrometerbewegung nach Nobert geschieht; ferner ein etwas anders construirtes, mit flachem zum 'Transport bequemen Kasten als Fuss und einem Triebwerk zur groben und feinen Einstellung. Mit diesem letzteren stimmt im Wesentlichen auch das einfache Mikroskop von Schiek in

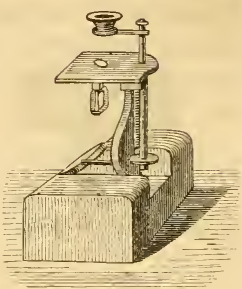

Figur 135. Berlin überein.

Das Stativ von Sim on Plössl in Wien (Fig. 136) hat eine dreiseitige Stange $a$ von 10 Centimeter Höhe, in deren hintere Seite die Süge für den 'Trieb $c$ eingelassen ist. Als Fussgestell dient ein kleiner Kasten, auf dessen Deckel die Mikroskopsäule aufgeschraubt wird. Der Objecttisch $b$ ist viereckig und wird durch den Trieb gegen die feststehende Linse $e$ bewegt; auf seiner obern Seite ist eine hufeisenfurmige Federklammer angebracht, welche durch eine Spiralfeder nach unten gezogen wird. Zur Beleuchtung dient ein Concarspiegel $f$ ron 2,5 Centimeter Durchmesser. - Eine ähnliche Einrichtung besitzt auch das cinfache Mikroskop ron $\mathrm{K}$ örner in Jena.

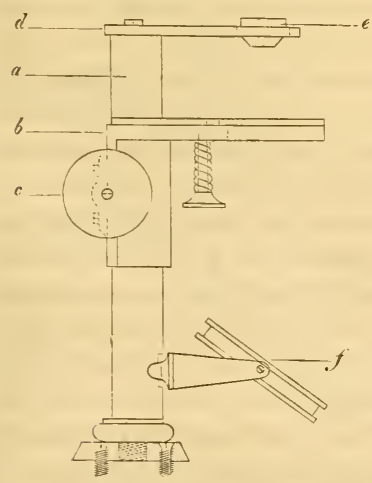

Figur 136.

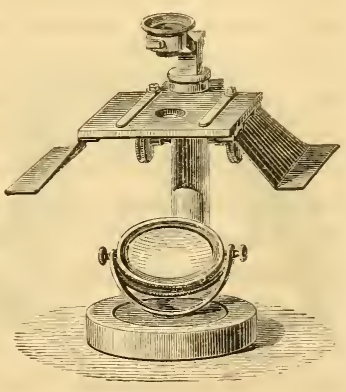

Figur $13 \%$.

Das Disscctionsmikroskop ron $\mathrm{N}$ a chet $\mathrm{und} \mathrm{Sohn}$ in Paris ist 220 in Fig. 137 dargestellt. Die Einstellung geschiieht durch ein Getriebe, 
welches die Linsen auf und nieder bewegt. Zwei am Objecttisch angebrachte Flügel dienen zum Auflegen der Hände während des Präparirens. - Auf Verlangen wird diesem Instrument noch ein

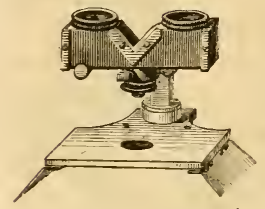

Figur 135 . binoculärer Apparat (appareil binoculaire de dissection, Fig. 138) beigegeben, welcher stereoskopische Bilder liefcrt.

Unter der grossen Anzahl ron Stativen, welche ron englischen Optikern ausgeführt werden, wollen wir hier nur zwei ihrer $\mathrm{Ei}$ genthümlichkeit wegen hervorheben, das eine mit sehr einfacher, das andere mit sehr complicirter Einrichtung. Einfach und zweckmässig ist das Taschenund Dissectionsmikroskop ron Quekett Fig. 139) zu nennen. Dasselbe hat, wenn es eben gebraucht wird, die Form eines quadratischen Schemels mit keilförmigen Seitentheilen, wclche das Fussgestell bilden. Diese Füsse sind durch Charniergelenke mit der Objectplatte verbunden und können nach Wegnahme des Spiegels nach innen zusammengeschlagen werden, so dass sie einander decken. Auf ihrer Innenseite und auf der Unterseite des Tisches befinden sich Ausschnitte, welche zur Aufnahme des Spiegels und der Linsen dienen. Ist das Instrument zusammengelegt, so beträgt seine Höhe circa $40^{\mathrm{m} \cdot \mathrm{m}}$, seine Länge und Breite circa 14 Centimeter.

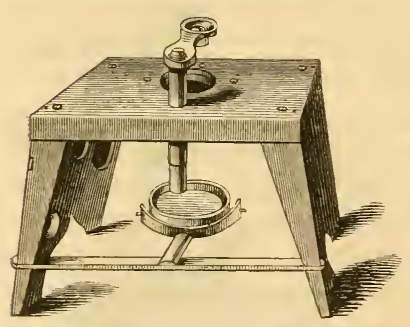

Figur 139.

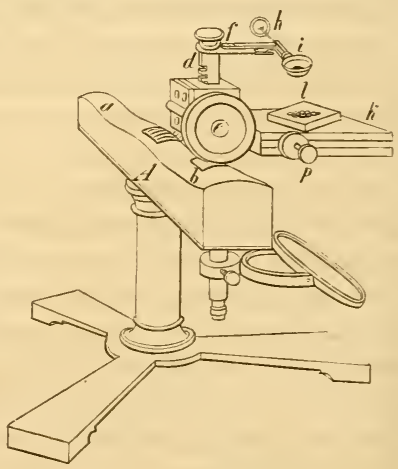

Figur 140.

Als Beispiel eines complicirten Stativs mag hier dasjenige ron Pritchard in London (welches übrigens noch keineswegs zu den complicirtesten gehört) Erwähnung finden. Dasselbe hat einen schweren Dreifuss mit fester, runder Messingsäule Fig. 140, womit dic 
übrigen Thcile des Instruments verbunden sind. Auf der Säule ruht ferner cin Holzkolben $A$, welcher zum Auflegen der Hände bestimmt und zu diescm Ende beiderseits bei $a$ und $b$ etwas ausgehöhlt ist. Der viereckige Objecttisch $k$ hat einen durch zwei hervorragende Knöpfe$p$ verschiebbaren Schlitten und trägt ein kleines Kästchen $l$ mit Glasboden, in welches die zu präparirenden Objecte kommen. Die Einstellung geschicht durch Hcbung oder Senkung des Linsenarmes $f$ mittelst Zahn und T'rieb $(l$ und $e)$. Der Linsenarm selbst ist in einer horizontalen Ebene drehbar und am Ende $l \iota$ zum Ueberfluss mit cinem Kugelgelenk versehen, wodurch sein vorderes Endc, das die Linsen $\dot{r}$ trägt, nach allen Richtungen beweglich wird.

Die übrigen Gestelle, welche in England verfertigt werden, stimmen entweder mit den bereits beschriebenen in der Hauptsache überein oder sind zu complicirt, als dass sie in Deutschland Verbreitung finden könnten.

II.

\section{Das Bildmikroskop.}

Was nun noch die Bildmikroskope betrifft, so brauchen wir22 I hierüber nicht viel Worte zu machen. Die einzige Bedeutung, die sie wenigstens indirect für die Wissenschaft haben, besteht darin, dass sie das vergrösserte Bild eines Gegenstandes vielen Zuschauern auf einmal vorzuführen gestatten, was allerdings bei Vorlesungen ror einem grösseren Publicum ein nicht unerheblicher Vorzug ist. Ihre Anwendbarkeit beschränkt sich indess auch hiebei rorzugsweise auf Objecte, welche mit dem zusammengesetzten Mikroskop schon bei schwächerer Vergrösserung deutlich gesehen werden; feinere Structurverhältnisse, welche stärkere Objective erfordern, werden im Bilde nicht scharf genug wiedergegeben, um sie Unkundigen demonstriren zu können. Es gilt diess namentlich für den Fall, dass die Bẹleuchtung durch elektrisches Licht oder durch das Drummond'sche Kalklicht vermittelt wird, welche beide dem directen Sonnenlicht an Intensität bedeutend nachstehen. Ueberdiess ist der Gebrauch des Instruments mit mancherlei Umständlichkeiten verknüpft, welche den praktischen Werth desselben wesentlich beeinträchtigen. Wir halten desshalb gute Abbildungen zum Zwecke der Demonstration immer noch für geeigneter, als die verschwommenen Bilder eines elektrischen oder Gasmikroskops. 
Die Objective der Bildmikroskope haben genau dieselbe Einrichtung, wie die der zusammengesetzten Mikroskope; nur werden die Flint- und Kronglaslinsen gewöhnlich nicht mit Canadabalsam zusammengekittet, weil dieses Verbindungsmittel durch die Wärme, welche die Beleuchtung verursacht, getrübt werden könnte. Indessen bemerkt Mohl, dass er gewöhnliche Objective ohne Schaden im Sonnenmikroskop angewendet und dass auch Plössl ihm geschrieben habe, er hätte nicht gefunden, dass das Zusammenkitten Schaden verursache.

Die mechanische Einrichtung des Beleuchtungsapparates ist natürlich je nach der Lichtquelle, die man benutzt, verschieden. Wir glauben indess auf eine Beschreibung derselben um so eher verzichten zu dürfen, als die in neuerer Zeit gebräuchlichen Apparate in jedem vollständigeren physikalischen Lehrbuch in Kürze besprochen sind und eine ausführliche Auseinandersetzung derselben, die jedenfalls mit zahlreichen Abbildungen begleitet sein müsste, um verständlich zu sein, nicht in unserer Aufgabe liegt. 


\section{Sechster Abschnitt. Mikroskopische Technik.}

I.

\section{Der Gebrauch des Mikroskops.}

Es liegt in der Natur der Sache, dass die mancherlei Regeln 222 und Kunstgriffe, deren Kenntniss die mikroskopische Beobachtung: vorausseszt, sich immer am leichtesten durch die praktische Unterweisung lehren und lernen lassen, und dass auch hiebei die eigene Uebung, die der Anfänger sich nach und nach erwirbt, stets die Hauptsache bleibt. Eine Anleitung durch das geschriebene Wort, wie wir sie hier zu bieten versuchen, scheint uns aber trotzdem nicht ganz überflüssig, da sie Denjenigen, welche jene praktische Schule in ungenügender Weise oder gar nicht genossen haben, immerhin einigen Ersatz gewähren und manchen Missgriff ersparen wird. Alles, was sich auf specielle Untersuchungen aus dem Gebiete der Anatomie, Morphologie etc., auf die Anwendung der Reagentien u. dgl. bezieht, glaubten wir indess zweckdienlicher für die betreffenden Kapitel aufzusparen, so dass uns hier nur einige allgemeinere Fragen zur Besprechung übrig bleiben.

\section{Die Beleuchtung.}

Für jede mikroskopische Untersuchung ist zunächst eine günstige 223 Beleuchtung ron Wichtigkeit. Da dieselbe zum Theil ron der Lage des Arbeitszimmers abhängt, so ist die Wahl des letzteren wo möglich so zu treffen, dass ein grösserer Theil des Himmels als Lichtquelle benutzt werden kann, ohne dass directes Sonnenlicht mit wirksam würde. Am geeignetsten ist natürlich ein Local mit Nordlicht und freier Aussicht, oder ein nach zwei Seiten mit Fenstern versehe- 
nes Eckzimmer, in welchem alsdann je nach dem Stand der Sonne die eine oder andere Seite in Gebrauch kommt. Reflectirtes Licht von gegenüberliegenden Gebäulichkeiten kann zwar unter Umständen ganz brauchbar sein, doch beschränkt sich seine Anwendbarkeit im günstigsten Fall auf bestimmte Tageszeiten. Desshalb sind in den Strassen der Städte die oberen Stockwerke der Häuser, welche die Strahlung des hellen Himmels bis in die Nähe des Horizontes zu verwerthen gestatten, vorzuziehen und Parterrewohnungen in engen Gassen gänzlich zu vermeiden.

Der zur Beleuchtung günstigste Zustand des Himmels ist nach unserem Darfürhalten eine gleíchmässige hellgraue Bewölkung; das reine Blau gibt zwar ebenfalls ein ganz angenehmes Licht, ist jedoch für die stärksten Objective nicht intensiv genug, um ihre ganze Kraft zu entwickeln. In schwierigeren Fällen leistet daher bei klarem Himmel eine weisse oder gelblichweisse, von der Sonne beschienene $W$ and bessere Dienste. Am ungünstigsten sind rasch vorüberziehende helle Wolken, weil das Auge bei dem fortwährenden Wechsel der Helligkeit und Farbe rasch ermüdet. Ebenso ist das blendende Licht, welches von der unmittelbaren Umgebung der Sonne ausgeht, zu vermeiden, oder wenn kein besseres zur Verfügung steht, durch Vorziehen weisser Rouleaux oder Gardinen zu dämpfen.

224 In Betreff der Aufstellung des Mikroskops findet man gewöhnlich angegeben, eine Entfernung von $6-9$ Fuss vom Fenster sei in schwierigen Fällen der gewöhnlichen von c. 3 Fuss vorzuziehen, weil dadurch ein günstigerer Lichteffect erzielt werde. Nach dem, was oben über dịe Beleuchtung mitgetheilt wurde, kann jedoch die Entfernung vom Fenster offenbar nur dann von irgend einem Einfluss sein, wenn dadurch die Oeffnung des einfallenden Lichtkegels bedingt wird, was bei Anwendung kleiner Blendungen, wie man sie gewöhnlich für stärkere Vergrösserungen gebraucht, nicht der Fall ist. Wendet man schiefes Licht an, so muss unter allen Umständen, die Entfermung mag grösser oder kleiner sein, dafür gesorgt werden, dass das vom Tisch und Stativ reflectirte Licht abgehalten wird, was am besten durch besonders hiefür bestimmte Blendungen mit seitlichen Oeffnungen oder auch durch seitliche Verschiebung der Blendungsöffnungen geschieht. Ebenso nothwendig ist bei manchen Untersuchungen der Ausschluss des von oben auf das Object einfallenden Lichtes, sei es nun durch Vorhalten der Hand oder mittelst eines Schirmes, weil dasselbe sowohl die Annehmlichkeit, als auch die 
Sicherheit der Beobachtung beeinträchtigt. Kurz, die Beleuchtung muss in allen schwierigen Fällen so regulirt werden, dass ausser dem einfallenden Lichtkegel von bestimmter Oeffnung und Neigung kein anderes Licht das Gesichtsfeld erreicht.

Welche Oeffnung oder Neigung des einfallenden Lichtkegels die günstigste sei, muss natürlich in jedem gegebenen Falle durch Probiren ermittelt werden. Man dreht oder verstellt den Spiegel und nöthigenfalls das ganze Instrument, indem man gleichzeitig durchs Ocular sieht, nach verschiedenen Richtungen und beobachtet dabei die Wirkung grösserer und kleinerer Blendungen oder bewegt dieselben, wenn die Einrichtung des Stativs diess gestattet, in der Richtung der Axe auf und nieder. Diese Versuche setzt man fort, bis man die günstigste Art der Beleuchtung ermittelt hat. Als Regel gilt im Allgemeinen, dass Streifungen, Liniensysteme u. dgl. am deutlichsten hervortreten, wenn das Licht möglichst schief darauf einfällt, wobei unter allen Umständen die gegenseitige Stellung von Spiegel und Object so gewählt werden muss, dass die Richtung der einfallenden Strahlen auf den Streifungen senkrecht steht.

$\mathrm{Da}$ die Lichtquelle in den meisten praktischen Fällen eine begrenzte oder ungleichmässig leuchtende ist, so liefert der Concavs piegel aus früher angegebenen Gründen in der Regel ein intensiveres Licht als der Planspiegel, d. h. er bedingt bei gleicher Oeffnung des einfallenden Lichtkegels eine grössere Helligkeit des Gesichtsfeldes. Bei starken Vergrösserungen bietet daher der Concavspiegel entschiedene Vortheile; bei schwächeren kann man des Guten auch leicht $\mathrm{zu}$ viel thun, weil ein $\mathrm{zu}$ grell erleuchtetes Gesichtsfeld die Augen angreift und rasch ermüdet. Die Anwendung von Beleuchtungslinsen oder Condensatoren ist in den meisten Fällen, wemn anders der Spiegel hinreichend gross ist und ziemlich nahe gerückt werden kann, überflüssig; sie hat nur da einen Sinn, wo man die Oeffnung des einfallenden Lichtkegels zu vergrössern beabsichtigt.

Wendet man auffallendes Licht zur Beleuchtung an, so 225 genügt es in den meisten Fällen, das Mikroskop dem Fenster soviel als möglich zu nähern, indem dadurch eine ziemlich ausgedehnte Fläche der Lichtquelle wirksam gemacht wird. Bei Vergrösserungen, welche über $100-120 \mathrm{Mal}$ hinausgehen, ist die Anwendung einer Beleuchtungslinse oder des Lieberkühn'schen Spiegels zu empfehlen. In einzelnen Fällen mag auch directes Sonnenlicht, das man durch Schiefhalten des Mikroskopstativs unmittelbar zwischen Objectiv und Object einfallen lässt, mit Vortheil zur Anwendung kommen; 
wir bezweifeln indess die Richtigkeit der Schacht'schen Angabe, dass man auf diese Weise die drei Liniensysteme ron Pleurosigma angulatum bei gleicher Vergrösserung deutlicher sehe, als mit gewöhnlichem durchfallendem Lichte, und möchten überhaupt die genannte Beleuchtungsmethode für transparente Objecte nicht empfehlen.

Künstliche Beleuchtung durch Lampenlicht ist bei zweckmässiger Dämpfung desselben durch mattgeschliffenes oder kobaltblaues Glas für manche Untersuchungen ganz brauchbar, greift jedoch die Augen immer etwas mehr an, als das jedenfalls weit angenehmere Tageslicht. Schon um desswillen sollte es sich Jeder, dem die Augen lieb sind, zur Regel machen, anhaltendere mikroskopische Beobachtungen auf den Tag zu beschränken. Nur wo, wie in England und im nördlichen Europa, das trübe Tageslicht oft für längere Zeit nicht mehr ausreicht, bleibt schlechterdings kein anderer Ausweg, als eine möglichst günstige künstliche Beleuchtung herzustellen. Dass hiebei die Brennweite des Hohlspiegels oder der Beleuchtungslinse mit zu berüclisichtigen ist, wenn die Convergenz der einfallenden Strahlen ein Maximum erreichen soll, bedarf nach dem früher Gesagten keiner Erörterung.

\section{Die Tahl der Vergrösserung.}

226 Das zu untersuchende Präparat wird zur vorläufigen Orientirung zweckmässig zuerst bei schwacher Tergrösserung betrachtet, weil man dadurch einen besseren Ueberblick über das vorhandene Material gewinnt und sich die besten Stellen der Schnitte oder die günstigsten Objecte zur genaueren Beobachtung bequem heraussuchen kann. Ist das schwächste Objectirsystem, welches zur Verfügung steht, noch zu stark, so kann eine weitere Verkleinerung des Bildes durch Verkürzung der Mikroskopröhre oder auch durch Abschrauben der rorderen Objectivlinsen erzielt werden. Die Schärfe des Bildes erfährt jedoch in letzterem Falle, wenn das Objectir nicht besonders hiefür construirt ist, eine merkliche Abnahme.

Geht man zu stärkeren Vergrösserungen über, so rergesse man nicht, dass das optische Vermögen vorzugsweise von der Brennweite der Objective, nicht von der Stärke der Oculare abhängt. Die Anwendung starker Oculare, d. h. solcher, welche 10 Mal und darüber vergrössern, gewährt in der Regel nur in solchen Fällen noch einige Vortheile, wo es sich um die Bestimmung von Formverhältnissen oder um die Vergleichung sehr kleiner Abstände handelt. Neue 
Details im Bilde wird man damit um so weniger wahrnehmen, je unrollkommener das Objectiv und je länger die Mikroskopröhre; die allerstärksten Nummern zeigen sogar in den meisten Fällen entschieden weniger, als die vorausgehenden schwächeren.

Welche Vergrösserungen sich für eine bestimmte Arbeit am besten eignen, wird Jeder, welcher das Mikroskop zu wissenschaftlichen Zwecken gebrauchen will, sehr bald beurtheilen lernen. Dass Immersionssysteme und andere von gleicher Stärke nur in ganz speciellen Fällen, wo es sich um schwer zu erkennende Einzelheiten der Structur u. dgl. handelt, Anwendung finden, ist an und für sich klar.

\section{Vom Gebranch der Deckgläser.}

Die meisten mikroskopischen Präparate werden in Wasser oder 227 in irgend einem anderen flüssigen Medium untersucht, sei es, dass man damit bloss die Ablenkung der Lichtstrahlen verringern oder aber die Erhaltung des Objects in einem bestimmten Zustande trocken, weich, aufgequollen etc. - erzielen wolle. Da nun diese Flüssigkeiten, wenn die Gegenstände nicht darin untergetaucht sind, die bekannten Adhäsionserscheinungen zeigen und in Folge dessen eine sehr unebene Oberfläche erhalten, so ist es für stärkere Tergrösserungen schon aus optischen Gründen nothwendig, Deckgläschen anzuwenden, welche die Oberfläche ebnen. Ueberdiess wird dadurch ein zu rasches Verdunsten der Flüssigkeit und das Beschlagen oder Eintauchen der Linsen in dieselbe vermieden. Bei schwächeren Vergrösserungen kann dagegen das Präparat auch unbedeckt bleiben, und es ist sogar in manchen Fällen, namentlich wenn man noch eine weitere Zergliederung desselben vornehmen will, ganz zweckmässig, es nicht zu bedecken.

Sind die Präparate der Art, dass es von Nutzen sein kann, dieselben umzukehren und von der unteren Seite zu betrachten, so thut man am besten, sie zwischen zwei grössere Deckplättchen zu bringen, die damn nach Belieben gewendet werden. Dieses Verfahren gewährt beim Studium übereinander liegender Zellschichten oder auch beliebiger anderer Objecte, deren räumliche Anordnung man kennen lernen will, oft wesentliche Vortheile.

Die Dicke der Deckgläschen ist für schwächere Objective ziemlich gleichgültig; die Wahl hat sich also mehr nach anderen Rücksichten, wie z. B. nach dem Druck zu richten, den man auf das Präparat ausüben will. Stärkere Systeme sind dagegen meist für dünne Deckgläschen construirt und erfordern, sobald die Dicke 1/2 m. m. 
und darüber beträgt, eine Correction. Bei ganz starken Objectiven sind schon wegen der äusserst geringen Focaldistanz nur die dünnsten Deckgläschen anwendbar.

Wo es darauf ankommt, das Präparat vor jedem noch so geringen Druck zu schützen, wird irgend ein geeigneter Gegenstand, wie z. B. ein Haar, eine Borste, ein Stïck Papier oder Stanniol u. dgl. unter das Deckgläschen gebracht, wobei natürlich der Objectabstand des Mikroskops mit zu berücksichtigen ist. Der Anfänger macht oft genug die Erfahrung, dass die Einstellung auf das zu untersuchende Object durch die beträchtliche Dicke der Flüssigkeitsschicht, welche darüber liegt, unmöglich gemacht wird, und bei sehr starken Objectiven kann dasselbe auch dem Geübten passiren. Zur Vermeidung dieses Uebelstandes ist es in der Regel vortheilhafter, das Deckglas nur mit dem einem Rande aufzulegen und hierauf nöthigenfalls soweit $\mathrm{zu}$ verschieben, bis sich das Object an einer hinreichend dünnen Stelle der keilförmigen Wasserschicht befindet.

Dass die Deckgläschen möglichst rein sein müssen und folglich auf dem optisch wirksamen Theil der Oberfläche nicht mit den Fingern berührt werden dürfen, ist selbstverständlich.

\section{Die Behandlnng res Instruments.}

225 Wer sein Mikroskop schonen und dessen ursprüngliche Leistungsfähigkeit unverändert erhalten will, muss vor Allem darauf bedacht sein, die Linsen des Objectirs, wie des Oculars, nach jeder Verunreinigung, die während des Gebrauchs stattgefunden, sorgfältig zu reinigen. Namentlich versäume man nicht, die Vorderfläche des benutzten Objectivsystems jedesmal nach geschehener Arbeit zu prüfen, da eintrocknende Flüssigkeiten, wie überhaupt alle Verunreinigungen, die allfällig daran haften geblieben sein können, leicht nachtheilig wirken. Die grösste Vorsicht erfordert aber immer die Anwendung von chemischen Reagentien während der Beobachtung, insbesondere solcher, welche das Blei des Flintglases afficiren. Chemische Proceduren, welche Schwefelwasserstoff, Chlor, Dämpfe flüchtiger Säuren und ähnliche Gase entwickeln, sollten nie im Zimmer, wo das Mikroskop steht, vorgenommen werden. Chlorsaures Kali mit concentrirter Salpetersäure, rauchende Salzsäure u. dgl. erfordern zum Schutz des Objectivs schon bei gewöhnlicher Temperatur möglichst grosse Deckgläschen und dürfen erhitzt nicht unter das Mikroskop gebracht werden.

Ist trotz aller Vorsicht eine Linse von dem Reagens benetzt wor- 
den, so spült man dieselbe zunächst mit destillirtem Wasser ab und reinigt sie nachher in gewohnter Weise. Am besten geschieht diess wohl mit einem feinen, durch offteres Waschen weich gewordenen Tuch oder auch mit weichem Leder. Andere pflegen zur weiteren Reinigung die frische Schnittfläche von trockenem Fliedermark zu verwenden, dessen auf der Linse zurückgebliebene Partikelchen sie endlich mit einem reinen Haarpinsel entfernen - ein gewiss ganz gutes, aber etwas umständliches Verfahren.

Wer das Mikroskop täglich benutzt und sich das jedesmalige Ein- und Auspacken ersparen will, bringt dasselbe zweckmässig unter eine Glasglocke oder bedeckt es vollständig mit einem Tuch, indem dadurch Stativ und Linsen hinlänglich vor Staub geschützt werden. Manche Beobachter pflegen übrigens in solchen Dingen nicht sehr ängstlich zu sein; sie verwahren höchstenss das Objectiv in dem hiezu bestimmten Etui, bedecken das Ocular und lassen das Instrument so stehen. Wir haben auch nicht gefunden, dass Mikroskope, welche sogar mit angeschraubtem Objectiv Jahre lang so behandelt wurden, dabei irgendwie gelitten hätten. Doch ist es immer besser, man thue des Guten eher zu viel, als zu wenig.

Um das Beschlagen der Ocularlinse mit Wasserdunst während der Beobachtung zu vermeiden, kann man entweder das Ocular schwach erwärmen oder das ganze Instrument vor dem Gebrauch in ein warmes Zimmer stellen.

\section{Schonung des Sehvermögens.}

Wer ein einigermaassen ausdauerndes Sehwerkzeug besitzt, wird $\mathbf{2 2 9}$ sich bald daran gewöhnt haben, täglich mehrere Stunden ohne irgend welche Nachtheile mikroskopischen Arbeiten zu widmen; nur mache man sich's zur Regel, die ersten Morgenstunden und die Zeit unmittelbar nach dem Mittagessen zu vermeiden. Stellt sich eine Ermüdung oder eine gewisse Reizbarkeit der Augen ein, so setze man für einige Tage aus.

$\mathrm{Ob}$ man das unthätige Auge während der Beobachtung schliesse oder offen behalte, ist ziemlich gleichgültig; man gewöhne sich aber, abwechselnd mit dem rechten und linken Auge zu beobachten. Beide Augen erfahren alsdann dieselben Veränderungen; sie stimmen vorausgesetzt, dass sie ursprünglich gleich waren - zeitlebens sowohl im Sehvermögen, als in der Sehweite überein, während sonst das beobachtende Auge gewöhnlich etwas kurzsichtiger wird. Der ausschliessliche Gebrauch des einen Auges soll überdiess eine eigenthüm- 
liche Reizbarkeit des andern zur Folge haben und bei anhaltender Arbeit Schmerzen in demselben verursachen. Diess ist jedenfalls insofern richtig, als das Auge, welches gewöhnlich unthätig ist, bein Sehen durchs Mikroskop einen weit helleren Lichteindruck erhält und, wenn man zur Abwechslung längere Zeit damit beobachtet, rascher ermüdet (was übrigens bei dẹın gesunden Auge des Anfängers auch der Fall ist. Was dagegen die Schmerzen betrifft, welche die anhaltende Arbeit verursacht, so lässt die Erfahrung es unentschieden, ob die abwechselnde Benutzung beider Augen nicht ebenso grosse Unannehmlichkeiten nach sich gezogen hätte. Jedenfalls gibt es viele Mikroskopiker, welche stets mit demselben Auge beobachten und diess bereits seit Jahren ohne Nachtheil gethan haben.

\section{Der Arbeitstisch.}

230 Eine nicht zu unterschätzende Annehmlichkeit ist die zweckmässige Einrichtung und bequeme Höhe des Arbeitstisches. Derselbe soll hinreichend gross und massiv und mit einer oder mehreren Schubladen ausgestattet sein, in welchen man die verschiedenen Nebenapparate, Zeichnenprismen, Glasgefässe etc. aufbewahrt. Für Zergliederungen empfiehlt sich eine in die Tischplatte eingelassene Schiefertafel, weil man die meisten Gegenstände auf schwarzem Grunde deutlicher sieht. Andere Einrichtungen, die vielleicht in diesem oder jenem Fall ganz zweckmässig sein mögen, im Allgemeinen aber entbehrlich sind, übergehen wir hier. Wer sich einen complicirteren Arbeitstisch mit all' den Beigaben, die etwa wünschenswerth erscheinen, machen lassen will, wird am besten thun, den Plan hiezu nach eigener Idee $\mathrm{zu}$ entwerfen.

\section{II.}

\section{Herstellung und Behandlung der Präparate.}

Es gibt im Ganzen nur wenige Gegenstände, welche ohne weitere Präparation auf dem Objectträger ausgebreitet oder durch Quetschen mit dem Deckglas isolirt werden können; die meisten bedürfen einer vorhergehenden Zergliederung in kleinere Theile oder müssen auf zarten Durchschnitten, deren Anfertigung eine gewisse Uebung voraussetzt, untersucht werden. Zweckmässiges Präpariren bleibt daher immer ein Hauptpunkt bei mikroskopischen Arbeiten: es ist 
wichtig, ein gegebenes Object der Betrachtung so zugänglich als möglich zu machen und alle hiezu erforderlichen Proceduren kennen zu lernen, jedoch selbstrerständlich ror Allem nothwendig, sich in der Handhabung der Präparirinstrumente praktisch zu üben. Die schriftliche Erörterung dieses Gegenstandes kann sich füglich auf eine kurze Angabe der Mittel und Wege beschränken, welche man zur Erreichung des gedachten Zieles zu wählen pflegt; alles Uebrige bleibt naturgemäss der praktischen Schule vorbehalten.

Das Zergliedern der Objecte, sowie das Freipräpariren bestimmter Theile, geschieht in der Regel mit Hülfe von Nadeln, und zwar in schwierigeren Fällen unter der Loupe oder dem einfachen Mikroskop.

Als Präparirnadel kann hiebei jede gewöhnliche Nähnadel dienen; wenn dieselbe mit einem hölzernen Stiel versehen ist, in welchem sie unbeweglich festsitzt. Wer indess auf eine bessere Ausstattung Werth legt, mag sich Nadeln von verschiedener Form und Grösse, darunter solche mit hakenförmig gebogener Spitze, und andere, die in ein kleines Messerchen auslaufen, anfertigen lassen und je nach dem Gegenstand, welcher zergliedert werden soll, diese oder jene gebrauchen. Nadeln, welche zu schwierigen Zergliederungen rerwendet werden, müssen natürlich eine feine Spitze haben und sobald sich dieselbe abgestumpft hat, wieder geschliffen werden; solche dagegen, welche man bloss zum Drücken auf das Deckgläschen oder zum Verschieben desselben behufs Drehung der Objecte oderauch zu gröberen Zergliederungen benutzt, sind auch mit stumpfen Spitzen noch brauchbar und oft sogar zweckmässiger, sie sollen überhaupt etwas stärker sein und nicht federn. Das Heft wird namentlich bei feinen Nadeln am besten so eingerichtet, dass man dieselben nach Belieben wechseln und mittelst einer Metallkappe jedesmal fest einklemmen kann.

Eine geschickte Handhabung der Präparirnadeln ist bei unanchen Objecten von grösster. Wichtigkeit. Die Mühe, welche das Zerzupfen derselben verursacht, wird in solchen Fällen durch die Sicherheit der Beobachtung, die man dadurch erzielt, mehr als aufgewogen. Anfänger fehlen gewöhnlich darin, dass sie mit zu grossen Massen operiren und die Operation nicht lange genug fortsetzen.

Sind in einem Präparate zellige oder körnige Elemente zwischen fibröse, die man untersuchen will, eingebettet, so lassen sich erstere zuweilen durch Auspinseln - eine Methode, die bei thierischen 
Präparaten häufig angewendet wird - entfernen. Der Gegंenstand wird auf dem Objectträger, in einem geeigneten Medium liegend,

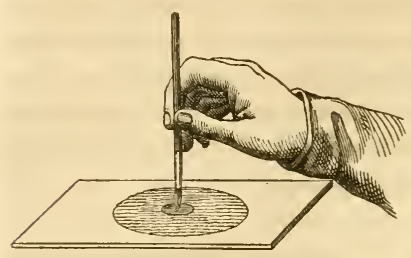

Fig. 141, so lange mit einem Malerpinsel in senkrechten Bewegungen betupft (Fig. 141), bis sich die Flüssigkeit trübt und das Gewebe sich aufhellt. Nöthigenfalls wird diese Procedur mehrere Male, verbunden mit Auswaschen und Wenden des Präparats und unter Zusatz neuer Flüssigkeit, wiederholt, bis endlich keine Trü-

bung mehr stattfindet.

Zür Anfertigung von Durchschnitten bedient man sich am häufigsten guter Rasirmesser; andere Schneideinstrumente, wie Doppelmesser, Scalpelle u. dgl. sind für botanische $Z$ wecke geradezu überflüssig, und so viel wir wissen, ist ihr Werth auch bei thierischen Substanzen nur ein sehr untergeordneter. Wer das Rasirmesser geschickt zu führen weiss, wird jedenfalls in der grossen Mehrzahl der Fälle damit ausreichen; nur ist es rathsam, je nach Umständen eine flach geschliffene oder eine hohl geschliffene Klinge $\mathrm{zu}$ benutzen. Handelt es sich z. B. un die Herstellung grösserer Durchschnitte durch verholzte Gebilde, so ist hiezu ein flach geschliffenes Messer, das auf dem Nagel nicht federt, erforderlich, während für weiche krautartige Gewebe sich im Gegentheil hohl geschliffene Rasirmesser mit elastisch biegsamer Schneide am besten eignen.

Vor dem Schneiden wird in der Regel sowohl die Klinge als das Object angefeuchtet, indem ein trocken geführter Schnitt gewöhnlich weniger gut ausfällt. Als Ausnahme sind indess ausgetrocknete gallertartige Substanzen, wie z. B. manche Flechtenthallome zu behandeln, weil sie im feuchten oder aufgequollenen Zustande nicht den nöthigen Widerstand bieten; hier ist höchstens eine Berührung mit der feuchten Lippe zulässig. Beim Schneiden selbst darf das Messer nicht etwa bloss wie ein Keil rechtwinklig zur Längsaxe durchgedrückt, es muss vielmehr hindurch gezogen werden, wenn die Schnittfläche möglichst glatt und rein ausfallen soll.

Sind die zu untersuchenden Gegenstände so dünn oder so klein, dass das Fassen mit der Hand und das richtige Ansetzen des Messers schwer fällt, so muss ihnen auf irgend eine passende Art der nöthige Halt gegeben werden. Handelt es sich um dünne fadenförmige oder 
lamellenartige Gebilde (Blätter etc.), so genügt es zuweilen, wenn man sie zu mehreren aufeinander legt und zwischen die Finger presst. Meistens aber ist es rathsam, dieselben zwischen Kork oder Hollundermark einzuklemmen oder, wenn die Natur der Substanz diess gestattet, in Gummischleim eintrocknen zu lassen. Dünne Wurzeln, einzelne Blätter, Stammspitzen und ähnliche Objecte mit saftigem Gewebe schneidet man z. B. am besten zwischen Hollundermark, das im Allgemeinen vor dem Kork den Vorzug verdient; nur muss der Druck natürlich immer so regulirt werden, dass keine Quetschung stattfindet. Bei etwas dickeren Gegenständen ist desswegen das Aushöhlen einer entsprechenden kleinen Rinne im Marke empfehlenswerth. Längsschnitte durch zarte fadenförmige Objecte gelingen zuweilen am besten, wenn man dieselben um die Kante einer Korkplatte herumbiegt, das eine Ende fest andrückt und hierauf das andere, das man nöthigenfalls mit ganz wenig Gummischleim aufklebt, rorsichtig von der Kante aus durchschneidet. Auf diese Weise erhielten wir z. B. noch dünne Medianschnitte durch, weiche Wurzelenden, nachdem zahlreiche Versuche zwischen Kork und Fliedermark fehlgeschlagen hatten. - Das Einlegen in Gummi ist nur bei solchen Objecten anwendbar, welche ohne Schaden eintrocknen und beim Aufquellen wieder ihre ursprüngliche Form annehmen, bei diesen aber jedem anderen Mittel vorzuziehen. Pollenkörner mit dicker Exine, Stärkekörner, die Aussenwandungen der Epidermiszellen, alle Flechtenthallome, manche Moos- und Algengewebe etc. kann man nach dieser Methode ohne alle Schwierigkeit in die dünnsten Lamellen zerlegen.

Für moderiges Holz und ähnliche Gewebe mit locker verbundenen Theilen soll unter Umständen auch die Injection mit geschmolzenem Stearin, das man später auf der Objectplatte mit Aether oder Benzin entfernt, zweckmässig sein. Schacht gibt an, er habe auf diese Weise noch zarte Durchschnitte durch stark vermodertes Holz aus Hünengräbern erhalten.

Objecte endlich, welche nur aus einer einzigen Zellreihe oder Zellschicht bestehen, wie z. B. Algenfäden und Moosblätter, werden gewöhnlich mit einem Tropfen Wasser auf den Daumennagel gebracht und durch eine schaukelnde Bewegung des Rasirmessers zerschnitten - ein Verfahren, welches bis zu einer gewissen Dicke der Gegenstände auch bei mehreren Zellenlagen noch Anwendung findet. 
Um die auf der Messerklinge oder auf dem Daumennagel liegenden Schnitte in die Beobachtungsflüssigkeit auf der Objectplatte überzutragen, bedienen sich manche Beobachter eines feinen Malerpinsels, an dessen feuchter Spitze die einzelnen Objecte leicht haften bleiben, während sie in Wasser sich eben so leicht wieder ablösen. Man kann aber auch das Rasirmesser flach auf die Glasplatte auflegen, so dass die Schneide den Rand der Flüssigkeit berührt, und nun Schnitt für Schnitt mittelst der Nadel in dieselbe herüberschieben. Es kommt in diesen Dingen, wie in so manchen andern, viel auf Gewohnheit und Uebung an. Wir pflegen den Pinsel zum Uebertragen der Präparate nie zu gebrauchen.

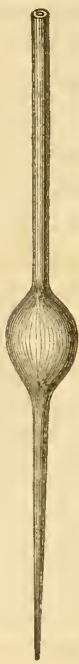

Sind die zu untersuchenden Gegenstände in einer Flüssigkeit suspendirt, so bedient man sich häufig der Pipette (Fig. 142), um dieselben aufzufangen und auf die Objectplatte zu bringen. Terschliesst man nämlich das obere Ende der Glasröhre durch Auflegen des Zeigefingers, so kann man das untere, in eine feine Spitze ausgezogene Ende in eine Flüssigkeit eintauchen, ohne dass diese eindringt. Entfernt man sodann augenblicklich den Finger, so dringt etwas Flüssigkeit sammt den darin suspendirten Körperchen in die Röhre ein und kann nach abermaliger Verschliessung des oberen Endes herausgehoben werden. Die Pipette empfiehlt sich namentlich, wenn man aus verschiedenen über einander gelagerten Flüssigkeitsschichten einzelne Proben auffangen und gesondert untersuchen will.

Die in neuerer Zeit vielfach empfohlenen Mikrotome - Apparate, welche die Herstellung dünner Durchschnitte durch harte Gewebe erleichtern sollen - finden gewiss in manchen Fällen, namentlich wo eine grössere Ausdiehnung und gleichnässige Dicke der Schnitte wünschenswerth ist, Fig. 142. wie z. B. bei mikroskopischen Cabinetsstücken, ganz zweckmässige Verwendung. Für wissenschaftliche Untersuchungen scheint uns dagegen ihr Werth sehr untergeordnet, da es hier meistens bloss daranf ankommt, kleine Stücke eines Objectes gut zu durchschṇeiden oder wenigstens beim Durchmustern der Schnitte brauchbare Stellen zu finden. Wir bekennen uns überhaupt zu der Ansicht Mohl's, dass mechanische Vorrichtungen dieser Art, welche das künstlich potenzirte Auge durch künstlich potenzirte Hände unterstützen sollen, der Wissenschaft wenig Nutzen bringen, und dass einfache Werkzeuge in geübter Hand vollkommen ausreichen und meist bessere 
Dienste leisten als complicirte. Auf eine Beschreibung der Mikrotome glauben wir daher um so eher verzichten zu dürfen, als die Verfertiger derselben gewöhnlich jedem abzugebenden Instrument eine Gebrauchsanweisung beilegen.

Die Scheere kommt nur, bei thierischen Präparaten öfter in 235 Gebrauch, bei pflanzlichen höchstens ausnahmsweise; jedenfalls reicht hier eine ganz gewöhnliche kleine Scheere vollkommen aus. Ebenso sind auch Meisel und Doppelmeisel, Säge, Hobel u. dgl., wenn sie auch in gewissen speciellen Fällen unentbehrlich sind, nicht eigentlich $\mathrm{zu}$ den Instrumenten des Mikroskopikers $\mathrm{zu}$ rechnen, so wenig als man Taschenmesser, Schraubstock, Zange, Locheisen u. dgl. als solche betrachten kann. Die Anwendung der gedachten Instrumente ist übrigens in den meisten Fällen selbstverständlich; man bedient sich der Säge bei versteinerten Hölzern, Knochen, Zähnen und ähnlichen Gegenständen, um dieselben zu durchschneiden oder in dünne Plättchen zu zerlegen, die man nachher eben schleift, — des Hobels bei hornartigen Gegenständen, um grössere Schnitte zu erhalten, - des Doppelmeisels, um aus harten Objecten ron beträchtlicher Dicke dünne Lamellen herauszuschneiden u. s. w. Wer in den Fall kommt, das eine oder andere Instrument mit Vortheil zu gebrauchen, wird auch leicht ermessen, welche Form und Grösse ihm am besten convenirt und demgemäss - wenn überhaupt eine Auswahl geboten ist - seine $\mathrm{W}$ ahl treffen. Es scheint uns überflüssig, hierüber noch weitere Anweisungen folgen zu lassen.

Sind die angefertigten Durchschnitte in Folge ihres Luftge- 236 haltes undurchsichtig, so muss die Luft auf irgend eine Weise entfernt werden. Manchmal genügt ein längeres Liegenlassen in der Beobachtungsflüssigkeit, insofern die letztere noch Luft zu absorbiren vermag; ein ganz sicheres Medium ist z. B. ausgekochtes $W$ asser, und nach Schach t auch Alcohol. In anderen Fällen führt ein schwaches Erwärmen des Präparates über der Weingeistlampe zum Ziel. Am wirksamsten und bequemsten ist indess immer die Anwendung der Luftpumpe, indem einige wenige Züge schon hinreichen, um die unter den Recipienten gebrachten Objecte vollständig luftfrei zu machen. Wer über eine grössere Luftpumpe, die immerhin zu den kostspieligen Apparaten zählt, nicht zu disponiren hat, kann sich eine kleinere von der Form einer Spritze leicht selbst anfertigen oder mit geringen Kosten anfertigen lassen. In eine unten zugeschmolzene 
Röhre von c. 1 Zoll Durchmesser wird ein mit einem Ventil versehener Kolben eingepasst, der beim Hineinschieben die Luft entweichen, beim Herausziehen aber nicht eintreten lässt. Das zu untersuchende Object muss freilich bei dieser Einrichtung schon vor dem Präpariren in hinreichend kleinen Stücken und mit etwas Wasser in die Röhre gebracht und später wieder herausgefischt werden, was gerade nicht bequem ist; dessenungeachtet wird eine solche Handluftpumpe in Ermangelung einer besseren oft mit Vortheil angewandt.

Rührt die Undurchsichtigkeit von Inhaltspartieen oder Einlagerungen in die Membran her, so ist natürlich bloss durch Entfernung der betreffenden Substanzen mittelst chemischer Reagentien Abhülfe zu schaffen. Hierüber soll später das Nähere mitgetheilt werden.

Das Quetschen der Präparate auf dem Objectträger wird in der Regel durch einen schwachen Druck, den man mit der Nadel auf das Deckgläschen ausübt, bewerkstelligt. Dieses einfache Verfahren gewährt den doppelten Vortheil, den Druck nach Belieben und unter Umständen abwechselnd steigern und mässigen, und, wo es zweckdienlich erscheint, auch mit einem Zug nach dieser oder jener Seite hin verbinden $\mathrm{zu}$ können, was bei manchen Objecten sehr wichtig ist. Handelt es sich dagegen darum, einen gewissen Druck längere Zeit constant zu erhalten, sei es um eine grössere Fläche bequem zu durchmustern oder um das Object mit der Camera lucida zu zeichnen, so leistet allerdings eine mechanische Vorrichtung, welche den Druck mittelst Schrauben auszuüben gestattet, wesentliche Dienste. Solche Vorrichtungen, sogenannte Compress orien, werden gegenwärtig von den meisten Optikern geliefert; sie figuriren z. B. in den Preisverzeichnissen von $\mathrm{H}$ a r tna $\mathrm{ck}, \mathrm{N}$ a c h et, Bénè che, Zeiss, Belthle, Schröder, Schiek und Plössl und sind je nach Grösse und Einrichtung zu 15-25 Fr., die complicirteren sogar bis zu 40 Fr. angesetzt.

III.

\section{Die Aufbewahrung der mikroskopischen Präparate.}

238 Das Sammeln mikroskopischer Objecte, namentlich solcher, die man einer mühsamen Zergliederung oder einem glücklichen Zufalle verdankt, hat in neuerer Zeit durch die Verbesserung der Aufbe- 
wahrungsmethoden eine Ausdehnung und Bedeutung erlangt, welche es gewissermaassen jedem Mikroskopiker zur Pflicht machen, die zur Herstellung solcher Präparate dienlichen Verfahren kennen zu lernen. Da es zunächst darauf ankomint, das zur Erhaltung der Objecte geeignete Medium zu wählen, so ordnen sich die in.Gebrauch gekommenen Methoden am besten nach diesen. Wir heben folgende hervor:

1) Luftals Medium fürtrockene Substanzen, wiez. B. Schmetterlingsschuppen, Diatomeen, Krystalle und Durchschnitte durch verschiedene Hartgebilde. Man bedeckt diese Gegenstände, nachdem man sich überzeugt hat, dass sie in Luft ein befriedigendes Bild gewähren, mit einem dünnen Deckgläschen und befestigt das letztere in irgend einer Weise auf dem Objectträger, am besten mit dicker Gummisolution oder mit Canadabalsam. Das Ganze wird hierauf zweckmässig wie auch bei Anwendung der folgenden Medien) mit einem Papier überzogen, welches über der Mitte des Deckgläschens einen Ausschnitt besitzt und an den Rändern des Objectträgers etwas übergreift.

2) Canadabalsam, für Hartgebilde aller Art: Diatomeen, fossile Hölzer, Knochen- und Zahnschliffe etc. Unter den harzähnlichen Stoffen, welche man als Medium für mikroskopische Objecte vorgeschlagen hat, ist keiner so wichtig und so allgemein in Gebrauch gekommen, als der canadische Balsam. Für vegetabilische Objecte findet er freilich nur eine beschränkte Verwendung, indem die meisten Zellmembranen darin zu durchsichtig erscheinen, um noch ein deutliches Bild zu gewähren; um so grösser ist dagegen seine Bedeutung für thierische Präparate. Das einzuschliessende Object wird durch Erwärmen oder auch über Schwefelsäure oder Chlorcalcium vollständig ausgetrocknet und hierauf mit Terpentinöl getränkt. Auf die Objectplatte wird alsdann ein Tropfen flüssigen Canadabalsams gebracht, das Präparat darin ausgebreitet und mit einem zweiten Tropfen bedeckt. Zur Entfernung der Luftblasen ist ein gelindes Erwärmen der Objectplatte (wobei natürlich kein Aufkochen stattfinden darf) zu empfehlen, und zwar wird dasselbe nöthigenfalls auch nach der Bedeckung mit dem Deckgläschen noch fortgesetzt, indem man das Präparat auf eine warme Unterlage im Winter z. B. auf die Platte eines Thonofens) bringt, wodurch zugleich ein schnelleres Erhärten des Balsains erzielt wird.

Da der Balsamverschluss immer etwas klebrig bleibt, so ist es rathsam, die Ränder des Deckgläschens nach etwa 8 Tagen noch mit irgend einem Lack zu bestreichen, welcher rasch zu einer festen, 
nicht klebrigen Masse eintrocknet. - Fester Canadabalsam wird vorher mit Terpentinöl oder auch mit etwas Chloroform verdünnt. Das Hartwerden an der Luft kann übrigens durch zweckmässige Aufbewahrung, am besten in weithalsigen Glasgefässen mit eingeschliffenen Stöpseln, ziemlich beschränkt werden. Ein allfälliger Ueberschuss des aufgetragenen Balsams, welcher an den Rändern des Deckgläsehens hervorquillt, wird nach dem Erhärten abgekratzt und hierauf die Glasfläche mit einem von Terpentinöl benetzten Lappen vollständig gereinigt.

Statt des gewöhnlichen dickflüssigen Balsams wird unter Umständen ein mit Aether oder Chloroform stark verdünnter mit Vortheil angewandt. Man trägt denselben mittelst eines Pinsels kalt auf die Objectplatte auf, legt das Präparat ein, setzt noch etwas Flüssigkeit zu und bedeckt schliesslich.

3) Glycerin, für die meisten Pfanzengewebe. Dasselbe empfiehlt sich namentlich für solche Präparate, wo die Erhaltung der Stärkekörner und des Chlorophylls von Wichtigkeit ist. Um die Contraction des Primordialschlauches, soweit es überhaupt möglich ist, zu beschränken, bringt man die Objecte vorerst in eine mit destillirtem Wasser sehr verdünnte Lösung, die man entweder in der Luft verdunsten lässt oder nach und nach durch concentrirtere Lösungen ersetzt. Die Eigenschaft des Glycerins, bis zu einem gewissen Concentrationsgrade Wasser aus der Luft anzuziehen, macht einen hermetischen Verschluss überflüssig; nur wo dasselbe bleibend einen grösseren Wassergehalt besitzen soll, muss natürlich die Verdunstung durch sorgfältiges Auftragen der unten zu erwähnenden Lacksorten verhindert werden. Doch braucht man sich damit keineswegs zu beeilen; man darf ruhig mehrere Präparate zusammenkommen lassen, ehe man zum Einkitten schreitet.

Statt des reinen Glycerins wenden Andere ein Gemisch von Glycerin und arabischem Gummi oder Gelatine an, weil durch das Erstarren dieser Flüssigkeit späteren Ortsveränderungen der Objecte vorgebeugt wird. Man erhält diese Mischung, indem man beispielsweise 1 Theil Gelatine in 2 Theilen Wasser erwärmt und hierauf das gleiche Volumen oder auch etwas mehr Glycerin zusetzt.

Farrants empfiehlt eine noch complicirtere Mischung, welche ans gleichen Theilen Glycerin, arabischem Gummi und gesättigter wässeriger Lösung von arseniger Säure besteht und wie Canadabalsam gebraucht wird. Eine Verkittung ist hier nicht nöthig, da die äussern Schichten bald erhärten und eine weitere Verdunstung verhindern. 
4) Chlorcalcium, fürdie meisten vegetabilischen Gewebe. Wird in ähnlicher Weise wie Glycerin angewendet und verlangt bei hinreichender Concentration ebensowenig, wie dieses, einen hermetischen Verschluss. Bei vorsichtiger Steigerung der Concentration bleiben die Wandungen der Zellen, selbst in jugendlichen Geweben, meist gut erhalten; die Farbstoffe werden dagegen mehr oder weniger verändert, die Stärkekörner quellen auf, der Primordialschlauch concentrirt sich. Dessenungeachtet ist die Chlorcalciumlösung in vielen Fällen dem Glycerin vorzuziehen. - Um die Bildung von basisch salzsaurem Kalk, welcher zuweilen auf dem Präparat auskrystallisirt, zu verhindern, säuert man die Lösung zweckmässig mit etwas Salzsäure an. Die Concentration der Chlorcalciumlösung richtet sich nach der Natur der Gewebe; verholzte Zellen ertragen eine vollständige Sättigung, während für jugendliche Gewebe eine verdünntere Lösung vorzuziehen ist.

5) Zuckerwasser, für Präparate, welche durch Glycerin oder Chlorcalcium zu sehr verändertwerden. Der Zuckergehalt hindert die sonst immer eintretende Zersetzung und die damit verbundene Trübung der Flüssigkeit. Um auch jede Pilzbildung zu verhindern, kann man die Lösung mit etwas Sublimat versetzen. Dieselbe erfordert selbstverständlich immer einen hermetischen Verschluss.

Ausser den genannten Conservirungsflüssigkeiten wurden noch $\mathbf{2 3 9}$ zahlreiche andere rorgeschlagen, die sich aber vorzugsweise für thierische Präparate eignen. Einige der gebräuchlichsten mögen hier noch Erwähnung finden.

Die von Pacini empfohlene Mischung - eine Modification der sogenannten Goadby'schen Flüssigkeit - besteht aus

Sublimat 1 Theil

Reines Chlornatrium 2 Theile

Glycerin $\left(25^{\circ}\right.$ Beaumé) 13 Theile

Destillirtes Wasser 113 Theile.

Diese Mischung soll zwei Monate stehen gelassen und dann mit dem dreifachen Gewicht destillirten Wassers verdünnt und durch Fliesspapier filtrirt werden. Zur Erhaltung der Blutkörperchen, Nerven, Ganglien, Krebszellen, sowie überhaupt zarter proteinhaltiger Gewebe, soll dieselbe sich ganz vortrefflich eignen.

Aehnliche Gemische werden auch im pathologischen Institut in Nāgeli u. S e hwendener, das Mikroskop. 
Berlin in verschiedenen Nunmern angewandt; sie haben nach Corn il H. Frey, das Mikr. p. 146) folgende Zusammensetzung.

\begin{tabular}{|c|c|c|c|c|c|c|c|}
\hline \multicolumn{2}{|l|}{ Nr. 1.} & \multicolumn{2}{|l|}{ Nr. 2.} & \multicolumn{2}{|l|}{ Nr. 3.} & \multicolumn{2}{|l|}{ Nr. 4.} \\
\hline $\begin{array}{l}\text { Sublimat } \\
\text { Chlornatrium } \\
\text { Wasser }\end{array}$ & $\begin{array}{r}1 \\
2 \\
100\end{array}$ & $\begin{array}{l}\text { Sublimat } \\
\text { Chlornatrium } \\
\text { Wasser }\end{array}$ & $\begin{array}{r}1 \\
2 \\
200\end{array}$ & $\begin{array}{l}\text { Sublimat } \\
\text { Chlornatrium } \\
\text { Wasser }\end{array}$ & $\begin{array}{r}1 \\
1 \\
300\end{array}$ & $\begin{array}{l}\text { Sublimat } \\
\text { Wasser }\end{array}$ & $\begin{array}{r}1 \\
300\end{array}$ \\
\hline Nr. 5. & & Nr. 6. & & Nr. 7. & & Nr.s. & \\
\hline $\begin{array}{l}\text { Sublimat } \\
\text { Essigsäure } \\
\text { Wasser }\end{array}$ & $\begin{array}{r}1 \\
1 \\
300\end{array}$ & $\begin{array}{l}\text { Sublimat } \\
\text { Essigsäure } \\
\text { Wasser }\end{array}$ & $\begin{array}{r}1 \\
3 \\
300\end{array}$ & $\begin{array}{l}\text { Sublimat } \\
\text { Essigsäure } \\
\text { Wasser }\end{array}$ & $\begin{array}{r}1 \\
5 \\
300\end{array}$ & $\begin{array}{l}\text { Sublimat } \\
\text { Phosphorsäure } \\
\text { Wasser }\end{array}$ & $\begin{array}{r}1 \\
1 \\
30\end{array}$ \\
\hline
\end{tabular}

Nr. 1 ist für gefässreiche Gewebe warmblütiger Thiere bestimmt, Nr. 2 für diejenigen der kaltblütigen Geschöpfe, Nr. 3 für Eiterkörperchen und verwandte Gebilde, Nr. 4 für Blutzellen, Nr. 5 für Epithelialzellen, Bindegewebe und Eiterzellen, wenn zugleich die Kerne hervortreten sollen, Nr. 6 für Bindegewebe, Muskeln und Nerven, Nr. 7 für Drüsen, endlich Nr. 8 für Knorpelgewebe.

Beale erwähnt eine Flüssigkeit, die nach folgender Vorschrift gemischt wird. $\mathrm{Zu} 6$ Unzen Methylalcohol und 3 Drachmen Kreosot wird soviel Kreidepulver zugesetzt, dass das Gemenge eine weiche Paste bildet. Letztere wird hierauf unter sorgfältigem Reiben in einem Mörser mit 64 Unzen Wasser, das man allmählich zugiesst, verdünnt, dann mit ein paar kleinen Kampherstückchen versetzt und etwa 14 Tage stehen gelassen. Endlich wird filtrirt und die Flüssigkeit in einer gut schliessenden Flasche aufbewahrt. - Ein ähnliches Gemisch gebrauchte Thw aites zur Conservirung der Desmidiaceen.

240 Nach dieser Aufzählung der Conservirungsflüssigkeiten bleibt uns noch die Herstellung eines hermetischen Verschlusses, welcher für

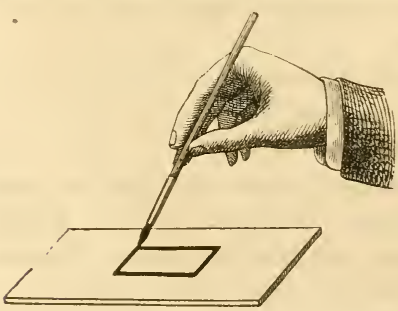

Fig. 143 . die meisten derselben nothwendig ist, zu besprechen übrig. Die Vorsichtsmaassregcln, die man hiebei zu beobachten hat, betreffen erstens die Unterlage, auf welche zur Vermeidung des Druckes das Deckgläschen zu liegen kommt, und zweitens das dauerhafte Einkitten der Ränder des Deckgläschens.

Sind die zu conservirenden Gegenstände nicht zu dick, so genügt es, mittelst eines Malerpinsels einen Rahmen von Kitt oder Lack auf dem Objectträger zu ziehen (Fig. 143), 
und zwar von solcher Form und Grösse, dass sein äusserer Umriss beim Auflegen des Deckgläschens etwas vorsteht. Sobald der Lack ungefähr halbtrocken, bringt man das Präparat in den eingeschlossenen Raum und füllt denselben mit der gewählten Flüssigkeit. Hat man zuviel von der letzteren zugesetzt, so kann der Ueberschuss mittelst des Pinsels leicht entfernt werden. Das Deckplättchen wird zweckmässig zuerst auf der einen Seite schief aufgesetzt (Fig. 144) und dann allmählich in die horizontale Lage gebracht, so dass es mit seinen Rän-

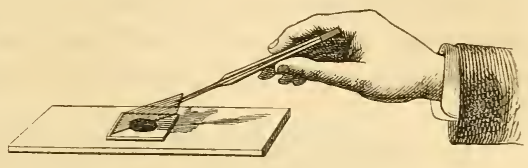

Fig. 144 . dern auf dem Lackrahmen haften bleibt. 'Tritt hiebei noch etwas Flüssigkeit hervor, so wird dieselbe vorsichtig mit Fliesspapier abgewischt, worauf endlich der Rand des Deckgläschens mit einem etwas dicken Lack derselben Art umzogen wird.

Statt eines geschlossenen Rahmens als Unterlage empfiehlt S chacht zwei parallele Lackstreifen, auf welche das Deckglas wie auf zwei Brückenpfeiler zu liegen kommt. Dadurch wird allerdings das Zurückbleiben von Luft neben dem Präparat leichter vermieden, die Herstellung eines hermetischen Verschlusses dagegen erschwert.

Sind die zur Aufbewahrung bestimmten Gegenstände so dick, dass Rahmen von Lack, auch wenn derselbe mehrere Male aufgetragen wird, nicht mehr ausreichen, so pflegt man solche - sogenannte Zellen oder 'Tröge =- aus Guttapercha, Kautschuk oder Glas herzustellen und auf den Objectträger aufzukitten. $\mathrm{Zu}$ den Guttaperchaund Kautschukzellen verwendet man am einfachsten die käuflichen Platten, indem man viereckige Stücke, etwas schmäler als die Object. platte, herausschneidet und mit einem Locheise ndurchbohrt (Fig. 145). - Glaszellen ron kreisförmiger Gestalt erhält man, indem man Ringe

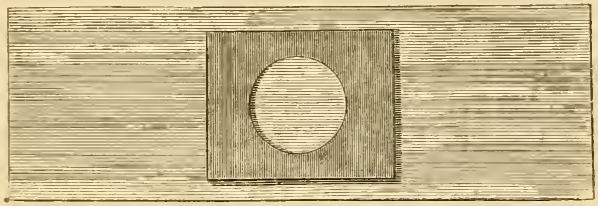

Fig. 145 .

von entsprechender Dicke von Glasröhren absägt und die Schnittflächen eben schleift; sie verlangen natürlich auch kreisrunde Deck- 
gläschen. Zweckmässiger sind indess viereckige Glasplatten mit kreisrunder oder ovaler Oeffnung, ähnlich den Guttaperchazellen, oder auch solche, welche aus linienbreiten Streifen von Spiegelglas zusammengesezt sind. Die letzteren kann man sich leicht selbst bereiten, indem man zweierlei Sorten von Streifen, eine von $15-20$, eine andere von $12-15 \mathrm{~m}$. $\mathrm{m}$. Länge schneiden lässt und sie $\mathrm{zu}$ viereckigen Rahmen zusammenkittet. Man kann auch einen einzigen Glasstreifen über der Gebläseflamme rechtwinklig biegen und die Enden zusammenschmelzen, doch gehört dazu eine geübtere Hand.

Eine Hauptsache bei der ganzen Procedur ist der endgültige Verschluss. Da manche Kitte und Lacke mit der Zeit zahlreiche feine Risse erhalten, durch welche Luft eindringt, so hängt die Dauerhaftigkeit des Präparates wesentlich ron der richtigen Wahl des Verschlussmittels ab. Schacht empfiehlt sowohl zum Aufkitten von Glaszellen als zur Einrahmung der Deckgläschen einen schwarzen Spirituslack, welcher in der Lackfabrik ron Beseler in Berlin (Schützenstrasse Nr. 66) als Maskenlack Nr. 3 zu beziehen ist. Gewöhnlicher werden indess diese beiden Operationen mit zwei verschiedenen Kitten vorgenommen. Zur Befestigung der Glaszellen bedient man sich z. B. des sogenannten Seeleimes (marine glue), einer Masse, welche aus gleichen Theilen Schellack und Kautschuk, beide in Benzin gelöst, zusammengesetzt ist, oder auch der von Har. ting empfohlenen Lösung von Guttapercha und Schellack in Terpentinöl. Beide werden erwärmt, resp. geschmolzen, aufgetragen und hierauf die Zellen oder Glasstreifen unter Erwärmen angedrückt. Zum Einkitten der Deckgläschen wird dagegen meistens der käufliche Asphaltlack, eine Lösung von Asphalt in Leinöl und Terpentin, angewendet; doch hat sich derselbe durch die bisherigen Erfahrungen gerade nicht besonders bewährt, indem er oft schon nach Wochen oder Monaten Risse und Sprünge erhält. Viel besser ist nach Frey (das Mikr. p. 152) ein von Maler Zi egler in Frankfurt a. M. (Friedbergergasse 23) erfundener weisser Kitt, welcher durch gelindes Erwärmen mit Terpentinöl leicht beliebig verdünnt werden kann und wie der Asphaltlack mit dem Pinsel anfgetragen wird. Dieser Kitt soll zwar sehr langsam fest werden und oft noch nach Monaten eindrückbar sein, dafür aber einen vollständig sicheren Verschluss gewähren. Auch der sogenannte Goldgrund oder Gold leim (gold size), wie ihn die Vergolder zum Festkleben der Goldblättchen gebrauchen, wird für den ersten Verschluss als ganz vortrefflich empfoh- 
len und $\mathrm{Harting}$ gibt an, er habe sich desselben lange Zeit ausschliesslich bedient. Frey empfiehlt dagegen noch eine letzte Verkittung mit dem oben erwähnten Ziegler'schen Kitt.

Endlich ist für die Etikettirung der Präparate und die ganze 242 Einrichtung der Sammlung auch die Form und Grösse der $\mathrm{O}$ bjectträger nicht ganz gleichgültig. In dieser Beziehung dürfte das bequeme und hübsche Format, welches Bourgogn e in Paris für seine bekannten Präparate gewählt hat Fig. 146), als Muster zu

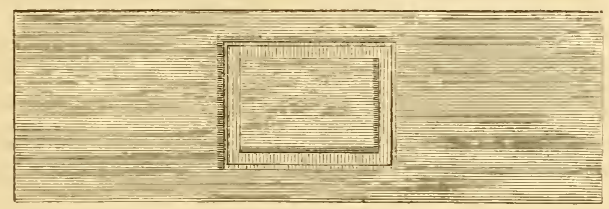

Fig 146 .

empfehlen sein. Es ist dasselbe, welches auch in den englischen Sammlungen eingeführt ist: Objectträger von $27 \mathrm{~m} . \mathrm{m}$. Länge' auf 24 m. m. Breite (3 Zoll engl. Maass zu 1 Zoll). Das vom Tauschverein in Giessen vorgeschlagene Format von $48 \mathrm{~m} . \mathrm{m}$. Länge auf $2 \mathrm{~S}$ m. m. Breite ist unseres Erachtens unschön und weniger bequem.

Zur Bezeichnung des Präparates pflegt man gewöhnlich zwei Etiketten anzubringen, eine auf der linken Seite des Objectträgers mit dem Namen des aufbewahrten Gegenstandes, eine zweite auf der rechten mit der Nummer der Sammlung oder sonstigen Bemerkungen. Ist es von Wichtigkeit, eine bestimmte Stelle im Präparat leicht wieder zu finden, so soll überdiess noch Raum für die betreffenden Zeichen übrig bleiben. Man hat zwar in neuerer Zeit zur Erleichterung dieses Wiederfindens sogenannte Indicatoren construirt, doch bleibt das von $\mathrm{H}$ of f man $\mathrm{n}$ vorgeschlagene Mittel: auf dem Objecttisch zu beiden Seiten der Oeffnung zwei Kreuze einzuschneiden und genau über denselben zwei gleiche Kreuze auf die Objectplatte zu zeichnen, nachdem das Object vorher in die Mitte des Gesichtsfeldes gebracht worden, immer das einfachste und zweckmässigste.

Will man mikroskopische Präparate auf einander schichten, um sie in einem möglichst kleinen Raume aufzubewahren, so ist es rathsam, zu beiden Seiten des Objectes schmale Glasstreifen, welche das Deckgläschen etwas überragen, quer über den Objectträger zu kitten. Manche pflegen diese Schutzleisten auch etwas breiter zu wählen 
und dann zugleich als Deckglas für die Etikette zu verwenden. Den Vorzug verdient indess immerhin die Aufbewahrung der Präparate in Kästchen von Holz oder Pappe, deren Seitenwandungen mit Rinnen versehen sind, in welche die Objectträger einzeln eingeschoben werden. Um ein Sinken der Präparate zu vermeiden, werden solche Kästchen am besten so gestellt, dass die Glasplatten horizontal zu liegen kommen. Auch das Auflegen der Objectträger auf flache Schubladen oder Platten mit niederem Rande, die entweder wie bei einer Kommode vorziehbar sind oder der Reihe nach abgehoben werden können, hat Manches für sich; nur ist diese Einrichtung zum Versenden der Präparate nicht zu gebrauchen.

In den Einzelnheiten der Einrichtung wird sich Jeder, der eine Sammlung anlegen will, nach den Verhältnissen richten und namentlich Zweck und Umfang derselben, sodann Herstellungskosten, Transportabilität etc. von Anfang an im Auge behalten, im Uebrigen aber seinen eigenen Ideen folgen. Es scheint uns überflüssig, auf diese nebensächlichen Dinge weiter einzugehen.

\section{IV.}

\section{Das Messen mikroskopischer Objecte.}

243 Wie wichtig die Grössenbestimmung der Objecte für die mikroskopische Untersuchung ist, bedarf hier keiner Erörterung; auch ist es nicht unsere Aufgabe, die verschiedenen mikrometrischen Methoden, welche in älterer und neuerer Zeit in Vorschlag gekommen sind, hier ausführlich zu besprechen. Wir beschränken uns auf das Messen mit Hülfe des Glas- und Schraubemmikrometers und auf die Bestimmung von Winkelgrössen mittelst des Goniometers.

Das Glasmikrometer, wie es gegenwärtig fast ausschliesslich

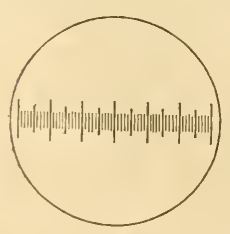

Fig. 147 . im Gebrauch ist, besteht aus einer im Oculareinsatz angebrachten oder zum Einschieben in denselben bestimmten Glasplatte, auf welcher mit dem Diamant eine hinreichend feine Theilung eingeritzt ist. Bei den meisten sind die grösseren $\mathrm{Ab}$. schnitte, wie auf einem gewöhnlichen Maassstab, durch vorspringende Theilstriche bezeichnet (Fig.

147); die älteren Theilungen mit quadratischen Maschen finden wir auf den neuesten Preiscourants nicht mehr ver- 
zeichnet. Die Ocularmikrometer der deutschen und französischen Optiker stimmen überdiess fast durchgehends darin überein, dass sie nach dem metrischen Maass und zwar so construirt sind, dass auf den Nillimeter 10 Theilstriche kommen. Diess gilt z. B. von Bén è che, Zeiss, Belthle, Merz, Schröder, Schiek, Hartnack, Nachet u. A. Unseres Wissens liefert gegenwärtig nur Plössl moch Mikrometer, deren Theilstriche um Bruchtheile einer anderen Einheit, des Wienerzolls, von einander abstehen.

Es versteht sich übrigens von selbst, dass die Theilungen des Ucularmikrometers zunächst nur dazu dienen können, die Grösse des reellen Bildes zu messen. Auf die Objecte selbst bezogen, fällt ihr Werth natürlich um so kleiner aus, je stärker die Objectivvergrösserung, und muss daher für die einzelnen Systeme besonders bestimmt werden. Wird z. B. die Vergrösserungsziffer zweier Objective in Verbindung mit dem Collectiv beziehlich zu 20 und 50 angenommen, so entspricht die Länge von 0,1 m. m. im Oculareinsatz, einem Objectdurchmesser ron 5 Mik. und 2 Mik.

Um den relativen Werth der Mikrometertheilungen zu bestimmen, bedient man sich am einfachsten der Objectmikrometer, wie sie gegenwärtig von den meisten Optikern zu diesem Zwecke gefertigt werden. Es sind Glastäfelchen, auf welchen der Millimeter in 100 bis 250 Theile und darüber getheilt ist, so dass also der Abstand der Theilstriche beziehungsweise nur 10 bis 4 Mik. oder auch weniger beträgt. Bringt man nun ein solches Täfelchen unter das Mikroskop und stellt das Ocularmikrometer dergestalt auf das reelle Bild desselben ein, dass seine Theilung sich leicht mit der bekannten des Objects vergleichen lässt, so kann der fragliche Abstand der Theilstriche offenbar in derselben Weise bestimmt werden, wie diess bei einem gewöhnlichen unbekannten Maassstab geschieht, den man auf einen bekannten gelegt hat. Nehmen z. B. 10 Abstände im Ocularmikrometer auf der Objectplatte einen Raum von 25 Mik. ein, so kommt auf den einzelnen ein Werth von 2,5 Mik.

Die Fehler, welche diesem Bestimmungsverfahren und den 244 darauf gestützten Messungen anhaften, hängen natürlich von der Genauigkeit der beiden Mikrometertheilungen ab; sie können jedoch bei der Vollendung der neueren Theilmaschinen nicht erheblich sein. Bein Ocularmikrometer, wo ohnehin nur die Gleichheit der Intervalle, nicht ihre absolute Grösse, in Betracht kommt, sind dieselben geradezu als rerschwindend $z u$ betrachten, wie man sich leicht über- 
zeugt, wenn man die Mikrometertheilung über das reelle Bild eines beliebigen Gegenstandes hingleiten lässt: das letztere deckt stets die nämliche Zahl von Theilstrichen. Dagegen kommen bei Objectmikrometern, wie $\mathrm{H}$ ar ting nachgewiesen hat, allerdings kleine Abweichungen in dem Sinne vor, dass die Intervalle dem rom Optiker bezeichneten Werth nicht genau entsprechen, sondern etwas zu gross oder zu klein ausgefallen sind. Bei Glasmikrometern ron Oberhäuser. soll die Differenz 0,041, bei solchen ron Plössl 0,009 des angegebenen Werthes betragen, so dass die Resultate der Messung um die genannten Bruchtheile reducirt werden müssen, um richtig zu sein. Inwieweit diese Angaben bei Mikrometertheilungen neueren Datums noch Geltung haben, wollen wir dahingestellt sein lassen; wir erinnern uns jedoch, ein und dasselbe Object wiederholt nach Plössl'scher und Oberhäuser'scher Eintheilung gemessen zu haben, ohne auf nennenswerthe Differenzen zu stossen. Genauere Untersuchungen über diesen Gegenstand haben wir absichtlich nicht angestellt, da wir die Wichtigkeit derselben nicht einsehen; wir sind vielmehr der Ansicht, dass die bei bekannteren Firmen vorkommenden Abweichungen mit Rücksicht auf die Maassbestimmung mikroskopischer Objecte (ganz specielle Fälle abgerechnet) von keinem Belang sind.

Bei vielen Untersuchungen, wo Messungen nothwendig sind, handelt es sich übrigens nur um relative Genanigkeit, d. h. um die Vergleichbarkeit der Resultate des nämlichen Beobachters. Der Letztere muss allerdings wissen, welche Tragweite die möglichen Fehler haben könnten, und selbstverständlich Fehlerquellen zu vermeiden suchen, durch welche die Richtigkeit seiner Schlüsse zweifelhaft würde. Er erreicht aber dieses Ziel in der Regel schon durch einige wenige rasch ausgeführte Messungen, in schwierigeren Fällen durch eine grössere Zahl sorgfältiger Messungen und Berechnung des arithmetischen Mittels; die Prüfung des Messinstruments selbst wird nur äusserst selten geboten erscheinen. Die Fehler, welche von letzterem herrühren, sind fast immer verschwindend klein gegen diejenigen, welche der Beobachter durch unrichtige Einstellung verschuldet. In Fragen, wo solche Fehler der Einstellung irgendwie ins Gewicht fallen, wird kein Mikroskopiker die Messungen eines Anderen mit seinen eigenen vergleichen wollen; er wird sogar von diesen meist nur Ziffern der nämlichen Beobachtungsreihe in Rechnung bringen. Man darf getrost behaupten, dass wenn Messungen verschiedener Beobachter bei irgend einer Untersuchung vergleichbar sind, diese Vergleich- 
barkeit noch fortbesteht, wenn die einzelnen Maasse um 5-10 Procent grösser oder kleiner gewählt werden .

Wenn manche Beobachter die Genauigkeit der directen Messung durch mehrmalige Wiederholung bis auf 0,1 Mik. gesteigert haben wollen, so sind solche Angaben für rein illusorisch zu halten, weil die Art der Einstellung innerhalb viel weiter gezogener Grenzen von der subjectiven Anschauung abhängt. Man lasse zwei geübte Beobachter an einem und demselben Object und mit demselben Mikroskop wiederholte Messungen ausführen. Das Object sei scharf begrenzt und die Messungen nach der üblichen Berechnungsweise bis auf 0,1 Mik. genau. Wenn alsdann nicht ein reiner Zufall im Spiele ist, so wird die Tergleichung der gefundenen Mittelwerthe Differenzen ergeben, welche bei Objecten von 10 Mik. Durchmesser und darüber das $5-10$ fache des vermeintlichen Fehlers betragen. Wozu also diese doch nur scheinbare Genauigkeit?

Die Fassung und Einrichtung der Ocularmikrometer gestattet 245 natürlich mancherlei Modificationen. Bei kleineren Instrumenten sind sie meist unbeweglich im Niveau der Blendung angebracht, womit jedoch der Nachtheil verbunden ist, dass sie von Augen mit verschiedener Sehweite nicht gleich deutlich gesehen werden, und dass die Einstellung eines Theilstriches auf einen bestimmten Punkt nur durch Verschicbung des Objectes bewerkstelligt werden kann. In dieser Hinsicht sind die zum Einschieben in den Oculareinsatz eingerichteten Mikrometer schon etwas bequemer; sie gewähren überdiess den nicht unerheblichen Vortheil, das nämliche Ocular zu Messungen und zụ Beobachtungen verwenden zu kömen, ohne bei letzteren die störendeu Theilstriche immer im Gesichtsfelde zu haben. Von complicirteren Einrichtungen, die natürlich auch in Preise beträchtlich höher stchen, sei hier noch B énèche's "Ocular mit verstellbarem Mikrometer « erwähnt, bei welchem das letztere mittelst einer Schraube seitlich verschiebbar ist, um die Einstellung zu erleichtern, und zugleich die Ocularlinse in einer Hülse auf und ab bewegt werden kann. Die Verschiebbarkeit des Oculars in senkrechter Richtung, erweist sich übrigens für die meisten Beobachter als ziemlich überflüssig, da die Theilstriche auch bei verschiedener Sehweite der Augen deutlich wahrnehmbar sind.

Die Maassbestimmung mikroskopischer Objecte, welche die 246 Intervalle der Mikrometertheilung nur theilweise ausfüllen, kann 
natürlich nur durch approximative Schätzung geschehen. Sind die Objecte fadenförmig, so geht man an sichersten, wenn man dieselben sich rechtwinklig mit den Theilstrichen kreuzen lässt. Das Verhältniss der Intervalle zur Fadendicke kann alsdann bis auf einen kleinen Fehler leicht bestimmt werden. Bei kugelförmigen Gegenständen empfiehlt sich, wo immer möglich, das Aneinanderreihen derselben und die Längenbestimmung der Reihe, mit deren Gliederzahl man alsdann das erhaltene Resultat dividirt. Nach demselben Princip berechnet man auch die mittlere Dicke der Schichten in Membranen, Stärkekörnern etc. und wo es angeht auch die durchschnittliche Grösse der Elementarorgane in Geweben.

247 Das Schraubenmikrometer wurde in neuerer Zeit durch die bequemen und riel wohlfeileren Glasmikrometer fast gänzlich verdrängt. Wir finden dasselbe in den Preiscourants der letzten Jahre nur noch bei Schiek und Schröder in Hamburg) aufgeführt, und es ist kaum anzunehmen, dass die genannten Firmen sich eines bedeutenden Absatzes erfreuen. - Die Einrichtung des Instruments beruht auf dem in der Technik (bei Linirmaschinen, 'Theilmaschinen etc. vielfach angewendeten Princip, dass die Bewegung einer Schraube dem Winkel proportional ist, un welchen ein beliebiger Punkt derselben gedreht wird. Ein nach Art eines Schlittens verschiebbarer Theil des Objecttisches, auf welchem das Object liegt, wird mittelst einer Mikrometerschraube mit sehr feinen Windungen wovon z. B. 5 auf 1 Millimeter gehen) hin oder her bewegt, bis die opponirten Randpunkte des Bildes nach einander mit einem im Ocular ausgespannten Faden zusammenfallen. Der von einem Punkt bis zum andern durchlaufene Weg kann alsdann an dem mit einer Gradeintheilung versehenen Schraubenkopf abgelesen werden, da der Werth eines Grades sich aus dem bekannten einer ganzen Umdrehung leicht berechnen lässt und folglich als gegeben zu betrachten ist.

Eine andere in England gebräuchliche Form des Schraubenmikrometers ist das Ocularschraubenmikrometer. Bei diesem sind zwei parallele Fäden im Gesichtsfelde des Oculars ausgespannt, von denen der eine durch die Mikrometerschraube gegen den andern feststehenden bewegt werden kann. Bringt man nun die Ränder des Objectivbildes mit diesen Fäden zur Deckung, so kann offenbar der Durchmesser desselben viel genauer bestimmt werden, als es mit Hülfe einer Mikrometertheilung auf Glas möglich ist. Uebrigens ist die Messung auch hier nur eine indirecte; der relative Werth der 
Schraubenwindungen muss für jedes Objectiv und jede Tubuslänge, ganz wie beim Glasmikrometer, besonders bestimmt werden.

Auf dem Ramsden'schen Princip, das Objectivbild statt des Ob- $\mathbf{2 4 8}$ jectes zu messen, beruht auch das neuerdings von $H$. v. Mohl vorgeschlagene Schraubenmikrometer (s. Schultze's Archiv für mikr. Anat. Bd. I. 1565). Mohl findet die gewöhnliche Art, wie dieses Princip in Anwendung kommt, entschieden fehlerhaft, weil das Bild des Objects durch das Ocular eine grössere oder geringere Verzerrung erleide, in Folge deren die Vergrösserung, je nach der Entfernung vom Centrum, etwas stärker oder schwächer ausfalle, wodurch natürlich, wie schon Harting gezeigt habe, der relative Werth der Mikrometertheilungen eine Aenderung erfahre. Um diesem störenden Einfluss der Ocularlinse zu entgehen, misst Mohl die Grösse des Objectivbildes nicht unter dem feststehenden Ocular durch Bewegung des Spinnenfadens, sondern führt das Ocular mit dem Fadenkreuz mittelst der Mikrometerschraube quer über das Bild weg, so dass bei der jedesmaligen Einstellung nur das Centrum desselben optisch wirksam ist.

Wir sind der Ansicht, dass der angeblich störende Einfluss der Ocularlinse, welcher durch das vorgeschlagene Verfahren beseitigt werden soll, in Wirklichkeit nicht vorhanden ist. Denn es ist völlig gleichgültig, ob die Ocularlinse gleichmässig oder ungleichmässig vergrössere, wofern nur das Bild, das sie entwirft, die zur genauen Einstellung nöthige Schärfe besitzt. Die Ebene des Objectivbildes fällt ja mit der Ebene der Mikrometertheilung zusammen, und der Raum zwischen den beiden Rändern, den die Nikrometerschraube $\mathrm{zu}$ durchlaufen hat, ist eine Grösse, welche ron der Verzerrung des Bildes durch die Ocularlinse ganz und gar unabhängig ist, da Bild und Maass durch das Ocular die gleichen Veränderungen erfahren. Sind die Ränder des Objectivbildes scharf und bestimmt gezeichnet, so dass die Fäden im Ocular genau darauf eingestellt werden können, so mag die Ocularlinse am Rande doppelt so stark vergrössern als in der Mitte, das Resultat der Messung bleibt hiervon unberührt. Die Harting'schen Grössenbestimmungen, wonach 10 Abtheilungen eines Glasmikrometers, nach einander einzeln und im Centrum des Gesichtsfeldes gemessen, im Durchschnitt je 75,8 Graden des Index entsprachen, während die Gesammtausdehnung der 10 Abtheilungen, direct gemessen, nur 73,5 Grade (statt 75,8) ausmachte, beweisen nur, dass das gemessene Objectivbild selbst ungleichmässig und zwar 
gegen den Rand zu schwächer vergrössert war. *) Es ist diess ein Uebelstand, dem man in höherem oder geringerem Grade wohl bei allen Mikroskopen begegnet und dessen schädlichen Einfluss man in den Fällen, wo es auf möglichste Genauigkeit ankommt, nur dadurch beseitigen kann, dass man den relativen Werth der Theilstriche oder der Schraubenwindungen des Mikrometers mit Hülfe eines Objectes bestimmt, welches mitten im Gesichtsfelde denselben Raum einnimmt wie das zu messende. Handelt es sich z. B. um die genaue Grössenbestimmung eines Objectes, dessen Collectivbild 5 Theilstriche im Ocularmikrometer bedeckt, so wählt man zur Bestimmung der Mikrometertheilungen oder Schraubenwindungen einen Abstand auf dem Objectmikrometer, welcher der nämlichen Zahl von Theilstrichen im Ocular entspricht. Daraus folgt denn auch, dass das zu messende Object immer in die Mitte des Gesichtsfeldes gebracht werden muss.

Das Mohl'sche Ocularschraubenmikrometer kann hienach keine andern Vortheile gewähren als diejenigen, welche allfällig mit der grösseren Schärfe des Bildes in der Mitte des Gesichtsfeldes verbunden sind, und es ist nicht anzunehmen; dass diese Vortheile bei Objecten von höchstens 20-30 Mik. im Durchmesser, für welche das Instrument bestimmt ist, nachweisbar seien.

249 Dass mit gut gearbeiteten Schraubenmikrometern sehr genaue Messungen ausgeführt werden können, bedarf keiner Erörterung. Nach Harting soll bei einem Plössl'schen Instrument der wahrscheinliche Fehler einer einzelnen Messung nur c. 1/3 Mik. und im Mittel aus einer Anzahl Messungen nur c. 1/10 bis 1/13 Mik. betragen. Dabei ist jedoch selbstrerständlich vorausgesetzt, dass der Beobachter richtig einstelle. Wer Interferenzlinien für die Umrisse des Objects ansieht oder durch optische Effecte anderer Art sich irre machen lässt, der wird auch mit dem genauesten Instrument höchst fehlerhafte Resultate erhalten, namentlich wenn der zu messende Gegenstand sehr klein ist. Das richtige Sehen bleibt demnach, wie bereits hervorgehoben, immer die Hauptsache.

250 Sollen wir schliesslich noch ein Wort über die Bezeichnungsweise der mikrometrischen Grössen hinzufügen, so geht unsere An-

*) Wie Harting dazu kommt, diese Differenzen aus der stärkeren Vergrösserung der Randpartieen zu erklären, ist uns unverstăndlich. - Ueber die Ursachen der gegen den Rand zu schwächern Vergrösserung vgl. man pag. $52 \mathrm{u}$. ff. 
sicht dahin, dass der Harting'sche Vorschlag, den Mikromillimeter (=0,001 m.m.) als Einheit zu gebrauchen, allgemeine Beachtung verdiene. Es scheint uns jedenfalls am zweckmässigsten, irgend eine Einheit, welche kleiner ist, als die meisten der zu messenden Objecte, ein für allemal festzusetzen, weil wir ja auch sonst sowohl Zeit als Raum mit solchen Einheiten zu messen pflegen. Da nun das französische Maass in der Wissenschaft unzweifelhaft das bekannteste ist und der Mikromillimeter überdiess auch für die kleinsten noch messbaren Objecte einen bequemen Maasstab bildet, so wüssten wir nicht, was sich gegen die Harting'sche Bezeichnungsweise einwenden liesse. Grössere Dimensionen werden natürlich immer in Millimetern, noch grössere in Metern ausgedrückt, so dass die maassbestimmende Zahl nie mehr als drei Ziffern erhält. Zieht man es vor, die gefundenen Werthe immer in Millimetern zu reröffentlichen, so eignet sich hiezu am besten ein Decimalbruch, wie z. B. $0,0048 \mathrm{m.m}$ (=4, 8 Mik.), da alsdann Jedermann weiss, dass in der dritten Decimale die Einheiten der Mikromillimeter zu suchen sind. Gewöhnliche Brüche, wie $\frac{1}{652}$ oder $\frac{1}{2 \varsigma 9} \mathrm{~m}$. m. geben unseres Erachtens eine ebenso unklare Vorstellung von der wirklichen Grösse eines Objectes, als die Ausdrücke $\frac{1}{652}$ oder $\frac{1}{259} \mathrm{Jahr}$ von der entsprechenden Zeit. Dazu kommt, dass dieselben für die Rechnung unstreitig weniger bequem sind, als ganze Zahlen oder Decimalbrüche. Vollends verwerflich aber sind die gewöhnlichen Brüche mit beliebigem Zähler, wie $\frac{7}{193}, \frac{3}{239}$ etc., da ja doch erst das Terhältniss des Zählers zum Nenner durch Division bestimmt werden muss, bevor man sich annähernd eine Vorstellung von der geınessenen Grösse machen kann.

Zur Vergleichung der verschiedenen Maasseinheiten, die man 251 bei Grössenangaben mikroskopischer Objecte neben dem Millimeter und Mikromillimeter noch anzuwenden pflegt, dient nachstehende kleine Reductionstabelle.

Die Pariser Linie ist

Der Pariser Zoll ist

$=2,2558$ Millimeter.

Die Englische Duodecimal-Linie ist $=\quad 2,1166$

Der Englische Zoll ist

Die Rheinische Linie ist

Der Rheinische Zoll ist

Die Wiener Linie ist

Der Wiener Zoll ist

$$
\begin{aligned}
& =25,3997 \quad \text { " } \\
& =2,1502 \text { » } \\
& =26,1622 \quad \text { » } \\
& =2,1952 \text { » } \\
& =26,3419 \text { » " }
\end{aligned}
$$


Das umgekehrte Verhältniss stellt sich hienach folgendermaassen heraus :

$$
\begin{aligned}
\text { Ein Millimeter } & =0,4433 \text { Pariser Linie. } \\
& =0,0369 \text { " Zoll. } \\
& =0,4724 \text { Englische Linie. } \\
& =0,0394 \quad \text { Zoll. } \\
& =0,4587 \text { Rheinische Linie. } \\
& =0,0384 \quad \text { " Zoll. } \\
& =0,4555 \text { Wiener Linie. } \\
& =0,0379 \quad \text { \#oll. }
\end{aligned}
$$

252 Was nun noch die Bestimmung von Winkelgrössen betrifft, so geschieht dieselbe am besten mit Hülfe des Goniometers. Dasselbe besteht aus einer mit dem Ocular verbundenen, in Grade getheilten Kreisplatte, auf welcher ein Nonius angebracht ist, mit dem gleichzeitig ein im Ocular ausgespanntes Fadenkreuz um seinen Kreuzungspunkt gedreht wird. In diesen letzteren kommt beim Gebrauch die Spitze des zu messenden Winkels zu liegen, während der eine der beiden Fäden nacheinander mit den Schenkeln desselben zur Deckung gebracht wird. Die hiebei erforderliche Drehung wird am Nonius abgelesen. - Andere Optiker bringen die Gradeintheilung an runden drehbaren Objecttisch an, so dass beim Messen das Fadenkreuz im Ocular unbeweglich bleibt, während der Tisch mit dem Objecte gedreht wird. Mit dieser Einrichtung ist jedoch der Nachtheil verbunden, dass das Object wegen mangelhafter Centrirung des Tisches beim Drehen desselben seinen Ort im Gesichtsfelde verändert und daher immer wieder eingestellt werden muss, was mit hinreichender Genauigkeit nur mittelst Schrauben, die auf den nach zwei Richtungen verschiebbaren Tisch wirken, geschehen kann. Aus diesem Grunde verdient das Oculargoniometer entschieden den Vorzug.

In Ermangelung eines Goniometers mag das Zeichnen des Winkels mit der Camera lucida als Nothbehelf dienen. Man verlängert die beiden Schenkel mit.Hülfe des Lineals und misst hierauf den Winkel mit einem gewöhnlichen Transporteur.

Wie man übrigens auch rerfahren mag, es bleibt immer eine Fehlerquelle zu berücksichtigen übrig, welche von der Genauigkeit des Messinstrumentes unabhängig ist. Wenn wir auch von den mancherlei Unregelmässigkeiten, welche die Schärfe der Linien beeinträchtigen und den Parallelismus parallel sein sollender Kanten stören, ganz und gar absehen; wenn wir voraussetzen, die Einstellung auf 
die beiden Schenkel des zu messenden Winkels sei mit aller nur wünschbaren Schärfe möglich, so lässt sich trotz alledem nicht entscheiden, ob die Ebene des Winkels genau mit derjenigen des Gesichtsfeldes zusammenfalle oder etwas gegen dasselbe geneigt sei. Nun ist einleuchtend, dass eine Hebung oder Senkung des Scheitels den Winkel zu gross, eine Drehung um den einen Schenkel dagegen zu klein erscheinen lässt; dass folglich die Ergebnisse der Messung je nach der Lage beträchtlich differiren oder auch bei ungleichen Winkeln gleich ausfallen können. Man kann diesen Uebelstand bei krystallographischen Untersuchungen nie ganz beseitigen, man kaun ihm nur einigermaassen steuern, indem man die Messungen an gleichwerthigen Flächen öfter wiederholt. In manchen Fällen ist es auch möglich, die Neigungen dergestalt zu controliren, dass man ganz bestimmt weiss, ob das erhaltene Maass eines Winkels, insofern es überhaupt ungenau ist, nach + oder - von der wirklichen Grösse abweicht. Handelt es sich z. B. um 'Tafeln, welche als verkürzte klinorhombische Säulen zu betrachten sind Fig. 14S), so ist die gleiche Breite der in der Figur schraffirten Säulenflächen ein Beweis, dass die Endfläche weder nach rechts, noch nach links geneigt ist. In dieser Lage können folglich die Winkel $a$ und $b$ jedenfalls nicht kleiner erscheinen, als sie wirklich sind, da eine allfällige Neigung in der Richtung von $a$ nach $b$ dieselben vergrössern müsste. Aehnliche Anhaltspunkte bieten auch manche andere Krystallformen, und

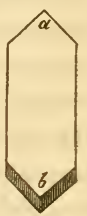
es ist die Aufgabe des Beobachters, sie in jedem gegebenen Falle, wo immer möglich, aufzufinden und zu berücksichtigen. Was nützen Goniometer, welche den Drehungsbogen bis anf 1 Minute genau abzulesen gestatten, wenn die vom Objecte herrührenden Fehler 1-2 Grade betragen? Und man glaube nicht, dass solche Fehler bei kleinen Octaedern, Rhomboedern etc. so ganz leicht zu vermeiden seien. Es gehört, wie uns vielfache Erfahrung gezeigt hat, alle Sorgfalt eines geübten Beobachters dazu, um eine Winkelbestimmung an Krystallen, wie sie gewöhnlich in Pflanzenzellen vorkommen oder nach Zusatz von Reagentien in der Beobachtungsflüssigkeit entstehen, mit Sicherheit bis auf $1 / 3$ Grad genau auszuführen. Das Goniometer darf unter solchen Verhältnissen geradezu als vollkommen betrachtet werden. 
V.

\section{Das Zeichnen mikroskopischer Objecte.}

253 Wer sich einlässlicher mit mikroskopischen Untersuchungen beschäftigt, soll im Stande sein, das Wahrgenommene in Abbildungen wiederzugeben, welche wenigstens in allen wesentlichen Punkten mit dem erhaltenen Eindruck übereinstimmen. Wir sagen : mit dem erhaltenen Eindruck, nicht mit dem Object selbst; denn eine weiter gehende Naturwahrheit, als eben diese relative, ist nicht denkbar. Man kann billiger Weise nicht verlangen, dass die Hand des Zeichners richtig darstelle, was das Auge des Beobachters unrichtig gesehen hat. Die Anforderungen, die man gewöhnlich an den Zeichner zu stellen pflegt: richtige Auffassung, Verständniss des Gegenstand̉es, Naturwahrheit ohne Subjectivität etc. müssen demnach streng genommen auf den Beobachter bezogen werden; der Zeichner hat bloss die Aufgabe, die Vorstellung, welche der Beobachter sich angeeignet hat, sie mag nun richtig oder unrichtig sein, in Anderen wieder zu erwecken. Absolute Naturwahrheit bleibt übrigens für den Mikroskopiker ein Ideal, nach dem er zwar streben soll, das er aber immer nur annähernd erreicht. Seine Zeichnungen sind im günstigsten Falle doch stets nur mit Rücksicht auf diejenigen Punkte naturgetreu, zu deren Versinnlichung sie angefertigt wurden. Mehr wird der Autor selbst, wenn er dieselben nach Jahren wieder zu Rathe zieht, nicht darin suchen.

254 Da die genaue Wiedergabe der Umrisse bei complicirteren Zeichnungen auch für den Geübten eine schwierige Sache ist, so bedient man sich verschiedener Hülfsapparate, welche das mikroskopische Bild auf die.Papierfläche zu projiciren gestatten. Die bekanntesten derselben lassen sich in folgende Kategorien bringen.

1) Apparate, welche die aus dem Ocular hervortretenden Lichtbündel durch Reflexion so ablenken, dass das Bild auf eine senkrechte oder mehr oder weniger geneigte Fläche projicirt wird. Die (letzte) reflectirende Fläche ist hiebei mit einer kleinen Oeffnung versehen oder von sehr geringer Ausdehnung, so dass das Auge in beiden Fällen durch einen Theil der Pupille noch die Bleistiftspitze sieht, mit der man die Umrisse des Bildes umzieht. Die Bleistiftspitze wird also direct, das mikroskopische Bild dagegen durch Spiegelung 
gesehen. Da nun nach Früherem mit einmaliger Spiegelung eine halbe Umkehrung des Bildes verbunden ist, so verdienen diejenigen Apparate den Vorzug, bei denen eine zweimalige Reflexion in der nämlichen Ebene -- bei Prismen cine zweimalige innere Totalreflexion stattfindet.

Hicher gehören der Sömmerring'sche Spicgel, das Zeichnen prisma nach Nachet und das gleichscitige Prisma - beicle mit einnaliger Reflexion, ferner die Camera lucida nach Wollaston, Milne Edwards, Amici und Oberhäuser - alle mit zweimaliger Reflexion. Dic letztgenannte iśt mit einem rechtwinklig gebrochenen Rohre $A$ (Fig. 149

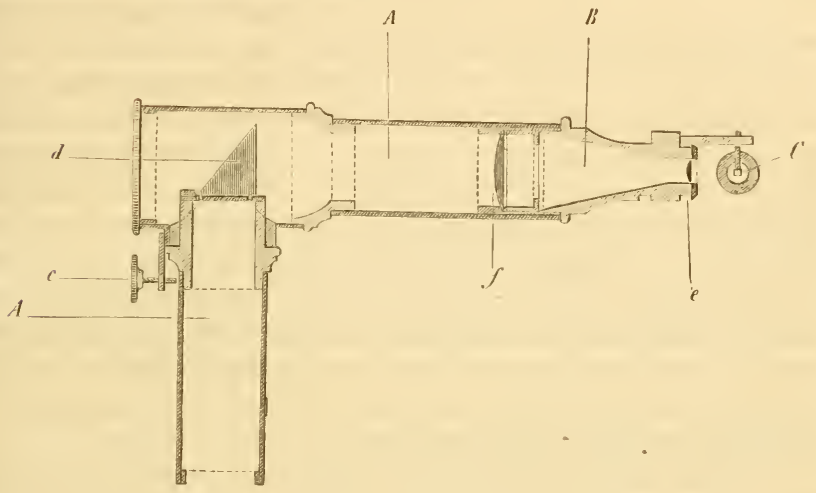

Fig. 11!1.

ausgestattet und gewährt dadurch den Vortheil, dass das als Projectionsebene dienende Zeichnungspapier ummittelbar auf den Arbeitstisch gelegt werden kann, cin besonderes Gestell also nicht nöthig ist. Beim Gebrauche wird der senkrechte Arm des Apparats nach Wegnahme des Oculars in die Mikroskopröhre cingeschoben und das Prisma $C$ durch Drehung der Röhre $B$ so gestellt, dass seine Reflexionsebene mit derjenigen von $d$ zusammenfällt. - Bei den übrigen Apparaten muss dic Projectionsebene eine solche Lage haben, dass die in der Richtung der Mikroskopaxe ausfahrenden Strahlen dieselbe nach der (letzten) Reflexion, rückwärts verlängert, senkrecht treffen. In Folge dessen wird es nothwendig, sich beim Zeichnen eines Gestelles zu bedienen, welches diese Bedingung zu erfüllen gestattet. Wird sie nicht erfüllt, so erscheint das projicirte Bild verzerrt. 
2) Apparate, welche die von der Bleistiftspitze ausgehenden Lichtstrahlen durch zweimalige Reflexion so ablenken, dass dieselben von Punkten des Gesichtsfeldes zu kommen scheinen. Das mikroskopische Bild wird hier durch eine Oeffnung der letzten reflectirenden Fläche oder neben derselben vorbei direct, die Bleistiftspitze dagegen indirect durch Spiegelung gesehen. Die Anwendung dieses Princips gestattet natür-

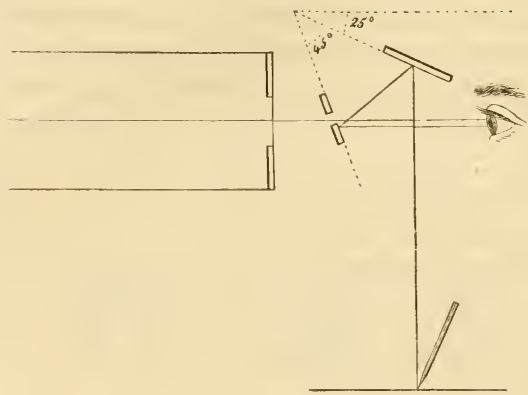

Fig. 15\%. lich ähnliche Modificationen, wie die des vorhergehenden. Uns sind indessen ron Vorrichtungen dieser Art nur das Hagenow'sche Dikatopter (Fig. 150) und der Zeichnenapparat nach Gerling bekannt: Ersteres ist nach Art der O berhäuser'schen Camera lucida mit einem horizontalen Rohre versehen, so dass das mikroskopische Bild eine halbe Unkehrung erfährt. - Beim Gebrauche gilt auch hier die Regel, dass die Projectionsebcne im Spiegelbilde mit dem Gesichtsfelde zusammenfallen oder doch wenigstens parallel sein muss.

Welche von den genannten Vorrichtungen hinsichtlich der bequemen Handhabung den Vorzug verdiene, mag dahingestcllt bleiben, da man hierüber je nach Gewohnheit und Uebung verschiedener Ansicht sein kann. Soviel wird indess Jedermam einleuchten, dass eine halbe Umkehrung, wie sie eine einmalige Reflexion veranlasst wobei z. B. eine rechtsgewundene Spirale in eine linksgewundene verwandelt wird), als wesentlicher Uebelstand zu betrachten ist, der nicht bloss dic Ausführung der Zeichnung erschwert, sondern unter Tmständen auch mancherlei Täuschungen zur Folge haben kann. Das mit dem Apparat in diesem Fall erhaltene Spiegelbild muss daher noch einmal umgekehrt werden, was am besten dadurch geschieht, dass man es am Fenster auf die Rückseite des Papiers durchzeichnet.

Die von Harting empfohlene Methode, das reelle Bild des Objectivs in einem Abstand von c. $400-500 \mathrm{~m} . \mathrm{m}$. aufzufangen und nachzuzeichnen, was natürlich nur mit durchsichtigem Papier ge- 
schehen kann, desgleichen das Verfahren von Stilling ${ }^{*}$ ), das ohnehin für stärkere Vergrösserungen nicht anwendbar wäre, dürften beide ihrer Umständlichkeit wegen kaum viele Nachahmer finden.

Da die Vergrösserung des projicirten Bildes von der Entfernung 255 der Projectionsebene abhängt, so ist es nothwendig, dieselbe für den gewohnten Abstand oder auch für verschiedene Abstände direct zu bestimmen (vgl. pag. 171). Diess geschieht zweckmässig ein für allemal für die verschiedenen Objective; die Vergrösserungsziffern werden tabellarisch zusammengestellt und nebst der Tabelle über die relativen Werthe der Mikrometertheilungen im Mikroskopkasten oder in der Mappe aufbewahrt.

Die Stärke der gewählten Vergrösserung sollte bei jeder Figur angegeben werden. Am einfachsten geschieht diess durch Beisetzen der Vergrösserungsziffer: $(60),(350)$ etc., oder auch in Form eines Bruches: $\frac{60}{1}, \frac{350}{1}$ etc. Das Hinzufügen eines Nenners ist übrigens ganz und gar überflüssig, da es zum Begriff der Vergrösserungszahl gehört, dass der Durchmesser des Objects als Einheit angenommen wircl. Nur wenn das Bild kleiner ist, als das Object, nimmt die Vergrösscrungszahl (die alsdann zur Verkleinerungszahl wird) nothwendig dic Form eines Bruches an.

Die mittelst der Camera lucida erhaltene Zeichnung muss sorg- 256 fältig mit dem mikroskopischen Bilde verglichen und nöthigenfalls corrigirt werden, bevor man an dic weitere Ausführung geht. Es kann nämlich leicht vorkommen, dass wesentliche Dimensionsverhältnisse, wie z. B. die Dicke der Wandungen bei Ziellgeweben, desgleichen gewisse Einzelnheiten der Form in Entwurf unrichtig ausfallen, die Nachhülfe der freien Hand zur Erzielung wahrer Contouren also durchaus nothwendig wird. Die Vollendung der Zeichnung ist ohnehin nur mit freier Hand möglich; es ist diess das schwerste und

*) H a rting beschreibt dieses Verfahren folgendermaassen: "Ein Stückchen Glaspapier wird mit etwas arabischem Gummi auf das Deckplättchen geklebt, unter dem sich ein mikroskopisches Präparat befindet. Nun bringt man dieses unters Mikroskop und mit einer Graveurnadel zeichnet man die Umrisse des rergrösserten Objects auf das Glaspapier. Weiterhin zeichnet man darauf ein Netz von Strichen, wodurch das ganze in viereckige Felder abgetheilt wird, und hierauf trägt man ein ähnliches Netz grösserer Vierecke auf ein Stück Papier auf und übertrïgt darauf die auf dem Glaspapier bewirkte Zeichnung." 
letzte Stück Arbeit, wobei neben der Gewissenhaftigkeit auch die Geschicklichkeit des Zeichners in Betracht kommt. Wer zeichnen gelernt hat, weiss schon mit einfachen Umrissen, die er hie und ‘la etwas verstärkt, mehr zu erreichen, als der Ungeübte mit Wischer und Farbc. Der Letztere ist in schwicrigen Fällen gar nicht im Stande, cin ammähernd naturwahres Bild herzustellen. Es ist daher Jedem, der sich mikroskopischen Forschungen widmet, dringend zı cmpfehlen, sich von Anfang an in Wiedergeben des Gesehenen zu üben. Am besten geschicht diess natürlich immer unter der Leitung eines Lchrers; Bücher bilden einen so schlechten Ersatz, dass wir gänzlich darauf verzichten, denselben hicr bieten zu wollen.

Man kann übrigens in der Ausführung der Abbildungen je nach dem Zwecke, den man erreichen will, sehr verschicden weit gehen. In manchen Fällen ist eine Umrisszeichnung zur Versinnlichung morphologischer oder anatomischer Verhältnisse vollkommen genügend; in anderen beschränkt sich die wcitere Ausführung auf eine rein conventionelle Schattirung gewisser Partieen, auf deren Hervorhebung man gerade Werth legt. In gleicher Weise kann bei einer geschichteten oder fibröscn Substanz der Schichten- oder Faserverlauf durch einfache Linien dargestellt werden; dic Linien bezeichnen aber in dicsem Fall weder dichtere noch weichere Schichten, sic deuten bloss das Vorhandensein derselben an und veranschaulichen ihren Verlauf.

Anders gestaltet sich die Anfgabe, wenn die Abbildung bis auf die kleinsten noeh darstellbaren Details naturwahr sein soll, in dem Sinne wenigstens, dass Licht- und Schattenvertheilung in rationcller Weise zur Veranschaulichung kommen. Man kann abcr auch daun noch auf zwei verschiedene Arten verfahren. Die grösste Annäherung an die Natur würde man freilich dureh genaue Wiedergabe der Lichtabstufungen, wie sie im mikroskopisehen Bilde wirkliel vorhanden sind, erreichen, wobei folgerichtig das Gesichtsfeld selbst einen seiner IIclligkeit entsprechenden Ton erhiclte. Die diehteren Schichten ciner Membran nüssten also hier am hellsten, die weicheren ctwas weniger hell, die Schatten in allen Uebergängen bis zum ticfen Schwarz dargestellt werden. Auf diese Weise könnte eine geschickte Hand die realistische Durchbildung der Zeichnung so wcit steigern, dass dieselbe dem mikroskopisehen Bilde täusehend ähnlich würde.

Von gleichem Werth für wissenschaftliche Zwecke wäre auch das entgegengesetzte Verfahren, wobci die hellsten Stellen an dunkelsten, die dunkelsten am hellsten gehalten werden. Es kommt ja 
hier, wie in der Kartographie, nur darauf an, die 'Keichnung nach einem bestimmten Princip, gleichviel nach welchem, durchzuführen. DerQuerschnitt einer cylindrischen Zelle, deren Membran aus zwei oberflächlichen dichteren und einer mittleren weicheren (röthlichen) Schicht besteht, liesse sich also nach dem Gesagten ebenso gut durch Fig. $151 b$ als durch Fig. $151 a$ darstellen. Die

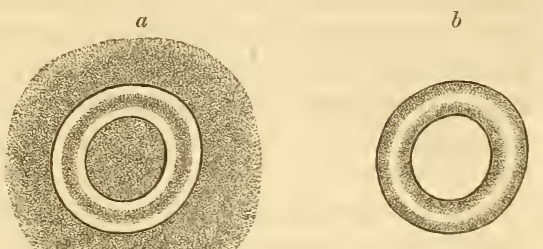

Darstellung auf weisseın Grund würde sich überdiess besser zur Vervielfältigung eignen und überhaupt mehr praktische Vortheile bieten.

Prüfen wir nun nach diesen Erörterungen die anatomischen Ab- 257 bildungen, wie wir sie in neueren mikroskopischen Arbeiten finden, so muss uns auffallen, dass in der Regel weder das eine noch das andere Princip festgehalten ist. Die meisten Zeichner (wir nehmen uns selbst nicht aus) verfahren bewusst oder unbewusst in willkürlich eklektischer $W$ cise, indem sie z. B. dickere Zellwandungen hell, dagegen die faserförmigen Verdickungen derselben, desgleichen die im Lumen enthaltenen Stärkekörner etc. dunkel darstellen. Jeder, der sich die Mühe nehmen will, ausgeführte anatomische Abbildungen hinsichtlich der Darstellungsweise zu prüfen, wird fast überall auf die angegebenen Inconsequenzen stossen. Wir wollen als Beispiel nur die eleganten Tafeln zum s Lehrbuch der Anatomie und Physiologie " ron $\mathrm{Sch}$ a cht erwähnen. Es finden sich dort manche Figuren, die man auf den ersten Blick für sehr ausgeführte Abbildungen halten möchte, die sich aber bei genauerer Untersuchung als blosse Umrisszcichnungen herausstellen, in welchen die willkürlichsten Schattirungen zur Hervorhebung gewisser Theile dienen. Die concentrischen Kreise, womit z. 13. die Schichtung der Bastzellen angedeutet ist $(\mathrm{V}, 3)$, entsprechen weder den weichen, noch den dichteren Sclichten; denn wollte man das annehmen, so wäre das Dickenverhältniss der beiden Schichten ein total unrichtiges. Dasselbe gilt auch von andern geschichteten Membranen (III, 15, 26-2S), sowie von den dargestellten Stärkekörnern. Um gewisse Zellcomplexe hervorzuheben, sind zuweilen die doppelt conturirten Membranen hell gelassen, die der umgebenden Zellen dagegen schattirt u. s. w. Wir kennen 
überhaupt keine mikroskopischen Darstellungen von Schacht, welche nicht in ähnlicher Weise schematisch gehalten wären. Es ist überHüssig zu bemerken, dass wir damit keineswegs eine tadelnde Kritik zu üben beabsichtigen, da ja die schematische Darstellungsweise ihre Berechtigung hat, so gut wie jede andere. Wir wollten nur eine Thatsache constatiren, deren sich Mancher, wie es scheint, gar nicht bewusst ist.

Zu den Willkürlichkeiten, die man sich bei der Darstellung mikroskopischer Objecte gewöhnlich erlaubt, muss auch die beliebige Combination verschiedener Einstellungen gerechnet werden. Durchschnitte durch parenchymatische Gewebe werden z. B. nicht selten so dargestellt, als ob die einzelnen Zellen genau in gleicher Höhe lägen und durchgehends in der Mitte durchschnitten worden wären. Bei Spiralgefässen, Ringgefässen etc. rereinigt man häufig die Flächenansicht mit der mittleren Durchschnittsansicht; zuweilen kommt sogar noch die abgekehrte Seite hinzu. Andere pflegen die mikroskopischen Objecte beliebig vergrössert in Gedanken zu construiren und dann so darzustellen, wie sie bei auffallendem oder durchfallendem Licht dem blossen Auge erscheinen würden. Nach diesem Princip ist z. B. in Fig. 152 eine abgerollte Spiralfaser gezeichnet. Man erlaubt sich dabei die wunderlichsten Freiheiten, indem man z. B. Zellmembranen voraussetzt, die durchsichtig und undurchsichtig zugleich sind; durchsichtig insofern, als die nach innen vorspringenden Verdickungen (Ring- und Spiralfasern etc.) sichtbar gedacht werden, undurchsichtig dagegen mit Rücksicht auf den Verlauf der Spirale (an den Kreuzungsstellen wird nur die zugekehrte Fig.152. Seite gezeichnet) und die Schattirung der umgebenden Hülle.
Die Spirale selbst wird bald auf der zugekehrten, bald auf Fig.152. Seite gezeichnet) und die Schattirung der umgebenden Hülle.
Die Spirale selbst wird bald auf der zugekehrten, bald auf der abgekehrten Seite schattirt oder schraffirt, eine bestimmte Beleuchtung aber weder im einen noch im andern Falle vorausgesetzt. Kurz es herrscht in der Darstellung mikroskopischer Objecte, wenn man von den Formverhältuissen in der Ebene der Zeichnung, die Jeder so genau als möglich giebt, absicht, eine Willkür, die buchstäblich keine Schranken kennt.

Die Widersprüche, an denen die übliche Darstellungsweise leidet, lassen auch nicht so bald cine gründliche Abhülfe erwarten. Einerseits das flächenhafte mikroskopische Sehen bei durchfallendem Licht und grosser Oeffnung der zum Auge gelangenden Lichtkegel; 
andererseits das Bestreben, die Objecte in ihrer Körperlichkeit oder doch in rerschiedenen Durchschnittsansichten zugleich darzustellen, dann die Gewohnheit, bei solchen Darstellungen sich an das Sehen mit blossem Auge und bei auffallendem Licht zu halten, und endlich die Schwierigkeit oder gar Unmöglichkeit, die Bedingungen des mikroskopischen Sehens für das blosse Auge herzustellen - wir wüssten in der That nicht, wie diese Gegensätze je in befricdigender Weise gelöst werden könnten. Die naturgemässe Wiedergabe des mikroskopischen Bildes in photographisch-treuer oder doch in rationellschematischer Weise ist und bleibt nur für eine bestimmte Einstellung denkbar, bei körperlichen Darstellungen ist sie ein Ding der Unmöglichkeit. 


\section{Siebenter Abschnitt. \\ Dic Polarisationserscheinungen.}

I.

\section{Einrichtung des Polarisationsmikroskops.}

259 Bei der Untersuchung mikroskopischer Objecte im polarisirten Licht ist vor Allem eine zweckmässige Einrichtung des Polarisationsmikroskops von Wichtigkeit. Wenn wir als bekannt voraussetzen, dass ein solches Instrument zwei polarisirende Vorrichtungen besitzen muss : einen sogenannten Polaris a to r unter dem Object und einen Analysator über dem Object, so bleibt uns zunächst zu erörtern übrig, wie dieselben am zweckdienlichsten hergestellt werden und wie sie unter den gegebenen Verhältnissen wirken; sodann knüpft sich hieran die weitere Frage, "elche Hülfsmittel und Nebenapparate für die Bequemlichkeit und Sicherheit der Untersuchung ausserdem noch wünschenswerth seien. Bevor wir jedoch diese P'unkte in Betracht ziehen, müssen wir die Bemerkung vorausschicken, dass wir im Folgenden zunächst nur wirkliche Mikroskope im Auge haben, d. h. Instrumente, welche nach Wegnahme der polarisirenden Apparate zu gewöhnlichen Untersuchungen benutzt werden künnen. Polarisationsapparate von wesentlich anderer Construction, wie z. B. das sogenanute Nörrenberg'sche Polarisationsmikroskop, sollen nachträglich, soweit sie bei mikroskopischen Objecten Verwendung finden können, besondcrs besprochen werden.

\section{Der Polarisator.}

2(6) Soll der Polarisator auch bei stärkeren Vergrösserungen noch brauchbar sein, so muss er cinen Lichtkegel liefern, dessen peripherische Strahlen mindestens um $\delta-10$ Grade von der Scnkrechten 
abweichen; denn da ohnehin bloss die Hälfte des einfallenden Lichtes durchgeht, so ist eine un so grössere Convergenz desselben zur Erleuchtung des Gesichtsfeldes nothwendig. Die Herstellung eines solchen Lichtkegels lässt sich in zweicrlei Weise denken: entweder wird er vom Polarisator direct geboten, indem derselbe Strahlen von verschiedener Neigung gleich vollständig zu polarisiren vermag, oder die austretenden polarisirten Strahlen sind unter sich annähernd parallel und werden nachträglich durch eine Sammellinse, welche zwischen Object und Polarisator angebracht ist, convergent gemacht. Die letztere Einrichtung finden wir bei den sogenannten Polarisationsapparaten, wie sie von Duve, Nörrenberg etc. hergestellt wurden; sie ist überall anwendbar, wo der Raum das Einschalten eines Condensors über den reflectirenden oder brechenden Vorrichtungen gestattet, und bedarf nach dem, was früher über die Beleuchtung im Allgemeinen gesagt wurde, keiner weiteren Erklärung. Die erstere Einrichtung ist dagegen die gewöhnliche der Polarisationsmikroskope; sie verdient hier auch entschieden den Vorzug, indem sic an jedem Stativ leicht angebracht werden kann und ohne weitere Nebenapparate vollständig polarisirtes Licht mit hinreichender Convergenz zur Wirkung bringt.

Die bekannteste polarisirende Vorrichtung dieser Art ist das $\mathbf{2}(\mathbf{6} \mathbf{1}$ Nicol'sche Prisma. Da die Construction desselben in jedem physikalischen Lehrbuche besprochen ist, so glauben wir sie hier als bekannt voraussetzen zu dürfen; wir wollen zur Orientirung bloss beifügen, dass in Fig. 153 a $b$ und of die beiden künstlich angeschliffenen Flächen darstellen, welche unter 6 is $^{\circ}$ gegen die Seitenkante $\iota d$ geneigt sind, während man in $b c$ und de noch die Flächen eines stumpferen Rhomboeders angedeutet sieht. Die Trennungsfläche $b e$, an der die beiden 1 fälften zusammengekittet sind, bildet mit den angeschliffenen Endflächen Winkel von $89^{\circ} 17^{\prime}$, die man folglich ohne grossen Fehler einem Rechten gleichsetzen kann. Alle genannten Flächen stehen senkrecht auf dem mit der Ebene des Pa- piers zusammenfallenden Hauptschnitt des Krystalls.

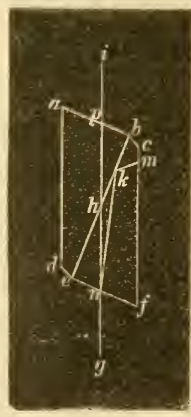

Fig. 153.

Die optische Wirkung eines solchen Nicol besteht nun darin, class der von unten einfallende Strahl $g n$ sich in zwei Strahlen theilt, wovon der ordentliche $u k$ an der Canadabalsams hicht eine totale 
Reflexion erfährt und an den geschwärzten Seitenflächen des Prismas verschluckt wird, indess der schwächer gebrochene a us serordentliche durchgeht und in der Richtung $p i$ das Gesichtsfeld erreicht. Beide Strahlen sind polarisirt und zwar der wirksame ausserordentliche senkrecht zur Ebene des Hauptschnittes; seine Polarisationsebene wird die Polarisationsebene des $\mathrm{Nicol}$ genannt. In der Queransicht des Prismas wird dieselbe durch die längere Diagonale bestimmt, indem die kürzere dem Hauptschnitt parallel geht.

262 Die grösstmöglichen Neigungen, welche die einfallenden Strahlen nach den verschiedenen Seiten hin erreichen dürfen, sind unter den gegebenen Verhältnissen offenbar durch die entsprechenden Grenzwinkel der totalen Reflexion an der Balsamschicht bestimmt. Verfolgen wir zunächst die in der Papierebene nach rechts abweichen-

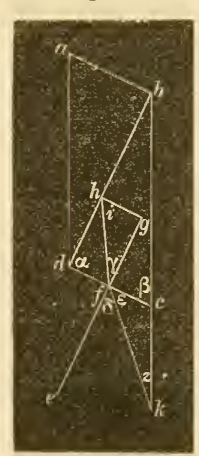

Fig. 154 . den Strahlen. Der Brechungscoefficient des Kalkspathes sei 1,6593 und derjenige des Canadabalsams nach Brewster 1, 549 ; dann ist für den ordentlichen Strahl der Sinus des Grenzwinkels $=\frac{1,6543}{1,549}$, was für den Winkel selbst $69^{\circ} 4^{\prime}$ ergiebt. Ist also lif (Fig. 154) ein nach rechts abweichender einfallender Strahl und $f h$ der ordentlich-gebrochene, so bildet dieser letztere, wenn er ein Grenzstrahl ist, mit dem Einfallsloth $h g$ den eben bezeichneten Winkel von $69^{\circ} 4^{\prime}$. Zieht man jetzt durch $f$ eine Senkrechte auf $d c$ und verlängert dieselbe bis $g$, so ist $\delta$ der Einfallswinkel, $\gamma$ der Brechungswinkel und $z$ die Neigung des einfallenden Grenzstrahls zur Axe. Im Viereck $d f h y$ ist aber nach Früherem $\alpha=89^{\circ} 17^{\prime}$, folglich, da die Winkel in $h$ und $f$ rechte sind, $g=90^{\circ} 43^{\prime}$. Man erhält demnach

$$
\begin{gathered}
\gamma=180^{\circ}-\left(69^{\circ} 4^{\prime}+90^{\circ} 43^{\prime}\right)=20^{\circ} 13^{\prime} \text { und da } \\
\sin \delta=\cos \varepsilon=1,6583 \sin \gamma \\
\varepsilon=55^{\circ} 2^{\prime} .
\end{gathered}
$$

Da ferner $\beta=\varepsilon+z$, folglich $z=\beta-\varepsilon$, so ergiebt sich als Maximum der Neigung

$$
z=12^{\circ} 5 \mathrm{~s}^{\prime} .
$$

Wird dagegen der Brechungscoefficient des Canadabalsams nach $\mathrm{W}_{\mathrm{o}} 1 \mathrm{l}$ aston $=1,52 \mathrm{~S}$ gesetzt, so erhält man für den Grenzwinkel • der gänzlichen Zurückwerfung $67^{\circ} 7^{\prime}$. Hiernach wird $\gamma=22^{\circ} 10^{\prime}$ und $z=16^{\circ} 41^{\prime}$. 
Weniger einfach ist die Rcchnung für die nach der andern Seite $\mathbf{2 6 3}$ geneigten Strahlen. Hier sind es die durchgehenden ausserordentlichen, deren Grenzwinkel die grösstmögliche Abweichung von der Senkrechten bestimmt; denn die ordentlichen treffen die Balsamschicht um so schiefer, je grösser die Neigung, und erfahren daher stets eine vollständige Reflexion. Der Brechungscoefficient der ausserordentlichen Strahlen ist nun aber eine veränderliche Grösse, welche nach Rudberg im Minimum 1,4\$635 beträgt und mit der Abweichung nach links allmählich zunimmt, bis die Richtung der krystallographischen Hauptaxe erreicht ist. Da die letztere im gegebenen Falle mit der Senkrechten einen Winkel von $63^{\circ} 44^{\prime}$ bildet, so ist der jedesmalige Werth für die verschiedenen Abweichungen durch den Leitstrahl einer Ellipse bestimmt, deren grosse Axe mit der krystallographischen Hauptaxe zusammenfällt und sich zur kleinen verhält wie 1,65S5 zu 1,4S635. Für einen im Krystall um $15^{\circ}$ nach links abweichenden Strahl ergiebt sich hienach als Brechungscoefficient 1,5636, welcher Werth gerade hinreicht, um an der Canadabalsamschicht, die der Strahl unter $82{ }^{\circ} 17^{\prime}$ trifft, eine Totalreflexion zu veranlassen (den Brechungsindex des Balsams zu 1,549 genommen). Wird die Brechung an der untern Fläche des Nicol mit in Rechnung gebracht, so ergiebt sich als Maximum der Neigung für die einfallenden Strahlen c. $11^{\circ}$. In Wirklichkeit mag diese Grösse, da der Brechungscoefficient des Canadabalsams von Wollas ton und Young etwas geringer angegeben wird, noch um 2-4 Grade lileiner ausfallen.

Die Gesammtöffnung des einfallenden Lichtkegels in der Rich- 264 tung von rechts nach links beträgt also nach dem Vorhergehenden $12^{\circ} 5 S^{\prime}+11^{\circ}$ für das eine, und $16^{\circ} 44^{\prime}+7^{\circ}$ für das andere Extrem, folglich in beiden Fällen nahezu $24^{\circ}$. Diese Grösse stimmt mit der an einem Nicol von Bénèche experimentell bestimmten ziemlich genau überein. - In der Richtung senkrecht zur Papierebene fallen die Neigungswinkel noch etwas grösser.aus; sie werden hier einzig und allein durch die Dimensionsverhältnisse des Prismas bestimmt.

Damit ist aber noch nicht gesagt, dass ein solcher Lichtkegel dem Gesichtsfelde des Nikroskops in seiner ganzen Ausdehnung zu Gute komme. Der in Fig. 155 genau construirte Strallengang zeigt vielmehr, dass diess nur unter den günstigsten Verhältnissen möglich ist. Die beiden Linien $m n$ und $p q$ stellen zwei Grenzstrahlen dar, 
welche das Prisma in den oben bestimmten Richtungen durchsetzen und an den Grenzflächen die angedeutete Ablenkung erfahren. Zieht

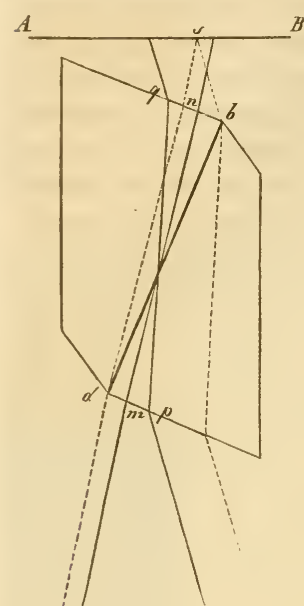

Fig. 155 . man nun durch die Endpunkte $b$ und $d$ der Canadabalsamschicht zwei Linien parallel zu diesen Grenzstrahlen und verlängert dieselben nach oben bis zu ihrem Durchschnittspunkt $s$, so ist einleuclstend, dass wenn $s$ im Gesichtsfelde $A B$ liegt, diess der einzige Punkt ist, welcher durch den vollen Lichtkegel beleuchtet wird. Zu allen übrigen Punkten gelangt nur ein Theil dieses Lichtkegels und zwar ein um so kleinerer, je grösser der Abstand von $s$. Man begreift auch, dass wenn die Einstellungsebene des Mikroskops in einem etwas höheren Niveau liegt, was gewöhnlich der Fall ist, sich die Oeffnung des Kegels auch für die Mitte des Gesichtsfeldes um so mehr reduciren muss, je weiter dieselbe von $A B$ absteht.

Für die Praxis ergiebt sich hieraus die Regel, das Nicol'sche Prisma der Einstellungsebene so viel als möglich zu nähern, da ein Fernerrücken wie eine Verkleinerung des Lichtkegels wirkt. Da jedoch der Optiker auch darauf zu sehen hat, dass der zum Einschalten der Gypsplättchen erforderliche Raum übrig bleibt, so darf er eine gewisse Grenze der Annäherung nicht überschreiten. Der optisch wirksame Theil des Lichtkegels reducirt sich in Folge dessen auf c. $20^{\circ}$ Oeffnung. Ein Polarisator von Bénèch e ergab für das Niveau des Objecttisches in der Mitte des Gesichtsfeldes $21^{1 / 2}{ }^{0}$. Wo eine solche Oeffnung nicht ausreicht, muss die Convergenz der Strahlen durch eine über dem Nicol angebrachte Beleuchtungslinse gesteigert werden.

Soll der Polarisator auch die mehr peripherischen Punkte des Gesichtsfeldes hinreichend erhellen, so darf der Durchmesser der Endfläche nicht zu klein sein. Da nun die Länge eines Nicol fast dreimal so gross ist, als dieser Durchmesser, so kommt ein solches Prisma sehr thener zu stehon.") Foucault suchte diesem Uebel-

Eine verbesserte und etwas wohlfeilere Construction des Nicol'schen Prismas will Hasert (Pogg. Annal. Bd. 113 pag. 1ss) dadurch erzielt haben, 
stande abzuhelfen, indem er den Canadabalsam durch eine Luftschicht ersetzte. Dadurch wird für den ordentlichen Strahl der Grenzwinkel der totalen Reflexion auf $37^{0} 5^{\prime}$ reducirt, und die Brechungsverhältnisse stellen sich am günstigsten heraus, wenn $\alpha$ in Fig. $156=51^{\circ}$ und $\beta=70^{\circ} 52^{\prime}$, welche letztere Grösse der natürlichen Neigung entspricht. Setzt man $c d=1$, so erhält man durch trigonometrische Berechnung $b c=0,915$. Das Foueault'sche Prisma ist hienach verhältnissmässig über dreimal so kurz als das Nicol. Dasselbe lässt sich daher aus kleineren Kalkspathkrystallen herstellen und kounmt in Folge dessen billiger zu stehen. Es leidet dagegen an dem Uebelstand einer sehr kleinen Oeffnung, indem die grösstmögliche Abweichung von der Senkrechten nur ungefähr $4^{\circ}-$ statt $12^{\circ}$ wie beim Nicol - beträgt. Ohne Condensor wăre daher ein sol-

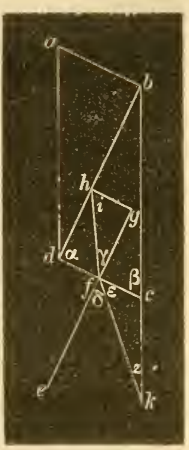

Fig. 156. ches Prisma für das Mikroskop kaum zu gebrauchen.

Neben den Kalkspathprismen wurden von jeher auch Turma- 266 line häufig zu Polarisationsuntersuchungen benutzt. Der Turmalin hat bekanntlich die Eigenschaft, in Platten von c. 1 m. m. Dicke, wenn sie der Axe parallel geschnitten sind, das ordentliche Bild zu absorbiren und nur die ausserordentlich-gebrochenen Strahlen durchzulassen. Diese Eigenschaft lässt sich namentlich bei Turmalinen, welche roth bis rothbraun oder grün gefärbt sind, leicht nutzbar machen, indem die Krystalle nicht nur hinreichend durchsichtig, sondern auch leicht so gross zu bekommen sind, dass man Platten von c. $5 \mathrm{~m} . \mathrm{m}$. im Durchmesser und darüber herausschneiden kann. Allcin da solche Platten nie die reinen Polarisationsfarben liefern, indem diese durch die eigene Farbe des Turmalins modificirt werden, so sind sie als Polarisatoren, so viel wir wissen, nie in Gebrauch gekommen. Dagegen werden sie hie und da als Zerleger benutzt.

Der nämliche Missstand macht sich auch bei der Verwendung

dass er statt des Canadabalsams ein Mittel wählt, dessen Brechungsindex demjenigen des ausserordentlichen Strahls im Kalkspath gleich ist. Er gibt an, dass der Schnittwinkel dadurch von $90^{\circ}$ auf $\$ 1^{\circ}$ reducirt werde, was natürlich einer entsprechenden Verkürzung des Prismas bei gleicher Grundfläche gleich kommt. Auch soll (was wir übrigens nicht begreifen) der Saum der Polarisationszone weder blau noch roth erscheinen, sondern nur eine schwache secundäre Färbung zeigen, etwa wie ein gut corrigirtes Objectiv. Solche verbesserte Prismen sind jederzeit von $\mathrm{H}$ as e $\mathrm{r} \mathrm{t}$ zu beziehen. 
der in neuester Zeit von Haidinger empfohlenen Herapathit krystalle fühlbar. Der Herapathit polarisirt zwar das Licht schon in Plättchen von $1 / 20 \mathrm{~m} . \mathrm{m}$. Dicke sehr vollständig, stört aber ebenfalls durch seine eigene grüne Farbe. Ueberdiess sind grössere Plättchen schwer zu erhalten und daher sehr theuer.

Unter diesen Verhältnissen verdient das Nicol'sche Prisma als polarisirender Apparat unbedingt den Vorzug. Seine Oeffinung ist gerade gross genug, um für ein hinreichend grosses Gesichtsfeld nur ausserordentliche Strahlen zu liefern, während die Foucault'sche Einrichtung auch schief einfallende ordentliche durchlässt, wenn nicht durch sehr kleine an der Fassung angebrachte Blendungen alle über $4^{\circ}$ gegen die Senkrechte geneigten Strahlen voin Gesichtsfelde abgehalten werden.

Die Fassung des Nicol wird am besten so eingerichtet, dass sie nach Art einer Cylinderblendung von unten in den Objecttisch eingeschoben werden kann. Die Blendung soll möglichst nahe über der Endfläche des Prismas angebracht sein und nöthigenfalls durch einen Condensor ersetzt oder mit demselben verbunden werden können, um die Convergenz der Strahlen zu steigern. Achromatische Condensatoren sind hier natürlich ebenso überflüssig, als bei der Beleuchtung mit gewöhnlichem Licht; eine planconvexe Linse von hinreichendem Durchmesser thut ganz dieselben Dienste.

26 Was die Stellung des Nicol zur Lichtquelle betrifft, so empfiehlt Mohl*), den Querdurchmesser der rhombischen Endfäche senkrecht zur Drehungsaxe des Beleuchtungsspiegels einzustellen, um dadurch auch das durch die Reflexion an der Spiegelfäche theilweise polarisirte Licht nutzbar zu machen. V a lentin ${ }^{* *}$ ) wendet hiegegen ein, dass die Verluste, wclche der Beleuchtungsspiegel durch theilweise Polarisation verursache, mit dem Stand der Sonne sich ändern, weil ja das rom Himmel einfallende Licht, wie Brewster gezeigt habe, bereits theilweise polarisirt sei und zwar in einer Ebene, die durch die gesehene Himmelsstelle, die Sonne und das Auge geht, oder in einer daranf senkiechten Ebene, die das Auge und die Himmelsstelle durchschneidet. Er folgert hieraus, dass sich eine allgemeine Regel über die günstigste Oricntirmug des Nicol nicht geben lasse.

*) Pogg. Ann. Bd. 105. 1659. pag. 141-153.

* Die Unters. der Pflanzen- und Thiergewebe im polar. Licht, pag. 101. 
Unseres Erachtens ist dieser Einwand Valentin's unbegründet. Denn die Verluste, welche das vom Himmel einfallende Licht durch den Beleuchtungsspiegel erfährt, sind von denjenigen, welche das reflectirte Licht beim Durchgang durch den Nicol erleidet, durchans nnabhängig. Erstere sind für den Beobachter durch die Lage des Arbeitszimmers und die dadurch bedingte Stellung des Spiegels in jedem Zeitmoment bestimmt. Sie mögen übrigens gross oder klein sein, der polarisirte Theil des reflectirten Lichtes ist unter allen Umständen in der Reflexionsebene polarisirt und wird daher vom Nicol ungeschwächt durchgelassen oder vollständig absorbirt, je nachdem die Polarisationsebene des ausscrordentlichen Strahls mit der Reflexionsebene des Spiegels zusammenfällt oder darauf senkrecht steht. Die Stellung des Nicol ist also maassbestimmend für den polarisirten Theil des einfallenden Lichtes, indess der nicht polarisirte Theil selbstverständlich in jeder Stellung zur Hälfte durchgelassen wird.

Theoretisch betrachtet ist demmach die ron Mohl gegebene Vorschrift begründet. Was dagegen ihren praktischen Werth betrifft, so möchten wir denselben nicht gerade hoch anschlagen, weil die Differenzen der Lichtstärke, die man beim Drehen des Polarisators beobachtet, doch immer so gering sind, dass man sie ohne irgend erheblichen Nachtheil vernachlässigen darf. Von grösserem Belang ist jedenfalls die Spiegelung der schiefen Endfläche, insofern nämlich das von oben und von der Seite einfallende Licht nicht vollständig abgehalten wird. Un dieselbe zu vermeiden, thut man gut, die schiefe Endfläche von der Lichtscite ab- und dem Zimmer zuzuwenden.

\section{Der Analysator.}

Von den mancherlei Modificationen, welche hier denkbar sind, 269 wollen wir zunächst die verschiedenen Stellungen zu den brechenden Flächen des Mikroskops in Betracht ziehen. Theoretisch ist es natürlich vollkommen gleichgültig, an welcher Stelle über dem Object die Zerlegung stattfinde; es ist bloss nothwendig, dass sie sich auf alle zum Auge gelangenden Strahlen erstrecke. Der Analysator kaun also ehenso gut über dem Ocular als über dem Objectiv, er kamn auch an einer beliebigen Stelle in der Mikroskopröhre angebracht sein, und wenn sein Oeffnungswinkel gross genug ist, sogar zwischen Object und Objectiv. Die Frage ist mur, welche praktischen Vor- und Nachtheile diese verschicdenen Stellungen mit sich bringen.

Befindet sich der analysirende Nicol nahe ü ber de m Objectiv- 
system, wie bei manchen Oberhäuser'schen Mikroskopen, so ist es nach Brücke*) nur durch starkes Abblenden möglich, bei rechtwinkliger Kreuzung der Nicols ein vollständig dunkles Gesichtsfeld herzustellen. Man verliert also diescr Angabe zufolge an Lichtstärke, was man an Vollständigkeit der Polarisation gewinnt. Ueberdiess lässt sich erwarten, dass das Objectivbild durch Einschaltung eines so massenhaften Körpers an Schărfe elwas verlieren muss und natürlich um so mehr, je unvollkommener dessen Flächen geschliffen sini. Andererseits wird man mit $\mathrm{H}$. v. Moh ${ }^{* *}$ ) cinen Vortheil darin finden, dass man durch diese Stellung ein grösscres Gesichtsfeld erzielt, als durch jede andere, und dass man dasselbe überdiess bequem überblicken kann.

Valentin $\left.{ }^{* *}\right)$ sucht die unvollständige Verdunkelung des Gesichtsfeldes durch die Divergenz der Strahlen nach dem Durchgange durch das Objectiv zu erklären. Sobald diese Divergenz, heisst es an der citirten Stelle, den Oeffnungswinkel des Nicol übertrifft, so gehen neben den ausserordentlichen auch ordentliche Strahlen durch, die entgegengesetzt polarisirt sind und folglich bei gekreuzten Nicols ein helles Gesichtsfeld geben. Das ist natürlich vollkommen richtig, allein da der Grenzwinkel der gänzlichen Zurückwerfung c. $12^{\circ}$ oder nach Valentin sogar $14-1 \mathrm{~S}^{\circ}$ für die Axe cles Nicol beträgt, so ist die $\Lambda$ nmahme einer so bedeutenden Divergenz durchaus ungerechtfertigt. Die bilderzeùgenden Lichtkegel, welche aus dem Objectiv hervortreten, stehen mit ihrer Basis auf der zweiten Hauptebene desselben und füllen je nach der Vergrösserung eine Oeffnung von c. $3-5 \mathrm{~m}$. m. aus. Das Maximum ihrer Neigung ist durch die Grössc der Blendung im Oculareinsatz bestimmt und beträgt bei den Mikroskopen, die wir kennen, nicht über $4^{\circ}$. Rechnet man hiezu die halbe Oeffnung der einzelnen Lichtkegel, die man auf c. $1^{\circ}$ veranschlagen kann, so ergiebt sich als grösstmögliche Neigung der Randstrahlen gegen die Mikroskopaxe c. $5^{\circ}$. Von einem Durchgehen der ordentlichen Strahlen kamn also hienach nicht die Riede sein.

Die Voraussetzung einer zu grossen Divergenz der austretenden Lichtbündel würde übrigens auch für den Fall, dass sic vollkommen begründet wäre, zur Erklärung der fraglichen Erschcinung nicht ausreichen. Denn da jeder Lichtkegel nach einem bestimmten Punkte im Bilde zielt, so müsste der mittlere 'Theil der Bildtläche, soweit er

\footnotetext{
Denkschr. d. Wiener $A$ kad. Bd. XV. 145̄๕. S. 69.

") Jogge. Ann. (VIII k5!. S. in
} 
von Strahlen mit weniger als $12^{\circ}$ Neigung entworfen wird, bei gekreuzten Nicols doch vollkommen dunkel erscheinen. Erst am Rande würde eine nach ausșen heller werdende Dämmerung bemerkbar, und dieser Randtheil könnte durch eine entsprechende Terklcinerung des Gesichtsfeldes leicht abgeschnitten werden.

Die weiteren Folgerungen, welche Valentin aus dieser eingebil- 270 deten Dirergenz der Lichtkegel zicht, bedürfen nach dem Vorhergehenden keiner Widerlegung. Es ist einleuchtend, dass die Stärke des Objectirsystems, sowie die Grösse der Blendung am Beleuchtungsapparat unter den im Nikroskop gegebenen Verhältnissen auf die Neigung der ausfahrenden Strahlen so gut wie keinen Einfluss üben, sondern bloss die Helligkeit des Gesichtsfeldes verändern. Ẻbenso wenig kam die Länge der Mikroskopröhre hier in Betracht kommen, da die dadurch bedingten Unterschiede verschwindend klein ausfallen. - Man begreift ferner, dass die Divergenz der optisch wirksamen Strahlen zwischen Objectiv und Collectiv überall dieselbe sein muss, da ja die Fortpflanzung eine gradlinige ist; dass jedoch der Querschnitt des lichterfüllten Raumes nach oben allmählich zunimmt und zuletzt nahezu den Durchmesser des Collectivs erreicht. Daraus folgt aber, dass es vollkommen gleichgültig ist, an welcher Stelle der Mikroskopröhre der Analysator cingeschaltet sei, vorausgesetzt, dass die an ihm angebrachte Blendung immer dieselbe relative Grösse besitze, d. h. zu dem eben erwähnten Querschnitt der gesammten Strahlenmasse in demselben Verhältniss stehe. Das Anschramben des Nicol an das untere Ende des Oculars, wie es von Hartïng empfohlen wurde, kann daher ummöglich Vortheile gewähren, die sich nicht auch bei tieferer Stellung erzielen liessen; es ist dagegen mit dem praktischen Nachtheil verbunden, dass das Prisma in jenem höheren Nivean beträchtlich grösser sein muss, um eine aequivalente Wirkung hervorzubringen.

Wir können nach unseren Erfahrungen das Einschalten des 271 Analysators zwischen die brechenden Flächen des Mikroskops aus dem einfachen Grunde nicht empfehlen, weil dadurch die vorhergehende Durchmusterung des Gesichtsfeldes und die genaue Beobachtung bestimmter Objecte erschwert wird. Es kann nämlich bei Untersuchungen im polarisirten Licht von Wichtigkeit sein und ist jedenfalls immer sehr bequem, das Präparat vorerst bei heller Beleuchtung und grösstmöglicher Schärfe des Bildes, also ohne Zerleger, untersuchen zu können und diesen letzteren erst nachträglich auf den 
zu prüfenden Gegenstand, nachdem man ihn in die Mitte des Gesichtsfeldes gebracht hat, wirken zu lassen. Um diesen Anforderungen zu genügen, kennen wir kein besseres Mittel als das schon von Talbot*) empfohlene: den obern Nicol über dem Ocular anzubringen. - In Betreff der Vollständigkeit der Polarisation haben wir dagegen nicht gefundẹn, dass ein in der Mikroskopröhre angebrachter Analysator bei gekreuzter Stellung in merklichem Grade Licht durchlasse; das Gesichtsfeld war vielmehr so vollständig verdunkelt, dass wir mit Rücksicht hierauf keiner andern Lage den Vorzug geben würden.

Die Stellung des analysirenden Nicol über dem Ocular setzt übrigens bei den meisten Mikroskopen eine beträchtliche Grösse desselben voraus, insofern das Gesichtsfeld nicht allzu klein ausfallen soll. Ueberdiess kommt hier die Lage des Augenpunktes und die damit zusammenhängende Convergenz der Lichtbündel in Betracht. Es verlohnt sich der Mühe, den Einfluss dieser beiden Factoren genauer ins Auge zu fassen.

Halten wir uns zunächst an einen bestimmten Fall. Aın Ocular Nr. 2 von Bén èche beträgt der Durchmesser des optisch wirksamen Theils der Ocularlinse c. $3,5 \mathrm{~m} . \mathrm{m}$. Die peripheri-

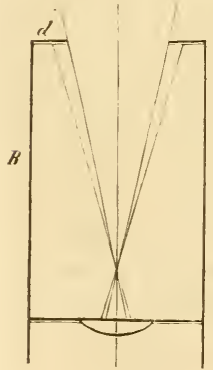

Fig. 157 . schen Lichtkegel, welche den Randpunkten des Gesichtsfeldes entsprechen, sind etwa $16^{\circ}$ gegen die optische Axe geneigt, der Augenpunkt liegt c. $6 \mathrm{~m} . \mathrm{m}$. über dem Ocular. Veranschaulichen wir uns diese Verhältnisse durch eine genaue Construction Fig. 157, wobei jedoch die Lichtbundel durch einfache Linien dargestellt sind) und denken wir uns ein Nicol mit seiner Fassung $B$ aufgesetzt, so ergeben sich — da die Verschiebung der Strahlen parallel mit sich selbst vernachlässigt werden darf - unmittelbar folgende Schlüsse:

1) Die peripherischen Strahlenbündel müssen durch die Blendung bei $d$ bis zu einer Neigung von c. $12^{\circ}$ (dem Grenzwinkel der gänzlichen Zurückwerfung für die ordentlichen Strahlen) abgehalten werden. Das Gesichtsfeld wird also hierdurch eingeschränkt.

2) Da die Blendung beträchtlich über dem Niveau des Augenpunktes liegt, so übersieht das Auge mit einem Male nur ein kleines Stück des Gesichtsfeldes und muss über der Blendung hin-und her bewegt werden, um nach einander auch die übrigen Theile wahrzu-

*) Pogg. Ann. XXXV. 1 $>35$. S. 330. 
nehmen. Der Uebelstand ist natürlich um so grösser, je höher die Fassung des Nicol im Verhältniss zum Abstand des Augenpunktes. Mann könnte indess das Ocular auch so construiren, dass der Augenpunkt in das Niveau der Blendung fiele, womit zugleich eine geringere Neigung der Strahlen zur Axe verbunden wäre. Das Auge würde alsdann von $d$ aus das ganze Gesichtsfeld des Mikroskops mit einem Male überblicken, und das Abhalten der peripherischen Strahlen wäre überflüssig. Nur müsste natürlich der Durchmesser des Nicol dem wirksamen Theil der Ocularlinse entsprechen.

Will man sich mit einem kleinen Gesichtsfelde, wie dasselbe 273 von Bénèche's Ocular Nr. 2 unter den in Fig. 157 dargestellten Verhältnissen 'geboten wird, begnügen, so kann das Nicol auch durch ein einfaches Kalkspathprisma ersetzt werden. Das Bild, welches die ordentlichen Strahlen liefern, erscheint nämlich so weit seitlich verschoben, dass ein in der Axe befindliches Auge nur das der ausserordentlich gebrochencu Strahlen wahrnimmt. Ein solches Prisma ist sogar in manchen Fällen dem Nicol'schen vorzuziehen, da es die Vergleichung des complementären ordentlichen Bildes mit dem ausserordentlichen ermöglicht, wodurch die richtige Deutung und Bezeichnung der Polarisationsfarben oft wesentlich erleichtert wird. Zur bequemeren Beobachtung des ordentlichen Bildes wird die Fassung zweckmässig so eingerichtet, dass sie mindestens eine kleine seitliche Verschiebung des Prismas gestattet, gross genug, um dem Auge nach Belieben das eine oder das andere Bild in der Richtung der Mikroskopaxe vorführen zu können. Dass sie ausserdem noch den Anforderungen zu genügen hat, die man überhaupt an clen Analysator stellen kann, ist selbstverständlich.

3. Der Ajparat zum Drehen der 0hjecte.

Die Beobachtung der Veränderungen, welche die Polarisations- 274 farben beim Drehen der Objecte erfahren, ist bei Untersuchungen im polarisirten Licht so wichtig, dass die gewöhnlichen Manipulationen, durch welche man sonst solche Drehungen auszuführen pflegt, dem Bedürfnisse nicht mehr genügen und daher höchstens als Nothbehelf dienen können. Zur vollständigen Ausstattung eines Polarisationsmikroskops gehört durchaus eine Vorrichtung, welche nicht nur ein langsames Drehen um eine senkrechte sowohl als eine horizontale Axe ermöglicht, sondern auch den Winkel abzulesen gestattet, um welchen man gedreht hat.

Das Drehen um eine sen krechte Axe lässt sich am einfach- 
sten mittelst einer zum Centriren eingerichteten Welcker'schen Drehscheibe bewerkstelligen, welche zum Behuf der Winkelbestimmungen mit einer Gradeintheilung versehen ist. Drehbare Objecttische nach gewöhnlicher Construction sind schon weniger bequem, weil die gleichzeitige Drehung der Mikroskopröhre auch die Stellung des Analysators verändert, wofern der letztere nicht mit der Hand oder durch eine besondere Vorrichtung festgehalten wird. Aber auch abgesehen hievon kann die Drehung der Objectivlinsen, wenn es auf geringe Farbenunterschiede ankommt, zu Täuschungen Veranlassung geben, da hiebei auch nach Wegnahme des Objectes nicht selten ein mehr oder minder deutlicher Wechsel, von der Anisotropie des Glases herrührend, bemerkbar ist. Man thut daher unter allen Unständen am besten, die Drehung auf das Object allein zu beschränken.

Die Bestimmung des Azimuths, in welchem man einen Gegenstand mit Rücksicht auf die Polarisationsebenen der Nicols eingestellt hat, ist übrigens auch mit Hülfe einer Gradeintheilung keineswegs mit der Genauigkeit möglich, die man sonst bei Winkelmessungen erreicht. Zwar lässt sich ein beliebiger Durchmesser der Drehscheibe ziemlich genau in die Diagonalebene des Polarisators bringen, da dieselbe durch die Kanten des Prismas in ihrer Lage bestimmt ist, und ebenso unterliegt auch die Orientirung des Analysators keiner besondern Schwierigkeit. Die rechtwinklige Kreuzung der Nicols ist bis auf einen Grad genau schon durch die grösstmögliche Dunkelheit in Gesichtsfelde bestimmt. Ganz anders verhält es sich aber, wenn das Azimuth eines mikroskopischen Objects, wie z. B. einer Krystallkante, mit Hülfe der Gradeintheilung auf der Drehscheibe gemessen werden soll. Hier handelt es sich nämlich darum, den Parallelismus von Linien herzustellen, wovon die eine nur mit dem rechten, die andere mit dem linken Auge gleichzeitig gesehen werden kann, und in diesem Umstande liegt für den Unkundigen eine sehr erhebliche Fehlerquelle: Legt man z. B., während das rechte Auge ins Mikroskop sieht, einen Bleistift oder ein Lineal so auf die Drehscheibe, dass es beim Doppelsehen mit dem im Gesichtsfelde liegenden Gegenstand genau,parallel verläuft oder vollends zusammenfällt, und sieht hierauf mit dem linken Auge ins Mikroskop, so bilden die verneintlich parallelen Richtungen bei abermaligem Doppelsehen einen Winkel von $6-10 \mathrm{Grad}$. Es liegt auf der Hand, dass man unter solchen Umständen seinen eigenen Augen nicht mehr trauen darf.

Die Ursache dieser auffallenden Erscheinung, die man übrigens in ähnlicher Weise auch beim stèreoskopischen Sehen wahrnimmt, 
ist physiologischer Natur, und es ist nicht unsere Aufgabe, sie hier darzulegen; *) wir haben nur zu constatiren, dass eine solche Täuschung - sie mag nun etwas grösser oder geringer ausfallen - unvermeidlich ist, und hieran die für uns allein wichtige Frage zu knüpfen, wie sich unter diesen Verhältnissen das wah re Azimuth eines mikroskopischen Objects am sichersten emitteln lasse.

In den meisten Fällen wird man der Wahrheit ziemlich nahe kommen, wenn man die Halbirungslinie des oben erwähnten Winkels von $6-10^{\circ}$ als maassbestimmend ansieht. Bei normalen (nicht schielenden) Augen, welche beim Sehen in der Richtung der Mikroskopaxe annähernd dieselbe Raddrehung erfahren, kann der hiebei mögliche Fehler jedenfalls nur ganz unbedeutend sein. Wo indess die grösstmögliche Genauigkeit erreicht werden soll, ist dieses Verfahren nicht mehr genügend oder doch wenigstens einer Controle bedürftig. Man kann alsdann zu folgenden Mitteln greifen:

1) Ist das Ocular mit einer Oeffnung zum Einlegen des Mikrometers versehen, so wird statt des letzteren ein kleines Lineal, ein Glasstreifen oder ein anderer geeigneter Gegenstand eingeschoben und mit dem Rand des zu untersuchenden Objects zur Deckung gebracht. Der aussen vorstehende Theil gibt alsdann die fragliche Richtung genau an, und es ist leicht, einen auf die Gradeintheilung zu legenden Zeiger damit parallel zu stellen.

2) Man stellt die Mikrometertheilung oder den Rand eines auf die Blendung gelegten Deckgläschens zu der in Frage stehenden Richtung im Gesichtsfelde parallel, entfernt nachher das Object und legt dafür eine hinreichend lange Glasplatte unter, deren im Gesichtsfelde als dunkle Linie erscheinenden Rand man in die nämliche, durch das Mikrometer bezeichnete Lage bringt. Die Verlängerung dieses Randes gibt alsdann auf der Gradeintheilung das gewünschte Azimuth. - Wird der Analysator auf die Mikroskopröhre aufgesetzt, so ist es rortheilhaft, ihn so anzubringen, dass seine Stellung beim Drehen des Oculars unverändert bleibt.

Das Drehen um eine wagrechte Axe geschieht ebenfalls 275 am besten mit Hülfe einer besondern Vorrichtung, welche zum Auflegen auf den Objecttisch oder zum Anschrauben an denselben eingerichtet ist. Die Construction derselben lässt sich natürlich in sehr

*) Die hier angeregten Fragen wurden in neuerer Zeit mehrfach erörtert. Man lese z. B. die einschlägigen Arbeiten von $\mathrm{Helmholz} \mathrm{in} \mathrm{"Archiv} \mathrm{für}$ Ophthalmologie " 1863 u. 1864 , und die dort citirten älteren Abhandlungen. 
verschiedener Weise denken; es mag jedoch genügen, wenn wir als einziges Beispiel das in Fig. $15 \mathrm{~S}$ dargestellte Modell erwähnen, das

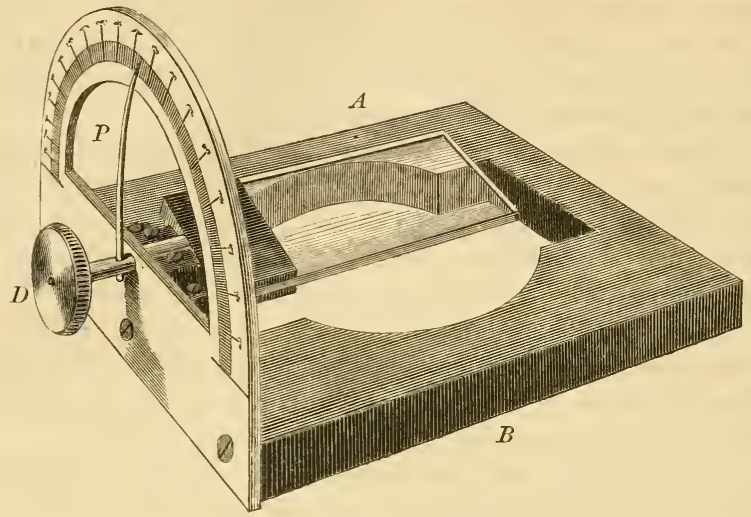

Fig. 15s.

wir nach unseren Erfahrungen als praktisch und vollkommen ausreichend empfehlen dürfen.

Auf der messingenen schwarz lakirten Platte $A \dot{B}$, welche in der Mitte durchbrochen ist, steht lothrecht ein mit Gradeintheilung. versehener Halbkreis, in dessen Krümmungscentrum der Halter $D$ so befestigt ist, dass er mit schwacher Reibung sich um eine senkrecht zur Kreisebene gestellte Axe drehen lässt. Dieser Halter endigt in zwei federnde Messinglamellen, zwischen welche die als Objectträger dienenden Glasplatten eingeklemmt werden. Der Zeiger $P$, welcher mit dem Halter in Verbindung steht, bewegt sich während der Drehung auf der Gradeintheilung und gibt den Drehungswinkel an.

Der Objectträger init doppelter Drehung nach Valentin Fig. 159 entspricht den Bedürfnissen nicht vollständig, weil er

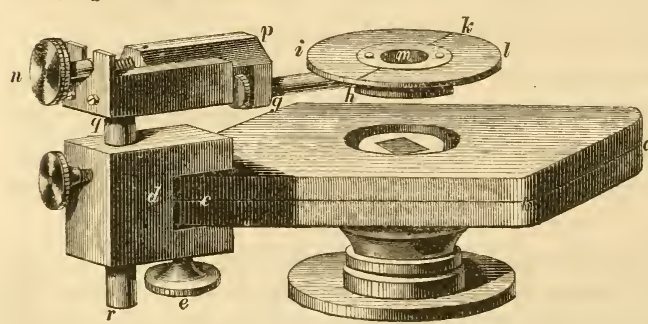

Fig. 159. keine Winkelbestimunungen gestattet; doch mag er immerhin in manchen Fällen Verwendung finden. Derselbe ist zum Anschrauben 
an den Objecttisch eingerichtet und mit Stellschrauben zum Centriren versehen. Die Scheibe hikl kann in ihrer eigenen Ebene und überdiess um die wagrechte Axe $g h$ gedreht werden.

\section{II.}

\section{Das Verhalten anisotroper krystallähnlicher Körper, einzeln beobachtet.}

Wir wenden uns jetzt zur Erörterung der Erscheinungen, welche $\mathbf{2 7 6}$ anisotrope krystallähnliche Körper im polarisirten Licht hervorrufen. Nicht dass wir uns hier die Aufgabe gestellt hätten, physikalische Lehren vorzutragen, die man in jedem Handbuch der Physik mitgetheilt findet, wir setzen vielmehr voraus, dass der Leser mit den Grundlehren der Doppelbrechung und der Polarisation vertraut sei ; allein es schien uns nichtsdestoweniger rathsam, die Beziehungen und Gesetze, die bei Anwendung der mikroskopischen Beobachtungsmethode von specieller Bedeutung sind, zunächst für krystallinische Medien zu entwickeln, um dadurch das schwierigere Studium der organisirten Substanzen vorzubereiten. Manche Begriffe und Benennungen, welche wir in der Folge doch erst festzustellen hätten, lassen sich an Krystallen leichter und unmittelbarer aus den Erscheinungen ableiten, als diess bei den complicirteren geschichteten Gebilden der Thier- und Pflanzengewebe der Fall sein würde. Jene bilden somit den natürlichen Ausgangspunkt für die Lösung unserer Aufgabe.

1. Das Elasticitätsellipsoid.

Das optische Verhalten doppelbrechender Krystalle findet be. $\mathbf{2 7 7}$ kanntlich in der Eigenschaft derselben, die Lichtwellen nach den verschiedenen Richtungen des Raumes mit ungleicher Geschwindigkeit fortzupflanzen, seine Erklärung. Die Fortpflanzungsfähigkeit erreicht nämlich in einer bestimmten Richtung ihr Maximum und in einer andern dazu rechtwinkligen ihr Minimum; dazwischen liegen die gesetzmässigen Uebergänge. Denkt man sich von einem beliebigen Punkt im Innern der Substanz aus Linien gezogen (Fig. 160), welche das relative Leitungsvermögen in den entsprechenden

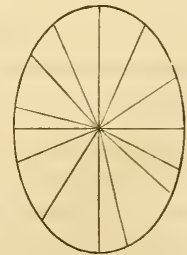

Fig. 160. Richtungen darstellen, so liegen die Endpunkte dieser Linien in einer Fläche von ellipsoidischer Gestalt, in welcher der gedachte Punkt den Mittelpunkt bildet. Es ist diess die sogenannte Elasti- 
citätsfläche oder das Elasticitätsellipsoid.* Dic geometriscleen Axen dieses Ellipsoids, die den Namen der E1asticitätsax en führen, fallen mit den Krystallaxen zusammen, wo diese rechtwinklig sind, weichen dagegen in den schiefwinkligen Systemen mehr oder weniger davon ab. Bei monoklinischen Krystallformen findet die Abweichung jedoch nur in der Ebene statt, welche dieselben in zwei symmetrische Hälften theilt.

In Krystallen mit einer Hauptaxe und gleichen Nebenaxen, wozu die tetragonalen, hexagonalen und rhomboedrischen Formen gehören, ist das Leitungsvermögen senkrecht zur Hauptaxe mach allen Richtungen gleich und parallel derselben am grössten oder am kleinsten; das Elasticitätsellipsoid stellt hier eine Rotationsfläche dar, deren Drehungsaxe in die krystallographische Hauptaxe fällt. Dagegen sind in Krystallen mit drei ungleichen Axen, wie sie das rhombische, monoklinische und triklinische System aufweist, auch die geometrischen Axen der Elasticitätsfläche ungleich; die letztere ist hienach ein Ellipsoid mit einer grössten, einer mittleren und einer kleinsten Axe.

278 Un diese Eigenschaften mit dem innern Bau in einen gewissen Zusammenhang zu bringen, ist es gut, sich die analogen des comprimirten oder expandirten Glases ins Gedächtniss zu rufen. In eimem Parallelepiped von Glas, welches mittelst einer Zange oder Presse zusammengedrückt wird, rücken bekanntlich die Massentheilchen in der Richtung der wirkenden Kraft sich gegenseitig etwas näher. Eine Kugel, welche man sich vor der Compression in das Glas hineindenkt $($ Fig. 161 A), plattet sich in Folge derselben in der angedeuteten Richtung ab (Fig. $161 \mathrm{~B}$ ) und wird dadurch zum Rotationsellipsoid, dessen Hauptaxe jener Richtung parallel geht. Findet die Compres-

*) Streng genommen ist die Elasticitätsfläche, wie sie Fresnel auf analytischem Wege bestimmte, kein Ellipsoid, sondern ein Fläche der vierten Ordnung, deren Gleichung, auf rechtwinklige Axen bezogen, folgende ist

$$
\left(z^{2}+x^{2}+y^{2}\right)^{2}=a^{2} x^{2}+b^{2} y^{2}+c^{2} z^{2} \text {. }
$$

Die Diametralschnitte durch diese Fläche sind aber annähernd Ellipsen und in zwei bestimmten Lagen, ganz wie bein Ellipsoid, Kreise. Das nämliche gilt auch von der Elasticitätsfläche des Druckes nach $N$ e u $\mathrm{m}$ an $\mathrm{n}$. In der mathematischen Optik wird desshalb statt der wahren Elasticitätsfläehe das viel leichter zu behandelnde Ellipsoid den weiteren Rechnungen zu Grunde gelegt.

Für die folgenden Betrachtungen ist übrigens eine bestimmte Voraussetzung in Betreff der Form der Elasticitätsfläche gar nicht nothwendig. Es genügt zu wissen, dass die Schnittflächen derselben im Allgemeinen ovale Figuren mit zwei unglcichen Axen und in zwei besonderen Fällen Kreise sind. 
sion in zwei rechtwinklig aufeinander stehenden Richtungen statt

Fig. $162 B \mathrm{rgl}$. mit $A$ ), so behält nur der senkrecht zur Papierebene
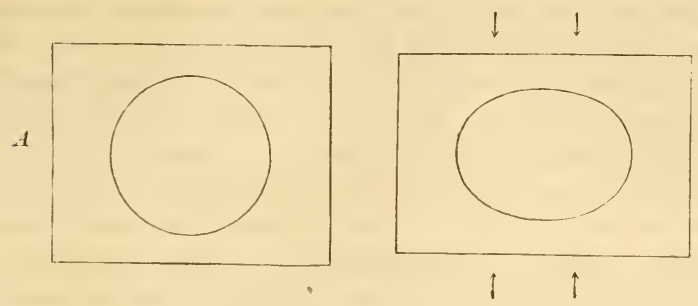

$b^{\prime}$

Fig. 161.
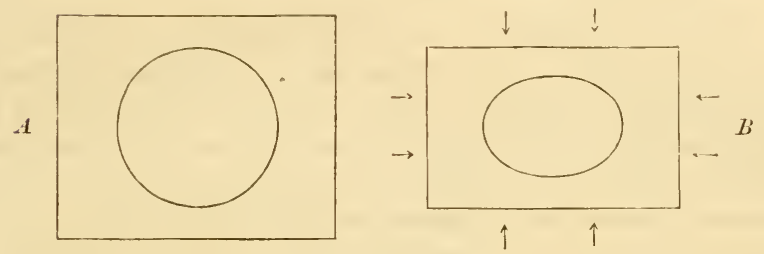

Fig. 162.

orientirte Kugeldurchmesser seine ursprüngliche Länge istreng genommen wird er durch den seitlich wirkenden Druck etwas verlängert), während die beiden andern sich um einen gleichen oder ungleichen Bruchtheil verkürzen, je nachdem die wirkenden Kräfte gleich oder ungleich sind. Gleiche Kräfte verwandeln hienach die Kugel in ein verlängertes Rotationsellipsoid, ungleiche in ein Ellipsoid mit drei ungleichen Axen.

Die Formveränderungen, welche die eingebildete Kugel in Folge der Compression erfährt, lassen sich also leicht bestimmen. Da num im comprimirten Glase die Anziehung der Massentheilchen mit der Annäherung zunimmt und die Abstossung des Aethers ihr stets das Gleichgewicht hält, so muss angenommen werden, dass die Dichtigkeit des Aethers durch die Compression eine Veränderung im gleichen Sinne erfahre wie die Substanz. Mit der Dichtigkeit des Aethers ändert sich aber auch die Fortpflanzungsgeschwindigkeit des Lịchtes, und wenn wir auch unerörtert lassen, wie diese Veränderung erfolgt, so ist doch einleuchtend, dass das resultirende Ellipsoid in analoger Weise, wie die Elasticitätsfläche der Krystalle, die optischen Eigenschaften des comprimirten Glases veranschaulicht. 
Es untẹliegt auch keiner Schwierigkeit, die Uebereinstimmung für die verschiedenen denkbaren Fälle experimentell nachzuweisen. Wird das Glas bloss nach einer Richtung comprimirt oder expandirt, so verhält es sich wie ein Krystall mit einer Hauptaxe, die in der Richtung der wirkenden Kraft dahingeht; die Elasticitätsfläche ist ein Rotationsellipsoid. Lässt man sodann senkrecht zur ersten cine zweite ihr ungleiche Kraft wirken, so verwandelt sich das Rotationsellipsoid in ein solches mit drei ungleichen Axen; das Glas verhält sich jetzt wie ein Krystall ohne Hauptaxe. Man kann überhaupt ganz allgemein sagen: Ein Parallelepiped von Glas kann stets so comprimirt werden, dass sein optisches $V$ erhalten einem gegebenen einoder zweiaxigen, positiven oder negativen Krystalle entspricht.

Die Art und Weise, wie die Aetherdichtigkeit auf die Bewegung des Lichtes einwirkt, ist durch die eben entwickelten Beziehungen im Allgemeinen festgestellt. Allein eine bestimmte Formulirung des fraglichen Abhängigkeitsverhältnisses ist damit noch nicht gewonnen. Jene Bezichungen genügen nicht, um das Elasticitätsellipsoid in ein gegebenes Medium mit bekannten optischen Eigenschaften, soweit sie durch Beobachtung bestimmbar sind, hineinzuconstruiren; es kann diess nur unter Voraussetzungen geschehen, welche der Theorie der Lichtbewegung entnommen und daher jedenfalls mit Thatsachen, wie sie die directe Beobachtung gibt, nicht zu verwechseln sind. Die Undulationstheorie in ihrer jetzigen Gestalt nimmt an, die Fortpflanzungsgeschwindigkeit des Lichtes sei bloss von der Aetherbeschaffenheit in der Richtung der Schwingungen, nicht aber von derjenigen in der Richtung der Strahlen abhängig. Das Elasticitätsellipsoid wird hienach so construirt, dass die Durchmesser desselben, welche den Schwingungsrichtungen beliebiger Strahlen parallel gehen, den aus den Brechungscoefficienten berechneten Geschwindigkeiten entsprechen, womit jene Strahlen das krystallinische Medium durchsetzen. Es erscheint also beispielsweise in positiveinaxigen Krystallen abgeplattet wie das Erdsphäroid, in negativeinaxigen dagegen eiförmig-verlängert.

Wir haben es vorgezogen, diese theoretischen Vorstellungen zu umgehen und unsere Erörterungen ohne alle und jede Theorie an das Ellipsoid des Glases, wie es durch Druck oder Zug aus der Kugel entsteht, anzuknüpfen. Den negativ-einaxigen Krystallen schreiben wir dem entsprechend ein an den Polen abgeplattetes Rotationsellipsoid zu, weil sie in Plättchen, die parallel zur optischen Axe 
geschliffen sind, wie eine Glasplatte wirken, welche in der Richtung jener Axe comprimirt wurde. Dagegen erhalten die positiv-einaxigen Krystalle ein in der Richtung der optischen Axe verlängertes Ellipsoid, weil sie sich optisch wie eine in gleicher Richtung expandirte Glasplatte verhalten. Die Vergleichung der doppelbrechenden Medien mit comprimirtem oder expandirtem Glas soll uns überhaupt immer das Mittel liefern, Form und Stellung des Elasticitätsellipsoids richtig zu bestimmen.

Die Benennung " Elasticitätsellipsoid " glauben wir füglich bei- $\mathbf{2 8 0}$ behalten zu dürfen, obschon wir eine genaue, algebraisch formulirbare Vorstellung ron der Art, wie die Lichtbewegung durch die Radien unseres Ellipsoids bestimmt wird, hier gar nicht damit verbinden. Das Abhängigkeitsverhältniss, welches für unsere Zwecke Bedeutung hat, braucht weder in Ziffern moch durch Formeln ausgedrückt zu werden, es kann auch ebenso gut ein reciprokes als ein directes sein; aber es ist selbstverständlich doch überall dasselbe. Darum verlangt denn auch die Consequenz überall dieselbe, den Erscheinungen gleich angepasste Orientirung.

2. Die Polarisationserscheinungen in ihren Beziehungen zum Elasticitätsellipsoid.

Wir gehen jetzt an die Feststellung der Beziehungen, welche 2\$1 zwischen dem Elasticitätsellipsoid und den Erscheinungen der Doppelbrechung und Polarisation bestehen, wobei wir jedoch die Bemerkung vorausschicken, dass wir uns nur mit den Fällen befassen, welche für die mikroskopische Beobachtung von Bedeutung sind. 'Thatsachen, welche bloss den Physiker oder Mathematiker interessiren können, glauben wir füglich übergehen zu dürfen.

Das Elasticitätsellipsoid, das wir uns in die Substanz hineindenken wollen, sei ein solches mit drei ungleichen Axen; die grösste sei $a$, die mittlere $b$ und die kleinste $c$. Dann sind die Schnittfächen, welche man sich in beliebiger Richtung durch das Centrum geführt denkt, im Allgemeinen Ellipsen, deren Excentricität am grössten ist, wenn sie in die Ebene der grossen und kleinen Axe fallen. In zwei Fällen jedoch - so lehrt die analytische Geometrie - werden diese Ellipsen zu Kreisen, und diese Kreisschnitte des Ellipsoids gehen stets durch die mittlere Axe oder sind ihr parallel. Die Neigung derselben zur Axe $a$ ist durch das Verhältniss $a: b: c$ bestimmt; man hat 


$$
\operatorname{tang} \delta= \pm \frac{c}{a} \sqrt{\frac{u^{2}-b^{2}}{b^{2}-c^{2}}},
$$

wenn näınlich $\delta$ den fraglichen Neigungswinkel bezeichnet. Die Normalen der Kreisschnitte, d. h. die Linien, welche dieselben senkrecht treffen, liegen folglich in der Ebene der grössten und kleinsten Axe; sie schneiden die erstere unter Winkeln, welche die eben erwähnte Neigung $\delta$ zu $90^{\circ}$ ergänzen.

Suchen wir diese Verhältnisse durch eine Figur zu veranschau-

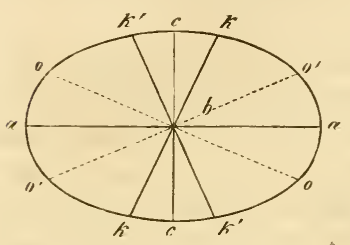

Fig. 163 . lichen. Es sei a a (Fig. 163) die grösste und $c c$ die kleinste Axe; die mittlere, welche senkrecht zur Papierfläche steht, erscheint alsdann in $b$ als Punkt. Die beiclen Kreisschnitte seien $k k$ und $k^{\prime} k^{\prime}$; sie stehen ebenfalls senkrecht zur Papierfläche und werden daher als Linien gesehen, welche mit den Normalen oo und $o^{\prime} o^{\prime}$ rechte Winkel bilden.

282

Mit diesen Eigenschaften des Elasticitätsellipsoids steht nun das optische Verhalten der doppelbrechenden Substanzen in folgendem

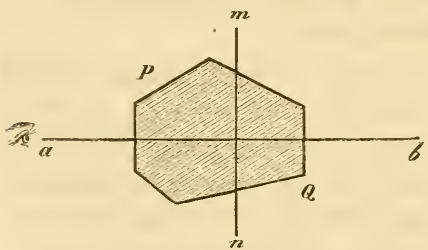

Fig. 164 . Zusammenhang. Ist $P Q$ (Fig. 164) ein Stück einer solchen Substanz mit beliebig orientirtem Elasticitätsellipsoid, so ist die Wirkung desselben anf das parallelstrahlige Lichtbündel $a b$ nur von den Elasticitätsverhältnissen in einer senkrecht zur Strahlenrichtung verlaufenden Ebene $m n$ abhängig und folglich durch die Ellipse bestimmt, welche den jener Ebene parallelen Diametralschnitt des Ellipsoids darstellt. Denken wir uns also ein beliebiges Object unter dem Mikroskop in langsamer Drehung begriffen, so dass sein Elasticitätsellipsoid Fig. 165 nach und nach alle möglichen Neigungen gegen die von unten einfallenden Lichtstrahlen amnimmt, so ist der Effect, den dasselbe hervorbringt, für jede Stellung durch die Schnittfläche $m b n b$ bestimmt, welche der Ebene des Gesichtsfeldes parallel geht. Mit andern Worten: Eine planplane Platte, die man sich beliebig aus der Substanz herausschneidet und auf den Objecttisch legt, wirkt stets nach Maassgabe eines Schnittes, welcher in gleicher Richtung durch 
das Elasticitätsellipsoid geführt wird. Ein solcher Schnitt ersetzt also gewissermaassen das Ellipsoid; er gibt ein vollständiges Bild der unter den gegebenen Verhältnissen wirksamen Elasticitäten und kann daher als wirksame Elasticitätsellipse bezeichnet werden.

Der fragliche Zusammenhang ist hiemit rom Raume auf die Ebene zurückgeführt und lässt sich hier leicht reranschaulichen. Sei $p q r s$ (Fig. 166) die wirksame Elasticitätsellipse und $p q$ die grössere, $r s$ die kleinere Axe; dann erfahren die (senkrecht zur Papierebene) einfallenden Lichtstrahlen eine Theilung in zwei $W^{\prime}$ ellensysteme, welche in den Ebenen der beiden Axen polarisirt sind. Die Schwingungen des einen Systems finden also parallel $p q$, die des andern parallel $r s$ statt. Die relative Grösse der Axen bedingt zugleich die Geschwindigkeiten, mit

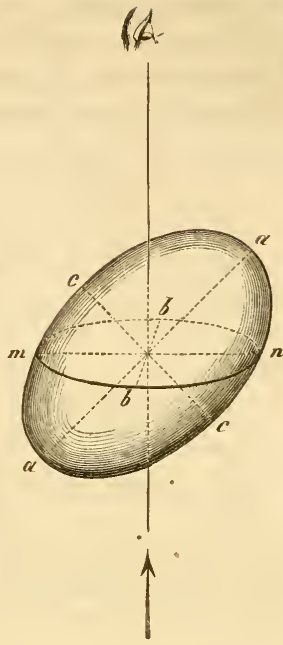

Fig. 165. welcher die beiden Systeme das Object durchsetzen; je grösser $p q$ im Verhältniss zu $r s$, desto grösser erweist sich die Differenz zwischen den beiden Fortpflanzungsgeschwindigkeiten, sowie der dadurch bedingte Phasenunterschied bei gegebener Dickedes Objects.

Beim Drehen des Objects ändert sich natürlich das Terhältniss zwischen $p q$ und $r s$, und es ist wichtig, sich über den Gang dieser Veränderungen zu orientiren. Wir

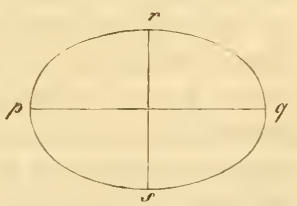

Fig. 161 . denken uns vorläufig, die Drehungsaxe falle mit der mittleren Axe des Ellipsoids zusammen und die Drehung selbst finde in unserer Seitenansicht Fig. 165) in der Ebene des Papiers statt: $a a$ ist alsdann die grosse, $c e$ die kleine Axe des Ellipsoids; die mittlere $(b)$ erscheint perspectivisch verkürzt. Betrachten wir nun zunächst die Stellung, in welcher $a$ a mit der Ebene des Gesichtsfeldes zusammenfällt, so geht hier die wirksame Elasticitätsellipse durch die Axen a $a$ und $b b$ des Ellipsoids Dieselbe hat also ungefähr die Form, wie sie in Fig. 167 unter $A$ dargestellt ist, indem natürlich $b b$ grösser als $\cdot C$ und kleiner als $a a$. Drehen wir jetzt das Ellipsoid um die Axe $b l$ 
und lassen es hiebei wie eine rollende Kugel von links nach rechts fortrücken, so entspricht selbstverständlich jeder Stellung eine andere Elasticitätsellipse. In sämmtlichen Ellipsen, die hiebei successive zur Wirkung kommen, hat aber die eine Axe, weil sie die Drehungsaxe

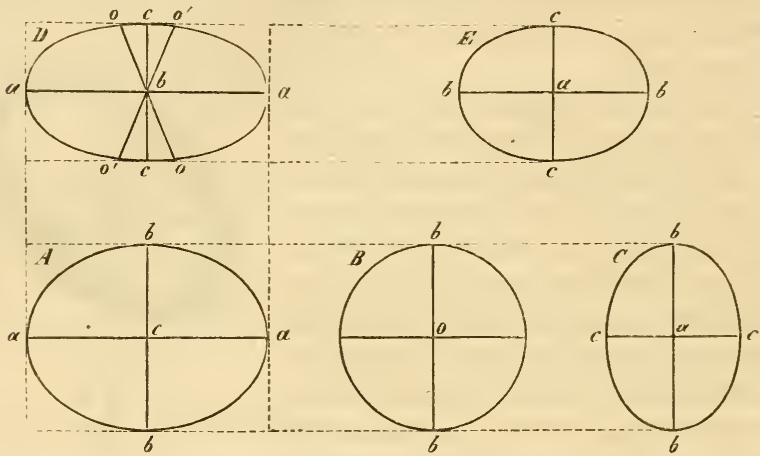

Fig. 167 .

ist, die constante Länge $b b$, indess die andere nach und nach alle Werthe zwischen $a a$ und $c c$ annimmt und nach einem halben Umlauf wieder gleich $a a$ wird. In der Ebene der Kreisschnitte $(k \%$ und $l^{\prime} l^{\prime}$ in Fig. 163) sind natürlich beide Axen einander gleich Fig. $167 \mathrm{~B})$; darüber hinaus wird die quergestellte Axe kleiner als $b b$ und nimmt continuirlich ab, bis sie endlich nach einer Drehung von $90^{\circ}$ mit der Axe $c c$ des Ellipsoids zusammenfällt (Fig. $167 C)$. Bei fortgesetzter Drehung wiederholen sich die möglichen Formen der Schnittfläche in umgekehrter Reihenfolge, bis a a zum zweiten Male in die Ebene des Gesichtsfeldes fällt. Hiemit sind die möglichen Stellungen des Ellipsoids erschöpft; denn da dic beiden Scheitel gleichwerthig sind, so ist das Wiedererreichen der horizontalen Lage mit der Rückkehr zum Ausgangspunkte gleichbedentend.

294 Die Lagen des Ellipsoids, in welchen die Kreisschnitte horizontal zu liegen kommen, verdienen nachträglich noch eine besondere Betrachtung. Die Elasticität des Aethers ist in diesen Lagen nach allen Richtungen im Gesichtsfelde gleich gross, ganz so, wie in einer isotropen Substanz. Dem entsprechend wird das ron unten einfallende Licht auch nur einfach gebrochen und die Polarisation unterbleibt. Die Normalen auf den Kreisschnitten entsprechen hienach 
den Richtungen, in welchen das Licht sich wie in einem einfach brechenden Medium bewegt; es sind diess die optischen Axen. Jie Linie, welche ihren spitzen Winkel halbirt, heisst die Mittellinie; je nachdem dieselbe mit der grössten oder mit der kleinsten Axe unseres Ellipsoids zusammenfällt, pflegt man die Körper optisch-positiv oder optisch-negativ zu nennen.

Kehren wir jetzt zu unserer Ausgangsstellung (Fig. 167 A) zu- 285 rück, um von hier aus die Drehung um die Axe a $a$ zu verfolgen. Wir stellen uns vor, das Ellipsoid werde auf der Papierfläche nach oben gerollt, so dass die Drehungsaxe nach einem Viertelumlauf mit u $a$ in Fig. $167 \mathrm{D}$ zusammenfällt. In dieser Lage steht offenbar $b \succ$ senkrecht zur Papierfläche und die kleinste Axe $c c$ wird optisch wirksam. Die Axen der Elasticitätsellipse sind also $a$ a und $c c$. In unserer Figur sind hier auch die optischen Axen ( $o o$ und $\left.o^{\prime} o^{\prime}\right)$, weil sie in die Ebene der Zeichnung fallen, dargestellt. -- Bei fortgesetzter Drehung würde natürlich die kleine Axe der Ellipse wieder zunehmen, bis sie nach einer halben Umdrehung zum zweiten Mal ihren Maximalwerth $b b$ erreicht hätte.

Drehen wir endlich das Ellipsoid noch um die dritte Axe $c c$, so bildet offenbar $c c$ die eine Axe der wirksamen Elasticitätsellipsen, welche den verschiedenen Stellungen entsprechen, indess die andere Axe nach und nach alle Werthe zwischen $a a$ und $b b$ annimmt. In unserer Figur ist die Ellipse dargestellt, die nach einer Drehung von $90^{\circ}$ zur Wirkung kommt (Fig. $167 \mathrm{E}$ ).

Es erübrigt jetzt noch, die Drehung um eine Linie zu verfol- 286 gen, die mit keiner der drei Axen zusammenfällt. Wir stellen uns vor, das Ellipsoid sei vorerst um die Axe $b b$ gedreht worden, bis es die in Fig. 165 dargestellte Neigung oder eine beliebige andere erreicht hatte, und beginnen nun, von dieser Stellung ausgehend, die Drehung um die Linie $m n$. Wir erhalten alsdann nach einer Drehung von $90^{\circ}$ eine Elasticitätsellipse, deren grosse Axe $a$ u und deren kleine $c c$ ist (Fig. 165). Diese Elasticitätsellipse ist aber, je nachdem die Drehung in dieser oder jener Richtung erfolgte, verschieden orientirt; sie ist nach rechts geneigt $(\mathcal{A})$, wenn man den oberen Scheitel in Fig. 165 unter die Papierebene sinken lässt, nach links dagegen $(B)$, wenn man ihn aus der Papierebene heraushebt. Die Ellipsen, welche Drehungswinkeln zwischen 0 und $90^{\circ}$ entsprechen, bilden mit Rücksicht auf Form und Stellung Uebergänge zwischen 

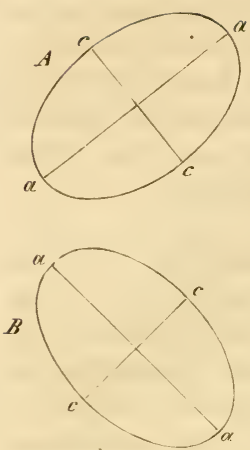

Fig. 168.

den beiden Endgliedern. Dem Winkel $0^{\circ}$ entspricht aber offenbar eine Ellipse, welche so $\sigma$ oder so 0 orientirt sein kann, je nachdem $m n$ grösser oder kleiner als die mittlere Axe. Die Uebergänge werden also im ersten Fall beispielsweise in der Art stattfinden, dass sich die Ellipse mit ihrem rechten Scheitel hebt und dabei gleichzeitig verlängert Fig. $169 A, B, C^{\prime}$, während im zweiten Fall mit ciner ähnlichen Streckung eine allmählich stärker werdende Neigung nach rechts verbunden ist (Fig. $170 A, B, C^{r}$ ).

Ebenso leicht lassen sich die Schnittflächen bestimmen, welche beim Drehen um einen beliebigen anderen Durchmesser in der Ebene des Gesichtsfeldles wirksam werden. Man hat nur nöthig, die bekannte Ellipse der Ausgangsstellung mit der ebenfalls bekannten nach einer Drehung von $90^{\circ} \mathrm{zu}$ vergleichen; die $Z$ wischenglieder bilden alsdann in Form und Stellung die Uebergänge.
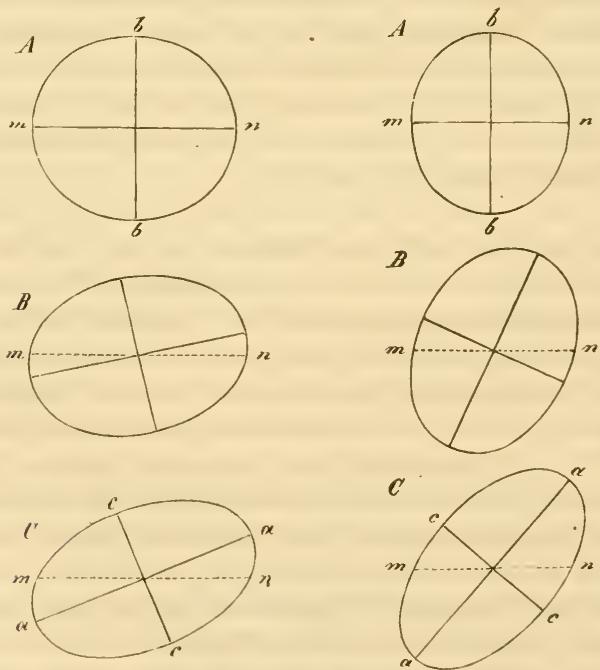

Fig. 169.

Fig. $1 ; 0$. 
Die Axenrichtungen der wirksamen Elasticitätsellipsen bleiben überhaupt unverändert, wenn die Drehung um einc in der Ebene des Gesichtsfeldes liegende Hauptaxe des Ellipsoids erfolgt; sie erfahren dagegen eine stetige Veränderung, wenn ein beliebiger anderer Durchmesser oder eine geneigt stehende Axe die Drehungsaxe bildet. Der approximative Gang dieser Veränderung ist durch die bekannten oder doch leicht zu construirenden Schnittflächen bestimmt, welche nach einer Drehung von $90^{\circ}$ wirksam werden.

Es unterliegt also, wie man aus dem Vorhergehenden entnehmen 287 wird, keiner Schwierigkeit, die Axenlage der Elasticitätsellipse für jede beliebige Neigung unseres Ellipsoids annähernd zu bestimmen und die während der Drehung erfolgenden Veränderungen in Betreff der Stellung und Excentricität, soweit nöthig, festzustellen. Mit der Axenlage sind aber auch die Polarisationsebenen der beiden Wellensysteme gegeben, und mit der Excentricität steigt und fällt auch der Phasenunterschied, welchen dieselben in einem Medium ron bestimmter Dicke erlangen. Der Phasenunterschied bedingt aber bekanntlich die Interferenzfarbe, und so gelangen wir denn zu dem Schluss, dass sich das optische Verhalten eines doppelbrechenden Mediums, dessen Elasticitätsellipsoid gegeben ist, für jede beliebige Richtung der durchgehenden Lichtstrahlen zum Voraus bestimmen lässt.

Wir haben die vorstehenden Erörterungen absichtlich an den 288 allgemeinen Fall, dass die drei Axen des Elasticitätsellipsoids ungleich sind, angeknüpft, weil die besonderen Fälle, die man sich denken kann, eigentlich schon darin enthalten sind. Doch mag es nachträglich zur Vervollständigung des Gesagten nicht ganz überflüssig sein, auch diese besonderen Fälle in Kürze zu erwähnen. Denken wir uns zunächst, die Differenz zwischen der mittleren und der kleinsten Axe des Ellipsoids werde allmählich kleiner und zuletzt gleich Null, so nähern sich die beiden Kreisschnitte immer mehr der Ebene der genannten Axen, indem sie immer spitzere Winkel mit derselben bilden, und fallen endlich mit ihr zusammen. Die beiden optischen Axen bewegen sich folglich in entgegengesetzter Richtung; sie fallen, wenn sie die grösste Axe des Ellipsoids erreicht haben, in eine einzige optische Axe zusammen. Das brechende Medium wird dadurch optisch einaxig und zwar positiv, weil es auch im zweiaxigen Zustande, bevor der Axenwinkel $=0$ wurde, der oben ge- 
gebenen Definition gemäss, positiv war. - Lassen wir dagegen die mittlere Axe allmählich der grössten gleich werden, so fallen die optischen Axen zuletzt mit der kleinsten Axe des Ellipsoids zusammen und das negativ zweiaxige Medium wird negativ einaxig.

Die Elasticitätsfläche ist folglich in einaxigen Medien stets ein Rotationsellipsoid, und zwar fällt die Rotationsaxe bei optisch negativen mit dem kleinsten, bei optisch-positiven mit dem grössten Durchmesser zusammen. Die Schnittfächen cines solchen Ellipsoids sind natürlich im Allgemeinen ebenfalls Ellipsen und nur, wenn sie senkrecht auf der Rotationsaxe stehen, Kreise. Die Veränderungen der Stellung und der Excentricität, welche die optisch wirksame Ellipse während der Drehung des Ellipsoids erfährt, lassen sich hier, da die Aufgabe durch die Gleichheit zweier Axen bedeutend vereinfacht wird, so leicht übersehen, dass uns eine besondere Besprechung derselben überflüssig erscheint.

\section{Bestimmung der Elasticitätsaxen.}

289 Die Verwerthung der im Vorhergehenden entwickelten Abhängigkeit des optischen Verhaltens von der Lage und Form des Elasticitätsellipsoids beruht auf dem Princip der Reciprocität. Wenn es möglich ist, aus der Richtung und relativen Grösse der drei Axen den Gang der Erscheinungen, welche man beim Drehen um eine beliebige senkrechte oder wagrechte Axe beobachtet, zum Voraus zu bestimmen, so muss es umgekehrt auch möglich sein, aus den bekannten optischen Erscheinungen die Richtung und relative Grösse der Elasticitätsaxen abzuleiten und so das Elasticitätsellipsoid gleichsam in das brechende Medium hinein zu construiren. Darin besteht aber gerade die Aufgabe, die man sich bei Untersuchungen im polarisirten Licht zu stellen hat; mit ihrer Lösung ist der Zweck, um den es sich gewöhnlich handelt, vollständig erreicht*).

290 Wir haben uns also jetzt mit der Frage zu beschäftigen, wie die Bestimmung der Elasticitätsaxen praktisch ausführbar sei. Der Beobachter hat hiebei zweierlei Unbekannte ins Auge zu fassen, die wir desshalb auch gesondert betrachten wollen, nämlich die Richtungen

*) Weiter gehende Fragen, wie z. B. ob und wie eine ungleichmässige Quellung das Verhältniss der Elasticitätsaxen ändere, ob die Ursache der Doppelbrechung in den einzelnen Molekülen (Atomgruppen) organisirter Körper, oder in der Anordnung dieser Moleküle liege etc., kommen jedenfalls erst in zweiter Linie in Betraeht und setzen die I,ösung der bezeichneten $\Lambda$ ufgabe voraus. 
der Axen und die relativen Längen derselben. Was zunächst den ersten Punkt, die Axenrichtungen, betrifft, so bedarf es für Leser, welche die Polarisationserscheinungen aus physikalischen Lehrbüchern einigermassen kennen, eigentlich kaum einer Anleitung, da es sich hier bloss um die Anwendung der Fundamentalgesetze handelt. Jedenfalls können wir uns auf einige kurz gefasste Sätze bcschränken.

1) Sind Polarisator und Analysator am Mikroskop so gestellt, dass sie sich rechtwinklig kreuzen, so ist bekanntlich das Gesichtsfeld dunkel. Ein doppelbrechendes Object erseheint alsdann cbenfalls dunkel, wenn die Axen der Elasticitätsellipse in die Polarisationsebenen der Nicols fallen, in jeder anderen Lage dagegen - wenn nicht zufällig ein Kreisschınitt des Ellipsoids der Fläehe des Gesichtsfeldes parallel geht - mehr oder weniger crleuchtet und zwar am intensivsten, wenn sie um $45^{\circ}$ von jenen Ebenen abweichen. Wir wollen diese letztere Stellung in der Folge als diagonale, erstere dagegen, in weleher das Object dunkel erscheint, als or thogonale Stellung bezeichnen. Es ist klar, dass jede dieser Stellungen die Axenrichtungen der Elasticitätsellipse bestimmt. Da jedoch die grösste Dunkelheit stets sicherer erkannt wird, als das grösste Licht, so verdient die orthogonale Stellung bei Winkelmessungen den Vorzug.

2) Um zu entscheiden, ob ein Object, das beim Drehen um eine verticale Axe dunkel bleibt, zu den einfach brechenden gehört, oder ob viclleicht gerade ein Kreisschnitt des Elasticitätsellipsoids optisch wirksam sei, hat man nur nöthig, die Beobachtung in verschiedenen andern Lagen des Objects, wie man sie durch Drehen um horizontale Axen erhält, zu wiederholen. Die Doppelbrechung muss sich alsdann kundgeben, wenn überhaupt eine solche stattfindet, freilich immer unter der Voraussetzung, dass die wirksame Schicht mächtig genug sei, um einen augenfälligen Effect hervorzurufen.

3) Ist das Object doppelbrechend und die Axenrichtung der wirksamen Elasticitätsellipse bekannt, so fragt es sich weiter, ob viclleicht die eine ihrer Axen oder beide zugleich Axen des Ellipsoids seien. Um diess zu erfahren, bringt man das Object in die diagonale Stellung und dreht es hierauf mittelst der oben (S. 306) beschriebenen Vorrichtung un die zu prüfende Axe und zwar successive nach entgegengesetzten Seiten. Finden hiebei die nämlichen Veränderungen statt, man mag nach dieser oder jener Seite hin drehen, d. h. beobachtet man bei gleichem Drehungswinkel in beiden Fällen denselben Farben- 
wechsel, so ist die auf der.Drehungsaxe senkrechte Richtung eine Axe des Ellipsoids. Man gelangt zu diesêr Folgerung durch Umkehrung des Satzes, dass zwei Schnittflächen, welche mit einer Axe des Ellipsoids gleiche Winkel bilden, unter sich gleich sind. - In der orthogonalen Stellung gilt in allen Fällen, wo das Drehen eine Erhellung zur Folge hat, dieselbe Regel, und wenn das Gesichtsfeld dunkel bleibt, so ist die Drehungsaxe selbst eine Axe des Ellipsoids.

4) Sind dagegen die Veränderungen, welche man beim Drehen nach der einen und anderen Seite hin beobachtet, ungleich, so liegt keine der Axen des Ellipsoids in der Ebene des Gesichtsfeldes. Man wiederholt alsdann dịe nämliche Probe an anderen Schnittfächen und setzt die Beobachtungen so lange fort, bis man endlich eine Fläche gefunden hat, welche den oben erwähnten Bedingungen Genüge leistet.

5) Ist eine der Axen des Ellipsoids bestimmt, so liegen die beiden andern selbstverständlich in einer darauf senkrechten Schnittfläche. Man hat daher nur nöthig, diese Schnittfläche zur Wirkung zu bringen und deren Elasticitätsaxen, welche zugleich die Axen des Ellipsoids sind, in bekannter Weise zu bestimmen.

Zum Ueberfluss mögen hier noch ein paar Beispiele Platz finden, welche das Gesagte erläutern. Ein tafelartig entwickelter Gypskrystall (Fig. 171), an welchem die Abstumpfungsfläche der scharfen Säulenkanten die vorherrschende ist, erscheint im Polarisations-

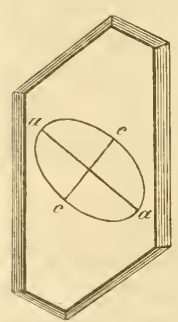

Fig. 171 . mikroskop bei gekreuzten Nicols dunkel, wenn die Richtungen $a a$ und $c c$ erstere bildet mit den Seitenlinien einen Winkel ron $50^{\circ}$ ) mit den Polarisationsebenen der Nicols parallel verlaufen, und folglich am hellsten, wenn dieselben in die diagonale Stellung gebracht werden. Diese Richtungen sind demnach die Axen der Elasticitätsellipse. Beim Drehen um die Axe $a$ a sind die Veränderungen nach beiden Seiten hin gleich, ebenso beim Drehen um die Axe $c c$. Beides sind also zugleich Axen des Ellipsoids; die dritte Axe steht folglich senkrecht zur tafelartigen Fläche. - Dreht man den Krystall um die linke oder rechte Kante, so dass die dritte Axe in die Ebene des Gesichtsfeldes zu liegen kommt, so kann dieselbe in gleicher Weise als solche erkannt werden; die auf ihr senkrecht stehende Richtung im Gesichtsfelde 
ist aber in diesem Falle keine Axe des Ellipsoids, was sich bcim Drehen des Krystalls um seine Queraxe auch sogleich kundgiebt*).

Ganz ähnlich verhalten sich auch flache Membranen freier Pflanzenzellen. Die Axen der Elasticitätsellipsen, welche bei Flächenansichten wirksam sind, erweisen sich beim Drehen stets als Axen des Ellipsoids. Die vorkommenden Richtungsverschiedenheiten beziehen sich also nur auf die Lage derselben innerhalb einer Ebene, d. h. auf die Winkel, welche die Axen mit der Längs- und Querrichtung der Zelle bilden. Auf senkrecht zur Membranfläche geführten Schnitten verläuft dem entsprechend eine Axe der wirksamen Elasticitätsellipse in der Richtung der Schichten; die andere steht senkrecht darauf und ist zugleich Axe des Ellipsoids. -- Von den Membranen der Gewebezellen gilt, soweit sie bekannt sind, dasselbe; allein die Beobachtung wird hier durch den Umstand erschwert, dass die beiden Lamellen, woraus die Scheidewände bestehen, eigentlich zwei Objecte darstellen, deren Elasticitätsaxen möglicher WV eise sehr verschieden orientirt sind.

Der zweite Punkt, welcher bei Bestimmung des Elasticitäts- 292 ellipsoids in Betracht kommt, nämlich die relative Grösse der Axen, setzt unter Umständen schon eine weiter gehende Kenntniss der Polarisationserscheinungen voraus. Tor Allem ist nothwendig, dass der Beobachter die Scala der.Interferenzfarben, welche bei allmählicher Zunahme des Gangunterschiedes zwischen den ordentlichen und ausserordentlichen Strahlen auftreten, wenigstens bis zur 3 ten oder 4 ten Ordnung aus eigener Anschauung kenne, und dass er über die Factoren, welche das Steigen oder Fallen der Farben verursachen, im Klaren sei. Diejenigen, welche diese Vorkenntnisse nicht besitzen, müssen wir daher zunächst auf die physikalischen Lehrbücher verweisen, da eine ausführliche Erörterung der betreffenden Erscheinungen uns hier zu weit führen würde. Wir halten es aber immerhin für unsere Aufgabe, die für das Terständniss wichtigeren Punkte in ihrem Zusammenhang vorzuführen und deren Beziehıngen zum Elasticitätsellipsoid darzulegen.

*) Zu solchen Beobachtungen sind übrigens bloss schmale, fast nadelförmige Krystalle geeignet. Grössere Tafeln erscheinen in aufrechter Stellung weiss oder geben wenigstens zu hohe Interferenzfarben, als dass die Veränderungen, welche das Drehen um eine wagrechte Axe hervorruft, sich deutlich genug wahrnelimen liessen. 
Ist $A B($ Fig. 172) ein in der Richtung der Pfeile comprimirtes Parallelepiped von Glas, z. B. das eine Ende eines Objectträgers, so hat dessen wirksame Elasticitätsellipse die in der Figur dargestellte Orientirung. Ein solcher Objectträger er-

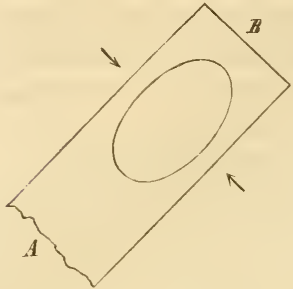

Fig. 172. scheint bei rechtwinkliger Kreuzung der Nicols am hellsten erleuchtet, wenn er mit den Polarisationsebenen derselben einen Winkel von $45^{\circ}$ bildet und sich also in diagonaler Stellung befindet. Er erzeugt alsdann im weissen Licht eine Interferenzfarbe, welche bei gegebener Dicke um so löher steigt, je stärker der seitliche Druck, je grösser folglich die Excentricität der Ellipse. Gestattet die Einrichtung eine allmähliche Steigerung des Druckes, so bilden die resultirenden Farben eine Reihe, welche mit derjenigen der Newton'schen Ringe übercinstimmt. - Dieselbe Reihe wird natürlich auch zu Stande kommen, wenn man die Dicke des brechenden Mediums durch Aufeinanderlegen einer grösseren Zahl gleich stark, aber nur wenig comprimirter Glasplatten allmählich verstärkt; denn es ist einleuchtend, dass der Gangunterschied, d̦en die unterste dieser Platten hervorruft, durch jede folgende um eine gleiche Grösse gesteigert wird. Ebenso erklärt sich auch die Wirkung eines Keils: die allmählich steigende Dicke ruft hier die Farben in ihrer natürlichen Reihenfolge neben einander hervor.

Wir gelangen also, da sich die krystallinischen Medien auch in dieser Beziehung ähnlich verhalten wie das comprimirte Glas, zu dem allgemeinen Gesetz, dass die Interferenzfarbe mit der Excentricität der wirksamen Ellipse und mit der Mächtigkeit des brechenden Mediums steigt und fällt.

294 Da die Farben der höheren Ordnungen sich bloss in rothen und grünen Tönen bewegen, die um so blasser werden, je mehr sie steigen, und sich daher immer undeutlicher von einander abstufen, so haben für die mikroskopische Beobachtung die drei ersten Ordnungen eine hervorragende Bedeutung und verdienen daher auch ein genaueres Studium. Aus diesem Grunde zählen wir nachstehend die unterscheidbaren Nuancen der tieferen Farben mit etwas grösserer Vollständigkeit auf, als es gewöhnlich in physikalischen Lehrbüchern geschieht. In der zweiten Columne sind überdiess für jede Ordnung 
die complementären Farben, welche den Newton'schen Ringen im durchgelasseuen Lichte entsprechen, angegeben.

\begin{tabular}{|c|c|c|c|}
\hline \multicolumn{2}{|c|}{ Erste Ordnung. } & \multicolumn{2}{|c|}{ Zweite Ordnung. } \\
\hline $\begin{array}{l}\text { Schwarz } \\
\text { Eisengrau } \\
\text { Graublau } \\
\text { Heller graublau } \\
\text { Hellbläulich } \\
\text { Grünlichweiss } \\
\text { Weiss } \\
\text { Gelblichweiss } \\
\text { Gelb } \\
\text { Braungelb } \\
\text { Bräunlich orange } \\
\text { Rothorange } \\
\text { Roth } \\
\text { Dunkelroth }\end{array}$ & $\begin{array}{l}\text { Lebhaftweiss } \\
\text { Weiss } \\
\text { Gelblichweiss } \\
\text { Gelbbräunlich } \\
\text { Gelbbraun } \\
\text { Braunroth } \\
\text { Rothviolett } \\
\text { Violett } \\
\text { Hellindigo } \\
\text { Graublau } \\
\text { Blau } \\
\text { Blaugrün } \\
\text { Blassgrün } \\
\text { Gelbgrün }\end{array}$ & $\begin{array}{l}\text { Purpurroth } \\
\text { Violett } \\
\text { Indigo } \\
\text { Blau } \\
\text { Blaugrünlich } \\
\text { Grün } \\
\text { Hellergrün } \\
\text { Gelblichgrün } \\
\text { Grünlichgelb } \\
\text { Reingelb } \\
\text { Orange } \\
\text { Lebhaft Orangeroth } \\
\text { Dunkel Rothviolett }\end{array}$ & $\begin{array}{l}\text { Hellgrün } \\
\text { Grünlichgelb } \\
\text { Lebhaftgelb } \\
\text { Orange } \\
\text { Orangebraun } \\
\text { Hellcarminroth } \\
\text { Purpurroth } \\
\text { Purpurviolett } \\
\text { Violett } \\
\text { Indigo } \\
\text { Junkelblau } \\
\text { Grünlichblau } \\
\text { Grün }\end{array}$ \\
\hline
\end{tabular}

\begin{tabular}{l|l|l|l}
\hline \multicolumn{2}{c|}{ I)ritte Ordnung. } & \multicolumn{2}{c}{ Vierte Ordnung. } \\
\hline Violett & Grünlichgelb & Hellviolett & Hellgrünlichgelb \\
Blau & Gelborange & Bläulichgrün & Hellrosa \\
Grün & Roth & Grün & Hellroth \\
Gelb & Violett & Hellgrünlichgelb & Lila \\
Rosenroth & Grünlichblau & Hellgelblichroth & Hellgrünlichblau \\
Roth & Grün & Hellroth & Hellgrün \\
\hline
\end{tabular}

\begin{tabular}{l|l|l|l}
\hline \multicolumn{2}{c|}{ Fünfte } & \multicolumn{2}{|c}{ Ordnung. } \\
\hline Hellblau & Hellrosa & Hellblau. & Hellrosa \\
Hellgrün & Hellroth & Sehr hellgrün & Hellroth \\
Weisslich & Weisslich & Weisslich & Weisslich \\
Hellroth & Hellgrün & Sehr hellroth & Hellgrünlich
\end{tabular}

Legt man zwei doppelbrechende Platten ron gleicher Dicke und 295 mit gleicher wirksamer Elasticitätsellipse so über einander, dass sie

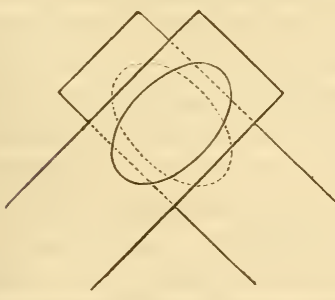

Fig. 173. sich rechtwinklig kreuzen (Fig. 173), so verhalten sie sich wie ein einfach brechendes Medium. Die Lichtschwingungen, welche in der untern Platte parallel der grösseren Axe stattfinden, fallen nämlich in der oberen mit der Ebene der kleinen Axe zusammen und ungekehrt. Das Verhältniss der Geschwindigkeiten, mit welchen die beiden Wellensysteme die untere Platte durchsetzen, wird folglich beim Eintritt in die obere ungekehrt, der erlangte Phasenunterschied also während des Durchgangs wieder ausgeglichen. Wäre die eine Platte um 
die Grösse $d$ dicker als die andere, so müsstc die Gesammtwirkung offenbar dieselbe sein, wie wenn eine Lamelle von der Dicke $d$ für sich allein beobachtet würde.

Dasselbe Raisonnement lässt sich auch auf Platten von beliebiger Dicke und beliebiger Elasticitätscllipse anwenden. Die Wirkungen werden sich immer addiren, wenn die beiden Ellipsen gleich orientirt sind, und theilweise oder gänzlich aufheben, wenn die Ellipsen sich rechtwinklig kreuzen. Nehmen wir z. B. an, die Interferenzfarbe der einen Platte sei Roth der ersten Ordnung, die der andern Gelb der ersten Ordnung (natürlich immer unter der Voraussetzung, dass die Stellung eine diagonale sei), so erhält man als Gesammtwirkung beider für die Additionslage eine Farbe der zweiten Ordnung (Gelb II) und für die Subtractionslage eine Farbe der ersten Ordnung Hellbläulich I), welche um eine dem Gelb entsprechende Stufenzahl tiefer steht als Roth.

Wir werden weiterhin auf diese Additions- und Subtractionsfarben zurückkommen und dieselben für eine Reihe von Combinationen, wie sie in der Praxis gewöhnlich vorkommen, zusammenstellen; hier handelt es sich nur darum, sie zur Bestimmung der relativen Grösse der Elasticitätsaxen zu verwerthen, und hiezu genügen die erwähnten Thatsachen vollkommen. Es ist einleuchtend, dass die Vergleichung eines beliebigen Mediums mit einer comprimirten Glasplatte, deren Elasticitätsellipse bekannt ist, ein sehr einfaches Mittel darbieten muss, das unbekannte Elasticitätsellipsoid richtig zu orientiren. Bezeichnen wir die drei Axen desselben, deren Richtungen wir als bekannt voraussetzen, mit $a, b$ und $c$, so hat man nur nöthig, die durch $a b$ gelegte Schnittfläche mit der Glasplatte zu combiniren; die Lage, in welcher Addition oder Subtraction stattfindet, entscheidet alsdann, ob $a$ oder $b$ grösser sei. In derselben Weise bestimmt man auf Schnittflächen, die parallel $b c$ geführt sind, das Verhältniss von $b$ zu $c$, und auf anderen durch $a c$ geführten das Verhältniss von $a$ zu $c$. Damit ist die Aufgabe, soweit es nach diesem Verfahren möglich ist, gelöst; man weiss, welche Richtung der kleinsten, mittleren und grössten Elasticität entspricht.

297 Die bereits oben angeführten Beispiele mögen auch hier zur näheren Erläuterung dienen. Wird der tafelartig entwickelte Gypskrystall Fig. 174) so auf die comprimirte Glasplatte gelegt, dass die Richtung $a$ a der grösseren Elasticitätsaxe im Glase parallel geht, 
so beobachtet man ein Steigen der Interferenzfarbe: die Wirkungen der beiden Medien addiren sich. Dreht man dagegen um $90^{\circ}$, so fin-

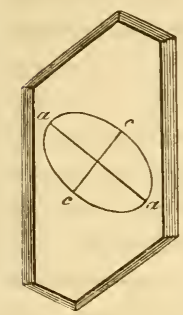

Fig. 174 . det Subtraction statt und die Interferenzfarbe fällt. Von den zwei Axen des Ellipsoids, welche den Richtungen $a a$ und $c c$ parallel gehen, ist hienach die letztere kleiner als die erste. - Was nun noch die dritte senkrecht stehende Axe betrifft, so ist die Bestimmung derselben mit einigen Schwierigkeiten verbunden. Aus der unsymmetrischen Lage der Axen a a und $c c$ geht zwar hervor, dass der Krystall ein zweiaxiger ist, was die Gleichheit der dritten Axe mit einer der bereits bestimmten ausschliesst; allein es bleibt immer noch zu untersuchen, ob dieselbe die grösste, oder die kleinste oder die mittlere Axe sei. Da nun Schnitte durch den Krystall in der Richtung der Hauptebenen nicht herstellbar sind, so bildet das Drehen um die beiden horizontalen Axen die einzige hier anwendbare Prüfungsmethode. Der Beobachter hat sich hiebei an folgende theoretische Folgerungen zu halten. 1) Ist die dritte Axe die grösste, so muss beim Drehen um a a eine Stellung erreicht werden, in welcher eine optische Axe die Richtung des durchgehenden Lichtes hat. Die Interferenzfarben müssen also rasch fallen, in der bezeichneten Stellung in Schwarz übergehen und bei weiterer Drehung wieder steigen. 2) Ist die dritte Axe die kleinste, so müssen die nämlichen Veränderungen beim Drehen um $c c$ eintreten. 3) Ist die dritte Axe die mittlere, so kann die Farbe in keinem Fall auf Schwarz heruntersinken. Die wirksame Elasticitätsellipse wird zwar bein Drehen um a $a$ sowohl als um $c c$ weniger excentrisch, jedoch ohne den Kreis jemals zu erreichen. Da nun der längere Weg, den die Lichtstrahlen in der geneigten Krystalltafel durchlaufen, andererseits den Gangunterschied verstärkt, so kann dieser Einfluss unter Umständen vorwiegend werden und trotz der geringeren Excentricität der Ellipse ein Steigen der Farbe verursachen.

Die Beobachtung ergibt nun, dass die Farbe eines Gypskrystalls (Gypsplättchens) beim Drehen un a a steigt und beim Drehen um $c c$ fällt. Dieser letztere Umstand beweist, dass die dritte Axe jedenfalls nicht die grösste sein kann; aber ob sie die kleinste oder die mittlere sei, lässt sich aus dem ganzen Verhalten kaum mit Sicherheit entnehmen, da die Neigung der durchgehenden Strahlen in Folge der Brechung an der Oberfläche nur bis zu einer gewissen Grenze gesteigert 
werden kann, die Richtung der optischen Axen also möglicher Weise nicht crreicht wird. Man müsste die Drehung in einem annähernd gleich dichten Medium, z. B. in Oel, ausführen und überdiess das Steigen und Fallen der Farbe genauer studiren, um hierüber Gewissheit zu erlangen. ${ }^{*}$ )

Viel einfacher gestaltet sich die Aufgabe bei flachen Membranen, wie überhaupt bei Objecten, die sich in beliebiger Richtung durchschneiden lassen. Sind hier zwei von den drei Axen be-

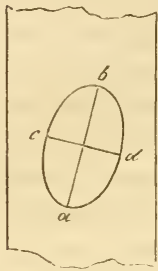

Fig. 175 . kannt, so wird ihr Verhältniss zur dritten Axe auf Durchschnitten, welche parallel den entsprechenden Hauptebenen geführt wurden, direct bestimnt. Ist z. B. abcd (Fig. 175) die Elasticitätsellipse eines flachen Membranstückes und zeigt ein parallel $c d$ geführter Querschnitt, dass die dritte Axe kleiner als $c d$, so ist sie natürlich die kleinste Axe des Ellipsoids. Wäre sie grösser, so müsste das Verhältniss zu $a b$ entscheiden, ob sie die grösste oder die mittlere sei.

Mit der relativen Grösse der Elasticitätsaxen ist zugleich, wie bereits bemerkt, die Ebene der optischen Axen gegeben, da dieselbe stets durch die grösste und die kleinste Elasticitätsaxe geht. Eine planplane Platte, welche parallel der mittleren Axe geschnitten ist, muss folglich beim Drehen um diese Axe zweimal in eine solche

*) Dreht man einen einaxigen Krystall ron geeigneter Form um die horizontal gestellte optische Axe, so bleibt die Elasticitätsellipse unverändert und das Steigen der Farbe rührt bloss von der Verlängerung des Weges in Folge der Neigung her. Die Vergleichung dieser Farbenänderung mit derjenigen eines unbekannten Krystalls muss folglich herausstellen, ob der Gangunterschied bei letzterem in stärkerem oder schwächerem Verhältniss wächst, womit zugleich entschieden ist, ob die Excentricität der Elasticitätsellipse während der Drehung zu- oder abnimmt. Für den Gyps erhält man auf diese Weise mit ziemlicher Sicherheit das Ergebniss, dass die dritte Axe die mittlere ist. Im Allgemeinen fallen indess die Resultate der Beobachtung zu unbestimmt aus, als dass ein näheres Eingehen auf diese und ähnliche theoretische Folgerungen gerechtfertigt erschiene.

Aus dem Vorstehenden erhellt übrigens zur Genüge, dass die Folgerungen, welche Valentin (die Untersuchung der Pflanzen- und der Thiergewebe im polarisirten Licht. S. 144) aus dem erwähnten Steigen und Fallen der Farbe bei Gypsplättchen zieht, durchaus unrichtig sind. Er sagt nämlich, die Ebene der optischen Axen entspreche »daher "der diagonalen Richtung $+45^{\circ}$ (die in unserer Figur mit $c c$ bezeichnet ist), während sie in Wirklichkeit mit der Ebene des Plättchens zusammenfällt. 
Lage kommen, dass die von unten einfallenden Strahlen sie in der Richtung einer optischen Axe durchsetzen; sie muss sich alsdann wie ein einfach brechendes Medium verhalten und bei gekreuzten Nicols schwarz erscheinen. Man hat also nur nöthig, die diesen Lagen entsprechenden Neigungen der Platte zu messen und dabei die Ablenkung an den Grenzflächen der Platte zu berücksichtigen, ưm den Winkel, den die optischen Axen unter sich bilden, annähernd zu bestimmen. Fallen auch solche Bestimmungen nicht gerade genau aus, so ist es doch in der Regel möglich zu entscheiden, ob das Object positiv oder negativ sei.

Um in der Deutung der resultirenden Interferenzfarben nicht irre $\mathbf{3 0 0}$ zu gehen, ist es immer rathsam, die Additions- und die Subtractionslage genau mit einander zu vergleichen. War die Deutung richtig, so muss die Subtraction eine Farbe ergeben, welche gegen die höhere der beiden combinirten Farben um eben so viel zurücksteht, als diese gegen die Additionsfarbe. Combinirt man z. B. Blau II mit Gelb I, so erhält man in der einen Lage ein Roth, welches der Geübtere als Roth II erkennt, in der andern ein Gelb, das mit Gelb I übereinstimmt. In der Farbenscala stehen auch in der That Roth II und Gelb I ungefähr gleich weit von Blau II ab, und die Wiederholung der Combination mit bekannten Gypsplättchen liefert vollends den Beweis, dass Blau II und Gelb I in der Additions- und Subtractionslage die oben erwähnten Farben geben.

Da eine solche Wiederholung der Combination stets die beste Controle gewährt, so lassen wir hicr noch zwei Tabellen folgen, in welchen die Additions- und Subtractionsfarben für eine Reihe von Fällen zusammengestellt sind. Die Benennungen gründen sich für die drei ersten Ordnungen auf die Eintheilung derselben in je 6 Farben, deren Abstände auf einem keilförmig geschliffenen Krystall ungefähr gleich sind. Bezeichnet man also die Farben der ersten Ordnung mit $1-6$, die der zweiten mit $7-12$ u. s. f., so lässt sich eine beliebige Combinationsfarbe durch Addition oder Subtraction der entsprechenden Ziffern zum Voraus bestimmen, wodurch jedenfalls die rasche und sichere Deutung der beobachteten Farbe wesentlich erleichtert wird. Die Farben 6 (Roth I) und 3 (Weiss I) geben z. B. in der Additionslage $6+3=9$ Grün II) und in der Subtractionslage $6-3=3$ (Weiss I). Wir bemerken übrigens, dass die Farben der käuflichen Gypsplättchen den eingebildeten Abstufungen nicht immer genau entsprechen und dass oft die gleichnamigen Nummern 
derselben Fabrik einen merklich abweichenden Farbenton hervorrufen.

Die zweite Tabelle gewinnt durch den Umstand, dass ein Gypsplättchen, welches Roth I gibt, das Steigen und Fallen der Farbe in der Regel am leichtesten erkennen lässt, einen besonderen praktischen Werth.

Erste Tabelle.

\begin{tabular}{|c|c|c|c|}
\hline \multicolumn{2}{|c|}{ Combinirte Farben } & $\begin{array}{c}\text { Additions - } \\
\text { Farbe }\end{array}$ & $\begin{array}{c}\text { Subtractions - } \\
\text { Farbe }\end{array}$ \\
\hline Grau I & Grau I & Hellbläulich I & Schwarz \\
\hline Hellbläulich I & Grau I & Weiss I & Grau I \\
\hline - & Hellbläulich I & Gelb I & Schwarz \\
\hline Weiss I & Grau I & Gelb I & Hellbläulich I \\
\hline- & Hellbläulich I & Orange I & Grau I \\
\hline- & Weiss I & Roth I & Schwarz \\
\hline Gelb I & Grau I & Orange I & Weiss I. \\
\hline - & Hellbläulich I & Roth I & Hellbläulich I \\
\hline - & Weiss I & Indigo II & Grau I \\
\hline- & Gelb I & Blau II & Schwarz \\
\hline Orange I & Grau I & Roth I. & Gelb I \\
\hline - & Hellbläulich I & Indigo II & Weiss I \\
\hline - & Weiss I & Blau II & Hellbläulich I \\
\hline- & Gelb I . & Grün II & Grau I \\
\hline- & Orange I & Gelb II & Schwarz \\
\hline Roth I & Grau I & Indigo II & Orange I \\
\hline 一 & Hellbläulich I & Blau II & Gelb I \\
\hline - & Weiss I & Grün II & Weiss I \\
\hline- & Gelb I & Gelb II & Hellbläulich I \\
\hline - & Orange I & Orange II & Grau I \\
\hline - & Roth I & Roth II & Schwarz \\
\hline Indigo II & Grau I & Blau II & Roth I \\
\hline- & Hellbläulich I & Grün II & Orange I \\
\hline - & Weiss I & Gelb II & Gelb I \\
\hline - & Gelb I & Orange II & Weiss I \\
\hline- & Orange I & Roth II & Hellbläulich 1 \\
\hline - & RothI & Violett III & Grau I \\
\hline - & Indigo II & Blau III & Schwarz \\
\hline Blau II & Grau I & Grün II & Ir digo II \\
\hline- & Hellbläulich I & Gelb II & Roth I \\
\hline - & Weiss I & Orange II & Orange I \\
\hline- & Gelb I & Roth II & Gelb I \\
\hline - & Orange I & Violett III & Weiss I \\
\hline - & Roth I & Blau III & Hellbläulich I \\
\hline - & Indigo II & Grün III & Grau I \\
\hline - & Blau II & Gelb III & Schwarz \\
\hline Grün II & Grau I & Gelb II & Blau II \\
\hline - & Hellbläulich I & Orange II & Indigo II \\
\hline - & Weiss I & Roth Il & Roth I \\
\hline - & Gelb I & Violett III & Orange I \\
\hline- & Orange I & Blau III & Gelb I \\
\hline - & Roth I & Grün III & Weiss I \\
\hline - & Indigo II & Gelb III & Hellbläulich I \\
\hline - & Blau II & Rosa III & Grau I \\
\hline- & Grün II & Roth III - & Schwarz \\
\hline Gelb II & Grau I & Orange II & Grün II \\
\hline
\end{tabular}




\begin{tabular}{|c|c|c|c|}
\hline \multicolumn{2}{|c|}{ Combinirte Farben } & $\begin{array}{l}\qquad \begin{array}{c}\text { Additions - } \\
\text { Farbe }\end{array} \\
\begin{array}{l}\text { Roth II } \\
\text { Violett III }\end{array}\end{array}$ & $\begin{array}{c}\begin{array}{c}\text { Subtractions- } \\
\text { Farbe }\end{array} \\
\begin{array}{l}\text { Blau II } \\
\text { Indigo II }\end{array}\end{array}$ \\
\hline 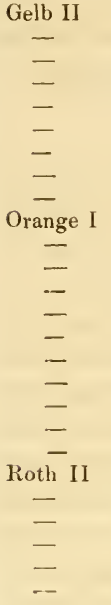 & $\begin{array}{l}\text { Hellblänlich I } \\
\text { Weiss I } \\
\text { Gelb I } \\
\text { Orange I } \\
\text { Roth I } \\
\text { Indigo II } \\
\text { Blau II } \\
\text { Grün II } \\
\text { Gelb II } \\
\text { Grau I } \\
\text { Hellbläulich I } \\
\text { Weiss I } \\
\text { Gelb I } \\
\text { Orange I } \\
\text { Roth I } \\
\text { Indigo II } \\
\text { Blau II } \\
\text { Grün II } \\
\text { Gelb II } \\
\text { Orange II } \\
\text { Grau I } \\
\text { Hellbläulich I } \\
\text { Weiss I } \\
\text { Gelb I } \\
\text { Orange I } \\
\text { Roth I }\end{array}$ & $\begin{array}{l}\text { Roth II } \\
\text { Violett III } \\
\text { Blau III } \\
\text { Grün III } \\
\text { Gelb III } \\
\text { Rosa III } \\
\text { Roth III } \\
\text { Bläulichgrün IV } \\
\text { Grün IV } \\
\text { Roth II } \\
\text { Indigo III } \\
\text { Blau III } \\
\text { Grün III } \\
\text { Gelb III } \\
\text { Orange III } \\
\text { Roth III } \\
\text { Violett IV } \\
\text { Blau IV } \\
\text { Grün IV } \\
\text { Grün IV } \\
\text { Violett III } \\
\text { Blau III } \\
\text { Grün III } \\
\text { Gelb III } \\
\text { Rosa III } \\
\text { Roth III }\end{array}$ & $\begin{array}{l}\text { Blau II } \\
\text { Indigo II } \\
\text { Roth I } \\
\text { Orange I } \\
\text { Gelb I } \\
\text { Weiss I } \\
\text { Hellbläulich I } \\
\text { Grau I } \\
\text { Schwarz } \\
\text { Gelb II } \\
\text { Grün II } \\
\text { Blau II } \\
\text { Indigo II } \\
\text { Roth I } \\
\text { Orange I } \\
\text { Gelb I } \\
\text { Weiss I } \\
\text { Hellblau I } \\
\text { Grau I } \\
\text { Schwarz } \\
\text { Orange II } \\
\text { Gelb II } \\
\text { Grün II } \\
\text { Blau II } \\
\text { Indigo II } \\
\text { Roth I }\end{array}$ \\
\hline
\end{tabular}

Zweite Tabelle.

\begin{tabular}{l|l|l}
\hline \multirow{2}{*}{$\begin{array}{c}\text { Object } \\
\text { ohne Gypsplättchen }\end{array}$} & \multicolumn{2}{|c}{ Combinirt mit Gypsplättchen Roth I } \\
\cline { 2 - 3 } & \multicolumn{1}{|c}{ Additionsfarbe } & \multicolumn{1}{|c}{ Subtractionsfarbe } \\
\hline Grau I & Indigo II & Orange I \\
Hellbläulich I & Blau II & Gelb I \\
Weiss I & Grün II & Weiss I \\
Gelb I & Gelb II & Hellbläulich I \\
Orange I & Orange II & Grau I \\
Roth I & Roth II & Schwarz \\
Indigo II & Violett III & Grau I \\
Blau II & Blau III & Hellbläulich I \\
Grün II & Grün III & Weiss I \\
Gelb II & Gelb III & Gelb I \\
Orange II & Rosa III & Orange I \\
Roth II & Roth III & Roth I \\
Violett III & Hellrothviolett IV & Indigo II \\
Blau III & Bläulichgrün IV & Blau III \\
Grün III & Grün IV & Grün II \\
Gelb III & Hellgrünlich IV & Gelb II \\
Rosa III & Hellrosa IV & Orange II \\
Roth III & Hellroth IV & Roth II \\
Hellviolett IV & Hellroth IV & Violett III \\
Bläulichgrün IV & Hellviolettroth V & Blau III \\
Grün IV & Hellblau V & Grün III \\
& &
\end{tabular}




\section{III.}

\section{Das Verhalten zweier übereinander liegender krystallähn- licher Körper, deren Schwingungsebenen sich schief- winklig kreuzen.}

301 Die bisherigen Betrachtungen finden in allen Fällen, wo das Untersuchungsobject ein krystallähnliches Medium darstellt, unmittelbare Anwendung; sie genügen also auch für flache Membranstücke und andere organisirte Gebilde, die sich wie Krystalle verhalten. In der Praxis ist es nun aber nicht immer möglich, die zu untersuchenden Gegenstände so zu präparirein, dass der optisch wirksame Theil jener Bedingung genügt, $d . h$. die Vergleichung mit einem einfachen Krystall rechtfertigt. Handelt es sich z. B. um horizontal liegende kleine Zellcn oder Fasern, welche aus concentrischen Molecularschichten bestehen, deren Elasticitätsellipsen-schief gegen die Längsrichtung der Zelle orientirt sind, so wirken zwar die in der Medianzone liegenden Stücke der Wandungen einzeln wie einfache Krystalle; allein man müsste die Fasern offenbar erst spalten, um diese Wirkungen gesondert beobachten zu können, und eine solche Spaltung ist in manchen Fällen nicht ausführbar. Ganz dasselbe gilt auch von mässig verdickten Membranen, welche die Scheidewände zwischen benachbarten Zellen bilden und daher als aus zwei Lamellen zusammengesetzt zu betrachten sind. Denn da die Verdickungen solcher Membranen (man denke an Spiralfasern, schiefgestellte Poren etc.) in der Regel ungleich orientirt sind, was auf eine entsprechende Lage der Molecularreihen deutet, so fallen voraussichtlich auch die Elasticitätsaxen der beiden Lamellen nicht in die nämliche Ebene.

Der Beobachter hat es also nicht selten mit zwei untrennbaren übereinander liegenden Medien zu thun, deren Elasticitätsaxen sich unter beliebigen Winkeln kreuzen. Er stösst somit auf ein neues Problem, welches augenscheinlich grössere Verwicklungen darbietet als das vorhergehende, und es fragt sich erst, ob dassclbe einer Lösung im nämlichen Sinne überhaupt fähig sei. Wir wollen es versuchen, diese Frage auf experimentellem Wege zu erledigen.

302 Seien $A B$ und $C D$ (Fig. 176) die Elasticitätsellipsen der beiden übereinander liegenden Körper und $e$ der veränderlich gedachte Winkel zwischen ihren grösseren Axen. Die Einstcllung werde stcts 
so gewählt, dass die Halbirungslinie $m n$ jenes Winkels unter $45^{\circ}$ gegen die gekreuzten Nicols orientirt bleibt. I)iess vorausgesetzt, erhält

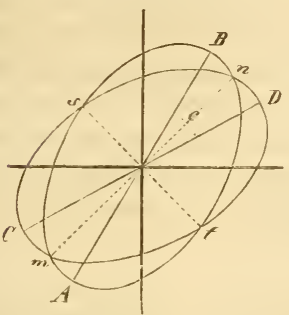

Fig. 176. man für die verschiedenen Werthe von $e$ erfahrungsgemäss folgende Wirkungen. Ist $e$ sehr klein, so verstärken sich die Wirkungen der beiden Körper fast so, als ob dieselben in der Additionslage, wo $e=o$, beobachtet würden : die resultirende Farbe erfährt bis zu einer Winkelgrösse vo̊n mehreren Graden keine erhebliche Veränderung. Bei weitergehender $\mathrm{Zu}$ nahme von $e$ erfolgt jedoch bald ein entschiedenes Fallen der Interferenzfarbe, das sich namentlich bis zu dem mittleren Werth von $45^{\circ}$ durch eine deutliche Aenderung des Farbentons ausspricht. Von da an bleibt zwar die Farbe annähernd dieselbe; das Gesichtsfeld rerfinstert sich aber immer mehr, bis endlich bei einem Winkel von $90^{\circ}$ vollständige Dunkelheit oder doch wenigstens - wenn nämlich die beiden Körper nicht genau gleich sind - die grösste Verfinsterung eintritt. Der Uebergang aus einem Farbenton in den andern geschieht allerdings in etwas anderer Weise als bei der Newton'schen Reihe, meistens so, als ob die beiden Farben in immer wechselndem Verhältniss mit einander vermischt würden; doch lässt sich das Steigen oder Fallen der Farbe in der grossen Mehrzahl der Fälle keineswegs verkennen.

Legt man z. B. zwei Gypsplättchen, von denen jedes Blassbläu- $\mathbf{3 0 3}$ lich der ersten Ordnung gibt, in der angegebenen Weise auf cinander, so erhält man für $e=o$ Giclb I, für $e=221 /{ }^{\circ}$ Hellgelb, für $e=45^{\circ} W$ eiss, endlich für $e=671^{1}{ }^{\circ}$ Bläulichweiss. Diese Farben entsprechen offenbar nur solchen Tönen, welche rückwärts anf Gclb I folgen. Einige weitere Beispiele sind in folgender Tabelle zusammengestellt.

\begin{tabular}{|c|c|c|c|c|}
\hline $\begin{array}{l}\text { Zwei Gyps- } \\
\text { plättchen }\end{array}$ & $e=o$ & $e=22^{1} / 2^{\circ}$ & $e=45^{\circ}$ & $e=671 / 2^{0}$ \\
\hline $\begin{array}{l}\text { Grau I } \\
\text { Hellbläulich I } \\
\text { Weiss I } \\
\text { Gelb I } \\
\text { Orange I } \\
\text { Roth I } \\
\text { Blau II } \\
\text { Grün II } \\
\text { Gelb II }\end{array}$ & $\begin{array}{l}\text { Hellbläulich } \\
\text { Gelb } \\
\text { Violett } \\
\text { Blau } \\
\text { Gelb } \\
\text { Roth } \\
\text { Grünlichgelb } \\
\text { Roth } \\
\text { Grün }\end{array}$ & $\begin{array}{l}\text { Weniger hell bläulich } \\
\text { Hellgelb } \\
\text { Hellviolett } \\
\text { Hellgrünlich } \\
\text { Gelb } \\
\text { Roth } \\
\text { Blaugrün } \\
\text { Weiss } \\
\text { Gelb }\end{array}$ & $\begin{array}{l}\text { Bläulich } \\
\text { Weiss } \\
\text { WVeiss } \\
\text { Gelborange } \\
\text { Dunklergelb } \\
\text { Dunklerroth } \\
\text { Blau } \\
\text { Grün } \\
\text { 1)unklergelb }\end{array}$ & $\begin{array}{l}\text { Dunkelbläulich } \\
\text { Bläulichweiss } \\
\text { Gelblichweiss } \\
\text { Gelb } \\
\text { Dunkelgelb } \\
\text { Dunkelroth } \\
\text { Blau } \\
\text { Dunklergrün } \\
\text { Dunkelgelb }\end{array}$ \\
\hline
\end{tabular}


Wie man aus dieser Zusammenstellung ersieht, stimmt die Farbe, welche man in der Stellung $e=45^{\circ}$ erhält, mit derjenigen der einzelnen Platte durchgehends so ziemlich überein, oder steht ihr wenigstens sehr nahe. Man kann somit - da die Additionsfarbe für die Stellung $e=o$ nach Früherem ebenfalls als gegeben zu betrachten ist - zum Voraus die Veränderungen bestimmen, welche die allmähliche Zunahme von $e$ bei einem beliebigen Plattenpaar hervorruft. Diese Veränderungen bestehen immer in einem allmählichen, aber directen Uebergang der Additionsfarbe in die Farbe der einzelnen Platte.

304 Es erübrigt jetzt noch, die Wirkung eines festrerbundenen Plattenpaars mit derjenigen eines Gypsplättchens oder überhaupt eines dritten doppelbrechenden Körpers zu combiniren. Wir haben gesehen, dass das Platteupaar für sich allein gewissermaassen wie ein einzelner Körper wirkt, dessen Elasticitätsellipse sich um so mehr dem Kreise nähert, je grösser der Winkel $e$. Stellt man sich vor, die Axen dieser Ellipse seien die Verbindungslinien der Punkte $m n$ und st (Fig. 177), in welchen die den beiden Platten entsprechenden

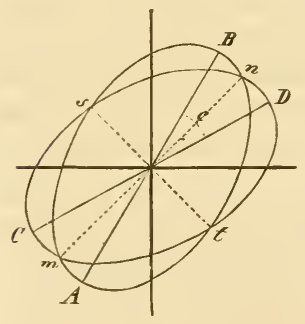

Fig. 177 . Ellipsen sich schweiden, so entspricht diese Vorstellung insofern der Wirklichkeit, als der Unterschied zwischen der grossen Axe $m n$ und der kleinen $s t$ in Uebereinstimmung mit der Interferenzfarbe continuirlich sinkt, wenn $e$ sich vergrössert, und endlich Null wird, wenn $e=90^{\circ}$; sie entspricht daher voraussichtlich auch der Gesammtwirkung eines Plattenpaars und eines Gypsplättchens. Die Lage, in welcher die eingebildete Elasticitätscllipse mit derjenigen des Gypsplättchens gleichc Orientirung hat, wird auch hier eine Additionsfarbe, diejenige dagegen, in welcher die homologen Axen sich rechtwinklig kreuzen, eine Subtractionsfarbe hervorrufen. So verhält es sich denn auch in der That, wie man aus folgender Zusammenstellung entuchmen wird. 


\begin{tabular}{|c|c|c|c|}
\hline \multirow{2}{*}{$\begin{array}{c}\text { Zwei } \\
\text { Krystallplatten }\end{array}$} & \multirow{2}{*}{$\underset{e}{\text { Winkel }}$} & \multicolumn{2}{|c|}{ Mit Gypsplättehen Roth I } \\
\hline & & Additionsfarbe & Subtractionsfarbe \\
\hline Sehwärzlichgrau I & $\begin{array}{c}0 \\
221 / 2^{0} \\
45^{0} \\
67^{1} / 2^{0}\end{array}$ & $\begin{array}{l}\text { Indigoviolett II } \\
\text { Violett } \\
\text { Röthlichviolett } \\
\text { Rothviolett }\end{array}$ & $\begin{array}{l}\text { Orange I } \\
\text { Röthlichorange } \\
\text { Rothorange } \\
\text { 1)unkelrothorange }\end{array}$ \\
\hline Grau I & $\begin{array}{c}0 \\
22^{1 / 2^{0}} \\
45^{0} \\
67^{1 / 2^{0}}\end{array}$ & $\begin{array}{l}\text { Blaugrün II } \\
\text { Grünlichblaı } \\
\text { Blau } \\
\text { Indigo }\end{array}$ & $\begin{array}{l}\text { Hellgelb I } \\
\text { ()rangegelb } \\
\text { (Orange } \\
\text { Röthlichorange }\end{array}$ \\
\hline Hellbläulichı I & $\begin{array}{c}0 \\
22^{1 / 3} 3^{0} \\
45^{0} \\
67^{1} / 2^{0}\end{array}$ & $\begin{array}{l}\text { Golb II } \\
\text { Grüngelh - } \\
\text { Hellgrün } \\
\text { Hellgrünlichblau }\end{array}$ & $\begin{array}{l}\text { Hellblüulich I } \\
\text { Weiss } \\
\text { Gelblichweiss } \\
\text { Hellröthlichorange }\end{array}$ \\
\hline Weiss I & $\begin{array}{c}0 \\
221 / 20 \\
45^{0} \\
6-1 / 2^{0}\end{array}$ & $\begin{array}{l}\text { Roth II } \\
\text { Hellrothorange } \\
\text { Grünlichgell, } \\
\text { Grünlichweiss }\end{array}$ & $\begin{array}{l}\text { Schwar\% } \\
\text { Grünlich } \\
\text { Grünlich weiss } \\
\text { W'eiss }\end{array}$ \\
\hline Gelb I & $\begin{array}{c}0 \\
22^{1 / 2^{0}} \\
45^{0} \\
67^{1 / 2^{0}}\end{array}$ & $\begin{array}{l}\text { Blaugrïn III } \\
\text { Grün } \\
\text { Gelb } \\
\text { Orange }\end{array}$ & $\begin{array}{l}\text { Weiss I } \\
\text { Weiss } \\
\text { Weiss } \\
\text { Bläulichlila }\end{array}$ \\
\hline ()range I & $\begin{array}{c}0 \\
22^{1 / 3} \\
45^{0} \\
67^{-1} / 2^{0}\end{array}$ & $\begin{array}{l}\text { Hellgelb } \\
\text { Gelborange } \\
\text { Orange } \\
\text { Rothorange }\end{array}$ & $\begin{array}{l}\text { Gelb I } \\
\text { Ifellorange } \\
\text { Weisslich } \\
\text { Lila }\end{array}$ \\
\hline
\end{tabular}

Die Farbenübergänge stimmen natürlich auch hier nicht mit denen der Newton'schen Reihe übcrein, doch ist das Steigen und Fallen der Farbe bei zunehmendem $e$ in der Regel dentlich ansgesprochen. Die höchste Additions- und die tiefste Subtractionsfarbe gibt selbstrerständlich dic Stellung $e=0$; wird $e=90^{\circ}$, so erhält man in allen Lagen das Roth des Gypsplättchens. - In Fällen, wo der Farbenwechsel ansnahmsweise undeutlich ist, kann derselbe durch Anwendung eines andern Gypsplättchens, z. B. Grau I, deutlicher gemacht werden.

Dreht man das Plattempaar, ohne den Winkel $e$ zu ändern, auf $\mathbf{3 0 5}$ dem Gypsplättchen um eine verticale Axe, indem man es z. B. aus der Additionslage allmählich in dic Subtractionslage überfülnrt, so bemerkt man hiebei Farbenübergänge, welche weder mit der Newton'schen Reihe noch mit den Farben einer cinzigen Platte in den ent- 
sprechenden Stellungen übereinstimmen. Während die letztere beim Drehen auf einem Gypsplättchen Töne hervorruft, die sich auf der Palette durch Mischung der Additions- oder Subtractionsfarbe mit der Farbe des Gypsplättchens herstellen lassen, erzeugt das Plattenpaar einen Farbenwechsel complicirterer Art, der bis jetzt nur für die einfacheren Fälle bestimmt formulirt werden konnte. Die praktische Bedeutung, die diesem Farbenwechsel zukoummt, erheischt aber dessenungeachtet cine ausführliche Erörterung.

Als durchgreifende Eigenthümlichkeit der Teränderungen, dic man beim Drehen des Plattenpaars auf einem Gypsplättchen beobachtet, kann die Verschiedenheit der Farbe in den beiden orthogonalen Stellungen, wo die Halbirungslinie des Winkels $e$ mit der Polarisationsebene des unteren oder des oberen Nicol zusammenfällt, bezeichnet werden. Diese Stellungen können in der That, wie man

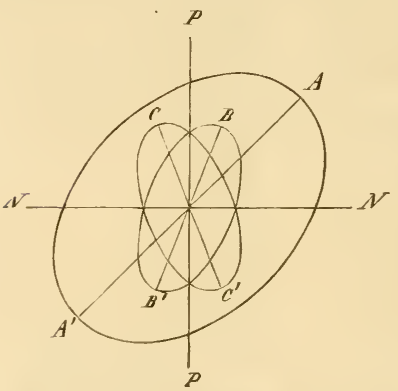

Fig. 179.

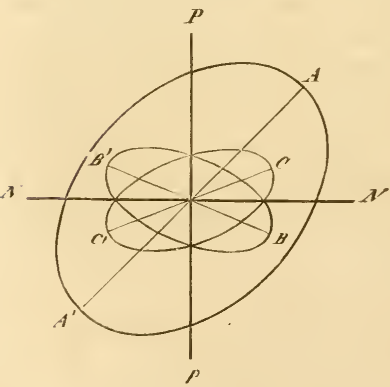

Fig. 17!. sich durch Veranschaulichung der drei wirksamen Elasticitätsellipscn in ihrer gegenseitigen Lage leicht überzeugen kamn, unter keinen Umständen ganz gleichwerthig sein. Sind z. B. $A A^{\prime}, B B^{\prime}$ und $C C^{\prime}$ (Fig. 178) die Ellipsen des Gypsplättchens und der beiden übereinander liegenden Krystallplatten in ihrer Reihenfolge von unten nach oben, ferner $P P$ und $N N$ die senkrecht zu einander gestellten Polarisationsebenen der beiden Nicols; dann ist aus unserer Figur sogleich ersichtlich, dass in der hier dargestellten Lage die homologen Schwingungsebenen der Ellipsen auf einander folgen, wie die Stufen einer Wendeltreppe, indem die alphabetische Ordnung der Buchstaben $A B C^{\prime}$ oder $A^{\prime} B^{\prime} C^{\prime}$ zugleich der Reihenfolge der entsprechenden Axen in der Richtung einer linksläufigen Spirale entspricht. Diess ist die orthogonale Consecutivstellung. Denkt man sich dagegen das Plattenpaar um $90^{\circ}$ gedreht Fig. 179), so fält $C C^{\prime}$ zwischen $B B^{\prime}$ 
und $A A^{\prime}$; die Ellipsenscheitel $A B C^{\prime}$ oder $A^{\prime} B^{\prime} C^{\prime}$ liegen also nicht mehr treppenförmig, sondern im Zickzack übereinander - eine Lage, die man im Gegensatz zur vorhergehenden als orthogonale Alternativstellung bezeichnet.

Die Verschiedenheit der Farben, die diese Stellungen hervorrufen, ist nun in vielen Fällen der Art, dass die Vergleichung derselben mit der Additions- und Subtractionsfarbe die erforderlichen Anhaltspunkte bietet, $u m$ eine gegebene orthogonale Stellung als Consecutiv- oder als Alternativstellung zu crkemnen. Ist diess der Fall, so ergiebt sich hieraus unmittelbar die Beantwortung der Frage, wic die wirksame Elasticitätsellipse in der oberen und in der unteren Platte geneigt sei. Ist z. B. Fig. 180 als Consecutiv-, Fig. 151 als Alternativstellung erkannt worden, so weiss man, dass die Ellipse $B B^{\prime}$ der unteren, $C C^{\prime}$ der oberen Platte angehört.

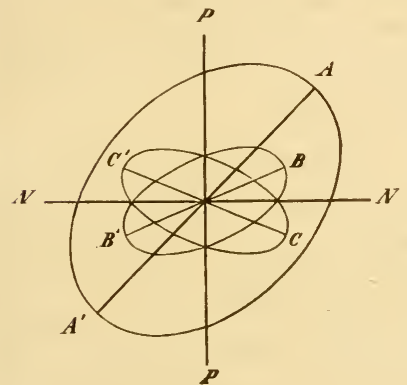

Fig. 150.

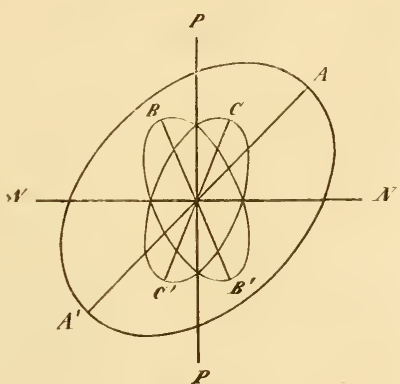

Fig. 1s1.

Zur Vergleichung der Farbentöne, um die es sich hicr handelt, 306 mag folgende Uebersicht dienen, welche nach Beobachtungen an verschiedenen Plattenpaaren, die sich unter Winkeln von $22^{1} /^{\circ}$, $45^{\circ}$ und $671^{\circ}{ }^{\circ}$ kreuzten, zusammengestellt ist. In der ersten Combinationsfolge bewegen sich dic Additionsfarben in der zwciten Ordnung, d. h. es sind Farben, welche für $e=0$ in die zweite Ordnung der Newton'schen Reihe fallen. Die zweite Combinationsfolge bezicht sich dagegen auf Additionsfarben, welche der dritten Ordnung angehören. Das Gypsplättchen, auf welchem die Drehung ausgeführt wurde, war Roth I. Die Farbe der Consecutivstellung ist mit C. , die der Altcrnatirstellung mit A. bezeichnet. 
Erste Combinationsfolge.

\begin{tabular}{|c|c|c|}
\hline Additionsfarbe & $\begin{array}{l}\text { Farben der orthogo- } \\
\text { nalen Stellungen }\end{array}$ & Subtractionsfarbe \\
\hline Rothriolett & $\left\{\begin{array}{l}\text { C. Junkelroth } \\
\text { A. Hellroth }\end{array}\right.$ & Innkelrothorange \\
\hline Räthliehviolett & $\begin{array}{l}\text { iC. Violettroth } \\
\text { is. Orangeroth }\end{array}$ & Rothorange \\
\hline Violett & $\begin{array}{l}\text { C. Hunkelrotil } \\
\text { iA. Hellroth }\end{array}$ & Röthlichorange \\
\hline Indigno & $\left\{\begin{array}{l}\text { C. Violettincligo } \\
\text { A. Rothorange }\end{array}\right\}$ & Röthlichorange \\
\hline Blau & C. Indigo & Orange \\
\hline Hellgrin & $\left\{\begin{array}{l}\text { ( } \mathrm{Blau} \\
\mathrm{A} \text {. Gelborange }\end{array}\right.$ & Gelbliehweiss \\
\hline Girüngelb & $\begin{array}{l}\text { (C. Blauindigo } \\
\text { (A. Bunkelorange }\end{array}$ & Weiss \\
\hline
\end{tabular}

\begin{tabular}{|c|c|c|}
\hline Additionsfarbe & $\begin{array}{l}\text { Farben der orthogo- } \\
\text { nalen Stellungen }\end{array}$ & Subtractionsfarbe \\
\hline Grïn & $\left\{\begin{array}{l}\text { C. Rothorange } \\
\text { A. Blauindigo }\end{array}\right.$ & Weiss \\
\hline Grünlichgelb & $\left\{\begin{array}{l}\text { C. Grün } \\
\text { A. Weiss }\end{array}\right.$ & Grünlichweiss \\
\hline Gelh & $\begin{array}{l}\text { (C. Orange } \\
\text { A. Bläulichweiss }\end{array}$ & Weiss \\
\hline Gelborange & $\begin{array}{l}\text { (C. Rothorange } \\
\text { iA. Nunkelindigo }\end{array}$ & Hellorange \\
\hline Orange & (A. Rothorange & SBlaulichlila \\
\hline Orange & $\left\{\begin{array}{l}\text { C. Röthliehorange } \\
\text { A. Violett }\end{array}\right.$ & Weisslich \\
\hline Rothorange & $\begin{array}{l}\text { 1C. Rothorange } \\
\text { 1. Violettroth }\end{array}$ & Lila \\
\hline Hellrothorange & $\left\{\begin{array}{l}\text { C. Grünlich } \\
\text { A. Hellroth }\end{array}\right.$ & Grünlich \\
\hline
\end{tabular}

In dieser Uebersicht lässt nur die erste Combinationsfolge, wo jede Platte für sich allein weniger als Weiss $I$, beide zusammen für $e=$ " daher nicht ganz Roth I geben, cine gewisse Gesetzmässigkeit erkennen. Hier blcibt die Farbe der orthogonalen Consecutivstellung, wie diejenige der diagonalen Additionsstellung, immer über, dic Farbe der Alternativ- und der Subtractionsstellung dagegen immer unter dem Roth des Gypsplättches, indem "Dunkelroth " das Roth bezeichnet, welches den Uebergang zu Violett II bildet, "Hellroth “ dagegen den Uebergaing zu Rothorange.") III. pag. 9५.

Vgl. Nïgeli, die Anwendung des Polarisationsmikroskops. Beiträge 
Die zweite Combinationsfolge wird durch Pare von Platten erhalten, von denen jede für sich allein IVeiss I oder eine höhere Furbe gibt. Die Farben der verschiedenen Stellungen sind hier an und für sich, da sie eines bestimmten additionalen oder subtractionalen Charakters entbehren, nicht zu einer Deutung geeignet.

Kehren wir jetzt das Problem um und fragen wir uns, welche 307 Anhaltspunkte die bereits entwickelten Beziehungen darbieten, um nach bekannten Polarisationsfarben die unbekannten Elasticitätsellipsen zweier über einander liegender Platten zu bestimmen. Zunächst ist klar, dass die Farben der stärksten Addition oder Subtraction, die man beim Drehen auf einem Gypsplättchen beobachtet, stets den beiden Stellungen entsprechen, die wir als diagonale Additions- und Subtractionsstellung bezeichnet haben; dass sic folglich Aufschluss darüber geben, wie der spitze $W$ inlicl $e$, den die grossen Axen der Elasticitätsellipsen unter sich bilden, orientirt sei. Dic Halbirungslinie dieses Winkels ist also hiedurch bestimmt.

In zweiter Linie entscheidet die Beobachtung, ob dic Farben der beiden orthogonalen Stellungen deutlich genug ausgeprägt sind, um hienach die Consecutiv- oder Alternativstellung als solche zu erkennen. Wo diess der Fall, ist dic Lage der unteren und der oberen Elasticitätsellipse in dem oben bezeichneten sinne bestinnt; wo es nicht der Fall, kann die Intersuchung in der Regel an kleineren Objecten derselben Art, welche eine beträchtlich tiefere Farbe erzcugen, wiederholt werden. Es gelingt aut diese Weise, bei clen meisten organisirten Gebilden, die wie ein Plattenpar wirken Membranen, Fasern, Prosenchymzellen u. dgl.), cinen Farbenwechsel zu erzielen, welcher unverkemmbar der ersten Combinationsfolge in obiger Zusammenstellung angehört und daher eine sichere Deutung gestattet.

Die möglichen Lagen der Elasticitätsellipsen reduciren sich jetzt auf den Spielraum, den der spitze Winkel $e$ noch übrig lässt. $\bigcup_{m}$ diesen Winkel zu bestimmen, kamu man es versuchen, die Farben der beiden Lamellen auf senkrecht zur Flächenausdehnung geführten Schnitten gesondert zu beobachten, un allfälig aus dem Steigen und Fallen derselben beim Drehen nach verschiedenen Sciten einige weitere Schlüsse zu ziehen. In der Mehrzahl der Fälle wird man indess die Ueberzeugung gewinnen, dass dieser Theil des Problems unlösbar ist. 
IV.

\section{Das Verhalten cylindrischer und kugeliger Objecte mit concentrisch gruppirten anisotropen Elementen.}

$30 \mathrm{~S}$

Ein ferneres Problem, das in der Praxis häufig vorkommt, ist die Bestimmung der Elasticitätsaxen in kugeligen oder cylindrischen Gebilden, deren Elemente in radialen Reihen um die Axe oder den Mittelpunkt liegen, wie diess bei Stärkekörncrn, cylindrischen Fasern und Röhren etc. der Fall ist. Die Schwierigkeiten, die man hiebei zu überwinden hat, sind ähnlicher Natur, wie im vorhergehenden Falle; sie liegen in der Ungleichheit der Stellungen der doppelbrechenden Elemente zum durchgehenden Lichtstrahl und in der Verschiedenheit der Annalınen, die sich mit Rücksicht hierauf machen lassen. Der Gang der Untersuchung ist dadurch vorgeschrieben: es handelt sich darum, die denkbaren Möglichkeiten vor Allem klar ins Auge zu fassen und hierauf durch die Beobachtung auf einen möglichst engen Kreis zurückzuführen.

\section{Cylindrische 0bjecte.}

309 Der Name Cylinder und IIohlcylinder bezieht sich hier selbstverständlich nicht sowohl auf die äussere Form, als vielmehr auf die innere Structur, d. h. auf die Anordnung der doppelbrechenden Elemente. Wir setzen voraus, dass die Elemente des gleichen Radius hinsichtlich der Lage ihrer Schwingungsebenen und der Grösse der wirksamen Elasticitäten übereinstimmen, dass alle Radien, welche in einer durch dic Axe gelegten Fbene liegen, einander gleich sind, und dass alle auf einem zur Axe rechtwinkligen Querschnitt befindlichen Radien sich so verhalten, als ob der nämliche Radius im Kreise herumgeführt würde.

Unter diesen Voraussctzungen bietet der Querschnitt durch den Cylinder dic einfachste Combination, indem hier die Wirkungen der übereinander liegenden Elemente sich addiren, wie in einem einfachen Krystall, und überdiess die Stellungen der auf einem Radius wirksamen Elasticitätsellipsen unter sich übereinstimmen (Fig. 182). Der Gesammteffect ergiebt sich hieraus von selbst. Jeder Durchmesser des Querschnitts verhält sich wie eine Krystallnadel (oder bei dickeren Schnitten wic eine senkrecht stehende Krystallplatte), und die Interferenzfarben, welche beim Drehen der Krystallnadel un eine scnk- 
rechte Axe $\mathrm{n}$ a ch einander zum Vorschein kommen, finden sich auf der Schnitttläche gleichzeitig n eben einander. 'Zwei diametrale Zonen $a b$ und $c d$, in welchen die Axen der Elasticitätsellipsen in die Polarisationsebenen $P P$ und $N N$ der Nicols fallen, wirken demzufolge wie einfach brechende Medien; sie erscheinen ohne Gypsplättchen schwarz und mit einem Gypsplättchen von der unveränderten In-

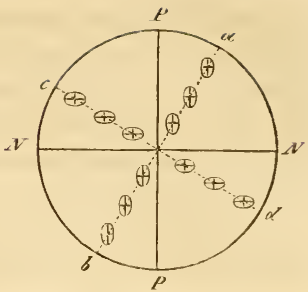

Fig. 14?. terferenzfarbe desselben erhellt. Die Mittellinien der dazwischenliegenden Quadranten zeigen daher nothwendig die lebhaftesten Farben, und zwar in Verbindung mit einem Gypsplättchen paarweise Additions- oder-Subtractionsfarben, je nachdem die homologen Axen der Ellipsen zusammenfallen oder sich rechtwinklig kreuzen. Auf' cinem Gypsplättchen Roth I, dessen Elasticitätscllipse dic in Fig. is 3 dargestellte Lage besitzt, würden also die mit 1 bezeichneten (Quadranten unseres Cylinders die Farbe steigern, während die mit $s$ bezeichneten dieselbe erniedrigen.

Auf Querschnitten durch Cylinder und Hohlcylinder ist hienach die Axenlage der wirksamen Elasticitätsellipsen leicht zu ermitteln. Wir fügen hinzu, dass allc bis jetzt bekannt gewordenen Fälle darin übercinstimmen, dass die eine Axe radial, die andere tangential verläuft, indem die neutralen Zonen, wclche das dunkle Kreuz bilden, stets in die Polarisationsebenen der Nicols fallen. Die in

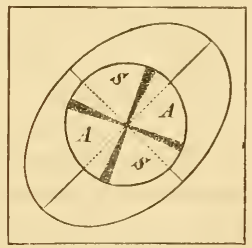

Fig. 1 -3. Fig. 152 und 183 dargestellte Abwcichung ist also nicht beobachtet, sondern bloss der Allgemeinheit wegen rorausgesetzt.

Der Querschnitt durch den Cylinder gibt uns also Aufschluss darüber, ob die Axenrichtungen der Elasticitätsellipsen mit dem Radius und der Tangente zusammenfallen oder dieselben schiefwinklig kreuzen, und im erstgenannten Fall, ob die tangentiale oder clie radiale Axe die grössere sei. Was ist nun aber damit gewonnen? Angenommen, die beiden Axen gchen wirklich dem Radius und der Tangente parallel, so fragt sich weiter, ob vielleicht die eine derselben zugleich Axe des Ellipsoids sei, oder ob man es mit einem beliebigen Diametralschnitt $\mathrm{zu}$ thun habe. Diese Frage ist nicht immer leicht $\mathrm{zu}$ beant- 
worten. Die oben erwähnte Prüfung mittelst Drehen um die beiden Axen kann nämlich nur in solchen Fällen zum Ziel führen, wo der Querschnitt im Verhältniss zum Cylinderdurchmesser nicht zu dick ist. Bei höheren Stücken ist das Verfahren schon deshalb nicht anwendbar, weil dieselben, wenn sie merklich schicf stehen, nicht mehr wie Querschnitte wirken. Um weitere Anhaltspunkte zu gewinnen, wird man also in der Mehrzahl der Fälle auf Längsschnitte und, wo diese nicht herstellbar sind, auf Längsansichten angewiescn sein.

311 Was zunächst die Längsschnitte betrifft, so ist einleuchtend, dass cine mittlere Lamelle B B' 'Fig. 154), wemn sic flach auf dem Ob-

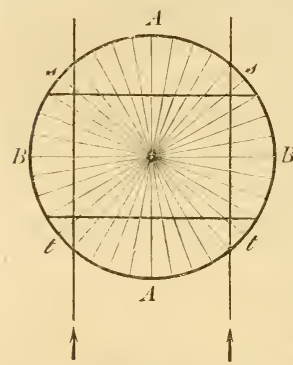

Fig. Inl. jectträger liegt, über die Axenlage der Elasticitätscllipse in der Diametralebene des Cylinders entscheidet Denn da die Randparticen einer solchen Lamelle annähernd wie cin Krystallplättchen wirken, so muss sich sogleich herausstellen, ob die beiden Axen der Längsund Querrichtung parallel gehen, oder ob sie diese Richtungen schiefwinklig kreuzen. Von diescm letzteren Falle dürfen wir übrigens vorlïufig gänzlich absehen, da eine solche Kreuzung, soweit die bisherigen Beobachtungen reichen, nirgends vorkommt.

Wir nehmen also an, die im Quer-und Längsschnitt wirksamen Elasticitätsellipsen haben die radiale Axe gemein. Die durch die beiden andern Axen grelegte Ebene steht alsdamn senkrecht auf dem Radius. Hieraus lässt sich nun, wenn man die Eigenschaften des Ellipsoids erwägt, der weitere Schluss zichen, dass die gemeinsame radiale Axe eine Axe des Ellipsoids sei und dass demzufolge die beiden audern Axen desselben in einer tangentialen Ebene liegen. Man halt also nur nöthig, die Elasticitätscllipse eines Tangentialschnittes, wie z. B. der Cylindersegmente $\perp A$ Fig. 151), zu bestimmen, um nicht bloss die Richtungen der fraglichen Axen, sondern auch die relative Grösse derselben festzustellen.

Das Verhältniss der bciden tangentialen Axen zur radialen ist nun aber damit noch nicht gegeben, oder doch nur in clem Falle, wo die ersteren der Längs- und Qucrichtung des Cylinders entsprechen. In jedem anderen Falle ist der Beobachter darauf angewiesen, dieses Verhältniss auf Schnitten, welche durch die zu vergleichenden Axen geführt 
sind, oder weun dieselben nieht zum Ziele führen, durch Neigen des Cylinders, wovon später die Rede sein wird, besonders auszumitteln.

Sollte es sich herausstellen, dass Schnitte, welche senkrecht zu 312 einer der drei Axen geführt wurden, sich wie einfach brechende Medien verhalten, so sind die beiden andern Axen unter sich gleich, die doppelbrechenden Elemente also optisch-e inaxig. Ruft dagegen jeder durch zwei Axen gelegte Schnitt Farben hervor, so sind die Cylinderelemente optisch-zweiaxig. Ob ein Object in die cine oder andere Kategorie gehöre, kamn im Allgemeinen nicht eher entschieden werden, als bis die Richtung einer optischen Axe auf experimentellem Wege, sei es auf Schnitten oder durch Drehen, crmittelt ist. Es gehört eine sehr mangelhafte Kenntniss der Erscheinungen dazu, wenn man sich einbildet, dic optischen Eigenschatten eincs Gegenstandes auf irgend einem beliebigen Durchschnitt erforschen zu können. *)

-) Die Verschiedenheiten, welche man auf solchen Durchschnitten beubachtet, werden von manchen Autoren mit Ausdrücken bezeichnet, welche in der krystallographischen Optik eine ganz andere Bedentung haben. Mohl und Valentin sprechen z. B. von negativer und positiver Farbe oder Beschaffenheit eines Objects, je nachdem die Elasticitätsellipse, welche auf (Querschnitten zur W'irkung kommt, radial oder tangential orientirt ist. An anderen Orten wird die grrosse oder kleine Axe der Ellipse, deren Wirkung man beobachtete, kurzweg dic opt is che Axe genannt, und also stillschweigend vorausgesetzt, die letatere liege in der Ebene des Gesichtsfeldes, u. s. w. Es erscheint uns überflüssigg, die Unzulässigkeit dieser und ähnlicher Benennungen, wie man sie in cler eiuschlägigen Literatur findet, hier noch besonders darzulegen. 1)er I.eser, welcher unseren bisherigen Erörterungen gefolgt ist, wird die nöthige Kritik selbst zu übeı wissen.

Beispielsweise mögen indess noch einige Angaben Valentin's über das Verhalten eylindrischer Gebilde Die Unters. der Pflanzen- und Thiergewebe im polar. licht, S. 161) in aller Kürze Frwähnung finden. Valentin setzt die einaxige Beschaffenheit der Cylinderelemente voraus und erklärt sodann das Zustandekommen des dunkeln Kreuzes in Querschnitt für die »drei Hanptrichtungen der optisehen Axe ": die senkrechte, die tangentiale und die radiale. Der senkrechten Stellung der optischen Axe entspricht das "Kreuz erster Ordnung ", der tangentialen das "Kreuz zweiter Ordnung ", endlich der radialen das "Kreuz dritter Ordnung “. Hiezu wird bemerkt, dass es Präparate aus dem Pflanzenreich Eiweiss von Phytelephas) gebe, in denen Kreuze erster und solche dritter Ordnung neben einander in einem und demselben Querschnitt auftreten. - Gegen diese Darstellung ist zunächst einzuwenden, dass schon die Voraussetzungen, wenigstens soweit sie vegetabilische Präparate betreffen, mit der Wirklichkeit im Widerspruche stehen, indem z. B. alle Zellmembranen, die man genau kennt (es sind freilich nur wenige), sich als optisch-zweiaxig erwiesen haben. 
Wir setzen zweitens den Fall, dass der Cylinder wegen seiner Kleinheit oder aus anderen Ursachen nicht gespalten werden könne und dass somit bloss Längsansichten des ganzen Cylinders zu Gebote stehen. Es ist vorauszusehen, dass solche Ansichten die diametralen Längsschnitte $(B B$ Fig. 184) in den meisten Fällen ersetzen, indem der Lichteffect, den die beiden Randzonen hervorrufen, im Wesentlichen offen bar derselbe ist. Die Uebereinstimmung wird um so vollständiger sein, je mehr man die Lichtbrechung, die mit dem Eintritt in die Cylindersubstanz verbunden ist, vermindert. Gelingt es, dieselbe durch geeignete Wahl des umgebenden Mediums Glycerin, Oel etc.) gänzlich zu beseitigen, so verhalten sich die von unten

Aber auch abgesehen davon, ist das "Kreuz erster Ordnung " unter dem Polarisationsmikroskop, zumal bei Vergrösserungen, wie sie bei den meisten der hieher gehörigen Objecte nothwendig sind, eine physikalische Unmöglichkeit, indem bei senkrecht stehender Axe der ganze Querschnitt dunkel erscheint. Nur bemerken wir ausdrücklich, dass wir unter Polarisationsmikrosk op ein gewöhnliches mit Polarisationsprismen ausgestattetes Mikroskop rerstehen - das einzige Instrument übrigens, mit dem sich die von Valentin selbst angeführten mikroskopisch kleinen Objecte, wie Bastzellen, Pflanzeneiweiss etc., beobachten lassen. Das Bild, welches ein solches Instrument von Cylinderquerschnitten liefert, rührt nämlich von Lichtkegeln her; deren Oeffuung mit derjenigen der Blenclung, resp. des polarisirenden Nicol, übereinstimmt. Der Gesammteffect eines solchen Kegels mit Rücksicht auf Doppelbrechung ist aber für unser Auge annähernd derselbe, als ob die verschieden geneigten Strahlen das Object in der Richtung der Mikroskopaxe durchlaufen hätten. Ein Krystallplättchen, dessen optische Axe senkrecht steht, zeigt denn auch in der That keine Spur von Doppelbrechung. Ganz anders wirken die Polarisations a p parate von Nörrenberg, 1 u ve etc., die man hie und da ebenfalls, wenn auch mit Unrecht, als Mikroskope zu bezeichnen pflegt. Das reelle Bild, welches hier zu Stande kommt und durch die Ocularlinse betrachtet wird, ist nicht das Bild des zu untersuchenden Gegenstandes; die Strahlen, welche sich in der Bildebene kreuzen, stellen im Gegentheil, rückwärts verfolgt, ein parallelstrahliges Bündel dar, welches den Gegenstand mit um so grösserer Neigung gegen die Mikroskopaxe durchsetzt, je weiter der Kreuzungspunkt von dieser Axe absteht. In jedem Punkt des Bildes kommen also einfallende Strahlen von bestimmter Neigung zur Interferenz, und auf diesem Umstande beruht die Bildung von Ringen, wie man sie an senkrecht zur Axe geschliffenen Kalkspathplatten beobachtet.

Das "Kreuz erster Ordnung " kommt nur im Polarisationsapparat, nicht aber im Polarisationsmikroskop) (ganz schwache Vergrösserungen ausgenommen) zu Stande. Valentin begeht in diesem wie in anderen Punkten (Combination mit einem Gypsplättchen, Bestimmung der Axenrichtung etc.) den Fehler, seine theoretischen Erörterungen auf die Wirkung eines Polarisationsapparates zu basiren und die erhaltenen Resultate ohne Weiteres auf Beobachtungen mit dem Polarisationsmikroskop überzutragen. Dass eine solche Methode, verbunden mit den Eingangs erwähnten willkürlichen Voraussetzungen, auf Irrwege führen muss, wird Jedermann einleuchten. 
einfallenden Strahlen vollends wie in einer planplanen Platte, $d . h$. sie crlangen zunächst dem Rande dieselben Gangunterschiede, wie wemn das Mittelstück $B B$ (Fig. 185) für sich allein wirksam wäre. Weiter nach innen kommen zwar noch die allmählich steigenden Effecte der dreieckigen Stücke $s$ und $t$ hin$\mathrm{zu}$; allein es ist klar, dass sie in den peripherischen Schichten des Cylinders auf keinen Fall das Uebergewicht erreichen. Die beiden Randzonen müssen folglich, wenn das umgebende Medium von annähernd gleicher Dichtigkeit ist, unter allen Umständen die Farben eines Diametralschnittes zeigen.

Die mittlere Zone verhält sich dagegen

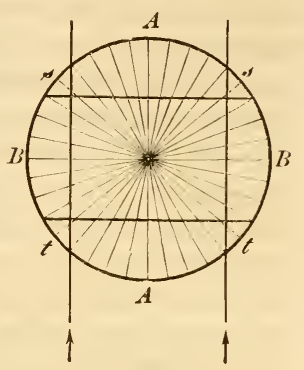

Fig. 15.5. in der Längsansicht, wie schon früher bemerkt, wie zwei übereinanderliegende Krystallplättchen. Die Beobachtung kann daher höchstens entscheiden, ob die Axen der Elasticitätsellipsen der Längs - und Querrichtung entsprechen oder sich schiefwinklig kreuzen, und im letzteren Falle, ob die Mittellinie des spitzen Winkels, den die grossen Axen unter sich bilden, längs oder quer gestellt und welche von den beiden Ellipsen die obere sei. Dass diese Data zur Construction des Elasticitätsellipsoids im Allgemeinen nicht ausreichen, bedarf nach dem, was oben (pag. 337) hierüber gesagt wurde, keiner Erörterung. Es ist aber nichtsdestoweniger wichtig, die verschiedenen Fälle, welche die Beobachtung bieten kann, nach einander zu prüfen und die Consequenzen, die sich daraus ziehen lassen, für jeden einzelnen festzustellen.

Es sei $A$ (Fig. 186) der liegende Cylinder oder Hohlcylinder und $B$ der dazu gehörige Querschnitt. Die Elasticitätsellipsen, welche bei ersterem in

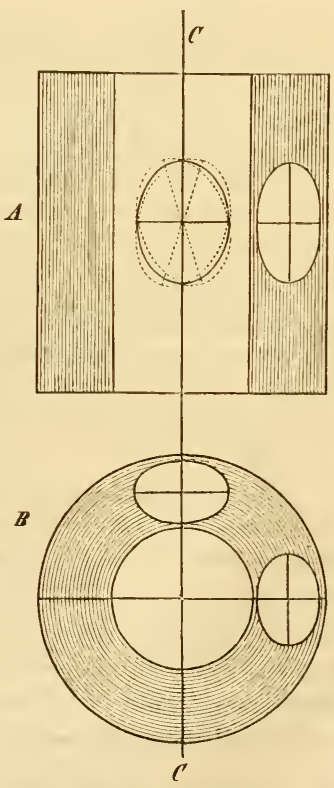

314 
der Mitte und am Rande wirksam sind, desgleichen diejenige des Querschnittes hier auf der Linie $C^{\prime} C^{\prime}$ liegend gedacht seien durch bcobachtung bestimmt. Man weiss also von jeder derselben, ob sie in der Richtung der Axe $C^{\prime} C^{\prime}$ oder in der darauf rechtwinkligen verlängert ist, oder obsie neutral wirkt und daher einen Kreisschnitt des Ellipsoids darstellt. Nur ist hiezu zu bemerken, dass diese Data für die Mitte des liegenden Cylinders, im Falle die Elasticitätsellipsen der zu- und abgekchrten Seite sich kreuzen, auf jene eingebildete Ellipse zu beziehen sind, welche nach Früherem die Wirkung der beiden übereinander liegenden repräsentirt. Da nun jede dieser drei Ellipsen längs oder quer zur (ylinderaxe gestellt orler auch ein Kreis sein kann, was wir mit $l$ längs), q quer und $o$ bezeichnen wollen, so ergeben sich im Ganzen 27 verschiedene Combinationen, wovon jedoch nur die folgenden 13 möglich sind.

\begin{tabular}{|c|c|c|c|c|c|c|c|c|c|c|c|c|c|}
\hline & 1. & 2. & 3. & 1. & 5. & 6. & $i$. & 4. & 9. & 10. & 11. & 12 & 13. \\
\hline Mitte & $l$ & $q$ & $l$ & $q$ & $l$ & $q$ & $l$ & $q$ & $l$ & 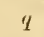 & $o$ & 0 & 0 \\
\hline Rand & $l$ & $q$ & $l$ & $q$ & $q$ & $\grave{l}$ & $l$ & $q$ & 0 & $o$ & $l$ & $q$ & $o$ \\
\hline
\end{tabular}

Dic übrigen 11 Combinationen, nämlich

\begin{tabular}{|c|c|c|c|c|c|c|c|c|c|c|c|c|c|}
\hline & & 15. & 11. & 17. & 15. & 19. & 20. & 21. & $2 \cdot 2$. & 23. & 24. & & 26.27 \\
\hline & $l$ & & 0 & $o$ & $l$ & $q$ & $l$ & 7 & $o$ & $o$ & $o$ & 0 & \\
\hline Rand & $q$ & $\hat{l}$ & $l$ & $q$ & $o$ & $o$ & $q$ & $l$ & $o$ & 0 & $l$ & $q$ & 0 \\
\hline Querschnitt & I & $l$ & $l$ & $q$ & $q$ & $l$ & 0 & 0 & $l$ & $q$ & 0 & 0 & $"$ \\
\hline
\end{tabular}

sind ummöglich, weil immer eine der drei angenommenen Stellungen, wie leicht nachzuweisen, mit den beiden andern unvercinbar ist. Man erhält z. 13. aus Combination 11, wenn man die längsgestellte Ellipsenaxe der Mcdian- und Randansicht mit $L$, die radiale Axe mit $l$ ? und die tangentiale mit $T$ bezeichnet, die Ungleichheiten : $R<T$, $R>L, L>T$, was unmöglich ist. Ebenso leicht ist der Beweis für die übrigen Combinationen zu liefern.

315 Dic Folgerungen, die sich aus den 1:3 möglichen Coubinationen ziehen lassen, ordnen sich naturgenåss in zw̧ei Ricihen. Die crste licihe enthält diejenigen Fälle, wo eine der drei Axen des Ellipsoids der Cylinderaxe parallel geht; die zweite umlasst alle übrigen nit beliebig schiefer Stellung der beiden tangentialen Axen. Beide: lieihen sind in nachstehender Uebersicht, der bcquemeren Verglcichung wegen, mit der Combinationsreihe zusammengestellt. Die dabei angewandten Bezeiehnungen haben folgende Bedcutung: \pm positiv oder negativ, d. h. unentschieden ob das eine oder das andere; Axenebene $=$ Ebene der optischen Axen; tangential = einer an die 
Cylinderoberfläche gelegten 'Tangentialebene parallel; radial $=$ in der durch den Radius und die Longitudinalaxe $(L)$ gelegten Ebene; transversal $=$ in einer auf der Axe $L$ senkrechten Ebene: $L=$ Lon gitudinalaxe, d. h. Axe des Elasticitätsellipsoids, welche in der ersten Reihe der Cylinderaxe parallel geht und in der zweiten Reihe weniger als $45^{\circ}$ gegen dieselbe geneigt ist; $T=$ Tingentialaxe, $d$. h. die Axe des Ellipsoids, welche auf der durch $L$ und den Cylinderradius gelegten Ebene senkrecht steht; $R=$ Radjalaxe.

\begin{tabular}{|c|c|c|c|c|c|}
\hline \multicolumn{4}{|c|}{ Combination. } & \multicolumn{2}{|c|}{ Optischer Charakterder ('ylinderelemente. } \\
\hline $\mathrm{Nr}$. & $\underset{\Xi}{\stackrel{\Xi}{\Xi}}$ & 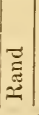 & 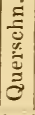 & $\begin{array}{c}\text { Erste Reihe: } \\
L \text { geht parallel der Cylin- } \\
\text { deraxe. }\end{array}$ & $\begin{array}{l}\text { Zwcite lieihe: } \\
L \text { steht schief, Neigung }<45^{\circ} \text {. }\end{array}$ \\
\hline 1. & $l$ & $l$ & $l$ & $\begin{array}{l}\text { Zweiaxig } \pm, \text { Axenebene } \\
\text { tangent. } \\
L \text { grösste, } T \text { kleinste } \\
\text { Elast.-Axe }\end{array}$ & $\begin{array}{l}Z \text { weiaxig } \pm \text {, Axenebene tangent. } \\
L \text { grösste, } T \text { kleinste Elast.-Axe }\end{array}$ \\
\hline 2. & $q$ & $q$ & $q$ & $\begin{array}{l}\text { Zweiaxig } \pm, \text { Axenebene } \\
\text { tang. } \\
T \text { grösste, } I \text { kleinste Axe }\end{array}$ & $\begin{array}{l}Z \text { weiaxig } \pm, A x e n e b e n e ~ t a n g . \\
T \text { grösste, } L \text { kleinste } A x e\end{array}$ \\
\hline 3. & $l$ & $l$ & $q$ & $\begin{array}{l}\text { Zweiaxig } \pm \text {, Axeneb. rad. } \\
I \text { grösste, } R \text { kleinste Axe }\end{array}$ & $\begin{array}{l}\text { Zweiaxig } \pm \text {, Axenebene radial } \\
I \text { grösste, } R \text { kleinste Axe. } \\
\text { Oder zweiaxig }+ \text {, Axenebene tangent. } \\
L \text { grösste, } T \text { kleinste Axe. } \\
\text { Oder einaxig }+ \\
L=\text { opt. Axe }\end{array}$ \\
\hline 4. & q & $q$ & $l$ & $\begin{array}{l}\text { Zweiaxig } \pm \text {, Axeneb, rad. } \\
l \text { grösste, } L \text { kleinste Axe }\end{array}$ & $\begin{array}{l}\text { Zweiaxig } \pm \text {, Axenebene radial } \\
R \text { grösste, } L \text { kleinste Axe. } \\
\text { Oder zweiaxig }- \text {, Axenebene tangent. } \\
T \text { grösste, } L \text { kleinste Axe. } \\
\text { Oder einaxig - } \\
L=\text { opt. Axe }\end{array}$ \\
\hline 5. & $l$ & $q$ & $l$ & $\begin{array}{l}\text { Zweiaxig } \pm, \text { Axenebene } \\
\text { transv. } \\
R \text { grösste, } T \text { kleinste Axe }\end{array}$ & $\begin{array}{l}\text { Zweiaxig } \pm \text {, Axenebene transv. } \\
\text { IR grösste, } T \text { kleinste Axe. } \\
\text { Oder zweiaxig }- \text {, Axenebene tang. } \\
L \text { grösste, } T \text { kleinste Axe. } \\
\text { Oder einaxig - } \\
T=\text { opt. Axe }\end{array}$ \\
\hline 6. & $q$ & $l$ & $q$ & $\begin{array}{l}\text { Zweiaxig } \pm \text { Axenebene } \\
\text { transv. } \\
T \text { grösste, } R \text { kleinste } \Lambda \text { xe }\end{array}$ & $\begin{array}{l}\text { Zweiaxig } \pm \text {, Axenebene transv. } \\
T \text { grösste, } R \text { kleinste Axe. } \\
\text { Oder zweiaxig }+ \text {, Axenebene tang. } \\
T \text { grösste, } L \text { kleinste Axe. } \\
\text { Oder einaxig }+ \\
T=\text { opt. Axe }\end{array}$ \\
\hline
\end{tabular}




\begin{tabular}{|c|c|c|c|c|c|}
\hline \multicolumn{4}{|c|}{ Combination. } & \multicolumn{2}{|c|}{ Optischer Charakterder Cylinderelemente. } \\
\hline Nr. & 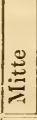 & 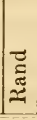 & 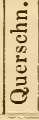 & $\begin{array}{c}\text { Erste Reihe : } \\
L \text { geht parallel der Cylin- } \\
\text { deraxe. }\end{array}$ & $\begin{array}{c}\text { Zweite Reihe: } \\
L \text { sttht schief, Neigung }<45^{\circ}\end{array}$ \\
\hline$i$. & $l$ & $l$ & $o$ & $\begin{array}{l}\text { Einaxig }+ \\
L=\text { opt. Axe }\end{array}$ & $\begin{array}{l}\mathrm{Zweiaxig}+, \text { Axenebene tang. } \\
\quad L \text { grösste, } T \text { kleinste Axe }\end{array}$ \\
\hline s. & $q$ & $q$ & $o$ & $\begin{array}{l}\text { Einaxig }- \\
L=\text { opt. Axe }\end{array}$ & $\begin{array}{l}\text { Zwejaxig - }, \text { Axenebene tang. } \\
\quad T \text { grösste, } L \text { kleinste Axe }\end{array}$ \\
\hline 9. & $l$ & $o$ & $l$ & $\begin{array}{l}\text { Einaxig }- \\
T=\text { opt. Axe }\end{array}$ & $\begin{array}{l}\text { Zweiaxig - , Axenebene tang. } \\
L \text { grösste, } T \text { kleinste Axe }\end{array}$ \\
\hline 10. & $q$ & $o$ & $q$ & $\begin{array}{l}\text { Einaxig }+ \\
T^{\prime}=\text { opt. Axe }\end{array}$ & $\begin{array}{l}Z \text { weiaxig }+ \\
T \text { grösste, } L \text { kleinste Axe }\end{array}$ \\
\hline 11. & 0 & $l$ & $q$ & $\begin{array}{l}\text { Finaxig }- \\
R=\text { opt. Axe }\end{array}$ & $\begin{array}{l}\text { Zweiaxig }+, \text { Axenebene tang. } \\
L \text { und } T=45^{\circ} \text { geneigt. } \\
\text { Oder zweiaxig } \pm \text {, Axenebene radial } \\
R \text { kleinste Axe. } \\
\text { Oder einaxig }+ \text {, opt. Axe } \\
\text { tang. und } 45^{\circ} \text { geneigt }\end{array}$ \\
\hline 12. & $q$ & $o$ & $l$ & $\begin{array}{l}\text { Eimaxig }+ \\
R \text { optische Axe }\end{array}$ & $\begin{array}{l}\text { Zweiaxig }- \text {, Axenebene tang. } \\
L \text { und } T=45^{\circ} \text { geneigt. } \\
\text { Oder zweiaxig } \pm \text {, Axenebene radial } \\
R \text { grösste Axe. } \\
\text { Oder einaxig }- \text {, opt. Axe } \\
\text { tangential und } 45^{\circ} \text { geneigt }\end{array}$ \\
\hline 13. & 0 & $\circ$ & 0 & Einfachbrechend & $\begin{array}{l}\text { Zweiaxig neutral, Axenebent tang. } \\
L \text { und } T=45^{\circ} \text { geneigt }\end{array}$ \\
\hline
\end{tabular}

Die Ableitung der in vorstehender Uebersicht zusammengestellten Folgerungen aus den durch Beobachtung bestimmten Stellungen der Elasticitätsellipsen ist ungemein einfach und bedarf eigentlich für Leser, die sich die gegebenen Verhältnisse klar vorstellen oder vielleicht durch Modelle oder Figuren versinnlichen, keiner Erörterung. Jedenfalls wird es vollständig genügen, wenn wir den $\mathrm{Weg}$, den man dabei einzuschlagen hat, an einem Bcispiele zur Anschauung bringen.

Die beobachtete Combination sei $7 l l$ (die erste in unserer Reihe) und die Längsaxe $L$ des Ellipsoids sei schief gegen die Cylinderaxe gestellt. Dạnn ist der Winkel, welchen die Axe $L$ mit der Cylinderaxe bildet, durch die sich kreuzenden Ellipsen, welche in der Mitte des licgenden Cylinders wirksam werden, in seinem Grenzwerthe 
bestimmt, d. h. er ist in unserem Falle jedenfalls kleiner als $45^{\circ}$. Diese Ellipsen haben also beispielsweise die in Fig. 187 dargestellte Orientirung wemn nämlich $C C$ der Cylinderaxe parallel geht. Man hat folglich $s t>m n$ und $L L$ grösser als $T T$. Die Durchmesser $m n$ und $s t$, welche der Quer- und Längsrichtung des Cylinders entsprechen, stellen aber offenbar je eine Axe der Ellipsen dar, die auf dem Querschnitt und am Rande des liegenden $\mathrm{Cy}$ linders zur Wirkung kommen; $m n$ ist die tangentiale Axe der Querschnittsellipse, st die längsgestellte der Randansicht. Aus

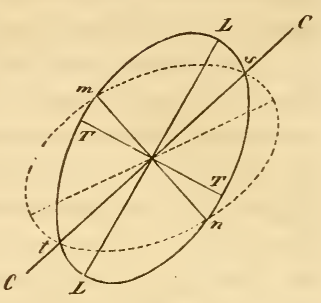

Fig. 157 . der Form dieser Ellipsen, wie sie durch die Combination $l l l$ bestimmt ist, ergibt sich aber, dass die radiale Axe $R$ des Ellipsoids grösser als $m n$ und kleiner als $s t$ ist; sie kann also nur die mittlere Axe desselben sein. Die Elemente sind also zweiaxig und die optischen Axen liegen in einer tangentialen Ebene. Das Verhältniss der Axe $R$ zu den beiden andern und die davon ablängige Lage der Kreisschnitte bleiben jedoch unbestimmt, die positive oder negative Natur der Elemente also zweifelhaft.

Von den dreizehn oben zusammengestellten Combinationen ver- $\mathbf{3 1 7}$ dienen einzelne wegen des optischen Effecles, den sie hervorrufen, nachträglich noch eine besondere Betrachtung. Wir heben zunächst den Fall hervor, der in den Combinationen 5 und 6 in unserer Reihe gegeben ist, dass nämlich Rand und Mitte des liegenden $\mathrm{Cy}$ linders Farben von entgegengesetztem Charakter hervorrufen. Dieser Fall charakterisirt sich bei der Beobachtung mit Gyps. plättchen angenblicklich durch die neutralen Längsstreifen, welche den Uebergang zwischen den entgegengesetzten Farben der Rand- und Flächenansicht, vermitteln

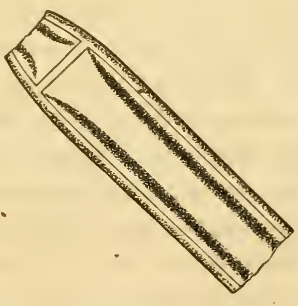

Fig. 14s, und welche daher ohne Gypsplättchen als dunkle Linien erscheinen (Fig 185). Diese Linien entsprechen den Stellen, wo die resultirende Elasticitätsellipse der Flächenansicht, welche natürlich nach beiden Seiten hin allmählich in die entgegengesetzt orientirte des Randes übergeht, die Form des Kreises erreicht hat, wo also die über ein- 
ander liegenden Ellipsen der zu- und abgekehrten Cylinderhälfte, sich rechtwinklig kreuzen. Eine rechtwinklige Kreuzung setzt aber, der symmetrischen Lage wegen, voraus, dass beide Ellipsen unter 45 gegen die Cylinderaxe geneigt seien.

Man könnte nun, wenn man die Sache vom rein geometrischen Standpunkt aus betrachtet, auf den Gedanken kommen, aus dem bekannten Abstande der neutralen Linien vom Rande den unbekannten Winkel $e$ zu bestimmen, welchen die übereinander liegenden Ellipsen in der Medianzone bilden; denn es ist einleuchtend, dass die erwähnte Neigung von $45^{\circ}$ in um so grösserer Entfernung von der Mittellinie erreicht wird, je mehr die Neigung auf der Mittellinie davon abweicht. Allein da jede Schicht im Cylinder ihre eigene neutrale Linie hat, welche gegen die der anliegenden Schichten seitlich verschoben und von der Interferenzfarbe derselben mehr oder minder erhellt erscheint, so fällt der Gesammteffect nicht bestimmt genug aus, um bei der Kleinheit der Objecte, die wir hier im Auge haben, in der angedeuteten Weise praktisch verwerthbar zu sein. Dassclbe gilt auch von der Bestimmung der optischen Axen, im Falle $e=0$. Es mag daher genügen, auf die diessfalls bestehenden, ohmehin ziemlich verwickelten Beziehungen hier nur ganz im Allgemeincn aufmerksam gemacht zu haben.

Die neutralen Längsstreifen treten am schönsten an dünnwandigen hohlcylindrischen Zellen, welche das Licht stark brechen, hervor; doch fallen sie auch bei stärkerer Verdickung noch ziemlich deutlich in die Augen. Wir beobachteten dieselben namentlich an vegetabilischen Haaren (z. 13. von Sta chys), aber auch die Gewebezellen liefern hin und wieder hiehergehörige Beispiele.

Einen zweiten Fall, der gewissermaassen das Gegenstück des vorhergehenden bildet, liefert die Combination 13. Hier erscheinen am liegenden Cylinder Rand und Mitte neutral; der erstere, weil eine optische Axe senkrecht steht, die letztere, weil die beiden übereinander liegenden Ellipsen sich rechtwinklig krenzen. Mit der Entfernung von der Mittellinie nehmen aber diese Ellipsen einc mohr aufrechte Lage an; sie schneiden sich jetzt spitzwinklig und bringen daher cine Wirkung hervor, welche der Stellung $l$ auf der Mittellinie entspricht. Gegen den Rand zu wird jedoch diese Wirkung wieder allmählich aufgehoben, weil die Differenz zwischen der grossen und klcinen Axe der Ellipsen immer kleiner und am Rande selbst Null wird. Wir erhalten also zwei dnrch Interferenzfarben erlenchtete 
Streifen zu beiden Seiten der Mittellinie, indess diese letztere und die beiden Ränder sich neutral verhalten.

Weun wir uns jetzt die Aufgabe stellen, die mancherlei Alter- 318 nativen, die in obiger Zusammenstellung figuriren, wo möglich auf eine kleinere Zahl zurückzuführen, so liegt wohl die Frage am nächsten, ob vielleicht die Richtung der optischen Axen sich experimentell bestimmen lasse. Theoretisch betrachtet ist die Sache, wie man leicht einsieht, ungemein einfach. Man hat nur nöthig, durch Neigen des Querschnittes nach verschiedenen Seiten die beiden Stellungen zu ermitteln, in welchen das Object wie ein einfach brechendes Medium wirkt, die optischen Axen also genau senkrecht stehen. Ebenso muss sich beim Neigen des liegenden Cylinders herausstellen, ob die optischen Axen in einer tangentialen Ebene liegen oder nicht; denn wo jenes der Fall, müssen die Ränder bei einer bestimmten Neigung, welche der senkrechten Stellung einer optischen Axe entspricht, sich nothwendig neutral verhalten.

Für die Praxis haben nun aber diese Regeln einen sehr untergeordneten Werth, aus dem einfachen Grunde, weil die Beobachtung nicht mit jener Sicherheit möglich ist, die man a priori erwarten möchte. Die Querschnitte sind in den meisten Fällen fast gar nicht zu gebrauchen, und auch die Randansichten geben häufig genug einen sehr zweifelhaften Effect. Dazu kommt, dass diese letzteren nur unter den günstigsten Verhältnissen die Anhaltspunkte bieten, die zur Bestimmung der Axenlage erforderlich sind. Da nämlich die Neigung des Elasticitätsellipsoids, resp. seiner Längsaxe $L$ zur Cylinderaxe im Allgemeinen umbekannt ist, so bleibt die positive oder negative Natur der Cylinderelemente zweifelhaft, wofern nicht der Winkel, den die optischen Axen mit einander bilden, annähernd gemessen oder das Vorhandensein einer einzigen optischen Axe nachgewiesen werden kamn. Die wenigen Regeln, die sich mit Rücksicht auf das Verhalten der Ränder beim Neigen praktisch verwerthen lassen, sind in folgenden Sätzen enthalten.

1) Ist es möglich, die Richtung der optischen Axen in der 'Tangentialebene zu ermitteln, so ist damit auch der Winkel, den sie mit den Elasticitätsaxen bilden, und folglich auch die Neigung dieser letzteren zur Cylinderaxe bestimmt. - Beispiel: Die Mitte des liegenden Cylinders gibt eine Farbe, welche der Stellung $l$ entspricht; der rechte Rand wird beim Neigen nach der einen Seite, wobei das vom Beobachter entferntere Ende sich senkt und das nähere sich hebt, 
nach einer Drehung von $40^{\circ}$ neutral, beim Drehen nach der entyegengesetzten Seite hin dagegen bei $20^{\circ}$; der linke Rand verhält sich umgekehrt. Die Cylinderelemente sind alsdamn negativ, der Axenwinkel ist $60^{\circ}$, und die Längsaxe $L$ des Ellipsoids ist in der Richtung einer (nach botanischer Terminologie) linkswendigen Spirale um $10^{\circ}$ gegen die Cylinderaxe geneigt.

2) Die Mitte des liegenden Cylinders gebe dieselbe Farbe wie im vorhergehenden Beispiel. Wird alsdann beim Neigen bis zu $45^{\circ}$ weder der eine noch der andere Rand neutral, so sind die Cylinderelemente optisch positiv.

3) Die Mitte des liegenden Cylinders gebe die Farbe der Stellung q. Wird alsdann beim Neigen bis zu $45^{\circ}$ weder der eine noch der andere Rand neutral, so sind die Cylinderelemente optisch negativ.

319 In zwei speciellen Fällen muss sich auch die Mitte des liegenden Cylinders bei einer bestimmten Neigung neutral verhalten. Der eine Fall tritt ein, wenn die horizontale Lage eine Farbe hervorruft, welche der Stellung $l$ entspricht, und wenn überdiess die radiale Axe des Ellipsoids die kleinste ist. In diesem Falle bedingt nämlich das Neigen des Cylinders eine allmähliche Annäherung der wirksamen Elasticitätsellipsen zur Querstellung, die sie nach einer Drehung von $90^{\circ}$ auch erreichen würden. Diese Ellipsen müssen daher bei einer bestimmten Neigung genau $45^{\circ}$ von der Längsrichtung des Cylinders abweichen und sich folglich rechtwinklig kreuzen. Ihre Wirkungen heben sich alsdann gegenseitig auf: die Mitte verhält sich neutral. Der zweite Fall ist diesem ersten analog; er tritt ein, wenn die Farbe der horizontalen Lage der Stellung $q$ entspricht, und wenn überdiess die radiale Axe des Ellipsoids die grösste ist. In diesem Falle nähern sich die beiden Ellipsen beim Neigen des Cylinders der Längsstellung und erreichen also ebenfalls eine Lage, wo sie sich rechtwinklig schneiden und in ihren Wirkungen aufheben. - Die Bedingungen der Neutralität sind übrigens in beiden Fällen auch dann noch gegeben, wenn die radiale Axe der mittleren gleich angenommen und damit die einaxige Beschaffenheit der Elemente vorausgesetzt wird.

Die Anwendung dieser Beziehungen auf die Combinationen 3 und 4 in obiger Uebersicht, welche allein den rorgeschriebenen Bedingungen Genüge leisten, gibt uns ein Mittel an die Hand, entweder die erste und dritte, oder aber die zweite der dort angeführten Möglichkeiten auszuschliessen. 


\section{Kugelige und ovale objecte.}

Hier ist zu allernächst zu bemerken, dass obige Benennungen $\mathbf{3 2 0}$ sich nur auf Objecte beziehen, deren doppelbrechende Elemente in mehr oder weniger concentrischen Schichten um einen Mittelpunkt gruppirt sind, wo also zwischen der äusseren Form und dem inneren Bau eine gewisse Uebereinstimmung besteht. Kugeln, die aus einem Krystall oder einem Cylinder geschnitten würden, müssten sich natürlich gerade so verhalten, wie diese Objecte selbst, und bedürfen somit keiner besonderen Betrachtung.

Die. Möglichkeiten, welche bei geschichtetem Bau mit Rücksicht auf das optische Verhalten der Objecte denkbar sind, zerfallen bei näherer Prüfung der Verhältnisse in zwei Kategorien, die sich beim Drehen des Objects während der Beobachtung immer leicht unterscheiden lassen. Entweder behalten die Polarisationsfarben in allen möglichen Ansichten, die man beim Drehen erhält, denselben Charakter und dieselbe Anordnung, d. h. man beobachtet immer dieselbe Stellung der neutralen Linien, der Additions- und der Subtractionsquadranten. Oder diese Uebereinstimmung der verschiedenen Ansichten findet nicht statt: das Bild zeigt beim Drehen des Objects einen sehr augenfälligen Wechsel der Erscheinungen, welcher nur dann unterbleibt, wenn zufällig die Drehungsaxe mit einem bestimmten Durchmesser des Objects, der vor den andern ausgezeichnet ist, zusammenfällt.

Man sieht leicht ein, dass bei Objecten der ersteren Art die doppelbrechenden Elemente hinsichtlich der Lage ihrer Elasticitätsaxen um jeden Radius und somit um jeden Punkt der Oberfläche symmetrisch gestellt sein müssen, während im letzteren Falle eine solche Symmetrie, ähnlich wie bei einem Cylinder, nur mit Bezug auf jene ausgezeichnete Richtung, die man als Axe bezeichnen kann, indicirt ist. Das Drehen der Objecte unter dem Mikiroskop gibt also Aufschluss darüber, ob dieselben als Kugeln mit gleichwerthigen Durchmessern oder aber als Körper mit einer bevorzugten Richtung (Axe) zu betrachten sind.

a) Objecte mit gleichen Durchmessern.

Die Stellung des neutralen Kreuzes zu den Polarisationsprismen 321 entscheidet hier zunächst die Frage, ob eine der drei Elasticitätsaxen der doppelbrechenden Elemente radial gestellt sei oder wenigstens in 
ciner bestimmten Beziehung zum Radius stehe, oder aber nicht; denn im ersteren Falle entsprechen die neutralen Linien den Polarisationsebenen der Prismen, während sie in letzteren dieselben schiefwinklig schneiden. - Streng genommen ist übrigens dieser letztere Fall mit der Gleichwerthigkeit der Durchmesser und mit der dadurch bedingten unveränderlichen Lage des neutralen Kreuzes nicht vereinbar. So oft nämlich die Elasticitätsaxen schiefwinklig gegen die Schichten oder den Radius gestellt sind, erheischt die Gleichwerthigkeit der Durchmesser alle möglichen Orientirungen in der tangentialen Ebene, d. h. die doppelbrechenden Elemente müssen alle die Stellungen einnehmen, welche ein einzelnes Elcment beim Drehen um einen radialen Durchmesser nacheinander einnimmt: die neutrale Liniè fällt also mit der Axe des Kegels, den das Element während der Drehung beschreibt, in dieselbe Verticalebene. - Wären die Elasticitätsaxen ganz beliebig nach allen Richtungen im Raume orientirt, die verschiedenen Stellungen also gleich häufig vertreten, dann müsste die Kugel wie eine einfach brechende Substanz wirken, und jede weitere Untersuchung wäre zwecklos.

Eine bestimmte Beziehung der Elasticitätsaxen zum Radius ist also schon durch das blosse Vorhandensein von Interferenzfarben indicirt: eine der Axen muss bei der vorwiegenden Zahl der Elemente mit dem Radius einen Winkel bilden, der gleich Null oder doch kleiner als $45^{\circ}$ ist. Für unsere weiteren Betrachtungen schliessen wir jedoch diesen letzteren Fall vollständig aus; wir nehmen auch hier wie beim Cylinder und bei einzelnen Nembranlamellen an, die doppelbrechenden Elemente seien durchgehends übereinstimmend gelagert, die Elasticitätsaxen folglich in allen Punkten des Objects so gestellt, dass eine derselben mit dem Radius zusammenfällt, indess die beiden andern in einer tangentialen Ebene, d. h. in der Ebene der Schichtenfläche liegen.

Unter dieser Voraussetzung verhält sich die Kugel in jeder beliebigen Lage, wenigstcns in ihren Randpartien, wie eine mittlere Lamelle $B B$ Fig. 159', die man sich aus derselben herausgeschnitten denkt, oder auch wie ein Querschnitt durch den Cylinder. Denn es lässt sich leicht nachweisen, dass die zugekehrte und die abgekehrte Kugelcalotte stets in gleichem Sinne wirken, wie das eingebildete Mittelstück, dass sie also den Effect desselben nur verstärken, nicht verändern. Bei einaxigen Elementen mit radial gestellter optischer Axe ist diess ohne Weiteres einleuchtend. Bei zweiaxigen gelangt man zu demselben Resultat, wenn man erwägt, dass die tangen 
tialen Elasticitätsaxen beliebig orientirt sind und daher auf den durchgehenden Lichtstrahl mit einem Werthe wirken, der zwischen der kürzeren und der längeren Axe die Mitte hält. Der Effect der über einander liegenden Elemente ist offenbar der nämliche, wie wenn dieselben bei gleicher Orientirung der tangentialen Axen in rascher Drelrung um ihre radiale Axe begriffen wären, und somit auch derselbe wie bei einaxigen Elementen mit radial gestellter optischer Axe.

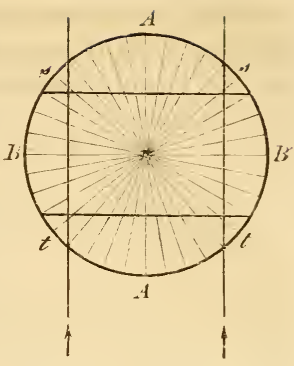

Fig. 1>9.

Das Bild, welches ein kugeliges Object im polarisirten Licht ge. 322 währt, entscheidet hienach die Frage, ob die radiale Axe des Elasticitätsellipsoids grösser oder kleiner sei als der mittlere Werth der beiden tangentialen; es lässt aber unentschieden, ob die Elemente einoder zweiaxig seien. Wird das Letztere angenommen, so bleibt ferner zweifelhaft, ob die radiale Axe die mittlere, oder je nach dem Farbencharakter die grösste oder die kleinste sei, d. h. es bleibt zweifelhaft, ob die optischen Axen in einer tangentialen oder in einer diametralen Ebene liegen.

Das neutrale Kreuz, welches dic Additions- und Subtractionsquadranten von cinander trennt, verhält sich genau so, wie bei $\mathrm{Cy}$ linderquerschnitten. Es erscheint rechtwinklig, wenn die durch das Sichichtencentrum gelegten Polarisationsebenen der Nicols die Schichten selbst rechtwinklig schneiden, im entgegengesetzten Falle dagegen schief winklig. Beikreisförmig verlaufenden Schichten ist das Erstere natürlich immer der Fall, bei elliptisch rerlaufenden nur dann, wenn die Axen der Ellipsen in die gedachten Polarisationsebenen fallen. In jeder anderen Stellung bilden die neutralen Linien schiefe Winkel, und wenn das Verhältniss der

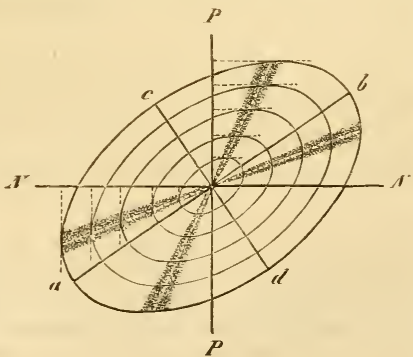

Fig. 190 . Axen nicht constant bleibt, so erscheinen sie überdiess mehr oder weniger gekrümmt. Sind z. B. $P P$ und $N N($ Fig. 190) die Schwingungsebenen der Nicols, und $a b$ und $c d$ die Axen der elliptischen 
Schichten, so müssen die neutralen Linien den in der Figur dargestellten Verlauf zeigen; sie verbinden die Berührungspunkte der von $P P$ und $N N$ rechtwinklig abgehenden Tangenten.

\section{b) Objecte mit einer Axe.}

Die doppelbrechenden Elemente sind hier um einen bestimmten Durchmesser, statt um ein Centrum, gruppirt. Nimmt man an, die Gruppirung sei eine durchgehends gleichmässige, so z. B. dass die Axen des Elasticitätsellipsoids mit dem Radius und dem Meridiankreis, die sich in scinem Mittelpunkt schneiden, überall dieselben Winkel bilden, dann verhält sich ein solches Object im Wesentlichen wie ein Cylinder. Es erzeugt bei horizontaler Stellung der Axe, wenigstens in einer inittleren Querzone, die man als Aequatorialzone bezeichnen kann, die Farben des liegenden Cylinders und bei senkrechter Stellung der Axe, wenn auch nur im peripherischen Theile, die Farben des Cylinderquerschnitts. Die Deutung des beobachteten Effectes kann daher in gleicher Weise geschehen, wie beim Cylinder. Wir bemerken übrigens, dass bis jetzt keine Objecte bekannt sind, welche in diese Kategorie gehören.

\section{V.}

\section{Ueber einige Eigenthümlichkeiten des Baues organisirter Substanzen.}

324 In den vorhergelienden Erörterungen ist durchgehends die Toraussetzung festgehalten, dass die Orientirung der Elasticitätsellipsen in allen Punkten der Substanz dem Effecte entspreche, den die übereinander liegenden Elemente hervorbringen. Wir haben angenom-

*) Dass die neutralen Linien in einem System ähnlicher Ellipsen, wo also das Verhältniss der kleinen Axe zur grossen dasselbẹ bleibt, ge ra de Linien sind, folgt unmittelbar aus der relativ gleichen Grösse der Ordinaten und Abscissen für die Berührungspunkte der Tangenten. Man sieht übrigens, dass die neutralen Linien in unserer Figur mit den in die Polarisationsebenen $P P$ und $N \boldsymbol{N}$ fallenden Durchmessern zwei Paare ron conjugirten Diametern darstellen, und sich folglich unter Winkeln schneiden, welche innerhalb gewisser Grenzen variiren.Die Construction der neutralen Linien für ein beliebiges System von ovalen Schichten unterliegt nach dem Gesagten keiner Schwierigkeit; man hat nur nöthig, die Tangenten zu ziehen und deren Berührungspunkte zu verbinden. 
men, dass die doppelbrechenden Elemente, aus welchen die Schichten einer Membran, eines cylindrischen oder kugelförmigen Objects zusammengesetzt sind, überall dieselbe gesetzmässige Anordnung zeigen, und auf Grund dieser Annahme gefunden, dass eine Elasticitätsaxe stets radial, die beiden andern tangential gestellt seien. Wir haben sodann die Richtung der letzteren nach dem Effecte bestimmt, den die Flächenansichten hervorrufen, oder sie unbestimmt gelassen, wenn diese Ansichten neutral wirkten.

Dieses Verfahren wäre bei krystallinischen Medien mit entsprechender Anordnung der kleinsten Theilchen selbstverständlich; bei organisirten ist es immerhin plausibel, aber es verdient herrorgehoben zu werden, dass eine absolute Nöthigung für die Annahme eines so regelmässigen Baues hier nicht besteht. Die organisirten Substanzen verhalten sich nämlich in wesentlichen Punkten anders als die nicht organisirten; ihr optischer Charakter ist nicht, wie bei diesen, von den Distanzveränderungen abhängig, welche die kleinsten Theilchen durch Druck oder Zug oder auch durch Quellungsmittel erfahren, er bleibt constant, selbst wenn die Veränderungen ein Vielfaches der ursprünglichen Entfernungen betragen. Man kann ein Haar, eine Bastfaser u. dgl. nach Belieben strecken oder krümmen, ohne deren Farbencharakter zu ändern, während beispielsweise eine feine Glasröhre schon bei geringer Krümmung die Farbe hervorruft, welche der dadurch bedingten Distanzveränderung ihrer Atome entspricht. Ebensowenig bewirkt die Quellung eines Membranstückes in Schwefelsäure oder Kupferoxydammoniak, wobei rielleicht die Dicke auf das Fünffache steigt, indess Länge und Breite nur wenig zunehmen, eine wesentliche Teränderung der optischen Eigenschaften. Daraus folgt aber, dass diese letzteren in jenen Atomgruppen, die man als Molecüle zu bezeichnen pflegt, ihren Sitz haben, dagegen mit der Entfernung derselben ron einander und mit den Spannungen, die sich allfällig zwischen ihnen entwickeln, in keinem Zusammenhange stehen. Jedes einzelne Molecül wirkt wie ein kleiner Krystall, und wenn sich die Wirkungen addiren, so steigt die resultirende Interferenzfarbe um so höher, je grösser die Zahl, die der durchgehende Lichtstrahl zu passiren hat, und wird dabei um so intensiver, je grösser diejenige, die auf die Flächeneinheit des mikroskopischen Bildes koommt.

Da nun die organisirten Substanzen, wie wir weiterhin darlegen werden, aus einem Gemenge verschiedener Verbindungen bestehen, die sich gegenseitig durchdringen und wovon vielleicht jede ihre be- 
sonderen Molecüle bildet, die möglicher Weise auch abweichend orien tirt sind; da ferner das Mischungsverhältniss dieser Verbindungen in den verschiedenen Schichten nachweisbar ungleich ist und überdiess die Nothwendigkeit einer immer gleichen Orientirung bei der Einlagerung neuer Molecüle zwischen schon vorhandene selbst bei gleichartiger Beschaffenheit nicht besteht oder wenigstens nicht bewiesen ist : so erfährt der durchgehende Lichtstrahl voraussichtlich die Wirkung verschieden orientirter Elemente, und die Ellipse, welche dem beobachteten Effecte entspricht, kann streng genommen nur als eine eingebildete oder resultirende gedeutet werden, welche mit Rücksicht auf Form und Stellung zwischen den wirklichen Ellipsen, die auf den Lichtstrahl einwirken, die Mitte hält. Es ist z. B. völlig gleichgültig, ob eine Axe der Elasticitätsellipse durchgehends radial gestellt sei, oder ob sie in den übereinander liegenden Elmenten, wenn die Zahl derselben unendlich gross ist, beispielsweise alle möglichen Abweichungen zwischen 0 und $30^{\circ}$ nach der einen und anderen Seite hin darbiete; der Effect ist in beiden Fällen derselbe. Ebensowenig kommt dabei in Betracht, ob die hintereinander liegenden Molecüle der nämlichen radialen Reihe gleich oder ungleich orientirt seien, wofern nur die übereinander liegenden Reihen die eben erwähnten Abweichungen zeigen. Man kann sich überhaupt eine ganz beliebige Anordnung der doppelbrechenden Elemente denken, wenn nur gewisse Stellungen, welche zusammen den beobachteten Effect hervorbringen, vorwiegend vertreten sind.

325 Eine weitere Eigenthümlichkeit, die mit dem innern Baue und mit der Wachsthumsweise der organisirten Substanzen zusammenhängt, ist der ungleiche $W$ assergehalt der dichtern und weichern Schichten und die dadurch bedingte Ungleichheit der doppelbrechenden Kraft. Es ist in Folge dessen unzulässig, Querschnitte und Flächenansichten hinsichtlich ihrer doppelbrechenden Kraft mit einander zu vergleichen, in der Absicht, aus den Farben, die sie hervorrufen, die relative Excentricität der wirksamen Elasticitätsellipsen zu erschliessen. WVenn z. B. eine 6 Mik. dicke Membran in der Flächenansicht mit einem Gypsplättchen Roth I die Additionsfarbe Blau II gibt, indess ein Querschnitt schon bei 4 Mik. Dicke dieselbe Wirkung hervorbringt, so folgt daraus nicht, dass die Elasticitätsellipse des Querschnitts eine im Verhälıniss grössere oder überhaupt eine grössere Excentricität besitze als die der Flächenansicht; denn bei letzterer bilden die wirksameren dichten Schichten nur einen Bruchtheil 
der Gesammtdicke, während sie im Querschnitt continuirlich ron einer Schnittfläche zur andern verlaufen. Eine Vergleichung im angegebenen Sinne ist daher nur zwischen den verschiedenen tangentialen Richtungen statthatt, wie sie auf Quer-, Längs- oder beliebigschiefen Schnitten, wenn sie durch einen Radius gehen, zur Wirkungkommen.

Dass Flächenansichten von Membranen, deren Schichten auf dem Querschnitt Farben ron entgegengesetztem Charakter hervorrufen, eine Deutung nach den früher angegebenen Regeln nicht gestatten, sobald mehr als zwei solche Schichten übereinander liegen, ist an und für sich klar.

\section{VI.}

\section{Zusammenstellung von Beispielen.}

Alle bis jetzt untersuchten organisirten Gebilde stimmen darin $\mathbf{3 2 6}$ überein, dass eine der drei Elasticitătsaxen radial gestellt ist. Die beiden in der Tangentialebene liegenden Axen zeigen dagegen die rerschiedensten Orientirungen; bald entsprechen sie der Längs- und Querrichtung der Zclle oder Faser, bald schneiden sie diese Richtungen unter verschiedenen Winkeln. Wir bezeichnen nachstehend mit Linksdrehung oder Rechtsdrehung die Stellungen, in welchen die längere der beiden tangentialen Axen beziehlich in der Richtung einer linksläufigen oder rechtsläufigen spirale (nach botanischer Terminologie dahingeht ${ }^{*}$ ). Der Winkel, welchen die Spiralwindungen mit der Längsaxe bilden, heisse $\varphi$. - Betreffend die Orientirung der Ellipsen im Querschnitt, auf diametralen Längsschnitten oder Randansichten und auf Flächenansichten cylindrischer Gebilde, so gebrauchen wir eine Bezeichnung, welche in Princip mit der oben (pag. 344) angewandten übereinstimmt, jedoch insofern davon abweicht, als sie für Quer- und Längsschnitte (und bei kugeligen Objecten für beliebige Durchschnittsansichten) auf die Beziehungzum Schichtenverlauf, nicht zum Durchmesser, basirt ist. Wir bezeichnen hienach mit $p$ parallel und mit $t$ transversal) die Stellungen der Elasticitätsellipsen, in welchen die grossen Axen derselben beziehlich in der Richtung der Schichten verlaufen oder, dieselben

* Eine gewöhnlicise Schraube besitzt nach botanischer Terminologie linksläufige Windungen, während sie in der Mechanik rechtswendig genannt wird. 
rechtwinklig schneiden. Diese Beziehung zum Schichtenverlauf ist übrigens nicht willkürlich gewählt, sondern der Natur selbst abge-

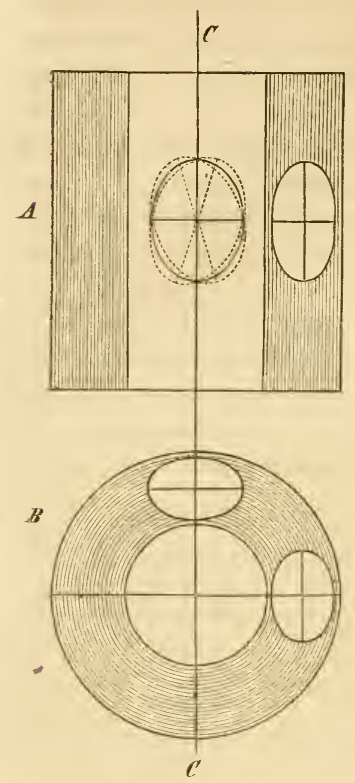

Fig. 191. lauscht, indem die Ellipsen der bekannten Objecte auf Längs- und Querschnitten fast ausnahmslos dieselbe Stellung zur Schichtung zeigen. Die in Fig. 191 dargestellte Orientirung der Ellipsen würde also beispielsweise folgendermaassen bezeichnet: Querschnitt $p$, Rand $p$, Fläche $p$. Wo statt der Randansicht diametrale Längsschnitte untersucht wurden, ist dementsprechend auch die Bezeichnung »Längsschnitt « statt » Rand “ gewählt. Die beiden orthogonalen Stellungen des Objects, welche nach Früherem zur Unterscheidung der Consecutiv - und Alternativlage diemen, sind durch quergestellte (=) oder aufrechte (II) Striche unterschieden, wobei natürlich durchgehends dieselbe Orientirung der Gypsplättchen und die gewöhnliche, diesen Strichen entsprechende Stellung der Polarisationsprismen vorausgesetzt ist. - Da die optischen Axen stets in die Ebene der grössten und kleinsten Elasticitätsaxe fallen, so war es überflüssig, die Lage der Axenebene noch besonders zu bezeichnen. Dagegen ist bei den wenigen $\mathrm{Ob}$ jecten, welche die nöthigen Data geliefert haben, die positive oder negative Beschaffenheit angegeben.

Das Elasticitätsellipsoid, auf das sich unsere Angaben beziehen, hat bei gleichgerichteten Axen eine andere Lage, als nach der gewöhnlichen Annahme; es ist mit Rücksicht hierauf ein um $90^{\circ}$ gedrehtes oder reciprokes Ellipsoid, indem die kleinste Axe desselben die Stelle der grössten nach gewöhnlicher Darstellung einnimmt, und umgekehrt. (Vgl. hierüber pag. 310). 


\section{A. Cylindrische Objecte.}

* Eine tangentiale Axe verläuft parallel zur Cylinderaxe.

C'aulerpa prolifera Lamourx. Stämmchen. Querschnitt $t$; Längsschnitt $t$; Fläche zweifelhaft, am nämlichen Membranstück stellenweise $t$, an andern Stellen $p$. Hieraus: grosse Axe radial. Nach dem Verhalten beim Drehen zweiaxig-positiv.

Chamaedoris annulata Mont. Querschnitt p, Längsschnitt $p$, Fläche $p$. Hieraus: grosse Axe longitudinal, kleine radial, mittlere quer-tangential. Wahrscheinlich optisch negativ; wegen der Unebenheit der Membranfläche nicht mit Sicherheit beobachtet.

Acetulularia mediterranea Lamourx. Stiel. Verhält sich wie Chamaedoris annulatu.

Talonia Aegagropila Ag. Querschnitt p, Längsschnitt $p$, Fläche $t$. Hieraus : grosse Axe quer-tangential, kleine radial, mittlere longitudinal. Optisch positiv; Winkel der optischen Axen c. $50^{\circ}$.

* * Die tangentialen Axen stehen schief zur Cylinderaxe.

Stachys spec. Dünnwandige Haare des Stengels. Erzeugen neutrale Längsstreifen in der Nähe des Randes. Die orthogonale Stellung $=$ erweist sich als consecutive, die darauf rechtwinklige ॥ als alternative; folglich Linksdrehung. Winkel $\varphi$ nach Messungen an halbirten Haaren c. $17^{\circ}$, Linksdrehung bestätigt. In Uebereinstimmung mit Vorstehendem hat man : Querschnitt $t$, Rand $t$, Fläche p. Hieraus: kleinste Axe quer zur erwähnten linkswendigen Spirale; das Terhältniss der beiden andern Axen unbekannt.

Trifolium rubens L. Dickwandige Haare des Fruchtkelches. Verhalten sich wie die Haare von stachys: mit neutralen Längsstreifen und Linksdrehung; Winkel $q$ unbekannt.

Abies excelsa DC: Altes Holz, durch Maceriren in Salpetersäure und chlorsaurem Kali in die einzelnen Zellen zerlegt. a Dünnwandige Holzzellen. Querschnitt $p$, Rand $p$, Fläche $p$. Die Stellung $=$ erweist sich als consecutive, die Stellung $\|$ als alternative; folglich Linksdrehung. Winkel $q$ nach Beobachtungen an halbirten Zellen der Neigung der Poren und (stärkeren spiraligen Streifen entsprechend, welche letztere jedoch zwischen $0^{0}$ und c. $45^{\circ}$ variirt; Linksdrehung bestätigt. Hieraus : grösste Elasticitätsaxe der Streifung parallel, das Verhältniss der beiden andern Axen im Allgemeinen unbekannt, auf längsgestreiften Zellen jedoch stets die ra- 
diale die kleinste. b) Dickwandige Zellen Querschnitt der sogenannten primären Membran $p$, der Verdickungsschichten $p$ oder neutral, selten $t$; Rand $p$; Fläche im Gesammteffect $p$. Die orthogonalen Stellungen neutral. Hieraus für die primäre Membrau: grösste Axe longitudinal, kleinste radial, mittlere quer-tangential. Die Vergleichung der Schichtenhöhen, welche auf Quer- und Längsschnitten (Randansichten) bestimmte Farben bedingen, ergiebt ferner, dass die beiden tangentialen Axen nur wenig differiren können oder möglicher Weise (da die Flächenansicht der primären Membran für sich allein nicht beobachtet ist gleich sind. DieElemente sind also negativeinaxig oder negativ-zweiaxig mit kleinem Axenwinkel. -- Für die Verdickungsschichten ergiebt sich aus Obigem: grösste Axe longitudinal, die beiden andern gleich oder doch, nach der schwachen Wirkung des Querschnittes zu schliessen, nur wenig verschieden; die Elemente folglich positiv-einaxig oder positiv-zweiaxig mit kleinem Axenwinkel.

Cedrus libanotica Lk. a' Poröse Holzzellen mit schief stehenden, einer linksläufigen Spirale entsprechenden Poren, deren Neigung gegen die Zellenaxe $45-50^{\circ}$ beträgt. Querschnitt $p$, Längsschnitt p, Fläche $t$. Linksdrehung. Hieraus: grösste Elasticitätsaxe in der Richtung einer linksläufigen Spirale, die beiden andern unbekannt. (1) Dickwandige Holzzellen mit zarten linksläufigen Spiralfasern. Querschnitt?, Rand in den äussern Schichten neutral, in den innern $p$; Fläche $p$. Hieraus: grösste Axe in einer tan-. gentialen Ebene, das Uebrige unbekannt.

T'axus baccata L. Dickwandige Holzzellen mit linksläufigen spiralfasern und gleich geneigten Poren, Neigung zur Zellenaxe c. $30-40^{\circ}$. Querschnitt $p$. Rand $p$, Fläche $t$. Hieraus: grösste Axe in einer tangentialen Ebene, alles Uebrige unbekannt. - Weitaus die meisten Holzzellen mit rechtsgewundenen, linksgewundenen, steilansteigenden oder niedergedrückten, sowie mit ringförmigen Fasern verhalten sich ebenso; die Poren haben indess durchgehends ungefähr dieselbe Neigung, sie entsprechen einer steilen, linkswendigen Spirale.

Gunnera sculbra lauiz et Pux. Spiralgefässe mit rechtsläufigen niedergedrückten Windungen, deren Neigung zur Axe $>45^{\circ}$. Querschnitt $p$, Rand $p$, Fläche $t$. Consecutivstellung mit Rücksicht auf die Zellenaxe \|| Alternativstellung $=$, folglich Rechtsdrehung. Die cinzelnen Spiralfasem verhalten sich im Qucrschnitt ziemlich neutral; ihre grösste Elasticitätsaxe ist longitudinal. ILicraus: grösste 
Elasticitätsaxe der Gefässe in der Richtung einer niedergedrückten rechtsläufigen Spirale, die beiden andern unbekannt, jedoch wahrscheinlich (nach dem Verhalten der isolirten Spiralfasern zu schliessen) wenig verschieden.

Periderm und Cuticula. Beliebige Durchschnitte $t$. Hieraus : grösste Axe radial.

Muskelfasern. Nach Brücke und eigenen übereinstimmenden Beobachtungen an Käfermuskeln. Längsansicht $p$ longitudinal, Querschnitt neutral, orthogonale Stellungen neutral. Hieraus: grösste Axe der Längsrichtung parallel, die beiden andern gleich oder jedenfalls wenig verschieden; optisch-positiv. (Die gegentheilige Angabe von $\mathrm{Mohl}$ beruht auf einem Irrthum.)

\section{B. Kugelige Objecte.}

Stärkekörner. Beliebige Durchschnittsansicht $t$, Fläche neu tral. Hieraus: Radiale Axe die grösste oder eine mittlere, welche der grössten näher steht als der kleinsten. - Wäre ein Grund vorhanden, für alle doppelbrechenden Elemente die gleiche Orientirung des Elasticitïtsellipsoids anzunehmen, so könnte aus obigem Terhalten die positiv-cinaxige Natur derselben gefolgert werden.

Inulinkugeln aus den Zellen der Scheibe von Aretalulariu, durch Liegen in Weingeist entstanden. Durchschnittsansicht $p$, Fläche neutral. Hieraus : radiale Axe die kleinste oder eine mittlere, welche der kleinsten näher steht als der grössten. Möglicherweise einaxig und dann negativ rgl. Stärkekörner .

\section{VII.}

\section{Ueber die Anwendung des Nörrenberg'schen ,,Polarisationsmikroskops“".}

Wir haben nachträglich noch dem Nörrenberg'schen "Polarisa- 327 tionsmikroskop", dessen optische Einrichtung wir hier im Wesentlichen als bekannt roraussetzen, eine kurze Bemerkung zu widmen. Valentin rühmt diesem Instrumente nach, dass es bei Untersuchungen im polarisirten Licht in vielen Fällen zum Ziele führe, wo das 
gewöhnliche Mikroskop nicht mehr genüge. Wir können uns dieser Ansicht nicht anschliessen. Unsere Ueberzeugung geht dahin, dass selbst den bestconstruirten Polarisationsapparaten irgend eine hervorragende Bedeutung für mikroskopische $Z_{w}$ ecke nicht zukommt. Die Polarisationsapparate sind ihrer Construction gemäss nur in solchen Fällen verwendbar, wo das $\mathrm{zu}$ untersuchende Object sich wie eine Krystallplatte verhält, und wo es überdiess das ganze Gesichtsfeld ausfüllt. Die starken Linsen, womit der Nörrenberg'sche Apparat ausgestattet ist, machen es zwar möglich, das Gesichtsfeld bis auf $0,1 \mathrm{~m} . \mathrm{m} . \mathrm{zu}$ verkleinern; allein es bleibt stets Bedingung, dass nur diejenigen Strahlen, welche die doppelbrechende Wirkung des Objects erfahren haben, zum Auge gelangen. Die Linse, welche als Ocular dient, ist nämlich auf eine Ebene eingestellt, welche mit der hintern Brennebene des Objectivs zusammenfällt oder doch nur wenig von ihr absteht. Man sieht also durchs Ocular nicht das reelle Bild des zu untersuchenden Gegenstandes, sondern bloss das System der Interferenzcurven, welche die einfallenden Strahlen in der Kreuzungsebene erzeugen.

Die Anwendbarkeit des Instruments beschränkt sich hienach auf krystallähnliche Objecte oder Theile von Objecten, welche gross genug sind, um sie isolirt beobachten zu kömnen. Als solche sind beispielsweise zu bezeichnen: grössere Durchschnitte durch Hornsubstanz und Chitin, Splitter von Muscheln, Zellmembranen von beträchtlicher Ausdehnung u. dgl. Man legt das Präparat, um alles fremde Licht abzuhalten, auf die feine Oeffnung einer dunkeln Unterlage, wozu sich z. B. ein Stanniolplättchen, das man auf den Objectträger klebt, ganz gut eignet. Die Interferenzcurven, welche alsdann zum Vorschein kommen, stimmen natürlich mit denjenigen überein, welche planplane Krystallplatten im Polarisationsapparate hervorrufen, und da hierüber jedes physikalische Lehrbuch die nöthige Auskunft gibt, so wäre es überflüssig, specieller darauf einzugehen.

328 Die grosse Mehrzahl der mikroskopischen Objecte bleibt für das sogenannte Polarisationsmikroskop unzugänglich. Man betrachte z. B. ein beliebiges Zellgewebe, etwa einen Durchschnitt durch Tannenholz, wo jede Zellwand wie ein entsprechend orientirtes Krystallplättchen wirkt; man wird es vergeblich versuchen, alle Zellwände bis auf eine einzige zuzudecken, um deren Interferenzcurven zu beobachten. Und erst die cylindrischen und kugeligen Gebilde, 
deren krystallähnliche Elemente noch viel kleiner sind als bei den erwähnten prismatischen Holzzellen!

Die Beobachtung der Zellgewebe im Polarisationsapparat lässt nur dann einen praktischen Erfolg hoffen, wenn gewisse Wandungen so vorwiegend vertreten sind, dass sie auf parallel zu denselben geführten Durchschnitten den optischen Effect bedingen, d. h. Erscheinungen hervorrufen, die von den übrigen Wänden nicht wesentlich gestört werden. 


\section{Achter Abschnitt. II i k r o p h y s i k. \\ I.}

\section{Flüssige Körper.}

1. Erkennung und Unterscheidung flüssiger Körper.

329 Während man im gewöhnlichen Leben den Aggregatzustand der Körper leicht und sicher durch unmittelbare Wahrnehmung erkennt, erfordert es bei mikroskopischen Untersuchungen schon einige Vorsicht, um in schwierigeren Fällen feste Körper von flüssigen und diese von luftförmigen zu unterscheiden. Der praktische Mikroskopiker weiss, dass es nicht immer leicht ist zu sagen, ob z. B. cine Spalte in einer festen Masse mit einer Flüssigkeit oder mit Luft gefüllt sei, ob kugelige in Wasser befindliche Gebilde aus einer festen oder ölartigen Substanz bestehen, oder ob ein scheinbarer Hohlraum in einem festen Körper nur als stark aufgequollener und daher gallertartiger Theil desselben oder als ein mit Wasser gefüllter Raum zu deuten sei u. dgl. Es ist in solchen Fällen nothwendig, die fraglichen Objecte genauer zu untersuchen und auf indirectem Wege zu ermitteln, was sich direct nicht entscheiden lässt.

Die flüssigen Körper nehmen bekanntlich in einem flüssigen Medium, mit dem sie sich nicht mischen, Kugelgestalt an, so z. B. Oel in Wascer, Luft in Wasser etc. Sie lassen sich nun freilich an dieser Eigenschaft keineswegs immer sicher erkennen, da die Adhäsion benachbarter Gegenstände modificirend auf die hydrostatischen Kräfte einwirkt, sodass z. B. ein Oeltropfen ganz abgeplattet oder in eine feine Spitze ausgezogen erscheinen kann. Es steht aber anch die weitere Eigenschaft damit im Zusammenhang, dass Flüssigkeitstropfen jeder Kraft, welche nur auf einen Theil der Oberfläche wirkt, also auch 
jedem mechanischen Druck nachgeben. Wenn es daher möglich ist, einen mechanischen Druck mittelst der Nadel und des Deckgläschens auf ein zu untersuchendes Object auszuüben, so sind Formveränderungen, welche dabei eintreten, ein sicheres Merkmal der flüssigen oder halbflüssigen Consistenz, während das Nichteintreten derselben auf eine feste Masse deutet. Im ersteren Fall lässt sich sogar, wenn der Druck von Zeit zu Zeit plötzlich nachlässt, aus dem rascheren oder langsameren Zurückkehren des Objects zur ursprüglichen Gestalt annähernd der Grad des Flüssigseins bestimmen. Ebenso gibt sich im zweiten Fall die grössere oder geringere Sprödigkeit der Substanz durch Zerbröckeln, Bildung von Rissen (z. B. bei Stärkekörnern) zu erkennen.

Eine fernere gemeinsame Eigenschaft der Flüssigkeiten, welche indess auch manchen festen Körpern zukommt, besteht darin, dass sie nie doppelbrechend sind. Als Kriterium kann dieselbe jedoch nur insofern gelten, als Medien, welche im polarisirten Licht sich als doppelbrechend erweisen, jedenfalls nicht flüssig sein können.

Handelt es sich um die Frage, ob eine scheinbare Flüssigkeit 330 wirklich als Lösung zu betrachten sei, so ist zunächst festzuhalten, dass jede wässerige Lösung, welche mit dem $W$ asser des Präparates in unmittelbarer Berührung steht, sich nach und nach gleichmässig in demselben verbreitet und folglich nie durch eine scharfe Grenzlinie von demselben geschieden sein kann. So erweisen sich z. B. die rothen und blauen Pflanzensäfte als ächte Lösungen, weil dieselben aus angeschnittenen oder irgendwo geöffneten Zellen rasch ausfliessen und spurlos im umgebenden Medium verschwinden, während rerdünnter Stärkekleister, obschon er unter dem Mikroskop eine klare Flüssigkeit zn sein scheint, sich nach der Blaufärbung mit Jod sogleich deutlich ron dem zugesetzten Wasser abgrenzt. Ebenso rerhalten sich auch die rothen und violetten Wolken, welche gewisse Flechtenfarbstoffe nach Zusatz von Kali bilden; sie folgen den Strömungen des Wassers, ohne sich je gleichmässig in letzterem zu rertheilen.

Man darf übrigens nicht vergessen, dass Lösungen, welche den eben gestellten Anforderungen einer gleichmässigen Tertheilung in Wasser, olne dass die Theilchen mikroskopisch wahrnehmbar wären, entsprechen, sich desswegen doch diosmotisch ungleich verhalten können. Die einen diosmiren nämlich durch thierische Häute oder Zellmembranen, die anderen sind diosmotisch unwirksam. Zu den 
letzteren ist z. B. die von Wasser, Schwefelsäure, Kupferoxydammoniak etc. gelöste Cellulose zu rechnen, welche sich im Uebrigen in jeder Hinsicht wie eine ächte Lösung verhält.

Die Gleichmässigkeit der Vertheilung einer gelösten Substanz im lösenden Medium ist eine nothwendige Folge der überall gleichen Anziehung, welche das letztere auf die Substanztheilchen ausübt. Eine Schicht von Kochsalz oder eine gesättigte Kochsalzlösung, welche den Boden eines mit Wasser gefüllten Cylinders bedeckt, muss z. B. nothwendig in das darüber befindliche Wasser diffundiren: die Salztheilchen wandern langsam von unten nach oben, die Wassertheilchen in entsprechender Zahl von oben nach unten, und es tritt nicht eher Gleichgewicht ein, als bis in jedem Punkte der Flüssigkeit dasselbe Verhältniss zwischen Salz und Wasser hergestellt ist. Die gegenseitige Anziehung überwindet also den Einfluss der Schwere; sie lässt überhaupt in Lösungen die Differenzen des specifischen Gewichts heterogener Stoffenichtzur Geltung kommen.

Für die Praxis dürfte diese letztere Eigenschaft in den meisten Fällen das brauchbarste Kriterium liefern. Jede Flüssigkeit, welche unter dem Mikroskope homogen erscheint und nach längerem Stehen oder unter dem Einfluss der Centrifugalkraft homogen bleibt, d. h. keinerlei Verschiedenheiten der Zusammensetzung erkennen lässt, ist als Lösung zu betrachten. Eine solche Lösung kamn aber immer noch diosmotisch wirksam oder diosmotisch unwirksam sein.

Die Unterscheidung tropfbarflüssiger Kïrper von elastischflüssigen ist keineswegs immer so leicht, als man sichs gewöhnlich vorstellt. Sie ist ganz allgemein nur dann möglich, wenn sowohl die Form des fraglichen Körpers, als auch das Brechungsvermögen des umgebenden Mediums annähernd bekannt ist. Ein Wassertropfen in Schwefelkohlenstoff gewährt ungefähr dasselbe Bild, wie eine Luftblase in Wasser, und eine platt gedrückte Luftblase in einer dichten Substanz wैiederum ungefähr dasselbe, wie eine etwas weniger abgeplattete Wasserkugel. Linsenförmige Hohlräume in Stärkekörnern, Krystallen etc. sehen von der Fläche gesehen röthlich, im Profil dagegen schwarz aus, sie mögen mit Luft oder mit Wasser gefüllt sein.

In Fig. 192 sind beispielsweise die beiden Ansichten eines Stärkekorns aus den trockenen Saamenlappen von Pisum sativum dargestellt, welche das Gesagte veranschaulichen. Der unregelmässig- 
linsenförmige Hohlraum desselben erscheint vollkommen dunkel, wenn man die schmale Durchschnittsansicht desselben $(\boldsymbol{B})$ beobachtet, in der Flächenansicht $(\boldsymbol{A})$ dagegen röthlich und schwach conturirt; er gewährt hier das Bild einer weicheren Sub$\operatorname{stanz}$, ungeben ron einer dichteren Hülle.

Diese Beispiele zeigen zur Genüge, dass das mikroskopische Bild für sich allein über den Inhalt eines gege-
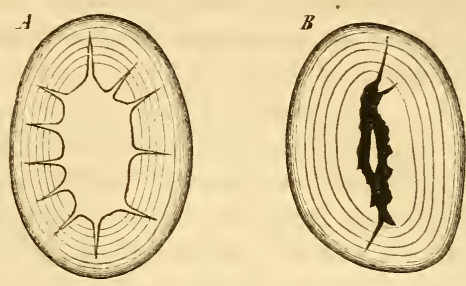

Fig. 192. benen Raumes nicht unmittelbar Aufschluss giebt. Die Irrthümer, welche selbst geübte Mikroskopiker in der Deutung des Gesehenen sich zu Schulden kommen liessen, belehren uns auch, dass Täuschungen oft schwer zu vermeiden sind. Kü tzing $\mathrm{z}^{*}$ ) hielt z. B. den Kern der Stärkekörner für eine mit Luft gefüllte Vacuole, Schleiden ${ }^{* *}$ ) bezeichnete denselben "mit völliger Gewissheit « als eine Höhlung in der Substanz, und auch $\mathrm{N}$ ägeli huldigte dieser Ansicht, bis er sich später durch genaueres Studium der Stärkekörner überzengte, dass der unveränderte Kern stets aus sehr weicher Stärke besteht. Eine ähnliche Meinungsverschiedenheit herrschte auch mit Rücksicht auf die Natur der wasserreichen Schichten, welche bekanntlich zuweilen den täuschenden Eindruck von Spalten gewähren. ***)

Dem Beobachter ist bei Fragen dieser Art immer sehr zu empfehlen, sorgfältige Vergleichungen mit Hohlräumen anzustellen, deren Inhalt er kennt, wie denn überhaupt das Anfertigen künstlicher Präparate von bekannter Beschaffenheit immer die zuverlässigsten Anhaltspunkte zur richtigen Deutung des Gesehenen liefert. Wie eine mit Wasser gefüllte Spalte in einem Krystall, einem Stärkekorn etc. aussieht, darüber orientirt man sich stets am besten, wenn man die betreffenden Körper unter Wasser zerdrückt und so Spalten hervorruft, welche natürlich nur Wasser enthalten können. Man überzeugt sich alsdann, dass solche Spalten oft ganz schwarz aussehen, als wären sie mit Luft gefüllt. Ebenso lässt sich der Eindruck, den kleine wasserführende Räume in einem ölartigen Medium hervor-

*) Grunclzüge der philos. Bot. I. pag. 262.

** Grundzüge der wiss. Bot. 3. Aufl. 1. pag. 17\%.

**+) Vgl, hierüber Nägeli, die Stärkek. pag. 54. 
bringen, am sichersten bestimmen, wenn man ein Tröpfchen Wasser auf dem Objectträger mit einem grösseren Oeltropfen mischt und so ähnliche Räume künstlich herrorbringt und dann untersucht. Solche Proben können auch den geübten Mikroskopiker vor Irrthümern bewahren.

\section{Die Capillaritätserscheinungen.}

332 Die Capillaritätserscheinungen, welche man direct unter dem Mikroskop beobachtet, bieten für Denjenigen, welcher das Phänomen aus den Lehrbüchern der Physik kenni, so gut wie nichts Neues. Es mag daher genügen, wenn wir auf diesen Punkt nur in aller Kürze aufmerksam machen.

Da der Raum zwischen Objectträger und Deckglas ein capillarer ist, so bewegt sich ein Flüssigkeitstropfen in demselben stets nach der Stelle hin, wo die Gläser genähert sind, während eine Gasblase die entgegengesetzte Bewegung zeigt. Dasselbe gilt natürlich auch von horizontal gestellten Röhren (Gefässen, Kanälen etc.). Wo die Luft rollständig daraus entweichen kann, füllen sich solche Räume immer sehr rasch mit Flüssigkeit; wo sie nicht entweichen kann dagegen nur insoweit, als das eingeschlossene Gas ron der Flüssigkeit absorbirt wird, was in den meisten Fällen ziemlich langsam von statten geht. Das Letztere beobachtet man z. B. bei den Zellhöhlungen ausgetrockneter Gewebe, den Porenhöfen des Tannenholzes etc.

333 Von grösserem Belange ist die Frage, ob die bekannten Gesetze der Capillarität auch für mikroskopisch enge Röhrchen bis zu den äussersten Grenzen der Wahrnehmbarkeit Geltung haben. Die Höhe, bis zu welcher Flüssigkeiten in Capillarröhren emporsteigen, steht bekanntlich, soweit die Beobachtungen reichen, im ungekehrten Verhältniss zum Durchmesser. Für Wasser beträgt dieselbe bei einer Röhrenweite von $1 \mathrm{~m} . \mathrm{m} .30 \mathrm{~m} . \mathrm{m}$. und bei einer Weite von $0,1 \mathrm{~m} . \mathrm{m}$. $300 \mathrm{~m} . \mathrm{m}$. Die Rechnung ergiebt hienach schon für Capillaren von 1 Mik. im Durchmesser eine Steighöhe von 30 Metern und führt somit folgerichtig zu der Annahme, dass die ungleich klcineren Molecularinterstitien der Membranen, sofern sie sich dem nämlichen Gesetze fügen, sich jedenfalls bis in die höchsten Pitzen der Bäume mit Wasser imbibiren müssen

Um zu erfahren, ob diese Folgerungen wenigstens bis zu mikioskopisch kleinen Grössen mit der Wirklichkeit übereinstimmen, stellten wir einige Experimente mit fein ausgezogenen Glasröhrchen 
an, deren Lumina zwischen 1-10 Mik. im Durchmesser variirten. Die Aufgabe war, wenn auch nicht die Steighöhe, so doch die Kraft ${ }_{\boldsymbol{B}}$ dor capillaren Ascension oder genauer die Widerstände, welche die capillaren Wassersäulen in solchen Röhrchen einem auf den Meniscus wirkenden.Drucke entgegensetzen, direct zu messen. Die Röhrchen wurden zu diesem Behufe mit Wasser gefüllt, dann mittelst eines Korkes in das umgebogene Ende $A$ einer langen Röhre Fig. 193) so cingefügt, dass die feine Spitze nach innen gekehrt war, und hierauf sorgfältig verkittet. Wurde nun in den langen Schenkel $B$ Quecksilber eingegossen, welches die Luft unterhalb A. comprimirte, so musste sich zeigen, auf welche Höhe $x$ der Druck gesteigert werden konnte, bis das $W$ asser aus der Capillarröhre verdrängt und durch Luft ersetzt wurde. Es blieb alsdann nur noch übrig, diese Höhe mit dem specifischen Gewicht des Quecksilbers = 13,6 zu multipliciren, um das Maass der capillaren Anziehung, sofern dasselbe mit dem gemessenen Widerstande übereinstimmt, in Wasser auszudrücken.

Diese Versuche gelangen indess nur mit Röhrchen, deren Weite nicht unter 3 Mik. betrug; bei den engern bis zu 1 Mik. Durchmesser traten Störungen ein, welche die Widerstände bedeutend vermehrten und dadurch das Ergebniss unsicher machten.") Bis zu der bezeichneten Grenze stellte sich aber als unzweifelhaft heraus, dass das umgekehrte Terhältniss der Durchmesser jedenfalls annähernd maassbestimmend bleibt; über-

Fig. 193. diess ist sicher, dass die Capillaranziehung auch über diese Grenze hinaus in irgend einem Verhältniss zunimmt. Diess geht auch aus den bekannten Versuchen ron Jamin hervor, wonach die Kraft, welche in festgestampftem Pulver von Zinkoxyd oder Stärke wirksam wird, eine Höhe ron $4-6$ Atmosphären erreicht.

Um indess noch weitere Anhaltspunkte zu gewinnen und für die $\mathbf{3 3 4}$ Molecularinterstitien der Membranen wenigstens eine untere Grenze

7) Näheres hierüber findet man in den Sitzgsber. der k. bayer. Akad. der Wiss. zu München, 1566 , wo diese und andere von uns angestellten Versuche über Capillarwirkungen mitgetheilt sind. 
in directer Weise zu ermitteln, wurde bei einem neuen Versuch die Capillarröhre durch einen aus frischem Tannenholz quer ${ }^{*}$ ) herausgeschnittenen Pfropf ersetzt, welcher mit Wasser durchtränkt und ebenfalls sorgfältig eingekittet wurde, jedoch so, dass die beiden Endflächen vollständig frei waren. Die Höhe der Quecksilbersäule wurde bei diesem Versuche allmählich bis zu $2250 \mathrm{~m} . \mathrm{m}$. gesteigert, was in Wasser ausgedrückt 30,75 Meter oder 102,5 badische Fuss ausmacht, ohne dass die im kurzen Schenkel eingeschlossene Luft durch den Pfropf herausgepresst worden wäre; das Niveau des Quecksilbers war vielmehr nach mehreren Wochen noch durchaus unverändert. Damit ist aber bewiesen, dass die Capillaranziehung die Zellwandungen wirklich bis zu einer Höhe von wenigstens 100 Fuss mit Wasser versehen kann, natürlich unter der Voraussetzung, dass der Bedarf die unter den gegebenen Verhältnissen mögliche Zufuhr nicht übersteige und dass keine andern Kräfte der Capillaranziehung entgegenwirken.

Es ist nun ohne Weiteres klar, dass, wenn im obern Theil eines Capillarröhrensystems Wasser durch Verdunstung verloren geht, die Capillaranziehung diese Verluste durch ron unten nachströmende Flüssigkeit sofort zu ersetzen strebt. Und zwar wird sich dieses Bestreben in den einzelnen Theilen des Systems genau auf dieselbe Höhe erstrecken, bis zu welcher das Wasser in den leer gedachten Capillarröhren steigen würde. Daraus folgt nun zwar, dass die Capillaranziehung in Verbindung mit der Transspiration eine continuirliche Strömung in der Richtung von unten nach oben, oder ganz allgemein nach den Terbrauchsstellen hin, zu erzeugen vermag; allein es ist einleuchtend, dass diess nur in solchen Fällen wirklich geschieht, wo die erforderliche Strömung nicht durch andere Kräfte, die den Wasserbedarf nach allen Seiten hin decken, dauernd unterhalten wird. Steht z. B. die Flüssigkeit in einem Capillarröhrensystem unter einem gewissen Druck, welcher die concaven Menisken in den Enden der

*) Versuche, welche mit längs herausgeschnittenen Pfropfen angestellt wur!en, wobei also die Holzzellen eine der Röhrenaxe parallele Lage hatten, misslangen, indem die Luft schon durch eine Quecksilbersăule von $200-400 \mathrm{~m} . \mathrm{m}$. ziemlich rasch herausgepresst wurde. Es konnte diess nur daher rühren, dass die Poren der älteren Holzzellen bereits wirkliche Löcher geworden, oder dass andere gröbliche Zwischenräume vorhanden waren. Desshalb wurde der Versuch mit einem quer herausgeschnittenen Pfropf, welcher aus innerem Rindenparenchym, Cambium und jungem Holz bestand, wiederholt. 
Röhrchen ebnet oder nach aussen wölbt, so ist es selbstverständlich dieser Druck, welcher die Strömung der Flüssigkeit verursacht, und die Capillarität bleibt ausser Wirkung.

Der Ersatz, den die Capillarität zu leisten im Stande ist, hängt überdiess unter allen Umständen von dem Widerstande ab, welchen die unter den gegebenen Verhältnissen wirksamen Kräfte zu überwinden haben. Es ist von vorne herein denkbar, dass das Wasserquantum, welches an den Verbrauchsstätten in der Zeiteinheit verloren geht, grösser ist als dasjenige, welches die capillaren Kräfte in derselben Zeit zu liefern vermögen, und in einem solchen Falle müsste natürlich das Wasserniveau allmählich sinken, bis die in Folge der zunehmenden Spannung der Dämpfe verlangsamte Verdunstung der gleichzeitig rascher gewordenen Zufuhr das Gleichgewicht hält. Unter welchen arithmetisch bestimmten Bedingungen aber für ein gegebenes System dieses Gleichgewicht besteht, kann selbstrerständlich nur durch den Versuch ermittelt werden.

Die experimentelle Prüfung dieser Frage liefert nun in der That das Ergebniss, dass die V erdunstung in feinen Capillarröhren schon in verhältnissmässig geringer Höhe die $W$ asserzufuhr überwiegt. Unter der Luftpumpe kann man diess sogar, wenn auch nicht gerade in auffallender Weise, schon bei fein ausgezogenen Glasröhren beobachten. Ist z. B. der Durchmesser einer solchen Röhre $=0,12 \mathrm{~m} . \mathrm{m}$, so steigt das Wasser nach vorher gegangener Befeuchtung mit einer Geschwindigkeit in die Höhe, welche für die ersten $60-70 \mathrm{~m} . \mathrm{m}$. durchschnittlich c. $10-12 \mathrm{~m} . \mathrm{m}$. per Secunde beträgt, für die letzten $11 / 2-2 \mathrm{~m} . \mathrm{m}$. aber auf c. $1 / 60 \mathrm{~m} . \mathrm{m}$. , also auf $1 \mathrm{m.m}$. per. Minute heruntersinkt. In derselben Röhre, wenn sie bis oben mit Wasser gefüllt und unten geschlossen ist, bedingt aber die Verdunstung unter der Luftpumpe, bei einer Temperatur von $6^{\circ} \mathrm{R}$. und einem Manometerstande von $1-2 \mathrm{~m} . \mathrm{m}$., ein gleichmässiges Sinken des Niveaus von $1,5 \mathrm{~m} . \mathrm{m}$. per Minute. Wenn also Verdunstung und Capillarität gleichzeitig wirksam sind, wie es bei der in Wasser gestellten Röhre der Fall ist, so gewinnt die Verdunstung für den obersten Theil der Wassersäule nothwendig die Oberhand: das Niveau muss sinken, bis die aufwärtsgehende Strömung die Geschwindigkeit von 1,5 m. m. per Minute erreicht hat. Erwägt man nun, dass die Verdunstung um so rascher erfolgt, je feiner die Capillarröhre, ${ }^{*}$ ) so sieht man ohne Weiteres ein,

* Drei Capillarröhren von 900,355 und 120 Mik. Weite, welche bis oben mit Wasser gefüllt waren, verdunsteten unter der Luftpumpe, bei $11 / 2-2 \mathrm{~m} . \mathrm{m}$. 
dass die Niveauveränderungen, welche jene hervorruft, in grösseren Steighöhen, wo die Geschwindigkeit des Aufsteigens sehr gering ist, in sehr augenfälliger W eise herrortreten müssen.

Viel geeigneter zu solchen Versuchen, als Glasröhren, sind indess feine Capillarsysteme, wie man sie erhält, wenn man weitere Röhren mit unlöslichen gepulverten Stoffen vollstopft. Wir verwendeten hiezu die käufliche Weizenstärke, und um ein gleichmässig mit Flüssigkeit durchdrungenes Capillarsystem zu erhalten, rührten wir dieselbe mit Wasser zu einem dümnflüssigen Brei an, welcher letztere in eine unten mit einem porösen Pfropf verschlossene Barometerröhre von c. 5 m. m. im Durchmesser eingefüllt wurde. Nachdem die Stärke sich etwas gesetzt hatte, wurde das darüber befindliche Wasser mittelst der Pipette entfernt und hierauf ein neues Quantum Stärkebrei nachgegossen. Zuletzt wurde der Röhre ein quadratisches Brettchen, das nach Art eines Schachteldeckels mit einer Randeinfassung rersehen war, aufgesetzt und ebenfalls mit Stärkebrei übergossen. Der dünne Stärkecylinder war auf diese Weise mit einer verdunstenden Schicht von c. 1 Quadratdecimeter Fläche und $6-10 \mathrm{~m}$. m. Dicke in Verbindung gebracht.

Der so hergestellte Apparat wurde jetzt mit dem unteren Ende in ein Gefäss mit Wasser gestellt und bei gewöhnlicher Zimmertemperatur stehen gelassen. Das Resultat war entscheidend. Schon am andern Tage fühlte sich die Oberfläche der verdunstenden Schicht ziemlich trocken an und bald darauf bildeten sich zahlreiche, netzförmig anastomosirende Risse. Die ganze Schicht trocknete nach und nach vollständig aus, und auch im obern Theil des Stärkecỵlinders zeigten sich deutliche Spuren der Trockenheit. Kein Zweifel, dass hier die Zufuhr gegenübẻr den durch die Verdunstung verursachten Verlusten verschwindend klein war.

Die Capillarität ist also nicht im Stande, ein System ron capillaren Räumen, welche nach oben in eine verdunstende Fläche ausmünden, auch nur bis auf einige Fuss über das Niveau des umgebenden

Barometerstand und $6^{\circ} \mathrm{K}$., während 10 Minuten $3 \frac{1}{6}$, S und $14 \mathrm{~m} . \mathrm{m}$. Die Verdunstungsmengen rerhielten sich also wie $1: 2,52: 4,42$, die 1)urchmesser umgekehrt wie $1: 2,33: 7,5$. Die Verdunstung findet übrigens um so langsamer statt, je länger der bereits entleerte Theil der Capillarröhre. Schon bei einem Abstande von $15-20 \mathrm{~m}$. m. vom obern Ende erreicht die Spannkraft der Wasserdämpfe einen solchen Grad, dass sie einer Wassersäule ron $70-50 \mathrm{~m}$. m. das Gleichgewicht hält und folglich in unten offenen Röhren das Niveau um eine entsprechende Grösse rückwärts drängt. Näheres hierüber in den oben citirten Sitzungsber. der k. bayer. Akad. d. Wiss. zu München 1\$66). 
Wassers hinauf im gefüllten Zustande zu erhalten, selbst dann nicht, wenn sie - wie diess in unserem Falle angenommen werden darf mit einer Kraft von $4-6$ Atmosphären wirksam ist. Die Folgerungen, welche sich hieraus für die Pflanze ergeben, liegen nahe. Ein Baum, in welchem wir uns ausser der Capillaranziehung keine andern Kräfte thätig denken, muss von oben nach unten austrocknen, bis endlich der aufsteigende Wasserstrom die durch Verdunstung herbeigeführten Verluste zu ersetzen vermag.

\section{Spannung der Gase und Flüssigkeiten.}

Wenn sich Gase in Flüssigkeiten entwickeln oder von aussen in $\mathbf{3 3 6}$ dieselben eingeführt werden, so sind die Spannungen, welche sie annehmen, durch diejenige der Flüssigkeit und durch die ihrer Abgrenzungsfläche entsprechende Capillaranziehung bestimmt. Eine kugelförmige Luftblase ron $1 \mathrm{~m}$. m. Durchmesser, welche in einem offenen Gefäss schwebend gedacht wird, muss beispielsweise eine positive Spannung besitzen, welche die des umgebenden Wassers und der äussern Luft um den Druck einer Wassersäule ron $30 \mathrm{~m}$. m. (der Steighöhe für eine Capillarröhre von $1 \mathrm{~m} . \mathrm{m}$. Weite übertrifft. Ebenso muss ein entsprechender Ueberschuss in Zellen rorhanden sein, welche in einem Theil ihres Lumens Luft und in dem andern Saft enthalten, vorausgesetzt, dass diesem letzteren Theil der erforderliche Zufluss ron aussen gesichert sei, so dass die capillaren Kräfte ungeschwächt zur Wirkung kommen.

Stellen wir uns vor, ein System von Capillarräumen sei zunächst ganz mit Wasser durchdrungen, so nimmt offenbar die Spannung der Flüssigkeit, ähnlich wie im Barometer, in arithmetischer Progression von unten nach oben ab. Bezeichnet man also die Spannung einer freien Wasseroberfläche, auf welcher der Druck einer Atmosphäre lastet, mit 0, so sinkt sie im Capillarsystem bei c. 10 Meter Steighöhe auf - 1 Atmosphäre herunter und nimmt sodann in grössern Höhen diesen letztern proportionale Werthe an, welche beispielsweise für 20 Meter $=-2$, für $30=-3$, für $40=-4$ Atmosphären betragen u. s. f. Führen wir jetzt in Gedanken kleine Luftbläschen in die Flüssigkeit ein, so zeigen natürlich auch diese eine von unten nach oben abnehmende Spannung, allein die letztere ist durchgehends um den oben bezeichneten, durch den Krümmungshalbmesser bedingten Ueberschuss grösser, als die der angrenzenden Flüssigkeit; sie kann dieselbe, wenn die wirksamen Menisken hinreichend klein sind, um eine volle Atmosphäre und mehr überwiegen. 
Diese capillaren Spannungsdifferenzen zwischen Luft und Flüssigkeit müssen in der lebenden Pflanze nothwendig hie und da vorkommen; dieselben beschränken sich aber, wie leicht einzusehen, auf diejenigen grössern Capillarräume, in welchen Luft und Wasser neben einander enthalten sind, d. h. auf die Höhlungen der Zellen. Membranen und $Z$ wischenzellräume kommen hier selbstverständlich nicht in Betracht, erstere, weil sie keine Luft, letztere, weil sie kein Wasser führen. Und da auch die Zellhöhlungen der eben erwähnten Bedingung selten genügen, da sie in der Regel gan z mit Luft oder gan z mit Zellsaft gefüllt sind; da überdiess der Durchmesser derselben, wenigstens bei höhern Pflanzen und soweit sie überhaupt je Luft enthalten, ein seh beträchtlicher ist, so ergiebt sich hieraus, dass jene Spannungsdifferenzen nur selten vorkommen und auch damn nur einen kleinen Bruchtheil einer Atmosphäre betragen können.

Uebrigens ist klar, dass ein ins Gewebe eingesenktes oder auf einen Querschnitt aufgesetztes Manometer nur die Spannung der Flüssigkeit, nicht die der eingeschlossenen oder beim Aufsetzen frei werdenden Luftbläschen anzeigt und auch jene nur dann, wenn ein zur Uebertragung der Spannung auf das Manometer hinreichendes Flüssigkeitsquantum bei gleichbleibendem Drucke in Bewegung gesetzt wird.

Sind Gase und Flüssigkeiten durch permeable Membranen von einander getrennt, so besteht zwar das Bestreben nach Ausgleichung. der Spannungen, die capillaren Wirkungen abgerechnet, auch in diesem Falle. Steht z. B. die Flüssigkeit unter einem höhern Druck als das Gas, so wird sie durch die trennende Scheidewand so lange hindurchströmen, bis der Gegendruck nahezu gleich ist, während im umgekehrten Falle das Gas, sofern es absorptionsfähig ist, theilweise in die Flüssigkeit übergeht. Da indess solche Ausgleichungen, wie alle Diffusionsvorgänge, langsam stattfinden, so mögen vorübergehend Differenzen vorkommen, die eine beträchtliche Höhe erreichen. Es kann sogar der Fall eintreten, dass Gasblasen, die in einem geschlossenen Raume entstehen, eine Spannung von mehreren Atmosphären entwickeln, so dass sie nach dem Auflösen odeı Oeffnen der Hülle sich auf ein Mehrfaches ihres ursprünglichen Volumens ausdehnen. Solche Spannungen kommen z. B. in Stärkekörnern, welche mit concentrirter Schwefelsäure oder Aetzkalilösung behandelt 
wurden, hie und da ror, ${ }^{*}$ sie bilden aber immerhin eine seltene Ausnahme.

Die Spannungen, welche nach den bis jetzt hierüber angestellten 338 Beobachtungen in Geweben vorkommen, differiren in der Regel, die Zeit des Thränens abgerechnet, nur wenig rom äussern Luftdruck; sie sind bald etwas grösser, bald auch etwas kleiner als derselbe. Diese geringen Differenzen, selbst in den höchsten baumartigen Gewächsen, haben auf den ersten Blick fast etwas Befremdendes; sie sind unerklärlich, wenn man von der Vorstellung ausgeht, dass die Zellsäfte durch die Wurzeln wie durch ein Pumpwerk nach oben getrieben oder durch capillare Kräfte gehoben werden, da im ersten Falle hohe positive Spannungen in den untern Theilen, im zweiten Falle hohe negative Spannungen in den obern 'Theilen der Pflanze vorhanden sein müssten. Dieselben werden aber sogleich erklärlich, wenn man die treibenden Kräfte, wie wir unten als nothwendig darlegen werden, in die Wandungen aller leitenden Zellen verlegt. In diesem Falle erhält jede einzelne Flüssigkeitsschicht des steigenden Saftstroms ihren besondern Impuls, ganz so, als ob sie in einer feineu Röhre durch die Ruderschläge eines Flimmerepitheliums gehoben würde. Ein hydrostatischer Druck der höheren Schichten auf die tiefern und die hier eingeschlossene Luft findet demzufolge nicht statt; es entwickeln sich höchstens kleine Spannungen in Folge der ungleich raschen Bewegung verschiedener Schichten. Rücken z. B. die oberen Schichten langsamer vorwärts als die unteren, so wird die zwischenliegende Flüssigkeit positiv, im umgekehrten Falle dagegen negativ gespannt. Eine eingeschlossene Luftblase würde sich im ersten Fall etwas verkleinern, im zweiten vergrössern, und ein in die Strömung eingetauchtes Manometer müsste um entsprechende Grössen steigen und fallen.

Die localen Spannungen, welche die sogleich näher zu bespre- $\mathbf{3 3 9}$ chenden endosmotischen Verhältnisse und die Erscheinungen des "Thränens " hervorrufen, bilden eine Frage für sich. Erstere können, wie später gezeigt werden wird, nur einen kleinen Bruchtheil einer Atmosphäre ausmachen. Von grösserem Belang ist dagegen der Druck, welchen der zur Zeit des »Thränens « in die Gefässe hineingepresste Saft auf das umgebende Gewebe ausübt. Da nämlich die

*) Man vergleiche $\mathrm{Nägeli}$, die Stärkekörner pag. $15 \S$. 
Gefässe, wenn sie überhaupt eine besondere stromerzeugende Kraft besitzen, jedenfalls nicht in dem Maasse damit ausgestattet sind, wie es das verhältnissmässig grosse Lumen derselben erfordern würde, so versetzt die in ihnen enthaltene $W$ assersäule nach und nach die ganze Umgebung in eine der Höhe entsprechende Spannung, die jedoch selbstverständlich mit der Entleerung ebenso allmählich wieder auf Null sinkt. Wie stark diese Spannung werden kann, lässt sich nach den von Hales und Anderen gemessenen Gesammitspannungen ungefähr beurtheilen; directe Beobachtungen hiẹrüber hat bis jetzt, soviel wir wissen, Niemand angestellt.

Die mikroskopische Bestimmung der Spannungen ist in der Regel mit unübersteiglichen Hindernissen verknüpft; sie ist selbstverständlich nur da möglich, wo es gelingt, die Ausdehnung der im Gewebe eingeschlossenen Luft beim Liegenlassen eines frischen Präparates unter dem Mikroskop zu beobachten. In den meisten Fällen bleiben daher Beobachtungen dieser Art der Experimentalphysiologie vorbehalten.

340 Soweit die Endosmose den hydrostatischen Druck des wässerigen Zellsaftes bedingt, ist derselbe in Zellen, die von Wasser umspült sind, voraussichtlich immer etwas stärker als eine Atmosphäre. Es' ist diess eine nothwendige Folge der Wasseraufnahme, welche die diosmotische Wirkung des Zellinhaltes, der sich ja immer wie eine verdünnte Lösung verhält, hervorruft. Die Wandung dehnt sich dabei so lange aus, bis sie eine Spannkraft erreicht hat, die der diosmotischen Kraft und dem dadurch bedingten hydrostatischen Druck das Gleichgewicht hält.

Von dem Torhandensein eines solchen Druckes überzeugt man sich, wenn man ein beliebiges Stück eines saftigen Gewebes unter dem Mikroskop beobachtet. Die Wandungen, welche von dem umgebenden $W$ asser bespült werden, wölben sich alsdann alle nach aussen, während sie im unverschrten Gewebe geradlinig waren. Besonders schön tritt diese Erscheinung an den Scheidewänden mancher Algenfäden, z. B. der Spirogyren hervor, wenn dieselben durch

"

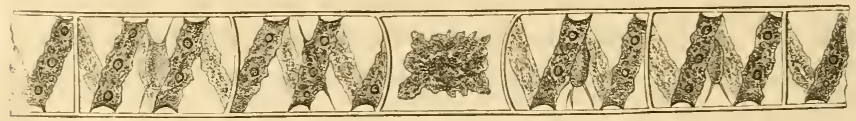

Fig. 191. 
einen quer geführten Schnitt blossgelegt, oder wenn einzelne Zellen verletzt wurden Fig. 194, $a$ eine verletzte oder abgestorbene Zellej .

Aehnliche Spannungsverhältnisse kommen aber auch bei Zellen und Geweben vor, welche theilweise von Luft, statt Wasser, umgeben sind, natürlich unter der Voraussetzung, dass die Verluste, welche die Verdunstung veranlasst, durch reichliche Wasserzufuhr fortwährend ersetzt werden. Im entgegengesetzten Falle nimmt die Spannung allmählich ab und schlägt auch wohl in die entgegengesetzte um, wie man das an Haaren beobachtet, welche durch den vorwiegenden Druck der atmosphärischen Luft eingestülpt oder zusammengefaltet werden.

Man kann diese Umkehrung der Spannung auch künstlich hervorrufen, wenn man die Zellen in Zuckerlösung oder Glycerin, überhaupt in ein Medium bringt, welches eine starke Exosmose bewirkt. Eine Formveränderung der Zelle ist indess nur dann damit rerbunden, wenn die Membran dem ron aussen wirkenden Druck nicht $\mathrm{zu}$ widerstehen vermag, was übrigens bei dünnen Membranen und rascher Einwirkung der Zuckerlösung der gewöhnliche Fall ist.

Jede Zelle hat in Folge der Spannung, welche der hydrostatische $\mathbf{3}+1$ Druck des Inhaltes hervorruft, das Bestreben, eine bestimmte Form anzunehmen. Eine eiförmige Zelle zeigt z. B., wenn sie sich frei ausdehnen kann, ein bestimmtes Verhiltniss zwischen Längs- und Querdurchmesser. Wirkt in der einen oder andern Richtung eine Kraft entgegen, welche die freie Ausdehnung verhindert, so wird jenes Verhältniss in der Art gestört, dass die Zelle in der entsprechenden Richtung zusammengedrückt, in der anderen ausgedehnt erscheint. Ihr Tolumen bleibt dabei unverändert, weil der flüssige Inhalt nicht compressibel ist.

Diese Folgerungen haben natürlich auch dann noch Geltung, wenn die gestaltverändernde Kraft, statt ron aussen auf die Membran einzuwirken, in dieser selbst ihren Sitz hat. Sie sind z. B. anwendbar auf jene plötzlichen Bewegungserscheinungen, welche bei irritabeln Pflanzen auf äussere Reize eintreten. Die mechanische Ursache der Bewegung kam hier nur in der Membran liegen; es müssen Terschiebungen ihrer kleinsten Theile stattfinden, in Folge deren die Zellen eine andere Form anzunehmen bestrebt sind, als vorher, und da sie plötzlich erfolgen, so ist eine gleichzeitige Volumenveränderung, die natürlich mit einer entsprechenden $\mathrm{W}$ asserabgabe oder Wasseraufnahme verbunden sein müsste, in dünnwandigen, intersti- 
tienlosen Geweben (wie man sie bei reizbaren Theilen trifft) wegen des Widerstandes der Meinbranen nicht denkbar. Dieselbe kann stets nur allmählich eintreten und folglich erst nach einiger Zeit bemerkbar werden; diess wird übrigens nur dann der Fall sein, wenn nach der Formveränderung der Zelle eine Spannung der Membran zurückbleibt, welche eine Vergrösserung oder Verkleinerung des Volumens bedingt, ist also keineswegs eine nothwendige Consequenz. ${ }^{*}$ )

Die Zelle verhält sich also, wie aus dem Gesagten hervorgeht, gewissermaassen wie ein elastischer Körper; sie erfährt durch äussere oder innere Kräfte gewisse Formveränderungen und kehrt nachher, wenn der Druck oder Zug aufgehört hat, zu ihrer früheren Gestalt zurück. Dasselbe gilt natürlich auch von Geweben. Saftige Gewebe befinden sich in der lebenden Pflanze fortwährend in einem Zustande der Spannung, weil sie mit anderen Geweben, die ihrer freien Ausdehnung Widerstand leisten und folglich in entgegengesetzter Weise gespannt werden, zu einem Ganzen verbunden sind. Hieraus erklärt sich die Erscheinung, dass ein Blatt (z. B. von Allium), dem auf der einen Seite die Epidermis abgezogen wird, sich nach der entgegengesetzten Seite krümmt, weil die Cuticula am unversehrten Blatt negativ, das Blattparenchym dagegen positiv gespannt ist. Auch das Aufspringen der Früchte, die Bewegungen der sensitiven Pflanzen etc. lassen sich darauf zurückführen, dass das im Zustand der Ruhe bestehende Verhältniss entgegengesetzter Spannungen durch eine neu hinzukommende Kraft plötzlich verändert, das vorhandene Gleichgewicht also gestört wird.

Diese Spannungsverhältnisse sind in neuerer Zeit vielfach Gegenstand der Untersuchung geworden und es steht jedenfalls fest,

*) Nach Hofmeister ist mit der dureh Reizung hervorgerufenen "Erschlaffung "irritabler Gewebe stets eine Volumenverminderung verbunden, die zwar in keinem beobachteten Falle sehr beträchtlich, in einigen aber, wenn auch nur gering, doch unzweifelhaft sein soll (Flora $1 \varsigma 62$, pag. 502). Da uns die betreffenden Beobachtungen unbekannt sind, wir also nicht wissen, wie und in welehem Zeitmomente die Messungen ausgeführt wurden, so müssen wir diese Angabe auf sich beruhen lassen. Aus den Thatsachen, welche Hofmeister in len Sitzungsherichten der k. sächs. Gesellschaft d. Wiss. (1559) und in Pringsheims Jahrbüchern für wiss. Bot. $(1559, \mathrm{II}, 2)$ veröffentlicht hat, lässt sich jedenfalls eine Raumrerminderung nicht ableiten. Hofmeister selbst sagt (Jahrb. p. 264) wörtlich : "Die freie Aussenfläche der Unterseite des Blattstielpolsters von Mimosa pudica) wölbt sich bei der lieizung in einem Maasse nach aussen, welches die Verkürzung des Längsdurchmessers völlig aufwiegt.ı' 
dass eine Reihe von Bewegungserscheinungen darin ihre Erklärung finden. ${ }^{*}$ Da jedoch die physikalische Erörterung solcher Spannungen sich leichter an die Elasticitätskräfte homogener Körper anknüpft, so wollen wir dieselbe einem späteren Capitel vorbehalten.

\section{Ungleiche Concentration der Lösung im Tropfen des Präjparats.}

Ein Tropfen einer beliebigen Lösung, den man auf Papier, 343 Kleider etc. bringt, breitet sich auf der permeabeln Unterlage aus und lässt beim Verdunsten immer zunächst der Peripherie die deutlichsten Spuren des gelösten Stoffes zurück. Man beobachtet diess z. B. an Wein- und Kaffeeflecken. Offenbar wird in solchen Fällen die ursprünglich gleiche Concentration der Lösung während der Ausbreitung ungleich: die gelösten Stoffe sammeln sich vorzugsweise zunächst der Peripherie.

Dasselbe findet nun auch in Tropfen statt, welche man unbedeckt auf dem Objectträger ausbreitet, und in weniger auffallendem Grade auch nach dem Auflegen eines Deckglases. Eine Salzlösung scheidet immer zunächst dem Umfange Krystalle aus, und wenn die Verdunstung vollendet ist, nimmt die trockene Substanz, welche zurückbleibt, von aussen nach innen an Masse ab. Es lässt sich nachweisen, dass in diesem Fall die Ursache der fraglichen Erscheinung in der rascheren Verdunstung an Unfange zu suchen ist; denn stürzt man über den Tropfeu einen Deckel, der durch eine kleine Oeffnung in der Mitte Luft zutreten lässt, so häufen sich die gelösten Substanzen unmittelbar unter der Oeffnung am stärksten an, weil alsdann hier die Verdunstung am lebhaftesten ist. ${ }^{* *}$ )

Es versteht sich übrigens von selbst, dass die Zunahme der Concentration an irgend einer Stelle wesentlich mit ron der Beschaffenheit der gelösten und lösenden Substanz bedingt wird. In einem Gemisch von Wasser und Salzsäure erfolgt sie nur so lange, bis die Grenze erreicht ist, wo sich beide in gleichem Maasse verflüchtigen, und ebenso in Wasser und Schwefelsäure nur bis zur Herstellung des

*) Vgl. Brücke: Ueber die Bewegungen der Mimosa pudica Müller's Archir f. Anat. und Phisiol. 1sts p. $4 t(1)$; ferner

Hofmeister: Ueber die durch die Schwerkraft bestimmten Richtungen ron Pflanzentheilen Pringsheims Jahrb. III). Ueber die Beugungen saftreicher P'flanzentheile nach Frschütterung (a. a. O. II). Ueber die Mechanik der Reizbewegungen von Pflanzentheilen (Flora $1>62$ p. 497).

* Näheres hieruber findet man in der Abhandlung von $\mathrm{N}$ ägeli: Die ungleiche Vertheilung gelöster Stoffe in dem Wassertropfen eines mikroskopischen Präparats Sitzungsberichte der k. bayer. Akad. d. Wiss. 1563. 14. Nov.). 
Gleichgewichts zwischen der Neigung, mit welcher das Wasser verdunstet, und der Kraft, womit die Schwefelsäure dasselbe zurückhält.

344 Für die nikroskopische Untersuchung sind die erwähnten Thatsachen in dreifacher Beziehung von Wichtigkeit. Sie dienen erstens dazu, ungleiche Veränderungen zu erklären. die an verschiedenen Stellen des Präparates eintreten. Sie erlauben zweitens, dieselbe Veränderung an dem nämlichen Präparat wiederholt und in beliebiger Langsamkeit eintreten zu lassen und dabei Differenzen zur Anschauung zu bringen; welche sonst übersehen werden. Endlich machen sie es möglich, die geringste Menge einer gelösten Substanz, die sonst in keiner Weise nachgewiesen werden kann, wahrzunehmen.

In Betreff des ersten Punktes wollen wir nur erwähnen, dass gewisse Stellen eines Präparates bei Anwendung von Reagentien ein stärkeres Aufquellen oder eine deutlichere Färbung etc. zeigen, als andere Stellen, obschon die Natur des Objects eine gleichmässige Einwirkung mit ziemlicher Sicherheit erwarten liesse. Diese Terschiedenheiten rühren denn auch in der That, wie die genauere Prüfung zeigt, in den meisten Fällen von Concentrationsdifferenzen in der Lösung her, wie sie durch die ungleichmässige Verdunstung der Beobachtungsflüssigkeit hervorgerufen werden.

Der zweite Punkt gewinnt namentlich dann Bedeutung, wenn es sich darum handelt, Lösungs-, Quellungs- oder Färbungsprocesse, welche von der Concentration der einwirkenden Flüssigkeit abhängen, genauer zu verfolgen. Wird nämlich die letztere zunächst in solcher Verdüńnung angewendet, dass sie keinerlei Veränderungen am Object bewirkt, so ruft die steigende Concentration während der Verdunstung nach und nach alle Stadien des fraglichen Processes hervor und da man weiss, in welcher Richtung die Einwirkung fortschreitet, so hat man den Vortheil, alle möglichen Uebergänge an neben einander liegenden Objecten beobachten und miteinander vergleichen zu können. Man erreicht zwar ungefähr dasselbe, wenn man das betreffende Reagens auf der einen Seite des Deckglases zusetzt «nd dessen fortschreitende Einwirkung während der Diffusion rerfolgt; doch ist dieses Verfahren in schwierigen Fällen entschieden weniger zweckdienlich, als das vorhin genannte.

Was endlich den dritten Punkt betrifft, so ist einleuchtend, dass geringe Spuren ron Substanzen, welche durch irgend eine Reaction kenntlich sind, dadurch nachgewiesen werden können, dass man sie an Rande eines unberleckten Tropfens sich ansammeln lässt. Es 
gelingt z. B. auf diese Weise nachzuweisen, dass kaltes Wasser entweder für sich allein oder mit einem geringen Zusatz von Iodwasserstoffsäure einen kleinen 'Theil der Flechtenschläuche, sowie auch der Membranén in den Samenlappen von Hymenaea, M ucuna etc. auflöst.

5. Beweghngen in einer Flüssigkeit, welche durch ungleiches specifisches Gewicht vimsacht werlen.

Wenn in einer Flüssigkeit Körper von verschiedenem specifi- 34.) sehen Gewicht enthalten sind oder sich darin entwickeln, so ordnen sic sich selbstverständlich nach ihrem specifischen Gewicht. Oeltropfen und Luftblasen strcben daher in einer wässerigen Lösung, wie sie im Zellinhalt gegeben ist, nach oben, Plasmakörper, Stärkekörner und Krystalle dagegen nach unten; beide steigen oder fallen so lange, bis sie auf ein Hinderniss stossen, das ihrer Bewegung ein Ziel setzt. Ein ruhiges Schweben eines festen Körpers im Innern eines Hohlranmes ist folgerichtig nur dann möglich, wenn derselbe durch relativ feste Gebilde (Plasmafäden etc.) in seiner Lage festgehalten wird oder wenn das umgebende Mediun nur ein halbflüssiges oder gallertartiges ist. In allen anderen Fällen muss er nothwendig dem Gesetze der Schwere folgen, wie man das auch deutlich an schwimmenden Plasmakörnern, Krystallen u. dgl. beobachtet; sic sammeln sich immer, welche Lage man auch einer Zelle geben mag, auf dem Grund derselben. Nur wo Plasmamassen und Chlorophyllkörner unbeweglich am Primordialsehlauch adhäriren, bilden dieselben ein zusammenhängendes Wandbeleg, das sich beim Drehen wie einc feste Masse verhält.

Dass es nicht ganz überflüssig ist, dergleichen physikalische Gesetze, wenn sie auch bei Erscheinungen im Grossen Jedem geläufig sind, in einem mikrographischen Werke zu crwähnen, bewcist der Umstand, dass man selbst in den neueren mikroskopischen Arbeiten hie und da Darstellungen findet, in welchen gerade diese Gesetze ganz und gar ignorirt werden. Man lässt bewegungslose Körper, welche specifisch schwerer sind als Wasser, auf oder in demselben schwimmen, als ob sich das von selbst verstünde; man vergisst dabei, dass die Schwere auch unter dem Nikroskop ihre Herrsehaft übt und nur durch eine gleiche, aber entgegengesetzt wirkende Kraft aufgehoben wird. Wenn z. B. Schwärmsporen von Vaucheria oder Ulothrix an der Oberfläche des Wassers zur Ruhe kommen und keimen, so muss rine solche Kraft im Spiele scin, da ja sonst ein Schwimmen 
auf dem Wasser nicht denkbar wäre. Dasselbe gilt auch von den einzelligen oder mehrzelligen Algen, wclche in membranähnlichen Colonicn das $\mathrm{W}$ asser bedecken.

346 Sehr schön tritt die Wirkung der Sehwere an den Plasmagebilden hervor, welche in der strömenden Zellflüssigkeit der Characeen enthalten sind. Ist die Indifferenzschicht, welche die beiden entgegengesetzten Ströme von einander scheidet, horizontal, der Strömungszirkel also lothrecht gestellt, so senken sich die grösseren Körper des unteren'Stromes nach und nach auf den Grund der Zelle, während diejenigen des oberen sich der Indifferenzschicht nähcrn, zuweilen auch wohl dieselbe durchsetzen und so in den unteren Strom gelangen. Nimmt weiterhin die Indifferenzschicht in Folge der bei den Charen häufigen Drehung allmählich eine verticale Lage an, so dass die beiden Ströme neben einander zu liegen kommen, so sammeln sich die schwereren Körper beiderseits auf dem Grund der Zelle; der obere Theil derselben enthält alsclamn nur Flüssigkeit, der untere nur Plasmagebilde. Wie sich die Wirkungen dieser verschiedenen Lagen in einer längeren Zelle, wo sie abwechselnd auf einander folgen, combiniren, mag hier unerörtert bleiben; wir verweisen in diesem Betreft auf die ansführliche Darstellung in den »Beiträgen zur wissenschaftlichen Botanik « von C. Nägeli, II. 1560.

\section{Das Saftsteigen.}

347 Nachdem wir im Vorhergehenden die Strömungsvorgänge im Allgemeinen, wenn auch unter Verhältnissen, wie sie in der Pflanze gegeben sind, erörtert haben, wollen wir hier noch speciell auf die Emporschaffung der Säfte in den höheren Pflanzen cingehen und uns zunächst unter Bezugnahme auf frühere Capitel und anclere bekannte Thatsachen die Frage vorlegen, was die bekannten physikalischen Kräfte, die hier in Betracht kommen können, zu leisten vermögen.

Was zunäehst die Capillarität betrifft, so wurde oben [S. $36 \mathrm{~S}$ ] dargethan, dass die Höhe, bis zu welcher Wasser und wässerige Lösungen in Capillarröhren emporsteigen, anch für die Molecularinterstitien der Membranen im umgekehrten Verhältniss zum Durchmesser stchen dürfte. Es ist Thatsache, dass die capillaren Kräfte, die in diesen Interstitien wirksam sind, einem Drucke von mehreren Atmosphären das Gleichgewicht halten. - Auf der andern Seite wurde gezeigt, dass die Strömung durch eapillare Räume über sehr geringe 
Höhen hinaus nur äusserst langsam von statten geht, so dass die Verluste, welche die Verdunstung verursacht, durch die Wasserzufuhr von unten nicht mehr gedeckt werden. Wo daher Verdunstung und Capillarität zusammenwirken, muss das Flüssigkeitsniveau auf einer Höhe stehen bleiben, in welcher Ströınungs- und Verdunstungsgeschwindigkeit einander gleich sind, - und diese Höhe reducirt sich, wemn die Luft nicht allzu feucht ist, auf einige wenige Fuss.

Dass die Capillaranziehung unter solchen Verhältnissen nicht im Stande ist, Bäumen und Sträuchern im Verlaufe der Vegetations periode das nöthige Wasserquantum zu liefern, liegt auf der Hand. Das Gewebe müsste, wenn nicht nebenbei noch andere Krälte wirksan wären, von oben nach unten austrocknen, wie man diess an abgestorbenen Pflanzen auch wirklich beobachtet. Da indess Zustände denkbar sind, in welchen die Verdunstungsgrösse nahezu Null wird, und da eine zeitweise Mitwirkung der Capillarität doch mindestens zugegeben werden muss, so verlohnt es sich immerhin der Mühe, die Leistungsfähigkeit derselben und die Erscheinungen, welche je nach Umständen mit ihrer Wirksamkeit verbunden sind, näher zu prüfen.

Es ist zunächst einleuchtend, dass die Flüssigkeit, welche ein $\mathbf{3}+\mathbf{9}$ System von Capillarräumen durchdringt, nicht nur in den feinen Interstitien, sondern auch in beliebig grossen Hohlräumen, die im Innern desselben vorkommen, durch die Capillaranzichung zurückgehalten wird, ganz so, wie diess auch bei weiten Glasröhren der Fall ist, welche oben in eine feine Spitze, beispielsweise mit einer Oeffnung von c. $1-2$ Mik., ausgezogen sind. Die Last, welche dic capillaren Kräfte unter solchen Umständen zu tragen haben, hängt offenbar bloss von der Höhe der Wassersäule und nicht von ihrem Durchmesser ab.

Anders verhielte es sich freilich, wemn ein mit Luft gefülltes Capillarsystem mit seinem untern Ende in Wasser gestellt würde. Alsdann könnte das letztere in den verschiedenen Theilen des Systems nur bis zu einer Höhe emporsteigen, welche im umgekehrten Verhältniss zum Durchmesser stünde, in Zellhöhlungen und anderen grösseren Räumen also ungleich weniger hoch als in den Molecularinterstitien. Ein solcher Fall lässt sich aber nur mit todten Geweben verwirklichen; die lebende Pflanze ist von Anfang an mit Saft gefüllt und baut sich im gefüllten Zustande allmählich in die Höhe. Hier ist demzufolge die Capillaranziehung, so lange nicht in Folge der negativen Spannung Luftausscheidung oder Dampfbildung eintritt, voll- 
kommen ausreichend, um ein Sinken der Säfte in allen Theilen des Gewebes zu verhindern. Es ist dagegen selbstvcrständlich absolut undenkbar, dass dicselbe ein Ausströmen der Säfte aus den obersten Zellen der Gewebe hervorrufe.

349 Wenn neben der Capillaranzichung noch andere Kräfte wirksam sind, wclche die Säfte nach oben oder nach allen Seiten gegen die Verbrauchsstellen hin treiben, so müssen zwei Fälle unterschierlen werden. Enlweder wirken diese Kräfte so intensiv, dass sie eincn continuirlichen Druck auf allc Punkte der Oberfläche ausüben und also eine grössere Menge Wasser zu liefern im Stande sind, als durch Verdunstung verloren geht. Das concave Flüssigkeitsläutchen in den Enden der Capillarräume wird alsdann abgeflacht oder sogar nach aussen gewölbt, und die Capillarität bleibt ausser Wirkung. Oder die Verluste sind stärker, als dass diese andern Kräfte sie zu ersetzon vermöchten; dann theilen sich dieselben mit der Capillaranziehung in die Arbeit, und wenn die Gesammtleistung nicht ausreicht, so zieht sich die Flüssigkeit von der Oberflüche zurüek, bis in Folge der dadurch verlangsamten Verdunstung das Gleichgewicht wieder hergestcllt ist.

350 Die Arbeit, welche der Capillaranziehung, sie mag nun im Verein mit andern Kräften oder für sich allein wirksam sein, bei der Unterhaltung eines continuirlichen Stromes zufällt, ist natürlich für jedes Niveau von der Grösse der Menisken abhängig, welche in den verschiedenen Punkten des Systems zu Stande kommen. Ist der mittlere Durchmesser dieser Menisken, in Millimetern ausgedrückt, gleich d und folglich die entsprechende Steighöhe c. $\frac{30}{d}$, so wirkt die Capillaranzichung mit einer Kraft, welche dem continuirlichen Druck eincr Wassersäule von $\frac{30}{d} \mathrm{~m} . \mathrm{m}$. gleichkommt. Sie vergrössert dadurch die Strömungsgeschwindigkeit und ruft zugleich Spannungen hervor, wie sie oben (S. 373) für den Gleichgewichtszustand angegeben sind.

Hier drängt sich nun aber die Frage auf, ob diese theoretischen Folgerungen, welche für Capillarröhren von messbarem Durchmesser unzweifelhaft richtig sind, auch für die Molecularinterstitien der Membranen Geltung haben, oder ob in dieser Hinsicht Imbibition und Capillarität zu unterscheiden sind. Ein Zug von mehreren Atmosphären ist allerdings vorhanden und es ist gleichgültig, wic man die 
Kraft nennt, welche ihn ausübt. Was jedoch die Fortpflanzung der spannungen betrifft, welche in Folge davon eintreten, so wissen wir lierüber Nichts. Es wäre möglich, dass in den lebenden Menbra. nen Kräfte wirkten, welche jenem Zuge schon auf geringe Entfernung das Gleichgewicht hielten und so die Rückwirkung desselben auf den Zelleninhalt oder auf grössere Zclleomplexe verhinderten. Man kann sich auch vorstellen, dass solche Kräfte gerade in Folge der Spannung frei werden.

Wie dem auch sei, es ist Thatsache, dass Spannungen von mehreren Atmosphären, wie sie nach Maassgabe des capillaren Zuges vorhanden sein müssten, in pflanzlichen Geweben nicht vorkommen, obschon die continuirliche Mitwirkung der Capillarität in jedem dürren Zweige eines Baumes, an jeder abgestorbenen Stelle eines Blattes etc. zweifellos und bei rascher Verdunstung auch in frischen Geweben mindestens sehr wahrscheinlich ist. Auf irgend eine Weise wird also die Fortpflanzung der Spannungen auf grössere Entfernungen verhindert, und da diess nur durch Kräfte geschehen kann, welche auf die Bewegung der Säfte mit einwirken, so folgt daraus immerhin, dass die Capillaranziehung im Verhältniss zur Gesammtsumme der stromerhaltenden Kräfte eine verschwindend kleine Grösse darstellt und folglich in der Physik des Saftsteigens eine höchst untergeordnete Rolle spielt.

Eine zweite Kraft, welche unzweifelhaft auf die Bewegung der 351 Säfte Einfluss übt, ist die sogenannte diosmotische oder endosmotische Kraft. Die Arbeit, welehe dieselbe zu leisten vermag, ist indess voraussichtlich eine sehr veränderliche Grösse; denn sie hängt sowohl von der Concentration der Säfte, als auch von der Natur der Stoffe ab, die darin gelöst sind. Man wird jedoch das Maximum der möglichen Leistungen erhalten, wenn man von der Annahme ausgeht, die in Lösung vorhandenen Stoffẹ wirken sămmtlich wie derjenige unter ihnen, welcher erfahrungsgemäss das grösste endosmotische Aequivalent besitzt, nämlich wie Zucker, und wenn man überdiess eine Concentration der Lösung voraussetzt, welche die bei Pflanzensäften beobachtete noch übertrifft. Dieses Maximum der Leistungen ist nun nachweisbar sehr gering.

Der Frühlingssaft des Zuckerahorns, dessen specifisches Gewicht 1,003-1,006 beträgt, würde $\mathrm{z}$. B. vermöge seiner Verwandtschaft zur Bodenfcuchtigkeit in einem gewöhnlichen endosmotischen Apparat noch nicht einen Meter, der Saft der Weinrebe mit einem spe- 
cifischen Gewicht von 1,0008 - 1,0009 keinen halben Meter hoch steigen (wobei allerdings vorausgesetzt ist, dass die vegetabilische Zcllmembran sich wie eine thierische Blase rerhalte). Wenn nun auch die Concentration der Zellsäfte und mit ihr die endosmotische Kraft den Sommer über beträchtlich höher steigt, so ist doch soviel sicher, dass dieselbe im günstigsten Falle höchstens einer Wassersäule von 5-10 Fuss das Gleichgewicht hält. Solche Kräfte dürfen im Vergleich mit der Arbeit, wclche unsere höchsten Bäume zu leisten haben, geradezu als verschwindend bezeichnet werden.

Betreffend die Concentrationsdifferenzen, welche möglicher Weise zwischen dem Zellsaft und dem Imbibitionswasser der Membranen bestehen, sowie ferner die Concentrationsveränderungen, welche beim Durchgang der Säfte durch vegetabilische Membranen stattfinden, so haben wir nicht nöthig, diese Punkte noch besonders in Betracht zu ziehen, da sie im Vorhergehenden bereits ihre Erledigrung gefunden. Wenn die grössten Concentrationsdifferenzen, die ïberhaupt in der Pflanze vorkommen, unter den günstigsten Verhältnissen nur eine Kraft repräsentiren, die einer Wassersäule von $5-10$ Fuss das Gleichgewicht hält, so ist an und für sich klar, dass die kleineren Variationen, die im Gewebe stattfinden, den Gesammteffect nicht erhöhen und folglich zu vernachlässigen sind.

352 Nach den bisherigen Erörterungen reicht also die Gesammtarbeit der Capillarität und Diosmose im Maximum bis zu einer Höhe von cinigen Metern, d. h. sie ist gerade ergiebig genug, um eine safterfüllte l'flanze von dieser Höhe im gefüllten Zustande zu erhalten. Dass diese Arbeitsgrösse zur Erklärung des Saftsteigens in unseren Bäumen nicht ausreicht, ist ohne Weiteres klar. Hicr müssen also nothwendig noch andere Kräfte wirksam sein, welche den Rest der zu verrichtenden Arbeit übernehmen, und wenn solche Kräftc den hohen Gewächsen zukommen, so ist die Annahme gerechtfertigt, dass sie auch bei weniger hohen vorhanden seien. Uebrigens deutet eine licihe von Erscheinungen, die wir unten specieller bezeichnen werden, darauf hin, dass diese Annahme eine thatsächlich begründete ist.

Ueber den Sitz der fraglichen Kräfte sind von vorne herein verschiedene Ansichten denkbar, von denen jedoch eine einzige mit den bereits erwähnten thatsächlichen Spannungsverhältnissen vereinbar ist. Wollte man z. B. annehmen, jene Kräfte haben ihren Sitz in den Wurzeln, so würde natürlich das ganze Gewicht des emporgetriebenen Saftes auf der Unterlage ruhen, ganz so, wie es bei einer 
Röhrenleitung der Fall ist, welche die oberen Stockwerke eines Hauses mit Wasser versieht. In einem Baum von 1S0-200 Fuss Höhe müsste alsdann der hydrostatische Druck des Zellsaftes in der Nähe der Basis e. 6 Atmosphären betragen. Die Messungen, die man bis jetzt über diesen Druck angestellt hat, ergeben indess, wie bereits frïher erwähnt, durchschnittlich so geringe Ziffern, dass man geradezu sagen kann, der hydrostatische Druek des Zellsaftes sei in der Regel vom äussern Luftdruck nur wenig verschieden und zwar bald etwas grösser, bald aber auch kleiner als derselbe. Eine Ausnahme hievon bildet nur die Periode des Thränens,. weil alsdann die safterfüllten Gefässe auch das ungebende Gewebe unter einen der Höhe der Wassersüule entsprechenden Druck versetzen. In diesem Ausnahmsfalle ist allerdings nicht zu bezweifeln, dass die Kräfte, welche jener Wassersäule das Gleichgcwicht halten, in der Wurzel ihren Sitz haben.

Versetzt man dagegen die bewegenden Kräfte in die Blätter oder überhaupt in die obern Enden der Bäume, so stösst man hiemit schon beim ersten Schluss auf die nämliche Ungereintheit, wie bei der Capillarität: die negativen Spannungen müssten in grösseren Iöhen einen Grad erreichen, welcher in Wirklichkeit nie vorhanden ist.

Denselben Widersprüchen begegnet man, wemn auch in geringerem Grade, auch dann, wenn man die Kräfte in verschiedenen Höhen, jedoch in ziemlicher Entfernung von einander, wirken lässt. Es bleibt also nichts Anderes übrig, als dieselben auf zahlreiche, nahe liegende P'unkte zu vertheilen, und da kein Grund vorliegt, sie auf bestimmte Zellen im Gewebe zu concentriren, so erscheint es am natürlichsten, jede einzelne saftführende Zelle damit auszustatten. Nur wenn die Arbeit des Baumes sich auf alle Zellen gleichmässig vertheilt, sind die geringen Spannungen, wie sie in der Pflanze vorkommen, erklärlich. Man begreift dann auch, dass unter $T_{m} m$ ständen sogar ein Ausfliessen cler Säfte in Höhen von 50 Fuss und darüber, wie man es beispielsweise bei Nectarien und hie und da auch bei Blättern beobachtet, stattfinden kann, sowie andererseits, dass gewisse Zellen durch entgegengesetzt wirkende Kräfte die Säfte nach unten oder bei horizontal liegenden Pflanzen rückwärts gegen die Wurzeln hintreiben, und dass gegenläufige Ströme sogar bei Zellen gleicher Art, wie z. B. bei Siebzellen, vorkommen können.

Gewisse Erscheinungen deuten überdiess in directer Weise dar- 353 auf hin, dass eine saftbewegende Kraft, unabhängig von der Capilla- 
rität, der Verdunstung und Diosmose, in den Zellen thätig ist, und dass sie sogar in abgeschnittene'n Zweigen und Zweigstücken noch einige 'Zeit fortwirkt. Nägeli* beobachtete diess z. B. bei Kartoffeln, welche der allmählichen Verdunstung ausgesetzt waren. Das Eintrocknen schreitet hier in sehr augenfälliger Weise von unten nach oben fort; das Gewebe erscheint am Grunde bald runzelig und weich, während es am Scheitel noch längere Zeit frisch und saftig bleibt und die Knospenanlagen zur Entwicklung bringt. Ebenso ist längst bekannt, dass Sprosse von sogenannten Fettpflanzen, denen die Wasserzufuhr abgeschnitten ist, an der Spitze fortwachsen und Blätter treiben, indess sie am Grunde vertrocknen und absterben. Solche Erscheinungen lassen sich nicht etwa auf einen vorwiegenden Wasscrverlust in der Scheitelregion zurückführen, weil dadurch selbstverständlich nur eine Strömung hervorgerufen würde, die eine gleichmässige Verthcilung des Wassers, nicht aber die Anhäufung des ganzen Vorrathes an der Verdunstungsstelle zur Folge lätte.

Welcher Natur die Kraft sei, die diese Wirkungen hervorruft, ist nicht bekannt. Nachdem es jedoch feststeht, dass elektrische Ströme ähnliche Bewegungen in Flüssigkeiten hervorrufen, dass sie den diosmotischen Strom verlangsamen oder beschleunigen können u. s. w., so liegt die Vermuthung nahe, es möchten auch hier solche Ströme in Spiele sein.

Zum Schlusse sei noch bemerkt, dass wir im Vorhergehenden nur die mechanische Seite der Saftbewegungen im Auge hatten. Die Wanderung der Stoffe in Allgemeinen ist damit keineswegs erschöpft. Es gibt eine Reihe von Erscheinungen, die zu neuen und interessanten Fragen Veranlassung geben, auf' die wir aber hier nicht eingehen können. Wenn z. B. die Stärke, die sich den Sommer über in den Blättern der Bäume gebildet, im Herbste, nachdem die Neubildungen bereits aufgehört haben, in gelöster Form den Stammtheilen und Wurzehn zugeführt und hier in Körnerform wieder aufgespeichert wird, so ist dicss nicht etwa als eine mechanische Fortschaffung einer Lösung zu betrachten, aus welcher sich später die Körner wieder ausscheiden; denn die Zellen des Stammes und der Wurzel, die den Winter über Stärke führen, waren ja vorher mit Saft gefüllt und folglich ausser Stande, eine zuströmende Flüssigkeit aufzunehmen. Es findet hier vielınehr eine Wanderung der Stärkeatome nach unten

*) Sitzungsber. d. k. bayer. Akad. d. Wiss. Vortr. vom 9. Febr. 1861. 
statt, indess die Flüssigkeit, deren Stelle sie später einnehmen, sich nach oben zurückzieht. Dieses eine Beispiel mag genügen, um die Schwierigkeiten, die eine Alles umfassende Theorie der Stoffwanderung zu üborwinden hat, wenigstens anzudeuten.

7. Strömungen dmch Capillaröhren und Membranen.

Die Geschwindigkeit, mit welcher Flüssigkeiten durch eine $\mathbf{3 5 5}$ Röhrenleitung fliessen, nimmt bekanntlich von der Innenfläche der Röhre nach der Mitte hin zu. Der mittlere Werth derselben, wie er aus der Ausflussmenge bestimmt wird, hängt von der Grösse der wirkenden Kraft, der Länge und Dicke der Röhre, sowie ferner von der Adhäsion zwischen Wandung und Flüssigkeit und von den Temperaturverhältnissen ab (s. Eisenlohr, Lehrb. d. Phys. S. 112). Die Anwendung der hierauf bezüglichen Gesetze auf Erscheinungen im Pflanzenleben betreffend, sei hier nur bemerkt, dass das Strömen der Pflanzensäfte in Milchsaftgängen, Gefässen und anderen Capillarsystemen Vorgänge sind, die sich den in der Hydrodynamik gültigen Formeln in mancher Beziehung nicht fügen, weil diese Formeln eine gewisse, nicht unbeträchtliche Grösse des Querschnittes voraussetsen, die hier nicht gegeben ist. Noch am ehesten liesse sich der Strömungsvorgang in Gefässen nach den mit Glasröhren von c. 0,1 m. m. Durchmesser angestellten Untersuchungen beurtheilen. Poiseuillc gelangte hicbei auf empirischem Wege zu der Formel

$$
Q=1 \mathrm{~S} 36,724\left(1+0,0336793 T+0,0002209936 T^{2}\right) \frac{H D^{2}}{L},
$$

in welcher $Q$ das in einer Secunde ausgeflossene Wasserquantum in Kubikınillimetern, $H$ die stromerhaltende Druckhöhe in Quecksilber bei $\left.0^{\circ}, 1\right)$ den Durchmesser und $L$ die Länge der Röhre, alles in Millimetern gemessen, bezeichnet. Der in Parenthesen stehende Ausdruck bestimmt die Correction für verschiedene Temperaturen $T$ in Centesimalgraden.

$\mathrm{Da}$ die in der Zeiteinheit ausfliessende Wassermenge durch $\frac{v I^{2} \pi}{4}$ ausgedrückt wird, wenn $v$ die Stromgeschwindigkeit bedeutet, so lässt sich die obige Formel auf die einfachere zurückführen

$$
v=\frac{H D^{2}}{L} \times \text { Const. }
$$

worin jedoch die Correction für verschiedene Werthe von $T$ vernachlässigt ist. Setzt man $T=15^{\circ}$, so wird Const. $=\frac{4}{\pi} \cdot 1836,724.1,5549$ $=3636,3$, und man hat 


$$
v=3636,3 \frac{I I T^{2}}{L} .
$$

Die Stromgeschwindigkeit ist hienach der Druckhöhe $H$ und dem Quadrate des Durchmessers direct, der Röhrenlänge $L$ umgekehrt proportional. Als absoluter Werth von $v$ ergiebt sich z. B. für eine Röhre von 100 Mik. Durchmesser und 3,6363 Meter Länge, wenn die Druckhöhe zu 760 m. m. angenommen wird, eine Geschwindigkeit von $7,6 \mathrm{~m} . \mathrm{m}$. auf die Secunde *). Hiebei ist jedoch die Capillarröhre horizontal zu denken; wäre sie vertical, so müsste obige Druckhöhe selbstverständlich um eine Grösse gesteigert werden, welche der Flüssigkeitssäule in der Röhre nach hydrostatischen Gesetzen das Gleichgewicht hielte, also im gegebenen Falle um 3,6363 Meter in Wasser oder c. $267 \mathrm{~m} . \mathrm{m}$. in Quecksilber. Man ersieht hieraus, wie bedeutend die Krraft sein müsste, welche im Stande wäre, in Gefässen von 36 Meter Länge und darüber, wie sie bei hohen Bäumen und Schlingpflanzen wirklich vorkommen, eine Stromgeschwindigkeit von nur 0,1 m. m. per Secunde hervorzurufen.

3.56 Gehen wir jetzt von diesem einfachen Fall zu dem im Pflamzenreiche gewöhnlichẹren über, dass die capillaren Röhren, in welchen die Flüssigkeiten strömen, durch zahlreiche Membranen, d. l. durch Systeme von ungleich feineren Capillarräumen unterbrochen sind, so haben wir es hier mit einer Erscheinung zu thun, deren Gesetze noch fast gar nicht näher bekannt sind. Soviel ist indess sicher, dass solche Unterbrechungen als neu hinzukommende Widerstände zu betrachten sind, welche demmach zu den Reibungswiderständen in ununterbrochenen Capillarröhren addirt werden müssen. Die stromerhaltende Kraft muss also jedenfalls beträchtlich grösser sein als in dem vorhin besprochenen Falle, und die wenigen Thatsachen, die man hierüber kennt, beweisen, dass sic unter Lmständen eine cnorme Höhe erreicht. Es bedurfte z. B. volle 4 Stunden, um durch einen aus frischem Tannenholz der Länge nach herausgeschnittenen Pfropf von $10 \mathrm{~m}$ m. Länge eine Wassersäule von $70^{\mathrm{m} . \mathrm{m} .}$ und gleichem Querschnitt, welche unter dem Druck einer (Quccksilbersäule von 760 m. m. stand, hindurch zu pressen. Diess ergiebt selbst für den

') Nach unsern Versuchen über die Strömung der Luft durch Capillarröhren bewegrt sich dieselbe unter ïbrigens gleichen Umständen c. (j) mal rascher als das Wasser. Die Strömungsgeschwindigkeit ist wie bei Flüssigkeiten der 1)ruckhöhe und dem Quadrate des Jurchmessers direct, der lö̈renlänge umgekehrt proportional. (Sitzungsber. der k. bayer. Akad. d. Wriss. 1566.) 
Fall, dass der Querschnitt der strömenden Flüssigkeit im Pfropf nur $1 / 10$ des Gesammtquerschnittes betrüge, die immerhin sehr geringe Geschwindigkeit von c. 1/21 m.m. per Secunde für den Druck einer Atmosphäre.

Andere Versuche, die wir mit quer herausgeschnittenen Pfropfen und mit solchen aus parenchymatischen Geweben anstellten, wobei ebenfalls eine Wassersäule von nahezu gleichem Querschnitt durch den Pfropf gepresst wurde, ergaben noch viel kleinere Ziffern. Die Resultate sind in folgender Uebersicht zusammengestellt.

\begin{tabular}{|c|c|c|c|}
\hline Pfropf von & $\begin{array}{c}\text { I.änge des } \\
\text { Pfropfs in Millim. }\end{array}$ & $\begin{array}{l}\text { Quecksilberdruck } \\
\text { in Millim. }\end{array}$ & $\begin{array}{l}\text { Strömungsgeschwindigkeit } \\
\text { per Stunde, in Millim. }\end{array}$ \\
\hline $\begin{array}{l}\text { Buchenholz } \\
\text { Kartoffelparench. } \\
\text { Runkelrübe } \\
\text { Apfelparenchym }\end{array}$ & $\begin{array}{l}15 \\
32 \\
35 \\
30\end{array}$ & $\begin{array}{l}500 \\
576 \\
520 \\
400\end{array}$ & $\begin{array}{l}0,03 \\
0,15 \\
2-2,5 \\
2-3\end{array}$ \\
\hline
\end{tabular}

Bei diesen Versuchen wurde der aus Buchenholz geschnittene Pfropf in die Glåsröhre eingekittet, die übrigen dagegen in eine der Glasröhre aufgesetzte, dickwandige Kautschukröhre eingezwängt und mit seidenen Bändern umwickelt. Der so erzielte Verschluss war jedenfalls ziemlich gut; doch lässt sich die Möglichkeit, dass vielleicht ein Theil des Wassers zwischen Pfropf und Kautschukwandung durchsickerte, nicht bestreiten. Die wirklichen Strömungsgeschwindigkeiten sind daher wahrscheinlich noch kleiner, als die in der Uebersicht angegebenen, und es dürfte ganz allgemein eher zu hoch als zu tief gegriffen sein, wenn man dieselben für safterfüllte dünnwandige Gewebe bei ungefälır gleicher Dicke (c. $30 \mathrm{~m} . \mathrm{m} \cdot$ ) und für den Druck einer Atmosphäre auf c. 2,5-3,6 m.m. per Stunde veranschlagt, was auf die Secunde im höchsten Fall einen Mikromillimeter ausmacht. In Geweben mit unlöslichem Zelleninhalte und mit dicken Wandungen ist natürlich ceteris paribus die Strömungsgeschwindigkeit noch kleiner und somit die Kraft, welche zur Ifervorbringung einer namhaften Strömung erforderlich ist, noch beträchtlich grösser.

Dic Frage, wo eine so bedeutende stromerhaltende Kraft zu suchen sei, wird natürlich durch vorstehende Erörterungen in keiner Weise berührt. Es sollte bloss nachgewiesen werden, dass eine solche Kraft, wo sie immer ihren Sitz haben mag, angenommen werden muss, um das Strömen durch pflanzliche Gewebe zu erklären. 
Die Verschiedenheiten betreffend, welche möglicherweise hinsichtlich der Durchlässigkeit der (nicht cuticularisirten) Zellmembranen für wässerige Flüssigkeiten vorkommen, so geben die bisherigen Bcobachtungen hierüber so gut wie keinen Aufschluss. Es ist jedenfalls unzulässig, aus der grössern Stromgeschwindigkeit, welche beispielsweise den im Holzkörper strömenden Säften im Vergleich mit denen der Rinde zukommt, auf eine grössere Durchlässigkeit der 'Zellmembranen des Holzes zu schliessen, da die vorausgesetzte Bczichung zwischen Stromgeschwindigkeit und Permeabilität offenbar nur dann besteht, wenn die Kraft, welche die Strömung unterhält, überall dieselbe ist, wie diess z. B. der Fall wäre, wenn die Emporschaffung der Säfte durch den Auftrieb der Wurzeln oder durch die an den oberen Enden wirkende Capillarität stattfände. Sobald aber Krälte, welche in den einzelnen Zellen ihren Sitz haben, sich bei dieser Arbeit betheiligen, wie es nachweisbar geschieht, wird natürlich jede auf die Stromgeschwindigkeit basirte Vergleichung der Permeabilität der Gewebe durchaus unstatthaft.

Die von Hofmeister (Flora 1862) ausgesprochene Ansicht, dass die Membranen lebender Holzzellen in weit höherem Grade perneabel seien, als die des saftreichen Parenchyms der Rinde, so dass die letztere den in Holzkörper aufsteigenden Saftstrom gleichsam eindämmen würde, findet in dem Vorhergehenden ihre Beleuchtung. Den weiteren Angaben, dass die Permeabilität durch Kochen und Trocknenlassen vermindert werde, können wir schon desswegen kciu Gewicht beilegen, weil die von Hofmeister im frischen Zustande beobachtete Strömungsgeschwindigkeit ganz entschieden darauf hinweist, dass mindestens $9 / 10$ der durchgegangenen Wassermenge den Weg durch gröbliche Räume (offene Poren u. dgl.), nicht durch Molecularinterstitien, genommen haben $\left.{ }^{*}\right)$. Die theilweise Verstopfung dieser Räume in Folge der Quellung, welche ein »wiederholtes und anhaltendes Kochen " bedingen musste, vielleicht auch in Folge der Coigulation von Eiweissverbindungen, ist ohne / wweifel die einzige Ursache der verminderten Durchlässigkeit im gekochten Zustande.

*) Hofmeister gribt an, dass ein Ilolzstüek von $43 \mathrm{~m}$. m. Länge im frischen Zustande unter dem Drucke von $330 \mathrm{~m}$. m. Wasser eine Wassersïule von circa $100 \mathrm{~m} . \mathrm{m}$. Länge und gleichem Querschnitt durchfiltriren liess -- eine stronıgeschwindigkeit, die nach unseren Versuchen ohne die Mitwirkung gröblicher liäume geradezu undenkbar ist. 
Ein fernerer Punkt, welcher für das Verständniss der Strömun- 35S gen wichtig, ist das Verhalten von Capillarröhren, in welchen kurze Flüssigkeitssäulen mit Luftblasen abwechseln. Hier erreicht der Widerstand, welcher dem Durchgang der Flüssigkeit entgegensteht, cine um so beträchtlichere Grösse, je zahlreicher die. Luftblasen. Durch Häufung der lctztcren in einer sehr engen capillaren Röhre brachte es J amin dahin, dass ein Druck von drei Atmosphären auf die cine Oeffnung der Röhre nur auf der zugekehrten Seite der Tropfenreihe eine Bewegung derselben zur Folge hatte, während die am wcitestcn abstehenden Flüssigkeitssäulen selbst nach 14 tägiger Einwirkung nicht die geringste Verschiebung zeigten. Die bewegende Kraft nimmt also hicr schr rasch von Tropfen zu Tropfen ab und wird endlich Null. Der Widerstand, welchen die einzelnen Tropfen dem Drucke cntgcgensetzen, ist um so grösser, je enger der capillare Raum, dabei aber unabhängig von der Länge derselben.

Diese Thatsachen erklären zur Genüge, warum die in den Holzzellen enthaltene Luft, trotz der offenen Verbindungen durch die Porenkanäle, durch den Saftstrom niemals gänzlich verdrängt odler in die Gefässe hinein getrieben wird, vielmehr theilweise in den \%ellen zurückblcibt, obschon der Saft zur Zeit des Thränens unter eincm hohen Drucke steht.

\section{S. Die Plasmaströmungen.}

Dic Bewegungserscheinungen, die man am l'lasma der Pflanzen- 359 zellen beobachtet, sind in neuester Zcit sowohl von Botanikern als Zootomen vielfach untersucht und mit analogen thierischer Organismen verglichen worden. Es ergab sich hiebei eine so auffallende Uebereinstimmung mit der thierischen "Sarkode ", dass man diese Benennung für die contractile Substanz der Thierzelle aufgab und dafür die in der Botanik übliche Bezeichnung Protoplasma auch auf jene ausdehnte. Inwieweit nun diese Identificirung gerechtfertigt sei, mag hier unerörtert bleiben; wir wollen nur constatiren, dass sic vorläufig mehr auf den übereinstimmenden Eindruck der Lcbensäusserungen im Allgemeinen, als auf die specielle Auffassung und Deutung derselben gegründet ist, da in dieser letzteren Hinsicht die Anschauungen in wesentlichen Punkten differiren.

Gewöhnlich schreibt man den Plasmabändern oder Plasmamassen, welche die fraglichen Erscheinungen zeigen, eine fliessende Bewegung zu, wobei die in das Plasma eingebetteten Körnchen, dercn Ortsveränderungen wir direct beobachten, mit fortgerissen würden, 
wie die Schlammtheilchen eines Flusses von dem strömenden Wasser. $\mathrm{Br}$ ücke*) erkennt dagegen die sogenannten Plasmaströmchen nicht als solche an; er unterscheidet vielmehr eine zweifache Bewegung: eine langsame ziehende oder kriechende Contractionsbewegung des Plasmakörpers, von der die Veränderungen in der Anordnung der Hervorragungen herrühren, und eine schnell fliessende, die sich in der Bewegung der Körnchen ausspricht. Nach ihm ist das Protoplasma überhaupt ein contractiler Körper, und in diesem Falle wird derselbe durchströmt von einer körnerreichen Flüssigkeit. De Bary ${ }^{* *}$ ) hält diese Annahme für unwahrscheinlich. Er bezweifelt, dass sich an dem Object, welches Brücke zu seinen Beobachtungen gewählt hatte, nämlich an den Brennhaaren der Nessel, überhaupt entscheiden lasse, ob eine oder zweierlei Bewegungen vorhanden seien. An günstigeren Objecten, den Staubfädenhaaren von 'Tradescantia, will er dagegen beobachtet haben, dass die Hervorragungen der Plasmastreifen sich ebenso schnell in der Strömungsrichtung fortbewegen, wie die Körnchen in Innern derselben. Wenn hie und da zwei gegenläufige Bahnen, die hart aneinander grenzen, in demselben Streifen vorkomınen, so beweise diess weiter Nichts, als dass die fliessenden Contractionsbewegungen des Plasmas gleichzeitig nach entgegengesetzten Richtungen vor sich gehen können und dass die ruhende Partie zwischen den entgegengesetzten Strömen zu schmal sei, um noch gesehen zu werden. De Bary vertheidigt also die herköınmliche Deutung der Körnchenbewegung, wonach dieselbe hervorgebracht würde durch strömendes Plasma.

Wir können uns weder der einen noch der andern Ansicht ganz anschliessen. Dass die Hervorragungen der Plasmastreifen mit gleicher Schnelligkeit fortrücken wie die Körnchen, kommt bei den Haaren der Tradescantien allerdings nicht sclten vor, ist jedoch keineswegs durchgreifende Regel. Fast ebenso häufig beobachtet man auch das entgegengesetzte Verhalten, welches die Brücke'sche Unterscheidung zwischen Plasmabewegung und Körnerbewegung rechtfertigt. Die Formverhältnisse der Plasmastreifen (Verdickungen, Verzweigungsstellen etc.) können in der That 10 Minuten lang und darüber ziemlich unverändert bleiben, indess die Körnchen in rascher Bewegung, den Ausbiegungen der Umrisse folgend, vorüberströmen.

*) B r ü cke, die Elementarorganismen. Sitzungsb. der k. k. Akad. in Wien 1562. Bd. XLIV, p. 351.

**) Flora $1>62$, p. 219. 
Oder es kann eine augenfällige, scheinbar kriechende Bewegung der Plasmastreifen stattfinden, welche zuweilen die Geschwindigkeit der Körnchen erreicht, in der Regel jedoch weit hinter denselben zurückbleibt. Die zweierlei Bewegungen sind also wirklich vorhanden; es ist diess eine unzweifelhafte Thatsache, von der sich Jeder, der eine hinreichende Zahl von Fällen untersucht, leicht überzengen kann.

Damit ist aber die Brücke'sche Ansicht noch keineswegs bewiesen. Wenn die Körnchen von einer strömenden Flüssigkeit fortgerissen würden, so müssten dieselben doch wohl im Innern der Plasmastreifen enthalten sein, sei es nun in wenigen grossen oder in vielen kleinen Kanälchen. Die Profilan. sicht zeigt aber, dass die Körnchen im Gegentheil vorzugsweise an der Oberfläche liegen, indem sie an der Unrisslinie in einer der Flächenansicht entsprechenden Zahl auftreten, und dass sie hier dentlich nach aussen hervorragen, als ob sie an das Plasma angedrückt wären (Fig. 195; b ein Plasmaband in der Durchschnittsansicht). Ja es erscheint sogar zweifelhaft, ob bei Tradescantia im Innern der Plasmabänder übcrhaupt Körnchen vorkommen; jedenfalls ist ein directes Beobachten derselben bei mittlerer Einstellung wegen der Kleinheit der Niveaudifferenzen

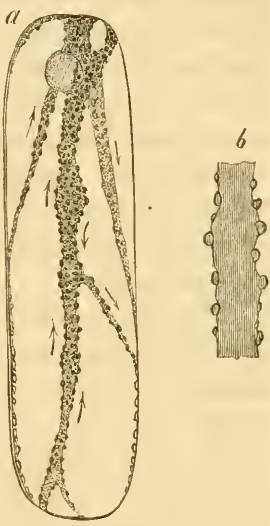

Fig. 195. zwischen der zu- und abgekehrten Fläche nicht leicht möglich. Uns scheint das Vorkommen der Körnchen im Innern der Plasmabänder, soweit die directe Beobachtung hier ein Urtheil erlaubt, unwahrscheinlich, und als vollkommen sicher betrachten wir es, dass weitaus die grössere Zahl derselben an der Oberfläche des Plasmas dahingleitet.

Die Beobachtung zeigt ferner, dass die Bewegung der Körnchen $\mathbf{3 6 1}$ kcine ganz gleichmässige ist. Man sicht deutlich, wie die relativen Abstände derselben während der Bewegung sich ändern, wie ein Körnchen hie und da etwas verzögert und in Folge dessen von einem nacheilenden eingeholt wird, wie dann das letztere bald vorauseilt, bald wieder zurückbleibt, bald auch eine Zeit lang mit dem andern in Bcrührung bleibt u. s. w. Gerade die Körner, welche bei unittlerer Einstellung an den Rändern der Plasmabänder hingleiten, zcigen 
diese Unregelmässigkeiten der Bewegung auf das Deutlichste. Nach der Brücke'schen Auffassung der Strömungserscheinungen ist nun aber eine befriedigende Erklärung dieser Thatsache nicht möglich. Die Annahme, dass die Körnchen, welche von der strömenden Flüssigkeit fortgeführt werden, an den Plasmawänden der Strömungscanäle sich reiben und dadurch mehr oder weniger verzögert werden, hätte zwar für das Innere eines Plasmabandes Manches für sich; allein da die Bewegung in gleicher Weise auch an der Oberfläche, ja wahrscheinlich nur an der Oberfläche stattfindet, so verliert dadı̊rch die Vorstellung einer das Plasma durchströmenden Flüssigkeit mindestens an Plausibilität. Sie wird vollends unhaltbar, wenn man erwägt, dass Kömer, welche viel dicker sind als die Plasmafäden, an denen sie dahingleiten, dieselben Erscheinungen zeigen wie diejenigen grosser Plasmabänder. Sie adhäriren an der Oberfläche des Fadens und bewegen sich darauf fort, wie ein Seiltänzer auf seinem Seil. An eine strömencle Flüssigkeit, welche die Körner mit fortschleppt, ist hier gar nicht zu denken.

Unseres Erachtens hat die Bewegung der Körnchen, soweit sie eine selbständige ist, am meisten Aehnlichkeit mit den Glitschbewcgungen, wie man sie bei den Desmidiaceen, z. B. bei Closterium, beobachtet.*) Man sieht hier, wie einzelne der Körnchen, welche in den bekannten Polarräumen Molecularbewegung zeigen, sich an die Innenfläche des Primordialschlauches anlegen und auf dieser Innenfläche bis gegen die Mitte der Zelle oder bis zum gegenüberliegenden Pol fortglitschen. Die motorischen Kräfte, welche bei freischwebenden Körperchen die tanzende Molecularbewegung hervorrufen, weil ihre Resultirende jeden Augenblick eine andere Richtung erhält, werden also hier durch den Contact der Körnchen mit Plasma soweit modificirt, dass sie eine in gleicher Richtung fortschreitende Bewegung bedingen. Es liegt nun sehr nahe, die Körnchenbewegung in den Tradescantienhaaren einer ähnlichen Ursache zuzuschreiben, vorausgesetzt, dass die Körnchen, wie es wahrscheinlich ist, der Oberfläche der Plasmabänder aufsitzen. Die Erscheinung wäre also hienach aufzufassen als die Wirkung von Kräften, welche in den Körnchen selbst ihren Sitz haben, und welche hinreichend stark sind, um die Reibungswiderstände der anliegenden Medien zu überwinden.

*) Pflanzenphysiol. Untersuch. 1. 
Auf ein ähnliches Spiel von Kräften muss auch die eigenthün- $\mathbf{3 6 2}$ liche Bewegung des Plasmas zurückgeführt werden. Es kamn Niemanden befriedigen, Lebensäusserungen, wie die in Frage stehenden, unter die Rubrik der Contractilitätserscheinungen gestellt zu sehen, aus dem einfachen Grunde, weil damit eigentlich gar Nichts crklärt ist, zumal der Begriff dcr Contractilität, wie er bei Plasmagebilden angewendet wird, bis jetzt der Klarheit und Fassbarkeit entbehrt. Hält man an der ursprünglichen, dem Sprachgebrauche conformen Fassung des Begriffes fest, so bedeutet Contraction einer organisirten Substanz nichts Andercs, als eine Annäherung ihrer festen Theilchen - ein Vorgang, welcher natürlich nur denkbar ist, wenn entweder Wasser aus den Molecularinterstitien austritt, oder wenn die Substanz sich senkrecht zur Contractionsrichtung ausdehnt. Im einen wie im andern Falle können Strömungen in einer halbflüssigen Substanz in Folge von Contractionen nur damn entstehen, wenn dieselbe in einer verhältnissmässig festen Röhre eingeschlossen ist und wenn die letztere sich entweder an einer bestimmten Stelle, ähnlich wie im Kreislauf des Blutes das pulsirende Herz, abwechselnd contrahirt und expandirt oder aber nach einer bestimmten Richtung wellenartig fortschreitende Pulsationen zeigt.

Von solchen Pulsationen ist nun aber an den strömenden Plasmafäden nichts zu sehen, und was die peripherische Hülle betrifft, welche man allfällig als relativ feste Röhre betrachten könnte, so ist dieselbe allerdings etwas dichter und membranähnlich; sie besteht aber nichtsdestoweniger aus einer halbflüssigen, selbst in Bewegung begriffenen Substanz, die bei der Vereinigung zweier Plasmafäden mit einer andern ähnlichen Substanz zusammenfliesst. Unter solchen Verhältnissen kann durch Contraction nur eine Formveränderung, nicht aber eine Strömung des Plasmas hervorgerufen werden.

Vom mechanischen Gesichtspunkte aus betrachtet, fehlt also der $\mathbf{3 6 3}$ Contractilitätstheorie, wie man sieht, alle und jede Berechtigung. Was nun noch die physiologische Seitc des Vorganges betrifft, worauf in neuester Zeit vorzugsweise Gewicht gelegt wurde, wir meinen das Verhalten des strömenden Plasmas zum galvanischen Strom, so will uns auch hier nicht einleuchten, dass die beobachteten Thatsachen zu den Folgerungen berechtigen, die man daraus gezogen hat. Die Versuche, die wir selbst mittelst eines kleinen Inductionsapparates, welcher durch ein Bunsen'sches Zinkkohlenelement getrieben wurde, mit verschiedenen Objecten (Vallisneria, Chara, Tradescantia) ange- 
stellt haben, und die Vergleichung der erzielten Effecte mit der Wirkung chemischer Reagentien bestärkten uns viehmehr in der Ueberzeugung, dass man es im einen wie im andern Falle mit Lebensstörungen, resp. mit Erscheinungen des Absterbens zu thun hat, deren Verlauf zwar theilweise von der Natur des Reagens abhängig ist, die aber dessenungeachtet im Allgemeinen übereinstimmen. Die erste Wirkung einer beliebigen störenden Ursache besteht immer darin, dass die Bewegung der in das l'lasma eingebetteten Körnchen aufhört. Manche Reagentien, wie z. B. Iodlösung, rufen überhaupt keine weiteren Veränderungen (ausser der Färbung) hervor, wenigstens nicht bei Tradescantia, deren Staubfädenhaare wir hier vorzugswcise im Auge haben. Bei Anwendung von Alkalien oder Säuren, desgleichen unter dem Einfluss elektrischer Schläge, kommen dagegen noch mehr oder minder auffallende Formveränderungen des Plasma's hinzu, welche bald in tropfenartigen Auftreibungen, bald in der Vereinigung und Abrundung vorher getrennter Plasmamassen bestehen.* ) Sehr eigenthümlich ist namentlich die Wirkung des Ammoniaks. Dasselbe bedingt in der Mehrzahl der Fälle ein langsames Zusammenfliessen der Plasmabänder in der Richtung gegen den Kern, wo man sie später sämmtlich zu einer unregelmässig-rundlichen Masse ohne alle Fortsätze verschmolzen findet. Hie und da kommt es auch vor, dass grössere Plasmapartieen, die sich eben in beträchtlicher Entfernung vom Kerne befinden, ein besonderes Vereinigungscentrum darstellen. Die Verbindungsfäden reissen dann ab und fliessen mit den beiden Massen zusammen.

Wollte man Erscheinungen, wie die eben erwähnten, als Contractionen bezeichnen, so würde diess zwar dem Eindruck, den sie gewähren, nicht gerade widersprechen. Uns scheint indess eine andere Auffassung, die den Thatsachen mindestens ebenso gerecht wird, viel näher zu liegen. Wir halten es für möglich und wahrscheinlich, dass alle die Formveränderungen, welche durch Reize hervorgebracht werden, einfach Folgen jenes Strebens nach Abrundung sind, welches bei jedem flüssigen oder halbflüssigen Medium zur Geltung kommt, sobald dic besonderen Kräfte, die ihm eine andere Gestalt verleihen, zu wirken aufhören. In den Plasmabändern wird sich dieses Streben um so deutlicher äussern, je weniger die Verschiebbarkeit der Molecüle durch die Einwirkung des Reagens leidet; es wird in

Näheres über die Wirkung des galvanisehen Stromes anf Thier- und J'flanzenzellen findet man weiter unten im Capitel über Elektricität. 
jedem einzelnen 'Theile vollständig erlöschen, sobald das Plasma durch Coagulation in den festen Zustand übergeführt ist. Damit ist aber auch die Möglichkeit gegeben, dass die abweichende Art und Weise, wie die verschiedenen Reize den Molecularzustand des Plasma's verändern, die mancherlei Abweichungen in Formenwechsel bedingen, welche man im Momente cler Einwirkung oder während des Absterbens beobachtet.

Die Vergleichung der durch Reize veranlassten Plasmabewegungen mit dem Tetanus der Muskeln erscheint also vorläufig mindestens gewagt, und vollends ungerechtfertigt ist es, die Strömungen in der lebenskräftigen Zelle damit in irgend einen Zusammenhang zu bringen.

Um bestimmtere Vorstellungen über die Wirkungsweise der $\mathbf{3 6 5}$ Kräfte zu gewinnen, welche das Strömen des Plasma hervorrufen, wird man am besten thun, die Erscheinung vorläufig so aufzufassen, wie sie sich dem Auge darstellt: als eine fortschreitende Bewegung eines halbflüssigen Mediums in einem leicht flüssigen. Alsdann ist zunächst klar, dass an der Grenzfläche der beiden Medien eine K raft wirken muss, welche das Fortrücken der einzelnen Theile bedingt. Welcher Natur die Kräfte auch sein mögen, die im strömenden Plasma selbst frei werden, sie setzen sich an der Grenzfläche der Plasmafäden jedenfalls in mechanische Kraft um, weil die Rewegung an und für sich ein mechanischer Vorgang ist. Der wässerige Zellsaft bietet dem Plasma, ähnlich wie das Wasser dem Fisch und die Luft dem Vogel, die Stützpunkte dar, deren es zum Fortschieben seiner Theile, wie jedes Object das die bewegende Kraft in sich selbst entwickelt, bedarf.

Für die Theorie ergibt sich hieraus die weitere Consequenz, dass die Wassertheilchen in der Umgebung der Plasmafäden einen Impuls in entgegengesetzter Richtung erhalten und in Folge dessen in eine gegenläufige Strönung versetzt werden, welche dieselbe Summe lebendiger Kraft repräsentirt, wie die Plasmaströmung. Dass wir die Wirkung dieser Gegenströmung, obschon sie auf die stärker hervorragenden Plasmamassen hemmend einwirken muss, nicht beobachten, erklärt sich durch die sehr natürliche Annahme, dass diese Massen vermöge ihres grösseren Querschnittes auch eine entsprechend stärkere motorische Kraft entwickeln. Die Vertheilung dieser Kraft an der Oberfläche der Plasmafäden lässt sich übcrhaupt in sehr verschiedener Weise denken, da ja die unbekannte Quelle derselben von Punkt zu Punkt variiren kann und mit den wechselnden Formver- 
hältnissen jedenfalls variiren muss. In dieser Beziehung ist offenbar jede Voraussetzung gestattet, welche zur Erklärung beobachteter Strönungsvorgänge nothwendig erscheint Man begreift auch, dass die mit den Formen wechselnde Vertheilung der Kräfte, verbunden mit dem Widerstande des umgebenden Mediums, eine allmähliche, aber regellose Verschiebung des ganzen Stromnetzes zur Folge haben muss.

Da die bewegende Kraft zunächst auf die Oberfläche wirkt, so müssen die Plasmatheilchen sich hier rascher bewegen als tiefer im Innern. Bei der halbflüssigen Natur des Plasma's ist sogar eine sehr beträchtliche Differenz der Geschwindigkeiten denkbar. Erwägt man diess, so kann die Erscheinung der gegenläufigen Strömungen im Plasma selbst, ohne dass eine indifferente Zone zwischen denselben bemerkbar wäre, nicht mehr auffallen. Denn wenn entgegengesetzte motorische Kräfte an benachbarten Punkten der Oberfläche wirksam sind, so fällt die Zone, wo sie sich gegenseitig aufheben, jedenfalls sehr schmal aus, und es wird begreiflich, dass sie sich unserer Beobachtung entzieht.

Vir haben im Vorhergehenden vorzugsweise die Plasmaströme in den Staubfädenhaaren von Tradescantia und die damit übereinstimmenden in den Brennhaaren der Nessel etc. in Auge gehabt. Die gegebene Darstellung lässt sich übrigens auch auf andere Strömungs- und Bewegungserscheinungen, die in oder ausserhalb der Zelle vorkommen, übertragen. Ueberall haben die motorischen Kräfte, so nehmen wir an, ihren Sitz an der Oberfläche sich berührender heterogener oder doch verschieden organisirter Medien; dic Unterschiede, die in den Effecten hervortreten, beruhen nur darauf, dass die Richtung der Resultirenden sich bald jeden Augenblick ändert, wie bei der sog. Molecularbewegung, bald längere Zeit constant bleibt, wie bei den Strömungen und Glitschbewegungen. Dazu kommt dann noch, dass zuweilen nur das eine der beiden Medien beweglich ist und dann auf dem ruhenden dahingleitet, während in andern Fällen zwei Flüssigkeiten auf einander einwirken, die beide verschiebbar sind. Die bekannten Rotationsströme der Charen werden z. B., wie sich aus den bekannten Thatsachen s. Nägeli, Beiträge zur wiss. Botanik Heft II) mit grösster Wahrscheinlichkeit ergibt, durch eine Kraft unterhalten, welche in dem unbeweglichen Primordialschlauch erzeugt wird und von hier aus sowohl dem anliegenden Plasma als dem wässerigen \%ellinhalt eine gleichsinnige Be- 
wegung crtheilt. $\left.{ }^{*}\right)$ Wären die Flächenelemente des Primordialschlauches beweglich, so müssten sie natürlich in entgegengesetzter Richtung rotiren.

Ueber die Natur der Kräfte, welche die Plasmabewegungen 367 bedingen, sind wir vorläufig rein auf Vermuthungen angewiesen. Was ist natürlicher, als dass man unter solchen Umständen zu elektrischen Strömen seine Zuflucht nimmt? Man weiss, dass solche Ströme auf die Bewegung der Flüssigkeiten bei der Diosmose influiren und hat daher eine gewisse Berechtigung, sie auch in unserem Falle motorisch wirken zu lassen. Allein auf der anderen Seite fehlen bis jetzt alle und jede Anhaltspunkte, welche etwa darauf hindeuteten, dass ein in bestimmter Richtung durch oder um die Zelle geführter galvanischer Strom gleichsinnige und gegenläufige Plasmaströme ungleich afficirt, z. B. den einen beschleunigt und den andern verlingsamt, wie es doch wohl der Fall sein müsste, wenn die bewegenden Kräfte selbst elektrischer Natur wären. - Vielleicht gelingt es der Experimentalphysiologie, in dieser Frage in nicht zu ferner Zukunft einen Schritt weiter zu thun.

*) Diese Auffassung der Strömungsvorgänge in den Charenzellen stützt sich namentlich auf die Art und Weise, wie die Stromgeschwindigkeit von der Oberfläche nach innen zu abnimmt, sowie auf die Unabhängigkeit derselben von der chemischen Beschaffenheit der im Zellsaft schwimmenden, bewegten Körper. Beide Momente sind unvereinbar mit jeder Theorie, welche die treibenden Kräfte in diese Körper selbst verlegen und dem Zellsaft eine rückläufige Bewegung zuschreiben wollte. Sie stehen auch im Widerspruch mit der Ansicht, welche neuerdings $\mathrm{H}$ of meister (Flora 1565 pag. 7 ) über die Mechanik der Plasnabewegungen mitgetheilt hat. Diese Ansicht will uns übrigens auch für die andern, von Hofmeister speciell angeführten Fälle nicht recht einleuchten, da uns die Vorstellung, worauf sie hinausläuft, dass nämlich in dem halbflüssigen Plasma zwei entgegengesetzte Strömungen stattfinden : eine fortschreitende der Plasmapartikelchen und eine rückläufige des eingelagerten Wassers, weder vom mechanischen Standpunkte aus günstig, noch vom atomistischen plausibel erscheint. Denı mechanisch hätte man es mit zwei entgegengesetzten Bewegungen kleinster Theilclien $\mathrm{zu}$ thun, welche die gleiche Summe lebendiger Kraft repräsentiren, dabei aber den Eindruck einer einseitigen (Plasma-) Strömung hervorrufen, atomistisch mit Kräften, welche an der Oberfläche der Plasmapartikelchen ihren Sitz haben und sowohl diese als die angrenzenden Wassertheilchen (etwa nach Art einer W'imperbekleidung) in Bewegung setzen. Das sind Vorstellungen, für welche, wie uns scheint, die Analogieen durchaus mangeln. 


\section{Feste Körper.}

\section{Dis brkennen des Aggregatzustandes.}

368 Wie sich die festen Körper von den flüssigen unterscheiden, lässt sich eigentlich schon aus den oben mitgetheilten Eigenschaften der Lösungen entnehmen, da cine Verwechslung mit luftführenden Räumen nicht leicht möglich ist. Das richtige Erkennen des Aggregatzustandes wird überhaupt nur in zwei Fällen schwieriger, nämlich 1) bei halbflüssigen gallertartigen Medien und 2) bei kleinen rundlichen Körperehen. Was die ersteren betrifft, so verhindern sie im Gegensatz zu den Lösungen sowohl die Molecularbewegung als das Steigen oder Fallen kleiner Körnchen, welche in denselben suspendirt sind, und liefern dadurch ein Kriterium, welches in manchen Fällen, wo es sich z. B. um die Frage handelt, ob der innere Theil eines festen Körpers gelöst oder aufgequollen sei, Anwendung findet.

Sind gallertartige Medien in unmittelbarer Berührung mit dem W asser, so behalten sie natürlich bestimnte Umrisse, die jedoch in schwierigeren Fällen, wovon hier allein die Rede ist, nicht wahrnehmbar sind. Die Grenzlinien treten indess dentlich hervor, wenn es gelingt, durch ein geeignetes Reagens eine versehicdene Färbung. (ler Gallerte hervorzurufen. So wird z. B. Stärkekleister in Wasser durch Iodlösung, die Extracellularsubstanz (Hüllınembran) mancher Algen durch Trübung des Wassers sichtbar.

Körnige Gebilde sind von kleinen Tröpfehen darin verschieden, dass sie nic die genaue Kugelform der letzteren zeigen und selbstverständlich auch nicht zusammenfliessen, während z. B. Oeltröpfehen nach Zusatz von Alkohol sich leicht vereinigen.

\section{Elasticität, Weichheit, Dehmbarkeit.}

:369 Zu den Eigenschaften eines festen Körpers, deren Kenntniss für dic mikroskopische Untersuchung von Bedeutung ist, gehört auch das Verhalten desselben gegen äussere Kräfte, welche eine Formveränderung zu bewirken streben. Nach dem grösseren oder geringeren Widerstande, welchen die Körper einem Druck oder Zug entgegensetzen, theilt man dieselben in harte und weiehe; beide sind clastisch oder unelastisch, je nachdem sie nach erfolgter Aenderung der Gestalt von selbst wieder ihre ursprüngliche Form anneh- 
men oder nicht. Die Körper sind ferner d ehnbar, wenn sie grössere Formveränderungen erleiden, ohne den Zusammenhang zu verlieren, und spröde, wenn sie diese Eigenschaft nicht oder nur in geringem Grade besitzen.

Un zu ermitteln, in welche Kategorie ein mikroskopisches Object gehört, ist in manchen Fällen ein directes Verfahren anwendbar, wie es der Physiker im Grossen einschlägt. Man drückt auf den hinlänglich isolirten Gegenstand durch Aufsetzen der Nadel auf das Deckgläschen oder, wo es angeht, auch direct; man zerrt ihn mit Hülfe zweier Nadeln auseinander u. s. w. Auf diese Weise überzeugt man sich z. B., dass die Stärkekörner und Proteinkrystalloide in hohem Grade spröde sind, indem sie schon bei geringem Druck Risse bekommen oder in Stücke zerfallen, während die Zellkerne, wie überhaupt die Plasmagebilde, sich dehnbar erweisen.

Ueber das Verhalten des Plasmaschlauches oder Primordialschlauches geben die Erscheinungen Aufschluss, welche man beim Ablösen desselben von der Zellwandung auf Zusatz von Zuckerlösung und beim Freiwerden der Schwärmsporen beobachtet. In beiden Fällen zieht er sich zuweilen an den Stellen, wo er an der Wandung oder an der Austrittsöffnung haften bleibt, in lange Fäden aus, welche beim Zerreissen nach Art einer schleimigen Flüssigkeit sich in die Hauptmasse zurückzichen, ohne hier irgend welche Erhabenheiten zu verursachen. So z. B. bei Spirogyra und beim Ausschlüpfen der Schwärmsporen von Stigeoclonium.

Der Plasmaschlauch ist also in hohem Grade dehnbar; er verhält sich wie eine halbflüssige Substanz, etwa wie Gummischleim. An Elasticität ist unter solchen Verhältnissen nicht zu denken; sie ist bei schleimigen Flüssigkeiten, deren Fäden in der angegebenen Weise zusammenfliessen, geradezu unmöglich. 1)ass der Schlauch bei der Volumenabnahme des flüssigen Zellinhaltes sich zusammenzieht, ohne Falten zu bilden, und sich nachher durch Wasseraufnahme wieder ausdehnt, gewihrt zwar den Anschein der Elasticität, beweist aber in Wirklichkeit nur die Verschiebbarkeit seiner Molecüle. Ein verletzter Plasmaschlauch behält jede Form, die man ihm durch Druck orler Zug gegeben hat, unabänderlich bei.

Die Eigenschaften der Zell membran sind mit denjenigen des Holzes qualitativ identisch. Man weiss, dass das letztere in hohem Grade elastisch, aber fast gar nicht dehnbar ist; die Membranen müssen sich daher ebenso verhalten. Es unterliegt übrigens keiner Schwierigkeit, sich hievon auch durch die mikroskopische Beobachtung zu über- 
zeugen. Bastfasern, Holzzellen etc., welche man durch mechanischen Druck biegt, kehren nach dem Aufhören des Druckes in ihre frühere Lage zurück; dic äussere Pollenhaut, welche in Folge der Einwirkung des Wassers sich nicht selten abstreift, wird zunächst durch den Druck des Zelleninhaltes ausgedehnt, zerreisst dann und zicht sich nach dem Abstreifen wieder auf ihren früheren Durchmesser zusammen. Dasselbe beobachtet man auch an der Cuticula der Baumwollenfasern während der Einwirkung von Kupferoxydammoniak. Die cuticularisirten Membranen scheinen überhaupt in höherem Grade dehnbar zu sein, als die nicht cuticularisirten, wesshalb bei jenen auch die Erscheinungen der Elasticität deutlicher in die Augen fallen. Bei den gewöhnlichen Zcllmembranen ist die Verlängerung oder Verkürzung, welche durch Zug oder Druck bewirkt wird, in der Regel so gering, dass sie mikrometrisch nicht gemessen werden kann. Das Buchenholz dehnt sich z. B. bis zur Elasticitätsgrenze nur um 1/600 seiner Länge, eine einzelne Zelle von 600 Mik. Länge also nur um 1 Mik. aus, und ähnlich verhalten sich auch die meisten anderen harten Membranen. Etwas augenfälliger ist die Dehnbarkeit jener weicheren Membranen, welche die Querwände der Algenfäden bilden und beim Isoliren der Zelle durch den hydrostatischen Druck der Zcllflüssigkeit nach aussen gewölbt werden. Da die Dicke der Zellen sich hicbei nicht merklich verändert, so ist die Wölbung nothwendig mit einer beträchtlichen Ausdehnung verbunden.

Die Elasticität der Zellmembranen bedingt natürlich auch diejenige der Gewebe: sie erklärt die mancherlei Spannungen und die dimmit zusammenhängenden Bewegungserscheinungen, welche wir an pflanzlichen Gebilden beobachten. Hier ist daher der Ort, diese schon oben (p. 37S) kurz angedeuteten Wirkungen der Elasticitätskräfte genauer ins Auge zu fassen und die Gesetze, denen sie unterworfen sind, soweit möglich festzustellen.

Wir haben hiebei in erster Linie die Frage zu crörtern, ob saftführende Gewebe und andere organisirte Gebilde im imbibirten Zustande sich gegen äussere Kräfte ähnlich verhalten wie ausgetrocknete oder nicht organisirte Körper, z. B. wie Stahl oder Elfenbein. Diese letzteren erleiden bekanntlich durch Druck oder Zug eine kleine Verminderung oder Vermehrung ihres Volumens. Ein Stahldraht, dessen Länge dlurch Ziehen von 1 auf $1+a$ zunimmt, wird ungefähr im Verhältniss von $1 \mathrm{zu} 1-\frac{a}{4}$ dünner und sein Volumen nimmt etwas zu. 
Ebenso bewirkt die Compression eines trockenen elastischen Körpers eine entsprcchende Volumenverminderung. Man könnte nun versucht sein, diese Verhältnisse ohne Weiteres auf safterfüllte organisirte Körper zu übertragen; allein bei näherer Berücksichtigung der Molecularstructur und der damit zusammenhängenden Eigenthümlichkeiten organisirter Substanzen erweist sich eine solche Uebertragung, wie wir sogleich darthun werden, unstatthaft.

Betrachten wir zunächst ein isolirtes und mit Wasser durch- 371 tränktes Membranstück, etwa cine Lamelle aus einem CaulerpaThallus, eine bis zum Verschwinden des Lumens verdickte Bastfaser, eine Spiralfaser etc., so ergiebt sich aus dem Verhalten derselben zum polarisirten Licht, dass Streckungen, Biegungen und andere ähnliche Einwirkungen die Anordnung der Atome in den krystallinischen Molecülen nicht merklich ändern (vgl. pag. 355), dass somit bloss die Entfernungen der Molecüle unter sich vergrössert oder verkleinert werden. Andererseits ist bekannt, dass das Wasser in imbibirten Membranen mit grosser Kraft zurückgehalten wird, und die mikroskopische Beobachtung lehrt, dass dasselbe durch Biegen oder Comprimiren des Objects sich nicht herauspressen lässt. Es bleibt demzufolge nichts anderes übrig, als anzunehmen, dass der Wassergehalt einer Membran im gespannten Zustande derselbe sei, wie in neutralen. Die Wassertheilchen werden also durch äussere Kräfte bloss verschoben, aber nicht verdrängt; sie bewegen sich z. B. beim Biegen eines Objects von der concaven nach der convexen Seite hinüber, füllen aber nach wie vor die Molecularinterstitien der Substanz vollständig aus und nehmen, da die Summe ihrer Spannungen nur wenig geändert ist, auch nahezu denselben Raum ein.

Wenden wir jetzt dasselbe Raisonnement auf interstitienlose saft- 372 erfüllte Gewcbe an, so ist an und für sich klar, dass die Membranen hier ebensowenig, wie im vorhergehenden Falle, eine Volumenveränderung veranlassen. Das Nämliche gilt aber auch von der in den Zellen enthaltenen Flüssigkeit. Es kann sich also nur noch fragen, ob vielleicht die Spannungsveränderungen, welche durch äussere Kräfte bewirkt werden, die Permeabilität der Membranen, wenigstens stellenweise, modificiren. Wäre diess der Fall, so müsste durch Zusammendrücken eines Gewebes, weil dadurch der hydrostatische Druck auf die Wandungen jedenfalls nicht verkleinert, der Widerstand der Membranen aber geschwächt würde, offenbar ein Theil der 
Zellflüssigkeit herausgepresst werden, und die so erzeugte Strömung würde selbstverständlich fortdauern, bis der allmählich sinkende hydrostatische Druck dem verminderten Widerstand der Membranen wieder das Gleichgewicht hielte. In gleicher Weise müsste das Anseinanderziehen eines Gewebes ein Einströmen von $W$ asser oder, wenn das Object isolirt ist, die Bildung eines leeren Raunes zur Folge haben. - Sind dagegen die Spannungsveränderungen, wie sie in der Pflanze vorkommen, ohne merklichen Einfluss auf die Permeabilität, so verhalten sich die Gewebe wie imbibirte Membranen: sie nehmen in jedem beliebigen Zustande der Spannung immer beinahe denselben Raum ein.

Die eben entwickelten Consequenzen sind sowohl für Membranen als für saftführende Gewebe streng genommen richtig, so lange das Spiel jener Molecularkräfte, die das Leben bilden, nicht alterirt wird. Man darf aber nicht vergessen, dass oft nur ein geringer Anstoss von aussen nöthig ist, um diese Alteration in sehr augenfälliger Weise herbcizuführen. Wenn z. B. die Membranen mancher Algenfä̀len in \%uckerlösung auf das Doppelte ihrer ursprünglichen Dicke anschwellen, ohne ihre Längendimension zu verändern; wenn eine ähnliche Quellung auch bei entzwei geschnittenen oder verletzten Spirogyrenzellen vorkommt, so sind das offenbar Erscheinungen, für welche die ron aussen einwirkenden Kräfte keinen Maassstab bieten. Wenn man ferner beobaehtet, dass der Primordialschlauch sich unter der Herrschaft des Lebens ander's verhält als in der todten oder tödtlich verletzten Zelle; dass Druck auf eine in Wasser befindliche /elle Exosmose, die sonst nicht eingetreten wäre, hervorruft und dass die letztere noch fortdauert, wenn der Druck zu wirken aufgehört hat, so kann man sich der Ueberzeugung nicht verschliessen, dass die kleinsten Theilchen der lebenden Zellhäute sich gewissermaassen in einem Zustande labilen Gleichgewichts befinden, welcher durch verhältnissmässig kleine Eingriffe leicht gestört wird. ')

Unter diesen Umständen lässt sich das Verhalten organisirter Gebilde unter dem Einfluss von Kräften, die eine Formveränderung bewirken, nicht ein für allemal feststellen. Wenn es auch nicht wahrscheinlich ist, dass Spannungen und Spannungsänderungen, wie sie z. B. zwischen der Epidermis und dem Parenchym der Blätter, zwischen der Rinde und den Gefässbündeln krautartiger Stengel

*) Vyl. Nägeli, Pflanzenphysiol. Unters. I pag. 32. 
oder Wurzeln etc. vorkommen, eine Alteration der molecularen Verhältnisse in dem eben bezeichneten Sinne hervorrufen, so kann doch in jedem gegebenen Falle nur der Versuch entscheiden, ob die Formveränderungen gespannter Gewebe mit Volumenveränderungen verbunden seien oder nicht, und ob diese letzteren langsam oder plötzlich stattfinden. Die mitgetheilten theoretischen Erörterungen werden übrigens dadurch keineswegs überflüssig, denn sie zeigen, dass eine allfällige ' Zu- oder Abnahme des Volumens von verschiedenen Ursachen herrühren kann und geben somit dem Beobachter Veranlassung, in der Deutung solcher Erscheinungen vorsichtig zu sein.

Wie die Elasticität, so sind natürlich auch die übrigen Eigen- 374 schaften der Gewebe von denjenigen der Membranen abhängig. Harte oder weiche Membranen werden dem Gewebe ihre Härte oder ihre Weichheit, dehnbare Membranen einen gewissen Grad von Dehnbarkeit verleihen u. s. f. Allein hiemit ist der Zusammenhang, welcher zwischen den Eigenschaften der Gewebe und denjenigen der Elementarorgane besteht, noch keineswegs erschöpft. Es fragt sich jetzt weiter, welche Momente überhaupt bei dieser oder jener Eigenschaft eines Gewebes in Betracht kommen und in wie weit sie maassbestimmend darauf einwirken.

Was zunächst die Elasticität betrifft, so lässt sich nachweisen, dass dieselbe in Geweben zum 'Theil von einem Factor herrührt, der von der Elasticität der Membranen unabhängig ist, oder mit andern Worten, dass ein Gewebe selbst dann noch elastisch sein müsstc, wenn die Wandungen der Zellen, woraus es besteht, bloss dehnbar, aber durchaus unelastisch wären. Diess folgt schon aus dem Verhalten der Zelle. Jede einzelne Zelle hat vermöge ihres flüssigen Inhalts das Bestreben, Kugelform anzunehmen, und bringt dasselbe zur Geltung, soweit der Widerstand ihrer Wandung, letztere mag nun aus Protoplasma oder aus Cellulose bestehen, diess gestattet. Sic nimmt also eine bestimmte Form an und kehrt nach jeder Aenderung derselben, welche durch äussere Kräfte veranlasst wurde, zu dieser Form zurück. Ganz dasselbe gilt natürlich auch für Gewebe. Ein beliebiger Zellcomplex muss unter dem Einfluss des hydrostatischen Druckes, den der Zellsaft ausübt, das Bestreben haben, sich abzurunden, und wenn die Membranen dehnbar sind, wie eine Plasmahant, so wird schon bei mässigem Druck das Gleichgewicht nicht cher hergestellt sein, als bis die Kugelform wirklich annähernd erreicht ist. 
Wir wollen dicss an einem Beispiel noch näher veranschaulichen. Man denke sich eine aus dehnbarer Substanz in grosscm Maassstab construirte Zellgruppe, bestehend aus $\delta$ wür-

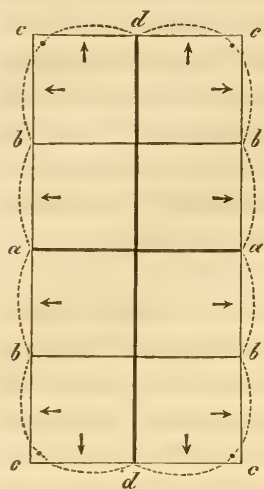

Fig. 196. felförmigen, durch feine Oeffnungen communicirenden Zellen (Fig. 196) und eingerichtet, um einen gleichmässigen hydrostatischen Druck von innen wirken zu lassen. In einem solchen Apparat lassen sich die Kräfte, welche dehnend auf die verschiedenen Scheidewände einwirken, leicht berechnen. Es sei der Druck, der von innen auf die Würfelfläche ausgeübt wird $=100$, der äussere Luftdruck belicbig kleiner, beispielsweise $=50$. Die peripherischen Würfelflächen wölben sich alsdann vermöge ihrer Dehnbarkeit nach aussen, wobei auch die Eck- und Seitenkanten eine schwache Krümmung in gleichem Sinne erfahren. Wir wollen jedoch, der einfacheren Vorstellung wegen, von dieser Krümmung vorläufig absehen, indem wir annehmen, die senkrecht zur Papierfläche verlaufenden Kanten $a, b$ und $c$ bestehen aus unbiegsamen Stäben, und die Krümmung der Kanten $a b$ und $b c$ in der Richtung senkrecht zur Papierebene sei zu vernachlässigen, wie es z. B. der Fall sein würde, wenn unsere Zellgruppe nach oben und unten von $2-3$ ähnlichen begrenzt wäre.

Diess vorausgesetzt, influirt die Vergrösserung der Würfelflächıcn durch Wölbung in den 4 mittleren Zellen bloss auf die Gesammtsumme der radialen Kräfte, die darauf einwirken; dicse Summe ist der jeweiligen Oberfläche proportional. Allein die Componente derselben, welche senkrecht zur Mittellinie $d d$, also in der Richtung der Pfeile wirksam ist, bleibt constant. Es ist nämlich ein allgemeines Gesetz, dass ein gleichmässiger Druck, der auf alle Punkte einer Halbkugel oder Kugelealotte in radialer Richtung ausgeübt wird, in scinem Effect auf die Grundfläche gleich ist dem Druck auf dicse Grundfläche solber. Die Grundfläche bleibt aber für die Aussenwandungen der mittleren Zellen dicselbe, wcil dic Entfernung der Scheidewände wegen der geringen Dehnung der Zellen in der Längrsrichtung sich so gut wie nicht verändert. Folglich bleibt auch der Gesammtdruck nach aussen derselbe. 
Anders verhalten sich dagegen die Eckzellen, weil hicr der einseitige Drúck eine Verschiebung der Kante $c$ und clamit eine Verkleinerung der entsprechenden Grundfächen zur Folge hat. Dic Verhältnisse sind ganz ähnlich wie bei einem Gewölbe, das auf zwei Mauern ruht. Wie diese letzteren durch die Last des Gewölbes nach aussen gedrückt werden, so müssen die Wölbungen $b c$, weil hier der 1)ruck von innen wirkt, die Kante $c$ nach einwärts, $d$. h. in den obern Ecken nach unten, in den unteren nach oben ziehen, indess die Wölbungen $c d$ aus demselben Grunde einen Zug gegen die Mittellinie $d d$ ausüben. Der Punkt $c$ muss also in der Richtung der Diagonale nach innen rücken.

Man mag nun den Druck, der in den Eckzellen wirksam ist, auf die beiden Pfeile vertheilen, wie man will, das Resultat bleibt in der Hauptsache dasselbe. Am natürlichsten ist es, den Punkt $c$ nach wic vor als Grenzpunkt zu betrachten. Dann ist offenbar die Kraftsumme, welche auf die Querrichtung fällt, geringer als in den 4 mittleren Zellen, weil die Grundfläche eine kleinere ist; sie mag beispielsweise durch 90 , statt durch 100 repräsentirt sein. Dieselbe Kraft wirkt auch parallel $d d$.

Der Zug, welcher auf die Scheidewände $a a, b b$ und $d d$ ausgcübt wird, berechnet sich jetzt wie folgt. Auf jede Wand wirkt der halbe Scitendruck der beiden anstossenden Zellen, also auf $a \iota=1 / 2(100+$ $100)=100$, auf $b b=1 / 2(100+90)=95$, endlich auf $d d=1 / 2(90+$ $90)=90$. Man ersicht hieraus, dass die Ausdehnung in der Richtung a $\iota$ am stärksten, in der Richtung $d d$ am schwächsten sein wird.

$\mathrm{Zu}$ demselben Resultat müsste man natürlich auch mit Bezug auf die zur Papierfläche senkrechte Richtung gelangen, man mag nun dic S Zellen für sich allein oder in Verbindung mit darüber und darunter liegenden ähnlich gruppirten betrachten. Man begreift auch, dass die Biegsamkeit der Kanten, welche im Vorhergehenden vernachlässigt wurde, die Berechnung der Kraftsummen zwar etwas complicirt, das Endresultat aber nicht wesentlich beeinträchtigt. Die Ausdehnung unserer Zellgruppe wird also nothwendig in der Richtung des kleinsten Durchmessers am grössten, in der Richtung des grössten Durchmessers am kleinsten sein. Sie wird bei hinreichender Dehnbarkeit der Membranen oder wenn die Membranen in einem ihren Spannungsverhältnissen entsprechenden Maasse durch Intussusception wachsen, zuletzt zur Kugelform führen **).

*) Dass das Streben nach Abrundung sich in der Wirklichkeit nur selten geltend macht, kann bei Zellen und Zellcomplexen, die noch im Wachsthum be- 
Die Form, welche ein Gewebe unter dem Druck des Zellinhaltes annimut, ist überhaupt ganz allgemein als ein Gleichgewichtszustand $\mathrm{zu}$ betrachten, in welchen dasselbe nach jeder Formveränderung, welche durch Druck oder Zug hervorgerufen wird, zurückkehrt, die Membranen mögen nun elastisch sein oder nicht. Der Unterschied besteht nur darin, dass elastische Membranen ein rasches Zurückkehren, nicht elastische ein um so langsameres bedingen, je grösser ihre Widerstandskraft.

Im Uebrigen stehen die Elasticitätsverhältnisse der Gewebe (Elasticitätsgrenze, Elasticitätsmodul, , wie aus dem Gesagten hervorgeht, mit der Dehnbarkeit und Elasticität der Membranen in einem ziemlich verwickelten Zusammenhang. Ein aus kugelförmigen Zellen bestehendes Parenchym kann z. B. beträchtlich verlängert oder verkürzt werden, obschon die einzelnen Membranen nur einer geringen Veränderung fähig sind. Es verhält sich gewissermaassen wie eine aus federnden Stahl- oder Kautschukringen bestehende Kette, deren Dimensionsveränderungen bekanntlich vorzugsweise auf der Formveränderung ihrer Glieder beruhen. Ein aus cylindrischen oder prismatischen Zellen zusammengesetztes Gewebe wird dagegen in der Längsrichtung jedenfalls sehr annähernd die Dehnbarkeit und die Elasticität der Membranen zeigen. Dieselbe Dehnbarkeit der Membranen bedingt also je nach der Form der Zellen und der Richtung der wirkenden Kräfte, und wir können hinzufügen je nach dem Druck, den der Inhalt auf die Wandungen ausübt, eine grössere oder geringere Dehnbarkeit der Gewebe. Die letztere ist aber unter allen Umständen nur eine Folge der ersteren und ohne dieselbe nicht denkbar.

377 Die übrigen Eigenschaften der Gewebe betreffend, so verdient nur die Biegungsfestigkeit oder Steifheit derselben eine genauere Bctrachtung. Dieselbe hängt bekanntermaassen nicht bloss von der Festigkeit der Membranen, sondern auch vom hydrostati-

griffen sind, nur daher rühren, dass die Membranen der Einlagerung von Molecülen zwischen die schon vorhandenen oder der Verschiebung der letzteren in den verschiedenen Richtungen ungleiche Widerstände entgegensetzen. Wenn z. B. cine Spirogyrenzelle in Folge ihres Wachsthums bei vorherrschendem inneren Druck um cin Vielfaches länger wird, ohne sich in der Mitte bauchig zu erweitern, so folgt hieraus, dass die Molecularreihen eine Einschiebung neuer Molecüle nur in der Iängsrichtung, nicht aber in der Richtung des Umfangs gestatten. 1)ie Dehnbarkeit oder Wachsthumsfähigkeit ist also nach verschiedenen Richtungen ungleich. 
schen Druck des Zelleninhaltes ab, und zwar gibt sich dieser letztere Einfluss bei dünnwandigen safterfüllten Geweben in sehr augenfälliger W cise kund. Ein solches Gewebe ist schlaff, wenn der hydrostatische Druck des Inhaltes und der äussere Luftdruck einander gleich sind; es wird dagegen mehr oder weniger steif, wenn die Membranen durch vorwiegenden Druck von innen, wie er im Zustande der Turgescenz immer vorhanden ist, negativ gespannt werden. Das Gewebe verhält sich in dieser Beziehung wie ein mit Wasser gefüllter Schlauch von Kautschuk, dessen Steif heit in gleicher Weise mit dem hydrostatischen Druck oder, was dasselbe ist, mit dem Volumen des Wassers, das in denselben hineingepresst wird, zunimmt.

So lange die Elasticitätsgrenze der Wandungen nicht überschritten wird, wächst die Spannung derselben nothwendig in dem nämlichen Verhältniss, wie der hydrostatische Druck; sie erreicht bei doppeltem Druck einen doppelten, bei dreifachem Druck einen dreifachen Werth u. s. f. In einem ähnlichen, wenn auch nicht genau zu bestimmenden Verhältniss wächst natürlich auch die Steifhcit des Schlauches oder des Gewebes. Je mehr Wasser ein Gewebe unter übrigens gleichen Umständen aufnimmt, desto grösser ist der Widerstand, den es einer Biegung oder einer beliebigen Formveränderung durch äussere Kräfte entgegensetzt.

Wenn wir also ein Gewebe in einem bestimmten Spannungszustande als gegeben betrachten, so kann cine Spamungsverminderung nur durch W asscrabgabe, eine Spannungsvermehrung nur durch Wasseraufnalıme bewerkstelligt werden, - natürlich unter der Voraussetzung, dass ausser dem hydrostatischen Druck und den constanten Elasticitätskrälten der Membran keine andern Kräfte wirksam scien. Das Gewcbe zeigt folglich bei jeder Spannungsveränderung eine unter Unständen messbare, der ausgetretenen oder aufgenommenen Wassermenge entsprechende Ab- oder Zunahme des Volumens.

Wie verhält es sich aber, wenn die Kräfte, welche die Veränderungen in der Biegungsfestigkeit bewirken, in den Membranen selbst ihren Sitz haben, wenn z. B. diese letzteren auf irgend eine äussere Veranlassung (Reiz) plötzlich das Bestreben zeigen, ihre Molecularconstitution zu verändern? In diesem Falle ist voraussichtlich eine Ab- oder Zuuahme des Volumens nicht unbedingt nothwendig. Die Membranen können ihren molecularen Bau und damit ihre Steifheit modificiren, ohne ihre äussere Gestalt merklich zu ändern. Demzufolge kamn auch ein Gewebe cinen höhern oder geringern Grad von Steifheit oder Schlaffheit annchmen, ohne dass damit eine nachweis- 
bare Volumveränderung verbunden wäre. Diese würde selbst dann nicht erfolgen, wenn die Membranen in Folge der molecularen Vorgänge das Bestreben hätten, sich auf einen kleineren Raum zusammen zu ziehen. Sie würden zwar unter dieser Voraussetzung einen Druck auf den Zellsaft ausüben; der letztere müsste aber desswegen nicht nothwendig ausfliessen, weil diess ja auch bei der Verstärkung der Spannung durch Endosmose nicht geschieht.

Die innern Veränderungen der Membranen bedingen also an und für sich, obschon sie möglicher Weise die Steifheit der Gewebe merklich modificiren, keine augenfälligen Volumveränderungen. Sie können sich aber, wie sich von selbst versteht, mit den obenerwähnten Factoren, der Vermehrung oder Verminderung des Inhalts, combiniren und also auch in jenen Fällen mitwirken, wo eine Ab-oder Zunahme des Volumens nachweisbar ist.

Aus alledem ergibt sich, dass weder die Thatsache einer Tolumenveränderung, noch die beobachtete Abgabe oder Aufnahme ron Flüssigkeit über die Spannungsveränderungen im Gewebe Aufschluss geben, selbst dann nicht, wenn die beiden Vorgänge einer genauen quantitativen Bestimmung fähig wären. Auch die Schwankungen des Widerstandes, welchen das Gewebe in verschiedenen Spannungszuständen einer Krümmung durch seitlichen Druck oder Zug entgegensetzt, können ummöglich einen genauen Maassstab fur die Einzelspannungen der Zellen liefern, weil die Formveränderungen, welche das Gewebe erfährt, schon an und für sich eine Ab-oder Zunahme jenes Widerstandes bedingen müssen. Doch ist zuzugeben, dass bei der Schwierigkeit, genaue Messungen über die Spannungsverhältnisse anzustellen, die Biegungsfestigkeit oder die sogenannte Gesammtspannung immerhin noch die besten Anhaltspunkte liefert.

Wir stellen uns jetzt weiter die Aufgabe, die Bedingungen zu ermitteln, unter welchen entgegengesetzt gespannte Gewebe, z. B. Parenchym und Cuticula, die zu einem Ganzen verbunden sind, sich im Zustande des Gleichgewichts befinden. Wir beschränken uns hiebei auf den möglichst cinfachen Fall, dass ein saftiges Gewebe von parallelepipedischer Form mit zwei opponirten Flächen an Gewebelamellen grenzt, welche die freie Ausdehnung des erstcrn hemmen, wic diess bei einem viereckigen Stück, das aus einer Blattspreite herausgeschnitten wird, der Fall ist. Das saftige Gewebe ist alsdann um einen gewissen Bruchtheil kürzer, als im isolirt gedachten Zn- 
stande, und in Folge dessen positiv gespannt; die beiden Lamellen erfahren dagegen eine entsprechende Streckung, so zwar, dass die dadurch hervorgerufene $n$ eg a ti v e Spannung der positiven das Gleichgewicht hält. Diese entgegengesetzten Spannungen geben sich bekanntlich dadurch kund, dass eine Theilung des ganzen Complexes in zwei symmetrische Hälften eine Krümmung dieser Hälften zur Folge hat.

Es wäre nun von praktischem Interesse, diese Krümmung für verschiedene Voraussetzungen in Betreff der Dimensionsverhältnisse, der Elasticität und Dehnbarkeit mathematisch zu bestimmen, um dann umgekehrt aus bekannten Krümmungen und Dimensionsverhältnissen Schlüsse auf die Elasticität und Dehnbarkeit ziehen zu können. Die streng mathematische Lösung dieses Problems war jedoch für uns nur unter Voraussetzungen möglich, deren Zulässigkeit uns nicht ganz zweifellos erschien *), und aus diesem Grunde erach-

*) Wir gingen hiebei von der gekrümmten Gleichgewichtslage aus und suchten die Summe der Spannkräfte zu bestimmen, welche in den concentrischen Schichten ron $A$ und $B$ (Fig. 197) nach Maassgabe ihrer Verlängerung oder Verkürzung wirksam sein können. Diess geschah in folgender Weise.

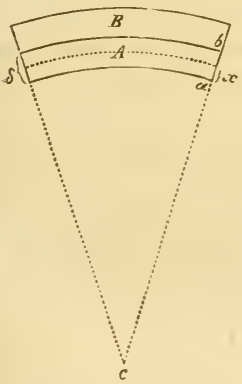

Fig. 197.

Sei die ursprüngliche Länge von $A$ gleich $l$, die Längenzunahme der innersten Schicht in Folge der Spannung gleich $\frac{l}{n}$, der Krümmungsradius $c a=r$ und die Dicke $a b=\delta$; dann ist die Lünge einer beliebigen Schicht, deren Krümmungsradius $r+x$ beträgt, gegeben durch

$$
\frac{r+x}{r} l\left(1+\frac{1}{n}\right)=l+\frac{r+(n+1) x}{n r} l .
$$

Die Verlängerung beträgt also $\frac{r+(n+1) x}{n r}$. Da nun die resultirende Spannung innerhalb der Elasticitätsgrenzen dieser Grösse proportional ist, so ergiebt sich als algebraischer Ausdruck derselben, wenn man die Dicke der Schicht mit $d x$ bezeichnet,

$$
\frac{k}{n r}[r+(n+1) x] d x \text {. }
$$

Der Coefficient $k$, welcher zu den bekannten Grössen hier noch hinzugekommen ist, hat einen constanten, nur von der Dehnbarkeit des Materials abhängigen Werth.

Lässt man nun die Variable $x$ von $x=o$ bis $x=\delta$ zunehmen und substituirt die successiven Werthe in obiger Formel, so erhält man die sämmtlichen Spannungen, welche in den auf einander folgenden Schichten wirksam sind. Die Summe dieser Spannungen ist aber offenbar gegeben durch das Integral

$$
\left.\frac{k}{n r} \cdot \int_{0}^{\delta}[r+n+1) x\right] d x=\frac{k}{n r}\left\{r \delta+\frac{n+1}{2} \delta^{2}\right\}
$$


ten wir es für rathsam, uns vorläufig mit einigen allgemeinen, durch Raisonnement gewonnenen Resultaten zu begnügen.

380 Seien $A$ und $B$ (Fig. 198) zwei elastische Parallelepipede von nicht ganz gleicher Länge. Man denke sich nun $B$ durch irgend eine Kraft, welche auf die obere Endfläche drückt, bis auf die Länge ron $A$ verkürzt und dann in allen Punkten der nach links gekehrten Fläche aufs Innigste mit $A$ verbunden. Unter dieser Voraussetzung muss in dem Augenblicke, wo die beiden Parallelepipede sich selbst überlassen werden, eine Formveränderůng eintreten, durch welche die positive Spannung in $B$ insoweit gehoben wird, bis die dadurch hervorgerufene negative Spannung in $A$ ihr das Gleichgewicht hält. Ist die Verschiebung der Molecüle nur in der Längsrichtung möglich, so beschränkt sich die Formveränderung auf eine grössere oder kleinere Streckung in der nämlichen Richtung, wobei jedoch die resultirende Länge immer kleiner ist, als die ursprüngliche von

Fig. 195. B. Haben dagegen die Spannkräfte einen durchaus freien Spielraum nach allen Seiten, so tritt eine nach rechts convexe Krümmung ein, weil der rechte Rand in dem Bestreben sich auszudehnen geringeren Widerständen begegnet, als der linke. Wir wollen die im einen und

Ganz ebenso erhält man als Summe der positiven Spannungen in $B$, wenn die Verkürzung der äussersten Schicht $\frac{1}{n^{\prime}}$ der ursprünglichen Länge beträgt und der Krümmungsradius derselben mit $R$ bezeichnet wird - während die übrigen Grössen bloss durch Accente von den vorhergehenden unterschieden werden - das Integral

$$
\left.\frac{k^{\prime}}{n^{\prime} R} \int_{0}^{\delta^{\prime}}\left[R+n^{\prime}=1\right) y\right] d y=\frac{k^{\prime}}{n^{\prime} R}\left\{R \delta^{\prime}+\frac{n^{\prime}-1}{2} \delta^{\prime 2}\right\}
$$

Die Gleichsetzung der zweiten Glieder ergiebt

$$
\frac{k}{n r}\left[r \delta+\frac{n+1}{2} \delta^{2}\right]=\frac{k^{\prime}}{n^{\prime} R}\left[R \delta^{\prime}+\frac{n^{\prime}-1}{2} \delta^{\prime 2}\right]
$$

in welche Gleichung man bloss die nöthigen Data zu substituiren braucht, um die übrigen zu bestimmen. Sind z. B. $r, \delta, \delta^{\prime}$ bekannt und $k=k^{\prime}$, so lässt sich bei gegebenen ursprünglichen Längen der Parallelepipede sowohl das Verhältniss von $n$ zu $n^{\prime}$ als auch die La'ge der neutralen Axe berechnen.

Wir halten es für überflüssig, die nach obiger Formel bezeichneten Beispiele mitzutheilen und bemerken nur, dass die Resultate der Rechnung mit unsern durch Raisonnement erhaltenen Regeln übereinstimmen. 
anderen Falle resultirende Form als gerade und als gekrümm Gleichgewichtslage von einander unterscheiden.

Die näheren Bedingungen dieser Gleichgewichtslagen lassen sich natürlich nur unter bestimmten Voraussetzungen über Querschnitt und Dehnbarkeit feststellen. Wir heben folgende Fälle hervor.

1) Haben $A$ und $B$ congruente Querschnitte und überdiess gleiche Dehmbarkeit und Elasticität, so muss die gerade Gleichgewichtslage offenbar dann eintreten, wenn die gemeinsame Länge der beiden Parallelepipede zwischen den beiden ursprünglichen Längen clas Mittel bildet*). Bezeichnet man diese ursprünglichen Längen mit $L$ und $l$ und die gemeinsame resultirende mit $L^{\prime}$, so ist $L^{\prime}=\frac{L+l}{2} \cdot-$ Lassen wir jetzt die gerade Gleichgewichtslage in die gekrümmte übergehen, so wird der linke Rand in unserer Figur sich hiebei etwas verkürzen uifd der rechte sich eben so stark verlängern, wogegen die in der Mitte befindliche Berïhrungsfläche ihre ursprüngliche Länge beibehält. Da nun diese Berührungsfläche auf einem Durchschnitt parallel der Papierebene als Linie erscheint, so wollen wir in der Folge jede solche Linie, die beim Uebergang aus der geraden in die gekrümmte Gleichgewichtslage sich weder verlängert noch verkürzt, ganz allgemein als n eutrale Axe unterscheiden. In unserem Falle liegt also die neutrale Axe in der Mitte zwischen den beiden Rändern.

2 Haben $A$ und $B$ ungleiche Querschnitte, aber gleiche Dehnbarkeit, so ist die gemeinsame Länge in der geraden Gleichgewichtslage, wie man leicht einsieht, grösser oder kleiner als im vorhergehenden Fall, je nachdem $B$ oder $A$ im Querschnitt überwiegt. Der genaue $\mathbb{W} \epsilon$ rth derselben ist gegeben durch die Formel

$$
\left.L-L^{\prime}\right)=\frac{1}{n}\left(L^{\prime}-l\right\rangle,
$$

worin $L, L^{\prime}$ und $l$ die unter 1) erwähnten Längen bezeichnen, während $n: 1$ das Verhältniss des grössern Querschnittes zum kleineren ausdrückt. Denkt man sich nun die Berührungslinie einstweilen nicht dehnbar und lässt alsdann die gerade Gleichgewichtslage in die gekrümmte übergehen, so wird der rechte Rand sich,nahezu bis zur Länge $L$ ausdehnen und der linke sich um eine $n$ mal kleinere

* Eine Kraft, welche einen elastischen Körper um $\frac{1}{n}$ verlängert, verursacht, wenn sie in entgegengesetzter Richtung wirkt, auch eine Verkürzung ron $\frac{1}{n}$. 
Grösse verkürzen, d. h. es wird eine kleine Drehung der Kante $a b$ (Fig. 199 um den unbeweglich gedachten Endpunkt der Berührungs-

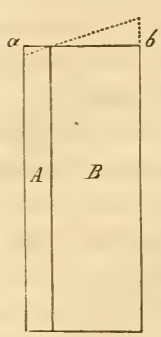

Fig. 199. linie stattfinden. Das Ausdehnungsbestreben von $B$ wird dadurch ungefähr zur Hälfte befriedigt; denn um den rechten Rand wieder auf die Länge $L^{\prime}$ zu rerkürzen, wäre nahezu dieselbe Kraft erforderlich, diein der Berührungsfläche noch wirksam ist. Dagegen sind die Spannungen im Parallelepiped $A$, auch wenn die Verkürzung des linken Randes etwas stärker ist als wir angenommen, nur um einen kleinen Bruchtheil rermindert; 'der übrig gebliebene Rest ist also jedenfalls überwiegend gegenüber demjenigen von $B$.

Geben wir jetzt der Berührungslinie ihre Dehnbarkeit wieder zurück, so wird sie der überwiegenden negativen Spannung von $A$ sogleich nachgeben und sich etwas verkürzen. Die neutrale Axe kommt also jedenfalls mehr nach rechts, innerhalb $B$, zu liegen.

3 Haben $A$ und $B$ gleiche Querschnitte aber ungleiche Dehnbarkeit, so nähert sich die resultirende Länge offenbar mehr der ursprünglichen des weniger dehnbaren Parallelepipeds. Gehen wir von einem extremen Fall aus, indem wir uns $A$ aus Elfenbein und $B$ aus Kautschuk bestehend denken, so müsste die Streckung von $A$ im Vergleich mit der Verkürzung von $B$ verschwindend klein ausfallen und könnte daher ohne merklichen Fehler $=0$ gesetzt werden. Eine Krümmung müsste aber nichtsdestoweniger auch unter dieser Voraussetzung eintreten, wofern nur die beiden isolirt gedachten Lamellen lang genug sind. War aber die gemeinsame Länge in der geraden Gleichgewichtslage der ursprünglichen von $A$ nahezu gleich, so wird die Lamelle $A$ bei der Krümmung sich auf der linken Seite etwas verkürzen und auf der rechten verlängern, ganz so, als ob sie durch seitlich wirkende Kräfte gekrümmt würde. Die neutrale Axe würde also unter dieser Toraussetzung beinahe in die Mitte von $A$ herüberrücken, und wir dürfen hieraus den Schluss ziehen, dass dieselbe auch in den Fällen, wo die Streckung von $A$ nicht Null, sondern nur geringer ist als die Verkürzung ron $B$, stets etwas links ron der Berührungslinie zu liegen kommt, und zwar um so mehr, je grösser die Differenz in der Dehnbarkeit.

$\mathrm{Zu}$ demselben Resultat gelangen wir auch durch die für den vorhergehenden zweiten Fall gewählte Betrachtungsweise. Denkt man sich nämlich die Berührungslinie zwischen $A$ und $B$ nicht dehnbar 
und lässt nun die gerade Gleichgewichtslage in die gekrüınte übergehen, so wird sich der linke Rand ron $A$, wenn dieses nur wenig verlängert war, hiebei auf seine ursprüngliche Länge zusammenziehen und dadurch das Maass der negatiren Spannung auf die Hälfte reduciren. Dagegen kann sich $B$, welches stark verkürzt war, relativ nur wenig verlängern; der Rest der positiven Spannung wird daher, sobald wir uns die Berührungslinie wieder dehnbar denken, die negative von $A$ überwiegen und folglich eine Streckung der Berührungslinie veranlassen. Die neutrale Axe kommt also jedenfalls innerhalb $A$ zu liegen.

Ebenso müsste im entgegengesetzten Falle, wenn $A$ dehnbarer als $B$, ein Hinüberrücken der neutralen Axe auf die rechte Seite der Berührungslinie sich als nothwendige Folge herausstellen.

4) Haben $A$ und $B$ ungleichen Querschnitt und ungleiche Dehnbarkeit, so behalten die unter 2 und 3 abgeleiteten Schlüsse im Allgemeinen ihre Geltung, d. h. die neutrale Axe fällt in der Regel nicht in die Berührungslinie. Das Verhältniss der Querschnitte lässt sich übrigens in verschiedener Weise mit dem der Dehnbarkeit combinirt denken, sodass die Wirkungen der Ungleichheit sich bald gegenseitig unterstützen, bald theilweise aufheben, und im letzteren Falle bald das Verhältniss der Querschnitte, bald das der Dehnbarkeiten den Ausschlag gibt.

\section{Innerer Bau der festen Körper.}

Die festen Körper zerfallen nach der Anordnung ihrer kleinsten 381 Theile und nach den damit zusammenhängenden Eigenschaften in zwei grosse Kategorien : in organisirte und unorganisirte Körper. Erstere sind quellungsfähig, d. h. sie besitzen das Vermögen, Wasser und wässerige Lösungen bis zu einem bestimmten Grenzverhältniss, das nicht überschritten wird, zwischen ihre kleinsten Theile einzulagern und beim Trocknen wieder abzugeben, ohne dabei ihre Molecularconstitution zu ändern. Letztere dagegen sind nicht quellungsfähig; eine Einlagerung von Wasser findet entweder nur in gröbliche Räume statt, oder sie bedingt, wenn das Wasser in hinreichender Menge geboten wird, die Lösung der Körper.

Uebergänge zwischen diesen beiden Kategorien gibt es, genau genommen, nicht. Sie können nur insofern vorkommen, als einzelne nicht organisirte Verbindungen, wie z. B. das Gummi, durch einen allmählichen Umbildungsprocess aus organisirten entstehen und wohl 
auch stellenweise, wo nämlich die Umbildung nicht durchgreift, organisirt bleiben. Dagegen besteht zwischen den organisirten Verbindungen und den nicht organisirten Colloidsubstanzen (Thonerdehỵdrat, Gerbstoff, coagulirtes Albumin etc. keine eigentliche Terwandtschaft. Man kann nicht sagen, dass diese Colloidsubstanzen im bezeichneten Sinne quellungsfähig seien, da die Volumenzunahme, welche das eindringende Wasser bedingt, entweder auf der Einlagerung desselben in gröbliche Räume beruht oder aber unbegrenzt fortdauert und dann als eine Lösungserscheinung zu betrachten ist, und da andererseits die vollständige Entziehung des Wassergehaltes bei $\mathrm{Hy}$ draten eine Veränderung der Molecularconstitution im Gefolge hat.

Sowohl bei organisirten als bei nicht organisirten Körpern muss unterschieden werden zwischen den mikroskopisch nicht wahrnehmbaren Molecularinterstitien und allfälligen gröblichen Zwischenräumen, die in der Substanz auftreten. ") Wir wollen die Körper, in welchen solche Zwischenräume rorkommen, als grobporöse von den übrigen nicht grobporösen unterscheiden. $\mathrm{Zu}$ jenen gehören beispielsweise unter den organisirten das $\mathrm{Holz}$ und die Knochen, unter den nicht organisirten der Hydrophan und die Sphaerokrystalle der Acetabularien ${ }^{* * *}$; zu diesen einerseits die

*) Wie $\mathrm{H}$ ofmeister (Flora $1 \triangleleft 62$, dazu kommt, die Zellmembranen den Colloidsubstanzen beizuzählen, vermögen wir nicht einzusehen. Wie aus seiner Jarstellung hervorgeht, stützt er sich hiebei auf die "Fähigkeit der lebenden Zellhaut, auf geringfügige äussere Einflüsse einen Theil des an ihrer Zusammensetzung betheiligten Wassers auszustossen ", natürlich unter entsprechender Abnahme des Volumens, und auf die vermeintliche Uebereinstimmung dieses Vorganges mit dem Gerinnen der Colloidsubstanzen. Das Eine wie das Andere erscheint uns zweifelhaft. Einmal lässt sich die gedachte Fähigkeit aus den uns bekannt gewordenen Thatsachen nicht folgern; sie kann also höchstens als eine möglich e Eigenschaft der. Membranen bezeichnet werden. Zweitens bezweifeln wir, dass diese. Fähigkeit es ist, „die in dem leichten Uebergange von Colloidsubstanzen in den ron Graham betonten pectösen Zustand, in dem leichten Gerinnen dieser Substanzen hervortritt ". Sowohl der Gerinnungsprocess des Eiweisses beim Erwärmen, als derjenige von Leimlösungen beim Erkalten ist eine Erscheinung ganz anderer Art, die weder mit Wasseraufnahme noch mit Wasserabgabe verbunden ist, und was den pectösen Zustand betrifft, so kann derselbe von vorne herein nicht als Vergleichungspunkt dienen, da die Membranen irritabler Gewebe, die doch Hofmeister speciell im Auge hat, jedenfalls nicht pectös sind.

**) Die physikalischen Lehrbücher unterscheiden gewöhnlich nicht zwischen Porosität und Imbibitionsfähigkeit. Sie betrachten das Eindringen von Wasser und wässerigen Lösungen in vegetabilische Membranen, ganz wie das Eindringen in ein Stück Kireide, als eine einfache Porositätserscheinung vgl. z. B. M ülle rPouillet, Lehrb. der Phys. p. 20).

**) Siehe das Nähere hierủber bei Nägeli: Sitzungsber. d. k. bayer. Akad. 
Stärkekörner, Membranen etc., andererseits die gewöhnlichen Krystalle. Ob das Collodium organisirt oder nicht organisirt sei, scheint uns zweifelhaft; jedenfalls ist es grobporös.

Die gröblichen Zwischenräume lassen sich nicht immer ohne Weiteres erkemnen, namentlich dann nicht, wenn sie (wie bei den oben erwähnten Sphaerokrystallen) sehr klein und zahlreich und mit einem flüssigen Medium erfüllt sind. Ihr Vorhandensein verräth sich aber sogleich, wenn man die Substanz etwas erwärmt, bis die Flüssigkeit durch Terdunstung verschwunden und durch Luft ersetzt ist. Der Körper erscheint alsdann wegen der vielen luftführenden Räume schwarz.

Das Verhalten der festen Körper gegen chemische und physi- 392 kalische Reagentien berechtigt zu der Ammahme, dass ihre kleinsten Theile im Allgemeinen polyedrisch sind und eine bestimmte regelmässige oder unregelmässige Anordnung zeigen. Nennen wir diese kleinsten Theile mit ihren Aethersphären Atom e $\mathrm{e}^{-}$, so müssen nach der atomistischen Theorie folgende Verschiedenheiten der Lagerung angenommen werden, um den bekannten Erscheinungen Rechnung zu tragen.

1) Die Atome liegen auf den drei senkrecht sich kreuzenden Richtungen des Raumes man mag sich dieselben beliebig orientirt denken) in durchweg gleichen Abständen von einander entfernt und werden auch nach allen drei Richtungen von gleichen Kräften sollicitirt; eine belicbige Drehung einzelner Atome um $90^{\circ}$ verursacht keine Störung des Gleichgewichts. Der Körper wird alsdann isotrop genannt, weil er im Verhalten gegen die Imponderabilien (Licht, Wärme etc.) keinerlei Verschiedenheiten der Richtung bemerken lässt. - So rerhalten sich indess nur die Krystalle des regulären Systems. Die hier möglichen Krystallfächen entsprechen, wie überhaupt bei allen Krystallen, den Ebenen, die man sich durch je 3 Atome gelegt denken kann; sie kommen um so leichter zur Ausbildung, je geringer der Abstand der Atome in der Ebene.

2) Die Atome sind nach rerschiedenen Richtungen ungleich weit ron einander entfernt und von ungleichen inneren Kräften solli-

d. W'iss. zu München, Vortrag rom ร. März 1562. Vgl. ferner die Mittheilungen ron $\mathrm{S}$ a ch s über die Sphaerokrystalle des Inulins, Bot. Zeit. 1\$64, p. S0.

* Manche Autoren bezeichnen die kleinsten Theile mit ihren Aethersphären als Molecüle und reserviren den Ausdruck A tom für die Massentheile ohne die Aethersphären. 
citirt; die Orientirung ist aber durchgehends die nämliche, gleichwerthige Richtungen sind also parallel. Die räumliche Anordnung der Atome lässt alsdann noch mancherlei Veschiedenheiten $\mathrm{zu}$, wie sie bei den 5 hieher gehörigen Krystallsystemen vorkommen; sie ist aber stets der Art, dass die Intensität dadurch bedingter Eigenschaften mit der Richtung sich in gleichem Verhältniss ändert, wie der jedesmal parallel gedachte Durchmesser eines entsprechend orientirten Ellipsoids oder Rotationsellipsoids. Das Nähere hierüber wurde bereits bẹ Erörterung der Polarisationserscheinungen mitgetheilt.

3) Die Atome sind ungleich orientirt oder unregelmässig angeordnet, jedoch so, dass, wenn auch nicht die einzelnen Abstände, doch die mittlere Grösse derselben auf jeder beliebigen geraden Linie immer dieselbe ist, eine Verschiedenheit der Richtungen also nicht besteht. Die Körper verhalten sich alsdann wie isotrope; sie bilden aber keine Krystallflächen aus, weil die in einer Ebene liegenden A tome nicht übereinstimmend gestellt oder abcr ungleichmässig vertheilt sind. - Eine solche Constitution müssen wir im geschmolzenen Zustande selbstverständlich bei allen sonst festen Körpern roraussetzen; bleibt sie auch während des Erstarrens erhalten, so ist der Körper isotrop, aber amorph. So das Glas, trockenes Gummi etc.

4) Die Atome gruppiren sich zu kleinen, jedoch mikroskopisch nicht wahrnehmbaren Krystallen, die wir Molec üle nenneu wollen. Diese treten selbst wieder nach ähnlichen Gesetzen zu grösseren Massen zusammen, nur dass hiebei eine etwas grössere Freiheit zur Geltung kommt, indem die Molecüle sich bald in ebene, bald in krumme Flächen ordnen. Ueberdiess können die Molecüle, ohne ihre Anordnung zu verändern, sich soweit von einander entfernen, dass Atome anderer Substanzen, zu denen sie Affinität haben, sich zwischen dieselben einschieben und eine förmliche Hülle um sie bilden.

\section{3}

Auf der letzterwähnten Gruppirung der Atome beruht das Wesen der organisirten Substanz. Das Wasser, womit sich dieselbe imbibirt, dringt nur zwischen die Molecüle, nicht in diese letzteren ein, und wird beim Verdunsten wieder abgegeben. Findet vollständiges Austrocknen statt, so nähern sich die Molecüle bis zur unmittelbaren Berührung, und da nicht anzunehmen ist, dass sie luftführende Räume zwischen sich lassen, weil dadurch die Durchsichtigkeit der Masse gestört würde, so müssen die benachbarten Molecularschichten ziemlich genau auf einander passen oder in einander greifen, wie die Oberflächen eines beliebigen Objectes und seines galvanoplastischen 
Abgusses. Die Gestalt der Molecüle muss daher im Allgemeinen eine polyedrische sein, wie die der Krystalle, und zwar eine regelmässige, wenn sie sich in parallele Ebenen gruppiren, wie bei den Proteinkrystalloiden, eine unregelmässige und mehr oder weniger keilförmige, wenn die Anordnung eine concentrisch-krummflächige ist, wie bei den Stärkekörnern. Die Ausbildung von Krystallflächen lässt sich natürlich nur im ersten Falle, hier aber nach den verschiedensten Krystallsystemen erwarten, wie demn auch bereits rhombische und klinorhombische (rhomboedrische?) Formen von organisirten Substanzen bekannt sind. Jede durch drei Molecüle gelegte Ebene bezeichnet alsdann eine mögliche Krystallfläche.

$\mathrm{Ob}$ die Krystallform der Molecüle mit derjenigen ihres Aggregates in einem bestimmten Zusammenhang stehe oder vielleicht gar mit der letztern identisch sei, lässt sich nicht mit Sicherheit bestimmen. Doch ist kaum anzunehmen, dass ein Krystalloid mit rechtwinkligen Axen sich aus Molecülen mit schiefwinkligen aufbaue oder umgekehrt; es ist rielmehr am wahrscheinlichsten, dass wirklich Uebereinstimmung zwischen den beiden Krystallformen bestehe. Soviel ist jedenfalls sicher, dass die optischen Eigenschaften der Krystalloide, wie überhaupt eines beliebigen Aggregates von Molecülen, nur von der Beschaffenheit dieser letzteren, nicht aber von ihrer Anordnung abhängen, so dass also optisch negative Molecüle auch ein optisch negatives Verhalten des Aggregates und ebenso isotrope Molecüle den Isotropismus des Aggregates bedingen. Diese Schlüsse ergeben sich, wie oben 'p. 355 gezeigt wurde, aus den bekannten Farbenerscheinungen, welche das polarisirte Licht in Membranen und Stärkekörnern in den verschiedenen Stadien der Quellung hervorruft.

Die Grenzen, bis zu welchen die Molecüle sich in Folge der Quellung der Substanz von einander entfernen und beim Austrocknen wieder näher rücken, sind durch die hierdurch bedingten Volumenveränderungen bestimmt. Bei gallertartigen Membranen, welche beim Austrocknen sich auf 1/8 ihres Volumens zusammenziehen, müssen sich z. B. die Centren der Molecüle durchschnittlich auf ${ }_{1}^{3} 1 / s=1 / 2$ ihrer ursprünglichen Entfernung nähern. Hätten die Molecüle selbst Würfelform, so müssten im aufgequollenen Zustande die Interstitien den Durchmesser eines $W$ ürfels erreichen.

Eine weitere Eigenthümlichkeit der organisirten Substanz be- $\mathbf{3 8 4}$ steht - soweit wenigstens die genauer bekannten Beispiele ein Ur- 
theil erlauben - darin, dass sie sich stets als ein Gemenge zweier chemisch verschiedener Substanzen erweist, welche durch Lösungsmittel ron einander getrennt werden können. So bestehen z. B. die Stärkekörner aus Granulose und Cellulose, desgleichen die Zellmembranen durchgehends aus zwei Substanzen ron ungleicher Löslichkeit, und auch die Proteinkrystalloide lassen einen Theil ihrer Masse durch verdünnte Säuren ausziehen, während ein anderer Theil

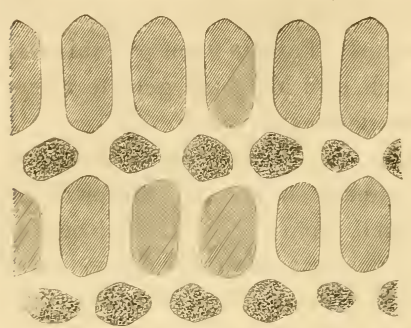

Fig. 200. unter Beibehaltung der Krystallform zurückbleibt. Man kann sich nun die Molecularconstitution eines solchen Gemenges in rerschiedener Weise denken. Entweder bilden die beiden Substanzen Molecüle ron nicht sehr verschiedener Grösse und Anordnung Fig. 200/; dann ist selbstrerständlich jedes beliebige Terhältniss zwischen den beiden Substanzen denkbar. Oder die regelmässige Form und Anordnung beschränkt sich auf die Molecüle der einen Substanz, indem die der andern unregelmässig in die Interstitien eingelagert sind, etwa wie der Mörtel zwischen die Steine

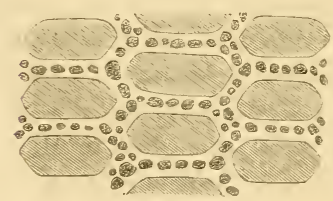

Fig. 201. eines Mauerwerkes Fig. 201, Eine dritte Anmahme, dass nämlich die Molecüle selbst aus Atomen beider Substanzen zusammengesetzt seien, ist mit der Krystallnatur der Molecüle nicht wohl rereinbar, da eine theilweise Lösung der integrirenden Bestandtheile bei Krystallen nicht möglich ist. Die Krystallnatur der Molecüle spricht auch gegen die Voraussetzung, dass die Atome verschiedener Substanzen Molecüle mit gleichen Winkeln bilden. Unter den möglichen Combinationen hat somit die Einlagerung der einen Substanz in die Molecularinterstitien der andern die grösste Wahrscheinlichkeit.

\section{Cohäsion und Adhäsion.}

35.5 Die Ausdrücke Cohäsion und Adhäsion bezeichnen in manchen Fällen sehr nah rerwandte Begriffe, ja sie sind oft geradezu als synonym zu betrachten. Die Schichten einer organisirten Substanz cohäriren oder adhäriren, je nachdem man von dieser oder jener Vor- 
stellung über die Molecularconstitution derselben ausgeht. Nach dem gewöhnlichen Sprachgebranche würden die ursprünglich getrennten Zellen des Endosperms, welche sich in der Folge zu einem geschlossenen parenchymatischen Gewebe verbinden, durch Adhäsion, die durch Theilung entstandenen Zellen dagegen durch Cohäsion zusammengehalten; beide Gewebe sehen aber vollkommen gleich aus. Wollte man den Ausdruck Cohäsion für den Zusammenhang chemisch gleicher Molecularschichten reserviren, ohne Rücksicht darauf, ob sie ursprünglich getrennt waren oder nicht, so würde in allen Fällen, wo gewisse Schichten der Membran sich chemisch verändern, wie z. B. bei der Umwandlung in Korksubstanz Cuticula), die Cohäsion in Adhäsion übergehen. Diese Beispiele mögen genügen, um zu zeigen, dass ein strenges Auseinanderhalten der gedachten Ausdrücke nicht möglich ist.

$\mathrm{Ob}$ die adhärirenden Flächen zweier Körper bis auf den gewöhnlichen Abstand der Molecüle genähert oder durch einen beträchtlich grösseren Zwischenraum voll einander getrennt sind, ob also die Adhäsion rollkommen oder unvollkommen sei, lässt sich mikroskopisch nicht unterscheiden. Der Primordialschlauch legt sich z. B. so innig an die Zellmembran an, dass eine Scheidelinie zwischen ihm und der inneren Membrangrenze nirgends bemerkb.ur ist. Dessenungeachtet löst er sich an den meisten Stellen leicht ron der Membran ab, während er an andern haften bleibt und sich hier unter Umständen in lange Fäden auszieht. Die Adhäsion kann also nur an diesen letzteren Stellen vollkommen oder wenigstens möglichst vollkommen sein; an ersteren muss zwischen den Molecülen der Nembran und des Schlauchs ausser dem umhüllenden Imbibitionswasser eine trennende Wasserschicht angenommen werden, welche den gegenseitigen Abstand vergrössert und dadurch die Adhäsion schwächt. Ob diese Wasserschicht selbst wieder an verschiedenen Stellen ungleiche Mächtigkeit erreicht, wie man aus dem ungleichzeitigen Ablösen des Primordialschlauches folgern möchte, lässt sich durch directe Beobachtung ebensowenig entscheiden, weil ja selbst die dicksten Stellen jenseits der Grenze mikroskopischer Wahrnehmbarkeit liegen. Wir ziehen hieraus den allgemeinen Schluss, dass sich die Vollkommenheit oder Unvollkomınenheit der Adläsion mikroskopisch nicht erkennen lässt.

Da die Einlagerung von Wasser zwischen die Molecüle einer Substanz den gegenseitigen Abstand derselben vergrössert und die Wassertheilchen unter sich nur mit einer Kraft cohäriren, welche jedenfalls viel geringer ist als bei festen Körpern, so ist einleuchtend, 
dass die Cohäsion mit der Zunahme des Wassergehaltes abnimmt. Gallertartige Membranen zeigen in Folge dessen nur eine geringe Cohäsion, während z. B. die wasserarmen des Eichenholzes beinahe diejenige des geschmiedeten Kupfers erreichen.

\section{Qnellumg und Iiosmose.}

\section{a) Arten der Quellung.}

396 Die durch Einlagerung von Flüssigkeiten bedingte Tolumenzunahme einer organisirten Substanz wird bekanntlich als Quellung bezeichnet. Dieselbe kann mit oder ohne Veränderung der Molecularconstitution erfolgen. Im letzteren Falle zieht sich der Körper, wenn ihm das Wasser auf irgend eine Weise durch Erwärmen, concentrirtes Glycerin etc.) entzogen wird, wieder auf sein früheres Tolumen im trockenen Zustande zusammen, wie man diess an Membranen und Stärkekörnern, welche von Wasser, sehr schwachen Alkalien oder Säuren durchdrungen sind, beim Auswaschen und Trocknen beobachtet. - Da es eine allgemeine Regel ist, dass angesäuertes oder schwach alkalisches Wasser in etwas grösserer Menge eingelagert wird, als reines, so verhalten sich in Wasser liegende Substanzen gegen verdünnte Lösungen, wie trockene gegen Wasser; sie quellen auf Zusatz von schwachen Säuren oder Alkalien stärker auf und ziehen sich beim Auswaschen mit reinem Wasser wieder zusammen. Bei günstigen Objecten wie z. B. den Stärkekörnern tropischer Euphorbien ist diese Erscheinung sogar sehr augenfällig.

Im Gegensatz zu solchen Quellungen stehen diejenigen, welche gewöhnlich stärkere Säuren und Alkalien, sowie Kupferoxydammoniak hervorrufen. Die aufgequollene Substanz verliert nämlich die Fähigkeit, sich nach der Entfernung des Quellungsmittels durch Auswaschen wieder auf ihr früheres Volumen zusammenzuziehen; sie erfährt demnach Veränderungen in der Molecularconstitution, die wahrscheinlich darauf beruhen, dass die Molecüle sich in kleinere theilen.

Die Quellungserscheinungen sind bei den Stärkekörnerı und Proteinkrystalloiden genauer bekannt.*) Von den Membranen weiss man wenigstens so viel, dass sie eine Reihe von Abstufungen bilden, die sich einerseits an die verschiedenen Stärkearten anschliessen und

*) Nägeli, die Stärkekörner p. 6 - u. ff., 144 u. ff.; Sitzungsberichte der k. b. Akad. d. Wiss. in München 1562. 
andererseits im cuticularisirten $\mathrm{Zustande}$ weit davon abstehen. Die $\mathrm{Cu}$ ticula selbst scheint nur in sehr geringem Grade quellungsfähig zu sein.

Die Einlagerung von Lösungen zwischen die Massenbestandtheile organisirter Substanzen ist übrigens stets mit einer Concentrationsveränderung dieser Lösungen verbunden, $d$. h. die letzteren dringen in einem stärker verdünnten oder auch in concentrirterem Zustande in die Substanz ein.- Thierische Membranen (Herzbeutel, Harnblase) nehmen z. B. von einer Kochsalzlösung eine Flüssigkeit auf, deren Procentgehalt nur $0, \mathrm{~S} 2$ bis 0,84 der Lösung beträgt*). Umgekehrt nehmen Stärkekörner in verdünnter Kalilösung eine concentrirtere Flüssigkeit auf; denn setzt man nach und nach mehr Körner zu, so werden die Quellungserscheinungen schwächer und zuletzt unmerklich. Die umspülende Flüssigkeit muss also verdünnter, folglich die eingelagerte concentrirter geworden sein.

b) Absorption ron Gasen in quellungsfähigen Körpern.

Die V'erwandtschaft der festen Körper zu den Flüssigkeiten, 397 von denen sie durchdrungen werden, spricht sich auch in den hygroskopischen Eigenschaften derselben aus, d. h. in dem Vermögen, die Dämpfe jener Flüssigkeiten in sich niederzuschlagen. Die Bewegungen, welche durch die $\mathrm{Zu}$ - und Abnahme der aufgenommenen $\mathrm{W}$ assermenge verursacht werden, sind bekanntlich bei manchen regetabilischen und animalischen Gebilden Schleudern der Equisetensporen, Fruchtstiele der Moose etc.) so auffallend, dass man dieselben als Hygroskope gebrauchen kann.

Eine ähnliche Verwandtschaft besteht auch zwischen den festen Körpern und Gasen, und es ist bekannt, dass sich dieselbe bei manchen unorganischen Substanzen, wie z. B. Kohle, Platinschwamm etc., in sehr augenfälligem Grade kundgibt. An organisirten Gebilden wurde eine Verdichtung von Gasen zwar nicht direct beobachtet; allein die Luftblasen, welche während der Einwirkung ron conc. Schwefelsäure oder Aetzkalilösung in Stärkekörnern auftreten, machen die Annahme einer solchen sehr wahrșcheinlich.

c) Menge und Vertheilung der Imbibitionsflüssigkeit.

Der Gehalt eines Körpers an Imbibitionsflüssigkeit ergibt sich $\mathbf{3 8 8}$ unmittelbar aus der Volumenzunahme desselben während der Quellung oder der Volumenabnahme während des Austrocknens. Wenn

*) Ludwig, Lehrb. d. Physiol, des Menschen p. 61. 
z. B. eine ausgetrocknete Kugel in einer Lösung auf das Doppelte ihres ursprünglichen Durchmessers aufquillt und folglich einen smal grössern Raum einnimmt, so werden \%/s dieses Raumes von der eingelagerten Flüssigkeit ausgefüllt.

Die Vertheilung der Quellungsflüssigkeit im Innern der Substanz richtet sich nothwendig nach der Molecularconstitution. Das Verhältniss der Substanz zur Lösung und dem entsprechend auch die Ausdehnung der Körper während der Quellung, sowie die Contraction beim Austrocknen, ist daher im Allgemeinen in den verschiedenen Richtungen ungleich. Man würde jedoch sehr irren, wenn man aus den beobachteten Dimensionsveränderungen ohne Weiteres die Differenzen im Flüssigkeitsgehalt ableiten wollte, da eine solche Ableitung nur unter Voraussetzungen zulässig ist, welche in der Wirklichkeit selten zutreffen. Ein homogenes parallelepipedisches Membranstück wird allerdings beim Austrocknen an Länge, Breite und Dicke in demselben Verhältniss einbüssen, in welchem die Flüssigkeitstheilchen zwischen die Substanztheilchen eingelagert sind, weil hier der Annäherung der Molecüle in jeder beliebigen Richtung keinerlei Hindernisse im Wege stehen. Sobald aber ein solches Membranstück aus abwechselnd dichten und weichen Schichten besteht, wie es gewöhnlich der Fall ist, beschränkt sich die erwähnte Proportionalität auf die radiale Richtung, weil in tangentialer die freie Aeusserung der Molecularkräfte wasserreicher Schichten durch die Adhäsion an dichten gehemmt wird. Sind überdem die Schichten gestreift, d. h. aus alternirenden dichten und weichen Streifen zusammengesetzt, so giebt uns die Dimensionsverminderung in keiner Richtung einen genauen Maassstab für die Wassereinlagerung.

Sind die Molecularschichten concentrisch geordnet, so ruft der Gegensatz zwischen radialer und tangentialer Richtung Spannungen hervor, die sich allmählich bis zur Bildung von Rissen steigern, wie man diess an ausgetrockneten Stärkekörnern, die man wieder in Wasser gelegt hat, sowie auch bei der Quellung derselben in verdünnter Kalilösung wahrnimmt. Die Richtung der Risse, diese mögen nun durch Austrocknen oder durch Quellung entstanden sein, gibt alsdann nicht selten einigen Aufschluss über die Vertheilung der Imbibitionsflüssigkeit. Diese Richtung hängt übrigens selbstverständlich nicht bloss von den Spannungen, sondern auch von den Cohäsionsverhältnissen und unter Umständen wohl auch von den Punkten ab, wo die Risse zuerst auftreten. In den Stärkekörnern scheint z. B. der radiale Verlauf derselben zum Theil dadurch bedingt zu sein, dass die Bildung in 
Kerue beginnt und nach aussen hin fortschreitet. Ohne diese Voraussetzung wäre es nämlich kaum erklärlich, warum nicht zuweilen zwei dichtere Schichten, die durch eine sehr weiche von einander getrennt sind, sich beim Austrocknen des Korns von einander ablösen und eine Spalte zwischen sich lassen.

Aus vorstehenden Andeutungen geht soviel hervor, dass die Er- 389 mittelung der Wasservertheilung aus den Erscheinungen des Austrocknens bei kugeligen und cylindrischen Gebilden keine so ganz leichte Aufgabe ist. Die an den Stärkekörnern beobachteten Thatsachen *) führten zu dem Schlusse, dass der Wassergehalt in tangentialer Richtung grösser sei als in radialer, vorausgesetzt, dass die Cohäsion der Substanztheilchen in den beiden Richtungen gleich sei. Rücksichtlich der näheren Begründung dieser Ansicht verweisen wir auf die am angeführten Orte mitgetheilten Erörterungen.

Achnliche Schwierigkeiten bieten zuweilen auch die Erscheinungen des Aufquellens in Alkalien und Säuren, namentlich dann, wemn sich die verschiedenen Theile des Objects ungleich verhalten. Dass cylindrische Bastzellen z. B. der Chinarinde), deren peripherische Schichten, im Querschnitt beobachtet, beim Aufquellen in Schwefelsänre bersten, in radialer Richtung mehr Säure einlagern, als in tangentialer, ist Jedermann einleuchtend. Wie sich dagegen ein Querschnitt durch einen Hohlcylinder verhält, dessen innere Schichten sich beim Aufquellen falten oder radial zerreissen, ist schon eine complicirtere Aufgabe. Eine Faltung wird beispielsweise eintreten, wenn die Ausdehnung der ganzen Wand in radialer Richtung stärker ist, als in tangentialer, so dass in Folge dessen das Lumen kleiner wird, und wenn überdiess eine innere dichte Lamelle der Membran nach aussen an weiche Substanz grenzt, welche der durch die Faltung bedingten Verschiebung ihrer Molecüle geringen Widerstand leistet. Diese letztere Bedingung ist wesentlich; denn wäre die Wandung homogen, so müsste bei übrigens gleichen Quellungsverhältnissen ein Zerreissen der peripherischen Schichten, also Bildung von radialen Rissen am Umfange erfolgen. Umgekehrt deuten radiale Risse, welche auf der Innenfläche eines Hohlcylinderquerschnittes auftreten, auf eine vorwiegend tangentiale Ausdehnung der Wandung. - Dasselbe Raisomnement gilt mutatis mutandis auch für Hohlkugeln und kann mit einigen Einschränkungen auch auf Kugeln ausgedehnt

+) Nägeli, die Stärkekörner S. 56 u. ff. 
werden. Wenn daher in einer Kugel oder Hohlkugel radiale Risse im mittleren Theile auftreten (Fig. 202, welche sich nach aussen und

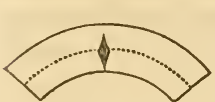

Fig. 202. innen verlieren, so folgt daraus, dass in den äusseren Schichten die tangentiale, in den inneren die radiale Ausdehnung vorwiegt.

Die Ausdehnung in tangentialer Richtung kann übrigens bei Körpern, welche eine Längsaxe besitzen, in sehr verschiedener Weise stattfinden, da das Quellungsvermögen im Allgemeinen den Leitstrahlen einer Ellipse entspricht, deren Axen bald mit der Quer- und Längsrichtung zusammenfallen, bald schief gegen dieselben gestellt sind. Das letztere ist der Fall, wenn die Molecularreihen der concentrischen Schichten rechts und links gewundene, beliebig geneigte Spiralen bilden, wie es z. B. bei Bast, und Holzzellen häufig vorkommt; das erstere, wenn diese Reihen längs und quer verlaufen und daher stets rechtwinklig gegen einander gestellt sind. Ein kreisförmiges Flächenelement nimmt also unter allen Umständen eine elliptische Form an, wenn das Quellungsvermögen in verschiedenen Richtungen ungleich ist; aber die Axen der Ellipse sind nur bei rechtwinkligen Molecularreihen diesen letzteren parallel, bei schiefwinkligen wird der spitze Winkel rom rechten der Axen eingeschlossen (Fig. 203).
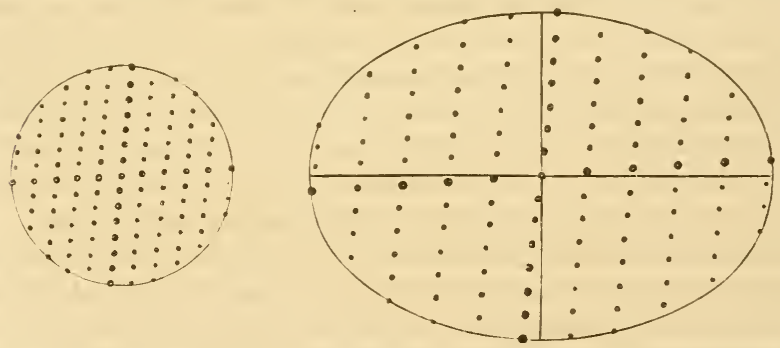

Fig. 203.

\section{0}

Aus dem Angeführten ergiebt sich ferner, dass ein kugelförmiges Element einer quellungsfähigen Substanz durch ungleichmässige Einlagerung der Quellungsflüssigkeit zum Ellipsoid wird, dessen Axenlage von der Richtung und Ausdehnung der Molecularreihen abhängig ist. Diese Lage für gewisse Voraussetzungen zu bestimmen, ist Sache einer mathematischen Betrachtung, auf die wir hier nicht näher eingehen können. Wir beschränken uns auf die Hervor- 
hebung zweier Fälle, welche speciell beim Aufquellen cylindrischer und hohlcylindrischer Zellen Anwendung finden. Der erste bezieht sich auf eine einzelne Membranschicht, der zweite auf Complexe von concentrischen Schichten.

1) Ein unendlich dünner Hohlcylinder, dessen Molecüle nach zwei Richtungen Reihen bilden, welche beliebig gegen die Längsaxe geneigt sind und folglich im Allgemeinen zugleich rechts- und linksläufige Spiralen bilden, ist in seinem Verhalten beim Aufquellen durch das in der Richtung der einen und andern Spirale bekannte Quellungsvermögen noch nicht bestimmt. Er kann sich verkürzen oder verlängern, an Umfang zu- oder abnehmen, je nach dem Einlagerungsverhältniss in einer dritten Richtung, welche die beiden genannten unter beliebigem Winkel schneidet. Man hat es überhaupt, wenn man die Formveränderungen, welche die Quellung bedingt, durch Construction bestimmen will, immer mit den drei Seiten eines Dreiecks zu thun, welche den gegenseitigen Abständen dreier Molccüle, z. B. der unmittelbar neben einander liegenden, entsprechen. Die Construction ist nur ausführbar, wenn das Verhältniss der Seitenlängen vor und nach der Quellung bekannt ist oder sich aus bekannten Daten ableiten lässt.

2) Denkt man sich mehrere solcher Hohlcylinder in einander geschachtelt, so ist an und für sich klar, dass mit dem Umfang auch die Abstände derselben in radialer Richtung sich proportional vergrössern müssen. Wenn daher bei einer cylindrischen Zelle das Quellungsvermögen der Membran in radialer Richtung grösscr oder kleiner ist als in der Richtung des Umfanges, so treten Spannungen ein, welche das Verhalten der einzelnen concentrischen Schichten modificiren. Ein Vorherrschen der Dickenzunahme bewirkt z. B. bei Bastzellen eine sehr starke Verkürzung der peripherischen Schichten, wobei die durch die Streifung angedeutete steilere Spirale der Molecularreihen niedergedrückt wird.

In der Praxis lassen sich die unter 1) erwähnten Beziehungen 391 in folgender Weise ermitteln. Der Quellungscoefficient der spiralig verlaufenden Molecularreihen ergibt sich, insofern dieselben durch die Streifung der Membran deutlich bezeichnet sind, aus der Längenzunahme des Hohlcylinders und aus dem Neigungswinkel der Streifen vor und nach der Quellung. Ist die Länge des Cylinders im nicht gequollenen Zustande $L$, im gequollenen $L^{\prime}$, und sind die entsprechenden Neigungen eines bestimmten Streifensystems zur Längsaxe 
$\alpha$ und $\alpha^{\prime}$, so ist die Länge der damit parallelen Molecularreihen vor der Quellung durch $\frac{1}{\cos \alpha} L$ und nach der Quellung durch $\frac{1}{\cos \alpha} L^{\prime}$ gegeben.

Ist die Neigung der Molecularreihen bloss im gequollenen $\mathrm{Zu}$ stande für die beiden sich kreuzenden Spiralsysteme, im nicht gcquollenen dagegen bloss für das eine derselben durch Streifung angedeutet, oder umgekehrt, so kann dessenungeachtet auch die Neigung der im einen oder andern Zustand unsichtbaren Streifungen und damit auch das Quellungsvermögen der entsprechenden Molecularreihen durch Rechnung bestimmt werden. Bezeichnet man nämlich mit $C$ den Umfang des Hohlcylinders im nicht gequollenen $\mathrm{Zu}$ stande, mit $L$ dessen Länge und mit $\alpha$ und $\beta$ die Neigungen der beiden Streifensysteme zur längsaxe; ferner mit $C^{\prime} L^{\prime} \alpha^{\prime}$ und $\beta^{\prime}$ die entsprcchenden Grössen im aufgequollenen 'Zustande, so hat mandie Relation

$$
C: C^{\prime}=L(\operatorname{tang} \alpha+\operatorname{tang} \beta): L^{\prime}\left(\operatorname{tang} \alpha^{\prime}+\operatorname{tang} \beta^{\prime}\right),
$$

nach welcher sowohl $\alpha$ oder $\beta$, als überhaupt jede belicbige der 8 Grössen bestimmt werden kann, wenn die 7 andern bekannt sind.

$$
\text { d) Quellung absterbender Membranen. }
$$

392 Mit den Quellungserscheinungen lassen sich gewissermaassen auch die Verschiebungen der Molecüle vergleichen, welche das Ab-

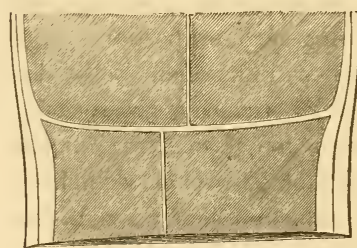

Fig. 204 . sterben der Membranen, resp. der Zellen, verursacht. Durchschnittene Zellen von Schizomeris ziehen sich z. B. in Folge der Verletzung etwas zusammen und verdicken dabei in sehr augenfälligem Grade ihre Wandung (Fig. 204).*) Man könnte versucht sein, diese Erscheinung einer rein mechanischen Ursache, nämlich dem Aufhören des hydrostatischen Druckes der Zellflüssigkeit auf die Wandungen zuzuschreiben; zumal die Thatsache, dass auf Zusatz von Glycerin, Zuckerlösung etc., wodurch dieser Druck aufgehoben oder umgekehrt wird, die nämliche Verdickung der Membranen erfolgt, ganz entschieden darauf hinzudeuten scheint. Andere Gründe machen es aber wahrscheinlicher, dass die Molecularkräfte selbst beim Absterben eine Vcränderung erfahren, in Folge welcher die Molecüle sich etwas verschieben und der Wassergehalt der Membranen in radialer Richtung beträchtlich zunimmt.

*) Vgl. Näg eli, Pflanzenphỵsiol. Unters. 1. pag. 32. 


\section{e) Schichtung und Streifung.}

Die Schichtung und Streifung der Membranen, sowie $\mathbf{3 9 3}$ überhaupt der organisirten Substanz, kann natürlich nur eine Folge abwechselnd stärkeren und geringeren Wassergehaltes sein. Wir haben bereits oben darauf hingewiesen, dass die Molecüle in wasserreichen Partieen kleiner sein müssen, als in dichteren, weil bei gleicher Dicke der Wasserhülle nur dadurch der grössere Wassergehalt erklärlich wird. Hier wollen wir nur noch bemerken, dass die Streifung der Membran nach zwei verschiedenen Richtungen sich bei vielen Zellen direct nachweisen lässt und daher wahrscheinlich auch bei den übrigen vorhanden ist. Die Kreuzungsstellen der beiden dichten Streifensysteme bilden stets, wie man in günstigen Fällen deutlich

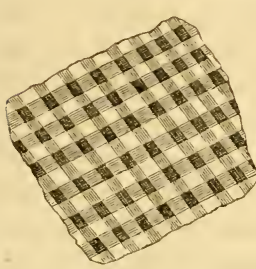

Fig. 205. sieht, die dichtesten Partieen der Membran. Letztere wird demnach durch die Grenzlinien der Streifen in Parallelogramme (räumlich gedacht in Parallelepipede) von vierfach verschiedener Dichtigkeit zerlegt, wie diess in nebenstehender Fig. 205 angedeutet ist. - Die Vermehrung der Streifen während des Wachsthums geschieht in gleicher Weise, wie die der Schichten, durch Spaltung der dichteren (nicht der weicheren) in zwei Lamellen, also durch Bildung wasserreicherer Substanz in den dichten Parallelepipeden.

\section{f) Diosmose.}

Da die Flüssigkeit, welche den wässerigen Zellinhalt bildet, ver- 394 schiedene Substanzen in Lösung enthält, so ruft das Eintauchen der Zellen in Wasser oder in andere Lösungen sogleich diosmotische Strömungen hervor, welche die Verschiedenheiten der Flüssigkeiten auszugleichen streben. Hiebei werden die entgegengesetzten Strömungen im Allgemeinen ungleich sein, so dass mit Rücksicht auf die Zelle bald die Endosmose, bald die Exosmose vorwiegt, die Menge der Zellflüssigkeit also bald vermehrt und bald vermindert wird. Eine Vermehrung findet beispielsweise statt wenn dieZelle in reines Wasser, eine Verminderung wenn sie in Zuckerlösung, Glycerin, Alkohol, Säuren, Alkalien, überhaupt in wasserentziehende Medien gebracht wird.

Die physikalische Ursache dieser Ungleichheit entgegengesetzter 395 diosmotischer Ströme liegt bekanntlich in der ungleichen Verwandt- 
schaft der Membranen zu den im Austausch begriffenen Substanzen. Die nächste Folge davon ist, dass die während der Quellung eindringende Imbibitionsflüssigkeit eine andere Zusammensetzung annimmt, als die umspülende Lösung, woraus sie geschöpft wurde, oder als die beiden heterogenen Flüssigkeiten, welche durch die Membranen diffundiren. Befindet sich z. B. auf der einen Seite einer organisirten Membran eine concentrirte Lösung von Kochsalz, auf der andern reines Wasser, so umgibt sich jedes Molecül mit einer Flüssigkeitshülle, die zunächst seiner Oberfläche nur aus Wasser besteht, da hier die volwiegende Anziehung zwischen diesem und der Substanz die Einlagerung von Salztheilchen nicht gestattet. Diese Einlagerung beginnt erst in einiger Entfernung von der Oberfläche und nimmt sodann bis gegen die Grenzflächen der sich berührenden Flüssigkeitshüllen, wo der Salzgehalt sein Maximum erreicht, quantitativ zu. Die Molecularinterstitien, welche der Salzlösung am nächsten liegen, führen also in ihren mittleren Theilen die nahezu unveränderte Lösung, in der Nähe der Wandungen dagegen reines Wasser; nach der anderen Seite hin nimmt natürlich der Salzgehalt allmählich ab. Diese mittleren Theile verhalten sich hienach in ihrer Gesammtheit wie ein System von Röhren, welche auf der einen Seite in Wasser, auf der andern in die nämliche Salzlösung münden würden; sie befördern daher ebensoviel Salz nach der einen als Wasser nach der andern Seite hinüber. Die salzarme Wandschicht erfährt dagegen bloss eine einseitige oder doch einseitig vorwiegende Anziehung nach der Salzlösung hin; sie wird daher in continuirlicher Strömung dieser Lösung zufliessen und sich immer wieder aus dem anstossenden Wasservorrathe ergänzen.

$\mathrm{Zu}$ der Wassermenge, welche durch den mittleren Theil der Molecularinterstitien strömt und welche der nach der entgegengesetzten Seite wandernden Salzmenge gleich ist, kommt also noch eine zweite durch die einseitige peripherische Strömung hinzu, so dass im Ganzen nothwendig mehr Wasser nach der einen, als Salz nach der anderen Seite hin befördert wird.

Es lässt sich auch voraussehen, dass das Verhältniss der beiden Ströme zu einander sowohl von der Natur der Membran als auch von der Concentration der Lösung und der Natur des gelösten Stoffes abhängig sein muss; dass es z. B. für Kali ein anderes sein wird als für Kochsalz, und für Collodiumhäutchen ein anderes als für vegetabilische Zellmembranen. Denn mit der Natur der Körper wechseln selbstrerständlich auch die wechselseitigen Anziehungen, welche hier 
die treibenden und die Widerstand leistenden Kräfte sind, und mit der Concentration der Salzlösung ändert sich auch die Strömungsgeschwindigkeit für Wasser und Salz. Ebenso ist ersichtlich, dass der salzlose Theil der Flüssigkeitshüllen um so mehr ins Gewicht fallen muss, je kleiner die Interstitien, weil überhaupt in engen Räuınen verhältnissmässig mehr Theile der Wand näher liegen, als in weiten. Das endosmotische Aequivalent wird also unter übrigens gleichen Umständen in Membranen mit gröblichen Räumen (Pergamentpapier, Harnblase etc.) stets kleiner ausfallen als in solchen von homogener Beschaffenheit, und in diesen letzteren um so kleiner, je dichter (wasserärmer) die Substanz. *)

Es wäre ein Leichtes, diese theoretischen Betrachtungen auf Grundlage der atomistischen Anschauung noch weiter auszuspinnen und zugleich darzulegen, dass die auf diesem Wege gewonnenen Schlüsse mit den bis jetzt durch Versuche erzielten Resultaten übereinstimmen. Für unsere Zwecke mag indess das Vorstehende genügen. Es sollte vor Allem gezeigt werden, dass die Brücke'sche Theorie der Diffusionserscheinungen sich nicht bloss auf gröbliche Räume, wie sie in den thierischen Bindegeweben (Herzbeutel, Harnblase) vorkommen, sondern auch auf die Molecularinterstitien der Membranen anwenden lässt.- Das Uebrige findet man in den Lehrbüchern der Physik und der Physiologie, auf welche wir hiemit verweisen, mit genügender Ausführlichkeit dargelegt. ${ }^{*}$ )

Um die Wirkungen zu verstehen, welche die durch Diosmose 396 bedingte $\mathrm{Zu}$ - oder Abnahme des Inhaltes in den Zellen hervorruft, ist es nöthig sich zu vergegenwärtigen, dass die umhüllenden Häute derselben, der Primordialschlauch und die Zellmembran, sich wesentlich ungleich verhalten. Der Primordialschlauch leistet dem Druck, welcher von innen oder aussen auf ihn wirkt, nur einen äusserst geringen Widerstand; wäre er isolirt, so müsste er sich vermöge seiner ausserordentlichen Dehnbarkeit beinahe unbegrenzt ausdehnen oder zusammenziehen.

*) Mit der Abnahme des Wassergehaltes werden die Molecüle grösser und mit der Grössenzunahme der Molecüle werden die Abstände ihrer Oberflächen kleiner, die Wasserhüllen also dünner. Siehe Nägeli, Stärkekörner, pag. 333, $345 \mathrm{ff}$.

**) Man vergleiche namentlich Ludwig, Lehrb. d. Physiol. des Menschen, 1. u. 2. Abschnitt; Fick, Medicinische Physik pag. $40 \mathrm{ff}$., sowie die dort angeführten Originalarbeiten. 
Die Membran dagegen ist in der Regel relativ starr; sie wird durch Vermehrung des Zellinhaltes gespannt, ohne sich merklich auszudehnen, und platzt, wenn der hydrostatische Druck zu stark wird. Ebenso widersteht sie einem von aussen wirkenden Drucke ohne merkliche Formveränderungen; selbst dünne Membranen contrahiren sich nicht*), sondern werden nur eingeknickt, wie eine Blechbüchse, aus welcher man die Luft auspumpt. Aus diesen Gegensatze erklärt sich das Ablösen des Schlauches von der Membran bei vorwiegender Exosmose und das Freiwerden desselben nach dem Zerreissen der Membran bei vorwiegender Endosmose. Der letztere Vorgang ist indess noch an dic weitere Bedingung geknüpft, dass der Schlauch sich leicht von der Membran abhebe; wo diess nicht der Fall, findet an der gerissenen Stelle der Membran auch ein Platzen des Schlauches statt.

Eine membranlose Zelle (Schwärmspore $u$. dgl.) vergrössert sich in Folge der Endosmose so lange, bis der Widerstand des Primordialschlauches (und der sich bildenden Zellmembran) der endosmotischen Kraft das Gleichgewicht hält. Von diesem Zeitpunkte an erfolgt der Austausch der Flüssigkeiten ohne Volumenzunahme, d. h. die beiden entgegengesetzten Ströme sind gleich stark.

Lebende und todte Zellen verhalten sich diosmotisch nicht gleich. Der lebende Plasmaschlauch ist bekanntlich für gelöste Farbstoffe (Erythrophyll, Anthocyan) undurchdringbar, er hält dieselben in den Zellen zurück, in welchen sie sich bilden; der todte dagegen lässt sie ungehindert austreten. Eine bestimmte Ursache für diese Erscheinung lässt sich nicht angeben. Nur im Allgemeinen ist es gewiss, dass beim Absterben des Primordialschlauches Veränderungen in den wirksamen Molecularkräften eintreten, wie diess früher auch für die absterbende Membran angenommen wurde.

*) Eine schwache Contraction muss natürlich inmer angenommen werden; sie ist jedoch bei den meisten mikroskopischen Objecten kaum messbar und darf daher bei Betrachtungen, wie die obige, geradezu vernachlässigt werden. 


\section{III.}

\section{Licht.}

\section{Bestimmung des Brechungscoefficienten.}

Nachdem die Erscheinungen der Lichtbrechung in mikroskopi- 397 schen Objecten bereits in der Theorie der mikroskopischen Wahrnehmung besprochen worden, bleibt uns hier noch die praktische Verwerthung derselben zur Bestimmung der Brechungscoefficienten zu erwähnen übrig. Den Polarisationserscheinungen wurde ihrer hervorragenden Wichtigkeit wegen ein besonderer Abschnitt gewirlmet.

Schon Brewster benutzte das Mikroskop zur Bestimmung des Brechungscoefficienten kleiner Flüssigkeitsmengen, indem er die ringförmige, oberseits vorstehende Fassung einer gleichscitigen biconvexen Linse, welche als Objectiv diente, mit der betreffenden Flüssigkeit füllte und dann cin gewöhnliches Deckgläschen darüber legte. Dadurch wurde die Linse in eine planconvexe Doppellinse ungewandelt, folglich ihre Brennweite vergrössert. War das Mikroskop vorher auf ein beliebiges Object scharf eingestellt, so musste es jetzt etwas gehoben werden, und zwar ist die Verschiebungsgrösse offenbar abhängig rom Brechungscoefficienten der Flüssigkeit. Ist der Abstand des reellen Bildes vom Objectiv $I^{\prime}$ und die entsprechende Objectdistanz für die biconvexe Linse vor und nach der Terbindung mit der zu untersuchenden Flüssigkeit beziehlich $p$ und $p+d$; bezeichnet man ferner den Brechungscoefficienten der Linse mit $n$, den (ler Flüssigkeit mit $n^{*}$ und den gemeinsamen Krümmungsradius mit $r$, so ist die Brennweite der Doppellinse gegeben durch $\frac{2(n-1)}{r}-$ $\frac{n^{*}-1}{r}$. Es bestehen somit nach Früherem die Gleichungen

$$
\begin{aligned}
\frac{1}{p} & =\frac{2(n-1)}{r}-\frac{1}{P} \\
\frac{1}{p+d} & =\frac{2(n-1)}{r}-\frac{n^{*}-1}{r}-\frac{1}{P}=\frac{1}{p}-\frac{n^{*}-1}{r}
\end{aligned}
$$

Hieraus erhält man durch eine leicht zu übersehende Umsetzung

$$
n^{*}=1+\frac{r d}{p(p+d)} \text {. }
$$

Diese Formel ist jedoch nur unter der Voraussetzung richtig, dass die Dicke der Linsen gegen die Objectabstände vernachlässigt werden darf. Thre Anwendung ist überdiess mit dem Nachtheil ver- 
bunden, dass die Bestimmung des Krüımungsradius bei kleinen Linsen eine schwierige Aufgabe ist. Die genaueste Lösung wird immer noch dadurch erzielt, dass man die Linse etwas geneigt auf den $\mathrm{Ob}$ jectträger bringt und das von derselben erzeugte Spiegelbild eines Gegenstandes von bekannter Grösse und Entfernung mikrometrisch misst.

Moser und ebenso Bertin gaben der zu untersuchenden Substanz die Form einer Lamelle mit parallelen Endflächen und bestimmten sodann die Tubusverschiebung, welche nothwendig ist, um ein Object vor und nach der Bedeckung mit einer solchen Lamelle deutlich zu sehen. Man sieht leicht ein, dass die Beziehung der Verschiebungsgrösse $x$ zum Brechungscoefficienten $n$ der Substanz durch die nämliche Formel gegeben ist, welche früher (pag. 56) für die Wirkung der Deckgläschen aufgestellt wurde, nämlich

$$
x=D\left(1-\frac{\operatorname{tang} \alpha^{\prime}}{\operatorname{tang} \alpha}\right)
$$

wobei $\alpha$ und $\alpha^{\prime}$ die Einfalls- und Brechungswinkel der vom Objecte ausgehenden Strahlen bezeichnen. Vergleicht man mit dieser Formel, die strenge richtig ist, die Moser'sche

$$
x=D\left(1-\frac{1}{n}\right),
$$

so ist klar, dass diese letztere nur so lange annähernd richtig sein kann, als die Tangenten der Einfalls- und Brechungswinkel sich nahezu wie die Sinus, d. h. wie $1: n$ verhalten, was bekanntlich nur bei sehr kleinen Winkeln der Fall ist. Die Moser'sche Formel ist daher nur für Objective mit sehr kleinen Oeffnungswinkeln brauchbar. *)

Bertin verfuhr nach einem andern Princip. Er bestimmte bei feststehendem Objectiv und ausziehbarem Ocular die Vergrösserungen $G, \gamma^{\prime}, g$ eines Objectivnikrometers oder sonst eines geeigneten $\mathrm{Ob}$ jectes von bekannter Grösse, wenn dieses auf dem Tisch des Mikroskops nacheinander a $\mathrm{f}$ die zu untersuchende Lamelle, dann unter dieselbe gelegt und endlich nach Wegnahme der Lamelle beobachtet wird. Der Brechungscoefficient soll alsdann durch die Relation gegeben sein

*) Setzt man z. B. $a$ in obiger Formel $=18^{\circ}, n=1,5$ und berechnet nun für die gewöhnliche Dicke eines Deckgläschens die Hebungsgrösse $x$, so erhält man durch Substitution der letzteren in die zweite Formel $n=1,54$, also um 0,04 zu viel. 


$$
n=\frac{\gamma}{\mathrm{g}} \cdot \frac{G-g}{G-\gamma} .
$$

Die Richtigkeit dieser Formel ist indess ebenfalls, wie aus der Ableitung zu ersehen ist, an die Bedingung geknüpft, dass $\frac{\operatorname{tang} \alpha^{\prime}}{\operatorname{tang} \alpha^{\prime}}=\frac{1}{n}$ (s. die Ableitung derselben Ann. de Chim. et Phys. $3^{\text {ième }}$ Serie 1849 T. XXVI. p. 28s).

Bei sehr dicken Lamellen empfiehlt Bertin die Vergleichung mit anderen, deren Brechungscoefficient $n^{\prime}$ bekannt ist, wobei folgende Formcl in Anwendung kommt, in welcher $e$ und $e^{\prime}$ die Dicke der beiden Lamellen bedeutet

$$
\frac{e\left(1-\frac{1}{n}\right)}{e^{\prime}\left(1-\frac{1}{n^{\prime}}\right)}=\frac{\frac{1}{g}}{\frac{1}{g^{\prime}}}-\frac{\frac{1}{\gamma}}{\frac{1}{\gamma^{\prime}}} .
$$

Die mitgetheilten Controlmessungen dürfen in Ganzen befriedigend genannt werden, da die erhaltenen Werthe höchstens um 0,02 von den wirklichen abweichen und oft genau übereinstimmen. Dic angewandten Vergrösserungen betrugen beispielsweise

$\begin{array}{ccc}G & \gamma & g \\ 106,7 & 28,6 & 21,1 \\ 330,0 & 65,0 & 46,0\end{array}$

$\mathrm{Zu}$ diesen eben besprochenen Methoden fügt Harting eine $\mathbf{3 9 9}$ dritte, welche zwar nur für Flüssigkeiten passt, aber sehr genaue Resultate liefern soll. Sie stützt sich auf die früher besprochene Eigenschaft der Luftblasen, von Gegenständen, welche in den einfallenden Lichtkegel eingetaucht sind, virtuelle Bilder zu entwerfen, deren Lage und Grösse vom Brechungsvermögen des umgebenden Mediums abhängt. Die Lage ist für grössere Entfernungen des Gegenstandes, wie man leicht einsieht, dureh die Brennweite $f$ bestimmt, da das Bildchen sehr annähernd in die Focalebene fällt; die Grösse lässt sich aus der bekannten des Gegenstandes und dem gegebenen Verhältniss der Vereinigungsweiten leicht berechnen. Nach Früherem (pag. 194) ist die Brennweite der Luftblase $f=-\frac{r}{(2 n-1)}$, wobei $r$ den Radius und $n$ den Brechungscoefficienten der Flüssigkeit bezeichnet. Hieraus ergiebt sich

$$
n=\frac{2 f-r}{2 f}
$$


oder wenn das Grössenverhältniss zwischen Object und Bild durch $\frac{M}{m}$ und der Objectabstand durch $p$ ausgedrückt wird

$$
n=1+\frac{M}{m} \cdot \frac{r}{2 p} \text { (vgl. pag. 199). }
$$

Hiebei darf aber nicht vergessen werden, dass diese Formeln nur für Centralstrahlen gelten und folglich in der Praxis nicht unmittelbar anwendbar sind, weil das Mikroskop sogar Randstrahlen von $30^{\circ}$ Neigung und darüber zum Auge leitet. Es wurde schon oben gezeigt, dass hiedurch die Brennweite einer Luftblase in Wasser ungefähr um 0,2 des Radius verkürzt wird. Dazu kommt noch (insofern man die Brennweite durch successive Einstellung auf die Mitte der Luftblase und auf deren Bildchen bestimmt) eine weitere Verkürzung, welche vom Uebergang des Lichtes aus Wasser in Luft herrührt und welche nur dadurch beseitigt werden kann, dass man den Raum zwischen Objectiv und Deckgläschen ebenfalls mit Wasser oder mit der zu untersuchenden Flüssigkeit ausfüllt (vgl. pag. 235 u. f.).

Eine analoge Wirkung ist zu berücksichtigen, wenn man das Grössenverhältniss zwischen Object und Bild durch Beobachtung bestimmt. Die Strahlen, welche von den Randpunkten des Objects ausgehen, werden beim Uebergang in die Beobachtungsflüssigkeit (die als Träger dienende Glasplatte kann vernachlässigt werden) so gebrochen, dass sie rückwärts verlängert innerhalb jener Randpunkte fallen. Das Object erscheint also, von der Luftblase aus gesehen, kleiner als es wirklich ist, und das von ihr entworfene Bildchen entspricht diesem verkleinerten, nicht dem wirklichen Object. Auch dieser Uebelstand kann nur gehoben werden, indem man den Raum zwischen Object und Glasplatte mit der nämlichen Flüssigkeit aus. füllt, was natürlich schon grössere Quantitäten der letzteren voraussetzen würde.

Harting erwähnt nun auffallender Weise von all' diesen Fehlerquellen kein Wort. Er misst einfach den Objectabstand $a$, den er der einfacheren Rechnung wegen zu $100 \mathrm{~m} . \mathrm{m}$. festsetzt, dann den Durchmesser des Objectes $b$, sowie den der Luftblase $d$ und des Bildchens $c$. Hieraus bestimmt er den Brechungscoefficienten $n$ nach folgender von seinem Collegen van Rees entwickelten Formel

$$
n=\frac{1}{2}+\sqrt{\frac{1}{4}+\frac{(b-c) d}{4 u c}}
$$

oder da $c$ im Verhältniss zu $b$ als unendlich klein gelten kann 


$$
n=\frac{1}{2}+\sqrt{\frac{1}{4}+\frac{b d}{4 a c}}
$$

Harting gibt über die Voraussetzungen, unter welchen van Rees diese Formel erhielt, keinerlei Andeutungen; wir haben es daher versucht, dieselben aus der Formel selbst abzuleiten, um hierdurch einen Maassstab für ihre Genauigkeit zu erhalten, und geben nun nachstehend die Entwicklung derselben.

Sei $C$ (Fig. 206) das Centrum der Luftblase, $P Q$ die untere Grenzfläche der umgebenden Flüssigkeit, deren Brechungscoefficient $n$ bestimmt werden soll; ferner $A B$ das Object und $\alpha \beta$ das von der Luftblase entworfene Bild. Alsdann werden die von $A$ und $B$ ausgehenden Strahlen an der Grenzfläche $P Q$ so gebrochen, als ob sie von den Punkten $A^{\prime} B^{\prime}$ ausgingen. Da der Abstand des Punktes $C^{\prime}$ von $P Q$ vernachlässigt wer-

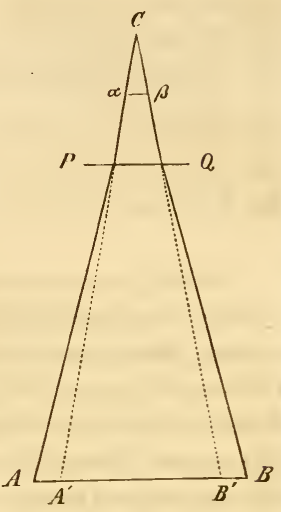

Fig. 206. den darf, so besteht die Beziehung

$$
A^{\prime} B^{\prime}=\frac{\operatorname{tang} a^{\prime}}{\operatorname{tang}} \cdot A B,
$$

wenn $\alpha$ und $\alpha^{\prime}$ die Neigungswinkel der Geraden $A C$ und $A^{\prime} C^{\prime}$ bezeichnen. Sind diese Winkel sehr klein, so verhalten sich ihre Tangenten, wie ihre Sinus, und man hat

$$
A^{\prime} B^{\prime}=\frac{1}{n} A B \text {. }
$$

Wird nun der Abstand des Bildchens vom Centrum der Luftblase gleich der Brennweite $f$ angenommen, was bei einer hinreichend grossen Objectsweite unbedingt erlaubt ist, so ergiebt sich, wenn wir die Harting'schen Bezeichnungen einführen, die Proportion

$$
\begin{aligned}
\frac{1}{n} b: c & =a: f, \quad \text { folglich } \\
b: c & =a: \frac{1}{n} f \text { und hieraus } \\
\frac{1}{n} f & =\frac{a c}{b}
\end{aligned}
$$

oder wenn man statt $f$ seinen Werth für Centralstrahlen setzt

$$
\frac{r}{2 n(n-1)}=\frac{d}{4 n(n-1)}=\frac{a c}{b} \text {. }
$$

Durch eine leicht zu übersehende Umsetzung erhält man hieraus die quadratische Gleichung 


$$
n^{2}-n=\frac{b d}{4 a c},
$$

deren Auflösung die obige Formel von van Rees ergiebt. Dieselbe ist also nur unter der Voraussetzung richtig, dass das Bildchen in den Brennpunkt für Centralstrahlen falle, und diese Voraussetzung ist, wie wir gezeigt haben, durchaus unzulässig. Die Brennweite für Centralstrahlen beträgt in Wasser, wenn $n=\frac{4}{3}$ gesetzt wird, genau 1,5 $r$, der Abstand des Bildchens dagegen bei mittlerer und starker Vergrösserung nur c. 1,368 - 1,30 $r$

Wie Harting dessenungeachtet zu Resultaten gelangen konnte, welche bis zur 4 ten Decimale genau sein sollen, ist uns unbegreiflich. Unsere Messungen ergaben für bekannte Flüssigkeiten (Wasser, Citronenöl etc.), wie sich erwarten liess, durchgehends zu hohe Werthe für $n$, für Wasser z. B. 1,354 bis 1,34s, und wir glauben hieraus mit Sicherheit entnehmen zu dürfen, dass die nach der Harting'schen Formel erhaltenen Ziffern ganz allgemein schon in der zweiten Decimale wenigstens um eine Einheit von dem wahren Werthe abweichen. Der Fehler müsste sogar noch etwas grösser ausfallen, wenn in obiger Gleichung für $\frac{\operatorname{tang} \alpha^{\prime}}{\operatorname{tang} \alpha}$ der wahre Werth dieses Ausdrucks, statt $\frac{1}{n}$, gesetzt würde, und zwar ergiebt die Rechnung für die Harting'schen Messungen, wobei $a=5 b$, folgende Verhältnisse.

Die zu untersuchende Flüssigkeit sei reines Wasser, dann ist $\frac{\operatorname{tang} \iota^{\prime}}{\text { tang }{ }^{\prime}}=0,997658$. $\frac{1}{n}$ und die Brennweite der Luftblase für Randstrahlen von $15^{\circ}$ (bei stärkeren Vergrösserungen sind noch grösssere Neigungen maassbestimmend) $=1,3659 \cdot r$, also nur 0,91258 der Hauptbrennweite $f$. Führt man diese Werthe in die betreffenden Gleichungen ein, so erhält man

$$
n=\frac{0,9125 s}{0,99765} \cdot \frac{b f}{a c}=0,91474 \cdot \frac{b f}{a c}
$$

und hieraus wie oben

$$
n=\frac{1}{2}+\sqrt{\frac{1}{4}+0,91474 \cdot \frac{b d}{4 a c}}
$$

Das zweite Glied unter dem Wurzelzeichen ist also in der Harting'schen Formel zu gross. Um den Fehler annähernd gut zu machen, müsste im gegebenen Falle das Verhältniss von $b$ zu $a$ so gewählt 
werden, dass $\frac{\operatorname{tang} \iota^{\prime}}{\operatorname{tang} \alpha}=0,91255 \cdot \frac{1}{n}$. Die Brennweite der bilderzeugenden Strahlen würde zwar dadurch ebenfalls etwas verändert, jedoch nicht in erheblichem Grade.

Man ersieht aus dem Angeführten, dass es nicht wohl möglich ist, an der genannten Formel eine Correction anzubringen, welche ihr allgemeine Geltung verleiht, da die Correctionsgrösse wieder von dem unbekannten Brechungscoefficienten abhängig sein muss. Für die meisten Flüssigkeiten wird indess der oben für Wasser bestimmte Coefficient 0,91474 (oder auch 0,9 ) wenigstens die ersten beiden Decimalen richtig liefern.

Uebrigens scheint uns bei mikroskopischen Untersuchungen die 402 Bestimmung des Brechungscoefficienten von Flüssigkeiten weniger wichtig zu sein, als die von festen Körpern. Wir haben uns daher bemüht, eine ähnliche Formel auch für kugelige und cylindrische Körper, wic Stärkekörner, Bastzellen u. dgl., aufzustellen und experimentell zu prüfen. Sei $f$ die (wirkliche) Brennweite für Centralstrahlen, $F$ die gemessene Brennweite derselben, $n$ der Brechungscoefficient der Beobachtungsflüssigkeit, $n^{*}$ derjenige des kugeligen oder cylindrischen Gegenstandes und $D$ sein Durchmesser; dann ist nach Früherem für Centralstrahlen (wegen der Verkleinerung der Niveaudifferenzen, vgl. pag. 235 $f^{\prime}=n F^{\prime}$, folglich

$$
\begin{aligned}
n F & =\frac{n^{*} D}{4\left(n^{*}-n\right)} ; \text { hieraus } \\
n^{*} & =\frac{n^{*} F}{n F-\frac{1}{4} D}
\end{aligned}
$$

Nimmt man nun an, die Brennweite der maassbestimmenden Randstrahlen betrage 0,9 der in diesem Ausdruck figurirenden Hauptbrennweite, so muss der durch Messung erhaltene Werth von $F$ mit $\frac{10}{9}$ multiplicirt werden, wenn die Formel annähernd richtige Ergebnisse liefern soll. Ob diese Annahme bei einem gegebenen Objectiv mit der Wirklichkeit übereinstimmt, muss natürlich experimentell geprüft werden, indem man z B. Oeltropfen oder cylindrische Glasfäden, deren Brechungscoefficient bekannt ist, mikroskopisch untersucht. Wir wollen der Allgemeinheit wegen statt $\frac{10}{9}$ die Grösse $\beta$ in die Formel einführen; dann wird dieselbe für Objecte, die in Wasser liegen $(n=1,3356)$ 


$$
\begin{aligned}
& n^{*}=\frac{1,7 \varsigma 3 \varsigma F}{1,3356 F-\frac{1}{4 \beta} D} \text { oder annähernd }\left(n=\frac{4}{3}\right) \\
& n^{*}=\frac{16 F}{12 F-\frac{9}{4 \beta} D}=\frac{8 F}{6 F-\frac{9}{4 \beta} D}
\end{aligned}
$$

und für Objecte, die in Alkohol liegen $(n=1,364)$

$$
n^{*}=\frac{1,86 F}{1,364 F-\frac{1}{4 \beta} D}=\frac{8,3 i F}{6,1365 F-\frac{9}{8 \beta} D}
$$

Da der Coefficient $\frac{9}{\varsigma_{\beta}}$ jedenfalls annähernd der Einheit gleich ist, so muss der Werth von $n^{*}$ um so genauer ausfallen, je grösser $F$ gegen $D$. Ist z. B. $F=2 D$, was nach unseren Messungen bei kleinen kugeligen Stärkekörnern von 18-24 Mik. Durchmesser und ebenso bei cylindrischen Bastzellen nahezu der Fall ist, so ergeben sich für $n^{*}$ folgende Werthe

$$
\begin{aligned}
& \beta=\frac{10}{9} \text { dann wird } n^{*}=1,456 \\
& \beta=\frac{9}{5} \quad-n^{*}=1,454 \\
& \beta=\frac{8}{7} \quad-n^{*}=1,452 \\
& \beta=\frac{7}{6} \quad-n^{*}=1,450 .
\end{aligned}
$$

Die ersten beiden Decimalen dürfen also, wenn die Messungen genau sind, als richtig betrachtet werden, was bei vergleichenden Untersuchungen an verschiedenen Zellmembranen oder verschiedenen Quellungsstadien derselben Membran in den meisten Fällen ausreicht.

Zur annähernden Bestimmung des Brechungscoefficienten hohlcylindrischer Gebilde wurden bereits oben (pag. 203) einige Anhaltspunkte geboten, und es wäre ein Leichtes, jene Tabelle nach Belieben zu vervollständigen. Für die Praxis wäre jedoch damit nicht gar viel gewonnen, da die Hauptschwierigkeit, die man hier zu bekämpfen hat, darauf beruht, die Lage der (äussern) hellen Linien mit Rücksicht auf die Contouren der Wandung hinlänglich genau zu bestimmen. Es hält das in der Regel so schwer, dass das Verfahren nur zur Ermittlung grösserer Differenzen im Brechungsvermögen dienen kann. Immerhin aber genügt es vollkommen, um z. B. den grossen Unterschied zwischen den Membranen der Fadenalgen und den Haaren der Boragincen etc. nachzuweisen. 


\section{Die Durchleuchtung der Körper.}

Nach den Versuchen von J. S a ch s*) haben pflanzliche Gewebe 404 die Eigenschaft, die brechbaren Strahlen des Spectrums in stärkerem Verhältniss zu absorbiren, als die weniger brechbaren. Daraus folgt denn, dass Gewebelamellen, welche z. B. aus Kartoffeln, Früchten u. dgl. geschnitten wurden, nur bis zu einer gewissen Dicke weisses Licht durchlassen, dann aber - wenn die Dickenzunahme allmählich weiter und weiter über diese Grenze hinausgeht - der Reihe nach die violetten, blauen, grünen .... Strahlen absorbiren und daher dem beobachtenden Auge in der Mischfarbe der nicht absorbirten durchgehenden Strahlen, zuletzt also noch roth erscheinen.

Sachs stellte seine Beobachtungen mit Hülfe eines höchst einfachen Apparates an, welcher aus zwei in einander verschiebbaren und an den Enden mit kleinen Oeffnungen versehenen Röhren (Fig. 20i) bestand. Die zu untersuchende Gewebelamelle wurde bei $A$ zwischen die beiden Röhrenenden eingeklemmt und nun gegen die Sonne oder eine weisse Wolke gehalten, hiebei jedoch das andere zweckdienlich zugeschnittene) Ende des Apparates behufs Abhaltung alles fremden Lichtes möglichst dicht an die Umgebung des Auges angedrückt. - Um noch einen Schritt weiter zu gehen, kann man am Ocularende der Röhre ein Prisma einfügen welches die resultirende Mischfarbe zerlegt. Auf diese Weise gelang es Sach s, nicht bloss die Elementarfarben des durchgehenden Lichtes einzeln zur Wahrnehmung zu bringen, sondern auch zu zeigen, dass das in Plasma eingelagerte Chlorophyll grüner Gewebe genau dieselben Absorptionsstreifen im Spectrum hervorruft, wie sie bei Chlorophyll-Lös un g e n längst bekannt sind. **)

Näheres über die Einrichtung eines solchen » Diaphanoskops “ mitzutheilen, halten wir für überflüssig,

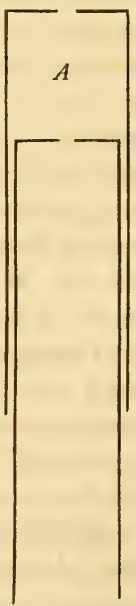

Fig. 20\%. da das Instrument in der Hand eines geschickten Beobachters gewiss noch manche Vervollkommnungen erfahren, und eine bloss dem Zweek einer vorläufigen Orientirung dienliche Construction schon nach dem Gesagten Niemanden schwer fallen wird. ${ }^{* *}$ )

*) Sitzungsber. der Wien. Akad. d. Wiss. Bd. XLIII. $1 \checkmark 60$.

**) Vgl. hierüber Harting, Pogg. Ann. Bd. 96. S. 543.

***) Eine Abbildung des von $\mathrm{S}$ a $\mathrm{c}$ h s benutzten nanalysirenden I)iaphanoskopsa findet man in dessen "Handbuch der Experimentalphysiologie" p. 7 . 
Man könnte uns hier, im Hinblick auf das eben skizzirte Beobachtungsverfahren, mit der Frage entgegentreten, ob Untersuchungen dieser Art, wobei die Gewebe nur in ihrer Gesanmtwirkung, gleichsam als homogene Massen, in Rechnung kommen, überhaupt in das Gebiet der Mikrophysik gehören. Diese Frage hätte insofern ihre Berechtigung, als das Mil:roskop für die Beobachtung der Lichtabsorption selbst allerdings so gut wie keine Bedeutung hat. Liesse sich auch ein schwach vergrösserndes Instrument leicht zweckentsprechend einrichten, indem man die Lichtstärke möglichst steigerte und durch eine Beleuchtungslinse directes Sonnenlicht in convergirenden Strahlen auf das Object einfallen liesse, so hätte ein solches Verfahren doch offenbar nur dann einen Werth, wenn die Kleinheit des Gegenstandes die Beobachtung mit blossem Auge erschweren würde, und dieser Fall kann aus dem einfachen Grunde nicht leicht eintreten, weil eine gewisse und zwar oft ziemlich beträchtliche Ausdehnung in der Richtung der durchgehenden Strahlen nothwendig ist, um die erwähnte Lichtabsorption überhaupt wahrnehmbar zu machen. - Andererseits lässt sich aber nicht in Abrede stellen, dass eine vollständige Verwerthung der beobachteten Farbenerscheinungen, ja schon eine befriedigende Erklärung derselben, ohne die genaueste Kenntniss der Gewebe, welche sie hervorrufen, nicht möglich ist. Wie soll der Einfluss der verschiedenen Medien, welche hiebei in Betracht kommen: der Zellmembranen und Stärkekörner, der Plasmagebilde, Farbstoffe etc. bestimmt werden, wenn man nicht durch eine Reihe von Beobachtungen an Geweben, worin jene Medien in quantitativ verschiedener Weise combinirt sind, die Beziehungen ermittelt, welche zwischen der $\mathrm{Zu}$ - und Abnahme eines bestimmten Factors und der resultirenden optischen Wirkung bestehen? Der Beobachter hat es hier offenbar mit einem complicirten Problem zu thun, dessen Lösung nicht eher möglich ist, als bis so viele Beziehungen oder, um einen mathematischen Ausdruck zu gelırauchen, so viele Gleichungen ermittelt sind, als man Unbekannte zu bestimmen hat. Und weil die Daten, welche in diese Beziehungen eintreten, zum guten Theil anatomische sind, so muss der mikroskopischen Beobachtung bei solchen Untersuchungen immerhin eine wesentliche Stelle eingeräumt werden.

3. Einfluss des Lichtes anf Vegetationsprocesse.

406 Von den Wirkungen des Lichts auf das Pflanzenleben, welche der Beobachtung durch das Mikroskop zugänglich sind, wollen wir 
hier nur diejenigen erwähnęn, deren richtige Deutung zu den schwierigeren Aufgaben der mikroskopischen Forschung zu rechnen ist. Es wäre überflüssig, gewöhnliche entwicklungsgeschichtliche Torgänge, welche auf Präparaten, die die erforderlịchen Uebergangsstadien repräsentiren, so zu sagen direct beobachtet werden können, an dieser Stelle besonders in Betracht zu ziehen.

Eine der wichtigsten der hieher gehörigen Fragen, welche neuerdings von Sachs angeregt wurde, betrifft die Amylumbildung in den Chlorophyllkörnern. Sachs beobachtete, dașs Keimpflanzen, welche sich so lange im Finstern entwickelt hatten, bis die früher vorhandene Stärke und das Fett aus allen Organen verschwunden waren, im Verlaufe ihres weiteren Wachsthums am Tageslichte zuerst in den Chlorophyllkörnern der grün gewordenen Blätter, dann in den leitenden Geweben der Blattstiele und noch später in dem farblosen Parenchym kleine Stärkekörnchen enthalten, und dass diese Körnchen bei Abhaltung des Lichtes wieder verschwinden, um bei erneuter Lichteinwirkung zum zweiten Male zum Vorschein zu kommen.*) Er schloss hieraus, dass die Chlorophyllkörner die ursprüngliche Bildungsstätte der Stärliekörner seien, und dass hier der Wechsel von Tag und Nacht einen entsprechenden Wechsel von Stärkebildung und Stärkeauflösung bedinge, wovon jedoch die erstere während der langen Sommertage rorwiege.

Ist diese Darstellung richtig - und wir haben rorläufig keinen stichhaltigen Grund, dieselbe zu bezweifeln -- so müsste es wohl möglich sein, an günstigen Objecten die Thatsache einer periodisch stattfindenden Resorption zur Wahrnehmung zu bringen. Demn da die letztere, ähnlich wie bei der Keimung und der Einwirkung des Speichels, voraussichtlich an der Oberfläche vor sich geht, indess das Wachsthum unter dem Einflusse des Lichtes durch Intussusception geschieht, so müssten die im Chlorophyll enthaltenen Körner nach und nach das Aussehen ron in Auflösung begriffenen Kartoffelstärkekörnern annehmen, d. h. die Schichten müssten an der Oberfläche unter spitzern oder stumpfern Winkeln zu Tage gehen, und eine peripherische Schicht von dichterer Substanz und mit grösserer Widerstandsfähigkeit gegen Reagentien könnte nicht mehr vorhanden sein. Dieser letztere Punkt erscheint uns bei der Kleinheit der fraglichen Objecte, welche allerdings den Studium des Schichten-

*) Näheres hierüber findet man in der Abhandlung von Sachs: Ueber den Einfluss des Lichts auf die Bildung des Amylum's in den Chlorophyllkörnern (Bot. Ztg. 1562, 
verlaufes wenig Aussicht auf Erfolg eröffnen, besonders beachtenswerth. Es wäre vielleicht möglich zu zeigen, dass die Beschaffenheit der peripherischen Schicht bei kleinen Körnern, welche im Marke oder in der Wurzel etc. entstanden sind, eine andere ist als bei solchen, welche als Einschlüsse im Chlorophyll erscheinen und hier einem allnächtlich wiederkehrenden Auflösungsprocess ausgesetzt sind. Gelänge diess, so wäre damit immerhin eine werthvolle Thatsache gewonnen, welche die von Sachs aufgestellte Ansicht rechtfertigen würde.

407 Ein zweiter Punkt, der einer genaueren Untersuchung mit Hülfe des Mikroskops bedarf, ist die ebenfalls von Sachs*) beob. achtete Farbenänderung grüner Blätter im Sonnenlicht. Dieselben werden bei starker Insolation beträchtlich heller, ") um im Schatten nach kurzer Zeit wieder dunkelgrün zu werden. Durch theilweise Beschattung eines Blattes gelingt es, Schattenbilder auf seiner grünen Fläche zu erzeugen, die aber, sobald das ganze Blatt beschattet oder beleuchtet wird, wieder verschwinden, indem im ersteren Falle die ganze Fläche dunkler, im zweiten heller wird ". Eine Erklärung dieser Erscheinung ist bis jetzt nicht gegeben; es bestehen darüber bloss "Vermuthungen, die zunächst jedes Beweises entbehren ".

Unseres Erachtens handelt es sich hier um eine Erscheinung, welche im Zusammenhange mit den Farben der grünen Gewebe im Allgemeinen, speciell der Blätter, zu behandeln ist. Die Blattfarben differiren bekanntlich nicht bloss mit Rücksicht auf ihre Intensität, sondern auch hinsichtlich des Tons, den das ihnen eigenthümliche Grün besitzt. Es gibt grasgrüne, meergrüne, graugrüne Blätter u. s. w. Dass diese Verschiedenheit der Farbennuance nicht allein in der Farbe des Chlorophylls ihren Grund hat, sondern zum Theil von der grösseren oder geringeren Durchsichtigkeit der peripherischen Zellmembranen, von der Zahl und Grösse luftführender Zwischenzellräume, ${ }^{* *}$ ) von der Natur des Zellinhaltes u. dgl. abhängig

* Berichte der math.-phys. Kl. der Kgl. Sächs. Gesellsch. der Wiss. 1559. Einiges Nähere findet man im "Handb. der Experimentalphysiologie der Pflanzen " von dems. Verf. p. 16.

**) Wie sehr die Beschaffenheit der oberflächlichen Zellschichten auf die Färbung influirt, beweist beispielsweise das Verhalten mancher Flechten, deren Gonidienschicht im trockenen Zustande, d. h. wenn die darüber liegenden Rindenzellen Luft enthalten, kaum durchschimmert, während sie nach dem Eintauchen der Flechte in Wasser, weil dasselbe die Luft wenigstens theilweise verdrängt oder absorbirt, eine deutlich grüne Färbung der oberen Thallusfläche 
ist, lässt sich von vorne herein annehmen. Es würde sich also darum handeln, zunächst die Factoren kennen zu lernen, welche überhaupt bestimmend auf Ton und Intensität der Blattfarben einwirken, und sodann in zweiter Linie den Einfluss zu ermitteln, den Licht und Schatten auf diese Factoren ausüben.

\section{IV.}

\section{Wärme.}

Ueber die Wirkungen der Wärme und Kälte auf das Pflanzen- 408 leben besitzen wir bereits eine ganz ansehnliche Literatur. *) Dieselbe befasst sich jedoch, wie schon ein flüchtiger Ueberblick zeigt, zum weitaus grösseren Theile mit Gebieten, welche die Mikrophysik nicht berühren und folglich ausserhalb des Rahmens liegen, an den wir uns hier zu halten haben. Das Wenige, was auf mikroskopische Dinge Bezug hat oder doch Schlüsse auf mikroskopische oder moleculare Verhältnisse gestattet, lässt sich etwa in folgende Punkte zusammenfassen.

\section{Krystallbildungen bei dem Gefrieren.}

Lässt man Durchschnitte durch saftige Pflanzentheile, z. B. 409 durch Runkelrüben, bei einer Temperatur von $3-6{ }^{\circ} \mathrm{R}$. unter Null sich langsam abkühlen, so bedecken sie sich, wenn die Verdunstung durch Auflegen einer Glasplatte oder auf irgend eine andere Weise gehemmt wird, mit einer Eiskruste, welche eine Dicke von $2-3^{\mathrm{m}} \mathrm{m}$. und darüber erreichen kann. Diese Eiskruste besteht, wie die mikroskopische Untersuchung zeigt, aus kleinen, unregelmässig sechseckigen Krystallsäulen, welche pallisadenartig neben einander stehen und mit ihren Seitenflächen sich unmittelbar berühren. Der Durchmesser dieser Krystalle wechselt zwischen 0,1 und $0,3 \mathrm{~m}$. $\mathrm{m}$. und ist von der Grösse der darunter liegenden Zellen unabhängig. Von der Seite gesehen, zeigt das Innere der Krystalle höchst regelmässige Reihen von Luftblasen, welche den Kanten parallel laufen, und

bedingt. Diess gilt auch von solchen Flechten, welche eine der Epidermis vergleichbare, aus einer einzigen Zellschicht bestehende Rinde besitzen.

*) Man vergleiche J. Sachs: Handbuch der Experimentalphysiologie der Pflanzen, Leipzig 1 s65. 
deren einzelne Glieder bisweilen durch dünne Kanäle mit einander in Terbindung stehen; auch sieht inan häufig, dass kleine Krystalle ron der Schnittfläche aus wie Keile zwischen die grösseren eingeschoben sind, während umgekehrt auf der obern Seite niemals solche Eiskeile auftreten. Die Substanz der Krystalle ist nicht reines Wasser, sondern reagirt sauer, wie der Zellsaft.

Die Krystallbildung unterbleibt, wenn man die Pflanzentheile einer solchen Kälte $\left(12-20^{\circ}\right)$ aussetzt, dass sie zu harten Massen erstarren; sie unterbleibt ferner an all' den Stellen, wo die Verdunstung frei von-statten geht.*)

Aus diesen Thatsachen ergiebt sich zunächst, dass die krystallbildende Flüssigkeit von den Zellen, nicht von der Atmosphäre, geliefert wird. Daraus folgt aber ferner, dass der im Gewebe enthaltene wässerige Zellsaft bei einer Temperatur von $3-6^{\circ} \mathrm{R}$. unter Null noch nicht gefriert, vielmehr in flüssigem Zustande die Membranen durchströmt, um an der Oberfläche zu erstarren. Mehrere Procent des gesammten wässerigen Inhaltes werden auf diese Weise dem Gewebe entzogen und in Eis übergeführt.

410 Fragen wir nach den Kräften, welche eine solche Strömmng stundenlang zu unterhalten vermögen, so sind wir vorläufig auf mehr oder minder hypothetische Ansichten und T'ermuthungen angewiesen, die alle die Probe des Experiments noch nicht bestanden haben. Sachs (1. c. pag. 6) stellt den Vorgang mit dem Steigen des Saftes in Folge der Verdunstung in Parallele. Nach ihm ist jede freie Zellhautfläche mit einer dünnen Wasserschicht bedeckt, welche, wenn sie gefriert, sofort durch eine nachströmende zweite ersetzt wird, ganz so, als ob sie durch Verdunstung entfernt worden wäre. Die gefrorene Schicht soll sich hiebei wie eine Schicht von Asphaltlack verhalten, welche auf einer trockenen Harnblase oder auf trockenem Papier mit enormer Kraft hafte, sich aber in grossen Stücken ablöse, wenn die Blase oder das Papier mit Wasser benetzt werde, weil damit ebenfalls die Bildung einer feinen Wasserschicht zwischen Lack und Unterlage verbunden sei.

An dieser Darstellung ist der Grundgedanke, das Vorhandensein einer dümmen Flüssigkeitsschicht zwischen Krystallbasis und Unterlage und die fortwährende Erneuerung derselben durch nachströmen-

*) Einiges Nähere findet man in der Abhandlung von Sa ch s : "Krystallbildungen bei dem Gefrieren etc. (Ber. der K. Sächs. Ges. der Wiss. 1560), welcher wir obige Angaben entnommen haben. 
des Imbibitionswasser jedenfalls richtig. Es wird auch in überzcugender Weise nachgewiesen, dass die geringe Ausdehnung des Wassers von $4^{\circ}$ abwärts bis zum Gefrierpunkt und der dadurch hervorgebrachte Druck bei dieser Erneuerung nicht in Betracht kommt. Dieselbe findet nämlich in gleicher Weise auch dann noch statt, wenn der Versuch mit frischen Geweben von $10-12^{\circ}$ (wo das Wasser einen grössern Raum einnimmt als bei $0^{\circ}$ ) angestellt wird. Ebenso darf mit Sicherheit angenommen werden, dass die Contraction des Gewebes, welche mit der Krystallbildung verbunden ist, zum grössten Theil als eine Folge der Wasserabgabe und nicht als die Ursache derselben zu betrachten sei. *)

Dagegen erscheinen uns die herbeigezogenen Analogieen mit der Verdunstung und mit dem Ablösen der Asphaltschicht wenn auch nicht nachweisbar unzulässig, so doch mindestens von zweifelhafter Berechtigung. Beides sind Vorgänge, die allem Anschein nach mit dem in Frage stehenden Nichts gemein haben. Die Verdunstung entzieht einem feinen System von Capillarräumen, den Molecularinterstitien der Membranen, die obersten $W$ assertheilchen, und es ist natürlich, dass die capillaren Kräfte den Verlust sogleich ersetzen. Eine andere Wasserschicht als die, welche von den Wasserhüllen der peripherischen Molecüle gebildet wird, ist hier nicht vorhanden. Anders verhält es sich mit der zu erörternden Krystallbildung, soweit wenigstens die bisher angestellten Versuche darüber Aufschluss geben. Dieselbe spielt ausserhalb der Capillarräume, welche die Molecüle der Membranen trennen; sie beginnt mit dem an der Oberfläche (z. B. in durchschnittenen Zellen oder durch Auspressen) vorhandenen Wasser und veranlasst dadurch die Entstehung eines neuen, aber wahrscheinlich viel gröberen Capillargefässsystems, das an der Innenfläche der Eiskruste dahinzicht. Nur das Wasser, welches in

*) Eine der Wasserabgabe entsprechende Contraction ist bei einem safterfüllten Gewebe selbstverständlich. Wenn z. B. ein Querschnitt durch eine Runkelrübe, welcher im frischen Zustande 90 Gramm wiegt, während des Gefrierens 5 Gramm und bein Aufthauen noch 3 Gramm, also im Ganzen \& Gramm verliert, so ergiebt sich hieraus eine Volumveränderung von 90 auf $\varsigma 2$, was einer Contraction von c. $3 \%$ nach jeder Richtung gleichkommt. Bringt man bloss die 5 Gramm Gewichtsverlust während des Gefrierens in Rechnung, so würde diess eine Volumenabnahme von c. 106 auf 100 ausmachen; allein da das Wasser sich beim Gefrieren von 100 auf 109 ausdehnt, so behält dieser Factor das Uebergewicht und bedingt eine Ausdehnung von c. $1 \%$ nach jeder Richtung. Wir bemerken übrigens, dass die experimentelle Bestätigung dieser Rechnung noch nicht geliefert ist. S a chs, dem wir obige Gewichtsangaben entlehnt haben, unterliess es, die entsprechenden Volumenveränderungen zu bestimmen. 
dieses letztere System von Capillaren eindringt, gefriert, dehnt sich dabei etwas aus und bildet so neue Capillaren, in welchen der nämliche Process sich wiederholt. Und so geht es fort, so lange die Flüssigkeit nachströmt, ganz so, wie man es auch bei der Bildung künstlicher Krystalle vielfach beobachtet. *)

411 Diese Auffassung entspricht den bekannten Thatsachen jedenfalls besser, als die Annahme einer Eisbildung in den Wasserhüllen der peripherischen Membrantheilchen. So lange nicht experimentell nachgewiesen ist, dass ein durch eine continuirliche Membran abgeschlossenes Gewebe $(z$. B. benetzbare Früchte und saftige Blätter die in Rede stehende Erscheinung ebenfalls hervorruft, ohne dass vorher eine Wasserschicht ron mikroskopisch wahrnehmbarer Dicke die Oberfläche überzieht, so lange ist es gestattet, an der Möglichkeit einer solchen Eisbildung zu zweifeln. ${ }^{*+}$

Dass die einmal gebildete Eiskruste sich aus dem nämlichen Grunde ablöse, wie eine Lackschicht auf einer quellungsfähigen Substanz beim Befeuchten derselben, ist ebenso unwahrscheinlich. Die Lackschicht löst sich vorzüglich desshalb ab, weil die Quellung der Substanz eine seitliche Terschiebung ihrer kleinsten Theilchen bedingt und so den Zusammenhang mit den Lacktheilchen aufhebt, ein Vorgang, wozu in unserem Falle die Bedingungen offenbar fehlen.

Die Annahme, dass der wässerige Zellsaft aus dem engen Capillarsystem der Molecularinterstitien in das wahrscheinlich viel weitere der Eiskruste ausströme, hat unter den gegebenen Verhältnissen nichts Unwahrscheinliches. Die Capillarattraction, welche an der Oberfläche der Gewebe wirksam ist, hat nämlich bloss die Widerstände zu überwinden, welche die Zellmembranen dem Durchgang der Flüssigkeitstheilchen und vermöge ihrer Biegungsfestigkeit auch der

*) Das Wachsthum künstlicher Krystalle findet häufig in der hier bezeichneten Weise statt. Man beobachtet z. B., wie Krystallnadeln, die an den feuchten Wänden eines Gefässes anschiessen, ohne die Mutterlauge zu berühren, sich durch Anlagerung neuer Substanz zwischen Gefisswand und Krystall oft sehr bcdeutend verlängern.

**) Die von $H$ offmann (Pflanzenklimatologie 1557. p. 329) beobachteten und von $\mathrm{S}$ a chs erwähnten Krystallbildungen auf der Unterseite der Blătter ron Viburnum Tinus und Aucuba, bestehend aus feinen Eisnädelchen von charakteristischer Gruppirung, sind in dieser Frage nicht entscheidend, da sie möglicher Weise durch die Spaltöfinungen bedingt waren oder sogar von diesen ausgingen. 
Verkleinerung des Zelllumens entgegensetzen. Diese Widerstände sind voraussichtlich um so geringer, je dünner und weicher die Zellnembranen.

Die im Vorhergehenden besprochenen Krystallbildungen stim- 412 men wahrscheinlich mit einer Reihe anderer Erscheinungen überein, welche von Elliot, Herschel, Dana, Le Conte, Bouché und Caspary beobachtet wurden. Es sind diess nadelförmige, rechtwinklig von der Unterlage abstehende Eiskrystalle oder auch blattähnliche Bildungen, die sich an der Basis der Baumstänme, an den Stumpfen abgestorbener Disteln, an Zweigen verschiedener Pflanzen etc. entwickelt hatten und zum 'Theil eine beträchtliche Länge erreichten.*', Auch die Eisscheiben auf den Blattnarben der abgefallenen oder im Abfallen begriffenen Blätter, welche von Mohl beschrieben wurden (Bot. Ztg. 1560), gehören wahrscheinlich hieher. Alle diese Erscheinungen müssen indess erst genauer untersucht werden, ehe sie in der Mikrophysik Verwerthung finden können.

\section{Das fietrieren der fiewebe.}

Die den Winter über ausdanernden Pflanzentheile müssen bei 413 anhaltender grosser Kälte, auch wenn sie durch schlechte Wärmeleiter geschützt sind, offenbar nach und nach die Lufttemperatur annehmen und daher voraussichtlich gefrieren. Dass diess in vielen Fällen wirklich geschieht, beweisen die bekannten Erscheinungen, welche man nach der Einwirkung einer strengen Kälte an Früchten, Kartoffeln etc. beobachtet. Die Gewebe erscheinen alsdann rollkommen steif und brüchig und die Bruchflächen weisslich, was voraussetzt, dass ein grosser Theil ihrer Masse in einen andern Aggregatzustand übergegangen sei. Diess folgt auch aus dem Verhalten solcher Gewebe beim Aufthanen. Dieselben erwärmen sich viel langsamer als ungefrorene Gewebe von gleicher Temperatur, wie sich Eis von 0 Grad langsamer erwärmt als eine gleiche Menge Wasser; das Eine wie das Andere offenbar darum, weil die Wärme des umgebenden Mediums zunächst zum Schmelzen des Eises verwendet wird.

Welche Kältegrade das Gefrieren des wässerigen Zellsaftes mit $\mathbf{4 1 4}$ physikalischer Nothwendigkeit herbeiführen, ist bis jetzt nicht genauer festgestellt; nur soviel ist gewiss und in Anbetracht der un-

*) Näheres hieruber findet man bei Caspary: "Auffallende Eisbildungen auf Pflanzen « (Bot. Ztg. 1854. p. 665). 
gleichen Concentration der Säfte auch vorauszusehen, dass die Erstarrungspunkte bald höher bald tiefer, aber immer etwas unter Null liegen.

Der Gehalt an löslichen Bestandtheilen scheint übrigens nicht der einzige Unstand zu sein, welcher auf die Lage des Gefrierpunktes influirt; es ist wahrscheinlich, dass ausserdem noch die mikroskopische Kleinheit der Zellen und der darin enthaltenen Wassermengen in Anschlag kommt. Wir schliessen diess aus der bekannten Thatsache, dass kleine Wassertropfen und ebenso die Wassersäulen in feinen Capillarröhren bis unter 0 Grad flüssig bleiben und erst bei tieferen Temperaturen erstarren. *). In welchem Verhältniss aber der Widerstand, den die Molecularkräfte der Eisbildung entgegensetzen, mit der Kleinheit der Zelle zunimmt, ob vielleicht auch die besonderen Formverhältnisse darauf Einfluss üben, unter welchen Bedingungen endlich das Imbibitionswasser in den Molecularinterstitien der Membranen, des Protoplasma und der Stärkekörner gefriert, darüber lässt sich kaum eine Vermuthung aussprechen.

415 Betreffend die Volumenveränderungen, welche das Gefrieren der Gewebe bedingt, so sind zunächst folgende Punkte zu berücksichtigen. Ein gegebenes Quantum Wasser von 0 Grad dehnt sich beim Uebergang in Eis um ungefähr $1 / 10$ seines Volumens aus; die Ober-

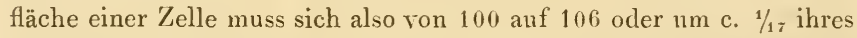
ursprünglichen Werthes vergrössern. Dieser Ausdehnungscoefficient bleibt auch dann noch nahezu derselbe, wenn die Zellflüssigkeit vor dem Gefrieren eine Temperatur von $15-20^{\circ}$ besitzt und sich folglich während der Abkühlung etwas contrahirt. Die Zellmembranen müssten sich also, wenn sonst keine Veränderungen stattfänden, in Folge der Eisbildung um c. $1 / 1$ i ihrer ursprünglichen Fläche oder um

* Mousson (Poggendorff's Annal. Bd. 105 [1555] p. 161) beobachtete, dass Wasser in Röhren unter $0,7 \mathrm{~m}$. m. in 1)urchmesser flüssig blieb, obschon das Thermometer im Beobachtungszimmer am Tage nie über $-2{ }^{\circ} \mathrm{C}$. stieg und in der Nacht auf $-5^{\circ}$ bis $-7^{\circ} \mathrm{C}$. sank. Es fand auch dann kein Gefrieren statt, wenn man die Röhren durch Stösse erschütterte.

Ebenso ergaben die Untersuchurgen 1) u four's Pogg. Ann. Bd.114.p. 530), dass Wasserkugeln (von mehreren M. M. Durchmesser), welche in einem specifisch gleich schweren Gemisch von Süssmandelöl und Chloroform frei schweben, bis zu 8 und $12^{\circ} \mathrm{C}$. unter Null, kleinere sogar bis $-20^{\circ}$ flüssig bleiben. Erschütterungen sind auch hier ohne Einfluss; dagegen bewirkt die Berührung mit Eis oder die Durchleitung eines starken elektrischen Funkens augenblickliches Frstarren. 
1/33 nach jeder Dimension ausdehnen. Allein es kommt hier noch ein physiologischer Factor in Betracht, welcher diese Schlussfolgerung modificirt. Die Zellen befinden sich nämlich, so lange sie leben, im Zustande der 'Iurgescenz, und zwar erreicht dieselbe einen um so höheren Grad, je kräftiger sie vegetiren. Da nun die vegetativen Processe während der Abkühlung allmählich schwächer werden und endlich vollständig erlöschen, so ist es leicht möglich, dass die Membranen im turgescirenden Zustande ebenso stark oder selbst stärker ausgedehnt sind als im gefrorenen. Der umgekehrte. Fall kann natürlich auch vorkommen, aber jedenfalls sinkt der Ueberschuss, welcher allfällig den gefrorenen Zellen im Vergleich mit den turgescirenden noch zukommt, auf eine so geringe Grösse herunter, dass ein Zerreissen der Membran in Folge der Eisbildung undenkbar ist.

Die directen Beobachtungen, welche auf diese Punkte Bezug haben, führen zu den nämlichen Ergebnissen. Blattstiele verschiedener Pflanzen waren nach Messungen von Sachs im gefrorenen Zustande um c. $1-3$ Procent kürzer als im turgescirenden; grössere Stücke von Rüben und Kürbisfleisch zeigten dagegen nach dem nämlichen Beobachter so gut wie keine Veränderung. Der dritte mögliche Fall ist zwar bis jetzt nicht beobachtet; es ist jedoch wahrscheinlich, dass sich unter einer grösseren Zahl von Pflanzen auch solche finden würden, die sich beim Gefrieren etwas ausdehnen, namentlich wenn sie vorher bei nicderer Temperatur vegetirten.

Zur Bildung von Rissen fehlt unter diesen Umständen jede Veranlassung. Die Beobachter sind auch einig darin, dass die stärksten Vergrösserungen keine Spur daron wahrnehmen lassen, und durch die diosmotischen Erscheinungen, welche man an gefrorenen und wieder aufgethauten Algenfäden beobachtet, wird überdiess der strenge Beweis geliefert, dass wenigstens hier ein Zerreissen der Zellen nicht stattfindet. Dieselben werden nämlich durch Glycerin oder eine concentrirte Zuckerlösung genau in derselben W eise zusammengedrückt und gefaltet, wie es an der lebenden Pflanze geschieht und wie es überhaupt nur bei vollständig unverletzten Blasen möglich ist. *)

\section{Veränderung der Zellhäute beim Aufthanen}

Es ist eine durch zahlreiche Versuche festgestellte Thatsache, $\mathbf{4 1 6}$ dass die verderblichen Wirkungen des Frostes auf das Zellenleben nicht durch das Gefrieren an und für sich, sondern durch zu rasches

*) Vgl. Näge li: Sitzysber. der k. Akad, der Wiss, in München 1\$61. p. 26ৎ. 
Aufthauen verursacht werden. Die empfindlichsten Blätter behalten ihre volle Frische, wenn man sie mit einer grossen Wassermenge, z. B. einem Liter, zu einem einzigen Eisklumpen erstarren und sodann in einer Luft von c. $4-5^{\circ} \mathrm{R}$. langsaın aufthauen lässt. Bringt man dagegen gefrorene Pflanzentheile in warme Luft oder in $\mathrm{T}$ asser von $10-20^{\circ}$ und darüber, so treten fast augenblicklich die Veränderungen ein, welche den Tod durch "Erfrieren " bezeichnen.

Diese Veränderungen bestehen, soweit sie äusserlich bemerkbar sind: a) im Verluste der Turgescenz und der damit verbundenen Straff heit und Elasticität, $b$ ) in der Aenderung der Farbe und Durchsichtigkeit in Folge der Infiltration der luftführenden Räume. Ein erfrorenes Gewebe ist schlaff und unelastisch; es lässt den wässerigen Zellsaft schon bei geringem Druck in Masse auslaufen, und durch starkes Pressen mit den Händen ist es möglich, die Flüssigkeit in dem Grade zu verdrängen, dass man zuletzt nur eine zähe, ziemlich trockene Masse übrig behält. Flüssigkeiten, welche im lebenskrättigen Gewebe in den Zellen zurückgehalten werden, wie Anthocyan, Gerbstoff u. dgl., diosmiren im erfrorenen von Zelle zu Zelle und in das umgebende $W$ asser, und genauere Beobachtungen zeigen, dass die diosmotischen Eigenschaften überhaupt wesentlich verändert sind.

Es bedarf nun keiner Erörterung, dass solche Erscheinungen eine tief eingreifende Veränderung der molecularen Kräfte voraussetzen; allein es ist schwer, über die Natur derselben eine bestimmte Forstellung zu gewinnen, welche etwas mehr als eine blosse Hypothese wäre.

Sachs betrachtet die genannten Vorgänge einfach als Folgen erhöhter Permeabilität der Zellhäute und lässt die letztere bedingt sein durch die Vergrösserung der Molecularinterstitien. Er stützt sich hiebei eincrseits auf die von Brücke, Ludwig und Fick ausgebildete Theorie der Diffusion, wonach die molecularen Poren einer Haut um so grösser sein müssen, je mehr Salz bei der Diffusion hindurchströmt, und andererseits auf die Beobachtung, dass erfrorene Gewebe in gleichen Zeiten ungleich grössere Mengen ron Salz aufnehmen als frische. Die Verkettung von Ursachen und Wirkungen wäre hienach folgende. Die plötzlich gesteigerte Permeabilität bedingt sofort eine entsprechende $W$ asserabgabe, die negative Spannung der Membran nimmt in Folge dessen ab oder sinkt auf Null, der hydrostatische Druck des Zellsaftes wird dem äussern Luftdruck gleich, die Turgescenz hört auf etc. 
Die Annahme einer Vergrösserung der Poren motivirt Sachs*) durch die Vergleichung mit gefrorenem und wieder aufgethautem Stärkekleister oder geronnenem Hühnereiweiss, welche beide im aufgethauten Zustande eine grobporige schwammige Substanz darstellen, aus welcher man mit leichtem Druck Wasser auspressen kann. Um diese Veränderungen zu erklären, nimmt er an, die Substanz- . atome Eiweiss oder Stärke) ziehen sich nach dem Gefrieren stärker an und bilden so ein bloss aus Eiweiss oder bloss aus Stärke bestehendes Netzwerk, in dessen Maschen das frei gewordene Wasser abgeschieden werde. Nichts hindere uns, die so gewonnene Anschauung auf die Zelle zu übertragen. - Hiezu kann bemerkt werden, dass es nicht nöthig wäre, eine unmittelbare Berührung der Eiweiss- oder Stärketheilchen anzunehmen; es würde genïgen, dass die Wasserhüllen durch das Gefrieren sich beträchtlich verkleinerten und dass die Molecüle ihre Lagerung soweit veränderten, um grössere Lücken zwischen sich zu lassen.

Aber gegen die ganze Theorie ist die Einwendung zu machen, dass die durch den Frost bewirkten molecularen Vorgänge im Eiweiss und Stärkekleister offenbar verschieden sind von denen in den Zellmembranen. In Eiweiss und im Stärkekleister werden die Veränderungen durch das Gefrieren selbst herbeigeführt, was wir uns ohne Zweifel so vorstellen müssen, dass das Imbibitionswasser kleine Eiskrystalle bildet, wodurch die Substanztheilchen eine dauernde Verschiebung erfahren und in einen andern Gleichgewichtszustand zu den Wassertheilchen treten. Die Hypothese, dass die Substanztheilchen dabei sich netzförmig anordnen, ist nicht wohl mit der Bildung von Eisnadeln zu vereinigen; diese Ursache dürfte wohl eher unregelmässige Anhäufungen derselben bewirken.

In der Zellmembran dagegen hat das Gefrieren selbst noch keine dauernde Veränderung zur Folge, demn bei langsamem Aufthauen der Zellen behält die Membran ihre frühern Eigenschaften. Diese Thatsache, in Verbindung mit der früher erwähnten, dass Wasser in feiner Vertheilung sehr schwer in Eis übergeht, macht es überhaupt unwahrscheinlich, dass das Imbibitionswasser der Zellwandungen gefriere. Die moleculare Umlagerung der Membrantheilchen in erfrorenen Zellen, soweit eine solche überhaupt vorkommt, dürfte daher wahrscheinlich durch den absterbenden Zelleninhalt verursacht werden. Sie ist ohne Zweifel die gleiche wie in allen krankhaft verän-

*) Handb. d. Experimentalphysiologie p. 60 . 
derten und absterbenden Zellen, und zu einer bestimmten Vorstellung über die molecularen Vorgänge dürfte zur Zeit wohl noch kaum genügendes thatsächliches Material vorliegen.

\section{Einfluss der Temperatur auf die Vegetationsprocesse.}

$4 \dot{8}$ Die Bestimmung des Einflusses, den die Temperaturunterschiede innerhalb der Grenzwerthe, zwischen welchen überhaupt das vegetabilische Leben möglich ist, auf den Verlauf der verschiedenen Lebensprocesse Assimilation, Stoffwechsel, Zellbildung etc.) ausüben, ist für die Experimentalphysiologie, wenn die Aufgabe in wahrhaft wissenschaftlichem Sinne aufgefasst wird *), mit grossen Schwierigkeiten verbunden, welche auch dem Antheil, der der mikroskopischen Beobachtung zufällt, keineswegs fehlen.

Handelt es sich z. B. um die Beobachtung des Wachsthums Zellenausdehnung und Zellentheilung' mikroskopischer Objecte bei möglichst constanten Temperaturen, so begegnet man den bis jetzt nicht überwundenen Schwierigkeiten der Cultur. Sowohl die Süsswasseralgen (Spirogyren, Cladophoren etc.) als diejenigen des Meeres zeigen eine so grosse Empfindlichkeit gegen Veränderungen ihres Mediums, dass es bis jetzt nicht geglückt ist, sie längere Zeit in normaler Vegetation zu erhalten, geschweige denn dasselbe Exemplar in einem geeigneten Apparat einige Tage oder Wochen bei $10^{\circ}$, dann bei $15^{\circ}$, dann bei $20^{\circ}$ u. s. w. zu beobachten, wie es doch zur Erreichung des beabsichtigten Zweckes nothwendig wäre. Die fraglichen Processe lassen sich also nicht verfolgen.

$\mathrm{W}_{\text {as }}$ bis jetzt in dieser Richtung geschehen ist und geschehen konnte, beschränkt sich auf Beobachtungen über die Geschwindigkeit der Zellsaftbewegungen bei Nitella, Vallisneria, in den Staubfädenhaaren von Tradescantia ctc., -- Erscheinungen, die zwar mit der Lebensthätigkeit im Allgemeinen in einem unverkennbaren Zusammenhang stehen, ohne jedoch einen Maassstab für bestimmte Processe darzubicten. ${ }^{* *}$ )

-) Wir theilen vollständig die Ansicht ron Sachs, dass die bezeichnete Aufgabe ihrer Lösung nicht um einen Schritt näher gebracht wird, wenn man sich damit begnügt, die Zeiträume zwischen Aussaat und Reife einer Pflanze bei gegebenen Mitteltemperaturen zu verzeichnen und die so erhaltenen Daten nach irgend einer willkürlich gewählten Formel in Rechnung zu bringen.

**) Die Geschwindigkeit der Plasmaströme steigt durchgehends bis zu einer Temperatur von $37-10^{\circ} \mathrm{C}$, nimmt sodann bei steigender Temperatur wieder $a b$ oder wird auch plötzlich Null. Vgl. Nägeli, Beiträge II. p. 7 ; ; Max Schultze, 
Bei Untersuchungen über die Abhängigkeit des Wachsthums von der Temperatur bei höheren Pflanzen kann das Mikroskop zur Unterscheidung der Zellenbildung von der Zellenstreckung Anwendung finden, in der Art, dass man Zahl und Länge der Zellen für die verschiedenen Regionen nach mittleren Werthen bestimmt. Eine nähere Darlegung dieses Verfahrens ist überflüssig.

\section{V.}

\section{Elektricität.}

Die Wirkungen der Elektricität auf den Zellinhalt haben in den $\mathbf{4 1 9}$ letzten Jahren, besonders mit Rücksicht auf die Plasmabewegungen, eine vielseitige Beachtung gefunden, und es lässt sich voraussehen, dass sie in Zukunft einen wichtigen Abschnitt der Experimentalphysiologie bilden werden. ${ }^{*}$ ) Sind auch die Folgerungen, die man aus den bis jetzt beobachteten Thatsachen gezogen hat, zum Theil mindestens gewagt, ja nach unserem Dafürhalten gänzlich ungerechtfertigt, so zweifeln wir desshalb doch nicht, dass das fortgesetzte Studium des Einflusses, welchen galvanische Ströme auf die Plasmabewegungen und auf das Zellenleben überhaupt ausüben, manche wichtigen Aufschlüsse über die Natur der im Organismus wirksamen Kräfte bieten wird. Wir glauben daher die Vorrichtungen, deren sich neuere Forscher für mikroskopische Untersuchungen dieser Art bedient haben, hier speciell erwähnen zu sollen; allfällige Abweichungen der Construction, die dem bestimmten Zwecke, den man

Das Protoplasma der Rhizopoden etc. p. 46; J. S a ch s, Experimentalphysiologie der Pflanzen p. 71.

*) Neuere Beobachtungen über den bezeichneten Gegenstand findet man in folgenden Schriften und Abhandlungen :

Th. J ürgensen (Studien des physiologischen Instituts zu Breslau 1 561 . II.)

F. Cohn: Contractile Gewebe im Pflanzenreiche Jahresber. d. Schles. Gesellsch. f. vaterl. Cultur 1561. I.).

Brücke: Das Verhalten der sogenannten Protoplasmaströme u. s. w. (Sitzungsber. der kais. Akad. d. Wiss. Wien 1s62. Bd. 46. 2. Abth.)

$\mathrm{H}$ eide $\mathrm{nh}$ a in (Studien des physiol. Instit. zu Breslau 1\$63. II. .

M ax Schultze: Das Protoplasma der Rhizopoden u. s. w. $1 \subseteq 63$.

W. Kühne: Unters. über das Protoplasma u. die Contractilität. 1564.

Vgl. ferner G. Quin cke: Ueber die Fortführung materieller Theilchen durch strömende Elektricität (Pogg. Ann. Bd. 113 [1561] p. 513). 
gerade im Auge hat, noch besser entsprechen, wird sich alsdann der Beobachter leicht selbst ausdenken.

Was zunächst die Elektricitätsquelle betrifft, so ist eine kleine Rotationsmaschine oder ein Inductionsapparat, der von 1-2 kleinen Elementen getrieben wird, in der Regel vollkommen ausreichend. Derselbe soll indess nicht bloss eine beliebige Abschwächung der Stromstärke gestatten, sondern auch mit einer Vorrichtung versehen sein, welche den durch Oeffnen und Schliessen des Hauptstroms erzeugten Inductionsströmen die nämliche Richtung gibt. Wie diess $\mathrm{zu}$ erreichen ist, darf wohl als bekannt vorausgesetzt werden, da hierüber jedes physikalische Lehrbuch hinlängliche Auskunft gibt.

Um nun zweitens den elektrischen Strom durch ein unter dem Mikroskop befindliches Object zu leiten, so hat man zu diesem Behufe verschiedene Einrichtungen vorgeschlagen, von denen wir folgende hervorheben. Harting (Mikr. p. 428) empfiehlt einen Objectträger, wie er in Fig. $20 \mathrm{~S}$ abgebildet ist. Die Herstellung des-

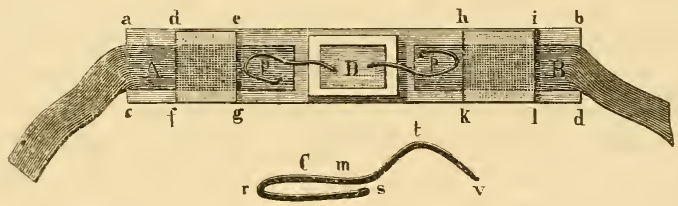

Fig. 20s.

selben ist ungemein einfach. Zwei Stanniolstreifen $A$ und $B$, die etwas schmäler sind als die Glasplatte $a b c d$, werden mit Stärkekleister so auf dieselbe geklebt, dass ein Theil des Stanniols an beiden Enden frei überragt und ein Raum von $25-30 \mathrm{~m}$. $\mathrm{m}$. dazwischen übrig bleibt. Zur Isolirung von der Klemmfeder des Objecttisches, welche das Ganze zu halten bestimmt ist, legt man sodann zwei Glasplättchen defg und hikl auf die betreffenden Stellen und befestigt dieselben mittelst einer Mischung von Pech und Harz oder auch mit Guttaperchaleim oder Seeleim. Die Poldrähte $p$ und $p$ bestehen aus geglühtem Kupferdraht oder noch besser aus Platindraht, der wie bei $C$ gebogen und dann bloss aufgelegt, nicht befestigt wird. Der Theil $r m s$ kommt hiebei auf den Stanniol, der andere in einer senkrechten Ebene gebogene mit seiner Spitze $v$ in die Beobachtungsflüssigkeit zu liegen. Nöthigenfalls bringt man das Object in einen kleinen Glas- oder Guttaperchatrog und taucht die Pole in das Was- 
ser, womit derselbe gefüllt ist. Die frei herabhängenden Enden der Stanniolstreifen dienen zur Verbindung mit den Leitungsdrähten des galvanischen Apparates.

Kühne bediente sich bei seinen "Untersuchungen über das Protoplasma und die Contractilität " eines Elektrodenpaars, wie es in Fig. 209 dargestellt ist. Zwei in der angedeuteten Art zugeschnittene Stücke von Platinblech wurden mittelst Siegellack auf die Glasplatte befestigt und hierauf die schmalen mittleren Streifen, auf welche das Object zu liegen kam, von beiden Seiten her bis auf ein kleines Stück von $1-2^{\mathrm{m}} \mathrm{m}$. Breite mit einem isolirenden Firniss

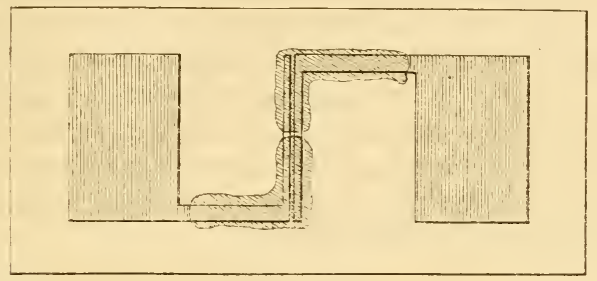

Fig. 209.

überzogen, wozu sich z. B. eine Auflösung von Dammarharz in Chloroform ganz gut eignet. Die breiten Theile der Elektroden wurden beim Gebrauche mit kleinen, an der unteren Fläche jedesmał blank geriebenen Bleiklötzen beschwert und durch diese mit den Enden der secundären Rolle des Inductionsapparates verbunden.

$\mathrm{U}_{\mathrm{m}}$ die Terschiebbarkeit des Objectträgers so bequem als möglich zu machen, empfiehlt $\mathrm{K} u ̈ h n e$, dünnen ausgeglühten Eisendraht, wie ihn die Chirurgen zum Nähen benutzen, an die Klötzchen zu schrauben. Solche Drähte folgen der Bewegung des Objectträgers, besonclers wenn sie spiralig aufgerollt sind, so gut wie ein Faden.

Die Vorrichtung, deren wir uns bedienten, um die Wirkung des galvanischen Stromes auf Plasmabewegungen zu beobachten, bestand aus einem gewöhnlichen Objectträger mit Stanniolelektroden, die mittelst Stärkekleister aufgekittet und in der Mitte bis auf c. 2 m. mgenähert waren. Behufs Herstellung einer bequemen Verbindung mit den Leitungsdrähten des Inductionsapparates waren beiderseits kurze Messingdrähte, die an den Rändern etwas hervorragten und hier mit einem Hacken endigten, auf die Stamiolstreifen gelegt und zur Erzielung eines guten Contactes zwei bis drei andere Stanniolplättchen darüber geklebt; ausserdem waren die Drähte am Rande 
mit Siegellack auf dem Objectträger befestigt. Eine theilweise Isolirung der Elektroden durch einen Firnissüberzug war überflüssig, da der Strom auch ohne dieses Mittel sich stark genug erwies.

Da es in der Praxis gewöhnlich darauf ankommt, den Moment zu beobachten, in welchem die Schliessung des galvanischen Stromes stattfindet, so muss dafür gesorgt sein, dass irgendwo in der Leitung die Herstellung und Unterbrechung des Contactes leicht und sicher bewerkstelligt werden kann, während das Auge ins Mikroskop sieht. $\mathrm{K} u ̈ h n e$ ersetzte zu diesem Behufe den rasch arbeitenden Hammer des Inductionsapparates durch ein eingeschaltetes Quecksilbernäpfchen, in welches er nach Belieben mit der Hand den mit einem Hacken versehenen Leitungsdraht der Kette eintauchte. Dieses Verfahren ist gewiss ganz zweckmässig; wir haben aber nicht nöthig zu bemerken, dass man den nämlichen Zweck auch durch directes Andrücken des Leitungsdrahtes an die vorstehenden Schraubenköpfe der Inductionsspirale oder auch an den entsprechenden Pol der Kette in völlig befriedigender Weise erreicht.

Ueber die Art der Einwirkung galvanischer Ströme auf das Plasma und die verschiedenen Grade derselben theilen wir nachstehend einige Einzelnheiten mit, welche der Darstellung Br ücke's *ै। nach Beobachtungen an den Brennhaaren der Nessel (Urtica urens" entnommen sind.

„) Die erste Veränderung, die man (nach einer kurzen Reihe von Inductionsschlägen) wahrnimmt, besteht in der Regel in dem Erscheinen einer grösseren oder geringeren Menge von Fäden, welche vom Zellenleibe aus (d. h. vom wandständigen Plasma) in die Intercellularflüssigkeit hineinragen. Ich habe sie nicht immer, aber doch bei weitem in der Mehrzahl der Fälle gesehen, und da sie von wechselnder Dicke, oft äusserst dünn sind, so mögen sie sich wohl das eine oder das andere Mal der Beobachtung entzogen haben. Manchmal sieht man sie wie Raketen aus dem Zellenleibe hervorschiessen, sobald man den Kreis des Magnetelektromotors schliesst. Sie haben oft eine beträchtliche Länge; ich habe deren solche beobachtet, die in gestreckten Zustande bis zur Axe in das Innere des Haares hineinragten. An ihrem Ende tragen sie eine grössere oder kleinere Anschwellung, und man sieht sie in einer fortwährenden, bald schwä-

-) Sitzungsber. d. k. k. Akad. der Wiss, in Wien, Bd. 46. 2. Abth. p. 35. 
cheren bald stärkeren, zitternden oder schlängelnden Bewegung begriffen. Bisweilen sieht man neben den Fäden auch stärkere Kolbenoder keulenartige Gebilde hervortreten. "

"Hatte die Einwirkung der Ströme einen gewissen Grad nicht überstiegen, so kann hiebei das Fliessen der körnerreichen Flüssigkeit in Zellenleibe noch eine Weile fortdauern, ja es kommt häufig vor, dass die Fäden und Kolben wieder verschwinden und der normale Zustand, soweit die Anschauung darüber Aufschluss gibt, wieder hergestellt ist. "

„War die Einwirkung heftiger oder schliesst man den Kreis des Nagnetelektromotors von neuem, so hört das Fliessen sofort auf und man sieht die Körnchen nur noch in einer unregelmässigen Bewegung, die ganz den Charakter der unter dem Namen der Molecularbewegung bekannten Erscheinung trägt. a

Weiter wird angegeben, dass in der bisher vollständig reinen und klaren Zellflüssigkeit Körnchen erscheinen, die zu kleinen Gruppen vereinigt Molecularbewegung zeigen, dass aber später auch diese Bewegung aufliöre, worauf der Zellenleib sich von der Wandung abzulösen und zu schrumpfen pflege.

Die Beobachtungen, die wir selbst an den Staubfädenhaaren vou Tradescantia anstellten, ergaben etwas weniger auffallende Resultate. Dieselben stimmen übrigens mit den hierauf bezüglichen Angaben von $K \ddot{~ u ̈ h n e ~ u ̈ b e r e i n . ~ D i e ~ W i r k u n g ~ d e s ~ g a l v a n i s c h e n ~}$ Stromes beschränkt sich hier auf kugelige oder papillenförmige Auftreibungen der Plasmabänder, verbunden mit einer raschen Coagulation des Zellkerns und der Plasmasubstanz, und die erste Veränderung, die man beobachtet, ist das Aufhören der Körnchenbewegung. Ebenso tritt auch in den Rotationsströmen der Charen und Vallisnerien beim Schliessen der Kette augenblicklicher Stillstand ein, ohne dass zunächst irgend welche Veränderung im Inhalte bemerkbar wäre. Eine vorhergehende Verlangsamung der Bewegung, wie sie Jürgensen für Vallisneria beschreibt, haben wir nicht beobachtet; doch mag diess wohl in der mangelhaften Einrichtung zur Normirung des Stromes seinen Grund haben.

Sämmtliche Beobachter stimmen darin überein, dass eine Terschiedenheit der Wirkung eines constanten Stromes auf gleich gerichtete oder gegenläufige Plasmaströme nicht zu constatiren ist. Eine Umkehrung der Ströme, wie man sie vielleicht erwarten möchte, findet also auf keinen Fall statt. Dasselbe gilt von inducirten Strö- 
men mit gleich gerichteten Inductionsschlägen. Die Veränderungen, welche die elektrischen Eingriffe hervorrufen, stimmen überhaupt, soweit die bisherigen Beobachtungen reichen, im Wesentlichen mit denjenigen überein, welche durch mechanische oder chemische Mittel, durch Wärme oder Kälte veranlasst werden. Es gehört immer ein gewisser Grad der Einwirkung dazu, um einen vorübergehenden Starrezustand, und eine etwas stärkere Einwirkung, um den Tod der Zelle herbeizuführen. 


\section{Neunter Abschnitt. II i k r o c he m i e.}

Obschon die mikrochemische Untersuchung bloss in der An- 423 wendung bekannter chemischer Verfahren auf mikroskopische Objecte besteht, so sind doch in manchen Fällen besondere Vorsichtsmaassregeln und Manipulationen erforderlich, die der Anfänger im Mikroskopiren erst lernen muss. Hiezu die nöthige Anleitung zu geben, ist der erste nächstliegende Zweck, den die folgenden Blätter erfüllen sollen.

Dazu kommt aber noch, dass manche schätzenswerthe Mittheilungen über chemische Reactionen und Prüfungsmethoden, darunter solche, die sich gerade auf die wichtigsten Producte des Lebensprocesses beziehen, in der Literatur zerstreut und daher weniger zugänglich sind. Diese Mittheilungen zu sammeln und zu sichten, soweit thunlich zu prüfen und hie und da auch zu vervollständigen, das war eine weitere, wesentliche Aufgabe, die wir uns für diesen Abschnitt gestellt hatten.

I.

\section{Allgemeine Regeln.}

Es ist zunächst von Wichtigkeit, ein bestimmtes Reagens in all- $\mathbf{4 2 4}$ mählich steigender Concentration anwenden zu können, um die Wirkung desselben Stufe für Stufe zu verfolgen. Man erreicht nun zwar diesen Zweck annähernd schon durch einfachen Zusatz der Flüssigkeit am Rande des Deckgläschens, indem alsdann die Vermischung mit dem Präparatwasser, wenigstens in einiger Entfernung vom Rande, nur durch Diffusion und daher sehr langsam geschieht; allein die so erzielten Uebergänge der Einwirkung sind gleichwohl nicht immer so stetig, wie es wünschenswerth wäre, und da gerade hievon nicht selten die Zuverlässigkeit der Beobachtungen abhängt, so ist es unter 
Umständen wichtig, auch feinere Verfahren zu kennen, welche die Langsamkeit der Einwirkung noch zu steigern gestatten. Als solche sind zu empfehlen :

1) Man bringt unter das Deckgläschen einen feinen baumwollenen oder leinenen Faden, dessen eines Ende unter dem Rande desselben hervorsteht, und tränkt nun dieses hervorstehende Ende mit einem Tropfen des Reagens. Das letztere fliesst alsdann durch den Faden unter das Deckgläschen und mischt sich dort mit der Beobachtungsflüssigkeit.

2) Steht das Reagens auch im ungelösten Zustande zu Gebote, so werden kleine Splitter desselben direct in die Beobachtungsflüssigkeit gelegt. Die gelösten Theile verbreiten sich alsdann ganz allmählich in der Umgebung der Splitter. Für die Iodreaction ist dieses Verfahren sehr zu empfehlen.

3) Ein Tropfen der sehr verdünnten Lösung, die an den darin vertheilten Objecten noch keine Veränderung hervorruft, wird auf dem Objectträger (ohne Deckgläschen) der Terdunstung überlassen. Da die letztere am Rande des Tropfens schon der Krümmung der Oberfläche wegen am raschesten erfolgt, d. h. für die Einheit der Grundfäche am grössten ist, so steigt hier auch die Concentration rascher als in der Mitte. *) Dieses Verhalten macht es möglich, dieselbe T'eänderung wiederholt auf dem nämlichen Präparat zu beobachten und die verschiedenen Stadien der Einwirkung sowohl nach einander in beliebiger Langsamkeit, als neben einander in den schönsten Uebergängen hervorzurufen. - Selbstverständlich ist jedoch eine solche Steigerung der Concentration nur denkbar, wenn in einer leichter verdunstenden Flüssigkeit eine schwerer verdunstende oder fixe Substanz gelöst ist, was übrigens der gewöhnliche Fall ist.

425 Ein zweiter Punkt betrifft die Herstellung eines mehr oder weniger raschen Stromes in der Beobachtungsflüssigkeit, wie er z. B. beim Auswaschen der Präparate ohne Wegnahme des Deckgläschens nothwendig ist. Bei dickeren Objecten, die einen beträchtlichen Abstand zwischen Objectträger und Deckplättchen bedingen, erreicht man den beabsichtigten Zweck einfach durch Neigung der Objectplatte und Zusatz von Flüssigkeit an dem nach oben gekehrten Rande des Deckgläschens, indem hiebei eine entsprechende Menge am unteren Rande abfliesst. Bei kleinen Objecten und geringem Abstand der Glastafeln, wo die grössere Reibung durch die Schwere des Was-

* Vgl. pag. 379. 
sers nur langsam überwunden wird, zieht man die Beobachtungsflüssigkeit am besten mit Fliesspapier aus, das man an einem Rande des Deckgläschens mit derselben in Berührung bringt, während man auf der andern Seite das betreffende Reagens oder das Auswaschwasser zusetzt.

Handelt es sich darum, einen langsamen Strom von Wasser längere Zeit zu unterhalten, so vermittelt man die Zufuhr durch einen Baumwollenfaden, welcher einerseits mit der Beobachtungsflüssigkeit und andererseits mit einer grösseren Wassermenge in Verbindung steht, deren Oberfläche jedoch im Niveau des Objectes oder höher liegen muss. Ein zweiter Baumwollfaden wird zum Behuf eines rascheren Wechsels an den anderen Rand des Deckgläschens gebracht und dessen herabhängendes Ende so gewählt, dass die durch ihn bewirkte Verdunstung der Zufuhr ungefähr das Gleichgewicht hält und so ein Ueberfliessen des $W$ assers auf den Objecttisch rerhindert. Auf diese Weise wird es möglich, Algenfäden, die unter dem Mikroskop liegen, längere Zeit lebend zu erhalten und ihre Entwicklung zu verfolgen.

Will man die Einwirkung einer höheren 'Temperatur auf die $\mathbf{4 2 6}$ Objecte untersuchen, so genügt in der Regel das directe Erwärmen des Objectträgers über der neben dem Mikroskop aufgestellten) Weingeistlampe. Man lässt die Flamme, je nachdem man eine gleichmässige Erwärmung oder aber eine stetige Abnahme der Einwirkung von einer Stelle des Präparats zur andern beabsichtigt, über die ganze Fläche oder nur auf den Rand desselben spielen, so dass in diesem letzteren Falle der gegenüber liegende Rand die geringste Einwirkung erfährt. Die Wärmequelle unter dem Objecttisch anzubringen, wie diess Harting u. A. empfehlen, finden wir im Allgemeinen weniger rathsam und überhaupt nur in seltenen Fällen wünschenswerth; denn abgesehen davon, dass man bei Anwendung von Reagentien, deren Dämpfe das Flintglas angreifen, das Objectiv durch eine besondere, unten mit einer Glasplatte versehene Hülse oder doch. mindestens durch ein grosses Deckplättchen schützen muss, ist damit für die Beobachtung gewöhnlich nicht viel gewonnen, da die in der Flüssigkeit stattfindenden Strömungen eine ununterbrochene Bewegung der Objecte verursachen.

Dagegen kann es für gewisse Untersuchungen von Wichtigkeit sein, das Präparat längere Zeit in einer constanten Temperatur über oder unter Null zu erhalten, was sich je nach den speciellen Anforderungen, 
die man stellt, in rerschiedener Weise ausführen lässt. Soll die Temperatur, der das Object ausgesetzt ist, möglichst genau bekannt sein, so dürfte ein Apparat, wie er in Fig. 210, III dargestellt ist, sich be-

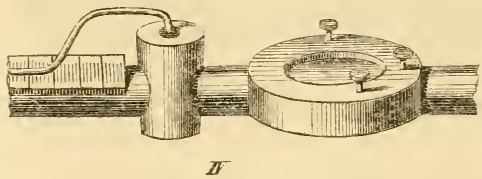

Fig: 210,
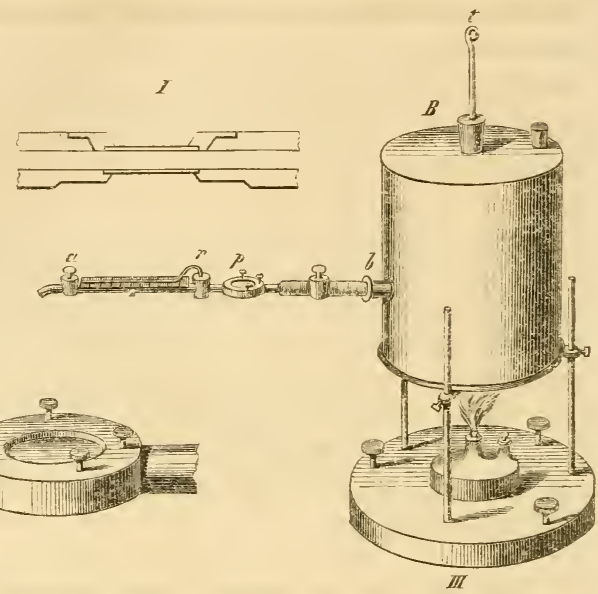

sonders empfehlen. Nägeli benutzte denselben, um die Geschwindigkeit der Saftströmung in den Zellen der Charen bei verschiedenen Temperaturen zu beobachten. Das Object wurde in der Mitte der Röhre $a b$ in einer scheibenförmigen Erweiterung $p$, die nach oben und unten durch parallele Glasplatten abgeschlossen war, befestiçt und das Mikroskop (nöthigenfalls mit einem Untersatz versehen darauf eingestellt. Durch die Röhre wurde ein langsamer, durch den Hahn bei a beliebig zu regelnder Strom von Wasser geführt, das im Behälter $B$ nach Belieben erwärmt oder durch eingelegtes Eis unter die Zimmertemperatur abgekühlt werden komnte. Zur Bestimmung der Temperatur dienten zwei Thermometer, woron das eine $t$ im Behälter bis zur Oeffnung der Ausflușsiöhre eingesenkt, das andere am Ende der Röhre horizontal angebracht und mit seiner Kugel bei $r$ in das Lumen derselben eingekittet war. Die Wärmedifferenzen, welche die beiden Thermometer anzeigten, waren übrigens nicht bedeutend; sie erreichten bei sehr langsamer Strömung 1 Grad, bei etwas rascherer, je nach der Zimmertemperatur, 1/3 bis $1 / 2$ Grad. *)

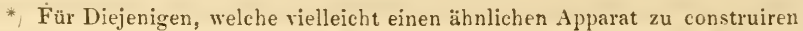
beabsichtigen, fügen wir noch des Näheren bei, dass zum Einlegen des Eises ein 
Will man kleinere Objecte, wie z. B. Diatomeen, Desmidiaceen u. dgl. beobachten, so können dieselben zwischen zwei Deckplăttchen, die man mit Wachs befestigt, oder in einem verschlossenen Glastrog von geringer Tiefe in die Röhre gebracht werden.

Eine andere Vorrichtung, welche zwar viel einfacher und mit ge- $\mathbf{4 2 7}$ ringeren Kosten herstellbar ist, dafür aber an Genauigkeit der eben beschriebenen nachsteht, wurde von Thomé (Bot. Ztg. 1565. p. 107) vorgeschlagen und durch eine Zeichnung veranschaulicht. Derselbe bedient sich eines erwärmbaren Objecttisches, welcher mit drei Metallspitzen auf dem Tisch des Mikroskopes ruht und beiderseits etwa 2 Zoll über denselben hervorragt. Zum Festhalten dienen gewöhnliche Federn, welche durch übereinander liegende Oeffnungen der beiden Tische gesteckt werden. Der auf der rechten Seite hervorragende Theil wird durch eine untergestellte Weingeistlampe erhitzt; auf der linken Seite befindet sich ein Thermometer, dessen Kugel in einer aufgesetzten Metallhülse ruht.

Vor der Anwendung des erwärmbaren Tisches wird durch vorläufige Versuche die wahre Wärme derjenigen Stelle bestimmt, auf welcher das Präparat liegt. Zu diesem Behufe legt man auf die Lichtöffnung einen Objectträger, misst dessen Wärme durch ein feines Thermometer und bestimmt durch öftere Tersuche oder durch Interpolation ein für allemal die Differenzen beider Thermometer für verschiedene Wärmegrade. Näheres über die Art, wie das feine Thermometer anzubringen sei und wie genau dasselbe in irgend einem bestimmten Falle die wahre Temperatur des Präparats angebe, ist nicht mitgetheilt.

Weit zweckmässiger eingerichtet ist jeclenfalls der auf demselben Princip beruhende heizbare Objecttisch ron M. Schultze.*; Da

hohlcylindrisches Gefäss (s. Fig. 210, II Durchschnittsansicht des Behälters) diente, welches mit einem entsprechenden Einschnitt zur Aufnahme der bis zum Centrum vordringenden Röhre versehen war. Ferner wurde eine möglichst gleichmässige Wärmevertheilung beim Erhitzen dadurch erzielt, dass etwa 1 Zoll über dem Boden des Wasserbehälters eine kreisförmige Scheibe angebracht war, welche die erwärmten Wassertheile zunächst nach der Peripherie hin leitete. Die Wand des Behälters war überdiess doppelt, um eine zu rasche Abkühlung zu vermeiden. - Das Gefäss, in welches das Object zu liegen kam Fig. 210, III $p$, I, IV), konnte nach oben geöffnet und wieder wasserdicht verschlossen werden. Die obere Glasplatte war nämlich mit einer Fassung von Messing versehen, welche nach Art eines Deckels eingepasst und mittelst Schrauben zu befestigen war. Der Zwischenraum $z$ wischen den beiden Glasplatten mochte etwas weniger als eine Linie betragen.

*) M. Schultze, Archiv für mikroskopische Anatomie I (1865), 1. Heft. 
derselbe in den meisten Fällen, so oft nämlich Fehler in der Temperaturbestimmung von c. $2{ }^{\circ} \mathrm{C}$. nicht in Betracht kommen, vollständig genügen dürfte, so geben wir nachstehend die ausführliche Beschreibung desselben, wie sie vom Erfinder a. a. O. mitgetheilt wurde.

") Der heizbare Objecttisch, welchen ich ron dem Mechaniker Herrn Geis sler hierselbst anfertigen liess, und welcher sich als ein sehr wichtiges Hülfsmittel bei vielen Untersuchungen bewährt hat, ist dazu bestimmt, auf den gewöhnlichen Objecttisch eines Mikroskopes aufgesetzt $\mathrm{zu}$ werden, den er etwa um 1 Centimeter erhöht (s. Fig. 211, wo derselbe von unten in ${ }^{1 / 3}$ natürlicher Grösse abgebildet ist). Derselbe besteht aus einer ungefähr hufeisenförmigen

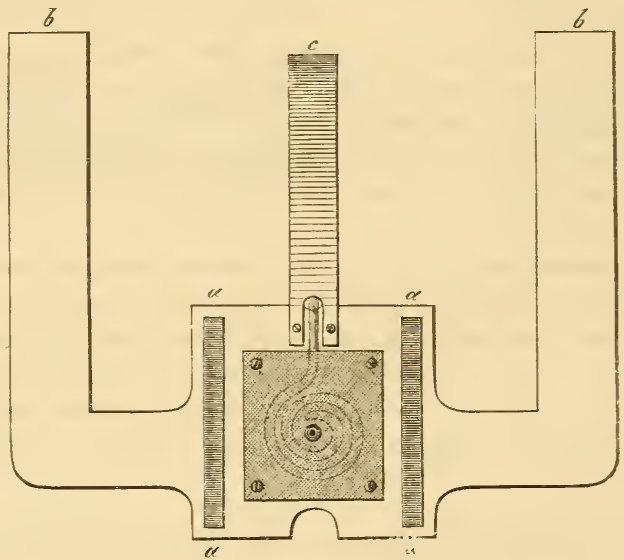

Fig. 211 .

Messingplatte von 1-2 m. m. Dicke. Der mittlere Theil hat die Ausdehnung und Form eines recht grossen gewöhnlichen Objecttisches und verlängert sich nach beiden Seiten in 3 Centimeter breite Arme, welche nach kurzem Verlaufe in rechtem Winkel nach vorn umbiegen und von da an noch eine Länge von $17-20$ C. M. besitzen. Unter ihnen brennen behufs der Erwärmung des Objecttisches Spirituslampen. Die Länge der Arme ist so gewählt, dass bei Erhitzung ihrer Enden durch kleine Flammen die Mitte des Objecttisches ungefähr Körperwärme, also $35-40^{\circ} \mathrm{C}$. annimmt. Diese Mitte ist. von kleiner Blendungsöffnung durchbohrt, welche bei der Befestigung des heizbaren Objecttisches jedesmal genau zu centriren ist. 
An die untere Seite des Tisches sind seitlich zwei von vorn nach hinten laufende viereckig prismatische Holzleisten $(a)$ befestigt, mittelst deren er auf dem eigentlichen Objecttisch des Mikroskopes ruht und durch welche eine Mittheilung der Wärme an letzteren, zugleich eine Berührung des in der Mitte unter dem Tisch angebrachten Thermometerkastens mit dem untern Objecttisch verhindert wird. Das Thermometer besteht aus einem spiralgewundenen, die Blendungsöffnung umkreisenden Quecksilberbehälter von zwei vollständigen Spiraltouren, aus welchem sich die Thermometerröhre nach vorn erhebt, um an eine aus starkem Messing gearbeitete durch Schrauben an den Tisch befestigte Scala $(c)$ zu gelangen, deren vorderer Seite sie anliegt. Die Scala steht schief nach vorn und aufwärts, so dass der Stand des Quecksilber's während der mikroskopischen Beobachtungen leicht abgelesen werden kann, und ist in ganze Grade nach Celsi us getheilt. Die Quecksilberspirale muss der unteren Fläche des messingenen Tisches womöglich mit einer abgcplatteten Fläche genau anliegen, um deren Temperatur schnell aufzunehmen, und ist in einen niedrigen Kasten von Messingblech eingeschlossen, welcher eine Verletzung derselben hindert, vor Abkühlung bewahrt, und indem er die Temperatur des Objecttisches annimmit, das Thermometer auch von unten her erwärmt. In die Mitte des Kästchens ist eine conisch ausgedrehte, imnen geschwärzte Blendung eingesetzt, etwa von den Dimensionen der Hartnack'schen Cylinderblendungen. "

Die Befestigung des heizbaren Tisches kann entweder durch Zapfen, welche in Vertiefungen des Objecttisches, natürlich unter Berücksichtigung der Centrirung, eingepasst sind, oder anch durch Klemmschrauben, wie sie Herr Geissler dem Apparat beigiebt, geschehen. Die Entfernung der Holzleisten $a a$, welche in dem abgebildeten Apparat c. 6 C. M. beträgt, richtet sich natürlich, weil dieselben dem Objecttisch aufliegen müssen, nach den Dimensionen des letzteren.

Zur Vermeidung der Unbequemlichkeiten, welche die raschere Verdunstung der Flüssigkeit bei erhöhter Temperatur mit sich bringt, bediente sich Schultze der ron Recklinghausen*) empfohlenen feuchten Kammer. Dieselbe besteht aus dem abgesprengten unteren Stück eines Lampencylinders, dessen glatt polirter Rand auf der hinreichend gross zu wählenden Objectplatte ruht, indess derobere engere Theil sich möglichst genau dem Tubus des Mikroskops anschliesst, ohne jedoch den auf- und absteigenden Bewegungen des

* Virchow' Archiv etc. Bd. XXviII, 1\$63, p. 152. 
letzteren hinderlich zu sein. Ein Streifen feuchten Fliesspapiers, den er auf die innere Fläche des Lampencylinders aufklebte, lieferte den zur Feuchthaltung der Kammer nöthigen Wasserdunst.

Zur Prüfung der Frage, ob die an der Scala abgelesene Temperatur derjenigen des Objectes entspreche, empfiehlt sich die Beobachtung des Schmelzpunktes von Fetten, von denen man im flüssigen Zustande ein mikroskopisches Präparat anfertigt, nachdem man vorher den Schmelzpunkt auf andere Weise genau geprüft hat. Nach Schultze, welcher diese Prüfung mit einer Anzahl ron Geissler gefertigter Apparate rornahm, gaben dieselben die gewünschte Temperatur bis auf c. $2{ }^{\circ} \mathrm{C}$. genau an.

Wir bemerken noch, dass $\mathrm{Geissler}$ bereits geprüfte Apparate vorräthig hält und zu`i 0 Thlr. abliefert.

Um bei der Anwendung von Lösungsmitteln nicht irre geführt $\mathrm{zu}$ werden, thut man am besten, das zu untersuchende Object möglichst $\mathrm{zu}$ isoliren. Es kommt nämlich öfters vor, dass Bildungen, die in ziemlich dickwandigen Zellen enthalten sind, sich äusserst langsam auflösen oder sogar unlöslich zu sein scheinen, während sie nach dem Zerreissen der Zellen, wenn das Reagens unmittelbar auf sie einwirkt, sogleich verschwinden. Wo ein Freipräpariren des Objectes nicht wohl möglich ist, bedarf es einer längeren Einwirkung des Lösungsmittels, oft sogar einer wiederholten Erwärmung über der WVeingeistflamme, um über die Löslichkeit oder Unlöslichkeit der Substanz ganz sicher zu sein.

\section{II.}

\section{Aufzählung der Reagentien.}

430 Wir gehen nun zur Aufzählung der Reagentien über, die man bei botanischen Untersuchungen zu rerwenden pflegt, wobei wir zugleich die Wirkung derselben kurz andeuten und, wo es nöthig ist, auch über die Bereitung und die beim Gebrauche erforderliche Vorsicht einiges Nähere beifügen.

1) Aetzkali. Wird in verdünnter Lösung zunächst dazu verwendet, die Gewebe durchsichtiger zu machen, wozu in manchen Fällen eine äusserst starke Verdünnung und kurze Dauer der Einwirkung, in andern eine etwas stärkere Concentration, verbunden mit Erwärmung, nothwendig ist. Welche Art der Behandlung am günstigsten wirkt, muss durch den Versuch ermittelt werden. Man setzt 
zuerst eine ganz schwache Lösung zu, dann eine stärkere u. s. f., erwärmt zuerst nur wenig, dann mehr, bis der gewünschte Effect eintritt. Gewisse Gewebe werden indess mit Kali niemals durchsichtig, sondern färben sich dunkel, oft tief rothbraun, so dass man zu andern Reagentien seine Zuflucht nehmen muss. Manche Gewebe werden nur auf eine kurze Zeit hell und nachher dunkel.

Das Kali verursacht eine mehr oder weniger starke Quellung der Zellmembranen und Stärkekörner, löst Fette (durch Verseifung), Proteinverbindungen etc. Termöge dieser Eigenschaften dient es zur "Purificirung incrustirter Membranen ", wie z. B. des Korkes. Der letztere färbt sich nach längerem Erhitzen in Kali auf Zusatz ron Iod und Schwefelsäure blau.

Die Aufbewahrung des Kali in gelöster Form bringt den Uebelstand mit sich, dass der Glaspfropfen, wenn er gut eingeschliffen ist, bei längerem Nichtgebrauch in Folge der Bildung eines Silicates fest mit der Flasche verwächst, der Korkpfropfen aber zerfressen wird, indess ein schlechter Verschluss die Aufnahme von Kohlensäure aus der Luft ermöglicht. Andererseits ist die Aufbewahrung des Kali in Pulver- oder Stäbchenform und die jedesmalige Bereitung der Lösung viel umständlicher und schon desswegen für die gewöhnlichen Fälle unpraktisch. Wir haben bis jetzt der Lösung, trotz der erwähnten Nachtheile, immer den Vorzug gegeben.

2) Wässerige und weingeistige Iodlösung. Dient vorzugsweise zur bekannten Färbung des Zellinhaltes und der Zellmembranen. Da sich bei längerem Stehen unter dem Einfluss des Lichtes Iodwasserstoffsäure in der Lösung bildet, so rerwendet man bei Lntersuchungen, wo die Reinheit des Reagens wichtig ist, am besten metallisches Iod, oder bereitet sich die Lösung unmittelbar vor dem Gebrauch. Manche Zellmembranen färben sich z. B. in alter Iodtinctur schön blau, während sie in frisch zubereiteter farblos bleiben, Man kann überhaupt ganz allgemein sagen, dass der Farbenton, den man bei der Iodreaction beobachtet, wesentlich von der Anwesenheit dritter Substanzen in der Beobachtungsflüssigkeit oder im Object abhängig ist. ${ }^{*}$ Bei genauen Untersuchungen kann hienach sogar ein Auswaschen des Präparates nothwendig sein, wenn die reine Iodlösung zur Wirkung kommen soll.

3) Iod gelöst in einer Iodverbindung. Hieher gehören die Iodzink-Iodlösung, die Iodkalium-Iodlösung, Iodammoniak-Iod-

*) Zahlreiche Belege hiefür gibt $\mathrm{N}$ ägeli in den Sítzungsberichten der k. b. $\Lambda \mathrm{kad}$. der Wiss. Vortrag r. 13. Dec. 1562. 
lösung etc. Alle diese Verbindungen verhalten sich im Wesentlichen gleich; sie bewirken dieselbe Blaufärbung der Cellulose, wie Iod in Verbindung mit Schwefelsäure oder Iodwasserstoffsäure. Eine besondere Vorschrift zur Bereitung dieser Reagentien ist im Grunde ziemlich überflüssig, da es ja bloss darauf ankommt, dass Iod in der betreffenden Iodverbindung gelöst sei; doch mag das Schultz'sche Recept zur Chlorzink-Iodlösung hier noch Platz finden: Man löse Zink in Salzsäure auf, dampfe die Lösung unter Berührung mit metallischem Zink bis zur Syrupdicke ab und löse darauf in diesem Syrup Iodkalium bis zur Sättigung. Alsdann wird Iod hinzugefügt und die Lösung, wenn es nöthig ist, mit Wasser verdünnt.

4) Concentrirte Schwefelsäure. Als Auflösungs- und Quellungsmittel der Zellmembranen vielfach angewendet. Mit etwas Wasser verdünnt eignet sie sich am besten zur Blaufärbung der Cellulose in Verbindung mit Iod. Die Färbung tritt am sichersten ein, wenn man das Präparat zuerst mit der Iodlösung betupft und damn clie Säure zusetzt.

5. Kupferoxyd-Ammoniak. Wie die Schwefelsäure als Lösungs- und Quellungsmittel zu gebrauchen und für manche Zellmembranen Baumwolle, Bastfasern etc.) vorzuziehen. Andere, wie z. B. die Membranen der Flechtenfasern, werden von diesem Reagens nicht angegriffen. Die Bereitung geschieht durch Auflösen frisch gefällten noch feuchten Kupferoxyds in ätzender Ammoniakflüssigkeit.

6. Salpetersäure. Findet verschiedene Anwendung. Werden Holzzellen in starker Säure so lange gekocht, bis sie farblos werden, und dann mit concentrirter Schwefelsäure behandelt, so lassen sie die Structurverhältnisse der Membran: Schichten, Streifungen etc. sehr schön erkennen. - Stickstoffhaltige Substanzen, die mit Salpetersäure .behandelt wurden, färben sich auf Zusatz von Ammoniak mehr orler weniger gelb; schon die Säure allein bewirkt einen gelblichen 'Ton.

Als Macerationsmittel wirkt dic Salpetersäure ähnlich, wie die bekannte zuerst von Schultz empfohlene Mischung derselben mit chlorsaurem Kali. Querschnitte durch Tannenholz lassen sich schon nach kurzem Erhitzen 'am besten in einer Kochröhre) in ihre einzelnen Zellen zerlegen; man hat zu diesem Ende nur nöthig, dieselben auf dem Objectträger mit dem Deckglas zu zerreiben. Da die Zellenstücke, die man auf diese Weise erhält, sich bequem drehen lassen, so ist diese Behandlung der Querschnitte bei manchen Untersuchungen sehr zweckmässig. Man rerschafft sich den nöthigen Vorrath von 
Untersuchungsmaterial, indem man eine grössere Menge von Schnitten in einer Kochröhre erhitzt und dann in eine reichliche Quantität von Wasser ausgiesst, um einer weiteren Veränderung vorzubeugen. - Das vollständige Schultz'sche Macerationsverfahren besteht in Folgendem: Man zerkleinert den Gegenstand, z. B. Holz, bis zur Dicke eines Schwefelhölzchens, bringt denselben in eine lange und mässig weite Kochröhre, gibt dem Volumen nach eben so viel chlorsaures Kali hinzu und so viel Salpetersäure, dass Holz und Kali mindestens davon bedeckt werden. Man erwärmt jetzt über der Weingeistlampe, es tritt bald eine lebhafte Gasentwicklung ein, worauf man die Kochröhre von der Flamme entfernt, aber das oxydirende Gemisch noch $1 \frac{1}{2}-3$ Minuten einwirken lässt und darauf das Ganze in eine Schaale mit Wasser schüttet. Mlan sammelt alsdann die noch ziemlich zusammenhängenden Stückchen, bringt sie abermals in eine Kochröhre und kocht sie wiederholt so lange mit Alcohol aus, als sich derselbe färbt, worauf man sie zuletzt noch einmal mit Wasser aufsiedet.

Sowohl das Erhitzen mit Salpetersäure allein, als mit chlorsaurem Kali und Salpetersäure, darf niemals in dem Zimmer stattfinden, wo die Mikroskope stehen, weil die sich entwickelnden sauren Dämpfe die Objective angreifen.

7 Salpetersaure Quecksilberlösung Millon'sches Reagens . Färbt stickstoffhaltige Verbindungen bei längerer Einwirkung, oder noch besser nach gelindem Erwärmen, ziegelroth.

$\mathrm{S}$ Kupfervitriol. In Verbindung mit $\mathrm{K}$ ali eines der besten Reagentien auf Traubenzucker und Dextrin, sowie auf Proteinverbindungen. Erwärmt man ein von Kupfervitriol durchtränktes Präparat mit Kali, so deutet ein rother Niederschlag in den Zellen auf Traubenzucker oder Dextrin und eine violette Färbung der Flüssigkeit auf eiweissartige Verbindungen.

9 Chromsäure. Ein Lösungsmittel für Cuticulargebilde. Die concentrirte Säure löst den Kork und die Exine der Pollenkörner vollständig auf. Von der Cuticula der Epidermis widersteht höchstens ein äusserst dünnes, vorwiegend aus Kieselerde bestehendes Häutchen Pollender, Bot. Zeit. 1862 p. 355.

10 Eisenchlorid, oder ein beliebiges Eisenoxydsalz. Färbt Gerbstoff- führende Zellen blauschwarz oder grün, je nachdem der Gerbstoff ein eisenbläuender oder ein eisengrünender ist. - Das Präparat wird in schwierigeren Fällen direct in die Lösung gebracht und sogleich beobachtet, weil sonst das Wasser den Gerbstoff auszieht und überschüssiges Eisenchlorid den entstandenen Niederschlag 
wieder löst. - Statt eines Eisenoxydsalzes empfiehlt Sanio das zweifach chromsaure Kali, welches mit den Gerbstoffen eine braune, im Reagens selbst unlösliche Masse bildet.

11) Glycerin. Als Aufbewahrungsmittel mikroskopischer Präparate, dann zum Ablösen des Primordialschlauches von der Membran (wozu übrigens Zuckerlösung, verdünnte Säuren etc. sich ebenso gut eignen in Gebrauch. Das concentrirte Glycerin kann ferner angewendet werden, um quellungsfähige oder lösliche Substanzen zunächst trocken zu beobachten und dann die Wirkung einer allmählichen Verdünnung mit Wasser zu verfolgen. - In Verbindung mit verdünnten Säuren wirkt das Glycerin lösend auf die Proteinkrystalloide.

12 Zuckerlösung. Färbt stickstoffhaltige Substanzen in Verbindung mit Schwefelsäure rosemroth. Man tränkt das Präparat erst mit Zuckerlösung und setzt hierauf ziemlich concentrirte Schwefelsäure hinzu (3 Theile englische Schwefelsäure und I Theil Wasser). Die Färbung tritt alsdann nach wenigen Minuten deutlich hervor.

13) Citronenöl oder ein anderes aetherisches Oel. Vermindert die Lichtbrechung und eignet sich daher zur Untersuchung starkbrechender Substanzen, wo sonst der Randschatten störend wirkt z. B. bei Beobachtungen im polarisirten Licht, ferner zur Untersuchung der Objecte im trockenen Zustand. In manchen Fällen leistet übrigens fettes Oel dieselben Dienste.

14) Karmin in Aetzammoniak. Wird zur Färbung des Protoplasma und des Zellkerns empfohlen. Ebenso essigsaures Cochenillenextract und in neuerer Zeit auch A nilinfarben.*)

15) Alcohol und Aether. Dienen zur Entfernung der darin löslichen Stoffe aus den zu untersuchenden Gegenständen. Der Alcohol ist überdiess ein Reagens auf fette Oele, indem derselbe das Zusammenfliessen kleiner Tröpfchen zu grössern bewirkt.

16) Essigsäure. Wird bei Untersuchungen über Zelltheilungen u. dgl. oft mit Vortheil den vorher mit verdünnter Kalilösung behandelten Präparaten zugesetzt; da sie den Inhalt trübt und die Membranen hell lässt, so gewinnt dadurch die Zeichnung des Zellennetzes oft sehr an Deutlichkeit. Dieselben Dienste leisten übrigens auch verdünnte Mineralsäuren.

*) Die Tinctionsmethoden finden bei der mikroskopischen Untersuchung thierischer Gewebe eine ausgedehnte Anwendung. Für die Botanik ist der Werth derselben nach den bisherigen Erfahrungen jedenfalls nicht hoch anzuschlagen. 


\section{III.}

\section{Art des Vorkommens chemischer Verbindungen.}

Ebenso wichtig als die Natur der chemischen Verbindungen ist 431 bei mikroskopischen Untersuchungen die Art ihres Vorkommens. Die pflanzlichen Gewebe bieten in diesem Betreff folgende Fälle: 1) organisirte Terbindungen, 2) krystallinische Bildungen, 3) Einlagerungen in organisirte Gebilde, 4) Stoffe, die in Wasser oder Oel gelöst sind, 5) Flüssigkeiten. Derselbe Stoff kann hier in dieser, dort in einer andern Gestalt auftreten, wie denn bekanntlich die Proteinverbindungen sowohl organisirt als gelöst oder in andere Gebilde eingelagert vorkommen, desgleichen der Kalk sowohl in Krystallform im Lumen der Zelle, als im eingelagerten Zustande in den Membranen u. s. w.

Solche Verhältnisse festzustellen und in jedem gegebenen Falle die Art des Vorkommens zu ermitteln, erfordert oftmals eine sorgfältige Untersuchung. Wie leicht man sich irren kann, beweist unter Anderem die in den Lehrbüchern rertretene Ansicht über die Natur der morgensternartigen Kalkgebilde in den Zellen von Ficus etc., wonach jede Spitze als ein Krystall und zwar als ein spitzes Rhomboeder zu betrachten wäre. Die Beobachtung der Auflösungserscheinungen und des nach der Auflösung (in Salz- oder Salpetersäure) zurückbleibenden Cellulosegerüstes, in Verbindung mit den Erscheinungen, die das polarisirte Licht zeigt, lehrt jedoch, dass der Kalk nur als incrustirende Materie in den geschichteten Zacken dieses Gerüstes enthalten sein konnte. - Ein ferneres Beispiel liefern die violetten und rothen Krystalloide in den Beeren ron Solanum nigrum. Auf den ersten Blick möchte man dieselben für krystallisirtes Anthocyan halten; die genauere Untersuchung lehrt aber, dass der Farbstoff in eine gallertartige, quellungsfähige Substanz, verbunden mit Plasma, eingelagert ist. Die vegetabilischen Farbstoffe scheinen überhaupt in krystallinischer Form nicht rorzukommen, sondern höchstens als Einlagerungen in Plasmagebilden. Diess dürfte auch bei jenen intensiv gefärbten Krystallkugeln der Fall sein, welche sich in den blauen Zellen der Blumenblätter ausscheiden, wenn der Primordialschlauch stark contrahirt wird.

Dass die Art des Vorkommens der verschiedenen Verbindungen 432 gewissermaassen von deren chemischer Zusammensetzung abhängig 
ist, in dem Sinne nämlich, dass verwandte Stoffe ein übereinstimmendes Verhalten zeigen, geht aus folgenden Beispielen herror. Alle gummi- und celluloseartigen, ebenso die eiweissartigen Stoffe kommen in der Pflanze nur in Lösung und im organisirten Zustande vor. In letzterer Form treten sie ferner stets als Gemenge von wenigstens zwei verschiedenen Terbindungen auf, wovon die eine durch ein Lösungsmittel ausgezogen werden kann, während die andere sich noch nicht löst. Stärkekörner, Zellmembranen, Proteinkrystalloide, Plasmagebilde stimmen in dieser Beziehung überein. Das Chlorophyll und die chemisch verwandten Farbstoffe der Algen und Flechten Phycocyan, rother Farbstoff der Florideen), kommen eingelagert in Plasmagebilden oder gelöst in aetherischen oder fetten Oelen, das Anthocyan oder Erythrophyll dagegen in wässeriger Lösung und in Farbkrystalloiden, aber nicht in andern Plasmagebilden der lebenden Zelle vor. Andere Farbstoffe beobachtet man bloss als Einlagerungen in Membranen.

IV.

\section{Krystallographische Untersuchungen.}

433

Als ein besonderer Theil der Mikrochemie ist in der Praxis die mikroskopische Bestimmung der Krystallformen zu betrachten, indem diese letzteren in vielen Fällen die sichersten Anhaltspunkte bieten, die chemische Natur krystallisirter Substanzen zu erkennen. Es ist daher für den Mikroskopiker ein Bedürfniss, sich auch mit krystallographischen Untersuchungen einigermaassen vertraut zu machen, sowie es andererseits dem Krystallographen, wenn er sich mit künstlichen Krystallen beschäftigt, öfters von Nutzen sein könnte, das Mikroskop zu Rathe zu ziehen.

Die mikroskopische Unterscheidung der Krystallformen setzt übrigens nicht bloss die Kenntniss der krystallographischen Systeme roraus; sie erfordert in der Regel auch besondere Manipulationen und Torsichtsmaassregeln, die beim Sehen mit blossem Auge theils wegfallen, theils in anderer Weise zur Anwendung kommen. Schon die genaue Messung der Winkel ist in manchen Fällen eine sehr schwierige Aufgabe, da eine schwache Neigung der Fläche, deren Kantenwinkel man misst, oder eine etwas schiefe Stellung der Kante, wemn 
ein Flächenwinkel bestimmt werden soll, das Resultat der Messung leicht um 2-3 Grade verändert. Wir haben hierüber bereits oben, bei Gelegenheit der Goniometermessungen (s. pag. 2S3), das Nähere mitgetheilt.

Selbstverständlich muss der Beobachter den Krystall successive so $z u$ drehen suchen, dass die zur vollständigen Flächenbestimmung nöthigen Messungen, sei es an Kantenwinkeln oder Flächenwinkeln, mit möglichster Genauigkeit vorgenommen werden können. Dass er dabei, je nach der Form des Krystalls, bald diese bald jene Combination von Winkeln zu wählen hat, ist ebenfalls einleuchtend. Haben die auf dem Objectträger liegenden Krystallindividuen eine verschiedene Lage und Ausbildung, so ist es rathsam, jede einzelne Winkelbestimmung an dem hiezu günstigsten Object auszuführen und die so gewonnenen Data zu combiniren. Eine vorläufige Orientirung über die vorkommenden Flächen durch Drehung eines bestimmten Krystalls ist indess immer unerlässlich, da ja sonst die richtige Deutung verschiedener Lagen nicht denkbar wäre.

Wie man aus bekannten krystallographischen Elementen die $\mathbf{4 3 4}$ davon abhängigen unbekannten berechnet, findet man in jedem Lehrbuch der Krystallographie angegeben. Es wäre überflüssig, hier auseinander zu setzen, wie aus dem Säulenwinkel eines rhombischen Prismas das Verhältniss der makro- und brachydiagonalen Axe bestimmt wird, oder wie man aus den gegebenen Kantenwinkeln eines Rhomboeders den Neigungswinkel der Flächen berechnet u. dgl. Dagegen mögen einige Formeln Platz finden, welche ausschliesslich oder doch vorzugsweise bei mikroskopischen Beobachtungen Anwendung finden, indem sie zur Verwerthung ron Winkeln dienen, die mit dem Reflexionsgoniometer nicht gemessen werden können.

Es seien erstens Rhomboeder oder klinorhombische Säulen mit schiefer Endfläche Hendyoeder zu bestimmen. Dieselben nehmen nicht selten eine solche Lage an Fig. 212 , dass zwei Flächen $(a b$ und $c d$ genau senkrecht stehen, so dass die Neigung derselben zu den Seitenkanten direct gemessen werden kann. Ebenso leicht lassen sich solche Krystalle auf eine der beiden Flächen $a b$ oder $c d$ bei Rhomboedern überhaupt auf eine Rhomboederfläche, wälzen, wodurch die ebenen Winkel derselben in gleicher Weise messbar werden. Diese beiden Messungen genügen, um den Winkel der in den Kanten $a c$ und

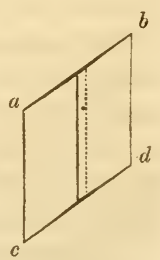

Fig. 212. 
$b d$ zusammenstossenden Flächen, den wir mit $\xi$ bezeichnen wollen, zu berechnen. Ist nämlich $b a c=\varphi$, ferner der ebene Winkel der Fläche $a b$, dessen Scheitel in $a$ liegt $=\varrho$, dann erhält man für den Säulenwinkel $\xi$

$$
\operatorname{tang} 1 / 2 \xi=\frac{\tan 91 / 2 \varrho}{\sin \psi}
$$

Dass die nämliche Formel auch bei andern Krystallen, z. B. bei vorwiegend entwickelten Flächen, welche die Ecken einer geraden Säuleabstumpfen etc., anwendbar ist, bedarf keiner Erörterung. Sobald überhaupt bei einer von drei Flächen gebildeten körperlichen Ecke zwei von den drei Grössen $\xi$, $\varrho$ und $\varphi$ Kantenwinkel einer Fläche, Neigungswinkel gegen die Kante der beiden andern, und Flächenwinkel dieser beiden andern) gegeben sind, kann die dritte nach obiger Formel berechnet werden.

Ein zweiter Fall, welcher zu noch complicirteren Berechnungen Veranlassung gibt, ist die vorwiegende Ausbildung von Flächen, welche mit keiner Axe des Krystalls parallel rerlaufen, wie z. B. der Octaederflächen am Rhombenoctaeder. Indem solche Flächen mit andern zum Durchschnitt kommen, entstehen Kantenwinkel, welche selbst in den ausführlicheren krystallographischen Werken nicht angegeben sind und sich auch nicht so unmittelbar aus den gegebenen Daten ableiten lassen. Ihre Kenñtniss ist aber in manchen Fällen unerlässlich, um über die Deutung eines gemesserien Winkels ins Klare zu kommen. Wir wollen die Aufgabe an einer bestimnten Krystallform, die dem rhombischen System angehören soll, zu veranschaulichen suchen.

Man denke sich ein mikroskopisches Rhombenoctaeder, an welchem die Abstumpfungsflächen aller Kanten und Ecken, dazu die Flächen des zweifach stumpfern Octaeders $(\%)$ ausgebildet sind. Eine der letzteren sei sammt der gegenüberliegenden tafelartig entwickelt, so dass die Durchschnittslinien mit den benachbarten Flächen die Umrisse der Tafel bilden, deren Winkel unter dem Mikroskop dieeinzig messbaren sein sollen. Die Untersuchung dieses Krystalls, so setzen wir ferner voraus, führe zu der Annahme, derselbe bestehe. aus einer bestimmten chemischen Terbindung, deren Krystallform genau bekannt ist. Man wird sich alsdann die Frage zu stellen haben, ob die in den krystallographischen Werken mitgetheilten Angaben mit den mikroskopischen Messungen übereinstimmen, ob überhaupt die angenommene chemische Zusammensetzung und die derselben entsprechende Krystallform mit der tafelartigen Ausbildung einer 
bestimmten Fläche, wemn die resultirenden Winkel gegeben sind, vereinbar seien.

Die Beantwortung dieser Frage durch Rechnung wäre sehr umständlich; man gelangt viel rascher zum Ziel, wenn man die fragliche Krystallform nach Neumann'scher Methode projicirt und die tafelartig gedachte Fläche als Projectionsebene wählt. Man denke sich rom Mittelpumkt des Krystalls, dem Kreuzungspunkt der Axen, Normale auf die einzelnen Krystallflächen gezogen und so weit verlängert, dass sie die Projectionsebene schneiden. Die Durchschnittspunkte bilden alsdann die O er ter der Krystallfäche in jener Ebene; sie stellen nicht bloss die krystallographischen Beziehungen und namentlich die Zonenverhältnisse höchst übersichtlich dar, sondern geben auch ein Nittel an die Hand, die Winkel zu bestimmen, welche die Durchschnittslinien der Krystallflächen mit der Projectionsebene unter sich bilden, d. h. die Winkel der tafelähnlich gedachten Krystallfäche. Verbindet man nämlich den Ort dieser letzteren in der Projection mit den Oertern der übrigen Flächen durch gerade Linien und errichtet auf letzteren Senkrechte, so stellen diese die Spuren der KrystallAächen auf der Projectionsebene und folglich die Ränder der Krystalltafel dar.

Als Beispiel eines solchen Terfahrens mag hier noch die Erläu- 436 terung einer nach bekannten Winkelgrössen ausgeführten Construction folgen. Es sei an dem zweigliedrigen Krystall mit den oben bezeichneten Flächen gegeben:

Das Verhältniss der Axen

$$
a: b: c=0,57: 1: 0,75 \text {. }
$$

Die Neigung der

Octaederfläche 0 , zur Säulenfläche $p$

Octaederfläche $(0)$ zur 2 fach stumpfern $\%$

Octaederfläche $\%$ zur Endfläche $c$

Octaederfläche $\%$ zur Abstumpfungsfläche der schar-

fen Säulenkante $b$ )

Mit Hülfe dieser Daten und denjenigen, die man durch Addition und Subtraction daraus ableiten kann, lassen sich nun die Oerter der Krystallflächen auf der Projectionsebene $A B$ Fig. 213), die wir uns mit der Octaederfläche $\%$ zusammenfallend oder parallel denken wollen, leicht construiren. Man wähle den Ort der Octaederfläche $\%$ als Ausgangspunkt und ziehe von dem beliebig gewählten Centrum $x$ des Krystalls Linien, welche die senkrecht zur Papierebene gedach- 
ten Krystallfächen rechtwinklig treffen und folglich mit der Richtung $x \%$ Winkel bilden, welche die entsprechenden Neigungswinkel

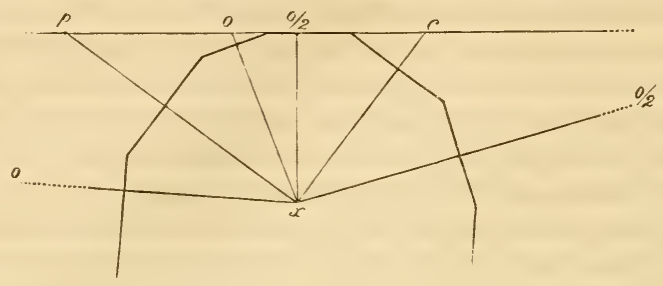

Fig. 213.

der Flächen zu $180^{\circ}$ ergänzen. Die Entfernungen $\% c, \% o$ etc. werden alsdann, wie diess in Fig. 214 in rerkleinertem Maassstabe geschehen, auf eine gerade Linie aufgetragen, deren Richtung auf der

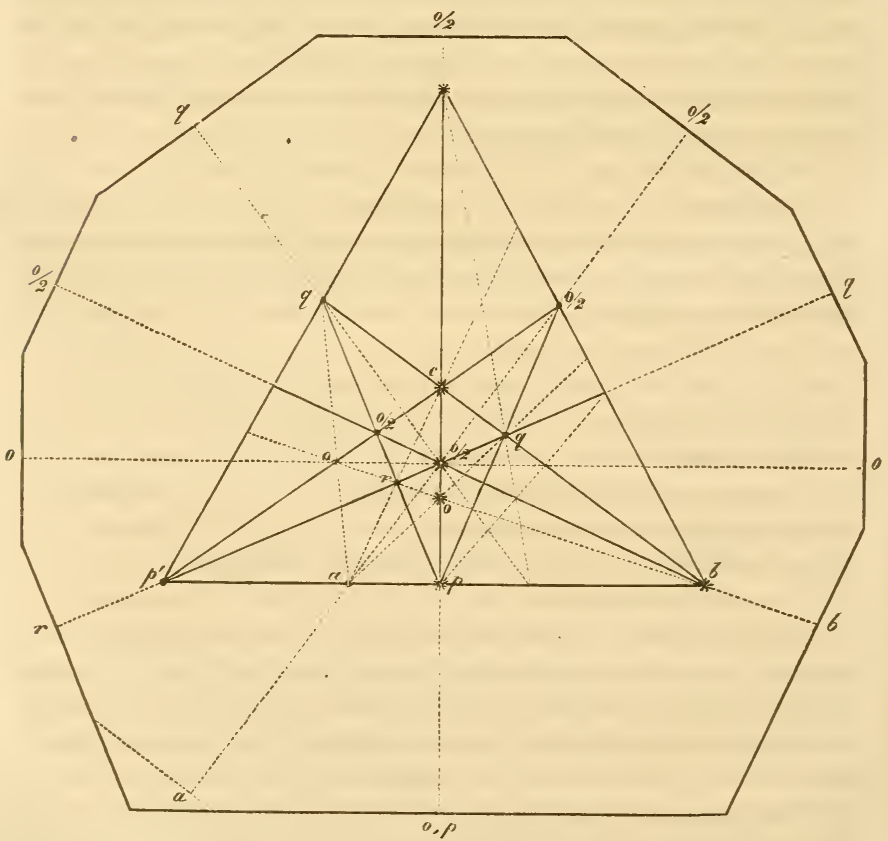

Fig. 214. 
zugehörigen Zonenaxe rechtwinklig steht; desgleichen die Entfernungen $\% / 2 b, \% p^{\prime}$ auf Linien, welche die diesen Flächenpaaren entsprechenden Kanten senkrecht treffen.

Die Construction dieser drei Linien setzt die Kenntniss der drei ebenen Winkel der Octaederfläche $\%$ voraus, weil ja die drei Zonenaxen den drei Seiten des Dreiecks, das jene Fläche darstellt, parallel verlaufen. Diese Winkel müssen demnach gegeben oder vorerst aus dem Verhältniss der Axen $a: b: c$ berechnet werden. Die Oerter der übrigen Flächen ergeben sich dagegen unmittelbar aus den Zonenverhältnissen, die auch der weniger Kundige an Krystallmodellen leicht überblickt. In unserer Figur sind nur die mit einem Sternchen bezeichneten Oerter construirt, alle übrigen abgeleitet. Die Abstumpfungsfächen $q$ der scharfen Endkanten am Hauptoctaeder sind z. B. durch Linien bestimmt, welche von $b$ durch $c$ und von $p^{\prime}$ durch die beiden $\%$ über und unter $c$ gezogen werden; ihre Oerter entsprechen den Kreuzungspunkten dieser letzteren zwei Linien mit der ersten. Ebenso erhält man die Oerter für $\%$ rechts und links von der Mittellinie, indem man z. B. die beiden $q$ mit $p$ rerbindet und die Verbindungslinien mit der Richtung $p^{\prime} c$ sich kreuzen lässt. Dieses Verfahren wird fortgesetzt, bis alle Flächen des Krystalls bestimmt sind. Wer sich einigermaassen mit den Zonenverhältnissen vertraut gemacht hat, wird sich bald darin zurecht finden.

Unsere Figur gibt ausser den genannten Punkten noch die Abstumpfungsfläche $a$ der stumpfen Säulenkante und das sogenannte dritte Paar $r$ die Abstumpfungsfäche der stumpfen Octaederkante); sie deutet überdiess durch punctirte Linien die mannigfachen Beziehungen der vorhandenen Flächen zu einander und die Oerter anderer, nach unserer Annahme nicht ausgebildeter, aber möglicher Flächen an.*)

Bis hierher ist das ganze Verfahren nichts anderes, als die Anwendung der Neumann'schen Projection auf den Fall, dass alle drei Krystallaxen schief gestellt sind. Man hat jetzt nur noch nöthig, rom Punkte $\%$, dem Ort der Projectionsfläche, Linien nach den übrigen Punkten $\left(q b p p^{\prime}\right.$ etc.) zu ziehen, in beliebiger Entfernung

* Die Zonenlehre ist wohl in den meisten besseren krystallographischen Werken, wenigstens in den Grundzügen, mitgetheilt. Sehr empfehlenswerth finden wir unter den kleineren Werken Rammelsberg, Lehrbuch der Krystallkunde; nur ist die dort angewandte Projectionsmethode eine andere, nämlich die Quenstedt'sche Linearprojection, welche im Gegensatz zu der hier angewandten die Flächen durch Linien und die Zonen durch Punkte darstellt. 
Senkrechte darauf zu errichten und dieselben zum Polygon zu verbinden. Das letztere hat alsdann genau die Form des eingebildeten tafelartigen Krystalls, indem die Seiten desselben, wie leicht einzusehen, den Durchschnitten der Krystallflächen mit der Projectionsebene parallel sind.

Will man zugleich den Verlauf der am Rande noch sichtbaren Kanten angeben, so kann diess einfach nach folgender Regel geschehen: Wenn zwei Flächen zusammenstossen, so steht die gebildete Kante senkrecht auf der Terbindungslinie ihrer Oerter. So ist z. B. die Kante, welche die Flächen $a$ und $p$ in unserer Figur am Rande bilden, parallel mit der Mittellinie, weil die Richtung ap dieselbe rechtwinklig trifft. Ebenso steht die Kante zwischen $o$ und $a$ links untenj senkrecht auf der Linie $a \circ q$ u. s. w.

In ähnlicher Weise lassen sich nun auch beliebige andere Krystallformen schematisch darstellen, vorausgesetzt, dass die erforderlichen Winkel bekannt sind. Solche Darstellungen gewähren immer, abgesehen von der im Vorhergehenden ins Auge gefassten Bedeutung, eine äusserst klare Uebersicht über die Zonenverhältnisse, welche die richtige Deutung der Flächen und Kanten oft wesentlich erleichtert.

Die Bestimmung der Krystallformen unter dem Mikroskop ist übrigens bei alledem, wie sich Jeder bald überzeugen wird, mit grossen Schwierigkeiten rerbunden. Die möglichen Fehler beim Messen der Winkel lassen es in manchen Fällen unentschieden, ob ein Krystall zum hexagonalen oder rhombischen, zum rhomboedrischen oder monoklinischen System gehöre. Ja es kann rorkommen, dass Krystalltafeln, welche dem ein- und eingliedrigen (triklinoedrischen) Sỵstem angehören, täuschend ähnlich aussehen wie rectanguläre, indem die schiefen Winkel der ausgebildeten Flächen zuweilen nur um $1^{0}$ von rechten differiren. Als ein Beispiel dieser Art sei hier das zweifach chromsaure Kali erwähnt, das auf dem Objectträger meist in achteckigen Tafeln mit nahezu gleichen Winkeln (bei gleichen oder ungleichen Seiten) krystallisirt

In solchen Fällen ist die Untersuchung im polarisirten Licht von Wichtigkeit, da die Farbenerscheinungen beim Drehen der Krystalle um eine senkrechte Axe und beim Neigen derselben nach verschiedenen Seiten gegen die Mikroskopaxe über die Lage und relative Grösse der optischen Axen Aufschluss geben. An den Tafeln des zweifach chromsauren Kali sieht man z. B. sogleich, dass sich die Farbe beim Neigen nach rechts und links ungleich verändert, dass 
folglich keine der drei Axen senkrecht steht, wie es bei Tafeln des rectangulären Systems der Fall sein müsste. Ebenso leicht sind rhombische Tafeln mit abgestumpften Ecken von regulär-hexagonalen zu unterscheiden, indem die erstern beim Drehen ihre Farbe verändern, letztere nicht.

Noch müssen wir hier zwei Methoden der Krystallbestimmung 438 erwähnen, welche neuerdings von Zenger und von Wertheim angewendet und beschrieben wurden. Zeng e r ${ }^{*}$ ) suchte die Fehlerquellen, welche mit der directen Winkelmessung verbunden sind, dadurch zu umgehen, dass er statt der Winkel die Diagonalen oder Kantenlängen der Flächen bestimmte und hieraus die Winkelgrössen trigonometrisch berechnete. Er bediente sich dabei eines grossen Plössl'schen Mikroskops mit Schraubenmikrometer und erzielte bei 60 - 130 facher Vergrösserung, den mitgetheilten Controlmessungen zufolge, eine Genauigkeit, die in der That wenig zu wünschen übrig lässt. Die Bestimmungen wurden an rhomboedrischen Metallen (Tellur, Arsenik, Wismuth, Antimon, Zink etc.) ausgeführt, an welchen ausser dem Hauptrhomboeder $(\boldsymbol{R})$ meist noch ein spitzeres Rhomboeder $2 R^{\prime}$ mit den Abstumpfungsflächen der Rhomboederecken entwickelt war. Dem entsprechend wurden je nach der Beschaffenheit des Krystalls direct gemessen:

1) die Diagonalen $d d^{\prime}$ der Rhomboederflächen, woraus nach der Formel

$$
\frac{d^{\prime}}{d}=\operatorname{tang} \alpha
$$

der halbe spitze Winkel $\alpha$ der Rhomben berechnet werden konnte; oder

2) die Seiten der gleichschenkligen Dreiecke, welche durch Abstumpfung der Seitenecken des Rhomboeders entstehen. Bezeichnet man diese Seiten mit $a, a, b$ oder $a, b, b$, wo immer $a>b$, so ist

$$
\frac{b}{a}=\operatorname{tang} \alpha
$$

wenn $\alpha$ wieder den halben spitzen Winkel der Rhomben bedeutet. Oder

3 eine Rhombenseite ( $l$ ) und eine Diagonale $\left(d\right.$ oder $\left.d^{\prime}\right)$, wobei

$$
\sin \varepsilon=\frac{d^{\prime}}{2 l}, \cos \alpha=\frac{d}{2 l} .
$$

*) Zenger: Mikroskopische Messungen der Krystallgestalten einiger Metalle. Sitzungsber. d. kais. Akad. der Wiss. in Wien. Bd. XLIV. 2. Abth. 
Sind die Kantenwinkel auf diese Weise bestimmt, so können sowohl die Flächenwinkel als das Axenverhältniss nach den bekannten Formeln für das rhomboedrische System berechnet werden.

Nach Zenger sind die Fehler, welche nach dieser Methode aus der ungenauen Horizontalstellung der Kanten und der fehlerhaften Einstellung entspringen, viel geringer als bei der directen Winkelmessung mittelst des Oculargoniometers. Wir verweisen in Betreff der näheren Begründung dieser Vorzüge und der Veranschaulichung derselben durch Beispiele auf die citirte Abhandlung.

Das Wertheim'sche Verfahren *) setzt voraus, dass der Beobachter mit den zur Bestimmung von Niveaudifferenzen im Gesichtsfeldle nöthigen Vorrichtungen (vgl. pag. 235) versehen sei. Dasselbe besteht wesentlich in der Lösung der Aufgabe: den Neigungswinkel zweier Flächen, was immer für eine Neigung zum Horizonte sie haben, zu bestimmen. Man sieht leicht ein, dass damit das Problem der Krystallbestimmung im Allgemeinen erschöpft ist.

"Es handelt sich vorerst darum, die Lage einer Ebene im Raume zu bestimmen. Diess geschieht durch die Bestimmung der Lage von drei beliebigen Punkten derselben. Leicht werden solche auffindbar sein, die sich auszeichnen und daher schnell und sicher wieder gefunden werden. Die ausnahmslos vorhandenen Rauhigkeiten, Risse und Sprünge auf den Flächen gestatten diess ohne Schwierigkeit. Nachdem man zuerst einen derselben in die Mitte des Gesichtsfeldes geschoben, auf ihn scharf eingestellt und nun sowohl die Lage der zwei ihm zugehörigen Horizontalcoordinaten als auch den Höhenstand des Tubus abgelesen und notirt hat, wiederholt man dieses Verfahren für die zwei anderen Punkte, womit die. mit dem Instrument zu vollziehende Arbeit beendet ist. Die Differenzen zwischen den jetzt abgelesenen Ständen und den als Nullpunkt angenommenen des erstbestimmten Punktes, mit den gleichen oder entgegengesetzten Zeichen versehen, je nachdem sie im gleichen oder entgegengesetzten Sinne von ihm abstehen, geben die gesuchten Dimensionen. DieseDaten genügen, um nach einer bekaunten Formel (die man in jedem Lehrbuch der analytischen Geometrie findet) die Lage der Ebene zu bestimmen. Dasselbe Verfahren wiederholt man bei der zweiten Ebene, die nicht an die erste $z u$ grenzen braucht, auch ausserhalb. des bisherigen Gesichtsfeldes liegen kann. Aus der bekannten Lage

*) Sitzungsber. d. kais. Akad. der Wiss. in Wien. Bd. 45 , pag. 157. 
beider Flächen ergibt sich sodann der Werth des von ihnen eingeschlossenen Winkels. "

Diese Methode mag unter Umständen ganz praktisch sein; sie ist aber offenbar nur bei Krystallen anwendbar, die mindestens einen grossen Theil des Gesichtsfeldes einnehmen. Die Resultate werden um so ungenauer ausfallen, je kleiner die Coordinatenunterschiede der drei Punkte im Verhältniss zu den unvermeidlichen Messungsfehlern, die leicht 1 -2 Mik. und darüber betragen können.

\section{V.}

\section{Specielle Betrachtung der wichtigsten chemischen Verbindungen.}

Von den zahlreichen Stoffen, welche in regetabilischen Geweben in grösserer oder geringerer Menge enthalten sind, wollen wir im Folgenden diejenigen, die vermöge ihrer allgemeinen Verbreitung und herrorragenden physiologischen Bedeutung ein besonderes Interesse gewähren, noch specieller betrachten. Es sind diess die Mineralstoffe Kalk und Kieselerde, dann die Pflanzensäuren, Gerbstoffe und Glycoside, die Farbstoffe und Chromogene, endlich die Kohlenhydrate und die Proteinverbindungen. Zum Voraus sei indess bemerkt, dass die mikrochemischen Methoden, die bis jetzt bekannt geworden sind, noch gar sehr der Ausbildung bedürfen, bis sie dem Beobachter die nöthigen Anhaltspunkte bieten, um die Vertheilung und Wanderung der genannten Stoffe im Organismus zu verfolgen. Was in dieser Beziehung bereits festgestellt ist, verdanken wir zum grössten Theil den Bestrebungen der organischen Chemie und insbesondere der Agriculturchemie. Dessenungeachtet lässt sich nicht in Abrede stellen, dass die Mikrochemie für die verschiedenen Richtungen der mikroskopischen Forschung, und besonders für die botanische, eine von Jahr zu Jahr steigende Bedeutung gewinnt und bereits eine Stufe erreicht hat, welche die specielle Berücksichtigung derselben in einen Werke wie das vorliegende nicht nur rechtfertigt, sondern fordert. Wir haben desswegen die in neuerer Zeit angewandten Reactionen, soweit sie uns nicht durch frühere Erfahrungen hinlänglich bekannt waren, durch besonders zu diesem Zweck angestellte Versuche geprüft, um über den praktischen Werth derselben aus eigener Anschauung urtheilen zu können. 


\section{Kalk und Kieselerde.}

441 Der $\mathrm{Kalk}$ findet sich in den Geweben bald als Einlagerung in den Membranen, bald ausserhalb derselben. Im eingelagerten $\mathrm{Zu}$ stande bildet er entweder mikroskopisch wahrnehmbare Körnchen diess wohl nur in der Extracellularsubstanz der Algen, , oder er verbindet sich mit den Membrantheilen zu einer homogenen Masse, die sich ron reiner Cellulose optisch nicht unterscheidet. Ausserhalb der Membranen ist er, abgesehen von den aus kohlensaurem Kalk bestehenden Incrustationen der Wasserpflanzen, nur als oxalsaurer Kalk bekannt, erscheint jedoch als solcher in vier verschiedenen Formen: als tetragonales Octaeder, als klinorhombisches Prisma früher für Gypskrystalle gehalten, als Nadeln, als morgensternförmige Drusen und in der Form ron kleinen rundlichen Körnern.

Die Kalkeinlagerungen, welche körniger Natur sind, lösen sich in verdümnten Säuren meist unter Aufbrausen und geben sich dadurch, sowie durch die Bildung feiner Gypsnadeln auf Zusatz von Schwefelsäure als kohlensauren Kalk zu erkennen. Diejenigen dagegen, welche die Homogeneität und Durchsichtigkeit der Membran in keiner Weise beeinträchtigen, lassen sich nur in der Asche oder im Skelett nachweisen, welches beim Verbrennen zurückbleibt. Es ist in diesem Falle zweifelhaft, ob der Kalk ebenfalls in Verbindung mit einer Säure oder aber als $\mathrm{CaO}$ in die Membran eingelagert war, da er durch den Verbremmungsprocess unter allen Umständen in kohlensauren Kalk übergeführt wird. Mancherlei Gründe sprechen indess zu Gunsten des basischen Zustandes als Calciumoxyd.

Von den chemischen Reactionen auf Kalk, welche sich unter dem Mikroskop verwerthen lassen, erscheinen uns namentlich folgende empfehlenswerth.

\section{*) Kalk in ungelöster Form.}

Löst sich in Essigsäure unter Gasentwicklung; auf Zusatz ron saurem oxalsaurem Kali zur Lösung bilden sich octaedrische Krystalle von oxalsaurem Kalk: kohlensaurer Kalk.

Unlöslich in Essigsäure und Oxalsäure, löslich in Salzsäure und Salpetersäure, aber ohne Gasentwicklung, zeigt auf Zusatz von Chlorbaryum keine Veränderung und verhält sich nach dem Glühen wie kohlensaurer Kalk: oxals a urer Kalk.

Löslich in viel Wasser $(500$ Theile, etwas leichter in Säuren, also in wenig Salz- oder Salpetersäure unlöslich; bedeckt sich auf 
Zusatz von Chlorbaryum mit kleinen Körnchen (von schwefelsaurem Baryt): schwefelsaurer Kalk.*)

\section{**) Kalk in Lösung.}

Bildet auf Zusatz von Oxalsäure oder löslichen oxalsauren Salzen kleine Krystalle von oxalsaurem Kalk, die sich in Salz- und Salpetersäure, nicht aber in Essigsäure und Ammoniak lösen.

Die Unterscheidung der verschiedenen organischen Säuren, an welche der Kalk gebunden sein kann, ist wegen der geringen Concentration der Lösungen in der Regel nicht möglich; die üblichen Reactionen sind hiefür nicht empfindlich genug.

Die Kieselerde findet sich gewöhnlich als Einlagerung in den $\mathbf{4 4 2}$ Membranen, so in der Epidermis vieler Pflanzen und in den Parenchymzellen der Blätter, zuweilen aber auch als Auskleidung oder als vollständiger Abguss der Zellhöhlung oder als rundliche Concretionen Cystolithen, Kieselhörner) im Zelleninhalt. Die beiden letzteren Arten des Vorkommens scheinen sich indess nur auf Zellen zu beschränken, welche bereits im Absterben begriffen sind, während die Verkieselung der Wandungen nach $\mathrm{M}$ oh $\mathrm{l}$ schon beginnt, wenn die Zellen noch lange nicht ausgewachsen sind und sich also in voller Lebensthätigkeit befinden.

Die Kieselerde lässt sich wegen ihrer Widerstandsfähigkeit g'egen die stärksten Säuren imit Ausnahme der Fluorwasserstoffsäure) und ihrer Unveränderlichkeit in der Glühhitze leicht nachweisen, da dieselbe nach der Zerstörung der organischen Substanz mittelst Schwefelsäure oder durch Verbrennung und nach der Behandlung der Aschenbestandtheile mit Salzsäure als Skelett zurückbleibt In dieser einfachen Form gewährt jedoch das Terfahren, besonders wenn es sich um dünnwandige und wenig verkieselte Membranen handelt, keinen befriedigenden Errfolg. Die Anwendung der concentrirten Schwefelsäure ist nach $\mathrm{Mohl}$ Bot. Ztg. 1561 p. 213 mit dem Nachtheil verbunden, dass dieselbe die organische Substanz nicht selten in eine zähe schwarzbraune Masse verwandelt, in welcher die Nachweisung eines Kieselskelettes sehr erschwert und häufig unmög-

* Die Krystalle im Gewebe der Scitamineen, im Rhizom von Iris etc., die man früher für Gyps hielt, desgleichen die rhomboederähnlichen Formen, die man als kohlensauren Kalk betrachtete, bestehen nach neueren Untersuchungen aus oxalsaurem Kalk. Der schwefelsaure Kalk scheint hienach in Pflanzengeweben nicht krystallinisch vorzukommen. 
lich wird. Andererseits ist die vollständige Zerstörung der organischen Substanz durch Verbrennung in vielen Fällen unmöglich, wenn man nicht vorher einen Theil derselben nebst den alkalischen Salzen auszieht. Auch kann es ohne diese Vorbereitung leicht vorkommen, dass die Kieselerde mit den Alkalien und Erden zusammenschmilzt, wodurch natürlich die Form des Kieselskelettes mehr oder weniger zerstört wird. Das zu untersuchende Gewebe muss also, wenn die Darstellung des Kieselskelettes gelingen soll, eine vorbereitende Behandlung erfahren, welche die Verbrennung erleichtert und zugleich die Verletzung des Skelettes verhütet.

Mohl fand es am besten, zuerst in der Schulze'schen Flüssigkeit $\left(\mathrm{NO}_{5}\right.$ und $\left.\mathrm{KO} . \mathrm{ClO}_{5}\right)$ zu kochen, bis Entfärbung eintritt, und hierauf das Kali durch Auskochen in Wasser wieder vollständig zu entfernen. Er empfiehlt überdiess, das ausgekochte Präparat nachträglich noch mit Alcohol auszuziehen und fügt dann bei: "So zubereitet, brennt sich der 'Theil in den meisten Fällen auf einem Platinbleche über der Spirituslampe schon bei schwacher Glühhitze schnell blendend weiss. Ist das Präparat sehr zart, so lege man dasselbe auf ein Deckgläschen und glühe es mit diesem auf dem Platinbleche. Den geglühten Theil muss man natürlicherweise mit Salzsäure ausziehen, un die alkalischen und Erdsalze zu entfernen. "

443 Will man ungekehrt die Kieselerde ausziehen, um die zurückbleibende organische Grundlage zu untersuchen, so ist nach Mohl die Flusssäure das geeignetste Reagens. Dieselbe besitzt die vortreffliche Eigenschaft, die Kieselerde leicht zu lösen, ohne die Zellwandungen in bemerkbarer Weise anzugreifen. Kaustisches Kali löst zwar die Kieseleinlagerungen ebenfalls, wirkt aber auch auf die vegetabilische Membran und namentlich auf die Cuticularschichten bedleutend ein. Die Anwendung der Flusssäure geschieht am einfachsten in der Art, dass man gepulverten Flussspath und Schwefelsäure in ein verschliessbares Gefäss von Blei bringt und das mit Wasser benetzte Object in einem Platinlöffelchen mit einschliesst. Auf diese Weise gelang es Mohl, den Diatomeenschaalen ihre Kieselerde innerhalb 24 Stunden vollständig zu entziehen. Die einzige Vorsicht, die man dabei anzuwenden hat, besteht darin, das Präparat nicht eintrocknen zu lassen.

44 Die Entfernung der organischen Substanz durch die Verbrennung bewirkt je nach ler Menge der eingelagerten Kieselerde eine 
stärkere oder schwächere Contraction der Membranen. Bei geringem Kieselgehalt erreicht dieselbe nicht selten einen solchen Grad, dass die geglühten Membranen kaum noch die Hälfte ihrer ursprünglichen Flächenausdehnung besitzen. Damit ist für die Untersuchung der Uebelstand verbunden, dass die dünnen und schwach rerkieselten Membranen, wenn sie mit einem stark verkieselten Theil, wie z. B. der Epidermis, in Terbindung stehen, bei der Einäscherung vielfach zerrissen und dann leicht übersehen werden. Dieselbe Ursache bedingt auch das Einrollen der Epidermis, weil dic peripherischen Schichten sich durch einen grösseren Kieselgehalt auszeichnen.

Zur Orientirung für den Beobachter fügen wir schliesslich noch $\mathbf{4 4 5}$ einige Beispiele bei, welche den Untersuchungen Mohl's entnommen sind. Soweit es möglich war, wurden dieselben so gewählt, dass die angeführten Pflanzen Jedermann zugänglich sind.

Die Epidermiszellen sind mehr oder weniger stark rerkieselt am Stengel von Equisetum und Calamus, an vielen Blättern aus der Gruppe der nesselartigen Pflanzeu, z. B. bei $T$ lmus campestris, bei Celtis occidentalis u. a. Arten, bei vielen Feigen, namentlich bei Ficus Sycomorus und trachyphylla Fenzl, bei Deutzia scubra, grandiflora etc. Wo die Epidermis mit hervorragenden Knötchen oder Haaren besetzt ist, sind oft nur diese verkieselt, so z. B. bei Scirpus palustris und mucronatus die Knötchen, bei Ficus Joannis Boiss., Urtica excelsa, lusitanica, lispida und zum Theil auch dioica die Haare. In andern Fällen geht die Verkieselung an der Basis der Haare auf die Epidermis über und s hreitet hier in concentrischen Kreisen fort, so dass jedes Haar von einer runden Kieselscheibe umgeben erscheint, so z. B. bei Cerinthe aspera und minor, Echium vulgare, Lithospermum officinale, Helianthus tuberosus.

Die Gefässbündel sind verkieselt in den Blättern von Ficus Sycomorus, trachyphylla, elastica, Deutzia scabra, Magnolia grandiflora, Heliopsis laeris etc. - Die Blattparenchymzellen sind verkieselt bei Ficus Sycomorus, Fagus sylvatica, Quercussuber, Deutzia scabra, Pliragmites communis.

Verkieselte Cystolithen finden sich in den Blättern der FicusArten, ferner bei Morus alba, bei mehreren Arten ron Parietaria etc. - Ausfüllungen der Zellhöhlungen mit Porenzapfen kommen vor in der Nähe der Gefässe in den Blättern ron Hirtella racemosa Lam., Darilla brasiliana Dc. 


\section{Pflanzensäuren und Gerbstoffe.}

446 Von den Säuren, welche gelöst in den Pflanzensäften vorkommen, sei es num frei oder an Alkalien oder Erden gebunden, lassen sich im Allgemeinen nur die Gerbsäuren oder Gerbstoffe mikrochemisch nachweisen. Für die übrigen Säuren gewähren die bekannten chemischen Verfahren in den meisten Fällen einen höchst zweifelhaften Erfolg; sie sind auch bis jetzt, so viel wir wissen, zu

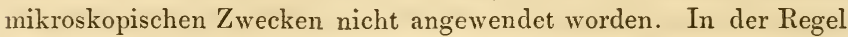
ist es nicht einmal möglich, das Vorhandensein einer beliebigen Säure im Safte unversehrter Zellen nachzuweisen, da eine Ausscheidung von Kohlensäure auf Zusatz von kohlensauren Alkalien selbst dann nicht erfolgt, wenn die Schnittflächen entschieden sauer auf Lakmuspapier reagiren. Die Anwendung der Lakmustinktur selbst aber ist bei lebenden Zellen nicht möglich, da der Farbstoff nur durch den todten Primordialschlauch diosmirt.

Wir beschränken uns desshalb auf den Nachweis der Gerbsäuren, deren Verhalten zu Eisenoxydsalzen in neuerer Zeit von verschiedenen Beobachtern verwerthet wurde. Die Gerbsäuren oder Gerbstoffe geben bekanntlich mit Eisenoxydsalzen einen blauschwarzen oder grünlichen Niederschlag und werden hienach als eisenbläuende und eisengrünende unterschieden. Diese Farben treten namentlich bei ersteren in so intensiven Tönen hervor, dass sie der Iodreaction auf Stärke an Sicherheit und Zuverlässigkeit kaum nachstehen. Die einzige Vorsicht, die man zu nehmen hat, besteht darin, die Lösung des Gerbstoffes im Präparatwasser oder das Diosmiren desselben in benachbarte Zellen zu verhüten. Diess geschieht am einfachsten dadurch, dass man die Schnitte unmittelbar in die Lösung des Eisensalzes legt und sogleich beobachtet, oder dass man zu den in Glycerin gelegten Schnitten rasch die Eisenlösung zusetzt.

47 So leicht übrigens die Gerbstoffe sich in Wasser lösen, so ist doch nicht zu befürchten, dass sie aus unversehrten Zellen so rasch ausgezogen werden. Diess geschieht im Gegentheil sehr langsam, indem z. B. die hellen rundlichen Gerbstoffmassen, wie sie in der Rinde von Quercus, Populus, Betula etc. vorkommen, selbst nach stundenlangem Liegen in $\mathrm{W}$ asser wenigstens an den dickeren Stellen des Schnittes noch fast unverändert sind. Es ist daher überflüssig und schon wegen der Unbequemlichkeit nicht zu empfehlen, 
die Schnitte vorher in Oel zu legen, wie Hartig*) es gethan, und hierauf die wässerige Lösung zuzusetzen. Man kann sich leicht überzeugen, dass das Präparat in Oel nicht anders aussieht, als in Wasser oder Glycerin, dass also in den letzteren Medien Nichts vom Inhalt verloren geht. Selbst wenn es sich um die Frage handelt, ob der Gerbstoff bloss gelöst im Zellinhalte vorkomme, oder ob er auch die Membranen durchdringe, gewährt die Anwendung von Oel keine grössere Sicherheit als die Beobachtung der Schnitte in wässeriger Lösung. Denn entweder diosmirt der Gerbstoff durch den lebenden Primordialschlauch und wird von der Membran in nachweisbarer Menge aufgenommen; dann muss sich die letztere durch Eisenchlorid bläuen, auch wenn man das Präparat zuerst in Wasser legt. Oder es findet keine Diosmose von Zelle zu Zelle oder wenigstens keine hinreichende Einlagerung statt, um eine deutliche Reaction herrorzurufen; dann bleiben die Membranen ungefärbt, wenn die Schnitte sogleich mit dem Reagens benetzt werden, wie man diess z. B. an den gerbstoffreichen Rinden ron Quercus und Populus beobachtet. Die Membranen der gebläuten Zellen bleiben hier vollkommen farblos, wenn das Eisenchlorid dem frischen Präparat zugesetzt wird; sie färben sich dagegen blau, wenn man dasselbe stundenlang in Wasser liegen lässt und dadurch eine Diosmose herbeiführt, wie sie in der lebenden Rinde nicht stattfindet.

S a nio empfiehlt Bot. Ztg. 1563, p. 17) statt eines Eisenoxyd- $\mathbf{4 4 8}$ salzes das doppelt chromsaure Kali als Reagens auf Gerbstoffe. Dasselbe soll namentlich den Vortheil gewähren, dass es mit dem Gerbstoff eine Verbindung eingeht, welche sich in einem Ueberschuss des Salzes nicht löst und dabei durch die rothbraune Färbung doch deutlich genug in die Augen fällt. S a n io tränkt ganze Aststücke, welche er vorher 12 Stunden austrocknen liess, mit einer verdünnten Lösung des genannten Reagens und untersucht nachher das Gewebe auf beliebig geführten Durchschnitten. Wir haben dieses Verfahren selbst nicht geprüft, doch scheint uns die Behandlung frischer Schnitte mit Eisenchlorid wenigstens für saftige Gewebe den Vorzug zu verdienen.

Ueber das Torkommen der Gerbstoffe mögen dem Beobachter, 449 der sich mit einschlägigen mikrochemischen Fragen $z u$ beschäftigen gedenkt, folgende Andeutungen genügen. Die Gerbstoffe finden sich theils gelöst in wässerigen Zellinhalt, theils in hellen ölartigen Mas-

+ Hartig, Bot. Ztg. 1565. Nr. 7. 
sen, welche jedenfalls aus einer viel concentrirteren Lösung bestehen und überdiess durch eine Plasmahaut von dem übrigen mit Chlorophyll und wässerigem Zellsaft ausgefüllten Theil des Zelllumens geschieden sind. Die erste Art des Vorkommens beobachtet man in Knospen, in Blattgebilden, welche später oder gleichzeitig Anthocyan enthalten, hie und da auch in den langen Zellen der Gefässbündel, in umreifen Früchten etc. Der Gerbstoff durchdringt hier in manchen Fällen auch die Membran und scheint demnach von Zelle zu Zelle zu diosmiren. Die zweite Art des Vorkommens charakterisirt die gerbstoffhaltigen Rinden ron Quercus, Populus. Betula u. a. Hier bleibt der Gerbstoff, ähnlich wie die Stärke, eingeschlossen in den Zellen, in denen er sich gebildet hat; er kann nur weitergeführt werden, nachdem er vorerst eine Umwandlung erfahren. Auf Zusatz von Wasser zerfallen die ölartigen Gerbstoffmassen in kleine Kugeln oder Körnchen, welche ein undurchsichtiges Conglomerat bilden; mach längerer Einwirkung erfolgt Lösung. Beim Austrocknen schrumpfen sie auf einen kleinen Theil ihres früheren Volumens zusammen und bilden dann nur noch ein verhältnissmässig dünnes, nach innen unregelmässig vorspringendes Wardbeleg. Die blaue Färbung, welche Eisenchlorid hervorruft, nimmt zuletzt einen braunen 'Ton an, woraus hervorgeht, dass neben dem eisenbläuenden Gerbstoff noch irgend eine andere Substanz oder ein anderer weniger empfindlicher Gerbstoff in den erwähnten ölartigen Massen rorkomm $\left.{ }^{*}\right)$. Näheres hierüber bleibt zu ermitteln.

*) Diese Angaben stïtzen sich auf eigene Beobachtungen, welche speciell zu dem Zwecke angestellt wurden, die Mittheilungen $\mathrm{H}$ artig's über das "Gerbmehl " (Bot. Ztg. 1565. Nr. 7) zu prüfen. Hartig bezeichnet die oben als zweite Art des Vorkommens aufgeführte Form als amorph und führt ausserdem noch drei andere Zustände auf, in welchen der Gerbstoff rorkommen soll, nämlich den körnigen, den krystallinischen und den Wandungszustand. Wir können indess die hierauf bezüglichen Angaben nicht bestätigen. Der körrn i g e Zustand erwies sich als kleinkörnige Stärke, welche allerdings etwas Gerbstoff aus dem Zellsaft aufgenommen haben musste, da sie sich mit Eisenchlorid schwachblau färbte, aber dessenungeachtet nicht zu verkennen war. Wir sahen in gleicher Weise Kartoffelstärke, die wir mit verdünnter Gerbstofflösung getränkt hatten, auf Zusatz von Eisenchlorid sich theilweise ebenso intensiv blau färben, und dieselbe Erscheinung kann man auch an Membranen, z. B. sehr schön an Collenchymzellen, beobachten. Die Blaufärbung ist also noch kein Beweis, dass das fragliche Object aus Gerbstoff bestehe. Der krystallin ische Zustand ist nach Hartig selbst noch problematisch, da hier die Gerbstoffreaction sehr zweifelhaft ausfiel. Wir halten diesen Zustand für oxalsauren Kalk und zwar für jene monoklinische Form desselben, welche neuerdings ron $\mathrm{Holzner}$ (Flora 1\$64) genau untersucht wurde. Was endlich den $\mathrm{T}$ and ung sz ustand betrifft, so dürfte die Vermuthung ge- 
Nach Wiga n ${ }^{*}$ ) sind die Gerbstoffe gewissermaassen als Chromo- 450 gene zu betrachten; sie finden sich in allen Zellen, welche in einer etwas späteren Entwicklungsperiode rothe oder blaue Farbstoffe enthalten und kommen auch noch ncben dicsen in den Zellen vor, so z. B. bei jungen Blumenblättern und bei đler herbstlichen Entfärbung der Laubblätter. Wir haben diese Angaben an einigen Beispielen, die sich auf die rothe Färbung der Blätter beziehen, geprüft und können dieselben bestätigen. Was indess die Reaction auf Zellen betrifft, welche bereits Erythrophyll enthalten, so ist bezüglich der Deutung eintretender Farbenveränderungen jedenfalls Vorsicht zu empfehlen, da es zweifelhaft sein kann, inwieweit dieselben ron dem vorhandenen Gerbstoff, und nicht etwa vom Farbstoff, herrühren. Der Beobachter muss wissen, ob das als Reagens angewendete Eisenoxydsalz neutral, sauer oder alkaliseh reagirt und darf im letzteren Falle nicht versäumen zu prüfen, ob die Bläuung im angesäuerten Präparatwasser in gleicher $W$ cise stattfindet.

Wigand fand ferner, dass zwisehen Gerbstoff und Stärke eine gewisse Wechselbeziehung besteht, in dem Sinne, dass in gewissen 'Kellen immer zuerst Gerbstoff' und erst später Stärke auftritt, oder dass ein periodisch wiederkehrender Wechsel stattfindet, indem der Gerbstoff gegen das Ende der Vegetationsperiode abnimmt und das Stärkemehl zunimmt. Im Winter soll der erstere sein Minimum, das letztere sein Maximum erreichen.

Der Gerbstoff ist bis jetzt vorzugsweise in baum-und straueh- $\mathbf{4 5 1}$ artigen Gewächsen nachgewiesen worden; er scheint indess aueh bei krantartigen, namentlich bei perennirenden, nicht gerade selten zu sein. Rochleder erwähnt denselben beispielsweise bei den Dryadeen (Fragaria, Potentilla etc.), den Gentianeen, Primulaceen, Sileneen ete., und es ist vorauszusehen, dass weitere Untersuchungen die Beispiele noch bedeutend vermehren werden. Die Gerbstoffe haben zweifelsohne eine viel grössere Verbreitung, als man ihnen früher zuzuschreiben geneigt war. - Die Vertheilung im Gewebe betreffend, so hält es schwer, hiefür ein durchgreifendes Gesetz aufzustellen. Man findet dieselben vorzugsweise in der Rinde, im jungen Holz,

stattet sein, dass er mit verdickten Wandungen, die etwas Gerbstoff enthalten, identisch sei. Wir bemerken übrigens, dass wir an den von $\mathrm{H}$ ar tig erwähnten porös-dickwandigen Zellen von S a l is bu ri a die Gerbstoffreaction gar nicht beobachteten.

*) Bot. Ztg. 1562. p. $123 \mathrm{ff}$.

Năgeli u. Sebwendener, das Mikroskop. 
in den dünnwandigen Zellen der Gefässbündel und in der Markscheide, hie und da aber auch in zerstreuten Zellen im Marke (z. B. bei $C$ issus) und ziemlich häufig im Gewebe der Blätter, Blumen und Früchte. Nicht selten finden sich zwei verschiedene Gerbstoffe neben einander in der nämlichen Zelle, was sich durch eine mehr oder minder deutliche Veränderung des Farbentons während der Einwirkung des Eisenoxydsalzes kundgibt. Man beobachtet z. B. hie und da (so bei Finca), dass rothe Zellen zuerst violett und dann spangrün werden und sich hierauf durch Töne, die wieder allmählich mehr ins Blaue gehen, entfärben. Solche Veränderungen setzen die Gegenwart zweier oder mehrerer Gerbstoffe voraus, von denen der eine etwas früher als der andere zn reagiren beginnt, so dass die resultirenden Farben sich in immer wechschndem Verhältnisse mischen.

Die von Schleiden ausgesprochene Ansicht, dass die Gerbstoffe nur in absterbenden Zellen vorkommen und also ein Product der Zersetzung seien, bedarf nach dem Vorhergehenden keiner Widerlegung. Doch wollen wir nicht unerwähnt lassen, dass Gerbstoffe immerhin als Zersetzungs - oder Rückbildungsproducte vorkommen können. Wir beobachteten z. B. an absterbenden oder bereits abgestorbenen Spirogyren, wie man sie im trocken gelegten Schlamme von Teichen und Tümpeln etc. findet, in manchen Zellen eine sehr entschiedene Bläuung auf Zusatz von Eisenchlorid. Die Färbung zeigte sich an häufigsten an den Plasmamassen des Inhalts, zuweilen aber auch an Querwänden, welche, wie wir annehmen, den ihnen im gelösten Zustande gebotenen Gerbstoff in grösserer Menge eingelagert hatten. *) Solche Fälle mögen auch bei höheren Pflanzen hie und da vorkommen.

\section{Glycoside.}

453 Unter den Reactionen, welche man in chemischen Lehrbüchern für gewisse Glycoside angegeben findet, müssten wohl manche auch unter dem Mikroskop sich anwenden lassen. Bis jetzt hat diess aber, soviel wir wissen, noch Niemand versucht. Hartig (Bot. Ztg. 1s63, p. 413) gibt zwar an, dass sich in Cambium und wahrscheinlich auch im Siebfasergewebe der Tanne ein dem Salicin ähnlicher Stoff, das Abietin, in Lösung befinde, welcher mit concentrirter Schwefelsäure

*) Die Membranen der Spirogyren (sowie viele andere) haben eine so grosse Affinität zu Gerbstoff, dass wenn man dieselben in verdünnte Gerbstofflösung bringt und dann Eisenchlorid zusetzt, sie eine tiefblaue Färbung annehmen. 
sich blauviolett färbe (während das Salicin durch Schwefelsäure roth wird und auf Zusatz von Wasser einen blauen, in Alkohol löslichen Niederschlag bilde. Er scheint aber diese Reactionen nur am ausgepressten Saft und auf grösseren Querschnitten mit blossem Auge beobachtet zu haben. Dasselbe gilt von den Beobachtungen Bö h m's*) an "Chromogendecocten ", welche beim Abschluss der Luft von noch ungefärbten Pflanzentheilen bereitet wurden, und deren Verhalten zu Schwefelsäure an die genannten Glycoside erinnert.

Bei dem vereinzelten Vorkommen der Glycoside und bei der vollständigen Unkenntniss der Rolle, die sie im Haushalt der Pflanze übernehmen, ist es übrigens gerechtfertigt, wenn die Mikroskopiker zunächst den allgemeineren Producten des vegetabilischen Lebensprocesses, deren physiologische Bedeutung in den Hauptzügen bereits bekannt ist, ihre Aufmerksamkeit widmen. ${ }^{* *}$ )

\section{Farbstofle.}

Die Farbstoffe zeigen dem Mikroskopiker vier wesentlich ver- $\mathbf{4 5 4}$ schicdene Arten des Vorkommens: als Lösungen in wässerigen Zellsaft, als Lösungen in fetten oder ätherischen Oelen, als Einlagerungen in der Zellmembran und als Einlagerungen in Plasmagebilden. Ueberdiess kommt bei den Flechten noch der besondere Fall vor, dass gelbe Farbstoffe an Körnchen von unbekannter Zusammensetzung haften, welche an der Oberfläche der Membranen adhäriren oder zwischen die Zellen eingelagert sind.

Zu den Farbstoffen des Protoplasmas gehören zunächst diejenigen, welche mit dem Assimilationsprocess im Zusammenhang stehen, wie das Chlorophyll, das Phycochrom und die verwandten Pigmente der Florideen und Diatomeen, sodann das Anthoxanthin der gelben Blumen, dessen Rolle in Lebensprocess unseres Wissens experimentell nicht festgestellt ist. Die nämlichen Farbstoffe kommen ausnahmsweise auch als Lösungen in Oelen vor. Im Zellinhalte gelöst finden sich die rothen und blauen Farbstoffe der Blumen und Blätter, die man als Anthocyan und Erythrophyll zu unterscheiden pflegt, endlich eingelagert in den Membranen verschiedene nicht und 405 .

*) Sitzungsber. der kais. Akad. der Wiss. in Wien, Bd. 45. 3. Abth. p. 404

**) Ueber die mögliche Rolle der Glycoside im Organismus vgl. R och leder, Phytochemie p. 327, sowie die Bemerkungen von $\mathrm{Saehs}$ über die dort geltend gemachten Anschauungen in dessen "Experimentalphysiologie der Pflanzen " p. 359. 
näher bekannte Pigmente, welche vom intensivsten Roth bis zum tiefsten Violett alle Farben des Spectrums zeigen.

a) Farbstoffe, welche eingelagert im Plasma vorkommen.

Der grüne oder rothe Farbstoff, welcher in den assimilirenden Zellen vorkommt, ist stets mit einer organischen Grundlage von Plasma und Wachs (?) verbunden und zwar in so verschwindend geringer Menge, dass man nach dem Ausziehen des Farbstoffes aus den grünen Körnern oder Plasmamassen keine Veränderung des Volumens oder der Dichtigkeit beobachtet. Es wird angegeben, dass die Blätter eines ganzen Baumes kaum die zu einer Elementaranalyse nöthige Menge reines Blattgrün liefern, und wahrscheinlich besteht ein ähnliches Verhältniss auch für die übrigen, dem Blattgrün verwandten Farbstoffe.

Von den genannten Farbstoffen ist nur das Chlorophyll isolirt und makrochemisch untersucht worden, aber auch hievon existiren bis jetzt nur wenige und nicht ganz übereinstimmende Elementaranalysen. *) Bei der üblichen Darstellungsweise kommen überdiess so kräftige Mittel in Anwendung, dass es zweifelhaft erscheint, ob der Farbstoff dabei nicht irgend eine Veränderung erleide. Wie dem auch sei, das rein dargestellte Chlorophyll ist amorph, unlöslich in Wasser, in verdünnten Säuren und Alkalien, löslich in WVeingeist, Aether, sowie in ätherischen und fetten Oelen - und in all' diesen Eigenschaften stimmt es mit dem unveränderten Chlorophyll überein. Die grün gefärbte salzsaure Lösung wird durch Einlegen von metallischem Zink entfärbt, gelblich, und beim Abdampfen auf dem Was. serbad wieder grün, eine Erscheinung, welche auf das Vorhandensein eines farblosen Chromogens hindeutet. Damit stimmt überein, dass auch das unveränderte Chlorophyll in bleichsüchtigen Pflanzen

* Nach M ulder ist die ehemisehe Formel des Chlorophylls $\mathrm{C}_{18} \mathrm{NH}_{9} \mathrm{O}_{8}$; es würde also hienaeh ein Aequivalent Stickstoff enthalten. Damit steht indess eine neuere Analyse von Pfaundler (Ann. Chem. u. Pharm. v. Liebig u. Wöhle r CXII. p. 37) im Widerspruch. Dieselbe crgab auf 100 Theile reinen Farbstoffes 0,037, also eine so geringe Menge von Stickstoff, dass dieser kaum als wesentlicher Bestandtheil zu betrachten sein dürfte. Nach den Untersuchungen von Verdeil, Gris, dem Fürsten von Salm-Horstmar, von Pfaundler und $\mathrm{S}$ a ehs, welche das übereinstimmende Ergebniss lieferten, dass die Gegenwart des Eisens für das Ergrünen der Pflanzen nothwendige Bedingung sei, indem künstlich herbeigeführter Eisenmangel die Chlorose erzeugt, ist es dagegen wahrscheinlich, wenn auch keineswegs erwiesen, dass das Chlorophyll eine geringe Menge von Eisen enthält. 
unter der Einwirkung des Sonnenlichtes so rasch zum Vorschein kommt, dass die Bildung desselben aus einem bereits vorhandenen farblosen Stoff (Leukophyll) wahrscheinlich ist. Durch die Versuche von Sachs (Flora 186i2, p. 129), wurde überdiess dargethan, dass in Zellen, welche später Chlorophyll enthalten, und nur in solchen, durch concentrirte Schwefelsäure augenblicklich eine intensiv spangrüne Färbung entsteht, ganz so, wie man sie an farbigen Chlorophyllkörnern beobachtet. Die Plasmapartieen, welche sich später grün färben, enthalten hienach bereits einen farblosen Stoff "Chromogen), welcher gegen Schwefelsäure wie Chlorophyll reagirt.

Die weiteren Reactionen, welche sich unter dem Mikroskop beobachten lassen, sind nicht sehr charakteristisch; doch zeigen sie immerhin, dass das Chlorophyll etwas weniger veränderlich ist als das Phycochrom. Es behält in verdünnten Alkalien eine freudiggrüne Farbe, wird in verdünnten Säuren $\left(\mathrm{SO}_{3}, \mathrm{ClH}, \mathrm{NO}_{5}, \mathrm{PO}_{5}\right)$ schmutzig gelbgrün bis goldgelb, nimmt dagegen in concentrirter Salzsäure oder Schwefelsäure einen blaugrünen, zuweilen fast indigoblauen Ton an.

Das Phycoehrom unterscheidet sich rom Chlorophyll durch $\mathbf{4 5 6}$ seine grössere Veränderlichkeit und durch die blaugrüne bis indigoblaue Farbe, die es gewöhnlich in lebenskräftigen Zellen besit»t. Diese blaugrüne Farbe scheint übrigens nur ein bestimmtes Entwicklungsstadium zu charakterisiren, da man sie in Zellfüden, wo die Reilıenfolge der Zellgenerationen bekannt ist, weder in den jüngsten noch in den ältesten Zellen beobachtet. Bei den Algenfäden aus der Gruppe der Scytonemeen (scytonema Heerianum Näg. u. a.) erscheint die Scheitelzelle und die nächstliegenden Gliederzellen, also die Region, in welcher Neubildung von Phycochrom stattfinden muss, stets

*) Nach Frémy (Ann. des sc. nat. 1860, XIII, p. 45) hätten indess diese Erscheinungen einen tiefer liegenden Grund. Nach ihm besteht der grüne Farbstoff aus einem Gemenge zweier Verbindungen, wovon die eine für sich allein gelb, die andere blau erscheint. Erstere bezeichnet er als Phylloxanthin, letztere als Phyllocyanin. Die Trennung derselben geschieht, indem man durch Weingeist ausgezogenes Chlorophyll mit einer Mischung von zwei Raumtheilen Aether und einem Theil verdünnter Salzsäure schüttelt; das Phyllocyanin bleibt alsdann in der Salzsäure, das Phylloxanthin in Aether gelöst. In vergeilten oder noch nicht grün gewordenen Blättern ist nun nach Frémy bloss Phylloxanthin vorhanden, und da das letztere, seinen Angalen zufolge, durch Behandlung in Aether und Salzsäure theilweise in blauen Farbstoff übergeführt wird, so würde sich hieraus die von Sachs beobachtete Reaction erklären. 
röthlich bis ziegelroth; dieser Ton geht dann allmählich in Blaugrün über und wird in den ältesten Zellen bräunlich oder braunorange. Bei den Flechten mit blaugrünen Gonidien ist diese Farbe in den jüngsten Theilen des Thallus in der Regel am schönsten entwickelt und geht in tiefer liegenden Schichten des Thallus oder in Thallusschuppen, die von anderen bedeckt sind, in Schmutziggelb bis Braunorange über. Diese letztere Farbe kann sich aber auch auf den ganzen Thallus erstrecken (Ephebe, Spilonema etc.), in welchem Falle es indess zweifelháft ist, ob die untersuchten Exemplare den lebenskräftigen Zustand der Pflanze repräsentirten.

Das blaugrüne Phycochrom wird durch Kalilösung gelbgrün bis goldgelb oder bräunlich-gelb, durch Salzsäure gelborange, schmutzigorange bis ziegelroth. Das bereits entfärbte gelbliche Pliycochrom der älteren Zellen erfährt dagegen weder in Säuren noch Alkalien eine augenfällige Veränderung, sondern erhält bloss einen etwas helleren oder mehr braunen Ton. In Betreff der Löslichkeit stimmt das Phycochrom mit dem Chlorophyll überein.

Dass Phycochrom und Chlorophyll nahverwandte Stoffe sind, lässt sich trotz der angeführten Verschiedenheiten kaum bezweifeln, da schon das Vorkommen unverkennbar auf diese Verwandtschaft hindeutet. Man findet bei den Flechten innerhalb der nämlichen Gattung (so bei Sticta, Endocarpon und Pannaria) Arten mit blauem Phycochrom und solche init gelbgrünem Chlorophyll. Aehnliche Fälle werden auch bei den einzelligen Algen angeführt; nur ist hier die angebliche Verwandtschaft der Chlorophyll-führenden mit den Phycochrom-führenden Arten nicht allgemein anerkannt und unseres Erachtens auch mindestens zweifelhaft.

457 Das Phycoerythrin oder der rothe Farbstoff der Florideen schliesst sich in seinem Verhalten gegen Reagentien zunächst an das Phycochrom an, da es mit diesem die grosse Veränderlichkcit gemein hat. Durch Kali und Ammoniak wird dasselbe blass olivengrünlich, fast farblos; Säuren stellen die rothe Farbe wieder her, jedoch meistens mit einem mehr violetten Ton. Concentrirte Schwefelsäure verändert die Farbe nicht. - - In älteren oder absterbenden Zellen tritt die grünliche Färbung von selbst ein; man beobachtet sie hie und da an noch lebenden Pflanzentheilen, aber namentlich häufig an solchen, welche an den Strand geworfen wurden oder an Ort und Stelle in Absterben begriffen sind.

Das Phycoerythrin ist, wie das Phycochrom und das Chloro- 
phyll, an Plasma gebunden und kommt meistens in Körnern vor, welche in Form und Grösse mit den Chlorophyllkörnern übereinstimmen. Aber nicht alle Bildungen dieser Art, welche sich durch eine rothe Färbung auszeichnen, sind Phycoerythrin. Schon Kützing (Philos. Bot. p. 166) gibt an, dass Rytiphla ea tinctoria durch einen Stoff gefärbt sei, welcher durch Wasser ausziehbar, in Alkohol und Aether aber unlöslich sei; Aetzammoniak verschönere die Farbe und Säuren verwandeln sie in Hellroth-orange. Wir haben das Verhalten gegen Säuren und Alkalien an getrockneten Exemplaren geprüft und diese Angaben richtig gefunden. Die Farbe ging auf Zusatz von Salpetersäure in Braungelb bis Orange über, Kali stellte das ursprüngliche Rothviolett verschönert wieder her. Ein abermaliger Zusatz von Säure färbte das Präparat wieder Orange und Kali rief zum zweiten Mal das Violett zurück.

Das Diatomin oder der braungelbe Farbstoff der Diatomeen $\mathbf{4 5 8}$ wird durch Alkalien und verdünnte Säuren grünlich, durch concentrirte Schwefelsäure schön spangrün! Eisenchlorid bewirkt keine Veränderung.

Zu den Farbstoffen, welche an Plasma gebunden in Zellinhalt 459 vorkommen, gehört endlich noch das Blunengelb oder An thoxanthin.*) Es reiht sich zunächst an das entfärbte ('hlorophyll, das sogenannte Xanthophyll *) an, welches bekanntlich die gelbe Farbe absterbender Blätter, sowie die Winterfarbe mancher perennirender Blätter bedingt. Das Anthoxanthin wird weder durch Alkalien noch durch verdünnte Salzsäure, Phosphorsäure oder verdünnte Schwefelsäure verändert, durch Salpetersäure dagegen grünlich gefärbt und dann farblos. In concentrirter Schwefelsäure geht es durch Grün in ein schönes Blau (dem Berlinerblau ähnlich) über, wird je-

*j In einigen wenigen Fällen rührt die gelbe Färbung der Blüthen nach Hildebrand (Pringsheim's Jahrb. für wiss. Bot. Bd. IIl. p. 6) von einem gelben Zellsafte her, wie z. B. bei den gelben Varietäten von Dallia variabilis, in anderen Fällen von einer dickflüssigen gelben Substanz, die vom farblosen Zellsaft deutlich abgegrenzt erscheint, so z. B. bei einigen Arten von Acacia. Ueber die chemische Natur dieser gelben Säfte ist leider nichts Näheres mitgetheilt.

**) Nach den oben erwähnten Angaben Frémy's wäre das Xanthophyll identisch mit dem von ihm als Phylloxanthin bezeichneten gelben Bestandtheil des Chlorophylls. Bei der herbstlichen Entfärbung der Blätter soll nämlich bloss das Phyllocyanin verschwinden, indess das Phylloxanthin zurückbleibt. 
doch durch blosses Auswaschen der Säure wieder gelb. Zum zweiten und dritten Mal mit Schwefelsäure behandelt und wieder ausgewaschen zeigt es immer wicder den nämlichen Farbenwechsel und zwar mit ungeschwächter Intensität. Dagegen haben Präparate, welche durch Salpetersäure entfärbt wurden, die Fähigkeit, sich durch Schwefelsäure zu bläuen, verloren. Die Salpetersäure verursacht hienach eine bleibende Veränderung, sei es in der Molecularconstitution oder in der chemischen Zusammensetzung.

b) Farbstoffe, welche im Zellsaft gelöst vorkommen. und die rothe Fürbung der Blätter bedingen, sind mit wenigen Ausnahumen *) im wässerigen Zellsaft gelöst; sie bleiben aber dessenungeachtet in den Zellen, in denen sie entstanden sind, weil der lcbende Primordialschlauch dieselben nicht diosmiren lässt. In ihrem Verhalten gegen die gewöhnlichen chemischen Reagentien zeigen die verschiedensten Nuancen, vom Scharlachroth des Papaver Rhoeas bis zum Blau der Gentianen, eine so grosse Uebereinstimmung, dass die Annahme identischer Zusammensetzung jedenfalls gerechtfertigter ist, als die übliche Unterscheidung von Erythrophyll und Anthocyan. Diese Uebereinstimmung spricht sich namentlich in der Reaction gegen Säuren und Alkalien aus. Verdünnte Säuren bewirken durchgehends eine Veränderung des Farbentons in der Richtung von Blau nach Roth, womit zugleich gesagt sein soll, dass Zellsäfte, welche bereits roth sind, keine Veränderung erfahren. Alkalien bedingen dagegen den umgekehrten Farbenwechsel; sie führen das

*) Eine schon lange bekannte und mehrfach erwähnte Ausnahme bildet Strelitzia Reginac, deren innere Perigonalblätter ihre dunkelblaue Färbung zahlreichen blauen Körnchen verdanken, welche dicht gedrängt im farblosen Zellsafte sehwimmen. Ein ähnliches Verhalten fand Hildebrand (Pringsheim's Jahrb. III. pag. 3) bei den Blütluen von Tillandsia amoena, wo die indigoblaue Färbung der Perigonzipfel von kugelförmlgen blauen Körpern herrührt, welche einzeln oder seltener zu mehreren beisammen in den Zellen enthalten sind. Diese Kugeln reagiren übrigens, den Angaben Hildebrand's zufolge, wie Anthocyan ; auch wird angegeben, dass bei einer anderen gleichgefärbten Pflanze derselben Familie (Billbergia iridifolia) die blaue Färbung in gewohnter Weise durch den blauen Zellsaft bedingt sei. Unter diesen Umständen ist zu vermuthen, class diese blauen Kugeln den Farbkrystalloiden verwandte Bildungen darstellen. Dieselbe Vermuthung dürfte vorläufig auch für die violetten und rothen Farbkörperchen gerechtfertigt sein, welche Hildebrand bei Amorpha fruticosa, rilia tricolor, Verbena chamaedrifolia etc. beobachtete. Die Sache verdiente übrigens, gerade mit Rücksicht hierauf, eine specielle Untersuchung. 
Roth durch Violett, Blau in Grün bis Gelblichgrün oder Gelb über, wobei nach längerer Einwirkung zugleich Entfärbung stattfindet.

Wir müssen bei diesem letzteren Punkt, weil hierüber die An- 461 gaben neuerer Beobachter sich theilweise widersprechen, einen Augenblick verweilen. Wiesner (Bot. Ztg. 1862. p. 359/ stellt den Satz auf, dass das Anthocyan als solches sich durch Alkalien blau, niemals grün, färbe. Wo die grüne Färbung zu Stande komme, rühre dieselbe von eisengrünendem Gerbstoff her, welcher durch Alkalien gelb werde; dieses Gelb des Gerbstoffes mische sich mit dem Blau des Anthocyans und bilde Grün. Hingegen bemerkt er ausdrücklich, dass die Gegenwart von eisenbläuendem Gerbstoff die Reaction des Anthocyans so gut wie gar nicht modificire. Wir können diese Angaben nicht bestätigen. Der Uebergang der rothen Farbe durch Blau in Grün ist nach unseren Beobachtungen eine das Anthocyan charakterisirende Erscheinung, welche nicht erst durch eisengrünenden Gerbstoff hervorgerufen wird. Es kann allerdings vorkommen, dass die Entfärbung, die gewissermaasen vom Farbenwechsel unabhängig zu sein scheint, schon eintritt, ehe das Grün erreicht ist. So werden z. B. die rothen Zellen im Fruchtfleisch von Solanum spec. Art mit dunkeln Beeren) durch Ammoniak und verdünnte Kalilösung hellblau und entfärben sich, ohne den Farbenton zu wechseln. Legt man aber die Schnitte in ziemlich conccntrirte Kalilösung, so geht das Roth in den meisten Zcllen in ein scliönes Spangrün über, und das ganze Präparat sieht für das blosse Auge intensiv grün aus. Die Entfärbung tritt in diesem Falle, wie wir annehmen, relativ später ein. Dass die grüne Färbung nicht etwa von eisengrünendem Gerbstoff herrührt, zeigt das Verhalten der rothen Zellen gegen Eisenchlorid; das letztere färbt reinblau, und diese Farbe bleibt während der Entfärbung unverändert. — Die nämliche Reaction zeigen auch die Blumenblätter der Gentiana verna. Wir sahen dieselben durch Alkalien grün werden, obschon der Gerbstoff, welcher nebst Anthocyan in den Zellen vorkommt, ein eisenbläuender ist. Legt man Stücke von Blumenblättern in eine verdünnte Lösung von Eisenchlorid, so färben sie sich zuerst violett und roth weil das Eisenchlorid sauer reagirt); dann bildet sich der den Gerbstoff verrathende schmutzigblaue Niederschlag, welcher endlich durch das überschüssige Eisenchlorid wieder gelöst wird. Man kann diese Stadien an der nämlichen Zelle nach einander beobachten, man sieht sie aber auch 
gleichzeitig neben einander an nämlichen Blumenblatt und zwar um so schöner, je langsamer die Einwirkung.

Wäre in diesen beiden Fällen eisengrünender Gerbstoff neben dem eisenbläuenden in den Zellen enthalten, so müsste sich derselbe durch eine entsprechende Veränderung des Farbentons kundgeben, wie man diess an andern Pflanzen auch wirklich beobachtet. Als Beispiel hiefür sei Vinç herbacea erwähnt. Die violette Zellflüssigkeit der Blumenblätter (welche durch Kalilösung intensiv grün wird) färbt sich auf Zusatz von Eisenchlorid zuerst roth. Nach einiger Zeit beginnt die Gerbstoffreaction. Das Roth wird momentan schön-violctt, dann schmutzig-violett, hierauf intensiv spangrün, nach und nach blasser und mehr bläulich, endlich farblos. In andern Zellen ging das Tiolett der ersten Einwirkung durch ein allmählich schwächer werdendes Blau in Farblos über, oder es wurde zuerst fast blau und dann schmutzigspangrün und hierauf durch bläulichgrün farblos. Diese Farbenerscheinungen erklären sich durch die Annahme, dass eisenbläuender und eisengrünender Gerbstoff neben einander, aber in wechselndem Verhältniss im Zellsafte enthalten sind, dass der eisenbläuende zuerst reagirt und überdiess weniger leicht gelöst wird.

Weitcre Belege dafür, dass die "Grünfärbung in Alkalien nicht durch eisengrünenden Gerbstoff hervorgerufen sein kann, bietcn die Blumenbliitter von Orohus vernus, Phlox, Daphne C'neorum und die oberflächlichen Zellen rother Aepfel und süsser Kirschen. Orolues vermus wird durch Eisenchlorid zuerst roth und entfärbt sich dann ohne Gerbstoffreaction; die übrigen führen nur eisenbläuenden Gerbstoff. Alkalien rufen jedoch durchgehends eine entschieden grüne Färbung hervor.

462 Die Fälle betreffend, in welchen die rothe Farbe, den Angaben Wiesner's zufolge, durch Alkalien ganz abweichende Veränderungen erfährt, indem sie beispielsweise durch Blau in Schmutzigroth und Gelb übergeht, so hatten wir nicht Gelegenheit, alle von Wiesner angeführten Beispiele zu untersuchen. Für Pelargonium zonale können wir indess seine Angaben nicht bestätigen. Die Abweichung reducirte sich hier darauf, dass bei der Entfärbung, welche constant von Scharlachroth durch Violett und Blau stattfand, eine Ueberführung in Grün durch Anwendung einer stärkeren oder schwächeren Lösung allerdings nicht gelang. Der schwache gelbliche 'Ton, welcher zuletzt noch zurückbleibt und in der Nähe der Gefässbündel 
etwas verstärkt erscheint, rührt offenbar nicht vom Farbstoff her, da er auch in weissen Blumenblättern ganz ebenso auftritt.

Die Farbenänderung, welche der rothe Farbstoff in alkalischen Medien zeigt, bleibt gewöhnlich bei Blau stehèn, wenn die Einwirkung nur eine sehr schwache ist. So wird z. B. der rothe Farbstoff der Kirschen an der Luft blau, weil das in letzterer enthaltene Ammoniak die im Zellsaft gelösten Säuren neutralisirt, aber weiter keine Veränderung hervorruft. Angesäuertes Wasser stellt die rothe Farbe wieder her.

Woher es kommt, dass gewisse Farbstoffe unter keinen Umständen in Grün übergehen, wollen wir dahingestellt sein lassen. Soviel ist jedoch sicher, dass die grüne Färbung in vielen Fällen• eintritt, wo die Gegen wart von eisengrünendem Gerbstoff sich nicht nachweisen lässt.

c) Farbstoffe, welche ursprünglich im Zellsaft gelöst sind und später von den Membranengespeichertwerden.

Untersucht man die verschiedenen Farbhölzer, welche zu technischen Zwecken verwendet werden, unter dem Mikroskop, so erscheinen die Zellwandungen durchgehends gefärbt. Der nämliche Farbstoff findet sich aber auch im Inhalt der Markstrahlen und stellenweise auch der Holzzellen. Da nun kein Beispiel bekannt ist, dass Pigmente, die in den Membranen entstehen, sich später auch im Inhalte anhäufen, der umgekehrte Fall dagegen nachgewiesenermaassen oft vorkommt, so ist es wahrscheinlich, dass die ursprüngliche Bildungsstätte auch bei den genannten Farbhölzern im Zelllumen zu suchen ist. Wir bemerken übrigens, dass das gewöhnliche Material, wie es durch den Handel bezogen wird, zur Lösung der Frage nicht ausreicht; die endgültige Entscheidung derselben bleibt in jedem gegebenen Falle der Untersuchung frischer Materialien vorbehalten.

\section{Farbstoff ron Rubia tinctorum.}

Frische Krappwurzeln erscheinen im Querschnitt, wie schon $\mathbf{4 6 - 1}$ Deca isne nachgewiesen, stets gelb, nie roth, und die mikroskopische Untersuchung zeigt, dass die meisten Rindenzellen eine gelbe Flüssigkeit enthalten, welche bei Luftzutritt sich rasch trübt und dann jene rothen Flocken bildet, wie man sie auf Durchschnitten durch die trockene Wurzel beobachtet. Es ist leicht, sich hievon durch den ersten besten Querschnitt einer frisch ausgegrabenen Wurzel zu überzeugen. Wir können hinzufügen, dass der gelbe Farbstoff sich ursprünglich nur gelöst in Zellinhalte findet, indem die jungen Wur- 
zeln stets vollkommen farblose Membranen besitzen. Die Färbung der letzteren beginnt erst später, wahrscheinlich in Folge einer Veränderung, vermöge welcher sie den Farbstoff zu speichern vermögen. Dafür spricht wenigstens die Thatsache, dass man in älteren $\mathrm{Wur}$ zeln häufig lebenskräftige Zellen beobachtet, deren Primordialschlauch sich auf Zusatz von Glycerin contrahirt und deren Membranen ziemlich intensiv gefärbt sind.

465

Das Verhalten des Krappfarbstoffes gegen chemische Reagentien ist bekannt. Kali färbt ihn purpurroth und bewirkt das Ausfliessen desselben in das ungebende Medium. Säuren stellen dic ursprüngliche Farbe mit einem etwas mehr orangefarbigen Ton wieder her. Die nämlichen Farbenerscheinungen beobachtet man auch am ungelösten, durch Einwirkung der Luft roth gewordenen Inhalt getrockneter Wurzeln oder einzelner Zellen, welche absichtlich mit der Nadel verletzt wurden, um die Wirkung des Luftzutrittes zu verfolgen. Der Inhalt färbt sich in diesem letzteren Falle augenblicklich orange und dann röthlich, wobei sich der Farbstoff in Flocken niederschlägt; Alkalien färben indess nach wie vor purpurroth und Säuren gelborange. Eisenchlorid färbt die gelbe Zellflüssigkeit orange und zuletzt bräunlich-roth, ohne dass eine Trübung erfolgt; Alkohol zieht den gelösten Farbstoff aus, lässt dagegen den veränderten rothen ungelöst. Die gelbe alkoholische Lösung kann mit Wasser verdünnt oder an der Luft stehen gelassen werden, ohne sich zu verändern; sie zeigt übrigens auf Zusatz von Alkalien und Säuren denselben Farbenwechsel, wie die Zellflüssigkeit.

\section{Farbstoffe der Varbhölzer.}

466 Dass der Farbstoff des käuflichen Brasilienholzes, des Blauholzes und des rothen Santalumholzes vorzugsweise in die Membranen eingelagert ist und diese gleichmässig durchdringt, ist eine bekannte 'Thatsache. Dagegen wurde, wie es scheint, weniger beachtet, dass der nämliche Farbstoff sich auch im Zellinhalte der Markstrahlen findet und sogar in den of verschwindend kleinen Lumina der Holzzellen hie und da in kleinen Körnchen wahrgenommen wird. Diese 'Thatsache scheint uns die Vermuthung zu rechtfertigen, dass das färbende P'rincip, ähnlich wie beim Krapp, zuerst gelöst im Zellinhalt vorhanden war und erst später von den Membranen gespeichert wurde. Die Untersuchung lebender Pflanzen wird lehren, ob unsere Vermuthung mit der Wirklichkeit übereinstimınt. 
Die genannten Farbstoffe erscheinen unter dem Mikroskop durehgehends gelb oder orange bis rothorange; sie lösen sich in Alkalien mit purpurrother, nur beim Blauholz mit violetter oder blauer Farbe; Säuren stellen den gelben Ton wieder her. Das Verhalten gegen Wasser ist bekannt; dasselbe löst das Pigment der Caesalpinien mit rother oder blauer Farbe, während dasjenige des Santalumholzes ungelöst bleibt. Setzt man zu den wässerigen Auszug des Roth- oder Blauholzes Eisenchlorid, so färbt sich die Flüssigkeit zuerst gelb, dann tritt eine starke Tanninreaction ein, indem sich ein blauer grumöser Niederschlag bildet. Der Uebergang von Gelb zu Blau geschieht durch ein schmutziges Grün, das übrigens nur bei langsamer Einwirkung deutlich in die Augen fällt. Ob zwischen Gerbstoff und Farbstoff, ähnlich wic beim Anthocyan und Erythrophyll, ein genetischer Zusammenhang bestehe, lässt sich natürlich hieraus nicht entnehmen; diese Frage muss durch Untersuchungen an frischem $\mathrm{Ma}$ terial entschieden werden.

\section{Farlostoff der Berberis-Wurzelı.}

In chemischen und pharmakognostischen Werken wird angege- $\mathbf{4 6 7}$ ben, dass der gelbe Farbstoff der Columbo- und der Berberiswurzeln in den Wandungen der Holzzellen und Gefässe enthalten sei. Diese Angabe ist insofern richtig, als diese Wandungen, wie schon ihre Farbe zeigt, jedenfalls Farbstoff führen; allein auch hier ınacht es die mikroskopisehe Untersuchung wahrscheinlich, dass derselbe zuerst im Inhalte gelöst war und von da in die Membranen wanderte. Bei Berboris erscheint nämlich die Rinde am intensivsten gefärbt, und zwar sind es vorzugsweise die Markstrahlen und die peripherischen Rindenzellen, welche durch ihren gelben wässerigen Inhalt die Färbung bedingen. Lässt man verdünnte Säuren (Salpeters., Oxals., Phosphors., Weinsteins.) darauf einwirken, so erfolgt zunächst Ausscheidung von kleinen gelben Tröpfchen mit Molecularbewegung (vielleicht von gelösten Eiweissverbindungen herrührend). Diese Tröpfchen fliessen nach und nach zu grösseren zusammen und nehmen dabei einen mehr orangefarbigen 'Ton an. Kali verursacht einen körnigen Niederschlag und zieht den Farbstoff, der sich dabei mehr orange färbt, nach und nach aus, indess die körnige Masse zurückbleibt. Den nämlichen Farbenwechsel rufen Säuren und Alkalien auch an den porös-dickwandigen Zellen der Rinde hervor, welche in dem sonst dünnwandigen Gewebe zerstreut liegen ; nur bedarf es einer längeren oder kräftigeren Einwirkung, um das Gelb der Membranen 
in Orange überzuführen. - Lässt man Durchschnitte durch die Rinde eintrocknen (wobei der Primordialschlauch abstirbt), so wird der Farbstoff der dünnwandigen Markstrahlen- und Rindenzellen durch kaltes Wasser rasch ausgezogen, während die Membranen ihre gelbliche Färbung behalten. Entfernt man jetzt die Schnitte und setzt zu der gelben wässerigen Lösung Salzsäure, so bilden sich zahlreiche gelbe; häufig strahlenförmig gruppirte Krystallnadeln, welche mit salzsaurem Berberin übereinstimmen. Es ist nun im höchsten Grade wahrscheinlich, dass die gelbe Färbung der Zellmembranen sowohl im Holz als in der Rinde ebenfalls von Berberin oder von einer Verbindung desselben herrührt, da jedenfalls angenommen werden muss, dass die wässerige Lösung die Membran durchdringe, sobald die Lebensthätigkeit des Primordialschlauches aufhört. Die Speicherung des Farbstoffes in der Membransubstanz wäre alsdann eine Folge der Anziehung, welche dieselbe nachweisbar auf die meisten gelösten Farbstoffe, selbst auf Anthocyan und Erythrophyll, ausübt.*)

\section{Rother und rioletter Farbstoff der Saamenschalen.}

468 Die Saamen von Abrus precatorius sind bekanntlich intensiv roth und nur in der Umgebung des Nabels schwarz gefärbt. Die mikroskopische Untersuchung zeigt, dass diese letztere Färbung von einem schön-violetten, erstere von einem rothen Pigment herrührt, welche beide in die dicken Wandungen der pallisadenartigen, die Oberfläche der Testa bildenden Zellen eingelagert sind. Beide Farbstoffe werden durch Alkalien 'blau und durch Säuren hochroth; sie verhalten sich also wie Anthocyan. Es lässt sich auch leicht zeigen, dass die Membran der gedachten Zellen eine starke Anziehung auf das Anthocyan ausübt und dasselbe zu speichern vermag. Bringt man nämlich vollständig entfärbte und ausgewaschene Membranen in den ausgepressten Zellsaft rother Blumenblätter, so färben sie sich ebenso intensiv wie vorher und behalten die Färbung beim Auswaschen bei. Dadurch wird es im höchsten Grade wahrscheinlich, dass die genannten Farbstoffe mit Anthocyan identisch und daher zuerst im Inhalte gelöst sind und erst später in die Membranen eingelagert werden.

d) Farbstoffe, welche nur eingelagert in die Membran vorkommen.

469 Ton den hieher gehörigen Farbstoffen wurde bis jetzt keiner genau untersucht. Alle unsere Kenntnisse hierüber beschränken sich

*) Die Membranen der Collenchymzellen färben sich in einer Lösung von 
auf gelegentliche Beobachtungen über Löslichkeit und Veränderung des Farbentons unter dem Einfluss der Reagentien. Die mikroskopische Beobachtung lässt es überdiess unentschieden, ob diese Farbstoffe wirklich in der Membran entstehen, oder ob sie vielleicht als Chromogene oder in äusserst geringer Menge fertig gebildet im Inhalte auftreten und von da in die Membran wandern. Da jedoch kein Grund vorhanden ist, die Bildungsstätte von Pigmenten, welche in nachweisbarer Menge nur in der Membran vorkommen, anderswohin zu verlegen, indem die Bedingungen zu chemischen Processen in der Membran ebensogut wie im Inhalte gegeben sind, so entspricht die unserer Eintheilung zu Grunde liegende Annahme wenigstens den bis jetzt beobachteten Thatsachen.

Als Beispiele von Farbstoffen, welche nur als Einlagerungen in Membranen bekannt sind, führen wir zunächst diejenigen an, welche bei den Nostochinen (Chroococcaceen und Nostochaceen) vorkommen. Sie zeigen die verschiedensten Nüancen zwischen Gelb und Blau, kommen aber namentlich einerseits in braungelben, anderseits in rothen und blauvioletten 'Tönen vor. Sie gehören zwei Verbindungen an.

Das Glöocapsin ist roth bis blau; durch Salzsäure wird es roth (schön rosenroth, rothorange oder bräunlichroth), durch Kali blaı oder blauviolett. Es findet sich vorzüglich bei Gloeocapsa, doch auch bei einigen Fadeualgen.

Das Scytonemin ist gelb bis dunkelbraun; es wird durch Salzsäure spangrün und durch Kali wieder gelb, oft fast goldgclb. Es kommt bei vielen fadenförmigen Nostochaceen (Scytonema, Schizosiphon etc.), selten bei Chroococcaceer vor.*)

Weitere Beispiele liefern die Pigmente mancher Saamenhäute, so z. B. das Gelb von Hippocrepis, welches durch Säuren und Alkalien so gut wie keine Veränderung erfährt (nur die Intensität ändert sich etwas), ferner das Gelb der Cuticula von Cycas und manchen anderen Pflanzen, das Braun der Zellen in der Umgebung der Gefässbündel bei gewissen Farrenkräutern etc. Dagegen scheint die braune oder braunrothe Färbung der Saamenschaalen von Phaseo-

Anthocyan intensiv blau, und mehr oder weniger deutliche Färbungen kann man auch an andern Geweben beobachten.

*) Diese beiden Farbstoffe sind in systematischer Beziehung sehr constant, so dass sie zum mindesten eine generische Verschiedenheit andeuten. Es müssen daher z. B. die Gloeocapsen mit gelben Membranen als besondere Gattung (Xanthocapsa Näg.) ausgeschieden werden. 
lus, Entada und anderen Leguminosen durchgehends von dem braungefärbten Inhalte herzurühren, in dem Sinne wenigstens, dass wenn hie und da auch die Membranen gefärbt sind, der Farbstoff doch nachweisbar zuerst im Inhalt vorhanden war.

Die Veränderlichkeit dieser braunen Pigmente ist eine sehr geringe. Alkalien rufen so gut wie keinen Farbenwechsel hervor; Säuren geben nur hie und da einen entschieden rötheren Ton (Phaseolus mesoleucus), der dann durch Alkalien wieder in Bläulichbraun und hierauf in Braun oder Braungelb übergeht. Bei Plaseolus mesoleucus scheint diescr Farbenwechsel von Anthocyan, welches im Inhalt zurïckblieb, herzurühren. Wenigstens nehmen die Membranen, welche auf Zusatz von Säuren roth werden, in Kali einen bläulichen Ton an, der sich später verliert, ganz so, wie man es an Membranen beobachtet, die wirklich Anthocyan enthalten.

471 Endlich sind hieher noch jene Flechtenfarbstoffe zu rechnen, welche die Färbung des Thallusrandes und des Fruchtgehäuses, in manchen Fällen auch der Rindenfasern bedingen. Auch hierüber lässt sich kaum etwas Allgemeines sagen. Es kommt nicht selten vor, dass Farbstoffe, welche nahezu gleich aussehen, sich gegen Reagentien ungleich verhalten. So beobachtet man z. B., dass jene bläulichschwärzlichen Membranen, wie man sie im »Hypothallus " und im Fruchtgehäuse hie und da wahrnimmt, durch Säuren und Alkalien gewöhnlich wenig verändert werden, während die bläuliche Farbe des Thallusrandes von Aspicilia calcarea durch Salpetersäure intensiv spangrün wird. Dagegen zeigen die gelben und braunen Pigmente, welche die dunkle Färbung der oberen oder unteren Rinde, der Fruchtgehäuse und der Haftfasern bedingen und welche nur bei wenigen Flechten ganz fehlen dürften, ein ziemlich übereinstimmendes Verhalten. Dieselben werden aus jugendlichen Geweben, sowcit wenigstens unsere Beobachtungen reichen, durch Alkalien ohne Farbenveränderung ausgezogen, während sie in späteren Stadien, wie z. B. in der schwarzen unteren Rinde mancher Imbricarien, in alten Fruchtgehäusen etc., widerstehen.

e) Farbstoffe, welche von den Zellen ausgeschieden werden und sich zwischendenselben oder ander freien Aussenfläche der Membranen ablagern.

472 Die Pigmente, welche die gelbe Färbung der oberen Rinde bei Parmelia parietina und anderen ähnlich gefärbten Flechten be- 
dingen, sind weder im Inhalt noch in der Membran enthalten, sondern in Gestalt von kleinen Körnchen an die Aussenfläche der Membran angedrückt oder zwischen die sich berührenden Zellen eingeklemmt. Dasselbe gilt von dem gelben Farbstoff der Solorina crocea, Sticta aurata etc., wo die gelben Körnchen die Oberfläche der Markfasern bedecken.

Die Erscheinungen, welche man auf Zusatz von Kali beobachtet, machen es in manchen Fällen sehr wahrscheinlich, dass der Farbstoff nicht als solcher ausgeschieden wird, sondern in eine farblose, aus einer quellungsfähigen Substanz bestehende Grundlage eingebettet ist. Darauf deuten namentlich die rothen und violetten Wolken, welche das Kali bei Physcia parietina, Solorina crocea und bei manchen gelben Krustenflechten hervorruft. Diese Wolken bestehen nämlich aus einer schwerflüssigen, fast gallertartigen Substanz, in welcher zahllose kleine Splitterchen suspendirt sind, und es scheint, dass die Färbung vorzugsweise von diesen letzteren herrührt. Ob die Körnchen, welche mit Kali eine gelbe Lösung bilden, die sich rasch entfärbt, ähnlich zusammengesetzt sind, müssen weitere Untersuchungen lehren.

\section{Pectinstofie.}

Seit den Untersuchungen Frémy's ist die Frage, wo das ur- $\mathbf{4 7 3}$ sprüngliche Material, aus dem die Pectinstoffe entstehen, die Pectose, ihren Sitz habe, wiederholt erörtert worden. Die einen hielten sie für einen Bestandtheil des Inhalts, die andern für einen Bestandtheil der Membran. Diese letztere Ansicht fand neuerdings zwei Vertreter in $\mathrm{Kabsch}^{*}$ ) und $\operatorname{Vogl}{ }^{* *}$ ), welche dieselbe für die untersuchten fleischigen Wurzeln Daucus Carota, Brassica Napus, Taraxacum officinale übereinstimmend dahin präcisirten, dass die äussern, die sog. primäre Zellwand bildenden Schichten in der Umwandlung in Pectose begriffen seien und dass diese Substanz in den genannten Wurzeln die Intercellularsubstanz bilde. Ebenso soll nach Vogl die Hülle der Milchsaftgefässe beim Löwenzahn sich als neine in der Pectinmetamorphose begriffene Cellulose " erweisen. Diese Angaben beruhen indess einzig und allein auf der theilweisen Löslichkeit der erwähnten Schichten in heissem Wasser, sowie in verdünnten Säuren und Alkalien, - Eigenschaften, die man häufig genug auch bei Algen und Flechten, überhaupt bei Pflanzen findet, welche keine

*) Pringsheim's Jahrb. Bd. III. p. 366.

**) Sitzungsber. der kais. Akad. der Wiss. in Wien. B.1. :5. 2te Abth.

Nägeli u. Schwendener, das Mikroskop. 
Pectinstoffe liefern, und die man folglich keineswegs als Kennzeichen der Pectose betrachten darf.

Wir halten die Ansicht, dass die Pectose einen Bestandtheil der Zellwandungen bilde, für durchaus unbegiündet. Untersucht man unreife Früchte, welche sich später durch ihren Pectingehalt auszeichnen (Birnen, Aepfel, Beeren etc.), so findet man durchgehends, dass das Fruchtfleisch aus einem ganz dünnwandigen Gewebe besteht, dessen Membranen sich beim Kochen in Wasser, sowie in verdünnten Säuren und Alkalien nicht merklich verändern und sich auch gegen andere Reagentien wie Cellulosemembranen verhalten. Die Pectose kann also nicht in den dünnen Wandungen, die ohnehin eine so bedeutende Menge von Material unmöglich liefern könnten, enthalten sein : sie muss einen Bestandtheil des Inhalts bilden.

\section{Kohlenhydrate.}

$474 \mathrm{Zu}$ den Kohlenhydraten, deren Eigenschaften und Vorkommen wir im Allgemeinen als bekannt voraussetzen, gehören bekannt lich zumächst die Zucker- und Gummiarten und das Inulin, welche als die Endglieder der stickstofffreien Assimilationsproducte zu betrachten sind, dann die ungelösten, organisirten Gebilde der Stärke und Cellulose, welche durch Umbildung (ohne Veränderung der chemischen Zusammensetzung) ans jenen entstehen und auch umgekehrt wieder in Zucker und Gummi übergehen, um mit den strömenden Säften weiter zu wandern. Die mikrochemischen Reactionen auf die verschiedenen Kohlenhydrate verdienen unter diesen Umständen besondere Beachtung, weil sie uns die Umbildungs- und Rückbildungsprocesse, soweit sie die stickstofffreien Verbindungen betreffen, zu verfolgen gestatten.

a) Traubenzucker, Dextrin, Rohrzucker.

475 Um diese Stoffe in den Pflanzengeweben mikrochemisch nachzuweisen, hat neuerdings Sachs die bekannte Reaction derselben auf alkalische Zuckerlösungen angewendet und dabei ein V'erfahren ausfindig gemacht, welches in der That eine ziemliche Sicherheit der Beobachtung gestattet. Da dieses Verfahren auf eine der wichtigsten Erscheinungen im Lebensprocess, nämlich die Wanderung assimilirter Stoffe von Zelle zu Zelle Bezug lat, so mag hier die umständliche Beschreibung desselben, wie sie von Sachs selbst (Flora 1862 pag. 259) mitgetheilt wurde, Platz finden.

„ Die zu untersuchenden Längs- und Querschnitte der Pflanzen- 
theile werden in eine concentrirte Lösung von Kupfervitriol , welche sich in einem kleinen flachen Porcellanschälchen befindet, gelegt. Wenn es darauf ankommt, die in Inhalt der Zellen gelösten Stoffe aufzusuchen, so dürfen die Schnitte nicht zu dünn sein, sie müssen wenigstens eine bis zwei Schichten unverletzter Zellen enthalten; will man dagegen Färbung der Zellhäute hervorrufen, so ist es besser, dünnere Schnitte zu nehmen, welche keine ganzen unverletaten Zellen enthalten, weil in diesem Falle die etwaigen Reactionen im Zellinhalt den Eindruck stören würden. Auch die Zeit, wie lange die Schnitte in der Kupfervitriollösung liegen müssen, ist darnach einzurichten; im Allgemeinen müssen die Schnitte länger in der blauen Flüssigkeit liegen, wenn man auf die Zellhäute reagiren will. In diesem Falle können die Präparate zuweilen schon nach 5- $10 \mathrm{Mi}$ nuten zur weiteren Behandlung kommen, zuweilen müssen sie aber mehrere Stunden in der Kupferlösung liegen. Um die in der Zellflüssigkeit vorhandenen Stoffe nachzuweisen, genügt dagegen meist ein Verweilen von $2-3$, seltener von $5-10$ Minuten in der Lösung. Doch muss man aus dem nämlichen Pflanzentheil immer gleichzeitig mehrere und verschieden dicke Schnitte in die Flüssigkeit legen und sie bei der folgenden Behandlung mit Kali nach einander vornehmen.

Es wird nun in einem kleinen, etwa S-10 C. C. fassenden Porcellanschälchen Kalilösung letwa 1 Gewichtstheil Wasser auf 1 Gewichtstheil kaustisches Kali bis zum Kochen erhitzt, indem man das Schälchen in eine Drahtöse setzt, die an einem Holzgriff befestigt ist, und es damit über die Spiritusflamme hält. Dann setze ich das Schälchen vor mich hin, nehme mit einer feinen Pincette einen Schnitt aus der Kupferflüssigkeit und schwenke ihn einigemal in einer grösseren Wassermasse (am besten in einer grossen Porcellanschale enthalten) hin und her, um die äusserlich anhängende Knpferlösung zu entfernen, was für das Gelingen der Reaction maassgebend ist; sodann lege ich den Schnitt in die heisse Kalilauge. Entweder erfolgt die nun zu beschreibende Reaction schon jetzt, oder man muss das Schälchen sammt dem darin liegenden Schnitt nochmals über die Flamme halten.

Ist Traubenzucker oder Dextrin in den Zellen, so bildet sich in dem vorher farblosen Gewebe ein zinnoberrother bis mennigrother Niederschlag von reducirtem Kupferoxydul. Tritt ein solcher Niederschlag nicht ein, so darf man mit Bestimmtheit auf Abwesenheit von Traubenzucker und Dextrin schliessen. 
Ist in dem Parenchym Rohrzucker vorhanden, so nimmt das mit Kupferflüssigkeit getränkte Gewebe im Kali eine schöne blaue Färbung an, und bei dem Erhitzen tritt keine Reduction von Kupferoxydul auf, die Flüssigkeit bleibt blau und diffundirt in das umgebende Kali. Tritt bei dem Eintauchen des mit Kupfervitriol getränkten und abgewaschenen Schnittes in Kali (vor und nach dem Erhitzen) in den Zellen eine violette Flüssigkeit auf, so ist diess ein Beweis für die Gegenwart von eiweissartigen Stoffen. "

Die weiteren Bemerkungen, welche Sachs noch hinzufügt, geben wir hier in Ausznge wieder. Um auf Zellhäute, 'Traubenzucker und Dextrin zu reagiren, können die mit Zuckerlösung getränkten Schnitte auch auf dem Objectträger in Kali gelegt werden, wobei die Reaction der Zellmembran sogleich, die des wässerigen Zellinhaltes nach dem Erhitzen über der Weingeistflamme eintritt. - Die Reaction auf Rohrzucker ist unter den oben angegebenen die am wenigsten sichere, jedoch bei grösserem Zuckergehalt, wię z. B. im Gewebe der Runkelrüben, nicht zu verkennen. Die blaue Färbung der Zellmembranen, wie man sie am Collenchym, an jungen Bastzellen und am Holzcambium beobachtet, darf dagegen nicht als Rohrzuckerreaction gedeutet werden.

\section{b) Inulin.}

476

Von den Eigenschaften des Inulins heben wir hier nur diejenigen hervor, welche zur Nachweisung desselben in mikroskopischen Objecten dienen können. Wir halten uns hiebei an die Angaben von Sachs, *) dem es zuerst gelang, Reactionen ausfindig zu machen, die für das Inulin charakteristisch sind und unter dem Mikroskop sich leicht und sicher wiederholen lassen.

Das Inulin kommt hienach in den lebenden Parenchymzellen, wie schon Payen und Mohl richtig erkannt hatten, immer gelöst im Zellsafte vor. Wo es in grösserer Menge vorhanden ist, wie in den reifen Knollen von Helianthus tuberosus, Dahlia variabilis und Inula Helenium, scheint die Lösung eine sehr hohe Concentration zu besitzen, da sie in den unverletzten Zellen, wenigstens bei schwächerer Vergrösserung, den Anschein eines dünnen hellgelblichen Oeles gewährt. Taucht man einen frischen Schnitt von inulinhaltigen Knollen in Alkohol ein, so bildet sich ein feinkörniger Nierler-

*) Ueber die Sphaerokrystalle des Inulins und dessen mikroskopische Nachweisung in den Zellen (Bot. Ztg. 14ti-1 p. $7 \%$. 
schlag, dessen Körnchen eine lebhafte Molecularbewegung zeigen. Hie und da beobachtet man auch grösscre Kugeln, welche bei schwacher Vergrösserung Oeltropfen ähnlich sind (Fig. 215 A). "In vielen Zellen hat der Niederschlag aber ein anderes Aussehen; es scheint so, als ob sich eine schaumige, vacuolige, stark lichtbrechende Masse an die Zellwand angelagert hätte. Lässt man ein derartiges Präparat nun 5-10 Minuten in Alkohol liegen, so geschieht es oft, doch nicht immer, dass sich einzelne Zellengruppen klären, indem der feine Niederschlag verschwindet und statt dessen grössere Kugeln ron 10-15 Mikromill. Durchmesser auftreten; oft hängen sie tranbig zusammen, meist sitzen sie, halbkugelförmig, mit der flachen Scite an der Zellwand, zuweilen sind sie völlig rund und isolirt." (Fig. $215 A$ ).

Bringt man nun einen so vorbereiteten Schnitt in kaltes Wasser, so treten die grösseren Kugeln klarer hervor, indess dic kleinen Niederschlagskörnchen verschwinden. Sämutliche Kugeln zeigen radiale Risse, die schönsten derselben zugleich einige concentrische Schichten (Fig. $215 B$. Die Uebereinstimmung mit den Sphaerokrystallen des Inulins (Fig. $215\left(C^{\prime}\right)$, wie man sie ausserhalb der Pflanze aus warmen wässerigen Lösungen beim Stchenlassen, oder indem
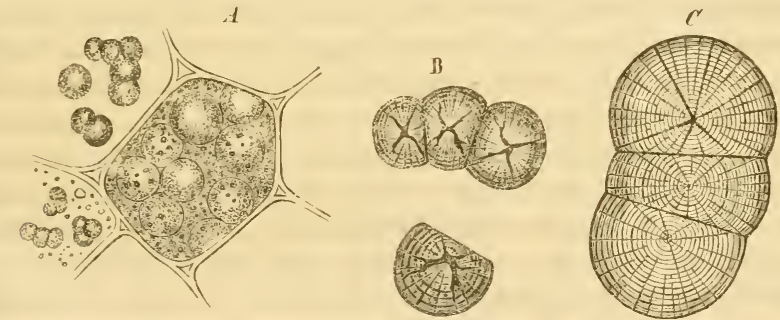

Fig. 215.

man Alkohol langsam hinein diffundiren lässt, erhält, ist jetzt nicht mehr zu verkennen. Dass die letzteren beträchtlich grösser und ausgebildeter sind, erklärt siclı einfach durch ihre langsamere Entwicklung. Uebrigens hat Sachs gezeigt, dass man ebenso schöne, oft colossale Formen von Sphaerokrystallen erhält, wenn man grössere Stücke von inulinhaltigen Ḱnollen in Alkohol oder in Glycerin einige 'Tage, Wochen oder Monate lang liegen lässt. Man bemerkt alsdann auf glatten Durchschnitten schon mit freiem Auge kleine Körnchen im Gewebe, welche einen ganzen Complex von Zellen eimnehmen, und die mikroskopische Untersuchung zeigt, dass neben diesen gros- 
sen Krystallen auch zahlreiche kleinere vorhanden sind, welche das Lumen einer einzigen Zelle oder auch nur einen 'Theil desselben ausfüllen. Dasselbe beweisen auch die von $\mathrm{Nägeli*)} \mathrm{beschriebenen,}$ zweifelsohne aus Inulin bestehenden Sphaerokrystalle in Acetabularia mediterranea (alte Weingeistexemplare), welche hinsichtlich ihrer Ausbildung die von Sachs dargestellten noch übertreffen.

477 Die mikroskopische Nachweisung des Inulins' geschieht also nach dem Gesagten dadurch, dass man frische Schnitte mit Alkohol behandelt oder, was besser ist, die zu prüfenden Pflanzentheile in grösscren Stücken Tage, Wochen oder Monate lang in Alkohol oder Glycerin liegen lässt. Bilden sich bei dieser Behandlung die in unserer Figur dargestellten charakteristischen Formen der Sphaerokrystalle, so darf man mit Sicherheit auf die Gegenwart von Inulin in den untersuchten Pflanzentheilen schliessen,

Wer die Sphaerokrystalle einmal aus eigener Anschauung kennen gelernt hat, wird eine weitere mikroskopische Prüfung derselben kaum für nöthig erachtc1. Für zweifelhafte Fälle mögen indess noch folgende Reactionen, die sich mikroskopisch leicht beobachten lassen, Erwähnung finden. Die Sphaerokrystalle des Inulins zeigen auf Zusatz von Wasser, Säuren oder Alkalien keine Quellungserscheinungen; sie sind nicht imbibitionsfähig, wie die Stärkekörner oder die Proteinkrystalloide, wohl aber porös wie Tuffstein. Dem entsprechend erscheinen sie unter dem Mikroskop durchsichtig, so lange die Poren mit einer Flüssigkeit gefüllt sind, undurchsichtig dagegen, sobald die letztere durch Verdunstung verschwunden ist. Lässt man Schwefelsäure, Salpetersäure, Salzsäure oder Kalilösung darauf einwirken, so findet gewöhnlich zunächst ein Zerfillen derselben in mehrere Sectoren, dann aber die vollständige Auflösung der Theile von aussen nach innen statt. Wässerige oder alkoholische Iodlösungen dringen in die Sphaerokrystalle ein und erzeugen eine braune Färbung, die indess von der lodlösung allein herrührt; eine Aufspeicherung oder Verdichtung des Iod, etwa ähnlich wie in Stärkekörnern oder Zellkernen, findet nicht statt.

\section{c) Stärke.}

478 Die Stärkekörner färben sich bekanntlich auf Zusatz von lodlösung blau. Die Färbung ist in der Regel so deutlich, dass selbst

•) Sitzungsber. der k. bayer. Akad. d. Wiss. zu München. Vortrag vom 8. März $1 \triangleleft 6 ; 2$. 
Körner von nur 2-3 Mik, im Durchmesser noch sicher als Stärke erkannt werden können. Da sic überdiess bei vorsichtigem Iodzusatz schon beginnt, ehe das Plasma die geringste Veränderung zeigt, so ist die Reaction auch in solchen Fällen sicher, wo die Stärkekörner von Plasmamassen eingehüllt sind. Uebrigens kann man in diesen Fällen die eiweissartigen Stoffe des Plasmas durch längeres Liegenlassen der Schnitte in Kali auszichen und hierauf die aufgequollenen Körner mit Iod färben. Ebenso kann das Chlorophyll, wenn es die Sicherheit der Beobachtung beeinträchtigt, vorher durch Alkohol entfernt werden.

Die Beobachtung dieser wenigen Vorschriften genügt in der $\mathbf{4 7 9}$ Regel, um die Gegenwart von Stärkekörnern nachzuweisen. Um jedoch in zweifelhaften Fällen nicht irre zu gehen, ist das Verhalten derselben gegen Iodlösungen im Gegensatz zu anderen Stoffen, die in der Zelle vorkommen, noch genauer ins Auge zu fassen. Aus den betreffenden Untersuchungen ) heben wir nachstehend die für unsere Zwecke wichtigeren hervor.

1) Wenn Stärke mit geronnenen eiweissartigen Verbindungen gemischt und auf dem Objectträger in eine sehr verdünnte wässerige Iodlösung gebracht wird, so färbt sich vermöge ihrer vorwiegenden Affinität zuerst die Stärke und erst später das Eiweiss. Ebenso entzieht das Wasser bei der Entfärbung in Folge der Verdunstung zuerst dem Eiweiss und daun erst den Stärkekörnern das aufgenommene Iod. Aehnliche Verschiedenheiten bestehen übrigens auch zwischen den Stärkekörnern verschiedener Pflanzen. Kartoffel- und Weizenstärke zeigen z. B. die Reaction früher als Stärkekörner aus der Ingwerwurzel. Der Versuch gelingt am besten, wenn man die Objecte in reines Wasser legt und zwischen dieselben oder an den Rand des Deckgläschens ein paar Iodsplitter bringt.

2) Legt man durch Hitze coagulirtes Hühnereiweiss in wässerige Iodlösung, so färbt sich dasselbe allmählich durch und durch braun. Bringt man es nun in ein verschlossenes, mit Wasser und Stärke gefülltes Gefäss, so verlässt das Iod langsam das Eiweiss und färbt die Stärke. Dagegen vermag umgekehrt das coagulirte Eiweiss der gebläuten Stärke kein Iod zu entziehen. Aehnlich verhalten sich auch Dextrin, Flechtenschläuche, mit Schwefelsäure behandelte Baumwol-

+) Nägeli in den Sitzungsber. der k. bayer. Akad. d. Wiss. in München. Vortrag vom 13. Dec. 1562. 
lenfasern etc.; sie haben sämmtlich eine geringere Affinität zu Iod als Stärkemehl und werden daher von diesem entfärbt.

Aus diesen beiden Punkten ergiebt sich für den Beobachter die Regel, dass eine Bläuung, welche bei langsamer Einwirkung von Iod erst eintritt, nachdem das Plasma sich bereits gefärbt hat, nicht auf das Vorhandensein von Stärke schliessen lässt. Wenn z. B. in der Epidermis von Ornithogalum die allmähliche Einwirkung von Iod zuerst die Stärkekörner der Spaltöffnungszellen blau, dann das Plasına braungelb und zuletzt eine fragliche Substanz (angeblich gelösteStärke), die in Zellsaft gelöst ist, violett färbt, so folgt daraus, dass die letztere nicht Stärke sein kann.

480 Den Einfluss betreffend, welchen der Wassergehalt auf die Färbung der Stärke ausübt, so schienen die früheren Beobachtungen von Mohl und Nägeli*) zu dem Resultate zu führen, dass die Anwesenheit des Wassers nothwendige Bedingung der blauen Färbung sei. Iodstärke, welcher das Wasser entzogen wird, nimmt in der That allmählich einen braungelben, braunrothen bis dunkelbraunen Ton an und wird nach der Benetzung wieder blau. Die Schlüsse, welche aus diesen Beobachtungen gezogen wurden, bedürfen jedoch einer Berichtigung; sie müssen nach den erwähnten neueren Untersuchungen folgendermaassen formulirt werden.

1) Die Stärke nimmt verschiedene Farben an, je nachdem sie im Momente, in welchem das Iod eingelagert wird, mit mehr oder weniger Wasser imbibirt ist. Die reinblaue Färbung erlangt sie nur dann, wenn sie nahezu ihren vollen Wassergehalt hat. - Wasserfreie Iodtinctur, desgleichen Iod in ätherischem Oel gelöst oder in Dampfforın, färbt trockene Kartoffelstärke äusserst langsam und zwar zuerst gelb, dann gelbbraun. Wird der Iodtinctur etwas Wasser beigemischt, so erhält man, je nachdem man nur wenig oder etwas mehr genommen, rothgelbe, braune, rothbraune, kupferrothe und violette Töne.

2) Die durch Iod gefärbte und von Wasser durchdrungene Stärke kann die angenommene (blaue, rothe oder gelbe) Farbe unverändert behalten, wenn ihr das Wasser durch Verdunsten oder durch Alkohol entzogen wird. - Tritt während des Austrocknens eine Farbenänderung ein, so liegt die Ursache nicht in der Verminderung des Wassergehaltes an und für sich.

*) M ohl, Flora 1st0. Nägeli, Stärkekörner p. 1 ss. 
3) Unter übrigens gleichen Umständen bewirkt die grössere oder geringere Menge des eingelagerten Iod keine Verschiedenheit des Farbentons, sondern nur eine grössere oder geringere Intensität der Farbe. - Wo also beim Färben oder Entfärben ein Farbenwechsel bemerkbar ist, wird derselbe nicht durch den Iodgehalt, sondern durch andere Ursachen bedingt.

4) Die Ursachen verschiedener Färbung bei gleichem Iodgehalt sind zweierlei Art. Die Thatsache, dass die Stärke beim Entfärben mehr nach Roth gehende Töne annimmt, als beim Färben, und dass blaue Iodstärke, ohne sonst eine nachweisbare Veränderung zu zeigen, durch Erhitzen oder durch wiederholtes Ausziehen mit Alkohol zuerst violett, dann roth, braunroth und selbst braungelb und gelb wird, nöthigt zu der Annahıne, dass das Iod, ehe es die Stärke verlässt, zuerst seine Anordnung bezüglich der kleinsten Theilchen derselben verändert und dadurch verschiedene, eigenthüıliche Farben hervorbringt. Diess ist die eine Ursache; die andere liegt in fremdartigen Substanzen, welche die Iodstärke durchdringen. So bewirkt z. B. Iod in verdünnter Iodkaliumlösung eine schön blaue Färbung der Kartoffelstärke; lässt man aber die Lösung concentrirter werden, so treten mit der zunehmenden Concentration violette, rothe, kupferrothe, rothbraune und zuletzt braungelbe und gelbe Farbentöne auf. Aehnliche Färbungen erhält man, wenn man die Stärke zuerst in eine gesättigte Lösung von Glaubersalz, Kochsalz, Bittersalz etc. oder in Lösungen von Iodsäure, Iodwasserstoffsäure, Glycerin etc. bringt und dann Iodsplitter zusetzt, oder wenn man trockene blaue Iodstärke mit genannten Lösungen übergiesst und (nöthigenfalls wiederholt) eintrocknen lässt. Diese verschiedenen Salze und Säuren haben also das Vermögen, die Blaufärbung der Stärke zu verhindern und, wenn sie auf schon gebildete blaue Iodstärke einwirken, den blauen Farbenton durch Violett und Roth in Gelb überzuführen. *) Eine chemische oder physikalische Veränderung der Stärke findet dabei nachweisbar nicht statt; wenn sie mit Wasser ausgewaschen wird, so verhält sie sich wie unveränderte Stärke.

5) Es ist anzunehmen, dass die Einlagerung von Cellulose in die Schichten der Stärkekörner einen ähnlichen Farbenwechsel her-

*) Wie viel bei diesen Farbenänderungen auf Rechnung des durchdringenden Stoffes, wie viel auf Rechnung der geringeren Menge von Imbibitionswasser falle, lässt sich allerdings nicht bestimmen; soviel geht indess mit Bestimmtheit aus den Versuchen hervor, dass das Imbibitionswasser für sich allein nicht den Ausschlag gibt. 
vorruft. Darauf beruht wohl grösstentheils die Differenz zwischen den äussersten Schichten und der inneren Masse des nämlichen Korns, sowie das abweichende Verhalten der Getreidekörner im Gegensatz zu solchen aus Knollen und Wurzeln.

6) Von den verschiedenen Iodstärkeverbindungen entspricht die blaue der stärksten, die gelbe der schwächsten Verwandtschaft. Ungleiche Verwandtschaftsgrade bedingen auch eine ungleiche Anordnung der Iodtheilchen. Die Verwandtschaft wird durch die Anwesenheit von Wasser gesteigert, durch die Anwesenheit irgend einer andern Substanz dagegen vermindert, wobei gleichzeitig eine entsprechende Veränderung in der Anordnung der Iodtheilchen stattfindet.

481 Besondere Erwähnung verdient das Verhalten der Stärkekörner gegen das Speichelferment. ${ }^{*}$ Lässt man nämlich Speichel bei einer Temperatur von $45-50^{\circ} \mathrm{C}$. längere Zeit auf frisches, unverändertes Stärkemehl einwirken, so tritt ein allmählicher Auflösungsprocess ein, welcher an der Oberfläche beginnt und nach innen $z u$ fortschreitet. Die Substanz des Korns wird aber nicht vollständig gelöst, wie es bei der im Uebrigen ähnlichen Einwirkung der Diastase während der Keimung der Fall ist, sondern es bleibt je nach der schwächern oder stärkern Einwirkung entweder eine ununterbrochene Substanz von gleicher Form und Schichtung wie das unveränderte Korn, nur von geringerer Dichtigkeit, oder aber ein System von ineinander geschachtelten zarten Blasen, welche den theilweise aufgelösten dichteren Schichten des Korns entsprechen, zurück. Untersucht man die Körner in den verschiedenen Stadien der Resorption, so sieht man deutlich, wie die bereits angegriffene, zarte Randpartie allmählich breiter wird, indess der unveränderte centrale Theil, welcher vermöge seiner stärkern Lichtbrechung stark contourirt erscheint, sich gleichzeitig verkleinert und zuletzt verschwindet.

Haben die Körner Risse im Innern, so wird zunächst eine peripherische Substanzlage in der angegebenen Weise verändert. Später, wenn die Risse erreicht sind, dringt das Reagens in dieselben ein und wirkt fortan von ihrer ganzen innern Fläche aus. Das Korn wird dadurch in verschiedener Weise ausgehöhlt, oft so, dass die umschliessende Hülle zuletzt an mehreren Punkten durehbrochen erscheint oder in zwei oder mehr Stücke auseinander fällt.

*) Vgl. Nägeli, Stärkekörner pag. $113 \mathrm{ff}$. 
Der nach der Behandlung mit Speichel zurückbleibende Bestandtheil der Stärkekörner gehört nach seinem Verhalten gegen Iod zu den Cellulosearten. Wässerige Iodlösung färbt denselben entweder gar nicht oder blass kupferroth, und ebenso verhält sich frische Iodtinctur. Dagegen tritt nach dem Eintrocknenlassen mit Iodzinkiodlösung, Iodkalimmiodlösung, Iodtinctur oder wässeriger Iodlösung, welcher noch festes Iod beigemengt ist, beim Wiederbefeuchten mit W asser eine schöne violettblaue bis indigoblaue Färbung ein.

Das Cellulosekorn ist übrigens im Speichelferment keineswegs unlöslich, sondern nur weniger löslich als die Stärkesubstanz. Dasselbe wird schliesslich, wenn das Reagens lange genug einwirkt, ebenfalls gelöst und zwar von def Oberfläche aus nach innen und in den weicheren Partieen früher als in den dichtern. Es ist möglich, dass ein 'Theil der Cellulose schon früher gleichzeitig mit der Stärke verschwindct.

Die Stärkekörner sind also nach dem Vorhergehenden ein Gemenge von zwei Verbindungen, nämlich von Granulose und Cellulose, in der Art, dass in jedem Punkte beide Stoffe vereinigt sind. Die Mengungsverhältnisse sind bei den verschiedenen Stärkearten ungleich und variiren überdiess mit dem Wassergehalt der Schichten. Die weichen Schichten enthalten verhältnissmässig mehr, die dichteren weniger Granulose. In Ganzen ist die letztere bei den meisten Stärkearten weit überwiegend; in manchen Fällen möchte sie, nach der geringen Volumenverminderung während der Einwirkung des Speichels und der bedeutenden Dichtigkeitsabnahme zu schliessen, ungefähr $\% / s$ der ganzen Masse betragen. Fast ausschliesslich aus Cellulose besteht die äusserste Schicht der Stärkekörner, welche daher eine von der übrigen Substanz wesentlich verschiedene Rinde darstellt und sich theils durch grössere Unlöslichkeit theils durch ein abweichendes Verhalten bei der Iodreaction auszeichnet. Beide Eigenschaften müssen an aufgequollenen Körnern studirt werden.

\section{d) Cellulosearten}

Nach der gewöhnlichen Ansicht über die Zusammensetzung der $\mathbf{4 8 2}$ Zellmembranen, wie sie von Payen und v. Mohl begründet und seitdem von Chemikern und Botanikern ziemlich allgemein angenommen wurde, besteht die Grundlage aller vegetabilischen Zellmembranen, von der höchsten Pflanze bis zu den Pilzen abwärts, aus einer und derselben chemischen Verbindung, der Cellulose. Dieselbe soll in jugendlichen Zellmembranen in ziemlich reinem Zustande vorkom- 
men, in älteren dagegen durch fremdartige Einlagerungen (incrustirende Substanzen) chemisch und physikalisch mehr oder weniger verändert sein. Sie erlangt jedoch, so lehrte man weiter, ihre ursprünglichen Eigenschaften unter allen Umständen wieder, wenn die incrustirenden Substanzen durch geeignete Behandlung mit Säuren, Alkalien etc. ausgezogen werden. Als charakteristische Eigenschaft der purificirten Cellulose betrachtete man die Blaufärbung auf Zusatz von Iod und Schwefelsäure und die vollständige Unlöslichkcit dersclben in kaltem und heissem Wasser, sowie in verdünnten Säuren und Alkalien. Mohl ging sogar noch einen Schritt weiter, indem er der "gereinigten Cellnlose " die Fähigkeit zuschrieb, sich durch Iod und Wasser allein blau zu färben.*)

Diese Theorie lässt sich mit den neuern Untersuchungen**), welche entschieden gegen die angenommene Bedeutung der Incrustationen sprechen, nicht vereinigen. Die Eigenschaften der Membranen müssen nummehr folgendermassen formulirt werden.

1 Die vegetabilischen Zellmembranen bestehen in vielen Fällen nachweisbar aus zwei isomeren, innig mit einander gemengten Verbindungen von ungleicher Löslichkeit. Die eine derselben wird zuweilen schon in kaltem Wasser, noch leichter in kochendem Wasser ausgezogen und kann aus der Lösung durch Iod und Iodwasserstoffsäure als blaner oder blaugrüner Niederschlag gefällt werden. So verhalten sich z. B. die Saamenlappen von Hymenaea Cour baril, Muruna und andern Gattungen, desgleichen die Gonidienmembranen von Plıylliseum. In andern Fällen ist die Einwirkung einer verdünnten Säure erforderlich, um den leichter löslichen Bestandtheil auszuziehen, so z. B. bei den Flechtenschläuchen, denen durch verdünnte Salzsäure der mit wässeriger Iodlösung sich bläuende Theil entzogen wird. Es scheint überhaupt eine allgemeine Eigenschaft der Membranen zu sein, dass sie einen Theil ihrer Substanz an Lösungsmittel abgeben, welchen der andere Theil widersteht. .

Die mikrochemische Untersuchung der die Zellmembran zusammensetzenden Substanzen wird durch diesen Umstand bedeutend erschwert; denn da die isomeren Verbindungen, welche die organische Grundlage bilden, nur wenig von einander verschieden sind, so kann die leichter lösliche nur durch lange, viele Wochen und Monate

*) Bot. Ztg. 1547, Veget. Zelle p. 30 .

**) Vgl. Nägeli in den Sitzungsber. der k. bayer. Akad. der Wiss. in München, Vortrag vom 6. Mai und 13. Juni $1 \varsigma 63$. 
dauernde Einwirkung eines schwachen Lösungsmittels entfernt werden, und der Erfolg dieser Einwirkung muss von Zeit zu Zeit an kleinen Proben, die man unter das Mikroskop bringt, geprüft werden, bis endlich keine Veränderungen mehr eintreten. Unterlässt man diese Procedur, so ist bei dem wechselnden Verhältniss zwischen leichter und schwerer löslichen Bestandtheilen, verbunden mit der Verschiedenartigkeit der fremden Einlagerungen, eine solche Mannigfaltigkeit der Erscheinungen denkbar, dass bestimmte Folgerungen in Betreff der chemischen Zusammensetzung, wie sie Schleiden und Frémy*) gezogen haben, sich aus dem Verhalten der Gemenge

*) Frémy gelangte durch eine Reihe von Untersuchungen, deren Resultate er im Jahre 1559 der Akademie der Wissenschaften in Paris vorlegte und gleichzeitig in "Journal de Pharmacie et de Chimie " (t. XXXVI p. 6) zusammenstellte, zu den Schluss, dass die verschiedenen Gewebe der Hölzer aus ebenso vielen chemisclı verschiedenen und durch ihre ungleiche Iöslichkeit vollständig isolirbaren Substanzen bestehen, deren Namen, Vorkommen und Eigenschaften er folgendermaassen feststellte.

1) Cellulose, unmittelbar löslich in Kupferoxydammoniak, löslich in concentrirter Sehwefelsäure und in concentrirter kochender Kalilauge; bildet die Zellmembranen der Früchte, fleischigen Wurzeln, Bastfaser'n etc.

2) Paracellulose, löslich in concentrirter Schwefelsäure und in concentrirter kochender Kalilauge, unlöslich in Kupferoxydammoniak, wird in diesem letzteren Reagens löslich durch vorhergehende Behandlung mit Säuren und Alkalien, sowie durch feuchte und trockene Wärme; bildet die Membranen des Markes und der Markstrahlen.

3) Fibrose, unlöslich in Kupferoxydammoniak und in concentrirter kochender Kalilauge, löslich in concentrirter Schwefelsäure; bildet die Membranen der Holzzellen, der Pilzgewebe etc.

NB. Cellulose, Paracellulose und Fibrose bilden nach Frémy die Cellulosegewebe; sie haben sämmtlich die procentische Zusammensetzung der Kohlenhydrate und färben sich mit lod und Schwefelsäure blau.

4) Vasculose, unlöslich in concentrirter Schwefelsäure (oder Salzsäure) und in Kupferoxydammoniak, löslich in concentrirter kochender Kalilauge; bildet die Membranen der Gefässe.

5) Pectose, bildet mit Kupferoxydammoniak (welches die einhüllenden Cellulosemembranen löst) pectinsaures Kupferoxyd und geht durch Säuren in Pectin über; findet sich in Früchten und Wurzeln.

6) Cutine, unlöslich in concentrirter Schwefelsäure und in Kupferoxydammoniak, verseift sich mit den Alkalien wie ein ächtes Fett; bildet die cuticularisirten Schichten der Epidermis.

Dass diese Eintheilung Frémy's in der Hauptsache eine dưrchaus unhaltbare ist, geht schon aus dem Umstande hervor, dass die Differenzen zwischen gleichnamigen Gebilden, wie z. B. zwischen Gefäss und Gefäss oft weit grösser sind, als diejenigen zwischen Holzzelle und Holzgefäss, die angeblich aus zwei verschiedenen Substanzen bestehen. Die Gefässe fleischiger Wurzeln lösen sich, 
gegen kräftige Reagentien, man mag es nun mit ganzen Gewebepartieen oder bloss mit Membranschichten zu thun haben, nicht mehr ableiten lassen oder wenigstens nicht durch zwingende Gründe unterstützt werden.

2) Die ungleiche Löslichkeit der Zellmembranen in den verschiedenen Lösungsmitteln kann nicht wohl auf Rechnung der eingelagerten Substanzen geschrieben werden, da die festeren Zellınembranen (z. B. Tannenholz, Baumwolle etc.) auch nach der sogenannten Reinigung durch Säuren und Alkalien immer noch unlöslicher sind, als manche andern, die keinerlei vorläufige Behandlung erfahren haben, und da umgekehrt die weichen und jedenfalls nicht stark incrustirten Membranen der Gallertflechten dem Kupferoxydammoniak widerstehen, während die meisten Holz- und Bastzellen der höhern Pflanzen sich darin lösen. Es ist wahrscheinlicher, dass hier die Molecularconstitution den Ausschlag gibt, und zwar in Allgemeinen in dem Sinn, dass wasserreichere Membranen, welche kleine Molecüle besitzen, sich leichter lösen als die festen. Die letzteren können zwar durch geeignete Mittel in einen löslicheren Zustand übergeführt werden; allein sie quellen dabei so stark auf, dass sie die Weichheit einer wasserreicheren Substanz annehınen, was natürlich eine entsprechende Veränderung der Molecularstructur voraussetzt. Daraus folgt, dass verschiedene Substanzen organisirter Gebilde .nur dann eine Vergleichung zulassen, wenn sie annähernd gleiche Dichtigkeit oder Festigkeit besitzen.

484 3) Die Substanz der Zellmembranen (mit Ausschluss der Flechtenschläuche) wird durch Iod und Wasser allein nicht gebläut, sondern entweder gelblich, braungelb bis roth oder auch gar nicht gefärbt. Bei gleichzeitiger Einwirkung einer geringen Menge von

wenn man sie vorher mit Kalilauge und verdünnter Salzsäure behandelt, vollstänlig in Kupferoxydammoniak, während die Gefässe der Hölzer diesem Reagens Widerstand leisten. Erstere verhalten sich wie Paracellulose, nicht wie Vasculose. Aehnliche Unterschiede bestehen auch zwischen Holzzellen und Holzzellen, desgleichen zwischen den Markstrahlen kratutartiger und holzartiger Pflanzen, und zwar in verschiedenen Abstufungen, - der niederen Gewächse, welche für sich allein die mannigfaltigsten Verhältnisse darbieten, nicht zu gedenken.

Uebrigens ist selbst bei den Hölzern, welche Frémy speciell untersuchte, eine Trennung der Markstrahlen von Gewebe der Holzzellen in der angegebenen Weise nicht möglich, und auch in andern Punkten hat die Wiederholung der Frémy'schen Versuche wesentlich abweichende Resultate geliefert. (Vgl. Kabsch, Untersuchungen über die chemische Beschaffenheit der Pflanzengewebe ; Pringsheim's Jahrb. III.) 
Iodwasserstoffsạure oder eines Iodmetalls erfolgt blaue Färbung, indess steigende Mengen dieser Verbindungen einen violetten, rothen oder gelben Ton bedingen. Ebenso wird die Blaufärbung durch Schwefelsäure und Phosphorsäure vermittelt; es ist indess zweifelhaft, ob diese Säuren einen directen Einfluss üben oder ob sich unter ihrer Mitwirkung erst Iodwasserstoffsäure bildet, sei es durch Zersetzung des Alkohols im Reagens oder irgend einer organischen Verbindung im Präparat. Ob Chlorzink einen ähnlichen directen oder indirecten Einfluss übe, bleibt dahingestellt; jedenfalls wirkt die sogenannte Chlorzinkiodlösung vorzugsweise vermöge ihres Iodzinkund Iodkaliumgehaltes.

Die entgegengesetzten Angaben früherer Beobachter in Betreff der Blaufärbung mit Wasser und Iod finden ihre Erklärung darin, dass dieselben entweder ältere Iodtinctur gebrauchten, in welcher sich bereits Iodwasserstoffsäure gebildet hatte, oder bei Anwendung reiner Iodlösung die Bildung dieser Säure auf dem Objectträger veranlassten.

Was die Natur der Einwirkungen anbelangt, welche die genannten Säuren und Iodverbindungen ausüben, so sind dicselben nicht etwa als chemische und physikalische Veränderungen zu deuten, welche möglicherweise in der Membran stattfinden; denn es ist unter allen Umständen nothwendige Bedingung der Blaufärbung, dass dic genannten Stoffe nicht bloss eingewirkt haben, sondern bei der Einlagerung von Iod a $n$ wesend seien. Wäscht man die mit Schwefelsäure oder Iodwasserstoffsäure etc. behandelten Membranen sorgfältig mit Wasser aus, so färben sie sich in reiner Iodlösung nicht mehr blau. Auch ist bekannt, dass beliebige andere Quellungsmittel als specifisch bläuende, wie z. B. Salzsäure, Salpetersäure, Kupferoxydammoniak ctc., die erwähnte Iodreaction nicht vermitteln.

4) Die gelbe oder braungelbe Färbung, welche das Iod in man- 485 chen Membranen hervorruft, ist der Membransubstanz eigenthümlich; sie wird nicht etwa durch eingelagerte Proteinverbindungen bedingt. - Dieser Satz ergibt sich aus der Thatsache, dass viele Membranen (z. B. auf Längsschnitten von Begoniastengeln), in denen auf anderem Wege keine eiweissartigen Verbindungen nachgewiesen werden können, sich mit Iod sogar schöner und intensiver gelb oder braungelb färben, als das in den Zellen enthaltene Plasma.

5) Bezüglich der Farbennuance, welche die Einlagerung von Iod unter bestimmten Verhältnissen hervorruft, gelten die nämlichen Gesetze, wie für die Stärke. Die Menge des eingelagerten Iod be- 
dingt auch hier im Allgemeinen nicht den Character, sondern nur die Intensität der Farbe; man kann jeden Ton (Gelb, Orange, Roth, Violett, Blau) durch wenig Iod hell, durch eine grössere Menge intensiv erhalten. Ein Farbenwechsel tritt nur ein, wenn während der Einwirkung von Iod sich Iodwasserstoffsäure bildet oder wenn die Membran aus einer Mischung von zwei Stoffen besteht, von denen der eine das Iod mit blauer, der andere etwas später mit gelber Farbe einlagert. Im ersteren Falle kann der gelbe Ton in der Richtung nach Blau, in letzterem in der Richtung nach Braun verändert werden, wie man diess z. B. an Flechtenschläuchen sehr schön beobachtet. Trockene Membranen werden durch Ioddämpfe ohne Ausnahme gelb bis schwarzbraun gefärbt, sie mögen sich im befeuchteten Zustande noch so verschieden verhalten.

6) Die Entfärbung der mit Iod gefärbten Membranen ist wie bei der Stärke mit einem mehr oder minder deutlichen Farbenwechsel verbunden, welcher in der Richtung von Blau durch Roth nach Gelb erfolgt; blaue Membranen können ihre Farbe am meisten, gelbe gar nicht verändern; die geringste Veränderung beobachtet man an feuchten, die grösste an trockenen Membranen. Dabei ist jedoch vorausgesetzt, dass während der Entfärbung weder ein Austrocknen des feuchten, noch ein Benetzen des trockenen Präparates stattfindet.

7) Das Austrocknen einer mit Wasser imbibirten, durch Iod gefärbten Membran bewirkt an und für sich keine Farbenveränderung; wenn aber im Imbibitionswasser eine Substanz gelöst ist, die beim Verdunsten concentrirt wird, so kann dieser Umstand, wie bei der Stärke, eine andere Anlagerung der Iodtheilchen und dadurch einen Farbenwechsel bedingen.

486 Die Regeln, welche sich aus den vorstehenden Sätzen für die Untersuchungsmethode ergeben, liegen eigentlich schon in den Sätzen selbst; doch dürfte es zwockmässig sein, einige Punkte noch besonders hervorzuheben. Zunächst ist zu unterscheiden, ob eine Membran durch die 'angewendeten Reagentien eine chemische oder physikalische Veränderung erfahre, d. h. ob sie nach dem Auswaschen des Lösungs- oder Quellungsmittels sich anders verhalte als vorher. Findet eine Structurveränderung statt, indem z. B. die aufgequollene Substanz auch nach dem Auswaschen gequollen bleibt, so ist es nicht gestattet, ein abweichendes Verhalten bloss auf Rechnung der "Reinigung " zu schreiben, welche allfällig durch Entfernung gewisser Einlagerungen erzielt wurde. Die beliebte Unterscheidung von Holz- 
stoff und Zellstoff (vgl. Schacht, Mikr. p. 95), wovon der erstere in Kali und Salpetersäure löslich sein soll (weil diese Reagentien die Zcllstoffreaction vermitteln', entbehrt demmach einer thatsächlichen Begründung. Ueberhaupt kann das Kochen in starken Säuren oder Alkalien, da es stets mit einer bleibenden Quellung verbunden ist, nicht als eine blosse Reinigungsprocedur betrachtet werden. Wo es darauf ankommt, lösliche Substanzen auszuziehen, ohne die zurückbleibenden unlöslichen zu verändern, darf folglich das gedachte Verfahren nicht eingeschlagen werden; die Lösung muss vielmehr durch möglichst langsame Einwirkung eines schwachen Reagens erfolgen.

In zweiter Linie ist $\mathrm{zu}$ berücksichtigen, dass wirkliche Unterschiede in der Löslichkeit a priori eine doppelte Erklärung zulassen. Am nächsten liegt natürlich die Annahme einer chemischen V erschiedenheit, und so lange man es mit einer einzigen Substanz zu thun hat, ist diese Annahme die einzig mögliche. Allein da die organisirten Gebilde aus zwei oder mehreren Substanzen bestehen, die sich gegenseitig durchdringen, so können die beobachteten Abweichungen auch ebensogut durch die Verschiedenheit der Molecularconstitution bedingt sein. Es ist nämlich denkbar, dass eine an und für sich lösliche Substanz in einem gegebenen Falle durch eine unlösliche, die sie vollständig umhüllt, geschützt wird, während sie in einem anderen Falle für das Lösungsmittel zugänglich ist und folglich ausgezogen werden kann. Solche Möglichkeiten sind bei der Deutung bcobachteter Unterschiede jedenfalls in Betracht zu ziehen.

Bei Anwendung der Iodreaction endlich ist vor Allem auf Reinheit der Reagentien zu achten. Wo es gilt, die Färbung einer Membran durch Iod genau zu beobachten, thut man daher am besten, die Lösung auf dem Objectträger selbst zu bereiten, indem man metallisches Iod an den Rand des Deckgläschens oder zwischen die Objecte bringt. Auch ist es rathsam, das Experiment der Vergleichung wegen auch an solchen Präparaten zu wiederholen, welche vorher mit destillirtem Wasser ausgewaschen wurden, und die Einwirkung vom ersten Momente an zu beobachten. Tritt die Färbung bei hinreichender Concentration erst nach einiger Zeit ein, so ist zu vermuthen, dass sich unterdessen Iodverbindungen (gewöhnlich Iodwasserstoffsäure) gebildet haben, welche dieselbe vermitteln.

Will man das Iod auf die trockene Membran einwirken lassen, so lässt man dieselbe einige Zeit in einer Atmosphäre von Ioddämpfen liegeu oder bringt sie in eine Lösung von Iod in absolutem Alkohol, in aetherischem Oel oder in concentrirtem Glycerin. Die Einlagerung 
von Iod geschieht übrigens unter diesen Verhältnissen immer sehr langsam, so dass die Oberfläche dicker Membranen oft schon intensiv gefärbt erscheint, indess das Innere noch farblos ist.

Die hauptsächlichsten Verschiedenheiten, welche das Verhalten der Zellmembranen darbietet, findet man in folgender Zusammenstellung angegeben, welche dem Anfänger zugleich die zur Anstellung eigener Beobachtungen nöthige Uebersicht bieten wird.

\section{+ Löslichkeitsverhältnisse.}

1) In kaltem Wasser stark aufquellend, in kochendem verschwindend, d. h. wenigstens scheinbar gelöst.

Pflanzenschleim, wie z. B. die Terdickungsschichten der Samenhautzellen von Cydonia vulgaris, Linum usitatissimum etc., desgleichen der Schleim der Cacteen, der Salepknollen etc.

2) Löslich in concentrirter Schwefelsäure und in Kupferoxydammoniak.

Baumwolle, Bastfasern, Perisperm von Phytelephas (mehrfach bestätigt) ; desgleichen nach Frémy das Zellgewebe der Früchte und Wurzeln, welche Angabe jedoch von Kabsch (Pringsh. Jahrb. III) bezüglich des Kupferoxydammoniaks dahin gedeutet wird, dass Frémy die Intercellularsubstanz für die wahre Zellmembran gehalten habe. Das angebliche Pectosegewebe Frémy's würcle hienach von den inneren Membranschichten, insbesondere von der dem Kupferoxydammoniak am meisten widerstehenden "primären Membran " gebildet. Uebrigens soll auch die Intercellularsubstanz sich nicht lösen, sondern bloss mehr oder weniger stark aufquellen.

3) Löslich in concentrirter Schwefelsäure, unlöslich in Kupferoxydammoniak, wird in diesem letzteren Reagens löslich durch vorhergehende Behandlung mit Säuren und Alkalien, sowie durch feuchte und trockene Wärme (Frémy).

Mark und Markstrahlen der Hölzer.

* Frémy behandelte das Präparat mit Salzsäure in allmählich steigender Concentration zuletzt mit rauchender; oder er kochte dasselbe 24 Stunden lang in $W$ asser oder setzte es mehrere Stunden lang einer trockenen Wärme von $151{ }^{\circ}$ aus. Kabsch, welcher diese Versuche wiederholte, fand übrigens auch hier abweichende Resultate, und hebt namentlich hervor, dass zwischen Mark und 
1 Löslich in concentrirter Schwefelsäme, unlöslich in Kupferoxydammoniak, wird in dicsem letzteren Reagens löslich durch Behandlung mit der Schulze'schen Flüssigkeit.

Holzzellen von Pinus, Quercus, Taxus, porös-rerdickte Zellen der Birnen und im Marke von Hoya carnosa, Bastzellen der Chinarinde, Spiralfasern aus Mamillaria quadrispina ctc., desglcichen Pilz- und Flechtengewebe.

5) Unlöslich in concentrirter Schwefelsäure und in Kupferoxydammoniak, löslich in concentrirter kochender Kalilange (Frémy). *)

Cuticula und Gefässmembranen (Frémy's Cutine und Vasculose).

+*, B!ä u ung mit Iod.

I Färben sich durch Iod und W'asser allein blau. Flechtenschläuche.

2. Färben sich durch Iod und $\mathbb{W}$ asser allein nicht, sondern nur unter Nitwirkung einer Iodverbindung oder von concentrirter Schwefelsïure.

(1) Bläuung tritt eiı, nachdem das Präparat einige Zeit in reiner Iodlösung gelegen, wobei die Flüssigkeit, wahrscheinlich in Folge der Bildung von JH, eine saure Reaction annimmt.

Samenlappen von Hymenaea Courbaril, Mucuna urens; Sameneiweiss ron Gladiolus, Iris, Androsace, Cyclamen.

b) Bliiung tritt ein nach cin-oder mehrmaligem Eintrocknen mit reiner Iodlösung, wobei sich ebenfalls Iodwasserstoffsäure bildet, oder auch nach längerer Einwirkung einer hinreichend concentrirten Iodwasserstoffsäure, die man direct zusetzt.

Dünnwandiges Rindenparenchym der meisten Pflanzen (s. Moh], Verm. Schriften p. 341.

c) Bläıung tritt ein bei gleichzeitiger Einwirkung von concentrirter Schwefelsäure.

Markstrahlen ebenso bedeutende Verschiedenheiten bestehen, wie zwischen den Meubranen der übrigen Gewebe.

*) Auch diese Angaben Frémy's stehen in Betreff der Einwirkung der Kalilauge mit den Beobachtungen ron $\mathrm{K}$ absch im Widerspruch. Hienach würden nämlich die Gefässmembranen durch concentrirte kochende Kalilauge höchstens theilweise gelöst. Es will uns jedoch scheiner, die an den Seitenwandungen zurückgebliebenen » unregelmässig zerschlitzten Reste der Gefässmembran « sprechen weit eher zu Gunsten ihrer Löslichkeit, da eine'Trennung der löslichen und unlöslichen Bestandtheile in der hier angerleuteten Weise nicht wohl anzunehmen ist. 
Aeltere Parenchymzellen, innerer Theil der verdickten Holzzellen von Pinus und Abies, Bastfasern des Hanfes.

3 Zeigen die unter 2 angegebene Reaction erst nach vorhergegangener Behandlung mit Salpetersäure.

Alle Elementarorgane im Innern der Pflanzen, welche sich mit Iod und Schwefelsäure allein nicht blau färben, wie z. B. die äusseren Membranschichten der Holzzellen. und Gefässe, die braunen Yellen im Umkreis der Gefässbündel bei Farren etc.

4) Zeigen die unter 2 ) angegebene Reaction erst nach rorhergegangenem Kochen in Kali.

Kork, Epidermis, Periderm.

***) Verhalten gegen Kupferoxydammoniak.

1) Die Membranen zeigen weder Färbung noch Quellung.

Oscillatoria viridis Vauch. (Weiss und Wiesner) *', manche einzellige Algen Cramer), viele Flechten (Schwendener); ferner der Kork und die Zellstoffkeulen der Epidermiszellen von Ficus elastica Cramer, im Widerspruch nit Weiss und Wiesner, welche hier Bläuung angeben).

2) Die Membranen färben sich, ohne zu quellen, etwas intensiver blau, als das umgebende Reagens.

Hüllhäute von Gloeocapsa opaca Näg. und Gloeocystis vesiculosa Näg., Membranen von Caulerpa prolifera, Callithamnion Plumula Cramery; ferner die Membranen von Fucus vesiculosus, Echinoceras Hystrix, sowie der Holzzellen ron Taxus baccata, Quercus und Pinus Cram er, im Widerspruche mit W e iss und Wiesner, welche hier Bläuung mit (Quellung angeben).

3 Das Reagens bewirkt zuerst Bläuung und hierauf eine deutliche, oft sehr starke Quellung.

Die meisten Algen, sehr schön z. B. Cladophora fracta Ktz. C. congesta Zan. Conferva brevi articulata Zän. (Weiss und Wiesner); ferner nach denselben Beobachtern (z. Th. im Widerspruch mit Cramer): Callithamnion abbreviatum Ktz. C. corymbiferum Ktz. Fucus vesiculosus, Gracillaria compressa, Stilophora pa-

*) Sitzungsber. d. kais. Akad. d. Wiss. in Wien. Bd XLIV. 2. Abth. 
pillosa u. a.; desgleichen unter den Phanerogamen die Holzzellen von Taxus baccata, Pinus Cembra, Larix europaea, Pinus Picea, Acer Pseudoplatanus, Vitis vinifera etc. und ebenso alle untersuchten Parenchymzellen und Epidermiszellen (die Cuticula und die cuticularisirten Schichten färben sich mattgelb).

1) Das Reagens bewirkt Quellung und zuletzt Lösung.

Baumwolle, Bastfasern, Perisperm von Phytelephas Cramer); Zellgewebe der Früchte und Wurzeln (Frémy, im Widerspruch mit Kabsch, welcher bloss Quellung beobachtete).

\section{Proteinverbindungen.}

Auf das in den Lehrbüchern erwähnte Verhalten der Protein- $\mathbf{4 8 8}$ verbindungen gegen Salpetersäure, Schwefelsäure in Verbindung mit Zucker, gegen das Millon'sche Reagens etc. gründen sich ebenso viele mikrochemische Prüfungsmethoden, als charakteristische Farbeureactionen der genanuten Stoffe bekannt sind. Diese Methoden führen indess zu nicht ganz übereinstimmenden Ergebnissen, d. l. die Abgrenzung der Proteinstoffe in inikroskopischen Präparaten fällt verschieden aus, je nachdem man dieselben mit dem einen oder mit dem andern Reagens prüft. Die sogleich zu erwähnende violette Reaction, welche Kupfervitriol mit Kali hervorruft, tritt z. B. in den Zellen des gestreckten Parenchyms nicht mehr ein, obschon dieselben nach wie vor ein mit Iod sich gelb färbendes Plasma enthalten. Daraus folgt aber, dass entweder dieses Plasma kein Proteinstoff mehr ist oder dass die erwähnte Reaction nur bestimmte Modificationen der Proteinstoffe charakterisirt. Das Eine wie das Andere ist möglich. Yu der nämlichen Alternative führen auch die übrigen Reagentien; ausserdem kommt bei einigen noch der weitere Uebelstand hinzu, dass sie in gleicher Weise auch auf Stoffe reagiren, welche entschieden keine Proteinstoffe sind.

Uiter diesen Umständen kann von einem zuverlässigen Reagens auf Proteinverbindungen eigentlich nicht die Rede sein. Man wird je nach Umständen bald dem einen, bald dem andern den Vorzug geben und nöthigenfalls mehrere Reactionen combiniren, um in der 1)eutung der beobachteten Thatsachen möglichst sicher zu gehen.

Eine für manche Untersuchungen (z. B. über Stoffwanderungen) sehr empfehlenswerthe Methode, Proteinverbindungen in den Zellen 
nachzuweisen, besteht in der Behandlung derselben mit Kupfervitriol und Kali, ganz so wie es oben bei Besprechung der Zuckerund Dextrinprobe ausfülırlich erörtert wurde. Die Gegenwart der P'roteinverbindungen gibt sich hiebei im gelösten Zustande dadurch zu erkennen, dass der wässerige Zellinhalt, ohne sich zu trüben, eine schön violette Färbung annimmt, und ebenso im ungelösten Zustande durch eine gleiche Färbung der Substanz. Alle Stoffe aus der Gruppe der eiweissartigen Verbindungen, soweit sie makrochemisch näher bekannt sind, verhalten sich in dieser Hinsicht, den Untersuchungen von Piotrowsky und Czermak zufolge, vollkommen gleich; Hühnereiweiss, Casein, Legumin aus Bohnen, Kleber aus Getreidekörnern geben sämmtlich dieselbe violette Reaction. Die übrigen stickstoff haltigen Verbindungen, desgleichen die Kohlenhydrate, reagiren dagegen nicht oder in deutlich verschiedener Weise.

In diesem letzteren Umstande liegt der Hauptrorzug des gedachten Verfahrens vor den meisten andern, durch welche man sonst die eiweissartigen Stoffe nachzuw eisen pflegt. Die bekannte I o d reaction ist nicht bloss bei allen stickstoff haltigen Verbindungen ungefähr dieselbe, das Ior färbt auch gewisse Cellulosearten, wie bereits oben erwähnt, ebenso intensiv braungelb, als das in den Zellen enthaltene Plasma. Das Nämliche gilt von der Salpetersäure; die gelbe Färbung, welche die mit starker Sänre behandelten Proteinverbindungen charakterisiren soll, tritt hie und da auch in den Membranen fast ebenso deutlich hervor, ohne dass eine Einlagerung ron Proteinsubstanzen auf irgend cine andere Weise nachweisbar wäre. Die Salpetersäure wird überdiess nur zum Nachweis von ciweissartigen Verbindungen, die sich im festen Zustande befinden, empfohlen; in Lösungen wird der gelbe Ton durch deu vorwiegenden Wassergehalt leicht bis zur Unmerklichkeit abgeschwächt. *;

Ein drittes Reagens, bestehend in Z uckersolution und concentrirter Schwefelsäure, entspricht zwar den Anfordenungen in Bezug auf Empfindlichkcit besser; man erhält, wenn man dis

Harting (Mikr. p. 471), welcher die Reaction ron Kupfervitriol und Kali nicht kannte, gibt der Salpetersäure als Reagens auf ungeloste Proteinverbindungen den Vorzug. Er empfiehlt die Ernährungsflüssigkeit, welche namentlich bei thierischen Geweben immer Proteinverbindungen enthält, vorerst durch sorgfältiges Auswaschen des Präparates zu entfernen und die Salpetèrsäure nur auf die zurückbleibenden gereinigten Elementartheile einwirken zu lassen. Wenn alsdann in den isolirt daliegenden Fasern eine gelbe Färbung hervortretc, die beim Zusatz von Alkalien noch zunehme, so sei man sicher, dass Protein zu den Bestandtheilen der Fasern selbst gehöre. 
Präparat mit starker Zuckerlösung benetzt und hierauf die Säure zufliessen lässt, auch in ziemlich verdünnten Lösungen einen röthlichen Ton. Allein es ist wahrscheinlich, dass die nämliche oder wenigstens eine sehr ähnliche Farbenveränderung auch bei manchen andern Substanzen eintritt, die nicht zur Gruppe der Proteinverbindungen gehören, ja nicht einmal stickstoffhaltig sind. Wir erinnern in diesem Betreff an die bekannte Reaction des Salicin und an die nahekommende des von Hartig entdeckten Abietin (im Cambialsafte der 'Tannen). Böhm*) will sogar gefunden haben, dass die Färbung der Zellmembran oder des Zellinhaltes mit schwefelsäure und Zucker oder mit (hlorwasserstoffsäure) überhaupt nicht durch Eiweisssubstanzen, sondern durch Chromogene odcr Farbstoffe bedingt werde.

Was endlich das Millon'sche Reagens betrifft, welches die Proteinsubstanzen im gelösten wie ungelösten Zustande ziegelroth färbt, besonders wenn das Präparat erhitzt wird, so leidet dasselbe, wie die Salpetersäure, an zu geringer Empfindlichkeit, wodurch es namentlich bei Lösungen unzuverlässig wird.

Die näheren Eigenschaften der verschiedenen gelösten und ungelösten Protcinverbindungen sind zur Zeit noch viel zu wenig erforscht, als dass eine Scheidung derselben unter dem Mikroskop ausführbar wäre. Der Beobachter stösst sogar hie und da auf Erscheinungen, welche - obschon sie wahrscheinlich nur ron Proteinverbindungen herrührẹn - mit den Angaben, dic man hierüber in den chemischen Lchrbüchicrn findet, in directem Widerspruch stehen. Dahin gehören z. B. die Niedersçhlüge, welche zuweilen im wässerigen Zellsaft auf Zusatz von Ammoniak oder Kali entstehen, desgleichen die Differenzen im Verhalten des Plasmas gegen Kali und andere Lösungsmittel.

Unter diesen Verhältnissen erachten wir es für zweckmässig, die Resultate einer neueren Arbeit von Günsberg ${ }^{* *}$ ), soweit sie dem Mikroskopiker als Fingerzeige dienen können, hier in Auszuge mitzutheilen.

Wird eine durch Kochen des rohen Klebers mit Weingeist erhaltene klare Lösung des Gliadins oder Pflanzenleims auf dem Wasscrbade zur 'Trockne gebracht, so gibt diese trockene Masse an kaltes

* Beiträge zur näheren Kenntniss der Genesis und Function von PflanzenFarbstoffen. Sitzgsber, der kais. Akad. der Wiss, in Wien. Bd.45. 2. Abth. p. 399.

*) Ueber die in Wasser löslichen Bestandtheile des Weizenklebers. Sitzungsberichte der kais. Akad. der Wiss. in Wien. Bd. 44, 2. Abth. 
Wasser einen dunkelbraun gefärbten stickstoff- und schwefelhaltigen Körper ab, welcher nach genauen Analysen vollkommen identisch ist mit der in kaltem Wasser löslichen Substanz, die man direct durch Kochen des Klebers mit Wasser erhält. Ebenso ist auch der in kaltem Wasser unlösliche, in kochendem lösliche Theil des Gliadins identisch mit einem leimartigen Körper, welcher aus dem durch Kochen des Klebers erhaltenen Auszug beim Erkalten sich ausscheidet. Es geht daraus hervor, dass diese braune Substanz ein Bestandtheil des Klebers ist und dass der Körper, der bis jetzt Pflanzenleim oder Gliadin genannt wurde, aus einem Gemenge zweier Substanzen besteht, welche sowohl in ihrem Verhalten als in ihrer Zusammensetzung ganz verschieden sind.

Das Verhalten des in kochendem Wasser löslichen, in kaltem unlöslichen leimartigen Körpers gegen chemische Reagentien ist in - mancher Beziehung eigenthümlich und es ist nicht unwahrscheinlich, dass die analogen Erscheinungen, die man unter dem Mikroskop beobachtet, hierin ihre Erklärung finden. Wir heben folgende Punkte hervor.

1) Schwach angesäuertes Wasser, das kaum sauer reagirt, löst den Körper mit Leichtigkeit, ohne dass die Säure neutralisirt wird. Durch Zusatz von nur etwas mehr Säure entsteht in der Lösung eine starke Trübung, welche bei Zusatz von mehr Säure wieder verschwindet. Ein ähnliches Verhalten zeigt dieser Körper auch gegen Alkalien.

2) Mit concentrirter Schwefelsäure und Zucker in Berührung färbt sich der Körper nicht violett, er löst sich aber allmählich und in dem Maasse als er sich löst, färbt sich die Flüssigkeit rosenroth und nach vollständiger Lösung dunkel violettroth.

3) Galläpfelinfusion bringt in der Lösung einen schmutzig bräunlichgelben Niederschlag hervor, welcher in Säuren unlöslich, in Alkalien aber löslich ist.

4) Durch gelbes und rothes Blutlaugensalz wird die Lösung des Körpers in angesäuertem Wasser gefällt.

5) Sublimatlösung und dic ron salpetersaurem Quecksilberoxydul bringen weisse Niederschläge hervor. 


\section{Zehnter Abschnitt.}

\section{II o r p h o I 0 g g i e.}

Zur Morphologie im weiteren Sinne des Wortes gehört die ganze 491 Lehre vom Aufbau der Organismen aus den Elementen, woraus sie bestehen, - von den Molecülen, welche die Bausteine der Zelle bilden, bis hinauf zu den Einheiten der höchsten und letzten Ordnung, welche den vielfach gegliederten Bau der höheren Gewächse zusammensetzen. Die Morphologie hat zu ermitteln, unter welchen bestimmten Form- und Lagerungsverhältnissen die Molecüle und Molecularschichten sich vereinigen, um die Zelle und deren Theile zu bilden und während des Wachsthums weiter auszubanen; sie hat hierauf die Zelle als gegeben zu betrachten und zu untersuchen, nach welchen Gesetzen die Vermehrung derselben erfolgt, wie gleichsam Zelle auf Zelle gesetzt wird, um die grossen Complexe zu bilden, die wir als Organe kennen; sie hat ferner die Differenzirungen zu verfolgen, welche in solchen Zellcomplexen nachträglich stattfinden, und endlich auch die Entwicklung neuer Organe aus schon vorhandenen, sowie die Natur und die Stellungsverhältnisse derselben in Betracht zu ziehen. Alle diese Verhältnisse sind ausschliesslich oder vorzugsweise Gegenstand inikroskopischer Untersuchung; wir erachten es demgemäss als unsere Aufgabe, die Methoden, welche beim Studium derselben zu beobachten sind, hier eingehend zu erörtern. 
I.

\section{Aufbau der organisirten Substanzen.}

1. Stärkekörner nud Zellmembranen.

a) Anatomie.

492 Ueber die Anordnung der Molecüle in Schichten nnd Reihen, worauf es zunächst ankommt, geben uns die dem bewaffneten Auge sichtbaren Schichten und Streifen, von denen bereits oben bei Besprechung der Quellungserscheinungen die Rede war, die zuverlässigsten Anhaltspunkte. Die Polarisationserscheinungen können nur da als Kriterium dienen, wo die Molecularreihen der optisch wirksamen Schichten sich rechtwinklig kreuzen, weil in jedem andern Falle eine bestimunte Bezichung zwischen den Elasticitätsaxen und der Richtung der Molecularreihen nicht besteht.

Da nun die Schichtung und Streifung auf der Abwechslung wasserreicher Substanz mit wasserarmer beruht, so besteht die nächste Aufgabe des Beobachters darin, diese Abwechslung möglichst deutlich zu machen und dieselbe auch in Fällen, wo sie unter gewöhnlichen Verhältnissen nicht wahrnehmbar ist, nachzuweisen. Man erreicht diesen Zweck in der Regel schon durch Zusatz eines mehr oder weniger concentrirten Quellungsmittels zu dem unveränderten Präparat. So zeigen z. B. viele Bastzellen, die in Wasser beinahe homogen erscheinen, nach der Einwirkung starker Säuren zahlreiche und deutliche Schichten, manche derselben auf Flächenansichten auch spiralige Streifung. Ebenso wird bei Stärkekörnern die in reinem Wasser undeutliche Schichtung in schwachen Säuren und Alkalien meist sichtbarer. Es ist überhaupt immer ein bestimmtes Quellungsstadium, in welchem der Gegensatz zwischen weicher und dichter Substanz sich am deutlichsten kundgibt.

In anderen Fällen, namentlich bei stark verholzten Membranen, ist die Anwendung zweier oder auch mehrerer Reagentien nothwendig, um die feinen Streifensysteme zur Wahrnehmung zu bringen. Ein bei Holzzellen von Abies, P'inus u. a. zweckmässiges Verfahren ist folgendes. Man kocht die in grösserr Zahl angefertigten Schnitte in einem Reagensgläschen mit verdünnter Salpetersäure, bis die gelbe Färbung, welche das Präparat zuerst annimmt, wieder verschwunden ist. Die Zellen lassen sich in diesem Stadium, wenigstens bei dünneren Schnitten, leicht ron cinander trennen. Dic schnitte werden hierauf ausgewaschen oder sammt der Flüssigkeit in 
eine Schate mit $W$ asser ausgegossen, dann einzeln oder zu mehrerern auf den Objectträger gebracht und hier mit concentrirter Schwefelsäure behandelt. Es ist leicht, die letztere so zuzusetzen, dass das Präparat alle möglichen Uebergänge zwischen vollständiger Auflösung und beginnender Quellung zeigt. - Um den optischen Gegensatz zwischen dichten und weichen Streifen noch zu erhöhen, thut man gut, die mit Salpetersäure gekochten Zellen mit Iod zu färben, beror man das Quellungsmittel zusetzt, indem durch die ungleiche Einlagerung der Iodtheilchen eine ungleiche Widcrstandsfähigkeit der verschiedenen Streifen und eine ungleiche Intensität der Färbung bewirkt und dadurch der Contrast gesteigert wird.

sind die Membranen gallertartig, wie bei den Epidermiszellen mancher Früchte und Samen, so thut man oft gut, dieselben mit Iodlösung eintrocknen zu lassen und hierauf die Quellung durch verdünnte Iodwasserstoffsäure her vorzurufen.

Nicht zu verwechseln mit der auf ungleichem Wassergehalt be. ruhenden schichtung und Streifung der Membranen sind die oft ähnlich aussehenden Zcichnungen, welche durch wellenförmige Fältelungen oder durch Unebenheiten der Oberfläche hervorgerufen werden. Erstere sind bei aufgequollenen oder in Weingeist aufbewahrten Membranen, desgleichen bei gallertartigen, welche eingetrocknet waren und wieder aufgeweicht werden, eine häufige Erscheinung und hicr offenbar Folge der ungleichmässigen Aufnahıne oder Abgabe von Imbibitionsflüssigkeit. Eine Terwechslung derselben mit wahrer Streifung ist jedoch bei einiger Vorsicht leicht zu vermeiden, da die Falten bald im Querschnitt, bald im Längsschnitt, zuweilen auch auf beiden direct gesehen werden. Ebenso lassen sich auch die Unebenheiten der Oberfläche auf Durchschnitten direct beobachten und sind unter Umständen schon auf Flächenansichten daran zu erkennen, dass sie nur bei einer bestimmten Einstellung scharf hervortreten. Die ron der Messerklinge herrührenden Streifungen der Schnittfläche, sowie die zarten Risse, welche beim Durchschneiden hornartiger Gewebe sich bilden, sind überdiess dadurch charakterisirt, dass sie über den ganzen Schnitt parallel verlaufen.

In Fig. 216 ist beispielsweise die Aussenwand der Epidermiszellen von Hyacintleus orientalis in Längsschnitt und in der Flächenansicht dargestellt. Der Längsschnitt ( $A$ ) zeigt regelmässige, genau parallele nnd häufig gleich weit von einander entfernte Querstreifen, welche die Membranschichten rechtwinklig durchsetzen. 
Die letzteren sind sehr zart, oft sogar weniger deutlich als die Strei-
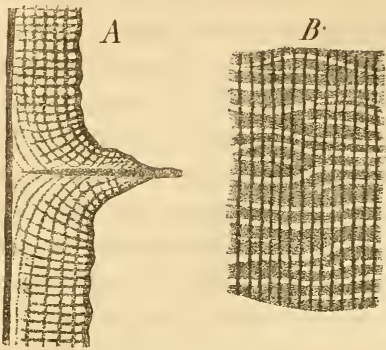

Fig. 216. fen; nur die innnerste Schicht erscheint vermöge ihrer grössern Dichtigkeit scharf abgegrenzt. Die Falten oder Kerben, welche diese Schicht zeigt, sind schon im frischen Zustande augenfällig, nach dem Austrocknen aber viel stärker; sie bedingen die in der Flächenansicht $(\boldsymbol{B})$ dargestellte Querstreifung. Die breitern dunkeln Streifen entsprechen den Erhabenheiten, die dazwischen liegenden hellen den Einkerbungen der Membranfläche. Rechtwinklig dazu verlaufen zarte Längsstreifen.

Der Verlauf der Schichten und Streifen, sowie die Art, wie sich die verschiedenen Systeme räumlich combiniren, verdienen besondere Beachtung. Was zunächst die Schichten betrifft, so sind dieselben von vorne herein als Lamellen zu betrachten, welche im Allgemeinen der Oberfläche der Complexe parallel gehen, und daher mit Bezug auf die ganze Zelle oder das ganze Korn als in einander geschachtelte Blasen oder Blasenstücke; es kann sich also nur noch um die Frage handeln, wie sich bei ungleicher Zahl der Schichten auf den verschiedenen Radien des Systems die einen an die anderen anschliessen, d. h. wie der Uebergang von einer geringern zu einer grössern Zahl von Schichten stattfinde. Die Frage ist erledigt, sobald es möglich ist, Verlauf und Ansatz der Schichten für jede einzelne derselben zu construiren oder wenigstens in der Hauptsache richtig darzustellen.

Bei den Streifen kommen dagegen noch andere Punkte von vorwiegender Bedeutung hinzu. Es fragt sich zunächst; ob die sich kreuzenden Streifensysteme, die wir an ganzen Membranen oder an Schichtencomplexen in der Flächenansicht wahrnehmen, in jecler einzelnen Schicht sich gegenseitig durchsetzen, oder ob die Streifen in der nämlichen Schicht nur nach einer Richtung, je in der vorhergehenden und folgenden aber nach der entgegengesetzten Richtung verlaufen und dadurch den Effect der Kreuzung hervorrufen.

Um diess zu entscheiden, genügt zuweilen schon die genaue Beobachtung der parketähnlichen Zeichnung, welche die Krreuzung 
bedingt, beim Höher- und Tieferstellen des Focus. Wenn hiebei die Seitenpaare der rhombischen oder rectangulären Felderchen bei der nämlichen Einstellung ihre grösste Dentlichkeit erreichen und bei Focusveränderungen gleichzeitig verschwinden und gleichzeitig wieder erscheinen, wenn sie überhaupt immer dasselbe Verhältniss der Deutlichkeit beibehalten; dann ist eine Uebereinanderlagerung abwechselnd nach rechts und links geneigter Schichten in höchsten Grade unwahrscheinlich und in Fällen, wo die einzelnen Schichten im Durchschnitt sich verhältnissmässig dick erweisen und überdiess die Zeichnung nur in den dichten Schichten deutlich hervortritt, fast unmöglich. In diesem letztern Falle würde nämlich die Kreuzung durch zwei übereinander liegende dichte Schichten hervorgerufen, und es ist kaum denkbar, dass die dadurch bedingte Niveaudifferenz der sich kreuzenden Linien im Bilde nicht bemerkbar sei.

Grössere Sicherheit, als solche Flächenansichten, gew ̈̈hrt jedoch immer die Beobachtung der Streifen auf Durchschnitten senkrecht zur Membranfläche. Die Schnitte werden an besten so geführt, dass sie dem einen Streifensystem annähernd parallel gehen. Das andere erscheint alsdann als radiale Streifung, und wenn die Zeichnung nur einigermaassen deutlich ist, so lässt sich leicht beobachten, ob die cinzelnen Streifen durchgehen und folglich allen Schichten angehören, oder ob nur je die zweite Schicht die fragliche Abwechslung von Hell und Dunkel zeige.

Auf die Fälle, in welchen grössere Schichtencomplexe, wie z. B. die innere und äussere Hälfte einer stark verdickten Membran, verschiedenläufige Streifungen zeigen, haben wir nicht nöthig, besonders aufmerksam zu machen, da die richtige Auffassung solcher Terhältnisse bei einiger Aufmerksamkeit keine Schwierigkeit macht.

Ein zweiter Punkt, den der Beobachter ins Auge zu fassen 495 hat, ist die Art und Weise des Verlaufs. Es handelt sich darum, zu entschciden, ob die einzelnen Streifen, sie mögen nun ein einziges oder zwei sich kreuzende Systeme bilden, spiralig verlaufen, oder ob sie quer oder schief gestellte Ringe bilden, indem jeder einzelne Streifen in seinem Verlaufe um die Zelle in sich selbst zurückkehrt. Die Beantwortung dieser Frage ist namentlich bei Zellen mit dicker Wandung und kleinem Lumen keineswegs leicht zu nennen: sie setzt jedenfalls voraus, dass man sich die Sache räum- 
lich und perspectivisch klar vorstelle, genau beobachte und dic Bilder, welche die verschiedonen Einstellungen gewähren, richtig combinire. Bestimmte Regeln hierüber lassen sich indess schon wegen der Mannigfaltigkeit der Fälle nicht wohl geben; es mag genügen, wenn wir in Fig. 217 ein Beispiel einer scheinbaren Spiralstreifung, die sich aber bei genauerer Untersuchung als Ringstreifung crweist, reranschaulichen.

Die Figur stellt die mit Schwefelsäure behandelten Längsansichtẹn dickwandigér Holzzellen von Ali ies execlsa dar. Die Streifung
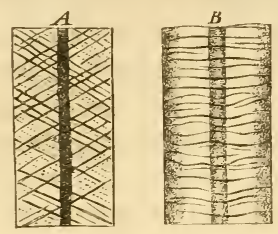

Fig. 21\%. ist nur stellenweise deutlich. In $A$ sind dic beiden sich kreuzenden Systeme gleich gegen die Axe geneigt und gewähren auf den ersten Blick ganz den Eindruck ron Spiralstreifen. In Wirklichkeit sind es aber aufrecht stehende Scheiben, welche sich in einer rechtwinklig zur Axe verlaufenden Linie durchsehneiden und dem entsprechend ihre Lage zum Auge beim Drehen der Zelle verändern. Nach einer Viertels - Umdrehung erscheinen die Streifen rechtwinklig zur Axe gestellt und wegen der jetzt schiefen Lage der Scheiben sehr undeutlich $(B)$; nach einer halben Umdrehung gelangt man wieder zu dem in $A$ dargestellten Stellungsverhältniss. - Die Ringstreifen zeigen übrigens nicht immer die angedeutete symmetrische Anordnung. Sie können in der Art unsymmetrisch gestellt sein, dass man auf einmal nur ein Streifensystem deutlich im Profil sieht, indess das andere erst nach einer kleinen Drehung seine grösste Schärfe erreicht. Die beiden Systeme erscheinen alsdann nie parallel, sondern kreuzen sich immer noch unter einem kleinen Winkel.

Es kann endlich vorkommen, dass bei T'ntersuchung der Streifungen noch eine dritte Frage von mehr mathematischer Natur sich aufdrängt. Zuweilen beobachtet man nämlich, dass ausser den beiden sich kreuzenden Spiralsystemen, welche die Membranfläche zeigt, bei günstiger Spiegelstellung noch ein drittes System hervortritt, welches die Richtungen der beiden andern (von denen jedoch bei gleicher Spiegelstellung höchstens das eine bemerkbar ist) schiefwinklig schneidet. Die Vermuthung liegt alsdann nahe, es möchte dieses System, ähnlich wic bei Pleurosigma angulatum, eine optische Wirkung der nämlichen Areolen sein, welche die beiden stärkeren 
Systeme hervorrufen; allein es bleibt immerhin zu untersuchen, ob diese Vermnthung mit der Wirklichkeit übereinstimmt. Diess geschieht in folgender Weise.

Man misst die Winkel, welche je zwei der bemerkbaren Systeme unter sich bilden, desgleichen die Abstände zweier benachbarter Streifen in jedem System. Beides ist mit ziemlicher Annäherung möglich. Die Abstände seien für das 1., 2. und 3. System beziehungsweise $a, b$ und $c$; der Winkel zwischen System 1 und 2 sei $=\alpha$, zwischen 2 und $3=\beta$, zwischen 1 und $3=\gamma$. Dann bestehen unter der Voraussetzung, dass die 3 Streifensy:teme durch die nämlichen Areolen gebildet werden, die Relationen

$$
a=\sin \alpha ; b=\sin \beta ; c=\frac{\sin \iota \sin \beta}{\sin \gamma} .
$$

Es sind bis jetzt keine Fälle bekannt, in welchen diese Bedingungen nicht erfüllt wären.

Die bisherigen Untersuchungen über Schichtung und $\mathbf{4 9 7}$ Streifung*) haben bezüglich der Anordnung der dichten und weichen Particen im Raume zu dem Ergebniss geführt, dass die Mcmbransubstanz aus drei verschiedenen Systemen von abwechselnd dichten und weichen Lamellen besteht, welche sich ähnlich, wie die Blätterdurchgänge eines Krystalls, gegenseitig durchsetzen. Das eine dieser Lamellensysteme hat immer die nämliche Lage zur Zelle: es ist die concentrische Schichtung der Membran. Die beiden andern sind dagegen sehr verschieden gestellt; sie gehen bald der Längsund Querrichtung der Zelle, bald beliebigen schiefen Richtungen parallel und kreuzen sich dabei unter schr verschiedenen Winkeln : diese bedingen die Streifung der Membran. Bei der spiraligen Streifung stehen die alternirend dichten und weichen Lamellen der beiden Spiralsysteme meist senkrecht auf den concentrischen Schichten; sie schneiden daher mit diesen abwechselnd dichtere und weichere, rectanguläre oder orthorhombische Prismen ab, welche ebenso viele übereinander liegende Lagen bilden, als Schichten vorhanden sind. Die relative Dichtigkeit dieser Prismen richtet sich bei jedem einzelnen nach der Dichtigkeit der Lamellen, durch deren Kreuzung dasselbe gebildet wird. Wenn wir beispielsweise annehmen, die dichten und weichen Lamellen haben in jeđem der drei Systeme eine an-

*) Siehe die Abhandlung ron $\mathrm{N}$ ägeli in den Sitzgsber. der k. bayer. Akad. der Wiss., Vortrag rom 7 . Mai \sti. 
dere Dichtigkeit, so dass sie im Ganzen 6 verschiedene Abstufungen repräsentiren, so erhalten wir für jede Membranschicht und für jede Streifenlamelle eine vierfach verschiedene Dichtigkeit der Prismen und im Ganzen eine Zusammensetzung aus Prismen von 8 verschie. denen Dichtigkeitsgraden. $\left.{ }^{*}\right)$

Das Nämliche gilt auch für die Ringstreifung, sofern die Ringe genau quergestellt sind und sich mit Längsstreifen combiniren; die Prismen sind alsdann rectangulär. Bei der gewöhnlichen schiefen Ringstreifung ist dagegen die räumliche Anordnung der drei Systeme complicirter. Die elementaren Prismen, welche durch die Kreuzung entstehen, haben hier eine an den opponirten Punkten der Zelle zwar gleiche, aber mit der Richtung des Durchmessers stetig wechselnde Gestalt, weil der Winkel, unter welchem die Ringe sich in den concentrischen Schichten der Zellhaut kreuzen, mit der Lage des Kreuzungspunktes sich ändert. Dieser Winkel erreicht nämlich, wie bereits oben bemerkt, an zwei opponirten Punkten die grösstmögliche Oeffnung und wird an zwei andern, welche um $1 / 4$ des UTmfanges davon abstehen, gleich Null; dazwischen liegen die Uebergänge. Dieselben Winkelveränderungen müssen daher auch die Prisinen, welche durch die beiden Ringsysteme abgeschnitten werden, in jedem Quadranten des Zellumfanges durchlaufen.

Es gibt Zellen, welche stellenweise deutliche Ringstreifung, an andern Stellen dagegen Spiralstreifung zeigen; an Bastzellen beobachtet man öfters, dass die beiden Streifungen in bestimmten Intervallen alterniren. Ueberdiess kommen Verschiedenheiten mit Rücksicht auf Neigung und Deutlichkeit vielfach vor.

$\mathrm{Ob}$ ausser der Spiral- und Ringstreifung noch andere Typen von wesentlich abweichendem Charakter vorkommen, muss durch weitere Untersuchungen ermittelt werden. Ebenso ist über die Entwickelungsgeschichte der Streifen zur Zeit kaum etwas Sicheres bekannt.

498 Ueber die Formverhältnisse der Membran, ihre Erhabenheiten und Vertiefungen und die dadurch bedingte gröbere Zeichnung

+) Die Combinationen, welche unter den gegebenen Verhältnissen mit 6 verschiedenen, paarweise auf die 3 Systeme zu beziehenden Dichtigkeiten 1, 2 \| 3,4 II 5,6 möglich sind, sind folgende:

$$
\begin{array}{llllll|lll|lll}
1 & 3 & 5 & 2 & 3 & 5 & 1 & 3 & 6 & 2 & 3 & 6 \\
1 & 4 & 5 & 2 & 4 & 5 & 1 & 4 & 6 & 2 & 4 & 5
\end{array}
$$

Es können natürlich nie zwei Ziffern, die sich auf dieselbe Fläche beziehen, nebeneinander figuriren. 
derselhen können wir uns kurz fassen. Es wurde bereits in einem frühern Abschnitt ('Theorie der mikroskopischen Wahrnehmung p. 215) die Frage erörtert, wie solche Unebenheiten in schwierigeren Fällen von den optisch gleich wirkenden Streifungen und ähnlichen Dichtigkeitsverschiedenheiten zu unterscheiden seien, und für die leichteren Fälle ist mit Rücksicht hierauf eine Besprechung ohnehin überflüssig. Wir beschränken uns daher auf die Hervorhebung einiger Punkte, deren Studium in dieser oder jener Hinsicht besondere Aufmerksankeit erheischt.

Dahin gehört zunächst die bei der UTntersuchung von Poren oft wiederkehrende Frage, ob an einer bestimmten Stelle in Porenkanal eine von der sogenannten primären Membran gebildete Scheidewand vorhanden sei oder nicht. Bekanntlich weichen die Angaben verschiedener Beobachter gerade in diesem Punkte hie und da sehr von einander ab, und die Differenzen der Anschauung, welche in Betreff der Siebporen und der Entstehungsweise der Porenhöfe sich geltend gemacht haben, stehen damit in Zusammenhang. Die Möglichkeit der 'Täuschung und der Controversen entspringt in diesen streitigen Fällen aus der nämlichen Quelle: es ist diess die beträchtlich grösserc oder geringere Dichtigkeit einer dünnen, mittleren oder äusseren Lamelle der Zellhaut, der sogenannten primären Membran, welche vermöge der ungleichen Lichtbrechung, die sie bedingt, auch da den tïuschenden Schein einer Scheidewand hervorruft, wo eine solche nicht vorhanden ist. Dazu kommt dann allerdings noch der weitere Umstand, dass die wirklichen Scheidewände in älteren Entwicklungsstadien der Zelle nicht selten wieder resorbirt werden; doch sind dic Fehler, welche dadurch veranlasst werden können, unschwer zu vermeiden, indem man die Zellen in verschiedenen Entwicklungsstadien und zwar vorzugsweise in den jüngern untersucht. Was dagegen die Gefahr der optischen Täuschung betrifft, so ist hier jedenfalls die grösste Vorsicht erforderlich. Das beste Mittel, dieselbe zu umgehen, bestände natürlich in der Herstellung von Präparaten, in welchen der Porus sowohl auf der zugekehrten als abgekehrten Seite angeschnitten und daher nur mit seinem mittlern Theil wirksam wäre; allein daran ist bei der Kleinheit des Porus in den meisten Fällen gar nicht zu denken. Es bleibt in der Regel nichts anderes übrig, als die besten Schnitte, die man bekommen kann, möglichst sorgfältig zu untersuchen, und zwar nicht bloss in Wasser, sondern auch in stärker brechenden Medien, welche die optische Wirkung der mittilem Lamelle schwächen oder aufheben. Ist der Porus mit Plasma 
gefüllt, so gibt zuweilen das Verhalten dieses letztern auf Zusatz von Reagentien oder auch ohne dieselben einige weitere Anhaltspunkte.

Die Form der Poren ist bei einiger Aufmerksamkeit leicht zu bestimmen, da hierüber die Flächenansichten der Membran in Verbindung mit geeigneten Durchschnitten senkrecht zur Flächc alle erforderlichen Anhaltspunkte darbieten. Dessenungeachtet werden manche Eigenthümlichkeiten der Form, wie z. B. die wendeltreppenartige Drehung bei spaltenförmigen Porenkanälen und ähnliche Dinge leicht übersehen,

499 In Fällen, wo sich Formverhältnisse mit Dichtigkeitsverschicdenheiten in complicirter Weise combiniren, wie z. B. bei den Sicbwänden von Cucurbita, ist es zweckmässig, dünne Schnitte durch das betreffende Gewcbe in Gummi eintrocknen zu lassen und dann in einer zur früheren rechtwinkligen Richtung abermals zu durchschneiden. Man erhält auf diese Weise Präparate, welche nicht nur die äussern Formverhältnisse des zu untcrsuchenden Objectes, sondern anch die räumliche Vertheilung der dichten und weichen Partieen im Innern und damit den ganzen Auf- und Ausbau desselben zu crmitteln gestatten.

\section{b) Wachsthum.}

500 Tun die Wachsthumsweise der Stärkekörner und Membranen 7.11 ermitteln, müssen zunächst, die in Torhergehenden besprochenen anatomischen Verhältnisse, insbesondere der Schichtenverlauf, genau festgestellt und jüngere und ältcre Stadien, wie bei allen entwicklıngsgeschichtlichen Untersuchungen, mit einander verghichen werden. Dabei ist wohl zu berücksichtigen, dass das blosse Vorhandensein von Schichten, welches auch ihre Lagerung sein mag, sich a priori mit sehr verschiedenen Bildungsgesetzen vercinbaren lässt: es kann durch innere Differenzirung oder durch Anlagerung von aussen, oder auch durch Beides zugleich erklärt werden, und jeder dieser Typen gestattet wieder mancherlei Modificationen. Der Beobachtẹr kann daher stets nur durch genauere Untersuchung ermittchn, in welcher W eise die Vermehrung der Schichton in eincm gegebenen Falle stattfinde. Als Richtschnur können hiebei die folgenden Regeln dienen.

1) Wenn wir in Geweben, deren Zellen alle nur wünschbaren Tehergänge der Verdickung und Schichtenbildung zeigen, keine Membranen beobachten, welche rom Lumen der Zelle durch eine 
weiche Schicht abgegrenzt sind, wenn wir vielmehr die Wahrnehmung machen, dass die an den Primordialschlauch grenzende Schicht durchgehends eine dichte ist, so genügt diese Thatsache, גım die Annahme auszuschliessen, dass sich abwechselnd dichte und weiche Schichten auf die Innenfläche der Membran ablagern; denn wäre diess der Fall, so müsste man nothwendig auch Stadien finden, in welchen eine weiche Schicht an der Oberfläche läge. - Dasselbe gilt natürlich auch für die Stärkekörner. Das constante Nichtvorhandensein einer weichen oberflächlichen Schicht liefert hier den Beweis, dass die Schichtenbildung nicht auf der Ablagerung neuer Substanz anf der schon vorhandenen beruhen kann.

2) Wenn in einer homogenen Scheidewand zwischen zwei Zellen eine mittlere heterogene Schicht auftritt Intercellularsubstanz, primäre Membran', so kann das in gleicher Weise, wie die Termehrung der Schichten, nur durch innere Differenzirung geschehen. Bei der Bildung ciner ähnlichen heterogenen Schicht an der Oberfläche ciner Mcmbran Extracellularsubstanz, Cuticula ist sowohl die Annahme einer Ausscheirlung als die einer Differenzirung möglich. Man hat alsclann nach weiteren Anhaltspunkten zu suchen, um diese beiden denkbaren Fälle gegen einander abzuwägen.

Eine sichere Beantwortung der Frage, ob Ausscheidung oder Differenzirung, ist übrigens in manchen Fällen gar nicht möglich. Namentlich sind die Belege, welche für den Nachweis einer Schichtenbildung durch Ausscheidung nothwendig sind, nur äusserst selten zu finden. Eine Ausscheidung ist mit Sicherheit nur da anzunehmen, wo die Identität der immern Membranschicht, aus welcher das Ausscheidungsproduct hervorgegangen sein müsste, mit der ursprünglichen ganzen Membran der Zelle sich strenge nachweisen lässt. Diess setzt aber eine charakteristische Zeichnung der Membranfläche, wie z. B. bei den Diatomeen, einen besonders günstigen Schichtenverlauf oder irgend ein ähnliches Merkmal voraus, welches die m* sprüngliche Aussenfläche oder doch die peripherische Schicht der Membran kennzeichnet. Man wird in der Praxis jedenfalls häufiger die Anhaltspunkte finden, welche mit Sicherheit auf eine innere Differenzirung schliessen lassen. - Als Ausscheidungsproduct ist beispielsweise die Extracellularsubstanz der Diatomeen, Desmidiaceen und Zygnemaceen zu betrachten; die Cuticula der höhern Gewächse entsteht dagegen in vielen Fällen unzweifelhaft durch Differenzirung.

3) In manchen Fällen geht schon aus der Anordnung der Schichtencomplexe und namentlich ans der V'ergleichung jüngerer 
Zustände mit ältereren ganz sicher hervor, dass die Vermehrung der Schichten auf der Spaltung schon vorhandener, nicht auf der Anlagerung neuer Substanz auf der Oberfläche, beruht. Diess ist z. B. bei zusaınmengesetzten Stärkekörnern der Fall, deren Kerne in jugendlichen Stadien nahezu in der Mitte der zugehörigen Schichten liegen, während sie in ausgewachsenen Korn viel weiter von der Trennungslinie zwischen den Theilkörnern, als von der freien Aussenfläche ihrer Schichtencomplexe abstehen (Fig. 218 A). Die Apposition

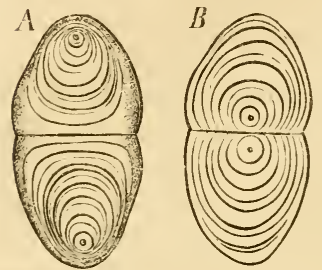

Fig. 215 . müsste offenbar eine Anordnung der Schichten wie in Fig. 2 is $B$ zur Folge haben. - Ebenso ist auch der Schichtenverlauf in Fig. $219 A$, welche einen Durchschnitt durch die Membran von Caulerpa prolifera an der Ansatzstelle einer Cellulosefaser darstellt, mit der Annahme einer Auflagerung unvereinbar; die letztere würde, da der jugendliche Zustand die Verhältnisse von Fig. 219 C; zeigt (die Faser als einfache Linie), einen Verlauf der Schichten bedingen, wie er in Fig. $219 \mathrm{~B}$ abgebildet ist.

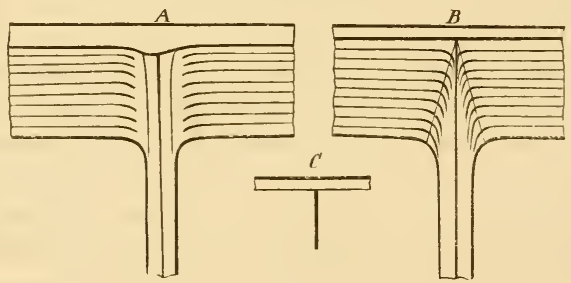

Fig. 219.

4) Es kann ferner vorkommen, dass eine Schichtung erst in spätern Entwicklungsstadien, nachdem dic Körner bereits eine anselnnliche Grösse und die Membranen eine beträchtliche Dicke erreicht haben, allmählich hervortritt. Solche Fälle, welche unverkenubar auf Wachsthumsvorgänge in Innern hindeuten, sprechen ebenfalls ganz entschieden gegen die Annahme einer Auflagerung von Schichten an der Oberfläche. - Ueberhaupt können Veränderungen, von denen nachgewiesen werden kann, dass sie im Innern geschichteter Gebilcle stattgefunden haben müssen, nur durch Intussusception erklärt werden. 
In zweiter Linie sind die mikrochemischen Reactionen, 501 welche das zu untersuchende Object in jüngern und ältern Stadien zeigt, in Betracht zu ziehen. Bei den Stärkekörnern wird man z. B. die Wahrnehmung machen, dass eine peripherische Substanzlage von geringer Dicke in jungen wie in ältern Körnern die grösste Widerstandsfähigkeit gegen Lösungsmittel besitzt und in Folge dessen als membranähnliche Hülle zurückbleibt, nachdem das Innere des Korns bcreits gelöst ist. Die innern Schichten grosser Körner sind stets weit löslicher und weicher als die peripherischen Schichten kleiner Körner. Daraus folgt aber, dass der innere Theil eines grossen Korns keineswegs identisch ist mit dem unveränderten jüngcrn Korn, dass folglich die Annahme einer Volumenzunahme des letztern durch blosse Auflagerung von Schichten den Thatsachen nicht genügt. - Aehnliche Anhaltspunkte, welche auf chemische Veränderungen im Innern der Substanz hindeuten, bieten auch die Membranen vielfach dar, und es ist immer genau zu erwägen, welche Schlüsse sich aus den beobachteten Reactionen ziehen lassen.

Die Modificationen betreffend, welche im Falle einer Schichten- 502 bildung durch Intussusception noch denkbar sind, so beschränken wir uns lierüber auf folgende Sätze.

1) Wenn die dichten Schichten sich stellenweise so aneinander anschliessen, dass die weicheren sich zwischen denselben auskeilen 'Fig. 220), 'so beruht die Vermehrung der Schichten auf der Bildung weicher Substanz im Innern der dichten und der dadurch bewirkten Spaltung der dichten Schichten in je zwei Lamellen. Kommt der entgegengesetzte Fall auch vor, so deutet diess auf Bildung dichtercr Substanz inner-

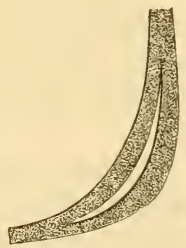

Fig. 220. halb der weichen, also auf Spaltung der wasserreichen Schichten.

2) Ein Schichtenverlauf wie der in nebenstehender Fig. 221 beweist, dass die Bildung der Schichten und damit auch das Dickenwachsthum im mittleren Theil der Membran am lebhaftesten ror sich geht. Wie der Verlauf sich gestalten müsste, wenn das vorwiegende Wachsthum in den äussersten oder innersten Schichten stattfände, ist hieraus leicht zu entnehmen.

3) Wenn geschichtete Gebilde in

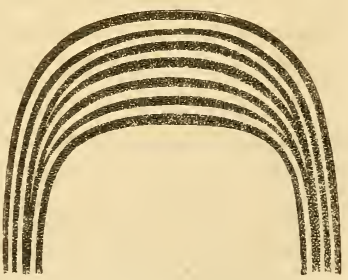

Fig. 221, 
jüngern und ältern Stadien aus zwei oder mehreren deutlich von einander abgegrenzten Complexen bestehen, so ergiebt sich das relative

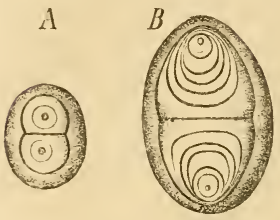

Fig. 222 . Maass des DickenwaGhsthums für jeden der selben und auf jeder Normale zum Schichtenverlauf unmittelbar aus der Vergleichung der Dimensionsverhältnisse auf verschiedenen Entwicklungsstufen. Die in Fig. 222 und 223 dargestellten Beispiele mögen dicss veranschaulichen.

In Fig. 222 ist ein halb zusammengesetztes Stärkekorn aus der Kartoffel im jugendlichen Zustand A und im weiter entwickelten $B$ abgebildet. Ein Blick auf die beiden Entwicklungsstadien genügt, um sich zu ïberzeugen, dass das Dicken-

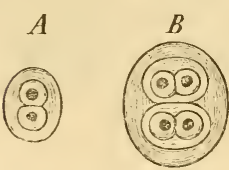

Fig. 223. wachsthum des Korns fast ausschliesslich auf der Vergrösserung der 'Theilkörner beruht, indem die peripherische Hülle so gut wie keine Dickenzunahme zeigt. Die excentrische Lage der Schichtencentren beweist überdiess das vorwiegende Wachsthum in der Richtung der Verbindungslinie.

Dagegen spricht sich in Fig. 223, welche zwei analoge Entwicklungsstadien ( $A$ und $B$ ) einer Glococapsa-Colonie darstellt, auch in den peripherischen Schichtencouplexen eine merkliche Dickenzunahme aus.

Analoge Verschiedenheiten, wie die Vermehrung der Schichten und das Dickenwachsthum im Allgemeinen, bictet auch das Flächenwachsthum der Membranen oder bestimmter Schichtencomplexe. Das absolute Maass der Flächenzunahme ist selbstverständlich auch hier durch die Grössenverhältnisse im jugendlichen und im ausgewachsenen Zustande gegeben; die Bestimmung desselben ist demnach Sache der Messung und Rechnung und bedarf als solche keiner Erörtcrung. Schwieriger ist es, die relativen Wachsthumsintensitäten für die verschiedenen Zonen oder Elemente der Fläche zu ermitteln. Es setzt diess immer, wie man leicht einsieht, eine bestimmte Zeichnung der Membran, oder irgend eine Abgrenzung verschiedcner Flächentheile dưch die Natur der Tmgebung, überhaupt das Vorhandensein fixer Puncte auf der Membranfläche voraus, deren Distanzveränderungen in Folge des Wachsthums bestimmbar sind. 
Solche fixen P'unkte bieten z. B. die faserförmigen Verdickungen der Spiral- und Ringgefässe, die Zeichnung der Diatomeen, ferner die Ansatzstellen der Scheidewände in Geweben, der seitlichen Verzweigungen bei Zellfäden und Zellflächen, der Cellulosefasern bei Caulerpa prolifcra u. s. w. Die Erörterung einiger speciellen Fälle wird am besten zeigen, wie sich die gebotenen Anlialtspunkte verwerthen lassen.

1) Die faserförmigen Verdickungen der Spiral- und Ringgefässe liegen unmittelbar nach ihrem Auftreten ziemlich dicht und in gleichmässiger Entfernung nebeneinander, werden jedoch durch die später erfolgende Streckung der Gewebe oft weit auseinander gerückt. Es giebt Gefässe bei denen die Abstände zwischen den successiven Windungen oder Ringen auch im ausgewachsenen Zustande nahezu gleich sind, wo daher das Längenwachsthum der Gefässmembran ein ziemlich gleichmässiges scin muss. Bei andern dagegen kommen periodische Ungleichheiten vor, oder es verändert sich das Wachsthum ron dem einen Ende nach dem andern hin.

2) Man beobachtet nicht selten, dass Scheidewände, Ausstülpungen, Terzweigungen u. dgl., welche in jungen Geweben eine bestimmte Lage zur Zelle einnehmen, indem sie z. B. der Mitte einer Wandfläche entsprechen, in ältern Stadien mehr oder weniger seitlich verschoben erscheinen. Diess deutet offenbar auf ein cinseitig vorwiegendes Wachsthum der Membran. Bei Callithamnion rücken z. B. die Verzweigungen der Gliederzellen mit der Verlängerung der letztern weiter nach oben, d. h. der untere Theil der Glicderzellen zeigt ein stärkeres $W$ achsthum als der obere.

3) Die Cellulosefasern von Caulerpa prolifera, welche bekanntlich quer oder etwas schief durch das Lumen der Zelle ausgespannt sind, bilden in der Scheitelregion dieser einzelligen Pflanze cin feines, dichtes Geflccht. Ihre Ansatzpunkte liegen auf der Membranfläche so dicht neben einander, dass die letztere in der Flächenansicht bei mässiger Vergrösserung fein punktirt erscheint. Mit der Entfernung rom Scheitel rücken dieselben allmählich weiter auseinander. Die Vergleichung der gegenseitigen mittleren Abstände muss folglich herausstellen, in welchem Grade und bis zu welcher Entfernung ron der Spitze die Membran in die Fläche wächst.

4) Besonders interessant sind die Wachsthumsverhältnisse bei den Diatomeen. Wir wählen als Beispiel Rlabdonema adriatium Fig. 221). Die ausgewachsene Zelle (unsere Figur giebt die Iächenansicht von zwei noch nicht ausgewachsenen Zellen besteht at zwei nahezu gleichen, übereinstimmend gezeichneten Hälften, 
welche durch eine streifenlose mittlere Zone $(\mathrm{mm})$ von cinander getrennt sind. Die starken Querstreifen, welche nahezu geradlinig von

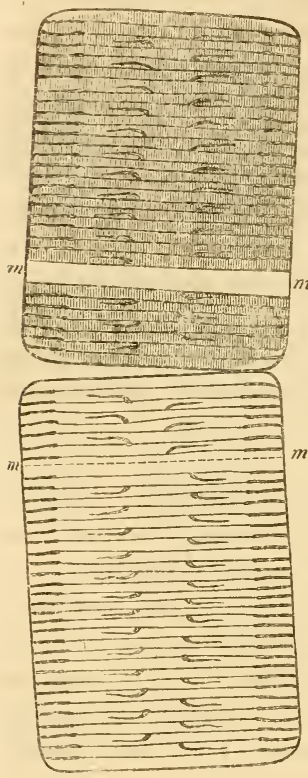

Fig. 221. (500) einem Rand bis zum andern verlaufen, sind faserförmige Verdickungen der Membran, welche in der schmalen Profilansicht tief in das Lumen der Zelle hineinragen ; die feinern Längsstreifen in der Figur nur in der einen Zelle dargestellt; sind ähnliche, aber entsprechend schwächere Vorsprünge. Zwischen den durchgchenden Querstreifen, deren Randparticen merklich stärker hervortreten, befinden sich zu beiden Seiten der Mittellinie noch kürzere, etwas gebogene Streifen, deren zugekehrte Enden knotenförmig verdickt und nach einwärts an die benachbarten Querstreifen angelehnt sind. Diese knotenförmigen Anschwellungen bilden in jeder Zellenhälfte zwei symmetrische Reihen, welche gegen die Medianzone zu schwach divergiren. Die weitern Eigenthümlichkeiten des Baues dürfen hier, als zum Verständniss des Folgenden nicht nothwendig, übergangen werden.

Bei der Durchmusterung einer grössern Zahl von Individuen begegnet man num hin und wieder solchen, welche aus zwei ungleichen IIälften bestehen und auf der Seite der kleineren Hälfte, zunächst der homogenen Medismzone, einen weit schwächern, oft undeutlichen Querstreifen besitzen, den man leicht als einen neu hinzugekommenen und noch unausgebildeten erkennt die punktirte Linic in der unteren Zelle der Figur). Man trifft solche Streifen in den verschiedensten Stadien der Ausbildung, aber immer nur auf der klcinem Hälfte und am Rande der Medianzone, nie zwischen bereits entwickelten Streifen. Daraus folgt ohne Weiteres, dass nur die kleinere Zellenhälfte im Wachsthum begriffen ist und dass sie ihren hauptsächlichsten Zuwachs von der Medianzone aus erhält, auf welche die Anlage neuer Streifen beschränkt ist. Dat ferner die ner angelegten Streifen durchschnittlich ungefähr gleich weit vom vohergehenden abstehen, wie die ältcrn Streifen unter sich, so ergist sich hieraus, dass das Flächenwachsthum der Membran mit dem Åf- 
treten der streifenförmigen Verdickungen so gut wie abgeschlossen ist.

Dass die Streifenbildung ansschliesslich auf die Medianzone besehränkt ist, folgt übrigens schon aus dem Verhalten der divergirenden Knotenreihen zu beiden Seiten der Mittellinie. Der Abstand derselben zunäehst der Medianzone ist nämlieh bei Exemplaren mit nahezu gleichen Hälften beiderseits gleich, bei solehen mit ungleiehen Hälften dagegen in der kleineren Hälfte merklich geringer, und zwar um so mehr, je grösser die Ungleichheit der Hälften. Zeigt die kleinere Hälfte erst einen oder zwei Streifen, so haben hier die Knoten denselben Abstand, wie auf der gegenüberliegenden, der Medianzone abgekehrten Seite der grössern Hälfte. Diese Thatsachen sind nur erklärlich, wenn die Anlage der Streifen in der Medianzone erfolgt und der Abstand der Knoten in jedem folgenden Streifen etwas grösser ausfällt als im vorhergehenden.

Wie bei Rhabdonema, so findet man auch bei den übrigen Diatomcen eine homogene Grenzzone zwischen den beiden Hälften der Zelle, und es lässt sich in rielén Fällen in ähnlicher Weise zeigen, dass das Wachsthum der Membran auf diese verhältnissmässig schmale Zone beschränkt ist. Auch ist es immer nur die kleinere Hälfte, welche von hier aus einen Zuwachs erhält; dieselbe nimnt in Folge dessen so lange an Grössc zu, bis sie der andern Hälfte ungefähr gleich ist, dann entsteht in der Mitte der Grenzzone eine Scheidewand, welche die Zelle in zwei Tochterzellen theilt, von denen in der Folge jede auf der der Scheidewand zugekehrten Seite eine neue Hälfte bildet.

5) Schliesslich mag hier noeh die eigenthümliche Membranbildung der Oedogonien Erwähnung finden. Bei diesen Algen geht jeder Theilung der Gliederzellen die Bildung eines gallertartigen Ringes voraus, den man in einzelnen Fällen bestimmt als zusammengesetzt aus mehreren deutlich von einander getrenṇten Cellulosepolstern erkennt. Ein solcher Polsterkranz ist in Fig. 225 , welehe eine keimende Spore von Oedo-

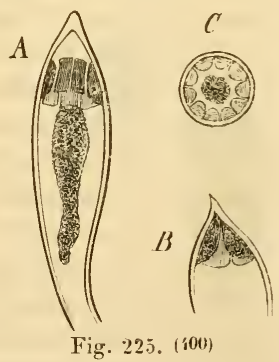
gonium capillare darstellt, in der Seitenansicht $(A$ und $B$ und in der Querschnittsansicht $\langle C$ ) abgebildet.

1)ie Präparate wurden mit Iod und Zuckerlösung behandelt. I)ie Cellulosepolster färben sich hiebei violett bis rothviolett, indess die äussere Membran farblos bleibt. Der Inhalt ist stark contrahirt. 
Die Kahl der Polster ist übrigens verschieden; zuweilen sind es nur $4-5$, in anderen Fällen $\delta--10$. Auch die Form derselben und die bald etwas höhere, bald etwas tiefere Stellung in der Zelle bietet mancherlei Abweichungen. Dass sie aus weicher, dehnbarer Cellulose bestehen, folgt aus ihrem weiteren Verhalten. Die Membran der Muttcrzelle wird nämlich in einem etwas spätern Entwicklungsstadium an der Aussenseite der Polster wie durch einen ringförmigen Einschnitt in ein oberes und unteres Stück getheilt, und nachdem diess geschehen, dehnt sich der Polsterkranz zu einer zarten Haut aus, welche die Ränder der beiden getrennten Membranstücke, die - dadurch auseinander gerüclit werden, mit einander verbindet s. Fig. 226). Der gallertartige Ring oder Polsterkranz ist also gewissermaassen als eine Ansammlung von Bildungsmaterial zu betrachten, welches in einem spätern Entwicklungsstadium der Zelle zum raschen Aufbau einer neuen Membran verwendet wird.

\section{4}

Ist das Wachsthumsvermögen der verschiedenen Schichtencomplexe ungleich, so kann es vorkommen, dass die Schichten, welche zu wachsen aufgehört haben, durch die weitere Ausdehnung der übrigen Schichten zerrissen werden. Bei den Membranen tritt dieser Gegensatz hin und wieder zwischen den innern und äussern Schichten und zwar in der Art hervor, dass eine peripherische Lamelle der Membran von Zeit zu Zeit in gesetzmässiger Weisc durchbrochen oder wie durch einen kreisförmigen Einschnitt in zwei gleiche oder ungleiche Stücke getheilt wird, welche sodann in Folge der fortdauernden Streckung der Zelle allmählich weiter auseinander rücken. Die Modalitäten dieses Vorganges bieten nätürlich

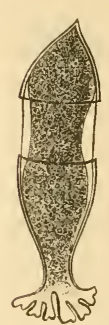

Fig. 226.

(4i10) mancherlei Verschiedenheiten, und es bedarf' oft eines genauen Studiums der Entwicklungsgeschichte, um dieselben festzustellen. In der Hauptsache ist jedoch das Verhalten der Membran schon durch die anatomischen Verhältnisse des fertigen Zustandes meist deutlich ausgesprochen.

Ein bekannter hicrher gehöriger Fạll ist die Bildung der sogenannten Kappen und Scheiden bei den Oedoygniaceen. Die Theilung der Zellen wird hier, wie bereits oben erwähnt, durch Bildung eines weichen, oft weit nach innen vorspringenden Celluloseringes ini obern 'T'heil der Zelle eingeleitet; dann reisst an dieser Stellc die äusecre Mem. bran, der liing dehnt sich in die Länge und erscheint jetzt als zarte 
Haut, welche sich ober- und unterseits an den Rand der äussern Lamelle ansetzt. In diesem letztern Stadium ist in Fig. 226 eine kci-

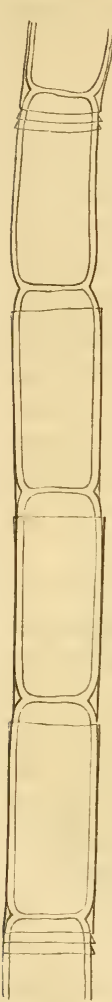
mende Spore von Oedogonium cupillare dargestellt; etwas später bildet sich die Scheidewand. - Der nänliche Vorgang wiederholt sich beim Aufbau des Zellfadens mit jeder Theilung der Zellen; es entstehen dadurch jene Systeme von in einander geschachtelten Kappen und Scheiden, wie sie in Fig. 227 für ein aus einer ursprünglichen Gliederzelle hervorgegangenes Fadenstück dargestellt sind.

Weitere Beispiele für das wiederholte Zerreissen einer peripherischen Schicht liefert die noch wenig bekannte Entwicklungsgeschichte der Scheiden bei den Rivularieen und scytonemeen. Hier wird, wie es scheint, eine peripherische Lamelle der Membranen, welche sich immer wieder neu bildet, von der fortwachsenden Spitze des Fadens in regelmässigen Intervallen durchbrochen, wächst dann aber nicht selten noch längere Keit in die Dicke und Fläche, in der Art, dass der obere 'Theil der Lamelle sich in Folge dessen trichterförmig erweitert. Diess ist z. B. bei Petulonema alatum Berliley Fig. 22s) der Fall. Die Schichten verlaufen hier zunächst der Scheitelregion $(A)$ der Längsaxe nahezu parallel, dagegen mit zunehmender Entfornung von derselben unter immer grösseren Winkeln nach aussen. Der Querschnitt zeigt dabei nach wie vor Fig. 22i. concentrische Schichtung. Bei ältern Fäden findet man hie und da einen
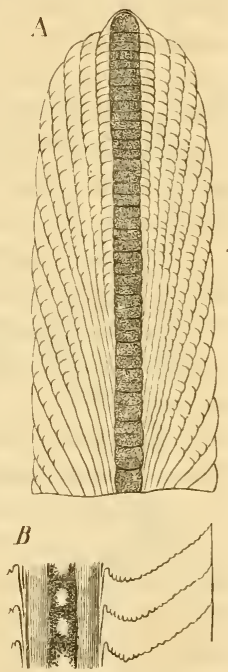

Fig. 225. (2.0)

Schichtenverlauf, wie er in Fig. $228 B$ dargestellt ist. Die Vergleichung mit at ergiebt, da die Vergrösserung dieselbe ist, ohne Weiteres, dass das selbständige Wachsthum der Schichten jedenfalls bis auf sehr bedentende Entfernungen vou Scheitel fortdauert.

Ferner gehört hieher die Bildung der Hüllmembranen bei den grössern I)iatomeen Biddulphia, Isthmia, Pyxidicula, Rhabdonema u. a). Es sind auch hier Membranlamellen, welche nach der 'Theilung der Zellen zı wachsen aufhören und sich über die jungen, 
neugebildeten Hälften gürtelförmig hinwegzichen. Zuweilen beobachtet man sogar zwei über einander liegende Hüllen, eine äussere schmälere, welche zuerst, und eine innere breitere, welche später gebildet wurde.

\section{Aufbau der Plasmagebilde.}

505 Da das Material, welches hier zur Verwendung kommt, halbflüssig ist und in Wasser meist Tropfenform annimmt, so lässt sich erwarten, dass die Plasmagebilde diese halbflüssige ${ }^{*}$ ) Consistenz beibelalten. Die Entstehung dieser Gebilde steht übrigenș mit dem Ausbau der Zelle im Zusammenhang. Junge Zellen (Sporen, Schwärmzellen etc.), welche nicht bereits einen mehr oder weniger ausgebildeten Inhalt von der Mutterzelle geerbt haben, sind ganz mit Plasma gefüllt; das letztere ist gewissermaassen als blosses Naterial vorhanden und wird erst durch die späteren Lebensprocesse der Zelle in verschiedener $W$ eise vertheilt, in Streifen und Bänder ausgezogen, zu kugeligen Bläschen oder fadenförmigen Bildungen verarbeitet, mit Farbstoffen durchtränkt u. s. w.

Um den Aufbau der Plasmagebilde zu studiren, ist es daher nothwendig, die allmähliche Differenzirung des Inhaltes in geeigneten jungen Geweben (an keimenden Sporen, in der Scheitelregion lebhaft vegetirender Algen, in Blattanlagen, Stammspitzen u. s. w.) zu beobachten, welche beim Uebergang in Dauergewebe die erwähnten Entwicklungsstadien durchlaufen. Man wird dabei stets die Wahrnehmung machen, dass alle Plasmapartieen, welche während der Ausbildung des Inhaltes isolirt werden, sich an der Oberfläche verdichten und so ein homogenes Häutchen bilden, das in seinen Eigenschaften mit dem Primordialschlauch übereinstimmt. Es ist diess dieselbe Erscheinung, die man auch durch mechanische Zertheilung des Zellinhaltes hervorrufen kann, so dass man annehmen muss, sie bestehe wesentlich in einer physikalischen Veränderung des Plasmas bei der Berührung mit Wasser. ${ }^{* *}$ )

† Man darf in dem Ausdruck halbflüssig, auf Plasmagebilde angewendet, nicht etwa einen Widerspruch mit der Annahme einer Organisation erblicken, da derselbe sich einzig und allein auf die Consistenz, nicht auf den innern Bau bezieht. Das halbflüssige Plasma ist allerdings von dem halbflüssigen Gummischleim wesentlich verschieden, da das erstere stets nur eine bestimmte Menge Wasser enthält, die mit seiner Organisation zusammenhängt, indess der letztere beliebig verdünnt werden kann; allein hinsichtlich ihrer Consistenz stimmen beide überein.

$\left.{ }_{* \rightarrow}\right)$ Siehe hierüber $\mathrm{Nägeli,} \mathrm{Pflanzenplysiologische} \mathrm{Untersuchungen} \mathrm{I.} \mathrm{p.} 9$. 
Das Vorhandensein eines solchen äusserst dünnen Häutchens bei Chlorophyllkörnern und Zellkernen, obschon bis auf die neueste Zeit vielfach bestritten, lässt sich in manchen Fällen mit Sicherheit nachweisen. Es genügt, dieselben $\mathrm{zu}$ isoliren und der Einwirkung des umspülenden Wassers zu überlassen. Sie quellen dabei etwas auf, das Plasma vertheilt sich und in den Zwischenräumen sammelt sich das durch Endosmose eingedrungene Wasser; eine Unterbrechung des peripherischen Häutchens findet aber nicht statt. Chlorophyllkörner und Zellkerne verhalten sich also genau wie membranlose junge Zellen. Die Uebereinstimmung spricht sich auch darin aus, dass das peripherische Häutchen, wie der Primordialschlauch, farblos erscheint, indem das Chlorophyll stets nur das innerhalb desselben liegende Plasma tingirt.

Als besonders günstige Objecte zur Beobachtung dieser Verhält- 506 nisse sind die Chlorophyllkörner der Nitellen und einiger Monoco-

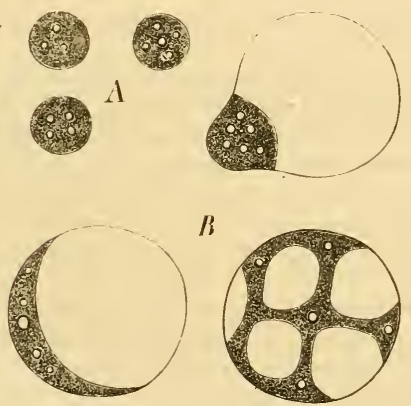

Fig. 229. (1000)
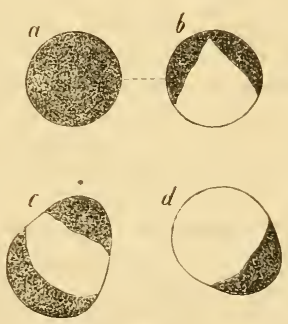

Fig. 230. (1000)

tyledonen, z. B. von Clivia und Aspidistra, zu empfehlen. Die Quellungserscheinungen, welche die Einwirkung von Wasser hervorruft, lassen sich hier sowoln auf Durchschnitten, namentlich durch jugendliche Organe, als an isolirten Körnern bei 4-500 maliger Vergrösserung leicht verfolgen. Die Existenz eines peripherischen Häutchens ist allerdings nur in besonders günstigen Fällen dir ect zu beobachten, da es nur selten doppelt contourirt erscheint, dieselbe kann jedoch aus der Anordnung der gefärbten und ungefärbten Inhaltspartieen mit Nothwendigkeit oder doch mit grösster Wahrscheinlichkeit gefolgert werden. Bei Clivia nobilis, wie bei Nitella, sieht 
man z. B. häufig Körner, bei denen das grüne Plasma nach der Quellung die in Fig. $229 \mathrm{~B}$ und Fig. 230 dargestellte Lagerung zeigt. Die Körner Fig. 229 sind aus Nitella syucarpa, sie enthalten mehrere kleine Stärkekörner; $A$ ist der unveränderte, $B$ der veränderte Zustand. Fig. 230 stellt dic aufgequollenen Körner von Clivia nobilis dar und zwar $a$ und $b$ das nämliche Korn in zwei verschiedenen Ansichten, $c$ und $d$ zwei andere Körner. $\left.{ }^{*}\right)$

\section{7}

Ton der halbflüssigen Beschaffenheit der Plasmagebilde sammt ihrer membranartigen. Umhüllung überzeugt man sich, indem man mehrere derselben mit einander in Berührung bringt und etwas quetscht, was z.:B. mit Chlorophyllkörnem, wenn sie als Wandbeleg auftreten, nach dem Ablösen des Primordialschlauches durch Glycerin sich hie und da leicht bewerkstelligen lässt. Sie fliessen alsdann zu Plasmakugeln zusammen, die sich wic ein einfaches Korn verhalten. Ebenso liefert die Thatsache, dass das Plama beim Freiwerden der Schwärmsporen zuweilen in lange Fäden ausgezogen wird, **) welche nach dem Zerreissen in die nun getrennten grössern

*) Mohl, welcher diese Erscheinungen ebenfalls beobachtete (s. Bot. Ztg. 15.55), erklärt dieselben, im Widerspruch mit obiger Darstellung, durch starkes Aufquellen einer im Innern des Korns befindlichen farblosen oder schwach gefärbten Substanz, in welcher sich durch Wasseraufnahme zuerst zahlreiche Vacuolen bilden, die sich endlich zu grösseren Blasen vereinigen und hierauf angeblich durch die umgebende Hülle nach aussen hervorbrechen, wobei die letztere an der Aussenfläche der Blasen hängen bleiben und dieselbe mützenartig bedecken soll.

Hiegegen ist erstlich einzuwenden, dass die Annahme einer quellungsfaligen Substanz, von der man an den unveränderten Chlorophyllkörnern nichts bemerkt. doch allzu hypothetisch ist, und dass überhaupt bis jetzt keine Substanz bekannt sein dürfte, welche in reinem Wasser aufquillt, dagegen in der neutralen oder schwachsauren Zellflüssigkeit nicht aufquillt. Die Annahme dagegen, dass die Chlorophyllkörner und Zellkerne in Wasser eine vermehrte Endosmose zeigen, ist in Uebereinstimmung mit dem Verhalten der ganzen Zelle.

Zweitens ist hervorzuheben, dass wenn auch die Mehrzahl der Fälle vielleicht die Mohl'sche Frklärung ebensowohl zulässt als die unsrige, doch einzelne sie ausschliessen. Dazu gehören namentlich diejenigen, wo das Häutchen der durch Wasser veränderten Chlorophyllkörner einen dopjelten Contour zeigt und das grüne Plasma deutlich umzieht.

Drittens ist noch zu bemerken, dass der Primordialschlauch in Zellen, die mit l'lasma gefüllt sind, eben so wenig direct zu beobachten ist, und dass solehe Kellen, wenn sie keine Membran besitzen und in Wasser kommen, die gleichen Veränderungen zeigen wie die Chlorphyllkörner und Zellkerne.

* Man vgl. z. B. die 1)arstellung der Schwärmsporenbildung bei Stigeocloninm insigne $\boldsymbol{N}$ ïg. in den "I'flanzenphysiol. Untersuchungena I. pag. 36 und 'Taf. I. 
Plasmamassen zurückfliessen, ohne hier irgend eine Erhabenheit zu verursachen, zugleich einen Beweis für die hohe Dehnbarkeit, wie für die Halbflüssigkeit der Plasmasubstanz. .

Zu den bläschenförmigen Plasmabildungen gehören ferner die 508 Spermatozoen. Das Studium ihrer Entwicklung aus dem Plasma der Mutterzelle macht im Allgeineinen keine besonderen Manipulationen nöthig; dagegen hält es schwer, über Zahl und Form der Wimpern olne Anwendung von Reagentien ins Klare zu kommen. Auch im Zustand der Ruhe treten sie erst deutlich hervor, wenn sie durch Iodlösung gefärbt werden. Da letztere die Spermatozoen tödtet, so wird sie am besten so zugesetzt, dass sie dieselben durch. Diffusion in allmählich steigender Concentration erreicht und dadurch eine langsame Vergiftung bewirkt. Man kann alsdann, während die Bewegung allmählich aufhört, zugleich die Natur dieser letateren und unter Umständen auch den Ruderschlag der Wimpern studiren.

Endlich gehören hieher auch die krystallähnlichen Plasmagebilde 509 oder die Proteinkrystalloide. Die Entwicklung derselben und die allmähliche Ausbildung der Krystallform kann in den Hauptpunkten durch Vergleichung jüngerer und älterer Zustände leicht ermittelt werden. Junge Krystalle sind immer rundlich, etwas später kommen dic Ecken zum Vorschein, zuletzt findet die Ebenung der Krystallflächen statt. Ueber die Art des Wachsthums geben, wie bei den Stärkekörnern und Membranen, die hie und da dentlich hervortretenden Schichten, die Trennungsspalten bei Doppelkrystallen etc., sowie ferner das Verhalten gegen chemische Reagentien Aufschluss. In letzterer Hinsicht ist namentlich zu beachten, dass die innern Partieen der Krystalloide, ähnlich wie bei den Stärkekörnern, stets quellungsfähiger und löslicher sind als die äussern, so dass nach vollständiger Auflösung der innern Substanz eine membranähnliche peripherische Hülle zurückbleibt. Alles das dentet darauf hin, dass das $W$ achsthum auch hier auf Intussusception, nicht auf Apposition beruht.

Wie ans dem Gesagten hervorgeht, ist die Methode, die man 510 bei entwicklungsgeschichtlichen Untersuchungen über'Plasmagebilde zu befolgen hat, im Grunde genommen dieselbe, die sich überhaupt bei allen Tntersuchungen dieser Art als selbstverständlich empfiehlt. Es handelt sich zunächst immer darmm, Ohjecte zu wählen, in wel- 
chen die zu untersuchenden Processe stattfinden, und sodann um eine genaue Vergleichung der verschiedenen Entwicklungsstadien. Ein Punkt verdient jedoch nachträglich noch besonders hervorgehoben $\mathrm{zu}$ werden. Es kann der Fall eintreten, dass sich in Betreff der Identität eines bestimmten Gebildes auf den verschiedenen Stufen der Differenzirung Zweifel aufdrängen. Wenn z. B., wic es bei der freien Zellbildung öfter vorkommt, sich im Inhalt der jungen Zelle zuerst kleine homogene Kügelchen ausscheiden, wenn hierauf in einem spätern Entwicklungsstadium grössere Kügelchen mit je einem kleinern als Einschluss und in einem dritten Stadium bereits fertige Zellen mit Nucleus und Nucleolus vorhanden sind, so ist oft schwer zu ermitteln, welche Theile der spätern Zustände mit den zucrst gebildeten Kügelchen identisch seien. Es sind hier a priori folgende Fälle denkbar.

1) Die primären Kügelchen entsprechen den eingeschlossenen Kügelchen in zweiten und den Nucleoli im dritten Stadium. Es würde hienach zuerst der Nucleolus, dann durch Auflagerung der Kern, endlich der übrige Inhalt der Zelle entstehen.

2) Die primären Kügelchen entsprechen im zweiten Stadium den grössern Kugeln und im dritten dem Zellkern. Hienach würde zuerst der Zellkern, dann in diesem durch Differenzirung das Kernchen, endlich durch Auflagerung der übrige Theil des Inhalts sich bilden.

3) Die primären Kügelchen entsprechen der ganzen Zelle; Kern und Kernchen entstehen im Inneru derselben durch Differenzirung.

Gegenüber solchen Alternativen, denen man hin und wieder begegnet, ist es vor Allem geboten, die Grössenverhältnisse der verschiedenen Theile in den jüngern und ältern Stadien genau zu berücksichtigen. Wenn z. B., um auf die eben erwähnte freie Zellbildung zurückzukommen, die Nucleoli der fertigen Zelle oder die Einschlüsse des zweiten Stadiums durchgehends kleiner sind, als die primären Kügelchen, so ist auf keinen Fall daran zu denken, dass die letzteren mit den erstern identisch seien. Besteht dagegen diese Ungleichheit in den drei Stadien, die wir als bekannt voraussetzen, nicht, so können nur die Uebergangszustände zwischen denselben weitere Aufschlüsse geben. Nehmen z. B. die primären Kügclchen, vom ersten Stadium an gerechnet, noch bedeutend an Volumen zu, bevor ein äusserer und ein innerer Contour, wie im zweiten Stadium, bemerkbar wird, so kann der peripherische Theil dieses zweiten Stadiums offenbar nicht durch Auflagerung entstanden scin, sondern 
muss als Product einer innern Differenzirung betrachtet werden. In gleicher Weise sind auch die Uebergänge zwischen dem zweiten und dritten Stadium hinsichtlich ihrer Grössenverhältnisse zu vergleichen, und dasselbe Verfahren muss überhaupt bei allen Untersuchungen dieser Art eingeschlagen werden.

\section{II.}

\section{Die Gesetze der Zellentheilung.}

Die Gesetze der Zellentheilung lassen sich natürlich nur an sol- 511 chen Zellcomplexen studiren, bei denen die Aufeinanderfolge der Scheidewände sich entweder aus der Lagerung der Zellen oder aus der relativen Dicke der Wandungen oder durch Vergleichung der verschiedenen Entwicklungsstadien mit Sicherheit ableiten lässt. Dass hiebei, wie bei allen Untersuchungen, vor Allem eine praktische Schule nothwendig ist, um jede beobachtete Thatsache richtig denten und verwerthen zu können, bedarf keiner Erörterung. Ebenso klar ist aber auch, dass in der Praxis nicht bloss die Uebung an und für sich, sondern auch die Methode ins Gewicht fällt, in der man sich übt. Beim Studium der Gewebebildung ist diess erfahrungsgemäss so entschieden der Fall, dass es uns nothwendig erschien, den einschlägigen Untersuchungsmethoden ein rielleicht über Verhältniss ausführliehes Capitel zu widmen. Hiezu gab uns überdiess noch die weitere Erfahrung Veranlassung, dass gerade diese Richtung der mikroskopischen Forschung noch lange nicht die Anerkennung erlangt hat, die sie vermöge ihrer Bedeutung für die Wissenschaft verdient. Hört man ja doch heut zu Tage noch einzelne Stimmen, welche das Studium der Zelltheilungen geradezu für eine minutiöse Spielerei erklären, die zu keinem sicheren Ergebiniss führen könne, als ob zu den Bedingungen der Erkenntniss des fertigen Zustandes nicht auch die Art und Weise gehörte, wie er geworden ist.

Wir haben in Folgendem die zu untersuchenden Objecte in Zell- 512 reihen, Zellflächen und Zellkörper eingetheilt, weil der Anfänger sich bei dieser Eintheilung am leichtesten zurecht findet. Der speciellen Betrachtung dieser drei Kategorien wollen wir hier nur einige wenige allgemeine Bemerkungen voransschicken.

Nägeli u. Sehwendener, das Mikroskop. 
Die Theilungsvorgänge lassen sich immer aın besten verfolgen, wenn die Objecte, die man zu untersuchen beabsichtigt, in lebhaftem Wachsthum begriffen sind. Man hat alsdann die grösste Wahrscheinlichkeit für sich, schon unter einer kleineren Zahl von Präparaten solche zu finden, bei denen die letzten Wände sich kurz vorher gebildet haben und daher um so leichter zu erkennen sind. Die glückliche $W$ ahl der Objecte und unter Umständen eine zweckentsprechende Cultur der betreffenden Pflanze, wobei die Zellen etwas grösser oder durchsichtiger werden $u$. dgl., sind daher bei solchen Untersuchungen von grosser Bedeutung.

Aus der Anordnung der Zellen kann nur dann auf die Entwicklungsfolge der Scheidewände geschlossen werden, wenn die gegenseitige Lage der letztern im Wesentlichen mit der ursprünglichen, wie sie durch die Theilung bedingt ist, übereinstimmt. Diess ist der Fall a) wenn das Wachsthum nach stattgefundener Theilung fast gänzlich aufhört, b) wenn die Theilzellen sich zwar allseitig ausdehnen, dabei aber ihre Gestalt nicht merklich ändern, c) wenn die 'Theilungsvorgänge so rasch aufeinander folgen, dass die inzwischen eintretenden Formveränderungen relativ klein erscheinen. In allen andern Fällen sind die auf die Gruppirung der Zellen basirten Schlüsse entweder ungerechtfertigt, oder es fehlen überhaupt alle Anhaltspunkte, um irgend welche Schlüsse zu ziehen.

Die Gestaltveränderungen, welche die Zellen in Folge ihres weitern Wachsthums erfahren und wodurch ihre ursprüngliche Anordnung oft total verwischt wird, müssen für sich allein zum Gegenstand der Untersuchung gemacht werden. Welcher Art sind diese Veränderungen? Ist es bloss das Bestreben der Zellen sich abzurunden, welches dieselben hervoriuft, wie man diess wohl bei Zellfäden mit tonnenförmigen Gliederzellen und ebenso bei isodiametrisch-parenchymatischen Geweben höherer und niederer Gewächse annehmen kann? Oder liegt denselben die ausgesprochene Neigung der Zellen zu Gruude, eine bestimmte Form anzunehmen, wie z. B. bei den sternförmigen Verzweigungen derselben, bei der Streckung in einer bestimmten Richtung, bei der Bildung von Ausbuchtungen an einzelnen Zellen u. s. w. Auch die Drehungen der Zellen oder ganzer Organe, sowie das ungleichmässige $W$ achsthum ursprünglich gleicher Zellen oder Zellcomplexe, wodurch Veränderungen der Stellung seitlicher Organe bewirkt werden, gehören hieher.

Der Aufbau der Gewebe ist überhaupt erst dann als erledigt zu betrachten, wenn ausser der Entwicklungsfolge der scheidewände 
auch alle Formveränderungen bekannt sind, welche die Zellen im Verlaufe des weitern Wachsthums erfahren.

\section{Zellreihen.}

Eine einfache Zellreihe ist unter dem Mikroskop leicht daran zu $\mathbf{5 1 3}$ erkennen, dass sie nur quer zur Längenausdehnung gestellte Scheidewände, aber selbst beim Drehen um ihre Axe keine Längswände zeigt. Die Fragen, welche bei einem solchen Zellfaden in Betreff der Wachsthumsrorgänge $\mathrm{zu}$ beantworten sind, können sich demgemäss, da von Richtungsverschiedenheiten nicht die Rede sein kann, nur auf die Unterschiede beziehen, welche zwischen den successiven Zellen der Reihe hinsichtlich ihres Theilungsvermögens denkbar sind.

Es ist in erster Linie $\mathrm{zu}$ untersuchen, ob die Bildung neuer Scheidewände sich in allen Zellen, sowohl bei jüngern als bei ältern Făden, mit ungefähr gleicher Lebhaftigkeit wiederhole, oder ob gewisse Zellen früher, andere später sich zu theilen aufhören. Die Kennzeichen, welche hierüber Aufschluss geben, sind je nach der Natur der Pflanze verschieden; bald sind es die Einkerbungen am Rande oder die ungleiche Dicke der Scheidewände, bald die relativen Längen der Zellen, bald die Schichten der Wandung, bald auch das mehr oder minder jugendliche Aussehen der Membran - alles Verhältnisse, welche der Anfänger, wenn er darauf achtet, leicht deuten lernt.

Ist die Theilungsfähigkeit der einzelnen Zellen ungleich; hat man es z. B. mit dem häufig vorkommenden Falle zu thun, dass die Endzellen sich anders verhalten als die Gliederzellen, indem sie entweder fortwährend, so lange das Organ wächst, oder doch bis zu einem gewissen Stadium der Entwicklung, sich augenscheinlich vorwiegend am Aufbau betheiligen (Scheitelwachsthum), so stellt sich dem Beobachter die weitere Aufgabe, die vorkommenden Verschiedenheiten genau zu präcisiren. Beruht vielleicht der ganze Unterschied darauf, dass gewisse Glieder der Reihe sich nicht mehr theilen, indess die übrigen sich unbegrenzt zu theilen fortfahren, wie z. B. bei den Nostocheen und den Gonidienketten der Collemeen? Oder handelt es sich zunächst um den Gegensatz zwischen Endzellen und Gliederzellen, und wenn diess der Fall, sind diese letztern überhaupt theilungsfähig oder nicht? Verhalten sich die Gliederzellen, wenn sie theilungsfähig sind, unter sich gleich, oder theilen sich die einen häufiger als die anderen? Ist die Zahl der Theilungen eine bestimmte oder unbestimmte, vielleicht 1, 2, 3 oder darüber? Wie stark ist das 
Längen- und Dickenwachsthum der ursprünglichen Gliederzellen, vom Zeitpunkte an gerechnet, wo sie von der Scheitelzelle abgeschnitten werden, bis sie aufhören zu wachsen? Das sind die Fragen, die sich hier aufdrängen und die auch bei der Untersuchung körperlicher Gebilde, so oft es sich um die Entwicklung von Zellreihen (im Canbium, Periderm, in der Rinde etc.) handelt, immer wiederkehren. Sie sind in manchen Fällen sehr leicht, in andern etwas schwieriger $\mathrm{zu}$ beantworten; oft bleiben auch einzelne Punkte zweifelhaft. Das Verfahren, das man bei der Untersuchung zu beobachten hat, mag an besten an einigen Beispielen erläutert werden.

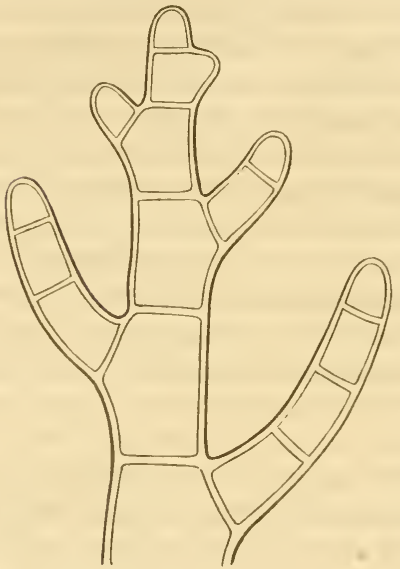

Fig. 231.

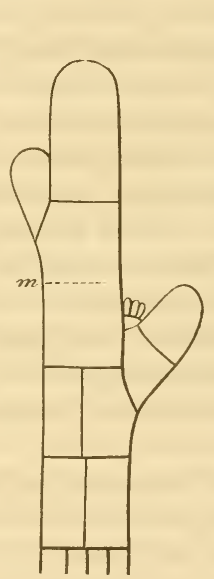

Fig. 232.

In Fig. 231 beobachtet man schon an den jüngsteu Gliederzellen Andeutungen der Verästlung. Die Aeste werden nach unten von Glied zu Glied grösser und die Gliederzellen selbst etwas länger und dicker, ohne dass neue Scheidewände zwischen den Aesten gebildet würden. Hier findet also keine Theilung der Gliederzellen des Stammes statt. Dasselbe Gesetz gilt auch, wie sich aus der stetigen Längenzunahme der Glieder und der eben so stetigen Dickenzunahme der Scheidewände ergiebt, für sämmtliche Aeste. In Fig. 232 ('Thallomende von Sphacelaria) ist dagegen das Auftreten neuer Scheidewände $(m)$ zwischen schon vorhandenen unzweifelhaft;

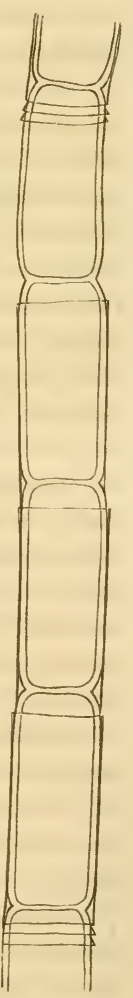

Fig. 233. 
jede Gliederzelle theilt sich aber nur einmal, wie man aus der späteren Vertheilung der Aeste und der Länge derZellen ersieht (C'hara, sphacelaria. Cladostephus). Eine öftere Theilung hat dagegen in Fig. 233, die eine ursprüngliche Gliederzelle eines Oedogonium-Fadens darstellt, stattgefunden. Hier entspricht die Zahl der später entstandenen Scheidewände derjenigen der Querstreifen (Kappen) an der obersten Theilzelle, - ein Verhältniss, das natürlich vorerst durch das Studium des Theilungsvorganges selbst fesigestellt sein muss. ${ }^{*}$ Ebenso ist in Fig. 234 die interealare Theilung der Gliederzellen durch die Einschachtelung der Schichten und die ungleiche Dicke der Wände (im Holzschnitt nicht deutlich genug hervorgehoben) genau bestimmt. Aehnliche Anhaltspunkte bieten sich auch in vielen anderen Fällen, und es gehörtmit zur Aufgabe des Beobachters, dieselben zu finden.

Gelingt es nicht, den ganzen Aufbau genau zu ermitteln, so ist es doch immer möglich, die allgemeineren Gesetze desselben festzustellen. Für die Flechtenfasern gilt z. B. die Regel, dass die Fasern, welche die Rinde bilden, sich bis auf eine gewisse Entfermung von der Oberfläche zu theilen fortfahren, während im Innern des Thallus bloss Verästlung, aber keine Theilung der Gliederzellen mehr statt- Fig. 231. findet. Wie sich die Enden der Aeste verhalten, welche im Marke verlaufen, bleibt noch zu ermitteln; nur soviel ist sicher, dass ihre ältern Gliederzellen sich ebenfalls nicht mehr theilen.

\section{Zellthächen.}

Mit dem Ausdruck Zellfläche bezeichnen wir einen Zelleomplex, 514 welcher aus einer einzigen Lage von Zellen besteht. Das Erkennen solcher Complexe unter dem Mikroskop bietet keinerlei Schwierigkeiten; bei kleineren Objecten, wie z. B. bei den Täfelchen von Pediastrum, bei einzelnen parenchymatischen Sporen u. dgl. geben hierüber die verschiedenen Ansichten, die man beim Drehen erhält, bei grössern blattähnlichen Gebilden die senkrecht zur Flächendimension geführten Durchschnitte zuverlässige Auskunft.

Die Theilungsvorgänge, welche den Aufbau einer Zellfläche vermitteln, bieten zunächst, ähnlich wie bei den Zellreihen, alle die Verschiedenheiten und Combinationen dar, welche mit Rücksicht

*) Vgl. hierüber pag. 550 . 
auf das Theilungsvermögen der einzelnen Zellen denkbar sind. Dazu kommen aber noch die Unterschiede bezüglich der Theil ungs richtung, indem die auftretenden Scheidewände in den verschiedenen Regionen der Fläche ungleich gestellt sein können. Es giebt hienach

a) Zellflächen mit unter sich gleichwerthigen Elementen, welche sich säımtlich in gleicher Weise zu theilen fortfahren, so lange das Organ wächst;

b) solche, in welchen nur die Randzellen unter sich übereinstimmen, indess die den Rand nicht berührenden Flächenzellen sich abweichend verhalten, sei es, dass sie sich gar nicht theilen oder dass sie eine nach Richtung und andern Merkmalen verschiedene Theilungsfähigkeit besitzen ;

c) solche, bei welchen zu dem Gegensatz zwischen Rand- und Flächenzellen noch weitere Verschiedenheiten zwischen den Randzellen unter sich oder zwischen den Flächenzellen unter sich hinzukommen.

$\mathrm{Ob}$ ein zu untersuchendes Object in die erste, zweite oder dritte Kategorie gehöre, muss hier vorzugsweise aus der Gruppirung der Zellen in Reihen oder in kleinere Complexe und aus dem mehr oder minder jugendlichen Aussehen des Gewebes erschlossen werden, was in manchen Fällen ohne alle Schwierigkeit möglich ist. Oft genügt sogar ein flüchtiger Blick, um eine bestimmte Region als die vorzugsweise bildungsfähige und gewisse Zellen derselben als besonders ausgezeichnete zu erkennen.

Eine grössere Aufmerksamkeit erfordern im Allgemeinen die Theilungsvorgänge selbst. Am leichtesten sind sie natürlich bei kleineren Gruppen zu ermitteln, welche nach stattgefundener

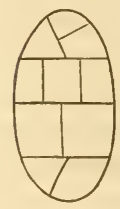

Fig. 235. Theilung keine Formveränderung erleiden und überdiess in den verschiedensten Entwicklungsstadien zu haben sind. Wie eine mehrzellige Brutknospe oder Spore (Fig. 235) sich aufbaut, lässt sich zuweilen ohne Weiteres aus der gegenseitigen Lage der Scheidewände erkennen; in andern Fällen genügt es, einige jüngere Zustände damit zu vergleichen, um sich über die zweifelhaften Punkte aufzuklären. Das Nämliche gilt hie und da sogar von beträchtlich grösseren Zellflächen. - Ebenso bieten auch die zu a) gehörigen Objecte keine erheblichen Schwierigkeiten, da es sich hier nur um die Frage handeln kann, ob dic Scheidewände eine gesetz- 
mässige Stellung einnehmen, oder ob sie regellos nach den verschiedenen Richtungen der Fläche orientirt seien.

Es bleiben also nur die Theilungsvorgänge in Zellflächen von $\mathbf{5 1 5}$ grösserer Ausdehnung, und soweit sie den unter b) und c) erwähnten Kategorien angehören, ausführlicher zu besprechen übrig. Hier ist vor Allem ein strenges Auseinanderhalten der Randzellen und der den Rand nicht berührenden Flächenzellen geboten, d. h. es ist nothwendig, das durch jene bedingte peripherische Wachsthum und das intercalare der Flächenzellen gesondert zu betrachten.

Halten wir uns zunächst an das peripherische Wachsthum, so ist leicht einzusehen, dass die Randzellen mit den ursprünglichen Flăchenzellen, welche durch die successiven Theilungen von jenen abgeschnitten werden, ein System von Zellreihen oder Zellfäden repräsentiren, von denen jeder sein selbständiges Wachsthum besitzt. Jede Randzelle ist die Scheitelzelle eines solchen Fadens, und die sämmtlichen Flächenzellen gruppiren sich genetisch in Reihen von Gliederzellen. Alle Eigenthümlichkeiten des peripherischen Flächenwachsthums sind hienach zurückführbar auf solche von Zellreihen. Einige Beispiele mögen zeigen, welcher Art die hier vorkommenden Verschiedenheiten sind.

In Fig. 236 ist die Flächenansicht eines Torkeims von Acrochaetium pulvereum Nüg. dargestellt. Man sieht auf den ersten Blick, dass das Wachsthum hier ein allseitig gleichmässiges ist, indem die radialen Zellreihen sich nach einwärts bis auf einen ziemlich centralen Punkt verfolgen lassen. Die Scheidewände, welche man in den Randzellen beobachtet, zeigen überdiess deutlich, wie die Vermehrung der Reihen mit zunehmendem Umfang stattfindet. Ebenso geht aus der ganzen Anord-

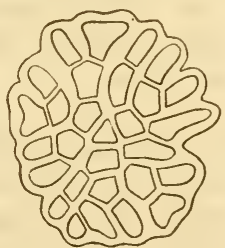

Fig. 236. nung der Zellen und der gleichmässigen Dicke der Scheidewände unzweifelhaft hervor, dass intercalare Zelltheilungen hier nicht stattgefunden haben. Zur Vervollständigung der Wachsthumsgeschichte bleibt also nur noch übrig, die jüngsten Zustände zu vergleichen, um hier die ersten Theilungen zu ermitteln.

Als zweites Beispiel ist in Fig. 237 die Thallusspitze von s'typopodium atomarium $K t z$. veranschaulicht. Die Abbildung ist halbschematisch, indem die Zellreihen, welche in Wirklichkeit zum 
Gewebe verbunden sind, hier als getrennte Fäden erscheinen. Der Verlauf dieser Fäden, welcher auch am Object selbst deutlich hervortritt, und die äussere Gestalt der ganzen Zellfäche zeigen deutlich, dass das Wachsthum nicht, wie im vorhergehenden Falle, ein allseitig-

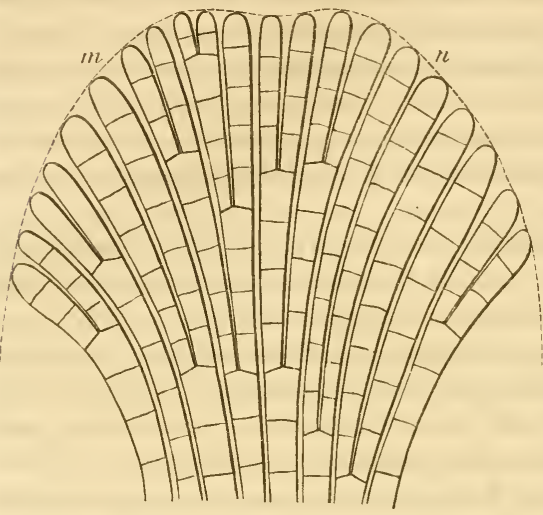

Fig. 237.

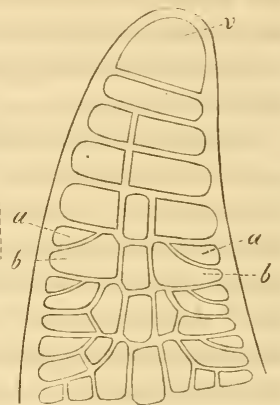

Fig. 23s.

gleichmässiges ist, sondern in der Zone zwischen $m$ und $n$ mit weitaus vorwiegender Lebhaftigkeit von statten geht. Man hat es also mit einer Zellfläche zu thun, welche eine vorzugsweise bildungsfähige Region besitzt, die man desshalb als Scheitelregion bezeichnen kann.

Ein ferneres Beispiel eines ausgesprochenen Scheitelwachsthums liefert die Thallusspitze von Delesseria Hypoglossum (Fig. 238). Hier ist es eine bestimmte Randzelle, die Scheitelzelle $r$, welche sich vor allen andern dadurch auszeichnet, dass sie allein das Längenwachsthum der Zellfläche vermittelt, indem sie sich immer wieder durch senkrecht zur Längsrichtung gestellte Wände theilt. Die 'Thallusspitze verhält sich also gewissermaassen wie ein einfacher Zellfaden, sie besteht aus einer Scheitelzelle und den davon abgeschnittenen Gliederzellen; das Unterscheidende liegt bloss darin, dass die letztern sich nach verschiedenen Richtungen weiter theilen. Man ersieht aus der Figur, dass in den Gliederzellen zunächst eine excentrische Längswand auftritt, dann eine zweite symmetrische auf der andern Seite, so dass dadurch eine aus zwei gleichwerthigen Rand- 
zellen und einer mittleren Flächenzelle bestehende Querreihe gebildet wird. Die Randzellen theilen sich nun durch schiefe und etwas gebogene Wände in zwei, worauf der innere Theil der untern durch eine kurze Scheidewand, die sich oberseits an die gebogene ansetzt, abgeschnitten und zur Flächenzelle wird, während der äussere als Randzelle weiter wächst. Die beiden neben einander liegenden Randzellen $a$ und $b$ verhalten sich von jetzt an wie die Scheitelzelle eines Zellfadens; sie theilen sich durch Wände, welche mit den eben beschriebenen annähernd parallel laufen. Der von der obern Randzelle durch jede neue Scheidewand abgeschnittene Theil berührt mit seiner Aussenseite die Peripherie, ist also abermals eine Randzelle. Dieselbe theilt sich, wie die mit ihr gleichwerthige Zelle $b$, durch längsverlaufende Wände und zwar ebenfalls so, dass immer nur die den Rand berührende Zelle thei-

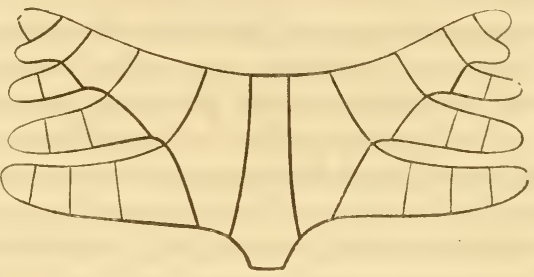

Fig. 239 . lungsfähig bleibt.

Die Zellfläche, welche durch die angedeuteten Theilungsvorgänge gebildet wird, lässt sich also auch hier auf ein System von Zellfäden zurückführen, wie es in Fig. 239 für ein einzelnes Glied veranschaulicht ist.

Das Näıliche gilt schliesslich auch für diejenigen Zellflächen mit Scheitelzellen, bei denen die Theilung der letztern durch abwechselnd nach rechts und links geneigte Wände erfolgt, wie es z. B. beim Moos-

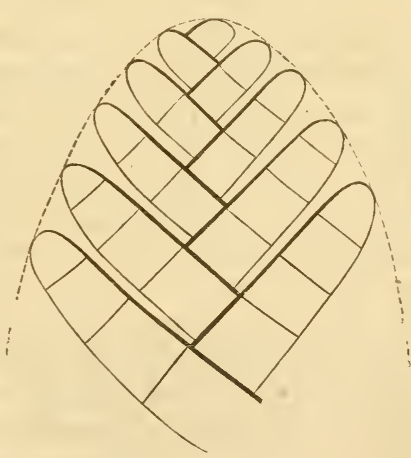

Fig. 240. blatt der Fall ist Sie lassen sich sạmmmtlich in Sympodien von Zellfäden auflösen, deren Scheitelzellen sich durch successive Querwände theilen (Fig. 240). 
Die Frage, ob eine Scheitelzelle vorhanden sei oder ob die Zellfläche mit mehreren oder vielen unter sich gleichwerthigen Randzellen, welche in der Krümmung der Scheitelregion liegen, in die Länge wachse, ist übrigens nicht immer so leicht $\mathrm{zu}$ entscheiden. Es kann im Gegentheil vorkommen, dass hierüber selbst der geübte Beobachter erst nach Vergleichung zahlreicher Präparate zu einer bestimmten Anschauung gelangt, indem Organe, welche nachweisbar eine Scheitelzelle besitzen, bei oberflächlicher Betrachtung oft gerade so aussehen wie solche ınit vielen Scheitelzellen. Dieser Fall muss in mehr oder minder täuschendem Grade immer eintreten, sobald die von der Scheitelzelle abgeschnittenen Glieder oder Segmente ein starkes peripherisches und intercalares Wachsthum zeigen, wobei zugleich die in den Randzellen auftretenden Scheidewände ähnlich gestellt sind, wie die successiven Wände der Scheitelzelle.

In Fig. 241 und 242 sind beispielsweise zwei Zellflächen, welche die bezeichneten Bedingungen erfüllen, abgebildet; Fig. 241 stellt das Thallomende von Nitophyllum laceratum, Fig. 242 dasjenige von Delesseria sinuosa dar. Die Scheitelzellen sind bei beiden

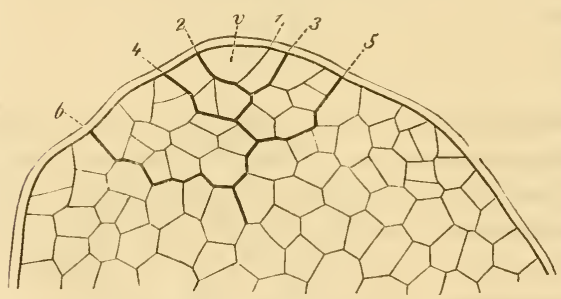

Fig. 241. (460)

mit $v$ bezeichnet und die den ersten Theilungen entsprechenden Wände im Gewebe, wenigstens in der Nähe der Scheitelzelle, durch stärkere Linien hervorgehoben. Wie man aus den Figuren ersieht, fgeschieht das Scheitel-

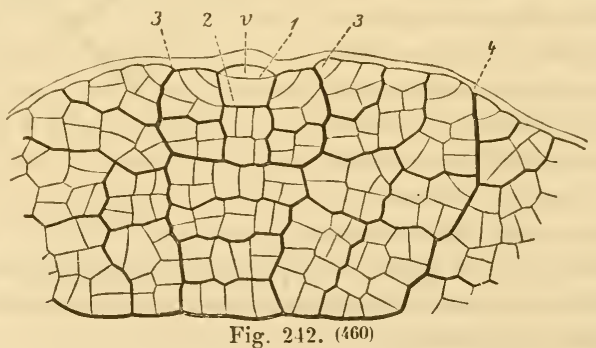

wachsthum bei Nitophyllum durch alternirend nach rechts und links geneigte Wände, welche indess durch die spätern Wachsthums- 
erscheinungen bald zickzackförmig gebrochen werden und in einiger Entfernung von der Scheitelzelle nicht mehr erkennbar sind; die Ziffern 1 bis 6 bezeichnen die Reihenfolge derselben von oben nach unten. Bei Delesseria dagegen erfolgt die Theilung durch Querwände ( 1 bis 4 in der Figur); man hat es hier mit aufeinander folgenden Gliedern zu thun, von denen die ältern beiderseits über die jüngern hinaufwachsen. Jedes Glied theilt sich zunächst, ganz wie bei Delesseria Hypoglossum, in zwei Randzellen und eine mittlere; allein hier ist die letztere, wie alle folgenden Flächenzellen, selbst wieder theilungsfähig.

Wir bemerken noch, dass die in den Zeichnungen durch stärkere Linien hervorgehobenen Wände am Object selbst keineswegs in diesen Abstufungen hervortreten, sondern im Gegentheil oft fast gar nicht von den übrigen verschieden sind. Die zusammengehörigen Zellgruppen lassen sich erst nach Zusatz von Quellungsmitteln einigermaassen überblicken, und selbst dann ist es immer unerlässlich, zahlreiche Thallusenden zu untersuchen und die günstigsten zu combiniren, um den Aufbau bis zu einer vorgerückteren Stufe der Entwicklung Zelle für Zelle festzustellen.

Die intercalaren Zelltheilungen, welche in den von den 518 Randzellen abgeschnittenen Flächenzellẹn, den Gliederzellen der Reihen, nachträglich stattfinden, lassen sich in allen Fällen, wo das pèripherische Wachsthum genau bekannt ist, leicht übersehen. Man hat nur nöthig, sich den Aufbau des Zellennetzes, welches durch die Theilungen der Randzellen gebildet wird, klar vorzustellen oder auf dem Papier zu construiren: die intercalaren Wände erscheinen alsdann als eingeschobene Stücke. So lässt sich z. B. aus der Stellung der Scheidewände im Blatte von Sphagnum leicht entnehmen, dass jede Zelle der schief verlaufenden Reihen, aus welchen die Zellfläche besteht, sich zuletzt durch eine Querwand und hierauf die untere 'Theilzelle durch eine Längswand theilt. Gewöhnlich gehen diesem Theilungsvorgang noch andere intercalare Theilungen voraus, die sich aber in dem ursprünglichen Zellennetz ebenso leicht erkennen lassen. Erst wenn die Zahl der intercalaren Scheidewände beträchtlich grösser ist, wie in den olıen erwähnten Thallusenden von Delesseria sinuosa und Nitophyllum laceratum, ist die Ermittelung der Aufeinanderfolge mit Schwierigkeiten verbunden und zwar mit um so bedeutenderen, je stärker die Formveränderungen der Zellen. 


\section{Zellkörper.}

519 Als Zellkörper bezeichnen wir diejenigen Zellcomplexe, welche aus zwei oder mehreren Lagen von Zellen bestehen. Da die äussern Formen derselben sehr verschieden sind und die Wachsthumsverhältnisse theilweise damit im Zusammenhang stehen, so müssen folgende Fälle unterschieden werden.

a) Zellkörper, welche aus Zellflächen entstehen.

Es gibt blattähnliche Gebilde, deren Scheitelregion aus einer Lage, wenn auch nur von wenigen Zellen besteht, indess die ältern Particen derselben zwei oder mehrere solcher Lagen aufweisen. Man hat es in solchen Fällen mit Organen zu thun, bei welchen auf das Flächenwachsthum ein davon durchaus unabhängiges Dickenwachsthum folgt, das sich bald auf die ganze Breite ausdehnt, bald anf einen mittleren Theil beschränkt bleibt. Die Theilungsvorgänge, welche dieses Dickenwachsthum bedingen, können indess auf Durchschnitten, welche senkrecht zur Flächenausdehnung geführt wurden, genau in derselben Weise ermittelt werden, wie die Theilungen bei Zellflächen, und bedürfen daher keiner weitern Erörterung. Das Wachsthum kann auch hier ein rein peripherisches sein, indem Btets

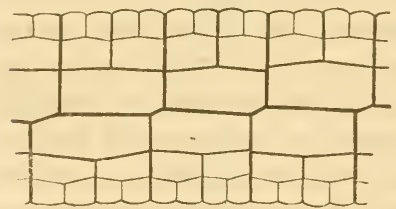

Fig. 243. nur die die Oberfläche berührenclen Zellen theilungsfähig sind, oder es könren auch die im Innern liegenden Zellen sich wieder theilen. Das erstere ist z. B. der Fall bei $D e-$ lesseria, bei Stypopodium (Fig. 243, Stück eines Querschnittes durch die Thallomspitze), das letz-

tere bei der Mittelrippe der Moosblätter. Wo die Reihenfolge der Scheidewände im fertigen Zustande zweifelhaft ist, muss dieselbe, wie inmer, nach Quer- oder Längsschnitteu durch jüngere Entwicklungsstadien festgestellt werden.

b) Kleinere Zellgruppen, welche aus ciner einzigen Zelle entstehen.

520 Das Studium solcher Zellgruppen, denen man bei einzelligen Algen, Flechtengonidien, Drüsenhaaren etc. häufig begregnet, beginnt naturgemäss mit der Ermittlung der anatomischen Verhältnisse: die Anordunng der Zellen im entwickelten oder doch in einem vorge- 
rüekteren Zustande muss zuerst bekannt sein, ehe man die Frage aufwerfen kann, wie sie zu Stande kommt. Zu diesem Behufe muss das Object, auch wenn es nur aus zwei übereinander liegenden Zellenlagen besteht, unter dem Mikroskop so lange gedreht werden, bis man das Zellennetz der Oberfläche zu construiren im Stande ist und die einzelnen Zellen in jeder beliebigen Lage wieder erkennt. Diese Manipulation setzt allerdings einige Uebung voraus, doch kann sie in der Regel dadureh bedeutend erleichtert werden, dass man das Deckgläschen mit dem einen oder mit beiden Rändern auf Papierstreifen legt. Die letztern bilden alsdann beim Drücken mit der Nadel eine elastische Unterlage, welche eine langsame Strömung im Wasser und damit eine langsame Drehung des Objectes hervorzurufen gestattet.

Um zu ermitteln, ob alle Zellen der Gruppe die Oberfläche berühren, oder ob vielleicht einzelne im Centrum liegen, welche allseitig umschlossen sind, ist es oft zweckmässig und ausreichend, den \%ellinhalt durch wasserentziehende Reagentien zu contrahiren. Dadurch wird es möglich, eine grössere Zahl von Zellen mit einem Blick zu übersehen und die übereinander liegenden Zellen in ihren natürlichen Niveauverhältnissen zu beobachten. So z. B. bei den Gonidiengruppen der Flechten, den Keimhäufchen und Antheridien der Florideen in den ersten Entwicklungsstadien, den Brutknospen der Moose und Lebermoose, den Colonieen einzelliger Algen etc. Sind die Complexe grösser, so führt in manchen Fällen ein Durchschneiden derselben zum Ziel, was namentlich bei solehen, die man ohne Nachtheil in Gummi eintrocknen lassen darf, sich ohne alle Schwierigkeit ausführen lässt. -- Uebrigens ist das Studium der Zelltheilungen in kugelförmigen Gebilden eine der schwierigsten Aufgaben dieser Art, die bis jetzt nur für 2 bis 3 Zellenlagen im Durchmesser gelöst worden ist.

c) Zellkörper mit peripherischem Wachsthum ohneausgezeichnete Scheitelzellen, meist durch bogenförmig gegen die Oberfläche verlaufende Zellreihen eharakterisirt.

Lässt man die Zellflächen (Fig. 236 u. 237), deren Wachsthums- 521 verhältnisse oben besprochen wurden, in Gedanken um eine Längsoder Queraxe rotiren, indem man zugleich den Verlauf der Zellreihen auf den durchlaufenen Raum überträgt, so geben die Körper, welche man auf diese Weise erhält, gewissermaassen einen Begriff von den 
Verschiedenheiten, welche zwischen den hieher gehörigen Wachsthumstypen obwalten. Eine kreisförmige Fläche mit ringsum gleichmässigem Wachsthum, oder ein beliebiger Abschnitt derselben, wird auf diese Weise zur Kugel oder zum Kugelsegment, in welchen beiden die Zellreihen strahlenförmig von innen nach aussen verlaufen. Ebenso entsteht durch Umdrehung der Fläche Fig. 237 (p. 564) um ihre Längsaxe ein cylindrischer Zellkörper mit Scheitelwachsthum, in welchem die Zellreihen nach allen Seiten bogenförmig gegen die Oberfläche divergiren, und in gleicher Weise lassen sich auch die laub- und krustenartigen Thallome der Algen und Flechten auf entsprechende Zellflächen zurückführen: sie repräsentiren im Raume das, was die erzeugende Fläche in der Ebene ist.

Die Fragen, welche bei der Ủntersuchung solcher Zellkörper zu entscheiden sind, ergeben sich hienach von selbst. Es handelt sich, wie bei den Zellflächen, zuerst um die Feststellung der peripherischen Wachsthumsvorgänge, und sodann in zweiter Linie um die intercalaren Theilungen der Innenzellen, d: h. der innerhalb der oberflächlichen Schicht gelegenen Gliederzellen der Reihen. Beides wird hier durch den Umstand erschwert, dass die bei der Theilung auftretenden Scheidewände nach verschiedenen Richtungen 'des Raumes orientirt sind und folglich nur durch Combination verschiedener Durchschnitte oder Durchschnittsansichten, namentlich radialer und tangentialer, räumlich construirt werden können. Wie diess geschieht, mag am besten durch einige Beispiele erläutert werden.

Denken wir uns, die Fig. 244 stelle einen longitudinalen Me-

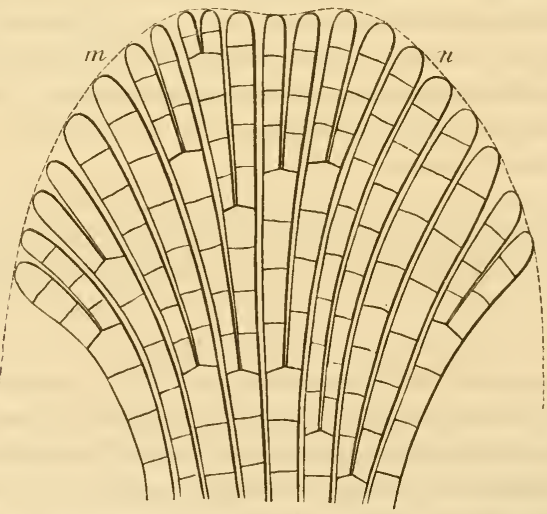

Fig. 244 . 
dianschnitt durch ein cylindrisches Thallom dar. Der Beobachter hat alsdann zunächst alle die Fragen zu lösen, die sich bei der einfachen Zellschicht ebenfalls darbieten, dazu aber ferner die Stellungsverhältnisse und die Aufeinanderfolge der Scheidewände zu ermitteln, welche in den Randzellen und vorkommenden Falls auch in den Innenzellen auftreten. In unserer Figur ergibt sich aus der Art, wie sich die Zellreihen aneinander anschliessen, dass die Verzweigung derselben in Folge des peripherischen Wachsthums eine dichotomische

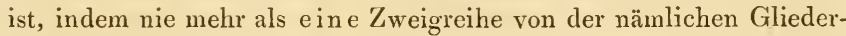
zelle abgeht. Stünden die Zweigreihen gepaart oder in Quirlen, so müsste sich diess auf Längsschnitten ebenso deutlich kundgeben. Es bleibt also nur zu untersuchen, ob die auf einander folgenden Gabelungen derselben Reihe in Ebenen liegen, die sich rechtwinklig kreuzen oder irgend eine andere gesetzmässige Beziehung zu einander zeigen, und hierüber geben theils die Durchschnittsansichten, theils die Ansichten der peripherischen Zellen von der Oberfläche die nöthigen Anhaltspunkte.

d) Zellkörper, welche eine Scheitelzelle besitzen.

$\mathrm{Ob}$ ein zu untersuchendes körperliches Gebilde mit mehreren 522 oder vielen 'Zellreihen in die Länge wachse, oder ob es eine einzige Scheitelzelle besitze, welche sich durch schiefe oder quergestellte Wände theilt, ist in manchen Fällen keineswegs leicht zu entscheiden. Die Zellkörper können in dieser Beziehung zu den nämlichen Täuschungen Veranlassung geben, welche oben (pag. 566) bei den Zellflächen erwähnt wurden. Es ist alsdann nothwendig, die Gruppirung der Zellen in der Scheitelregion, welche letztere schon durch den jugendlichen Habitus des Gewebes sich immer hinlänglich auszeichnet, auf Längs- und Querschnitten genau zu studiren und nöthigenfalls durch Constructionen auf dem Papier sich über das Zustandekommen der Reihen und Complexe, in welche die Zellen mehr oder minder deutlich geordnet erscheinen, Rechenschaft zu geben.

Auch die Theilungsweise der Scheitelzelle, ob durch Querwände oder durch schiefe, muss in schwierigen Fällen vorzugsweise aus der Stellung der Zellcomplexe erschlossen werden. In andern ist die Sache freilich sehr leicht. Es ist klar, dass eine Anordnung der Zellen wie in Fig. 245 nur durch successive Querwände, diejenige der Fig. 246 nur durch alternirend nach rechts und links geneigte Wände entstanden sein kann. Dieser letztere Typus wird allerdings etwas verwischt, wenn der Winkel, den die alternirenden Scheidewände 
mit einander bilden, sehr spitz ist, jedoch nur in dem Sinne, dass das Vorhandensein einer Scheitelzelle zweifelhaft wird; eine Ver-

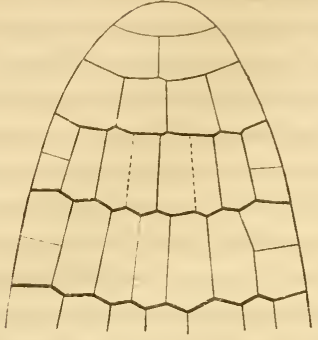

Fig. 245.

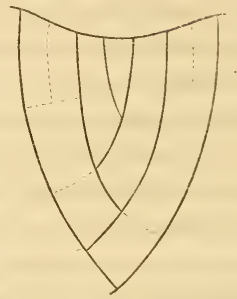

Fig. 246.

wechslung mit dem vorhergehenden ist in diesem Falle nicht möglich. Dagegen kann es vorkommen, dass je zwei alternirende Scheidewände, die unter sehr stumpfem Winkel zusammenstossen, wie eine einzige schwach gebogene Querwand aussehen, aber auch diess nur dann, wenn die ursprüngliche Lage der Wände bereits eine kleine Veränderung erfahren hat. An günstigen Präparaten, welche das Stadium unmittelbar nach der letzten Theilung repräsentiren, ist die schiefe Stellung der Wände nicht zu verkennen.

Ob schief gestellte Wände bloss nach zwei Richtungen des Raumes geneigt sind, was bei Zellkörpern ebenfalls vorkommt, oder ob sie nach Art der spiralig gestellten Blätter nach verschiedenen Richtungen von der Längsaxe divergiren, gibt sich zuweilen schon in der Seitenansicht kund, sofern nämlich die senkrechte oder schiefe Stellung einer Wand, die beim Heben und Senken des Focus leicht zu unterscheiden sind, hierüber entscheidet. Zur Controle und um bei spiraliger Anordnung die Divergenzen zu ermitteln, darf man indess nie versäumen, die Scheitelzelle und deren Umgebung auch von oben $\mathrm{zu}$ betrachten.

Bei zweiseitig gestellten Scheidewänden ist übrigens wohl zu beachten, dass die Ansicht Fig. 246 nur einer ganz bestimmten Lage des Objects entspricht. Dreht man solche Objecte um ihre Längsaxe, bis das eine System der Scheidewände dem Auge zugekehrt, das andere abgekehrt ist, so erhält man oft Bilder, welche mit Fig. 245 eine grosse Aehnlichkeit haben. Es ist desswegen absolut nothwendig, die Scheitelregion von verschiedenen Seiten oder in verschiedenen Durchschnittsansichten zu beobachten. 
Findet unmittelbar unter der Scheitelzelle oder in der Umgebung derselben ein beträchtliches Dickenwachsthum statt, wodurch das Gewebe undurchsichtig wird, so ist es nothwendig, eine mittlere Lamelle, welche nach oben in die Scheitelzelle endigt, herauszuschneiden, um zur Feststellung der Theilungsgesetze den Aufbau des Organs nach rückwärts verfolgen zu können. Die mittlem Zellreihen eignen sich hiezu immer am besten, weil die Theilungen und Formveränderungen hier weniger rasch als in der Nähe der Oberfläche erfolgen. Dass man bei blattartigen Organen parallel mit der Blattfläche zu schneiden hat, um das Flächenwachsthum, und senkrecht dazu, un das Dickenwachsthum zu ermitteln, versteht sich von selbst.

Die Entwicklungsfolge der Scheidewände in den von der Schei- $\mathbf{5 2 3}$ telzelle abgeschnittenen Gliederzellen betreffend, so ist zum Voraus z.u bemerken, dass dieselbe bis jetzt nur für die einfacheren Fälle und zwar vorzugsweise für Organe mit rein peripherischem Wachsthum festgestellt ist. Die complicirteren Theilungsvorgänge, welche die Gewebebildung bei höheren Pflanzen vermitteln, lassen sich höchstens für einen Theil der Scheitelregion, dann aber nicht mehr, Zelle für Zelle verfolgen. Zur Veranschaulichung der dabei einzuschlagenden Untersuchungsverfahren mögen folgende Beispiele dienen.

*) Die Scheitelzelle theilt sich durch Querwände.

Hier ist zunächst zu untersuchen, ob die von der Scheitelzelle abgeschnittenen Gliederzellen sich vorerst ein oder mehrere Male durch Querwände theilen oder ob das Dickenwachsthum ohne diese vorläufige Quertheilung beginnt. Man verfährt hiebei in gleicher Weise, wie bei einfachen Zellreihen.

Die Hauptaufgabe besteht sodann darin, die Richtung und Aufeinanderfolge der Längswände in den Gliederzellen zu ermitteln. Hiezu sind natürlich Querschnittsansichten der verschiedenen Entwicklungsstadien erforderlich. In Fig. 247 sind solche Ansichten
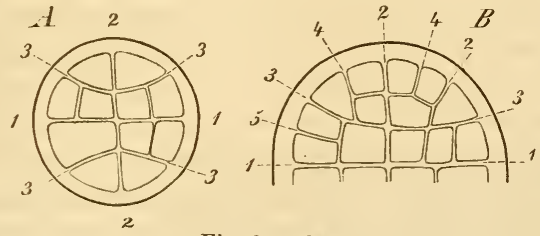

Fig. 217 (300). 
von Schizomeris Leibleinii $\mathrm{Kg}$. dargestellt; $A$ ist ein noch junges, $B$ ein etwas vorgerückteres Stadium. Die Anordnung der Scheidewände ergibt sogleich die durch die beigefügten Ziffern angedentete Entwicklungsfolge (nur für 1 und 2 ist die Reihenfolge in der Figur unbestimmt. Geht die Theilung noch weiter, so lassen sich auch die späteren Wände, welche in den Randzellen auftreten, ohne Schwierigkeit deuten und construiren.

Dasselbe gilt für Sphacelaria und für die quirlständigen Aeste von Cladostephus (Fig. 248 A, B, C, drei verschiedene Theilungsarten); nur kommen hier noch Quertheilungen der peripherischen Zellen hinzu, welche natürlich nur auf Längsansichten oder Längsschnitten verfolgt werden können. Um das Verhältniss
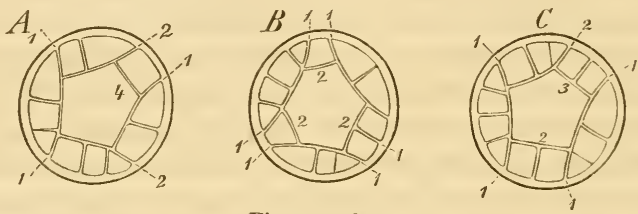

Fig. 21S (350).

der beiden Theilungsvorgänge, nämlich der Quer- und Längstheilungen, zu einander festzustellen, d. h. um die Scheidewănde im Raume construiren zu können, ist es merlässlich, einzelne Glieder langsam zu drehen und während der Drehung das oberflächliche Zellennetz Stück für Stück zu skizziren. Gelingt es, dasselbe Stück auch im Querschnitt zu beobachten, so ist danit ein sicherer Anhaltspunkt zur Controlirung gegeben; gelingt diess nicht, so muss das Theilungsgesetz aus der Zahl der Längs- und Querwände im Zellennetz ermittelt

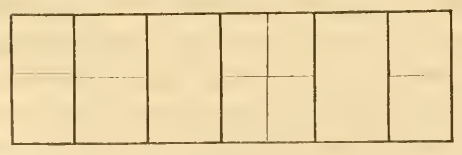

Fig. 219. werden. Kommen z. 13. $3-4$ Querwände auf $5-7$ Längswände (Fig. 249), und hat sich die letztere Zahl als die gewöhnliche der peripherischen Zellen erwiesen, so ist sicher, dass sich diese zuerst durch

Querwände und dann erst durch Längswände theilen.

Das Drehen dünner cylindrischer Stücke unter dem Mikroskop geschieht, wie bei kugeligen Zellgruppen, dadurch, dass man durch schwaches Drücken mit der Nadel langsame Strömungen hervorruft, 
welche eine ebenso langsame Drehung bewirken. Dickere Stücke, welche mit ihrer obern Fläche das Deckgläschen berühren, lassen sich auch wohl durch Verschieben desselben wie eine Walze rollen.

Ein weiter gehendes Dickenwachsthum, wobei die Randzellen längere Zeit theilungsfähig bleiben und die Innenzellen sich ebenfalls wiederholt theilen, bietet indessen auch dem geübten Mikroskopiker sehr bald unüberwindliche Schwierigkeiten; er muss sich für die späteren Stadien darauf beschränken, die allgemeineren Theilungsgesetze festzustellen, wie diess $j a$ auch bei den Geweben höherer Pflanzen durchgehends der Fall ist.

Ein schwieriges Object dieser Art sind schon die Stammenden ron Cladostephus. Die ersten Theilungen erfolgen, wie die Querschnitte durch günstige Thallusenden ergeben, nach dem in Fig. 250 dargestellten Typus (die Ziffern bezeichnen die Reihenfolge der Scheidewändej; dann aber werden die Verhältnisse rasch so complicirt, dass es schwierig wird, den Aufbau Kelle für Zelle weiter zu verfolgen. Dazu kommt noch, dass die dünnen $W$ andungen der Zellen, schon weil sie das Eintrocknenlassen in Gummi nicht gestatten, die Anfertigung guter Querschnitte erschweren, was jedenfalls mit zur Er-

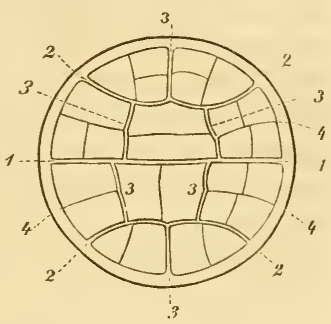

Fig. 250. müdung des Beobachters beiträgt. Die allgemeineren Wachsthumsverhältnisse: ein vorherrschend peripherisches Wachsthum, die Bildung radialer Reihen, die sich im Querschnitt dichotomisch verzweigen, das scheinbare Hineinwachsen der Aeste ins Gewebe etc. lassen sich dagegen ohne Schwierigkeit auf Durchschnitten durch den ältern Stamm ermitteln. Wir werden weiter unten hierauf zurückkominen.

Sind die ersten Theilungen in den einzelnen Gliedern bekannt, 524 so ist anch die weitere Frage von Interesse, ob die erste Längswand einer beliebigen Gliederzelle zu derjenigen des vorhergehenden oder nachfolgenden Gliedes in einem bestimmten Stellungsverhältnisse stehe, ob überhaupt eine gewisse Abhängigkeit der Theilungsvorgänge von einander sich nachweisen lasse. Die Untersuchung dieser Frage geschieht am sichersten auf Querschnitten, bei welchen die beiden Schnittflächen durch zwei successive Glieder gehen. Die höhere Ein- 
stellung zeigt alsdann die Scheidewände des oberen, die tiefere diejenige des unteren Gliedes. Zur Sicherheit kann man es auch versuchen, die Stücke umzukehren und nach einander von oben und unten zu betrachten. Auf diese Weise findet man z. B., dass die ersten Scheidewände bei Polysiphonia, ähnlich wie die Blätter bei höheren Pflanzen, spiralig gestellt sind und dass bei 4 Aussenzellen jede folgende um ungefähr $1 / 4$ des Kreisumfanges von der vorhergehenden divergirt. Ebenso scheinen auch bei sphacelaria und bei den Aesten von Cladostepluus regelmässige Divergenzen vorzukommen.

*) Die Scheitelzelle theilt sich durch schiefe Wände.

Als Beispiel eines solchen Wachsthums ist in Fig. 251 die sicheitelregion des Equisetum-Stammes abgebildet; $A$ ist ein in der Längsrichtung geführter Medianschnitt, $B$ die schematisirte Ansicht von oben. Man erkennt hier die dreieckige Scheitelzelle auf den ersten Blick; überdiess zeigt die Querschnittsansicht $B$, dass die in derselben successiv auftretenden Scheidewände nach drei verschiedenen Richtungen, die nahezu um den dritten Theil des Umfanges von einander abstehen, orientirt sind. Die 4 . Wand läuft also parallel der ersten, die 5. parallel der 2. u. s. f. Die Reihenfolge der Wände von unten
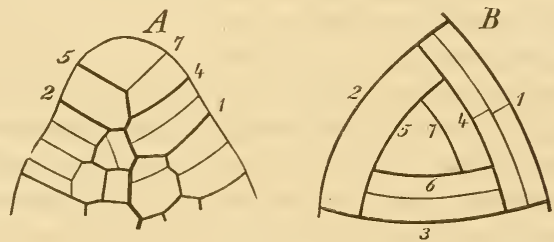

Fig. 251.

nach oben ist in $B$ durch dic entsprechenden Ziffern bezeichnet. In $A$ sind natürlich nur die Wände 1,4 und 7 und die damit parallelen auf der einen Seite, sowie 2 und 5 auf der andern Seite sichtbar; das dritte System (nämlich 3, 6 und die damit parallelen Wände) geht dem Gesichtsfelde parallel oder steht doch zu schief, um noch gesehen zu werden.

Aus den beiden Ansichten $A$ und $B$ ist ferner zu entnehmen, wie die von der Scheitelzelle abgeschnittenen Zellen sich weiter theilen. Die zuerst auftretenden Wände (zwischen 1 und 4 in $A$ und $B$, ferner zwischen 3 und 6 in $B$ ) verlaufen den ursprünglichen parallel; 
dann folgen radial gestellte $W$ ände (zwischen 1 und 4 in $B$ ), welche die Segmente in zwei gleichwerthige Hälften theilen. Dic spätern Theilungen sind schon schwieriger zu ermitteln; Alles, was bis jetzt darüber festgestellt ist, bezieht sich auf einige wenige der ursprünglichen Segmente.

\section{III.}

\section{Allgemeinere Wachsthumsgesetze.}

1. Wachsthumsvorgänge: Zellenbildmg und Zellenansdehnung.

Wenden wir uns jetzt zur Untersuchung derjenigen Organe, 526 deren Wachsthum sich nur noch im Allgemeinen, aber nicht mehr Zelle für Zelle verfolgen lässt, was bekanntlich sowohl bei Stämmen und Wurzeln, als auch bei Blättern höherer Pflanzen der Fall ist. Schon bei den Gefässkryptogamen finden wir in der Scheitelregion ein kleinzelliges Parenchym, und wenn auch eine Scheitelzelle bei den meisten nachgewiesen und die Theilungsweise derselben festgestellt ist, so zeigt doch das Gewebe unterhalb der Scheitelzelle durchgehends denselben Charakter, wie bei den Phanerogamen. Wir wissen nur, dass seine Zellen sich eine Zeit lang nach allen Richtungen des Raumes theilen, und weiter nichts. An die Stelle von einzelnen Zellen treten also hier gewissermaassen Zellcomplexe; der Gegensatz zwischen Randzellen und Flächenzellen etc. geht über in denjenigen verschiedener Gewebe Cambium, Mark, Rinde etc.), deren Elementarorgane mit Rücksicht auf 'Theilbarkeit oder Ausdehnungsfähigkeit nach dieser oder jener Richtung übereinstimmen.

Dem entsprechend modificirt sich auch die Aufgabe des Beobachters. Er hat es hier nicht mehr mit der Entwicklungsfolge bestimmter Scheidewände, sondern mit den $W$ achsthumsprocessen und Theilungsvorgängen in grösseren Partieen zu thun. Wie entstehen in einem ursprünglich homogenen Parenchym Gewebe von ganz anderer Beschaffenheit? Wie verhalten sich nach stattgefundener Differenzirung die verschiedenen Theile; welche fahren fort zu wachsen und welche nicht! Geschieht das Wachsthum bloss durch Zellenausdehnung oder durch Theilung und, wenn das letztere der Fall, in welcher Richtung treten vorzugsweise die neuen Scheidewände auf? Wo erlischt die Entwicklungsfähigkeit eines Gewebes - sowohl im Querschnitt als im Längsverlaufe beobachtet - zuerst und nach wel- 
chen Gesetzen schreitet der Uebergang in Dauergewebe fort? Das sind die Fragen, die sich der Beobachter bei Ermittelung des Wachsthums der höheren Pflanzen zu stellen hat. Ehe wir jedoch näher darauf eingehen und mit specieller Berücksichtigung der Gefässpflanzen den Gang der Untersuchung präcisiren, wollen wir, um den oben abgebrochenen Faden wieder aufzunehmen, zunächst untersuchen, inwieweit die allgemeineren Wachsthumsgesetze für den älteren Stamm von Cludostephus sich feststellen lassen.

Der Querschnitt durch ein nicht allzu junges Internodium zeigt hier deutlich eine mittlere Gruppe von Zellen, welche durch Form und Anordnung sich von den umgebenden unterscheiden und also eine Art Mark bilden. Man sieht auch deutlich, dass einzelne Zellen sich nachträglich noch getheilt haben, das Wachsthum also jedenfalls kein rein peripherisches ist. Diese mittlere Gruppe ist von einer rindenartigen Hülle umgeben, deren Zellen sich in deutliche radiale Reihen ordnen und gegen die Peripherie zu etwas kleiner werden. Die Verzweigung der Reihen bei zunehmender Dicke des Stammes geschieht durch Theilung der Randzellen in der in Fig. 252 angedeuteten Weise, seltener durch eine radiale Wand. Ein weiteres intercalares Wachsthum dieser Reihen findet nur ausnahmsweise statt; in der

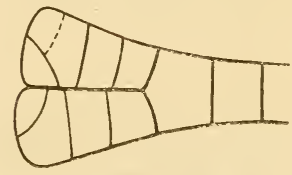

Fig. 252. Regel ist sogar die Zellenausdehnung sehr unbedeutend. Die Längsschnitte ergeben ferner, dass die mittleren Zellen langgestreckt, die peripherischen dagegen kurz sind. Am längsten sind immer die zwei oder drei centralen; es kommen hievon in den älteren Stadien, wie in den jüngsten, nur zwei auf ein Internodium. Im Centrum haben also offenbar keine Quertheilungen mehr stattgefunden, während dieselben weiter aussen im Marke wiederholt eintreten mussten, da hier 4-8 Zellen auf ein Internodium gehen. Die Rinde endlich zeigt noch kürzere und unregelmässig gruppirte Zellen, welche offenbar auch durch intercalare Scheidewände sich vermehren und überdiess nicht unerhebliche Formveränderungen und Verschiebungen erfahren. Es ist daher nur an günstigen Schnitten möglich, einige etwas deutlicher hervortretende Zickzacklinien als frühere Scheidewände zu erkennen und hienach auf die ersten Theilungen der peripherischen Zellen zurückzuschliessen. Diese scheinen, was den Verlauf der Wände auf solchen Längsansichten betrifft, in ähnlicher Weise 
zu erfolgen, wie oben bei Delesseria Hypoglossum (pag. 564). Das Dicken wachsthum ist jedenfalls, trotz der intercalaren Theilungen, ein vorwiegend peripherisches. Dass die quirlständigen Aeste scheinbar in den Stamm hineinwachsen, erklärt sich in gleicher Weise, wie bei unseren dicotylen Bäumen.

Wie in dem angeführten Beispiel die grössere Länge der centra- $\mathbf{5 2 7}$ len Zellen sich daraus erklärt, dass dieselben sich während der Streckung der Internodien bloss verlängern ohne sich durch Querwände zu theilen, so lässt sich nun auch die Entstehung der langgestreckten Cambiumzellen im ursprünglichen Bildungsgewebe der Gefässpflanzen oder überhaupt in einem kurzzelligen Gewebe denken. Es ist einleuchtend, dass wenn gewisse Zellen sich bloss durch Längswände theilen, während die umgebenden sich nach allen Richtungen des Raumes zu theilen fortfahren, die Tochterzellen der ersteren sehr bald die drei- bis vierfache Länge der letzteren erreichen müssen. Diess ist jedoch keineswegs der einzig mögliche Process, worauf die Bildung des Cambiums nothwendig beruhen müsste. Die Verlängerung kann auch, wie diess neuerdings wirklich beobachtet wurde, dadurch herbeigeführt werden, dass gewisse Zellen ein vorwiegendes selbständiges Längenwachsthum besitzen und, indem sie ihre Enden bei einander vorbeischieben, ein prosenchymatisches Gewebe bilden. Es kommt sogar vor, dass Querwände, welche in prosenchymatischen Zellen auftreten, wach und nach eine immer schiefere Lage annehmen und endlich als Längswände erscheinen (Fig. 253).

Der Beobachter hat demnach zu entscheiden, welcher der beiden Vorgänge in einem gegebenen Falle statthabe, oder ob vielleicht beide mehr oder weniger an der fraglichen Differenzirung Antheil nehmen. Wir können hinzufügen, dass diese Entscheidung in der Regel eine sehr schwierige Sache und gerade für den normalen Wachsthumstypus der Gefässpflanzen zum 'Theil erst von der Zukunft zu erwarten ist.

Zur Zeit ist nur die Ausscheidung der Cambiumbündel im Bildungsgewebe der Stammspitze, sowie der Wurzeln und Blätter, unzweifelhaft festgestellt; man weiss, dass die verlängerten Cambiumzellen

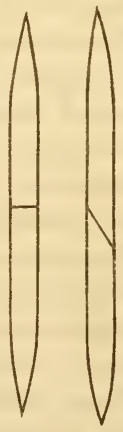

Fig. 253. durch vorwiegende oder ausschliessliche Längstheilung der parenchymatischen Bildungszellen entstehen, und dass diese Längs- 
theilung einige Zeit fortdauert. Wie dagegen die Zellvermehrung im ausgeprägten Cambium älterer Organe stattfinde, erheischt durchaus eine genauere Untersuchung. Man ist zwar gewohnt, die wiederholte Längstheilung der Cambiumzellen stillschweigend vorauszusetzen und hierauf auch die Bildung der radialen Reihen,

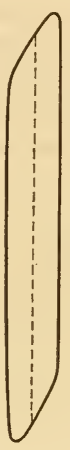
welche bekanntlich den älteren Verdickungsring charakterisiren, zurückzuführen; allein Niemand hat unseres Wissens eine solche Theilung der Cambiumzellen durch Längswände wirklich beobachtet, in der Art nämlich, dass die Lagerung zweier Tochterzellen, etwa wie in Fig. 254, mit Sicherheit auf ihre Zusammengehörigkeit schliessen liesse. Diese Theilung existirt also im Allgemeinen, streng genommen, nur in der 'Theorie, und wir dürfen uns nicht verhehlen, dass die wirklich beobachteten Quertheilungen im Cambium und die darauf folgende Zuschärfung der Theilzellen, wobei sich ihre Enden bei einander vorbeischieben, diese Theorie etwas erschüttert haben, so dass sie zum Mindesten einer neuen Stütze bedarf. Jedenfalls ist die Längstheilung, wie bereits er-

Fig. 254. wähnt, nicht der einzige Process, worauf die Vermehrung der Cambiumzellen beruht, und es bleibt zu untersuchen, welche relative Bedeutung daneben der Quertheilung zukommt.

528 Nach der Ausscheidung der Cambiumbündel müssen die Wachsthumsvorgänge innerhalb derselben von denjenigen des umgebenden Parenchyms geschieden werden. Wenn auch der Antheil am Dickenwachsthum, welcher auf dạs Parenchym fällt, in all' den Fällen, wo es sich um perennirende Organe handelt, die zeitlebens an Umfang zunehmen, relativ gering oder selbst verschwindend klein ist, so erscheint er dagegen bei manchen einjährigen Gebilden, namentlich bei fleischigen Axen- und Blattorganen um so bedeutender. Der Beobachter muss sich jedenfalls immer die Frage vorlegen, bis zu welcher Entfernung von der Scheitelregion Theilungen im Parenchym, die als Dickenwachsthum zu deuten sind, vorkommen, und bis $\mathrm{zu}$ welcher anderen noch Ausdehnung der Zellen in demselben Sinne stattfinde. Die letztere ergibt sich, wie leicht einzusehen, aus der Vergleichung der mittleren Zellendurchmesser, die erstere aus der Zahl der Zellen zwischen gegebenen Punkten.

Wenn z. B. das Mark einer dicotylen Pflanze unmittelbar nach dem Auftreten der Cambiumbündel 10 \%ellen im Durchmesser zählt 
und diese Zahl in den folgenden Internodien auf 12, 15 und 18 steigt; wenn dagegen das ältere Mark durchschnittlich aus 20 Zellen im Durchmesser besteht, so bleibt die Theilungsfähigkeit offenbar bis zu der Stelle erhalten, wo diese Durchschnittsziffer erreicht ist. Nimmt vou da an der I)urchmesser des Markes noch zu, so kann diess nur durch Ausclehnung der Zellen geschehen, die man übrigens auch durch Einzelmessungen leicht nachweisen kann.

Erscheinen die peripherischen Zcllen des älteren Markes bei übrigens gleicher Form kleiner als die mittleren, so ist diess ein Beweis, dass die letzteren früher aufgehört haben sich zu theilen. Dasselbe Raisonnement gilt natürlich auch für die Rinde und mutatis mutandis auch für die Parenchymwände zwischen den Gefässbündeln der Monocotyledonen, desgleichen für das Markstrahlenparenchym zwischen den Bastgruppen der Dicotyledonen etc. Es handelt sich immer darum, Kellenausdehnung und Zellentheilung auseinander zu halten und jede der beiden Erscheinungen sowohl nit Rücksicht auf ihre relative Daner, als auf die Art ihres Erlöschens zu verfolgen.

Die $\mathbb{W}$ achsthums-und Verholzungsprocesse im Cam - 529 bium selbst erfordern ein besonderes Studium. Hier ist zu ermitteln, wo die ersten Verholzungsproducte: Spiralgefässe, Bastzellen etc. auftreten und in welcher Richtung der Uebergang in Dauergewebe fortschreitet, sowie ferner, wie das letztere in seinen älteren und jüngeren Theilen beschaffen sei und ob es in Folge späterer Wachsthumserscheinungen noch Veränderungen erleide. Die beiden ersteren Punkte können auf successiven Querschnitten, die man durch die Scheitelregion des zu untersuchenden Organs führt, untersucht werden; die beiden letzteren erfordern überdiess die Vergleichung der Längsschnitte.

Welche Verschiedenheiten mit Rücksicht auf die gedachten Punkte vorkommen können, wird am besten aus einigen Beispielen klar werden. In der Stammspitze der Phanerogamen beginnt die Gefässbildung stets auf der Innenseite der Cambiumbündel und schreitet nach aussen in radialer Richtung fort. In den Wurzeln dagegen treten die ersten Gefässe ganz allgemein an der Peripherie auf - in den Wurzeln der Gefässkryptogamen, der Dicotyledonen und mancher Monocotyledonen (sowie auch im Stengel der Lycopodiaceen) am Umfange des centralen Cambiumcylinders, bei dickeren Monoco. tyledonenwurzeln an der äussern Seite der Cambiumstränge - und die weitere Verholzung geschieht zunächst von aus̉sen nach innen, 
nachher, wenn sie andauert, in den zwischen den ursprünglichen Gefässgruppen befindlichen Zwischenräumen von innen nach aussen. In den Stengeln der Farnkräuter, wo die Cambiumbündel kreisförmig gestellt sind, beginnt der Process meistens in zwei tangential neben einander liegenden Randpunkten der einzelnen Bündel und schreitet von da nach innen zu fort.

Achnliche Verschiedenheiten beobachtet man auch bei der Bastbildung. In den Stämmen der Phanerogamen treten die Bastzellen entweder nur auf der Aussenseite der Cambiumbündel oder an zwei in radialer Richtung opponirten Punkten, also aussen und innen zugleich auf; in den Wurzeln dagegen liegen dieselben im äussern

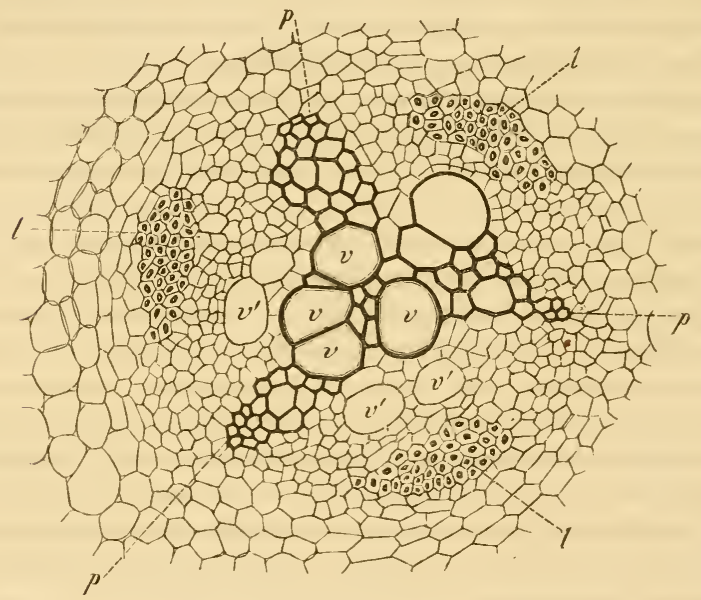

Fig. 255 (150).

Theile der anfänglichen Cambiummassen zwischen den ursprünglichen Gefässgruppen, also tangential neben einander. Sie werden, wem die Theilung im Cambium fortdauert, von demselben später nach aussen geschoben. Diese Lagerung ist in Fig. 255, welche einen Querschnitt durch die junge Pfahlwurzel von Lathyrus purpureus darstellt, veranschaulicht. Die Bildung der Holzelemente hat hier in den drei Punkten $p p p$, wo die Spiralgefässe $z u$ suchen sind, begonnen, ist bis zur Mitte des Cambiumcylinders fortgeschritten und geht bereits wieder nach aussen; die mit $v$ bezeichneten grossen Gefässe sind schon vollständig ausgebildet. Ebenso haben 
auch die Bastzellen, welche die tangential neben den Spiralgefässsträngen liegenden Bündel $l l l$ bilden, ihre vollständige Ausbildung erreicht. Innerhalb dieser Bündel befindet sich noch cambiales Gewebe; $v^{\prime} v^{\prime}$ sind junge Gefässe mit zarten Membranen.

Mit Rücksicht auf die Beschaffenheit des aus dem Cam-530 bium entstehenden Dauergewebes Holz- und Bastkörper, Xylem und Phloem), so kann dasselbe, abgesehen von der Bildung der Holzgefässe und Siebröhren, in drei wesentlich verschiedenen Formen auftreten. Entweder behalten die Zellen den prosenchymatischen Habitus des Cambiums bei (Holz- und Bastzellen); oder es theilen sich die prosenchymatischen Zellen, nachdem die Verdickung ihrer Wandungen bereits begonnen hat, durch Querwände und verwandeln sich in prosenchymatische Zellgruppen Holz- und Bastparenchym); oder es entsteht aus dem Cambium durch frühzeitige Quertheilung ein wirkliches, dem Mark und der primären Rinde ähnliches Parenchym Kartoffel, weisse Rübe etc.).-- Das markähnliche Aussehen des letztern kann leicht zu voreiligen Deutungen Veranlassung geben, die zu einer wesentlich unrichtigen Auffassung der Dinge führen können. Man beobachtet beispielsweise eine Wurzel, welche im Querschnitt einen Kreis von Gefässbündeln und $\mathrm{Hol}_{\mathrm{z}}$ zellen zeigt, und innerhalb dieses Kreises ein markähnliches, dünnwandig-parenchymatisches Gewebe. Man schliesst daraus ohne Weiteres, dass sich das Cambium, ganz wie bei den Stämmen der Dicotyledonen, in Form eines Ringes ausgeschieden habe*), während doch die genauere Untersuchung herausstellt, dass man es wie gewöhnlich mit einen Cambiumcylinder zu thun hat, dessen centrale Zellen sich aber nicht in Holz und Gefässe, sondern in dünnwandiges Parenchym umwandeln.

Ausser diesen Verschiedenheiten, welche sich vorzugsweise auf die Formverhältnisse der Zellen beziehen, hat der Beobachter ferner die ungleichartige Verdickung der Membranen (Poren mit und ohne Höfe, netzartige Verdickung etc.), dann die Natur des Inhalts Stärke, Luft etc.) und bei Gefässen das Verhalten der ursprünglichen Scheidewände zu berücksichtigen. Es gibt Gefässe, bei denen die Scheidewände siebartig durchlöchert erscheinen, andere, wo dieselben vollständig resorbirt sind; ferner Holzzellen init behöften Po- 
ren nebst spiraliger Verdickung, andere mit kleinen Poren und verschiedenem Inhalt u. s. w. $\left.{ }^{*}\right)$

2. Weitere Veränderungen im Gewebe.

Zu den späteren Veränderungen der Gewebe, welche Gegenstand einer besondern Untersuchung sein können, gehören zunächst die Bildung der Thyllen in Gefässen, die Unwandlung von Splint in Kernholz, die Entstehung der luftführenden Kanäle, der Harz- und Gummigänge u. s. w. Es bedarf wohl keiner besondern Erörterung, dass das Studium dieser Veränderungen, wie jeder andern Wachsthumserscheinung, erst dann als abgeschlossen zu betrachten ist, wenn man die verschiedenen Stadien der Ausbildung hinlänglich genau kennt, um sie mit vollkommener Sicherheit als Momente eines bestimmten, allmählich vor sich gehenden Entwicklungsprocesses zu deuten und jede andere Erklärung auszuschliesen.

Wir wollen mit Rücksicht hierauf beispielsweise die Entstehung von Lücken und Gängen im Gewebe etwas ausführlicher erörtern. Dieselbe kann nach den jetzt bekannten Thatsachen in dreifach-rerschiedener Weise gedacht werden : durch Auseinanderweichen der Zellen, durch Desorganisation von Zellen und Zellcomplexen und durch Zerreissen der Gewebe.

Das Auseinanderweichen der Zellen wird durch die Ausscheidung von Flüssigkeit oder Luft zwischen denselben veranlasst. Bei der Desorganisation gehen die Zellmembranen in eine zähflüssige, schleimige Beschaffenheit über und vermischen sich zuletzt vollständig mit dem Inhalte. Das Zerreissen ist Folge eines andauernden Wachsthums rings um eine Stelle, in welcher die Ausdehnung aufgehört hat.

Von diesen drei Entstehungsarten verräth sich die letztere meistens schon bei oberflächlicher Untersuchung durch die abgerissenen Membranen, welche in die Höhlung hineinragen ; das Erkennen derselben unterliegt also keiner Schwierigkeit. Dagegen sind die beiden übrigen in manchen Fällen schwer von einander zu unterscheiden. So leicht es ist nachzuweisen, dass die Zwischenzellräume und die grössern luftführenden Räume in den Blättern, im Gewebe vieler Wasserpflanzen etc. durch Auseinanderweichen der Zellen entstehen, da hier die verschiedensten Entwicklungsstufen oft neben-

*) Vyl. Sanio: Vergleichende Untersuchungen über die Elementarorgane des Holzkorpers. Bot. Ztg. 1563. 
einander vorkommen oder doch auf successiven Schnitten zur Genüge vorhanden sind, so schwierig ist es, in diesem Punkte bei manchen Harz- und Gummigängeu, welche die erforderlichen Entwicklungsstadien nur selten darbieten, vollständige Sicherheit zu erlangen.

Früher nahm man bekanntlich an, dass Gummi und Harz ursprünglich flüssige Secretionsproducte seien, welche in eigenen, durch Auseinanderweichen der Zellen gebildeten Gängen sich anhäufen. Genauere Bcobachtungen stellten jedoch bald heraus, dass diese Annahme in einzelnen Fällen mit den thatsächlichen Verhältnissen im Widerspruch steht. Das Traganthgummi erwies sich sogar im käuflichen Zustande als ein rundzelliges Gewebe mit gallertartigen, deutlich geschichteten Wandungen und Stärke-führenden Lumina, und ein gleiches Verhalten beobachtete W ig a n ${ }^{*}$ ) neuerdings auch beim Bassorin (Gummi Bassora, Gummi Kutera). Eines weitern Beweises, dass diese beiden Gummiarten als umgewandelte Gewebe zu betrachten sind, bedarf es natürlich nicht.

Für das Kirschgummi und einige andere Gummiarten und Gummiharze gelangte Wigand zu demselben Ergebniss durch seine anatomischen und entwicklungsgeschichtlichen Untersuchungen an Gummiführenden Geweben. Bald sind es die in der Gunmimasse vorkommenden Einsclılüsse (z. B. Stärkekörner), welche mit der Annahme einer Secretion im Widerspruch stehen, da nicht einzusehen wäre, wie dieselben in eine ausgeschiedene Substanz hineinkommen; bald deutet die Natur des Gewebes in der Umgebung des Gummiganges, insbesondere der nächstliegenden Membranen, auf eine stattgefundene oder noch stattfindende Desorganisation. Zuweilen geht auch schon aus der Anordnung der Zellen, welche solche Gänge umschliessen, z. B. aus dem geraden Verlaufe der Zellreihen u. dgl. ganz deutlich hervor, dass ein Auseinanderweichen derselben nicht stattgefunden hat, so dass also nur eine Verflüssigung oder Umwandlung von Zellwandungen oder von ganzen Zellcomplexen angenommen werden kann.

$\mathrm{Ob}$ alle Gummigänge, sowie ferner die Harzgänge der Coniferen in der angegebenen Weise entstehen, bleibt dessenungeachtet näher zu untersuchen. Man begegnet namentlich bei den Harzgängen hin und wieder Verhältnissen, welche für sich allein mehr dagegen als dafür sprechen, und es ist nicht unmöglich, dass weitere Beobachtungen über diesen Punkt zu verschiedenen Typen führen.

* Pringsheim's Jahrb. für wiss. Bot. III. 1. 1561. 
Als Veränderungen eigener Art, welchen bestimmte Theilungsvorgänge vorausgehen, können ferner die Entstehung der Spaltöffnungen und die Periderm- und Borkenbildung erwähnt werden.

Die Spaltöffnungen bilden sich bekanntlich zwischen zwei eigenthümlich gestalteten Zellen der oberflächlichen Schicht, den sogenannten Spaltöffnungszellen oder Schliesszellen; es sind Lücken, welche gleich den Zwischenzellräumen im Gewebe durch Auseinanderweichen der Zellen entstehen. Die Schliesszellen sind jedoch nicht gleichwerthig mit den gewöhnlichen Epidermis-

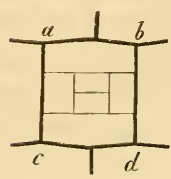

Fig. 256 . zellen, sonderu es sind Zellen einer jüngern Generation, wobei die Bildung der Spaltöffnung zuweilen durch einen regelmässigen Theilungspro. cess eingeleitet wird. Eine jugendliche Epidermiszelle $a b c d$ theilt sich $\mathrm{z}$. B. in der in Fig. 256 dargestellten Weise, und erst die innersten Tochterzellen entwickeln sich in der Folge zu Schliesszellen .

Die Art, wie diese Theilungen erfolgen, dann die Formveränderungen und Verschiebungen, welche später eintreten und wodurch die Spaltöffnungszellen zuweilen über die Epidermis emporgehoben, manchmal auch in das Gewebe vertieft werden, bieten natürlich mancherlei Verschiedenheiten, welche der Beobachter theils auf Flächenansichten, theils auf senkrecht zur Fläche geführten Durchschnitten zu ermitteln hat.

Bei der Peridermbildung, wo die Verschiedenartigkeit der Theilungsvorgänge noch weit grösser ist, sind zunächt die hierauf bezüglichen Fragen zu beantworten. Beginnt die Theilung in der Epidermis, wie bei manchen Cacteen, oder in der äussersten Schicht der primären Rinde, also unmittelbar unter der Epidermis, wie bei der Eiche, Buche, Birke etc., oder in einer tiefer liegenden Rindenschicht und in welcher? Wie schreitet die Theilung in den ursprünglichen Mutterzellen fort - von aussen nach innen, oder von innen nach aussen, oder vielleicht gleichmässig in allen Theilzellen? Wie gross ist die Theilungsfähigkeit der Mutterzelle, d. h. wie viele Theilzellen bilden sich durchschnittlich in jeder derselben? Wiederholt sich die Peridermbildung, nachdem das Theilungsvermögen in der ersten Zellschicht erloschen ist, in der unmittelbar darauf folgenden (ausdauerndes Periderm), oder aber tiefer im Innern der Rinde, so dass im letzteren Falle die aufeinander folgenden Peridermzonen durch mehrere Rindenzellschichten getrennt sind (Borkenbildung)? Stehen diese getrennten Peridermzonen, wenn man sie im ganzen 
Umfang des Organs beobachtet, unter sich durch Anastomosen in Verbindung (Schuppenborke), oder bilden sie vollständig getrennte concentrische Ringe Ringelborke)?

In zweiter Linie ist die Umwandlung der Cellulosemembranen in Korksubstanz und das Verhalten des durch Peridermzonen abgeschnittenen Gewebes (Epidermis, Borke) zu beobachten. Die Verkorkung schreitet, soweit die Beobachtungen reichen, stets von aussen nach innen fort; da indess Abweichungen von dieser Regel nicht unmöglich sind, so verdient die Sache immerhin eine genauere Prüfung. Es kann auch der Fall eintreten, dass die stärker verdickten Stellen der Zellwandung nur unvollständig oder auch gar nicht verkorken. Ebenso können in der absterbenden Borke Veränderungen stattfinden, welche Beachtung verdienen.

\section{IV.}

\section{Bildung seitlicher Organe.}

Die Verzweigung von Zellreihen als Wachsthums- und Thei- $\mathbf{5 3 4}$ lungsvorgang wurde schon in Vorhergehenden mehrfach erwähnt, da es uns zweckmässig erschien, gewisse Zellcomplexe auf Systeme von Zellfäden zurückzuführen, die sich nach bestimmten Gesetzen verästeln. Wir hielten es jedoch nicht für gerathen, auf die verschiedenen Arten der Verästlung schon bei der Gewebebildung genauer einzugehen, da wir damit doch nur einen speciellen Fall aus einer Reihe analoger Erscheinungen heransgegriffen hätten. Als analog müssen nämlich alle Wachsthumsvorgänge betrachtet werden, durch welche an beliebigen Organen seitliche von gleicher oder ungleicher Art erzeugt werden; denn wie die bisher betrachteten Processe die Massenentwicklung der verschiedenen Glieder des Pflanzenstockes bedingen, wie sie jedes Organ, eimmal angelegt, in die Länge und Dicke weiter bauen, so bedingt die Bildung neuer Organe jene mannigfaltigen Combinationen von Haupt- und Nebenbauten, wie sie uns bei den meisten Pflanzen entgegen treten, oder wie man sich gewöhnlich auszudrücken pflegt: sie bedingt die Architectonik des Pflanzenstockes.

Wir stellen daher die Bildung seitlicher Organe bei höheren und niederen Pflanzen zusammen, indem wir die für die Entwicklungsgeschichte wichtigen Fragen, die im Wesentlichen immer dieselben 
sind, den verschiedenen im Vorhergehenden besprochenen Stufen entsprechend formuliren und so Stufe für Stufe fortschreitend die Punkte hervorheben, auf die es gerade ankommt.

1. Morphologischer 0rt der Entstehung.

535 Die erste Frage, welche sich uns aufdrängt, ist die: wo o der woraus entsteht das neue Organ? Bei einzelligen Pflanzen, wo alle Theile nur Ausstülpungen der einen Zelle bilden, ist natürlich eine genauere Bestimmung der Verzweigungsstellen nicht wohl möglich, man müsste denn vergleichbare Anhaltspunkte finden, um die verschiedenen Alterszonen der Zellmembran zu unterscheiden, was bis jetzt nicht gelungen ist. Alles, was hier zu ermitteln übrig bleibt, bezieht sich auf Punkte, die im Bereiche der drei folgenden Fragen liegen. Dagegen bieten die gegliederten Zellfäden, wo die Verzweigung mit Scheidewandbildung verbunden ist, schon eine ziemliche Zahl denkbarer Fälle, die in der Natur auch wirklich vertreten sind.

Zunächst ist hier zu untersuchen, ob die Verzweigung von der Scheitelzelle oder von einer Gliederzelle ausgehe. Hienach ordnen sich.die sämmtlichen Verzweigungen in zwei grosse Kategorien. Die Verzweigung der Scheitelzelle kann selbst wieder in sehr ver-
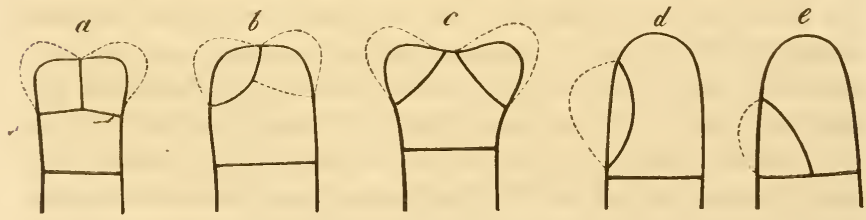

Fig. 257 .

schiedener Weise eingeleitet werden, wie man sogleich ans den in Fig. 257 dargestellten Theilungen ersieht, und es ist nicht immer leicht zu entscheiden, ob ein bestimmter Fall als wahre Dichotomie oder als Astbildung zu deuten sei. Eine vollkommene Gleichwerthigkeit der beiden Tochterscheitelzellen besteht nämlich streng genommen nur in Fig. $257 a$. In Fig. $257 c$ kann die eine Wand vor der andern auftreten; sie kann möglicher Weise auch etwas weiter nach unten rücken, so dass die nachfolgende zweite Wand mit ihrem oberen Rand sich an dieselbe ansetzt. Die Fig. $257 c$ stimmt alsdann im Wesentlichen mit Fig. $257 \zeta$ überein. Ebenso lässt sich denken, dass 
die excentrische und nach innen convexe Wand in Fig. $257 d$ dem Centrum etwas näher rücke und in Folge dessen die Querwand berühre, womit ein Tebergang zu Fig. $257 a$ wenigstens angedeutet wäre. Man sieht, dass sich eine scharfe Grenze zwischen Dichotomie und Terästlung, oder wie man sonst die Unterschiede , bezeichnen könnte, mit Rücksicht auf den Theilungsmodus der Scheitelzelle kaum ein für allemal ziehen lässt. Die Tntersnchung muss daher immer zunächst feststellen, ob die Verzweigung des Scheitels constant in derselben Weise erfolge oder ob am nämlichen Individuum oder an Individuen derselben Species abwechselnd der eine und andere 'Typus zur Geltung komme.

Geht die Zweigbildung von den Gliederzellen aus, so ist oft noch eine nähere Bezeichnung derselben nothwendig. Bei den Charen theilt sich z. B., wie bereits erwähnt, jede von der Scheitelzelle abgeschnittene Gliederzelle in zwei, wovon nur die obere Zweige bildet. Fin ähnliches Verhältniss beobachtet man auch bei Cladostephus. Bei Polysiphonia ist jedes Glied ohne Ansnahme verzweigungsfähig, bei den Callithamnieen oft nur je das 2te, 4te u. s. f. Dieselbe Gesetzmässigkeit herrscht auch bei der Blattbildung der Moose, indem jede von der Scheitelzelle abgeschnittene Segmentzelle ein Blatt anlegt. - In der Regel wird man auch die Wahrnehmung machen, dass Abzweigungen, welche die Function von Wurzeln verrichten, desgleichen die Berindungsfasern (bei Florideen etc.) vorzugsweise vom unteren Theil der Mutterzelle abgehen, während die gewöhnlichen Zweige fast immer am oberen Ende derselben ihren Ursprung nehmen. Jedenfalls ist zu untersuchen, ob solche Verschiedenheiten, wenn sie überhaupt vorkommen, einem bestimmten Gesetze unterliegen oder nicht.

Bei einfacher gebauten Zellflächen und Zellkörpern sind es über- \$:36 haupt nicht seltẹn morphologisch genau zu bestimunende Zellen, aus denen die neuen Organe hervorgehen, - bei den erstern gewisse Rand- oder Flächenzellen, bei den letztern gewisse Aussen- oder Innenzellen. Zuweilen geht in der betreffenden Zelle ein bestimmter Theilungsprocess voraus, welcher erst die Zelle liefert, die als die Anlage der seitlichen Organe zu betrachten ist.

Eine ähnliche Gesetzmässigkeit herrscht auch bei den complicirter gebauten Pflanzen; allein da der Aufbau sich hier nicht mehr Zelle für Zelle ermitteln lässt, so kann es sich folgerichtig nur noch un die Frage handelı, welchen Zellcomplexen, Zellschichten oder 
Partieen dcs Gewebes die neuen Organe ihre Entstehung rerdanken, wobei natürlich vorausgesetzt ist, dass die Anatomie und die Wachsthumsweise des Mutterorgans bereits bekannt sei. Vor Allem wichtig ist die Unterscheidung zwischen oberflächlichen und bedeckten Geweben oder, was auf dasselbe herauskommt, die Unterscheidung zwischen Organen, die an der Oberfläche entstehen und solchen, die aus dem Innern hervorbrechen. Die genauere Bezeichnung der Bildungsstätte kommt erst in zweiter Linie in Betracht.

Für die Phanerogamen und Gefässkryptogamen, die wir hier als die bekanntesten Beispiele vorausschicken, darf man vor der Hand als festgestellt betrachten, dass nur folgende verschiedene Gewebe seitliche Organe bilden können: 1/ die Epidernis, 2) das oberflächliche Bildungsgewebè der Stammspitze, des jungen Blattes "etc.), 3) das bedeckte Bildungsgewebe der Wurzelspitze, 4) das Cambium und die das Cambium umschliessende Parenchymschicht. Es bleibt also nur noch zu untersuchen, welches von diesen Geweben in einem gegebenen Falle den Ausgangspunkt bilde.

Als Organe, welche von der Epidermis ausgehen, sind die Trichomgebilde Haare, Stacheln, Schuppen etc.; ; als solche, welche im Bildungsgewebe der Stammspitze vor dem Auftreten der Epidermis) ihren Ursprung haben, die Blätter mit ihrem Axillargebilden und die Gabelzweige; als Producte des bedeckten W urzelscheitels die durch Gabelung entstehenden Wurzeläste, endlich als Producte des Cambiums und der angrenzenden Parenchymzellen die Wurzeln und Adventiväste zu erwähnen. *

Was die Verzweigung und Lappenbildung der Blätter betrifft, so wäre zu untersuchen, ob die Anlage seitlicher Theile constant nur an solchen Stellen stattfinde, resp. dentlich werde, wo eine Epidermis noch nicht vorhanden ist. Wie die Epidermisbildung selbst und mit ihr die Differenzirung der Gewebe am primären Blattstrahl fortschreitet, ist eine Frage, welche nicht hieher gehört, sondern mit der Wachsthumsgeschichte dieses Strahls zusammenhängt. Es ist bekannt, dass die Blattbasis in vielen Fällen noch aus einem durch und durch gleichförmigen Bildungsgewebe besteht, wenn die Blattspitzc die ersten Stadien der Differenzirung schon zurückgelegt hat. Daher

*) Ob die Pfahlwurzel der Dikotyledonen durch unmittelbare Verlängerung der Keimachse des Embryo entstehe, wie gewöhnlich angegeben wird, und also im Gegensatz zu den ïbrigen Wurzeln an der Oberfläche eines Bildungsgewebes angelegt werle, ist zum Vindesten zweifelhaft und für einzelne Fälle sicher unrichtig. 
lässt sich denn auch von vorne herein erwarten, dass auch am unteren Theil des Blattes, ähnlich wie in der Stammspitze, neue seitliche Organe zum Vorschein kommen.

Die Anwendung der im Vorhergehenden entwickelten Principien auf Moose, Lebermoose und die niedern Kryptogamen bietet keinerlei Schwierigkeiten. Es handelt sich immer um die Frage: Wird das neue Organ vor oder nach der Differenzirung des Gewebes angelegt und wenn nachher, in welchem Theile entsteht die neue Anlage! So findet man z. B., dass die Apothecienanlage im Flechtenthallus unterhalb der Rinde in der Gonidienzone entsteht und später die Rinde durchbricht, während die Adventivzweige der strauchartigen Flechten von der Rinde abgehen.

Dit es a priori unwahrscheinlich ist, dass morphologisch gleichwerthige Organc in ungleichartigen Geweben gebildet werden, so ist in Fällen, wo man diess zu sehen glaubt, immer die grösste Vorsicht zu empfehlen.

2. Horphologische Unterscheidung der 0rgane.

Die seitlichen Organe, welche an ihren respectiven Mutterorga- 5.37 nen auftreten, zeigen in morphologischer Hinsicht, wenn man das ganze Gewächsreich vergleichend überblickt, mancherlei Unterschiede. Je höher eine Pflanzc steht, d. h je complicirter der Bau ihrer Organe, um so reicher ist gewöhnlich auch die architectonische Gliederung, um so grösser die Zahl der Abstufungen, welche in den seitlichen Organen sich kundgeben

Bei den einfachsten Pflanzen, welche seitliche Organe erzeugen, sind diese letztern blosse Wiederholungen des Mutterorgans und mit demselben morphologisch gleichwerthig, so z. B. bei den Rivularieen, Scytonemeen etc. Solche Pflanzen gehören mit den unverzweigten Diatomeen, Palmellaceen etc., ferner mit den Nostocheen in dieselbe grosse Kategorie: es sind Phy tome.

Dagegen begegnen wir schon bei manchen einzelligen Algen (Botrydium, Caulerpa u. a.), daun bei den meisten Fadenalgen Conferven u. a., einem deutlichen morphologischen Gegensatz zwischen dem verzweigten oder unverzweigten Hauptkörper der Pflanzen und jenen haarähnlichen seitlichen Gebilden, welche bei Botrydium und Rhizoclonium die Wurzelhaare, bei andern die Berindungsfasern etc. darstellen; wir haben also hier eine zweite Kategorie von Gewächsen : Thallome mit Trichomen.

Auf der nämlichen Stufe steht die Giliederung des Pflanzen- 
stockes auch bei den höhern Algen, den sämmtlichen Fucoideen und Florideen, sowie ferner bei Flechten und Pilzen. Nur begegnen wir hier einer grössern Mannigfaltigkeit der Formen. Das Thallom ist bekanntlich bald krustenartig oder blattartig und dann einblätterig oder zierlich gelappt, bald strauchartig und dann mehr oder weniger verzweigt; die Trichome stehen bald einzeln bald $\mathrm{zu}$ besondern Bïscheln rereinigt; bald sind sie ferner frei, bald auch zu einem förmlichen Gewebe oder zu grössern Haftorganen verflochten oder verwachsen.

Erst bei den Lebermoosen und Laubmoosen differenzirt sich das Thallom in Stam und Blatt, welche beide wieder Trichome bilden können, und von den Gefässkryptogamen an aufwärts erzengt der Stamm noch ein weiteres Organ, die Wurzel. - Die am höchsten organisirten Pflanzen besitzen also vier wesentlich verschiedene Organe: Stamm, Blatt, Wurzel und Trichom, von denen natürlich jedes wieder mancherlei Abstufungen der Entwicklungsfähigkeit und überdiess zahllose Formverschiedenheiten darbietet.

535 Die richtige Unterscheidung dieser Organe, so leicht sie bei viclen Pflanzen erscheinen mag, ist in andern Fällen eine sehr schwierige Aufgabe und erfordert alsdann die Berücksichtigung aller Verhältnisse. Wir beschränken uns hierüber auf folgende Andeutungen.

Bei den Thall omp flanzen sind zunächst die Trichome, welche als Wurzelhaare auftreten, jedenfalls immer als solche zu erkennen; bei denjenigen, deren Thallome Zellkörper sind, ist ferner ganz allgemein eine Verwechslung mit andern Gebilden nicht möglich, weil die Trichome hier durch die Entstehung aus den Epidermiszellen scharf charakterisirt sind. An diesem Merkmal erkennt man z. B. die Faserbüschel von Fucus und vieler andern Algen, desgleichen die Paraphysen und die Fäden, an denen die Sporen und Antheridien entstehen, als Trichome; auch die Berindungsfäden der Florideen und Fucoideen, dann von Batrachospermum u. a. gehören meistens hieher. Dagegen lässt sich die Frage, ob manche Verzweigungen von einzelligen oder gegliederten Fadenpflanzen (Siphoneen, Confervaceen, Callithamnieen, Schimmelpilzen etc.) als begrenzte Thallomzweige oder als Trichome aufzufassen seien, bloss durch Analogie mit einiger Wahrscheinlichkeit entscheiden.

Auch bei den beblätterten Pflanzen Mooscn und Gefässpflanzen) sind die Trichome Haare, Borsten, Stacheln, Warzen, Schülfern' ohne Ausuahme Bildungen der Epidermiszellen. Sie ent- 
stehen zwar schon an den jüngsten Partieen der Stengel, Blätter und Wurzeln, aber doch erst in derjenigen Entfernung vom Scheitel, wo die Epidermis bereits angelegt, das peripherische Dickenwachsthum also vollendet ist. In dieser Entstehungsweise liegt, da keines der drei andern Organe auf die nämliche Art angelegt wird, das wesentlichste Merkmal. Damit stehen denn auch die Stellungsverhältnisse der Trichome in einem gewissen Zusammenhang, indem denselben eine regelmässige Stellung in der Art, dass sie sich in eine oder in mehrere gerade oder schraubenförmige Reihen anordnen liessen, wobei je das oberste das jüngste wäre, nicht zukommt.

Die praktische Erkennung der Organe hängt also von der Entscheidung $\mathrm{ab}$, ob an der Bildungsstätte derselben die Epidermis bereits vorhanden sei. Diess ist dann der Fall, wenn in den Aussenzellen keine Theilungen durch tangentiale (mit der Oberfläche parallele) Wände mehr stattfinden, ein Stadium, welches bei manchen Organen schon sehr früh eintritt. Demgemäss sind die Spreuschuppen der Filices und andere haar - und schuppenförmige Bildungen mit übereinstimmender Entwicklungsweise unzweifelhafte Trichome.

Die Blätter werden im Gegensatze zu den Trichomen an der Stengelspitze angelegt, ehe das peripherische Dicken wachsthum vollendet, somit ehe die Epidermis vorhanden ist. Bei den einfachern der hieher gehörigen Pflanzen namentlich bei den Moosen), wo man das Blatt bis auf die erste Zelle zurückverfolgen kann, lässt sich sogar der Ursprung aus den Segmentzellen, d. h. aus den durch die Theilungen der Scheitelzelle abgeschnittenen Zellen nachweisen. Damit hängt denn auch die regelmässige Anordnung der Blätter in Spiralen oder Quirle **) zusammen, womit ein weiterer Unterschied gegenüber den 'Trichomen gegeben ist.

*) Hofmeister (Beiträge zur Kenntniss der Gefässcryptogamen Il p. 6 t6 sagt zwar das Gegentheil: „Der Nägeli'schen Difinition von Blattorganen und Haargebilden nach würden sie (die Spreublättchen) unzweifelhaft zu den ers tern in Folge eines Druckfehlers steht letztern) gehören, wie ich früher auch angenommen." Es ist allerdings richtig, dass das Dickenwachsthum noch lange nicht vollendet ist, wenn die fraglichen Gebilde angelegt werden, denn die intercalaren Theilungen dauern noch einige Zeit fort. Allein das peripherische Dickenwachsthum, worauf es ankommt, und damit auch die Anlegung der Epidermis ist schon früher beendigt.

**) Nach so eben gemachten, noch nicht veröffentlichten Untersuchungen des Herrn Stud. Re es entstehen bei Equisetum aus jedem Segment mehrere Blätter, und die Quirlstellung der Blätter wird dadurch erzeugt, dass je drei Segmente d. h. je ein Cyclus derselben) durch ungleiches Wachsthum sich soweit verschieben, dass sie in gleiche Höhe zu liegren kommen und einen Quirl bilden. 
Schwieriger ist der Unterschied zwischen Stamm und Blatt festzustellen. Auf mikroskopischem Wege gelingt es wohl gar nicht. Denn sowohl Bau als Wachsthum bieten keinerlei durchgreifende Merkmale, und die Entstehungsweise der Axillarknospen und der Verzweigungen bei den Gefässkryptogamen ist noch zu wenig bekannt, als dass sie mit der Blattbildung verglichen werden könnte. Man ist daher auf morphologische Methoden angewiesen, deren Auseinandersetzung jedoch nicht hieher gehört.

Die anatomische Structur der Organe kann ganz allgemein nicht zur Unterscheidung von Stamm-, Blatt- und 'Trichomgebilden benutzt werden. Denn wie es einerseits Blätter giebt, die in der Beschaffenheit der Gewebe und namentlich auch in der Gruppirung der Gefässbündel kreisförmig, die Spiralgefässe nach innen gekehrt mit den Stammorganen übereinstimmen, so findet man andererseits auch verkümmerte Blattgebilde, die genau so gebaut sind, wie Stacheln, Warzen, Schülfern, selbst wie Haare. Nur in einer Bezichung verdient der innere Bau Berücksichtigung, insofern nämlich die Trichome nie Gefässbündel besitzen. Es ist diess eine nothwenaige Folge ihrer Entstehung aus der Epidermis.

Die Wurzeln unterscheiden sich von allen andern Organen dadurch, dass der zellenbildende Scheitel von einem Dauergewebe, der Wurzelhaube, bedeckt und umhüllt ist. Dieses Merkmal zeigt uns z. B., dass Psilotum keine Wurzeln besitzt und dass seine sogenannten Wurzeln unterirdische Stengel sind, was auch dadurch bewiesen wird, dass sie verkümmerte, nicht über die Oberfläche hervortretende Blattanlagen besitzen, die unter dem Mikroskop an der Anordnung der Zellen erkannt werden.

Die Wurzeln entstehen im Innern des Gewebes und durchbrechen daher dessen oberflächliche Schichten; dadurch unterscheiden sie sich genetisch von den Blättern und von den Trichomen. Ferner geht die Gefässbildung bei allen Wurzeln anfänglich von aussen nach innen, so dass die später gebildeten porösen und Treppengefässe innerhalb der Ring- und Spiralgefässe zu liegen kommen; dadurch unterscheiden sie sich anatomisch von allen Stengeltheilen der Phanerogamen. Wo der Stengel nach unten in eine Pfahlwurzel übergeht, lässt sich sogar die Grenze zwischen beiden mit der grössten Genauigkeit bestimmen. Endlich bilden die Wurzeln keine Blätter, die dem Stengel wohl immer, wenigstens der Anlage nach, zukommen. 
3. Entwicklungsfolge nud stellungsverhältnisse.

Eine dritte Frage, welche bei der Bildung seitlicher Organe in 540 Betracht kommt, betrifft die Entwicklungsfolge und die damit zusammenhängenden Stellungsverhältnisse. Sie ist jedoch selbstverständlich nur auf Organe von gleicher Natur, z. B. auf die successiven Blätter oder auf die Wurzeln zu beziehen. Es kommt hier namentliclı darauf an, zu untersuchen, ob die neuen Organe in ganz beliebiger Folge und Stellung zwischen bereits vorhandenen auftreten, oder ob mit kücksicht hierauf ein gewisser, in jedem gegebenen Falle näher zu bestimmender Grad von Regelmässigkeit obwalte. Die Abstufungen, welche hiebei unterschieden werden können, sind etwa folgende.

a) Die Organe entstehen regellos über, unter und neben den schon vorhandenen in ganz beliebiger Stellung, wie man es beispielsweise an Haaren, an manchen Wurzeln und an Adventivknospen beobachtet.

b) Die Organe entstehen in Längsreihen. Für die neu hinzukommenden Glieder einer Reihe bestehen alsdann noch zwei Möglichkeiten : sie werden entweder regellos über und zwischen den schon vorhandenen angelegt, oder sie setzen dic Reihe derselben nach einer Seite (oder auch nach beiden Seiten hin fort. - Hieher gehörige Fälle beobachtet man namentlich da, wo die Organ-bildenden Gewebe selbst eine bestimmte Anordnung zeigen. So stehen ๘. B. die Wurzeln nicht selten in deutlichen Reihen, weil sie sich nach gewissen Gefässgruppen, Cambiumbündeln oder Parenchymzellenreihen richten, welche im Mutterorgane der Länge nach verlaufen. Auch begegnet man in vielen Fällen, insbesondere bei Gefässkryptogamen und Monokotyledonen, einer regelmässigen Entwicklung in der Art, dass die jüngsten Wurzelanlagen in jeder Reihe immer zunächst der Scheitelregion gefunden werden. Mit der Reihenbildung selbst steht jedoch selbstverständlich diese Gesetzmässigkeit in keinem Zusammenhang.

c) Die Organe entstehen in Quirlend. h. sie bilden Querreihen auf der eben gelegten Oberfläche des Mutterorgans. In diesem Falle ist darauf zu achten, ob die einzelnen Glieder eines Quirls gleichzeitig hervortreten oder ob sie nach einander in einer gewissen Reihenfolge zum Vorschein kommen. Ueberdiess ist die Beziehung der successiven Quirle zu einander ins Auge zu fassen.

Als Beispiel sei hier die Verzweigung der Charen erwähnt. Die zweigbildende Zelle ist sowohl bei den Stämmchen als bei den Quirl- 
zweigen die obere 'I'heilzelle einer ursprünglichen Gliederzelle. Bei den Stämmchen theilt sich dieselbe zunächst durch eine mediane Längswand in zwei gleichwerthige Tochterzellen, von denen in der Folge jede in eine Innenzelle und mehrere Aussenzellen zerfällt Fig. 255 A); die letztern sind die Anlagen der seitlichen Organe. Die
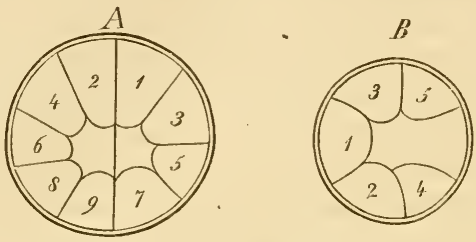

Fig. 25y (250).

Quirlzweige verhalten sich ähnlich, nur fehlt hier den Knotenzellen die mediane Längswand. Die erste Theilung geschieht lier durch eine excentrische Wand, an welche sich die folgenden nach beiden Seiten hin anschliessen (Fig. $258 \mathrm{~B}$ ). Die Reihenfolge der Scheidewände ist in den Figuren durch die den Zellen beigesetzten Ziffern bezeichnet; die Anlage beginnt hienach mit der Zelle 1 und schreitet nach rechts und links bis zur gegenüberliegenden Seite fort. In derselben Reihenfolge treten auch die von diesen Zellen gebildeten Zweige auf. Zwischen den successiven Quirlen besteht das Verhältniss, dass der erste Zweig eines folgenden Knotens um einen bestimmten Theil des Kreisunfanges vom ersten des vorhergehenden absteht, so dass alle ersten $\mathrm{Zweige}$ zusammengenommen meistens eine fortlaufende Spirale bilden.

d Die Organe entstehen in einer fortlaufenden spirale oder in einer Zickzacklinie, jedes neu hinzukommende über dem vorhergehenden und in horizontaler Richtung um eine beśtimmte, meist immer gleiche Grösse von diesem wie voun nächstfolgenden entfernt. - Dieser Fall ist von den vorhergehenden dadurẹ ausgezeichnet, dass hier sämmtliche Organe nur ein System bilden, in welchem die Stellungsverhältnisse nach allen Richtungen gesetzmässig sind. Zwischen Spirale und Zickzacklinie bildet die alternirend zweizeilige Stellung den Uebergang. - Beispiele für diese Entwicklungsfolgen liefert die Blattbildung bei den Moosen und vielen Gefässpflanzen. 
Die Stellungsverhältnisse der a usgebildeten Or- 541 gane sind natürlich von den eben besprochenen der Anlagen mehr oder weniger abhängig, jedoch selten in dem Grade, dass zwischen dem jugendlichen und dem ausgebildeten Stadiun eine vollständige Uebereinstimmung bestände. Es kommen im Gegentheil sehr häufig Verschiebungen vor, wodurch die ursprüngliche Stellung wesentliche Veränderungen erfährt, indem z. B. Blattdivergenzen vergrössert oder verkleinert, Spiralen in scheinbare Quirle übergeführt werden u. dgl.

Mit Rücksicht auf diese Veränderungen während der Ausbildung der Organe müssen bei allen Gefässpflanzen drei Zustände unterschieden werden, von denen meist nur zwci der Beobachtung zugänglich sind, nämlich a) die ursprüngliche Anlage, d. h. die Bildung der ersten Zellen, aus welchen ein seitliches Organ entsteht, b) das erste Sichtbarwerden des seitlichen Organs als Zellgewebshöcker, c) die Stellung im entwickelten Zustande.

Von diesen drei Zuständen ist der erste bis jetzt bloss in einigen wenigen Fällen thatsächlich beobachtet, so z. B. bei einigen Gefässkryptogamen die Anlegung der Seiten wurzeln in den Mutterw urzeln und die Entstehung der Blätter aus den 'von der Scheitelzelle abgeschnittenen Segmentzellen des Stengels. Gewöhnlich erkennt man die seitlichen Organe erst, wenn sie als vielzellige Complexe (Höcker, Wülste etc. an der Oberfläche hervortreten oder im Innern des Gewebes sich abgrenzen, und da möglicherweise bis zur Erreichung dieses zweites Zustandes bereits Verschiebungen stattgefunden haben, so ist es nicht erlaubt, die Stellung der Höcker mit derjenigen der ursprünglichen Anlagen zu identificiren. Dass solche Verschiebungen in der That vorkommen, beweist das Beispiel von Equisetum, wo die ursprünglichen Zellen in einer Schraubenlinie stehen, die Höcker aber als Quirle sichtbar werden. Das Nämliche ist wahrscheinlich bei sehr vielen Quirlbildungen der Fall. Dass dieselben ursprünglich ebenfalls als Spiralen angelegt werden, dafür spricht ausser andern morphologischen Gründen namentlich auch der Umstand, dass sie, wie bei Equisetum, sich ausnahmsweise in Sipiralen auflösen, d. h. dass die ursprüngliche Schraubenstellung nicht in die quirlförmige Anordnung übergeht.

Von dem Zustande des ersten Sichtbarwerdens bis zur vollständigen Ausbildung der seitlichen Organe können ebenfalls noch Stellungsveränderungen vor sich gehen und zwar

a) durch ungleiches Auseinanderweichen in der Längsrich. 
tung, sei es, dass die einen Internodien sich stärker entwickeln als die andern, was ungleiche verticale $A$ bstände der Blätter und $Z$ weige zur Folge hat, oder dass die scitlichen Organe theilweise mit dem Mutterorgan verwachsen und dadurch höher zu stehen kommen als andere, die neben oder über ihnen angelegt werden, wodurch eine unregelmässige Aufcinanderfolge der Blätter und Zweige zu Stande kommt.

b Durch ungleiches Auseinanderweichen in der Querricht ung, indem entweder die eine Seite des Mutterorgans sich stärkur entwickelt, so dass die seitlichen Organe auf der gegenüber licgenden Seite zusammengedrängt erscheinen, oder indem das Mutterorgan sich dreht und dadurch Veränderungen in den Divergenzen hervorruft, wobei die letztern balk grösser und bald kleiner werden.

512 Noch ist bezüglich der Stellungsverhältnisse seitlicher Organe ein wichtiger Punkt ins Auge zu fassen, der nämlich, dass sehr häufig ein grösserer oder kleinerer Basaltheil eines seitlichen Organs mit dem Mutterorgan verwachsen bleibt und eine sehr wesentliche Partic desselben constituirt. So besteht z. B. in Stamme von Equisetum. struthiopteris und vieler anderer Pflanzen der grösste Theil des Gewebes aus verwachsenen Blattbas n.

Verzweigt sich num ein solches Organ schon am Grunde, so gewährt diess den Anschein, als ob das Mutterorgan eben sovielc selbständige seitliche trage, als Verzweigungen vorhanden sind Auf diese Weise erklär't sich z. B., dass viele Stipulae scheinbar nicht am Grunde des Blattes, sondern am Stengel befestigt sind. Dieser Umstand kann indess nur dann möglicherweise irre führen, wenn die seitlichen Verzweigungen des Tochterorgans sich ganz so ausbilden, wie der mittlere Theil desselben, was bei den Nebenblättern in cler Regel nicht der Fall ist. Eine Ausnahme macht Galium und die verwanclten Gattungen.

Von besonderer Wichtigkeit sind die hier angeregten Punkte bei Untersuchungen über den Bau der Blüthen, wo nicht selten dnurch Verzweigung oder Spaltung eine Verdoppelung oder Vervielfachung gcwisser Blätter einzutreten scheint, welche bald einer Stipularbildung wie bei Galium, bald auch der wirklichen Bildung von Foliolis ihr Dasein verdanken mag.*;

Vyl. A. W. Eichler, Ueber den Bhüthenbau der Fumariaceen etc, in Flora 1565. 
Die wahren Verhältnisse sind zuweilen in den frühesten sichtbaren Zuständen, wo die seitlichen Organe eben als kleine Höcker zum Vorschein kommen, noch deutlich erkennbar; zuweilen erheben sich aber schon diese Höcker, obschon sie zum Theil als seitliche Bildungen anderer zu betrachten sind, scheinbar sclbständig über die Stengeloberfläche. Der Beobachter ist in solchen Fällen, sofern es ihm nicht gelingt, die Anlegung der Organe weiter zurück zu verfolgen, auf morphologische Erwägungen angewiesen, deren Erörterung jedoch nicht in unserer Aufgabe liegt.

\section{Systeme gleichwerthiger 0rgane.}

Der vierte Punkt endlich, der bei der Bildung seitlicher Organe $\mathbf{5} 13$ von Bedeutung ist, betrifft die Ausbildung gleichwerthiger Organe zu verschiedenen architectonischen Systemen, d. h. das Zustandekommen jener vielgestaltigen, aus Strahlen verschiedener Ordnungen bestehenden Gerüste, wie wir sie beispielsweise in den Blüthenständen der höheren Pflanzen und in den zierlich verzweigten 'Thallomen der Florideen vor uns sehen. Es handelt sich hier, nachdem das Verhältniss der Tochterorgane zu einander und zum Mutterorgan im Vorhergehenden besprochen worden, einzig und allein um das Entwicklungsvermögen der verschiedenen Organe und um die vorkommenden Verzweigungsgrade. Diese beiden Factoren in einem gegebenen Falle festzustellen, ist die Aufgabe der Untersuchung.

Ehe wir auf die thatsächlichen Verhältnisse, wie sie der Pflanzenstock darbietet, näher eingehen, mögen ein paar schematische Darstellungen die Verschiedenheiten andeuten, welche der Beobachter vorzugsweise ins Auge zu fassen hat. Es sei Fig. 259 ein System gleichwerthiger Organe, wie sie im rollkommen ausgebildeten Zustande sich darstellen. Ein solches System lässt sich nun in sehr verschiedener Weise aufgebaut denken, wie man aus folgenden drei Fällen, welche noch keineswegs alle Möglichkeiten erschöpfen, entnehmen wird.

a) Die Mittellinie entspricht dem Mutterorgane Fig. $259 \mathrm{~A}$, die rechts und links davon abgehenden (2) sind gleichwerthige seitliche Organe, ähnlich wie die Blätter am Stamme. Das Mutterorgan besitzt hier das grösste Entwicklungsvermögen; dic seitlichen Organe hören dagegen früh auf zu wachsen und verzweigen sich nicht.

b Die Mittellinie wird von Strahlen verschiedener Ordnungen 1, 2-- 14 Fig. 259 $B$ /gebildet, indem der obere Theil eines jeden Strahls von dem zugehörigen 'Tochterstrahl auf die Seite geschoben 
wird Sympodium). Der eine verzweigt sich, der andere nicht, und so geht es fort, so lange das Organ wächst Fig. $259 \mathrm{~B}$.
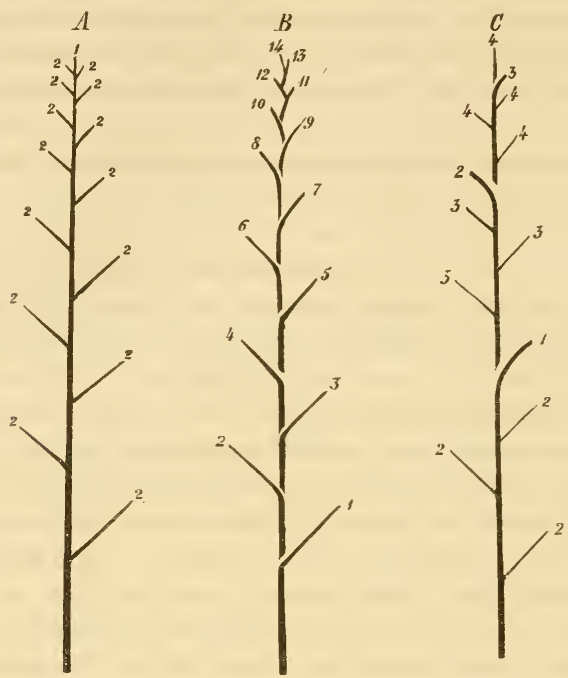

Fig. 259 .

c) Die Mittellinie besteht ebenfalls aus Strahlen verschiedener Ordnungen; aber jeder dieser Strahlen erzeugt 4 seitliche, von denen je der oberste den Aufbau weiter führt (Fig. $259 \mathrm{C}$ ).

Ein zweiter Fall ist in Fig. 260 dargestellt: ein einfaches Organ geht nach oben in zwei oder in mehrcre über, welche doldenförmig
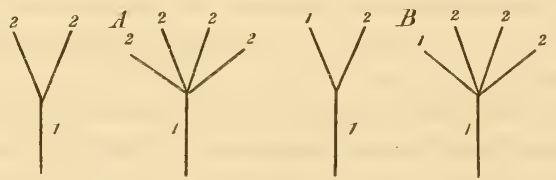

Fig. 260.

gestellt sind. Hier müssen zwei verschiedene Arten des Aufbaues unterschieden werden, deren Charakteristik in den Figuren $A$ und $B$ durch die den Doldenzweigen beigesetzten Ordnungszahlen gegeben ist. In $\boldsymbol{A}$ geht das Mutterorgan nur bis zur Verzweigungsstelle; die 
Aeste sind sämmtlich Strahlen zweiter Ordnung. In $B$ dagegen setzt sich das Mutterorgan über die Verzweigungsstelle hinaus fort und bildet einen Doldenstrahl.

Je complicirter das fertige System, um so grösser ist natürlich auch die Zahl der denkbaren Combinationen successiver Strahlen. Man begreift, dass nur ein Zurückgehen auf die ersten Anlagen neuer Organe es möglich macht, die Entstehungsfolge der verschicdenen Elemente des Systems mit Sicherheit festzustellen. Es ist nöthig, dic Verzweigungsstellen in dem Stadium zu beobachten, wo man noch deutlich sieht, welches der beiden Organe das Mutterorgan ist. Nur ansnahmsweise lässt sich die Frage auch nach anderen Anhaltspunkten, bei höheren Pflanzen z. B. nach der Stellung der Blätter und Knospen unterscheiden.

Ein weiteres Beispiel mag veranschaulichen, wie umgekehrt zwei $5 \mathbf{4 t}$ Systeme, die in der Anlage vollständig übereinstimmen, durch die spätere Entwicklung einen durchaus verschiedenen Habitus erhalten. Die beiden Systeme bestehen aus einem primären Strahl mit quirlständigen oder spiraligen secundären Strahlen Fig. 261). Diese letzteren besitzen bei dem einen ein sehr begrenztes Entwicklungsvermögen; sie bleiben kurz und unverzweigt, während der Hauptstrahl sich beträchtlich verlängert. Bei dem andern ist das Verhältniss umgekehrt; der Hauptstrahl hört auf zu wachsen, sobald die seitlichen Organe angelegt sind, während die letzteren sich in die Länge strecken und möglicherweise selbst wieder Verästelungen bilden.

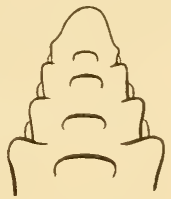

Fig. 261. Auf diese Weise erhält das erste System das Aussehen ciner Aehre, das zweite dasjenige einer Dolde.

Diese Betrachtungen zeigen deutlich genug, dass Anlage und spätere Ausbildung eines Organcomplexes für die Entwicklungsgeschichte zwei Momente sind, die man nicht mit einander verwechseln darf. Verschiedenheiten, die sich mit Rücksicht auf das eine ergeben, dürfen demnach bei der Combination mit den Kategorien, welche das andere liefert, diesen letzteren nicht coordinirt, sie müssen vielmehr übergeordnet oder untergeordnet werden.

Beschäftigen wir uns jetzt nach dieser vorlänfigen Orientirung 545 etwas genauer mit der Frage, wie die Art der Anlegung seitlicher Organe, d. l. deren Entwicklungsfolge, sich durch Beobachtung jugend- 
licher Stadien ermitteln lasse. Diese Aufgabe ist keineswegs immer so leicht, wie sie vielleicht Manchem auf den ersten Blick erscheinen mag. Es gelingt in Gegentheil oft nur nach langem, mülssamem Suchen zu entscheiden, ob der primäre Strahl nach stattgefundener Verzweigung sich unbegrenzt weiter entwickle und immer neue seitliche $\mathrm{Or}$ gane erzenge, oder ob umgekehrt diese vorwiegende Entwicklungsfähigkeit dem secundären Strahl oder doch bestimmten secundüren Strahlen zukomme, das Mutterorgan also in Wachsthum zurückbleibe.

Diese Schwierigkeit tritt uns z. B. bei dem in Fig. $262 \mathrm{~A}$ dargestellten Thallusende von Cullith amuion entgegen. Der Aufbau
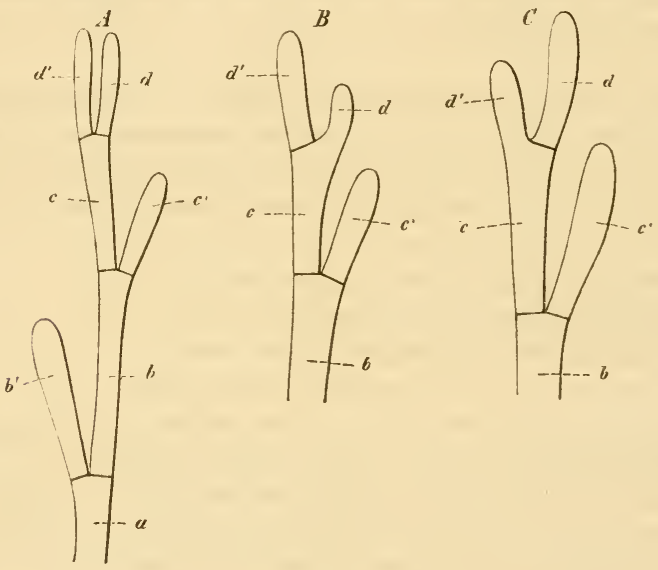

Fig. 262 .

kam hier so stattgefunden haben, dass "lord die successiven Gliederzellen des primären Strahls bilden, an welchen nach einander die alternirenden Zweige $l^{\prime}$, $r^{\prime}$ und $d^{\prime}$ aufgetreten sind. Er lässt sich aber ebenso gut auch so denken, dass $a b^{\prime}$ als primärer Strahl, $b r^{\prime}$ als secundärer, $c d^{\prime}$ als tertiärer, endlich $d$ als quartärer Strahl aufzufassen, das Ganze also als Sympodium zu deuten wärc. Findet man dagegen Thallusenden, in welchen das genetische Verhältniss der Endzellen $d d^{\prime} \mathrm{klar}$ ausgesprochen ist, etwa so wie in Fig. $262 B$, so ist die eine der beiden Möglichkeiten abgeschnitten; denn da die knrzen strahlen $l l^{\prime} r^{\prime}$ ' und die vorhergehenden regelmässig alterniren, so muss $d$ ' ebenfalls kurz bleiben, 1 . h. das Mutterorgan bleibt in 
der Entwicklung stehen, während das Tochterorgan $d$ den Aufbau weiter führt. Mit derselben Sicherheit lässt sich aus dem umgekehrten Verhältniss Fig. $262 C$ ) - ceteris paribus - der Schluss ziehen, dass die Glieder $a b c d$ dem nämlichen Strahl angehören, der Auf ban also ein monopodialer sei.

Dass die nämlichen Anhaltspunkte auch dann noch genügen, 5\%; wenn die Stellung der kurzen Strahlen eine spiralige oder quirlige ist, leuchtet olne Weiteres ein. Man begreift auch, dass es keineswegs nöthig ist, das Scheitelwachsthum der Organe Zelle für Zelle zu kennen, wie in dem angeführten Beispiel, das es ja nur darauf ankommt, nach der letzten Verzweigung in der Scheitelregion das Mutterorgan von dem neu gebildeten seitlichen zu unterscheiden. Alle im Vorhergehenden gezogenen Schlüsse gelten daher auch für die höheren Pflanzen; ja die Phanerogamen bieten sogar in mancher Beziehung geringere Schwierigkeiten als die Zellenpflanzen, da die Blattstellungsverhältnisse hier neue und wichtige Anhaltspunkte liefern. Wir wollen an einigen Beispielen zeigen, wie sich diese Verhältnisse verwerthen lassen, zugleich aber auch darthun, wie sic, für sich allein betrachtet, unter Umständen auch irre leiten können.

Eine Pflanze mit regelmässig alternirenden Blättern (Fig. 2633 zeigt an den Knoten Axenorgane, z. B. Blüthenstiele oder Ranken, welche den Blättern opponirt stehen. Eine solche Pflanze kann, wenn das Wachsthum normal stattfindet, nur ein Sympodium seín; denn da regelıässig gestellte Axenorgane stets blattwinkelständig sind, so müssen die successiven Internodien $a, b, c, d$ als Basilarstücke von Axillarzweigen gedeutet werden, welche je vom nächst unteren Knoten ausgehen. Der primäre Spross schliesst also mit $b^{\prime}$, der secundäre mit $c^{\prime}$ ab u. s. f. Allein es sind anormale Verhältnisse denkbar, welche die Sache verwickeln. Die Axillarzweige können bis zum nächstfolgenden Knoten mit dem Stamm verwachsen, resp. während der Entwicklung in die Höhe gehoben werden. Unter dieser Voraussetzung wäre unsere Figur offenbar als Monopodium aufzufassen; $r^{\prime}$ wäre der

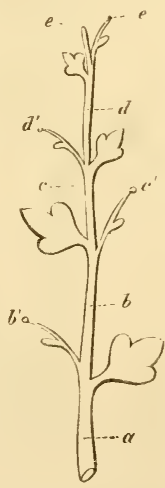

Fig. $26 i 3$. Axillarspross des untersten, $d^{\prime}$ der des zweiten Blattes u. s. f.

Da ähnliche Verwachsungen in der Natur wirklich rorkommen, so erhellt hieraus, dass die Stellıngsverhältnisse allein die Entwick- 
lungsweise der Axenorgane nicht immer verrathen. Kommen auch in manchen Fällen, namentlich wenn die Sprossenden $b^{\prime} c^{\prime}$ etc. beblättert sind, noch weitere Kennzeichen hinzu, welche die Wahrscheinlichkeit eines monopodialen oder sympodialen Aufbaues oft fast bis zur Gewissheit steigern, so ist doch eine vollständige Gewisshcit nur durch das Studium der Entwicklungsgeschichte erreichbar. Es handelt sich auch hier, wie bei Callithamnion, vor Allem un die Frage, welcher von den beiden Endsprossen $e$ und $e^{\prime}$ der relativ primäre sei; dadurch erst erhalten die späteren Stadien und die Stellungsverhältnisse im entwickelten Zustande ihre wahre Bedeutuing.

Ein zweites Beispiel ist in Fig. 264 dargestellt. Wenn man ron der Blattstellung absieht, die hier der Einfachheit wegen zweizeilig

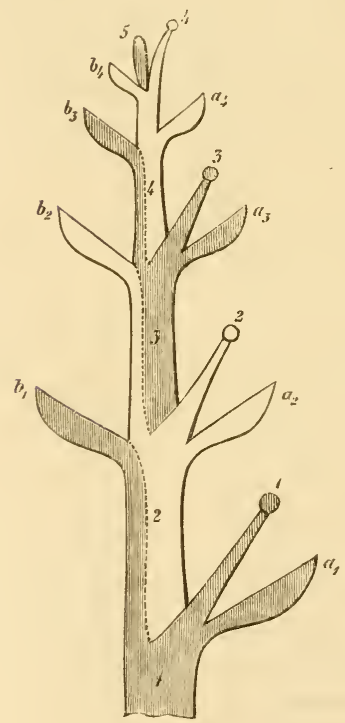

Fig. 261 . angenommen ist, so entspricht dieses Schema ziemlich genau manchen Pflanzen aus der Familie der Solaneen. Nah dem unteren Theil der Figur zu schliessen, bildet das Ganze ein Monopodium mit annäherud opponirten Blättern, wovon das eine einen Axillarspross trägt. Ein 13lick auf die Stammspitze zeigt aber sogleich, dass der Aufbau in Wirklichkeit ein sympodialer ist, weil der init 5 bezeichnete Strahl sich unzweifelhaft als Axillarknospe erweist. Indem diese Axillarknospe sich vorwiegend entwickelt, drängt sie den Strahl 4 so auf die Seite, dass derselbe später in der Achsel des Blattes $\boldsymbol{u}_{4}$, in derselben Reihe mit 1, 2, 3 zu stehen scheint. Da ferner $b_{3}$ und $a_{4}$ ein Blattpaar darstellen, so muss das folgende Blattpaar aus dem Tragblatt $b_{4}$ und dem ersten Blatt seines Axillarzweiges $a_{5}$ gebildet werden. Diess ist aber nur unter der Voraussetzung möglich, dass das Blatt $b$, durch das spätere intercalare Wachsthum in die Höhe gehoben wird oder, wie man sich gewöhnlich auszudrücken pflegt, mit dem Spross 5 verwächst, wïhrend $a_{4}$ und $b_{3}$ ihre gegenseitige Lage beibehalten. 
Hienach geschieht also das Wachsthum des Pflanzenstockes bei diesen Pflanzen in folgender Weise. Der primäre Spross 1 entwickelt zwei Blätter $a_{1}$ und $b_{1}$, das letztere mit einer entwicklungsfähigen Axillarknospe, dem secundären Strahl 2. Dieser verhält sich wie der primäre; er trägt zwei Blätter $a_{2}$ und $b_{2}$, wovon das obere den Trieb 3 mit den beiden Blättern $\iota_{3}$ und $b_{3}$ erzeugt $u$. s. f. In der Figur sind die auf einander folgenden Triebe des leichteren Verständnisses wegen samnt den zugehörigen Blättern abwechselnd dunkel und hell gehalten. - Mit dieser Entwicklung stimmt denn auch die wirkliche Blattstellung am Sympodium überein. Die beiden mit $a$ und $b$ bezeichneten Blätter der successiven Sprosse stehen nämlich um c. 16.5" also nicht viel weniger als die Hälfte des Kreisunfanges von einander ab, und gehören abwechselnd einer rechts- und linksläufigen Spirale an. Die beiden in gleicher Höhe stehenden Blätter $\alpha_{2}$ und $b_{1}, a_{3}$ und $b_{2}$ etc.) zeigen dagegen nur eine Divergenz von $1000^{\circ}$.

Als drittes Beispiel eines eigenthümlichen, olt unrichtig gedeuteten Wachsthums wollen wir noch die wilde Rebe und die Weinrebe anführen. Gewöhnlich betrachtet man dieselben als Sympodien, an welchen die Ranken die Enden der auf einander folgenden Sprosse darstellen. Diese Auffassung steht indess mit dem Verhalten der Stengelspitzen (Fig. 265, das obere Ende in $B$ stärker vergrössert)
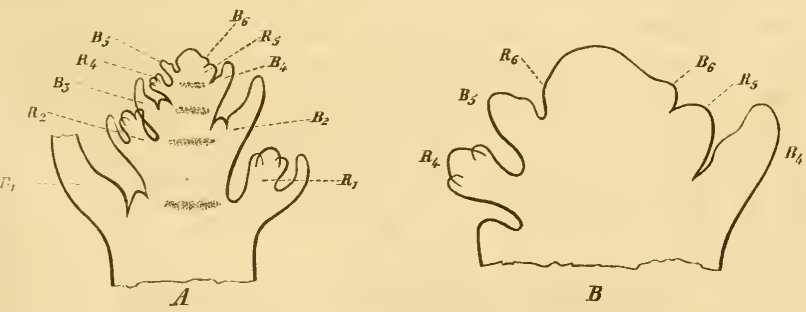

Fig 265.

in augenfälligem Widerspruch. Verfolgt man nämlich die zusammengehörigen, in nahezu gleicher Höhe opponirten Blätter und Ranken $B_{1} R_{1}, B_{2} R_{2}$ etc. von unten nach oben, so ergiebt sich schon aus den Form- und Stellungsverhältnissen des Blattes $B_{5}$ und der entsprechenden Ranke $R_{5}$, dass die letztere nicht wohl als Scheitel des Sprosses gedeutet werden kann, an welchem das Blatt $B_{5}$ eingefügt ist. Noch weniger wäre eine solche Deutung mit Rücksicht auf die Nägeli u. Schwendenex, das Mikrosknp. 
Blattanlage $B_{6}$ und die kaum angedeutete Rankenanlage $R_{6}$ gerechtfertigt; denn diese Anlagen sehen in jeder Beziehung gerade so aus, wie man sie bei Pflanzen, die entschieden keine Sympodien sind, beobachtet.

Die entwicklungsgeschichtlichen Thatsachen führen also zu dem Schluss, dass die Rebe als ein gewöhnliches Monopodium mit alternirenden Blättern und blattwinkelständigen Knospen (in Fig. $265 \mathrm{~A}$ bei $B_{1}$ bis $B_{3}$ durch kleine Höcker angedeutet $\mathrm{zu}$ betrachten ist, in dessen. Scheitelregion jedoch ausnahmsweise auch ausserhalb der Blattachseln regelmässig gestellte Axenorgane, die sich später zu Ranken ausbilden, angelegt werden. Man sieht auch, dass diese Rankenanlagen schon ursprünglich den Blättern opponirt stehen, und wenn man eine Reihe von Stammspitzen untersucht, so ergibt sich ferner, dass dieselben durchgehends etwas später auftreten, als das zugehörige Blatt. In all' diesen Punkten verhalten sich die zahme und die wilde Rebe, wie es scheint, vollkommen gleich.

Was nun noch die beblätterten Kryptogamen betrifft, so geben die morphologischen Verhältnisse im entwickelten Zustande hier noch weniger Aufschluss, als bei den Phanerogamen. Die neuen Sprosse entstehen nämlich nicht in den Blattwinkeln, sondern am Vegetationskegel des Stengels über den sichtbaren Blattanlagen, entweder durch wirkliche Dichotomie oder durch gewöhnliche Verzweigung eines Hauptstrahls. Es handelt sich also bei der Untersuchung zunächst darum, eine ächte Gabelung von einer bloss scheinbaren zu unterscheiden. Erst wenn es feststeht, dass die Verästlungen in der Regel unterhalb der Scheitelzelle angelegt werden, kann bei regelmässiger Stellung derselben die relative Entwicklungsfähigkeit der Mutter- und Tochterstrahlen und damit die Wachsthumsweise der Pflanzen bestimmt werden. Sind dagegen die beiden Strahlen gleichwerthig, wie bei der ächten Gabelung, so kann bloss noch in Frage kommen, ob sich dieselben auch gleichmässig entwickeln, und wenn nicht, wie die in der Entwicklung zurückbleibenden Strahlen am Stamme gestellt sind. Von diesem letzteren Punkte war indessen schon oben die Rede.

Die Unterscheidung der ächten Dichotomie von der unächten ist nun aber bei Organen, deren Scheitelwachsthum nicht genauer bekannt ist, eine schwierige Sache, ja streng genommen geradezu unmöglich. Man findet bei Lyropodium und Selaginella Stammspitzen mit einem in zwei rollkommen gleiche Höcker getheilten 
Punctum vegetationis und andere, bei denen der junge Spross etwas unterhalb der eigentlichen Spitze angelegt und in Folge dessen stärker gegen dic Längsaxe geneigt erscheint. Dessenungeachtet scheinen die Verästlungen, so weit wenigstens die Stellungsverhältnisse darüber Aufschluss geben, vollkommen gleichwerthig zu sein. Die scheinbare oder wirkliche Gabelung kommt übrigens nur bei Kryptogamen häıfiger vor; bei Phanerogamen ist sie selten und unseres Wissens bis jetzt nur an Wurzeln beobachtet.

Noch verdient der Aufbau der Blüthenstände einer be- 550 sondern Erwähnung. Hier kommt neben der Entwicklungsfähigkeit der verschiedenen Strahlen auch die Frage in Betracht, ob jeder derselben mit einer Blüthe endige oder nicht. Bei den geschlossenen Systemen geht der primäre Strahl, sowie alle übrigen, in eine Blüthe aus; bei den ungeschlossenen dagegen endigen nur die seitlichen Strahlen in Blüthen, indess der primäre Strahl (Spindel) sein Längenwachsthum mit einer sterilen Spitze abschliesst. Es ist diess ein weiterer Unstand, der für die Charakteristik der Blüthenstände von Bedeutung ist. Zwei Systeme von Axenorganen können in der Blüthemregion hinsichtlich der Anlage und der Dimensionsverhältnisse im ausgebildeten Zustande vollkommen übereinstimmen, und nur in der Vertheilung der Blüthen auf die verschiedenen Strahlen differiren. Solche Differenzen kommen hie und da bei natürlichen Pflanzenfamilien, deren Inflorescenzen habituell übercinstimmen, vor und können durch genaue mikroskopische Untersuchung der jüngsten Zustände sicher nachgewiesen werden.

\section{V. \\ Entwicklung der Fortpflanzungszellen.}

Die allgemeinen Gesichtspunkte, nach welchen die vegetativen $\mathbf{5 5 1}$ Wachsthumserscheinungen in den vorhergehenden Capiteln erörtert wurden, sind auch hier als die leitenden zu betrachten. Denn auch die Bildung der Fortpflanzungszellen ist ein Entwicklungsprocess, welcher wie jeder andere auf bestimmten Theilungen oder Neubildungen von Zellen oder auf Differenzirungen im Gewebe beruht, allerdings verbunden mit der späteren Trennung der Zellen oder Zellcomplexe, die jedoch in regetativen Geweben ebenfalls vorkommt; 
seine ganze Eigenthümlichkeit liegt streng genommen nur in der physiologischen Bedeutung der Zellen. In Berücksichtigung der grössern Mannigfaltigkeit, welche die Fortpflanzungserscheinungen darbieten, und der Constanz der darauf bezüglichen morphologischen Verhältnisse erscheint es aber nichtsdestoweniger gerechtfertigt, denselben nachträglich eine besondere Betrachtung zu widmen.

1. Bildungsweise der Fortpflanzungszellen.

552 zellen zu den erzeugenden, d. h. um die Art der Zellbildung, welcher dieselben ihren Ursprung verdanken. Man kann in dieser Beziehung folgende Fälle unterscheiden:

Die Fortpflanzungszelle entsteht

a) Unmittelbar durch Metamorphose einer vegetativen Zelle. Sie verdankt somit ihre Entstehung keinem besondern reproductiren Zellbildungsprocess. So bei der Sporenbildung der Nostochaceen (Rivularia, Cylindrospermum etc.).

Eine besondere Form dieses Processes besteht darin, dass der Plasmaschlauch einer vegetativen (d. h. durch regetative Zelltheilung entstandenen) Zelle sich mit èiner neuen Membran umhüllt, wobei er entweder sich bloss zuvor contrahirt oder auch durch eine auf verschiedene Weise gebildete Oeffnung die ursprüngliche Zelle verlässt. Hieher gehört z. B. die Bildung der Schwärmsporen bei Oedogonium.

b) Durch besondere Zelltheilung, die von derjenigen des vegetativen Auf baues verschieden erscheint. Mit dem Ausdruck Zelltheilung bezeichnen wir diejenige Art der Zellbildung, bei welcher der ganze Plasmainhalt durch Einfaltung und Abschnürung des Plasmaschlauches in zwei oder mehrere Tochterzellen zerfällt, gleichviel ob unter simultaner Bildung von trennenden Cellulosewänden oder ohne dieselbe.

a. Ohne deutliche Wandbildung. Die Zellen erhalten erst später Membranen, sei es, dass sie in ihre Lage bleiben oder sich von einander trennen und schwärmen. - Bei dieser Entstehungsart der Zellen zerfällt das den ganzen Zellraum erfüllende Plasma gleichzeitig oder durch rasch sich wiederholende Zweitheilung in mehrere oder viele Partieen, welche erst nur durch zarte, dann stärker hervortretende Linien getrennt erscheinen, sich aber später mit deut. lichen, der Mutterzelle nicht anhaftenden Membranen umkleiden. So bei der Sporenentwicklung der Mucorinen, der Zoosporenbildung der Saprolegnieen und Peronosporeen, ferner bei der Entwicklung 
der Schwärmsporen von Pediastrum und andern Palınellaceen, desgleichen bei Ulothrix, Ulva ete.

$\beta$ Mit deutlicher Scheidewandbildung. Auch in diesem Falle erhalten die Zellen nachträglich oft noch besondere Membranen. Der Vorgang der Theilung ist übrigens von dem bekannten vegetativen nicht verschieden; nur dass in manchen Fällen eine simultane Viertheilung, statt der gewöhnlichen Zweitheilung stattfindet. - Kommt vor bei vielen einzelligen Algen Diatomeen, Palmellaceen etc.), ferner bei der Bildung der Tetrasporen und Keimhäufchen vieler Florideen, bei der Sporenbildung der höhern Kryptogamen, bei der Pollenbildung der Phanerogamen etc.

c) Durch Ausstülpung und Abschnürung. Ist im Grunde von der ächten Zelltheilung nicht principiell verschieden, jedoch der Form nach ausgezeichnet. Die Abschnürung kann in einem oder an mehreren Punkten gleichzeitig stattfinden, ohne sich zu wiederholen (simultane Abschnürung); oder es können mehrere bis viele Abschnürungen am nämlichen Punkte, eine nach der andern, erfolgen (succedane Abschnürung). Simnltane Abschnürung beobachtet man z. B. an den Basidien sämmtlicher Hymenomyceten und Gastromyceten, sowic bei manchen andern Pilzgruppen, succedane Abschnürung in verschiedener Form bei manchen Hyphonyceten (Sporenköpfchen bei Botrytis Bassiana u. a., einfache Sporenketten bei Cystopus, ästige Sporenketten bei Periconia u. a.).*)

d) Durch freie Zellbildung, wobei sich innerhalb des Primordialschlauches kugelförmige Plasmapartieen individualisiren, von denen sich später jede zu einer 'Kelle ausbildet. Der Inhalt wird immer nur theilweise zur Anlage verwendet; der Rest bleibt in der Mutterzelle und wird später entweder resorbirt oder stirbt mit der Mutterzelle ab. Die Entwicklung der Tochterzellen innerhalb eines Ascus geschieht bald simultan, wie bei den Flechten und der Mehrzahl der Ascomyceten, bald succedan, wie bei manchen 'Tu. beraceen und im Embryosack der Phanerogamen, dabei in constanter oder in veränderlicher Zahl.

Eine besondere Form der freien Zellbildung ist die, dass der aus Plasma bestehende Wandbeleg der Multerzelle durch Theilung in kleine Portionen zerfällt, wovon jede zur besondern Zelle wird. In der Mutterzelle bildet sich somit eine wandständige Schicht von Tochterzellen. Diess ist der Fall bei Endococus Näg. und wahrschein-

*) Vgl. D e Bary in Hofmeister's Handbuch der physiol. Bot. II, S. 111 u. ff. 
lich auch bei Hydrodictyon. Von ersterer Gattung sind in Fig. 266 drei verschiedene Stadien der Theilung dargestellt.

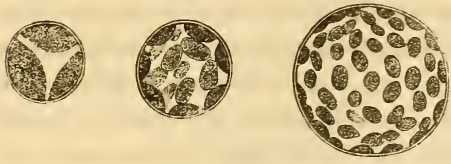

Fig. 266., (1000)

e) Durch Copulation $\mathrm{zweier}$ gleichwerthiger Zellen. Die sich copuliren. den Zellen gehören bald dem nämlichen Individuum, bald zwei verschiedenen Individuen an; überdiess ist die Art und Weise, wie die Copulation stattfindet, hinsichtlich der Form des Verbindungskanales, der Lage der Zygospore u. dgl. sehr verschieden. Es ist ferner darauf zu achten, ob der Inhalt der beiden Zellen ganz oder nur theilweise zur Bildung der Spore verwendet wird.

f) Durch Befruchtung einer grossen weiblichen durch eine kleine männliche Zelle. Auf diese Weise entstehen die Sporen bei Vaucheria und die Theilsporen der Fucoideen. Die Bildung der Membranen, beziehungsweise der Scheidewände erfolgt hier erst nach stattgefundener Befruchtung.

Die hier aufgezählten Zellbildungsprocesse sind übrigens nicht scharf von einander geschieden. Es giebt solche, die so allmählich in einander übergehen, dass eine bestimmte Grenzlinie zwischen denselben unmöglich zu ziehen ist. Solche Uebergänge beobachtet man namentlich zwischen $a$ ) und $b$ und zwischen $b$ ) und $c$. In andern Fällen ist der wirkliche Charakter der Zellenbildung schwer zu erkènnen. Die Zelltheilung ohne Scheidewandbildung kann 2. B. unter Umständen leicht mit der freien Zellbildung verwechselt werden. Die Bildung der Zellen aus einem wandständigen Plasmabeleg kann ferner leicht für wiederholte Zweitheilung der Zelle angesehen werden.

In allen Fällen, die Fortpflanzungszellen mögen nun dieser oder jener Art der Zellbildung ihre Entstehung verdanken, sind auch die e in leitenden Processe in der Mutterzelle von Wichtigkeit. Dahin gehören z. B. die Bildung eines neuen secundären Kerns neben dem primären oder nach Resorption des letztern die Bildung von Kernen tür die Tochterzellen, Veränderungen in der Beschaffenheit und Anlagerung des Inhaltes u. s. w.

2. Lage der keimbildenden Zellen.

5.53 Eine zweite Frage, welche bei allen mehrzelligen Pflanzen sich auldrängt, betrifft das räumliche oder morphologische Verhältniss der 
reproductiven Zellen zum Organ, auf dem sie entstehen. Behalten wir die oben gewählte Eintheilung der Organe in Zellreihen, Zellflächen und Zellkörper bei, so sind mit Rücksicht auf diese Frage folgende Fälle zu unterscheiden.

a Zellreihen. Die keimbildenden Zellen sind hier entweder Endzellen oder Gliederzellen. Sie nehmen im letzteren Falle, sofern die Glieder ungleichwerthig sind, bald eine bestimmte, morphologisch definirbare Stelle ein, bald entwickeln sie sich ohne nachweisbare Gesetzmässigkeit aus den verschiedensten Zellen.

Beispiele für diese Entwicklungstypen liefern die endständigen Sporen mancher Hyphomyceten, die Mutterzellen der Schwärmsporen bei Cladophora, Ulothrix u. a., die aus Gliederzellen entstandenen Oogonien und Antheridien der Oedogonien, die Brutzellen mancher Pilze, welche durch Zerfallen isolirter Fäden in ihre einzelnen Zellen entstehen u. s. w.

b) Zellflächen. Die keimbildenden Zellen sind entweder Flächenzellen oder Randzellen mit gesetzmässiger oder regelloser Anordnung, einzeln oder zu mehreren beisammen.

Beispiele : die Schwärmsporen-Mutterzellen bei Ulva, die Oogonien- und Antheridien-bildenden Zellen bei Coleochaete u. a.

Ob eine reproductive Zelle als Randzelle oder als Flächenzelle zu deuten sei, muss in schwierigeren Fällen nach jugendlichen Zuständen, wo die Keime noch als Anlagen vorhanden sind, entschieden werden, da spätere Stadien leicht zu irrigen Schlüssen führen. So oft nämlich eine Randzelle zur Fortpflanzungszelle wird, hört natürlich die Betheiligung derselben am peripherischen Wachsthum der Zellfläche auf. Die nebenan liegenden Zellreihen wachsen in Folge dessen darüber hinaus und schliessen sich ausserhalb derselben wieder zusammen, so dass die ursprüngliche Randzelle schcinbar zur Flächenzelle wird. Diess ist z. B. bei Coleochuete scutatu und andern Arten dieser Gattung der Fall, von denen Pringsheim an-

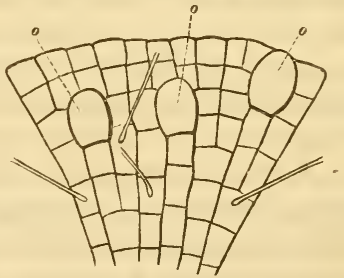

Fig. 26\%.(100) giebt, dass sich beliebige Flächenzellen zu Oogonien ausbilden, während jugendliche Zustände (Fig 267) beweisen, dass es ursprünglich Randzellen sind. In unserer Figur erscheinen die drei jungen Oogonien (o) noch deutlich als Endzellen von radialen Reihen, von denen 
jedoch eine einzige rechts) die Peripherie erreicht, indess die beiden andern im Wachsthum zurückgeblieben, d. h. von den benachbarten umschlossen sind.

c) Z ellkörper. Die keimbildenden Zellen entstehen entweder an der Oberfläche oder im Innern des Gewebes, von einer oder mehreren Zellschichten bedeckt, ferner einzeln oder zu mehreren beisammen in verschiedener Anordnung, bald nach Art der vegetativen Gewebe durch Differenzirung bestimmter Zellparticen, bald auf einem besondern Keimboden, welcher die verschiedensten Formen (eben, convex, concav etc.) annehmen kann.

Die Hauptpunkte, auf welche der Beobachter sein Augenmerk zu richten hat, sind in diesen Worten kurz angedeutet; allein bei der grossen Verschiedenartigkeit der hieher gehörigen Fälle erheischen dieselben eine etwas weitere Ausführung.

Die Frage, ob die reproductiven Zellen oberflächliche Bildungen seien, oder ob sie im Innern des Gewebes entstehen, kann oft nur durch entwicklungsgeschichtliche Untersuchungen entschieden werden, da hierüber das anatomische Verhalten des fertigen Zustandes nur in den leichteren Fällen Aufschluss giebt. Als Beispiel sei hier nur die Fruchtschicht der fucusartigen Algen erwähnt. Dieselbe befindet sich, ähnlich wie bei den Pyrenomyceten und angiocarpen Flechten in einem Receptaculum, welches mit einer kleinen Oeffnung Porus, Ostiolum) nach aussen mündet; sie scheint also, nach diesem fertigen Zustande zu urtheilen, in Innern der Fruchtäste entstanden zu sein. Allein die Entwicklungsgeschichte lehrt das Gegentheil : die Zellen der Fruchtschicht sprossen aus der Oberfläche hervor, welche letztere sich an dieser Stelle in der angegebenen Weise einstülpt. Die Fruchtschicht der Pyrenomyceten und Flechten dagegen wird in Innern des Thallus angelegt und die Bildung des nach aussen mündenden Porus beruht auf dem Auseinanderweichen der peripherischen Zellen im Verlaufe des Wachsthuins.

Eine Frage verwandter Natur ist bei kleinen reproductiven Organen (Antheridien, Sporangien u. dgl.) die, ob das ganze Gewebe sich in reproductive Zellen umwandle, oder ob eine oberflächliche, epidermisähnliche Zellschicht vorhanden sei, welche später von den Fortpflanzungszellen durchbrochen wird. Auch in diesem Punkte können, wie aus den widersprechenden Ansichten neuerer Autoren hervorgeht, 'Täuschungen leicht vorkommen. Den Farrenantheridien schreiben z. B. noch gegenwärtig die einen Beobachter eine peripherische vegetative Zellschicht zu, während sie andere in Abrede stel- 
len, indem sie die Umhüllung für eine einfache Membran erklären. In allen uns bekannten Fällen ist es übrigens entschieden immer eine Zellschicht; allein die wenigen Zellen, woraus sie besteht, sind bei älteren Antheridien meist so abgeplattet, dass sie in der That wie eine einfache Membran aussehen. - In Fig. 26S ist ein solches Farren-
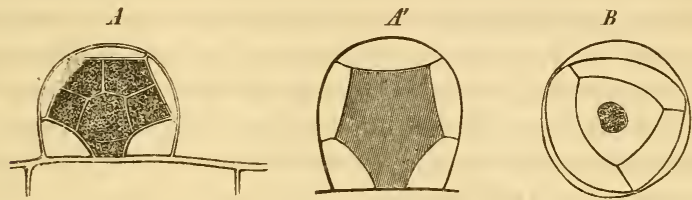

Fig. 265.

antheridium abgebildet; $A$ und $A^{\prime}$ sind Seitenansichten jugendlicher Zustände, $B$ stellt ein entleertes Antheridium von oben gesehen dar.

Die Anordnung der reproductiven Zellen ist in der Regel, wenn man von den complicirteren Stellungsverhältnissen (Spiralen u. dgl.) absieht, sowohl bei oberflächlicher Lage, als bei der Vertheilung derseiben im Gewebe unschwer zu ermitteln. Es handelt sich hier zunächst darum zu entscheiden, ob dieselben einzeln über die Oberfläche oder im Gewebe zerstreut, oder aber in Gruppen, Zonen oder zu grösseren Gewebepartieen vereinigt sind. Einzeln und oberflächlich stehen $\mathrm{z}$ B. die Sporenmutterzellen gewisser Formen von Dictyota, in Gruppen vereinigt die Antheridien der nämlichen Pflanzen und vieler andern, desgleichen die Sporen bei einer grossen Zahl von Florideen und Fucoideen; einzeln im Innern die Eizellen der Archegonien, der Embryosack der Phanerogamen etc.; zu vieren im Innern die Macrosporen der Selaginellen; zu vielen im Innern die Sporen und Spermatozoen Mutterzellen der Moose und Lebermoose, die Pollenkörner u. s. w.

In zweiter Linie ist zu untersuchen, ob die reproductiven Zellen allein oder in Begleitung von vegetativen (Paraphysen, Paranemata, Schleudern; auftreten, welcher letztere Fall bekanntlich sowohl bei Land-als Wasserpflanzen häufig vorkommt.

Die speciellen Stellungsverhältnisse, d. h. die genaue räumliche Anordnung der keimbildenden Zellen, spiralige Stellungen u. dgl. übergehen wir hier, da in diesem Betreff die nämlichen Fragen in Betracht kommen, wie bei den vegetativen Wachsthumsprocessen.

Was nun noch den letzten Punkt anbelangt, die Frage nämlich, ob 
die reproductiven Zellen aus einem besondern Keimboden hervorsprossen oder wenigstens anatomisch mit einem solchen zusammenhängen, so mögen bei einfach gebauten Pflanzen einzelne Fälle vorkommen, wo mit Rücksicht hierauf, bei vollständiger Kenntniss der thatsächlichen Verhältnisse, verschiedene Auffassungen möglich sind. Die Mehrzahl der Fortpflanzungsorgane gehört jedoch entschieden in die eine oder in die andere Kategorie. Ohne Keimboden ist z. B. das reproductive Gewebe der Antheren; der Sporangien und Antheridien bei Farren, Moosen etc. ; einen ausgeprägten Keimboden besitzen dagegen die reproductiven Organe der Flechten, Hymenomyceten und Pyrenomyceten, die Cystocarpien der Florideen, die Conceptacula der Fucaceen, die Antheridien der Charen etc.

Bei oberflächlicher Lage der keimbildenden Zellen stellt gewissermaassen das entsprechende Stück Oberfläche den Keimboden dar; hier kommt es indess vorzugsweise darauf an, ob der Keimbildung bestimmte Theilungsprocesse rorausgehen oder nicht.

\section{Ursprung und Entwicklungsfolge der keimbildenden Zellen.}

Soll die Entwicklungsgeschichte reproductiver Zellcomplexe zu einem befriedigenden Abschluss gebracht werden, so ist es nothwendig, dieselbe bis zu einem Anfangsstadium zu verfolgen, wo die fraglichen Bildungsprocesse sich unmittelbar an die bekannten vegetativen Wachsthumsvorgänge anschliessen. Besteht z. B. das reproductive Gewebe, wie es bei Zellkörpern häufig der Fall ist, aus vielen neben und übereinander liegenden Zellen, so fragt es sich, ob diese vielen Zellen aus einer einzigen ursprünglichen Zelle, oder aus einer einfachen Zellschicht, oder aus einer körperlichen Gruppe von Zellen hervorgehen. Für alle diese Fälle gibt es in der Natur Beispiele genug. Aus einer einzigen Zelle entstehen z. B. die Sporen in den Sporangien der Farren, der Equiseten, Selaginellen u. a., die Keimhäufchen der Callithamnien etc. ; aus einer Zellreihe die Pollenmutterzellen in manchen Antheren, aus einer Zellfläche die Sporen nebst Schleudern bei Frullania (nach Hofmeister), aus einer hohlcylindrischen Zellschicht die Sporen der Laubmoose, aus einer körperlichen Zellgruppe endlich die Pollenmutterzellen gewisser Pflanzen.

Ist dagegen im ausgebildeten Zustande eine einzige oder eine geringe /ahl von Fortpflanzungszellen vorhanden, so ist die Möglichkeit ins Auge zu fassen, dass die junge Anlage deren mehrere oder viele besitzt, von denen sich aber nur eine oder wenige entwickeln, indless die übrigen resorbirt werden. Diess ist z. B. bei den 
Makrosporen der Pilularien der Fall. Das junge Sporangium enthält eine grössere Zahl von Sporen in tetraedrischen Gruppen. Von diesen Gruppen verschwinden in der Folge alle bis auf eine, und von dieser entwickelt sich eine einzige Zelle zur Makrospore.

Ein anderer Gesichtspunkt betrifft die Frage, ob alle Zellen, die einen einheitlichen Ursprung haben, sofern sie nicht durch Resorption verschwinden, zur Bildung von Fortpflanzungszellen verwendet werden, oder ob ein Theil derselben anderweitige Umbildungen erfahre. Im letztern Falle ist weiter zu untersuchen, welche Zellen die eine und welche die andere Verwendung erhalten. Zur Erläuterung dieser Frage erwähnen wir beispielsweise die Sporenbildung bei Polysiphonia, wo eine der peripherischen (die Centralzelle umgebenden) Zellen sich zunächst in 2 oder 3 äussere Zellen und eine innere Zelle theilt, von denen die letztere in eine untere und eine obere Zelle zerfällt. Die obere ist die Sporenmutterzelle. In Fig. 269 ist diese Theilung dargestellt; $A$ ist ein gewöhnliches vegetatives Glied mit einer
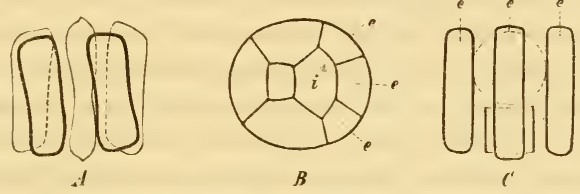

Fig. 269.

centralen und 4 peripherischen Zellen in der Längsansicht; $B$ ein reproductives Glied im Querschnitt mit der Sporenmutterzelle $i$ und 3 äussern Theilzellen $e ; C$ stellt den Complex der 3 äussern und der beiden immern Zellen in der Längsansicht von aussen gesehen dar.

Die En twickl ung s folge der reproductiven Zellen betreffend, so ist zu untersuchen, ob die Ausbildung derselben in einer bestimmten Reihenfolge, z. B. von unten nach oben oder von oben nach unten etc. oder vielleicht simultan stattfinde. Als Beispiel sei erwähnt, dass die Schwärmsporenbildung bei Ulothrix in der Scheitelregion beginnt und nach unten hin fortschreitet, indess die Entwicklung der Antheridienzellen bei Callithamnion (Dasythamnion) u. a. sich umgekehrt von unten nach oben vollzieht. Sind die reproductiven Zellen zu einer Fruchtschicht (Hymenium) vereinigt, so kann das Wachsthum derselben ein vorwiegend peripherisches, oder ein vorwiegend intercalares oder ein durchweg gleichmässiges sein. 
4. Veränderungen benachbarter Zellen und Zellcompleve.

Die Entwicklung der keimbildenden Zellen ist in vielen Fällen mit Veränderungen in den angrenzenden vegetativen Zellen und Zellcomplexen verbunden, welche der Beobachter mit zu berücksichtigen hat. Dahin gehören z. B. die Modificationen des Inhaltes oder der Membran, wie man sie hin und wieder an den Gehäusen der Flechtenapothecien beobachtet, ferner die Resorption von Zellen und Zellschichten an der Innenseite der Antheren - und Sporangienwände und in der Umgebung des Embryosackes, namentlich aber die erhöhte Theilungs- und Entwicklungsfähigkeit der benachbarten Zellen. Zur nähern Erläuterung dieser letztern Erscheinung mögen folgende Beispiele dienen.

Bei Nitophyllum ist die Sporenmutterzelle eine Flächenzelle des einschichtigen Thalloms; die dieselbe umgebende Partie wird jedoch durch zweimalige Theilung dreischichtig. - In den A uthe ren zeichnet sich die innerste Schicht der IV andung, bevor sie resorbirt wird, durch eine eigenthümliche Theilungs- und Entwicklungsfähigkeit aus, indess andere Partieen des Gewebes spiralige Verdickungen erhalten. Aehnliche-Metamorphosen beobachtet man auch bei allen Sporangien. - Bei manchen Flechten Parmelia, Sticta etc.) entwickelt sich die das reproductive Gewebe umschliessende Rinde zu einer Scutella, deren Rand über die in die Höhe gehobene Fruchtschicht hinausragt; bei Solorina kommt sogar auf der Unterseite des Thallus an dem den Apothecien entsprechenden Stellen eine schön-parenchymatische Rinde zu Stande, welche dem vegetativen Thallom mangelt.

In andern Fällen erzeugen die regetativen Zellen, welche den keimbildenden zunächst liegen, besondere Trichomgebilde Paraphysen etc.), wie sie namentlich bei Fucoidcen in der verschiedensten Anordnung vorkommen.

Wir haben uns im Vorhergehenden auf die Hervorhebung derjenigen Punkte beschränkt, welche sich auf das Verhältniss der Fortpflanzungszellen zu den erzeugenden, sowie ferner auf die Lage und die Entwicklungsweise der letztern und auf die Veränderungen benachbarter Zellen in reproductiven Organ beziehen. Eine erschöpfende Darstellung der Fortpflanzungserscheinungen würde nun weiter das Verhältniss des reproductiven Organs zur ganzen Pflanze zu berücksichtigen haben. Da indess die Fragen, welche hier in Betracht kom- 
men, die nämlichen sind, wie bei den vegetativen Organen, so verweisen wir in diesem Betreff auf das früher Gesagte.

\section{VI.}

\section{Gefässbündeluntersuchungen.}

Die Art und Weise, wie die Gefässbündel des Blattes sich mit $\mathbf{5 5 6}$ denen des Stammes verbinden: ob sie vom Stamme in die Blätter hinauswachsen oder ungekehrt von diesen in jenen herein, und welche Regeln den Längsverlauf der entwickelten Blattspuren und die damit zusammenhängende Beziehung zur Blattstellung beherrschen das Alles ist in neuerer Zeit wiederholt Gegenstand der Untersuchung gewesen. Es scheint jedoch, dass manche Beobachter gerade bei diesen Untersuchungen (sowohl technisch als theoretisch) höchst unsichere Wege eingeschlagen haben, da die gewonnenen Resultate selbst in Punkten differiren, die bei richtiger Behandlung des Objects sich in directester Weise entscheiden lassen. Mit Rücksicht hierauf mag es daher nicht ganz überflüssig erscheinen, wenn wir den Gefässbündeluntersuchungen ein besonderes Capitel widmen.

Wie man schon aus den oben gestellten Fragen ersieht, handelt es sich bei diesen Untersuchungen um zwei wesentlich verschiedene Dinge, einmal um die Beschaffenheit des fertigen Gefässnetzes und zweitens um seine Entwicklungsgeschichte. Beide verlangen zuvörderst geeignete Präparate, welche die vorhandenen Bündel auf Querund Längsschnitten mit Sicherheit erkennen lassen. Manche Pflanzengewebe sind nun zwar von Natur so durchsichtig, dass man auf dünneren Durchschnitten jedes einzelne Gefäss deutlich wahrnimmt; allein da es wichtig ist, zuweilen auch dickere Schnitte und selbst ganze oder halbirte Stammenden für die Untersuchung verwerthen zu können, so erscheint es selbst in diesem günstigsten Falle vortheilhaft, Reagentien zu gebrauchen, welche die Durchsichtigkeit der Präparate steigern. In vielen anderen Fällen ist diess geradezu unerlässlich, da die Elementarorgane auch auf den dünnsten Durchschnitten nicht deutlich genug hervortreten. Die Ermittelung einer möglichst zweckmässigen Behandlung der Präparate muss alsdann jecler weiteren Untersuchung vorausgehen. Ueber diesen Punkt mögen desshalb auch hier zuallernächst einige Bemerkungen folgen. 


\section{Behandlung der Präparate.}

557

Welche Reagentien auf die verschiedenen Gewebe am günstigsten einwirken, lässt sich natürlich nicht ein für allemal feststellen, da diese Wirkuqg, wie leicht einzusehen, wesentlich vom Iuhalt der Zellen abhängt. Bei einer grossen Zahl-von Pflanzen hat sich indess verdünnte Kalilösung als sehr geeignet erwiesen; sie kann als Universalmittel zur Behandlung der Präparate bezeichnet werden. Oft genügt es, einen Tropfen dieser Flüssigkeit dem Wasser, in welchem die Schnitte liegen, zuzusetzen und den günstigsten Augenblick der Einwirkung abzuwarten. In anderen Fällen, namentlich wenn die Schnitte sehr dick sind, wie diess z. B. bei Stammenden, die man der Länge nach halbirt hat, immer der Fall ist, muss eine concentrirtere Lösung angewendet und das Präparat oft längere Zeit erhitzt werden, bis es hinreichend durchsichtig wird. Das Erhitzen geschieht immer am besten auf dem Objectträger selbst. Ist es nöthig, den Druck des Deckgläschens beim Verdampfen der Flüssigkeit zu vermeiden, so legt man Papierstreifen unter oder setzt von Zeit zu Zeit einen 'Tropfen neuer Lösung zu.

Ist das Gewebe bereits verholzt, so gelingt es bisweilen, die Spiralgefässgruppen durch Kochen in starker Salpetersäure, Auswaschen und nachherigen Zusatz von Kali deutlich zu machen. Die Säure muss in der Regel so lange einwirken, bis die Schnitte, die sich zunächst dunkler färben, vollständig farblos geworden sind. Sind Harze, Oele etc. in den Zellen enthalten, so mag man es versuchen, diese Substanzen durch die entsprechenden Lösungsmittel auszuziehen und dann erst Kali zuzusetzen.

Die nit Kali behandelten Präparate behalten zuweilen nur kurze Zeit dieselbe Durchsichtigkeit und trüben sich hierauf wieder. Die Veränderung kann so rasch eintreten, dass es nicht möglich ist, eine grössere Zahl von Schnitten, die auf dem Objectträger liegen, im günstigen Stadium der Einwirkung zu beobachten und genau zu vergleichen. Unter solchen Umständen thut man am besten, die Schnitte der Reihenfolge nach einzeln in verdünnte Kalilösung zu bringen und die Anordnung der Gefässbündel, wo es nöthig ist, Schnitt für Schnitt zu skizziren.

2. Verlauf der Gefässbündel.

558 Die Methode betreffend, die man zur Feststellung des Ge. fässbündelverla ufes einzuschlagen hat, so beschränken wir uns hier auf die Combination successiver Quprschnitte und zusammenge- 
höriger Längshälften ; wo diese nicht zum Ziele führen, ist mit Maceriren oder Freipräpariren der. Gefässbündel auch Nichts gewonnen. Die successiven Querschnitte müssen natürlich so dünn und so durchsichtig sein, dass sich die einzelnen Gefässbündel in jedem folgenden Schnitte wieder erkennen, folglich die vorkommenden Verschmelzungen oder Trennungen sich leicht verfolgen lassen. In den Knoten kann sogar ein Umwenden einzelner Schnitte nothwendig werden, um über die Veränderungen, welche von einer Schnittfläche zur andern stattfinden, ins Klare zu kommen. Zur raschen und sichern Verwerthung des Gesehenen für die Darstellung der räunlichen Veränderungen im Längsverlaufe der Bündel ist übrigens unter allen Umständen eine gewisse Uebung erforderlich, die man sich nach und nach erwerben muss; doch bringt es jeder Anfänger bald dahin, die Aufgabe für die leichteren dicotyledonen Pflanzen zu lösen.

Da die Stellung der Blätter als gegeben zu betrachten ist, so lässt sich auch ein allfällig spiraliger oder geschlängelter Verlauf aus der allmählichen Ab- und Zunahme der Winkelabstände bekannter Bündel bestimmen, wie denn überhaupt die Querschnitte für sich allein Alles bieten, was zur Kenntniss und genauen Construction des Gefässbündelnetzes nothwendig ist. Die unten angeführten Beispiele mögen hiezu als Belege dienen.

Wo es darauf ankommt, auch die Längenverhältnisse dieses Netzes genau zu kennen, d. h. jede Veränderung im Querschnitt auf das richtige Niveau zu beziehen, bringt man auf der Oberfläche des zu untersuchenden Stammstückes in bestimmten Abständen, etwa von $5 \mathrm{zu} 5^{\mathrm{m} . \mathrm{m}}$, beliebige Zeichen an, welche die Höhe der successiven Schnittflächen zu bestimmen oder approximativ zu schätzen gestatten. Zuweilen kann auch das Einritzen einer Längslinie in die Oberfläche zur leichteren Orientirung und genaueren Bestimınung seitlicher Verschiebungen auf den successiven Querschnitten zweckclienlich sein. Um die Vergleichung zı erleichtern, ist unter allen Umständen zu empfehlen, die wichtigeren Schnitte mittelst der Camera lucida zu skizziren und die einzelnen Bündel mit Buchstaben oder Ziffern zı bezeichnen.

Die Combination zusammengehöriger Längshälften $\mathbf{5 5 9}$ geschieht am besten in der Art, dass man dieselben mit den Schnittflächen nach oben gekehrt neben einander legt und wo es nöthig ist mit der Camera lucida skizzirt. Man achte hiebei darauf, dass die 
unteren Enden der Stammhälften in beiden Skizzen in dieselbe Horizontale fallen, da alsdann auch die jüngsten Knoten in Internodium sich entsprechen müssen. Zur Controle ist es zweckmässig, durch das untere Ende des Stammes, bevor man denselben halbirt, einen oder mehrere Querschnitte zu führen, um dieselben mit den Längsansichten der untersten Internodien zu vergleichen. Das vollkommene Verständniss der Längsschnitte setzt natürlich voraus, dass man auf den letzteren alle im Querschnitte wahrnehmbaren Bündel wieder erkenne, sowie ferner, dass zu jedem durchschnittenen Bündel in der andern Hälfte die Fortsetzung gefunden werde.

Je schwieriger es ist, solche Längsschnitte durch Kochen in Kali durchsichtig zu machen, desto sorgfältiger müssen natürlich Blätter, Schuppen, Haare u. dgl. vorher entfernt werden. Seltener ist das Wegpräpariren der Rinde zu empfehlen, da man hiebei gar zu leicht die Gefässbündel verletzt. Fhe man irgen̨d einen Druck auf die gekochten Schnitte anwendet, suche man alles Thatsächliche so weit als möglich festzustellen, um die Fragen, die noch zu lösen bleiben, zu präcisiren. Man prüfe alsdann, wie ein schwacher Druck auf die verschiedenen Stellen wirkt, weil es dadurch möglich wird, das Zerquetschen der weichen Partieen, bevor man sie untersucht hat, zu verhüten. Zuweilen trägt auch ein Umwenden der Schnitte dazu bei, gewisse Gefässbündel deutlicher zu machen.

560 Die Darstellung eines räumlich bestimmten Verlaufes der Blattspuren durch die Zeichnung lässt sich in verschiedener Weise denken. Man kann sich das ganze Gefässbündelnetz auf eine umhüllende Cylinderfläche projicirt, hierauf die letztere der Länge nach aufgeschnitten und in der Ebene des Papiers flach gelegt denken. Oder man kann sich dre Stammspitze durchsichtig vorstellen und die Gefässbündel so wiedergeben, wie sie dem Auge unter dieser Voraussetzung perspectivisch erscheinen wïrden. Bei einer dritten Art der Darstellung endlich denkt man sich die Gefässbündel in einer Kegelfläche mit grosser Oeffnung und projicirt dieselben auf die Grundfläche des Kegels. Die Längslinien erscheinen alsdann als Radien und die Querschnitte als concentrische Kreise. Von diesen drei Projectionsarten sind jedoch die beiden letzteren nur für besondere Fälle zu empfehlen; in der Regel verdient die erste der grösseren Uebersichtlichkeit wegen den Vorzug.

561 Wir lassen nun einige Beispiele folgen, welche das besprochene Untersuchungsverfahren noch näher reranschaulichen sollen. 
1) Die Stammspitze von Iberis am ar a zeigt auf Querschnitten das in Fig. 270 dargestellte Verhalten. Die Blätter besitzen je ein centrales Gefässbündel, welches an der Insertionsstelle in den Gefïssbündelkreis des Stammes hereintritt. Die Blattdivergenz beträgt ziemlich genau $5 / 13$. Verfolgt man die hereingetretenen Stränge auf successiven Querschnitten, die man von Zeit zu Zeit mittelst der Camera lucida zeichnet, nach unten, so findet man, dass jeder Strang durch 10-11 Internodien herunterstēigt und sich dann ohne Ausnahme mit dem Strang des 5. unteren Blattes vereinigt, also 6 mit 1,7 mit 2 u. s. f. Ueberdiess ergibt sich, wenn man in jedem Knoten die Winkelabstiinde der

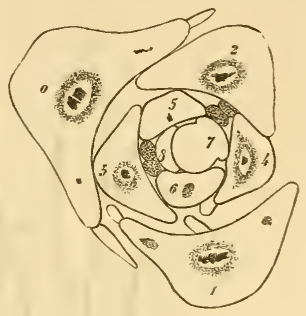

Fig. 270 . heruntersteigenden Blattspuren unter sich und im Verhältniss zu dem neu hereintretenden Strang vergleicht, noch folgendes Nähere über den Verlauf. Jedes Gefässbündel weicht zuerst nach der einen, dann nach der anderen Seite von der Verticallinie $\mathrm{ab}$ und beschreibt also bis zur Vereinigung mit dem fünftunteren ein lang gezogenes S. Der Gesammtverlauf der Blattspursympodien ist überdiess ein spiralig schiefer, und zwar ergiebt die Thatsache, dass der Strang des 14. Blattes, statt auf den senkrecht unter ihm befindlichen 1. zu treffen, sich nach dem 9. hinbewegt, eine Drehung von beinahe $3^{\circ}$ auf jedes Internodium oder genauer $360^{\circ}$ auf 65 Internodien. In Fig. 271 (s. S. 622) ist dieser Terlauf in der Cylinderprojection dargestellt.

2) Die Laubtriebe von Euphorbia pilosa besitzen spiralig gestellte Blätter mit einer Divergenz von c. $5 / 13$. Auf Durchschnitten durch die Knoten sieht man sogleich, dass von jedem Blatt 3 Stränge in den Gefässbündelkreis hereintreten, wovon jedoch zunächst der Stammspitze nur der mittlere entwickelt ist Fig. 272). Bezeichnet man diesen mittleren Strang durchgehends mit $a$, die beiden seitlichen mit $b$ und $c$, und setzt den Buchstaben die den Knoten entsprechenden Indices 1, 2, 3, 4 ețc. bei, so findet man durch successive Querschnitte über dem 11. Knoten folgende Anordnung (Fig. 273). Die Medianstränge $a_{6}, a_{7} \ldots \ldots a_{10}$ sind noch isolirt und der Blattstellung entsprechend angeordnet, während die der oberen Knoten sich mit dem drittunteren Lateralstrang $b$ rereinigt haben, also $a_{5}$ mit $b_{8}, a_{4}$ mit $b_{\tau}$ etc. Aehnliche Vereinigungen haben zwi- 


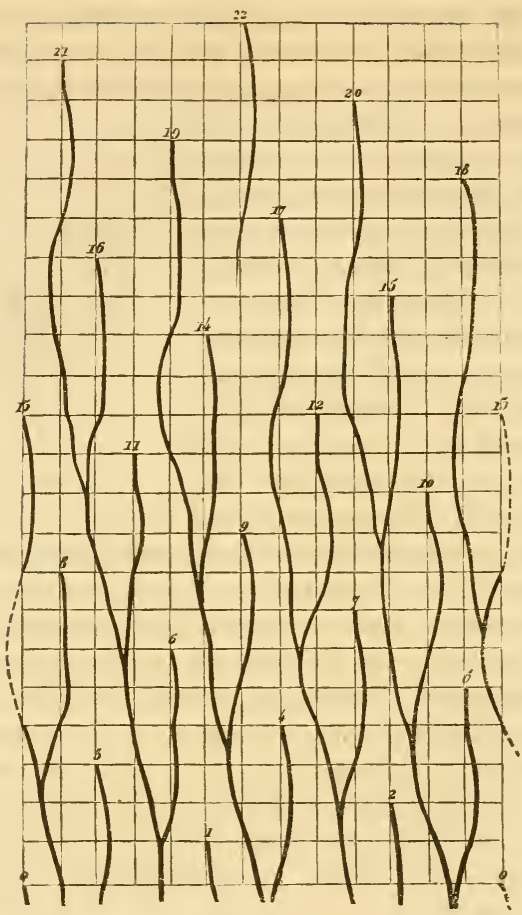

Fig. 271 .

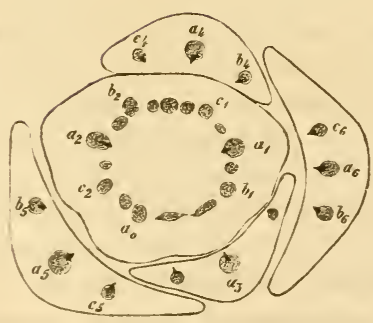

Fig. $2: 2$.

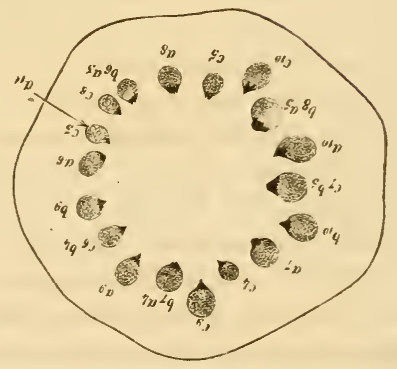

Fig. 273. 
schen $c_{7}$ und $b_{5}, c_{6}$ und $b_{4}$ etc. stattgefunden. Die Verschränkung der Blattspuren betreffend, so kommt $b$ constant zwischen $a$ und $c$ des zweitunteren, $c$ zwischen $a$ und $b$ des drittunteren, endlich $a$ zwischen $a$ und $c$ des fünftunteren Knotens zu liegen. Setzt man die

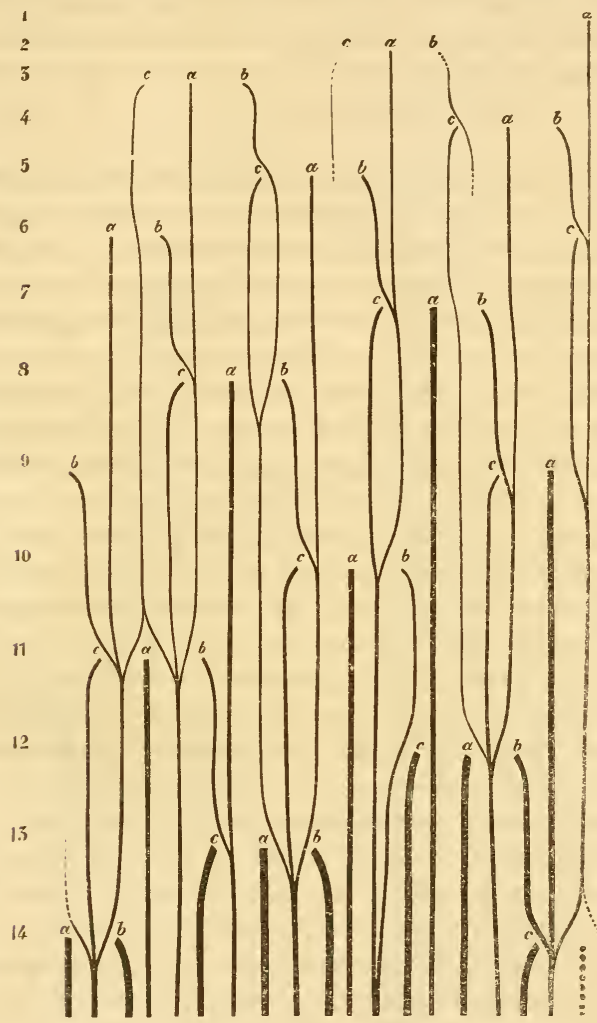

Fig. 27s.

Schnitte noch ein Stück weiter fort, so spaltet sich das Bündel $c_{3}$, um das Medianbündel $a_{11}$ in den $Z$ wischenraum eintreten zu lassen.

Diese Verhältnisse genügen, um den Längsverlauf der Gefässbündel nicht bloss für die 10 oder 11 untersuchten Internodien, sondern auch für die nächstfolgenden bis zum 14. Knoten zu bestimmen, 
womit bei der angenommenen Divergenz von $5 / 13$ die Reihe der vorkommenden Beziehungen abgeschlossen ist. Denn wie sich $c_{3}$ gegen $a_{11}$ verhält, so muss - natürlich unter der Voraussetzung eines gesetzmässigen Verlaufes - auch $c_{6}$ gegen $a_{14}$ sich verhalten. Mit $c_{6}$ steht aber $b_{4}$ und mit diesem $a_{1}$ in Verbindung, dessen Verhalten zu dem senkrecht darunter befindlichen $a_{14}$ folglich gegeben ist. - Die schematische Darstellung dieses Längsverlaufes in der Cylinderprojection ist in Fig. 274 gegeben.

Ton der nämlichen Pflanze ist in Fig. 275 ein Längsschnitt dargestellt. Die beiden in Kali gekochten Stammhälften liegen mit den schnittflächen nach oben gekehrt neben einander. Da die Knoten in der Stanmspitze sehr genähert und die Blätter überdiess ungleich kurz abgeschnitten sind, so ist eine sorgfältige Vergleichung nothwendig, um die Nummern der Blattspuren in der Zeichnung bis zu den obersten noch wahrnehmbaren Bündeln richtig anzusetzen; doch machen es die im unteren Theil der Figur ausgesprochenen Beziehungen, combinirt mit den Blattstellungsverhältnissen, möglich, diese Operation in der Weise, wie es in der Figur geschehen, auszuführen. Es bleibt also nur noch übrig, jedes einzelne Bündel nach unten zu verfolgen, bis es sich an ein anderes ansetzt, wobei allerdings die am Rande liegenden Bündel, weil sie meistens durchschnitten sind, nicht selten aus zwei bis drei Stücken, die abwechselnd in der rechten und linken Hälfte liegen, zusammenconstruirt werden müssen. So ist $z$. B. $b_{5}$ in unserer Figur im Knoten 8 durchschnitten; der obere Theil liegt in der linken, der untere in der rechten Hälfte. Dasselbe gilt vom Medianstrang $a_{2}$, welcher ungefähr in der Höhe des fünften Knotens durchschnitten wurde; ferner von $b_{10}$ und $a_{7}$, deren gemeinsame Fortsetzung rom 9. Knoten an ebenfalls im andern Längsschnitt zu suchen ist. Der Strang $b_{10}$ scheint nach der Zeichnung links von $r_{12}$ zu verlaufen, allein er liegt in einem höheren Niveau und daher in Wirklichkeit rechts. Solche Terhältnisse kommen öfter vor, namentlich wenn die Schnitte gequetscht werden, und es ist desshalb immer wichtig, auf die Nireaurerschiedenheiten der Blattspuren genau zu achten.

\section{Entwicklung der fefüssbündel.}

563 Die successiven Querschnitte durch die Terminalknospe und noch besser die halbirten Stammspitzen bieten zugleich die nöthigen Anhaltspunkte, um die Entwicklung der Gefässbündel zu 
verfolgen. Man sieht ohne Weiteres, ob die Median- oder die Lateralbündel der Blattspur zuerst auftreten, ob sie in ihrem Verlaufe nach unten stärker oder schwächer werden oder ganz verschwinden etc. Diese Beobachtungen beziehen sich indess nur auf die Bildung

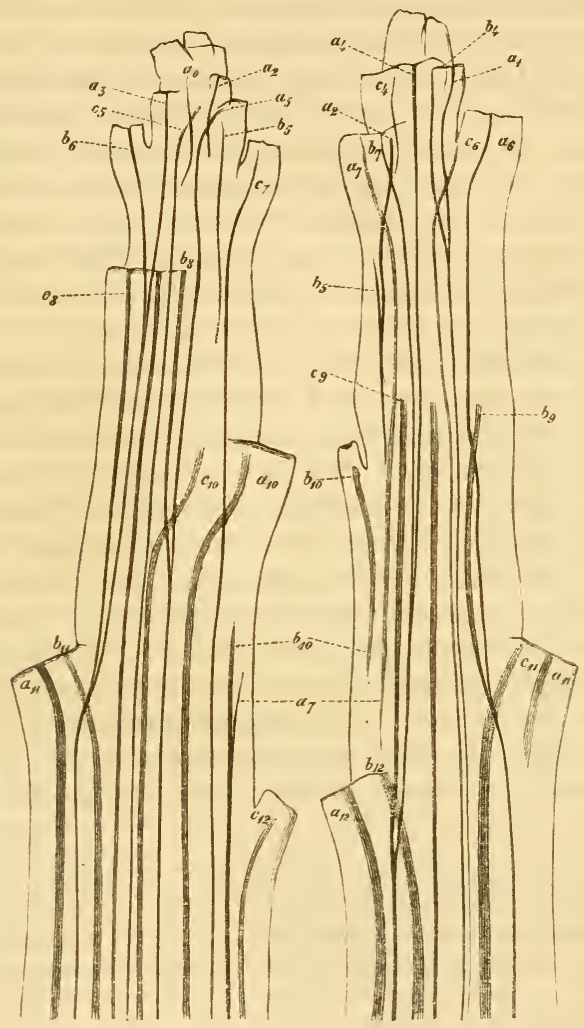

Fig. 275 .

der ersten Ring- oder Spiralgefässe, und es wäre denkbar, dass die Entwicklungsfolge der Cambiumpartieen nicht genau mit der späteren Gefässbildung übereinstimmte. Das Cambium selbst zu verfolgen ist in der grossen Mehrzahl der Fälle nicht möglich. 
Die Antwort auf die oben erwähnte Frage, ob die Gefässbündel vom Stamme in die Blätter hinauswachsen oder umgekehrt von diesen in jenen herein, lässt sich sowohl nach Querschnitten als nach Längsansichten durchsichtiger Stammenden leicht feststellen. Die Beobachtung lehrt, dass das erste Gefäss einer Blattspur in der Blattbasis zur Entwicklung kommt und von da nach unten in den Stamm und nach oben in das Blatt hinein sich verlängert. Man sieht namentlich auf Längsschnitten sehr schön, dass das oberste Gefässführende Blatt beispielsweise ein aus $2-3$ Zellen zusammengesetztes Gefässstück, das nächst untere ein etwas längeres, welches mitten im Parenchym verschwindet, das drittuntere endlich ein Gefässbündel besitzt, das sich in gesetzmässiger Weise mit einem andern vereinigt. Zuweilen kommt es auch vor, dass der untere Theil eines Spurstranges zunächst der Ansatzstelle fast gleichzeitig mit dem oberen angelegt wird, das mittlere Stück also zuletzt erscheint.

Die entschieden umgekehrte Entwicklungsweise, wobei die Gefässbündel von ihrer unteren Ansatzstelle nach oben wachsen und dann in das entsprechende Blatt ausbiegen, scheint bei Phanerogamen nur selten rorzukommen. Wir beobachteten sie bis jetzt nur bei Begonia dipetala, hier jedoch in so ausgeprägter Weise, dass man schon nach wenigen Schnitten durch die Terminalknospe darauf aufmerksam wird; indem immer neue Bündel, die der Stellung nach den höheren Blättern entsprechen, zwischen den schon vorhandenen auftreten. Für die Kryptogamen liefert Marsilea Nägeli, Beiträge I. Taf. 1 ein hieher gehöriges Beispiel, und allem Anschein nach rerhalten sich noch manche andere Repräsentanten ebenso. Sicher ist, dass von unten nach oben wachsende Gefässbündel fast bei allen Kryptogamen vorkommen; allein es ist in manchen Fällen zweifel-

Jass Schacht auf seinen "äusserst zarten Längsschnitten " dergleichen Dinge nicht gesehen hat (rgl. Mikroskop 3. Aufl. p. 146j, ist begreiflich; denn solche Schnitte sind am allerwenigsten geeignet, über die fraglichen Verhältnisse Aufschluss zu geben. Die Sache ist aber nichtsdestoweniger sehr einfach. Es handelt sich hier in der That nicht etwa um schwierige Objecte, die leicht zu Täuschungen Veranlassung geben, sondern einzig und allein um eine verständige Lntersuchungsmethode. Jeder, der sich die Mühe nimmt, 5-10 m. m. lange, noch im Wachsthum begriffene dünne Stammspitzen krautartiger Pflanzen zu halbiren und die beiden Hälften je nach Úmständen mit schwächerer oder stärkerer Kalilösung auf dem Objectträger zu behandeln, erforderlichen Falls auch auf dem Objectträger zu erhitzen und bei angemessenem Druck auf das Deckgläschen zu beobachten, wird sich von der Richtigkeit der obigen Darstellung leicht überzeugen. 
haft, ob diese Bündel wirklich Blattspuren darstellen, d. h. der Reihe nach in die successiven Blätter ausbiegen, oder ob sie vielleicht stammeigen sind, d. h. im Stamme bleiben und hier unausgesetzt nach oben wachsen. Stammeigene Bündel sind nämlich nur dann mit Sicherheit zu erkennen, wenn sie über die Ansatzstellen der untersten gefässlosen Blätter hinaufreichen. Sind z. B. $A$ und $B$ Fig. 276 die obersten Gefäss - führenden Blätter einer Stammspitze, so müssen die zwei im Stamme verlaufenden Bündel $s$ und $t$, an welche die Blattspuren sich ansetzen, ungefähr bis $n$ und o hinaufreichen, wenn sie sich als stammeigen erweisen sollen, oder es müssen wenigstens die Blattspuransätze für $C$ und $D$, wenn bei $x$ und $y$ bereits solche vorhanden sind, sich entschieden als spätere seitliche Bildungen herausstellen. Gehen die stammeigenen Bündel nur bis $p$ und $q$, so bleibt die Sache zweifelhaft, da sie ja immer noch nach $C$ ' und $D$ ausbiegen könnten, in welchem Falle sie natürlich als Blattspuren zu deuten wären. Gerade diesem letzteren Stadium begegnet man aber bei manchen Kryptogamen am häufigsten,

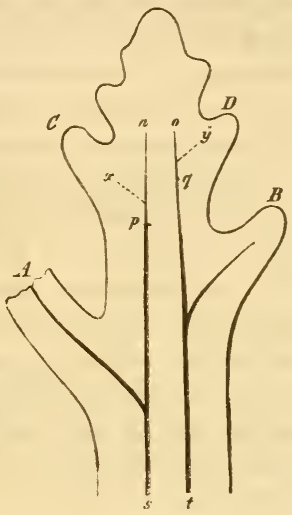

Fig. 276 . und wir glaubten um so eher darauf aufmerksam machen $\mathrm{zu}$ müssen, als dasselbe von Unger irrthümlich als Beleg für die Stammeigenheit angeführt und abgebildet wurde.

So lange man keine entscheidenden Stadien beobachtet hat, müssen die Untersuchungen fortgesetzt werden, da möglicherweise andere Stammspitzen sich günstiger erweisen. Sollte es sich herausstellen, dass die Blattspuransätze durchweg gleichzeitig mit der nach oben gehenden Fortsetzung angelegt werden, ohne dass sich entscheiden liesse. welcher der beiden $Z_{w}$ eige den Stammstrahl bildet, dann ist eine Lösung der Frage durch directe Beobachtung gar nicht möglich.

Ist die Art und Weise, wie die einzelnen Gefässbündel im $\mathbf{5 6 4}$ Stamme angelegt werden und in der Längsrichtung sich fortentwickeln, festgestellt, so kann noch die weitere Frage in Betracht kommen, wie die Entwicklung der Gefässbündel im Querschnitt vor sich gehe und ob vielleicht ein und dasselbe Bündel sich in verschie- 
denen Höhen ungleich verhalte. Es ist klar, dass die successiven Querschnitte auch über diesen Punkt Aufschluss geben; ja es genügt eigentlich schon die genaue Betrachtung eines einzigen Querschnittes, um allfällige Verschiedenheiten zwischen den Blattspuren der nächst oberen und denjenigen der höheren Knoten festzustellen. Denn es lässt sich voraussehen, dass die eben hereingetretenen Blattspuren sich tiefer unten im Stamme gerade so verhalten werden wie diejenigen, welche bis zum Niveau der Schnittfläche bereits eine entsprechende Zahl von Internodien durchlaufen haben. Die Vergleichung der verschiedenen Blattspuren in Querschnitt muss also dieselben Ergebnisse liefern, wie das Verfolgen einer bestimmten Blattspur durch die successiven Internodien.

Als Beispiel einer merklichen Verschiedenheit des Querschnittes im obern und untern Theil der Blattspuren mag hier die Palmengattung Chamaedorea Erwähnung finden. Die Veränderungen im Bau der spurstränge, welche bei dieser Pflanze vorzugsweise in die Augen fallen, bestehen darin, dass der obere Theil viel Holz Xylem mit Spiralgefässen und wenig Bast, der untere dagegen wenig $\mathrm{Holz}$ mit porösen Gefässen und viel Bast besitzt. Wenigstens gilt diess für die inneren Stränge, welche tief in das Mark eindringen; die Verschiedenheit ist um so geringer, je mehr sie der Rinde genähert bleiben.

*) Vgl. Nägeli, Beiträge z. wiss. Bot. I, S. 19 u. 132. 


\title{
Preisverzeichnisse
}

\section{der neueren Mikroskopverfertiger.}

\author{
Ni. 1. \\ E. Hartnack, Nachfolger von G. Oberhäuser in Paris, \\ Place Dauphine 21. *
}

(Preise in Francs.

1864 .

\section{A. Preise der Mikroskope.}

1. Achromatisches Mikroskop No. 1 mit zwei Linsensystemen und 2 Ocularen, Vergrösserungen von 50, 65, 220-300. Mit einer Linse zur Beleuchtung opaker Gegenstände, 12 Glasplatten, Messingpinzette, Skalpell und Präparirnadeln in verschliessbarem Mahagonikästchen . . . . . . . . . . . . $100 \mathrm{Fr}$.

Dasselbe Instrument mit drei anderen Linsensystemen und einem Ocular, um 600 fache Vergrösserung zu erhalten . . . . . . . . . 150 Fr.

2. Achromatisches Mikroskop No. 2, coudirt mit einem breiteren Objecttisch und drehbarem Diaphragma, Vergrösserungen von $50,65,220-300$ in einem ähnlichen Kästchen . . . . . . . . . . . . . . $115 \mathrm{Fr}$.

Um Vergrösserungen bis zu 660 zu erhalten . . . . . . . $165 \mathrm{Fr}$.

3. Achromatisches Mikroskop mit kleinem Trommelstativ, feststehendem und breiterem Objecttisch, Vergrösserungen von 50, 65, 220-300 mit drehbarem Diaphragma, in

ähnlichem Kästchen . . . . . . . . . . . . . $140 \mathrm{Fr}$.

Un Vergrösserungen bis zu 600 zu erhalten . . . . . . . . . . . . $190 \mathrm{Fr}$.

3. a. Achromatisches Mikroskop No. $3 \mathrm{~A}$, ähnlich dem obigen Instrumente, aber mit einem hufeisenförmigen Fusse und einem Gelenke zum Schiefstellen; Vergrösserungen

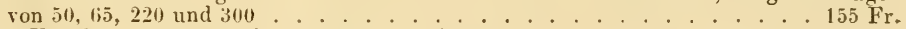

Un Vergrösserungen bis zu 600 zu erhalten. . . . . . . . . . 205 Fr.

4. Achromatisches Mikroskop No. 4; Vergrösserungen ron $50,65,220-300$, nit drehbarem Tische (schwarzer Glastafel), Cylinderblendungen und Beleuchtungslinse für opake Objecte in Mahagonikästchen . . . . . . . . . 300 Fr.

Mit drei an leren Linsensystemen und einem Ocular um Vergrösserungen bis zu 600 zu erhalten . . . . . . . . . . . . . . 360 Fr.

5. Achromatisches Mikroskop, grosses Stativ No. 5; Vergrösserungen 50, 65, 150, 172, 220 und 300 mit drehbarem Tisch (schwarzer Glastafel), Cylinderblendungen, Beleuchtungslinse, in Mahagonikästchen. . . . . . . . . 340 Fr.

Iit drei anderen Linsensystemen und einem Ocular, um Vergrösserungen bis zu 600 zu erhalten . . . . . . . . . . . . . $400 \mathrm{Fr}$.

6. Achromatisches, bildumkehrendes Dissektionsmikroskop, mit grosser Fokaldistanz, um darunter zu arbeiten; Vergrösserungen ohne Linsen- und Ocularwechsel von 10-100, mit drehbarem Glasplatten-Tisch, in Mahagonikasten. . . . . . 250 Fr.

7. Neues, grosses Stativ, dessen dioptrische und mechanische Construction wesentlich von dem älteren grossen (O b erhäus er'schen) Gestell abweicht.

${ }^{*}$ ) Für das südwestliche Deutschland und die Schweiz sind Hartnack'sche lnstrumente durch den Optiker Th. Erus $\mathrm{t}$ in $\mathrm{Z}$ ï rich zu beziehen. 
Dieses ganz neu hergestellte Instrument bietet Vortheile dar, welche mit dem früheren Stativ nicht zu erhalten waren.

Es besteht aus 5 Linsensystemen, ron denen eines mit Immersion und Correctionsapparat, und 5 Ocularen, eines darunter mit Mikrometer. Die Vergrösserungen dieser Systemreihen und ()culare erlauben alle wissenschaftlichen Arbeiten.

$\mathrm{Zu}$ diesem Instrumente gehört eine grosse Beleuchtungslinse für opake Objecte; ferner die nothwendigen Hilfsapparate, Glasplatten, Scheibe mit farbigen Gläsern, alles enthalten in einem Mahagonikasten. . . . . . . . . . . 750.Fr.

Dasselbe Stativ mit einem Charnier, welches schiefe Stellung gestattet . . 800 Fr.

๖. Neues kleineres Gestell, dessen Einrichtung dieselben Vortheile darbietet, wie No. 7, mit Ausnahme des drehbaren Objecttisches, mit 3 Linsensystemen und 3 Ocularen; Vergrösserungen 50 - 601 (1)

$275 \mathrm{Fr}$.

Dasselbe Stativ mit drei Linsensystemen, von welchen eines mit Immersion und Corrections-Apparat und drei Ocularen, eines derselben mit Mikrometer . . . $390 \mathrm{Fr}$.

Mit einem Charnier zur Schiefstellung erhöht sich der Preis des erwähnten Stativs um weitere $50 \mathrm{Fr}$.

Mikroskope "pour hospices" mit 300 facher Vergrösserung . . . . . $60 \mathrm{Fr}$.

Dasselbe Instrument mit breiterem Objecttische, ähnlich dem Stativ No. 265 Fr.

Ein nener beweglicher Nikrometer kann bei allen diesen Instrumenten gebraucht werden. Verselbe zeigt mit grosser Genauigkeit, ohne dass eine Veränderang der Einrichtung vorgenommen werden muss, $1 / 10,0000 \mathrm{Mm}$.

5) Fr.

NB. Der Polarisationsapparat gestattet bei seiner Einrichtung eine Anwendnng

für die Instrumente von No. 3 an bis zu No. S.

\section{B. Kinzelpreise der Linsensysteme (welche man nach Bedürfniss an jedem Stative verwenden kann) und der sonstigen Apparate.}

\section{Systeme älterer Construction.}

System No. 1 nit dem mittleren Ocular vergrössert

$$
20
$$

12 Fr.

\begin{tabular}{|c|c|c|c|c|}
\hline , &, & & , & , \\
\hline , & , & & , & , \\
\hline , & , & & ", & , \\
\hline , & , & & , & , \\
\hline , & , & & $\because$ & , \\
\hline , & , & & , &, \\
\hline$:$, & , & & , & , \\
\hline$\Rightarrow$ & , & & , & , \\
\hline
\end{tabular}

$\begin{array}{ll},, & ,, \\ ,, & \text { ", } \\ , & \text {, } \\ , & \text {, } \\ , & \text {, }\end{array}$

40
50
65
100
200
300
400
500

20,

20

20 ,

30,

35,

35,

40,

60),

Neue Systeme mit grösserem Oeffnungswinkel.

System No. 1 mit dem mittleren Ocular vergrössernd

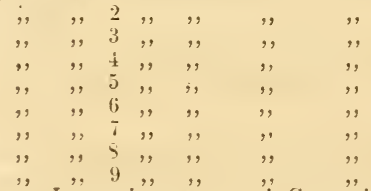

Neues Immersionssystem mit Correctionsapparat No. 9; Vergrösserung mit dem mittleren Ocular 6.50

Neues Immersionssystem mit Correctionsapparat No. 10; Vergrösserung mit dem mittleren Ocular 750

Neues Inmersionssystem mit Correctionsapparat Nr. 11; Vergrösserung mit dem mittleren Ocular 5.50

Dujardin'scher (achromatischer) Beleuchtungsapparat

Mikrometer, den Millimeter in 100 getheilt

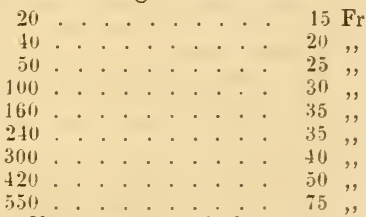

Camera lucida von Oberh äuser zugleich das Nikroskop in ein horizontales unwandelnd .

Camera lucida von II in e-Ed w a r ds und Do yère. . . . . . .

Jedes Ocular

Ocular mit Stellschraube. 
Beweglicher Objecttisch . . . . . . . . . . . . . . . $25 \mathrm{Fr}$.

Mikrophor von Strauss. . . . . . . . . . . . . . . . . . . 20, ,

Einfaches Compressorium . . . . . . . . . . . . . . 20,

Compressorium von $\mathrm{Qu}$ a tre f $\mathrm{g}$ e s . . . . . . . . . . . . 30,

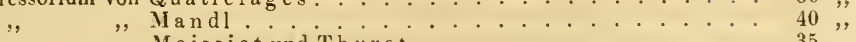

, "Maissiat und Thut ............ 35 ,

Lupen". . . . . . . . . . . . . . . . . 5-14,

Polarisationsapparate . . . . . . . . . . . 50-70,

Goniometer . . . . . . . . . . . . . . 60 ,

Glasplatten (Dutzend) . . . . . . . . . . . . . . . . . 2 , ,

Dünne Deckgläschen (Dutzend). . . . . . . . . . . . . . . . . . 1 ,",

1)ie Stative No. 1, 2, 3, 3 a sind mit Systemen älterer Construction versehen; die anderen Gestelle haben neue Systeme.

\section{Ni. 2. \\ Nachet \& Sohn in Paris, Rue St. Severin 17. \\ (Preise in Francs.) \\ 1563.}

1. Grosses Mikroskop mit verbessertem Stativ. An der horizontalen Axe aufgehängt, um eine Schiefstellung und Fixirung in jeder Position zu gestatten. Die gröbere Einstellung durch ein in der vierkantigen Stange verborgenes Triebwerk, die feinere durch eine an der Mitte des Rohres angebrachte Mikrometerschraube geschehend. Der Mechanismus letzterer Bewegung besteht in einer doppelten inneren Röhre, an welche die Objective angeschraubt werden und wo sie durch den beim Berühren des Objectes stattfindenden IViderstand aufsteigen können. Die gleiche federnde Röhre kann durch eine in der Mitte angebrachte Stellschraube und kleine Hebelvorrichtung fixirt werden. Das ganze Rohr in der Hülse drehbar. 1)rehbarer mit Glas eingelegter Objecttisch, mit einer durch eine Schraube beweglichen Vorrichtung zum Verschieben des Präparates, welches überdiess durch Federklemmen gehalten werden kann. Ebener und coneaver Spiegel mit einer Beweslichkeit für Anwendung der schiefen Beleuchtung. Eine zwisehen Spiegel und Tivch befindliche, senkreeht verstellbare und mit einem Hebel versehene Vorrichtung ge-tattet die Diaphragmen zu verändern und den Condensor mit grosser Sehärfe in den Jocus zu hringen. Vorrichtung, um den Glasmikrometer in jedes Ocular einzulegen; jener lässt sich durch eine kleine schraube in den Focus bringen und nach den versehiedenen Stellen des Sehfeldes bewegen. Acht Objectivsysteme mit Correctionsvorrichtung ron No. $0-7$ und Vergrösserungen von $30-1500$ linear, 3 Oculare. Goninometer, Camera lucida, Polarisationsapparat mit Gypsplatten, Condensor, Ocular und Objecttischmikrometer. Beleuchtungslinse für opake Gegenstände ; übrige Präparationsbedürfnisse, wie Glasplatten und feine Deckgläschen; anatomische Instrumente, wie Nadeln, Scalpelle, Scheeren, feine Pincette etc. Das ganze Instrument ist in einem starken, äusserlich mit messingenen Ecken und innen mit Sammtüberzuy versehenen Kasten enthalten, und die Linsensysteme überdiess in einem Maroquin-Etuis . . . . . . . . . . . $1300 \mathrm{Fr}$.

2. Grosses Mikroskop. Befestigung an der Axe und drehbarer mit eingelegtem Glas versehener Objecttisch, wie bei No. 1. Gröbere Einstellung durch Verschiebung des Rohres in der Hülse, feine durch eine Mikrometerschraube; beweglicher Träger der Diaphragmen und des Condensor; ebener und enncaver Spiegel mit freier Beweglichkeit für schiefe Beleuchtung. Mikrometer durch eine Vorrichtung in jedes Ocular einfügbar; 3 Oculare, 6 gewöhnliche Linsensysteme, No. 0, 1, 2, 3, 5, 7 mit Vergrösserungen von $30-1300$. Camera lucida, Objecttischmikrometer, Beleuchtungslinse, Präparationswerkzeuge etc., Mahagonikasten mit messingenen Ecken etc. . . $600 \mathrm{Fr}$.

3. Grosses vertikales Stativ mit drehbarem Tiseh, doppelter Bewegung zum Einstellen, einem Apparat zum Tragen und Ausweehseln der Blendungen und Beleuchtungsrorrichtungen, Glasmikrometer, durch eine Vorrichtung in jedes Ocular einzufüren, Objecttischmikrometer. Fünf gewöhnliche Linsensysteme, No. 1, 2, 3, 5 und 7 , welche nit 3 Ocularen Vergrösserungen von $70-1300$ ergeben. Camera lucida, Präparationswerkzeuge etc., in einem Kasten mit Handhabe . . . . . . . . . . 500 Fr. 
4. Mittleres, schief zu stellendes Stativ, etwas kleiner als das vorhergehende ; in Drehtisch, Einstellungs- und Beleuchtungsvorrichtungen dem vorigen ganz ähnlich, mit denselben Linsensystemen und Ocularen etc., Beleuchtungslinse und einem Kasten mit Handhabe . . . . . . . . . . . . . . . $420 \mathrm{Fr}$.

5. Mittleres, vertikales Mikroskop, ähnlich dem Instrumente No. 3, mit einfachem Mikrometerocular und Objecttischmikrometer, einer Beleuchtungslinse, in einem Kasten mit Handhabe . . . . . . . . . . . . . . . . $350 \mathrm{Fr}$.

6. Kleines, schief zu stellendes Mikroskop mit frei beweglichem Spiegel, einer Drehscheibe als Diaphragma, 2 gewöhnlichen Linsensystemen, No. 1 und 3, mit zwei Ocularen; Vergrösserungen von $30-380$, Beleuchtungslinse etc. . . . . . 150 Fr.

Dasselbe Instrument mit den Linsensystemen No. 1, 3 und 5, sowie 3 Ocularen und einer Vergrösserung bis zu 600 . . . . . . . . . . . . 200 Fr.

7. Kleines, vertikales Mikroskop, mit frei beweglichen Spiegel, 2 Linsensystemen No. 1 und 3 , zwei Ocularen und einer Beleuchtungslinse etc. . . . . . . . . 125 Fr.

Dasselbe Instrument mit 3 Systemen und 3 Ocularen, um Vergrösserungen bis zu $600 \mathrm{zu}$ gewinnen . . . . . . . . . 175 Fr.

Cylinder für Blendungen und Condensor in den Tisch der beiden Instrumente einfügbar.

$10 \mathrm{Fr}$.

๑. Drehbarer Tisch für die beiden letzten Instrumente . . . . . . 25 Fr.

9. Einfaches kleines Mikroskop (Trommelgestell, mit einem Ocular und einer schwachen, sowie dem System No. 3 mit einer bis 300 gehenden Vergrösserung . . . . 70 Fr.

10. Binoculäres stereoskopisches Mikroskop, mit einem schief zu stellenden Stativ, zwei verstellbaren Röhren, grober und feiner Bewegung, 3 Systemen No. 0, 1 und 3. 500 Fr.

11. Binoculäre stereoskopische Vorrichtung, um an älteren Instrumenten angebracht zu werden, mit verstellbaren Röhren und 2 Ocularen . . . . . . $150 \mathrm{Fr}$.

Dieselbe Einrichtung mit einem ähnlichen, aber etwas stärkeren Stativ wie No. 6 , 3 Systemen und 2 Ocularen etc. . . . . . . . . . . 350 Fr.

12. Stereoskopische und pseudoskopische binoculäre Vorrichtung . . . . $225 \mathrm{Fr}$.

13. Mikroskop mit zwei Röhren zur Beobachtung für zwei Personen, mit 3 Objectivsystemen, Beleuchtungslinse etc. ............... $300 \mathrm{Fr}$.

14. Vorrichtung derselben Art mit 2 Röhren, um an gewöhnliche Instrumente angebracht zu werden, nebst 2 Ocularen (aber ohne Linsensysteme) . . . . . . . s0 Fr.

15. Mikroskop mit 3 Röhren, grober und feiner Bewegung, 3 Linsensystemen, No. 0,1 und 3 etc. . . . . . . . 400 Fr.

16. Umgedrehtes Stativ für Chemiker, mit vergoldetem Objecttisch, + Linsensystemen, No. 0, 1, 3 und 5 , einem Ocular, einem beweglichen Ocularmikrometer, einem Goniometer, um die Winkel von Krystallen zu messen, und sonstigem Zubehör . . 350 Fr.

17. Taschenmikroskop $90 \mathrm{Mm}$. lang und $50 \mathrm{Mm}$. breit mit den Linsensystemen No. 1, 3 und 5 , einem Ocular etc. . . . . . . . . . . 200 Fr.

15. Dissections- und Observations-Mikroskop (auch als einfaches Mikroskop verwendbar), mit den Objectivsystemen 1 und 3 , einem Ocular und 3 Doublets ron verschiedener Stärke etc.

19. Stativ des vorhergehenden Instrumentes, nur als einfaches Mikroskop verwendbar, mit 3 Doublets etc. . . . . . . . . . . . . . . $50 \mathrm{Fr}$

20. Dissectionsmikroskop . . . . . . . . . . . . . 120 Fr.

21. Photographir-Mikroskope . . . . . . . . . . . 300 Fr.

\section{B. Einzelpreise der Linsensysteme und sonstigen Apparate.}

22. Gewöhnliche Linsensysteme ohne Correctionsrichtung.

$$
\begin{aligned}
& \text { No. "1- } 15 \mathrm{Fr} . \\
& , 1-20, \\
& , 20, \\
& , 3-25, \\
& , 4-30, \\
& , 5-35, \\
& , 6-50, \\
& , 7-50,
\end{aligned}
$$

24. Gewöhnliche Immersionssysteme.

$$
\begin{gathered}
\text { No. } j-50 \text { Fr. } \\
, 6-f i l, \\
, i-1(0),
\end{gathered}
$$

23. Linsensysteme mit Correctionsapparat.

$$
\begin{gathered}
\text { No. } 3-50 \mathrm{Fr} . \\
, 4+60, \\
, 5-75, \\
., 4-100, \\
.7-125,
\end{gathered}
$$

25. Immersionssysteme mit Correctionsapparat.

$$
\begin{gathered}
\text { No. } 5-60 \text { Fr. } \\
, 6-120,, \\
, 75-150, \\
, 5-200,
\end{gathered}
$$


Die linearen Vergrösserungen der einzelnen Systeme mit den verschiedenen Ocula ren gestalten sich im Allgemeinen, wie folgt: No. 02555 , No. 160150 , No. 2 125-290,No. $3200-420$, No. $4250-500$, No. $5300-600$, No. $6450-900$, No. $7560-1350$, No. $8650-1500$.

26. Einfaches Mikroskop.

$60 \mathrm{Fr}$.

27. Einfaches stereoskopisches Jikroskop . . . . . . . . . . . . . . 60 ,"

28. Grösserer Lupenträger . . . . . . . . . . . . . . . . . . . . . . . 40,

29. Kleinerer Lupenträger . . . . . . . . . . . . . . . . . . . . . 15 ,"

30. Derselbe ohne Triebrad . . . . . . . . . . . . . . . . . . s,",

31. Brücke'sche Iupe . . . . . . . . . . . . . . . . . . . . . 15 ,,

32. Joublets, $20-5 \mathrm{Mm}$. Focallänge . . . . . . . . . . . . . . . 6 , ,

Uieselben mit einem Focus von 5 - 2 IIm. . . . . . . . . . . . . . . 10,

33. Objecttischmikrometer in Messing gefasst, der Millimeter in to0 Theile . . 10,

34. Derselbe, den Millimeter 500 fach getheilt . . . . . . . . . . . 20 ,",

35. ,, ,, , looofach, . . . . . . . . . . . 30 ,

36. Camera lucida (eigenthümlicher Construction) . . . . . . . . . . 25,

37. Gewöhnliche Camera lucida . . . . . . . . . . . . . . . . 1s,,

3५. Bildumkehrendes Prisma . . . . . . . . . . . . . . . . . . . . . . . 25,

39. Dasselbe verbessert und mit einem Ocular versehen . . . . . . . . . . . 35,

40. Revolvervorrichtung, zum schnellen Wechseln der Linsensysteme . . . . 25 ,,

41. Condensor für gerade Beleuchtung . . . . . . . . . . . . . . . 25 ,,

42. ,, für schiefes Licht . . . . . . . . . . . . . . . . 15 ,

13. Amici'sches Beleuchtungsprisma . . . . . . . . . . . . . . 25,

4. Beleuchtungsvorrichtung auf schwarzem Grunde . . . . . . . . . . . . . 15 ,"

45. Polarisationsapparat mit zwei Nicols . . . . . . . . . . . . . . 10 ,",

46. Goniometer . . . . . . . . . . . . . . . 25, ,

47. Compressorium. . . . . . . . . . . . . . . . . 25,

tร. Oculare . . . . . . . . . . . . . . . . . . 10 ,"

49. Mikrometer Ocular . . . . . . . . . . . . . 15 ,

50. Handlupe . . . . . . . . . . . . . . . . . . . . . . . 与,",

51. Grosse Lupen von schwacher Vergrösserung . . . . . . . . . . . . $5-12$,",

52 . Coddington'sche Lupe etc . . . . . . . . . . . . . . . . . 5, ,

\title{
No. 3.
}

\section{Simon Plössl in Wien. Wieden, 'Theresianumgasse No. 12.}

\section{(Preise zu österreichischer Währung.}

\author{
1563.
}

1. Lupe nach Wilso $\mathrm{n}$, nit einer Linse in messingener Fassung. . . . I fl. ts kr.

2. Derlei aplanatisch aus zwei achromatischen Linsen von 6- bis 25 maliger Vergrösserung . . . . . . . . . . . . . . . fl. $-\mathrm{kr}$.

3. Derlei mit zwei Linsen, mit Deckeln . . . . . . . . . . . . . 3, ,,

4. Einfache Lupe, in Büffelhorn gefasst . . . . . . . . . . . . 1,,24,

5. Derlei doppelte. . . . . . . . . . . . . . . . . . . . . . 2 ,, 20,

6. Derlei dreifache . . . . . . . . . . . . . . . 3 , , ,

7. Lupe, in Büffelhorn gefasst, mit gläsernem Li e be rk ü h n'schen Spiegel 3,20, ,

$\checkmark$ Aplanatische Lupe, aus zwei achromatischen Linsen zusammengesetzt, von i" bis $2^{\prime \prime}$ im Durchmesser, von 3- bis bmaliger Vergrösserung, in Messing gefasst, in Futteral von Maroquin . . . . . . . . . . . . 5-9 fl. - kr.

Baumgartner's und ron Ettingshausen's Zeitschrift, Bd. VIII. S. Is9.

9. Derlei aus zwei achromatischen Linsen von $1 / 2$ " bis $1^{\prime \prime}$ im Durchmesser, zum Auseinanderschieben, um sie auch einzeln zu gebrauchen (wie Doppel-Lupen), von 6- bis 16 maliger Vergrösserung, in Elfenbein gefasst. . . . . $5 \mathrm{fl}-\mathrm{kr}$.

10. Botanisches Handmikroskop mit 3 Linsen, mit Li e berkühn'schen Spiegeln, auf messingenem Griffe, Objectnadel, Messerchen und Nadel mit elfenbeinernen Heften und Pincette, in Futteral ron Maroquin. . . . . . . . . $15 \mathrm{fl}-\mathrm{kr}$.

\footnotetext{
-) Wurde uns 1866 als neuestes Preisverzeichniss eingesendet.
} 
11. Derlei mit elfenbeinernem Griffe, einer Linse mit Lieberkühn'schem Spiegel, einer Lupe und Objectnadel, in Futteral von Maroquin .

6 fl. $30 \mathrm{kr}$.

12. Derlei mit schildkrötenem Griffe . . . . . . . . . . . . . . . \&, - ,

13. Pincette, Messerchen und Nadel dazu . . . . . . . . . . . 1 ,, 20 ,"

1. Grosses zusammengesetztes Mikroskop, dessen Körper durch Triebwerk gegen den feststehenden Objecttisch bewegt wird und einer Mikrometerschraube zur höchst feinen Einstellung bei den starken Vergrösserungen, auf messingenem Postamente, auf welchem sich auf einem Arme das Mikroskop in seiner Axe bewegen lässt, mit drei Ocularen und neun achromatischen Linsen; der starke Linseneinsatz ist so eingerichtet, dass derselbe mit oder ohne Deckgläser gebraucht werden kann. Der Objecttisch mit zwei Klammern für Objectträger und Glastafeln aller Art; einem gläsernen concaven Reflexionsspiegel zur transparenten Beleuchtung auf einem beweglichen Doppelarme, um auch unter jedem beliebigen Winkel beleuchten zu können, der schwarzen Rückseite desselhen, und einem sphärischen Beleuchtungsprisma (nach Selligue mit Bewegung, zur Beleuchtung opaker Objecte. Einer grossen Lichtverstärkungslinse bei Lampenlicht anzuwenden) auf besonderem Fusse zur Verstärkung der Beleuchtung bei stärkeren Vergrösserungen sowohl transparenter als opaker Objecte; einem concaven Glase für Flüssigkeiten, einer mcssingenen Wils on'schen Lupe und einer messingenen Pincette, dazu noch zwei auf Glas getheilte Mikrometer mit Theilungen der Wiener Duodecinallinie in 30 und 60 Theile, oder des Millineters in 25 und 50 Theile, in messingener Einfassung, und sind in das Ocular No. 2 einzuschieben und mittelst einer daran angebrachten Schraube zum Einstellen für das Auge vorgerichtet. Alles in einem hölzernen polirten Kasten mit Schloss, beiläufig $14^{\prime \prime}$ lang, $9^{\prime \prime}$ breit und 5 t/2" hoch, mit Sammt gefüttert. Die Vergrösserungen gehen von $2.5 \mathrm{mal}$ bis zu $500 \mathrm{mal}$ linear, oder $625 \mathrm{mal}$ bis $250,000 \mathrm{mal}$ der Fläche, mit vollständiger Klarheit und Schärfe, zusammen um . . . . . . . $20 \% \mathrm{fl}-\mathrm{kr}$.

$\mathrm{Zu}$ obigem Mikroskop einen Iinseneinsatz, der mit dem No. 2 Ocular eine 700 malige Linearvergrösserung gibt

$63 \mathrm{fl} .-\mathrm{kr}$.

Ein solches Mikroskop mit der Vorrichtung zum Messen der Objecte bis auf 0,00001 Par. Zoll linear, mittelst Mikrometerschraube nach Fra e $\mathrm{nh}$ of er . $302 \mathrm{fl}$. - kr.

Ein aplanatisches Ocular aus zwei achromatischen Linien, mit schwacher Vergrösserung von $10-12 \mathrm{mal}$, um besonders opake Objecte mit höchster Schärfe zu sehen

Ein Prisma zu diesem Mikroskope zum Horizontaleinsehen und zum Zeichnen

$15 \mathrm{fl} .75 \mathrm{kr}$.

2. Kleines zusammengesetztes Mikroskop, dessen Körper durch Triebwerk gegen den feststehenden Objecttisch bewegt wird, auf messingenem Postamente, mit 2 Ocularen aus einfacher Linse und Collectivglas bestehend, zum Aufstecken, und sechs achromatischen, aplanatischen Linsen. Der starke Linseneinsat/ ist so eingerichtet, dass derselbe mit und ohne Deckgläser gebraucht werden kann. 1)er Objecttisch mit zwei Klammern für Objectträger und Glastafeln aller Art; einem gläsernen concaven Reflexionsspiegel zur transparenten Beleuchtung, auf einem beweglichen Doppelarme, um auch unter jedem Winkel beleuchten zu können, der schwarzen Rückseite desselben, und einer Beleuchtungslinse mit Bewegung für opake Objecte; einem concaven Objectglase für Flüssigkeiten und zwei flachen Glastafeln für trockene Objecte. Eine Wilson'sche Lupe, in Messing gefasst, und eine messingene Pincette. Zwei auf Glas getheilte Mikrometer mit Theilung der Wiener Duodecimallinie in 30 und 60 Theile oder des Millimeters in 25 und 50 Theile, in messingener Fassung, und sind in das Ocular No. 1 einzuschieben und mittelst einer daran angebrachten Schraube zum Einstellen für das Auge vorgerichtet. Die Vergrösserungen gehen von 25- bis $350 \mathrm{mal}$ linear, oder von 625 - bis $122,500 \mathrm{mal}$ der Fläche. Alles in einem hölzernen polirten Kästchen mit Schloss und mit Sammt gefüttert, heiläufig $11^{\prime \prime}$ lang, $63 / s^{\prime \prime}$ breit und $t^{2} / 2$ " hoch . . . . . . . . . . . . $95 \mathrm{fl}$. $\mathrm{kr}$.

3. Zusammengesetztes Taschen- oder Reisemikroskop nit einem auf dem Deckel des Kästchens aufzuschraubenden Fuss, dèssen in zwei Hälften zerlegbarer und in einander zu schraubender Körper auf einem horizontal beweglichen Arme steht; mit einem durch Triebwerk gegen die Linsen zu bewegenden Objecttische mit zwei lilammern, zwei Ocularen und sechs achromatischen Linsen, wovon der starke Einsatz so eingerichtet ist, dass derselbe mit und olıne Deckgläser gebraucht werden kann; einem beweglichen Reflexionsspiegel auf einem beweglichen Arme, um auch unter jedem beliebigen Winkel beleuchten zu können, dessen schwarze Rückseite nebst einer beweglichen Beleuchtungslinse zum Aufstecken, zur Beleuchtung opaker Objecte dient; einem flachen und concaven Glase für flüssige und trockene Objecte, und 
einer messingenen Pincette. Die Vergrösserungen gehen von 25- bis 350mal linear, oder 625 - bis 122,500 mal der Fläche. Alles in einem polirten Kästehen, mit Sammt gefüttert und mit Schlos`, beiläufig $5^{1} / 2^{\prime \prime}$ lang, $4 \frac{1}{2}{ }^{\prime \prime}$ breit und $1 \frac{1}{2}$ " hoch $\$ 4 \mathrm{fl}$. - $\mathrm{kr}$.

4. Kleineres zusammengesetztes Reisemikroskop auf messingenem Fusse, dessen Körper auf horizontalem festen Arme steht; mit einen durch 'Triebwerk gegen die Linsen beweglichen Objecttische mit zwei Klammern, einem Oculare und vier achromatischen Ohjectlinsen zum Uebereinanderschranben ; einem beweglichen concaven Reflexionsspiegel für transparente Objecte, dessen schwarze Rückseite nebst einer bewegliehen Beleuchtungslinse zum Anfstecken, zur Beleuchtung opaker Objecte dient, einem flachen und coneaven Glase für flüssige und trockene Objecte und einer messingenen Pincette. Die Vergrösserungen gehen von 25 - bis $150 \mathrm{mal}$ linear, oder 625 - bis 22,500 der Fläche. Alles in einem mit Leder gefütterten Futteral von Maroquin $55 \mathrm{fl}$ - $\mathrm{kr}$.

5. Neues kleines, nach eigener Idee zusammengesetztes Arbeitsmikroskop auf rundem messingenen Fusse, dessen Körper auf horizontalen beweglichen Arme steht, mit einem durch Triebwerk gegen die Linsen beweglichen Objecttische mit zwei Klammern, einem Oculare und drei achromatischen Objectivlinsen, einem beweglichen concaven Reflexionsspiegel für transparente Objecte, einem flachen und concaven Glase, einer Objectnadel zum Aufstecken und einer messingenen Pincette.

Dieses Mikroskop ist so eingerichtet, dass es die Objecte nicht verkehrt zeigt; daher kann man bequem Objecte unterm Mikroskop zergliedern.

Die Vergrösserungen gehen von 20 - bis 240 mal linear oder 400 - bis 57,600 der Fläche, welche durch Verlängerung des Mikroskopkörpers stufenweise hervorgebracht werden können. Mit einem Maroquinfutteral . . . . . . $54 \mathrm{fl}$ - $\mathrm{kr}$.

6. Einfaches Reise- oder Taschenmikroskop mit einem auf dem Deckel des Kästchens aufzuschraubenden Gestelle, einem durch 'Triebwerk gegen die Linsen zu bewegenden Objeettische mit zwei Klammern, für Objectträger und Glastafeln aller Art; einem gläsernen concaven Reflexionsspiegel mit doppelter Bewegung, zwei planen und einem concaven Objectglase; einer Objectnadel nit Pincette zum Áufstecken und eine messingene Pincette. Dazu sechs getasste Doppellinsen nach W oll a s to n, auf einem beweglichen Arme, welche Vergrösserung von 12- bis 300mal linear oder 141bis $90,000 \mathrm{mal}$ der Fläche geben. Alles in einem polirten hölzernen Kästchen, mit Sammt gefüttert, beiläufig $5^{1} / 2$ " lang, $4^{\prime \prime}$ breit und $2^{\prime \prime}$ hoch . . . . . $59 \mathrm{fl}$. - $\mathrm{kr}$.

7. Derlei Mlikroskop mit einfachen Linsen . . . . . . . . . . . . . 12 fi. $-\mathrm{kr}$.

$\checkmark$ Derlei Mikroskop mit drei Doppellinsen nach Wolla s to $n$, welele Vergrösserungen von 12 - bis luomal linear oder $14 \mathrm{t}$ - bis $110,000 \mathrm{mal}$ der Fläche geben . $32 \mathrm{fl}$. - $\mathrm{kr}$.

9. Derlei mit 3 einfachen Linsen

$26 \mathrm{H}$. $-\mathrm{kr}$.

10. Sonnenmikroskop, ganz von Messing, mit einer $4^{\prime \prime}$ grossen Beleuchtungslinse, 6 achromatischen Objectivlinseneinsätzen, nebst einer Lupe, Pincette und 6 Objectschiebern mit Probeobjecten. Alles in polirtem Kasten mit Schloss. $155 \mathrm{fl}$. - kr.

11. Derlei mit einer $3^{\prime \prime}$ grossen Beleuchtungslinse, vier achromatischen Objectiven zum Uebereinanderschrauben, nebst Lupe, Pineette und 4 Objectschiebern mit Probeobjecten. Alles in polirtem Kasten mit Schloss . . . . . . . $105 \mathrm{fl} .-\mathrm{kr}$.

12. Gasmikroskop mit einer $3^{1} / 2^{\prime \prime}$ grossen Beleuchtungslinse, sechs achromatisehen Objectivlinseneinsätze, einer Uhr zur Umdrehung des Kalkcylinders, alles so eingerichtet, dass nur ron dem Gasapparat, welcher hier nicht mitbegriffen ist und nur auf besondere Verabredung geliefert wird, die Gasleitungsröhren anzupassen sind. Jinseneinsätze, Iupe, Pincette und sechs Objeetsehieber mit Probeobjecten ; in einem hölzernen polirten Kästchen . . . . . . . . . . . . . $210 \mathrm{fl}$. $\mathrm{kr}$.

13. Derlei mit einer $3^{\prime \prime}$ grossen Beleuchtungslinse, drei achromatischen Objectivlinseneinsätzen, den Kalkcylinder nittelst einer Schraube nachzustellen, und so eingeriehtet, dass nur die Gasleitungsröhren anzupassen sind. Die zwei Objectsehieber mit Probeobjeeten, eine Lupe und Pincette; in Futteral von Maroquin. $105 \mathrm{f} .-\mathrm{kr}$.

14. Eine Mikrometertheilung auf Glas von 20 bis 60 Theilen linear der Wiener Duodeeimallinie; in einer Kapsel von Elfenbein

15. Eine derlei mit Theilung der Wiener Linie in 100 Theile

16. Eine derlei mit Theilung der Wiener Linie in 200 Theile

17. Eine derlei auf Elfenbein, die Wiener Linie in 20 Theile

15. Eine derlei auf Glas, das Mikrometer in ! 00 Theile

19. Apparat zum Elektrisiren unter dem Mikroskope im Ohjecttisch einzuklammern; in

Futteral von Maroquin . . . . . . . . . . $6 \mathrm{fl}-\mathrm{kr}$.

$4 \mathrm{fl} .-\mathrm{kr}$.

$5,,-$,

$6,,-$,

$3,,-$,

, , , ,

20. Zwölf Objectschieber, ganz Glas, zum Oeftnen, für sehr feine Objecte, hei starker Vergrösserung

21. Objectquetscher, nach Professor Purkinje

22. Objectquetscher, nach Plössl.

1i) $\mathrm{H} .50 \mathrm{kr}$.

$12,,-$,

10, , - , 
1. Camera lucida mit Prisma, nach Wollaston, mit Stativ in Futteral ron Maroquin. . . . . . . . $12 \mathrm{fl.}-\mathrm{kr}$.

2. Derlei zum Anschrauben an das Zeichnungsbrett angeheftet . . . . . 16 , - ,

3. Derlei mit Stativ, das aber zugleich angeschraubt werden kann . . . . 16 , - ,

4. Derlei ohne Prisma, mit metallenem Planspiegel, wo der Zeichnungsstift besser zu sehen ist, mit Stativ und Futteral von Maroquin. . . . . . . . . $16 \mathrm{fl}$ - $\mathrm{kr}$.

5. Derlei zum Anschrauben an das Zeichnungslirett vorgerichtet . . . . . $20,,-$,

6. Sömmering' scher Spiegelchenapparat an Mikroskope und Fernröhre jeder Art und Grösse anzuwenden . . . . . . . . . . . 6 fl. $30 \mathrm{kr}$. Obige Zeitschr. Band IV. S. 1.

7. Derlei mit Statir, um mit freiem Auge zu zeichnen, in Futteral von Maroquin 11 , , - ,

๙. Camera obscura mit einem sphärischen Prisma nach Chevalier); wird nach Verschiedenheit der Einrichtung auf besondere Bestellung geliefert.

Alle übrigen zum Unterrichte in der Optik erforderlichen Apparate werden auf besondere Bestellung und Verabredung verfertigt.

Es wird ersucht, bei Bestellungen den Jahrgang des Verzeichnisses, nach welchem die Bestellung gemacht wird, gefälligst anzuzeigen.

\section{No. 4.}

\section{F. W. Schiek in Berlin. Halle'sche Strasse No. 15.}

\section{Preise in Thalern.}

$$
1563 .
$$

\section{A. Grösstes zusammengesetztes Mikroskop.}

Nach Oberhäuser.)

Auf messingenem Hufeisenfuss. Zum Ueberlegen construirt. Der Tisch ist um seine Axe drehbar. Die grobe Einstellung des Objects geschieht durch Zahn und Trieb, die feine durch Cylinder oder Prisma. Schiefe Spiegelstellung und Cylinderblendungen, welche auf- und abzubewegen sind. Es enthält 6 vollständige Systeme Objectivlinsen, 3 orthoskopische und ein einfaches Ocular, eine Beleuchtungslinse, Insektenglas, Handpincette, Probeobjecte, Object- und Deckgläser etc. in rerschliessbarem Nahagonikasten. Linearvergrösserung $20-1500 \mathrm{mal}$. . . . . . . . . . 200 Thlr.

\section{B. Gronses zusammengesetztes Mikroskop.}

Auf messingenem zusammenzulegenden Dreifusse.

Die grobe Einstellung des T'ubus wird durch Zahn und Trieb bewirkt, die feinere durch eine Druckschraube gegen den Objecttisch. Es enthält sechs Systeme Objectivlinsen, 3 orthoskopische und ein einfaches Ocular, eine Beleuchtungsinse, eine Lupe, ein Insektenglas, eine Handpincette, zwei Ohjectenschieber mit \& Probeobjecten und ein Dutzend Objectenträger und Deckgläschen, Alles in einem verschliessbaren Mahagonikasten. Linearvergrösserung $20-1500 \mathrm{mal}$. . . . . . . . . . $170 \mathrm{Thlr}$.

Wird dazu ein Schraubenmikrometer verlangt, so erhöht diess den Preis un 30 Thlr., mithin bis auf. . . . . . . . . . . . 200 Thlr.

\section{Vittleres zusammengesetztes Mikroskop.}

Das Stativ ist wie bei rorhergehendem; mit fünf Systemen Objectivlinsen, einem orthoskopischen und drei einfachen Ocularen, einer Belcuchtungslinse, einer Lupe u. s. w. Iinearvergrösserung $20-\varsigma 00 \mathrm{mal}$

100 Thlr.

\section{Kin Mikroskop nach dem grossen Oberhäuser'schen Modell.}

Der Tisch, um seine Axe drehbar, mit fünf Systemen Objectivlinsen, drei orthoskopischen und einem einfachen Ocular u. s. w. Linearvergrösserung 20-900mal . . 130 Thlr.

N13. Diese Mikroskope sind für schicfe Spiegelstellung eingerichtet und mit Cylinderblendungen versehen, welche auf-und abzubewegen sind. 


\section{E. Vittleres zusammengesetztes Mikroskop.}

(Nach O berhäuser.)

Auf messingenem Hufeisenfuss. Nicht zum Ueberlegen construirt. Der Tisch ist um seine Axe drehbar. Die grobe Einstellung geschieht mit dem Tubus aus freier Hand, die feine durch Prisma. Schiefe Spiegelstellung. Schieberblendung unter dem Objecttisch. Es enthält 3 Objectivlinsen und 2 vollständige Objectivsysteme, drei Oculare etc. in verschliessbarem Mahagonikasten. Linearvergrösserung $25-600 \mathrm{mal}$. $100 \mathrm{Th} / \mathrm{r}$.

\section{F. Kleines zusammengesetztes Mikroskop.}

An einer Säule construirt.

J) grobe Finstellung durch Verschiebung des Tubus in einer Hülse, die feinere Einstellung durch eine Schraube, welche gegen den Objecttisch wirkt, mit vier Objectivlinsen, einem orthoskopischen und zwei einfachen Ocularen u. s. w. Linearvergrösserung $35-500 \mathrm{mal}$

50 Thlr.

\section{(i. Kleines zusammengesetztes Mikroskop}

nach der Construction der kleinen Oberhäuser'schen Instrumente, dessen gröbere Bewegung aus freier Hand, die feinere aber durch eine Schraube-am Objecttisch bewerkstelligt wird. Es enthält rier Objectivlinsen and zwei Oculare u. s. w. Linearvergrösserung $10-500 \mathrm{mal}$

40 Thlr.

\section{Einfaches Mikroskop.}

1)asselbe befindet sich ebenfalls in einem Mahagonikàstchen und enthält 3 achromatische. Objectivlinsen. Linearrergrösserung $40 \mathrm{mal} . \ldots . . . . .20$ Thlr.

\section{Einzelne Giegenstände.}

Ein Schraubenmikrometer

30 Thlr.

Ein Compressorium

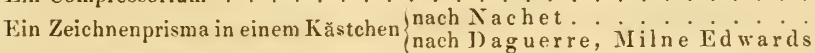

Ein orthoskopisches Ocular.

Eine Pincette

Fin einfaches Ocular.

Ein Ocularglasmikrometer, ein Nillimeter in 10 Theile

Fin Objectirnikrometer, ein $\mathrm{Mm}$. in $100 \mathrm{Th}$.

Ein Ocular mit verschiebbarem Mikrometer

Polarisation am Mikroskop

5 ,

6,

10,

6 ,

$10 \mathrm{Sgl}$.

4 Thir.

Ein Goniometer für das Mikroskop, zwei Minuten angebend, mit Mikrometerschraube versehen . . . . . . . . . . . . . T l l .

Ein Dutzend (jojectträger . . . . . . . . . . . . . . . . 24 Sgr.

Ein Dutzend Deckgläschen . . . . . . . . . . . . . . . . . . . . . . . 10 ..

Achromatische Lupen in Elfenbeinfassung, 6-, 10- und 15mal vergrössernd, das Stück

Eine Brï cke'sche achromatische Stativlupe ................

\section{No. 5.}

L. Bénèche in Berlin, Belle-Alliance-Strasse No. 33.

(Preise in Thalern.)

1866.

\section{A. Zusammengesetzte Mikroskope.}

A. Hufeisenförmiger Fuss; horizontal und vertikal verstellbarer Spiegel; Schlitten, um seitlich die Blendungen $z u$ wechseln; um die Achse drehbarer Tisch; Mikrometer- 
bewegung an der Tubussäule. - System 4. 7. \$. 10.11. Ocular 1 bis 5. Ocularmikrometer zum Einlegen. Das Mikroskop zum Umlegen . . . . . . 170 Thlr.

B. Stativ dem von A. gleich, nur etwas kleiner. - System 4. 7. 5. 9. Ocular 1 bis 5.

Ocularmikrometer zum Einlegen. Das Mikroskop zum Umlegen . . . . 100 Thlr.

Dasselbe Mikroskop mit System 4. 7. 5. 10 .

C. Hufeisenförmiger Fuss; horizontal verstellbarer Spiegel; Schieber zum verticalen Verstellen der Blendung; Mikrometerbewegung an der Tubussăule. - System 4. 7. 9. Ocular 2. 3. ̌. Ocularmikrometer zum Finlegen . . . . . . . . . 50 Thlr. Dasselbe mit System 4. 7. 10

so) ,

D. Runder Fuss; horizontal verstellbarer Spiegel; Mikrometerbewegung am Tisch; Blendung unterhalb des Tisches. - System 4. 7 . 8. Ocular 2. 3. 4

Dasselbe Mikroskop mit System 4. 7. 9 30 Thlr.

d. Runder Fuss; Mikrometerbewegung am Tisch; Blendung unterhalb des Tisches 2 Oculare; 8 Vergrösserungen; Ocularmikrometer; 6 Objectträger; 12 Deckgläschen; Pincette . . . . . . . . . . . . . $15 \mathrm{Thhl}$.

-E. Runder Fuss; Mikrometerbewegung am Tisch; Blendung unterhalb des Tisches; 1 Ocular; 3 Vergrösserungen . . . . . . . . . . . $10 \mathrm{Thlr}$.

\section{B. II ïlfsapparate}

zu zusammengesetzten Mikroskopen.

Goniometer .

Ocular mit verstellbarem Mikrometer

20 Thlr.

Polarisation (der Analyseur über dem System

Polarisation (der Analyseur unter dem Ocular) . . . . . . . . . . . . . . $20, "$

Beleuchtungslinse auf Stativ $3^{\prime \prime}$ Durchmesser . . . . . . . . . . . . . . . 15 ,"

Beleuchtungslinse auf Stativ $2 "$ Durchmesser . . . . . . . . . . . . . . 10 ",

Objectivmikrometer $100 \mathrm{Th} .=1 / 2 \mathrm{Mm}$. . . . . . . . . . . . 5 ,

Ocularmikrometer $10 \mathrm{Th} .=1 \mathrm{Mm}$. . . . . . . . . . . . . 1 ,

Compressorium

Zeichnenprisma . . . . . . . . . . . . . .

Oculare No. 1 bis 5 à Stück . . . . . . . . . . . . . . . . . . . 2 ,",

Objectträger mit ungeschliffenen Kanten à Dutzend . . . . . . . . . . . . 1/5 ",

Deckgläschen", geschliffenen Kanten à Dutzend

Den Mikroskopen A. bis E. liegen Objectträger und Deckgläser für den ersten

Gebrauch bei. Die stärksten Vergrösserungen lassen sich in ungefähren Zahlen bei $250 \mathrm{Mm}$. Sehweite, wie folgt, angeben:

Bei A. 2000 - B. 1300 - C. $900-$ D. 500 - d. 460 - E. 300.

\section{Präparirmikroskop.}

Ein Klotz mit Backen dient als Fuss; Mikrometerbewegung am Tisch; mit 2 Doublets

Dasselbe, mit 3 Doublets.

\section{Lupen.}

Präparir-Doppellupe auf Stativ

Aplanatische Lupe in Elfenbeinfassung.

$$
\text { , in Hornfassung }
$$

Dreifache Lupe in Hornfassung .

Doppellupe in Horn-oder Messingfassung

Einfache Lupe in Hornfassung

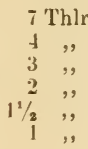

\section{Preise der einzelnen Objectivsysteme.}

System No. 4

No. 5

No. 7

No.

No. 9

No. 10

Immersion mit Correction 
No. 6.

Carl Zeiss in Jen a.

Preise in Thaleru.)

$1>66$.

\section{A. Zusammengesetzte Miliroskope.}

1. Grosses zusammengesetztes Mikroskop; (Stativ ()) hufeisenfösmigér Fuss, drehbarer Tisch, S'chlitten um die Cylinderdiaphragmen zu wechseln ohne das Object zu verrücken, Hohl- und Planspiegel, seitlich, hoch und niedrig zu stellen, grobe Einstellung des Tubus durch Verschiebung, feine durch Mikrometerschraube. - Systeme A. B, C, D, E, F ; Oculare 1, 2, 3, 4; Vergrösserungen 20 bis 1500 . Polarisationsapparat; grosse halbkugelige $3^{\prime \prime}$ im Durchmesser haltende Beleuchtungslinse auf Stativ; Camera lucida zum Zeichnen; Vorrichtung zur Messung der Dicke der Deckgläser 1)eckglastaster); Objectivmikrometer $1 \mathrm{NIm}$. getheilt in 100 Theile. Ocularmikrometer; Compressorium . . . . . . . . . . . . . 200 Thlr.

2. Dasselbe Instrument; Systeme A, C, D, F; Oculare 1, 2, 3, 4; Vergrösserungen 20 bis 1500 ; Camera lucida zum Zeichnen; Deckglastaster; Ocularmikrometer $133 \mathrm{Thlr}$.

3. Grösseres zusammengesetztes Mikroskop; Stativ I b) hufeisenförmiger Fuss; drehharer Tisch, gewölbte Blendungsscheibe dem Objectträger sehr genähert, Hohl- und Planspiegel durch eine neue Einrichtung nicht nur seitlich, sondern auch nach vorn verstellbar, um von jeder Seite schiefes Licht geben zu können, grobe Einstellung des Tubus durch Verschiebung, feine durch IIikrometerschraube. - Systeme A, B, C, D, E, F ; Oculare 1, 2, 3, 4; Vergrösserlingen 20 bis 1500 ; Polarisationsapparat, grosse halbkngelige $3^{\prime \prime}$ im Durchmesser haltende Beleuchtungslinse auf Stativ; Camera lucida zum Zeichnen; Deckglastaster; Objectivmikrometer $1 \mathrm{Mm}$. getheilt in 100 Theile; Ocularmikrometer; Compressorium . . . . . . . . . . . 156 Thlr.

4. Dasselbe Instrument; Systeme A, C, D, F ; Oculare 1, 2, 3, 4; Vergrösserungen 20 bis 1500 ; Camera lucida zum Zeichnen; Deckglastaster; Ocularmikrometer 116 Thlr.

5. Dasselbe Instrument; Systeme A, C, E; Oculare 1, 2, 3, 4; Vergrösserungen 20 bis 900 ; Camera lucida zum Zeichnen; Ocularmikrometer

$90 \mathrm{Thl}$.

6. Grösseres zusammengesetztes Mikroskop; (Stativ I) runder ringförmiger Fuss, gewölbte Blendungsscheibe, Hohl- und Planspiegel nicht nur seitlich, sondern auch nach vorn verstellbar, grobe Einstellung durch Verschiebung, feine durch Yikrometerschraube. - Systeme A, B, C, D, li, F; Oculare 1, 2, 3, 4; Vergrösserungen 20 his 1500; Polarisationsapparat; grosse halbkugelige Beleuchtungslinse auf Stativ; Camera lucida zum Zeichnen; Deckglastaster; Ocularmikrometer. . . . 166 Thlr.

7. Dasselbe Instrument; Systeme A, C, D, F ; Oculare 1, 2, 3, 4; Vergrösserungen 20 bis 1500 ; Camera lucida zum Zeichnen; Deckglastaster; Ocularmikrometer 105 Thlr.

จ. 1)asselbe Instrument; Systeme C, F ; Cculare 1, 2, 3, 4; Vergrösserungen 50 bis 1500

73 Thlr.

9. Dasselbe Instrument; Systeme A, C, E; Oculare 2, 3, 4 ; Vergrösserungen 30 bis 900 .

69 Thlr.

10. Dasselbe Instrument; Systeme C, E; Oculare 1, 2, 3, 4: Vergrösserungen 50 bis 900

65 Thlr.

11. Dasselbe Instrument; Systeme A, D; Oculare 2, 3, 4; Vergrösserungen 30 bis 740

jt Thlr.

12. Mittleres zusammengesetztes Mikroskop: (Stativ II) runder Fuss; Blendungsscheibe, Spiegel etc. wie bei I, nur ein wenig kleiner; Systeme C, E, F; Oculare 1, 2, 3, 1; Vergrösserungen 50 bis 1500 ; Ocularmikrometer . . . . . . . ST Thlr.

13. Dasselbe Instrument; Systeme A, C, E; Oculare 2, 3, 4; Vergrösserungen 30 bis 9(1): Ocularmikrometer

65 Thlr.

14. Dasselbe Instrument; Systeme $\mathrm{A}$, 1) Oculare 2, 3, 4; Vergrösserungen 30 bis 740

47 Thlr.

15. Kleineres zusammengesetztes Mikroskop; Stativ III b) hufeisenförmiger Fuss, das Uebrige wie bei I nur kleiner; Systeme A, C, D, F; Oculare 1, 2, 3, 4; Vergrösserungen 20 bis 1500 ; Deckglastaster; Ocularmikrometer (s. Schacht, mdas Mikroskop" III. Aufl. S. 290 . . . . . . . . . . . . . . . 91 Thlr.

16. Dasselbe Instrument; Systeme A, C, E; Oculare 1, 2, 3, 4; Vergrösserungen 20 bis 900 ; Ocularmikrometer

65 Thlr. 
17. Wasselbe Instrument; Systeme C, F; Oculare 1, 2, 3, 4; Vergrösserungen 50 bis 1501 ; Ocularmikrometer. . . . . . . . . . 65 Thlr.

15. Dasselbe Instrument; Systeme A, D; Oculare 2, 3, 4; Vergrösserungen 30 bis 740

19. Dasselbe Instrument ; System C ; Oculare 2, 3, 4, Vergrösserungen 75 bis $330 \quad 36$ ",

20. Kleineres zusammengesetztes Mikroskop; (Stativ III c) viereckiger schwerer Fuss, drehbarer Tisch, das Uebrige wie bei I, nur kleiner; Systeme A, B, C, D, E, F; Oculare 1, 2, 3, 4; Vergrösserungen 20 bis 1500; Camera lucida zum Zeichnen; Deckglastaster; Ocularmikrometer . . . . . . . 130 Thlr.

21. Dasselbe Instrument; Systeme A, C, D, F; Oculare 1, 2, 3, 4; Vergrösserungen 20 bis.1500 ; Camera lucida zum Zeichnen; Deckglastaster; Ocularmikrometer 104 Thlr.

22. Dasselbe Instrument; System A, C, E; Oculare 2, 3, 4; Vergrösserungen 30 bis 900 ; Ocularmikrometer . . . . . . . . . . . Thlr.

23. Dasselbe Instrument; Systeme A, D; Oculare 2, 3, 4; Vergrösserungen 30 bi 741 . . . . . . . . . . 53 Thlr.

24. Kleinstes zusammengesetztes Mikroskop; (Stativ IV) runder Fuss; seitlich verstellbarer Hohlspiegel; grobe Einstellung durch Verschiebung, feine durch Mikrometerschraube; Grösse wie III b; Systeme A, C, E; Oculare 2, 3, 4; Vergrösserungen 30

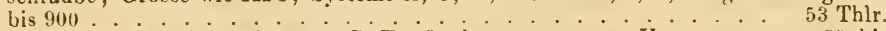

25. Nasselbe Instrument; Systeme C, E; Oculare 1, 2, 3, 1 ; Vergrösserungen 50 bis 900 . . . . . . . . . . . . $49 \mathrm{Thl}$.

26. Dass. Instr. : Syst. A, D ; Oculare 2, 3, 4; Vergrösserungen 30 bis 740. . 35 ",

27. Dass. Instr.; Syst. C; Oculare 1, 2, 3, 4: Vergrössermugen 50 bis 330.230 ",

25. Dass. Instr.; Syst. C; Oculare 2, 3; Vergrösserungen 75 bis 200 . . . . 27 ,",

29. Dass. Instr.; Syst. A ; Oculare 2, 3;.Vergrösserungen 30 bis $115 . . .21$ "

30. Kleinstes zusammengesetztes Mikroskop, (Stativ V) runder Fuss, Finstellung des Tubus durch Verschiebung, Grösse wie III b; Syst. A; Oculare 2, 3; Vergrösserun-

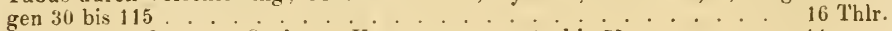

31. Jass. Instr.; Syst. A Ocular 2; Vergrösserungen 30 bis $75 . . .214$,

Die verschiedenen Statire, die oben an den betreffenden Stellen näher beschrieben sind, werden zu folgenden Preisen notirt:

\begin{tabular}{|c|c|c|c|c|c|}
\hline Stativ & 0 & nclus. & Etuis & 55 & Thlr. \\
\hline , & 1 & , & ,, & $2 i$ & ," \\
\hline , & I b & , & , & 35 & , \\
\hline ,, & II & ," & ," & 20 & ," \\
\hline ," & $111 \mathrm{~b}$ & ,", & , , & is & ," \\
\hline , , & III c & ," & ," & 26 & , , \\
\hline , & $1 \mathrm{~V}$ & ", & ,, & 11 & ," \\
\hline
\end{tabular}

Die Stative 1", I, I b, bilden die grossen, II ein mittleres, III b, III c , IV und V die kleineren Stative.

\section{Veryrösserungen der Systeme.}

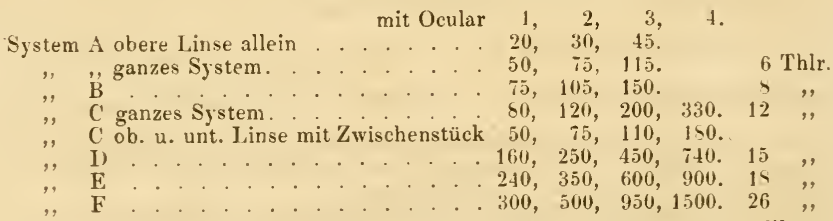

NB. Die obere Linse von A gibt, allein gebraucht, wenn auch kein ganz vollkommenes (von einer Linse unmöglich, , so doch ein für viele $Z$ wecke brauchbares Bild.

Bei Anwendung von $\mathrm{C}$ obere und untere Linse wird das zu C gehörige Messingzwischencylinderchen zwischen die obere und untere Linse geschraubt, die mittlere Linse aber weggelassen, während bei Anwendung des ganzen Systems jenes Cylinderchen ausser Gebrauch kommt.

Bei System $\mathbf{E}$ und $\mathbf{F}$ sind die mittleren Gläser nur eingesteckt und können nach $\mathrm{Ab}-$ schrauben des untersten Glases leicht herausgezogen werden. Beim Wiedereinstecken ist auf das Zeichen zu achten. 


\section{Oculare.}

No. $1,2,3,4$, jedes

2 Thlr.

Bei Verbindung meiner Systeme mit andern Stativen, welche einen abweichenden Beleuchtungsapparat haben, ist der Effect mit durch jenen Apparat bedingt. Verănderungen anderer Stative, behufs Armirung mit meinen Systemen, können mit Ausnahme des nöthigen kleinen Zwischengewindes an dem Tubus, nicht übernommen werden.

Sollte Jemand für seine $\mathrm{Zwecke}$ eine andere Combination wünschen als in den 31 Nummern oben zusammengestellt sind, so wird der Preis derselben aus den letzten Zeilen leicht ersichtlich und reicht bei den betr. Aufträgen die einfache Ausdrucksweise wie I. C, F; 1, 2, 3, 4. 73 Thlr.

vollkommen aus.

$$
\text { III b A, C, D, F; 2, 3, 4. -3 , etc. }
$$

\section{B. Nebenapparate}

des zusammengesetzten Mikroskops.

32. Ocularmikrometer zum Einlegen in's Ocular $5 \mathrm{Mm}$. in 50 Theile, in Etuis 3 Thlr.

33. Mikrometerocular No. 2 mit $5 \mathrm{Mm}$. in 50 Theile

34. Objectivmikrometer $2 \mathrm{Mm}$. in 50 Theile, in Etuis

35.

36.

37.

$1 \mathrm{Mm} .,, 50$,, ,, ,

$1 \mathrm{Mm} ., 100,,,,$,

$1 / 2 \mathrm{Mm} ., 100$

3). Vorrichtung zur Messung der Dicke der Deckgläser, Deckglastaster, mit $1 / 10$ Millimeter angebend, Schätzung bis $0,0.5$ genau, in Etuis .

39. Camera lucida, Zeichenprisma zum Mikroskop, nach $\mathrm{Nachet,} \mathrm{in} \mathrm{Etuis}$

40. Camera lucida nach $\mathrm{Nob}$ er $\mathrm{t}$, in Etuis

41. Camera lucida aus 2 Prismen

42. Compressorium, mikroskopischer Quetscher, eingerichtet, dass man den Gegenstand zugleich mit der Object- und Deckplatte, so wie man ihn früher zur Beobachtung hatte, zwischen den Quetscher und mit solchem zurück unter das Mikroskop bringen kann, in Etuis .

43. Beleuchtungslinse auf Stativ, 3" Durchinesser, halbkugelförmig, in polirtem Etuis

15 Thlr.

44. Beleuchtungslinse, $1^{1 / 2}$ " Durchm., mit Kugelbewegung, zum Einstecken in Fuss, für Stativ I.

45. Dies. wie vorher, mit Messingfuss, auch für die übrigen Stative anwendbar "; ",

47. Polarisationsapparat zum Mikroskop mit 2 Nicols, der Analyselur über dem System, in Etuis

15 Thlr.

4. Derselbe Apparat mit Flintglas-Condensorlinse, Hoch- und Nidrigstellung der letzteren und des Polariseurs, separater Drehung des Objects und Jinrichtung zum Unterlegen dünner Plättchen, mehr für die grösseren Stative anwendbar, in Etuis 20 Thlr.

49. Derselbe Apparat wie vorher, der analysirende Nicol von grosser Oeffnung im Ocular, zu welchem Zweck ein separates Ocular No. 2 verwendet wird in Etuis . 23 Thlr. NB. Bei Bestellung von Polarisationsapparaten zu früher gefertigten Stativen müssen diese letzteren eingesendet werden.

\section{Einfache Mikroskope.}

50. Einfaches Mikroskop, fester 'Tisch, grobe Finstellung durch Verschiehung, feine durch Schraube, drehbarer Planspiegel, darüber eine verstellbare Beleuchtungslinse. Das Ganze liegt in einem polirten Nussbaumetuis und ist zum Daraufschrauben eingerichtet Beigegeben sind 4 Doublets von 15-, 30-, 60- und 12ufacher Vergrösserung . . . . . . . . . . . 16 Thlr.

51. Dasselbe Instrument mit $15-, 30-$ und 17 facher Vergrösserung . . . . 13 ,,

52. Dasselbe lnstrument mit 15-, 30- und fiofacher Vergrósserung, ohne Beleuchtungslinse, aber mit Präparirfuss zum Präpariren . . . . . . . . . . 13 Thlr.

53. Dasselbe Instrument ohne Beleuchtungslinse mit 10-, 15- und 30facher Vergrösserung und Präparirfuss, hauptsächlich zum Präpariren . . . . . . . . . 12 Thlr.

Die 10fache Vergrösserung wird als Lupe in Extraetuis beigegeben und gibt nach

Entfernung des oberen Glases eine 5 fache Vergrösserung.)

54. Präparirfuss von Nussbaumholz mit Backen zum Auflegen der Hände und Messingmutter zum Aufschrauben des Instruments. Einzeln . . . . . . . 20 Sgr. 
j5. Einfaches Mikroskop, ähnlich wie die vorhergehenden, aber mit einem grossen Tisch

( Quadratzoll Par. M.). Der Beleuchtungsspiegel auch für seitlichschiefe Beleuchtung eingerichtet. Unter dem Tisch eine Drehscheibe mit vershiedenen Blendungen und eine Beleuchtungslinse. Dazu ein Präparirfuss ron Mahagoni mit Backen und Messingmutter. Beigegeben sind 4 Doublets mit 15-, 30-, 60- und 120fach 9 r Vergrösserung. Alles liegt in einem Mahagonietuis, worin noch 2 kleinere für die Linsen und andere Utensilien . . . . . . . . . . . . . . 20 Thlr.

(Die 3 schwächeren Vergrösserungen haben einen zum Präpariren bequemen Focalabstand.

56. Dasselbe Instrument wie das vorhergehende mit 15-, 30- und 60facher Vergrösserung, hauptsächlich zum Präpariren 1; Thlr.

57. Dasselbe wie vorher, mit noch einer Lupe mit 10-und 5facher Vergrösserung 19 ,,

Die diesen Instrumenten beigegebenen Linsencombinationen, Doublets werden auf Verlangen auch einzeln in speciellen Etuis abgegeben. Preis wie folgt :

5`. Doublet mit 15 maliger Linearvergrösserung in Etuis .

59. , , , $30 \quad$,

bi).,,, 60,

61 .

N'B. Obige Doublets passen in alle früher oder "später gefertigten einfachen M̆$^{\prime}$

,

"s kroskope obiger Art.

62. Kleinstes Taschenmikroskop für Moossammler mit 5-, 10- und 30facher Linearvergrösserung, Tisch und Planspiegel und eingerichtet zum Aufschrauben des Stativs auf den Deckel des Etuis, welches nur $65 \mathrm{Mm}$. lang und $50 \mathrm{Mm}$. breit ist . . $5^{1} / \mathrm{s}$ Thlr.

63. Kleines Handmikroskop zur Untersuchung durchsichtiger Objecte mit 3ofacher Linearvergrösserung, einige Glasplättchen, Nadeln, einem Trichinenobject und einer Gebrauchsanweisung zur Untersuchung des Fleisches in No. 7 der Gartenlaube 1564 empfohlen), in Etuis

3 Thlr.

64. Lupe aus 2 Linsen mit 10 facher Vergrösserung, mit einem kleinen polirten Holzstativ, auf welches ein Objecttisch von Messing geschraubt, über dem sich die Lupe in einem Halter auf- und abschieben lässt. Anf dem Tisch eine Federklammer und unterhalb ein Planspiegel. Hiezu ein kleines Pappetuis zum Aufbewahren der Lupe, und Objectplatten

3 Thlr.

65. Dasselbe Stativ mit 30facher Vergrösserung und Pappetuis zu Linsen und Objectplatten

66. Dasselbe mit 10 - und 30 facher Vergrösserung

4 T'hlr.

67. Dasselbe mit 10 - und 60 facher Vergrösserung

5 ,

6ৎ. Obige Lupe mit 10 facher Vergrösserung in leichter Messingfassung, nebst einem kleinen Gestell mit 2 Kugelbewegungen und einer Holzschraube, um die Lupe beim Gebrauch vom festen Punkt entfernen und das Gestell auf der Tafel befestigen zu können; für Präparationen unter Wasser, oder an verhältnissmässig grossen Gegenständen etc. zu medicinischem und ähnlichem Gebrauch

3 Thblr.

69. Lupe ans 3 Iinsen in Messing gefasst, mit 6maliger Linearvergrösserung, in Etuis

2 Thlr.

70. Vorrichtung, um dieselbe zur Präparation mit obigen einfachen Mikroskopen zu gebrauchen

71. Lupe aus 2 Linsen in Messing gefasst, mit 10maliger Vergrösserung den einfachen Mikroskopen ohne Zwischenstück brauchbar)

2 Thlr.

72. Lupe nach Wils on mit einer Linse in Messingfassung, ebenfalls zu obigen Instrumenten brauchbar. In Etuis

1 Thlr.

73. Lupe aus 2 Linsen, jede für sich allein, achromatisirt. In Messing gefasst. In Etuis

3 Thlr.

74. Lupe, einfache, mit 6maliger Linearvergrösserung. in Büffelhorn, zwischen Schalen zu Excursionen

75. Lupe, zweifache, mit 6- und 12 maliger Linearvergrösserung

15 Sgr.

6. Lupe, dreifache, mit $6-$ Excursionen . . . . . . . . . . . 12/5 Thlr.

77. Achromatische Lupe in Elfenbein, zwischen Elfenbeinschalen zum Einschlagen wie die vorhergehende, mit 2 achromatischen Linsen . . . . . . . $4^{3} / 3$ Thlr.

75 . Lupe, ärztliche, 2 Linsen von grösserem Durchmesser als die vorhergehenden, zwischen Schalen zum Taschengebrauch . . . . . . . . $1 \frac{1}{6}$ Thlr.

79. Lupe aus 2 planconvexen Linsen mit grosser Oeffnung, in Horn, zum Auseinanderschrauben.

s). Dergleichen mit einer biconvexen Linse, in circa 4 maliger Linearvergrösserung

$1^{1} / 6$ Thlr.

$15 \mathrm{Sgr}$. 


\section{Allgemeine Nebenapparate.}

81. Objectgläser Träger) aus geschliffenem Tafelglas, auf den Kanten facettirt, à Dtzd. $10 \mathrm{Sgr}$. 82. Dergleichen, auf den Kanten nicht facettirt, zum Aufbewahren der Objecte, à Dtzd.

\$3. Objectglas, in der Mitte hohl geschliffen, für Flüssigkeiten, à Stück . . . 15

\$4. Deckgläser, à Dutzend

85. Dergleichen, von bestimmter Stärke, à Dutzend . . . . . . . . . . . i $^{1} "$ ",

86. Kleine Maassstäbchen von Messing, einen Decimeter lang, in 100 Millimeter getheilt. Die Kante ist facettirt, um Distanzen auf Zeichnungen direct mit dem Maassstab messen zu kömen . . . . . . . . . . . . . $15 \mathrm{Sgr}$.

87. Messingring für Kork, zur Bereitung botanischer Pflanzenschnitte . . . $\quad-1 / 2$,

85. Botanisches Besteck, Lederetuis, enthaltend ein Skalpel, eine Stahlpincette mit Schieber, eine anatomische Scheere, eine Nadel in Heft . . . . . . . . $2^{1 / 3}$ Thlr.

89. Botanisches Besteck, Lederetuis, ausser den Gegenständen der vorigen Nummer noch enthaltend ein Heftchen mit zwei runden Nadeln zum Wechseln und ein Heftchen mit zwei lanzettförmigen Nadeln

3 Thlr.

90. Stahlpincette mit feinen, innen glatten Spitzen . . . . . . 12 Sgr.

91. Stahlpincette mit innen gerieften Spitzen u. einem Schieber zum Feststellen 20,,

92. Messingpincette, nach der Grösse . . . . . . . . . . 5-10,

93. Doppelpincette von Messing, die eine Seite mit Knöpfchen, hält das Object ohne Druck der Hand . . . . . . . . . . . . . $12 \mathrm{Sgr}$

94. Skalpel, Messerchen mit gerader Schneide . . . . . . . . . . 10 ,

95. Ein Heftchen mit zwei runden Nadeln zum Wechseln . . . . . . . . 9 ",

96. Ein Heftchen mit zwei breiten lanzettförmigen Nadeln zum Wechseln . . 9 ,",

97. Fine Nadel fest im Heft . . . . . . . . . . . . . . 5 ,

\section{No. 8.}

Fr. Belthle, Nachfolger von C. Kellner, in Wetzlar. (Preise in Thalern.)

1566.

\section{Mikroshope.}

1. Grosses Mikroskop. Grobe Einstellung durch Zahn und Trieb und feine desgl. mit Mikrometerschraube. - Polarisationsapparat. - Ocularglasmikrometer. - Zeichenapparat. - Spiegel concav und plan für schiefe Beleuchtung. - Bewegung des Instrumentes um die optische Axe. - Ocular orthoskopisch I., II., III. und IV. und System $0 ., 1 ., 2 ., 3$. und 4. Vergrösserungen von $25-15001 . . . .9120$ Thlr.

2a. Mittleres Mikroskop. Grobe Finstellung durch Zahn und Trieb und feine desgl. mit Mikrometerschraube. - Spiegel concar und plan, für schiefe Beleuchtung. Ocularglasmikrometer. - Bewegung des Instrumentes un die optische Axe. Ocular I., II., und III. System 0., 1., 2. und 3. Vergrösserungen von $25,35,50,75$, $110,145,15 \%, 220,300,320,500-700 \ldots . . .25$ Thlr.

Dasselbe ohne Bewegung um die optische Axe . . . . . . . . 80

2b. Mittleres Mikroskop. Mechanische Theile wie bei 2a. - Ocular I., II. und III. Sỵstem $0 ., 1$. und 3 . Vergrösserungen von $25,35,50,75,110,145,320,500-700$

75 Thlr.

3a. Kleines Mikroskop. Grobe Einstellung durch Tubusrerschiebung, feine desgl. durch Mikrometerschraube. - Spiegel für schiefe Beleuchtung. - Ocular I., II. und III. System 0., 1. und 3. Vergrösserungen von $25,35,50,75,110,145,320,500-700$

50 Thlr.

Dasselbe Mikroskop, mit einem weiteren Systeme 2. Vergrösserungen von 25, $35,50,75,110,145,150,220,300,320,500-700 \ldots \ldots$. . . . . . 60 Thlr.

3b. Kleines Mikroskop. Neues Modell. Grobe Einstellung durch Tubusverschiebung und feine desgl. durch Mikrometerschraube. - Spiegel für schiefe Beleuchtung. Tisch viereckig, Fuss viereckig. - Ocular I., II. und III. System 0., 1. und 3. Vergrösserungen von $25,35,50,75,110,145,320,500-700 . .+. .50$ Thlr. 
Dasselbe Mikroskop mit Bewegung um die optische Axe $55 \mathrm{Thlr}$

4a. Kleinstes Mikroskop. Grobe Einstellung durch Tubusverschiebung und feine desgl. durch Nikrometerschraube am 'Tisch (nach $\mathrm{Mohl}$ ). - Spiegel für schiefe Beleuchtung. - Ocular I. und II. System 0., 1. und 3. Vergrösserungen von 25, 35, 60,

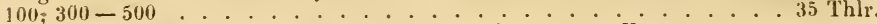

Dasselbe Mikroskop mit einem weiteren System 2. Vergrösserungen von 25, $35,60,100,140,220,300-500 \ldots . . . . . .45$ Thl.

th. Kleinstes Mikroskop. Grobe Einstellung durch Tubusverschiebung und feine desgl. durch Nikrometerschraube am Tisch (nach $\mathrm{M}_{\mathrm{O}} \mathrm{hl}$ ). - Spiegel für auffallendes Licht. Ocular I. u. II. System 1. und 3. Vergrösserungen von $60,100,300-50025$ Thhr.

tc. Mikroskop zur Untersuchung des Fleisches nach Trichinen. - 2 Oculare u. 1 System. Vergrösserungen ron $40-90 \ldots . . . . . . .15$ Thlr

Siehe Leuckart's Schrift zweite Auflage Untersuchungen über Trichina spiralis 1s66. Seite 109 .

万. Mikroskop. Bestimmt zur photographischen Aufnahme mikroskopischer Objecte, nach Ge rlach. System 3 und Ocular I., II. und III. . . . . . . . 40 Thlr.

Dasselbe Mikroskop ohne Beigabe der optischen Theile . . . . . . 20

Die Mikroskope 1-3 können auf Verlangen zum Umlegen, ebenso mit Hufeisenfuss eingerichtet werden.

Die Vergrösserungen obiger Mikroskope betragen auf s Zoll Sehweite bezogen, in Mittelzahlen:

\begin{tabular}{|c|c|c|c|c|c|c|c|}
\hline & Ocular 0. & Ocular I. & Ocular II. & Ocular III. & $\begin{array}{c}\text { Ocular IV. } \\
\text { orthosk. }\end{array}$ & \multicolumn{2}{|c|}{$\begin{array}{l}\text { Vocal- } \\
\text { Abstand. }\end{array}$} \\
\hline System 0. & 20 & 25 & 35 & 50 & 90 & 3,0 ： & Mm. \\
\hline System 1. & 60 & 75 & 110 & 145 & 155 & 5,5 & ," \\
\hline System 2. & 120 & 145 & 220 & 300 & 350 & 1,5 & , \\
\hline System 2a. & 200 & 220 & 350 & 500 & 550 & 1,45 & ," \\
\hline System 3. & 250 & 320 & 500 & 700 & 750 & 1,06 & , \\
\hline System 4. & 450 & 650 & 1200 & 1500 & 1580 & 0,5 & , \\
\hline System 5. & 500 & 700 & 1400 & 1500 & 1890 & 0,4 & \\
\hline
\end{tabular}

\section{Objectiv - Systeme.}

6. System 0 , mit einer achromatischen Linse

7. System 0. mit zwei achromatischen Linsen

$\checkmark$ System 1. mit zwei achromatischen Linsen

1). System 1. mit drei achromatischen Linsen

10. System 2 .

11. System 2a.

12. System 3 .

13. System 4. neueste Construction

14. System 5 .

\section{Immersionssysteme.}

15. System 1. Focus 1/8"

20 Thlr.

16. System 2. Focus

25,

17. System 3. Focus $1 / 16^{\prime \prime}$

30 ,

\section{Oculare.}

15. Orthoskopische Oculare I., II., III. u. IV.

(i) Thlr.

19. Aplanatische Oculare I., II., III. u. IV.

\%,

20. Gewöhnliche Oculare 0., I., II. u. III.

\section{Lupeu.}

21. Stativlupe zun Präpariren. Grobe Einstellung durch Schiebung, feine desgl. durch Mikrometerschraube, Doublett I., II. u. III. Vergròsserungen 10, 20 u. 30 is Thlr. Vocalabstand bei Doublett I. $17 \mathrm{Im}$., bei II. $10 \mathrm{IIm}$., bei III. $5,5 \mathrm{Mm}$.

22. Stativlupe zum Präpariren. Einstellung durch Schiebung mit e in em Doublett. 25 mal. Vergrösserung. Vocalabstand $6 . \mathbf{M m}$. 
23. Doppelte Handlupe, achromatisch. $10 \mathrm{mal}$. Vergrösserung mit grossem Sehfelde.

24. Doppelte Handlupe, achromatisch, $12 \mathrm{mal}$. Vergrösserung mit Etui und Griff 24. Doppelte Handlupe, achromatisch. 12 mal. Vergrösserung mit Etui und Griff 25. Einfache Handlupe, achromatisch. 6mal. Vergrösserung mit Etui und Griff.

26. Lupe nach Brücke je nach Grösse von 5 - 10 Thlr.

27. H aiding er'sche dichroskopische Lupe . . 2 Thlr. $15 \mathrm{Sgr}$.

\section{Nebenapparate.}

28. Polarisationsapparat nach Angabe von $\mathrm{H}$. v. Mohl je nach Grösse der Nicol'schen Prismen in Etui . . . . . . . . . . . . . . 10-15 Thlr.

29. Polarisationsapparat, Analiseur mit Turmalinplatte je nach Grösse des Nicols und der Platte . . . . . . . 6- . . . Thlr.

30. Heizbarer Objecttisch, nach Angabe von M ax Schultze. . . . . 10,

31. Ocularglasmikrometer, mit Fassung zum Einlegen, ganze Länge der Theilung $2 \% \mathrm{Mm} ., 1 \mathrm{Mm}$. in 10 Theile . . . . . . . . . . . . . 2 Thlr.

32. Ocularglasmikrometer, $1 \mathrm{Im}$. in 20 Theile $\ldots 2$ Thlr. 15 Sgr.

33. Mikrometerocular, orthoskopisch. Der Mikrometer fest in der Blende gefasst

34. Objectirmikrometer, $1 / 2 \mathrm{Mm}$. in 50 Theile . . . . . . . . . . . 4 Thlr.

35. Zeichenprisma, nach Ge rling in Etui . . . . . . . . . 4, ,

36. Zeichenprisma, nach Nobert in Etui . . . . . . . . . 4 Thlr. 15 Sgr.

37. Dasselbe, Prisma zum Verstellen . . . . . . . . . . . . . . . 5 Thlr.

35. Beleuchtungslinse, auf Stativ mit Kugelbewegung. 2" Durchmesser . . . 10 ,"

39. Beleuchtungslinse, auf Stativ mit Kugelbewegung. 1,5" Durchmesser . . 7 ,"

40. Beleuchtungslinse, auf Siativ mit Kugelbewegung. 1" Durchmesser. . . 5, ,,

41. Einrichtung für Cylinderblenden, mit Schlitten, zum Abschieben unter den Tisch 6 Thlr.

42. Einrichtung zum Horizontalsehen, bestehend aus einem rechtwinkeligen Prisma mit Knie, auf den Tubus aufzustecken

10 Thlr.

43. Compressorium

4. Objectträger mit concavem Ausschliff, per Dtzd. . . . . . . Thir. It S̈r.

45. Objectträger, gewöhnliche, per Dtzd. . . . . . . . . . . . 10

46. Objectträger, gewöhuliche, mit geschliffenen Kanten, per Dtzd. . . . . . 15 ,"

47. Deckgläschen, in gewöhnlicher Grösse, nach der Dicke sortirt und auf beiden Fläclien polirt von $1 / 5-1 / 20 "$ " Dicke, per Dtzd.. . . . . . . . . . . . 10 ,"

48. Deckg!äschen in gemischter Dicke und Grösse . . . . . . . . . . . . . 5 ,, Jedes Mikroskop ist in einem polirten verschliessbaren Etui sorgfältig verwahrt.

\section{No. 8. \\ G. \& S. Merz, vormals Utzschneider \& Fraunhofer, in München.}

1866.

\section{A. Complete Ilikroskope.}

Mikroskop No. 1 mit Stativ Nr. 1, vertical feststehender, horizontal drehbarer Tisch, grobe* und feine Bewegung am Tubus, Beleuchtung in und ausser der Axe, Doppelspiegel und Lupe foür opace Gegenstănde.

Das Instrument versehen mit 6 Objectivsystemen : $2 / 3{ }^{\prime \prime}, 1 / 9{ }^{\prime \prime}, 1 / 22^{\prime \prime}, 1 / 15^{\prime \prime}, 1 / 18^{\prime \prime}, 1 / 24$ ", und 5 Ocularen: $1.1 \% 2.2$. 3. 4., gewährt eine $60-1920$ malige Durchmesser-Vergrösserung. Es besitzt ein Schraubenmikrometer, welches noch 0.0001 eines pariser 
Zolles messen lässt, einen Polarisationsapparat und ein Compressorium. Das Ganze in elegantem Kästchen ............ . . $420 \mathrm{fl} .=240 \mathrm{Thlr}$. Mikroskop No. 2 mit Stativ No, 1, versehen mit 5 Objectivsystemen: '1/3", 1/9", '/12", $1 / 15^{\prime \prime}, 1 / 18^{\prime \prime}$ und 4 Ocularen: 1. $11 / 2.21 / 2,4 . ;$ gewährt es $60-1410$ malige Vergrösserung. Beigegeben sind ein Ocular- und ein Objectiv-Glasmikrometer, ein Polarisations-A pparat, ein Zeichnungsprisma u. ein Compressorium . . $250 \mathrm{fl} .=160 \mathrm{Thlr}$.

Mikrosk op No. 3 mit Stativ No. 1, rersehen mit + Objectivsystemen : '1/3", '/3", 1/12", 1/15" u. 3 Ocularen: 1. 2. 3., gewährt es 60-900 Vergrösserung. Beigegeben ein OcularGlasmikrometer . . . . . . . . $165 \mathrm{fl} .=96 \mathrm{Thl}$.

Mikroskop No. 4 mit Statir No. 2, vertical und horizontal feststehender Tisch, grobe /s. Anm. S. (615) und feine Bewegung am 'Tubus, Beleuchtung in und ausser der Axe, 1)oppelspiegel, ohne Lupe für opace Gegenstände.

Das Instrument versehen mit 2 Objectirsystemen: $1 / 3^{\prime \prime}, 1 / 12^{\prime \prime}$ und 3 Ocularen: 1. 2. 3., gewährt $60-720$ Vergrösserung ....... 7 . fl. $=44$ Thlr. Mikroskop No. 5 mit Statir No. 3, grobe Einstellung an Tubus, feine am Tische, Beleuchtung in der Axe.

Das Instrument hat 1 Objectivsystem: 1/," und 2 Oculare: 1. 2. von 200- und 400 maliger Vergrösserung . . . . . . . . . . $42 \mathrm{fl} .=24$ Thlr

\section{B. Mikroskopische Gegenstände.}

Objectivsysteme.

Brennweite der aequiv. Linse:

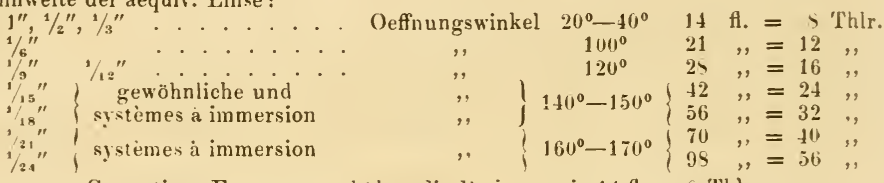

Corrections-Fassungen erhölen die l'reise um je $14 \mathrm{fl} .=\mathrm{S} \mathrm{Thlr}$.

Oculare: No. 1, 1 1/2, 2, 21/2, 3, 4

Ocularmikrometer, Ocular sammt Mikrometer

Objectivmikrometer, Millimeter in 100 Theile.

Schraubenmikrometer. , , , , , , , , , ,

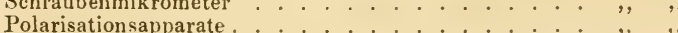

Zeichnungsprisma . . . . . . . . . . . ,, ,

Compressorien . .

Lupen: Doubletten von $5-, 12-, 17-, 24-$ u. 32 maliger Vergrösserung

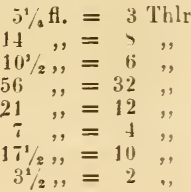

Bei Mangel an Reverenzen Versendungen nur gegen Nachnahme.

\section{No. 9.}

\section{Preis-Courant des optischen Instituts von $\mathbf{H}$. Schröder in $\mathrm{H}$ a m b u r g, holländischer Brook 31 .}

\section{Mark Hamb. Cour. = 12 Sgr.}

\section{A. Miliroskope.}

Stative in Kasten von Mahagoni.

1. Runder Fuss, runder Tisch, gerades und schräges Licht, Hohl- und Plan-Spiegel grobe Stellung aus freier Hand, feine Stellung durch eine federnde Platte nach Mo hl, drehbare Blendscheibe ........... 30 Mark = 12 Thlr.

2. Iufeisenförmiger Fuss, grosser ovaler Tisch, gerades und sehräges Licht, Hohl-und Planspiegel, grobe Stellung durch Trieb, feine Stellung durch eine federnde Platte nach $\mathrm{Moh}$ l, drehbare Blendscheibe . . . . . . 50 Mark $=20$ Thlr,

3. Runder Fuss, runder drehbarer Tisch, gerades und schräges Licht, Hohl- und Planspiegel, grobe Stellung durch Trieb, feine Stellung durch Mikrometerschraube, Blendungen von unten zu wechseln. 
4. Wreifuss, runder drehbarer Tisch, gerades und schräges Licht, Hohl- und Planspiegel, grobe Stellung durch Trieb, feine Stellung durch Mikrometerschraube, das ganze Instrument zwischen zwei Axen beweglich zum Neigen, Blendungsrorrichtung an einen Schlitten befestigt unter dem Objecttisch. . . . 150 Mk. $=60$ Thlr.

\section{B. Oculare.}

1. Gewöhnliche, aus 2 Planconvex-Linsen No. 1.2. 3. pr. St. .7 Mk. Sch. $=3$ Thlr.

2. Orthoskopische, aus 1 Biconvex-Linse und 1 Achromat. Nr. 1. 2.3. 4 pr. Stück

3. Aplanatische, aus 2 Achromaten. Nr. I und 2 . . pr. Stück $25,,=10$ Thlr

4. Aufrichtende (orthoskopisch) zum Präpariren . . . , , , , $25, ",=10,$,

\section{Systeme.}

No. 1. bestehend aus 2 durch ein Rohr getrennte Achromaten. Aequivalent 1/2" par.

$15 \mathrm{Mk} .=6 \mathrm{Thlr}$.

Dialytische Systeme.

No. 1. Aequivalent $1 / \mathrm{s}^{\prime \prime}$ par. ............ . 35 Mk. $=14$ Thlr.

No. 2.

No. 3 .

No. 4 .

$1 / 8 ", "$,
$1 / 12 ", "$,
$1 / 16 "$,

$35,=14$,

$42 \mathrm{Mk} .5 \mathrm{Sch} .=17$,

Diese Systeme zeichnen sich durch sehr schöne, helle und scharfe Bilder vor der gewohnlichen ältern Construction aus.

I $\mathrm{mmersionslinsen,}$

die durch einen Tropfen Wasser auf dem Deckglase mit dem Object verbunden werden, ausserdem eine Schraube zur Einstellung der Correction für verschiedene Deckglasdicken besitzen.

No. 1. Aequivalent '/s" etwas stärker wie Oberhä user's No. i zeigt bei gerader Beleuchtung, ohne Condensor, bei Pleurosigma angulatum Streifung. Abstand $5 /,-1 \frac{1}{2} \mathrm{Mm}$. Oeffnungswinkel $151^{\circ}$........ . $50 \mathrm{Mk} .=20 \mathrm{Thlr}$

No. 2. Aequivalent, $12^{\prime \prime}$. Oeffnungswinkel $160^{\circ}$. . . . . . . $65,,=26$, ,

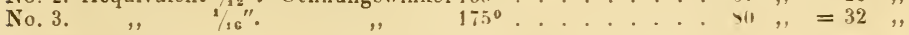

\section{Nebenapparate.}

1. I.ieberkühn'scher Spiegel zu No. 1

$$
15 \mathrm{Mk} .=6 \mathrm{Thlr} \text {. }
$$

2. Zwei kleine Polarisationsprismen, gefasst . . . . . . 1. " $=6$,

3. Zeichnenprisma, gleichseitig . . . . . . . $15, "=6$,

4. "nach Nachet. . ..... 17 Mk.8 Sch. = 7, ,

5. Ocularmikrometer $=1$ Centimeter in 100 Theile . . $\quad$ i $\mathrm{Mk}, \mathrm{Sch} .=3$,

6. Schraubenmikrometer . . . . . . . . $75 \mathrm{Mk}=31, "$,

Beleuchtungslinsen, Condensor, Quetscher etc., je nach der Grósse, Vollständigkeit und Eleganz, zu verschiedenen Preisen.

Alle zu einem Instrument ausgesuchten Theile werden ohne Erhöhung des Preises in einem Kasten rereinigt.

Ferner werden alle in das Gebiet der Optik fallenden Arbeiten auf Bestellung angefertigt. 
No. 10.

B. Hasert in Eisenach.

(Preise in Thalern.)

1564.

NB. Allestative sind fertig verpackt in Mahagonikistchen.

Grosses Stativ mit Drehtisch für gerade und schiefe Beleuchtung, mit achromatischer Condensationslinse für wenig schiefes Licht, mit 3 Ocularen und einer Beleuchtungslinse für opake Gegenstände zu . . . . . . . . . . . 40-50 Thlr.

Kleines Stativ mit Drehtisch für gerade und schiefe Beleuchtung, achromat Condensationslinse und Beleuchtungslinse für opake Gegenstände mit 2 Ocularen 25-27 Thlr.

Kleines Stativ ohne Drehtisch mit Cylinderblendung und schiefer Beleuchtung, Beleuchtungslinse für opake Gegenstände mit 2 Ocularen . . . . . . . . 15-17 Thlr.

A. Objective erster Qualität von 1/16 Zoll aequivalent Brennweite, welche ohne Immersion alle bekannten Probeobjecte vollständig lösen. . . . . . 45-50 Thlr.

B. Objective erster Qualität von ${ }^{1 / 12}$ Zoll. aequiralent Brennweite, welche ebenfalls die Sechsecke auf Pleurosigma angulatum rollständig gut zeigen, sowie auch die Streifen auf Grammatophora subtilissima ohne Immersion zu . . 35-40 Thlr.

C. Objective erster Qualität von $1 / 5$ Zoll aequivalent Brennweite, welche ebenfalls ohne Immersion die Sechsecke auf Pleurosigma angulatum gut zeigen bei jedem Licht, zu . . . . . . . . . . . . 20-25 Thlr.

D. Objective zweiter Qualität von geringeren Bremnweiten, welche die Querstreifen der Schmetterlingsschuppen und Streifungen ron Pleurosigma attenuatum gut zeigen, und wo durch Abschrauben der vorderen Linse zugleich ein niedrigeres Objectiv erzielt wird, von . . . . . . . . . . Die Preise der vollständigen Mikroskope können durch Addition der verlangten Objective leicht gefunden werden, z. B. :

Mikroskop ersten Ranges mit Objectiv A. C. und D, welches 4 Objectivergrösserungen gestattet von $60-2400$ linear, zu . . . . . . . . . . . . . 125 Thlr.

Mikroskop mit Drehtisch, kleines Modell, mit Objectiven $B$. und $D$., welche drei Objectivvergrösserungen gestatten, und welches für die schwierigsten Beobachtungen ausreicht, da dasselbe 1200-1500 linear. Vergrösserungen gibt, zu . . . . 75 Thlr.

Dasselbe mit Objectiven C. und 1).

$60-65$

Kleines Stativ ohne Irehtisch mit Objectiv $C$. und $\dot{1}$., welches zu den meisten Beobachtungen völlig ausreicht. Vergrösserung $600-700, \mathrm{zu} . . .936-50 \mathrm{Thl}$.

Das kleine Mikroskopstativ nit zwei Ocularen und einem Objectiv, dessen vordere Linse abschraubt und so ein zweites niederes Objectiv bildet, mit Vergrösserungen bis zu $400, \mathrm{zu}$. . . . . . . . . . . . . . 25-27 Thlr.

NB, Die besten Objectivsysteme werden ohne Immersion gebraucht, geben nebelfreie klare Bilcler, und die stärksten bedürfen keiner Correction für Deckglasdicken.

\section{No. 11.}

Franz Schmidt \& Haensch in Berlin, *) Dragonerstrasse No. 19.

\section{Preise in Thaleru.}

I $\$ 65$.

\section{A. Zusammengesetzte Hikroskope.}

1. Kleinstes Mikroskop No. 1. Mikrometerbe̊wegung durch Schieflegen des Tisches: mit 1 Ocular und 3 achromatischen Objectiven, 1 Pincette, 2 Präparirnadeln, Objectträger und Deckgläser in einem Mahagonikasten. Linearvergrösserung 40- bis 150mal (siehe Virchow's Schrift »über die Lehre von den Trichinen . . . . . 12 Thlr.

*) Das vollständige Prcisverzeichnisse dieser Firma (mit 122 Nummern und 16 Abbildumgen) ist durch die Hirs chwald'sche Buchhandlung in Berlin zu beziehen. 
2. Mikroskop No. 1 a. Dasselbe Modell mit Messingfuss. 2 Oculare. Linsensystem 1 und 2, 4, Objectträger und Deckgläser in einem Mahagonikasten. Linearvergrösserung bis $320 \mathrm{mal}$

25 Thlr.

3. Nikroskop No. 2. Kleines Modell S chiek. Die grobe Einstellung durch Verschieben des Tubus, die feinere durch eine Mikrometerschraube, welche den Objecttisch in eine schiefe Ebene lcgt; mit 2 Ocularen, System 1 und 2, 4, Objectträger und Deckgläser in einem verschliessbaren Mahagonikasten. Linearvergrösserung 20bis $350 \mathrm{mal}$

35 Thlr.

4. Mikroskop No. 3. Modell wie No. 2, nur grösser, mit vollendeter Spiegelbewegung. 3 Oculare, Systeme 1 und 2, 4, Objectschieber und Deckgläser in einem verschliessbaren Mahagonikasten. Linearvergrösserung 20 -bis $500 \mathrm{mal}$ (s. Abbild. No.6) $45 \mathrm{Thlr}$,

5. Mikroskop No. 4. Complettes Instrument, zum Ueberlegen construirt, der Tisch um seine Axe drehbar, die grobe Einstellung durch Verschieben des Tubus, die feinere mittelst Cylinder und Mikrometerschraube am Tubus. Bei Anwendung schiefer Beleuchtung ist die Cylinderblende durch den unter dem Objecttisch befindlichen Schlitten seitlich zu entfernen. Höbe des Instruments bei ausgezogenem Tubus 11", Grösse des Tisches : 3" lang, 3" breit. Zubehör : 3 Oculare, System 1 und 2, 4, 6. 1 Ocularmikrometer, Objectträger und Deckgläser; in einem verschliessbaren Mahagonikasten. Linearvergrösserung 20- bis $750 \mathrm{mal} . . .606$ Thlr.

Dieses Modell, von uns nach den bekanntesten Verbesserungen grösserer Stative zusammengestellt, erlauben wir uns ganz besonders zu empfehlen, da es den Anforderungen theurer Stative entspricht, und mit den Hülfsapparaten wie Polarisation etc. einzurichten ist.

t. Mikroskop No. 5. Modell wie No. 4, grösser auf 2 Säulen construirt, der Tisch um seine Axe vertical und horizontal drehbar, Cylinderblenden, die grobe Finstellung durch Zahn und Trieb, die feinere durch Mlikrometerbewegung am T'ubus. Der Spiegel zum Hoch- und Niederstellen, so dass das Object genau im Focus stehen kann. Höhe des Instrumentes 12", Grösse des Tisches 3" lang, 3" breit. Mit 4 Ocularen, System 1, 2 und 3, 4, >, 1 Ocularmikrometer, Objectträger und Deckgläser in einen verschliessbaren Iahagonikasten. Linearvergrösserung 10-bis $1100 \mathrm{mal} 100$ Thlr.

7. Mikroskop No. 6. Ganz grosses Modell, nach Art der grossen O ber häus er, auf 2 Säulen construirt, mit horizontaler und verticaler Bewegung, Cylinderblenden, die grobe Einstellung durch Zahn und Trieb, die feinere durch Mikrometerbewegung am T'ubus. Jer Spiegel zum Hoch- und Niederstellen. Höhe des Instrumentes 14", Grösse des 'Tisches $3^{\prime \prime} / 2^{\prime \prime}$ breit, $3^{1}{ }_{2}$ " lang. Zubehör: 5 Oculare, System 1, 2 und 3, 4, 6, 9. i Ocularmikrometer, Objectträger und Deckgläser, in einem verschliessbaren Mahagonikasten. Linearvergrösserung 20 - bis $1600 \mathrm{mal}$.

1 so Thlr.

Bei den Mikroskopen 1 a bis 6 sind die Linsensysteme von gleicher Güte.

\. Neues heliographisches Mikroskop, zur photographischen Aufnahme mikroskopischer Objecte. Der Preis richtet sich nach der Anzahl der beizugebenden Objectivsysteme und der gewünschten Construction.

\section{B. Einfache Mikroskope.}

9. Simplex nach Zeiss mit 2 Linsensystemen, auf den Mahagonikasten aufzuschrauben à .

12 Thlr.

10. Simplex nach $\mathrm{Z}$ e is s mit 3 Linsensystemen, auf den Mahagonikasten aufzuschrauben à.

14 Thlr.

Auf Wunsch wird diesen Mikroskopen ein Präparirklotz beigegeben, der gleichzeitig als Fuss dient, zum Preise von $20 \mathrm{Sgr}$.

\section{Preise der einzelnen Linsensysteme.}

11. System No. 1

12 .

13.

14.

15.

16.

17.

No. 1 und 2.
No. 1,2 und 3.
"No. 4.

Sämmtliche "Linsensysteme haben eine gemeinschaftliche Schraube, so dass "bei Nachbestellungen eine Zurücksendung des Mikroskops nicht erforderlich ist. 


\section{Nebenapparate.}

18. Aplanatische Doppellupe in Elfenbein

4 Thlr.

19. Brück e'sche Lupe auf Stativ

20. Zeichnenprisma nach Oberhäuser, im Etuis s. Abbild. No. 10)

21.

22.

, Nachet, im Etuis 's. Abbild. No. 11) "Nobert,

s. Abbild. No. 12 .

23. Beleuchtungslinse auf Stativ, $3^{\prime \prime}$ Durchmesser

25. Ocularmikrometer, "10 Theile $=1 \mathrm{Mm}$.

26. Objectivmikrometer, 100 Theile $={ }^{1 / 4} \mathrm{Mm}$.

27. Polarisation am Mikroskop

25. Schraubenmikrometer

29. Compressorium (s. Abbild. No. i3)

30. Objectenträger à Dutzend

31. Deckgläser à Dutzend

32. Gewöhnliche Oculare

33. Orthoskopische Oculare

34. Gyps- und Glimmerblättchen nach v o $\mathrm{I}$ o h l für mikroskopische Untersuchungen. p. Collect. von \$ Stück

35. Gypskeile mit breiten Streifen zu demselben $Z$ weck.

\section{No. 12.}

\section{R. Fuess in Berlin, Mauerstrasse No. 84 . Preise in Thalern.)} 1565.

\section{A. Mikroskope.}

1. Runder broncirter Fuss, Messingsäule, grobe und feine Einstellung, Blendenscheibe, Hohlspiegel, gerade und schräge Beleuchtung, Ocularmikrometer $5 \mathrm{Mm}$. in $50 \mathrm{Th}$., 3 Objectivlinsen und 2 Oculare. Vergrösserung 60-, 100-, 120-, 190-, 250-, 300mal linear; zeigt bei günstiger Beleuchtung die Schrägstreifung der Pl. angulata, sowie die Querlinien auf den Schuppen von Hipparchia janira bereits bei mittlerer Vergrösserung. In Mahagonikasten. . . . . . . . . . . . 17 Thlr.

2. Fuss nebst Säule von Eisen (broncirt, grobe und feine Einstellung, Hohlspiegel, gerade und schräge Beleuchtung: Ocularmikrometer $5 \mathrm{Mm}$. in $50 \mathrm{Th}$., 3 Objectivlinsen und 1 Ocular. Vergrösserung (60), 120-, 250mal linear. Probeobject: Querstreifung der Hipparchia janira oder $\mathrm{Pl}$. attenuata. In Mahagonikasten

12 Thlr.

3. Dassel be Instrument mit 2 Ocularen . . . . . . . . . . . . . . . 14,

4. Mikroskop nach S chäffer, Vergrösserung $30-50 \mathrm{mal}$ linear. . . . . . . S, ,

\section{B. Mikrometertheilungen anf Glas.}

Ocularmikrometer:

1 Centimeter in 100 Theile à Stück . . . . . . . . . . . . 1 Thlr.

5 Millimeter

4 ,

$1 \quad, 2,50$

$6 \quad,, 300$

Tischmikrometer in Etuis :

1 Millimeter in 100 Theile à Stück . . . . . . . . . . . . . . . 2 2 ,

$1 / 2 \quad, ", 50, "$, . . . . . . . . . . . . . . $11 \frac{1}{2}$,

Es werden 'sämmtliche physikalische und mathematische Instrumente auf Bestellung angefertigt. 


\section{No. 13.}

\section{Andrew Ross (jetzt Thomas Ross*) in I,ondon. 2, Featherstone building, Holborn. \\ Preise in Pfl. St.}

No. 1 A. Grosses zusammengesetztes Mikroskop mit rotirendem Objecttisch, welcher auch nach zwei rechtwinkligen Richtungen I" weit verschiebbar ist; Bewegung des optischen Theiles durch ein Triebwerk; das ganze Instrument in jeder geneigten Lage stellbar; Hülfsobjecttisch zur Aufnahme der Beleuchtungs- und Polarisationsvorrichtungen, Ocular A und B, mit planem und concavem Spiegel, drehbarem Diaphragma, Objecttischpincette, 2 Glasplatten mit Rändern . . . . . . 30 Pfd.

No. 1 B. Dasselhe Mikroskop mit gewöhnlichem rotirendem Objecttisch; der Apparat von gleicher Vollständigkeit . . . . . . . . . . . . . 24 Pfd.

No. 2. Kleineres Mikroskop, Bewegung des Objecttisches $3 / 2$ ", gewöhnliche Rotation, in allen Theilen dem vorigen Instrumente ähnlich . . . . . . . . . . . $21 \mathrm{Pfd}$.

No. 2. Ohne Hülfsobjecttisch . . . . . . . . . . . . 7 Pfd

No. 2. Ohne Hülfsobjecttisch, feine Schraubeneinstellung oder beweglicher 'Tisch, zwei Oculare, ein Linsensystem von 1 Zoill und ein anderes von $1 / 2$ " mit einem Oeffnungswinkel von $95^{\circ}-$ Grundlage der vollständigen Mikroskope . . . . 1s Pfd. 11 Sh.

Yo. 2. Complicirter Objecttisch . . . . . . . . . . . . . . . 4 , 10,,

Yo. 2. Feine Einstellungseinrichtung . . . . . . . . . . . 2 ,, 14 ,"

No. 2. Hülfsobjecttisch und senkrechte Schraubenbewegung . . . . $4,, 10$,"

No. 3. Completes kleineres Stativ, complicirter Objecttisch, Vorrichtung zum feinen Einstellen des optischen Theiles, 2 Oculare . . . . . . 13 Pfd. 10 Sh.

No. 3. Dasselbe Instrument ohne den beweglichen Objecttisch und die feine Einstellungsvorrichtung, 2 Oculare, ein achromatisches Linsensystem von 1 Zoll, ein zweites von $1 / s^{\prime \prime},-$ Grundlage eines vollständigen Mikroskops . . . . . 14 Pfd. 15 Sh.

No. 3. Complicirter Objectlisch . . . . . . . . . . . . . . . 4 Pfd.

No. 3. Feine Finstellungsvorrichtung . . . . . . . . . . . . . 2 $\mathrm{Pfl}$.

No. 3. Mikroskopstativ ohne Schiefstellung, ohne beweglichen Objecttisch und Schraubenvorrichtung zum Einstellen; ein Ocular. - Grundlage eines vollständigen Instrumentes. . . . . . . . . . . . . う Pfd. 10 Sh.

No. 4. Vollständiges Stativ eines zusammengesetzten und einfachen Mikroskops für Reisen, wie No.2 . . . . . . . . . 12 Pfd. 12 Sh.

Mahagoni- und sonstige Kasten von 5 Pfd, 5 Sh. -1 Pfd. 10 Sh.

\section{Achromaticehe Linsensysteme.}

Oculare:

\begin{tabular}{|c|c|c|c|c|c|c|c|c|c|}
\hline & & & & $A$ & B & $\mathrm{C}$ & D & Pfd. & Sh. \\
\hline & Zoll & $50^{\circ}$ & Ocffnungswinkel & 20 & 30 & 40 & 60 & 3 & - \\
\hline $1 \frac{1}{2}$ & , & 20 & , & (10) & 5.5 & 70 & 90 & 3 & - \\
\hline i &, & 15 &, & 1;0 & 40 & 100 & 120 & 2 & - \\
\hline I &, & 25 &, & 60) & Si) & 100 & 120 & 3 & 10 \\
\hline & ," & 65 & ,, & 100 & 130 & $1>0$ & 220 & 5 & 3 \\
\hline &, & 95 &, & $221)$ & $351 \%$ & 500 & 520 & 5 & 5 \\
\hline &, & 134 &,, & 320 & 510 & 700 & 910 & s & s \\
\hline &, & 150 & ," & 400 & 670 & 900 & 1200 & 10 & 10 \\
\hline $1 / 12$ & , & 170 &, & 650 & 900 & 1250 & 2000 & is & $\rightarrow$ \\
\hline
\end{tabular}

Sonstige Apparate in grosser Auswahl.)

Neue Systeme von Th. Ross (dem Sohn und Nachfolger):

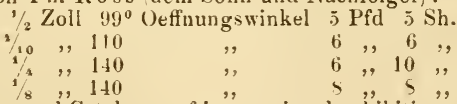

Im "Official illustrated Catalogue of international exhibition" of 1862 " sind ohne Preisangabe folgende Systeme von $\mathrm{T} h$. R oss notirt:

*) Dieses, sowie das folgende Verzeichniss sind zum grössten Theile aus Reinicke's Beiträgen Heft 3, 1862 auszugsweise entnommen. 


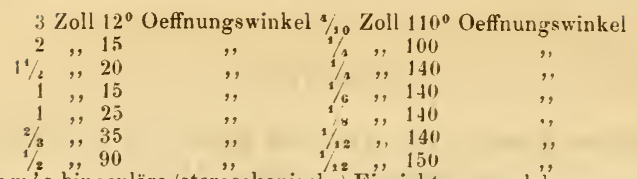

II e n ham's binoculäre (stereoskopische) Einrichtung, welche, wenn sie anbringbar ist, mit jedem zusammengesetzten achromatischen Mikroskop verbunden werden kann, mit 3 Ocularen, einem analysirenden Trisma, Triebwerk an den beiden Röhren und allen Umänderungen . 8 Pfd. $10 \mathrm{Sh}$.

\title{
No. 14.
}

\section{Powell \& Lealand in I, on d o 11. 4, Seymour Place, Euston Square. Preise in Pfil. St.}

\author{
1565.
}

1. Grosses zusammengesetztes Mikroskop von verbesserter Construction, mit einem $3 / \mathbf{s}^{\prime \prime}$ durch Schraube und Trieb rechtwinklig verschiehbaren und zugleich um die Axe rotirenden Objecttisch (nebst Präparatenhalter und Federklemme), welcher sehr dünn ist, um die schärfste Beleuchtung zu gestatten, sei es durch den Spiegel oder ein achromatisches Prisma, und einen graduirten Kreis besitzt, um als Goniometer benutzt zu werden. Grobe und feine Bewegung des Rohrs; letzteres mit einer graduirten ausziehbaren Röhre. Secundärer Objecttisch mit rotirender, horizontaler und verticaler Bewegung für den Gebrauch des achromatischen Condensor, Paraboloid etc.: getheilte Platte mit einer Linse, um als Objectfinder zu dienen, einem ansehnlichen planen und concaven Spiegel mit doppeltem Arme; zwei Oculare . . . . . . $32 \mathrm{Pfd} .10 \mathrm{Sh}$.

2. Grosses zusammengesetztes verbessertes Mikroskop mit einem um $3 / \mathrm{s}^{\prime \prime}$ durch Schraube und Trieb rechtwinkelia verschiebbaren Objecttisch, nebst verstellbarem und rotirendem Objecthalter mit Federklemme; grobe und feine Einstellung des graduirten und ausziehbaren Rohres; Accessorischer Objecttisch mit rotirender rechtwinkliger und senkrechter Bewegung für Condensor, Paraboloid etc.; ebener und concaver Spiegel mit doppeltem Arme, wodurch sehr schiefes Iicht auf das Object geleitet werden kann; 2 Oculare . . . . . . . . . . . . . . $22 \mathrm{Pfd}$.

3. Kleineres Mikro-kop in der Einrichtung dem vorigen ahnlich, mit einem um $3 /{ }^{\prime \prime}$ verschiebbaren 'Tisch, 2-2 Ocularen, 1)rehscheibe und Lister's Lichtstopfer, aber ohne den secundären Objecttisch und den doppelten Arm des Spiegels. . . . . . 16 Pfd.

4. Tragbares zusammengesetztes Mikroskop mit $3 /{ }^{\prime \prime}$ Verschiebung des Tisches, einem verstellbaren und rotirenden Objecthalter nebst Federklemme; grobe und feine Bewegung, accessorischer Tisch, ebener und concaver Spiegel an doppeltem Arme, um sehr schiefe Beleuchtung zu erhalten; in Mahagonikasten. . . . . 16 Pfd. $16 \mathrm{Sh}$.

5. Zusammengesetztes Mikroskop mit einem um $3 / s^{\prime \prime}$ durch einen Hebel verstellbaren Objecttisch, grober und feiner Bewegung, planem und concavem Spiegel, Drehscheibe, L i s ter's Lichtstopfer und 2 Ocularen . . . . . . . . . . $10 \mathrm{Pfd} .10 \mathrm{Sh}$.

\section{1)as Gestell ron Eisenguss}

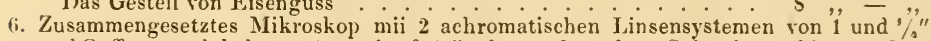
und Oeffnungswinkeln von 25 und $95^{\circ}, 2$ (Ocularen, doppeltem Spiegel, drehbarem Diaphragma und Li is ter's Lichtstopfer . . . . 12 Pfd. 10 Sh.

7. Zusammengesețtes Mikroskop für Studirende, mit den gleichen Linsensystemen, wie No. 6, einem Ocular und doppeltem Spiegel . . . . . . $10 \mathrm{Pfd} .10 \mathrm{Sh}$.

Jissectionsstative.

Mahagonikasten für das Mikroskop No. i

Kasten für die Instrumente No. 2 und 3 mit Laden für Objecte. etc. etc.

$\begin{array}{rrrr}3 & , & 3 & , \\ 4 & , & 4 & , \\ 4 & , & 10 & ,\end{array}$


Achromatische Linsensysteme für Mikroskope.

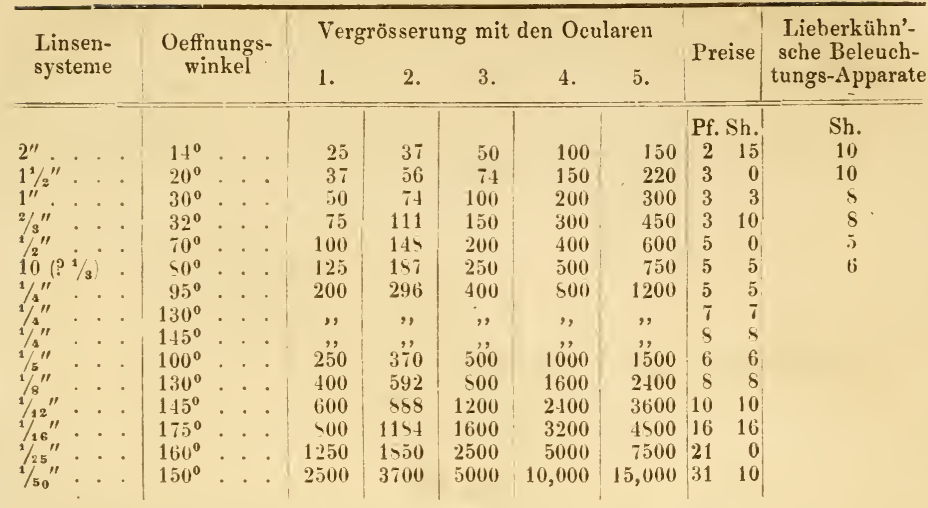

Hierzu noch eine Menge einzelner Apparate, darunter:

W en ham's stereoskopische Vorrichtung. . . . . . . . . . $8 \mathrm{Pfd} .10 \mathrm{Sh}$ Verbesserter Condensor mit $170^{\circ}$ Oeffnungswinkel . . . . . . . . S " , \&,

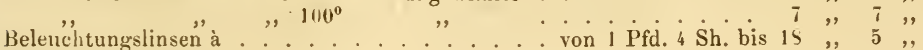
Polarisationsapparat. . . . . . . . . . . . . . 2,10, Golliometer . . . . . . . . . . . . . . . 3 " 3 , Mikrometerocular . . . . . . . . . . . 1 , 5 , Schraubenmikrometer . . . . . . . . . . . . . . . . . 4 ", 4, Oculare

\section{No. 1 .5.}

Smith, Beck \& Beck in London. 6, Coleman Sitreet. Preise in Pfil. St.) 1859 u. 1563.

Die Instrumente sind in 3 Klassen getheilt und No. 1 (auf welche wir uns hier besehränken) die beste Qualität darstellend.

1. Verbessertes kleines Mikroskop; 3 Oculare, Systeme $2 / 3^{\prime \prime}\left(30^{\circ}\right)$ und '/s" $\left.\$ 55^{\circ}\right)$, Vergrösserungen $60,105,150,240,430$ und 720 . Bildumdrehendes Glas.

Die Leiste, welche clen Körper trägt, ist am Gestell fortgesetzt bis unter den Tiseh.

Dieser hat einen beweglichen Cylindereinsatz, um alle Beleuchtungsapparate leicht und sicher einstellen zu können. I)ie Säule, welche den Körper trägt, hat ein Gelenk für schiefe Stellung und ist auf ihrem Fusse drehbar. Der Körper hat grobe und feine Bewegung und eine graduirte Röhre. 1) Tisch ist $1 / 2$ Zoll dick und besitzt verticale, sowie horizontalc Bewegung, 1)rehscheibe und Klammern. Diaphragma mit drehbaren und zurückziehbaren Einsätzen. Planer und concaver Spiegel auf bev eglichem Arn:e. Seitliche Beleuchtungslinse, L i e b e r k ü hn' scher Apparat etc.; mit Kasten.

$30 \mathrm{Pfd}$.

2. Ein ähnliches Instrument, aber mit dem Gestell des verbesserten grossen Mikroskops, mit 2 Säulen etc. . . . . . . . . . . . . . . . . . 35 Pfd.

3. Verbessertes kleines Mikroskop mit 3 Ocularen, 3 Objectivsystemen $2 / 3$ Zoll $\left(30^{\circ}\right)$, $\left.1 / 10^{\prime \prime} 55^{0}\right)$ und $1 / 5^{\prime \prime}\left(100^{\circ}\right)$ und zahlreichen Beigaben . . . . . . . . . . 50 Pfd. 
4. Derselbe optische Theil mit dem Stativ des grossen Mikroskops . . . . 55 Pfd.

5. Vollständig verbessertes grosses Mikroskop mit 5 Jinsensystemen, $1^{1} / 2$ Zoll $20^{\circ}$, $2 / 3^{\prime \prime}\left(30^{\circ}\right), 1 / 10^{\prime \prime}\left(75^{\circ}\right), 1 / 5^{\prime \prime}\left(100^{\circ}\right)$ und $1 / 8^{\prime \prime}\left(120^{\circ}\right), 3$ Ocularen, Vergrösserungen ron 20-1300. Beleuchtungsvorrichtungen, verbessertem Condensor, Polarisationseinrichtungen und zahlreichem Nebenapparat . . . . . . . . . St Pfd.

f. Neues Universalmikroskop (1563) mit 2 Objectivsystemen $i^{\prime \prime}$ und $i / s^{\prime \prime}$ und 2 wei

Ocularen . . . . . . . . . . . . . . . 5 Pfd.

Einzelpreise von Linsensystemen (alle Systeme, welche stärker als $2 / 3$ Zoll sind, ausgenommen nur $1 / \mathrm{a} "$, mit Correctionsapparat: :

$$
\begin{aligned}
& 2 \text { Zoll } 10^{\circ} \quad 1 \text { Pfd. } 10 \text { Sh. } 6 \mathrm{~d} \text {. } \\
& 1 \frac{1 / 2}{2}, 20^{\circ} \quad 3,10, \text {, } \\
& 1,222^{\circ} \quad 2, " 10,-, \\
& 2 / 3,, 30^{\circ} \quad 3,, 3,,-,
\end{aligned}
$$

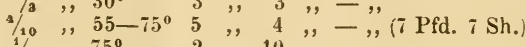

$$
\begin{aligned}
& 1 / 8,75^{\circ} \quad 2,, 10,,-,
\end{aligned}
$$

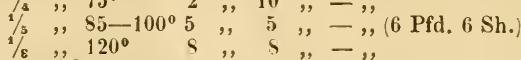

Zahlreiche Stative und Nebenapparate."

\section{No. 16.}

\section{Preiscourant über die zur Fertigung mikroskopischer Präparate nöthigen Glasgegenstände. Von Heinrich Vogel, Glasermeister in Giessen.}

\section{1 s66.}

1. Objectträger, Vereinsformat $48 \mathrm{Mm}$. lang, 2s breit) . . . . . . 50 Stück à 1 $\mathrm{kr}$.

2. Dieselben mit abgestumpften Ecken . . . . . . . . . . . . . 56 , 24 ,

3. Schmale Schutzleisten . . . . . . . . . . . . . . $100, "$ "

4. Breite Schutzleisten . . . . . . . . . . $100, " 9$,

5. Deckgläschen von c. $1 / 10$ bis $1 / 1$ Linie Dicke unter folgenden Nummern :

No. I. Quadratische Pláttchen von $18 \mathrm{Mm}$. Seite . . . . 50 Stück à 36 ",

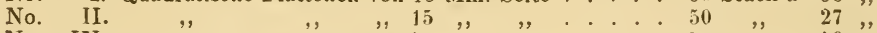

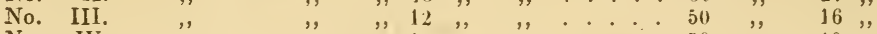

No. IV. $, ", 10,, \quad, \quad . . .550,4,10$,

No. V. Plättchen von 26 M̈m. Länge und 21 Breite . . . . $50, " 1 \mathrm{fl} .24$,

No. VI. , , , 22 , , , $16 \quad, \quad$. . . . 50 , 54 ,"

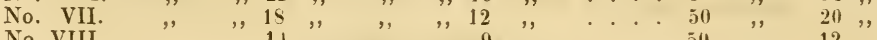

No. VIII. $,, \quad, 14,, \quad, \quad, \quad 9 \quad, \quad \ldots . .950,, 12$,

6. Pa p päst chen zum Aufbewahren mikroskopischer Präparate. Jedes Kästchen fasst $40-50$ Stück. Preis eines Kăstchens . . . . . . . . . . $36 \mathrm{kr}$. 






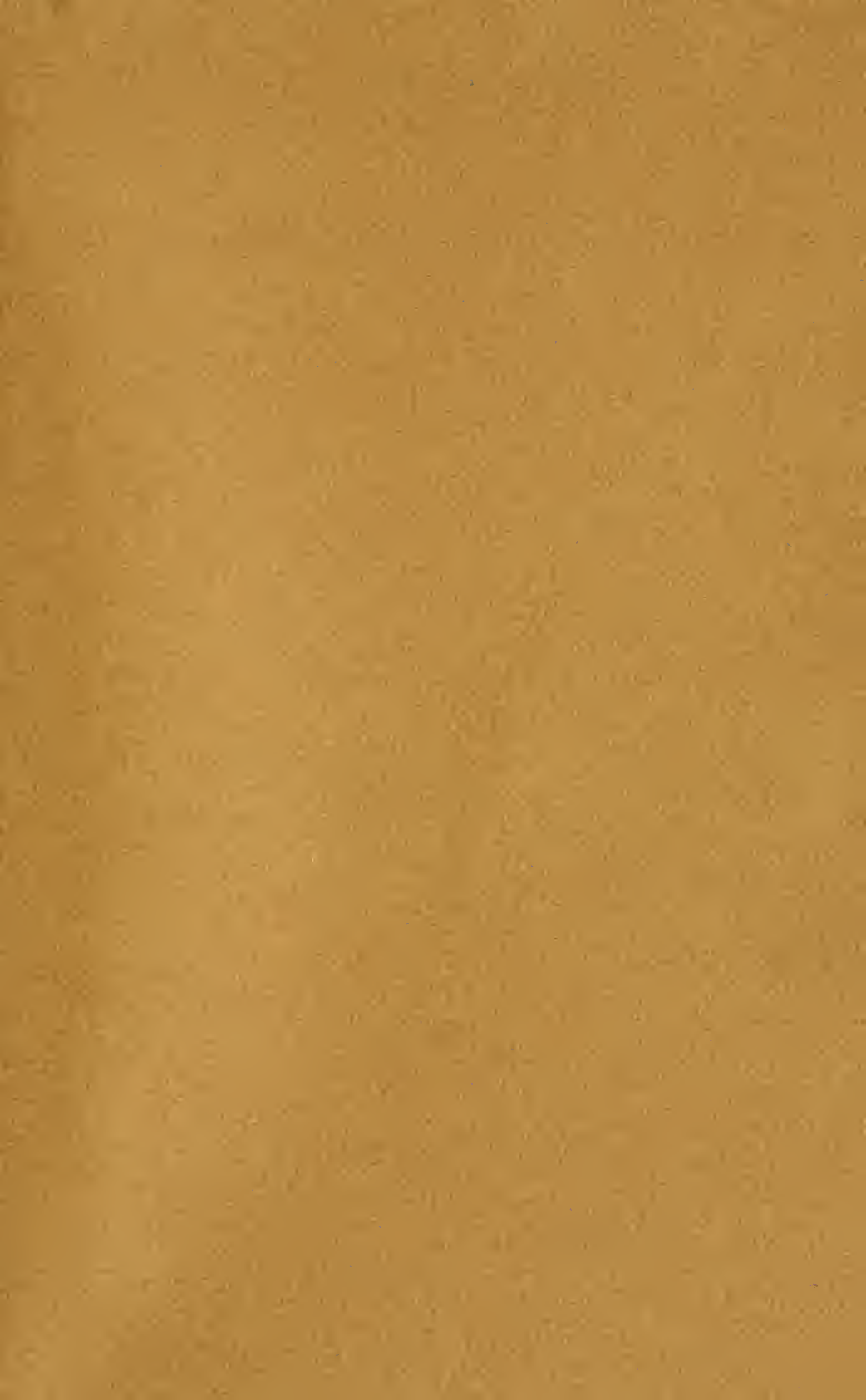




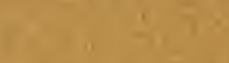

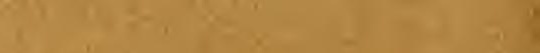
$x^{2}=$

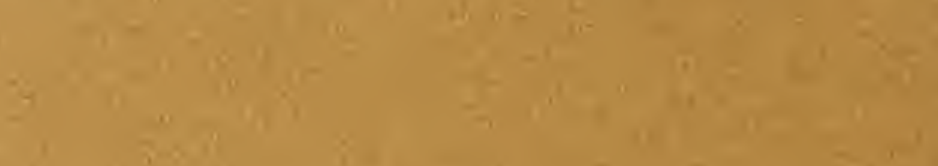
$6 \times 2 \times 2=0$

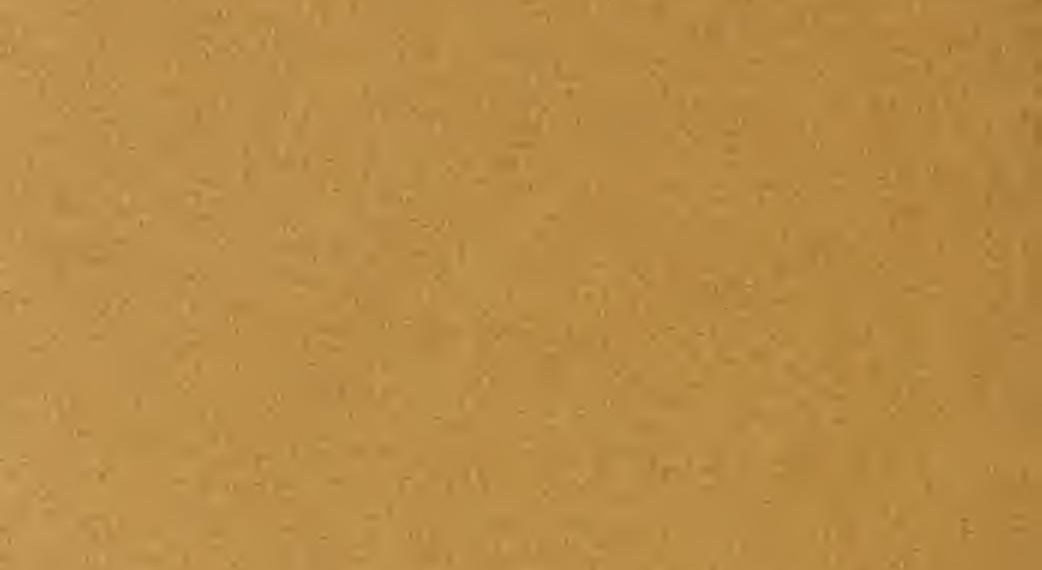

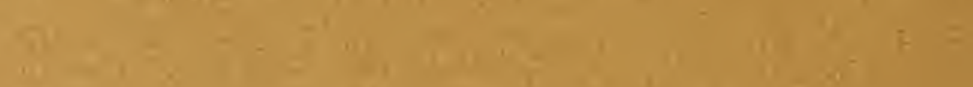

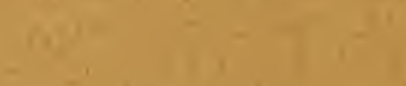

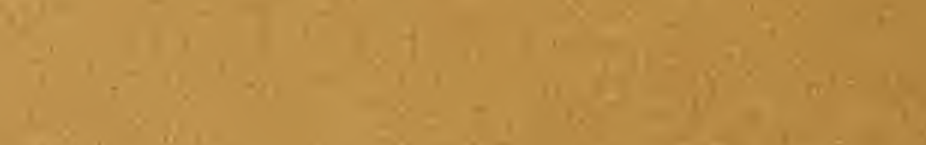

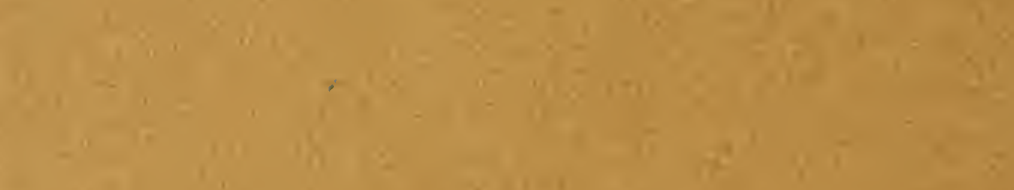

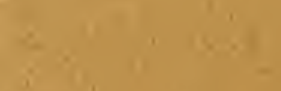
$x^{2}+2,5$

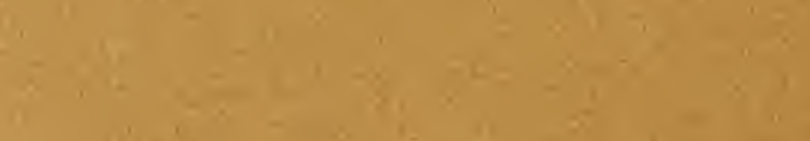

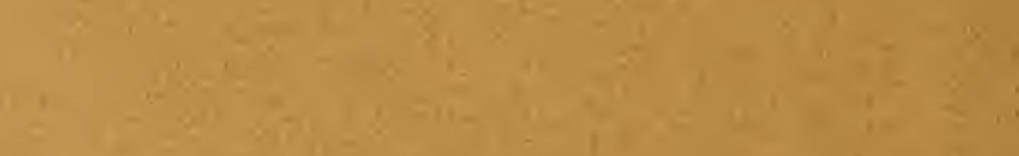

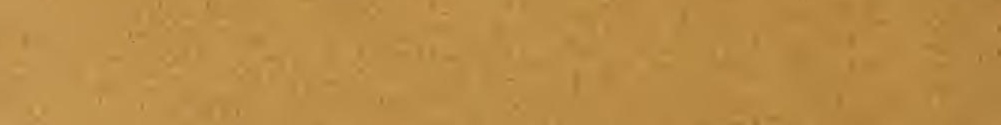

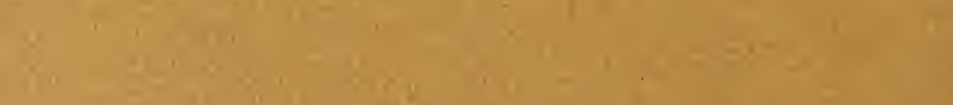

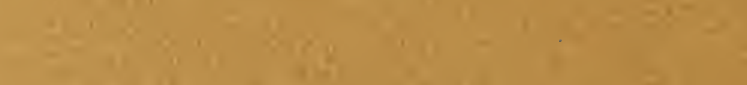

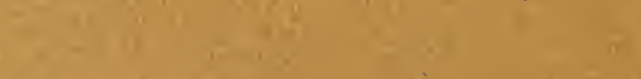

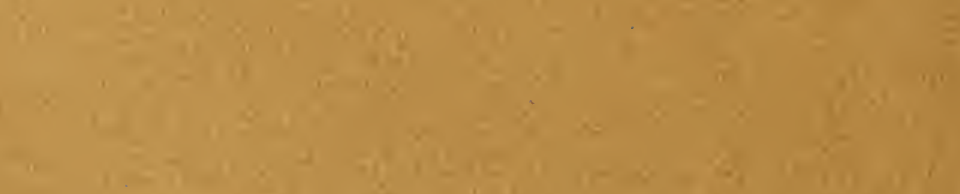

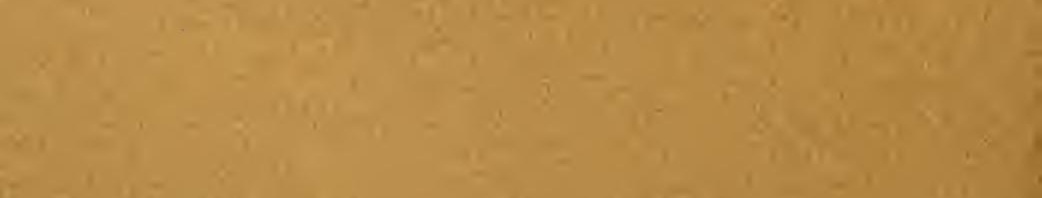


(5)

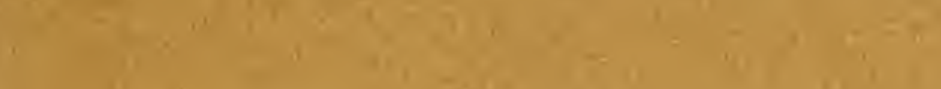

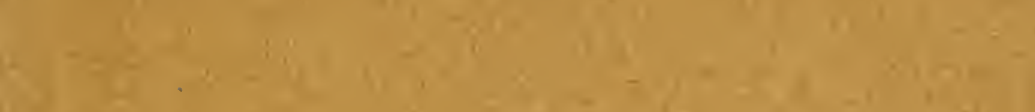

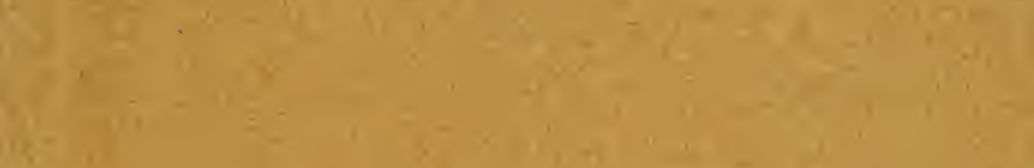
$1 x^{*}+1$

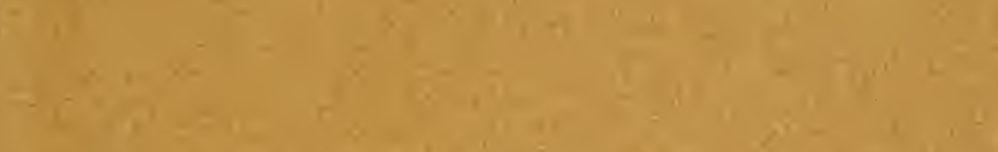

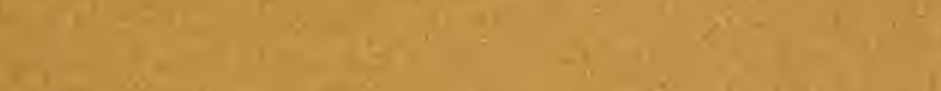

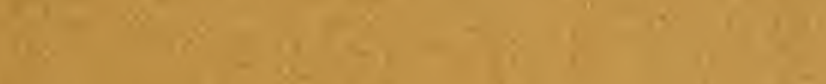

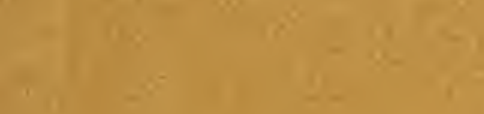<smiles>CC=C1CCC=C1C(C)=O</smiles>

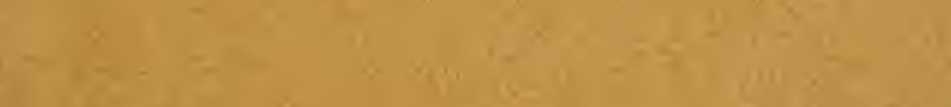

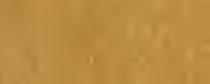

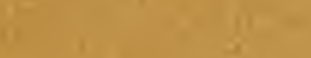

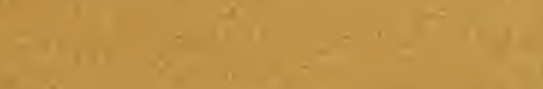

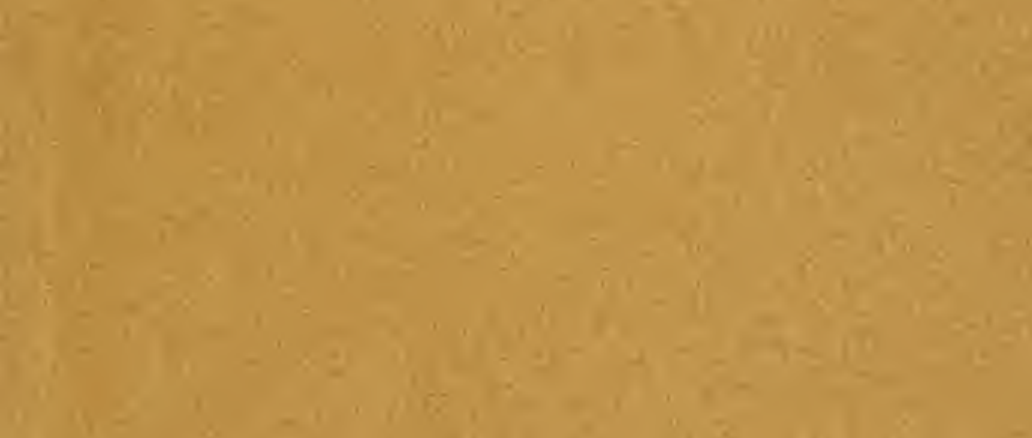

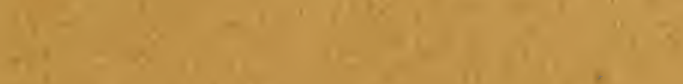

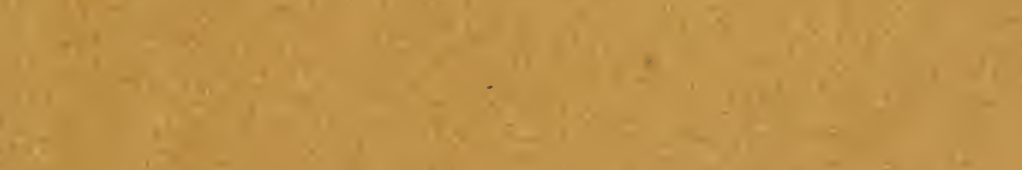

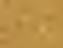
2

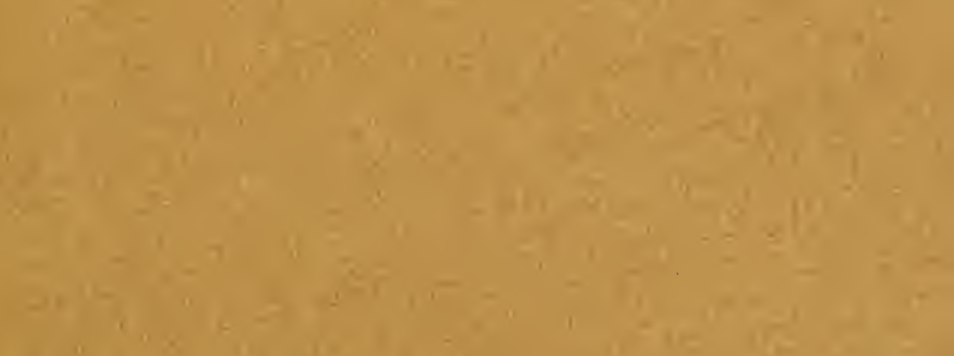
11 


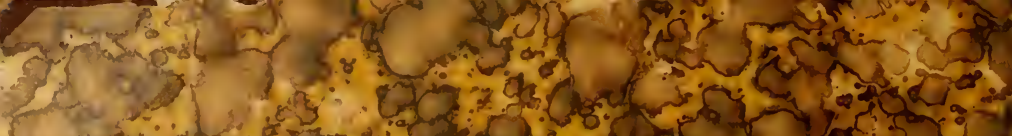

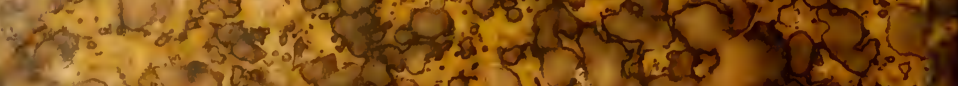

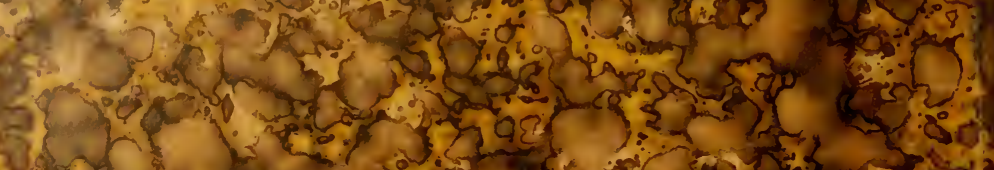

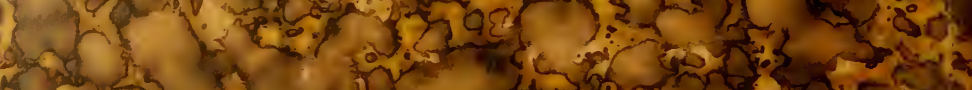

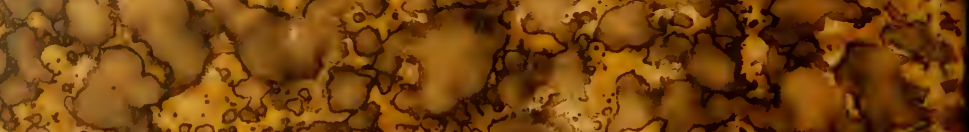

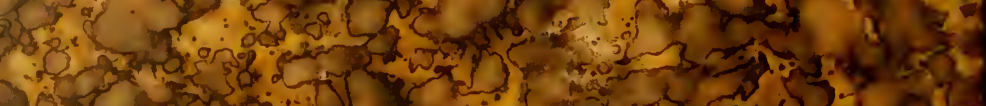

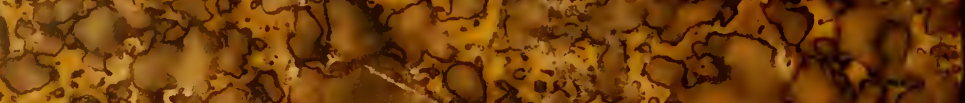

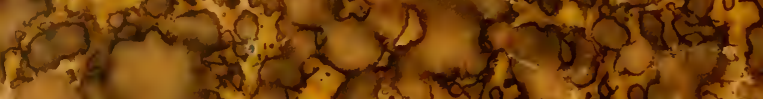

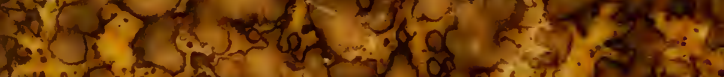

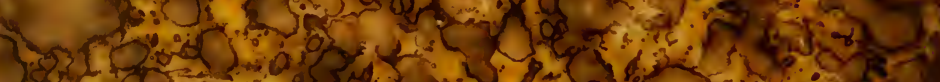

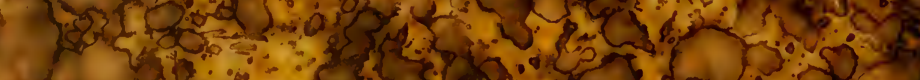

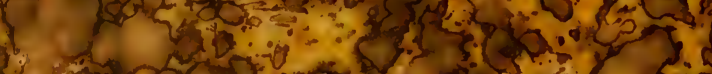

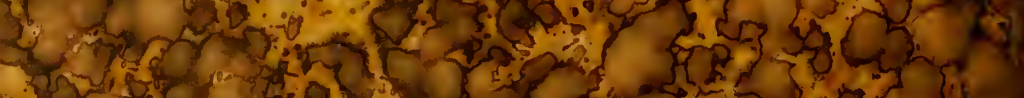

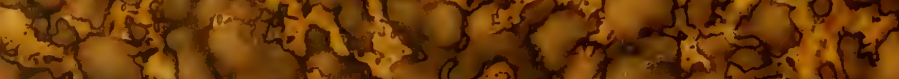

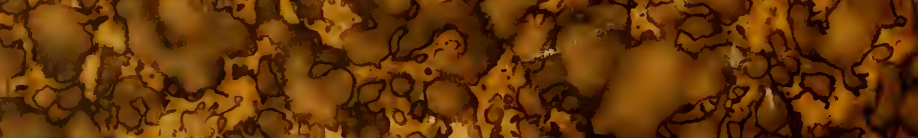

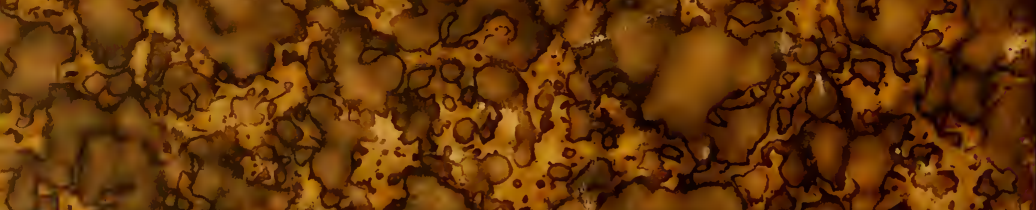

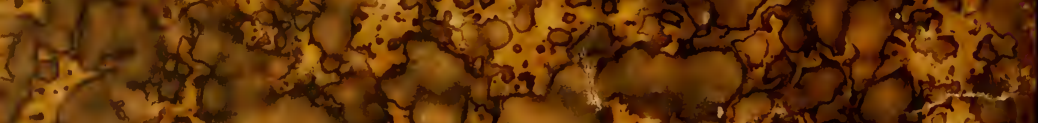

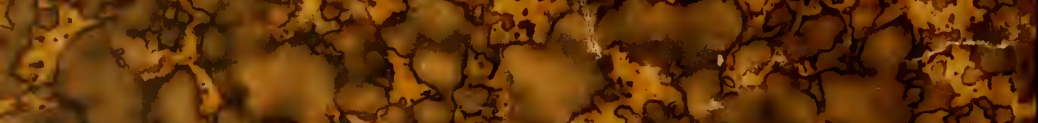

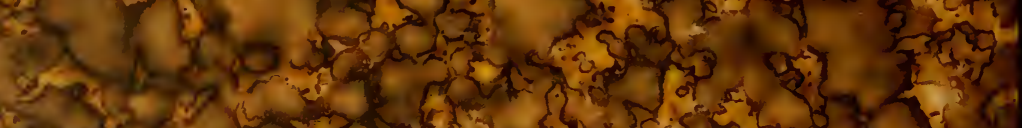

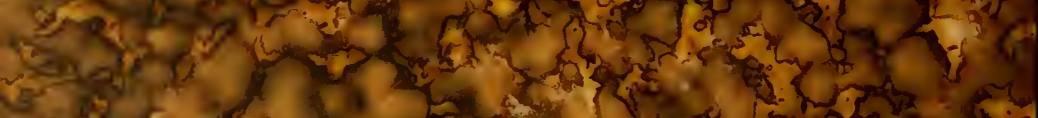

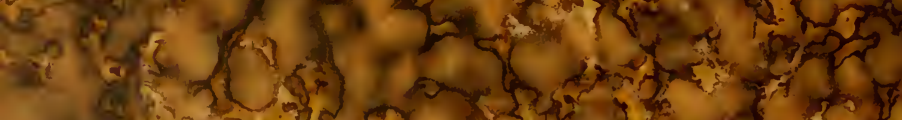

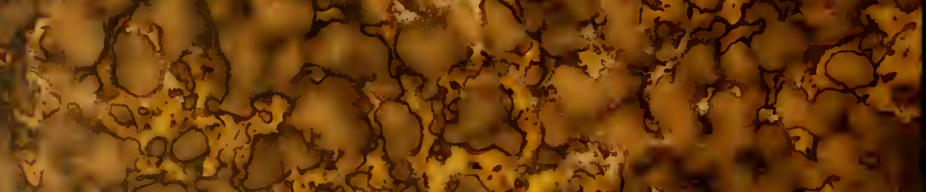

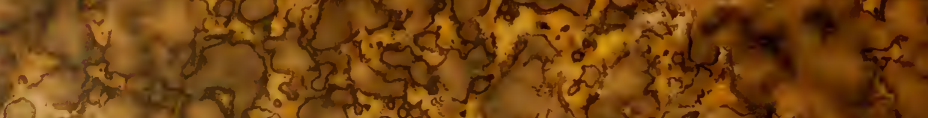

Q

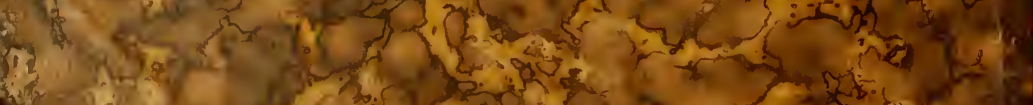

